Sozialtheorie

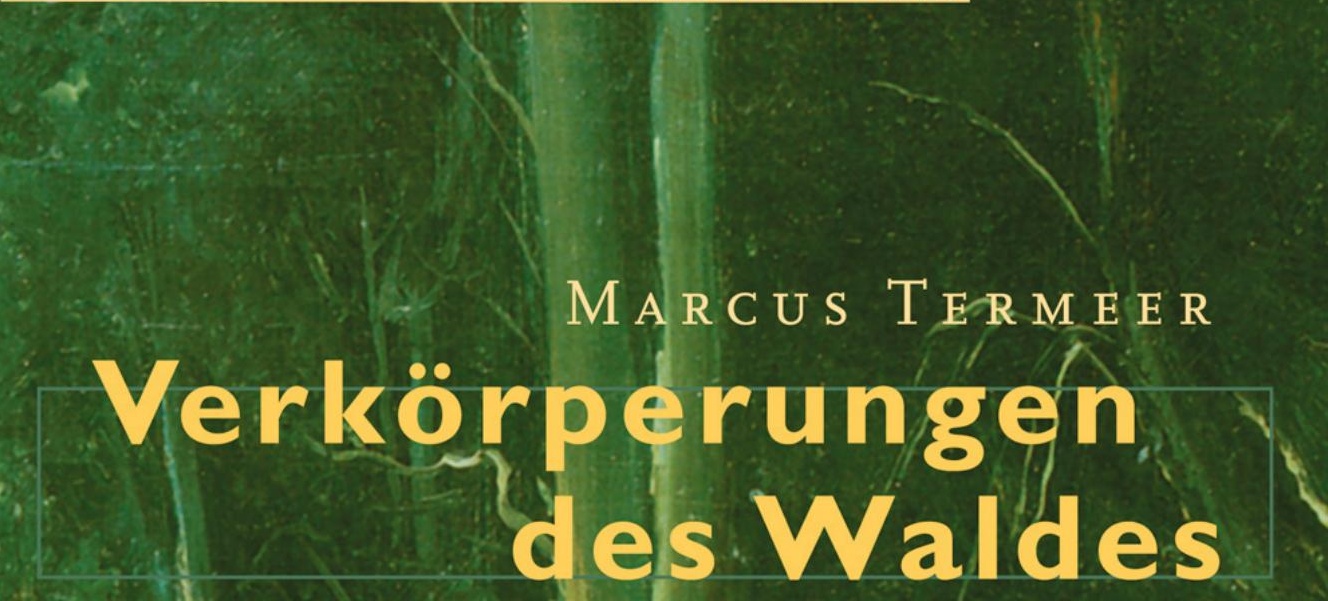

Eine Körper-, Geschlechter-

\title{
und Herrschaftsgeschichte
}

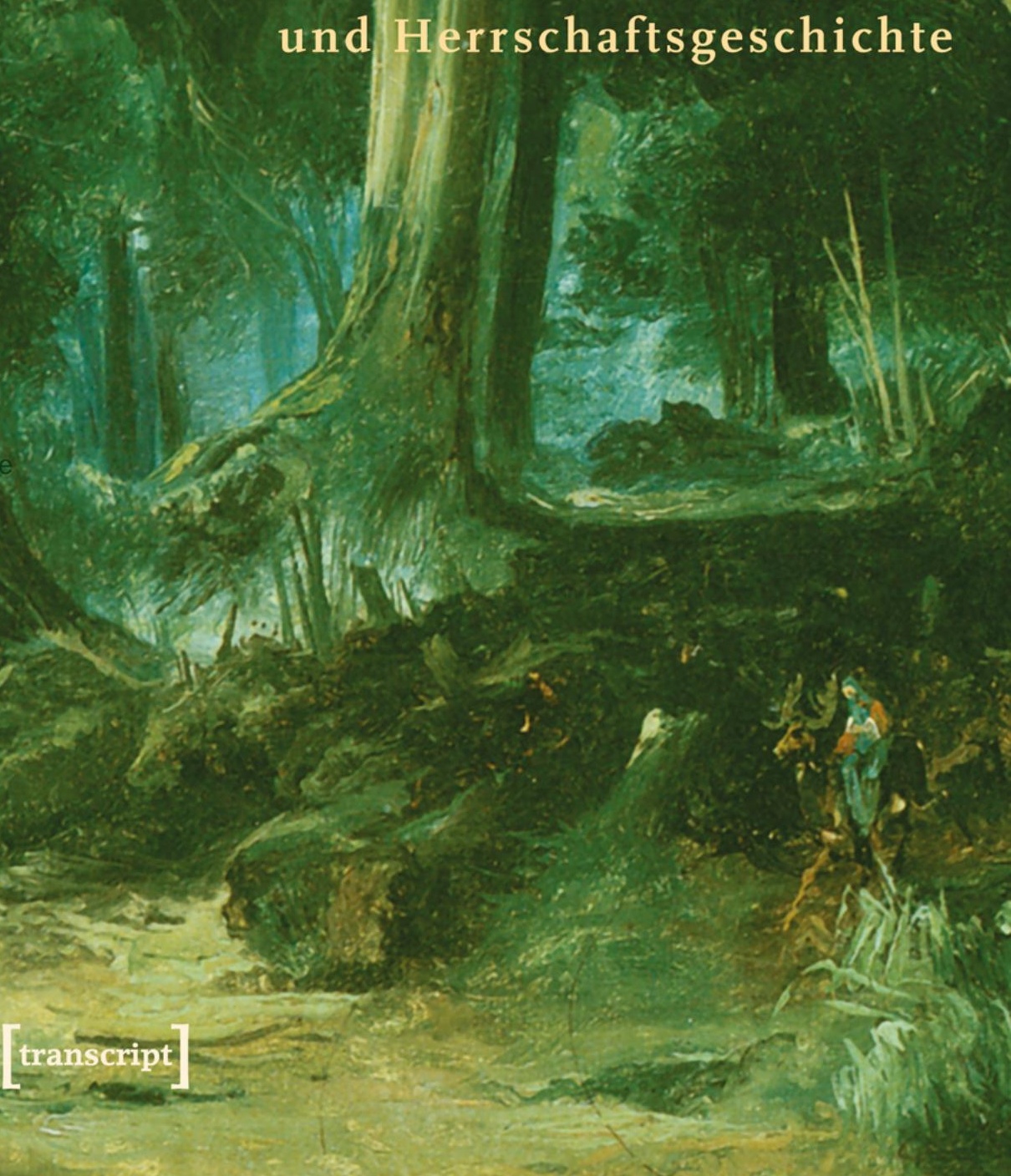


Verkörperungen des Waldes 
Marcus Termeer (Dr. phil., M.A.) promovierte an der Universität Münster in Soziologie. Er lebt als freier Autor - Schwerpunkte: Kultursoziologie, Dialektik der Zivilisation - und Journalist in Münster. 
MARCus TERMEER

Verkörperungen des Waldes

Eine Körper-, Geschlechter- und Herrschaftsgeschichte 


\section{Bibliografische Information der Deutschen Bibliothek}

Die Deutsche Bibliothek verzeichnet diese Publikation in der Deutschen Nationalbibliografie; detaillierte bibliografische Daten sind im Internet über http://dnb.ddb.de abrufbar.

(C) 2005 transcript Verlag, Bielefeld

\section{(c) $\$($ This work is licensed under a Creative Commons BY NC ND Attribution-NonCommercial-NoDerivatives 3.0 License.}

Umschlaggestaltung und Innenlayout: Kordula Röckenhaus, Bielefeld Umschlagabbildung: Karl Blechen, »Waldrand bei anbrechendem Tag«, um I83I-I835 (Staatliche Museen zu Berlin, Kupferstichkabinett, Foto: Jörg P. Anders); (C) Bildarchiv Preußischer Kulturbesitz

Lektorat \& Satz: Marcus Termeer

Druck: Majuskel Medienproduktion GmbH, Wetzlar ISBN 3-89942-388-7

Gedruckt auf alterungsbeständigem Papier mit chlorfrei gebleichtem Zellstoff.

Besuchen Sie uns im Internet: http://www.transcript-verlag.de

Bitte fordern Sie unser Gesamtverzeichnis und andere Broschüren an unter: info@transcript-verlag.de 
$\begin{array}{ll}\text { Vorwort } & 7\end{array}$

Einleitung $\quad 9$

>Wildnis $<$ hat eine Geschichte $\quad 14$

Naturverhältnisse als Geschlechterverhältnisse $\quad 19$

$\begin{array}{ll}\text { Körpertransformationen } & 21\end{array}$

Von aggregativen zu generativen Bedeutungsstrukturen 27

>Innen< und >Außen< $\quad 29$

Verkörperungen - Bilder:

$\begin{array}{ll}\text { theoretische Begriffsbestimmungen } & 37\end{array}$

Das >soziale Geschlecht $`$ der äußeren Natur Teil I:

>Weiblicher Wald $\quad 67$

Schwankender Untergrund und Geilwuchs - feuchte Wälder als
Gegenwelten

Hexenbäume und Katzen $\quad 89$

Ungezügelte Pflanzen und Reptilien $\quad 108$

Sexualisierung als Taxonomie: Ordnung für den Geilwuchs $\quad 121$

Böse Ausdünstungen aus dem Leib der Erde $\quad 132$

Von der endgültigen Abschaffung des >Matriarchats` 147

$\begin{array}{ll}\text { Die weibliche Wildnis der >neuen Welt } & 176\end{array}$

$\mathrm{Zu}$ erobernde Jungfrauen $\quad 180$

Die totale Inversion männlicher Herrschaft: Kannibalinnen $\quad 190$

Arkadischer Imperialismus $\quad 198$

>Weiblicher Wald - >männlicher Wald 
Das >soziale Geschlecht` der äußeren Natur Teil II: >Männliche Wildnis،

Wildnis und Kultur als diaphane Konstruktion 215

Die Asketisierung der »Wilden Leute« zu Urahnen 220

Die Junggesellengeburt eines »unvermischten Volkes« 232

Entgrenzungen - Begrenzungen:

der Herkynische Wald als Reterritorialisierung 236

Dämme 240

Das neue bürgerliche Subjekt entdeckt die Landschaft 245

Die Hure Babylon 258

Der Wald als >reckenhafter Ort ist ein späteres Produkt $\quad 271$

>Deutscher Wald und 〉Deutscher Wald $\quad 277$

Forst I: Der Wald als Körper des Königs 278

Exkurs I: Diana im Blumentopf 300

Forst II: Der Wald als absolutistische Staats-Maschine 307

Verflechtungen 325

Tätige Geometrie $\quad 329$

Die Logik der Maschine 339

Der Aufmarsch der >Ständeく $\quad 348$

Das Verschwinden von Werden und Vergehen $\quad 369$

Der Aufmarsch der Soldaten 387

Exkurs II: Die (lasterhafte) Stadt als Frau und Wildnis 412

Der Wald als Ort des >Daseinskampfes $\quad 440$

Organismus versus Mechanismus? 441

>Wildnis $<$ als Wurzel der Volksgemeinschaft und $>$ Wildniß $\ll$ als utopische ständische Idylle $\quad 457$

Die Natur erhält ein Haus im Kampf ums Dasein $\quad 470$

Der Wald als kämpferische Volksgemeinschaft 485

Den Wildwuchs transformieren: Idealbild Wald 499

Zur Erhabenheit verfeinert $\quad 502$

$>$ Heilige Hallen $<$ I 513

Monströse Leiber zu idealschönen Körpern $\quad 524$

Das Wirken des Maschinengotts $\quad 542$

>Heilige Hallen< II 554

Die Schönheit der Ruinen $\quad 570$

$\begin{array}{ll}\text { Bürgerliche Naturmystik } & 577\end{array}$

Ausleitung: Bilder dritter Ordnung 585

Abbildungsverzeichnis 605

$\begin{array}{ll}\text { Bibliographie } & 607\end{array}$ 


\section{Vorwort}

Die vorliegende Publikation ist die leicht erweiterte Version meiner Dissertation, die 2004 von der Philosophischen Fakultät der Westfälischen Wilhelms-Universität Münster unter dem Titel »Verkörperungen des Waldes. Dominante gesellschaftliche Naturbeziehungen in historisch wechselnden Bedeutungsräumen« angenommen wurde.

Mein erster Dank geht an Prof. Dr. Hanns Wienold vom Institut für Soziologie für die Betreuung und Erstellung des Erstgutachtens in einer besonderen Situation. Sehr dankbar bin ich auch Prof. Dr. Hans-Jürgen Krysmanski für die kurzfristige Übernahme des Zweitgutachtens.

Ohne das fachliche Know-how und das technische Equipment von Matthias Zölle hätte es keine Abbildungen gegeben. Herzlichen Dank.

Meiner Mutter Margot Khodaverdi Ourmieh und meinem Vater Klaus Termeer bin ich überaus dankbar für die jeweilige Unterstützung, die sie mir gegeben haben.

Simone Kannengieser hat mein Projekt von Anfang bis Ende begleitet, inhaltliche Fragen diskutiert, Korrektur gelesen und war bei computertechnischen Problemen eine unerlässliche Hilfe. Ihr, die mir so vieles erst ermöglicht hat, ist dieses Buch gewidmet.

Münster, im Mai 2005

Marcus Termeer 



\section{Einleitung}

»Die Soziologie hat sich im Kern als Wissenschaft der modernen Industriegesellschaft diszipliniert, womit praktische wie normative Prämissen und Basisgewißheiten des gesellschaftlichen Modernisierungsprozesses in das fachliche Selbstverständnis übernommen wurden. Natur - gedeutet als gesellschaftlich unberührte Außen- oder naturalisierte Innenwelt, als Reservoire und Ressource - blieb in den Bezugsrahmen soziologischer Theoriebildung weitgehend ausgespart bzw. als unhinterfragte Selbstverständlichkeit vorausgesetzt. « ${ }^{1}$

Angelika Poferl spricht von der Wichtigkeit einer Suche nach neuen »Zugängen, neuen Unterscheidungen und Verknüpfungen, mithilfe derer es erst gelingen kann, Leerstellen und `blinde Flecken` zu erhellen sowie nicht Wahrgenommenes sichtbar und Unverstandenes begreifbar zu machen «. ${ }^{2}$ Matthias Groß untersucht die Scheu der Mainstream-Soziologie der letzten fünfzig Jahre gegenüber der materiellen Umwelt unter dem Diktum des Antinaturalismus. Ihm geht es darum nachzuweisen, dass in der klassischen Soziologie diese >Naturvergessenheit stand, so verweist er auf Marx' Begriff der Natur als unorganischem Körper des Menschen, Émile Durkheims Auffassung der Dinge als soziale Gegenstände oder Max Webers Überlegungen zum Zusammenhang von protestantischer Ethik und Naturausbeutung. ${ }^{3}$

1 Poferl, Angelika: Doing Gender, Doing Nature? Einführende Bemerkungen zur Intention des Bandes, in: Nebelung, Andreas et al. (Hg.): Geschlechterverhältnisse - Naturverhältnisse Feministische Auseinandersetzungen und Perspektiven der Umweltsoziologie. Opladen: Leske $+\mathrm{Bu}-$ drich 2001, S. 14.

2 Ebda., S. $10 \mathrm{f}$.

3 Vgl. Groß, Matthias: Die Natur der Gesellschaft. Eine Geschichte der Umweltsoziologie. Weinheim, München: Juventa 2001. 
Der Anspruch, Soziales mit Sozialem zu erklären, widerspricht einer Untersuchung der belebten und unbelebten Dinge in der Natur tatsächlich nicht. So sollen im Folgenden mit einer Soziologie des Waldes gesellschaftliche Einschreibungen in den Natur-Dingen aufgespürt werden. Naturorte und ihr Inventar sind soziale Orte. Sie umfassen soziale Projektionen und Rückprojektionen. Dass dabei die Zurichtungen der >inneren Naturく des Menschen den Umgang mit `äußerer Natur` prägen, ist in unterschiedlicher Weise in den letzten dreißig Jahren untersucht und nachgewiesen worden, so hat etwa Rudolf zur Lippe den frühneuzeitlich beginnenden Prozess gezeigt, in dem »die äußere Natur zum Projektionsfeld der Unterdrückung von innerer« wird. ${ }^{4}$ Desgleichen aber wirkt diese äußere Natur auf die innere zurück. »In Wahrheit wird das Naturbild der gesellschaftlich bedingten Auffassung des Menschen nachgebildet und diese letztere dann, im Zirkel, wiederum aus dem Naturbild erschlossen«, wie schon Franz Borkenau 1934 schreibt. $^{5}$

Ich untersuche gesellschaftliche Naturverhältnisse als - um es mit Norbert Elias zu sagen - »Interdependenzgeflechte $«,{ }^{6}$ und damit auch die ıäußere Natur` als historischen Prozess. Anders als die Zivilisationstheorie von Elias fasse ich den Prozess allerdings als qualitativen, dialektischen auf, nicht als strikt lineare »große Zivilisationskurve«, verlaufend von weitgehender Unbefangenheit - und desgleichen Desintegration - hin zu weitgehender Befangenheit - und Integration (s.u.).

Das bedeutet für mich genauer, die $\mathrm{Zu}$ - und Einschreibungen von >Geschlecht $`$ in ihren historisch je unterschiedlichen Ausprägungen zu verfolgen. Naturorte werden damit abgebildet als »Topographien der Geschlechter« (Sigrid Weigel), ${ }^{7}$ etwa in der Konstruktion >weiblicher Wildnis` (Sabine Schülting) ${ }^{8}$ als der >Anderen`, der Bedrohung bzw. In-

4 Lippe, Rudolf zur: Naturbeherrschung am Menschen II. Geometrisierung des Menschen und Repräsentation des Privaten im französischen Absolutismus. Frankfurt/M: Syndikat 1979 (1914), S. 436 f.

5 Borkenau, Franz: Der Übergang vom feudalen zum bürgerlichen Weltbild, S. 304; zit. n. Lippe, a.a.O., S. $210 f$.

6 Vgl. Elias, Norbert: Über den Prozess der Zivilisation. Soziogenetische und psychogenetische Untersuchungen. Bd. 1: Wandlungen des Verhaltens in der weltlichen Oberschicht des Abendlandes. Bd. 2: Wandlungen der Gesellschaft. Entwurf einer Theorie der Zivilisation. Frankfurt/M: Suhrkamp $1995^{18}$ (Basel 1939). Im Folgenden zit. als PDZ 1 bzw. 2.

7 Vgl. Weigel, Sigrid: Topographien der Geschlechter. Kulturgeschichtliche Studien zur Literatur. Reinbek: Rowohlt 1990.

8. Schülting, Sabine: Wilde Frauen, fremde Welten. Kolonisierungsgeschichten aus Amerika. Reinbek: Rowohlt 1997 
version männlich definierter Ordnung (Monika Wehrheim-Peuker), ${ }^{9}$ aber auch konträr in der Konstruktion >männlicher Wildnis` als >Eigener innerhalb eines Musters, dieser männlichen Ordnung eine >kämpferische Ewiggültigkeitく zu verleihen.

Den menschlichen Körper als historisch-sozialen Prozess zu begreifen, bedeutet ebenso zu versuchen, Wahrnehmungen und Zuschreibungen von Körper-Formierungen bzw. unförmiger Leiblichkeit des Waldes aufzuspüren. Es besteht ein enger Zusammenhang zwischen den Transformationen des Körpers - vom Besitzer je eigener ständischer >Natur in vorbürgerlichen Gesellschaften hin zum physisch demokratisierten »Ausdrucksmedium« (Gunter Gebauer) ${ }^{10}$ und zugleich zu zwei biologisch begründeten und derart hierarchisierten Geschlechtern (Claudia Honegger; Thomas Laqueur; Londa Schiebinger) ${ }^{11}$ in der bürgerlichen Gesellschaft - und einer semantischen Verknappung. In vorbürgerlichen Gesellschaften gibt es offenbar, folgt man Peter Czerwinski und Michael Sonntag, eine Vielzahl von aggregativ, parataktisch angeordneten Bedeutungs-Räumen, während in der bürgerlichen Gesellschaft ein Raum besteht, in dem Bedeutung generativ aufgebaut ist. ${ }^{12}$ Daraus ergeben sich Konsequenzen, was den Umgang mit und die Wahrnehmung von Natur-Orten betrifft.

9 Wehrheim-Peuker, Monika: Der Kannibale - die Kannibalin. Zum Zusammenspiel von kolonialem und misogynem Diskurs, in Hanau, Katharina et al. (Hg.): GeschlechterDifferenzen. Beiträge zum 14. Nachwuchskolloquium der Romanistik (Greifswald, 4.-6. Juni 1998). Bonn: Romanistischer Verlag 1999.

10 Gebauer, Gunter: Ausdruck und Einbildung. Zur symbolischen Funktion des Körpers, in Kamper, Dietmar/Wulf, Christoph (Hg.): Die Wiederkehr des Körpers. Frankfurt/M: Suhrkamp 1982.

11 Vgl. Honegger, Claudia: Die Ordnung der Geschlechter. Die Wissenschaft vom Menschen und das Weib 1750-1850. Frankfurt/M, New York: Campus 1991; Laqueur, Thomas: Auf den Leib geschrieben. Die Inszenierung der Geschlechter von der Antike bis Freud. Frankfurt/M, New York 1992; Schiebinger, Londa: Schöne Geister. Frauen in den Anfängen der modernen Wissenschaft. Stuttgart: Klett-Cotta 1993 (Cambridge/Mass 1989).

12 Vgl. Czerwinski, Peter: Der Glanz der Abstraktion. Frühe Formen von Reflexivität im Mittelalter. Exempel einer Geschichte der Wahrnehmung I. Frankfurt/M, New York: Campus 1989; Ders.: Gegenwärtigkeit. Simultane Räume und zyklische Zeiten, Formen von Regeneration und Genealogie im Mittelalter. Exempel einer Geschichte der Wahrnehmung II. München: Wilhelm Fink Verlag 1993; Sonntag, Michael: »Das Verborgene des Herzens«. Zur Geschichte der Individualität. Reinbek: Rowohlt 1999. 
Dass Wildnis, Wald, Natur immer einer sozialen Konstruktion unterliegen, zeigt etwa Astrid E. Schwarz am Beispiel der Ökologie im ausgehenden 19. Jahrhundert, in der liberale, konservative und funktionale Gesellschaftsmodelle die jeweilige Matrix von >Ökosystemen bilden. ${ }^{13}$ Diese soziale Konstruktion, besser Produktion, deren `Inhalt die in historischen Prozessen sich ändernden bzw. veränderten Weisen der sinnlichen Wahrnehmungen sind, schließt die belebten und unbelebten Dinge in der Natur ein. Diese >Dinge insofern, als dass das in sie >eingeflossene »verdinglichter Form« äußert (Martin Burckhardt). Es gibt demnach eine sich historisch wandelnde »Psycho-Logik» der Dinge (Friedrich W. Heubach). ${ }^{14}$ Wahrnehmung erzeugt Wahrnehmung.

In der vorliegenden Studie neu ist eine systematische historische Spurensuche nach sozialen Einschreibungen und Rückprojektionen in den Natur-Dingen selbst. Baumarten, Ökosysteme und Tiere sowie Erscheinungsbilder von Wäldern werden unter der Fragestellung beschrieben, welche Funktionen ihnen in unterschiedlich konnotierten Gegenwelten (Unorten oder Idyllen) und Berufungsinstanzen zukommen.

Daher musste ich u.a. auf kulturgeschichtliche, ältere ethnobotanische, auch populärwissenschaftliche Kompendien zurückgreifen, was sich nicht immer als unproblematisch erwiesen hat, da hier oft Vermengungen unterschiedlicher historisch-semantischer Ebenen aufgelöst werden mussten. Der Ansatz der Arbeit ist notwendigerweise ein interdisziplinärer; soziologische, historische, philosophische, ethnologische, literaturwissenschaftliche, kunstwissenschaftliche Studien wurden genauso herangezogen wie Quellen aus der Botanik, der Forstwissenschaft, der Evolutionsbiologie, aus Religion und Mythologie, Literatur und bildender Kunst, um die wichtigsten zu nennen.

Die Notwendigkeit einer soziologischen Beschäftigung mit der Umwelt wird begründet mit nach wie vor massiver weltweiter Umweltzerstörung. Die Aneignung und Zerstörung natürlicher Lebensräume aus ökonomischen Motivpräferenzen bzw. Zwängen lässt sich - auch in historischer Betrachtung - nicht in Frage stellen. Nun hat schon Friedrich Engels darauf hingewiesen, dass nach »materialistischer Geschichtsauffassung [...] das in letzter Instanz bestimmende Moment in der Ge-

13 Vgl. Schwarz, Astrid E.: Wasserwüste - Mikrokosmos - Ökosystem. Eine Geschichte der »Eroberung« des Wasserraums. Freiburg/Br: Rombach 2003.

14 Burckhardt, Martin: Metamorphosen von Raum und Zeit. Eine Geschichte der Wahrnehmung. Frankfurt/M, New York: Campus 1994; Heubach, Friedrich W.: Das bedingte Leben. Theorie der psycho-logischen Gegenständlichkeit der Dinge. München: Wilhelm Fink Verlag 1996. 
schichte die Produktion und Reproduktion des wirklichen Lebens« sei, aber: »Wenn nun jemand das dahin verdreht, das ökonomische Moment sei das einzig bestimmende, so verwandelt er jenen Satz in eine nichtssagende, absurde Phrase. ${ }^{15}{ }^{15}$ Die Ideologie jeder gesellschaftlichen Formation hat nicht nur die Funktion, den ökonomischen Prozeß dieser Gesellschaft zu spiegeln « - schreibt Wilhelm Reich 1933 -, »sondern vielmehr auch die, ihn in den psychischen Strukturen dieser Gesellschaft zu verankern «. ${ }^{16}$ Hier soll es aber nicht um eine verkürzte Repressionshypothese, um die Umweltzerstörung als >Außenpolitikı innerer Repression gehen, sondern, mit Michel Foucault argumentiert, um Re-Produktion, genauer, die Verwandlung vitaler Bedürfnisse in Herrschaftstechniken, um Ausübung und Einschreibungen von Macht, um verwandelnde Zugriffe, in denen eine säußere Natur` entsteht, die dem »Haushalt des Begehrens« (Dietmar Kamper) entspricht. ${ }^{17}$

Ich grenze den Untersuchungsgegenstand in zweifacher Weise ab. Zum einen befasse ich mich mit Entwicklungen, die Landschaftsbilder hervorrufen, wie sie im 19. Jahrhundert anzutreffen sind. Begründet ist das in aktuellen >Zielkonzepten ২ in Naturschutz und >Umweltplanungく, die sich an >Biotopausstattungen<, wie sie Anfang des 20. Jahrhunderts existiert haben sollen, orientieren, bzw. daran, dass die extensiv bewirtschafteten Kulturlandschaften des 18. und 19. Jahrhunderts besonders den >ästhetischen Ansprüchen` an die Umwelt gerecht würden und daher die bevorzugten Naherholungslandschaften seien. Ökologisch wird diese Auffassung gestützt mit der Begründung, dass im 19. Jahrhundert die größte Artenvielfalt anzutreffen sei. ${ }^{18}$

Zum anderen beschäftige ich mich mit Dominanzverhältnissen, mit Einschreibungen von Macht bzw. Wahrnehmung von Bedrohung derselben, d.h. dass oppositionelle Konzepte hier nur teilweise gestreift oder aber als Argumentationsbasis verwendet werden, ansonsten aber nicht in den Rahmen meiner Untersuchung gehören.

15 Engels, Friedrich: Brief an J. Bloch (1890), in: MEW 37. Berlin (O): Dietz 1968, S. 463f.

16 Reich, Wilhelm: Die Massenpsychologie des Faschismus. Köln: Kiepenheuer \& Witsch 1986 (Kopenhagen 1933/Maine 1942), S. 39.

17 Kamper, Dietmar: Unmögliche Gegenwart. Zur Theorie der Phantasie. München: Wilhelm Fink Verlag 1995, S. 73.

18 Vgl. Ausleitung. 


\section{,Wildnis` hat eine Geschichte}

Die gängigen Dichotomien von Kultur und Natur, Zivilisation und Wildnis behaupten eine wechselseitige Abgegrenztheit und Unverbundenheit. Bereits am Wald der mitteleuropäischen Steinzeit lässt sich aber zeigen, dass Durchdringungen der >Wildnis $`$, gesellschaftliche Transformationen der Wildnis - und seien sie weder bewusst noch geplant noch direkt stattgefunden haben.

Das Bild eines >unberührten〈, eines »völlig natürliche[n]« Waldes in Mitteleuropa ist bekannt. Der in Naturschutz und Forstwissenschaft dafür gängige Begriff ist der der »potentiellen natürlichen Vegetation«, die - von >Sonderstandorten abgesehen - dominiert werde von Buchenwäldern. Hansjörg Küster hat anhand von Pollenanalysen dargestellt, dass die Auffassung doppelt unhaltbar ist. Illusorisch sei schon die mit der »potentiellen natürlichen Vegetation« implizierte Entwicklung »ein[es] völlig natürliche[n] Bild[es]« bei sich selbst überlassenen Wäldern. Bereits »etwa 7000 Jahre lang« sei die mitteleuropäische Umwelt anthropogen beeinflusst, und damit deutlich länger »als allgemein angenommen«. Ein »wirklich natürlich zu nennender Wald« sei an menschlichen Siedlungsorten infolge von Rodungen und Ackerbau nirgendwo mehr entstanden.

»Prähistorisches [...] Siedelwesen hielt sich über Jahrtausende. Die Zusammensetzung der Wälder änderte sich dadurch tiefgreifend; immer wieder waren neue Waldparzellen gerodet worden, und die Wälder hatten sich nach einigen Jahrzehnten der Nutzung immer wieder geschlossen. Der jungfräuliche Urwald kam nie wieder zurück; Veränderungen des Waldbildes, die sich vielleicht auch ohne Einfluß des Menschen abgespielt hätten, liefen nun auf jeden Fall beschleunigt ab. Nach einigen Jahrtausenden hatte sich das Aussehen des Waldes in Mitteleuropa vollständig gewandelt; er war schon damals nur noch Teil einer Natur aus zweiter Hand. $\ll^{19}$

Buchenwälder beginnen »in vielen Gegenden Mitteleuropas genau in der Zeit häufiger zu werden [...], in der die Besiedlung durch den vorge-

19 Küster, Hansjörg: Geschichte des Waldes. Von der Urzeit bis zur Gegenwart. München: C.H. Beck 1998, S. 90ff. Vergleichbares findet sich bei Joachim Radkau und Ingrid Schäfer bezüglich tropischer Wälder. Demnach sei schon in den 60er Jahren darauf hingewiesen worden, dass es sich bei derartigen >Urwäldern` »häufig um Sekundärwälder, die im Gefolge von Brandrodungen entstanden sind «, handele; vgl. Radkau, Joachim/Schäfer, Ingrid: Holz. Ein Naturstoff in der Technikgeschichte. Reinbek: Rowohlt 1987, S. 31 
schichtlichen Ackerbauern begonnen hatte«, wenn auch »nur allmählich «. ${ }^{20}$ Hingegen habe der »>echt natürlicheく Wald vor der Siedlungsgründung« aus vielen »Ulmen, Eichen und Haselbüschen« bestanden. Dieser habe sich aber, trotz wiederkehrender völliger Aufgabe von Siedlungsflächen, nie mehr eingestellt. Im »Wald, der Natur aus zweiter Hand war, gab es kaum noch Ulmen, aber viele Buchen«. Mit Beginn der Zyklen von »Rodungen, Aufgeben von Siedlungen und Neubildungen von Wäldern« sei in der Jungsteinzeit die Ausbreitung der Buchen zunächst im südlichen Mitteleuropa begünstigt worden. Buchen seien zu dieser Zeit bereits in »einigen höheren Mittelgebirgen Süddeutschlands« vorgekommen. Von dort seien die Früchte offenbar von Tieren in die ehemaligen Rodungsflächen der Niederungen gebracht worden, wo sich Buchen allmählich ausbreiten konnten und »den generellen Charakter des Waldes mit der Zeit veränderten«, insbesondere wegen des Schattens, den sie werfen. ${ }^{21}$

Dass sich eine ursprüngliche Wildnis nie mehr eingestellt hat, erklärt Küster so: »Jeder Fleck in der Landschaft wird nicht nur durch die momentan herrschenden Gegebenheiten geprägt, sondern auch durch das, was sich früher auf ihm abgespielt hat; man kann sagen, die Landschaft hat ein >Gedächtnis` für das, was sich früher in ihr ereignet hat und auch für das, was die Kultur des Menschen mit sich brachte.« So könne man ehemalige Viehrastplätze am Bewuchs von stickstoffliebenden Gewächsen wie dem schwarzen Holunder identifizieren. ${ }^{22}$

In älteren Darstellungen der Ökologiegeschichte setzt die anthropogene Veränderung der Umwelt erst im Mittelalter ein, so ist nach Charles R. Bowlus Europa um das Jahr 1000 »ein Meer von Wäldern mit nur einzelnen Inseln menschlicher Besiedlung«. Dreihundert Jahre später »jedoch gab es demgegenüber fast überall Dörfer und fast nirgendwo Wälder«. ${ }^{23}$ Rolf-Jürgen Gleitsmann hat in dieser Weise sechs Phasen der Waldnutzung beschrieben, darunter die abwechselnden großflächigen Rodungen seit dem Hochmittelalter und die mehrfache Rückkehr des Waldes als »Wüstungen« infolge der Pest des 14. Jahrhunderts und später des Dreißigjährigen Kriegs. Danach ist der Wald erst seit der frühen Neuzeit anthropogen geprägt, in seiner Baumartenzusammenset-

20 Küster, a.a.O., S. 87f. Vgl. Kap. `Heilige Hallen` I.

21 Ebda., S. 88ff.

22 Ebda., S. 90f.

23 Bowlus, Charles R.: Die Umweltkrise im Europa des 14. Jahrhunderts, in: Sieferle, Rolf Peter (Hg.): Fortschritte der Naturzerstörung. Frankfurt/M: Suhrkamp 1988, S. 15. 
zung zum Teil bewusst oder aufgrund übernutzter und ausgelaugter Böden stark verändert. ${ }^{24}$

Selbst im praktischen Sinn lässt sich unter Rückgriff auf Küster zeigen, dass eine Landschaft, die als Wildnis wahrgenommen wird, menschliche Einschreibungen >speichert Unberührtheit geraten damit ebenso ins Rutschen wie solche, dass bis zum Ende des Mittelalters Menschen einseitig unter der Herrschaft der Natur existiert hätten.

In Wildbeutergesellschaften, schreibt der Ethnologe Klaus E. Müller, leben die Menschen "gewissermaßen von der Hand in den Mund. Sie bedienen sich wie nach Belieben am reich gedeckten Tisch so jedenfalls könnte es scheinen $« .{ }^{25}$ Einschränkend werden hier klimatische und territoriale Gründe genannt. Im gemäßigten Klima Europas der >Steinzeit< (ebenso in den Subtropen und Tropen) aber scheint die Ernährung - überwiegend »Sammelkost«, in sehr viel geringerem Maß Fleisch und Fisch ${ }^{26}$ - grundsätzlich mindestens ausreichend gewesen zu sein. Der Vorteil einer »unspezialisierten Wild- und Feldbeuterei« ist hier ein doppelter. Es wird gegessen, was die Umgebung hergibt: Pflanzen, Wurzeln, Früchte, Pilze, Honig, kleine und größere Tiere, Fisch. Da diese »sich in räumlicher wie in artenspezifischer Hinsicht zumeist in bestimmter Weise verteilt« finden, »nötigt« das die Menschen zu einer »gewissermaßen >nomadischen` Lebensführung«. Was aber dazu befähigt, bei erschöpften Nahrungsquellen in andere Gebiete zu wandern. So ist »das Leben dieser Menschen tatsächlich weitgehend krisenfest « ${ }^{27}$ Wenn auch offenbar nur in den fest definierten Grenzen der jeweiligen eigenen Territorien einzelner $»$ Familien, Lokalgruppen oder übergeordnete[r] Einheiten $\ll .{ }^{28}$ Die >Natur $<$ - im je eigenen Territorium - scheint hier demnach nicht als bedrohliche wahrgenommen worden zu sein. ${ }^{29}$

24 Vgl. Gleitsmann, Rolf-Jürgen: Und immer wieder starben die Wälder. Waldnutzung und Energiewirtschaft in der Geschichte, in: Calließ, Jörg et al. (Hg.): Mensch und Umwelt in der Geschichte. Pfaffenweiler: Centaurus 1989.

25 Müller, Klaus E.: Die bessere und die schlechtere Hälfte. Ethnologie des Geschlechterkonflikts. Frankfurt/M, New York: Campus, S. 37.

26 Ebda., S. 36.

27 Ebda., S. 27f.

28 Ebda., S. 37. Nach Müller ist das Betreten oder Durchqueren fremder Territorien nur nach vorhergehender Erlaubnis der Besitzer möglich. Andernfalls komme es sofort zu Waffengewalt. »Die meisten quasi >kriegerischen Auseinandersetzungen unter Wildbeutern hatten in derartigen Grenzkonflikten ihren Anlaß. Sie bedeuteten eben eine Bedrohung der Existenzfähigkeit; denn die Sammel- und Jagdgründe einer wildbeuteri- 
Das ändert sich in den folgenden, agrikulturellen Gesellschaften erstmals ca. 8000 v.u.Z. in Vorderasien gegründet, aber auch in den folgenden Jahrtausenden noch kaum verbreitet -, deren zwingende Basis die Sesshaftigkeit ist. Diese >Emanzipation` aus der Abhängigkeit von der Natur verschärft andererseits spezifisch die Abhängigkeit; ein Ausweichen in andere Territorien ist ohne Weiteres nicht mehr möglich bzw. stark eingeschränkt. Der >Ausstieg` aus den Vorgaben der Natur per Aufgabe des >Nomadischen` lässt die >Kräfte der Natur` bedrohlich werden (zumindest die Bedrohung deutlich steigen), da nun der Natur als Immobilie abgerungen werden muss, was zuvor um den >Preis Mobilität einfacher zu haben war, und die Immobilie als solche zur stets durch Naturkräfte gefährdeten wird. Wo Nahrungsmittel menschlicher Produktion entspringen, erhalten sie tendenziell einen vorher so nicht gehabten Wert. Der »perennierende[] Proze[ß], der Natur zu Stoff und Materie machte $\aleph^{30}$ - wie Max Horkheimer und Theodor W. Adorno formulieren - zu handhab-, veränder-, steuerbaren Dingen, bringt einerseits eine Verfeinerung und Ausweitung des Speiseplans. Andererseits aber wird in gleichem Maß die >Eigenregung/ der Natur, zuvor noch unerlässliche Voraussetzung der Subsistenzsicherung, nun als Kampfansage ans menschlich Produzierte wahrgenommen.

So entsteht ein >Keim durch Arbeitsteilung - hier zunächst zwischen Männern und Frauen - ist zugleich Regression, weil unbestreitbare Einengung von Frauen aufs bloß Reproduzierende, ins häusliche Umfeld. Diese - zumindest - erhebliche Vergrößerung des hierarchischen Geschlechter-Gefälles hat eindeutige Tendenzen: Männer werden nun um so mehr zu Eroberern der Welt außerhalb der unmittelbaren Lebenswelt. Sesshaftigkeit als Zurückbleiben wird zum kennzeichnenden Prinzip des Weiblichen, eingehegt wie die Gärten, in denen sie arbeiten. Die Herrschaft über die Natur wird damit eine umfänglich männliche.

»Jeder Versuch, den Naturzwang zu brechen, indem Natur gebrochen wird, gerät nur um so tiefer in den Naturzwang hinein. So ist die Bahn der europäischen Zivilisation verlaufen«, fassen das im Zeitraffer

schen Gesellschaft bilden praktisch die alleinige Basis ihres Unterhaltserwerbs, ihr Produktionsmittel schlechthin.«

29 Müller spricht sehr wohl von beängstigend wahrgenommenen Exosphären, von vegetationslosen Orten, wo »Unheilsmächte« regieren (ebda., S. 349). Aber das scheint mir nicht dasselbe zu sein wie die spätere Bedrohung der sesshaften Produktionsprozesse.

30 Horkheimer, Max/Adorno, Theodor W.: Dialektik der Aufklärung. Philosophische Fragmente. Frankfurt/M: Fischer 1993 (1969/Los Angeles 1944), S. 248. 
Horkheimer/Adorno zusammen. ${ }^{31}$ Aber noch handelt es sich um sehr frühe Geschichte. Noch wird über Jahrhunderte die äußere Natur nicht als beherrschte gelten, wird damit - im >Abendland < zumal - eine >Gartenkultur` jenseits bloßer Nutzflächen, wird der Garten als Verkörperung der Beherrschung noch auf sich warten lassen.

In Pflanzergesellschaften sind »neben den Pflanzungen weiter draußen« bereits Gärten »direkt beim Haus oder in der unmittelbaren Umgebung des Dorfes« angelegt worden, »die sich also noch im engeren Tätigkeitsbereich der Frauen befinden und daher auch ausschließlich von ihnen betreut werden«. Hier wird schon relativ intensiv angebaut - Gemüse, Kräuter, Gewürze -, »verschiedentlich gedüngt« und durchaus mit »Sorgfalt« gepflegt. ${ }^{32}$ Mit dem Aufkommen bäuerlicher Gesellschaften gewinnt die Gartenarbeit wesentlich an Bedeutung. Das hier von Frauen »angebaute Gemüse und Obst deckt in der Regel einen nicht unerheblichen Teil des familiären Eigenbedarfs. Und häufig [...] werden auch Blumen gezogen, deren Pflege natürlich ebenfalls Sache der Frauen ist«. »Bauernkulturen « - kennzeichnend sind »extensive[r] Dauerfeldbau mit regelmäßigen, gezielten Bodenverbesserungsmaßnahmen (insbesondere mittels Düngung)«, Bodenbearbeitung mit dem Pflug betreiben Viehhaltung und Ackerbau, hauptsächlich von Getreide und Hackfrüchten. Die bäuerliche Ökonomie »bildete sich mit den archaischen Hochkulturen Altvorderasien[s] heraus«. Als Überschusswirtschaft ermöglicht sie die Existenz anderer, von ihr abhängiger Bevölkerungsgruppen, mithin die Entstehung städtischer Gesellschaften. ${ }^{33}$

Neueste Funde legen nahe, dass es nicht >Lebensnot` war, die zur bäuerlichen Kultur, zur Sesshaftigkeit zwang, sondern dass es der Kult, die Religion war, die Siedlungs- bzw. Städtebau hervorgerufen hat. Das zumindest schließt das Deutsche Archäologische Institut Berlin aus den Ausgrabungen der Siedlung Görekli-Tepe in Ost-Anatolien. Der Ort aus steinernen Häusern und Kultstätten sei rund 9000 v.u.Z. errichtet worden, zu Zeiten noch wildbeuterischer Gesellschaften.

31 Ebda., S. 19.

32 Müller, a. a. O., S. 44.

33 Ebda., S. 58f. 


\section{Naturverhältnisse als Geschlechterverhältnisse}

»Die Interpretation und Verortung von Weiblichkeit in den komplementär und hierarchisch gedachten Restkategorien von Privatheit/Natur/Irrationalität im Gegensatz zu männlich codierter Öffentlichkeit/Kultur/Rationalität weist diese als >gesellschaftsabgewandte Seite der Geschlechterdifferenz sowie im konkreten Fall weiblicher Zuwendung, Tätigkeit und Arbeit als `Naturressource aus. Auch wenn Grenzen der Übertragbarkeit bestehen, so sind beide Themenfelder von einer systematisch erklärbaren theoriepolitischen und wissenschaftshistorischen Randständigkeit geprägt. « ${ }^{34}$

Wahrnehmung und Zuschreibung der Weiblichkeit von zu erobernden Landschaften, einer nährenden Mütterlichkeit der Natur usw. sind bereits häufiger untersucht und dargestellt worden. Landschaften wird eine >Jungfräulichkeitく zugeschrieben, sie erscheinen als noch nicht Besessene, die daher auf ihre Entdeckung warte - das »Unentdeckte enthält schon im Begriff das Ziel der Entdeckung, zur Vorstellung wird es überhaupt erst über deren Antizipation ${ }^{35}$-, auf ihre Eroberung und Befruchtung/Kultivierung. Andererseits werden Landschaften zum »Mutter-Land « allegorisiert, als in rechtmäßigem Besitz Befindliche. ${ }^{36}>$ Unberührtheit` und >Jungfräulichkeit` für Landschaften und Wälder sind Begriffe, die die Wahrnehmung von (vorgeblich) wilder >äußerer Natur als >weiblich $<$ deutlich machen. Derartige Orte haben keinen Besitzer, können bzw. müssen >erobert`, `penetriert`, >befruchtet` und `kultiviert werden. ${ }^{37}$ Das heißt auch, sie müssen aus einer Situation des >wuchernden Stillstands $<$ befreit, und in einen Zustand des >geordneten Fortschritts< überführt werden. ${ }^{38}$

Daran werde ich anknüpfen, darüber hinaus aber zu zeigen versuchen, dass geschlechtliche Konnotationen bzw. Kategorien auch in anderer Weise wirksam sind. Zum einen darin, dass einzelne Dinge weibliche Eigenschaften haben können, so z.B. bestimmte Bäume und ihre Umgebung. Das gilt insbesondere für von Wasser oder Sumpf geprägte Wälder und die dort vorkommenden Tier- und Pflanzenarten. Hiermit werden in der frühen Neuzeit immer wieder dämonische Kräfte, Hexen

34 Poferl, a.a.O., S. 14.

35 Weigel, a.a.O., S. 124.

36 Vgl. Kap. Die weibliche Wildnis der >neuen Welt .

37 Vgl. ebda.

38 Vgl. Kap. Das Verschwinden von Werden und Vergehen. 
in Verbindung gebracht (Claudia Honegger, Silvia Bovenschen, Carlo Ginzburg). ${ }^{39}$

Zum anderen kann >Wildnis` einen strikt männlichen Charakter zugeschrieben bekommen, so, wenn Wälder als soldatische Formationen konstruiert werden. Gerade die Konstruktionen des `Kämpferischen`, des >Trutzigen` usw. benötigen dann eine vorgebliche >Urlandschaft $\iota$, auch, um >männliche Tugenden « und eine >Ewiggültigkeit` patriarchaler Gesellschaftsstrukturen zu behaupten. Derartige Zuschreibungen sind vor allem historisch veränderlich, können aber auch innergesellschaftlich fließend sein. Wenn Elias Canetti den Wald als grundlegendes »Massensymbol« vorstellt, wobei er ein unverrückbares, stehendes Heer beschreibt, das sich lieber »in Stücke hauen läßt« als zu weichen oder fliehen, bzw. als >Kathedrale`, die sich über den Menschen wölbe, ${ }^{40}$ dann sind hiermit schon Probleme der historischen Einordnung angesprochen. Der Wald als >kirchlicher` oder >soldatischer` Ort lässt sich seit dem ausgehenden 18. Jahrhundert nachweisen; wobei im Rückgriff auf antike Zeugnisse >Kontinuitäten` gebildet werden. Derartige Geschichtskonstruktionen, die an Landschaft, an Wald gebunden werden, gibt es bereits im >deutschen Humanismus« des 16. Jahrhunderts, wobei allerdings in spezifischer Weise die antike >germanische Wildnis als >barbarisch` anerkannt wird (Gernot Michael Müller), ${ }^{41}$ zugleich aber in einer diaphanen Konstruktion der zeitgenössischen Kulturlandschaft Bezugsgröße bleibt. Bruchlose Konstruktionen dieser >germanischen Wildnis entstehen erst im 19. Jahrhundert. ${ }^{42}$

In dieser Zeit kommt es systematisch zur Inversion der Ortszuschreibung von >Wildnis $\prec$. In dem Maße, in dem Großstädte nun als >Treibhäuser`, als bedrohliche, weiblich konnotierte >Dschungel wahr-

39 Vgl. Honegger, Claudia: Die Hexen der Neuzeit, in: Dies. (Hg.): Die Hexen der Neuzeit. Studien zur Sozialgeschichte eines kulturellen Deutungsmusters. Frankfurt/M: Suhrkamp 1977; Bovenschen, Silvia: Die aktuelle Hexe, die historische Hexe und der Hexenmythos, in: Becker, Gabriele et al. (Hg.): Aus der Zeit der Verzweiflung. Zur Genese und Aktualität des Hexenbildes. Frankfurt/M: Suhrkamp 1977; Ginzburg, Carlo: Hexensabbat. Entzifferung einer nächtlichen Geschichte. Berlin: Wagenbach 1990 (Turin 1989). Vgl. Kap. Schwankender Untergrund und Geilwuchs feuchte Wälder als Gegenwelten.

40 Vgl. Canetti, Elias: Masse und Macht. Frankfurt/M: Fischer 1992 (1960), S. $92 \mathrm{f}$.

41 Vgl. Müller, Gernot Michael: Die »Germania generalis« des Conrad Celtis. Studien mit Edition, Übersetzung und Kommentar. Tübingen: Niemeyer 2001.

42 Vgl. Kap. Wildnis und Kultur als diaphane Konstruktion u. Kap. Organismus versus Mechanismus? 
genommen bzw. beschrieben werden (Walter Benjamin; Sigrid Weigel; Lutz Musner), ${ }^{43}$ werden Landschaft und Wald nun zu Orten der Harmonie, des gesellschaftlichen Friedens und überwiegend der hierarchischen Ordnung. ${ }^{44}$

Auch in der Naturwissenschaft lassen sich Zuordnungen von Geschlechterkategorien nachweisen. Geschieht das vorbürgerlich nach den Kategorien der >Ähnlichkeit`, so ist in den Klassifizierungen und Taxonomien der Naturgeschichte eine Sexualisierung der Pflanzen grundsätzlich bis heute wirksam durch Carl von Linné (François Delaporte; Londa Schiebinger). ${ }^{45}$ Da Geschlechtergeschichte Körpergeschichte beinhaltet, werde ich im nächsten Abschnitt weitere Beispiele ansprechen.

\section{Körpertransformationen}

Zur Körpergeschichte und den historisch-sozialen Funktionen des >Körpers« hat Maren Lorenz eine Einführung vorgelegt, um einen Überblick über die inzwischen »unübersehbare Flut von Arbeiten« zu geben. ${ }^{46} \mathrm{Im}$ Folgenden gebe ich einen Überblick über diesbezügliche historische Transformationen.

Herrschaft ist in der mittelalterlichen Gesellschaft "polyzentrisch» und »aggregativ« aufgebaut, aus vielen unterschiedlichen Einzelrechten und Gewalten, die »von Land zu Land und von Herr zu Herr« differieren, bei Abwesenheit von »Souveränität staatlicher Gewalt « ${ }^{47}$ Dementsprechend "aggregativ« ist auch die Abhängigkeit: »Ein und dieselbe Person kann von verschiedenen Herren in unterschiedlicher Weise ab-

43 Vgl. Benjamin, Walter: Charles Baudelaire. Ein Lyriker im Zeitalter des Hochkapitalismus Hg. von Rolf Tiedemann. Frankfurt/M: Suhrkamp 1974 (1937/39); Weigel, a.a.O.; Musner, Lutz: Stadt. Masse. Weib. Metropolenwandel, Massenphobie und Misogynie im Fin-de-Siècle, in: Hödl, Günther et al. (Hg.): Frauen in der Stadt. Linz: Österreichischer Arbeitskreis für Stadtgeschichtsforschung 2003.

44 Vgl. Exkurs II: Die (lasterhafte) Stadt als Frau und Wildnis und Kap. $>$ Wildnis als Wurzel der Volksgemeinschaft.

45 Vgl. Delaporte, François: Das zweite Naturreich. Über Fragen des Vegetabilischen im XVIII. Jahrhundert Frankfurt/M, Berlin, Wien: Ullstein 1983 (Paris 1979); Schiebinger, Londa: Am Busen der Natur. Erkenntnis und Geschlecht in den Anfängen der Wissenschaft. Stuttgart: Klett-Cotta 1995 (Boston 1993). Vgl. Kap. Sexualisierung als Taxonomie.

46 Vgl. Lorenz, Maren: Leibhaftige Geschichte. Einführung in die Körpergeschichte. Tübingen: Edition Diskord 2000, S. 9.

47 Sonntag, a.a.O., S. 55f. 
hängig sein, Leibeigener des einen, zinspflichtiger Bodenbewirtschafter eines anderen, gerichtspflichtig einem dritten. $\ll^{48}$

Nach Ernst H. Kantorowicz ist der Herrscherkörper konstruiert als »zwei Körper«, der »natürliche« und der »politische«, der alle >Gebrechen des ersten aufhebt, so Krankheiten, Kindheit oder >falsches` Geschlecht. ${ }^{49}$ Regina Schulte et al. führen das insbesondere am Beispiel von Queen Elizabeth I. aus. ${ }^{50}$

In einer Gesellschaft, in der die menschlichen Körper Besitzer von Eigenschaften sind, je nach Standeszugehörigkeit von unterschiedlicher >Natur ${ }^{51}$ in der die soziale »Synthesis in unmittelbar erfahrbaren Dimensionen erfolgt, liegt die Identität der Mitglieder einer sozialen Gruppe noch ganz im Sinnlichen, in den Körpern und Dingen. Im Funktionieren ihrer Körper sind die Menschen >volk und vollständig da, in deren Signalen allein mitteilsam «. ${ }^{52}$ Die hier vorherrschende $» W a h r-$ nehmungsstruktur« lässt »Sinnlichkeit und Abstraktion als ihre Aggregatzustände unverbunden nebeneinander erscheinen«, »frühe[] Abstraktionsleistungen« zeigen sich als »parataktisches Verhältnis von Konkretem und Allgemeinem, von Körperlich-Dinglichem und Abstraktem, von Handeln und Denken «. ${ }^{53}$ Demgemäß folgt die »'parataktische Struktur des Psychischen« einer Ordnung, in der eine Trennung von innerpsychischer und äußerlicher Generierung, von »psychischen und sozialen Ordnungsmustern« sinnlos ist, da »sozialer Status und Gruppenzugehörigkeit den jeweiligen Verhaltenskanon und Tugendkatalog bestimmen ${ }^{54}$

Gunter Gebauer zeichnet die Transformation des menschlichen Körpers vom Besitzer »gegebene [r] Eigenschaften« in ein Medium des symbolischen Ausdrucks von Eigenschaften im 19. Jahrhundert (und seit-

48 Ebda., S. 42f.

49 Vgl. Kantorowicz, Ernst H.: Die zwei Körper des Königs. Eine Studie zur politischen Theologie des Mittelalters. München: dtv 1990 (Princeton 1957).

50 Vgl. Schulte, Regina (Hg.): Der Körper der Königin. Geschlecht und Herrschaft in der höfischen Welt seit 1500. Frankfurt/M, New York: Campus 2002.

51 Vgl. Gebauer, Gunter: Ausdruck und Einbildung. Zur symbolischen Funktion des Körpers, in: Kamper/Wulf (Hg.): Die Wiederkehr des Körpers. Frankfurt/M: Suhrkamp 1982, S. 313f. Vgl. Kap. Zu erobernde Jungfrauen und Kap. Forst I: Der Wald als Körper des Königs.

52 Czerwinski: Der Glanz der Abstraktion, S. 34., Fn. 19. Den Ausdruck des »vollen« Körpers übernimmt Czwerwinski von Karl Marx (Grundrisse, S. $80)$.

53 Ebda., S. 23.

54 Sonntag, a.a.O., S. 75f. 
dem) nach als »politische[n] Prozeß« einer bürgerlich geprägten »phy sische[n] Demokratisierung «. ${ }^{55}$ Noch das $»$ politische Denken des 16. Jahrhunderts verankert die soziale Ungleichheit zwischen Adeligen und Nicht-Adeligen in angeborenen und vererblichen Eigenschaften des menschlichen Körpers«. Jeder Mensch wird mit vom Vater per »Samen« übertragenen Eigenschaften ausgestattet. »Oben und Unten der Person im sozialen Kosmos wird aufgrund körperlicher Eigenschaften determiniert.« Bauern, die Erde bearbeiten müssen, sind daher auch »schwerfällig«, wohingegen die adligen Körper aufrecht, tugendhaft und höheren Geistes sind, da sie nicht durch Arbeit beschwert und beschmutzt werden. ${ }^{56}$ Der Besitz von Körpereigenschaften kann frühneuzeitlich auch spezifisch >ansteckend s sein. Von Werner Danckert stammt die schon klassische Untersuchung zu den gesellschaftlich notwendigen, aber »unehrlichen Berufen« wie etwa dem des Henkers, deren >Unehrlichkeit bei Berührung übertragen wird. ${ }^{57}$ Seit dem 18. Jahrhundert kommt es zu verstärkten (wissenschaftlich fundierten) Bemühungen der Bourgeoisie, die Unhaltbarkeit der Ungleichheit der Körper nachzuweisen, steht sie doch dem sozialen Aufstieg im Weg. ${ }^{58}$ Allerdings entstehen, wie etwa Richard Sennett zeigt, solche Argumentationen als Reaktionen auf längst eingesetzte Prozesse, in denen die ökonomische Zeit die >Natur des alten Körpers qua nicht mehr zyklischer Produktionsweise obsolet werden lässt. ${ }^{59}$ Die neue lineare Zeit im Zeichen der $»$ mechanischen Uhr« beginnt grundsätzlich schon im Spätmittelalter, markiert hier zunächst aber eine philosophische »Zeit-Revolution«, schreibt Martin Burckhardt. ${ }^{60}>\mathrm{Maß}$ und Zahl» werden frühneuzeitlich zu gemeinsamen Kennzeichen von Askese und Frühkapitalismus und somit zur Grundlage neuer bürgerlicher Ehekonzepte (Stephan Wyss). ${ }^{61}$ Mit der »Demokratisierung der Körper« werden diese, da untere Schichten auf Distanz gehalten werden müssen, zum »bevorzugte[n] Distinktionsmittel «, ${ }^{62}$ mit dem per Habitus und Kleidung »Geschmacksdistanzen« zwischen den

55 Gebauer, Gunter, a.a.O., S. 313.

56 Ebda., S. 314ff.

57 Vgl. Danckert, Werner: Unehrliche Leute. Die verfemten Berufe. Bern, München: Francke 1963

58 Vgl. Gebauer, a.a.O., 316f.

59 Sennett, Richard: Fleisch und Stein. Der Körper und die Stadt in der westlichen Zivilisation. Frankfurt/M: Suhrkamp 1997 (New York 1994), S. $251 \mathrm{ff}$.

60 Burckhardt, Martin: Metamorphosen von Raum und Zeit, S. 63.

61 Vgl. Wyss, Stephan: AskeSe. Ein Essay zum Selbstverständnis des herrschenden Mannes. Fribourg/Brig: Exodus 1989, S. 184ff.

62 Gebauer, a.a.O., S. $326 f$. 
Schichten inszeniert und anerkannt werden. Gebauer beruft sich hier auf Pierre Bourdieu und dessen Untersuchungen, wonach in dieser Weise die Körper zu »gesellschaftlichen Produkten« geformt werden, »Klassen-Körper«, deren Bestandteile »unmittelbar als Indiz[ie] für eine gesellschaftlich gekennzeichnete >moralische` Physiognomie gelesen« werden. ${ }^{63}$

Ein wesentliches Resultat dieses Prozesses hat Gebauer allerdings nicht im Blick. Die physische Egalisierung der Körper führt zu einer qualitativ neuen `natürlichen Differenz`, der der Geschlechter. Anatomische Darstellungen des Innenlebens des weiblichen Unterleibs der Renaissance-Medizin bzw. -Gynäkologie stellen dieses als inkorporiertes Negativ der männlichen Genitalien dar. Besonders einflussreich und oft kopiert ist die Vagina als 〉Penis` mit dem längs angeordneten Doppelkammer-Uterus als >Hoden〈 aus Vesalius' »Fabricia« von $1492 .{ }^{64} \mathrm{Die}$ Abbildung in Georg Bartischs »Kunstbuch« von 1575 könnte sowohl einen Penis mit Blase und Testikeln, als auch die weiblichen Organe zeigen. Das Rätsel löst sich erst im nebenstehenden Bild. Hier ist die Vorderseite des Uterus entfernt und präsentiert ein Kind. ${ }^{65}$ Die Sezierung von Menschen ist längst geübte Praxis. Nichtsdestotrotz werden die weiblichen Genitalstrukturen mit den männlichen als isomorph dargestellt: »hier werden sie geradewegs als solche gesehen «. ${ }^{66}$ Schon Esther Fischer-Homberger hat die antiken Auffassungen bei Hippokrates und Aristoteles »der Frau als Missbildung bzw. Mindergeburt« und den jahrhundertelangen Werdegang derartiger humoralpathologischer $\mathrm{Zu}$ schreibugen gezeigt. ${ }^{67}$

Am Ende des 18. Jahrhunderts, schreibt Londa Schiebinger, entwickeln Europas Anatomen »die Vorstellung eines männlichen und eines weiblichen Körpers, von denen beide ihr spezifisches Telos hatten«. Hier physische und intellektuelle Kraft, da Mütterlichkeit. »Männer und Frauen« werden nun »als zwar verschieden, doch je vollkommen gedacht«. Schiebinger sieht hier ein Paradox: »Auch nach dem revolutionären Wandel im Verständnis der Geschlechterdifferenz blieb die jahrhundertealte Dominanz des Mannes über die Frau erhalten - obwohl dies der grundlegenden Voraussetzung dieser Revolution widersprach:

63 Bourdieu, Pierre: Die feinen Unterschiede. Kritik der gesellschaftlichen Urteilskraft. Frankfurt/M: Suhrkamp $1994^{7}$ (Paris 1979), S. 310f.

64 Vgl. Laqueur, a.a.O., S. 100, Abb. 20 u. S. 102, Abb. 23.

65 Vgl. ebda., S. 106, Abb. 30, 31.

66 Ebda., S. 100.

67 Fischer-Homberger, Esther: Krankheit Frau (und andere Arbeiten zur Medizingeschichte der Frau). Bern: Huber 1979 (1969), S. 52. 
daß Körperlichkeit nicht geschlechtsneutral zu denken sei. « ${ }^{68}$ Aber: Vor »dieser Revolution« ist die (differente) Anatomie Signum des sozialen Geschlechts, seither umgekehrt die soziale Position Signum des biologischen Geschlechts. Beiden gemein ist die Einteilung in Wesen superiorer und inferiorer Art. Da das biologische Geschlecht ein >Kind des sozialen ist, lässt die `Entdeckung` zweier verschiedener und »je vollkommener« Geschlechter die hierarchisierende Differenz eben nicht obsolet erscheinen. Claudia Honegger hat beschrieben, wie sich die Entwicklung und Stabilisierung der »weiblichen Sonderanthropologie«, des »modernen Deutungsmuster[s] 〉Geschlechterdifferenz«« vollzogen hat aus einem Geflecht "von mannigfaltigen Handlungsproblemen, alltagsweltlichen Interpretationen, tradierten und erodierenden Wissensbeständen und wissenschaftlichen Systematisierungen«, letztere in einem komplexen Prozess der Szientifizierung von >Differenz $<.{ }^{69}$

Allerdings ist nicht zu übersehen, dass die alte Einkörpertheorie nicht gänzlich verschwunden ist. In den zentralen Theorien Sigmund Freuds spielt sie in gewisser Weise die Rolle eines Wiedergängers, den es regelmäßig zu bannen und auszuschalten gilt. Hier muss beim >Weibe < in der Pubertät das »homologe Lustzentrum«, der »verkümmerte[] Penis«, muss die »männlich-phallische Befriedigung« an der Klitoris aufgegeben werden zugunsten »der als Herberge des Penis geschätz$\mathrm{t}[\mathrm{en}] \ll$ Vagina. $^{70}$

Werner Kutschmann zeichnet die (wissenschaftliche) Distanzierung vom Körper nach. So werde in der Renaissance in der bildenden Kunst (bei Dürer etwa) und in der Philosophie begonnen, nach einem »unbeteiligten und unversehrten Körper«, einem »)reinen〈 Körper, der sich aus den Prozessen der Natur heraushält«, zu verlangen. Die Forderung nach einem »enthaltsamen Körper« unterstelle einen »Zusammenhang von `Natur und Natur`, der des Erkenntnisobjekts und -subjekts«, einen Zusammenhang, der »stillgestellt und suspendiert« werden soll.

Kutschmann geht es hier um die Transformation der Mimesis von einer der Gewalt in eine der Rationalität. Noch im ausgehenden Mittelalter werde »Hand an die Natur« gelegt, die als zu bekämpfendes oder zu

68 Schiebinger, Londa: Schöne Geister, S. 270.

69 Honegger, Claudia: Die Ordnung der Geschlechter, S. 213f.

$70 \mathrm{Zu}$ diesem Thema ausführlich gearbeitet hat Renate Schlesier: Konstruktionen der Weiblichkeit bei Sigmund Freud. Zum Problem von Entmythologisierung und Remythologisierung in der psychoanalytischen Theorie. Frankfurt/M: Europäische Verlagsanstalt 1981. Schlesier bezieht sich bei ihrer Darstellung (ebda., S. 36ff.) u.a. auf Freuds »Über infantile Sexualtheorien« (1908), »Neue Folge der Vorlesungen zur Einführung in die Psychoanalyse« (1933) und »Das Ich und das Es« (1923). 
überlistendes »beseeltes Wesen« gelte. »Der Bergmann des Mittelalters, der in den Berg einfuhr [...], legte damit gleichsam Hand an den (weiblichen) Körper der Erde an; er hatte Gelübde der Keuschheit und der lauteren Absicht abzulegen [...]. Allgemein galt der Eingriff in den Berg als [...] kaum rechtfertigbarer Frevel am >Körper der Natur «. ${ }^{71}$

Kutschmann beruft sich hier auf Carolyn Merchant und ihre Aussagen zur »Weiblichkeit der Natur«. Danach hat das »Bild von der Erde als einem lebendigen Organismus und einer nahrungsspendenden Mutter« vorneuzeitlich »als kulturelle Handlungshemmung« gegen übermäßige Ausbeutung gewirkt. »Man schlachtet nicht mir nichts dir nichts seine Mutter, wühlt in ihren Eingeweiden nach Gold oder verstümmelt ihren Leib «. ${ }^{72}$ Kathrin Braun und Elisabeth Kremer, die zeigen, wie Francis Bacon die wissenschaftliche Erkenntnis als quasi ersehnten Sexualakt charakterisiert, "um endlich einmal aus den Vorhallen der Natur, welche schon von einer Unzahl von Besuchern erfüllt sind, in ihr innerstes Heiligtum vorzudringen ${ }^{73}{ }^{73}$ und dann in diesem innersten Heiligtum der Natur auf Maschinen zu stoßen, ${ }^{74}$ kritisieren Merchants Reklamation des mütterlich nährenden Leibs und verweisen auf hierarchischen Dualismus, der dieses >weibliche Prinzip $<$ lediglich den vom >männlichen Geist` noch zu formenden Rohstoff liefern lässt, so bei Aristoteles. $^{75}$

Für die Projektion auf die äußere Natur sind Transformationen von swuchernden Leibern` in >formierte Körper` historisch zu beobachten. Das bezieht sich ebenso auf die Ebene der Wahrnehmung, wie auch auf die der tätigen Umgestaltung. ${ }^{76}$ In den frühen Bannforsten, die als exklusive Räume zur herrschaftlichen Jagd okkupiert werden, lässt sich der Wald als \Körper des Königs` nachvollziehen, in den sich die Herrscher rituell >einschreiben`, dessen >Wildnis` Voraussetzung einer rituellen Wiederholung der Unterwerfung ist. ${ }^{77}$ Mit dem Beginn der Genese des absolutistischen >Maschinen-Staats« werden Forsten zu Körper-Formationen, die `komponiert` werden als aufmarschierende Ständeversamm-

71 Kutschmann, Werner: Der Naturwissenschaftler und sein Körper. Die Rolle der »inneren Natur« in der experimentellen Naturwissenschaft der frühen Neuzeit. Frankfurt/M: Suhrkamp 1986, S. $110 \mathrm{ff}$.

72 Merchant, Carolyn: Der Tod der Natur. Ökologie, Frauen und neuzeitliche Naturwissenschaft. München: C.H. Beck 1987 (Berkeley 1980), S. 20f.

73 Braun, Kathrin/Kremer, Elisabeth: Asketischer Eros und die Rekonstruktion der Natur zur Maschine. Oldenburg: BIS 1987, S. 25.

74 Vgl. ebda., S. 1.

75 Vgl. ebda., S. 8.

76 Vgl. Kap. Monströse Leiber zu idealschönen Körpern.

77 Vgl. Kap. Forst I. 
lungen oder Soldaten. ${ }^{78}$ In Wahrnehmungen und Aneignungen des Waldes, die pseudo-organische Entwürfe gegen den Mechanismus, Industrialisierung und entfremdende Strukturen der Modernisierung darstellen, in völkisch nationalen Konstruktionen vor allem, gerät der Wald zum >wilden Recken`, Ort einer `kämpferischen Symbiose` von Natur und Gemeinschaft. ${ }^{79}$

\section{Von aggregativen zu generativen Bedeutungsstrukturen}

»Wie also die Möglichkeit einer Wahrnehmung von (rein quantitativ) Unbekanntem allein der historischen Möglichkeit einer Denkform des immer schon Bekannten, der Logik des systematischen Raumes entspringt, erwächst in einer noch aggregativen Raum-, Denk- und Weltstruktur die beständige Konstatierung des Bekannten aus der Realität des (qualitativ) Unbekannten. ${ }^{80}$

Dass in dieser Weise die >neue Welt « von den ersten `Entdeckern « mit bekannten Figuren bevölkert wird, zeigt Christian Kiening. ${ }^{81}$ Erst mit den Entdeckungsfahrten des 15. und 16. Jahrhunderts beginnt eine »Logik der Einheit der Welt, ihrer grundsätzlichen Bekanntheit, ihrer totalen, lediglich temporär noch ans Ende zu bringenden rationalen Erfahrbarkeit «. ${ }^{82}$ Die Anordnung einer Vielzahl semantischer Räume in vorbürgerlichen Gesellschaften beschreibt Czerwinski so: »Die selbständigen, nebeneinander liegenden Blöcke aggregativ organisierter Räume [...] nehmen sich, anders als die vertikalen, nur mehr reflexiv vermittelten Schichten des einen, systematischen generativen Raumes« - in der bürgerlichen Gesellschaft - »wechselseitig nicht ihr soziales Recht, machen einander nicht zum Schein. Aggregative Räume sind also noch eine Summe von konkreten, qualitativen Orten, erzeugen kein in seiner Abstraktion höher geltendes System reiner Vermittlung, lediglich quantitativer Differenz ${ }^{83}$

78 Vgl. Kap. Forst II: Der Wald als absolutistische Staatsmaschine.

79 Vgl. Kap. Der Wald als Ort des >Daseinskampfes $<$.

80 Czerwinski, Peter: Gegenwärtigkeit, S. 92.

81 Vgl. Kiening, Christian: Ordnung der Fremde. Brasilien und die theoretische Neugierde im 16. Jahrhundert, in: Krüger, Klaus (Hg.): Curiositas. Welterfahrung und ästhetische Neugierde in Mittelalter und früher Neuzeit. Göttingen: Wallstein 2002. Vgl. Kap. Die totale Inversion männlicher Herrschaft: Kannibalinnen.

82 Czerwinski, a.a.O.

83 Ebda., S. 86. 
Vergleichbar zeigt Michel Foucault die noch im 16. Jahrhundert bestehenden Wahrnehmungsmuster nach »Formen der Ähnlichkeit «. ${ }^{84}$ »Der Raum der unmittelbaren Ähnlichkeit wird zu einem großen offenen Buch. Es starrt von Schriftzeichen. [...] Man muß sie nur noch entziffern.« Denn es herrscht ein »Gewimmel von Ähnlichkeiten« und diese sind zunächst unsichtbar. Um sie sichtbar zu machen, gibt es die »Signaturen«. Denn: »Um zu wissen, daß der Eisenhut unsere Augenkrankheiten heilt, oder daß die im Mörser zerstampfte Nuß mit Weingeist unsere Kopfschmerzen heilt, muß man durch ein Zeichen darauf aufmerksam gemacht werden. ${ }^{85}$

Belege für solche aggregativen Wahrnehmungs- und Handlungsstrukturen finden sich etwa in Joachim Allmanns Mentalitäts- und Sozialgeschichte frühneuzeitlicher bäuerlicher Waldnutzung im Konflikt mit obrigkeitlichen Ordnungsvorstellungen, ${ }^{86}$ ebenso in den parataktischen Bedeutungen von Sümpfen, Auen und Brüchen und der dort vorkommenden Flora und Fauna. Weiden etwa sind `Hexenbäumeく, werden magisch gegen das >Böseく genutzt, desgleichen ökonomisch. ${ }^{87}$ Damalige Naturgeschichten, wie Konrad von Megenbergs »Buch der Natur« (14. Jahrhundert) oder der »Physiologus« führen neben >realen` Tieren auch Geschöpfe wie »arpen«, gefräßige Vögel mit menschlichen Gesichtern oder »Basilisken«, schlangenartige Monster an. ${ }^{88}$ Die in der Moderne »so evidente Trennung« zwischen Überliefertem, Legenden, Dokumenten und Beobachtungen existiert in dieser Weise noch nicht. ${ }^{89}$

»Vermittlungsformen aber, unter denen sich die selbständigen Teile einer aggregativ organisierten Welt bewegen, gibt es manche. Eine davon, die im mittelalterlichen Epos dominiert, ist beispielsweise jener Sprung, der den Heroen an die ihm >objektiv bestimmten, doch nur parataktisch zusammenhängenden und einer subjektiven, intentionalen Vermittlung nicht zugänglichen Punkte bringt: der Sturm, das Meer, der Wilde Wald, das Zauberpferd, der ziellose Ritt etc.; eine andere Form der Aggregation, bestimmend für die Darstellungsweisen des Schwankhaften, Karnevalesken, ist die Verkehrung, die Ge-

84 Foucault, Michel: Die Ordnung der Dinge. Frankfurt/M: Suhrkamp 1974 (Paris 1966).

85 Ebda., S. 56f.

86 Vgl. Allmann, Joachim: Der Wald in der frühen Neuzeit. Eine mentalitätsund sozialgeschichtliche Untersuchung am Beispiel des Pfälzer Raumes 1500-1800. Berlin: Duncker \& Humblot 1989; vgl. Kap. Das Verschwinden von Werden und Vergehen.

87 Vgl. Kap. Hexenbäume und Katzen und Kap. Ungezügelte Pflanzen und Reptilien.

88 Vgl. Wyss, Stephan: AskeSe, S. 85.

89 Vgl. Foucault, a.a.O., S, $169 f$. 
genbildlichkeit (die folglich besser und weniger mißverständlich >Nebenbildlichkeit $\ll$ hieße). ${ }^{90}$

Der Wald als Gegenwelt ist demnach eigentlich eine Nebenwelt, die betreten und verlassen werden kann. Dass in den aggregativ angeordneten Räumen die jeweiligen Bedeutungen gleichwertig nebeneinander stehen, besagt keine Unantastbarkeit. Die >Beseeltheit` der Wälder steht demnach in keinem Widerspruch dazu, dass sie geplündert, gerodet werden. Auch das gehört zur aggregativen Struktur, die auf »keine innere Einheit der Person zentriert « ist und deren »Bestandteile« ebenso wenig »hierarchisch z.B. `nach den Regeln der Vernunft ' geordnet « sind. ${ }^{91}$

Der Wandel von aggregativen zu generativen Bedeutungen korrespondiert mit Veränderungen innerer, psychischer Strukturen mit sich, es entsteht »Unterbewusstsein«, d.h., auch die Bedeutungen bekommen Untergründe, >unterirdisch` wirksame Kanäle. Diese Transformationen sollen in den einzelnen Kapiteln im jeweiligen Kontext entfaltet werden. $^{92}$

\section{sInnens und >Außens}

»Der Mensch soll seiner höheren Bestimmung gemäß immer mehr und mehr zum Siege über die materielle Natur gelangen, der einzelne Mensch zur Herrschaft über seine eigene Natur, die Menschheit im Ganzen zur Herrschaft über die Natur im Großen. $\ll^{93}$

Die Kategorien von >Innen turverhältnissen bezeichnen einander überlagernde, sich ebenso wechselseitig bedingende Dimensionen, wobei desgleichen Diskontinuitäten zu beobachten sind. Zum einen geht es um die Endo- und Exosphäre der Gesellschaft. Diese Aufteilung in Sphären von >Innen` (Haus, Dorf) die Orte, an die Frauen verwiesen werden, in denen Männer aber die dominante soziale Position besitzen - und >Außen « (Wald, fremde Territorien) - Orte, die weitgehend exklusiv von Männern aufgesucht werden entstehen historisch schon sehr früh, grundsätzlich in sesshaften, agrari-

90 Czerwinski: Gegenwärtigkeit, S. 479f.

91 Sonntag, a.a.O., 73.

92 Vgl. insbesondere Kap. Entgrenzungen - Begrenzungen: Der Herkynische Wald als Reterritorialisierung.

93 Schreber, Daniel Gottlob Moritz; zit. n. Makowski, Henry/Buderath, Bernhard: Die Natur dem Menschen Untertan. Ökologie im Spiegel der Landschaftsmalerei. München: Kindler 1983, S. 37. 
schen Gesellschaften. Eine Trennung, die auch fürs Mittelalter beschrieben wird, bis hin zu streng unterschiedlichen >Sprachen` der Geschlechter (Bernd-Ulrich Hergemöller). Auch wenn eine Verständigung der Geschlechter zwangsläufig stattfindet - im Herrschaftsbereich, in Handel, Handwerk, Landwirtschaft -, sei diese Kommunikation jedoch je »apriori aufgrund der unterschiedlichen Sozialisation von essentiellen Unterschieden geprägt, die sich vor allem im Wortschatz, in der Wortwahl, der Grammatik und der Fremdsprachenkenntnisse manifestiert haben werden $\ll{ }^{94}$ Sprachkompetenz im gesamten Mittelalter sei androzentrisch. ${ }^{95}$ Auf der einen Seite also ist die Frau >innen`, zugleich wird sie, als von der männlich besetzten Norm Abweichende, als >draußen`, als die >Andere $<$ wahrgenommen.

Zum anderen, aber damit verbunden, geht es also um das >Innen< als einem beherrschten, sich ausdehnenden Raum und das >Außen $<$ als einem unbeherrschten Raum. Dass die Aufspaltung in >Innen $<$ und >Außen - und damit zugleich die wechselseitige Bedingung von >Innen und >Außen $<$ - im heutigen Sinn in der frühen Neuzeit entstanden ist, ist häufig gezeigt worden. Geht man von aggregativen Strukturen zuvor aus, lässt sich das weiter stützen, da dort offenbar eher von >Nebeneinander`, als von Innen und Außen gesprochen werden kann. ${ }^{96}$ Die Landschaft als ästhetisch erfahrbarer und gestaltbarer Ort, als Raum >draußen`, in dem möglicherweise positiv konnotierte >Gegenwelten ২ vermutet werden können, entsteht frühneuzeitlich erst mit der Genese des städtischen bürgerlichen Subjekts. ${ }^{97}$

»Aufklärung ist radikal gewordene, mythische Angst. Die reine Immanenz des Positivismus, ihr letztes Produkt, ist nichts anderes als ein gleichsam universelles Tabu. Es darf überhaupt nichts mehr draußen sein, weil die bloße Vorstellung des Draußen die eigentliche Quelle der Angst ist. ${ }^{98}$

94 Hergemöller, Bernd-Ulrich: Masculus et femina: Systematische Grundlinien einer mediävistischen Geschlechtergeschichte. Hamburg: HHL-Verlag 2001, S. 76.

95 Vgl. dazu Lorenz, Maren, a.a.O., S. 129 (mit weiterführenden Literaturangaben) und Rivera Garretas, María-Milagros: Orte und Worte von Frauen. Eine Spurensuche im europäischen Mittelalter. München: dtv 1997 (Barcelona 1990), S. 103ff. Zum Absondern, Eingrenzen und strikten Überwachen der Frauen als »Eckstein des Wertesystems« im adligen Haushalt vgl. Duby, Georges: Das Gefährliche: die Frauen und die Toten, in: Ariès, Philippe/Ders. (Hg.): Geschichte des privaten Lebens 2. Vom Feudalzeitalter zur Renaissance. Augsburg: Bechtermünz 2000 (Paris 1985), S. 87ff.

96 Vgl. Sonntag, a.a.O., S. $67 \mathrm{ff}$.

97 Vgl. Kap. Das neue bürgerliche Subjekt entdeckt die Landschaft.

98 Sonntag, a.a.O., S. 22. 
Das berühmte Diktum von Horkheimer/Adorno, das sich kurz in >was außen ist, soll innen werden keine Einbahnstraße. Die soziale Inkorporation des >Außen〈, die Vergesellschaftung der ıäußeren Naturく kann nur nach den Bedingtheiten des >Innen〈, der >inneren Natur erfolgen. Klaus Theweleit: »Über das Verhältnis zum eigenen Körper und $\mathrm{zu}$ anderen menschlichen Körpern entwickelt sich die Beziehung jedes menschlichen Körpers zur übrigen Objektwelt und aus dieser die Sprechweise dieser Körper von sich, den Objekten, den Beziehungen zu den Objekten. « ${ }^{99}$ Mit Theweleit werde ich vor allem die Konstruktion von `soldatischen Wäldern`, >Wildnissen`, die `Innen` sind, und die Bändigung des `weiblichen` Wassers untersuchen. $^{100}$

Seit dem Beginn der Moderne sind die Grenzen nach außen immer weiter ausgedehnt worden. Götz Großklaus spricht von »kognitiv-symbolischen Karten«, die »Grundmuster raum-analoger, soziokultureller Orientierung und Bewegung" festlegen und die sich aus Texten europäischer Literatur rekonstruieren lassen. Sie »geben die unterschiedlichen Routen an, auf denen wir die Grenzen [...] unserer Innenräume überschreiten können: nach oben (in die Höhe), nach unten (in die Tiefe) - nach außen (ins Weglose, Ungeordnet-Dichte von Wildnis/Dschungel - ins Weglos-Ungeordnet-Offene des Meeres). Es sind Routen, die aus den jeweils geschichtlichen kulturellen Binnen- und Eigenräumen hinausführen«, aber ebenso zurück. ${ }^{101}$ Wo die Grenzen zwischen »Eigenem« und »Fremdem« verlaufen, und wie offen sie sind, »ist mit dem [...] Zivilisationsprozeß im ganzen verknüpft« und äußert sich »deutlich seit dem Anfang des 18. Jahrhunderts« in aufeinanderfolgenden »Perioden massiver Eingrenzung (Aneignung, Befriedung) des Natur-Fremden« und solchen »revoltierende[r] Entgrenzungen«, der Reklamationen "auf den Aufbruch in die Fremde, den Gang in die Wildnis, das Überschreiten der jeweiligen Grenze«. Und diese »Grenzen zwischen Eigenem und Fremdem verlaufen >innen die erlernten psychischen Mechanismen der >Affektdämpfung « und der Triebregulierung bzw. -modellierung vom Fremden und Wilden in uns selbst ab. Nach außen versperren uns insbesondere die erlernten Codes der Wahrnehmung den Blick auf das Fremde und Andere außerhalb un-

99 Theweleit, Klaus: Männerphantasien Bd. 1: Frauen, Fluten, Körper, Geschichte. Frankfurt/M: Verlag Roter Stern 1977, S. 40.

100 Vgl. Kap. Der Aufmarsch der Soldaten, Kap. Der Wald als kämpferische Volksgemeinschaft und Kap. Von der endgültigen Abschaffung des >Matriarchats<.

101 Großklaus, Götz: Natur - Raum. Von der Utopie zur Simulation. München: Judicium 1993, S. $20 f$. 
ser«. Wobei diese Grenzen immer weiter nach ") vorne〈 verschoben« worden seien, Wildnis immer weiter verschwunden sei. ${ }^{102}$ Großklaus übersieht allerdings, dass dieses $>$ Fremde $<$ und $>$ Wilde $<$ in $>$ uns $<$ gesellschaftlicher Produktion entspringt; desgleichen das $>$ Fremde $</>$ Wilde außerhalb, wie die Konstruktionen der Anderen`, der Inversion männlicher Ordnung und Herrschaft in der Figur der >Kannibalin` (in Analogie zur europäischen Hexe) und der damit korrespondierenden Landschaft, wie sich das aus Reiseberichten frühneuzeitlicher Kolonisatoren in Brasilien rekonstruieren lässt. ${ }^{103}$

Für die Moderne skizziert Astrid E. Schwarz die >Innen-Außen〈Perspektive für den »Raum« (mittelbare und abstrakte Natur, Binnenland, bearbeitetes Land, Nähe versus unmittelbare, konkrete Natur, Übersee, Land als Ressource, Ferne), für die »Gesellschaft« (das `Eine, Mann, Kapital, Vernunft, modern, industriell, Nation, Begrenztheit versus das >Andere`, Frau, Natur, Gefühl, fremd, exotisch, antimodern, ausgedehnt), für das »Subjekt» (Beherrschung, Verfügbarkeit von (materieller) Natur, Maschine, Körper, imperiale Beziehung versus Genuss der (idealen) Natur, Unterwerfung unter sie, arkadische, kontemplative Beziehung). >Innen (aus der modernen Subjektperspektive sei zudem die »äußere, physische Erscheinung der Natur«, >außen` demgegenüber die »innere, psychische Erscheinung der Natur«. Das modernde Subjekt veräußere »sich selbst in der Natur metaphysisch" und mache sich dort sichtbar, "wo es sich physisch (noch) nicht geäußert hat. Die konkrete und unmittelbare Natur, also >Landschaftı, wird zum Symbol jener Natur, die in der städtisch industriellen Welt nicht mehr vorkommen kann. >Landschaft $\iota$ ist dann der >symbolische Kristallisationspunkt des modernen Unbehagens an der Moderne « ${ }^{104}$

Eine Studie, die gesellschaftliche Naturverhältnisse aus einer Perspektive der langen Sicht untersucht, kommt um eine Auseinandersetzung mit der Zivilisationstheorie von Norbert Elias nicht herum. Schon weil Elias, anders als Horkheimer/Adorno, keinen Prozess der Aufklärung untersucht hat, der sich weitgehend im philosophischen Überbau abspielt, sondern versucht hat, Mentalitätsgeschichte zu begründen, die Transformationen von Fühlen, Denken und Handeln >wirklicher` Menschen im historisch-sozialen Prozess nachzuzeichnen, das Wirken der Macht in den wechselseitigen Verflechtungen von Individuum und Gesellschaft.

102 Ebda., S. 83f.

103 Vgl. Kap. Kannibalinnen.

104 Schwarz, a.a.O., S. 112ff. Binnenzitat von Hard, Gerhard: Selbstmord und Wetter - Selbstmord und Gesellschaft. Stuttgart 1988, S. 263. 
Man kann ihn zugleich als einen »fondateur de discusivité« bezeichnen, der nicht nur sein Werk geschaffen, sondern andere >ermöglicht $\prec$ hat, der einen Diskurs begründet hat, an dem es kein Vorbei mehr gibt (wie desgleichen Marx, Freud, Foucault selbst). ${ }^{105}$

Für Norbert Elias stellt die Wald-Wildnis ein Bedrohungspotential ersten Ranges dar und mit der »zunehmenden Pazifizierung« der Landschaft »ändert sich zugleich auch die Sensibilität der Menschen für ihr Verhalten im Verkehr miteinander«:

»Die Art, wie langsam im Anstieg des Mittelalters und dann beschleunigt vom 16. Jahrhundert ab die >Natur erlebt wird, ist dadurch gekennzeichnet, daß immer größere Menschenräume immer entschiedener befriedet werden; erst damit hören Wälder, Wiesen und Berge allmählich auf Gefahrenzonen erster Ordnung zu sein, aus denen beständig Unruhe und Furcht in das Leben des Einzelnen einbricht; und nun, wenn das Wegnetz, wie die Verflechtung dichter wird, wenn Raubritter und Raubtiere langsam verschwinden, wenn Wald und Feld aufhören, der Schauplatz ungedämpfter Leidenschaften, wilder Jagden auf Menschen und Tiere, wilder Lust und wilder Angst zu sein, wenn sie statt dessen mehr und mehr durch friedliche Tätigkeiten [...] modelliert werden, nun wird den befriedeten Menschen die entsprechend befriedete Natur in einer neuen Weise sichtbar. ${ }^{106}$

Die Minimierung äußerer Angstquellen wird zur Bedingung der Triebdämpfung. Bei »Primitiveren«, schreibt er, »ist auch der Naturraum noch in weit höherem Maße eine Gefahrenzone; er ist von Ängsten erfüllt, die der zivilisierte Mensch nicht mehr kennt «. ${ }^{107}$ Er nimmt diese Ängste der »Primitiven« rein aus einer größeren Umweltunsicherheit an, zugleich sieht er Ängste moderner Menschen vor >Wildnis` offenbar als inexistent an.

Das Elias-Konzept ist in verschiedener Hinsicht eindimensional. So verläuft der Zivilisationsprozess bruchlos in einer großen linearen Kurve. Dass Elias hier und da von Brüchen und Rückwärtsbewegungen spricht, hat eher den Charakter eines Einräumens. Und es verläuft praktisch ausnahmslos gesellschaftlich von >oben nach >unten ${ }^{108}$ Zugleich wird das Leben seit dem Ende des Mittelalters beständig friedlicher. Phänomene wie die Hexenverfolgung existieren in dieser Theorie

105 Foucault, Michel: Qu'est-ce qu'un auteur?, in: Bulletin de la Société française de Philosophie 63 (1969), Nr. 3, S. 89.

106 Elias, Norbert: PDZ 2 , S. 405f.

107 Ebda., S. 405.

108 Vgl. ebda., S. $341 \mathrm{ff}$. 
nicht. ${ }^{109}$ Die Geschlechterhierarchie erscheint bei ihm noch im Mittelalter als bloß auf physische männliche Überlegenheit gegründet, weshalb der Zivilisationsprozess auch als sozialer Machtzuwachs von Frauen verlaufe. ${ }^{110}$ Das Ansteigen von Scham und Peinlichkeit beschreibt bloße Quantitäten. Qualitative Veränderungen werden hier ebenso wenig angenommen, wie die Möglichkeit, dass aus Gefühlen von Scham und Peinlichkeit Aggressionen entstehen, diese seien vielmehr Instanzen, die die Affekte umlagern und in Schach halten. ${ }^{111}$ Zwar übernimmt er die Terminologie von »Es«, »Ich« und »Über-Ich« von Freud, ${ }^{112}$ er fundiert sie aber lerntheoretisch. Daher werden die Menschen stets auf die gesellschaftlich erwünschten Verhaltensweisen hin »konditioniert«. »Gesellschaftlich unerwünschte Trieb- und Lustäußerungen werden mit Maßnahmen bedroht und bestraft, die Unlust erzeugen oder dominant werden lassen«. Permanentes Bestrafen verbinde dann das Verhalten »zwangsläufig« mit der »Unlustdominante «. ${ }^{113}$ Unerwünschte Verhaltensweisen hingegen entstammen ungenügenden Konditionierungsleistungen und sind keine sozialen Produkte. ${ }^{114}$ Diese Grundsätze sind auch vor dem Hintergrund seiner Ablehnung jeglicher Dialektik zu sehen. ${ }^{115}$

Obwohl er dem Leser abverlangt, umzudenken, wie er das selbst getan habe, ${ }^{116}$ bewegt er sich historisch-semantisch völlig im einen bürgerlichen Raum. Er kennt keine qualitativ anderen Gesellschaften, so werden Menschen auf >früheren Zivilisationsstufen`zu Mängelausgaben der >höher Zivilisierten`. »Beides, Lust und Unlust entlud sich hier offener und freier nach außen. Aber das Individuum war ihr Gefangener; der Einzelne wurde oft genug von seinen eigenen Empfindungen, wie von Naturgewalten, hin und her geworfen. Er beherrschte seine Leidenschaften weniger; er war stärker von ihnen beherrscht.« ${ }^{117}$ Dafür gibt es zwei wesentliche Voraussetzungen: Die Bindung der wechselseitigen Vernetzungen an einen zentralistischen Staat. Wo dieser weitgehend fehle, herrsche weitgehende Desintegration, kaum »Selbstzwang« und

109 Das ist auch Klaus Theweleit - neben anderen Punkten - aufgefallen; vgl.

Männerphantasien Bd. 1, S. 386.

110 Vgl. PDZ 2, S. $109 \mathrm{ff}$.

111 Vgl. ebda., S. 398f.

112 Vgl. ebda., S. 400.

113 PDZ 1, S. $282 \mathrm{f}$.

114 Vgl. ebda., S. 329.

115 Vgl. Elias, Norbert/Lepenies, Wolf: Zwei Reden anläßlich der Verleihung des Theodor W. Adorno-Preises 1977. Frankfurt/M: Suhrkamp 1977.

116 Vgl. PDZ 1, S. LXXXI.

117 PDZ 2, S. $329 f$. 
bestenfalls sporadisch $»$ Fremdzwang $«{ }^{118}$ Das $»$ soziogenetische Grundgesetz«, das Elias vom "phylogenetischen Grundgesetz« Ernst Haeckels übernimmt, ${ }^{119}$ besagt, dass die Soziogenese in jeder Psychogenese aufs Neue durchlaufen wird. Daraus leitet er aber im Umkehrschluss eine vergleichsweise geringe Differenz zwischen Erwachsenen und Kindern auf >niedrigeren Zivilisationsstufen $<$ ab. ${ }^{120}$

Es muss in diesem Rahmen bei einem Anreißen der kritisierten Punkte bleiben. ${ }^{121}$ Ich werde in einigen Kapiteln näher auf bestimmte Aspekte eingehen. ${ }^{122}$

118 PDZ 1, S. 278f.

119 Ebda., S. 330.

120 Vgl. ebda., S. 192 u. 277.

121 Zur (unterschiedlich vorgebrachten) Kritik an Elias vgl. insbesondere Baumann, Zygmunt: Dialektik der Ordnung. Die Moderne und der Holocaust. Hamburg: Europäische Verlags-Anstalt 1992 (Oxford 1989); Breuer, Stefan: Die Gesellschaft des Verschwindens. Von der Selbstzerstörung der technischen Zivilisation. Hamburg: Junius 1992; Duerr, Hans Peter: Der Mythos vom Zivilisationsprozeß. 5 Bde. Frankfurt/M: Suhrkamp 1988-2002; Modelmog, Ilse: Die zwei Ordnungen. Industrielles Bewußtsein und Subjektanarchie. Opladen: Westdeutscher Verlag 1989; Oesterdiekhoff, Georg W.: Zivilisation und Strukturgenese. Norbert Elias und Jean Piaget im Vergleich. Frankfurt/M: Suhrkamp 2000; Sonntag, Michael, a.a.O. Auch diese Ansätze kann ich hier nicht näher diskutieren.

122 Vgl. Kap. Hexenbäume und Katzen und Kap. Verflechtungen. 



\section{Verkörperungen - Bilder: theoretische Begriffsbestimmungen}

»Es mag irritierend anmuten, von einem >praktischen Diskurs `Sprache der Dinge` reden zu hören - gleichwohl ist damit nichts anderes gemeint als jenes Denken, das in die Dinge einfließt und hier sich in verdinglichter Form äußert. Tatsächlich stimmt es ja nicht, daß die Dinge stumm sind, sondern es liegt, wenn wir von einem >Sachzwang` reden, in Wahrheit ein Denkzwang vor, der nur die Gestalt einer Sache angenommen hat. Dieses verdinglichte, in den Artefakten eingeschlossene, oder eigentlich: in die Wirklichkeit hinausgelegte Denken ist dem, was sich selbst als Denken definiert, deutlich voraus - und zwar so, daß das, was wir Denken nennen, zum Nachdenken verdammt ist (oder schlimmstenfalls, wie im Falle der spätmittelalterlichen Philosophie: zum Gegen-die-Dinge-Andenken, zur systematisierten Wahrnehmungsstörung). Descartes, vor dem Hintergrund der mechanischen Uhr, und damit: vor dem Prospekt seiner Megametapher betrachtet, ist kein Neuerer, sondern ein Nachzügler des Denkens. ${ }^{1}$

Burckhardt spricht nur vom »Denken«, das einfließe in die Dinge. Es muss allerdings >Wahrnehmen $<$ heißen, da das auch >Fühlen $<$ beinhaltet (das Denken, die Ideologie kommt später). Die Erfahrung der Unordnung des Primärwaldes, oder dessen, was dafür gehalten wird, des Chaos' der Dinge ist 〉Gefühl`, ein 〉Gefühl«, das in der Weise historischen Prozessen unterliegt, wie auch der Leib nicht Essenzielles sein kann, sondern historischen Prozessen unterliegt. ${ }^{2}$ Umgekehrt trifft das ebenso auf die Wahrnehmung von >gefestigten Strukturen

1 Burckhardt, Martin: Metamorphosen von Raum und Zeit, S. 15.

2 Vgl. Kap. Bürgerliche Naturmystik. 
etwa als >stehendes Heer oder als Großkirche empfunden, konstruiert, propagiert wird.

Mit Friedrich W. Heubach ist von einer »materiale[n] Repräsentanz, die dem Psychischen in den Dingen gegeben ist « auszugehen. ${ }^{3}$ Die »Gegenständlichkeit der Dinge« stellt demnach »keine den Dingen inhärente Qualität, kein objektives Datum dar, sondern ein (psycho-logisches) Konzept«. Die Dinge sind nicht nur Ausdruck von Psychischem, vielmehr erfährt dieses in ihnen »auch eine gegenständliche Modellierung«. Heubach entwickelt seine Thesen im Hinblick auf die Ontogenese in der Moderne. Auf vormoderne Gesellschaften ist das, wie gezeigt, nicht anwendbar. Dass die Dinge dort sprechen, ist mit Foucaults »Formen der Ähnlichkeit« und »Signaturen« bereits erwähnt worden.

Von einer Sprache der Dinge auszugehen heißt, die Dinge der äußeren Natur als historische >Kulturgegenstände` aufzufassen, die soziale Funktionen erfüllen. Diese Funktion ist vor allem eine der Sinnproduktion. Die soziale Produktion der Naturdinge weist ihnen mimetische Eigenschaften zu, >weiblicheく oder >männlicheく Eigenschaften, die desgleichen historischen Prozessen unterliegen.

Die Dinge sprechen. Ihre Sprache besteht aus Verkörperungen. Die lebendigen Dinge der ıäußeren` Natur symbolisieren also nicht, sondern sie verkörpern - abhängig von den historisch unterschiedlichen Gesellschaftsstrukturen, vom menschlichen Körper als historischem Prozess jeweils etwas: Das, was >innen gefühlt wird, dabei gefürchtet und/oder ersehnt, wird ebenso >außen zen von inner- und außerleiblichen (bzw. -körperlichen) >Erfahrungsräumen . Die Existenz dieser Korrespondenzen hat bereits Marx mit dem Begriff des »unorganische[n] Leib[s] des Menschen ${ }^{4}$ angedeutet, mit dem dieser im permanenten Prozess des »Stoffwechsels« bleiben müsse, wobei mittels Arbeit ein permanent interdependentes Austauschverhältnis in der Interaktion von Gesellschaft und Natur bestehe. ${ }^{5}$ »Arbeit ist« bei Marx »das prägende Mittel in diesem sozial-ökologischen Verfahren. Mit ihr verändert der Mensch« in geschichtlich jeweils eigener Art »nicht nur die äußere, sondern auch seine innere Natur «. ${ }^{6}$ Derselbe Marx hat aber rund 30 Jahre später in seiner »Kritik des Gothaer Programms den Lassalleanern« vorgehalten, »nicht die Arbeit

3 Heubach, Friedrich W.: Das bedingte Leben, S. 103

4 Marx, Karl: Ökonomisch-philosophische Manuskripte, in: MEW Ergänzungsband 1 Berlin (O): Dietz 1981 (1844), S. 516.

5 Ebda., S. 573f.

6 Kropp, Cordula: »Natur«. Soziologische Konzepte, politische Konsequenzen. Opladen: Leske + Budrich 2002, S. 154f. 
allein sei, wie unter Vulgärsozialisten herzubeten üblich war, die Quelle gesellschaftlichen Reichtums « ${ }^{7}$ Ebenso wäre zu ergänzen, dass >Arbeit in den gesellschaftlichen Naturverhältnissen nicht das einzige Moment ist, wollte man nicht auch hier einer »Hypostasis« das Wort reden, die »die Illusion von der Vormacht des erzeugenden Prinzips nur fort[setzt] ${ }^{8}{ }^{8}$ Matthias Eberle hat gezeigt, dass die von Marx angeführte (aber historisch nicht datierte) »ursprüngliche Akkumulation« einhergehe mit einer ästhetischen Aneignung der >äußeren Natur übertreten und ästhetischen Umformen, das erst dem städtisch sich von der Landschaft sich separierenden und (proto-)kapitalistisch produzierenden bürgerlichen Subjekt seit der frühen Neuzeit möglich sei. ${ }^{9}$

Es geht also um die unterschiedlichen Weisen der sinnlichen und ästhetischen Wahrnehmung, der Körpererfahrung im historischen Prozess und die Verkörperungen dieser Erfahrungen in der >äußeren Naturく. Und wenn Sennett »argumentiert, daß urbane Räume weithin durch die Weise Gestalt annehmen, wie die Menschen ihren eigenen Körper erfahren «, ${ }^{10}$ dann trifft das eben nicht nur auf urbane, sondern ebenfalls auf die Räume in der ‘äußeren Natur`zu. Räume, die hier wie da in spezifischer Weise als Bilder erscheinen.

Burckhardt merkt an, dass in den Parks des Absolutismus eine BildGrammatik zur direkten Erfahrung werde. »Bildraum« und »Erfahrungsraum « gingen untrennbar ineinander über, da der Bildbetrachter in diesem Bild sei und gleichzeitig ein Selbst-Bewusstsein als Betrachter habe. ${ }^{11}$ Das ist ergänzungsbedürftig. Diese Bilder und ihre »Grammatik« sind weder auf geometrisierte Barockgärten, noch auf Gärten und Parks überhaupt beschränkt. Die Gleichzeitigkeit von Bild- und Erfahrungsraum betrifft desgleichen Wälder, die >freie Landschaft`, und zwar nicht erst dann, wenn sie ihrerseits (um-)gestaltet werden, sondern bereits mit dem Augenblick ihrer Bemächtigung. Zwar verweist >Grammatik auf regelhafte Gestaltung. Und der Unterschied zwischen Garten und >freier Natur` ist die bewusste Gestaltung des ersteren. Aber das, was in der >freien Natur angetroffen wird, ist als >Bild ২ bereits gesellschaftlich vorgeformt und wird demgemäß wahrgenommen (was sowohl

7 Adorno, Theodor W.: Negative Dialektik. Frankfurt/M: Suhrkamp 1975 (1966), S. 179.

8 Ebda.

9 Eberle, Matthias: Individuum und Landschaft. Zur Entstehung und Entwicklung der Landschaftsmalerei. Gießen: Anabas-Verlag 1980, S. 8f. u. $44 \mathrm{ff}$.

10 Sennett: Fleisch und Stein, S. 456.

11 Burckhardt, a.a.O., S. 205f. 
von affirmativem als auch pejorativem Bewusstsein dieser formenden Gesellschaft sprechen kann).

Die Erfahrungsräume sind Bilder, weil sie gesellschaftlich vermittelt, weil sie, mehr noch: in komplexer Weise erzeugt werden. In ihnen werden ebenso (gesellschaftlich vermittelte) Erfahrungen erzeugt. Für Gärten und Parks scheint das naheliegend. Hier werden bewusst Lebewesen architektonisch zugerichtet, nach wissenschaftlichen und ästhetischen Prinzipien so präsentiert, dass Bedeutungen, dass >Stimmungen erzeugt werden. ${ }^{12}$ >Stimmungen ( und Bedeutungen, die im konstitutiven Prozess zwischen Gesellschaft, Individuum und >äußerer Naturく entstehen. `Schönheit`, >Ästhetik` ist dabei Resultat des ordnenden Zugriffs, der Herrschaftsausübung, aber auch des Widerspruchs dagegen, der allerdings seinerseits neue Formen des ordnenden Zugriffs hervorbringt.

$\mathrm{Zu}$ Gärten und Parks zählen kategoriell auch Naturschutzgebiete, Renaturierungsareale (und in der Praxis die Prinzipien des Waldschutzes, des Landschaftsbaus usw.). Darüber hinaus stellt sich die Frage nach dem Inhalt von Schutzgebieten, Reservaten, >unberührten landschaften (auch ohne Schutzstatus). Dass sich hier die Natur >frei entfalten $<$ kann, ist nicht Eigenregung, sondern Erzeugnis. Auch >Urwald ist etwas Erzeugtes, wird erst mit seiner diesbezüglichen Wahrnehmung zu solchem; in doppelter Weise. Zum einen als >Wildnis $\measuredangle$, die aus seit langem ungenutzten, >verwilderten` Wirtschaftswäldern entstanden ist. Die gängige These, dass die Beseitigung von Naturwäldern schon vor Jahrhunderten ein logisches Nichtwissen über ihr reales Aussehen hervorruft, ${ }^{13}$ weshalb >fälschlich` andere Vor-Bilder - alte Stiche, die ebensolche Hute- oder Niederwälder zeigen, frühromantische Definitionen, die derartige Orte kurzerhand zu Ur-Orten erklären -, herhalten müssten, greift zu kurz. Dass solche Orte, insbesondere im Kontrast zu geregelten Forsten, als Wildnis sinnlich wahrgenommen werden, verlangt ihr Funktionieren im »Haushalt des Begehrens«. Zum anderen bekommen etwa Wälder mit ihrer >Entdeckung〈 und >Eroberungく die bekannten >Grammatiken` der >Jungfräulichkeit` zu- bzw. eingeschrieben, wird erneut andererseits der »Herkynische Wald « im »Germanien« des deutschen Humanismus des 16. Jahrhunderts zur diaphanen Kon-

12 Wie das zu geschehen hat, ist von Gartentheoretikern und -praktikern wie Friedrich Ludwig von Sckell (Beiträge zur bildenden Gartenkunst für angehende Gartenkünstler und Gartenliebhaber. Worms: Werner 1982 [Reprint von München 1825]) und Hermann Fürst von Pückler-Muskau (Andeutungen über Landschaftsgärtnerei verbunden mit ihrer praktischen Anwendung in Muskau. Hg. v. Günter J. Vaupel. Frankfurt/M, Leipzig: Insel 1996 [Stuttgart 1834]) immer wieder thematisiert worden.

13 Vgl. Kap. >Heilige Hallen` I. 
struktion zeitgenössischer Zivilisation und gleichzeitig zum Urort der >Ahnen<.

In der, wie Orvar Löfgren das nennt, »neue[n] bürgerliche[n] Naturmystik « ${ }^{14}$ seit dem 19. Jahrhundert wird >Wildnis` dann zu etwas >heimischem $<$, die heimische Landschaft, der Wald zu etwas, was in Relation zu Walter Benjamins »Bildersprache des 19. Jahrhunderts ${ }^{15}$ und dessen »Hauptstadt« zu setzen ist. Im Passagen-Werk (1927-1940) spricht Benjamin von der »gelobten Stadt des Flaneurs, der >Landschaft aus lauter Leben gebaut`, wie Hoffmannsthal sie einmal nannte«; denn:

»Landschaft, das wird sie in der Tat dem Flanierenden. Oder genauer, ihm tritt die Stadt in ihren dialektischen Polen scharf auseinander: sie eröffnet sich ihm als Landschaft, sie umschließt ihn als Stube. - Noch eines: jener amnestische Rausch, in dem der Flaneur durch die Stadt zieht, zieht nicht nur Nahrung aus dem, was ihm sinnlich vor Augen kommt, sondern vermag des bloßen Wissens, ja toter Daten wie eines Erfahrenen und Gelebten sich zu bemächtigen. Dieses gefühlte Wissen geht, wie sich von selbst versteht, vor allem als mündliche Kunde vom einen zum andern. Aber es hat sich im Laufe des $19^{\text {ten }}$ Jahrhunderts doch auch in einer fast unübersehbaren Literatur niedergeschlagen. ${ }^{16}$

Benjamin geht es um >Traumbilder`, genauer darum, sich der »Bildsprache des neunzehnten Jahrhunderts« als »Traumdeuter « ${ }^{17} \mathrm{zu}$ nähern, sei doch der Kapitalismus »eine Naturerscheinung, mit der ein neuer Traumschlaf über Europa kam und in ihm eine Reaktivierung der mythischen Kräfte ${ }^{18}{ }^{18}$ Das 19. Jahrhundert sei

»ein Zeitraum (ein Zeit-traum), in dem das Individualbewußtsein sich reflektierend immer mehr erhält, wogegen das Kollektivbewußtsein in immer tieferem Schlafe versinkt. Wie nun der Schläfer - darin dem Irren gleich - durch seinen Leib die makrokosmische Reise antritt und die Geräusche und Gefühle des eigenen Innern, die dem Gesunden, Wachen sich zur Brandung der Gesundheit zusammenfügen, Blutdruck, Bewegungen der Eingeweide, Herz-

14 Löfgren, Orvar: Natur, Tiere und Moral. Zur Entwicklung der bürgerlichen Naturauffassung, in: Jeggle, Utz et al. (Hg.): Volkskultur in der Moderne. Reinbek: Rowohlt 1986, S. 135. Vgl. Kap. Bürgerliche Naturmystik u. Ausleitung.

15 Tiedemann, Rolf: Einleitung des Herausgebers, in: Benjamin, Walter: Gesammelte Schriften V.1. Frankfurt/M: Suhrkamp 1982, S. 19.

16 Benjamin, Walter: Das Passagen-Werk, in: Gesammelte Schriften V.2. Frankfurt/M: Suhrkamp 1982, S. 1053f.

17 Tiedemann, a.a.O., S. 18f.

18 Benjamin: Das Passagen-Werk, in: Gesammelte Schriften V.1, S. 494. 
schlag und Muskelempfinden in seinen unerhört geschärften innern Sinnen Wahn oder Traumbild, die sie übersetzen und erklären, zeugen, so geht es auch dem träumenden Kollektivum, das in Passagen in sein Inneres sich vertieft $\ll{ }^{19}$

Benjamins Methode besteht in einer $\gg$ Auflösung der $>$ Mythologie in den Geschichtsraum «, ${ }^{20}$ mit dem Ziel des »dialektischen Umschlagens«, dem »Versuch [...] zu erwachen . $^{21}$ Die »Architektur» sei »wichtigstes Zeugnis der latenten >Mythologie

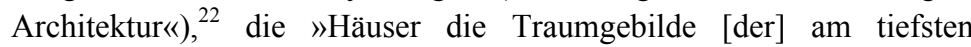
schlummernden Schicht« des 19. Jahrhunderts, jede »Kollektivarchitektur « dieser Zeit stelle »das Haus des träumenden Kollektivs «. ${ }^{23}$

$\mathrm{Zu}$ der von Benjamin angeführten Flut zeitgenössischer Literatur über die Großstadt zählt nicht nur die Thematisierung einer Kulturlandschaft, wie in Aragons »Paysan de Paris«, sondern weit häufiger die des Urbanen als bedrohliche Wildnis, als Großstadtdschungel. ${ }^{24}$ Die >freie Landschaft $\iota$, darin Wälder etwa als `heilige Hallen $\prec,{ }^{25}$ gilt demgegenüber zeitgenössisch in der realen Aneignung wie im literarischen und künstlerischen Mainstream als Hort tradierter, fest verwurzelter Ordnung. Auch dies eine Art der »Kollektivarchitektur« in Benjamins Sinn. Zwei wesentliche Momente bei Benjamin lassen sich daher desgleichen in diesen sentimental-romantisch aufgeladenen bürgerlichen »Freizeitlandschaft[en] « ${ }^{26}$ dieser Zeit (und seither) ausmachen: Zum einen die »dialektischen Pole« der - geschaffenen - Landschaft und der umschließenden »Stube«, in der der Bürger - im Gegensatz zu seiner

19 Ebda., S. 491f.

20 Das Passagen-Werk, in: Gesammelte Schriften V.2, S. 1014. »Mythologie« bezieht sich hier auch konkret auf Louis Aragons »Paysan de Paris« und dessen bloßes Verharren »im Traumbereiche«, dem »impressionistische[n] Element«, der »Mythologie«, die es aufzulösen gelte (ebda.).

21 Ebda., S. 1002.

22 Ebda.

23 Ebda., S. 1012.

24 Vgl. Exkurs II. Benjamin selbst - unter Berufung auf Friedrich Rückerts »Urwälder im Kleinen«, eigentlich aber im cartesianischen Duktus - verwendet als Bild für seine Methode die Urbarmachung von Gebieten, »auf denen bisher nur der Wahnsinn wuchert. Vordringen mit der geschliffenen Axt der Vernunft und ohne rechts noch links zu sehen, um nicht dem Grauen anheimzufallen, das aus der Tiefe des Urwalds lockt. Aber aller Boden mußte einmal von der Vernunft untergemischt, vom Gestrüpp des Wahns und des Mythos gereinigt werden. Dies soll für den des $19^{\text {ten }}$ Jahrhunderts hier geleistet werden«; a.a.O., S. 1010.

25 Vgl. Kap. >Heilige Hallen I u. II.

26 Löfgren, a.a.O., S. 125. 
Selbstwahrnehmung innerhalb der (industrialisierten) »Produktionslandschaft $\ll^{27}-$ sich >ganz bei sich selbst wähnt. Zum anderen das »gefühlte Wissen«. Vergleichbar mit dem des Flaneurs, erlebt auch der Spaziergänger, Wanderer, Urlauber neben seiner sinnlichen Wahrnehmung bloße Wissensdaten, die mündlichen, literarischen, bildnerischen Quellen entstammen. Mehr noch, das >unmittelbare Erleben in der >freien Natur ist gespeist aus derartigen Vor-Bildern. Wie sich zeigen wird, ist dieses 19. Jahrhundert wiederum Bild- und Erfahrungsraum, der dem Natur-Begehren der gegenwärtigen Gesellschaft am ehesten entsprechen soll.

Der Begriff des Bildes, wie ich ihn verwende, soll eine wesentliche Dimension in den historisch veränderlichen interdependenten Prozessen gesellschaftlicher Naturverhältnisse sichtbar machen. Hierzu soll zunächst das von Thomas Jahn/Peter Wehling ausgearbeitete Konzept diskutiert werden. Es knüpft zwar in dem Bestreben einer »kritische[n] Theorie der gesellschaftlichen Naturverhältnisse $\aleph^{28}$ an Marx, die sozialkonstruktivistische Position Serge Moscovicis ${ }^{29}$ oder die ältere kritische Theorie an. So könne Natur »nicht >an sich`, d.h. unabhängig von den jeweiligen Formen ihrer gesellschaftlichen Bearbeitung, Wahrnehmung und Symbolisierung erfahren oder erkannt werden«, da weder sie, noch die Gesellschaft »als separate Entitäten außerhalb eines Vermittlungsverhältnisses« existierten; vielmehr stellten sie »die aufeinander bezogenen Pole einer Differenz dar ${ }^{30}{ }^{3}>$ Natur bezeichne so in zweifacher Hinsicht »eine Grenzbestimmung gesellschaftlicher Bearbeitung und Wahrnehmung«, als Bedingung für »vermittelnde gesellschaftliche Aktivitäten« und als sozial form-, aber nicht völlig kontrollierbare Entität:

»Darüber konstituiert sich die Erfahrung der Unabhängigkeit und Eigenständigkeit von Natur. Es ist aber von entscheidender Bedeutung, daß diese Eigenständigkeit gerade nicht getrennt von gesellschaftlicher Wahrnehmung und Bearbeitung existiert, sondern dadurch überhaupt erst zugänglich wird. Vor

27 Ebda.

28 Jahn, Thomas: Krise als gesellschaftliche Erfahrungsform Umrisse eines sozialökologischen Gesellschaftskonzeptes. Frankfurt/M: IKO - Verlag für interkulturelle Kommunikation 1991, S. 119.

29 Moscovici, Serge: Versuch über die menschliche Geschichte der Natur. Frankfurt/M: Suhrkamp 1982 (Paris 1977).

30 Jahn, Thomas/Wehling, Peter: Gesellschaftliche Naturverhältnisse - Konturen eines theoretischen Konzepts, in: Brand, Karl-Werner (Hg.): Soziologie und Natur. Theoretische Perspektiven. Opladen: Leske + Budrich 1998, S. 82f. 
diesem Hintergrund grenzen Gesellschaften Natur als eine >nicht-gesellschaftliche< Realität von sich ab - und beziehen sie als solche gleichzeitig in gesellschaftliche Prozesse mit ein. Was von (und in) den Gesellschaften historisch und kulturell jeweils als >Natur`wahrgenommen, symbolisiert und von Gesellschaft abgegrenzt wird, ist offensichtlich variabel; die Unterscheidung als solche ist jedoch nicht kontingent. Daran orientieren sich sowohl alltägliche, lebensweltliche Wissensformen, die zwischen gesellschaftlichen und natürlichen Phänomenen unterscheiden, als auch die ausdifferenzierten Wissenschaftskulturen der Natur- und Sozialwissenschaften. ${ }^{31}$

Daraus folge, dass Gesellschaft und Natur »nicht als >ganze, als homogene und undifferenzierte Groß-Entitäten miteinander in Beziehung treten, sondern dass unterschiedliche soziale und naturale Elemente prozesshaft miteinander verknüpft werden. Gesellschaft ist in dieser Perspektive ebenso in sich differenziert wie Natur. Unterschiedliche Akteure fungieren in/auf ebensolchen sozialen Bereichen und Handlungsebenen, wobei komplette Landschaften wie kleinste Teilchen in intendierte oder nicht-intendierte soziale Prozesse eingebunden werden können.

Jahn/Wehling entwerfen also ein >pluralisiertes` Konzept der Naturverhältnisse und fokussieren »die vielfältigen Formen der ökonomischen, wissenschaftlich-technischen, politischen etc. Regulierung« dieser Verhältnisse - was allerdings nicht negiere, »daß bestimmte Formen des materialen Umgangs mit [...] oder [...] kulturelle Deutungen von Natur gesellschaftlich hegemonial werden können «. ${ }^{32}$ Sie verneinen einen ") holistische[n] ( Naturbegriff« und betonen die »zentrale[] Bedeutung« der naturwissenschaftlich erfolgten »Auflösung von >Naturく in Prozesse und Relationen auf unterschiedlichen räumlichen und zeitlichen Skalen« für ihr Konzept als die wesentliche Differenz zur Kritischen Theorie und deren »überwiegend philosophisch und psychoanalytisch geprägten« Natur-Begriff. ${ }^{33}$

Letzteres erscheint mir nicht unproblematisch. Naturwissenschaftliche Auflösungen von Natur treffen historisch nicht auf alle Gesellschaften zu und dort, wo sie dominieren, befinden sie sich nach

31 Ebda., S. 83.

32 Ebda., S. 83f.

33 Ebda., S. 84, Fn. 9. Zugleich setzen sie sich von konstruktivistischen Positionen $\mathrm{ab}$, da in diesen meist die Diskrepanz zwischen der symbolischen, diskursiven Konstruktion von ökologischen Problemen und deren materiellem Gehalt betont werde, was oft übersehe, wie enorm prägend. die diskursive Konstruktion von Problemen für deren institutionelle und soziale materielle Bearbeitung sei. Daher sei es entscheidend, Differenz und Zusammenhänge zwischen materieller und symbolischer Dimension der Regulierung von Naturverhältnissen zu analysieren. Ebda., S. 86. 
Jahns/Wehlings eigener Grundlegung innerhalb einer Pluralität der Naturverhältnisse. Vor allem aber droht dabei die gesellschaftlich produzierte/reproduzierte >direkte` sinnliche Wahrnehmung aus dem Blickfeld zu verschwinden. Die Prozesse naturwissenschaftlicher Distanzierung >innerer` wie ıäußerer Natur८, die »Auflösung« von »Natur« zu fokussieren, birgt die Gefahr der Hypostasierung, zugleich die Gefahr des Verschüttens der Transformationen sinnerer Natur` und ihrer Beziehungen zur >äußeren`. Das Moment des >Vermittelten` steckt eben nicht nur im >Abstrakten`, Zeichenhaften usw., sondern ebenso im `Konkreten<.

Horkheimer/Adorno bescheinigen der Aufklärung, sie sei »totalitär wie nur irgendein System«, wobei ihre »Unwahrheit« nicht, wie der stete Vorwurf ihrer »romantischen Feinde« laute, »analytische Methode, Rückgang auf Elemente, Zersetzung durch Reflexion« sei, »sondern daß für sie der Prozeß von vornherein entschieden ist«. Die »klassische Forderung, das Denken zu denken«, sei damit suspendiert. Vielmehr verdingliche sich das Denken »zu einem selbsttätig ablaufenden, automatischen Prozeß, der Maschine nacheifernd, die er selbst hervorbringt, damit sie ihn schließlich ersetzen kann«. Mathematik und Denken seien so gleichgesetzt, Natur »das mathematisch zu Erfassende«, seit Galilei »selbst unter der Leitung der neuen Mathematik idealisiert«. Sie werde, mit Edmund Husserl gesprochen, »selbst zu einer mathematischen Mannigfaltigkeit«. ${ }^{34}$

Das Ganze bedeutet nun explizit nicht, dass Horkheimer/Adorno »einen Technikdeterminismus« kritisieren, sondern vielmehr die sozialen Verhältnisse als Grundlage der Technik-Produktion und -Anwendung, den »Zusammenhang von Herrschaft, Vernunft und gesellschaftlicher Arbeitsteilung«, wie Christoph Görg verdeutlicht, ${ }^{35}$ dem es darum geht, mit Horkheimer/Adorno die dominant postulierte Alternative »zwischen Unterordnung unter oder Beherrschung der Natur« als falsche zu dekonstruieren. ${ }^{36}$

Gerade »dem soziologischen Denken« werfen Horkheimer/Adorno vor, mit dem Versuch, eine entfesselte Technik mittels »Sozialtechnologie« zu bändigen, »selbst nur ein Motiv der Naturbeherrschung zu wiederholen ${ }^{37}$ - Folge des $»$ gesellschaftliche[n] Verblendungszusammenhang $[\mathrm{s}] \ll{ }^{38}$ Das in der gesellschaftlichen Herrschaft enthaltene Potential

34 Dialektik der Aufklärung, S. 31.

35 Görg, Christoph: Regulation der Naturverhältnisse. Zu einer kritischen Theorie der ökologischen Krise. Münster: Westfälisches Dampfboot 2003, S. 37.

36 Ebda., S. 27.

37 Ebda., S. 37.

38 Horkheimer/Adorno, a.a.O., S. 48. 
zur Natur-Distanzierung generiere »die Ideologie der beliebigen Verfügbarkeit von Natur« und ihrer kompletten »Beherrschbarkeit [...] als Abstraktion von allen besonderen Qualitäten«. In dieser Prägung des Naturverhältnisses »durch soziale Herrschaftsbeziehungen« sei »die soziale Herrschaft, obwohl ihrerseits eine Voraussetzung des naturbeherrschenden Denkens, selbst durch das Naturverhältnis vermittelt «. ${ }^{39}$

Im Bemühen um einen erst noch zu findenden »positiven Begriff« der Aufklärung, um sie mittels Kritik »aus ihrer Verstrickung in blinder Herrschaft « zu lösen, ${ }^{40}$ und jenseits der >falschen Alternativeく Naturbeherrschung versus Unterjochung unter sie, ${ }^{41}$ ist bei Horkheimer/Adorno das Verhältnis zur >inneren Natur`, zum Körper über weite Strecken nur angedeutet. So, wenn sie vom »bürgerliche[n] Ideal der Natürlichkeit« sprechen, das "nicht die amorphe Natur" meine, "sondern die Tugend der Mitte. Promiskuität und Askese, Überfluß und Hunger sind trotz der Gegensätzlichkeit unmittelbar identisch als Mächte der Auflösung. Durch die Unterstellung des gesamten Lebens unter die Erfordernisse seiner Erhaltung garantiert die befehlende Minorität mit ihrer eigenen Sicherheit auch den Fortbestand des Ganzen « ${ }^{42}$ Erst am Ende, in der Skizze zum »Interesse am Körper«, geht es dann etwas näher um die »unterirdische« Geschichte, die »[u]nter der bekannten Geschichte Europas läuft«, um die »durch Zivilisation verdrängten und entstellten menschlichen Instinkte und Leidenschaften«. Und um das Verhältnis des Individuums zum eigenen wie fremden Körper, in dem als »Grausamkeit« die »Irrationalität und Ungerechtigkeit der Herrschaft« wiederkehre.

»Die Haßliebe gegen den Körper färbt alle neuere Kultur. Der Körper wird als Unterlegenes, Versklavtes noch einmal verhöhnt und gestoßen und zugleich als das Verbotene, Verdinglichte, Entfremdete begehrt. Erst Kultur kennt den Körper als Ding, das man besitzen kann, erst in ihr hat er sich vom Geist, dem Inbegriff der Macht und des Kommandos, als der Gegenstand, das tote Ding, >corpus`, unterschieden. In der Selbsterniedrigung des Menschen zum corpus rächt sich die Natur dafür, daß der Mensch sie zum Gegenstand der Herrschaft, zum Rohmaterial erniedrigt hat. Der Zwang zur Grausamkeit und Destruktion entspringt aus organischer Verdrängung der Nähe zum Körper, ähn-

39 Görg, a.a.O., S. 36. »Die Distanz des Subjekts zum Objekt, Voraussetzung der Abstraktion, gründet in der Distanz zur Sache, die der Herr durch den Beherrschten gewinnt «, heißt es dann auch in der »Dialektik der Aufklärung. Horkheimer/Adorno, a.a.O., S. 19.

40 Horkheimer/Adorno, a.a.O., S. 6.

41 Vgl. ebda., S. 38.

42 Ebda., S. $37 f$. 
lich wie nach Freuds genialer Ahnung der Ekel entsprang, als mit dem aufrechten Gang, der Entfernung von der Erde, der Geruchssinn, der das männliche Tier zum menstruierenden Weibchen zog, organischer Verdrängung anheimfiel. In der abendländischen, wahrscheinlich in jeder Zivilisation ist das Körperliche tabuiert, Gegenstand von Anziehung und Widerwillen. ${ }^{43}$

Geschrieben ist das Mitte der 1940er Jahre ausdrücklich vor dem Hintergrund »der faschistischen Gegenwart « ${ }^{44}$ Aber, dass die »Selbsterniedrigung« auch in gewisser Weise produktiv wirkt, wird hier durchaus gesehen. "Der Körper ist nicht wieder zurückzuverwandeln in den Leib.« Er bleibe »die Leiche«, selbst »wenn er noch so sehr ertüchtigt wird«. Diese mit der Bezeichnung 〉Körper〈, 〉corpus` angezeigte »Transformation ins Tote sei - vollends seit der historischen Transformation »der Herrschaft in die durch Handel [...] vermittelte bürgerliche Form« Teil des fortlaufenden Prozesses, »Natur zu Stoff und Materie« zu machen. Die zivilisatorischen Leistungen seien »Produkt der Sublimierung, jener erworbenen Haßliebe gegen Körper und Erde, von denen die Herrschaft alle Menschen losriß. In der Medizin wird die seelische Reaktion auf die Verkörperlichung des Menschen, in der Technik die auf Verdinglichung der ganzen Natur produktiv «. ${ }^{45}$ Aller Zivilisationsfortschritt »hat mit der Herrschaft auch jene Perspektive auf deren Beschwichtigung erneuert«. Wo aber »die reale Geschichte aus dem realen Leiden gewoben ist, das keineswegs proportional mit dem Anwachsen der Mittel zu seiner Abschaffung geringer wird«, sei »die Erfüllung der Perspektive auf den Begriff angewiesen«. Was als Wissenschaft die Menschen von der Natur distanziere, ermögliche jedoch zugleich »als Selbstbesinnung des Denkens [...] die das Unrecht verewigende Distanz« zu verstehen. In diesem »Eingedenken der Natur im Subjekt, in dessen Vollzug die verkannte Wahrheit aller Kultur beschlossen liegt, ist Aufklärung der Herrschaft überhaupt entgegengesetzt « ${ }^{46}$

Das »Eingedenken« - und das ist hier wichtig - bezieht sich nicht allein auf die vergesellschaftete >innere Natur`, sondern ebenso »in erkenntniskritischer Hinsicht [...] auf die subjektiven Konstruktionsprozesse >äußerer Natur «. ${ }^{47}$ Görg erkennt »drei Ebenen« auf denen sich der basale »Vermittlungszusammenhang« - Individuum, Gesellschaft, Natur - ebenso reflektiere, wie »die drei Dimensionen der Naturbeherrschung [...]: die Vermittlung von Natur und Individuum, von Natur und Gesell-

43 Ebda., S. $246 f$.

44 Ebda., S. 246.

45 Ebda., S. $248 f$.

46 Ebda., S. 46f.

47 Görg, a.a.O., S. 48. 
schaft und von Individuum und Gesellschaft« - was zugleich die »Folie« für die historisch je unterschiedliche konkrete »Selbstständigkeit der Relate Individuum und Natur« liefere. Mit dem Begriff der »zweiten Natur ${ }^{48}{ }^{48}$ den Görg bezieht auf die »ihrer selbst unbewußte Gesellschaft «, als die Adorno »das transzendentale Subjekt « dechiffriert, ${ }^{49}$ geht es also um eine »Kritik von Naturalisierungen«, die »Zurückführung verselbstständigter Verhältnisse auf einen >sozialen Grund « ${ }^{50}$

Gerade Adorno, so Görg, habe »Motive des poststrukturalistischen Denkens vorweggenommen und sich mit Motiven einer >Dekonstruktion` der Kategorien beschäftigt«, wobei er allerdings abziele auf einen »erneuerten Materialismus « - der nicht verharre in der Feststellung der Relativität begrifflicher und praktischer Konstruktionen und zugleich auf einen »mit dem Begriff nicht-identischen Gehalt« hinauswolle. Eine »kritische Negation begrifflicher Konstruktionen«, die die Erkenntnis befördere, dass Natur zwar stets »ein kulturell-sprachliches wie technisches Konstrukt« sei, aber »in seinen gesellschaftlichen Konstruktionen nicht aufgeht . $^{51}$ Das Moment des »Nicht-Identischen« ist seinerseits nicht etwas jenseits der Konstruktion Entdeckbares, ihr Entzogenes: real >unberührte Naturく. Es kann nicht anders als abhängig von sozialen Vermittlungen und »kulturellen Bedeutungen aufgezeigt werden $«{ }^{52}$ Wenn Adorno vom »Etwas als denknotwendiges Substrat des Begriffs $«{ }^{53}$ spricht, dann - sagt Görg - bezeichne das keine spezifische Eigenschaft des Dings, "sondern es sind im Erkenntnisprozess und seinen begrifflichen Konstruktionen zum Vorschein kommende nichtidentische Momente, die ein 〉Substrat〈 konstituieren«. Und der Begriff könne »immer nur ein noch in seiner gesellschaftlichen Aneignung und Konstruktion nicht-identisches Moment dieser Konstruktion >erinnern««. Es gehe also nicht um »ein unverrückbares >An-sich«« der Dinge, sondern um ihre »unaufhebbare Mehrdeutigkeit«. »Jede einzelne Konstruktion« könne den Dingen »nicht gerecht werden«, da sie stets partikular bleiben müsste und »eine kontingente Perspektive an ihnen zum Vorschein bringt«. Kontingenz ernst zu nehmen, erfordere, ein Ding oder Phänomen auch als Singuläres in seinem Kontext »und als Zusammenfassung vieler Möglichkeiten « zu sehen. Die prinzipielle Veränderbarkeit gesellschaftlicher Verhältnisse bedeute, dass, das, was »auch anders sein kann, [...]

48 Ebda., S. 48f.

49 Adorno: Negative Dialektik, S. 179.

50 Görg, a.a.O., S. 44.

51 Ebda., S. 45.

52 Ebda., S. 46.

53 Negative Dialektik, S. 139. 
als es selbst als Anderes erkannt werden« müsse, um nicht doch »eine unverrückbare Identität« zu behaupten. ${ }^{54}$

Da noch »die Kategorie der Nicht-Identität« dem Verständnisproblem unterliegen könne, sie als endgültigen »Rest« bzw. »Identität jenseits der Konstruktion « ${ }^{55}$ zu erklären, sucht Adorno, konträr zum prinzipiell nicht erkennbaren Kantschen >Ding-an-sich〈, nach einer spezifischen $»$ Bestimmtheit der Objekte an sich $«,{ }^{56}$ die nicht ausschließlich auf ein erkennendes Subjekt bezogen sei und »der Erfahrung und Reflexion zugänglich $«{ }^{57}$ Es geht ihm um $»[\mathrm{~d}]$ as, worin die Gegenstände kommunizieren $«,{ }^{58}$ ihren Zusammenhang. »Mit der Formulierung einer $>$ Kommunikation der Gegenständeく ist aber nicht eine Angleichung an einen sprachlichen Kommunikationszusammenhang gemeint, sondern ein den Gegenständen immanenter Zusammenhang, der sich erst der Reflexion erschließt, wie er umgekehrt der Erkenntnis auch einen >Maßstab< vorgibt.« Dies mit der Intention einer »Selbstkritik des subjektivistischen Konstruktivismus« und einer materialistischen »unreglementierten Erfahrung der Gegenstände «. ${ }^{59}$

Festzuhalten bleibt zunächst: Der einem Dualismus von Gesellschaft und Natur widersprechende kritisch-theoretische Begriff der ızweiten Natur` umfasst >innere` wie `äußere Natur` und ermöglicht es daher, alle beteiligten Dimensionen zu erfassen.

Nach Jahn/Wehling lassen sich zwei zwar analytisch trennbare, sich aber real permanent wechselseitig durchdringende und verändernde Dimensionen gesellschaftlicher Naturverhältnisse und ihrer Regulierungen ausmachen: Materialität - die »mit wirkungsabhängigen Folgen« korrespondierenden, in "Stoffwechseln" regulierten "stofflich-energetischen Aspekte von Phänomenen« - und Symbolisierung - bezogen auf »den Aspekt der Zeichenhaftigkeit von Phänomenen«, die korrespondieren »mit deutungsabhängigen Folgen von Ereignissen«, reguliert in »kulturellen Deutungen von Natur und Naturverhältnissen«. Dazu zählten »religiöse, ästhetische oder ethische Bilder und Entwürfe von Natur« und besonders wissenschaftlich-technische Deutungen, Erklärungen und Konstruktionen« bzw. »Modellierungen« oder »Leitbilder«. Letztere dominierten zunehmend die »materielle Regulierung von Naturverhältnis-

54 Görg, a.a.O., S. 46.

55 Ebda., S. 47.

56 Negative Dialektik, S. 36

57 Görg, a.a.O.

58 Adorno, a.a.O.

59 Görg, a.a.O. 
sen«, wobei sie »keine rein normativen Ideen darstellen«, vielmehr auch selbst geprägt würden vom jeweiligen wissenschaftlich-technischen Potential zur Naturgestaltung, das Gesellschaften oder einzelne Gruppen haben. ${ }^{60}$

Die Autoren gehen zudem abweichend von »gängigen« sozialwissenschaftlichen Zugriffen auf die ökologische Problematik auch von »basalen, für die gesellschaftliche Reproduktion unverzichtbaren Naturverhältnissen (wie Ernährung, Fortpflanzung, Gesundheitssicherung etc.)« aus, um »eine neue heuristische und analytische Perspektive auf die Formen, Prozesse und Praktiken « materieller und symbolischer sozialer Regulierung zu bilden, »eine problemorientierte Querschnittsperspektive, die zu neuen Verknüpfungen gesellschaftlicher Akteure, technischer Infrastrukturen, kultureller Deutungsmuster, wissenschaftlicher Aussagensysteme und natürlicher Elemente und Ressourcen führt «. ${ }^{61} \mathrm{Sie}$ reflektieren, dass die »Regulierung gesellschaftlicher Naturverhältnisse »keineswegs immer intentional« erfolge, vielmehr, inklusive ihrer ökologischen und sozialen Aus- und Rückwirkungen, oft »das (nicht-intendierte) Resultat sozialer Praktiken, die unmittelbar ganz anderen Interessen und symbolischen Orientierungen folgen könne«, seien. Dabei spielten auch »explizite Naturbilder der beteiligten Akteure nicht selten nur eine sehr geringe und indirekte Rolle«, existierten »aber auch Konfliktfelder, wie sie etwa um die Gentechnik oder die Reproduktionsmedizin herum entstanden sind « und die Grenzen zwischen Natur und Ge-

60 Jahn/Wehling, a.a.O., S. 84ff. »Der Begriff der Regulierung der gesellschaftlichen Naturverhältnisse verweist zunächst auf eine zwar schwache, aber doch bewußte Analogie zur ökonomischen Regulationstheorie (Aglietta, Lipietz u.a.)«. Deren Stärke liege in einer neuen Perspektive auf kapitalistische Produktions- und Reproduktionsverhältnisse, weil hier kein »(über-)mächtiger zentraler Akteur [...] eine unveränderliche Kernstruktur der kapitalistischen Produktion gewissermaßen hinter dem Rücken der Gesellschaft immer wieder stabilisiert. Vielmehr bilden sich in einem komplexen, konflikthaften Geflecht sozialer Auseinandersetzungen und Definitionskämpfe, institutioneller Praktiken, kultureller Normen etc. historisch veränderliche« Reproduktionsformen kapitalistischer Produktionsverhältnisse heraus. Die Regulierungstheorie gesellschaftlicher Naturverhältnisse teile diese Perspektive und sehe zwar »einen präformierenden Einfluß« der »Regulierungen der Produktions- und Geschlechterverhältnisse«. Abweichend gehe es hier aber nicht um die Konzentration auf eine »ökonomische Kern-Struktur« und deren bloße Erweiterung, sondern - trotz einer unbestreitbar hohen Prägung - um die ebenso notwendige Einbeziehung von Wissenschaft, Technik, Politik, kulturellen Symboliken. Ebda., S. 87

61 Ebda., S. 86f. 
sellschaft, Leben und Tod zur Disposition stellten und neu verhandelten. $^{62}$

Dem ist an sich nicht zu widersprechen. Ebensowenig der Auffassung, dass materielle Phänomene »symbolische Bedeutungen« erhalten und »symbolische Deutungen [...] in materielle Prozesse und Praktiken eingebunden« sind, wobei zugleich die Differenz zwischen beiden »Aspekten weder deckungsgleich ist mit der Differenz von Gesellschaft und Natur noch mit der Gegenüberstellung von Realität und (sozialer) Konstruktion «. ${ }^{63}$ Aber: Naturverhältnisse bestehen nicht nur aus Materialität und Symbolisierung, genauer: nicht nur aus stofflicher Nutz- bzw. Formbarkeit der >Natur und Zeichenhaftigkeit, sondern ebenso aus veränderlichen Formen des Erlebens, damit auch der affektiven, emotionalen und vegetativen Reaktionen von Menschen. Zudem lässt sich unter »energetischem Aspekt « - weiter, als Jahn/Wehling - auch das verstehen, was klassisch freudianisch »Libido« heißt, was Gilles Deleuze und Félix Guattari konträr zu Freuds Fixierung auf einen jeweiligen Zielpunkt den »Wunsch zu Wünschen« genannt haben. ${ }^{64}$ Wenn also etwa von zunehmend hegemonialen naturwissenschaftlich-technischen Deutungsmustern die Rede ist, muss das auch die Frage implizieren, wie in derartigen gesellschaftlichen Verhältnissen >Natur erlebt wird. Das ist für das `Zielkonzept` einer Landschaft des 19. Jahrhunderts, wie es landschaftsplanerisch und anscheinend breit gesellschaftlich präferiert wird, von einiger Bedeutung. ${ }^{65}$

Die Gesellschaft »konstituiert sich [...] in einem Prozeß und als ein Proze $\beta$, worin naturale und soziale Handlungselemente miteinander ver-

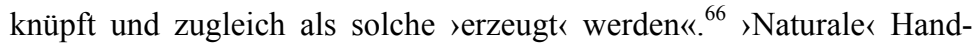
lungselemente werden erzeugt: Die Bild- und Erfahrungsräume, die ich thematisiere, werden betreten, erlebt, sinnlich wahrgenommen, erfahren, sie rufen - und darauf wird es immer wieder hinauslaufen - Gefühle hervor: Enthusiasmus, Ausgeliefertsein, Abscheu, Ekel, Geborgenheit usw., Erfahrungen zwischen >Abwehr und Verlangen`. Diese sind selbstverständlich Diskursen, epistemischen Brüchen, Dispositiven unterworfen. Aber, es geht mir dezidiert um Materialität und Phänomenalität der Dinge und nicht nur um deren Vermittlungen. Diese Dinge sind, wie der Körper und das Körpergefühl, die deren Materialitäten historisch und

62 Ebda., S. 88.

63 Ebda., S. 85.

64 Deleuze, Gilles/Guattari, Félix: Anti-Ödipus. Kapitalismus und Schizophrenie I. Frankfurt/M: Suhrkamp $1992^{6}$ (Paris 1972), S. 68ff.

65 Ich komme in der Auseinandersetzung mit Donna Haraways $>$ Hybrid <-Begriff weiter unten darauf zurück.

66 Jahn/Wehling, a.a.O., S. 82. 
gesellschaftlich je unterschiedlich auf sich einwirken lassen, historische Prozesse (s.o.). Diese Einwirkungen - die Furcht vor einem Phänomen, die Anziehung durch es - sind nie anders, als gesellschaftlich vermittelt möglich, nichtsdestotrotz reale und direkte Erfahrungen. So können Wälder, Flora und Fauna (Dinge überhaupt) in vorbürgerlichen Gesellschaften neben den ihnen auch bürgerlich zugebilligten Nutzen andere spürbare - Qualitäten haben: >magischeく. So erfahren mittelalterliche Pilger und Eremiten weite dichte Wälder als >Wüsten`, >leere Einöden So schildert viel später der Comte de Buffon seinen Ekel angesichts von Sümpfen und krummen, ungeregelten Wäldern, wird in dieser Zeit die 〉Erhabenheit` angesichts >gewaltiger` Gebirge oder Wälder nicht nur reflektiert, sondern eben auch gespürt. All das entspringt Diskursen und kann sich auf neue Diskurse auswirken. `Schnittpunkteく aber sind Affekte, Emotionen etc., wie >verschoben` sie sich auch immer äußern sollten. Und schließlich können Gefühle und Diskurse, historisch variabel, ebenso antagonistisch sein (und sind das häufig); dialektische Pole auch sie.

Es geht um Konstruktionen (bewusst oder unbewusst), Anordnungen von Dingen, die so mit Bedeutungen aufgeladen werden. Zugleich ist damit untrennbar verbunden das Wissen um die Lebendigkeit dieser Dinge. Konstruktionen, die Unlust oder Lust, Anziehung oder Schrecken erzeugen, oft numinos erscheinen - was in besonderer Weise mit der Lebendigkeit zusammenhängt. Dietmar Kampers »Idylle« (s.o.), das ins »Bildchen« transformierte, gebannte Unerträgliche, spricht davon in einer Hinsicht, Walter Benjamins »gefühltes Wissen«, das sich-Einfühlen in bloße Daten, als sei das darin Enthaltene sinnlich wahrgenommen worden, in einer anderen.

Der von mir verwendete Bild-Begriff ist mehrschichtig. Die Beschäftigung mit der Transformation der >äußeren Natur` ins Bild umfasst auch >richtige` Bilder, Quellen aus der bildenden Kunst, in denen jeweilige gesellschaftliche Naturverhältnisse sichtbar gemacht, abgebildet werden und die historisch später etwa zu Vor-Bildern werden (können). Vor-Bilder, aus denen erlebbare >Reetablierungen` ihrer selbst werden. In diesen fungiert die $>$ Natur als Platzhalterin ihrer selbst. Bildende Kunst oder Architektur sind, wie gesagt, selbst Abbilder gesellschaftlicher Naturverhältnisse. Sie müssen nicht >zwischengeschaltet sein, um jene Bild- und Erfahrungsräume entstehen zu lassen, in denen die >Natur` als Platzhalterin ihrer selbst fungiert, etwa >Wälder`, die >männliche` oder >weibliche` Eigenschaften verkörpern. Genauer: unterschiedliche >Wälder fungieren entweder als >amorphe Leiber`, als >bedrohlich weibliche`, noch zu unterwerfende, noch nicht vergesellschaftete Gebilde - Au-, Bruch-, Sumpfwälder - oder als ihre Opposition, als überwundene Leiber, formierte Körper - geregelte Forsten, >heroische`, 
>soldatischeく Wälder, >Waldesdomeく. Neben diesen >männlichen` Körpern existieren historisch seit den Anfängen des Naturschutzes auch weibliche - analog zum Garten - in denen eine `zweite Natur`, der 〉Körper letztlich geschützt werden muss vor den Angriffen einer vermeintlich >ersten`, des >Leibes`, der sich im `Körper` noch immer verborgen hält. ${ }^{67}$

Das alles ist nie zu trennen von Diskursen, den Aussagen, die ihre Objekte formieren und transformieren, von den Aussagen und ihren Beziehungen zueinander. Das Bild als Verkörperung ist aber nicht einfach deckungsgleich mit den Bildern, die von ihm gemacht werden, seiner jeweiligen Menge von Zeichenfolgen innerhalb eines Aussagesystems. Es handelt sich um Vorgänge, die in der Phänomenologie mit dem `Nachvollzug` der `äußeren Natur` durchs >leibliche Ich` beschrieben werden. Wobei aber klar sein muss, dass dieses >leibliche Ich >Befindlichkeiten`, aus deren 〉Modifikationen` Wahrnehmungen bestünden, historisch-gesellschaftlichen Veränderungen unterliegen. ${ }^{68}$

Bild - Abbildung - Formation - Körper. Im Bild wird das Lebendige als Objekt »von Anziehung und Widerwillen« gebannt. Dieses Bannen funktioniert in kategoriellen Zuordnungen wie Alterisierung oder Entalterisierung. So können in Bildern Wuchern, Untiefen etc. erzeugt werden, um die Notwendigkeit der Domestikation, Subsumption zu beweisen. Im Gegensatz dazu kann in anderen Bildern das bedrohliche Wuchern, der Wildwuchs stillgestellt werden, bleibt aber sozusagen am Leben, um Harmonie, Ordnung zu erzeugen. >Erzeugen` und `Beweisen ist hier gleichzusetzen mit >Wahrnehmen Bild- und Erfahrungsräume sind der jeweilige Rahmen, in der Natur als Verkörperung fungiert. Raum und Körper des Wahrnehmenden sind dabei jeweils untrennbar verbunden. Erst durch den Körper erhält der Raum Bedeutung, wird zur Verkörperung von Identität oder Widerspruch.

Mit den Weisen von Verkörperungen und den sozialen Prozessen der Konstruktion von Natur hat sich Donna Haraway beschäftigt. `Natur`, so fasst Cordula Kropp Haraways Position zusammen, stelle »keine von unserem Wissen und Handeln unabhängige objektive Wirklichkeit oder anzueignende Ressource dar, sondern muss als eine Welt der Verkörperungen gedacht werden, die eine eigene Aktivität besitzt und eine gemeinsame Konstruktionsleistung einer Vielzahl unterschiedlicher menschlicher, organischer und technischer Akteurinnen ist $\ll .{ }^{69} \mathrm{Im}$ Fol-

67 Vgl. Kap. Arkadischer Imperialismus, insbesondere den Schluss.

68 Vgl. das Ende von Kap. Bürgerliche Naturmystik.

69 Kropp, Cordula: »Natur«, S. 183. 
genden sollen daher die Grundannahmen Haraways zu einer »soziokulturellen Kontextualisierung « der Objekte, ${ }^{70}$ die sie zwar bezüglich der Konstruktionsprozesse in der Wissenschaft aufgestellt hat, die aber gesamtgesellschaftlich übertragbar sind, diskutiert werden.

Haraway hat den Begriff des »situierten Wissen[s] $\aleph^{71}$ geprägt. Dieses situierte Wissen entstehe in einem »Interaktionsprozeß materiell-semiotischer AkteurInnen«, deren Körper »Apparate der körperlichen Produktion « seien. ${ }^{72}$ Das heißt zunächst: Es gebe keine prädiskursive Natur, keine passiven Objekte, die von körperlosen, rein geistigen Subjekten >entdeckt<, >erkannt $<$ bzw. schlicht konstruiert werden. Das heißt für eine >Sprache der Dinge $<$ :

»Die Welt spricht weder selbst, noch verschwindet sie zugunsten eines Meister-Dekodierers. Die Kodierungen der Welt stehen nicht still, sie warten nicht etwa darauf, gelesen zu werden. [...] In einem kritischen Sinn, auf den die unbeholfene Kategorie des Sozialen oder der Handlungsfähigkeit grob hinweist, ist die in den Wissensprojekten erforschte Welt eine aktive Entität. ${ }^{73}$

Die Kategorie der »Handlungsfähigkeit« der »AkteurInnen« zielt begrifflich gegen einen körperlosen bzw. -verleugnenden Konstruktivismus, will »Darstellungen einer >wirklichen〈 Welt die Treue halten«, trotz aller Vermitteltheit und Widersprüchlichkeit dieser »Welt«, was explizit unessentialistisch gemeint ist. Die »Aktivität im wissenschaftlichen Konstruktionsprozess « könne nicht reduziert werden »auf sprachlich vermittelte Handlungen und Praktiken«, weshalb eine Reformulierung des Verhältnisses »von Diskurs, Sprache, Körper und Referenzialität« notwendig sei. So müsse Wissen stets als situiertes, »als Verknüpfung von Körpern und Bedeutung gedacht « werden. Hierbei ist auch die >äußere Natur〈, sind etwa Tiere in der Forschung, aktiv beteiligt, ")soziale Teilnehmer im wissenschaftlichen Erkenntnisprozess. Das hier generierte Wissen ist welterschließend und handlungsorientierend «, stecke daher »den Rahmen für mögliche Verhältnisse« ab und stelle »bestimmte Selbst- und Fremdwahrnehmungen her. $^{74}$

70 Ebda., S. 177.

71 Haraway, Donna: Situiertes Wissen. Die Wissenschaftsfrage im Feminismus und das Privileg einer partialen Perspektive, in: Die Neuerfindung der Natur. Primaten, Cyborgs und Frauen. Herausgegeben und eingeleitet von Hammer, Carmen/Stieß, Immanuel. Frankfurt/M, New York: Campus 1995 (Original 1983-1989), S. $91 \mathrm{f}$.

72 Ebda.

73 Ebda., S. 94.

74 Kropp, a.a.O., S. 184. 
Haraways dezidiert linke, feministische Position ist ein Versuch, mittels eines letztlich subjektkritischen Ansatzes die neuzeitliche Naturbeherrschung, die »hierarchische Trennung von Natur und Kultur bzw. Gesellschaft « zu »unterlaufen $«{ }^{75}$ Einer der Ausgangspunkte der gelernten Biologin ist dabei der (eigene) »Frauenkörper als Objekt« einer unter dem Anspruch von Objektivität operierenden »'patriarchalen talistischen Wissenschaft«. Subjektkritik heißt für sie, die »jedes Wissen als einen verdichteten Knoten in einem antagonistischem Machtfeld « erachtet, auch, »die marxistisch-feministische und insbesondere ökofeministische Reaktion nicht länger [zu] teilen, die eigene wissenschaftliche Tätigkeit als privilegierteren und >besseren` Wirklichkeitszugang aus unterworfenem Standpunkt zu betrachten «. ${ }^{76}$ Haraway erkennt die enorme politisch-gesellschaftliche Bedeutung von >Natur »Konstruktions- und Projektionsfläche « an, verlangt, »sich auch in die semiotischen Konstruktionen von >Naturく einzumischen, auch sie nicht allein den 〉Herrschenden « zu überlassen«, ohne allerdings »den Diskurs über >Natur $[$ [...] mit seinem Gegenstand zu reifizieren«. >Natur liege dabei den Projektionen "weder als Objekt noch als Text«, als determinierende Entität zugrunde, sei vielmehr stets Artefakt, »als Faktum wie als Fiktion, gemacht $\ll .^{77}$

>Natur८, so Haraway in »Monströse Versprechungen«, gehöre zu den »unmöglichen Dinge[n], die wir [...] nicht begehren können«. Sie sei zwar immer wieder als >Andere〈 »diskursiv konstituiert« worden »in den Geschichten des Kolonialismus, Rassismus, Sexismus und der vielgestaltigen Klassenherrschaft«. Trotzdem sei im Begriff 〉Natur« etwas zu finden, »das wir zwar nicht `haben`, ohne das wir aber auch nicht auskommen können. Jenseits von Verdinglichung und Besitzergreifung müssen wir zur Natur ein anderes Verhältnis finden«. Sie sei weder ein besuchbarer »physikalischer Ort«, noch ein umfriedeter oder gehorteter »Schatz«, nichts zu ent-deckendes Verborgenes, kein wissenschaftlich dekodierbarer »Text«, nichts ursprüngliches oder dienstbares »Andere[s]«, sie ist »weder Mutter noch Amme noch Sklavin und insofern weder Matrix noch Ressource noch Werkzeug für die Reproduktion des Menschen/Mannes « ${ }^{78}$ Vielmehr sei sie

75 Ebda., S. $184 f$.

76 Ebda., S. 180.

77 Ebda., S. $185 f$.

78 Monströse Versprechen. Eine Erneuerungspolitik für un/an/geeignete Andere. Hamburg 1995; zit. n. Kropp, a.a.O., S. 185 
»ein topos [...]; im strengen Sinne ist die Natur ein Gemeinplatz, dem wir uns (als Thema oder Topik) zuwenden, um unseren Diskurs zu ordnen, unser Gedächtnis zu sortieren. Wenn wir Natur in diesem Sinne als Topik verstehen, erinnern wir uns auch daran, daß die englische Sprache im 17. Jahrhundert als topick gods die lokalen Hausgötter bezeichnete. Wir brauchen diese Geister, zumindest rhetorisch, wenn es gar nicht anders geht. Wir brauchen sie zur Wiederbelebung genau jener allgemeinen Plätze - Lokalitäten, die allen offen stehen, die unwiderruflich lokal, weltlich, be-geistert, also topisch sind. In diesem Sinne ist die Natur der Ort, wo die öffentliche Kultur neu zu errichten ist ${ }^{79}{ }^{79}$

Sie sei desgleichen

»ein trópos, eine Trope. Sie ist Figur, Konstruktion, Artefakt, Bewegung, Verschiebung. Die Natur kann nicht vor ihrer Konstruktion existieren. Diese Konstruktion beruht auf einer bestimmten Art von Bewegung - auf einem trópos, einer Wendung. Getreu dem griechischen Wortsinn geht es bei der als trópos verstandenen Natur um Wendungen und Windungen. Die Trope vollziehend wenden wir uns der Natur zu, als wäre es die Erde, der Urstoff. Wir sind geotrop, physiotrop. Topisch reisen wir der Erde, einem Gemeinplatz entgegen«.

Der so geführte Diskurs über Natur sei ein sich Abwenden »von Plato und dem Blendstern seines heliothropen Sohnes«, um eine »andere Gestalt« zu sehen. Mithin kein grundsätzliches sich Abwenden vom »Sehen, der Vision«, sondern die Suche nach etwas anderem »als Aufklärung« im »Sichten der >science studies als >cultural studies « «. ${ }^{80}$

Haraways Sicht bietet hier durchaus zwei weitere Hinweise für eine These über Bilder als Verkörperungen: Die Rede von »topick gods« lässt sich lesen als Thematisierung lokaler >Be-Geisterungen`, also klassen- und schichtenspezifische (Neu-)Errichtungen öffentlicher Kultur, was auch die >Gleichzeitigkeit des Ungleichzeitigen` beinhaltet - so etwa im Konflikt zwischen traditionellem bäuerlichen und kameralistischem Verständnis von Wald und seiner Nutzung im 18. Jahrhundert. ${ }^{81}$ Sie ist zugleich Thematisierung des Gemeinplatzes, dass von allen sozialen Gruppen das selbe gemeint sei. Und Konstruktion ist hier nicht reduziert auf >Textく, auf Textualisierung von Dingen und Phänomenen, sondern es geht um ihre Materialität: Konstruktion als Resultat von Be-

79 Ebda.

80 Ebda.

81 Vgl. Kap. Das Verschwinden von Werden und Vergehen. 
wegung - was den Doppelsinn des Begriffs der >Wendung «, sprachliche und körperliche Vermittlung, berücksichtigt.

Die >Natur` als Artefakt, permanent erneuertes Resultat verschiedenster AkteurInnen. Haraway beschäftigt sich schließlich konkret mit »Mischwesen«, mit »Cyborgs«, in denen Subjekt und Objekt, Männliches und Weibliches, Abstraktes und Konkretes, Organismus und Kybernetik, Kreatur und Technologie, Lokales und Globales miteinander verschmelzen, was zur Implosion der für die Moderne so wesentlichen binären Strukturen, der Antagonismen, der scheinbar so strikt getrennten Kategorien führe. Sie differenziert hierbei historisch/sozial zwischen der Moderne, für die »eines der bestimmenden Merkmale« der »Glaube an die stabile Trennung von Subjekten und Objekten in der experimentellen Lebensweise« sei, und dem »Ende des Zweiten Jahrtausends«, in dem die »Implosion« dieser Trennung in den es »bevölkern[den]« Wesen das Charakteristikum »einer neuen historischen Konfiguration« sei. ${ }^{82} \mathrm{Ihr}$ hier häufig genanntes Beispiel ist die gentechnisch manipulierte, Brustkrebs herausbildende »OncoMouse ${ }^{\mathrm{TM}}$ «, die Technologie und Metapher gleichzeitig sei, medizinisches Experiment, systematisches Krankheitsmodell und »Waffe« gegen diese Krankheit sowie patentierter Privatbesitz. $^{83}$

Was bei Haraway die »cyborgs «, sind in Bruno Latours »Versuch einer symmetrischen Anthropologie« mit dem programmatischen Titel $»$ Wir sind nie modern gewesen« (1995) »Hybride«, untrennbare Vermengungen von >Natur und Gesellschaft, für deren Erzeugung das »Labor $[. .$.$] der offensichtlichste Ort« sei. \mathrm{Zu} » H y b r i d e «$ könne man »letztlich jede Art von Technik und Technikfolgen zählen«; ihr unkontrolliertes Anwachsen, etwa in der Biotechnologie sei »das uneingestandene Charakteristikum moderner Gesellschaften «. ${ }^{84}$ Auch Latour kommt von den >science studies $<$. Aber auch seine Theorien haben gesamtgesellschaftliche Relevanz. Zumal er » - vergnüglich das Durkheim'sche Diktum der Verdinglichung sozialer Tatsachen spiegelnd - die soziale Wirkung materieller und dinglicher [...] Artefakte« betone, wenn auch vornehmlich "wissenschaftlich-technischer «. ${ }^{85}$ »Symmetrische Anthropologie «, heißt, dass Latour mittels der »Akteur-Netzwerk-Theorie« tradierte Differenzierungen zwischen Gesellschaft/Technik und Natur me-

82 Haraway: Anspruchsloser Zeuge@Zweites Jahrtausend. FrauMann@trifft OncoMouse $^{\mathrm{TM}}$. Leviathan und die vier Jots: Die Tatsachen verdrehen (1996); zit. n. Kropp, a.a.O., S. 189.

83 Ebda.

84 Kropp, a.a.O., S. 193.

85 Ebda. 
thodologisch unterlaufen will, »so dass technische Systeme, Landschaften oder menschliche Subjektivitäten gleichermaßen symmetrisch, dass heißt in ihrer sozialen und natürlich-materiellen Fabrikation beschrieben werden können«, was keiner »einseitigen Logik» gehorche, sondern »Resultat der Verknüpfung heterogener Elemente« sei. ${ }^{86}$

Latour verweist - Ironie der Aufklärung - zurecht darauf, dass die als Kennzeichen der Moderne geltende basale Differenzierung zwischen `Natur` und Gesellschaft`, die als unumkehrbarer Fortschritt gegenüber der magisch-mythischen Vormoderne hypostasiert werde, "Selbsttäuschung" sei - ontologisiere sie doch den Antagonismus Natur - Gesellschaft trotz der gegenteiligen realen Praxis ihrer Vermischung in der Moderne. $^{87}$

Festzuhalten bleibt an dieser Stelle, dass Theorien über wechselseitige Verknüpfungen von Körpern und Bedeutungen, materiell-semiotischen AkteurInnen in permanenten Prozessen, Artefakten oder Hybriden weitgehend in eine Richtung weisen, in der hier von Bildern die Rede ist. Einwände habe ich sowohl gegenüber den Behauptungen von Auflösungen bisheriger binärer Kategorien und den daraus abgeleiteten Hoffnungen, als auch gegenüber Unschärfen bezüglich historisch und gesellschaftlich unterschiedlichen Funktionen von >Hybriden .

Donna Haraways (und vergleichbar Bruno Latours) Theorie ist bis zu einem bestimmten Punkt durchaus vereinbar mit der Kritischen Theorie. Das auch vor dem Hintergrund von Adornos materialistisch fundierter Vorwegnahme poststrukturalistischer >Dekonstruktion < (s.o.). Beide fordern eine immanente Kritik, um die Normativität des Faktischen zu entschleiern. Und wenn bei Horkheimer/Adorno vom »Eigensinn der Natur« die Rede ist, dann bei Haraway die von »einer gewissen Art >Eigengesetzlichkeitく [...] oder >Widerständigkeitく des NichtMenschlichen bzw. Nicht-Gesellschaftlichen«. Sie illustriert das mit dem »Trickster«, der afrikanisch-mythischen Figur, die sich durch ihre »Unberechenbarkeit und permanenten, koyotenhaften Wandlungen auszeichnet $\ll .{ }^{88}$ Dies ist explizit unessentialistisch gemeint. Natur wird von Haraway »vor allem über ihre Negativität« definiert, »um so ihrer NichtIdentität und ihrem Inkommensurablem gerecht zu werden ${ }^{89}{ }^{-}$was erneut an Adorno erinnert. Daher: Adorno würde zwar »viele Argumente in der Kritik der >Reinigungsarbeit der Moderne von Latour sowie an der Kritik verfestigter Dichotomien bei Haraway teilen«, aber »die Pole

86 Ebda., S. 194.

87 Vgl. ebda., S. 202f.

88 Ebda., S. 186.

89 Ebda., Fn. 25. 
Natur und Gesellschaft/Technik letztlich doch nicht zusammenfallen lassen, sondern dem eine dialektische Vermittlung durch die Extreme hindurch entgegensetzen ${ }^{90}{ }^{90}$

Es lässt sich also - mit der Kritischen Theorie - ein dringender Einwand erheben: Wenn der Kollaps, die Implosion der für die »Geschichte der Moderne« so grundlegenden binären, antagonistischen Kategorien Kultur - Natur, Mann - Frau, aktiv - passiv, Produktion - Reproduktion etc. diagnostiziert wird, mithin eine Tendenz zur totalen Immanenz, darf die Frage, was denn als jeweils Drittes aus den ineinandergestürzten Polen entsteht, nicht vergessen werden. Demgegenüber warnt Latour, der die aktive »Mitwirkung natürlicher Aktanten an der Produktion von Welt betont«, ebenso die »beidseitig unabgeschlossene[] Kette der Vermittlungen und Transformationen zwischen Materialität und gesellschaftlichen Zeichen«, vor der »Gefahr«, dass »dialektische Vermittlungstheorie[n]«, wie bei Marx oder Moscovici, »die - wenn auch materiell strukturierte und strukturierende - Gesellschaft als alleinige Ursache und Vorgabe« sehen könnten. >Gesellschaftく und >Natur〈 »erscheinen als unsere Konstruktion bzw. Produktion, immanent in die Hände der >demiurgischen Übermenschen` gelegt, die zugleich eine Geschichte der Natur und der Gesellschaft weben«, wie Kropp, die sich dieser Einschätzung anschließt, das zusammenfasst. ${ }^{91}$ Derartiges klingt in Haraways Kritik des »Meistersubjekt[s] « ${ }^{92}$ ebenfalls an. Eine solche Gefahr ist gar nicht von der Hand zu weisen. Andererseits laufen Theorien, die in den >Auflösungen < tradierter binärer und hierarchischer Strukturen »Hoffnungen« (Latour) und »Chancen« (Haraway) begreifen, selbst Gefahr, einer Vernebelung der gesellschaftlichen Verhältnisse zu unterliegen.

Schon, weil sie das grundsätzlich Artefaktische von >Natur herausstellt, sieht Haraway Cyborgs wie Krebsmäuse oder technisierte Frauenkörper trotz ihrer Ambivalenz als Chance, die »überkommenen Dichotomien und Grenzen« tätig zu dekonstruieren. $^{93}$ »OncoMouse und FrauMann sind im Schoß der Moderne und der Aufklärung gereift, aber ihre Existenz bringt die Matrix ihres Ursprungs durcheinander." Gesellschaft - Natur, Mensch - Tier kollabieren Haraway zufolge als Begriffspaare. Der Antagonismus Mensch - Natur und seine »Konsequenzen für die Geschlechter« als Basis der Geschichte der Moderne sei

90 Görg, a.a.O., S. 52.

91 Kropp, a.a.O., S. 196f. Binnenzitat aus Latour: Wir sind nie modern gewesen, S. 92.

92 Ebda., S. 184.

93 Ebda. S. 189. 
»durchbrochen worden«. Das Versprechen »von Fortschritt, Herrschaft, Vernunft, instrumenteller Rationalität« scheine »für die Kinder ungültig zu sein«. Kaum habe der Mensch »ein Bild von sich gewonnen«, habe er »sseine Stellung« verloren. Die »Natur war kaum gebändigt, ehe sie Rache nahm; das Imperium war mit Mühe gefestigt worden, bevor es zurückschlug«. Und der »Traum des Mannes von der Selbstgeburt« als »endgültige[r] Herrschaft über die natürlichen anderen zum besten des einen « zerstöre sich selbst. ${ }^{94}$

Es ist richtig, dass die »Technoscience «, der überbordende »kapitalistisch geprägte[], mittlerweile globale Zusammenhang von Wissenschaft und Technik «, ${ }^{95}$ alles bisher vermeintlich sauber Getrennte durcheinander wirft (oder werfen kann). Und es ist sicher notwendig, dies in seiner Faktizität zur Kenntnis zu nehmen, um politisch-emanzipatorische Reaktionen darauf zu finden. Das ändert aber gerade nichts an der notwendigen Frage, wie und woraus das jeweils entstehende >Dritte $<$ beschaffen ist und wie Herrschaft darin auch weiterhin wirkt.

Adorno - darauf hat ebenfalls bereits Görg hingewiesen ${ }^{96}$ - formuliert in der »Negativen Dialektik« den entscheidenden Punkt:

»Nichts ist möglich als die bestimmte Negation der Einzelmomente, durch welche Subjekt und Objekt absolut entgegengesetzt und eben dadurch miteinander identifiziert werden. Subjekt ist in Wahrheit nie ganz Subjekt, Objekt nie ganz Objekt; dennoch beide nicht aus einem Dritten herausgestückt, das sie transzendierte. Das Dritte tröge nicht minder. ${ }^{97}$

Zurecht betont Görg, dass die von Adorno beschriebene »Verfestigung« eines herrschaftlich verfassten Natur-Gesellschaft-Dualismus sich eben nicht auflöse im »heute prominente[n] Versuch [...], eine Einheit beider in einem Dritten zu behaupten: den Hybriden, den Netzwerken o.ä.«; diese »Dritten«, diese »reale[n] Synthese[n]« seien vielmehr selber Ergebnisse historischer Prozesse, und daher notwendig zu hinterfragen, anstatt sie »als gewordene« zu hypostasieren.

»Was Natur und Gesellschaft jeweils sind, das ergibt sich mit Verweis auf ihr Gegenteil. Dies zeigt, wie sehr beide miteinander auch wechselseitig identifiziert werden, Gesellschaft als das Andere der Natur, Natur als das Andere der Gesellschaft angesehen wird. Dies zuzugestehen, impliziert nicht notwendig,

94 Haraway: Anspruchsloser Zeuge@Zweites Jahrtausend; zit. n. ebda., S. $189 f$.

95 Ebda., S. 188, Fn. 26.

96 Vgl. Görg, a.a.O., S. 52f.

97 Adorno: Negative Dialektik, S. 177. 
beide Pole als Derivate eines Dritten anzusehen. Denn entweder wäre dieses Dritte ein ursprüngliches [...], [was] einen Gottesbegriff restituieren würde. Oder das Dritte ist selbst Resultat eines geschichtlichen Prozesses. Dann aber muss es als Zusammengesetztes analysiert werden [...]. Gegen eine Hypostasierung der Synthese in der Theorie wendet sich Adorno mit dem Argument, dass dadurch der Antagonismus zwischen den beiden Polen überspielt und negiert würde. Wenn Natur und Gesellschaft realgeschichtlich getrennt und praktisch auch immer wieder entgegengesetzt sind, dann kann eine theoretischbegriffliche Synthese diesen Antagonismus nicht kraft subjektiver Reflexion überwinden - und erst recht darf der Antagonismus nicht einfach überspielt und die Krise gesellschaftlicher Naturverhältnisse dadurch geleugnet werden. ${ }^{98}$

Neben der Notwendigkeit, einer Verschleierung der Antagonismen (in welcher neuen Gestalt auch immer) entgegenzuwirken, muss auch zwischen historisch und sozial unterschiedlichen Funktionen bzw. Wahrnehmungen von >Hybriden (differenziert werden.

Als Cyborgs und Hybride werden die unaufhaltsam produzierten Klonschafe, Genmäuse, Mensch-Maschine-Schnittstellen usw. angeführt. Hybride sind aber ebenso bereits kanalisierte Flüsse, geregelte Forste oder Naturschutzgebiete, traditionelle Zuchtarten von Pflanzen und Tieren. Eine Differenzierung scheint hier bei Haraway nicht zu erfolgen. Bestenfalls klingt derartiges an, ohne näher beleuchtet zu werden, wenn sie eine durch die »technoscience« seit dem Ende des 20. Jahrhunderts initiierte »(auch reale) Implosion der vormals stilisierten, kategorialen Gegensätze [Hvhbg. v. m.; M. T.]« sieht, die eine »neue historische Konfiguration« darstelle. ${ }^{99}$ Latour sieht Platons »Politeia« als Anfang der »modernen Verfassung«, der »Selbsttäuschung« über die strikte Trennung von Gesellschaft und Natur, deren Zementierung allerdings erst bei Hobbes und Boyle. ${ }^{100}$ Er führt als Beispiel für $»$ Assoziationen«, in denen "Akteure ihre Welt-Konstruktionen« stabilisierten, etwa den barocken Park, der eine Hierarchisierung von Betrachtern und Spaziergängern bewirke, an, nennt aber ebenso Schlüsseltechnologien, die »Zugänge und Anschlüsse« definierten. ${ }^{101}$ Cordula Kropp macht in ihrer Beschäftigung mit diesen Konzepten zunächst ebenfalls keinen Unterschied:

98 Görg, a.a.O.

99 Kropp, a.a.O., S. 188.

100 Ebda., S. 203. Kropp zitiert »Wir sind nie modern gewesen«, S. 23ff.

101 Ebda., S. 194. Kropp bezieht sich auf Latours 1987 erschienene Arbeit $»$ Science in Action«. 
»Der kanalisierte Fluss und die umzäunte Wildnis im Bayrischen Wald, der um das Huntington-Chorea-Gen erleichterte Embryo im Reagenzglas, die importierte Stammzelle, das Ozonloch, die Kadaverhaufen von MKS- oder BSEverdächtigem Vieh - gehören diese eigenartigen `Objekte` zur Natur oder zur Gesellschaft? Sind sie transzendent gegeben oder immanent zu verantworten? Oder handelt es sich um flüchtige Mischwesen, welche die Zuordnung unterlaufen? ${ }^{102}$

Später betont sie dann aber die Notwendigkeit einer "politische[n] Diskussion und Verantwortung« über und für die Produktion von Hybriden »durch bewusste und verortete Deliberation, die nicht mehr auf Vor-abGewissheiten und -Differenzierungen zurückgreifen kann - und doch nicht differenzlos bleibt!« Andernfalls drohten womöglich Naturschutzgebiete und Müllhalden »gleichermaßen als unqualifizierbare, hybride Naturproduktionen sich wandelnder, technisch, sozial, kulturell und materiell bedingter Natur-Gesellschafts-Zusammenhänge« zu erscheinen. ${ }^{103}$ Mit den »hybridorientierten Ansätzen«, schreibt Kropp, gelinge es, "sowohl die dialektische Beschwörung der Geschichtlichkeit als auch der Vermischung bzw. Verschmelzung von >Natur` und >Gesellschaft erheblich zu qualifizieren $\ll .{ }^{104}$ Das ist richtig, solange Hybride als Zusammengesetzte analysiert werden. Richtig ist ebenso - das schreibt Kropp auch, dass vor allem Latours Netzwerkbegriff als »zu wissenschaftsorientiert und zu machiavellistisch angelegt zu kritisieren« sei und überdies »in >ungerechter Weise die Unterschiede, bspw. Zwischen Organismen und Maschinen, Müllhalden und Naturschutzreservaten « nivelliere. Nun komme es darauf an, nach der Nivellierung von Differenz, Differenzen bewusst zu setzen «. ${ }^{105}$

Hybride entstehen nicht nur auf technischem Weg bzw. unter Mitwirkung technischer Verfahren, geschweige denn ausschließlich wissenschaftlich. Sie haben zudem (affirmative, pejorative, numinose) soziale Funktionen, die historisch Kontinuitäten wie epistemischen Brüchen unterliegen können, die desgleichen bewussten oder unbewussten Intentionen unterliegen oder diesen widersprechen. So gibt es offenbar eine deutliche Differenz zwischen den sozialen Funktionen >moderner ( bzw. auch vormoderner) und >postmoderner ${ }^{106}$ Hybride und ihrer Wahrneh-

102 Ebda., S. 147.

103 Ebda., S. 188.

104 Ebda., S. 212.

105 Ebda.

106 Die Unterteilung in >modern Anlehnung an Haraways Begriff »postmoderne[n] Körper«. Dies.: Die 
mung: Kanalisierte Flüsse, Forsten, Naturschutzgebiete, Zuchtarten usw. >beweisen < ein binäres Verhältnis, die Existenz eines Antagonismus von Kultur und Natur. Derartige >moderne` Hybride machen die Herrschaft der Kultur über die Natur (vermeintlich) erfahrbar. Gentechnisch veränderte Organismen, Krebsmäuse, Klontiere oder gar -menschen lassen dagegen den Antagonismus tatsächlich als von einer Implosion ergriffen erscheinen. Die Wahrnehmung der Bedrohung einer >einmaligen Schöpfung`, also besonders des Menschen und seiner >Individualität` durch irreversibel verändernde und auflösende biotechnologische Machbarkeiten ist gesellschaftlich virulent. Die Irritation entsteht hier aus einem vermeintlichen Paradox. Um die Natur >neu zu erfinden`, braucht es die Herrschaft über sie, den Antagonismus von Gesellschaft/Technik und Natur. Die biotechnologische >Auflösung` dieses Antagonismus erwächst also auf der Basis seiner Behauptung.

Ich werde mich im Folgenden auf vormoderne und moderne >Hybride konzentrieren. Schon, weil ich glaube, dass unter den Eindrücken rasanter biotechnologischer >Auflösungen` und globaler Transformationen und der wissenschaftlichen Fokussierung auf sie, vermeintliche Alternativen, also historisch vorhergehende Erfahrungsräume in ihrer >Konstruiertheit aus dem Blick geraten könnten. Ich verwende auch daher den Begriff der Bilder.

Hierbei muss auch zwischen vorbürgerlichen Gesellschaften und ihren aggregativen semantischen Räumen und dem generativen Bedeutungsraum bürgerlicher Gesellschaften differenziert werden. Auch vorbürgerliche Körper als Besitzer unwandelbarer Eigenschaften haben ihre Verkörperungen in der >äußeren Natur` (Bauern das >Krummholz` im Niederwald, Hochadelige den Königsforst etc.), was aber offenbar nichts mit unterbewussten Vorgängen zu tun hat, sondern mit den Kategorien der >Ähnlichkeiten`. Hier haben >Monstrositäten`, Phänomene überhaupt, eigene Sinnproduktionen (wie Bachtin, Czerwinski u.a. zeigen), die beim >Sprung` in einen semantischen Raum zum Identitätswechsel des Springenden führen können. Erst mit den Prozessen, die zum einen semantischen Raum der bürgerlichen Gesellschaft mit seinen >verborgenen Unter- und Hintergründen führen - vielfach verkoppelt mit der von Latour angeführten »Trennung von Fragen der Epistemologie und Fragen der Gesellschaftsordnung $«,{ }^{107}$ den Postulaten des Antagonismus von Gesellschaft/Kultur und Natur bei realer Vermischung - kommt es

Biopolitik postmoderner Körper. Konstitutionen des Selbst im Diskurs des Immunsystems, in: Die Neuerfindung der Natur, S. $160 \mathrm{ff}$.

107 Kropp, a.a.O., S. 203. 
zu Bildern, die den Produktionen des Unterbewusstseins entstammen oder hiervon mitgeprägt sind.

Bilder sind - erstens - durch Tätigkeit oder Wahrnehmung bewusst oder unbewusst geschaffene und gestalte Räume, Verkoppelungen von Körpern und Bedeutung derart, dass sie Verkörperung der >inneren Natur` in der >äußeren` darstellen. Die Bändigungen erfolgen als praktische Transformationen snatürlicher Regungen< in Herrschaftstechniken: 〉Zivilisierung « der >Wildnis $\prec$. Desgleichen lässt sich >Wildnis` erzeugen. Wenn frühneuzeitliche Reisende und Eroberer fremde Landschaften, Wälder, Flüsse, Sümpfe, feminisieren und sexualisieren, wie das ihren Berichten zu entnehmen ist, dann entstehen mittels Alterisierung, also bereits mittels Wahrnehmung (und Zuschreibung) `Hybride $\prec$, ohne, dass bis dahin Technik angewandt worden ist (abgesehen von der Technik, die die Schiffsreise ermöglicht hat). Daran sind auch die Objekte als >Aktanten $<$ beteiligt. Was schon daran ersichtlich wird, dass sich Weltbilder in solchen >Entdeckungs $<-$ und Eroberungsprozessen verändern können.

Bilder produzieren Ordnung, vergesellschaftete Harmonie oder `konstruieren< Gegenwelten: Wildwuchs als Bedrohungen, Inversionen von Ordnungen, die es zu überwinden, Unbeherrschtes, das es zu erobern gelte - andererseits Gegenwelten zu negativ empfundenen Gesellschaften: positive Utopien von >edler Wildnis`.

»Das Dritte tröge nicht minder«: Der Begriff des Bildes behauptet zweitens - das Trügerische in der Konstruktion, in der sich eben nicht alles auflöst, etwas Widersprüchliches, Widerständiges bleibt. Dietmar Kamper zeigt, dass Idyllen eine nur flache Realität aufweisen. Sie verkleinerten das Überwältigende auf ein »handhabbar[es]« Format, spannten es als Ausschnitt zwischen Rahmen - und täuschten doch die BetrachterInnen, da das Lebendige in ihnen doch nur eine pseudo-reanimierte Leiche sei. ${ }^{108}$ Aber nicht nur die Idylle geht auf und doch nicht. Gleiches trifft aufs Gegenformat, die serhabene < Landschaft, die >Waldkathedrale $<$ zu. Auch die Vergrößerung macht die Natur gewissermaßen handhabbar, erklärt sie wahlweise zum Transzendenten, Schicksalhaften oder zum Beweis eines überlegenen menschlichen Geistes im Angesicht ihrer physischen Überlegenheit.

Zwischen >Idylle $<$ und >erhabener Größeく ist solchen Bildern gemein, dass sie einen Rahmen für Verkörperungen bieten, in dem Geschichte stillgestellt ist. Sie transportieren etwas >Unwandelbares` bzw. seine Behauptung, eine Erstarrung inmitten der Linearität der Zeit, des Fort-

108 Vgl. Kamper: Unmögliche Gegenwart, S. 73ff. Vgl. Ausleitung. 
Schritts: >Weibliche` Zyklizität, Verhaftetsein im Immergleichen oder >männliche` Ewiggültigkeit von Normen und Werten. Das >weiblich wuchernde, verschlingende Chaos als traditionelle Opposition, zu beseitigende oder formbare Materie, verfällt in der Moderne seinerseits zur nun schützenswerten Idylle. Der Schrecken ist auch so gebannt.

Die Untersuchung endet mit einer Betrachtung von >Bildern dritter Ordnung`, einer erwünschten Landschaft und ihrer Wälder, deren Vor-Bilder häufig Gemälde, Fotos, (ebenso literarische Schilderungen) sind. In diesen Vor-Bildern entfaltet sich eine Landschaft, deren Existenz sich weitgehend aus ihnen ergibt; offensichtlich kaum aus noch vorhandenen sauthentischen` Erfahrungen. In Bildern - im gebräuchlichen Sinn werden Naturräume, beseitigte Erfahrungsräume als ehedem real existierende >erkannt`, aus diesen Bildern heraus im nächsten Schritt erneut >realisiert<. Eine Rekonstruktion, die doch immer Konstruktion ist. Dieses Verfahren der Umweltplanung ähnelt, >trotz` aller Wissenschaftlichkeit in der Realisation - Quellenkritik, Pollenanalysen usw. -, augenfällig anderen markanten Konstruktionen von Bildern dritter Ordnung: Paradies(-Garten) ${ }^{109}$ und 〉Urwald (s.o.).

Die Naturwissenschaft selbst liefert gar die Vor-Stellungen, die über Empfindungen, sich in mehr oder weniger naturnahen Erfahrungsräumen zu bewegen, entscheiden können. So können bei ökologisch gesinnten >NaturliebhaberInnen geobotanische und pflanzensoziologische Vorkenntnisse (auch und häufig aus populären `Naturführern $<$ ), mit denen sich bestimmen lässt - bzw., die bestimmen -, wie z.B. ein Erlenbruchwald aussehen soll, zu Lust- oder Unlustgefühlen führen abhängig vom Grad der Übereinstimmung mit dem wissenschaftlich Bestimmten. Vorhandene Waldkiefern etwa (angepflanzt oder aus benachbarten Pflanzungen >eingewandert $<$ ) gelten hier als `natürlicherweise $<$ im westeuropäischen Flachland >standortfremd und deswegen als >störend . Mittels dieser wechselseitig verwobenen »materiell-semiotischen

109 Der >Garten Eden « der Bibel ist konstruiert nach dem Vorbild des ummauerten oder umzäunten persisch-antiken Lustgartens, "pairidaëza«, der vor allem auch der herrschaftlichen Jagd diente. Der Begriff »bedeutet seinem Ursprung nach nichts anderes als >Umzäunung, Umwallung«", woraus im spätjüdischen eben der Name `Edens` wurde. Reale Gärten seit dem Mittelalter wiederum entstehen als Versuch einer Reetablierung des >Gartens Eden<. Mayer-Tasch, Peter Cornelius/Mayerhofer, Bernd: Hinter Mauern ein Paradies. Der mittelalterliche Garten. Frankfurt/M, Leipzig: Insel 1998, S. 171; vgl. Kawami, Trudy S.: Antike persische Gärten, in: Carroll-Spillecke et al. (Hg.): Der Garten von der Antike bis zum Mittelalter. Mainz: von Zabern 1995, S. 93f. 
AkteurInnen« - >innere Natur`, >äußere Natur« und naturwissenschaftliche Disziplinen - entsteht ein Raum als Objekt der Konservierung, der Unterschutzstellung, vielleicht aber auch nur als Relikt in einer ansonsten vielfach transformierten Landschaft oder gar als Resultat von >Renaturierung〈, also 〉künstlich`. »Hybrid« aber ist offenbar allein schon der reine Erfahrungsraum (hier Erlenbruch) der jeweiligen BesucherInnen, denn ohne die naturwissenschaftliche Vor-Stellung würde er nicht als >naturnah` erkannt und wäre als solcher inexistent.

>Bilder dritter Ordnung in der gegenwärtigen Umweltplanung sind also >Hybride`, Verkörperungen, die die Funktion haben, Harmonie und Ganzheit hervorzurufen und zu erfahren, deren Aufbau wiederum auf einer Entmischung der Landschaft in abwechselnde und somit voneinander abgegrenzte >naturnahe bis >naturferne` Biotope beruht. Sie stellen damit als >traditionelle $<$ Hybride gewissermaßen einen Gegenentwurf zu den bedrohlichen >postmodernen neben einer vermeintlich damals noch sheilen`, deutlich weniger zersiedelten und industrialisierten Umwelt - eine wesentliche Begründung dafür, dass die Landschaft des 19. Jahrhunderts (in Deutschland und Westeuropa) als gegenwärtige Sehnsuchtslandschaft fungiert, auf die sich Gesellschaft (bzw. deren interessierte Mitglieder) und UmweltplanerInnen einigen können. Eine re-rekonstruierte 〉befriedeteく, >harmonisierte Landschaft - die so einen Höhepunkt bürgerlicher Naturbeherrschung darstellt - vergesellschaftet in einer Weise, die den Antagonismus Kultur - Natur wahrnehmbar, erfahrbar macht und derart eine vorgebliche >Versöhnungく. 


\section{Das ısoziale Geschlecht ` der äußeren Natur Teil I: sWeiblicher Waldı}

Erst in agrarischen Gesellschaften sind klare Grenzen zwischen Innen und Außen erkennbar, und erst mit dem Ackerbau erhält desgleichen der Wald scharf konturierte Ränder, die es ohne Rodungen nicht geben würde, da natürlicherweise »eine Gradienten-Situation zwischen Wald und Offenland «, mithin eine Situation dynamischer Übergänge besteht. ${ }^{1}$ Die gesellschaftliche Produktion von Innen und Außen unterliegt einem weiteren Moment: Durch die Fixierung auf den Ertrag eines bestimmten Stücks Land steigt die Bedrohlichkeit der Wildnis. Zunächst erscheint die Zuordnung von >männlich` und >weiblich` in agrarischen Gesellschaften klar geregelt. Das alltägliche weibliche Leben ist auf die Endosphäre, den engen Siedlungsbereich (den Hof, das Haus) beschränkt. In der Endosphäre, die zugleich gemeinsamer Lebensbereich der Geschlechter ist, herrscht die männlich bestimmte soziale Ordnung. Die Exosphäre, die >Wildnis`, wird privilegiert von Männern aufgesucht.

Zwar beginnt hier »auch die Transzendenz, die gleichsam eine Überhöhung der Exosphäre ins Kosmische darstellt. In Busch und Wald, im Meer, in den Wolken und in den Himmeln darüber, unter der Erde, auf dem Grund der Flüsse und Seen, in einer anderen, eben der >jenseitigen< Welt, hausen und herrschen die Ahnen, Geister und Götter. Und auch dort dominiert, wie auf Erden, das männliche Geschlecht «. ${ }^{2}$ Das heißt aber nicht, dass diese Wildnis >männlichく ist. Hier ist >die Fremdeく sehr wohl mächtig, hier ist der Aufenthalt für Männer durchaus gefährlich, denn unter denjenigen Geistern, die in die Geschicke der Menschen

1 Küster, Hansjörg: Geschichte des Waldes, S. 52.

2 Müller, Klaus E.: Die bessere und die schlechtere Hälfte, S. 269. 
eingreifen, dominieren in den Schaden und Unheil stiftenden Fällen die weiblichen. So begegnen den Männern an besonders unheimlichen Orten (Sümpfe, Dickicht, Höhlen) »plötzlich hexenartige Spukgestalten [...], Greisinnen mit langen fliegenden Haaren, flammenden Augen, übergroßen, über die Schultern geschlagenen Brüsten und Nägeln wie Krallen, deren Anblick so grauenvoll ist«, dass der ihrer angesichtig werdende Mann augenblicklich wahnsinnig wird oder stirbt. Desgleichen können die bösen Weiber auch als freundliche Alte (die den Mann schlachten und verspeisen will) oder schöne junge Frau erscheinen, als Sirenen oder Nixen, die mit erotischen Avancen locken, den Betörten dann aber in Untiefen ertrinken lassen, oder mit Impotenz und Siechtum schlagen. ${ }^{3}$

In zahlreichen mittelalterlichen Erzählungen tauchen sagenhafte Frauengestalten in der Wildnis auf. Hier ist gegenüber den archaischen Mythen eine Entwicklung zu beobachten. Die Gegenwelt Wald wird als »wilder Wald" aufgefasst - wobei im mittelhochdeutschen Sprachgebrauch »unbekannt, fremd, ungewohnt, fremdartig, entfremdet, wunderbar, seltsam, unheimlich [...], dämonisch« mitschwingen -, als schrecklich und gefährlich, mithin »Antithese zum höfischen Raum«, aber eben auch als jenseits vom Nutz- und Jagdwald, ${ }^{4}$ vom Forst. >Forst‘, >forest $\iota$, >forêt` werden »von dem lateinischen Begriff >forestis« abgeleitet«, der allerdings »eine sprachliche (und rechtliche) Neuschöpfung des 7. Jahrhunderts n. Chr.« darstellt. ${ }^{5}$ Wahrscheinlich ist »forestis « abgeleitet von »foris« - >draußen ${ }^{6}{ }^{6}$ Dabei ändert dieses >draußen Charakter. »Das gesamte Mittelalter hindurch vergrößerten sich die Siedlungen mit ihren sinnen genden Wälder hinein und zogen sich daraus wieder zurück. Dieser Vorgang, aus der Luft mit dem Zeitraffer betrachtet, kann mit den pulsierenden Bewegungen einer Amöbe verglichen werden. [...] Die Außenwand der Amöbe ist zwar nicht stabil, aber stets klar definierbar«, die »Grenze der Markung« hingegen »stets unscharf«. Eine durch Rodung

3 Vgl. ebda., S. 271.

4 Frühe, Ursula: Das Paradies ein Garten - der Garten ein Paradies. Studien zur Literatur des Mittelalters unter Berücksichtigung der bildenden Kunst und Architektur. Frankfurt/M u.a.: Peter Lang 2002, S. 312f.

5 Küster, a.a.O., S. 124.

6 Nach Küster ist diese Abstammung von »foris« nicht mehr mit letzter Sicherheit zu ermitteln (ebda.). Nach Simon Schama ist die Abstammung allerdings sehr wahrscheinlich, vgl. Schama, Simon: Der Traum von der Wildnis. Natur als Imagination. München: Kindler 1996 (New York 1995), S. 163. Vgl. Harrison, Robert P.: Wälder. Ursprung und Spiegel der Kultur. München, Wien: Hanser 1992, S. 90. 
erzeugte klare Waldgrenze besteht hier nur temporär, weil der Wald sich immer wieder ausbreitet. Frühmittelalterlich gelten Wälder, in denen »ländliche ortsfeste Siedlungen eingesprengt« liegen und weitere Rodungen vorgenommen werden, anfangs als »res nullius«, werden dann aber (zuerst von den fränkischen Königen) zum Besitz der Grundherren erklärt, zum Forst. Forsten, in denen nicht nur Wald, sondern auch Heide oder Weideflächen liegen können, werden häufig Adligen und Orden geschenkt, so dass mit der Errichtung von Burgen und Klöstern - wie geplant auch immer - die Kolonisation und Zähmung weiter voranschreitet. »Im Forst, den man später auch Wildbann oder Bannwald nannte«, legt der Grundherr die Nutzungen fest, entscheidet über Rodungen und die Ansiedlung neuer Dörfer. »Wildbann« bezeichnet die nun kolonisierte ehemalige Wildnis. Ein wesentliches Waldnutzungsrecht ist die Jagd, die überwiegend am Waldrand stattfindet, was häufig Konflikte mit den Bauern verursacht in der durch Ackerflächen veränderten Landschaft, die andererseits zu einer starken Vermehrung der bevorzugten Jagdtiere beiträgt: Rehe und Hasen, die zuvor, als noch geschlossener Wald vorherrschte, kaum vorhanden waren, nun aber im Mosaik der Kulturlandschaft Deckung im Wald und Nahrung auf den Feldern finden. Oft wird schon damals regelrechte Hege betrieben, um die Jagdstrecke zu erhöhen. ${ }^{7}$

Der tiefe, dunkle und undurchdringliche, der menschenferne wilde Wald der mittelalterlichen Literatur bietet keinen materiellen Nutzen und »kein Jagdwild mehr, er ist ausgestattet mit grotesk-phantastischen Tieren, die dem Bösen und Unheimlichen Gestalt verleihen «, ${ }^{8}$ mit >Waldmännern ${ }^{9}$ und Werwölfen. ${ }^{10}$ Hier erscheinen sehr häufig Feen, »Repräsentantinnen einer jenseitigen Welt«, die »ursprünglich dem irokeltischen Sagenkreis entstammen«, durch »[ü]berirdische Schönheit, Reichtum und magische Kräfte« ausgezeichnete »idealisierte Frauengestalten«, die »den auserkorenen Helden zu sich locken, um ihm ihre Liebe zuteil werden zu lassen«, bzw. ihn zu ehelichen. ${ }^{11}$ Diese Feen sind streng ortsgebunden, überwiegend an Wald und Wasser. So die häufig in der Artusliteratur erwähnte Fee »Morgan«, die, ursprünglich Herrin der

7 Küster, a.a.O., S. 124ff.

8 Frühe, a.a.O., S. 334. Dieser menschenferne Wald ist gleichwohl nicht völlig menschenleer. Hier, wo »die Regeln der höfischen Welt aufgehoben « sind, finden Randgruppen, Ausgestoßene, Verbrecher Zuflucht (ebda., S. 315f.), hierher ziehen sich aber auch Eremiten und Asketen zurück (ebda., S. 324ff.).

9 Vgl. ebda., S. 318ff.

10 Vgl. ebda., S. $327 \mathrm{ff}$.

11 Ebda., S. 330. 
Insel Avalon (»Insel der Apfelbäume « ${ }^{12}$ ), nun in einem Wald lebt, »da irs duns vil was«, oder Merlins Geliebte Ninienne, die sich an einem See »in eym großen tieffen walde« aufhält. $^{13}$ »Die eigentliche Waldfee ist Melusine.« Sie ist (in der deutschen Prosafassung von Thüring von Ringoltingen) gebunden an den »turstbrunnen« im »Wald von Columbier ${ }^{14}{ }^{14}$ In anderen Gattungen wie etwa den Aventiureromanen verirren sich die männlichen Protagonisten bei der Jagd, werden von besonderen Tieren weggelockt - »meist ist es eine (weiße) Hindin oder ein Eber « und treffen »oft jenseits eines breiten Wassers« auf Feen. So auch Partonopeus oder Partonopir, der hinter einem mächtigen Eber her ist, sich immer tiefer im dunklen Wald verliert, schließlich an ein Meer kommt und per Schiff in ein Zauberland gelangt. Hier trifft er auf Meliur, Königstochter von Konstantinopel, also keine Fee, aber deutlich mit feenhaften Zügen ausgestattet. ${ }^{15}$ Die lockenden Tiere sind dabei anders, als noch in antiken Mythen, in denen den Jägern, wie Aktaion, unheimliches zustoßen kann, indem sie in Tiere oder Pflanzen verwandelt werden - nun selbst unheimlich, was auch mit der Ambivalenz des Ziels zusammenhängt: »In mittelalterlichen Dichtungen und in Sagen

12 Ranke-Graves, Robert von: Die weiße Göttin. Sprache des Mythos. Reinbek: Rowohlt 1985 (New York 1948), S. 125. Nach Robert von RankeGraves ist Morgan ursprünglich die Göttin »Morgan la Faye« der keltischen Sage, Schwester König Arthurs, die dessen Leichnam auf die Toteninsel Avalon bringt (ebda.). Die Morgan der keltischen Sage ist auch unter dem Einfluss der frühen christlichen Kirche (die so etwas allerdings als »die teuflischste, allerunverzeihlichste Ketzerei« bekämpfte) - >Maria Magdalena $<$ mithin die »Dritte in dieser althergebrachten Trinität «, in der >Maria〈 mit der »Dreifältigen Göttin« gleichgesetzt bzw. aus drei Figuren zu einer verschmolzen wurde. Und: »Morgan ist in der irischen Sage $>$ the Morrigan`, d.h. die `Große Göttin`, eine Todesgöttin, die die Gestalt eines Raben annahm; und >le Faye < bedeutet >das Schicksal (fate). Laut Cormacs Glossary wurde die Morrigan im Gefecht angerufen, und zwar mit einer Nachahmung des Rabenkrächzens durch die Schlachthörner. Sie war keineswegs jene freundliche Gestalt, wie der Leser des Morte d'Arthur sie kennt, sondern war, wie die sschwarze kreischende Hexe Cerridwen ' in der Romance of Taliesin, >großmäulig, dunkelhäutig, aufbrausend, rußig, hinkend, und schielte auf dem linken Auge« (ebda., S. 163). Im Spätmittelalter wird in den Arthur-Erzählungen die »Romance von Ogier dem Dänen und Morgan la Faye« auf der Burg Avalon thematisiert, wobei Ogier nur »eine entstellte Form von 〉Ogyr Vran««, also »Bran der Böse«, der Totengott, skandinavisch »Ogir«, Gott der Meere und der Toten, sei (ebda., S. 520). Bran ist ebenso Gott der Krähe, des »oft von den Auguren konsultierte[n] Vogel[s]« (ebda., S. 75).

13 Frühe, a.a.O., S. 330.

14 Ebda., S. 331f.

15 Ebda., S. $332 \mathrm{ff}$. 
und Liedern aus ganz Nordeuropa führen überirdische Hirsche und Hinden Jäger, die ihnen nachstellen, zu Liebe und Ruhm oder in ihr tragisches Verderben. ${ }^{16}$ Es führen aber in den Dichtungen nicht nur weiße Hirsche Jäger zu Liebesabenteuern (oder anderem), Hirsch - in der griechischen Antike noch Symbol der Feigheit, seit dem 9. Jahrhundert »geadelt $«{ }^{17}$ - und Hinde werden zur »Metapher für die Nachstellungen der Liebenden«. Die »Liebesjagd« wird insbesondere im französischen und deutschen Sprachraum »vom 12. bis 16. Jahrhundert [...] zu einem regelrechten literarischen Genre $\lll$, in unzähligen Varianten anfangs brachialer, dann bis zur Renaissance zunehmend auch courtoise verfeinert. »Allegorien der erotischen Jagd « waren darüber hinaus in der bildenden Kunst und als Verzierungen von Einrichtungsgegenständen weit verbreitet. ${ }^{18}$ Insofern scheinen die Sphären des tiefen >wilden Waldes $\triangleleft$ des Nutzwaldes und der höfischen Gesellschaft (zunehmend) durchlässig zu sein. Mit Konsequenzen für den >wilden Wald .

Mächtige, numinose Frauengestalten, unsterblich, zugleich schicksalhaft an die menschenferne Wildnis gekettet. Erlösung bringen die angelockten Männer, besser: Herauslösung. Durch Heirat verlieren die Wald- und Wasser-Frauen zwar ihre Unsterblichkeit (und damit einen Großteil der Macht), aber werden von ihrer strikten Ortsgebundenheit befreit. Das funktioniert allerdings, wie die Melusine-Erzählung zeigt, nur unter der Bedingung, dass der Freier oder Gatte sich an ein >Gelübdeく hält, daran, das Geheimnis der >wahren Natur` der Fee nicht anzutasten, nicht erforschen zu wollen.

Der Schrecken, das Chaos des >wilden Waldes` und das Lockende, Begehrte - die >Fee $<$ - sind hier ungetrennt. Die Aufspaltung in den `locus amoenus` und den >locus terribilis` existiert aber längst. In den >Lustort einer idealen Natur, in dem Dante Beatrice trifft, oder den mit der im 12. Jahrhundert aufkommenden Marienminne verbundenen shortus conclusus`, dem Sinnbild der >Jungfräulichkeit`, den >Rosenhagen Baumgärten der Malerei, die allerdings während des Humanismus im deutschen Sprachraum (nicht von ungefähr unter dem Einfluss der von Konrad Celtis übersetzten »Germania«) auch hier zur Landschaftsma-

16 Cartmill, Matt: Tod im Morgengrauen. Das Verhältnis des Menschen zu Natur und Jagd. München: Artemis \& Winkler 1993 (Cambridge/Mass, London 1993), S. 95.

17 Vgl. Kap. Forst I.

18 Cartmill, a.a.O., S. 91ff. Peter Czerwinski zufolge ist es allerdings fraglich, ob in einer Gesellschaft der prinzipiell noch aggregativ aufgebauten semantischen Räume schon die Abstraktion zu Metaphern und Allegorien existiert, bzw. in welchem Maß sie in den hier behandelten Jahrhunderten bereits möglich erscheint. 
lerei wird. ${ }^{19}$ Zugleich spielen einzelne Bäume in der Landschaft (im Bild wie real) eine »wichtige Rolle [...] als Mariensymbol«:20 so tritt sie als sneue Eva` gegenüber der >alten` unterm Paradiesbaum auf, wie in Furtmayrs »Missale« von $1481,{ }^{21}$ auf frühchristlichen Elfenbeintafeln im Zusammenhang mit der >Auferstehung ${ }^{22} .{ }^{22}$ »Auch sonst spielen Bäume in der Marienverehrung eine wichtige Rolle, wobei sich christliche und heidnische Vorstellungen miteinander vermischen können. Wir finden den Baum in den Namen von Wallfahrtsorten wie Maria-Eich, MariaLinden, Maria Grün und Maria Buch. $\ll^{23}>$ Marien-Eiche`:

$»$ Der Kult der Jungfräulichkeit besetzt nicht wahllos Objekte, sondern solche, die ihn gefährden. ${ }^{24}$

Im paganen Glauben »Liebes- und Fruchtbarkeitsbaum«, kultisch verehrt »ihrer gewaltigen Ausmaße wegen«, Baum Donars nicht nur als Gewittergott, sondern auch, weil von »dessen Wohlwollen die Fruchtbarkeit der Pflanzenwelt abhing«, wird die Eiche schon wegen ihrer Früchte als Nahrungsreserve in Notzeiten »zum mütterlich-fertilen Nährbaum« und so zum Pilgerobjekt »heiratslustiger« Mädchen und Paare. Im Christentum erhält sich der Kult, allerdings bei umgetauftem Objekt:

»Ist aber die Eiche sowohl der Baum der Fruchtbarkeit als auch der Jungfrau, so wird er zum ausgezeichneten Sinnbild für die patristische Ehemoral - castum connubium, keusches Beilager, Fortpflanzung ohne Begierde. $\varkappa^{25}$

Der Florentiner Jacopo Ligozzi schafft im Kontext »der starken Affinität des heiligen Franziskus zu einer christianisierten Naturverehrung« und der daraus resultierenden »besonders emphatische[n] Tradition von Erlöserbäumen« der »Franziskaner des 17. Jahrhunderts« eine GrafikenSerie über die »Bergzuflucht Monte Verna in Piemont«, darin 1607 das Blatt »Die Madonnenbuche in La Verna«. Es zeigt eine »Buche in Kreuzesform«, in ihrer Astkrone eine »Erscheinung der Jungfrau Maria mit dem Jesuskind«, im Stamm eine gewaltige »Höhlung, um das Grab

19 Vgl. Eschenburg, Barbara: Landschaft in der deutschen Malerei. Vom späten Mittelalter bis heute. München: C.H. Beck 1987, S. 34f.

20 Steigner, Beate: Paradiesbaum und Kreuz, in: Gercke, Hans (Hg.): Der Baum. Heidelberg: Braus 1985, S. 100.

21 Vgl. ebda., S. 94ff.

22 Vgl. ebda., S. 100.

23 Ebda.

24 Wyss, Stephan: AskeSe, S.159.

25 Ebda. 
der Auferstehung anzudeuten «. ${ }^{26}$ Marien-Bäume ${ }^{27}$ als Wallfahrtsorte entstehen vor allem während des Dreißigjährigen Kriegs, aber auch im weiteren Verlauf des 17. und 18. Jahrhunderts. Hier wurden häufig Kirchen »um Bäume herum gebaut«. Hier soll jeweils >Maria〈 in einer Baumkrone erschienen sein, eine Vorstellung "wahrscheinlich in Weiterführung des altägyptischen Hathorglaubens«. Insbesondere Bäume, »die von altersher weiblichen Gottheiten zugeordnet waren«, werden zu »Symbolen Mariens«, Maria wird »geradezu zur >arbor bona«: Olive, Zeder, Zypresse in Konrad von Megenbergs »Buch der Natur« (ca. 1350), oder auch die »Darstellung Mariens im Dornenbusch als Sinnbild ihrer jungfräulichen Mutterschaft« in okzidentaler und orientalischer Tradition. ${ }^{28}>$ Materia , das verwendbare Holz, >mater`, die Mutter, >Matrix ^, die Gebärmutter, Stammform, Keimschicht, der Baumstamm, der neue Triebe erhält.

Der >locus amoenus` als Liebesgarten >erotischerer` Art - das für die Marienminne zu ewiger Jungfernschaft variierte `Hohelied ist auch hier Vor-Bild - öffnet sich zum entschärften, spielerischen, aber geordneten Arkadien der Renaissance. So in Jacopo Sannazaros 1519 in Venedig erschienenem »Arcadia«, dem »Prototyp[en]« dieses Genres. Es greift »alle vertrauten Themen der Eklogen auf: unglückliche Liebe an Schauplätzen von unglaublicher Anmut; das Goldene Zeitalter, als die Felder in Gemeinbesitz waren und die Fülle gleichbleibend war und es weder Eisen noch Krieg oder Zerstörung gab«. Hier gibt es »Vogelgezwitscher, wilden Honig und Blumensträuße im Mondschein«; diese Idyllen werden aber um »eine spektakuläre Szenerie« erweitert, »um dunkle Emotionen zum Ausdruck zu bringen«: hier und da »Wasserfälle (natürlich immer mit weißem Schaum)«, dazu »Klippen, von denen sich liebeskranke Hirten hinabzustürzen drohten«. Das ganze Arkadien wird überragt von einem recht leicht besteigbaren Berg, »der von riesigen Zypressen und Pinien bewachsen war. Es gab die erotische Landschaft, die auf dem Körper der Nymphe Amaranta erschien, zwischen deren knospenden Brüsten ein Weg in tiefe und schattige Haine hinablief«. Die »Schwellungen und Höhlungen ihres Körpers« werden, wie auch die der liegenden Nackten der Idyllen Tizians, Giorgiones und Domenico

26 Schama, Simon: Der Traum von der Wildnis, S. 247.

27 Die Transformation paganer Epiphanien ins Christliche führt Selbstverständlich auch zu Bäumen des 〉Erlösers` und allerlei Heiliger. Vgl. ebda.

28 Kastner, Angelika: Wallfahrt, Weihnachten und Stammbaum, in: Gercke, Hans (Hg.): Der Baum, S. 102ff. Vgl. auch die Abb. der in Holzhausen/Starnbergersee um 1420 gepflanzten Linde, in deren hohlem Stamm eine Marienfigur steht, ebda., S. 51. 
Campagnolas, »zu einem weiteren locus amoenus $« .{ }^{29}$ Der $»$ Leib der Erde« codiert als »alles versprechende[r] Frauenleib[] «. ${ }^{30}$ In seinem Innern, »einer seiner Höhlen, die >innen wunderbar geglättet` ist« gibt es bei Sannazaro die hölzerne Statue des Waldgottes, das »Gesicht rot wie eine reife Erdbeere«, auf dem Kopf »zwei Hörner, [...] ganz gerade und zum Himmel gerichtet« ${ }^{31}$ Eher »ein Schäker, als ein Vergewaltiger«, kommentiert Schama, der den »Humanisten der Renaissance« das Vexierspiel mit den fließenden Grenzen zwischen >fanum bescheinigt, das Durchbrechen der von Mauern und Zäunen des shortus conclusus`, Signum unbefleckter Empfängnis, der »Fruchtbarkeit ohne [...] Tierisches « - mit »ernsthafte[n] Folgen für die Trennung des wilden vom kultivierten Arkadien «. ${ }^{32}$ Folgen aber eher für die >Wildnis $`$, die nun integriert, vor allem aber geschaffen wird. So entstehen >Gärten der Lüste $\prec$, in der Literatur und Malerei, aber auch real in der Landschaft, in »kühnste[n] Entwürfe[n] für Villengärten«, die »Landschaften mit Wald, Wasser und Felsen« schaffen, »in die man von regelmäßiger angelegten Bereichen aus gelangte« und deren Grenzen von torsischen Hermen markiert werden. Die unregelmäßig gestalteten Gegenden können dabei »die Form eines sacro bosco, eines `heiligen Hains`, annehmen, also nicht eines Waldes, sondern eines sorgfältig ungepflegten Gebiets am Rande des Gartens « ${ }^{33}$ Wobei - wie gesagt - die >rohen Areale` sorgfältig als solche angelegt sind. Auch Francis Bacons Entwurf für einen königlichen oder fürstlichen Garten sieht ein »ein Gebüsch oder eine Wildnis (heath or desert) am Ausgang « vor. ${ }^{34}$

Diese idealen, paradiesischen Natur-Orte sind >innen`. Demgegenüber der Ort der Hexen: Sümpfe und ihre chaotischen Wälder, auch »Dornenbuschwälder, stachlige Heiden und Steppen, mit Dornen gespickte Orte, das Thema ist hier das Zerzauste, Verquickte, der Zustand einer Natur, von der die Hexe absorbiert ist, die sich über ihr geschlossen hat ${ }^{35}$ Eine >unfruchtbare ${ }^{2}$ Natur allemal (wie das noch beim Naturgeschichtler Buffon deutlich wird), die sich - auch das Zeichen der

29 Schama, a.a.O., S. 570.

30 Theweleit, Klaus: Männerphantasien 1, S. 376.

31 Sannazaro, zit. n. Schama, a.a.O.

32 Schama, a.a.O., S. 570f.

33 Ebda., S. 571.

34 Diese »Wildnis« wünscht Bacon sich »soweit wie möglich als natürliche [...] gestaltet«. Vgl. Wimmer, Clemens Alexander: Geschichte der Gartentheorie. Darmstadt: Wissenschaftliche Buchgesellschaft 1989, S. 88.

35 Barthes, Roland: Vorwort zu Michelet, Jules: Die Hexe, zit. n. Droß, Annemarie: Die erste Walpurgisnacht. Hexenverfolgung in Deutschland. Reinbek: Rowohlt 1984, S. 14. 
Symbiose von Hexe und gefallener Natur - bösartig gegen die männlich verfasste Gesellschaft wendet. Denn den Frauen als auszurottenden Hexen werden stets »verderbliche[] Einflüsse [...] auf die Naturereignisse« nachgesagt, ${ }^{36} \gg$ die Hexe ist die Natur $«,{ }^{37}$ das Weib ist, so definiert es der Hexenhammer, von Natur aus »fleischlicher gesinnt [...] als der Mann, wie es aus den vielen fleischlichen Unflätereien ersichtlich ist «. ${ }^{38}$ Eine derartige >Unersättlichkeit` allein ist schon >unfruchtbar`, weil contra naturam: die Frauen begehren beim Koitus oben zu sitzen, was nach verbreiteter Meinung die Befruchtung verhindern kann, oder es wird das $>$ dafür vorgesehene Gefäß verwendet. Dazu kommen immer wieder direkte Angriffe auf Zeugungsfähigkeit, können die Hexen doch »die Zeugungskraft oder den Liebesgenuss verhindern «, ${ }^{39}$ durch »gauklerische Vorspiegelung die männlichen Glieder behehen, so dass sie gleichsam gänzlich aus den Körpern herausgerissen« erscheinen. ${ }^{40}$ Schließlich können »die Hexen-Hebammen« - und Hebammen richten den »größten Schaden« an, »wie reuige Hexen uns und anderen oft gestanden« - »die Empfängnis im Mutterleibe auf verschiedene Weisen verhindern, auch Fehlgeburten bewirken, und, wenn sie es nicht tun, die Neugeborenen den Dämonen opfern «. ${ }^{41}$ Dass die Hexe (die Frau) »die Natur« ist und zugleich contra naturam handelt, ist nur konsequent, wenn die in Rede stehende Natur die >verfallene〈 ist. Das »Weib« ist »nur ein unvollkommenes Tier«, das »immer täuscht«, zugleich geringer im Glauben, »also femina $=$ die weniger Glauben hat $\ll$. Mängel, die bereits zu Tage treten »bei der Schaffung des ersten Weibes, indem sie aus einer krummen Rippe geformt wurde, d.h. aus einer Brustrippe, die gekrümmt und gleichsam dem Mann entgegen geneigt ist $« .{ }^{42}$ Gekrümmt und gegen die männliche Ordnung gerichtet, wie die >Hexenbäumeく in den Sümpfen und entlegenen Wäldern, deren Eigenleben insbesondere nachts bedrohlich erscheint: »In der halbtierischen oder von Tieren umgebenen nächtlichen Göttin«, so Carlo Ginzburg, »die im Zentrum eines ekstatischen

36 Bovenschen, Silvia: Die aktuelle Hexe, die historische Hexe und der Hexenmythos. Die Hexe: Subjekt der Naturaneignung und Objekt der Naturbeherrschung, in: Becker, Gabriele et al.: Aus der Zeit der Verzweiflung, S. 299.

37 Honegger, Claudia: Die Hexen der Neuzeit, in: Dies. (Hg.): Die Hexen der Neuzeit, S. 93.

38 Sprenger, Jakob/Institoris, Heinrich: Der Hexenhammer. Malleus maleficarum. A. d. Lat. übertragen u. eingeleitet v. J. W. R. Schmitt. München: dtv 1987 (Reprint v. Berlin, Barsdorf 1906), 1. Teil, S. 99.

39 Ebda., S. $127 \mathrm{ff}$.

40 Ebda., S. 136ff.

41 Ebda., S. $157 \mathrm{ff}$.

42 Ebda., S. 99. 
Kultes schamanistischen Typs stand und von den Kanonisten und Inquisitoren mit Diana gleichgesetzt wurde, hatten wir eine entfernte Erbin der eurasischen Schutzgottheiten der Jagd und des Waldes erkannt «. ${ }^{43}$ Vielgestaltig infolge einer »komplexe[n] kulturelle[n] Schichtung«, erscheinen hinter »Diana und Herodias« in Bußbüchern des Frühmittelalters »Protagonistinnen einer Reihe von lokalen Kulten«, fließen in einem »Geflecht von Annäherungen, Synonymien und Hybridisierungen« prähistorische keltische, mediterrane und mittellöstliche >große Göttinnen in der Gestalt der »Herrin der Tiere« zusammen: »Artemis Agrotera (d.h. die Wilde)«, Diana usw. ${ }^{44}$ Die >jungfräuliche Göttin ganen Mythos noch anders definiert, keinem Mann untertan, zugleich unverletzlich. »Ihre Jungfräulichkeit bezog sich unter anderem auf die unberührten Wälder jenseits der Grenzen der Polis und der bebauten Felder.« Was möglicherweise ebenso »ihren ursprünglichen Status als Außenseiterin unter den olympischen Göttern« widerspiegele. ${ }^{45}$ Sie »gehörte zu den dunklen und unzugänglichen Regionen«, ist Herrin der Tiere und der Jagd, »unsichtbar, ungreifbar, rätselhaft, grausam «, ${ }^{46}$ Herrin der Geburt und des Todes: >mater.$^{47}{ }^{47}$ /hre Jungfräulichkeit« ist die »urtümliche Keuschheit [der] Waldabgeschiedenheit«, sie »zieht sich hinter die Schatten der Wälder in ihr Gedankenreich zurück, zu dem Menschen keinen Zugang haben können oder haben dürfen «. ${ }^{48}$ Viel später, nach dem Kippen des Mythos, im Gefolge einer `Beherrschung`der Natur, die derartige Wälder nicht mehr duldet, wird solche »Unordnung in der Welt [...] mit dem Hexenmuster dem Teufel und seinen naturnahen Untertaninnen zugeschrieben ${ }^{4}{ }^{49}$

Die >Unfruchtbarkeit der Hexe korreliert mit der Fruchtbarkeit ihrer mythischen Vorgängerin, dem >Wuchern`, den »verschlingend-fruchtbaren Schlünde[n] ${ }^{50},{ }^{2}$ die sich der männlichen Kontrolle widersetzen, die damit ınegativ<, weil bedrohlich sind bzw. werden. Dies in einer »Epoche der >Ostentation von Herrschaft gegenüber unkultivierten Unterprivilegierten und gegenüber der phantastischen Vielfalt der Naturhervorbringungen « «, hier »konnte sich das überkommene Bild der Hexe zu seiner vollen gefährlichen Größe entfalten. Die Hexe als Verkörperung des

43 Ginzburg, Carlo: Hexensabbat, S. 211.

44 Ebda., S. 210.

45 Harrison, Robert P.: Wälder, S. 40.

46 Ebda., S. 41.

47 Vgl. ebda., S. 47.

48 Ebda., S. 41.

49 Honegger, a.a.O., S. 93.

50 Menninghaus, Winfried: Ekel. Theorie und Geschichte einer starken Empfindung. Frankfurt/M: Suhrkamp 2002, S. 176. 
chaotischen Naturprinzips und als Unterprivilegierte zugleich mußte vernichtet werden«. ${ }^{51}$ Zumal doch für »die männlichen des 16. und 17. Jahrhunderts [...] die weiblichen Heerscharen Satans noch unmittelbare Verkörperung ihrer Angst vor der Rache der unterworfenen Natur « ${ }^{52}$ waren. Noch. Denn mit der Aufklärung beginnt die Wissenschaft, die Medizin, >weibliche Schwäche〈 in der »Fragilität weiblicher Organe $~^{53}$ $\mathrm{zu}$ erkennen - allerdings ohne, dass das Moment der Bedrohung verschwindet. »Die mit der Gebärfunktion zusammenhängenden Prozesse gelten jetzt als störungsanfällig, müssen daher zur Erhaltung ihrer gesellschaftlichen Aufgabe ständig gewartet und geschützt werden. ${ }^{54}$ Gewartet und geschützt zur Erfüllung gesellschaftlich notwendiger Produktion: Das trifft auch auf den Wald zu, der Ressourcen liefern muss und ab dem 19. Jahrhundert verbreitet auch >Schönheit`. Er muss Idealkörper sein oder werden, um legitimiert zu sein. ${ }^{55}$ Als störanfällig wird auch der Wald in seinem ästhetischen bzw. ökologischen Gleichgewicht erkannt und bedarf so des Schutzes. `Frau Naturaく, die Nährerin der Welt, »bei Bacon wird sie zur Allegorie der Wissenschaften«, wird doch ihr sphinxhaft entworfenes >Geheimnis« nun als lösbar postuliert, bleibt »bis ins 19. Jahrhundert hinein eine durchgängig positive Symbolgestalt«, allerdings längst dem Bedeutungswandel unterzogen »repräsentiert[] sie nunmehr männliche Herrschaft $\aleph^{56}$ und bedarf des Schutzes - vor ihrem >zweiten Ich < und dessen >Wuchern .

Das ist die eine Linie, die >weiblicheく. In den indogermanischen Sprachen, so der Etymologe Jost Trier, entstammt das Wort >Mutter dem biologischen Bereich, >Vater der Sphäre der Rechtsordnung. ${ }^{57}$ Die männliche Linie also konstruiert >Ordnung < - selbst noch in der >Wildnis $\prec$. Sie tut das vor allem retrospektiv.

Im nächsten Kapitel werde ich mich mit jenen Orten beschäftigen, die aufgrund ihrer Charakteristika als spezifisch >weibliche` Orte, als chaotische Gegenwelten aufgefasst worden sind - wobei diese Gegenweltlichkeit vorbürgerlich eher eine Nebenweltlichkeit ist: Auwälder, Bruch-

51 Honegger, a.a.O., (Binnenzitat: Lippe, Rudolf zur: Naturbeherrschung am Menschen II, S. 409.)

52 Ebda., S. 94.

53 Ebda., S. 121.

54 Ebda.

55 Vgl. Lorenz, Maren: Leibhaftige Vergangenheit, S. 115.

56 Bovenschen, a.a.O., S. 296f.

57 Vgl. Kastner: Wallfahrt, Weihnachten und Stammbaum, in: Gercke, Hans (Hg.): Der Baum, S. 105. 
wälder, Sümpfe. Was derartige Orte >andersartig^ macht, skizziert der Waldbiologe Wolfgang Scherzinger für Auwälder:

$»$ Kein anderer Lebensraum ist durch eine derart auffällige Dynamik gekennzeichnet - und belastet - wie der Auenwald. Seine Entwicklung steht in unmittelbarem Verbund mit dem Wasserregime: Überschwemmungen, Hochwasser und Trockenfallen können in kurzem Wechsel aufeinander folgen. Die Wassergewalten reißen Uferbänke und Inseln mitsamt dem Baumbestand fort, landen frischen Boden an anderer Stelle wieder an, schichten Schotterkegel auf und verschlammen die Tümpel. Der Auenwald reagiert auf einen raschen Milieuwechsel mit einer >tropisch Bäumen, wobei die kurzlebigen Standorte durch Weiden, Aspen, Erlen, Pappeln, Traubenkirsche sowie einer Fülle von Sträuchern (Hartriegel, Holunder, Schneeball, Weißdorn) und Hochstauden besiedelt werden. Die Bäume dieser Weichholz-Aue samen auf Schlick, Sand oder Kies rasch an oder regenerieren aus zurückgebliebenen Wurzel- und Stammteilen. ${ }^{58}$

Es herrscht eine andauernde Dynamik, die Landschaft ändert sich permanent. Mit der fehlenden Statik fehlt auch ein >geregelter/ Wuchs. Nicht nur die Vegetation, auch der Untergrund ist in stetiger Bewegung. Er schwankt, da er durch Mäander und Hochwasser verschoben wird. In Sümpfen und Brüchen, die auf Niedermooren wachsen, schwankt er sozusagen horizontal, da er bei jedem Schritt nachgeben kann, einsinken lässt. Was in Mitteleuropa schon seit längerem nur noch in Relikten vorhanden ist, ist in der frühen Neuzeit zum Teil noch landschaftsprägend.

58 Scherzinger, Wolfgang: Naturschutz im Wald. Qualitätsziele einer dynamischen Waldentwicklung. Stuttgart: Ulmer 1996, S. 77. 


\section{Schwankender Untergrund und Geilwuchs - feuchte Wälder als Gegenwelten}

"geil Adj. (<8. Jh.). Mhd. geil, ahd. geil, as. gêl, aus g. *gaila- Adj. >lustig, lüstern`, auch in ae. Gâl, erweitert im anord. geiligr `schön` und im gt. gailjan >erfreuen`. Im Deutschen entwickelt sich die Bedeutung einerseits zu >sexuell lüstern`, andererseits zu `üppig, aber kraftlos wachsend` (von Pflanzentrieben). $\ll^{59}$

Der Zusammenhang sei vergleichbar auch beim lateinischen »follis « für »unzüchtig« und »wildwachsend" zu beobachten. Der »heute vorherrschende Gegensatz« zu »keusch« sei »deutlich seit dem 15. Jahrhundert« belegt, heißt es an anderer Stelle, die Bedeutung für üppiges Wachsen und Wuchern von Pflanzen (und Tieren) werde ab dem 19. Jahrhundert selten. ${ }^{60}$ Grimms »Deutsches Wörterbuch« jedenfalls verzeichnet für den >Geilwuchs`von Pflanzen einige wenige positive Beispiele wie »geiler acker« für fruchtbares Feld, »aber vorwiegend « werde "geil" hier mindestens seit dem 16. Jahrhundert »doch in tadelndem ton « verwendet: »saat wächst zu geil, zu schnell und dick«; »bäume, die zu geil treiben, quae luxuriantur«; »vitis luxuriosa, geyle oder wütige weinräb, die zevil holz scheüszt«; »von bäumen luxuriantur sind wütig, wenn sie überflüssig schieszend «, »ein geyl zweyg der böumli, so er zu mächtig zholz legt und ausschieszt, lascivens«. Goethe schließlich wende den Begriff wieder rückwirkend auf Menschen und deren Erziehung an: »wo faulheit der gärtner sie geil aufschieszen läszt (die früchte in unseren schulen, die doch pflanzgärten sein sollten!)«. ${ }^{61}$ Dass etwa Weiden sehr schnell wachsen, schreibt Konrad von Megenberg: »salix haizt ain waid ist als vil gesprochen als ain springerinn, dar umb, dasz der paum schnell aufspringt und wechst.« In mittelalterlichen Darstellungen wer-

59 Kluge, Friedrich: Etymologisches Wörterbuch der deutschen Sprache. 23., erweiterte Auflage. Bearb. v. Elmar Seebold. Berlin, New York: de Gruyter 1999, Stichwort »geil«, S. 307.

60 Vgl. Etymologisches Wörterbuch des Deutschen. Erarbeitet im Zentralinstitut für Sprachwissenschaft Berlin. 2. Auflage, durchgesehen und ergänzt v. Wolfgang Pfeiffer. Berlin: Akademie Verlag 1993, Bd. 1 A-L, Stichwort »geil«, S. 414. Der ahd. Sinn von »geil« für »übermütig«, »froh«, »überheblich«, »erhaben« (mhd. für »von wilder Kraft«, »mutwillig«, »üppig«, »begierig« sei ebenfalls noch bis ins 19. Jahrhundert belegt (vgl. ebda.).

61 Deutsches Wörterbuch von Jacob und Wilhelm Grimm. Vierten Bandes erste Abtheilung. Zweiter Theil. Bearb. v. Rudolf Hildebrand u. Hermann Wunderlich. Leipzig: Verlag von S. Hirzel 1897, Stichwort »geil«, Sp. 2582ff. 
den zudem die Früchte der Weide als für den Menschen unnütz, ihr Saft als bitter beschrieben. ${ }^{62}$

»Ein Sinnbild der Unfruchtbarkeit ist auch die Weide. Sie gilt schon für Homer (Odyssee 10,150) als `fruchtverderbend dieses Baums, weil er schon vor der Reifung abfällt, als ein >Mittel, um die Weiber unfruchtbar zu machen`. Die mittelalterlichen Enzyklopädisten wie Albertus Magnus und der Botaniker Konrad von Megenberg haben den alten Aberglauben übernommen, wenn man bei letzterem z.B. liest: >Der paum plüet, er trait aber nit früht, und wer die plüet in trinken nimt, der wird unperhaft (gebärunfähig), sam die zaubrær sprechent.〈 Ihre vermeintliche Unfruchtbarkeit macht gerade aus der Weide den spezifischen Hexenbaum. ${ }^{63}$

Zumal die »Unfruchtbarkeit« von Weiden gepaart ist mit einer vergleichsweise großen Vermehrungsfähigkeit. Die Bäume vermehren sich nicht nur über eine Unzahl von Samen, die vom Wind oder vom Wasser transportiert werden, sie vermehren sich auch vegetativ, über >Stockausschlag`oder natürliches >Klonen`, indem abgebrochene Zweige und Äste im Schlamm eingesunken Wurzeln bilden und als neue Gehölze weiter wachsen. Weiden >wuchern`, vermehren sich >ungezügelt $<$, >chaotisch und gelten doch noch zumindest bis weit in die frühe Neuzeit hinein als unfruchtbar. Das ist, wie zu zeigen sein wird, kein Widerspruch.

Wilhelm Fraenger, von dem das Zitat über den >unfruchtbaren Hexenbaum s stammt, beschäftigt sich an dieser Stelle mit Hieronymus Boschs »Versuchung des Heiligen Antonius« (um 1500), genauer: mit der »Hochzeit des Frosches« auf dem rechten Innenflügel des im Lissaboner Nationalmuseum hängenden Werks. In dieser `Froschhochzeit 〈 ist bereits sehr viel dessen dargestellt, was die Gegenwelts-Semantik feuchter Wälder ausmacht. Bosch plaziert eine hohle, morsche und »aufgeschlissen[e]« Weide, deren Äste nach links wachsen, die bisher von einem großen roten Tuch verhüllt war, nun aber vom »Froschteufel« enthüllt wird. Wie bei der »Schwarzen Messe« im Mittelteil des Bildes handele es sich auch hier um eine »Kommunion«, bei der der Frosch allerdings »in voller Menschengröße« und »als leibhaftiger Dämon« auftrete. An seinem Rücken befinden sich »absonderliche Flügel«, ein »Mittelding« aus »überdimensionierte[r] Orchidee« und »den großäugigen

62 Deutsches Wörterbuch von Jacob und Wilhelm Grimm. Vierter Band. I. Abteilung, 1. Teil. Bearb. v. Alfred Götz u. d. Arbeitsstelle des Deutschen Wörterbuchs zu Berlin. Leipzig: Verlag von S. Hirzel 1955. Stichwort $»$ Weide«, Sp. 540ff.

63 Fraenger, Wilhelm: Hieronymus Bosch. Dresden, Basel: Verlag der Kunst 1994 (Dresden 1975), S. 409. 
Schwingen eines Nachtschmetterlings«, was die »zentrale[n] Füllhörner« andeuteten. »Der wollüstig zurückgewälzte Rumpf des Frosches geht demnach aus der Glitschigkeit des Bauchs in eine Zauberblüte über, wie er sich zugleich in der taumeligen Trunkenheit und sensitiven Spürigkeit der Nachtfalter bewegt.« Die verschieden Orchideen-Arten der Knabenkräuter dienten seit »alters« aufgrund »ihrer hodenförmigen Wurzelknollen oder ihres Bocksgeruches als Aphrodisiaka zur Kräftigung der männlichen Potenz«, so als »Satyrion« bei Dioskurides, als »herba priapisca« bei Pseudo-Apuleius, desgleichen in »einer mittelalterlichen Glosse «. ${ }^{64}$

Kennzeichen des Froschs sei »seine Zweigeschlechtlichkeit. Denn über seinem maskulinen Genital ist mitten in den Schamhügel ein feminines eingezeichnet, wonach in seiner sumpfigen Androgynie das weibliche dem männlichen Prinzip übergeordnet und vorangestellt erscheint«. Laut Fraenger »ein für den Sinnzusammenhang der Szene richtungweisender Befund «. Denn auch in der zweiten Person im Bild, der »ikonographisch singuläre[n] Darstellung der >Großmutter des Teufels««, die in »Volkssagen« den Co-Vorsitz neben dem Teufel, wenn nicht gar den Vorsitz beim Hexensabbat habe, erscheine das Feminine »übergeordnet und vorangestellt«. Mit dieser »Buschgroßmutter« und damit »Königin der Moosweibchen«, dieser »Wilde[n] Großmutter« usw., sei »ein alter Fruchtbarkeits- und Regenzauber« verknüpft. Sie figuriere im räumlichen Bildzusammenhang »als höchste Handlungsträgerin der Szene«. Das »alte Weib« mit seinem ausgemergelten, verkniffenen, zahnlosen Gesicht und dem dünnen, straff zurück gebundenen Haar werde als »Hohepriesterin«, wenn nicht »Gottheit« dargestellt. Sie hat einen orchideenblütenartigen Nimbus, der in direkter Verbindung der »Wunderblüte« des Frosches stehe, und zwar per Sakramentsspendung, Kommunion, »Libation« - »im Zeichen des Satyrion«. Aus einem Krug gießt sie Wein in die Schale, die der Frosch hoch hält, wobei »die Genitalien des Froschs in der genauen Achse des herabrinnenden Weines liegen«. Sie befruchte als »Urmutter« damit ihren »Enkel« (den Frosch): eine »Selbstanbetung und Selbstverherrlichung des Froschgeschlechts«, eine »Urfamiliarität der schlammigen Erdentiefe ${ }^{65}$

Diese »inzüchtige Selbstvermehrung «, ${ }^{66}$ könnte ihre reale Entsprechung in der vegetativen Vermehrung der Weiden haben. Im Spalt der Weide befindet sich eine »nackte, junge Hexe«, deren Gesichtszüge der der Alten stark ähneln. Sie steht fast knietief im Wasser, ist »an die >ma-

64 Ebda., S. 408f.

65 Ebda.

66 Ebda., S. 409. 
teria prima` des urmütterlichen Sumpfes gefesselt«. Sie presst mit der rechten Hand einen »schmale[n] Streifen Seidenflor« in ihren Schoß. Der Seidenflor ist verbunden mit dem Glied des Frosches. Fraenger verweist auf die Ähnlichkeit in Pieter Bruegels d.Ä. »Die Wollust«. Auch hier findet in der Höhlung einer morschen Weide eine solche Begattung statt. Eine »Luxuria«, die sich die linke Hand zwischen die Schenkel presst, sitzt auf dem Schoß eines großen Frosches, der nach ihrer Brust greift und ihr die Zunge in den Mund steckt. Zugleich trägt ein Dämon einen Krug zur »Libation « heran. ${ }^{67}$

Eine »Fern- und Doppelzeugung« im »Urschlamm» spiele sich in der »Versuchung« ab, »worin der androgyne Frosch in seiner weiblichen Potenz von oben her besamt wird, doch zugleich in seiner männlichen Potenz die Hexe schwängert, die dadurch in die Kindschaft der Urmutter aufgenommen wird«. Eine Teufelszeugung und damit »unfruchtbar«, denn sie verneine grundsätzlich den »gottgewollten Sinn der Zeugung«. Nach der »Volkssage« sei der »Teufelssamen « kalt. ${ }^{68}$ Aber gerade auch Dämonologen wie Sprenger/Institoris oder Jean Bodin verbreiten derartige Botschaften. So die Theorie der wechselnden Geschlechtlichkeit des Teufels, der selbst keinen Samen produzieren kann, der sich als Succubus in weiblicher Gestalt beim Beischlaf in den Besitz des Spermas bringe, das er in männlicher Gestalt als Incubus zur Zeugung verwende. ${ }^{69}$ Bereits Augustinus hat Pan und andere ithyphallische und bocksfüßige Waldgötter als Incubi bezeichnet. ${ }^{70}$

In frühneuzeitlichen Hexenprozessen kommt es bisweilen $\mathrm{zu}>\mathrm{Ge}$ ständnissen «, »daß von Hexen geborene Früh- oder Mißgeburten die Frucht eines teuflischen Beischlafs gewesen seien $\kappa^{71}$ Paracelsus betont $1537 \mathrm{im} »$ Liber primus de generationibus rerum naturalium« explizit die Entsprechung von ungewöhnlicher Physiognomie und schlechter bzw. böser Herkunft. Monstra würden »gemäß göttlicher Naturgesetze« wegen ihres Aussehens »von ihren Artgenossen gehaßt und ausgegrenzt [...], da >got ein greuel und ein misfallen ab den monstris hat und keines selig mag werden, diweil sie nit die bildnus gottes tragen««; ebenso wegen der ihnen nachgesagten Entstehungsarten.

67 Ebda., S. 63.

68 Ebda., S. 409.

69 Vgl. Hexenhammer, 1. Teil, S. 46 u. 55.

70 Vgl. Ewinkel, Irene: De monstris. Deutung und Funktion von Wundergeburten auf Flugblättern im Deutschland des 16. Jahrhunderts. Tübingen: Niemeyer 1995, S. 193, Fn. 176.

71 Ebda., S. 190. 
Abb. 1: Hieronymus Bosch: Die Versuchung des heiligen Antonius (Detail des rechten Innenflügels), um 1500

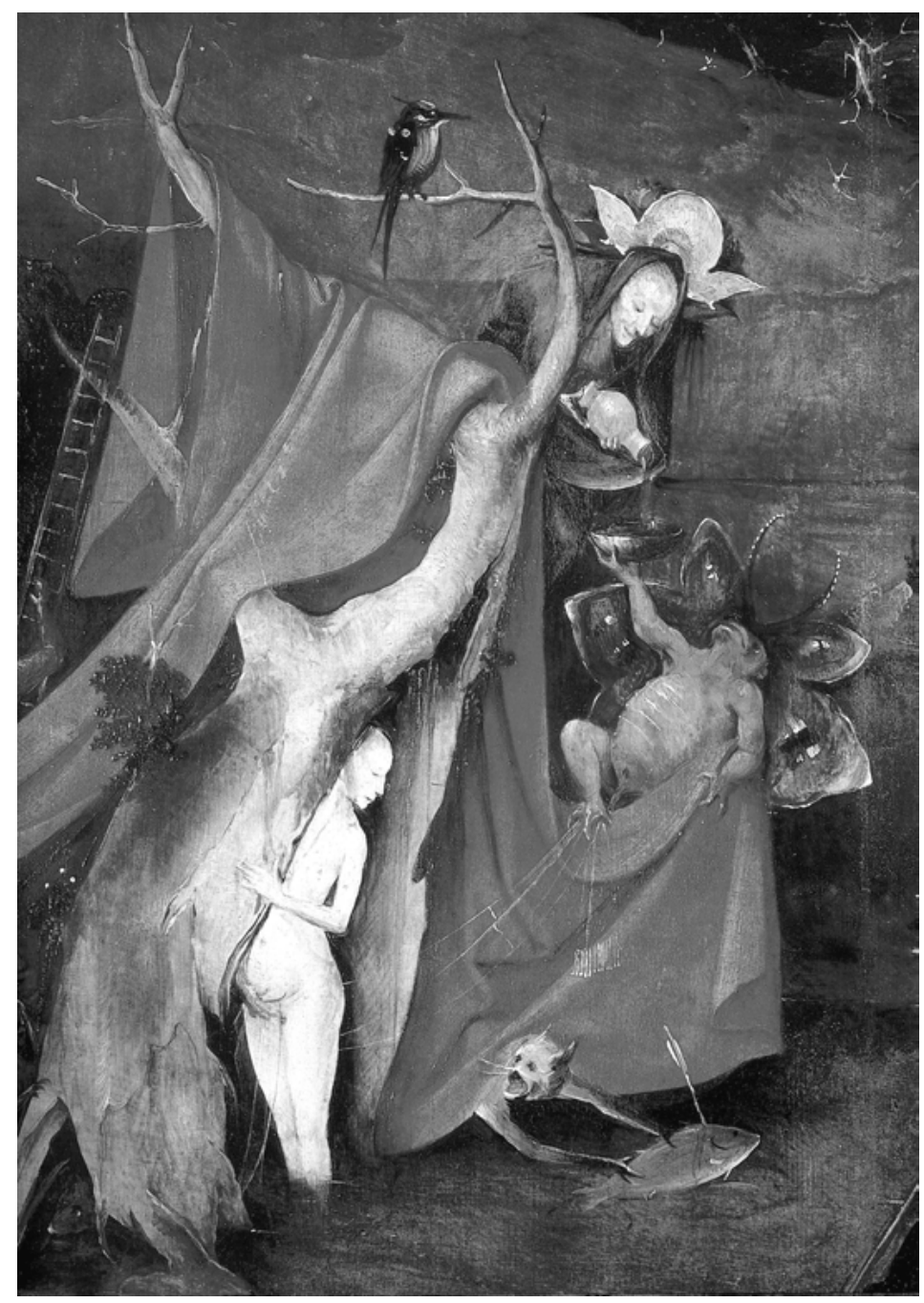


Monstra entstammen dem nach »der Sodomie oder der künstlichen Erzeugung durch >putrefaction $<-$ d.h. durch >Fäulung « im Reagenzglas sowie [aus] astralen« oder teuflischen Einflüssen. Dem Teufel gelänge es, mittels Weckung von »böser lust«, »böser begirde«, »bösen gedanken « in Schwangeren, die Leibesfrucht zu entstellen. ${ }^{72}$

Eine ungezügelte weibliche Imagination gilt grundsätzlich als wesentliche Quelle von Monstren. Derartige zeitgenössische Wahrnehmungstheorien basieren auf der Humoralpathologie, die in den Schriften des Hippokrates entwickelt und von Aristoteles und Galen weitergegeben werden. Danach ist der weibliche Körper kälter und feuchter als der männliche, wie die Menstruation zeige, was die Basis der Lehre einer weiblichen Inferiorität bildet. Eine derartige physische Schwäche, gepaart mit einem kleineren Hirn (und damit Verstand) führen auch die Inquisitoren an, wenn sie, wie Bodin im »Außgelasnen Wuetigen Teüffelsheer«, Frauen als leichte »Opfer ihrer Begierden« und Einbildungen darstellen. ${ }^{73}$ Neben diesen unkontrollierbaren inneren Bildern sind es die Umweltreize, die über die Augen aufgenommen werden. ${ }^{74}$

Dass derartige Augenlüste fatal sind, und dass sie es besonders in der freien Natur sind, erklärt auch Boccaccio: »Die Mädchen von heute sollten sich Camilla zum Vorbild nehmen: eine selbständige, erwachsene junge Frau, die mit dem Köcher umgürtet frei nach Belieben Feld und Wald und die Verstecke der wilden Tiere durchstreifte und in unablässiger Selbstzucht die Verführungen der lockenden Sinnenlust niederkämpfte, die Lustbarkeit und üppiges Wesen, raffinierte Speisen und ausgesuchte Getränke ausschlug, die es standhaft ablehnte, mit jungen Männern auch nur zu reden, von Liebesaffären ganz zu schweigen«, mahnt er in seinem 〉Frauenbuch $\iota^{75}$ seinem Spätwerk (1361-1375). So

72 Ebda., S. 189

73 Ebda., S. 174f.

74 Vgl. ebda., S. 158.

75 Boccaccio, Giovanni: De claris mulieribus, ausgewählt, übersetzt und kommentiert von Irene Erfen und Peter Schmitt, Erläuterungen. Stuttgart: Reclam 1995, S. 235. Während im »Decamerone« (1348-1353) vor dem Hintergrund der Flucht vor der Pest eine >verkehrte Welt< entsteht, in der auch im Geschlechterverhältnis alles möglich scheint, wird hier auf die herrschende Geschlechterhierarchie insistiert. Und so sollten sich die vermeintlich angesprochenen jungen Frauen (denn Boccaccios Publikum, so Erfen/Schmitt dürfte wohl hauptsächlich aus Männern bestehen) am Beispiel Camillas »klarmachen, daß man sich nicht alles wünschen darf, was erlaubt ist, und daß nicht alles mit Tugend und Moral vereinbar ist. Nur so werden sie klug und bewahren die Blüte der Jungfräulichkeit, um zu gegebener Zeit auf Geheiß der Eltern in den heiligen Stand der Ehe zu treten« (ebda.). 
wird frühneuzeitlich die Disziplinierung der weiblichen Sinne immer wieder thematisiert. Gefordert wird eine äußere Kontrolle, Beschäftigung mit >angemessenen Dingen`, der Verweis in die häusliche Sphäre und eine »Unterstützung der Selbstkontrolle«, das Verbot »zuchtloser Augen«, das Anhalten zu Fleiß, um Imaginationen gar nicht erst aufkommen zu lassen. Beschränkungen, die einher gehen »mit den übrigen Bestrebungen der Konsolidierung der Geschlechterrollen«, zumal die Imaginationslehre »ein nützliches Mittel zur >Domestizierung ‘ der Frauen [war], da sie beschränkend auf deren äußeren - und mittels der Selbstzensur der Gedanken - sogar >inneren` Aktionsradius wirken konnte «. ${ }^{76}$ Zumal als Drohung die pränatale Entstellung der Nachkommen existiert, und das schon durch unpassende Bilder im Haus. ${ }^{77}$

Der Akt in Boschs »Versuchung« ist unfruchtbar, wird »durch drei Tiersymbole als sterile Schmutzerei« gebrandmarkt: den Wiedehopf im Geäst der Weide, ${ }^{78}$ der »Dreckvogel« aus Konrad von Megenbergs »Buch der Natur«, er niste »in unrainikait und verunraint auch sein aigen nest $«,{ }^{79}$ der »eunuchische[] Biber«, der einen pfeildurchbohrten Fisch präsentiert, das getötete christliche Fruchtbarkeitswahrzeichen. ${ }^{80}$ Unfruchtbar heißt hier für Fraenger, dass >matriarchalische〈 Monstren entstehen. Er verweist auf das »Bauchgesicht» in der unteren Bildecke, unter einer »übergroße[n] rote[n] Haube, die es mütterlich behütet« mit einem Klumpfuß an zwei Beinen. »Diese Einfüßigkeit setzt [es] zu den Naturmüttern und Schicksalsfrauen in Beziehung«, stünden doch »Fuß und Schuh« für »erdmütterliche[] Fruchtbarkeit«, wie Bachofen gezeigt habe, ebenso wie Singularität: In »der Singularität des Auges, Zahnes und der amazonischen Brust ist die noch ungeteilte matriarchale Abkunft tellurischer Schöpfung mythologisiert, worin das männlich zeugende Prinzip nur eine anonyme Rolle« spiele. Eine solche »Spottgeburt« wie das »Bauchgesicht« stelle »die größtmögliche Assimilation an den matriarchalen Archetypus dar, was sich zuletzt noch in der Unter-

76 Ewinkel, a.a.O., S. 178f. u. 184.

77 Vgl. ebda., S. 164f. Tommaso Campanella etwa empfiehlt im »Sonnenstaat« das Aufhängen von Bildern berühmter Männer und Frauen im Schlafgemach »als 〉Zuchtmittel« für wohlgestalteten Nachwuchs«.

78 Fraenger, a.a.O., S. 409.

79 Zit. n. Wyss, Stephan: AskeSe, S. 160.

80 Fraenger, a.a.O. Der eunuchische Biber scheint sich auf einen Bericht des »Physiologus« zu beziehen, wonach sich ein Biber auf der Flucht vor einem selbst kastriert und die Hoden dem Verfolger hinwirft. Dieser »medizinische[] Irrtum« - es müsste sich um die Drüsen des »Bibergeil« handeln - ordnet aber den »friedfertigen« Biber der Tugend zu. Der Jäger hingegen »ist der Teufel«. Wyss, a.a.O., S. 46. 
drückung seines maskulinen Prädikates äußert«. Und die große Gefahr, die dem Individuum bei eine Nicht-Lösung vom mütterlichen Imago drohe, sei eine »Grundeinsicht der Psychoanalyse «. ${ }^{81}$

An dieser Stelle von Fraengers Bildinterpretation wird deutlich, dass hier mehrere sich überlagernde Schichten auseinandergehalten werden müssen. Da ist das (wissenschaftliche) Interesse, eher aber noch Unbehagen des 19. und frühen 20. Jahrhunderts am >Sumpf «, am nicht Klassifizierten, am Vermischten, Entgrenzten, an einer tellurischen Schöpfung, an amorphen, fluiden Orten, in denen Dämonen und Hexen hausen. Diese Wesen aber hausen hier untergründig. Freud vergleicht die $>$ Ich-Werdung « des >Es` mit der Trockenlegung der Zuydersee. ${ }^{82}$ Sümpfe, Ströme, Fluten sind Metaphern für ein ungeregeltes menschliches Begehren. Auch bei Johann Jakob Bachofen geht es wesentlich um das Trockenlegen von Sümpfen. Seine Konstruktion des Matriarchats beschreibt eine erste Phase in der Analogie von Frau bzw. Mutter und Erde, eine anfängliche weibliche Selbstzeugung, einen erst später entstehenden Mann, eine aus der Mütterlichkeit entstammende Geschwisterlichkeit und Humanität, zugleich dunkle Schrecknisse. Das Geschlechterverhältnis ist vollständig ungeregelt, unterliegt der weiblichen Natur der »hetärischen Sumpfzeugung«. Dabei sei, »analog zu den Prozessen pflanzlichen Wachstums, die Frau >die Erde selbst « ${ }^{83}$ eine »Stofflichkeit«, die aber auch zur permanenten Vergewaltigung durch die Männer führt. Der Ausweg aus der Sumpfwildnis ist - nach zwischenzeitlichem »Amazonentum« - der ihrer Kultivierung zur agrarischen ehelichen Gynaikokratie. ${ }^{84}$ Aber, weibliche Lust und Grausamkeit bleiben unberechenbar und verschlingend, was schließlich zur gewaltsamen patriarchalen Revolution und »Civilisation«, zur männlichen Befreiung aus den Fesseln der Stofflichkeit führt, in der die Frau jedoch verharrt. ${ }^{85}$ Es sind gesellschaftliche Deutungsmuster des ausgehenden 19. Jahrhunderts, ${ }^{86}$ die Fraenger schließlich in Boschs Bild hineinliest und so auf das beginnende 16. Jahrhundert anwendet.

81 Fraenger, a.a.O., S. $410 \mathrm{f}$.

82 Freud, Sigmund: Neue Folge der Vorlesung zur Einführung in die Psychoanalyse, in: Gesammelte Werke Bd. XV. Frankfurt/M: Fischer 1970, S. 86.

83 Bachofen, Johann Jakob: Über das Weiberrecht (1857); zit. n. Schröter, Susanne: Frauenmacht oder Sklaverei der Urzeit. Wissenschaftliche Annäherung an einen Mythos. Frankfurt/M: VAS 1989, S. 25.

84 Vgl. Bachofen: Das Mutterrecht (1861); zit. n. ebda., S. $26 f$.

85 Vgl. ebda., S. 30.

86 Vgl. Kap. Abschaffung des >Matriarchats $<$. 
»Es geht um das Zerreißen einer imaginären Einheit, metaphorisch eines ganzheitlichen Körpers, die sich in der Zeit Boschs allüberall und auf den verschiedensten Ebenen auswirkt«, schreibt Peter Gendolla zur »Versuchung«. Thema sei die »Askese«, die »wider ihren Willen einen bestimmten Reichtum, ihre eigene Versuchung« produziere. »Die Einsamkeit soll den Körper mit dem göttlichen Geist vereinen, nichts soll ihn mehr ablenken, verwirren und aufsplittern. Doch da geht der Krieg erst los, der Kampf mit der eigenen Vorstellungskraft. Der Wunsch nach der wirklichen Einheit, einem reinen Sein, produziert erst den Schein. ${ }^{87}$ Im Werk Boschs sei ein gesellschaftlicher Bruch erkennbar. Hier »werden das Ich und die Phantasie zwei verschiedene Dinge, strenger Halt auf der einen, chaotische Einbildungskraft auf der anderen Seite, die aber eben, weil sie einander so ausschließen, sich nur wechselweise verstärken «. ${ }^{88}$ Das mag für den frühbürgerlichen Maler zutreffen. Die angesprochene Phantasie aber ist keine frei produzierende, sie wird sich zwangsläufig im vorhandenen gesellschaftlichen Fundus bedienen. Der von Fraenger dargestellte Zusammenhang von Sümpfen, Tümpeln, Weiden, >wuchernder Unfruchtbarkeit` ist Bestandteil dieses Fundus. Nur, vorbürgerlich - in der noch vorhandenen >Volkskultur - gibt es offenbar noch keine Untergründe, weder historisch (Matriarchat) noch mental (Einbildung), sondern ein Nebeneinander von semantischen Räumen, in denen die Körper und Dinge - hier Orte, Bäume, Tiere - jeweils eine »sinnliche >Selbständigkeit«", in denen sie »gesellschaftlich unmittelbar relevante Konkretheiten « besitzen, die sie historisch später, im entstehenden $»$ Raum universaler, funktionaler Vermittlung aber verlieren «. ${ }^{89}$ Daraus wird bürgerlich die semantische Verengung aufs Symbolische. Davon abgespalten werden die Dinge selbst rationalisiert. Vorbürgerlich also sind bestimmte Orte, die hier wachsenden Bäume, Sträucher, Krautpflanzen, die hier lebenden Tiere >dämonisch`, schreckenerregend, ebenso überwiegend >weiblich`, daneben sind sie >immateriell gegen das >Böse` nutzbar in magischen Ritualen und Praktiken, und sie sind materiell nutzbar in der traditionellen bäuerlichen Niederwaldwirtschaft. Dass hier gewissermaßen ein »kollektiv-regeneratives« Naturverhältnis $\mathrm{zu}$ finden sei, wie Christoph Spehr anmerkt, ${ }^{90}$ sollte allerdings nicht mit

87 Gendolla, Peter: Phantasien der Askese. Über die Entstehung innerer Bilder am Beispiel der »Versuchung des heiligen Antonius«. Heidelberg: Winter 1991, S. $100 \mathrm{f}$.

88 Ebda., S. 109.

89 Czerwinski, Peter: Gegenwärtigkeit, S. 75.

90 Vgl. Spehr, Christoph: Die Jagd nach Natur. Zur historischen Entwicklung des gesellschaftlichen Naturverhältnisses in den USA, Deutschland, Großbritannien und Italien am Beispiel von Wildnutzung, Artenschutz 
einem grundsätzlich >schonenderen`Umgang mit Natur verwechselt werden, was etwa anhand von allfälligen (grausamen) Tieropfern zu zeigen ist. $^{91}$

Mit den planmäßigen Umgestaltungen, Neuordnungen der Landschaften insbesondere seit dem ausgehenden 18. Jahrhundert verschwinden im nun »allgemeinen Raum ${ }^{92}$ prozessual auch die $>$ subkulturellen »besonderen Gegenden und Zeiten «. ${ }^{93}$ Das `Dämonischeく, >Magischeく der Dinge wird im einen, generativen semantischen Raum bürgerlicher Gesellschaften zum 〉Symbolischen` oder >Attributiven` (oder Unbewussten), von einer lebensweltlichen Realität zu Märchen und Mythen in den Sammlungen der Grimms, Stoffen von Volkskundlern. Die Dinge selbst werden rationalisiert in den Taxonomien und Klassifikationen der Botanik, Zoologie, sowie handgreiflich in ihrer Reorganisation. Ungebändigte Fließgewässer und ihre Auen, Hoch- und Niedermoore werden systematisch kultiviert, gebändigt, kanalisiert, trockengelegt, zum Verschwinden gebracht (und mit ihnen nicht nur ungenutzte Wälder sondern auch weitgehend traditionell genutzte: Nieder- und Mittelwälder; >Hexenbäume werden von der geregelten Forstwirtschaft seit dem späten 18. Jahrhundert zu waldschädlichem »Forstunkraut«, zu »Schanddekkeln« >rationalisiert und zur obligatorischen Exklusion ausersehen), um dann am bisherigen Ende der Entwicklung mühsam unter Schutz gestellt oder rekonstruiert, >renaturiert $\mathrm{zu}$ werden. Betrachtet aus der Perspektive eines »gesellschaftlich notwendigen, historisch jeweils adäquaten Bewußtseins «, ${ }^{94}$ entsteht eine Abfolge: Zunächst eine Gegenweltlichkeit derartiger mehr oder weniger >wilder $<$ Naturorte, die eher als >Nebenweltlichkeit` erscheint (noch bis in die Frühmoderne, was waldbäuerliche Ökonomie und der hier notwendige »eigenständige Charakter des Waldes « angeht ${ }^{95}$ ), aber - zumindest partiell - frühneuzeitlich einen starken Schub ins Ordnungs- und Lebensbedrohende erhält. In den Durchdringungen, Verschmelzungen der Themen »vom Komplott, das eine Sekte oder feindliche soziale Gruppe geschmiedet haben soll«, wie sie »von Inquisitoren und Laienrichter« ausgearbeitet werden, und den »Elemente[n] schamanistischer Provinienz, die in der Volkskultur bereits fest verwurzelt waren $«,{ }^{96}$ verfallen auch diese Naturorte und ihr le-

und Jagd. Frankfurt/M: IKO - Verlag für interkulturelle Kommunikation 1994, S. 62.

91 Vgl. dazu die folgenden Kapitel.

92 Czerwinski, a.a.O.

93 Ebda.

94 Ebda., S. 83.

95 Allmann, Joachim: Der Wald in der frühen Neuzeit, S. $289 \mathrm{ff}$.

96 Ginzburg, Carlo: Hexensabbat, S. 293. 
bendes Inventar dem Verdikt des Hexischen. Mit den Landschaftsneuordnungen schließlich, den systematischen >Meliorationen` (teils schon im 17., besonders aber ab dem 18. und 19. Jahrhundert) werden sie eine zu überwindende Nur-noch-Gegenwelt.

\section{Hexenbäume und Katzen}

Weiden und Erlen, Baumarten also, die von Natur aus ausschließlich an feuchten Orten wie Sümpfen, Brüchen und Auen wachsen, werden traditionell spezifisch weibliche und akulturelle Eigenschaften zugesprochen. So gelten Erlen als »das Unheimliche«, »das Weib«, »Feuer«, »Wasser«, »Erde«, »unter ihren Wurzeln hausen Kröten und Schlangen. Irrlichter leuchten zwischen ihnen. Es sind unheimliche Orte, an denen vielleicht auch der Teufel ${ }^{97}$ wohnt. Das ist nicht erst Bestandteil der christlichen Semantik, »denn die Erle bringt Unglück, sie wächst an trügerischen Gewässern und verbrennt schnell, aber ohne wärmende Flamme«, weshalb nach der »Lex Salica«, die »bestimmt, daß kein Mensch das Recht auf Schutz hat, der nicht einer Familie angehört, derjenige Mensch, der »seine Familie verlassen wollte und das Verbrechen des Individualismus beging" vor dem Thingrichter »vier Erlenstöcke über seinem Haupt brechen« und unter Abschwören auf die Erbschaft und jede Beziehung zur Sippe »nach vier Seiten werfen« muss. »Dieser heidnische Brauch sollte einem plötzlichen oder gewaltsamen Tode wehren. $"{ }^{98}$ In der griechischen Mythologie werden Erlenhaine im Zusammenhang mit Orakelstätten genannt. So lässt Homer um die Grotte der Nymphe Kalypso, die Odysseus sieben Jahre lang festhält, »geheimnisvolle« Er-

97 Beuchert, Marianne: Symbolik der Pflanzen. Frankfurt/M: Insel 1995, S. 83.

98 Rouche, Michel: Abendländisches Frühmittelalter, in: Ariès, Philippe/Duby, Georges (Hg.): Geschichte des privaten Lebens Bd. 1: Vom Römischen Imperium zum Byzantinischen Reich. Augsburg: Bechtermünz 2000 (Paris 1985), S. 437. Rouche erklärt, »daß es solche Furcht gab, verrät die Schrecken der Wirklichkeit. In der römischen Gesellschaft erlaubte der umfassendere rechtliche Schutz des Einzelnen die Existenz kleinerer `Familien`, die nur aus Großeltern, Eltern, Kindern und Sklaven bestanden. In der fränkischen Gesellschaft hingegen oder, besser gesagt, in der von keltischen und germanischen Traditionen geprägten Gesellschaft [...] mußte die Familie sehr groß sein, wenn sie überleben wollte«. Immerhin ist es die Erle und ihre Umwelt, die die Bedrohung, ja das Gegenteil dieses Überlebens darstellt. 
len wachsen, ebenso im »feuchten Umland der verhexten Insel >Aia Wohnort der Zauberin Kirke ${ }^{99}$

Die zugeschriebene weibliche Symbolik der Erlen, deren Holz ähnlich hart wie das der Eichen werden könne, belegt Beuchert anhand eines >germanischen (Urmythos:

»Erlenholzmörser wurden mit Eschenholzquirlen bearbeitet, um Feuer zu erzeugen. Dies wurde als ein Akt der Begattung angesehen, und in der germanischen Mythologie symbolisiert die Erle das Urweib und die Esche den Urmann. ${ }^{100}$

Auch hier erscheint das männliche Prinzip als das aktive, produktive, das weibliche als das passive. Nach Seligmann dienen Erlen, wie auch andere wassernahe Bäume (Faulbaum und Traubenkirsche) »in Deutschland« dem Schutz »gegen Teufel und Hexen«. ${ }^{101}$ Zudem würden bestimmte, >unnormal gewachsene Triebe in Sachsen als »Alpruten«, also gegen Alpdrücken verwendet, die Rinde gegen Rotlauf bei Kühen. Behexte Äcker werden mit kleinen Erlentrieben, -wurzeln oder -kätzchen »entzaubert«. Die rote Farbe ihres Saftes scheint ihre »Zauberkraft« auszumachen. ${ }^{102}$ Das »Bluten« des roten Holzes beim Fällen »erweckte bereits im Altertum beunruhigende und beklemmende Ahnungen«, gesteigert durch das Vorkommen der Erlen »auf feuchten, sumpfigen, oft unwegsamen und gefährlichen Standorten«, Totenorte im archaischen Europa, auch später noch oft unkultiviert: »Die früher häufigen düsteren Erlenbrüche und Moore zählten im Mittelalter zum sogenannten >Unland , also unbebautem Land. ${ }^{103}$

Auch die Weide wird offenbar in unterschiedlichen Mythologien mit dem Tod in Verbindung gebracht. Im >germanischen Mythos »bewohnt der Todesgott Viddharr das Weidengebüsch« und Menschenopfer seien

99 Laudert, Doris: Mythos Baum. Was Bäume uns Menschen bedeuten. Geschichte, Brauchtum, 30 Baumporträts. München, Wien, Zürich: BLV 2000, S. 117.

100 Beuchert, a.a.O. Ferdinand Wirz hingegen schreibt, dass nach germanischer Mythologie »der erste Mensch aus Ask, einer Esche, die erste Frau aus Embla, einer Ulme geschaffen« worden sei. Woraus sich auch die »Ursprünglichkeit des Wortes Stammbaum mit seinen weitverzweigten Geschlechterfolgen« erkläre; Wirz: Auf den Busch geklopft. Der Wald und unsere Sprache. Melsungen: Neumann-Neudam 1999, S. 10.

101 Seligmann, Siegfried: Die magischen Heil- und Schutzmittel aus der belebten Natur. Aus dem Nachlaß bearbeitet und herausgegeben von Jürgen Zimmermann. Berlin: Reimer 2001. Bd. 1: Das Pflanzenreich, S. 99.

102 Ebda., S. 101f.

103 Laudert, a.a.O. 
in dieser archaischen Gesellschaft »in mit Steinen beschwerte Weidenkörbe« eingeschlossen und im Moor versenkt worden. Die Weide sei hier als Baum der »Ehrlosigkeit«, »das Tragen von Weidenzweigen« gelte daher »als eine der entwürdigendsten Strafen«. Auch in der griechischen Mythologie steht die Weide für den Tod - zugleich aber für »junges, sich entfaltendes Leben und Geburt. Als Verkörperung des Lebensflusses wachte sie sogar über die Geburt der hellenistischen Göttereltern«. Sie wird mit Demeter, der »Göttin des Ackerbaues und der Fruchtbarkeit« in Verbindung gebracht, ebenso mit »deren Tochter Persephone, Göttin des Todes und der Wiedergeburt«, weil der »düstere[] Baum, der im Alter oft völlig vermorscht, aber dennoch ungebrochen grünt «. ${ }^{104}$ Und abgebrochene, eigentlich `tote` Äste und Zweige bilden im Schlamm neue Wurzeln und leben weiter bzw. wieder.

Weiden stehen für Geburt, »Frühlingsahnen« schreibt Beuchert, da sie sehr früh blühen, und damit Fruchtbarkeit anzeigen, sie stehen aber auch für Gefahr und Tod, »moralische Schwäche« und weibliche Sexualität, andererseits für Keuschheit, so auch in ihrer christlichen Verwendung am Palmsonntag. ${ }^{105}$ Pagane Bedeutungen der Weide werden »gewandelt in das Christentum übernommen, so die Vorstellung, daß Weiden am himmlischen, lebenserzeugenden Wasser wurzeln und damit Vorbild des jenseitigen Lebens sind, aber auch die (falsche) Meinung, Weiden seien unfruchtbar und daher ideale Keuschheitssymbole«. Dieser Irrtum beruhe auf der »Zweihäusigkeit der Salix«, wobei »auf einem Baum oder Strauch immer nur Blüten eines Geschlechtes anzutreffen sind «. Wegen der größeren Schönheit der männlichen Blüten der Salweide »hat man die Stecklinge der leicht auf diese Weise zu vermehrenden Pflanzen über sehr lange Zeiten hin nur von diesen genommen, die logischerweise keine Früchte brachten «. ${ }^{106}$

Beuchert liefert eine >vernünftige`, logozentristische Erklärung, die zudem die Sexualisierung der Pflanzen seit der Linnéschen Nomenklatur zur Voraussetzung hat. Auch impliziert sie, dass Erfahrungen nur mit Stecklingen gemacht worden seien. Die Behauptung der Unfruchtbarkeit des Baumes bezieht sich bei Homer und Plinius desgleichen direkt auf die Fruchtstände, weshalb diese kontrazeptiv sein sollen (s.o.), erscheint aber als Folge des Abfallens vor der Reife. Auf heute überzeugende Erklärungen kommt es aber nicht an. Wichtig ist die Gleichzeitigkeit von Fruchtbarkeit und Unfruchtbarkeit, von Leben, Tod und Wiedergeburt.

104 Ebda., S. 208f.

105 Beuchert, a.a.O., S. 336f.; vgl. Laudert, a.a.O.

106 Beuchert, a.a.O. 
Dass Weiden diese Eigenschaften haben sollen, prädestiniert sie zu einer wesentlichen mythischen Rolle.

In Mittel- und Nordeuropa werden sie am Ende des Mittelalters zu Kennzeichen bedrohlicher weiblicher Ausschweifung: Hexerei.

»Während man in Ostasien die laszivsten Symbole in der Weide findet, sind es im westlichen Raum Sinnbilder von düsteren Todesdrohungen, Hexenzauber und Teufelswohnung, die man damit verbindet. [...] Die Königin der Hexen trug als Szepter einen Weidenzweig. Da der Teufel bevorzugt in alten Weidenbäumen hauste, mußten junge Hexen, die die Kunst erlernen wollten, unter einer Weide Gott abschwören und ihre Seele dem Teufel schenken. RankeGraves schreibt, daß im nördlichen Europa die Verbindung von Weiden und Hexen so eng war, daß die englischen Wörter $>$ witch $८=$ Hexe, $>$ Will-o `-the wisp $\_=$Irrlicht, $>$wicked $\_=$böse, auf dem gleichen Wortstamm beruhen, der auch die Wurzel von >wicker $\ll=$ Weidenkorb bildet. ${ }{ }^{107}$

Gleichzeitig wird der Baum, bzw. werden seine Teile als Mittel gegen Hexerei und bösen Zauber genutzt. Geweihte »Palmzweige« schützen vor Hexen, an Fenster oder Türen gesteckt, oder ans Vieh verfüttert. In nordischen Sagen »setzt der Bauer längs jedem Flachsfeld Weidenreiser, damit es nicht unter den sengenden Augen der bösen Frauen welke «. ${ }^{108}$ Die Bäume werden häufig genutzt, um mittels magischer Prakti ken Krankheiten von Menschen weg auf sie zu >übertragen<. ${ }^{109}$ Ihre Fruchtbarkeit soll etwa traditionell zu Ostern in Mittelosteuropa übertragen werden, indem junge Männer junge Frauen mit Weidengerten schlagen. ${ }^{110}$ Fruchtbarkeit oder "geschlechtliche Begierde« ist desgleichen mit Weidenblättern zu verhindern. Diese sollen in Byzanz auf »die Schlafstelle der Priester« gestreut werden, oder, nach dem »New Kreutterbuch« von Leonard Fuchs (1543) als Tee verabreicht werden, was »Lust und neygung zur unkeuschheyt« vertreibe. 1715 wird die Einnahme von Weidenblättern mit Zucker ärztlich empfohlen bei »der allzu großen Begierde beim Beyschlaf und Geilheit, wenn der Mann allzu hitzig« sei. Kontrazeptiv wird Frauen schon bei Dioskurides und noch bis ins 17. Jahrhundert das Trinken von Kaltwasserauszügen geraten. Vaginalzäpfchen aus Korbweidenblättern sollen ebenfalls als samenschädigend Schwangerschaften verhüten. ${ }^{111}$

107 Beuchert, a.a.O., S. 335f.

108 Seligmann, a.a.O., S. 282f.

109 Vgl. ebda., S. 284.

110 Vgl. ebda., S. 281.

111 Vgl. Laudert, a.a.O., S. 210. 
Verhexung und ihre Abwehr, Begierde und ihre Dämpfung, Fruchtbarkeit und ihr Ausschluss. Es kommt eine weitere Dimension hinzu. Im Schottischen bezeichnet »Greymalkin« die Fruchtstände der Hexenbäume, die >Kätzchen` der Sal- und Aschweiden. „'Greymalkin oder Grimalkin, eine >graue Katze«« sei ebenso die »traditionelle Vertraute der Hexen«, deren Göttin in altschottischen Mythen »die Mither o` the Mawkins, Mutter der Mawkins [war], wobei >mawkin` oder >malkin entweder einen Hasen oder eine Katze bezeichnen kann«. Ursprünglich sei der Hase das Totemtier dieser Mondgöttin. Mit ihrem Erscheinen in Britannien nehmen Hauskatzen »recht schnell« diese Stelle der Hasen ein und werden »zum primären Tier des Mondes« (daher könnte der volkstümliche Begriff >Dachhase` stammen). ${ }^{112}$ Wann diese offenbar aus Ägypten stammenden Tiere ${ }^{113}$ nach West- Mittel- und Nordeuropa gelangen, bleibt unklar, ebenso, ob ihre Erfüllung eines Hexenmusters eine Übertragung der altägyptischen Katzenverehrung darstellt. ${ }^{114}$

Artemis-Diana, die >Herrin der Jagd`, >Göttin der Fruchtbarkeit` trete »häufig in Gestalt einer Katze« auf. Sie werde »mit der ägyptischen Katzengöttin Bastet gleichgesetzt«, deren Feste »fröhlich, mit Musik, Tanz, Scherzen und sexuellen Riten verbunden waren«, deren dunkler Aspekt aber »Hathor als die Löwin-Sphinx, Sachmet, welche die Menschen zerriß und verschlang«, sei. Das altägyptische Wort »mau« bzw. der lautmalende »Terminus $m j w \ll$ in Inschriften bezeichne sowohl die »Katze« (als Nachahmung ihres Rufs), als auch die Mutter-Silbe. ${ }^{115}$

Katzen sollen der >Mondgöttin` als »besonders heilig« gelten. Ihre »Augen leuchten im Dunkel, sie nähren sich von Mäusen (dem Symbol

112 Walker, Barbara G.: Das geheime Wissen der Frauen. Ein Lexikon. Frankfurt/M: Zweitausendeins 1993 (New York 1983) S. 534.

113 Vgl. Lorenz, Günther: Tiere im Leben der alten Kulturen. Schriftlose Kulturen, alter Orient, Ägypten, Griechenland und Rom. Wien, Köln, Weimar: Böhlau 2000, S. 75f.; Benecke, Norbert: Der Mensch und seine Haustiere. Die Geschichte einer jahrtausendealten Beziehung. Stuttgart: Theiss 1994, S. 344ff.

114 Robert von Ranke-Graves (Die weiße Göttin, S. 260f.) vermutet, dass die keltische Göttin Cerridwen (Wolfsgöttin wie Artemis, Sau-Göttin und Katzen-Göttin, Tiergestalten, die in enger Verbindung mit dem Mond stehen [s.u.]) »zwischen 2500 und 2000 v. Chr. mit den langschädeligen Ackerbauern der Neueren Steinzeit aus Nordafrika nach Britannien gelangte «. Er berichtet auch von einem archaischen irischen Katzenkult, einer schlanken schwarzen Katze im Orakeltempel von Clough (damals Connaught) als Gegenstück zur ägyptischen Pascht oder Bastet.

115 Walker, a.a.O., S. 534; Lorenz, Günther, a.a.O., S. 75. Walker nimmt an, der (mittelalterliche) Glaube an die neun Leben einer Katze stamme »wahrscheinlich über die mythische Gestalt der Neunfachen Göttin von den ägyptischen Enneaden«. A.a.O., S. 533 
der Pest), sie kopulieren in aller Offenheit und laufen unhörbar herum, sie sind fruchtbar, fressen aber ihre eigenen Jungen, und ihre Farbe wechselt, wie die des Mondes, von Weiß über Rötlich bis Schwarz«. Ähnliches gelte für Wölfe (sie haben leuchtende Augen, heulen den Mond an, fressen Kadaver und streifen durch Wälder) und Schweine (auch ihre Farbe wechselt [s.o.], sie fressen Kadaver, sind fruchtbar und fressen den Nachwuchs, sie haben mondsichelförmige Stoßzähne). ${ }^{116}$ Und neben »Kirschbaum, Apfelbaum und Erle zählt die Weide in unserem Kulturkreis zu den >Mondbäumen`, die einstmals als Bäume der großen Göttin hoch geachtet wurden «. ${ }^{117}$ Die Salweide wird als heiliger Baum der Hekate bezeichnet, ${ }^{118}{ } \gg$ der eng mit Artemis verbundene[n] Totengöttin «. ${ }^{119}$ Auch ihre Verbindung zu Katzen ist damit eine mittelbare, über die Fruchtstände des Baumes.

Der mythisch-strukturelle Zusammenhang ist der von Geburt, Tod und Wiedergeburt, wie Carlo Ginzburg herausgearbeitet hat. Er spricht von der »tiefe[n] Ähnlichkeit«, die alle später in die Konstruktion des nächtlichen Hexensabbat

»eingeflossenen Mythen untereinander verbindet. Alle verarbeiten ein gemeinsames Thema: die Reise ins Jenseits, die Rückkehr aus dem Jenseits. Dieser elementare Erzählkern hat die Menschheit Jahrtausende hindurch begleitet. Die unzähligen Variationen, die verschiedendste, auf Jagd, Viehzucht, Ackerbau basierende Gesellschaften eingeführt haben, veränderten seine Grundstruktur nicht «. ${ }^{120}$

Das »Bild des Sabbat« sei eine Verschmelzung von Zutaten der »Volkskultur und in Auflösung begriffene[r] Häresien, wenig glaubwürdige[r] Geständnisse sexueller Promiskuität und mythische[r], mit der Totenwelt verbundene[r] Frauengestalten«, die sich dann in einer gesellschaftlichen Umbruchsituationen »herauskristallisieren «. ${ }^{121}$

Auch weibliche Sexualität wird in den »Kätzchenweiden« symbolisch repräsentiert. Im Englischen heißen sie »pussywillows«. Darin steckt die umgangssprachlich Bezeichnung für das weibliche Genital.

»Le chat, la chatte, le minet bedeuten in der französischen Umgangssprache dasselbe, was pussy auf englisch (und Muschi auf deutsch) bedeutet, und jahr-

116 Vgl. Ranke-Graves, a.a.O., S. 261.

117 Laudert, a.a.O., S. 209.

118 Vgl. Walker, a.a.O.

119 Ginzburg, a.a.O., S. 101.

120 Ebda., S. 301.

121 Ebda., S. 296. 
hundertelang hat man damit Obszönitäten ausgedrückt. Die französische volkstümliche Überlieferung mißt der Katze als Metapher oder Metonymie für Sexualität besondere Bedeutung bei. Bis ins 15. Jahrhundert geht die Empfehlung zurück, Katzen zu streicheln, wenn man einer Frau mit Erfolg den Hof machen wollte. ${ }^{122}$

Nach Fraenger ist das Katzenfell, das Boschs »Verlorener Sohn« an seinem Reisekorb hängen hat, eine Anspielung auf unzüchtige $>$ Niederjagden $<.{ }^{123}$ Und eine $»$ Spruchsammlung des 18. Jahrhunderts formulierte die sexuelle Anspielung" des Sprichworts »Nachts sind alle Katzen grau« eindeutig: »Das soll besagen, daß des Nachts alle Frauen schön genug sind. ${ }^{124}$ Die Katze als anmutiges, verführerisches, triebhaftes Wesen, hinter dessen Pelz das erschreckende Geheimnis des alles verschlingenden gierigen Schlundes mit seinen Reißzähnen liegt: vagina dentata. Spätmittelalterlich wird Hexen nachgesagt, »Impotenzzauber mit Hilfe von präparierten Katzenfellen« zu verüben. ${ }^{125} 1409$ weist ein Inquisitor in den Westalpen auf die angeblich auch hier auftauchenden »neuen Sekten und verbotenen Riten« hin, auf »Hexen, die den Körper mit Salben einrieben, worauf sie sich, vom Teufel betrogen, in Katzen zu verwandeln glaubten «. ${ }^{126}$ Dass Hexen als Katzen herumlaufen, >belegen` häufige Erzählungen, wonach verprügelte Tiere anderntags als Frauen mit blauen Flecken oder gebrochenen Knochen angetroffen werden. ${ }^{127}$ Und verstümmeln soll man (fremde) Katzen, um sie an der Sab-

122 Darnton, Robert: Das große Katzenmassaker. Streifzüge durch die französische Kultur vor der Revolution. München, Wien: Hanser 1989 (New York 1984), S. 112.

123 Insbesondere in Verbindung mit dem Löffel, der »im damaligen Sprachgebrauch« den »moralischen Nebensinn von lüderlicher Liebschaft« habe, den Geiler von Kaiserberg 1510 in seiner Volkspredigt »Die Spinnerin« als Kennzeichen der »unrain liebe« verwende, in der jemand »als ain löffel ain närrin lieb hat« oder »der metzen wolgefall und lauft jnen nach wie der stier der kue«. Auch Johannes Fischart habe im 8. Kapitel seines Gargantua eine »schwelgerische[] Löffellitanei« geschrieben. Fraenger: Hieronymus Bosch, S. 259.

124 Darnton, a.a.O., S. 113.

125 Vgl. Hergemöller, Bernd-Ulrich: Krötenkuß und schwarzer Kater. Ketzerei, Götzendienst und Unzucht in der inquisitorischen Phantasie des 13. Jahrhunderts. Warendorf: Fahlbusch 1996, S. 419. Hergemöller hat diesen Hinweis aus: Hansen, Joseph: Quellen und Untersuchungen zur Geschichte des Hexenwahns und der Hexenverfolgung im Mittelalter, mit einer Untersuchung der Geschichte des Wortes Hexe von Johannes Franck. Bonn 1901 (ND Hildesheim 1963), Nr. 42, S. 231-235, hier: S. 232f.

126 Ginzburg, a.a.O., S. 292.

127 Vgl. Darnton, a.a.O., S. 109f.; Hexenhammer, II. Teil, S. 102f. 
batteilnahme zu hindern. ${ }^{128}$ Zugleich wird die Katze - wie auch die Weide - häufig dazu benutzt, Schäden und Krankheiten auf sie zu >übertragen`. Sie wird in Hausfundamente eingemauert, oder bei Umzügen als erste ins neue Haus geschickt, um Unheil auf sie zu lenken. Ebenso dienen Körperteile oder Exkremente des Tiers zur Medikation. ${ }^{129}$

Katzen sind der Legende nach nicht von Gott geschaffen, wie es im jüdischen Glauben heißt, oder der christlichen Überlieferung nach nicht etwa auf der Arche Noah aufgenommen worden, sondern erst im Nachhinein »aus den Nasenlöchern eines Löwen `herausgeniest « ${ }^{130}$ Sie gelten oft generell als Dämonen, wie es etwa der Inquisitor Nicholas Remy ausdrückt, oder sind die Wesen, in denen z.B. lombardische Hexen des 14. Jahrhunderts den Teufel verehren sollen. ${ }^{131}$ Sie sind »das ständige Sinnbild der Ungläubigen«, so »wie der Hund das der Prediger nach der Schrift « sei, heißt es bei Sprenger/Institoris. ${ }^{132}$

Anscheinend wird kein anderes Tier so sehr mit der Hexe identifiziert wie die Katze (und umgekehrt). Ihre Rolle im traditionellen Volksglauben ist nach Grimm eindeutig:

»Das volk sagt: eine zwanzigjährige katze werde zur hexe, eine hundertjährige hexe wieder zur katze. [...] Wie bei den nachtfrauen kommen in fast allen hexenprocessen beispiele vor, und besonders oft wird von verwundeten katzen erzählt, die man hernach an verbundnen weibern wieder erkannte. begegnende katzen sind zweideutig. fremden katzen soll man nichts zu leid thun; die hexe könnte sich rächen. [...] Man soll aber auch der katze schonen, weil sie Frouwas thier war; $[\ldots]$ nachtfrauen und hexen scheinen aber im gefolge dieser gottheit zu ziehen. ${ }^{133}$

»Frouwa« sei ein anderer Name von Freya, der Großen Muttergöttin der germanischen Mythologie, deren Wagen von Katzen gezogen werde. Überhaupt sind es die großen Muttergöttinnen der Antike, deren Vor-

128 Vgl. Darnton, ebda.

129 Vgl. Ebda.; Seligmann: Die magischen Heil- und Schutzmittel aus der belebten Natur. Bd. 2: Das Tierreich, S. 166f.

130 Vgl. Walker, a.a.O., S. 534.

131 Vgl. Ebda.

132 Hexenhammer, a.a.O. Gemeint sind offenbar die »Wachhunde des Herrn« bzw. Papstes, die Dominikaner (denen auch Sprenger und Institoris angehören), die seit 1231 mit der Inquisition betraut sind; vgl. Perrig, Alexander: Albrecht Dürer oder: Die Heimlichkeit der deutschen Ketzerei. Die Apokalypse Dürers und andere Werke von 1495 bis 1513. Weinheim: VCH 1987, S. 4.

133 Grimm, Jacob: Deutsche Mythologie II. Band. Frankfurt/M, Berlin, Wien: Ullstein 1981 (Göttingen 1835), S. $918 f$. 
bild- und Anführerinnenfunktion im Glauben und der Erfahrungswelt des Volkes aber auch der inquisitorischen Dämonologie des Mittelalters und der frühen Neuzeit behauptet wird, die in enger Verbindung zu Katzen stehen.

Abb. 2: Hans Baldung Grien: Die Hexen, 1510

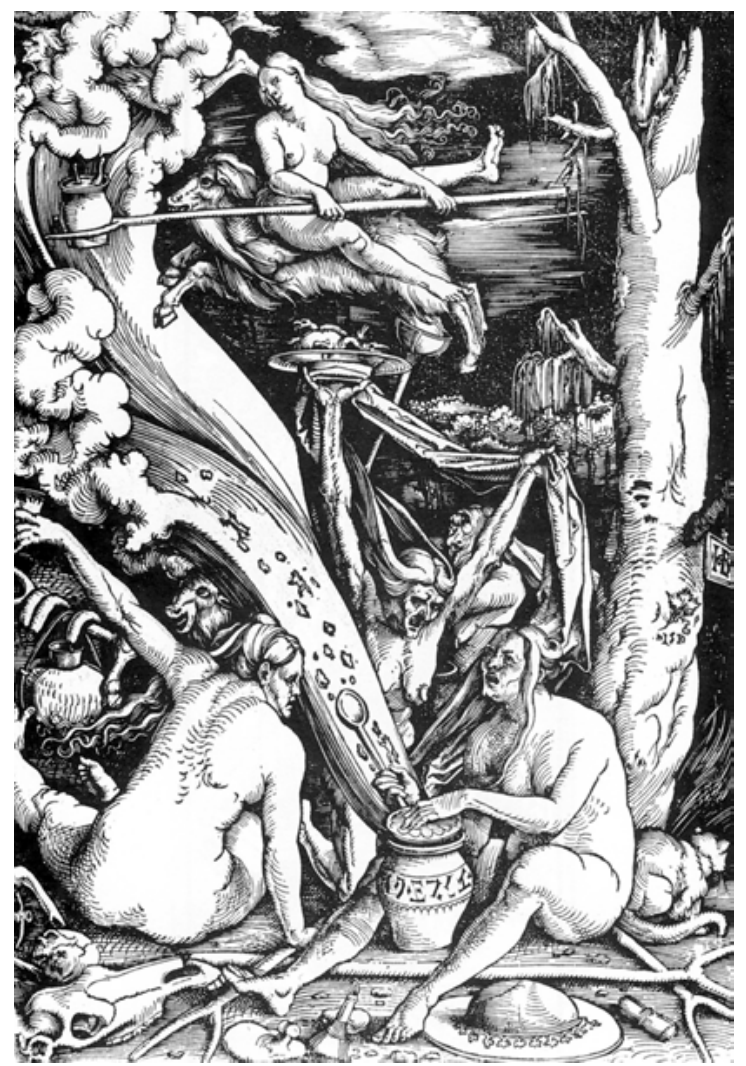

Hans Baldung Griens Holzschnitt hat alle Zutaten des Genres: Ein frevelhafter Ort im Wald. Unter dem unfruchtbaren Baum hockt die Katze. Dem Hexenkessel entströmen u.a. Reptilien. Links hängen >abgehexter männliche \Schamglieder` wie Würstchen über dem Kochfeuer.

Jeffrey Burton Russell beschreibt den Mythos der Verwandlung in als bösartig geltende Tiergestalten als Identitätswechsel, grundlegende psychologische Entlastungsfunktion (aus Sicht der »Nachtfahrenden«), um Handlungen auszuführen, die der in die herrschende Ordnung eingebet- 
tete Alltag verbietet, und die zumeist »deutliche sexuelle Elemente« aufweisen, was schon Freuds Hinweis auf die symbolische Entsprechung von Pelz und Schamhaar andeute. ${ }^{134}$ Hierzu lässt sich mehreres einwenden. Burton spricht lediglich von Wölfen und Vampiren - zumeist also Inkarnationen des `wilden Mannes`, aber der Identitätswechsel ist ja nicht einfach nur behauptete Erfahrung von »Nachtfahrenden«, sondern auch Unterstellung der Hexenverfolger. Wenn aber - neben »Irren« und »Armen" - hauptsächlich in immer wiederkehrender Stereotypie (und oft vielleicht auch Autostereotypie) Frauen als der (sündhaften) Natur verhaftet gelten, dann müsste ihnen die >Verwandlung « in >Bestien ২ sehr viel einfacher gelingen. Und

»auch die Hexe ist die Natur. In dieser Epoche der >Ostentation von Herrschaft gegenüber unkultivierten Unterprivilegierten und gegenüber der phantastischen Vielfalt der Naturhervorbringungen` konnte sich das überkommene Bild der Hexe zu seiner vollen gefährlichen Größe entfalten. Die Hexe als Verkörperung des chaotischen Naturprinzips und als Unterprivilegierte zugleich mußte vernichtet werden. Ihr alter Bund mit dem Teufel verstärkte diese Feindbildfunktion «. ${ }^{135}$

Auch die »deutlich sexuellen Elemente«, die der Alltag verbiete, träfen weit überwiegend die Frauen, eigenständige weibliche Sexualität, die verhindert, sehr viel mehr eingedämmt, observiert und kanalisiert werden muss. Und das erschreckende Geheimnis hinter dem Pelz (dem Schamhaar) beträfe ebenfalls grundsätzlich Frauen. Das männliche Genital ist nicht geheimnisvoll, nicht versteckt, ragt ja heraus, tritt offen zutage (und ist umfassendes patriarchales Kultursymbol).

Wesentlicher aber ist, dass Burton psychoanalytisch und orientiert an der Moderne argumentiert, mit einem >Identitätswechsel als Funktion des Unterbewusstseins. Die hier vorhandene »Entlastungsfunktion« kann aber spätmittelalterlich/frühneuzeitlich so gar nicht bestehen. Schon, weil der »Hexensabbat« und andere Vorkommnisse Gestalt annehmen durch die »Konvergenz zwischen der (spontanen, weit häufiger aber herausgeforderten oder erzwungenen) Bereitwilligkeit der Angeklagten« zum Geständnis, »und dem Willen der Richter«, diese anzunehmen. ${ }^{136}$ Zudem geht es um eine gesellschaftliche Realität, in der

134 Russell, Jeffrey Burton: Hexerei und Geist des Mittelalters, in: Honegger, Claudia (Hg.): Die Hexen der Neuzeit, S. 169.

135 Honegger, Claudia: Die Hexen der Neuzeit. Analysen zur Anderen Seite der okzidentalen Rationalisierung, in: Ebda., S. 93; Binnenzitat von Rudolf zur Lippe: Naturbeherrschung am Menschen Bd. II., S. 449.

136 Ginzburg, a.a.O., S. 296. 
Tat und Identitätswechsel auf einer Ebene liegen, in der dämonische Wesen >existieren $\prec$. Allerdings zeigt sich in der Konstruktion der Hexe (und zeitgleich der Kannibalin in der $>$ Neuen Welt ${ }^{137}$ ) eine Reaktion auf eine Auflösung der sozialen Ordnung, wie auch das allfällige Bild der »verkehrten Welt«, der auch ökonomisch gewähnten »Weiberherrschaft $\ll,{ }^{138}$ die Reorganisation von Ordnung insinuiert.

»Alle Unordnung in der Welt wurde mit dem Hexenmuster dem Teufel und seinen naturnahen Untertaninnen zugeschrieben, und das zu einer Zeit, da Störungen der natürlichen Ordnung von Gott längst nicht mehr verantwortet wurden und von der Wissenschaft noch nicht erklärt werden konnten, die Männer sich jedoch mehr denn je um eine Sublimierung, um eine Systematisierung der Lebensführung und eine >rationale Weltauslegung bemühen mußten. ${ }^{139}$

Katzen sind Wesen der Unordnung, selbst (oder besser: gerade) als domestizierte Spezies. Mittelalterliche und besonders frühneuzeitliche >Reinigungs-Riten »An bestimmten Feiertagen wie Mittsommer, Ostern oder Karfreitag war es üblich, Katzen in Weidenkörben zu verbrennen. $"{ }^{140}$ Vielleicht ist es ja sogar der eigentümliche Schrei der zu Tode gepeinigten Katzen, dieses langanhaltende »markerschütternde« Kreischen, das neben dem wilden Toben im Korb - gefangenen Teufeln gleich - als >Beweis $`$ ihrer Dämonie herhält. ${ }^{141}$

»Tierquälerei, besonders die Folterung von Katzen, war eine volkstümliche Lustbarkeit überall im Europa der frühen Moderne. « ${ }^{142}$ So beim »Charivari«, im deutschen Sprachraum »Katzenmusik« genannt, bei dem nach Darnton im Burgund zur »mißtönenden Musik« das Katzenquälen, »faire le chat«, gehört. Bei der Verspottung z.B. eines »Hahnreis« reichen »die jungen Burschen eine Katze herum« und bringen sie durch Fellausreißen zum Schreien. ${ }^{143}$ Auch hier scheint es eine ältere Tradition zu geben. In den Westalpen verkörpern Anfang des 14. Jahrhunderts »die Teilnehmer an den polternden Umzügen des Charivari in den Augen der Zuschauer die von Herlechinus angeführten Scharen der herumstreifenden Toten«. Für Ginzburg Zeichen eines »bald expliziten, bald latenten Isomorphismus« der von ihm analysierten Mythen

137 Vgl. Kap. Kannibalinnen.

138 Vgl. Kap. Dämme.

139 Honegger, a.a.O.

140 Walker, a.a.O.

141 Vgl. Darnton, a.a.O., S. 113.

142 Ebda., S. 106.

143 Ebda., S. 100. 
und Riten, deren »Symmetrie« später in der Konstruktion des Hexensabbat »bis zur Unkenntlichkeit« entstellt werde, da die »Inquisitoren immer häufiger den Bericht realer physischer Ereignisse« darin sehen. ${ }^{144}$

Darnton betont eine tiefe volkskulturelle Verankerung ritueller Katzentötungen, die sich auch in der Literatur von Rabelais über Cervantes »bis hin zu Germinal« zeige. In Semur werden am »dimanche des brandons« Katzen von Kindern an Marterpfähle gebunden und auf Scheiterhaufen verbrannt. In Aix-en-Provence findet zu Fronleichnam das »jeu du chat « statt, bei dem Katzen in die Luft geschleudert werden, um sich beim Sturz am Boden die Knochen zu zerschmettern. Im London der Reformationszeit werden die Tiere mit rasierten Tonsuren und >Priestergewändern` an Galgen aufgehängt. ${ }^{145}$

Norbert Elias stellt Katzenverbrennungen in den Mittelpunkt seiner Untersuchungen $\mathrm{zu}$ den »Wandlungen der Angriffslust «, als ein Beispiel, das ihm wie kein anderes die Grausamkeit als normale Affektäußerung auf einer »niedrigeren Zivilisationsstufe $« \mathrm{zu}$ belegen scheint, »weil es eine Inkarnation dieser durchs Auge befriedigten Grausamkeit zeigt, in der die Freude am Quälen besonders rein, nämlich ohne jede rationale Rechtfertigung und Verkleidung als Strafe oder als Zuchtmittel, in Erscheinung tritt $:^{146}$

»In Paris gehörte es während des 16. Jahrhunderts zur Festesfreude des Johannestages, ein oder zwei Dutzend Katzen lebendig zu verbrennen. Diese Feier war sehr berühmt. Das Volk versammelte sich. Festliche Musik spielte auf. Unter einer Art von Gerüst wurde ein mächtiger Scheiterhaufen errichtet. Dann hing man an dem Gerüst einen Sack oder Korb mit den Katzen auf. Sack oder Korb fingen an zu glimmen. Die Katzen fielen in den Scheiterhaufen und verbrannten, während sich die Menge an ihrem Schreien und Miauen erfreute. Gewöhnlich waren König und Hof anwesend. Zuweilen ließ man dem König oder dem Dauphin die Ehre, den Scheiterhaufen anzuzünden. Und wir hören, daß einmal auf besonderen Wunsch König Karls IX. ein Fuchs gefangen und mitverbrannt wurde. ${ }^{147}$

Eigentlich sei dieses Schauspiel zwar nicht schlimmer als Ketzerverbrennung oder (öffentliche) Martern und Hinrichtungen. Es erscheine, »nur deswegen als schlimmer, weil sich hier die Lust, Lebendiges zu quälen, so nackt, unverhüllt, zweckfrei, nämlich ohne eine Entschuldi-

144 Ginzburg, a.a.O.

145 Vgl. Darnton, a.a.O., S. 106f.

146 Elias, Norbert: PDZ 1, S. 281.

147 Ebda., S. $281 f$. 
gung vor dem Verstand zeigt «. ${ }^{148}$ Eigentlich hätten Elias die etymologische Nähe von »Ketzer« und »Katze«, bzw. die hochmittelalterlich gern genutzte »etymologische[] Möglichkeit [...], den Ketzernamen auf die Katzentiere zurückzuführen «, ${ }^{149}$ der Festcharakter, die Anwesenheit des Hofstaats und vor allem das Datum stutzig machen können. ${ }^{150}$ Der Johannestag - oder vielmehr die Johannesnacht - ist die christliche Transformation der Mittsommernacht. Es ist wohl kein Zufall, dass Johannes der Täufer zum Namenspatron des Mittsommers gewählt wird, denn auf diese Weise wird auch dieses Fest ıgetauft . Diese Nacht des 24. Juni ist - neben der Walpurgisnacht - ein festes Datum im Kalender der nachtfahrenden Hexen und Zauberer. ${ }^{151}$

Die Katzenverbrennung ist also eine Hexenverbrennung. Das grauenhafte Ritual ist demnach aus frühmoderner Sicht weit davon entfernt, keine »Rechtfertigung « zu besitzen, es hat sinnstiftenden Charakter. Es ist eine Strafe, kollektives Reinigungsritual. Selbstverständlich ist die Lust an der Grausamkeit hieran beteiligt. Aber es ist keine »kindlich unbefangene«, sondern eine sozial sanktionierte und postulierte Grausamkeit. Das Reinigungsritual ist weit verbreitet. Zwar variiert die Zeremonie in den verschiedenen Orten, »die Requisiten« aber sind »überall dieselben: ein feu de joie (Freudenfeuer), Katzen und eine Atmosphäre ausgelassener Hexenjagd«, schreibt Darnton für Frankreich. So gehöre zum Johannesfest das Tanzen ums und Springen über das Feuer, das Verbrennen von »Zaubergegenständen«, alles, um »Unglück abzuwenden und sich das Glück für das kommende Jahr günstig zu stimmen«. An-

148 Ebda., S. 282.

149 Hergemöller: Krötenkuß und schwarzer Kater, S. 14. »Ketzer« stammt von »Katharer« und dieses vom griechischen »katharós« (»rein«). In den zeitgenössischen Zuschreibungen werden die Häretiker zu »catiers«, zu »Katerern«, weil sie in ihren geheimen Versammlungen den Teufel in Gestalt des »Cattus maximus«, des hundsgroßen stinkenden schwarzen Katers anbeten, diesen auf seinen Anus küssen sollen (ebda., S. 138ff.).

150 Die Gleichsetzung von Katzen und Hexen beschreibt schon Grimms Deutsche Mythologie. Darnton verweist auf eine Darstellung der Verbrennung der Tiere als Hexen von 1900 (Benoist, A.: »Traditions et anciennes coutumes du pays messin«, in: Revue des traditions populaires, XV); A.a.O., S. 308, Anm. 16. Seligmann gibt zum Thema eine ganze Reihe von Quellen (um 1900 und früher) an (a.a.O., S. 339, Anm. 336). Elias selbst beruft sich auf A. Franklin: Paris et le Parisiens au sezième siècle, Paris 1921, S. 508f. (a.a.O., S. 328, Anm. 113). Dass Elias den Zusammenhang nicht gekannt hat, ist wenig wahrscheinlich. Die Vermutung liegt nah, dass er viel mehr von seinem Wissen um die Nichtexistenz von Hexen und sonstigen übernatürlichen Gestalten ausgeht (s.u.).

151 Vgl. Duerr, Hans Peter: Traumzeit. Über die Grenze zwischen Wildnis und Zivilisation. Frankfurt/M: Syndikat 1978, S. 172f. 
ders als in Paris, wird dabei in Saint Chamond eine brennende Katze von den »Courimauds (cour à miaud, Katzenjäger)« - der Eigenname verdeutlicht die Institutionalisierung - durch die Straßen getrieben. In der Metzer Gegend werden sie »dutzendweise in einem Korb« in Feuer geworfen. In der Stadt selbst noch bis 1765 »mit großem Pomp«. Dabei ziehen die Honoratioren in einer Prozession zu einem bestimmten Platz, wo unter den Salven der Garnisonsfüsiliere die Katzen auf den Scheiterhaufen geworfen werden. ${ }^{152}$ In Schottland werden schwarze Katzen noch bis Mitte des 17. Jahrhunderts verbrannt. ${ }^{153}$

Elias betont zwar, dass es sich um »eine gesellschaftliche Institution« handele, aber um eine »wie Boxkämpfe oder Pferderennen in der heutigen Gesellschaft «. ${ }^{154}$ Er rückt das Beispiel ins Zentrum seiner Beweisführung der Historizität der Affekte. Aufgrund seiner bloß quantitativen, in nur einem (dem bürgerlichen) semantischen Raum angesiedelten und lerntheoretisch fundierten Zivilisationstheorie kann er keinen nachvollziehbaren gesellschaftlichen Sinn des Rituals entdecken, außer dem eines rein sadistischen »Vergnügens «. Übrig bleibt seine zivilisierte »Unlust «. ${ }^{155}$ Wenn er also den historisch je unterschiedlichen »Inkarnationen eines gesellschaftlichen Affektstandards, in dessen Rahmen sich alle individuellen Affektmodellierungen halten $«{ }^{156}$ hervorhebt, dann läuft das unzweifelhaft auf ein weitgehendes Fehlen innerer wie äußerer Zwänge in dieser frühneuzeitlichen Gesellschaft hinaus - zumindest, was den Umgang mit Tieren angeht. So spricht er auch von der damaligen »Lust«, die mit Katzenverbrennungen befriedigt werde. Die heute damit verbundene Unlust entspringe

"auch hier offenbar de[m] einfache[n] psychische[n] Mechanismus, aufgrund dessen sich die geschichtliche Transformation des Affektlebens vollzieht: Gesellschaftlich unerwünschte Trieb- und Lustäußerungen werden mit Maßnahmen bedroht und bestraft, die Unlust erzeugen oder dominant werden lassen. In der ständigen Wiederkehr der als Strafe durch irgendeine Bedrohung erweckten Unlust und in der Gewöhnung an diesen Rhythmus verbindet sich die Unlustdominante zwangsläufig mit dem Verhalten, das an der Wurzel auch

152 Vgl. Darnton, a.a.O., S. 100f.

153 Vgl. Seligmann, a.a.O., S. 166.

154 Elias, a.a.O., S. $282 \mathrm{f}$.

$155 »$ Der Widerwille gegen solche Vergnügungen, der sich in uns beim bloßen Bericht von dieser Institution regt«, müsse »für den heutigen Standard der Affektregelung als >normal gelten« (ebda.). Den blutigen Sport der Parforcejagd, bei der etwa Füchse von Hundemeuten zerrissen werden und der noch gut 60 Jahre nach seiner Arbeit am >Prozessbuch zum Prestige der britischen Oberschicht beiträgt, erwähnt Elias nicht.

156 Ebda. 
lustvoll sein mag. Und so kämpft die gesellschaftlich erweckte Unlust und Angst - heute, aber keineswegs immer und auch heute keineswegs allein repräsentiert durch die Eltern - mit einer verdeckten Lust. Was hier von verschiedenen Seiten her als Vorrücken der Schamgrenze, der Peinlichkeitsschwelle, des Affektstandards sichtbar wurde, mag in Zusammenhang mit solchen Mechanismen in Gang gesetzt worden sein «. ${ }^{157}$

Eine dauerhafte »Konditionierung«, vorgerückte »Schamgrenze[n]« und »Peinlichkeitsschwelle[n]«, die derartige 〉Lüsteく umlagern, müssen hier demnach noch weitgehend fehlen. Dass es sich bei den geschilderten Ritualen um Inkarnationen ausgeprägter sozialer Zwänge, Äußerungen einer spezifisch zugerichteten Triebstruktur, `Schauspiele`, die eine sozial aufbauende Funktion besitzen, um sozial erwünschte Triebäußerungen, handelt, dass Destruktion überhaupt sozialen Zwängen entstammt (oder entstammen kann), ist der Elias-Theorie genauso fremd, wie die Möglichkeit qualitativ anderer Gesellschaften, die mit einem Konzept bloßer Schamquantitäten nicht erfassbar sind. ${ }^{158}$

Auch Mario Erdheim hat in den Katzenverbrennungen Hexenverbrennungen erkannt und daraus »eine Kritik an Elias' Darstellung des Absolutismus« entwickelt. ${ }^{159}$ Dabei vermutet er merkwürdigerweise, dass für Elias die Hexenverfolgung bei der zugleich stattfindenden »Entstehung des neuzeitlichen absolutistischen Staates« deshalb »kein Thema gewesen« sei, weil sie ihm »womöglich« als »)zivilisierter«« erschienen seien, »da sie in einem gewaltigen religiösen Rechtfertigungszusammenhang standen «. ${ }^{160}$ Abgesehen davon, dass für Elias zurecht die Religion »jeweils genauso >zivilisiert` [ist], wie die Gesellschaft oder wie die Schicht, die sie trägt «: ${ }^{161}$ Seine Nichtberücksichtigung der Hexenverfolgung hat offenbar einen ähnlichen Hintergrund, wie ihn Erdheim bei Friedrich Meinecke und Wilhelm Dilthey sieht. Beide betrachteten Ideen von Staatssouveränität und absoluter Königsmacht »offenbar als vernünftig und dem Geist der Zeit entsprechend, die Hexenvorstellungen jedoch als unvernünftig, irrational; als kaum erwähnens-

157 Ebda.

158 Vgl. Einleitung.

159 Erdheim, Mario: Unbewußtheit im Prozeß der Zivilisation, in: Rehberg, Karl-Siegbert (Hg.): Norbert Elias und die Menschenwissenschaften. Studien zur Entstehung und Wirkungsgeschichte seines Werkes. Frankfurt/M: Suhrkamp 1996, S. 165.

160 Ebda., S. 164.

161 Elias, a.a.O., S. 277. 
werte Überbleibsel aus früheren Epochen «. ${ }^{162}$ Wobei sich Elias der Wertungen wie »vernünftig« enthält.

Seinerseits zurecht verweist Erdheim, wie vor und nach ihm auch andere AutorInnen, ${ }^{163}$ auf den Zusammenhang von Absolutismus und (Hexen-)Verfolgung. Hier zunächst auf Jean Bodin, in dessen Werk sich eine der herausragenden Theorien der Souveränität und die »Demonologie « miteinander verflechten, ${ }^{164}$ um dann am »Beispiel des Absolutismus« zu zeigen, »wie die Entwicklung von komplexeren Formen des sozialen Zusammenlebens nicht nur mit der Produktion neuer Formen von Bewußtsein einhergeht, sondern auch mit der Produktion von Unbewußtheit«. So komme es in »den Phantasmagorien« von Hexen und Teufel

»zur Wiederkehr des Unbewußten, nämlich der unbewußten Aggression gegen die Konzentration von Macht und Gewalt in einem Zentrum, dem königlichen Hof. Die Gestalt des Teufels, dessen Macht sich angeblich immer mehr ausdehnte, spiegelt die vom Unbewußten verzerrten Züge des absoluten Fürsten. Da man aber den Teufel statt des Königs bekämpfte, und nicht den Adel, sondern die Hexe jagte, dienten diese Ersatzbildungen letztlich der neuen Staatsform und ihrer Vergöttlichung der Macht«. ${ }^{165}$

Hexen und Teufel als Ersatzbildungen, gegen die sich unbewusst die Aggressionen gegen die neue Ordnung lenken? Das ist zumindest stark verkürzt. Dass im Zusammenhang von Absolutismus und der Verfolgung all jener, die »sich in die neuen Ordnungsmuster nicht einpassen« können oder wollen, ${ }^{166}$ neue Formen von Bewusstsein und Unbewusstem entstehen, ist evident. »Diese Individualisierung sozialer Disziplin durch die Institutionalisierung ihrer Instrumente und Praktiken legt einen vertieften Schnitt zwischen >oben und forciert die Abgrenzung der herrschenden Schichten von einem als Pöbel qualifizierten >großen Haufen`.« Zuwiderhandelnden wird mit systematisierter »Zwangsgewalt« begegnet, mit Inklusionen »in Anstalten« und Exklusionen, »Verbannung, Folter, Hinrichtung«. Gesamtgesellschaftlich (wenn auch hierarchisiert) geht es um

162 Erdheim, a.a.O., S. 165.

163 Vgl. Honegger, a.a.O., S. 94ff.; Braun, Kathrin/Kremer, Elisabeth: Asketischer Eros, S. 81f.; zuletzt Sonntag, Michael: »Das Verborgene des Herzens«, S. $138 \mathrm{ff}$.

164 Vgl. dazu genauer die Kap. Dämme u. Verflechtungen.

165 Erdheim, a.a.O., S. 165 f.

166 Sonntag, a.a.O., S. 138. 
»den qualitativen Wechsel der handlungsleitenden und -motivierenden Dispositionen und >Kräfte` von der Gruppe und den Formen sozialer Identität und Subsidiarität auf das einzelne Ich, um den Um-Bau seiner Normstrukturierung von kollektiven auf individuelle Kriterien ${ }^{167}$

Dass sich dabei schließlich auch Aggressionen gegen die Herrschenden gegen dafür freigegebene Marginalisierte wenden, ist ebenso zugestanden. ${ }^{168}$ Erdheim verfolgt aber den historischen Verlauf der Rituale nicht. Der gesellschaftliche Zwang, die Angst der Menschen gebiert Dämonen, Hexen und ihre Reinkarnate, die als die Negation jeder sozialen und sexuellen Ordnung - überhaupt der (göttlichen) Ordnung - rituell vernichtet werden. Diese Rituale sind zu verfolgen von aggregativ angeordneten Gesellschaftsstrukturen, in denen die Menschen >wissen`, ${ }^{169}$ dass es übernatürliche Wesen, Identitätswechsel, >beseelte Wälder` usw. gibt, bis hin zu den Anfängen generativ angeordneter Gesellschaftsstrukturen. Ginzburg zeigt, dass die Geschichte der Zuschreibungen und Verfolgungen gebunden ist an Gruppen sozialer Außenseiter. Als mythischen Kern des Hexenmotivs, des >Nachtfahrens〈 und der »Tierverwandlungen« bezeichnet er die >Reise ins Totenreich` und die >Rückkehrく daraus. »In einer Gesellschaft von Lebenden [...] können die Toten nur durch Personen verkörpert werden, die unvollkommen in den sozialen Körper eingefügt sind. « ${ }^{170}$ Dazu gehören insbesondere Frauen, da sie (auch) in archaischen Gesellschaften »innen und außen stehen, zum Clan gehören und ihm fremd sind«. Beim spätmittelalterlich/frühneuzeitlich entstehenden Hexenmuster bilden soziale Außenseiter das `Bindeglied zwischen archaisch tradierten volkskulturellen Vorstellungen (s.o.) und obrigkeitlichen Zuschreibungen von Komplotten. Auch hier sind »Marginalität, unvollkommene Assimilation« die Kennzeichen. Sind es hochmittelalterlich Lepröse, Juden, Ketzer, die auch durch bestimmte Kleidung, »Schildchen, Klappern« stigmatisiert und der Verschwörungen

167 Ebda., S. 138ff.

168 Auf so etwas läuft Darntons Darstellung im konkreten Fall hinaus. Die Arbeiter einer Druckerei in Paris Ende des 18. Jahrhunderts veranstalten, alte Traditionen nutzend, ein Massaker an Katzen, darunter die Lieblingskatze der Chefin. Sie rächen sich für Ausbeutung und schlechte Arbeitsbedingungen, indem sie mit der Katze Madames diese als Hexe und Hure identifizieren, die Meisterin symbolisch vergewaltigen und dem Chef so >Hörner aufsetzen. Unbewusst ist daran allerdings offenbar nichts. Darnton nennt das eine metonymische Beleidigung. Vgl. Darnton, a.a.O., S. $116 \mathrm{ff}$.

169 Vgl. Czerwinski: Gegenwärtigkeit, S. 81.

170 Ginzburg, a.a.O., S. $293 f$. 
bezichtigt werden, ${ }^{171}$ so sind es frühneuzeitlich Frauen, die des Umsturzes der Ordnung, des Chaos verdächtig sind. Ginzburg hält es für leicht vorstellbar, »daß in der Gruppe derer, die der Hexerei beschuldigt wurden, die Frauen«, insbesondere alleinstehende und sozial ungeschützte, »als die Marginalsten unter den Marginalen erscheinen mußten«. Einerseits erscheine diese Marginalität als »Synonym für Schwäche«, andererseits reflektiere sie »vielleicht auch auf mehr oder minder obskure Weise die Wahrnehmung einer Nähe zwischen denen, die das Leben hervorbringen, und der gestaltlosen Welt der Toten und Ungeborenen «. ${ }^{172}$ Hexen erscheinen als Inversion männlicher Ordnung, in der vorgeblichen Verbindung von Magie und Sexualität, der Anmaßung der männlichen, aktiven Rolle. Die Bedrohung geht so aus von weiblicher Produktivität insgesamt, von sozialen Nischen relativer weiblicher Selbständigkeit, zu denen Heil- und Geburtskunde gehören, aber auch spätmittelalterliche Möglichkeit von Handel und Gewerbe.

Mit Ginzburg lässt sich auch die Rolle der Katzen und >Hexen-Bäumeく verstehen. Beide sind »unvollkommen in den sozialen Körper eingefügt«, stehen »zugleich innen und außen«. Offenbar folgen Katzen »halbwild" schon frühgeschichtlich den Menschen, seitdem diese Vorräte anlegen und somit schädliche Nager wie Mäuse anlocken, werden schließlich als »willkommene[] Schädlingsvertilger« gezähmt, wobei ihre »Fortpflanzung bis zum heutigen Tag schwer zu kontrollieren ist. Die Züchtung ausgeprägter Rassen ist somit recht aufwendig. Dementsprechend bleiben auch die generellen Domestikationserscheinungen, die andere Arten so offensichtlich verwandelt haben, bei der durchschnittlichen Hauskatze bis zum heutigen Tage eher gering«. Und bei historischen Bild- oder Textquellen falle es schwer, »ein Tier als wild, gezähmt oder domestiziert einzustufen «. ${ }^{173}$

Vergleichbares gilt für Erlen und Weiden (wobei hier rituelle Vernichtungen offenbar nicht bekannt sind, was mit ihrer ökonomischen Nutzung zusammenhängen könnte). Sie sind `außen`, wachsen an >Unorten «: an Flussufern, die sich ohne aufwendige Domestizierung, Begradigung, Kanalisierung nicht kontrollieren lassen, die sich in hoher Dynamik ständig verändern, in Sümpfen, auf einem unkontrollierbaren Untergrund, an >Totenorten «. Auch ihre Fortpflanzung ist - im >wilden $<\mathrm{Zu}$ stand gewissermaßen >unkontrolliert`. Neben der >geschlechtlichen Fortpflanzung durch Bestäubung und Aussaat - die, wie gesagt, bis zur Durchsetzung der Linnéschen Taxonomie offenbar weitgehend als ine-

171 Ebda.

172 Ebda., S. 295.

173 Lorenz, Günther, a.a.O., S. 75. 
xistent angesehen wird - kommt es zur im botanischen Fachjargon >vegetativ genannten Vermehrung. Während Erlen durch unterirdische »Wurzelbrut« und »Stockausschlag« neue Tochterpflanzen bilden können, ist dies bei Weiden gar durch natürliche >Klone` möglich. Äste oder Zweige, beispielsweise vom Wind abgebrochen, sinken in den Schlamm, bilden dort recht schnell Wurzeln und werden so zu neuen Pflanzen, die sich oftmals >chaotisch « durch ältere Gehölze winden. Erlen und vor allem Weiden wachsen zudem häufig mehrstämmig. So berichtet dann das »Deutsche Wörterbuch« der Brüder Grimm vom »Weidenbaum« grundsätzlich: »auch dasz er ohne menschliches zuthun wächst, wird zum bilde: mancher wächst im freyen willen auff wie ein weydenbaum. Lehman, flor. pol. 4, 121 «. ${ }^{174}$

Gleichzeitig sind die Bäume >innen`. Sie sind ein ökonomischer Faktor, werden teils großflächig kultiviert, wobei die spezifischen Eigenschaften der Bäume genutzt werden: sie werden traditionell als Niederwald bewirtschaftet, >auf den Stock gesetzt`, d.h. in bestimmter Höhe gefällt, wobei dann aus den verbleibenden Stümpfen relativ schnell Äste und Zweige wieder ausschlagen, die erneut geerntet werden können. Aber auch hier zeigt sich eine soziale Marginalisierung. Die Bäume und die aus ihnen gefertigten Produkte sind zwar gesellschaftlich notwendig, entstammen aber dem Produktionsbereich der bäuerlichen Unterschichten. In Niederwäldern wird Brennholz, aber kein Nutz- und Bauholz geerntet. ${ }^{175}$ Ein wichtiges Gewerbe ist dabei die Gewinnung von »Weidenruten zum Korbflechten und für die Herstellung von Faßreifen«. ${ }^{176}$ So werden die Hexenzweige im anderen semantischen Raum zum Weidenkorb (wobei der Zusammenhang im Englischen - »wicker«, »Hexenkorb « - sprachlich erhalten bleibt), Rohstoffe auch für Mauerflechtwerk an Fachwerkhäusern, zur Befestigung von Strohdächern, für Zäune und zur »Ufer- und Hangbefestigung«, als Binderuten für Weinreben. Daneben dienen sie als >Arme-Leute-Schuhbänder`, wird die Samenwolle von Weiden und Pappeln zur Füllung von >Arme-Leute-Kissen` verwendet. $^{177}$

In Deutschland ist die Gewinnung von Weidenruten bis ins 20. Jahrhundert betrieben worden, »in Niederungsgebieten, wo man in der Neuzeit sogar Korbweidenkulturen anlegte. Dafür eigneten sich weite Flußtäler besonders gut, wo es immer wieder zu Hochwasser kam und das

174 Deutsches Wörterbuch von Jacob und Wilhelm Grimm. Vierter Band. I. Abteilung, 1. Teil. Stichwort»Weidenbaum«, Sp. 578.

175 Radkau/Schäfer: Holz, S. 30ff.

176 Küster, Stefan: Geschichte des Waldes, S. 164.

177 Vgl. Laudert, a.a.O., S. 207. 
Wasser schlecht abfloß«. Zentren dieser Korbweidenkultur lagen unterhalb Hamburgs an der Elbe, am Niederrhein und am oberen Main. ${ }^{178}$

Währenddessen verschwinden die unkultivierten Orte der Bäume immer mehr. Wenn Wilhelm von Humboldt klagt, »es sei schlimm genug, daß so oft Bäume, die wirklich auf große Schönheit Anspruch machen können, durch Menschenhände und ewiges Behauen ganz um ihren freien und großartigen Wuchs gebracht werden«, wie es den Weiden ergehe, die, "wenn man sie frei und ungehindert wachsen läßt, zu starken, hohen und malerisch schönen Bäumen« würden, ${ }^{179}$ dann entspricht das schon der auf Unterwerfung basierenden Konstruktion einer "Harmonie« der Natur, wie sie bei seinem Bruder Alexander als »Objekt wissenschaftlicher Betrachtung« und »Gegenstand des Kunstgenusses« erscheint. ${ }^{180}$ So, wie am Ende der Hexenverfolgung die Konstruktion >weiblicher Unschuld, , in der allerdings eine nur gezügelte Wildheit sich verberge, steht. ${ }^{181}$ Mit Beginn der zunächst kameralistisch geprägten geregelten Forstwirtschaft geraten dann auch Niederwälder ins Visier einer planmäßigen Beseitigung zugunsten eines geordneten Altersklassenforstes. Das Holz von Erlen, Weiden und anderen Arten ist desgleichen lange Zeit als >Weichlaubholzく verpönt. ${ }^{182}$ Das Verrufene bleibt, wenn auch in andere, rationale Sinnstrukturen transformiert.

\section{Ungezügelte Pflanzen und Reptilien}

»Oberhalb von 30 Metern beherrschen imposante Stieleichen, Feld- und Flatterulmen das Bild, aber auch Esche, Silber- und Schwarzpappel. Und auch die Silberweide gedeiht hier viel besser, wird bis zu 35 Meter hoch; in der Silberweidenaue, wo sie alleine herrscht, mißt sie dagegen kaum mehr als 20 Meter. [...] Unter der Etage der Baumriesen beherrschen Feld- und Bergahorn, Zitterpappel, Winterlinde und Bergulme das Bild. Sie werden 15 bis 18 Meter hoch und überragen immer noch die kleineren Grau-Erlen, Sal- und Reifweiden, neben einzelnen Vertretern des echten Wildapfels und der sehr seltenen Wildbirne. Ein undurchdringliches Pflanzengewirr, das bis in die Kronen der höchsten Bäume hinaufreicht - den Eindruck eines Tropenwaldes verstärken die verschiedenen Lianen im Auwald, der Baum-Efeu, die Waldrebe und die wilde Weinrebe.. [...] Weiter unten, in der Wuchsklasse zwischen vier und acht Metern, tummeln sich die >Sträucher`, darunter Weißdorn, Pfaffenhütchen, Faulbaum und Schlehe, seltener die Kornelkirsche und der Kreuzdorn.

178 Vgl. Küster, a.a.O.

179 Zit. n. Laudert, a.a.O.

180 Weigel, Sigrid: Topographien der Geschlechter, S. 127f.

181 Vgl. ebda., S. 130.

182 Vgl. Kap. Taxonomie u. Kap. Der Aufmarsch der 〉Ständeく. 
Typisch für den >Taubergießen`: Auch die >Sträucher` wachsen nicht wie anderswo, indem sie sich kurz über dem Boden reich verzweigen; sie können im Auwald bis zu neun Meter hoch werden, zu kräftigen Bäumen heranwachsen, mit kräftigem Stamm. Dieser Wechsel vom Strauch- zum Baum-Wuchs unterstreicht den Tropenwald-Charakter des >Taubergießen drucksvoll, daß er einzigartig ist in Mitteleuropa. ${ }^{183}$

So wird 1989 eine Rest->Wildnis` am Oberrhein beschrieben, die der französische Wissenschaftler Roland Carbinier als die »bei weitem komplexeste und höchstentwickelte Waldgesellschaft Europas « ${ }^{184}$ bezeichne, die zeige, wie sich selbst überlassener Wald aussehe.

Armin Maywald zählt hier allein an Gehölzen 27 Baumarten, 20 Straucharten und sechs Arten von Lianen »im üppigen Pflanzengewirr «, ${ }^{185}$ das in mehreren Stockwerken wächst. Er selbst verweist bei seiner Erkundung des »Taubergießen« auf die Unmöglichkeit, das >Dschungelgewirr im Vorbeifahren mit dem Boot zu analysieren und zu klassifizieren, ein System zu entdecken. Er sei dazu »verurteilt, zu genießen«, drückt sich der Naturschützer aus. ${ }^{186}$ Vermischung der Elemente, fehlende sichtbare Ordnung. Es ist ein Ort des Zweifels, des Verbergens und Verborgenen, des Ungeklärten. Die Natur ist in dieser >primären` Erscheinungsweise >unbeherrscht`, nicht quantifizierbar und bleibt unbegreiflich. Die Natur genügt sich selbst, existiert für sich, ohne bewertet werden zu können. Erst ihr Zerlegen in ihre Bestandteile macht eine ernsthafte (den >Naturgesetzen` gehorchende) Bewertung möglich. Die >Verurteilung zum Genuss` ist eine Ästhetisierung zur Gegenwelt, zur »Oase «. Das repräsentiert die Umkehrung des Topos vom 〉Locus amoenus in der Wildnis` in der Moderne, in der diese Wildnis nun die industrialisierte Landschaft als Bedrohung der >Naturoase $<$ bezeichnet. Nicht nur in der Umkehrung liegt eine Ironie, sondern auch darin, dass die Oase - die >Insel $<$ - ohne die sie umschließende >Wüste semantisch inexistent wäre.

Auch mittelalterlich und frühneuzeitlich dürften solche Orte nicht bedeutend anders ausgesehen haben. Auch hier sind sie Orte der Unordnung. Allerdings ist ihre Wahrnehmung eine andere. Die ist geprägt vom reichen »semantischen Raster« der »Formen der Ähnlichkeit«, wie Foucault gezeigt hat.

183 Maywald, Armin: Naturoasen in Deutschland. Ravensburg: Maier 1989, S. $126 \mathrm{f}$

184 Ebda., S. 120.

185 Ebda., S. 124.

186 Maywald, a.a.O., S. 124. 
»Bis zum Ende des sechzehnten Jahrhunderts hat die Ähnlichkeit im Denken (savoir) der abendländischen Kultur eine tragende Rolle gespielt. Sie hat zu einem großen Teil die Exegese und Interpretation der Texte geleitet, das Spiel der Symbole organisiert, die Erkenntnis der sichtbaren und unsichtbaren Dinge gestattet und die Kunst ihrer Repräsentation bestimmt. ${ }^{187}$

Die wichtigsten Ähnlichkeiten seien die »convenientia«, die »aemulatio«, die »Analogie« und die »Sympathie«. Die »convenientia« bezeichnet eher eine »Nachbarschaft von Orten« als eine Ähnlichkeit bzw. »eine mit dem Raum in der Form des unmittelbar Benachbarten verbundene Ähnlichkeit. Sie gehört zur Ordnung der Konjunktion und der Anpassung « und daher »weniger zu den Dingen selbst, als zur Welt in der sie sich befinden «. Hier findet eine Verkettung der Elemente statt. ${ }^{188}$ Die »aemulatio« hingegen ist »eine Art Konvenienz, die aber vom Gesetz des Ortes frei ist und unbeweglich in der Entfernung ihr Spiel hat«. Hier sei die räumliche 〉Duldsamkeit` ansatzweise »gebrochen«, seien die »Ringe der Kette« voneinander gelöst, um eine »berührungslose[] Ähnlichkeit« zu reproduzieren, wobei nach Art konzentrischer Kreise Ähnliches von Ähnlichem »umhüllt« werde. Zugleich gebe es in der »aemulatio« so »etwas wie den Reflex oder den Spiegel; in ihr antworten die in der Welt verstreuten Dinge aufeinander«, wobei `schwächere` von 〉stärkeren< beeinflusst werden können. ${ }^{189}$ Die beiden genannten Ähnlichkeitsformen überlagern sich in der »Analogie«. Sie stelle sowohl »die wunderbare Gegenüberstellung der Ähnlichkeit durch den Raum hindurch sicher«, als auch die »Anpassungen« und »Verbindungen«. »Ihre Kraft ist immens, denn die Ähnlichkeiten, die sie behandelt, sind nicht jene sichtbaren und massiven der Dinge selbst; es genügt, daß es die subtileren Ähnlichkeiten der Verhältnisse (rapports) sind.«»Analogien« sind reversibel, ohne dadurch »in Frage gestellt zu sein $« .{ }^{190}$ Es ist eine solche "Analogie«, die zwischen Frauen (Hexen), Weiden, Erlen, Katzen, Reptilien, Sümpfen usw. wahrgenommen wird. Und da Analogien reversibel und re-reversibel sind, kann das >Böse zum Schutz vor dem 〉Bösen` dienen. Die Ähnlichkeit der »Sympathie« schließlich ist völlig ungebunden, "sspielt in freiem Zustand in den Tiefen der Welt«. Sie kann durch plötzliche Berührung entstehen und ist so stark, dass sie als »Ursprung der Mobilität«, alle Räume durchbrechend, »die Annäherung der entferntesten Dinge« bewirken kann. Dabei hat

187 Foucault, Michel: Die Ordnung der Dinge, S. 46.

188 Vgl. ebda., S. 47.

189 Vgl. ebda., S. 48f.

190 Ebda., S. 51. 
diese »Instanz des Gleichen« die bedrohliche Macht »zu assimilieren, die Dinge miteinander identisch zu machen«, jede Individualität aufzuheben, zugunsten einer »homogenen Masse«, zur »finster[n] Gestalt des Gleichen«, in der alles sich gegenseitig erhalten würde in »bruch- und distanzlos[er]« Kommunikation. Daher hat sie als kompensatorischen Zwilling die Antipathie, die die Isolation der Dinge aufrecht erhält und Assimilation verhindert. Und so, wie die Sympathie die »Wurzeln ins Wasser« treibt, sorgt die Antipathie für Ausgleich: »Da sie durch die Hitze der Sonne und die Feuchtigkeit der Erde wachsen, muß jeder Baum, der dicht und undurchdringlich ist, für den anderen ebenso wie die wurzelreichen verderblich sein. So werden sich durch die Zeit die Wesen der Welt hassen und ihren wilden Appetit gegen jede Sympathie aufrechterhalten. ${ }^{191}$

Das System der Ähnlichkeiten aber ist kein geschlossenes. Die Ähnlichkeitsformen zeigen die Wege, "sagen uns, wie die Welt sich verschließen, sich reduplizieren, sich reflektieren oder verketten muß, damit die Dinge sich ähneln können«. Aber sie sagen »nicht, wo die Ähnlichkeit ist, oder wie man sie sieht, noch an welchem Merkpunkt man sie erkennt«. Um diese Offenheit zu 〉verschließen`, gibt es die »Signaturen«. Es sind Zeichen an der Oberfläche, die erst Hinweise auf die jeweiligen ansonsten verborgenen Ähnlichkeiten geben: ${ }^{192}$ die >wuchernde Unfruchtbarkeit` der Weiden, die stockende, giftige Schwärze der Sümpfe, die >warzige «, >schleimige $<$ Haut und der >stechende Blick` der Kröten.

Ist die Ähnlichkeit »die unsichtbare Form dessen, was aus der Tiefe der Welt die Dinge sichtbar machte«, dann kehrt das »System der Signaturen [...] die Beziehung zwischen dem Sichtbaren und Unsichtbaren um«, damit das Unsichtbare mittels sichtbarer Dinge ans Licht kommt. Und so ist die Welt übersät mit sich wiederholenden oder überkreuzenden Zeichen, die nur entziffert werden müssen. »Stimmt es nicht, daß alle Gräser, Pflanzen, Bäume und so weiter, die aus dem Innern der Erde kommen, ebenso viele Bücher und magische Zeichen sind?«, fragt dann auch Oswald Crollius 1624 in seinem » Traktat über die Signaturen«. ${ }^{193}$

Orte der Unordnung: Schlingpflanzen wie Hopfen, Bittersüßer Nachtschatten oder Waldrebe (die Clematis vitalba heißt im Volksmund »Hexenhaar«), und ein - wegen der relativ hohen Lichtdurchlässigkeit des Baumlaubes - >üppig wuchernder Unterwuchs aus Sträuchern, Blumen, Farnen, Moosen und Gräsern. Und in den Gewässern »Nymphen und »Huren«. Unter dem Stichwort »Weibliche Kollektivnamen« ver-

191 Ebda., S. $53 \mathrm{f}$.

192 Vgl. ebda., S. 56.

193 Ebda., S. 57. 
zeichnet »Dr. Aigremont«, Mitarbeiter von Friedrich S. Krauss und Magnus Hirschfeld auf dem Gebiet der Ethnobotanik, die Bezeichnungen »Puppe«, »Seepuppe«, auch »Muhme«, »Mümmel« u.a. für die Wasserrose (lat. »Nymphaea alba«). Die Blumen hätten als verwandelte Seejungfrauen gegolten, als Nixen, »die um Mitternacht als weiße Elfinnen auf dem Wasser tanzten«, wobei die Blätter als Schiffchen dienten. Man dürfe sie »nicht mit einem Messer abschneiden, denn dann würde Blut aus dem Stengel rinnen, und Angstträume würden den Frevler heimsuchen. Die Sage hat viele Fälle aufbehalten, daß der unvorsichtige Räuber der Blume von dunklen Gestalten in die Tiefe des Schlammes gezogen und erwürgt worden sei«. Der »stinkende Gänsefuß« (lat. »Chenopodium vulvaria «) werde auch »nackte«, oder »stinkende Hure« genannt. $^{194}$

Es fehlt an >geregeltem<, >ordentlich sich emporreckendem Stammwuchs, an sicherem Untergrund. Derartige Landschaften befinden sich nicht nur auf von Schlamm und Wasser, wechselnden Flutrinnen und Quellsümpfen kontrolliertem Boden, sie sind auch Hauptsiedlungsorte von Reptilien und Amphibien wie Schlangen, Fröschen, Kröten, Lurchen und Eidechsen. Orte des Sündenfalls: »Wurmgärten«. In Dichtungen des Hochmittelalters wird der Begriff einige Male verwendet etwa in der »Vorauer Sündenklage«, wo es heißt:

»nu hilf mir sundaere heim/uz diseme wurmgarten,/da wir in geworfen wurden/durch Adames missetat. ${ }^{195}$

Hier, an einem Ort, »der im Gegensatz zum lichten, friedvollen Garten des Paradieses stand «, den man sich vorstellte als »feuchten, bruchigen Wald, bevölkert mit Schlangen und Drachen [...], >denn die Vorstellung, daß die Schlangen und Drachen den feuchten Wald oder Bruch lieben, war damals schon lebendig « ${ }^{196}{ }^{19}$ werde >Adams Missetat $<$ und 〉Evas Schuld deutlich.

194 Dr. Aigremont: Volkserotik und Pflanzenwelt. Eine Darstellung alter wie moderner erotischer und sexueller Gebräuche, Vergleiche, Benennungen, Sprichwörter, Redewendungen, Rätsel, Volkslieder erotischen Zaubers und Aberglaubens, sexueller Heilkunde, die sich auf Pflanzen beziehen. = Rätsch, Christian: Reihe Ethnomedizin und Bewußtseinsforschung. Historische Materialien 7. Berlin: Verlag für Wissen und Bildung 1997 (Reprint v. Leipzig, Halle/S 1907-1910)Bd. 2. S. 102f.

195 Zit. n. Hennebo, Dieter: Gärten des Mittelalters. München, Zürich: Artemis-Verlag 1987, S. 111.

196 Hennebo, a.a.O.; Binnenzitat von Lauenstein, D.: Der deutsche Garten des Mittelalters bis zum Jahr 1400. Göttingen 1900, S. 36. 
Ein solcher »Wurmgarten« ist ein locus terribilis, ein Schreckensort der mittelalterlichen Literatur, aber in dieser Weise als böses Gegenstück noch ein notwendiger Bestandteil gesellschaftlicher Weltproduktion und Wahrnehmung. Ein Ort weiterhin auch des >magischen Nutzens`. Frühneuzeitlich wird daraus offensichtlich eine Metonymie für die Verflüssigung der Materie, Auflösung der (sozialen) Ordnung.

Es ist ein weiblicher Ort, denn das Weibliche wird in der schon auf aristotelische Tradition zurückgehenden Zuschreibung dem Flüssigen zugeordnet, dem Substanzlosen, einer gestaltlosen Masse, erst vom Männlichen formbar. Hier entzieht sich das >Weibliche ২ bisher der Formung. Und dort, wo Sümpfe stocken, entstehen obendrein bedrohliche, giftige Dämpfe, >Miasmen $\times{ }^{197}$

Die potentielle Anwesenheit von Reptilien und Amphibien trägt also zum Schrecken der Erlen und Weiden und der Orte, in denen sie wachsen, bei. Frösche etwa

»waren im Mittelalter die Totemtiere von Hexen. Das ging auf alte Traditionen zurück, die den Frosch mit Hekate bzw. mit der ägyptischen Hekat verbanden, die als Königin der himmlischen Geburtshelferinnen galt. Die ÄgypterInnen benutzten den Frosch als Symbol für den Fötus. Hekates heiliges Froschamulett trug die Worte `Ich bin die Auferstehung`, eine Formel der Geburtsmagie, die von den frühen Christen übernommen wurde «. ${ }^{198}$

Frösche und Kröten werden ebenso traditionell mit dem Uterus gleichgesetzt. Im antiken Rom »sah sich der Arzt Soranus veranlaßt, der Meinung entgegenzutreten, daß die Gebärmutter ein Tier sei«. Die »besondere Beziehung« der Tiere »zur Gebärmutter und den damit zusammenhängenden Krankheiten, wie Menstrualblutung, Krebs u. dergl.«, konstatiert Seligmann. Die Kröte sei »geradezu »Symbol der >Bärmutter «, die nach »dem Volksglauben [...] als Kröte aus dem Mund heraus« krieche, "um sich zu baden« und zurückkehre »während die Kranke schlafe«. Kröten als Votivfiguren aus Wachs oder Silber werden in Teilen Mittelwesteuropas anscheinend noch zu Beginn des 20. Jahrhunderts »fabrikmäßig« produziert und »von hysterischen und unfruchtbaren Frauen« in »der Mutter Gottes geweihten Kappellen« deponiert. Solche Votivkröten aus Materialien wie Bronze, Goldblech, Silber, Elfenbein usw. lassen sich bis in die Antike und die frühe Bronzezeit zurückver-

197 Vgl. Kap. Böse Ausdünstungen.

198 Walker, a.a.O., S. 285. 
folgen $^{199}$ (nach antiken, hippokratischen Vorstellungen wird Hysterie durch eine >Wanderung « der Gebärmutter - »hystéra« - hervorgerufen).

Frösche symbolisieren desgleichen das äußere weibliche Genital:

»In Rom galt der Frosch als das heilige Tier der Venus, von der Hekate einen Aspekt verkörperte. Ihre dreifache Yoni wurde zuweilen als eine Lilie dargestellt, die sich aus drei Fröschen zusammensetzte. Noch heute wird ein bestimmter, aus einer Kordel bestehender Kleiderverschluß, der wie eine Lilie geformt ist, im Englischen frog, >Frosch`, genannt. Ein alter Schneiderbrauch besagte, daß zu jedem Gewand genau neun frogs gehören sollten, was sich möglicherweise auf babylonische Rollsiegel zurückführen läßt, auf denen neun Frösche als Fruchtbarkeitszauber abgebildet waren. Die Neunfache Göttin herrschte über die neun Monate der Schwangerschaft. $\ll^{200}$

Seit der Antike (bei Plinius) gelten Kröten »[w]egen ihrer häßlichen Gestalt, ihrer garstigen, warzenbedeckten Haut, ihres Aufenthaltes in dunklen, feuchten Erdlöchern und ihrer auffallend glänzenden Augen« als »ein giftiges, heimtückisches, dämonisches Tier«, das den »bösen Blick« habe, und so auch vor ihm schütze. Laut Marcellus Empiricus sei das Tier >giftanziehend empfehlen Paracelsus und andere Kröten gegen die Pest. ${ }^{201}>$ Giftigkeit und >böser Blickı sind analoge Eigenschaften der Kröte und des >weiblichen Geschlechtsapparats〈 während der Menstruation: »Der böse Blick der Menstruierenden und die Giftwirkung des Menstrualblutes waren dem Mittelalter geläufige Dinge«, schreibt Esther Fischer-Homberger. Die Giftigkeit des Blutes, das Wein und Milch sauer mache, Früchte verdorren und Spiegel erblinden lasse, das Hunde, wenn sie davon »schlecken«, tollwütig werden lässt, wird schon bei Plinius behauptet und ist fester Bestandteil volksmedizinischer Traditionen. Der böse Blick der Menstruierenden wird von Albertus Magnus diagnostiziert, laut Konrad von Megenberg »verursacht er die Pocken«. 1491 erklärt Johannes von Ketham im »Fasciculus Medicinae« die Zusammenhänge: Danach steigen die giftigen Dämpfe des Bluts in den Kopf und verschafften sich Ausgang durch die >porösen` Augen. In dieser grundsätzlichen »Porosität« liege auch die Gefahr für die Opfer des Blicks, deren Augen so »Eingangspforten für das von den Menstruierenden

199 Vgl. Seligmann: Die magischen Heil- und Schutzmittel. Bd. 2: Das Tierreich, S. 181.

200 Walker, a.a.O.

201 Vgl. Seligmann, a.a.O., S. 177ff. 
Ausgestrahlte« seien. Dass letztere sich nicht vergiften, liege an ihrer Gewöhnung. ${ }^{202}$

Frösche, Kröten und Schlangen bedeuten >Unkeuschheit` in der abendländischen Ikonographie, weshalb sie allenthalben auch als ewige Peiniger derartig sündiger Frauen erscheinen. Meyer Schapiro beschreibt die Skulptur »Bestrafung der Unkeuschheit» an der Westwand der Kirche von Moissac (12. Jahrhundert), die er ähnlich wie die ebenfalls nackte Figur der Luxuria in Charlieu wegen der Durchmodellierung und Ausdrucksstärke, der »massigen Gliederung und den fließenden Umrissen« als »für diese Zeit [...] merkwürdig weit entwickelt« ansieht: den "völlig symmetrischen Körper der verdrehten Figur«, die Parallelität der erhobenen Hände und hängenden Brüste, an denen die gleichförmig gemusterten Schlangen saugen.

»In der Mitte dieses kraftvoll plastischen Gebildes sitzt die Kröte, die die Geschlechtsteile der Frau verschlingt, gerahmt von den Oberschenkeln und den hängenden Schlangenkörpern, die sich mit dem Körper verbinden, um so ein wunderschönes symmetrisches Schema aus fließenden Linien und Erhebungen zu ergeben. $\ll^{203}$

Die Verkörperung der »Unkeuschheit« durch »eine nackte Frau, die Schlangen an der Brust und zuweilen Kröten im Schambereich hat « sei üblich im Programm der Kirchenskulpturen und -reliefs dieser Zeit, und »der romanischen und moslemischen Phantasie gemeinsam «. ${ }^{204}$ Höllenqualen als Verschlingungen durch dämonische Tiere. In Boschs Höllendarstellung im rechten Innenflügel des »Tausendjährigen Reichs« sitzt »das verführte Mädchen« an den Hochstuhl des Teufels, unter dem sich eine Kloake befindet, gesunken. Verführt ist sie vom Spiegel, damit vom Teufel, der in dieser Funktion als Hintern mit dem »Spiegel als hinterrückses Teufelsauge« abgebildet ist. Die Beine laufen aus zu Haselruten, da, so Fraenger, »nach dem Volksglauben des Mittelalters der Teufel gern in Haselbüschen seine Liebschaft sucht«. Die Verführte ist ein Double der Eva im »Garten Eden« des linken Innenflügels, nun aber mit aufgegangenem, »zerflossen[em]«, feuchtem Haar, »Stellvertreterin des ganzen weiblichen Geschlechtes«. In dem »Augenblick, der ihr die Teufelsfratze neben dem eigenen Antlitz abgespiegelt zeigt, erlöschen ihr

202 Vgl. Fischer-Homberger, Esther: Krankheit Frau, S. 56f.

203 Schapiro, Meyer: Die romanischen Skulpturen in Moissac I und II, in: Ders.: Romanische Kunst. Ausgewählte Schriften. Köln: DuMont 1987 (New York 1977), S. 426; vgl. Abb. 114, S. 441.

204 Ebda., S. 79f. vgl. S. 126, Abb. 10: »Luxuria«-Relief in Santiago de Compostella. 
die Sinne und sie sinkt zurück. Fühlt sie sich doch gleichzeitig von den Salamanderfüßen des unversehens neben ihr empor getauchten Teufels tödlich kalt umarmt, spürt sie doch plötzlich eine nasse Kröte zwischen ihre Brüste kriechen«, wie Fraenger das formuliert. ${ }^{205}$

Derartige aggregative Sinnstrukturen fließen in Konstruktionen von Hexerei ein. Auch hier lässt sich leicht der Zusammenhang von Geburt, Tod und Wiedergeburt rekonstruieren. Im »Hexenhammer« dienen Schlangen der magischen Hemmung der Zeugungskraft: »Und der Grund ist, weil Gott bei diesem Akte, durch den die erste Sünde verbreitet wird, mehr zuläßt, als bei den anderen Handlungen der Menschen; so ist es auch mit den Schlangen, die mehr auf Beschwörungen hören als andere Tiere. Daher ist auch öfters von uns und anderen Inquisitoren gefunden worden, daß sie durch Schlangen oder eine Schlangenhaut dergleichen Hinderungen bewirkt haben. ${ }^{206}$

Kröten werden als Bestandteile des »Hostienfrevel[s]« vorgestellt. Da nimmt eine Hexe den `Leib des Herrn`, verbirgt ihn »also vom Dämon unterwiesen, in einen Topf, in dem eine Kröte war, und verbarg ihn in der Erde im Stalle nahe bei der Scheune ihres Hauses«. Durch »die Liebe Gottes« aber hören Zeugen aus der Erde ein Kind weinen, sehen schließlich die Hexe den Topf unter ihrem Mantel verbergen. Sie wird gefangen und gesteht unter der Folter, mit der Hostie und der Kröte ein Schadenspulver herstellen zu wollen. ${ }^{207}$ Kröten werden von »Norditalien über Deutschland, die Ukraine bis nach Polen« als »)Fee〈, 〉Hexeく, >Zauberer bezeichnet«. Daher dienen sie desgleichen der Abwehr von Hexen und böser Zauberei. Dazu werden sie am Hals oder an den Füßen in Häuser oder Ställe gehängt, aufgespießt, getrocknet usw. ${ }^{208}$

Ginzburg weist auf den Zusammenhang von Fliegenpilz, Kröte und »Geh-Anomalien« hin. Sie stellten offenbar »in vielen Kulturen einen symbolischen Mittler zum Unsichtbaren dar«. Der Fliegenpilz (Amanita muscaria), der allerdings nur unter Birken (im Norden) bzw. Tannen (im Süden Europas) wächst, sei wahrscheinlich seit 4000 v. u. Z. »zur Her-

205 Fraenger, a.a.O., S. 62, vgl. Abb. 18. Das Sujet ist häufig in Spätmittelalter und Renaissance. Bei Fraenger findet sich die Illustration der »Hoffart« aus Brants »Narrenschiff«, das ebenfalls den selbstgefälligen Blick einer jungen Frau in den Spiegel zeigt, hier vor einem Haselstrauch mit Teufel (der aber nicht im Spiegel ist). »So geht gerade der Witz, auf den es ankam, in die Brüche.« (ebda.). Ebenso bekannt ist der Holzschnitt aus dem »Buch des Ritters vom Turm« (1493, Basel). Hier ist der Hintern des Teufels im Spiegel, in den die junge Frau blickt.

206 Hexenhammer, 2. Teil, S. 76.

207 Vgl. ebda., S. 73f.

208 Vgl. Seligmann, a.a.O., S. $177 \mathrm{ff}$. 
beiführung eines ekstatischen Zustandes« in schamanischen Kulten verwendet worden. In zahlreichen Sprachen Europas, aber auch im Chinesischen würden dieser Pilz oder Lamellenpilze insgesamt als »Krötenpilz«, »Krötensitz«, »Krötenhaar« etc. bezeichnet. Zugleich scheine eine

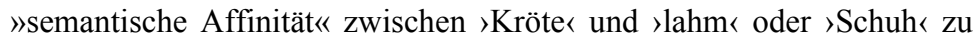
bestehen, so in norditalienischen Dialekten, wo Kröten »scarpa« (Schuh) oder »ciabatta« (Hausschuh) hießen. ${ }^{209}$ Das Hinken etwa des >Teufels oder Aschenputtels Schuh in den durch die Jahrhunderte variierenden Versionen des Märchens seien zurückzuführen auf alte Mythen und Riten der >Wiedererweckung`von Opfertieren, bei denen regelmäßig ein Knochen fehle. Vorkehrungen, »die in denkbar verschiedenen Kulturen bezeugt sind «, und die »eine möglichst vollkommene Auferstehung von Tieren und Menschen« gewährleisten sollen. In ihnen komme als Handelnde häufig eine »Herrin der Tiere« vor. Ende des 14. Jahrhunderts in der Lombardei »ersetzten die Anhängerinnen der Oriente die fehlenden Knochen der Ochsen, deren Fleisch sie bei den nächtlichen Banketten verzehrt hatten, durch Stückchen von Holunderholz. In einer Tiroler Sage wird ein Mädchen, das zuerst geschlachtet und dann, mit einem Erlenzweig anstelle einer Rippe, wieder auferweckt wird, >Erlenholzhexe genannt $\ll .{ }^{210}$ Volkskulturelle Tradierungen, die in diskursiven Verschränkungen mit Inquisition und obrigkeitlicher >Dämonologie $\mathbf{z u}$ >nachtfahrender Hexereiく werden. »Verwandlungen, Ritte, Ekstasen, auf die der Auszug der Seele in Tiergestalt folgt, sind verschiedene Wege, die zu ein- und demselben Ziel führen. Zwischen Tieren und Seelen, Tieren und Toten, Tieren und dem Jenseits besteht ein tiefer Zusammenhang.« Ein Zusammenhang, der offenbar vielfach ethnologisch belegt ist. ${ }^{211}$ Dass in Protokollen von inquisitorischen Verhören von »abstoßenden oder wunderlichen « Tränken berichtet wird, die aus Krötenkot hergestellt seien, könnte, so Ginzburg, durchaus auf »Mißverständnis[sen] der Inquisitoren« beruhen. »Von Europa bis nach Amerika werden die Pilze oft mit Namen belegt, die an Urin, tierische Fäkalien oder Ausdünstungen erinnern. $\ll^{212}$

Nach Ranke-Graves gehören Fliegenpilze neben Efeu zu den »wichtigste[n] mänadische[n] Rauschmittel[n]« während der Zeit der mythischen »ausschweifenden Bacchanalien«, bei denen die »Bassariden wild durch die Berge streiften, wobei sie die Tannenzweige der Königin Artemis (oder Ariadne) schwenkten«, die im Zeichen des »Herbst-

209 Ginzburg, a.a.O., S. 299f.

210 Ebda., S. 248f. Vgl.

211 Vgl. Ebda., S. 266ff.

212 Ebda., S. 300. 
Dionysos « mit Efeu umwunden sind. »In ihrer Ekstase rissen sie Rehkitze, Kinder und sogar Männer in Stücke«. ${ }^{213}$ Efeu und Wein »nähern sich zur Jahreswende einander und sind gemeinsam der Auferstehung geweiht . Hier treffen sich mythisch Dionysos und Bacchus als Spender der Fruchtbarkeit und Schützer des Landbaus. ${ }^{214}$

$»$ F. W. Otto schreibt, daß sich gerade in diesen Pflanzen das doppelte Wesen dieser Götter, das zwischen Licht und Dunkel, Wärme und Kühle, Lebensrausch und ernüchterndem Todeshauch hin und her schwankt, besonders deutlich zeigt. ${ }^{215}$

Die ineinanderfließenden Gegensatzpaare von Rausch und Ernüchterung, Belebung und Vergiftung, »Licht« und »Dunkelheit«, »Leben« und »Tod« entstammen offenbar einer Besonderheit der Pflanze. Das Efeu scheint die einzige mitteleuropäische Pflanze zu sein, die zwei verschiedene Arten von Blättern gleichzeitig ausbildet: Während die an den der Sonne zugewendeten Blütensprossen wachsenden Blätter ungelappt, rautenförmig und glänzend sind, erscheinen die Blätter der im Schatten wachsenden Klettersprossen dreieckig und gelappt, mit stumpf dunkelgrüner Ober- und hellerer Unterseite.

In England sei der Efeubusch »seit jeher das Zeichen der Weinstuben« und im Mittelalter sei ein »stark berauschendes« Bier, »Ivy-Ale«, gebraut worden. ${ }^{216}$ Die psychotrope Droge Efeu, als Attribut von Rausch und wilder Triebhaftigkeit, wächst in klimatisch begünstigten Auwäldern zusammen mit wildem Wein und Hopfen, mit Hopfen an Flussund Bachauen, in Bruchwäldern.

Die Kletterpflanze wächst aber auch in anderen Wäldern und wird seit langer Zeit weitverbreitet angepflanzt an Hausmauern, und Gärten. ${ }^{217}$ Efeu wächst sehr ausdauernd, über den >Tod senen Baumes hinaus. Das bringt der Pflanze, die weithin als »Schmarotzer« gilt, obwohl sie »die Unterlage nur als Kletterhilfe« nutze, ${ }^{218}$

213 Ranke-Graves, a.a.O., S. 212.

214 Die Anhänger Dionysos' »meinten, daß Efeu das sicherste Zeichen seiner Anwesenheit sei. Wo reichlich Efeu wuchs, da wäre er gegangen«. Beuchert: Symbolik der Pflanzen, a.a.O., S. 64.

215 Ebda., S. 64.

216 Ranke-Graves, a.a.O., S. $212 \mathrm{f}$.

217 Und - seit diese Gartencharakter angenommen haben - auf Friedhöfen; hier als Symbol >ewiger Treue über den Tod hinaus<. Aber schon die ersten Christen scheinen gläubige Verstorbene zum Zeichen der durch die Taufe empfangenen Unsterblichkeit auf Efeu gebettet zu haben; vgl. Beuchert, a.a.O., S. 63.

218 Ebda. 
eine ambivalente (weibliche) Rolle ein. Im mittelalterlichen England gewinnt Efeu »die Bedeutung von Vettel, widerspenstiges Weib, ein Vergleich, der durch die Tatsache gestützt wurde, daß der Efeu den Baum erstickt, den er umrankt«. Die »Rivalität zwischen Steineiche und Efeu« als Repräsentanz des »häuslichen Krieg[s] der Geschlechter« gehe offenbar auf Erntebräuche zurück, bei denen »die letzte in einem Kirchspiel eingebrachte Erntegarbe mit dem Efeu des Osiris bekränzt und $>$ the Harvest May<, 〉the Harvest bridge` oder >the Ivy Girl ' genannt wurde«. Der bei der Ernte letzte Bauer »erhielt zur Strafe das Efeumädchen« als schlechtes Omen für das folgende Jahr. ${ }^{219}$

Mit dem ausgehenden 18. Jahrhundert wird das Doppel aus Eiche und Efeu dann vollends zum Bild der ehelichen Treue, vor allem der weiblichen Treue, die die >anlehnungsbedürftige`, daher >weibliche Pflanze symbolisiert. ${ }^{220} »[$ E]r die Eiche, sie der Efeu, der einen Teil seiner Lebenskraft aus den Lebenskräften der Eiche saugt«, schreibt Joachim Heinrich Campe, der mit ihr in die Lüfte wächst, mit ihr steht und mit ihr fällt - ohne sie ein niedriges Gesträuch, das von jedem Vorübergehenden zertreten wird «. ${ }^{221}$

Eingangs war von einer >Rest-Wildnis` am Oberrhein Ende des 20. Jahrhunderts die Rede. Hier, so Armin Maywald, wachsen Efeu, wilder Wein, Hopfen und all die anderen Sträucher und Bäume >dschungelartig`, so dass er sich außerstande sieht zu einer klassifizierenden Wahrnehmung oder unwillig, bestehende Systeme anzuwenden. Derartige Klassifikationen und Taxonomien entstehen im 18. Jahrhundert. Sie bringen Ordnung ins Gewirr.

Und letztlich ist alles ganz einfach, wie Jean-Baptiste Lamarck in der »Vorrede« seiner »Flore française« (1778) ausführt. Er gibt hier eine »Gebrauchsanweisung« am Beispiel einer »fiktive[n] Flora von elf Pflanzenarten« in Linnéscher Nomenklatur und stellt die zur Klassifikation notwendige Serie von Fragen dar. Das eigentliche Werk aber umfasst mehrere Hundert Seiten, in denen die Pflanzenanalyse »über eine Serie von Verweisen von Abbildung zu Abbildung« verläuft, mit der man alle beschriebenen Arten sicher herausfindet. Sollte das dem Leser

219 Ranke-Graves, a.a.O., S. 213.

220 Vgl. Beuchert, a.a.O., S. 64.

221 Zit. n. Westhoff-Krumacher, Hildegard (Hg.): Als die Frauen noch sanft und engelsgleich waren. Die Sicht der Frau in der Zeit der Aufklärung und des Biedermeier. Münster: Westfälisches Landesmuseum für Kunst und Kulturgeschichte 1995, S. 94, vgl. Kat. Nr. 28: Das Gemälde »Wilhelm Isaak von Gillé und seine Frau um 1832« von Caroline Bardua, die das Paar neben eine efeuumschlungene Eiche plaziert. 
zu mühsam sein, erinnert ihn Lamarck »an >das Wesen der geometrischen Progression. Tatsächlich erreicht man, wenn man die Summe 4096 fortwährend durch 2 dividiert, nach der elften Teilung die [unbekannte] Einheit««. Das heißt, »ein Dutzend Fragen reicht aus, um Tausende von Arten zu erfassen «. ${ }^{222}$

Mit solchen Mitteln soll in dem Gewirr der bisherigen »Formen der Ähnlichkeit« in der Wissenschaft eine strenge, von allem >Unzugehörigen bereinigte Systematik entstehen - der Comte de Buffon wundert sich sehr über den »Schwall von Geschriebenem«, der »keine Beschreibung, sondern Legende« sei, bei einem Naturforscher wie Ulisse Aldrovandi (»Monstrorum historia«, 1648), der über »Schlangen im Allgemeinen« noch ohne Unterschied »Anatomie, Wappen, Lebensverhältnisse, mythologische«, medizinische und magische Werte, Fabeln und sonstiges zusammenträgt. ${ }^{223}$ Und mit der Systematik in der Wissenschaft soll vor allem rigoros Ordnung in den >Dschungel gebracht werden können. Aber nicht nur damit. »Die Botanik ist eine Technik zur Beherrschung der Triebe. ${ }^{224}$ Das ist eine passend mehrdeutige Feststellung. Mit der beginnenden neuzeitlichen Botanik wird der »hetärischen Sumpfzeugung«, wie Bachofen später analogisiert, der Garaus gemacht. Denn mit der Sexualisierung der Pflanzen bei Linné und in seiner Nachfolge endet nicht nur die >Unfruchtbarkeitı der Weiden. Sie könnte in eine höchst ehrbare Fruchtbarkeit überführt werden. »Die Bäume, die Büsche, die Pflanzen sind Schmuck und Gewand der von Natur belebten und mit ihrem Hochzeitsgewand bekleideten Erde«, schreibt Rousseau in den »Lettres élémentaires sur la botanique«. Und Charles Bonnet sieht in »L'Amour végétal ou les noces des plantes« eine >unschuldige Braut ohne jeden »Schandfleck« und empfiehlt daher diesen »liebenswerte[n] Abschnitt der Naturgeschichte« den Damen zum Studium und zum »Entzücken«, könnten sie doch »auf noch anregendere Weise« lernen, »durch Analogie in der pflanzlichen Liebe reine und köstliche Genüsse $\ll$ zu finden. ${ }^{225}$

222 Drouin, Jean-Marc: Von Linné zu Darwin: Die Forschungsreisen der Naturhistoriker, in Serres, Michel (Hg.): Elemente einer Geschichte der Wissenschaft. Frankfurt/M 1995 (Paris 1989), S. 586.

223 Foucault: Die Ordnung der Dinge, S. 70f.

224 Delaporte, François: Das zweite Naturreich, S. 122.

225 Zit. n. ebda., S. 123. 


\section{Sexualisierung als Taxonomie: Ordnung für den Geilwuchs}

»Hermaphroditische Pflanzen, von monströsen Müttern `kastriertı. Bäume und Sträucher, in >Hochzeitskleidern〈. Blütenblätter als >Brautbettく für einen frischgebackenen Bräutigam und seine heißgeliebte Braut. Berichte einer Akademie der Wissenschaften [...]. Bei der im 18. Jahrhundert vollzogenen Revolution im Studium des Pflanzenreiches war die pflanzliche Sexualität kein zufälliges Beiwerk, sie war ihr Herzstück. «226

Dass Pflanzen unterschiedliche Geschlechter zugeschrieben werden, ist - wie gesehen - historisch nichts Neues. Nur geschieht das zuvor nach »Formen der Ähnlichkeit« und deren Signaturen. So wird bei Plinius der Weihrauch zur männlichen Pflanze wegen seiner »hodenähnlichen Gestalt«. Erst in der Renaissance bekommen die späteren 〉Genitalien` der Blühpflanzen Namen, werden die später >männlichen〈 Blütenteile »stamen« (lat. für den »Kettfaden eines Gewebes«), die >weiblichen« »pistillum« (lat. für »Stößel«) genannt. ${ }^{227} \mathrm{Im}$ 18. Jahrhundert aber wirken ganz andere Prinzipien. Es geht um Kontinuität und Trennung, um Linearität und hierarchisierende Selektion. Das entspricht der gesellschaftlichen Umwälzung, der linearen Zeit als Sphäre (früh-)kapitalistischen Produzierens, in der die Körper ihre zuvor jeweils fest gefügte `Natur verlieren, was einerseits zu einer >physischen Egalisierung bei sozialer Ungleichheit führt, andererseits auch zu neuer physischer Ungleichheit, den nun biologisch fundierten und normierten Geschlechtern. Der weibliche Körper wird seit dem Ende des 18. Jahrhunderts nicht mehr - wie in der vormaligen Ein-Körper-Theorie - als unvollkommene Variante, als Negativ des männlichen betrachtet. Von nun an existieren zwei unabhängige und jeweils komplette Körper. Ist zuvor der weibliche Körper Zeichen sozialer Inferiorität, so ist die soziale Inferiorität nun Zeichen der biologischen.

Foucault beobachtet fürs 18./19. Jahrhundert zwei wesentliche Transformationen: die der Herrschaft und die der Symbolik. Die Transformation der Herrschaft über den Tod in die über das Leben beschreibt er anhand der »politischen Technologie des Lebens«, der Verknüpfung der Disziplinierungstechniken des Körpers mit den Verfahren der Regulierung im Sinne von Arterhaltung, Nachkommenschaft und kollektiver Gesundheit: »Der Sex eröffnet den Zugang sowohl zum Leben des Körpers wie zum Leben der Gattung. Er dient als Matrix der Disziplinen

226 Schiebinger, Londa: Am Busen der Natur, S. 26f.

227 Vgl. ebda., S. 36. 
und als Prinzip der Regulierungen. « ${ }^{228}$ Die Transformation der Symbolik ist die »von einer Symbolik des Blutes zu einer Analytik der Sexualität «. ${ }^{229}$ Das Blut als Symbol der Zugehörigkeit, Verwandtschaft, aber auch der Macht.

»Sein Wert liegt in seiner instrumentellen Rolle (Blut vergießen können), in seinem Funktionieren innerhalb der Ordnung der Zeichen (ein bestimmtes Blut haben, vom selben Blut sein, bereitwillig sein Blut wagen) und auch in seiner Gefährdetheit (es ist leicht zu vergießen, und droht zu versiegen, es vermischt sich nur allzu leicht und verdirbt im $\mathrm{Nu}$ ). Gesellschaft des Blutes oder richtiger des >Geblütes $<$ : im Ruhm des Krieges und in der Angst vor dem Hunger, im Triumph des Todes, in der Souveränität des Schwertes, der Scharfrichter und der Martern spricht die Macht durch das Blut hindurch, das eine Realität mit Symbolfunktion ist. Wir hingegen leben in einer Gesellschaft des \Sexes vielmehr der `Sexualität $`$ die Mechanismen der Macht zielen auf den Körper, auf das Leben und seine Expansion, auf die Erhaltung, Ertüchtigung, Ermächtigung oder Nutzbarmachung der ganzen Art ab. Wenn es um Gesundheit, Fortpflanzung, Rasse, Zukunft der Art, Lebenskraft des Gesellschaftskörpers geht, spricht die Macht von der Sexualität und $z u$ der Sexualität, die nicht Mal oder Symbol ist sondern Gegenstand und Zielscheibe. ${ }^{230}$

Wobei das Dispositiv der Blutsymbolik gerade in Deutschland durchaus noch erhalten bleibt. ${ }^{231}$ Aber der grundlegende Wandel lässt sich beobachten, so im deutschen Begriff des 〉Geschlechts`, der ja zunächst die Bezeichnung der Genealogie, des >Geblüts〈 ist und seit dem 18. Jahrhundert die Mann-Frau-Polarität benennt.

Der schwedische Naturforscher Carl von Linné schafft mit seiner 1735 erschienenen und kontinuierlich erweiterten Abhandlung »Systema naturae« die Basis der modernen biologischen Systematik. Grundlage der von ihm eingeführten und größtenteils bis heute gültigen binären Nomenklatur bei der Einteilung der Arten sind die von ihm rentdeckten »Geschlechtsorgane« der Pflanzen. Linnés Klassifikation erfolgt nicht so sehr aufgrund natürlicher Gegebenheiten, sondern viel mehr mittels der Projektion patriarchaler Sexualvorstellungen, indem er »aktive«

228 Foucault, Michel: Der Wille zum Wissen. Sexualität und Wahrheit 1. Frankfurt/M: Suhrkamp 1988 Paris 1976), S. 173ff.

229 Ebda., S. 176.

230 Ebda., S. $175 f$.

231 Das zurückbleibende Wesen der Ideologie zeigt sich am Beispiel des >Blutes« nicht nur in seiner Symbolik im Faschismus (oder vorher in der nationalistischen deutschen Heimatbewegung), in der $>$ Verwurzelung in der Scholle`, im 〉Blut und Boden`, der 〉Blut- und Rassereinheit`. Vgl. dazu immer noch Reich: Die Massenpsychologie des Faschismus, S. 90ff. 
»Staubblätter« (Penis), und »passive«, oft mit erhöhtem »Schamgefühl« ausgestattete Narben (Vulva), Stempel oder Fruchtblätter (Vagina) zugrundelegt. Die Staubfäden entsprechen so den Samenleitern, die Staubbeutel den Hoden, das Sperma sei der reife Blütenstaub. Dementsprechend erscheint das Röhrchen im Stempel als Eileiter, die Fruchthülle als befruchteter Eierstock. ${ }^{232}$

»In der Tat basiert sein berühmter `Schlüssel zum Sexualsystem` auf den nuptiae plantarum (der Vermählung der Pflanzen), also auf ihrem Liebesbund und nicht auf ihrem Dimorphismus. Linné war der Ansicht, die Pflanzen hätten im vollen Wortsinn - Geschlechtsverkehr. Für ihn hatte die Sexualität der Pflanzen etwas Romantisches, Erotisches, mal war sie gesetzwidrig und mal geheiligter Ausdruck der ehelichen Liebe. ${ }^{233}$

Und Sexualisierung impliziert einen geregelten Ablauf, nämlich strikte Heterosexualisierung, Ehelichkeit und Hierarchisierung: Im Linnéschen System entscheiden die >männlichen Teile` der Pflanzen über die Zugehörigkeit zur in der Taxonomie übergeordneten Kategorie, der »Klasse«, die >weiblichen Teile über die Zugehörigkeit zur untergeordneten Kategorie, der »Ordnung«. »Eine empirische Rechtfertigung« gibt es nach Schiebinger dafür nicht. Aber eben eine des sozialen Geschlechts. ${ }^{234}$ So erhalten die »Klassen« Namen, die auf der griechischen Bezeichnung Ehemann - »aner« - basieren und somit auf »andria« enden. Die »Ordnungen« enden auf »gynaia«, nach der griechischen Bezeichnung für Ehefrau - »gyne«. Und so ist bei Linné (und anderen) permanent von >geschmückten Brautbetten de. $^{235}$ Das Sexualleben der Pflanzen ist hier nahezu exklusiv an die 〉Ehe gebunden. Die »Hauptgruppen der Pflanzenwelt unterscheiden sich nämlich durch die Formen der Eheschließung - etwa dadurch, ob die Ehe >öffentlich` (bei den Publicae) oder heimlich (bei den Clandestinae) geschlossen wird «. Dass dies so ist, führt Schiebinger auf die Entwicklung des realen Eherechts zurück. Bis Mitte des 18. Jahrhunderts sei die klandestine Ehe in Europa durchaus noch üblich gewesen und in England erst 1753 per Gesetz abgeschafft worden. Zugleich reflektieren die >Liebesheiraten` der Pflanzen offenbar die diesbezügliche reale Entwicklung innerhalb der Oberschichten der Zeit. ${ }^{236}$

232 Schiebinger, a.a.O., S. 38.

233 Ebda., S. 42.

234 Vgl. ebda., S. 34.

235 Vgl. ebda., S. 42.

236 Vgl. ebda., S. 45. 
Allerdings gibt es nur eine Pflanzenklasse, die >monogam lebt‘, die der »monandria«. Diese »haben nur ein Staubblatt (bzw. einen Ehemann) auf einer hermaphroditischen Blüte«. Alle anderen Klassen leben in »Ehen mit zwei, drei, zwanzig oder mehr `Ehemännern〈, die das Ehebett (das heißt die Blütenblätter derselben Blüte) mit einer einzigen Ehefrau teilen«, oder bei den "polygamia« leben die >Männer« mit »ihrer Frau und mehreren Huren (später Konkubinen genannt)«. Das und die meist >freizügigen< Schilderungen des pflanzlichen Geschlechtsverkehrs lassen sich, so Schiebinger, ebenfalls als Reflex »auf die Lockerung der traditionellen sozialen Kontrollen « lesen, in denen »[d]ieselben sozialen Kräfte«, die auch die neue Neigungsehe begünstigt hätten, ebenso die »Entstehung des pornographischen Romans samt seiner [...] besonderen Nähe zur mechanistischen Naturphilosophie« begünstigt hätten. ${ }^{237}$

Mit den »monadria« ist ein weiteres Problem der >Pflanzensexualitätく angesprochen: es gibt >Hermaphroditen<. »Der Hermaphroditismus existiert nur im Mythos. Verwirklicht in einem Wesen aus Fleisch und Blut oder aus Faser und Saft, ist er eine Monstrosität, denn er beschwört die Vorstellung einer doppelten Impotenz herauf. ${ }^{238}$ Der Hermaphroditismus, bei dem die Pflanzen >männliche gane < besitzen, betrifft die überwiegende Zahl der Blütenpflanzen. Ein drittes Geschlecht, Zwitterwesen, widerspricht jedoch eigentlich der binären Logik, schon gar der Konstruktion zweier klar voneinander abgegrenzten Geschlechter in der menschlichen Gesellschaft. „So begeistert sich die damaligen Botaniker den Sexualdimorphismus zu eigen machten, so schwer taten sie sich mit der Vorstellung von hermaphroditischen«, manchmal auch >androgyn genannten Pflanzen. ${ }^{239}$ Aber, wenn die Vorstellungen der pflanzlichen Fortpflanzung aus der tierischen abgeleitet werden, dann gibt es Lösungen. Zum einen hat Swammerdam mit seinen Berichten »über die Liebesbeziehungen der Schnecken« Hermaphroditismus unter niederen Tieren gezeigt. Zum anderen erklärt sich die weit überwiegende pflanzliche Androgynie gegenüber der weit überwiegenden tierischen »Unisexualität« mittels des Verweises auf Mobilität und Immobilität. Da Pflanzen unbeweglich an einen Standtort gebunden sind, ist der Hermaphroditismus notwendiger Ausgleich, denn »auf diese Weise können sie ohne die Nähe anderer Pflanzen zeugen «, wie 1793 Christian Konrad Sprengel »Das entdeckte Geheimnis der Natur im Bau und in der Befruchtung der Blumen « kundtut. Zumal ja die `Sexualorgane $<$ zu einem ordnungsgemäßen heterosexuellen Paar perso-

237 Ebda., S. 46.

238 Delaporte, a.a.O., S. 89.

239 Vgl. Schiebinger, a.a.O., S. 40f. 
nifiziert werden, mit dem Blütenkelch als Hochzeitsbett. ${ }^{240}$ Daraus entsteht jedoch ein neues Problem: wie sind dann - die ebenfalls unbeweglichen - >eingeschlechtlichen〈Pflanzen zu erklären und wie der 〉Geschlechtsverkehr` zweier Bäume über mehrere Meilen hinweg? Auch die Befruchtung über Wind und Insekten als Fernverkehr bringt nur ein weiteres Problem: das der Unordnung. Muss es nicht permanent zu Hybriden kommen, zu Befruchtungen von Nussbäumen mit dem Samen von Eichen etwa? Also müssen die weiblichen `Sexualorgane mit den männlichen entwickelt und reif sein, um den passenden Samen aufzunehmen. Trotzdem aber werden Hybriden beobachtet, etwa verschiedenfarbiger Mais. Dieser »Verstoß gegen die Endogamieregel« wird jedoch zum »unzweideutig[en]« Beweis der 〉Sexualität . »Die Zwiegeschlechtlichkeit garantiert« demnach »die legitimen Vereinigungen, während die Eingeschlechtlichkeit die illegitimen Vereinigungen zu begünstigen scheint «. ${ }^{241}$

Neben den »Sexualisten" gibt es in dieser Zeit auch die »Agamisten«, jene Botaniker, die sich für das Modell der >viviparen` anstatt der >oviparen Fortpflanzung entscheiden. Was also dem Sexualismus als vegetabile Geschlechtsorgane erscheint, wird im Agamismus zu Verdauungsorganen erklärt. ${ }^{242}$ Der Durchsetzung des Sexualismus aber stehen sie nicht im Weg.

Im 18. Jahrhundert ist die geforderte Voraussetzung jeder $>$ Naturgeschichte , eine »Kontinuität der Natur« nachzuweisen, in ihr eine »Ordnung zu errichten «, die verallgemeinerbaren Kategorien gehorcht. ${ }^{243}$ Ohne Kategorien gibt es kein Gesetz, bzw. ohne Gesetz keine Kategorien, die wiederum die Existenz des Gesetzes, der errichteten Ordnung anzeigen. Dabei kommt es nicht so sehr darauf an, ob diese Kategorien »real und von manifesten Trennungen vorgeschrieben oder bequem und ganz einfach durch unsere Vorstellungen abgetrennt « sind. "Allein das Kontinuierliche kann garantieren, daß die Natur sich wiederholt und daß die Struktur infolgedessen zum Merkmal werden kann. ${ }^{244}$ Linnés Nomenklatur ist die des »Systematiker[s]«, das heißt, die Kontinuität besteht hier

»nur aus der sprunglosen Nebeneinanderstellung der verschiedenen Gebiete, deren klare Trennung die Merkmale gestatten. Es bedarf nur einer ununterbro-

240 Vgl. Delaporte, a.a.O., S. 88f.

241 Ebda., S. $91 \mathrm{f}$.

242 Vgl. ebda., S. $103 \mathrm{ff}$.

243 Vgl. Foucault: Die Ordnung der Dinge, S. 191.

244 Ebda., S. $191 f$. 
chenen Abstufung der Werte, die im ganzen Gebiet der Arten die als Merkmal gewählte Struktur annehmen kann. Geht man von diesem Prinzip aus, wird sich herausstellen, daß alle diese Werte mit wirklichen Wesen besetzt sind, sogar, wenn man sie noch nicht kennt. >Das System zeigt die Pflanzen an, sogar die, die es nicht erwähnt hat; die Aufzählung eines Katalogs kann dies niemals $\operatorname{tun} \ll{ }^{245}$

Die Natur wird zur »ununterbrochenen Fläche«, auf der die Kategorien bei unaufhörlicher »Nebeneinanderstellung« keine bloß »arbiträre[n] Übereinkommen« sind: einmal bestimmt, treten sie in eine Korrespondenz mit den auf dieser kontinuierlichen Natur-Fläche getrennt existierenden Gebieten. Im System der Flächen werden die Kategorien so zur Realität, »wie die Einzelwesen« auch, nur ausgedehnter. Mit dem Sexualsystem, betont Linné, seien zweifelsfrei die Gattungen entdeckt. Und es seien die Gattungen, die die Merkmale bestimmen und nicht umgekehrt. ${ }^{246}$ Demgegenüber stehen die vom Comte de Buffon und Charles Bonnet vertretenen Methoden, »für die die Ähnlichkeiten in ihrer evidenten und massiven Form als erste gegeben sind«. Hier erscheint die Natur-Kontinuität nicht als bloß »negative[s] Postulat« einer Exklusion von »weißen Flecken zwischen den getrennten Kategorien«, sondern als positives. Gefordert ist vielmehr eine Natur als »großes Gewebe, in dem die Wesen sich vom einen zum andern ähneln, in dem die benachbarten Einzelwesen untereinander unendlich ähnlich sind«. Was größere Einheiten jenseits der nuancierten Differenzen der Einzelwesen, also Kategorien zu irrealen erklärt. »Es handelt sich um eine verschmolzene Kontinuität, in der jede Allgemeinheit rein nominal ist.« Für Buffon sind die allgemeinen nur aus spezifischen Begriffen zusammengefügt und beziehen sich auf eine unendliche »Kette von Dingen«, bei der eigentlich nur die »mittleren Glieder« sichtbar würden, die extremen Punkte aber kontinuierlich »unsichtbar«. Je größer die Anzahl bekannter Natur-Dinge werde, »desto näher kommt man der Wahrheit«, weil nur die Einzeldinge real existierten und Klassen und Ordnungen pure Imagination seien. Bei Bonnet gibt es ebenfalls »keine Sprünge in der Natur«, hier sei alles »abgestuft und schattiert«, und damit sind stets »mittlere Geschöpfe« zu entdecken, so »den Polypen zwischen den Pflanzen und dem Tier, das fliegende Eichhörnchen zwischen dem Vogel und den Vierfüßler, den Affen zwischen dem Vierfüßler und dem Menschen«. Kategorien seien

245 Ebda., S. 190. Binnenzitat: Linné: Philosophie botanique, § 156.

246 Vgl. ebda., S. $190 f$. 
rein nominal und nur Hilfskonstruktion begrenzter menschlicher Erkenntnismöglichkeiten. ${ }^{247}$

Die Notwendigkeit einer neuen Klassifikation entspringt im 17. Jahrhundert nicht nur der sukzessiven Abkehr der wissenschaftlichen Botanik von ihrer Verbindung mit der praktischen Medizin und der vormaligen Ordnung der Pflanzen nach ihrem Gebrauch und Nutzen, sondern vor allem dem Kolonialismus und der >Entdeckungsreisen`, die eine Vervierfachung der Anzahl bekannter Pflanzen zwischen 1550 und 1700 mit sich bringt. Es folgt eine »Epidemie« von Taxonomien und Klassifikationssystemen, die größtenteils kontrovers angelegt sind. 52 solcher Systeme zählt 1799 Robert Thornton in seiner populärwissenschaftlichen Ausgabe von Linnés »Systema naturae «. ${ }^{248}$ Hierin steckt in gewisser Weise auch ein Dilemma der Wissenschaftler. Je weiter und genauer das »Kontinuum der Einzelwesen« und die jeweiligen Kategorien erforscht und beschrieben würden, desto größer wäre ihre Verankerung im Allgemeinen. »Die Identitäten der Natur würden sich gleichsam in allen Buchstaben der Vorstellungskraft anbieten, und das spontane Gleiten der Wörter in ihrem rhetorischen Raum würde in vollen Linien die Identität der Wesen in ihrer wachsenden Allgemeinheit reproduzieren. Die Naturgeschichte würde unnütz, oder vielmehr wäre sie bereits durch die Alltagssprache der Menschen gebildet.« Der postulierten Unerlässlichkeit der Naturgeschichte kommt aber ein Umstand zur Hilfe: Das Kontinuum der Natur stellt sich immer wieder als »zerstückelt«, mit klaffenden Lücken versehen, als verwirrt, verwirrend, ungeordnet dar. ${ }^{249}$ So bleibt dann die Natur doch

»eine konfuse Mischung aus Wesen [...], die der Zufall einander angenähert zu haben scheint. Hier wird das Gold mit einem anderen Metall, mit einem Stein oder mit Erde gemischt. Dort wächst die Eiche neben dem Veilchen. Unter diesen Pflanzen irren ebenfalls der Vierfüßer, das Reptil und das Insekt umher. Die Fische mischen sich sozusagen mit dem wässrigen Element, in dem sie schwimmen, und mit den Pflanzen, die auf dem Grunde der Gewässer wachsen«,

notiert Michel Adanson. Aber, diese Konfusion dient nichtsdestotrotz der Begründung der Naturgeschichte, denn: »Diese Mischung ist sogar

247 Vgl. ebda.

248 Vgl. Schiebinger, a.a.O., S. $29 \mathrm{ff}$.

249 Vgl. Foucault, a.a.O., S. 192. 
so allgemein und so vielfältig, daß sie eines der Naturgesetze zu sein scheint. $\ll^{250}$

Der »implizite Rückgriff auf das (soziale) Geschlecht zur Strukturierung der botanischen Taxonomie und der explizite Rückgriff auf sexuelle Metaphern zur Durchsetzung bestimmter Vorstellung von der pflanzlichen Reproduktion $\aleph^{251}$ beginnt nicht mit Linné, sondern bereits Ende des 17. Jahrhunderts. In Frankreich streiten sich Claude Geoffroy und Sébastien Vaillant um die Urheberschaft. Der Brite Nehemia Grew wird als gesicherter `Entdecker` des männlichen Genitals im Staubblatt (das in der älteren Botanik noch als nutzlos gilt) genannt. In seiner »Anatomy of Plants« (1682) befindet er, der »Halm (oder das Staubblatt) hat allerhand Ähnlichkeit mit einem kleinen Penis und die Hülle am oberen Ende mit dem praeputium [der Vorhaut]《. Und »sobald der Penis erigiert ist«, tritt das »Sperma der Vegetabilien« aus und fällt »herab auf die Fruchthülle oder Gebärmutter und berührt sie mit seiner Zeugungskraft«. Die Definition bestimmter Pflanzenteile als >männlich oder >weiblich 〈 durch die Botaniker erfolgt dabei, »ohne recht eigentlich den Grund zu wissen«, wie Geoffroy einräumt. Diese Vorstellungen werden allerdings regelmäßig »aus der Kenntnis der Tiere « abgeleitet. ${ }^{252}$ Selbiges trifft auf die Analogisierung von Pflanzenernährung - »Saftkreislauf « - und Blutkreislauf in der mechanistischen Botanik (und Philosophie) zu. ${ }^{253}$

In der Botanik aber lässt sich ein Idealfeld realisieren, indem sowohl die neuzeitlich geforderte $»$ Leibfreiheit der Naturerkenntnis $«,{ }^{254}$ die wissenschaftliche Distanzierung vom (eigenen) Körper, als auch die hierarchisierende Sexualisierung der menschlichen Körper stattfindet. »Seit dem XVIII. Jahrhundert hat man festgestellt, daß es eine Affinität zwischen dem Studium der Botanik und der Religion gab«. Botaniker würden »freiwillig die moralische Zensur akzeptieren, welche die freie Befriedigung der Begierden betrifft. Eine Haltung, die mit frömmelnden Empfindungen nicht unvereinbar ist. Und das Pflanzensammeln ist die Vorzugstätigkeit, wenn nicht gar -unterhaltung der Puritaner«. ${ }^{255}$ Und, diese Beschäftigung mit Pflanzen ist in Maßen auch für Damen geeignet. ${ }^{256}$ Der Abscheu hingegen,

250 Adanson, Michel: Cours d'histoire naturelle fait en 1772; zit. n. ebda., S. $192 \mathrm{f}$.

251 Schiebinger, a.a.O., S. 28.

252 Vgl. ebda., S. $37 \mathrm{ff}$.

253 Vgl. Delaporte, a.a.O., S. 10f. Vgl. Kap. Die Logik der Maschine.

254 Kutschmann, Werner: Der Naturwissenschaftler und sein Körper, S. 193.

255 Delaporte, a.a.O., S. 121.

256 Vgl. Schiebinger, a.a.O., S. 51. 
»den man angesichts der Tiere empfindet, [bringt] nur den Ekel zum Ausdruck, den die fleischliche Liebe erweckt. Wer auch immer sich für das Tier interessiert, wird der Sodomie verdächtigt. Die Verfolgung, der Kampf oder die kämpferische Begegnung, sind Beschäftigungen, die nur Rohlingen anstehen. Die sensiblen Seelen sind ebenfalls von der kleinen Welt der Insekten angewidert. Muß man sie nicht aufspießen? Im übrigen nimmt das Studium der Tiere mit der Anatomie eine wahrhaft abstoßende Wende. >Welch eine entsetzliche Einrichtung, ein anatomisches Amphitheater, stinkende Kadaver, eitriges und bleiches Fleisch, Blut, widerliche Eingeweide, entsetzliche Skelette, verpestete Dämpfe? [...] Kein Zweifel, daß die Sektion den Beobachter in eine zweideutige Lage versetzt: die Öffnung, der Einbruch. Kurz, das Tier ist dem Menschen viel zu nahe ${ }^{257}$

Aber auch Minerale sollen ähnliche Phantasien auslösen, müsse man doch, um sie zu studieren, zuerst »die Eingeweide der Erde durchwühlen« und sie »herausreißen«. Desgleichen sei die Beschäftigung mit pharmakologischen Ideen zu vermeiden, da diese an mögliche Drogenbestandteile der Pflanzen erinnere. »Kurz, alles was an den Körper und seine Bedürfnisse erinnert, ist Gegenstand der Unterjochung." Wobei »die Botanik wie ein Heilsweg erscheint«. Erfülle doch »die Beobachtung der Flora die Forderungen einer repressiven Verdrängung: benennen, klassifizieren, statt träumen! « ${ }^{258}$ Dieser »Puritanismus« steht nicht im Widerspruch zur Sexualisierung der Pflanzen. Diese erscheint als legitime bürgerliche Vereinigung und gar als »fromme[s] Bild«, in dem Gott Künstler ist »und die Botanik ein Zweig der Ästhetik. Von der Pflanze bis zum Menschen bewundert man die verschiedenen Fortpflanzungsweisen, die Geschicklichkeit des Schöpfers. Und die Vorstellung von einer hierarchisierten Reihe lebender Formen hat auf natürliche Weise ihren Platz im Rahmen der natürlichen Ökonomie«. Im Bild der Blüte verwandelt sich Natur in Kultur - wenn auch in höchst widersprüchlicher Weise. Bei Rousseau und anderen wird

»umgekehrt die Frau Blüte. Das heißt Geschlecht, und um ihr Wesen besser zu enthüllen, kleidet und schmückt sie sich. Daher die Negation des Unterschieds zwischen Nacktheit und dem verhüllten Körper. Aber die Freude ist nicht von Dauer, denn der Widerspruch zwischen Natur und Kultur ist bereits durch die Gleichsetzung der Blüte und der Frau wiederhergestellt. Letzten Endes wird der Unterschied verstärkt. Das Geschlecht ist dunkel und übelriechend. Die Blüte dagegen ist Duft und Schmuck [...]. Es [geht dann] darum, wie Rousseau oder Gleichen die Blüten mit weiblichen Gesichtern zu vergleichen. Die Blü-

257 Delaporte, a.a.O., S. $121 \mathrm{f}$.

258 Ebda., S. $122 \mathrm{f}$. 
ten bieten also >bezaubernde und graziöse Gestaltungen`. Daher sind umgekehrt die Gesichter Blüten, das heißt Geschlechter. Und der Schleier, der das Gesicht der Frau bedeckt, enthüllt ihr Wesen«. ${ }^{259}$

Zeitgenössisch werden auch in anatomischen Darstellungen Frauen als Blüten und Pflanzen veröffentlicht. Diese Art der Rückprojektion lässt aber auch eine andere zu. Der Sexualismus bleibt durchaus nicht unumstritten, wird meist aus empirischen Gründen attackiert, aber auch aus moralischen. So wird die Unschuld junger Mädchen gefährdet gesehen, etwa von Goethe. Erasmus Darwin, der als Freigeist und Liberaler gilt, veröffentlicht 1789 »Loves of the Plants«, allerdings zunächst ohne Anstoß zu erregen. "Anders als die Linnéschen halten sich die Darwinschen Pflanzen bei ihren Sexualbeziehungen keineswegs an die Grenzen der heiligen Ehe. Vielmehr leben sie jeden nur denkbaren heterosexuellen Liebesbund in aller Freizügigkeit aus. ${ }^{260}$ Aber infolge der französischen Revolution und des Wirkens Mary Wollstonecrafts werden Stimmen laut, die hinter Derartigem die Propaganda illegitimer Sexualbeziehungen, weiblicher Gleichberechtigung und Demokratie wähnen. Im Umkehrschluss dichtet so der Reverend Richard Polwhele u.a. Verse über Wollstonecrafts >schändliches Leben` und bezeichnet sie darin als »Venusbusch«, aus dessen Augen »gift'ge Wollust» schieße. Der Titel seines Gedichts über »die Amazonenhorde« lautet »The Unsex'd Females «. ${ }^{261}$ Hier geht es also zurück in den 〉Sumpf «.

Die Vegetation scheint mit ihrer taxonomischen Sexualisierung grundsätzlich dem Chaos entrissen und einer geregelten patriarchalen Ordnung überantwortet. Das trifft damit auch zu auf die Erle und die Weide, die - ehedem »Unsex'd Female« - nun als >zweihäusig` erkannt, also nicht einmal hermaphroditisch ist. Forstwirtschaftlich und -wissenschaftlich bleibt vor allem die Salweide zusammen mit anderen »Weichlaubhölzern« wie Birke, Eberesche, Espe, Faulbaum, verschrieen und wird in den Forstanleitungen des ausgehenden 18. Jahrhunderts als 〉Forstunkraut« »forstliches Unkraut« und »Schanddeckel der Forstbediensteten« zur Verfolgung ausgeschrieben. Daran hat sich grundsätzlich bis heute nichts geändert. $^{262}$

259 Ebda., S. 124f.

260 Schiebinger, a.a.O., S. 53f.

261 Ebda., S. 58f.

262 Vgl. Leder, Bertram: Bisherige Beurteilung und Definition des Begriffs »Weichlaubhölzer«, in: LÖBF (Hg.): Weichlaubhölzer und Sukzessionsdynamik in der naturnahen Waldwirtschaft. Möglichkeiten, Erfahrungen, Grenzen. Schriftenreihe der Landesanstalt für Ökologie, Bodenordnung 
Allerdings lässt sich die Fähigkeit der Weiden zur vegetativen, zur ehedem >zügel- und regellosen`Vermehrung ohne einen männlich besetzten Akt der >Begattungく, in eine Regelhaftigkeit versetzen. Weiden bilden, wie mehrfach angesprochen, natürliche Klone, wie Erlen bilden sie auch >Wurzelbrut<; und sie bilden Hybride. In einer Genealogie allerdings, die sich spezifisch von einer geregelten unterscheidet.

»Die Fähigkeit zur Bastardisierung scheint ein Familienmerkmal zu sein, denn Weide wie Pappel verfügen über einen unstillbaren Drang, neue Merkmalskombinationen zu schaffen. Deshalb werden für die genaue Bestimmung u.a. chemische und genetische Merkmale (Chromosomenzahl) herangezogen. Weil Weidenhybriden dabei außerdem [...] fortpflanzungsfähige Nachkommen erzeugen können, ist die Abgrenzung einzelner Arten teilweise unmöglich «. ${ }^{263}$

>Hermaphroditen` sind sie nicht, sondern, dank des Linnéschen Systems >zweihäusig`. Aber, diese einzelnen `Geschlechter` pflanzen sich selbsttätig, >asexuell« fort. Dabei entsteht eine unkontrollierbare »Produktion an Biomasse ${ }^{264}$ bei der sich genetisch gleiche >Tochterpflanzen` oftmals >chaotisch` durch ältere Gehölze winden. Und selbst die >geschlechtliche< Fortpflanzung durch Bestäubung und Aussaat führt zu oft unklassifizierbaren Bastarden.

»Klon« stammt aus dem Griechischen und bezeichnet den 〉Schößling` oder `Zweig`, das Material zur Produktion genetisch identischer Nachkommenschaft. Es ist eine traditionelle gärtnerische Tätigkeit, die vegetative Vermehrung nutzbar zu machen. Stecklinge werden geschnitten und kontrolliert bewurzelt. Der Prozess, der als »natürlicher`, das heißt, ungeregelter, genauer: zufällig stattfindender Ablauf womöglich >unheimlich erscheint, ist nun ansatzweise usurpiert, ins Geregelte überführt, in die Hände des >Gärtners`. Aber, noch soll gerade die Stecklingskultur die Vermutung der Unfruchtbarkeit von Weiden bestätigen, weil die nur >männliche` Stecklinge verwandt worden seien. Es braucht also die wissenschaftliche Entdeckung der Fruchtbarkeit. Mit Linnés System der Geschlechtlichkeit der Pflanzen geschieht das.

und Forsten/Landesamt für Agrarordnung Nordrhein-Westfalen Bd. 4. 1995, S. 9f.

263 Laudert, Doris: Mythos Baum, S. 204.

264 Ebda. 


\section{Böse Ausdünstungen aus dem Leib der Erde}

Jahrhunderte lang gehört die Miasmen-Theorie zum festen Repertoire der Naturwissenschaften. Sie trägt nicht wenig zur Einführung der Schwemmkanalisationen bei. Der europaweit als Koryphäe geltende Hygieniker und Verfechter der Bodentheorie Max von Pettenkofer kritisiert vehement die Wasserversorgung Münchens: Seit sieben Jahrhunderten sei der »Untergrund der Stadt« regelrecht »durch die Exkremente von Menschen und Thieren sowie durch Abfälle von Haushaltungen und Schlachthäusern durchseucht«, was zu einer ständigen Verschlechterung des Wassers in den Stadtbrunnen führen müsse. ${ }^{265}$ Als sich 1872 Pettenkofers Warnungen mit der großen Choleraepidemie zu bestätigen scheinen, wird die »einheitliche Wasserversorgung« eingeführt, was auch in anderen Kommunen Nachahmung findet. Pettenkofers »»bodentheoretische< Leitsätze werden von den Stadtvätern bedenkenlos übernommen - mit schlimmen Folgen $\ll .{ }^{266}$

Zumindest in Deutschland wird diese Boden-Theorie erst am Ende des 19. Jahrhunderts widerlegt werden, und zwar im Disput um den Auslöser der großen Cholera-Epidemie in Hamburg im August 1892. Hier kann sich schließlich der Bakteriologe Robert Koch mit seiner Trinkwasser-Theorie gegen Pettenkofer durchsetzen. Koch fällt auf, dass die Cholera in allen Stadtteilen zugleich und in großer Anzahl aufgetreten war, überall dort, »wo in Hamburg Leitungswasser getrunken wurde, das man - trotz jahrelanger Proteste - noch immer - ohne ausreichende Reinigung einfach der Elbe entnahm «. ${ }^{267} 1895$ gelingt der endgültige Beweis der Trinkwasser-Theorie mit dem mikroskopischen Nachweis der Erreger im Trinkwasser und der Entwicklung eines spezifischen Serums gegen die Cholera. ${ }^{268}$

Alain Corbin schildert die Flut von >Miasmen`, die im 18./19. Jahrhundert aus Fäkaliengruben, geöffneten Gräbern, Sickergruben, dem Brackwasser der Häfen etc. entsteigen. Die Boden-Theorie bezieht sich aber keineswegs ausschließlich auf in den Boden gelangte organische Abfälle in großen menschlichen Ansiedlungen. Die Luft ist gefährlich. Denn sie nimmt »jene Substanzen« auf, die sich »von den Körpern lösen«. Ein gigantischer Behälter sei die Atmosphäre, Speicher der »Ausdünstungen der Erde«, desgleichen der

265 Zit. n. Kluge, Thomas/Schramm, Engelbert: Wassernöte. Umwelt- und Sozialgeschichte des Trinkwassers. Aachen: Alano 1986, S. 105.

266 Kluge/Schramm, ebda.

267 Ebda., S. 112.

268 Vgl. ebda., S. 113. 
"pflanzlichen und tierischen Absonderungen. Die Luft ist eine bedrohliche Brühe, in der sich alles mischt: Rauch, Schwefel, wasserhaltige, flüchtige, ölige und salzige Dämpfe, die von der Erde aufsteigen, ja gegebenenfalls auch die feurigen Materien, die unser Boden ausspuckt, die aus den Sümpfen kommenden Dünste sowie winzige Insekten, deren Eier, allerhand Aufgußtierchen und, schlimmer noch, die ansteckenden Miasmen der verwesenden Körper «. ${ }^{269}$

Corbin hebt die »wesentliche Rolle« des Geruchssinns unter den sich verändernden sozialen Bedingungen der frühen Neuzeit bei der »Erforschung der Fäulnisprozesse« hervor. Allerdings werde schon im 5. bzw. 4. Jahrhundert v.u.Z. von der Hippokrates-Schule betont, »welch starken Einfluß Luft und Gegend auf die Entwicklung der Leibesfrucht, das Temperament, die Wollust, die Sprache und das Wesen der Völker ausüben «. ${ }^{270}$ Im 16. Jahrhundert beschäftige sich Francis Bacon ansatzweise mit der Thematik, eigentlicher »Vater der Fäulnistheorie« sei jedoch Johann Joachim Becher, der Fäulnis als permanente »Bewegung in den Gedärmen« definiert. Diese Bewegung liege im dauernden Kampf mit dem vom »balsamische[n] Geist des Blutes« betriebenen »elementare[n] Feuer«. Der »widerwärtige penetrante Geruch faulender Körper« entstammt in dieser mechanistischen Sicht »der Mobilität der von ihren Fesseln befreiten Moleküle«, womit der Gestank »integraler Bestandteil des Prozesses selbst« ist und nicht lediglich Zeichen von Fäulnis. »Gestank und Feuchtigkeit definieren den Zerfall. Die wässrigen Teile der organischen Materie verwandeln sich in Jauche und Eiter, die flüchtigen Teile entweichen in Form übelriechender Moleküle. Was bleibt, ist Erde.« Erst die Zerstörung des Kräftegleichgewichts in den Eingeweiden, die Stockung des balsamisch durchgeistigten Blutflusses bewirkt die Katastrophe. ${ }^{271}$ Die Miasmentheorie entstammt dem alten Glauben »an die Gefahren der Erdausdünstungen«, die besonders die »wissenschaftliche Auseinandersetzung in der ersten Hälfte des 18. Jahrhunderts beeinflußt hat $\ll .{ }^{272}$ Danach ist es ein »zentrales Feuer ${ }^{273}$ das die - weiblich gedachte - Erde einer ständigen Gärung und Fäulnis aussetzt, die zu schädlichen Ausdünstungen führt. Die Erde und ihr Mittelpunkt als Ort der Hölle:

269 Corbin, Alain: Pesthauch und Blütenduft. Eine Geschichte des Geruchs. Berlin: Wagenbach 1984 (Paris 1982), S. 23.

270 Ebda., S. 24.

271 Vgl. ebda., S. 28f.

272 Ebda., S. 35.

273 Abbé du Bois; zit. n. Corbin, ebda. 
»Jacques Guillerme weist darauf hin, daß die Fäulnis häufig - etwa bei Schlegel - in die Nähe des Teuflischen gerückt wird. Unterstützt wird dieser Gedanke durch die immer wieder betonte Korrelation zwischen dem Gestank und den Abgründen der Hölle; von Milton bis Cowper Powys haben sämtliche Autoren, die sich in einer Beschreibung der Gehenna versucht haben, diesen Aspekt hervorgehoben. $\ll^{274}$

In Dantes achtem Höllenkreis werden die »Schmeichler« in einen Brei, »den die Kloaken schienen herzuschicken«, in Kot also getaucht. ${ }^{275}$ Überhaupt scheint »ekelerregender Gestank«, wie ihn etwa Honorius von Autun im 12. Jahrhundert zu den neuen klassifizierten Höllenstrafen zählt, ${ }^{276}$ obligatorisch für diese zu sein.

Ein besondere Rolle könnte den >Unorten` zukommen. Wälder aus Erlen und Weiden, die frühneuzeitlich in Verdacht stehen, Wohnungen des Teufels und seiner Buhlschaft, den Hexen zu sein, und Morast können nach den vormodernen Formen der Ähnlichkeit zu »Signaturen« dessen werden, was in der »Tiefe der Welt« unsichtbar vor sich geht. Auch zu Beginn des 19. Jahrhunderts treten unsichtbare Gefahren aus, auch wenn das nun wissenschaftlich gewendet daherkommt. Auch hier sollen es explizit morastige Dämpfe sein, die als besonders gefährliche Träger tödlicher Miasmen gelten, wenn »eine unangebrachte Urbarmachung« von Wildnis, von »seit jeher unbebaute[m] Boden ${ }^{277}$ Gefahr bringt:

»Wie viele Kolonien in der Neuen Welt sind nicht schon die unglücklichen Opfer schrecklicher Fieber geworden, deren einzige Ursache in den todbringenden Ausdünstungen einer unberührten, schlammigen Erde liegt? « ${ }^{278}$

Der Leib der Erde dünstet Schreckliches aus. Immanuel Kants »Ende aller Dinge« liefert vier »ekelhafte Gleichnisse« für die Welt als Gesamtheit. Hier ist es nicht die Hölle, sondern die Erde, die mit Kot und Fäulnis angefüllt ist. Das Gleichnis von der »Welt als ein Kloak, wo aller Unrath aus andern Welten hingebannt worden« ist, stellt eine Reformulierung der Geschichte vom Sündenfall dar. Da, wo bei Augustinus die

274 Ebda., S. 34.

275 Vgl. Ravenna, Nino/Samek-Ludovici, Sergio: Göttliche Komödie. Nach einer Handschrift aus dem 15. Jahrhundert. Gütersloh u.a.: Bertelsmann 1979, S. 37.

276 Vgl. Minois, Georges: Die Hölle. Zur Geschichte einer Fiktion. München: Diederichs 1994 (Paris 1991), S. 241.

277 Corbin, a.a.O., S. 36.

278 Tourtelle, Etienne: Eléments d'hygiène. Paris 1815, Bd. 1., S. 278; zit. n. Corbin, ebda. 
Erfindung der Genitalien erfolgt, kommt es bei Kant zur Erfindung »der Ausscheidungsorgane und der Exkretion «. ${ }^{279}$ Das Paradies ist hiernach

»in den Himmel versetzt, in welchem Garten Bäume genug, mit herrlichen Früchten reichlich versehen, anzutreffen waren, deren Überschuß nach ihrem Genuß sich durch unmerkliche Ausdünstung verlor; einen einzigen Baum mitten im Garten ausgenommen, der zwar eine reizende, aber solche Frucht trug, die sich nicht ausschwitzen ließ. Da unsre ersten Eltern sich nun gelüsten ließen, ungeachtet des Verbots dennoch davon zu kosten: so war, damit sie den Himmel nicht beschmutzten, kein andrer Rath, als daß einer der Engel ihnen die Erde in weiter Ferne zeigte mit den Worten: >Das ist der Abtritt für das ganze Universum, « sie sodann dahinführte, um das Benöthigte zu verrichten, und darauf mit Hinterlassung derselben zum Himmel zurückflog. Davon sei nun das menschliche Geschlecht auf Erden entsprungen ${ }^{280}$

Kants Garten Eden ist, so Winfried Menninghaus, »der Ort des Genießens ohne >Abtrittı, der vermiedenen Exkremente, die Seligkeit [ist] die Spurlosigkeit des Stoffwechsels, die >unmerkliche< und quasi-pneumatische >Ausdünstung`, eine ideale, unsichtbare und nicht-riechende Transpiration«. Er vergleicht das mit Herders Äußerungen in dessen »Studien und Entwürfe zur Plastik«. Die darin entworfene »Physiologie der seligen Natur« verhalte sich zu Kants »Kloake der Erde«, wie »der idealschöne Statuenkörper, diese >Plastik [...] des Paradieses`, zu den unschönen Tiefen und Auswürfen des >wirklichen` Körpers«. So blieben dann auch selbst "am schönen Hohlkörper jene Zonen, die an der Körperoberfläche ins Körperinnere und aus ihm heraus führen: die Körperöffnungen« als nicht tilgbare bestehen, als »das eigentliche Skandalon der klassischen Ästhetik und Politik des Körpers. Sie sind zugleich das Signifikat des Ekels und bedürfen daher einer elaborierten Reglementierung. Was die Autoren über Mund, Nase, Ohren und Brustwarzen zu sagen haben, erweist sich als dieser schwierigen Aufgabe gewachsen. Von den unteren Körperöffnungen jedoch wird die Theorie selber >eckel (im Sinne von heikel) und beläßt es bei wenigen Andeutungen ${ }^{281}$

Die Geschichte der bösen Erdausdünstungen folgt dem alten Muster der »Erde als Lebewesen «. ${ }^{282}$ Dieses Lebewesen ist weiblich. Im 16./17. Jahrhundert wird die Natur noch als belebt wahrgenommen, »wobei die

279 Menninghaus, Winfried: Ekel, S. 86.

280 Kant: Das Ende aller Dinge, S. 331; zit. n. ebda.

281 Ebda., S. 86f..

282 Bredekamp, Horst; zit. n. Weigel, Sigrid: Topographien der Geschlechter, S. 127. 
Darstellung der Erde mit Hilfe der Leibmetaphorik eine Identifikation zwischen Mensch und Natur impliziert«. ${ }^{283}$

Nach Hans Peter Duerr >gestehen die »nachtfahrenden Weiber«, die Hexen in spätmittelalterlichen Verhörprotokollen häufig, an ekstatischen Zusammenkünften unter Führung >Dianas` teilgenommen zu haben. ${ }^{284}$ Versammlungsort ist der »Venusberg«. Duerr rekonstruiert diese >Diana zunächst als griechische Artemis, »die ungebundene Herrin der Vegetation «, ${ }^{285}$ deren Attribut »Parthenos« (Jungfrau) anfangs noch die Bedeutung einer freien, keinem Mann unterworfenen Frau habe, um hinter dieser Fruchtbarkeitsgöttinnen der letzten Steinzeit zu entdecken. ${ }^{286}$ So schildert er den Kult der »Heiligen Höhle« u.a. am Beispiel der Halbinsel Akrotiri, der Bärenhöhle der Artemis Kourotrophos. Es handele sich um eine Tropfsteinhöhle, »von deren Decke beständig ein leicht mineralhaltiges Wasser tropft ${ }^{287}$ und in deren Boden sich ein senkrechter schmaler Schlund öffne, durch den man in drei kleine Grotten herabrutschen könne. ${ }^{288}$ Die Erde als weiblicher Leib, ihr Mittelpunkt als Uterus. Ein Mythos, der sich hartnäckig hält, mögen seine Bedeutungen auch zu denen des Schreckens transformiert sein; eines Schreckens, der besonders mit den Öffnungen dieses Leibes zusammenhängt.

Frühneuzeitlich werden bevorzugt $»$ Veränderungen der Erdoberfläche, die Entstehung von Gebirgen, Flüssen, Vulkanen, auf Vorgänge im Innern der Erde zurückgeführt, welche im Bild von Schwangerschaft und Geburt beschrieben sind «. Das werde in den Naturbildern Leonardo da Vincis anschaulich. Im Rahmen der Naturgeschichte kommt es zur Feminisierung der Natur und Sexualisierung ihrer Vorgänge, wird die Geologie mit dem Blutkreislauf verglichen ${ }^{289}$ und damit unterirdische Flussläufe gleichgesetzt. Erzminen werden, beeinflusst vom mittelalterlich-arabischen »Picatrix«, einer Sammlung von magischen und astrologischen Texten mit Eingeweiden verglichen, Grotten und Höhlen mit dem Schoß »als Ort von Zeugungs-, Austragungs- und Geburtsvorgängen«. Die Hölle als Bauch der Erde werde damit vor allem seit dem 17. Jahrhundert zunehmend verdrängt. ${ }^{290}$

283 Weigel, ebda.

284 Vgl. Duerr, Hans Peter: Traumzeit, S. 25ff.

285 Ebda., S. 30.

$286 \mathrm{Vgl}$. ebda.

287 Ebda., S. 37.

288 Ebda.

289 Vgl. Weigel, a.a.O.

290 Vgl. Helas, Philine: Madensack und Mutterschoß. Zur Bildgeschichte des Bauches in der Renaissance, in: Benthien, Claudia/Wulf, Christoph (Hg.): Körperteile. Eine kulturelle Anatomie. Reinbek: Rowohlt 2001, S. 186. 
Die weibliche Personifizierung der Erde, die semantische Verschmelzung mit dem Bauch als Verkörperung von Fruchtbarkeit ist schon bei Hesiod (»Theogonie«, ca. 700 v.u.Z.) mit »der Figur der Gaia«, die »zuerst aus dem Chaos entsteht« und den Himmel und das Meer gebiert, zu beobachten. Philine Helas verweist auf die bis in die Neuzeit gültige Entsprechung von Mikro- und Makrokosmos, die »die körperlichen und kosmischen Strukturen parallel setzt. ${ }^{291}$ Dabei beschäftigt sie sich mit den verschiedenen mittelalterlichen Personifizierungen der »Natura«. Ein »neuer Typus« trete seit dem 15. Jahrhundert »im Kontext der Popularisierung« antiker Autoren auf. Zuerst in einer nur noch aus einer Schilderung bekannten »reich illuminierten PliniusHandschrift« im Besitz des Kardinals Giovanni d'Aragona. Natura erscheine hier als schöne sitzende Frau, die Milch aus ihren Brüsten auf die Welt, die sie vor sich hält, strömen lasse. Das Motiv wird von zwei erhaltenen Miniaturen aufgenommen. So die lateinische Version von Themistius' Paraphrase der aristotelischen »Physica« (Neapel, um 1490) für den Herzog von Atri. Das Frontispiz zeigt Natura als »im All schwebende«, wie sie eine »Weltkugelscheibe [...] zwischen ihren Schenkeln $\mathrm{zu}$ halten scheint, und mit der sie gleichsam verwachsen wirkt. Aus der sichtbaren Brust spritzt sie ihre Milch, die so den Ozean füllt«. Das Frontispiz des griechischen »Physica«-Textes für den selben Auftraggeber (ca. 1496) präsentiert Natura mit einer Erdkugel, die Europa, Afrika und Asien zeigt (mehr ist noch nicht bekannt), in ihrem Schoß. Die Kugel, auf die sie - im Stil zeitgenössischer Brunnenfiguren - Milch aus ihren Brüsten presst, ähnelt einem schwangeren Leib. Sie ist so »Nährende« und »Gebärende«. Ikonographisch sei das eher an »christliche[n] Bildformulare[n] « wie der »allumfassenden Weisheit, die den Erdkreis wie einen Unterleib vor sich hält« oder an »mappaemundi wie die Ebstorfer Weltkarte, wo der bewohnte Erdkreis den Leib Christi« bilde, orientiert. 1470 entsteht dann auch in Florenz die oft kopierte Bibel des Federico da Montefeltro. Deren Frontispiz stellt Gott als Gebärenden mit der Kugel im Schoß dar. Die ersten drei Tage der Genesis zeigen eine nach und nach größer werdende Kugel, die ihm aus dem Schoß zwischen die Schenkel gleitet. »Gott bekommt hier, wie Natura in den anderen Miniaturen, die >Mutterrolle zugewiesen, wobei Leib und Erde, Bauch und Kugel verschmelzen ${ }^{292}$

291 Vgl. ebda., S. 183. Vgl. Wind, Edgar: Heidnische Mysterien in der Renaissance, S. 130; Kutschmann, a.a.O., S. 80; Sennett, David: Fleisch und Stein, S. 323ff.

292 Helas, a.a.O., S. $183 \mathrm{ff}$. 
Eine Usurpation ist aber auch schon früher zu beobachten. In antiken Texten werde »Natura« als »kosmische Potenz«, Besitzerin von »unerschöpfliche[r] Lebenskraft«, als »Allgöttin«, die »Macht über die Geister besaß«, behandelt, schreibt Curtius. Bei Ovid, dessen Kosmologie mit dem Chaos, dem Kampf des Kalten mit dem Warmen, des Feuchten mit dem Trockenen, des Weichen mit dem Harten, Schweren mit Schwerelosem beginnt, werde dieser Kampf geschlichtet von einem »Gott« bzw. einer »freundlichere[n] Natur«; zwischen beiden werde nicht unterschieden. 400 Jahre später werde Claudian das Thema wiederaufnehmen. »Das Weltbild hat sich gewandelt.« Nun sei »Natura« eine so mächtige Göttin, dass sie als »Ehewalterin« der Götter, die zugleich dem »jugendliche Zeus« eine göttliche Dienerschaft zuweist, fungiere. Das werde zum Thema früher »christliche[r] Polemik«. Prudentius rechnet $\mathrm{zu}$ »den überwundenen heidnischen Gottheiten [...] die Natur. Gott ist ihr Herr. Sie ist nicht Erzeugerin, nur Ernährerin der Menschen«. Auch, wenn »die heidnische Natura nie ganz dem Bewußtsein« entschwinde, finden sich »Nachklänge dieser Polemik [...] während des ganzen Mittelalters «. ${ }^{293}$ So insbesondere bei Alanus von Lille. Hier bleibe Natura zwar Mittlerin »zwischen Gott und Mensch«, sei aber »nicht mehr gebärende Mutter, sondern züchtige Jungfrau. [...] Die ontologischen Verhältnisse werden durch grammatische Metaphern verdeutlicht. Die Macht Gottes ist der Superlativ, die der Natur der Komparativ, die des Menschen der Positiv «. ${ }^{294}$

»Frau Welt« ist die andere Möglichkeit, die Erde feminisiert darzustellen.

»Es gibt nebeneinander [!] eine `Zeit der Sünde und eine Zeit der Gnade`, eine der Schlacht und eine des Hofes, eine des Genusses und eine der Buße; Frau Welt - das vielfach gestaltete Bild des Mittelalters für diese Verdoppelung ist nicht außen glänzend und innen verrottet, sondern sie strahlt vorne und stinkt hinten: ein Unterschied, der gar nicht überschätzt werden kann. Denn man kann sie drehen und wenden, wie man will, und doch behalten die beiden Seiten den gleichen Grad von >Realität $\iota$, von gesellschaftlicher Bedeutung, stehen nicht in einem generativen, moralischen, sondern einem gleichberechtigten, aggregativen Verhältnis zueinander, so daß keine von ihnen der gänzlichen Verachtung anheimfällt. « ${ }^{295}$

293 Curtius, Ernst Robert: Europäische Literatur und lateinisches Mittelalter. Bern, München: Francke 1967 (1948), S. 116f.

294 Ebda., S. 128f.

295 Czerwinski: Der Glanz der Abstraktion, S. 246. 
Czerwinski zeigt das am Beispiel von Gottfrieds »Tristan«: »nein unde jâ sint beidiu dâ«. Das benenne »oxymerotische Teile der >Wirklichkeit « ${ }^{296}$ Diese Janusköpfigkeit lässt sich aber auch unter einer leicht anderen Perspektive betrachten. Es ist Frau Welt, und damit »ein gespaltenes Bild von Erde und (weiblicher) Natur: einerseits Leben und Freude spendend, andererseits bedrohlich«. Diese »Frau mit schöner, verführerischer Vorderseite und dämonischer, von Fäulnis und Getier zerfressener Rückseite $\ll^{297}$ ist zwar beidseitig von gleich großer gesellschaftlicher Bedeutung. Aber als >Frau $<$ und als $>$ Natur $\diamond$ ist dies eine inferiore und bestenfalls numinose.

»Die Metaphorisierung der Natur als Frauenleib hat zu einer Vorstellung der janusköpfigen Erscheinung weiblicher Natur geführt, die in der Literatur eine langlebige und zähe Tradition erhalten hat, und zwar im Topos der Verführung des Mannes durch die Frau, wobei die Frau als doppelgestaltig, verstellt oder aufgespalten in eine reine und eine dämonische Figur erscheint. ${ }^{298}$

Was auf die allegorische >Frau Welt $\prec$ zutrifft, muss auch schon mittelalterlich auf `wirkliche〈 Frauen nicht zutreffen. Der später heilig gesprochene Abt von Cluny, Odo, drückt sich hier im 10. Jahrhundert in seiner »berühmten Abhandlung « ${ }^{299}$ unmissverständlich aus. Hier ist von äußerem Glanz und innerer Verrottung die Rede:

»Die Schönheit des Leibes rührt allein von der Haut her. Wenn die Menschen nämlich sehen könnten, was sich unter der Haut verbirgt - gleich den Luchsen, von denen es bei Boethius heißt, sie hätten angeblich die Fähigkeit, die Eingeweide zu sehen - so würde ihm vor dem Anblick der Frauen grausen. Deren Schönheit besteht in Wirklichkeit aus Schleim, Blut, Wasser und Galle. Wenn einer an das denkt, was in den Nasenlöchern, im Hals und im Bauch ist, so findet er nichts als Schmutz. Und da wir doch Schleim und Kot nicht einmal mit den Fingerspitzen anrühren mögen, warum sollten wir einen Haufen Kot zu umarmen begehren? $\ll^{300}$

Die Frau - und offenbar nur sie - ist also nichts, als ein Haufen Kot, Schleim und anderer Dreck, das schöne Äußere nur die verbergende, täuschende Hülle. Da ist die Verwandlung der Schönheit in die ekelerre-

296 Ders.: Gegenwärtigkeit, S. 479.

297 Weigel, a.a.O., S. 127.

298 Ebda.

299 Fumagalli, Vito: Wenn der Himmel sich verdunkelt. Lebensgefühl im Mittelalter. Berlin: Wagenbach 1988 (Bologna 1987), S. 33.

300 Zit. n. ebda., S. 53f. 
gende Hexe im Handumdrehen vollzogen. Aber die Verwandlung ist ja eigentlich nicht einmal nötig, denn diese Ekelerregende steckt immer unter der betörenden Larve. Und damit ist die äußere Schönheit untrennbarer Bestandteil des ekelerregend hässlichen Inneren. Es ist somit eigentlich immer dieses Schreckliche, das unter Vorspiegelung falscher Äußerlichkeiten (die dem qua göttlicher Vernunft Sehenden ja nichts anhaben können) anlockt. Im 17. Jahrhundert kann Abraham a Sancta Clara Odo nur beipflichten, wenn er meint, »daß ein schönes und aufgeputztes Weib ein Tempel sei, welcher über eine Mistelachen (super Cloacam) aufgebauet... [...] Wer wird den Koth für einen Gott anbeten wollen? « ${ }^{301}$ Dass es hier eine >schöne Larve` über der Kloake innen gibt, behauptet eine Gefahr, die tatsächlich als eine von >Innen` gewähnt wird.

Ursprünglich bedeutet »Miasma« in der griechischen Mythologie »geistige Entweihung« und den »Fluch der Mutter«, der ein erbliches, über Generationen höchst ansteckendes unabwendbares Schicksal für Verbrechen gegen die Mutter bzw. gegen das traditionelle Gesetz der Muttergöttin vorsieht. Dieser Fluch könne durch nichts abgewendet werden. So finde der des unverzeihlichen Verbrechens Muttermord schuldige Orestes niemanden, der ihn gegen die Furien verteidige, da ihn das Miasma von jedem menschlichen Kontakt ausschloss. Das panikerregende Mittel des Fluchs aber sei das Menstruationsblut. Vor allem ältere Frauen nach der Menopause seien - da sie nun "weißes Blut« in sich trugen - nach dieser alten Theorie besonders mächtige Urheberinnen der Flüche:

»Deshalb gab es im Europa des Mittelalters den Glauben, jeder Zauber, der irgendwie mit Menstruationsblut zusammenhing, sei übermächtig. Und deshalb wurden gerade ältere Frauen als Prototypen der Hexen angesehen, deren Worte oder sogar Blicke Schrecken erregten. $\ll^{302}$

301 Zit. n. Deschner, Karlheinz: Das Kreuz mit der Kirche. Eine Sexualgeschichte des Christentums. Düsseldorf, Wien: Econ 1974, S. $205 f$.

302 Walker, Barbara G.: Das geheime Wissen der Frauen, S. 263. Die ambivalente `Zauberkraft « des Menstruationsblutes finde sich beispielsweise auch in der dänischen Sagenwelt, wo der Elfenkönig mit eben diesem Tote zu neuem Leben erwecken kann (ebda., S. 709). Die germanische Mythologie kennt eine Art patriarchaler Revolution: Der Gott Odin stahl das Blut der dreifachen Göttin, und begründete so seine Vormachtstellung. Das althebräische Wort für Blut ist »dam« (ebda., S. 261f.). Es findet sich in »Adam«, das sich aus dem ursprünglich weiblichen »adamah« (»blutiger Lehm«) ableitet (ebda., S. 698). 
Im englischen Sprachgebrauch hat sich der Begriff »the curse «, der »Fluch« als Bezeichnung für die monatliche Blutung erhalten. ${ }^{303}$

Auch auf diesem Gebiet ist von so etwas wie einer >unangebrachten Urbarmachung einer unberührten, schlammigen Erde die Rede. Im 17. Jahrhundert ist es für den bekannten Brüsseler Gelehrten Johann Baptista van Helmont

"gewiss, dass die Eva nach der Essung des verbotenen Apffels sich den Kützel der geylen Lust unterwürffig gemacht, auch den Mann zur fleischlichen Vermischung angereitzet und zugelassen: Daher die hiervon empfangene Menschliche Natur ins Verderben gerathen, und fortan in solcher Unart geblieben: um welches Verderbens willen die Nachkommen der vorigen unvergleichlichen Reinigkeit beraubet worden. [...] Solcher Gestalt ist dieser Fluch nun in die Natur eingegangen und wird auch so bleiben «. ${ }^{304}$

Die »blutige Verunstaltung an ihrer Natur $\aleph^{305}$ als Resultat des Naschens vom Baum der Erkenntnis. Gleichzeitig geht das Paradies, der ursprüngliche göttliche, geordnete Garten Natur verloren, macht dem Chaos der weiblich besetzten Natur Platz. Periodische Überflutung als Sündenmal.

»Als der Fluss der Begierde in Eva eingezogen war, wurden alle ihre Gefässe dem Blutstrom geöffnet. Daher erlebt jede Frau bei sich stürmische Vorgänge im Blute, so dass sie, ähnlich dem Ansichhalten und Ausfliessen des Mondes, die Tropfen ihres Blutes bei sich behält und vergiesst. [...] Denn wie der Mond zu- und abnimmt, werden beim Weibe Blut und Säfte während der Zeit des Monatsflusses gereinigt. Andernfalls würde es nicht am Leben bleiben können, weil es reicher an Flüssigkeit ist wie der Mann, und in schwere Krankheit verfallen. [...] Alle Gefässe des Weibes würden unversehrt und gesund geblieben sein, wenn Eva allezeit im Paradiese verblieben wäre«,

schreibt die gelehrte Äbtissin Hildegard von Bingen im 12. Jahrhundert. ${ }^{306}$ Nur der von Gott mit freiem Willen ausgerüstete Mensch kann nach damaligem Verständnis die Schöpfungsordnung gefährden. Woraus zwingend folgt, dass »die gesamte Schöpfung auf eine Ordo-Verletzung [...] reagiert «. ${ }^{307}$ Die biblische Ursünde verwandelt demnach alles

303 Vgl. ebda., S. $261 \mathrm{ff}$.

304 Zit. n. Fischer-Homberger, Esther: Krankheit Frau, S. 55.

305 Ebda.

306 Zit. n. ebda., S. 54.

307 Irene Erfen/Peter Schmitt: Nachwort, in: Boccaccio, Giovanni: De claris mulieribus (Die großen Frauen). Lateinisch/Deutsch. Ausgewählt, über- 
in natura lapsa. Kosmische oder Naturkatastrophen seien denn auch in Spätmittelalter und früher Neuzeit kontinuierlich beschworen worden als »Vorboten endgültigen Untergangs als Folge einer solchen Ordo-Verletzung«, schreiben Erfen/Schmitt. Das kann individuell verschuldet sein. Während männliche Homosexualität Überschwemmungen auslösen soll, bewirken »mangelnder Gehorsam der Frau oder gar Herrschsucht [...] Erdbeben und Kometenabstürze - ein snaturkundliches` Wissen, das zu einem allgemein verfügbaren Hausschatz gehört, aus dem sich noch die elisabethanischen Dramatiker bedienen $«{ }^{308}$ Und in modifizierter Weise auch noch die wissenschaftliche Auffassung im 18. und 19. Jahrhundert. Die lässt die Erde als weiblichen Leib beben, als ungehorsamen, der sich der Kultivierung verweigert, was sich zeigt im Auswurf der »Miasmen«.

»Miasmen« sind auch Folgen einer weiteren »unangebrachte[n] Urbarmachung«. Corbin verfolgt die Tradition der männlichen Auffassung vom weiblichen Geschlechtsgeruch als »Gestank« von Demokrit und Juvenal bis zur Aufklärung, und kommt zu dem Schluss, dass es demnach nicht die Menstruation - ihr Einsetzen mit der Pubertät präge lediglich eine »unstete Geruchsnote«, erhöhe durch die Gemahnung an die Fortpflanzungsfähigkeit die »Verführungskraft« der jungen Frau -, sondern der Geschlechtsverkehr, und damit das männliche Sperma sei, welche der Frau »eine echte Duftmarke« aufprägten. ${ }^{309}$ Aber:

»Exzessiver Geschlechtsverkehr bewirkt einen regelrechten Samensturz in den Körpersäften der Frau, zersetzt die Flüssigkeiten und erzeugt einen unerträglichen Gestank. So werden die Prostituierten zu putains, den \Stinkenden..${ }^{310}$

Nun ist es aber nicht das Sperma selbst, das Gestank verbreitet. Vielmehr entsteht Gestank durch seine Entwertung in der Verbindung mit den weiblichen Körpersäften; dies aber nur bei >unangemessener Anwendung, die nicht den Regeln - maßvoll und nur zur Fortpflanzung entspricht, sondern »zügelloser Hurerei« geschuldet ist, bei der die Schuldfrage von vornherein geklärt ist. Im ausgehenden 17. Jahrhundert schließlich wird »im Versuch einer naturwissenschaftlichen Erklärung der Hysterie« die alte Theorie einer Gebärmutterwanderung ersetzt durch eine solche, bei der »körperliche Säfte oder Dämpfe, die >Vapeurs , in den Mittelpunkt der Erklärung gestellt wurden«. Im folgenden

setzt und kommentiert von Irene Erfen und Peter Schmitt. Stuttgart: Reclam 1995, S. 273.

308 Ebda.

309 Corbin, a.a.O., S. 67.

310 Ebda. 
Jahrhundert wandelt sich die »Pathologisierung zur Psychiatrisierung des Weiblichen«, wird mittels »Nervenfasern bzw. -fibern [...] die Behauptung einer besonderen nervlichen Sensibilität des weiblichen Geschlechts erneuert«; ohne allerdings, dass der Uterus in dieser Weise bedeutungslos wird. ${ }^{311}$

Erdbeben, Risse und die Drohung, dass der Leib der Erde all das dort Angesammelte unweigerlich einmal wieder abgeben wird, bestimmen die »Miasmen-Panik« des 18. und 19. Jahrhunderts:

»Aus all diesen Überzeugungen erwächst das Schreckgespenst der Risse, der Zwischenräume, der auseinanderklaffenden Fugen. Bei jedem gefährlichen Gelände gilt es vor allem auf verdächtige Ränder zu achten, denn es sind stets die Nahtstellen, die verderbliche Dünste entweichen lassen. Die schlimmsten Risse entstehen naturgemäß durch Erdbeben. Nach Meinung von Tourtelle sind sie allein für die Epidemien verantwortlich, die Lissabon und Messina unmittelbar nach den katastrophalen Erdstößen heimgesucht haben. ${ }^{312}$

Der Leib kulminiert alles Schlechte, um es irgendwann wieder abzugeben:

»Aber die Erde scheidet nicht nur aus, sie saugt sich auch voll mit den unheilvollen Dämpfen, speichert die Produkte der Gärung und der Fäulnis. Sie dient als Aufbewahrungsstätte für Jauchen aller Art, und eines Tages wird sie beschließen, selbige in Form todbringender Dämpfe wieder auszuspeien. ${ }^{313}$

Die Bedrohungen durch »unheilvolle Dämpfe« ist eine umfassende. Sie grassiert sowohl auf dem Land, wo Bauern geraten wird, bei der Feldarbeit den Kopf nicht zu nah an den Boden zu halten, ${ }^{314}$ als auch vor allem in den Städten. Corbin spricht von der »Neudefinition des Unerträglichen«, der »Senkung der Toleranzschwellen«; er erwähnt, wie etwa die herkömmliche »Art der Kloakenentleerung, die ohne Ventilation, allein mit Hilfe undichter Fässer und Kübel ausgeführt wird«, in Paris zum Skandalon werde. ${ }^{315}$ Die Bedrohungen in Stadt und Landschaft müssen offenbar, trotz des eindeutigen Zusammenhangs, differenziert werden. Vor allem städtisch scheint bedrohlich all das, was dem Bürger auf den zu distanzierenden Leib rückt.

311 Vgl. Weigel, a.a.O., S. 125.

312 Corbin, a.a.O., S. 36.

313 Ebda.

314 Ebda.

315 Ebda., S. $81 \mathrm{ff}$. 
Aufgrund welcher sozialen Prozesse kann es zum seit dem späten 18. Jahrhundert allgegenwärtigen Gefühl der Bedrohung der ersehnten Balance und vegetativen Ruhe des bürgerlichen Subjekts, der Beunruhigung qua »inner- wie außerleiblicher Stofflichkeit«, Schweiß, Kot, Fäulnis und $\operatorname{Tod}^{316}$ kommen? Die städtischen `Eliten< sehen sich zunehmend mit dem Volk konfrontiert, der Kontakt gerät zusehends zu einem unmittelbareren, sich verstetigenden. Und das ist der von Christian Barthel angesprochene »bedrohliche Zustand der Vermischung«, der Gefahr des Identitätsverlustes, der »Besudelung, Berührung, Beimengung«, der Angst vor den »verwirrenden Zeichen des Lebendigen $«,{ }^{317}$ dem gleichzeitig Tod und Verderben in allen Schattierungen anhaftet in seiner/ihrer ganz konkreten Ausprägung.

Die Gesellschaft wandelt sich - um es mit Claude Lévy-Strauss zu sagen - zu weiten Teilen von einer anthropemen, einer sauswürgenden zu einer anthropophagen, einer >einverleibenden $\times{ }^{318}$ Diejenigen Bevölkerungsgruppen, die sich ehedem zumeist gewaltförmig an den Rand oder über denselben hinaus gedrängt sahen, werden sukzessive eingebunden in den Mechanismus der protokapitalistischen Ökonomie. Der ssoziale Schmutz` verfällt zunehmend nicht mehr der Ausscheidung, dem Auswürgen - was sonst ist der Stadtverweis und die Vogelfreiheit außerhalb der Mauern? - sondern verbleibt im \Leib der Stadt und ihren >Eingeweiden`. Die Peripherie dieses städtischen `Leibs` droht auseinanderzufließen, die Mauern werden durchlässig oder gar gänzlich geschleift. Die Stadt schwillt an, wird ein >monströser Körper`, innerhalb dessen die >Fluten des Schmutzes` diszipliniert, kanalisiert, beherrscht werden müssen. Und das heißt auch ganz konkret, dass die überkommenen sanitären Systeme, konzipiert im Mittelalter für weitaus geringere Bevölkerungszahlen, dem neuen Andrang nicht mehr gewachsen sind. So kommt es z.B. allsommerlich während des "great stink« der Themse zur Flucht derer, die es sich leisten können, aus London in ihre

316 Vgl. Barthel, Christian: Medizinische Polizey und medizinische Aufklärung. Aspekte des öffentlichen Gesundheitsdiskurses im 18. Jahrhundert. Frankfurt/M, New York: Campus 1989, S. 131.

317 Ebda.

318 Lévi-Strauss, Claude: Traurige Tropen. Frankfurt/M: Suhrkamp 1978 (Paris 1955), S. 382. Lévy-Strauss' konzeptionelle Gewichtung ist zwar eigentlich eine andere: Er stellt den Typus der »anthropophagischen«, der »menschenfressenden« Gesellschaften dem der »anthropemischen«, der "menschenerbrechenden " gegenüber und charakterisiert die "zivilisierte" westliche Kultur als anthropemische, da sie bedrohliche Individuen in Anstalten aussondere. Dass frühneuzeitliche Strafpraktiken aber eher ausschließenden Charakter haben und spätere Versuche der Sozialdisziplinierung eher einschließenden, lässt sich gleichwohl behaupten. 
frischluftumwehten Landhäuser. ${ }^{319}$ Eine neue Sensibilität, die allerdings wohl kaum bedeuten kann, dass der Gestank der Städte vormals regelrecht gôutiert worden wäre. ${ }^{320}$ Es ist der Gestank der >Anderen`, der vormals mehr oder weniger zuverlässig räumlich Getrennten, der dem bürgerlichen Subjekt nun als territoriale Überschreitung in die Nase sticht.

Das hat einige Konsequenzen für das bürgerliche Subjekt des ausgehenden 18. Jahrhunderts.

»Die [...] wachsende Sensibilität geht einher mit einer Verlagerung der Schmutzgrenzen von innen nach außen. Der innerleibliche Raum wird zusehends abgeblendet; die bedrohliche Alchemie der eigenen Schmutzproduktion wird zu bannen gesucht. Sicher, man spricht über das nunmehr Peinliche aber die Sprache selbst wird zum Modus der Verdrängung leiblicher Verrichtungen: eine Manie des Besprechens, Vermessens, des diätetisch zur Kenntnis Nehmens, die allerdings einem Bannen, Verschweigen, Abstrahieren der Leiblichkeit und der bedrohlichen Körperfunktionen entspricht. $\ll^{321}$

Christian Barthels Beschreibung verlangt nach einer Modifizierung. Den Ausscheidungsprodukten des Körpers und ihren Gerüchen selbst ist keine soziale Differenz, Hierarchie zu entnehmen. Nicht zu beeinflussende rektale Gleichmacherei: Das, was nach einem Gala-Diner in die Schüssel fällt, unterscheidet sich nicht wesentlich von den Überresten einer einfachen Bauern- oder ärmlichen Tagelöhnermahlzeit. Die ängstlich gewähnte soziale Vermischung findet hier ihren deutlichsten Ausdruck, die bürgerliche Identität als solche scheint nicht aufrechtzuerhalten, solange diese Differenz nicht zu konstruieren ist. Der eigene Leib wird so zum zu disziplinierenden sozialen Raum, definiert als Ab- bzw. Vorbild des zu usurpierenden realen sozialen Raums. Die Konstruktion der Differenz erfolgt anhand des Mechanismus der >Vernunft

»Im Rahmen diätetischer Selbstbeobachtung wird die Scheiße zum Siegel und Orakel einer vernünftigen, disziplinierten Lebensordnung; allemal gilt - ausräumen, wegschaffen, beseitigen was verstopft, fault, das Funktionieren der $>$ Körpermaschine` verhindert. ${ }^{322}$

319 Vgl. Glick, Thomas F.: Naturwissenschaft, Technik und städtische Umwelt: Der »große Gestank« von 1858, in: Sieferle, Rolf Peter (Hg.): Fortschritte der Naturzerstörung, S. 109ff.

320 So beschreibt Barthel das unter Verweis auf vormalige therapeutische Verwendungen von Fäkalien, wie sie etwa Paulis »Dreckapotheke« propagiert. Vgl. Barthel, a.a.O., S. 138.

321 Barthel, a.a.O., S. 131.

322 Ebda., S. 135. 
Der Leib als Maschine und die Stadt, die Gesellschaft als Leib. Beide werden zu Feldern disziplinierender und ökonomisierender Herrschaftstechniken erklärt. Der leibliche Innenraum wird einer dauerhaften Kontrolle unterzogen, die zugleich Bestandteil eines Diskurses ist. $\mathrm{Zu}$ »uferloser Breite« schwillen die Schriften zur »Überwachung der Menge und Beschaffenheit der Kost « an. Ebenso die Maßgaben der Entleerung. ${ }^{323}$ Damit aber kommt dem innerleiblichen Raum im Gegensatz zu Barthels nachfolgender Behauptung sehr wohl eine eminente öffentliche Funktion zu.

»In dem Maße, wie der innerleibliche Raum in die strenge Disziplin des sich selbst besorgenden Subjekts übergeht, wie ihm keine öffentlichen Funktionen mehr zukommen, und Sprache und Alltagshandeln vom Dreck befreit werden, wird die Haut als universale Problem- und Gefahrenzone entdeckt. Die ängstliche Aufmerksamkeit des sein Territorium überwachenden Subjekts konzentriert sich auf diese vorgeschobene Bastion. ${ }^{324}$

Die Peripherie des Körpers setzt sich in Beziehung zur Peripherie der Stadt. Das aufkommende Weichbild der Städte korrespondiert mit der Hartleibigkeit des bürgerlichen Subjekts. >Bessere Häuser` sind von der Straße ein >gutes` Stück zurückgesetzt, durch mehr als nur schmale Vorgärten (die später nur matte Kopien sind) getrennt. Sie werden territorial geschützt durch Auffahrten, Rasenstücke, Parks (wie in den Jahrhunderten zuvor nur die Adelshöfe) vor den >ortsüblichen Belastungen` der Straßen. Und müssen diese Straßen doch benutzt werden, so geschieht das in Wagen, versehen mit abweisenden >Kotflügeln`.

Noch droht ebenso allenthalben eine >Wildnis $<$ in der >äußeren Natur $<-$ und sei es eine imaginierte. Ungesunde Luft herrscht auch in noch nicht kultivierten Wäldern, wie Gottfried Albert Kohlreif 1794 konstatiert:

»Die Waldluft ist allgemein bekannt als eine ungesunde Luft. Alle Länder, die große Wälder haben, oder daran grenzen, haben ungesunde Luft; und je mehr die Wälder ausgehauen und das Land kultiviert wird, um desto gesunder wird das Klima desselben. Dieß ist unwiderlegliche Erfahrung, und hieraus folgere ich, daß die dicken Wälder von der Regel, gesunde Luft zu geben, abweichen, und nicht nach der Art aller frischwachsenden Pflanzen beym Sonnenscheine eine Menge dephlogistisirte Luft entwickeln; und im Dunkeln zwar keine 
phlogistische Luft, jedoch aber unbeträchtlich wenig ungenießbare Luft von sich geben. ${ }^{325}$

Die »dephlogisierte« Luft gilt als »Lebensluft«, also als »beste Atemluft«. Nach der von Georg Ernst Stahl (1660-1734) vor der Entdeckung des Sauerstoffs aufgestellten Phlogiston-Theorie enthält die Luft brennbare Teile. Die »phlogistische Luft» entspricht demnach dem Stickstoff. $^{326} \mathrm{Da}$ die zu »dicken Wälder« infolge ihrer Dunkelheit keine »Lebensluft« entwickeln können, sind sie selbst sozusagen das beste Argument für ihre Kultivierung. Das erinnert an Kants Argumentation in der »Kritik der Urteilskraft«, in der alles in der Natur einem System absichtlicher Zweckbestimmungen unterliegt. Gerade, wenn die Wildnis Unlust erzeuge, biete sie selbst den Antrieb zur Zivilisierung, etwa dann, wenn Moskitos die »Wilden« dazu brächten, zu dichte Wälder auszudünnen und Sümpfe trocken zu legen. ${ }^{327} \mathrm{Um}$ zum Bild der >Weiblichkeit` von Landschaft zurück zu kommen: Die >Jungfräulichkeit` liefert selbst das beste Argument zu ihrer Eroberung.

\section{Von der endgültigen Abschaffung des sMatriarchats`}

»Alles hat seinen Anfang im regellosen Chaos der fetten Sümpfe: die wilde Zeugung des \Stoffs` dominiert das geile und lüsterne Leben jeglicher Kreatur, auch des Menschen, der nur einem >ius naturale stitutionelle, etwa eheliche Festlegung und Einschränkung. Nach Lust und Laune gehen die Frauen ihre sinnlichen Verbindungen ein. Hier gibt es nur Mütter, weil niemand wissen konnte, wer der Vater ist «, ${ }^{328}$

kommentiert Monika Treut Johann Jakob Bachofens Versuch der Rekonstruktion der Ablösung des Mutterrechts durch das der Väter.

325 Kohlreif, Gottfried Albert: Abhandlungen von der Beschaffenheit und dem Einfluß der Luft, sowohl der freyen atmosphärischen als auch der eingeschlossenen Stubenluft auf Leben und Gesundheit der Menschen, S. 41; zit. n. Bayerl, Günter/Troitzsch, Ulrich (Hg.): Quellentexte zur Geschichte der Umwelt. Von der Antike bis heute. Göttingen, Zürich: Muster-Schmidt 1998, S. 182f.

326 Vgl. Corbin, a.a.O., S. 22 u. 26.

327 Vgl. Kap. Zur Erhabenheit verfeinert.

328 Treut, Monika: Die grausame Frau. Zum Frauenbild bei de Sade und Sacher-Masoch. Basel, Frankfurt/M: Stroemfeld 1984, S. 177f. 
Aphrodite, die 〉Göttin der Liebe $\iota$, des »regellosen Hetärismus « ${ }^{329}$ ist zugleich die Göttin der Sümpfe. So sieht Bachofen dann auch Aphrodite durch Demeter abgelöst:

»Die Sümpfe werden trockengelegt; an die Stelle der regellosen Sumpfzeugung tritt der geordnete Ackerbau; die eheliche Vereinigung von Frauen und Männern entsteht als ein >agrarisches Verhältnis`, in dem jetzt auch der Gatte und Vater einen gesellschaftlichen Status gewinnen, allerdings noch vollständig unter dem Primat der Frauen und Mütter. `Das Prinzip des Ackerbaus ist das der geordneten Geschlechtsverbindung «. Besonders dieser Periode gilt Bachofens Interesse: unter dem Zeichen der Erdgöttin Demeter steht das gynaikokratische Zeitalter auf der Grundlage eines >unentweihten Matronentums $\prec$. Es ist die Stufe eines geordneten Naturalismus. Demeter hat Aphrodite besiegt, die gute, orale Mutter hat die hetärische, chaotische Mutter der Sümpfe verdrängt. Milch und Honig symbolisieren den mütterlichen Überfluß in einer Zeit, deren >Poesieく durch das Gleichgewicht zwischen organischem Stoff und mildem Gesetz konstituiert ist. ${ }^{330}$

Instabilität verwandelt sich in Stabilität, sowohl, was Erdboden, als auch, was das Geschlechterverhältnis anbetrifft. Die ist allerdings nicht von Dauer.

Bachofens Matriarchat ist in seinem Ursprung ein Chaos des Geschlechterverhältnisses, unterliegt der »hetärischen Sumpfzeugung«, auf »der tiefsten, düstersten Stufe des menschlichen Daseins «, ${ }^{331}$ in der >weiblichen` Natur. Was auch - zwangsweise - zur Matrilinearität führt, erscheine doch der Mann »später als das Weib« und »dieses erscheint auch als die Offenbarerin des großen Mysteriums der Lebenserzeugung. Denn aller Beobachtung entzieht sich der Akt, der im Dunkel des Erdschoßes das Leben weckt und dessen Keim entfaltet; was zuerst sichtbar wird, ist das Ereignis der Geburt; an diesem hat aber nur die Mutter teil $«{ }^{332}$ Das »Weib« ist dabei »die Erde selbst«, wie diese will es ent-

329 Bachofen, Johann Jakob: Das Mutterrecht. Bd. 1., S. 29 (1861); zit. n. Schröter, Susanne: Frauenmacht oder Sklaverei der Urzeit, S. 25.

330 Treut, a.a.O., S. 179f. So ist die »Agape«, das >heilige Liebesmahl ursprünglich der Ritus der sexuellen Kommunion mit den heiligen Huren der Liebes- und Sumpfgöttin Aphrodite. Es wurde von frühchristlichen Sekten als »spirituelle Hochzeit« übernommen. Die Huren bzw. Horen Agape, Chione und Irene wurden als christliche Heilige kanonisiert und mit der Bezeichnung »jungfräuliche Märtyrerinnen« versehen. Obwohl die Kirche die Agapefeier im 7. Jahrhundert als ketzerisch erklärte, konnte sie durch das gesamte Mittelalter hindurch - und weiter bis heute - überdauern (vgl. Walker, a.a.O., S. 13f.).

331 Bachofen: Das Mutterrecht, Bd. 1, S. 20; zit. n. Schröter, a.a.O., S. 24.

332 Ebda., S. 159; zit. n. a.a.O., S. 23. 
sprechend seiner vom >Schicksal gegebenen >Natur fruchtet werden. Das so erzeugte Wachstum ist ein pflanzliches, vegetatives: Wildwuchs ohne erkennbaren männlichen Urheber. ${ }^{333}$ So wird auch diese Ur-Frau als Pflanze vorgestellt:

»Um nicht in den Armen eines Einzelnen zu verwelken, wird das Weib von der Natur mit allen Reizen, über welche sie gebietet, ausgestattet; das Gesetz des Stoffes verwirft alle Beschränkungen, haßt alle Fesseln und betrachtet jede Ausschließlichkeit als Versündigung an ihrer Göttlichkeit. « ${ }^{334}$

Das ungezügelt Vegetative, zugleich Tellurische, diese »Stofflichkeit $«,{ }^{335}$ das soll offenbar den >wahren Charakter einer solchen »Göttlichkeit» beweisen, ist zugleich Fluch, »Erniedrigung«, da das Weib dem andauernden »Mißbrauch des Mannes schutzlos hingegeben« und »durch dessen Lust zu Tode ermüdet« sei. Das lässt es »zuerst und am tiefsten die Sehnsucht nach geregelten Zuständen und einer reineren Gesittung« empfinden, »deren Zwang der Mann im trotzigen Bewußtsein höherer physischer Kraft nur ungern sich bequemt «. ${ }^{336}$

Bachofen konstruiert einen Zustand der Regellosigkeit, in dem eine später verschwundene »allgemeine Brüderlichkeit aller Menschen« infolge des " gebärenden Muttertums $«{ }^{337}$ waltet und zugleich finsterste Blutrache, in denen Männer zugleich naturnotwendig Vergewaltiger sind, Frauen reine Mütter. Ihnen fehlt jedes eigene erotische Interesse und dann doch nicht. Dieser >ersten Menschheitsphase heraus aus der Sumpfwildnis. Er gelingt den Frauen mit »List und Gewalt«, sie werden $\mathrm{zu}>$ Amazonen`, ein Zustand der »bis zur Unnatürlichkeit gesteigerte[n] Gynaikokratie«, um sich mit grausamer Waffengewalt gegen ihre potentiellen Vergewaltiger zu wehren: »Wer den Männermord in das Gebiet der Dichtung verweist, verkennt den Charakter des in seinem Blutdurste unersättlichen Weibes. « ${ }^{338}$ Dann aber erscheint der schöne wie siegreiche Heros, dem sich die Amazone, des Kriegerischen müde, willig unterordnet. Es kommt zur agrarischen ehelichen Gynaikokratie, in der »Keuschheit und Treue« strikte Normen sind, die Frauen herrschen über die Endosphäre (Haus, Land, Sklaven), die Männer sind außerhalb, meist mit Jagd und Krieg beschäftigt. Eine

333 Vgl. Ders.: Über das Weiberrecht (1857); zit. n. a.a.O., S. 25.

334 Ders.: Das Mutterrecht, Bd. 1, S. 38; zit. n. a.a.O.

335 Schröter, a.a.O.

336 Ebda., S. 121 u. 37; zit. n. a.a.O.

337 Ebda., S. 21; zit n. a.a.O., S. 24.

338 Ebda., S. 138 u. 227; zit. n. a.a.O., S. 26f. 
Zeit der Ritterlichkeit, die stets »mit dem Frauenkulte« einhergehe. ${ }^{339}$ Die verehrten Frauen aber ertragen vor lauter Lust und Grausamkeit die zuvor begehrte Regelhaftigkeit nicht länger, seien sie doch (inzwischen?) die Unersättlichen; »gewaltiger«, genauer: zehnmal so stark »als die Männer treibt die Weiber der Begierde Stachel«. Sie knechten und erniedrigen den Mann nun zum Lustwerkzeug, »zum Weibe«, entkräften und entwürdigen ihn so weit, dass sie »sich selbst zuletzt mit Verachtung « abwenden. ${ }^{340}$ Denn: »Vom Weibe geht das Verderben aus, vom Weibe wird es vollendet.« Es ist ebenso unberechenbar und verschlingend, wie die Erde selbst. Deren »geöffneter Schoß verschlingt alles, was er geboren hat. Mitten in den Kampf des Lebens werden wir von der grausamen Mutter hineingestellt«, die die »Verzweiflung« ihres »Sohnes« nicht interessiere, »wenn sie nur selbst den Brautschmuck anziehen und ihre Lust erfüllen kann «. ${ }^{341}$ Es folgt als »das Recht des Olympiers, der über der Erde in sonniger Höhe thront«, die gewaltsame patriarchale Revolution und »Civilisation«, die zur männlichen Befreiung aus den Fesseln der Stofflichkeit führt, in der die Frau jedoch verharrt, die männliche Suprematie zugleich »gerne« erleidet, um in der »Unterordnung der Liebe [...] ihre wahre Bestimmung « zu erkennen. ${ }^{342}$

Bachofen, der Außenseiter, dessen Gedankengebäude zu Lebzeiten »eher als kauzige Minderheitenmeinung ignoriert" worden sei, so Susanne Schröter, der aber »seit Ende des 19. Jahrhunderts - bis auf den heutigen Tag - stets heftig und kontrovers diskutiert« werde, ${ }^{343}$ komponiert ein >Matriarchat $\iota$, dessen gewaltsame Überwindung dringend geboten erscheint, aus historischen Quellen, der Mythologie und Archäologie, die er zwar »in erschlagende[r] Fülle« studiert, auch an »diver$\mathrm{se}[\mathrm{n}]$ historische[n] Orte[n] ${ }^{344}$ Dieses Matriarchat aber transportiert aktuelle Bedrohungswahrnehmungen des 19. Jahrhunderts: Den als >weiblich` wahrgenommenen >Großstadtdschungel`, Frauenfiguren, die schwanken zwischen Idealisierung und Zuschreibungen, die an die später entworfenen >Weiber als Verbrecherinnen und Prostituierte` Cesare Lombrosos und anderer erinnern, Männer, die desgleichen maß- und haltlos sind, solange sie nicht Herrschaft über die Frauen (und sich selbst) ausüben. Die >überzüchteten Treibhäuser` des >Turnvaters` Jahn

339 Ebda., S. 24, 100 u. 135; zit. n. a.a.O., S. $26 f$.

340 Bachofen: Versuch über die Gräbersymbolik der Alten, S. 88, Eine Sage von Tanaquil (1870), S. XXIV, Das Mutterrecht, Bd. 1, S. 47; zit. n. a.a.O., S. $27 \mathrm{ff}$.

341 Das Mutterrecht, Bd. 1, S. 217 u. 227; zit. n. a.a.O., s. 29 f.

342 Vgl. ebda., S. 199 u. 291; zit. n. a.a.O., S. 30.

343 Schröter, ebda., S. 22.

344 Ebda. 
und Joachim Heinrich Campes scheinen so in die >Urzeit` rückprojiziert. ${ }^{345}$ Bachofen selbst verweist nicht nur darauf, dass »Gesellschaften, die den Sprung zum Vaterrecht nicht erreicht haben«, charakterisiert seien »durch Demokratie, Humanismus - und die Unfähigkeit zu weiterer Entwicklung«, sowie mangelnde Moral. ${ }^{346}$ Er betont ebenso die Erniedrigung der Männer und warnt vor auch aktuellen Gefahren:

»Am tiefsten sinkt in solcher Ausartung der Mann [...]. Jede erotisch-sinnliche Civilisation wird zu demselben Resultate führen, das Weib über den Mann erheben und diesen zum Werkzeug der Lust erniedrigen, jenes mit allen Reizen eines verfeinerten Daseins ausstatten, diesen dem Wesen seiner Mannesnatur entfremden [...]. Mit der Schwächung des männlichen steigt stets die Kraft des weiblichen Geschlechts «. ${ }^{347}$

Abb. 3: Max Klinger: Eva und die Zukunft; Blatt 1: Eva, 1880

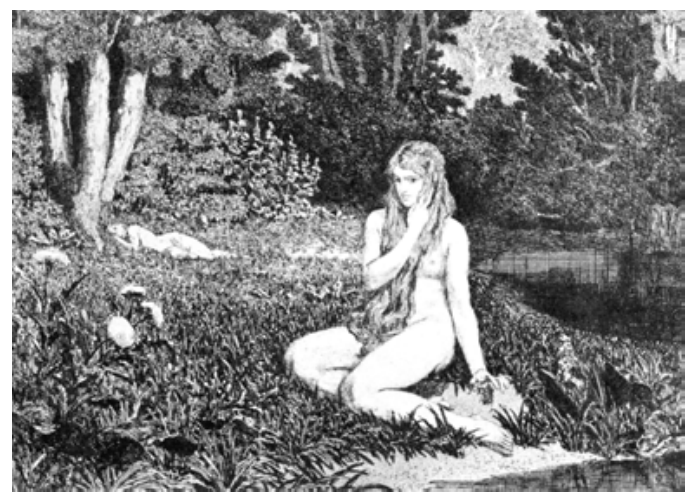

Auch Klingers »Eva« passt zum zeitgenössischen Diskurs um die >matriarchalischen Sümpfer. Die Frau als »Hauptfigur des Sündenfalls" kauert »sinnend am Ufer des Teiches" im >jungfräulichen 'Wald, während Adam noch unterm Baum schläft. Sie verführt ihn, wird - bei Klinger - »aber nach der Vertreibung aus dem Paradies seine Beute " ${ }^{348}$ - »selbstgewollt und selbstverschuldet «. ${ }^{349}$

$345 \mathrm{Vgl}$. Exkurs II.

346 Bachofen: Eine Sage von Tanaquil, S. XXXIII; zit. n. a.a.O., S. 31

347 Ders.: Das Mutterrecht, Bd. 1, S. 592; zit. n. a.a.O.

348 Gross, Friedrich: Max Klinger. Opus III. Eva und die Zukunft, in: Hofmann, Werner (Hg.): Eva und die Zukunft. Das Bild der Frau seit der Französischen Revolution. München: Prestel 1986; S. 174ff.

349 Hofmann, Werner: Evas neue Kleider, in: a.a.O., S. 13-23; hier S. 17. 
Das mythische Trockenlegen urweiblicher Sümpfe im 19. Jahrhundert korrespondiert womöglich auch mit anderen zeitgenössischen Vorkommnissen. Zur sittlich-ästhetischen Befleißigung im Programm der >Landesverschönerung` gehört es in der ersten Hälfte dieses Jahrhunderts, reale Sümpfe trockenzulegen. »Landesverschönerungsvereine« erleben in dieser Zeit einen Boom. Die Bewegung - sie hat ihren Schwerpunkt in den 1820er Jahren in Bayern - entstammt dem urbanen Umfeld, sieht ihr Wirkungsfeld aber überwiegend auf dem Land. Den »Absichten des Schöpfers« entsprechend, wie Heinrich von Nagel 1831 schreibt, solle der Mensch »sich die Erde zu einem Paradiese umschaffen «. ${ }^{350}$ Dazu zählt die Beseitigung von Feuchtgebieten:

»Hierher gehört auch die Austrocknung der Sümpfe und Moose [i.e. Moore], das Urbarmachen der Einöden und Wüsteneien. Die Natur selbst bedarf zuweilen von dem Menschen eine Unterstützung, und wenn er diese mit ihren übrigen Schönheiten zu verbinden weiß, so wird eine solche Nachhülfe, oft mit wenigen Kosten verbunden, sehr viel zur Verschönerung einer Gegend beitragen. $\ll^{351}$

Als spätaufklärerisch bezeichnet Sigrid Fährmann diese Absichten, in denen >Naturschönheit` kategorisch den Zwecken der »Nützlichkeit, Reinlichkeit, Ordnung, Harmonie« untergeordnet seien, wobei der Mensch als »Helfer« und »Vollender« der allein »unvollkommen[en] Natur erscheine. »Das Land der Erde ist in seiner Art eigenschön, ja unendlich schön; [...] aber es soll seine Naturschönheit vollendet, die schönbildende Natur soll von ihren eigenen Hindernissen, Schranken und Unglücksfällen befreit werden«, heißt es dementsprechend 1883 in Karl Christian Friedrich Krauses »Die Wissenschaft der Landesverschönerkunst«. Das Verhältnis der >Landesverschönerer〈 zur >Heimatschutzbewegung « sei »ambivalent«, schreibt Fährmann. Beide bevorzugen eine bäuerlich geprägte Kulturlandschaft. Andererseits werden die >Verschönerer 1908 vom inzwischen institutionalisierten »Bund Heimatschutz« als »Verschandelungsvereine« bezeichnet, da sie an unpassendsten Orten verschnörkelte Parkbänke, Aussichtstürme, künstliche Grotten und Ruinen aufgestellt hätten »und jeden Baum, jede Lichtung mit Namen tauften, die das Entzücken aller Mädchenpensionate waren«. Fährmann begründet das mit einem »veränderte[n] Zeitgeschmack« und

350 Fährmann, Sigrid: Der Göttinger Verschönerungsverein, in: Brednich, Rolf Wilhelm et al. (Hg.): Natur - Kultur. Volkskundliche Perspektiven auf Mensch und Umwelt. Münster u.a.: Waxmann 2001, S. 418.

351 Pötzsch, Eduard: Meine Ansicht über Landesverschönerung (1828); zit. n. ebda. 
verweist auf Paul Schultze-Naumburg, Architekt, Kulturkritiker und erster Vorsitzender des »Heimatschutzbundes« und dessen postulierte »Sachlichkeit und Funktionalität« bezüglich Architektur und Städtebau. ${ }^{352}$ Das ist nur bedingt richtig. Schultze-Naumburg und andere sind Verfechter eines viril-nationalen Pseudo-Organischen. ${ }^{353}$

Das Brechen von >Hochwasserregimes` ist im 19. Jahrhunderts (und seitdem) zum Großprojekt geworden. Der Rhein wird von Bachofens Heimatstadt Basel an nördlich jahrzehntelang mit großem Aufwand kanalisiert. Dabei werden die Gegenwelten tatkräftig zum Verschwinden gebracht. Auch diese Wildnis-Bändigung ist durchaus im Hinblick auf eine moralisch-hygienisch-ästhetische Programmatik entworfen.

»Den ersten Schlag versetzte der badische Pionieroberst und Wasserbauer Johann Gottfried Tulla der Auenwildnis, als er im Jahre 1817 begann, den gesamten Rhein in ein Korsett zu zwingen. Ein gigantischer technischer Eingriff: Unzählige Flußkrümmungen wurden da durchstochen und der in zahlreichen Rinnen fließende Strom nach und nach zwischen fast geradlinigen Hochwasserdämmen eingezwängt. Sechs Jahrzehnte dauerte es, da war der Rhein gebändigt und floß brav in der Kanal-Rinne daher. [...] Der Mensch nutzte die Gelegenheit, drang in die sterbende Naturlandschaft ein, rodete die Wälder und verwandelte sie in Äcker. Von den Auwäldern, die einst den Rhein zwischen Basel und Mainz säumten, sind ganze sechs Prozent verschont geblieben. $\ll^{354}$

Armin Maywald unterstellt eine eher unbeabsichtigte Zerstörung der Wildnis. Tulla habe nicht ahnen können, dass eine höhere Fließgeschwindigkeit des kanalisierten Rheins und eine damit verbundene tiefere Einschneidung ins Flussbett ein Absaugen des Grundwassers aus der Landschaft bewirken würde. ${ }^{355}$ Maywald unterstellt außerdem, dass die Gelegenheit zur Urbarmachung durch die Anwohner bloß ausgenutzt worden sei. Es ist aber nicht nur wahrscheinlich, dass die endlich mögliche Kultivierung ehemals unzugänglicher - und dadurch wertloser Landschaft, die agrarische Ausnutzung fruchtbaren Auenlehms und damit die Zerstörung der Auenwälder auch beabsichtigt oder zumindest einkalkuliert ist. Es ist von Tulla geplant. 1825 beschwört er die »möglichst gerade Leitung der Flüsse, die Abschneidung ihrer Nebenarme, die Demolirung der schädlichen Dämme usw.«. Die »Rektifikation der

352 Vgl. Fährmann, ebda., S. $418 \mathrm{ff}$.

353 Vgl. Kap. Der Wald als kämpferische Volksgemeinschaft u. Kap. >Heilige Hallen< II.

354 Maywald, Armin: Naturoasen in Deutschland, S. 122.

355 Vgl. ebda. 
Flüsse« sei »diejenige Operation, durch welche ihren Zerstörungen Einhalt gethan, und ihr Wasserspiegel so gesenkt wird, daß die Nachtheile der Ueberschwemmungen und die der Eisgänge vermindert, oder vollkommen beseitigt werden «. ${ }^{356}$ Arme müssen amputiert, nicht durch Ingenieurskunst, sondern klandestin entstandene Dämme »demolirt« werden. Das Ganze hat eine notwendig brutale, totale Operation zu werden, denn:

»Ohne die Rektifikation des Rheins werden die Sturmglocken nicht verstummen, das Brechen der Dämme nicht immer gehindert und bald dieser bald jener Ort und seine Gemarkung unter Wasser gesetzt werden; die Sümpfe werden nicht nur nicht verschwinden, sondern sie werden bedeutender werden und Niederungen, welche früher noch benutzt werden konnten, werden später die Zahl der Sümpfe vermehren, weil sich die Quellwasser vermehren und der Abfluß derselben immer mehr gehindert wird. ${ }^{357}$

Was nicht nur fatal fürs Vieh - wegen »sumpfiger Wiesen« und »saurer Gräser« - sei, sondern schlimmer noch für die Menschen (schon wegen der seuchenauslösenden Miasmen): »Mit der Vergrößerung dieser Uebel muß sich der Wohlstand der Rheinufer-Bewohner vermindern, ihr physischer Zustand sich verschlimmern und ihr moralischer sinken.« Sümpfe gebären Sümpfe, unaufhörlich. »Wann hört die Vergrößerung der Uebel auf? $\ll^{358}$

Gefährdet sind die sozialen Normen der »Sittlichkeit« und »Moral« und damit der »Gesundheit«, letztlich der Volksgesundheit. Tullas Argumentation steht offenbar in Zusammenhang mit der »medizinischen Polizey«, der umfassenden bürokratisch herrschaftlichen Regelungsversuche, des "gesamte[n] öffentliche[n] und private[n] Leben[s] nach gesundheitlichen Erfordernissen«, der Einführung der »Pastoralmedizin« und Nutzung von Zwangsinstitutionen dazu, »die Untertanen unter den Werten von Gottesfurcht, Sittlichkeit und Gesundheit zu arbeitsamen Untertanen zu erziehen«. Alfons Labisch spricht von einer ökonomischsozialen Integration auf der jeweiligen Klassenebene. Den »rationalen und individualistischen Lebensregeln der bürgerlichen Führungsschichten entsprechen die gleichzeitig auf einer niederen sozialen Integra-

356 Tulla, Johann Gottfried: Ueber die Rektifikation des Rheins, von seinem Austritt aus der Schweiz bis zu seinem Eintritt in das Großherzogthum Hessen, Karlsruhe 1825, S. 6f.; zit. n. Brüggemeier, Franz-Josef/ToykaSeid, Michael (Hg.): Industrie-Natur. Lesebuch zur Geschichte der Umwelt im 19. Jahrhundert. Frankfurt/M, New York: Campus 1995, S. 94.

357 Tulla, a.a.O., S. 51; zit. n. ebenda.

358 Ebda. 
tionsstufe in religiösem Gewande einhergehenden Verhaltensanforderungen an die bäuerlichen Unterschichten «. ${ }^{359}$ In England führt das utilitaristisch-sozialreformerische »sanitary movement « in der schon angesprochenen Anwendung der Miasmen-Theorie den Dreck als Krankheitsursache an. In Deutschland wird ab 1851 Friedrich Oesterlen diesen Ansatz der reinlichen - inklusive moralisch reinen - Lebensführung für die jeweiligen gesellschaftlichen Klassen propagieren.

»Nicht leicht kann das geistig-sittliche Leben im Elend der Armuth, mitten in Schmutz und schlechtem Beispiel von Kindheit an gedeihen, - bei Sklaven, Leibeigenen so wenig als z.B. beim heutigen Fabrik-Proletariat, überhaupt bei den ärmeren, verwahrlosten Volksclassen. ${ }^{360}$

Die »Lebensumstände« determinieren »auch das geistig-sittliche Leben der Menschen«: Die Disziplinierung der >inneren` wie >äußeren Natur lässt sich hier mit Tullas »Rektifikation« als Arbeit an ein und derselben Sache darstellen.

Flüsse werden in der Renaissance zu Bildern einer »Welt im Fluß« erklärt. ${ }^{361}$ Seit dem ausgehenden 18 . und beschleunigt seit dem 19. Jahrhundert dienen Flüsse als Identifikationsobjekte für »die Idee der Aufklärung « und für den (naturwissenschaftlich-technischen) Fortschritt. ${ }^{362}$ Hochwasser hingegen besitzt in der Moderne bestenfalls ein prekäres ästhetisches Potential als >eilende`, >flüchtige` aber >trügerische Art von >Naturschönheit`, gilt aber zugleich als höchst bedrohlich, weil das Wasser etwa landwirtschaftliche Flächen ertränkt. Der Schlamm am Grund erscheint gefährlich, enthält Giftstoffe, produziert Untiefen. Nach noch immer beachteten traditionellen Erfahrungen kann dieser Schlamm, der sich nach dem Rückzug des Wassers absetzt aber auch brauchbar, weil fruchtbar sein.

359 Labisch, Alfons: »Hygiene ist Moral - Moral ist Hygiene« - Soziale Disziplinierung durch Ärzte und Medizin, in: Sachße, Christoph/Tennstedt, Florian: Soziale Sicherheit und soziale Disziplinierung. Beiträge zu einer historischen Theorie der Sozialpolitik. Frankfurt/M: Suhrkamp 1986, S. $269 \mathrm{f}$.

360 Oesterlen, Friedrich: Handbuch der Hygiene (Tübingen 1851), S. 708; zit. n. ebda., S. 273.

$361 \mathrm{Vgl}$. Wind, Edgar: Heidnische Mysterien in der Renaissance. Frankfurt/M: Suhrkamp $1984^{2}$ (London 1958), S. 312. Wind verweist hier auf die Anwesenheit von Flussgöttern, Oreaden und einer Najade in der neuplatonischen Interpretation des »Urteils des Paris«, in der Aphrodite den Apfel erhält, bei Pico bzw. im Stich Marcantonio Raimondis.

362 Vgl. Schwarz, Astrid E.: Wasserwüste - Mikrokosmos - Ökosystem, S. $131 \mathrm{f}$. 
Hochwasser wird aber vor allem als 〉jenseits der Zeit«, der linearen Zeit, wahrgenommen: als zyklisch, periodisch, aber auch als stockend. Das zyklische >Hochwasserregime $\prec$, die stets wiederkehrende Ausdehnung, Überflutung ist eine Bewegung in die Breite, horizontal, eine Bewegung in der Gegenwart, oder deutlicher: in die Gegenwart. Der begradigte Fluss hingegen ist Fortschritt, bewegt sich linear. Er fließt nach vorn, und nur nach vorn. Seine Bewegung ist linear, in die Zukunft. Zwar bewegt sich auch das noch nicht gezähmte Fließgewässer in die Zukunft. Aber diese Linearität ist eben noch gleichberechtigt gepaart mit Zyklizität, ungeregeltem Mäandern, dem Abkommen vom rechten Weg in Nebenarmen, der beständigen Bedrohung der Kultur durch das Chaos, der Behinderung des Fortschritts.

Dabei sind großangelegte Trockenlegungen nichts exklusiv Neuzeitliches. In der ersten Phase der Kolonisation »Altpreußens« durch den »Deutschen Orden« kommt es nach Friedrich Mager zwischen 1280 und $1410 \mathrm{zu}$ einer starken $»$ Verminderung des Waldes in der westlichen und nordwestlichen Zone [...], wo trotz der altpreußischen Besiedlung noch ausgedehnte, wenigstens 60 v.H. des Gesamtareals einnehmende Waldund Bruchwildnisse zur Verfügung standen. Vorzugsweise in diesen wurden die deutschen Kolonisten angesetzt, die den Wald in der genannten Zeitspanne allenthalben stark zurückdrängten, seinen Zusammenhang sprengten und schließlich den offenen landwirtschaftlichen Kulturflächen weithin das Übergewicht über den Wald verschafften«. Mit der Rodung der Au- und Bruchwälder des Weichseldeltas sei erst um 1300 begonnen worden. Trotz technischer Probleme beim »Bau von Entwässerungsanlagen und Deichen«, seien im Laufe des 14. Jahrhunderts diese Wälder zugunsten von Agrarflächen weitgehend beseitigt gewesen. Die nordöstlich angrenzenden Bruchwälder der Weichsel-Nogat-Niederungen hätten in dieser Zeit »noch einen durchaus amphibischen Charakter« besessen. Sie »konnten freilich erst seit dem 16. und 17. Jahrhundert gerodet und besiedelt werden, nachdem die Aufschlickung und Verlandung dieser Zone die nötigen Fortschritte gemacht hatte ${ }^{363}$

Hans Hausrath zufolge hat es zur Absicherung der Landgewinnung an Flussufern im späten 15. Jahrhundert Aufforstungen gegeben.

»Die Mittel zur Verlandung waren wie heute: Faschineneinbauten, um die Strömung zu brechen und zu lenken; Schlammfänge und Entennester zur Beschleunigung der Aufhöhung und Pflanzung von Kopfhölzern und Weiden zur

363 Mager, Friedrich: Der Wald in Altpreußen, Bd. I. Köln, Graz: Böhlau 1960, S. 29. 
Schaffung der ersten Bestockung. [...] War die Bodenerhöhung weit genug fortgeschritten, so pflanzte man Eichen, Eschen, Ulmen und Pappeln und der Mittelwald war fertig. ${ }^{364}$

Landgewinnung und Landschaftsbau: Hier wird bereits eine 'zweite Natur` gegen die noch nicht gezähmte >erste` ins Feld geführt. Systematische Landgewinnungen per Entwässerung von Feuchtgebieten gibt es seit dem 17. Jahrhundert. Diese Kultivierungen werden nun »in Holland und England durch die stetige Expansion der ländlichen Marktwirtschaft und durch den Export holländischer Wasserbautechnologie beschleunigt«. Erste Windmühlen »als Energiequelle zur Trockenlegung von Sumpfland « entstehen bereits 1408, aber noch sind die Aufnahmekapazitäten der Entwässerungskanäle nicht groß genug. Im 17. Jahrhundert entwickeln Ingenieure wie Jan Leeghwater, Gilles van den Houten, Cornelius Janszoon Meyer oder Cornelius Vermuyden in den Niederlanden umfangreiche Pläne zur Entwässerung und optimierte Konstruktionen von Mühlen, Pumpen, Schleusen und Deichen. Ein von niederländischen Finanziers unterstütztes »technisches Expertenwissen, das man in Länder wie Italien, Frankreich und England exportieren konnte«. So können »in großem Stil« Binnenseen leer gepumpt und die verwendeten Windmühlen zum Antrieb der »ersten Industrien« dienen. Wird die »Ingenieurkunst « in den Niederlanden zumeist zur Landgewinnung aus dem Meer genutzt, geht es in England um die Trockenlegung der »fens«, in Italien vor allem der Pontinischen Sümpfe in der Umgebung Roms (ein Projekt, das allerdings erst vom faschistischen Staat, propagandistisch unterlegt, vollendet wird). ${ }^{365}$

Derartige Projekte, z.B. zur Gewinnung von Weideland, werden allerdings obrigkeitlich gegen den oft erbitterten Widerstand der »heimischen Bewohner, die ihre Lebensgrundlage gefährdet sahen« durchgesetzt, häufig mittels Vertreibung. Die Melioration der »fens« im 17. Jahrhundert »ist ein schlagendes Beispiel für die Auswirkungen frühkapitalistischer Landwirtschaft auf die Umwelt und die Armen«. Mit der Zerstörung der Landschaft verschwinden auch Fische und Vögel, die Bestandteil der Nahrung dieser Menschen gewesen sind, zugunsten einer »die folgenden drei Jahrhunderte« andauernden Verwandlung des gesamten Gebiets »in säuberlich bepflanzte Korn-, Zuckerrüben- und Kar-

364 Hausrath, Hans: Geschichte des deutschen Waldbaus. Von seinen Anfängen bis 1850. Freiburg/Br: Hochschulverlag 1982, S. 183.

365 Vgl. Merchant, Carolyn: Der Tod der Natur, S. 71f. 
toffelfelder [...], über die sich das geometrische Muster der Kanäle legte ${ }^{366}$

Was hier strenge Geometrisierung im Gitterraster ist, verlangt andernorts, unter den Maß-Gaben der ästhetisch-herrschaftlichen Repräsentation, nach anderen Formgebungen. Am großangelegten ordnenden Zugriff ändert das nichts. »Die Zisterzienser-Abteien von Fountains Rieveaulx-Abbey in Yorkshire sind größer, reicher und ausgedehnter als all die auf dem Kontinent. Das Naturgefühl des englischen 18. Jahrhunderts wünschte beiden eine gartenarchitektonische Fassung zu verleihen, und aus diesen hochoriginellen Versuchen spricht eine wirkliche Verehrung für die Baukunst des Mittelalters«, schreibt Harald Keller, der diese Anlage zur »große[n] Baukunst in großer Natur« erklärt, um sie von der bloß »skurrile[n]« Melange aus »Rokoko und Pseudo-Gotik« des Landhauses von Horace Walpole abzusetzen. Die Klöster, im 12./13. Jahrhundert in der Einsamkeit der >Waldwüste< gegründet, sollen von der englischen Gartenarchitektur des 18. Jahrhunderts »als Zielpunkte [...] landschaftsgärtnerischer Achsen« ins Malerische einbezogen werden. Das werde »noch im Spätbarock« von 1720 bis 1730 in Gestalt des Landschaftsgartens »The Wonder of the North« in der Nähe von Ripon (Yorkshire) verwirklicht. Zur »großartigen Natur wesentlich beitragen soll der zwei Meilen südwestlich fließende kleine $»$ River Skell«. Um mit ihm die Abtei Fountains mit dem Schlossgut Studley Royal zu verbinden, muss sein Lauf von Biegungen bereinigt werden. »Mit einer erstaunlichen Konsequenz begann die Familie Aislabie diesen Plan zu verwirklichen, schon 1718 wurde der Fluß kanalisiert, 1727-30 wurden die Ufer gartenarchitektonisch gestaltet, wodurch halbmondförmige Seen, von großen Laubkulissen eingerahmt, unmittelbar an den Flußlauf herantraten und auf dem schmalen Grünstreifen zwischen Fluß und Seen Statuen postiert wurden«. 1768 gelinge es dann »dem Sohne des Begründers des Wasserparks endlich, die Ruine Fountains in seinen Besitz zu bringen«. Nun kann der Flusslauf vollständig »auf die Ostfassade der Abtei« ausgerichtet und die Kulisse aus Bäumen bis zu diesem Punkt vorgezogen werden. »Wasser, die strenge Zisterzienser-Architektur und die umfassende Laubwand - sonst gibt es hier nichts. ${ }^{367}$

Was zu Beginn des 18. Jahrhunderts in England noch in vergleichsweise überschaubarem Rahmen und als exklusive landschaftsarchitekto-

366 Ebda., S. $72 \mathrm{ff}$.

367 Keller, Harald: Goethes Hymnus auf das Straßburger Münster und die Wiedererweckung der Gotik im 18. Jahrhundert. 1772/1972= Bayerische Akademie der Wissenschaften. Philosophisch-Historische Klasse. Sitzungsberichte, Jahrgang 1974, Heft 4. München 1974, S. $46 f$. 
nische Einschreibungen der Oberschicht erscheint, erhält mit Beginn des 19. Jahrhunderts, in Deutschland, am Rhein, systematische und gesellschaftliche Dimensionen. Und hierin liegt der Unterschied zu vorangegangenen Umsetzungen von Kanalisierung und Melioration. Die wechselseitigen Entsprechungen >innerer` und >äußerer Natur`, von Landschaft und »Haushalt des Begehrens «, ${ }^{368}$ die Wahrnehmung und Zuordnung von »Innenraum« und »Außenraum« beginnen, zu einer übergreifenden gesellschaftlichen Sinnproduktion zu werden. Der Fluss als Sinnbild des Fortschritts, der disziplinierten Natur. Der Fluss, der gebändigt, im Kanal gebündelt fort-schreitet, ist >innen`, sowohl, was seine wissenschaftliche Konstruktion, als auch, was seine Existenz als Landschaftsraum, in dem »sich Gemüt und Seele spiegeln «, ${ }^{369}$ angeht. Um 1800 heißt das:

»Flüsse müssen kontrolliert werden, ebenso wie die Individuen in der Gesellschaft zu ihrem eigenen Wohl vor Übergriffen in jeweils andere Interessensphären bewahrt werden müssen. Was in der Gesellschaft durch den Gesellschaftsvertrag und die Vernunft geleistet wird, wird beim Fluß - ebenfalls zu seinem Vorteil - durch die [...] >Bewallung〈 und durch >Dämme〈 bewerkstelligt. $\ll^{370}$

Neben der »Bewallung« flacher Ufer werden Manipulationen von Prallhängen empfohlen, ihre »allmählige, gleichförmige Abdachung « ${ }^{371}$ und ihr Bestecken »mit Reisern von Korbweiden«, wie Johann Friedrich Wilhelm Otto ausführt, denn solche Maßnahmen

»verhindern dann die weitere Ausbreitung des Gewässers über die niedrigen Gegenden des nahe gelegenen Landes. Der Strom wird genöthigt, in seinen Grenzen zu verbleiben; er behält dann den erforderlichen Grad der Geschwindigkeit, und reinigt dadurch den Boden in seinem Bette «. ${ }^{372}$

Die Bändigung bewirkt also, analog zur menschlichen Natur, die innere Reinigung von morastigen Untiefen. Auch auf diese Weise ist beim Fluss Moral Hygiene (bzw. umgekehrt).

Schwarz zeigt am Werk Ottos exemplarisch, wie und warum in dieser Zeit der Fluss >Innenraum〈 ist, während der See und ebenso »Sümpfe

368 Kamper, Dietmar: Unmögliche Gegenwart, S. $73 \mathrm{ff}$.

369 Schwarz, a.a.O., S. 112.

370 Ebda., S. 132.

371 Otto, Johann Friedrich Wilhelm: System einer allgemeinen Hydrographie des Erdbodens (Berlin 1800), S. 166f.; zit. n. Schwarze, a.a.O., S. 129.

372 Otto, ebda., S. ; zit. n. a.a.O., S. 132. 
und Moräste« noch >Außenraum〈 sind. ${ }^{373} »$ Flüsse sind technisch manipulierbar« und sollen das auch sein, etwa, um Versandung zu verhindern. Charakteristika der Fließgewässer sind ihr Fließen nach Gesetzen, ihr »Lauf» in »Kanälen" und ihre Beschreibbarkeit als physikalische Objekte. »Entsprechend werden die Flüsse der Logik einer naturwissenschaftlich-systematischen Natur folgend konstruiert, über die wiederum die technische Manipulierbarkeit zunehmend perfektioniert werden kann.« Natur wird zur Abstraktion, mit den Mitteln der Geometrie nicht nur Objekt der Beschreibung, sondern der Re-Konstruktion. »Der Fluß wird also vollkommen erfaßt von den Regeln der Geometrie, es bleibt kein noch so kleiner Rest an Unklarheit, oder >Un-faßbarkeit` zurück.« Nach diesen geometrischen Regeln ist alles am Fluss mess- und berechenbar: Tiefe wie »Normalbreite« von Ufer zu Ufer, seine Bewegung und die Wassermenge, sein »Profil ${ }^{374}$ Denn »man kann sich in jedem Flusse ebene Flächen gedenken, welche quer durch ihn gehen, auf seine Richtung senkrecht sind und ihn bis auf den Grund durchschneiden ${ }^{375}$ Der Fluss also als unendliche Reihe von senkrechten Flächen. Mehr noch, er besteht auch aus »Wassersäulen«, die den Newtonschen Gesetzen folgen: So wird das Fließgewässer »von der Quelle bis zur Mündung zu einer Reihe aufeinanderfolgender Wassersäulen, deren Masse und Bewegung den Gesetzen der Mechanik folgen«, zum abstrakten Gebilde, das nicht als konkrete physiognomische Gestalt wahrgenommen wird, sondern als »gestaltlos «. ${ }^{376}$ Gestaltlos heißt hier linear, unaufhaltsam, wie das Ticken der Uhr, der mechanistischen Zentralmetapher, die real nicht einfach Metapher bleibt, sondern >somatisch « wird, kein Verweilen und sich dort gemein Machen (〉Mäandern $২$ ) erlaubt. Gestaltlos heißt auch, Fortschreiten ohne Erinnerung, Abstreifen der Tradition, zugleich Immunisieren gegen neues, das vom linearen Weg abführt. Gestaltlos heißt: rein quantitativ, wird aber als Qualität behauptet und wahrgenommen. Es geht voran.

»Die Flüsse haben kein spezifisches Objekt; das Fließen will zunächst nichts als stattfinden, dann erst finden«, ${ }^{377}$ schreibt Theweleit zur Wunschproduktion, zur realen körperlichen und zur literarischen Übersetzung. Dieses Strömen hat eine ganz andere Gestaltlosigkeit: »Das Fließen der Libido wird besungen, sein allgemeinstes Prinzip: landen, wieder frei treiben [...] kein vorgegebenes Zielobjekt haben, weil alles

373 Vgl. Schwarz, ebda., S. 128.

374 Vgl. ebda., S. $129 f$.

375 Otto, a.a.O., s. 152; zit. n. ebda., S. $129 f$.

376 Schwarz, ebda., S. 131.

377 Theweleit, Klaus: Männerphantasien 1, S. 339. 
sein Objekt ist. Die Wasser fließen zu allen Küsten und von allen Küsten. ${ }^{378}$ Das ist der »Wunsch zu Wünschen«, wie Deleuze/Guattari, auf die Theweleit sich immer wieder stützt, ihn unter der Hülle des »Ödipuskomplexes « hervorgezogen haben. ${ }^{379}$ Und es ist die Zurückweisung Freudscher Zielfixierung. Keine Flusslandschaften, die sich mit denen Tullas oder Ottos zur Deckung bringen lassen. In Deleuzes/Guattaris »Wunschmaschinen funktioniert alles zur gleichen Zeit - begleitet aber von Pannen und Fehlzündungen, Stockungen, Kurzschlüssen, Unterbrechungen, von Zerstückelungen und Abständen und zudem innerhalb einer Gesamtheit, deren Teile sich niemals zu einem Ganzen zusammenfügen lassen: weil die Einschnitte produktiv sind und selbst Vereinigungen bilden «. ${ }^{380}$ Das wäre die Landschaft eines Flusses, der beständig $>$ Arme $<$ bildet und wieder abschneidet, sein 〉Bett $<$ wechselt, Ufer zerstört und neue aufbaut.

Der Fluss ist die wesentliche Entsprechung der `äußeren Naturく zur >inneren` des vergesellschafteten menschlichen Körpers. Insbesondere, was seine Eindämmung betrifft. Das Fortschrittsversprechen dieses Flusses ist ein doppeltes (und antagonistisches): Zum einen »Deterritorialisierung«, die Entgrenzung der Produktionsmöglichkeiten der Menschen«, die Geld-, Waren- und Arbeiterströme in Gang setzt und sich selbst mit den Blut- und Schweißströmen der Arbeiter und außereuropäischen Völker antreibt«, aber zugleich, mit dem Einreißen bisheriger sozialer Kontrollen, auch »eine Entfaltung der menschlichen Lüste« möglich werden lässt, und daher zum anderen »Reterritorialisierung«. Sie »entwirft den Menschen als >Beherrscher» der Maschine und den Lenker und Kanalisierer seiner und der gesellschaftlichen Ströme, ein reaktionäres Programm, denn Objekt dieser Aktionen ist sein eigenes Unbewußtes: stillgelegte Produktion dort, während die Geldströme flieBen ${ }^{381}$

Die Ströme des geometrisierten Flusses landen nicht, sie lassen sich nicht frei treiben. Es sind »codierte Ströme«, zuverlässig kanalisiert und in eine Richtung gelenkt. Es geht voran, und nicht in die Breite oder nach unten. Das bleibt den Seen (oder Sümpfen) vorbehalten. Seen sind bei Otto >Außenräume $<$ und sie sind physiognomisch erfassbar, »individuelle Gestalten«. Sie gehören zur »unmittelbaren, konkreten Natur«, sie gehorchen nicht den »Gesetzen der Mechanik« und werden daher nicht als »Aneinanderreihung von Wassersäulen beschrieben«. Zwar haben

378 Ebda., S. 328.

379 Deleuze, Gilles/Guattari, Félix: Anti-Ödipus, S. 68ff.

380 Ebda., S. 53.

381 Theweleit, a.a.O., S. 335. 
sie, analog zum »Bett« des Flusses, ein »Becken«, dazu einen »Rand«, »Ufer« und »Inseln«, also »einen mechanischen Anteil«, werden aber weder bis auf den Grund >durchschnitten`, noch bezüglich ihres »Wasserhaushaltes« bilanziert. Versuche, Angaben über ihre »morphologische[n] Regelhaftigkeiten oder physikalische[n] Gesetzmäßigkeiten« zu machen, verlieren sich überwiegend im Vagen, Etwaigen. ${ }^{382}$ Auch Horace Benedict de Saussure hat 1779 den See aus der Perspektive des >Innenraums (Fluss) als >Außenraum८, als »Fremdkörper« und Mangelerscheinung konstruiert. ${ }^{383}$ Seen sind dazu offensichtlich unproduktiv, da sie »Flüsse aufnehmen und wieder von sich lassen« oder aber »Flusswasser empfangen, aber keins abführen «. ${ }^{384}$ Sie haben eine bestenfalls »ergänzende Funktion «, ${ }^{385}$ werden »gegenüber den Flüssen gewissermaßen als defiziente Objekte betrachtet, da »ihre >Hauptkennzeichen ausschließlich in Bezug auf die Flüsse beschrieben werden «. ${ }^{386}$ Eine Abhängigkeit, die dann auch nicht folgenlos bleibt.

Während das 〉Gestaltlose`, Geometrische fassbar ist und bleibt, löst sich das »Gestalthafte« hingegen in dem Moment auf, in dem es »mit naturwissenschaftlich-systematischen Methoden beschrieben und erklärt wird «. ${ }^{387}$ Ein weiteres Mal wird die Geometrisierung zur einzig angemessenen Re-Konstruktion der Natur des fließenden Wassers, denn dessen »wichtigste[s] Attribut«, die »Bewegtheit», bedroht die Existenz der Seen, »indem diese durch den Einfluß des fließenden Wassers kleiner werden, wenn nicht gar völlig verschwinden«, wie Otto am Beispiel des Genfer Sees behauptet. Die »Natur des Flusses bedeutet eine Gefährdung für die Natur des Sees oder ist ihr wenigstens nicht angemessen«. Das schon, weil der See als ein »vorübergehendes und vom Fluß abhängiges Phänomen, ein `Surrogat` des Flusses (oder auch des Meeres)« gilt, was sich bei Otto und bereits bei de Saussure finden lässt. ${ }^{388}$ Der See ist abhängig, >Surrogat`, wird vom Fluss geschaffen und wieder gelöscht, er ist zwar gestalthaft und historisch, aber vergänglich. Er ist ein Fremdkörper und konkret. Seine Tiefen sind nicht messbar (dann verschwindet er). Er ist Bestandteil des >Außenraums $\prec$. In dieser Weise entspricht er dem »außereuropäische[n] und unbekannte[n] Raum, der Kolonie, dem »Anderen«, »Frau, Natur, Gefühl«, während der >Innenraum das Abstrakte, das »Binnenland«, das »Eine«, »Mann, Kapital,

382 Vgl. Schwarz, a.a.O., S. 133f.

383 Vgl. ebda., S. 127.

384 Otto, zit. n. ebda., S. 128.

385 Schwarz, ebda., S. 133.

386 Ebda., S. 128.

387 Ebda., S. 136.

388 Vgl. ebda., S. 134. 
Vernunft«, Nation« usw. repräsentiert, wie Schwarz das an anderer Stelle skizziert.

Der Fluss wird zur Berufungsinstanz eines gesellschaftlichen Fortschritts, der sich unbeirrbar linear bewegt und dabei alles im Weg Stehende beiseite räumt. »Jeder Fluß gräbt sich seinen Kanal durch eigene Kraft aus, und proportionirt ihn nach der Menge des abzuführenden Wassers«, dabei »ebenen« Flüsse »den Boden, worauf sie fort gehen«, wobei sie »unfehlbar allenthalben [...] alle Hindernisse weggeschafft« haben, »die ihrem gleichförmigen Laufe entgegen standen $« .{ }^{389}$ Der Fluss wird damit zur Metapher seines zumeist zukünftig noch zu schaffenden `Selbst` als Kanal. Schon deshalb sollte dieser Kanal als ıwahre Natur des Gewässers erscheinen. Denn nur ein kanalisierter Fluss räumt Hindernisse ausschließlich weg, reißt sie mit sich, nach vorn, »unfehlbar«. Ungebändigte Flüsse beseitigen zwar auch Hindernisse, sie schaffen aber zugleich ständig neue, indem sie Ufer abreißen, Bäume entwurzeln, Sandbänke aufschütten.

Die Flüsse des >Innenraums` dagegen halten sich nicht auf und nehmen nichts an; »entlang ihrer Ufer findet zwar Geschichte statt, aber sie selbst sind ihrem Wesen nach >geschichtslos`. Die Paradoxie in der Konstruktion der Flüsse besteht darin, daß sie, selbst geschichtslos, als Metapher für die historische Zeit herangezogen werden «. ${ }^{390}$ Der Fluss fließt quantitativ, der qualitative Kontakt zur Außenwelt ist untersagt, der Kanal schottet ab gegen das Konkrete. Der >Wunsch< wird transformiert zur >Sehnsucht» nach Irgendetwas in der zentralperspektivisch stetig unerreichbaren Ferne. Der Rest bleibt sentimentale Kulisse, die sich mit Gewinn genießen lässt. Rheinromantik.

Auch die Rheinromantik ist ein Abkömmling des Fort-Schritts. Zwar haben Georg Forster et al. schon vor 1800 ihre Rheinfahrten unternommen. Aber »zum Lieblingsfluß« eines regelrechten »romantischen Tourismus« wird der Rhein erst seit dem »zweiten und dritten Jahrzehnt des 19. Jahrhunderts«. Man kann die vorgebliche Ironie der Erzeugung einer "ganze[n] neue[n] Generation von Produzenten und Konsumenten fluvialer Mythen«, wie Simon Schama, »auf das Auftauchen von Dampfern auf den großen Flüssen ${ }^{391}$ zurückführen, greift damit aber etwas zu kurz. »An Deck eines Raddampfers konnte sich der eifrige Tourist über die Loreley belehren lassen oder Heines Version lesen (wenn nötig, in der Übersetzung von Mark Twain), während rheinische Burgen, Dörfer

389 Otto, a.a.O., S. 156; zit. n. ebda., S. 131.

390 Schwarz, a.a.O., S. 135.

391 Schama, Simon: Der Traum von der Wildnis, S. 392f. 
mit Fachwerkhäusern und Weinberge vorbeiglitten. « ${ }^{392}$ Diese Rheinromantik aber ist von der Kanalisierung nicht zu trennen.

In der Tat ist fürs ständige Besingen des >Vater Rhein` und dessen >romantischer Schönheitく das von Friedrich Silcher vertonte »Ich weiß nicht was soll es bedeuten..." ein herausragendes Beispiel, dessen Verbreitung und sinnstiftender Charakter so enorm gewesen ist, dass es selbst im faschistischen Deutschland gesungen werden durfte, wobei der Autor als »unbekannt « ausgewiesen werden musste, um den konvertierten Juden als Urheber verschwinden zu lassen. Als Heinrich Heine 1824 sein Loreley-Gedicht verfasst, ist es schon sieben Jahre her, dass der Oberst Johann Gottfried Tulla sein Jahrhundertwerk der Korsettierung des >Deutschen Stroms` begonnen hat. Die Kanalisierung der Gewässer, des Rheins, hat offenbar weniger zur Entfremdung von ihnen geführt, vielmehr besteht diese Entfremdung dem >wilden Zustand damit wäre die Begradigung und Korsettierung eine Art `Heimholung^. »Und ruhig fließt der Rhein«, stetig und majestätisch, ohne Ausbrüche und Schwankungen. Das kann er aber erst seit der Pioniertat Tullas und kaum vorher. Die Katastrophe des Schiffers »im kleinen Schiffe« ist verschuldet durch eine Regression. Es ist die Nymphe, die ihr zauberkräftiges Haar kämmt und eine »wundersame, gewaltige Melodei« singt, was ihn mit soviel »wildem Weh« ergreift, dass er nicht auf den Felsen achtet und in den Fluten versinken muss. Aber in denen der archaischen Frau (»Ein Märchen aus alten Zeiten«), zugleich denen der 〉Luxuria〈, wie der Kamm ausweist, ${ }^{393}$ und nicht in denen des >Vaters $<$ Rhein, der er wohl erst seit seiner >Heimholung « so richtig sein kann.

Diese touristische >Romantik $>$ Idylle $<$ im >Imposanten`: Burgen und Ruinen, Fachwerkhäuser, Weinberge- und Stuben; allesamt Bilder von etwas >Heilem`, einer >Versöhnung/ von Kultur und Natur. Idylle stammt vom griechischen »eidyllion« (Bildchen) und »meint einen Zustand des abgeschirmten Glücks, das im Bildcharakter des Realen gesucht wird und für die vielfältige Unbill der Wirklichkeit entschädigen soll«. ${ }^{394}$ Idyllen sind

»Substitute, mit denen sich leben läßt, jedenfalls vorübergehend. Es sind Signaturen einer Herrschaft über das Unerträgliche: über das gewaltige Göttliche,

392 Ebda.

393 Vgl. Bessler, Gabriele: Von Nixen und Wasserfrauen. Köln: DuMont 1995, S. 130.

394 Kamper, Dietmar: Unmögliche Gegenwart, S. $73 \mathrm{ff}$. 
das im Bilde gebannt ist und über das chaotische Leben, das gerade wegen seiner überbordenden Fülle erst in Grenzen erblüht «. ${ }^{395}$

So, wie der Rhein erst als Eingegrenzter »erblüht«. Das eben scheint ein Gegenteil von Entfremdung zu sein. Kamper selbst betont ja, dass »der Machtapparat« immer auf das »Funktionieren« der Idyllen »im Haushalt des Begehrens angewiesen« ist, was impliziert, »daß sie ihr Versprechen - wie verschoben auch immer - einlösen müssen «. ${ }^{396}$

Fließendes Wasser als quantifizierbare Abfolge von Wassersäulen. Die Geometrisierung hat eine Vorgeschichte. Rudolf zur Lippe hat sie erzählt, und nach ihm Klaus Theweleit. Es geht um das programmatische Circe-Ballett am Hof des französischen Königs Heinrich III. im ausgehenden 16. Jahrhundert, das explizit die Unterwerfung der chaotischen Natur - repräsentiert durch die von wilden Tieren umgebene »Demiurgin einer instabilen Naturordnung ${ }^{397}$ Circe - unter den Willen und die Macht des männlichen Geistes und seiner ordnenden Vernunft veranschaulicht, dargestellt als Jupiter, vom absolutistischen Herrscher selbst gespielt. Zugleich inszeniert der Tanz die Unterwerfung des >Naturwesens Frau unter das rationale Einzelsubjekt Mann, als gesamtgesellschaftlichen Vorgang ebenso, wie als je individuelle in der Ehe; vollzogen durch Königin Luise, die sich devot vor ihrem Ehemann verneigt. Die Inszenierung der Macht-Übernahme beansprucht Vollständigkeit, das Prinzip der chaotischen Natur (der Frau) unterliegt dem Prinzip der rationalen Kultur (des Mannes) und seiner geistig-technischen Macht: Circe erhält einen subalternen Platz und wird an erhöhter Stelle durch Pallas-Athene ersetzt, rein geistig gezeugte Kopfgeburt des Jupiter, Prototyp des asketischen Eros.

Circe erscheint als Symbol der Vermischung der Elemente, der »kreatürliche[n] Zeugung« und des »Begehren[s] im allgemeinen «. ${ }^{398}$ Sie »ist die Natur. Als Tochter des Sonnengottes und der Meeresgöttin Perseis ist sie Inbegriff jener $>$ Vermischung der Elemente< Feuer und Wasser, durch die >alle Dinge geschaffen sind « ${ }^{399}$ Circe, die »Zauberin« und »Verführerin« weicht im Ballett der männlichen Macht der Se-

395 Ebda.

396 Ebda.

397 Braun/Kremer: Asketischer Eros, S. 89.

398 Ebda.

399 Lippe, Rudolf zur: Naturbeherrschung am Menschen, Bd. 2, S. 428. Binnenzitat: Beaujoyeulx, Balthasar de: Le Balet comique de la Royne, faict aux nopces de Monsieur le Duc de Joyeuse \& mademoyselle de Vaudemont, sa sœur, Paris 1582. 
zession, Atomisierung und Rekonstruktion der Natur, repräsentiert durch Geometrie: Die Königin und ihre Hofdamen »formieren sich« als Najaden »bald zum carré, bald als rond und bald auch als Dreieck, zu Symbolen der sich durchsetzenden neuen Formen der Naturbeherrschung mit Hilfe der >Naturwissenschaften«". Najaden sind die reinen Quellnymphen der Fontaine des Gartens, und so ist es auch ein Springbrunnen, der im Ballett die Verwandlung des ehedem bedrohlichen weiblichen Wassers - via Macht der männlichen Technik - in »entsinnlichtes >weißes Wasser « ${ }^{400}$ und so die neue Ordnung verkörpert, den Triumph der Zivilisation des Fortschritts und der »königlichen Macht« über das »verwünschte Naturprinzip«. ${ }^{401}$ Vier Jahrzehnte später wird René Descartes den menschlichen Organismus in dieser Weise beschreiben:

»So wie man es in den Grotten und Fontänen in den Gärten unserer Könige sehen kann, daß allein die Kraft, mit der das Wasser sich bewegt, wenn es aus der Quelle entspringt, hinreicht, um dort allerhand Maschinen in Bewegung zu versetzen oder sogar einige Instrumente spielen oder einige Worte aussprechen zu lassen, je nach der verschiedenen Anordnung der Röhren, durch die das Wasser geleitet wird. Und tatsächlich kann man die Nerven der Maschine, die ich beschreibe, sehr gut mit den Röhren der Maschinen bei diesen Fontänen vergleichen, ihre Muskeln und Sehnen mit den verschiedenen Vorrichtungen und Triebwerken, die dazu dienen, sie in Bewegung zu setzen, ihre Spiritus animalis mit dem Wasser, das sie bewegt, wobei das Herz ihre Quelle ist und die Kammern des Gehirns ihre Verteilung bewirken. « ${ }^{402}$

Die Unterwerfung der >inneren` wie >äußeren Natur tistische Staatsmacht, den $>$ Maschinen-Staat ${ }^{403}$ wird inszeniert als $\gg$ profanes Ritual«. Die grundsätzliche Geometrisierung des Körpers in »Vitruvsche[r] Tradition«, seine Ausrichtung nach »Zirkel« und »Sanduhr«, also »Maß und Zeit« in den Tanzvorschriften, die Lippe untersucht, steht in einer wichtigen Beziehung zum Fechten und Springen, zu exakt geregelten physischen Abläufen des Kampfes. »Die Verwandtschaft zwischen den Bereichen wird von allen Tanzautoren mit Ausführungen über die antiken Kriegertänze ausführlich betont. « ${ }^{404}$ In der royalen Inszenierung des Kampfes zwischen männlicher Vernunft und weiblicher Natur wird

400 Theweleit: a.a.O., S. 401.

401 Lippe, a.a.O., S. 441.

402 Descartes, René: Über den Menschen (1625). N. d. frz. Ausgabe v. 1664 übers. und hg. v. Karl E. Rothschuh. Heidelberg: Schneider 1969, S. $56 f$. 403 Vgl. Kap. Forst II.

404 Lippe, a.a.O., S. $148 f$. 
»der Kampf der zentralistischen Ordnungsgewalt gegen spätfeudale Machtansprüche wie gegen diejenigen Ansprüche der Unterprivilegierten auf eine Reproduktion, die sie nicht kausal begründen konnten und wollten, zur rigiden Dichotomie stilisiert. Den Geistern, die dieser historischen Strategie zu Erscheinung und Wirksamkeit verhalfen, diente nun die äußere Natur zum Projektionsfeld der Unterdrückung von innerer. Indem die Auflehnungen gegen die gesellschaftliche Ordnung identifiziert wurden mit jener die vernunftbegabte Menschheit schlechthin bedrohenden Macht gleich Circe, konnte das Lustprinzip gewissermaßen zum Volksfeind deklariert und in den vergesellschafteten Menschen als äußerer Feind bekämpft werden «. ${ }^{405}$

Durch die Besetzung des Stücks - der König ist Jupiter, die Königin führt die Najaden, dargestellt von Herzoginnen, an - wird »das mythologische Geschehen unmittelbar auf den König« bezogen, »die Mythologie in aktuellen Mythos umgewandt «. ${ }^{406}$ Das »wirklich Wichtige $\ll$ sind »le Roy und la Géometrie«. ${ }^{407}$ Dazu wird ein ganzer Fuhrpark von Maschinen aufgeboten, »Bewegungsmaschinen« und »Flugmaschinen«, »in einer Wolke untergebracht« wird die Musik. »Die Wunder der Technik dienen im Hofballett grundsätzlich und auch mythologisch ausgewiesen dazu, die königliche Staatsordnung als politische Technik bewundern zu lassen.« Zur Maschinerie gehört auch Circes prachtvolles Feenschloss, das ihre Macht in Frankreich klar machen soll. Aus ihm stürzen, Furien gleich, ihre Tiere, nachdem es von den königlichen Truppen angegriffen worden ist. ${ }^{408}$

»Circe wird Tochter der Sonne und der Perseis genannt, weil das Verlangen und die Sinneslust den Tieren aus Hitze und Feuchtigkeit erwachsen: Wenn dieser natürliche Kitzel und ihr Stachel, der uns zur Wollust antreibt, die Oberhand über uns gewinnt, so drängt er uns zu Lastern, die uns den Tieren gleich machen: Unzucht, Fluchen, Grausamkeit und andere schlechte Eigenschaften. Doch wer von der Vernunft geleitet wird, ist vor solchen Giften sicher. ${ }^{409}$

So Odysseus, der anders als seine Gefährten, nicht in ein Tier verwandelt wird. Merkur tritt auf, Gott der Händler und damit Sinnbild der bürgerlichen Klasse, er kann allein nichts gegen Circe ausrichten, braucht die Hilfe Minervas, der staatlichen Justiz. Wie die Najaden, nachdem sie

405 Ebda., S. $436 f$.

406 Ebda., S. 440.

407 Ebda. S. 456f.

408 Vgl. ebda., S. 450.

409 Beaujoyeulx , a.a.O.; zit. n. ebda., S. 437. 
»im Halbkreis ihre geometrischen Figuren aufgegeben haben«, wird auch er von Circe »immobilisiert« und von den Tieren in die Natur zurückgeholt, in >naturhafte Stagnation` versetzt. Heinrich III. führt dagegen eine große »Koalition der Götter«, zu denen auch Pan gehört, »als eine Art von Gegennatur von Circe, verstärkt durch die »vier Dryaden« und die vier Königstugenden »Prudence, Temperence moderée, Sage mépris de la criante; Justice«. Den Ausschlag gibt die Kopfgeburt Pallas-Athene, Personifikation der »theoretische[n] Intelligenz« bzw. der Möglichkeit der Herrschaft des Verstands. ${ }^{410}$ Dass der König nicht selbst kämpft, sondern die (gesellschaftlichen) Kräfte dirigiert, macht seinen Triumph um so größer, schon weil er einen so mächtigen Gegner besiegt hat. ${ }^{411}$ Die »Apotheose« der Aufführung ist dann nicht die Niederlage Circes, oder ein \Volksfest , sondern das »grand ballet«, und zwar »derart daß ein jeder glaubte, Archimedes hätte die geometrischen Proportionen nicht besser verstehen können, als die Prinzessinnen und Damen, die sie in diesem Ballett praktizierten «. ${ }^{412}$

Theweleit bemängelt, Lippe vernachlässige einige wesentliche Punkte. So, dass die Königin sich an der Spitze des Najadendreiecks persönlich vorm Herrscher und Gemahl verneige, ihre persönliche Unterordnung in der Ehe inszeniere, womit das absolutistische Ritual das Muster der »bürgerliche[n] Kleinfamilie« bereits vorweg bilde. ${ }^{413}$ Auch im Ritual der Kopfgeburt Jupiters/Heinrich III. sei mehr zu beobachten. Daraus folge

»nämlich, daß die Prinzipien der neuen Staatsvernunft ohne fleischliche Beteiligung der Frau, durch eine Junggesellengeburt aus dem Hirn des zentralistischen Machthabers entspringen. Aller Zauber, alle Lust und Sinnlichkeit der Natur, die hier identisch mit Circe ist [...], ist aus den Zeugungen des neuen Lebens entfernt. Die Natur ist zum Ausbeuten da, was an ihr Lust verspricht, wird bekämpft, indem die sinnliche Frau bekämpft wird; selten ist dieser ständige Herrschaftssicherungsvorgang so gut greifbar wie hier «. ${ }^{414}$

Dafür stehen die Najaden/Herzoginnen, die »eigensten und reinsten Kräfte« des Landes, in ihrem »Hain«, der ein absolutistischer Garten mit Springbrunnen ist, gebändigte Natur, »Symbol des blühenden Reiches «. ${ }^{415}$ Eine Entäußerung weiblichen »Begehren[s]« zugunsten einer

410 Vgl. ebda., S. 443ff.

411 Vgl. ebda., S. 448.

412 Beaujoyeulx, a.a.O.; zit. n. ebda., S. 456.

413 Vgl. Theweleit, a.a.O., S. 401f.

414 Ebda., S. 399f.

415 Lippe, a.a.O., S. $440 f$. 
Verkörperung des »Begehren[s] des Mannes«, ${ }^{416}$ eine »öffentliche Inszenierung der Unterwerfung der weiblichen Produktivkraft, wie der Hof sie sich wünscht«, so Theweleit:

»Der Neubau des bürgerlich/absolutistischen Staats errichtet sich auf dem Fundament der Neuformierung der Sexualität der >höheren` Frau, die zum Modell für alle werden soll. Das Fließen der Ströme ist in einer Fontaine gefangen, die zur Lust des Mannes in seinem Garten sprudelt, entsinnlichtes >weißes Wasser`, gut zur Bewässerung des neuen Ordnungsstaats. Die Figuren des Tanzes sind dementsprechend entfleischlicht, die Demonstration einer Kanalisierung. ${ }^{417}$

Ganz anderes Wasser als das der Circe, dem »tiefen Schlund der Lüste« in dem die, »die führerlos wandeln« und »vom Wege« abkommen, »ertrinken« müssen, »ohne jedoch zu sterben«, weil der Geist unsterblich sei, »beraubt der Urteilskraft, unter der grausamen Kette der Lust, die unaufhörlich den Geist verhext«, wie die Worte von Pallas-Athene im Ballett lauten. ${ }^{418}$

Die Zuordnung des nichtkanalisierten Wassers als Element und natürlichem Ort verläuft eindeutig.

»Immer wieder: die Frau aus dem Wasser, die Frau als Wasser, als brausendes, spielendes, kühlendes Meer, als reißender Strom, als Wasserfall, als unbegrenztes Gewässer, durch das die Schiffe treiben, mit Seitenarmen, Tümpeln, Brandungen, Mündungen; die Frau als lockende (oder gefährliche) Tiefe, als Becher, in dem der Saft sprudelt, die Vagina als Welle, als Schaum, als dunkler Ort [...]. Die Vagina als Eingang in den Ozean, die Ozeane als Teil jeder Vagina. Wer durch das Tor tritt, beginnt eine Weltreise, ein Fließen um die Welt. Wer in der richtigen, in der Möse war, kennt alle Orte der Welt, die zu kennen sich lohnt. ${ }^{419}$

Die Symbolisierung der Frau, der weiblichen Sexualität und ihrer Anatomie durch das Wasser, die Analogie Wasser - Geburt - Frau, sind sicher schon sehr alt. Theweleit vermutet allerdings in der speziellen »Unterdrückung durch Überhöhung, durch Entgrenzung und Entwirklichung zu einem Prinzip«, die in der Wassersymbolik des »Fließens, der Weite, der unendlichen Lockung«, namenlos und entkonkretisiert, zum

416 Braun/Kremer: Asketischer Eros, S. 89.

417 Theweleit, a.a.O., S. 400f.

418 Vgl. Lippe, a.a.O., S. 445.

419 Theweleit, a.a.O., S. 358. 
Vorschein kommt, eine relativ neue Erscheinung, etwa seit dem 14. Jahrhundert, Ableger des Marienkults. »Jede einzelne wirkliche Frau wird unbrauchbar für die edlen Zwecke und paradiesischen Lüste der schöpferischen Herrn « ${ }^{420}$ - zum Beleg versammelt Theweleit eine ganze Reihe von Literaturbeispielen. Die Nymphen aber, die schaumgeborenen Aphrodite und Venus, ${ }^{421}$ derartige $»$ Frauenbilde $[r]$ « entstammen bekanntlich bereits der Antike, ${ }^{422}$ wie auch die Humoralpathologie, nach der die Frau aus ihrer größeren Feuchtigkeit und Kälte erklärt wird.

Zunächst: In der patriarchalen Analogie Frau/Wasser ergibt sich das Bild der »Untiefe« Frau, in die der Mann Angst hat zu versinken, bzw. in die er sich fallen lassen könnte, was eigentlich seinen geheimen Wunsch ausmacht, der aber verboten und daher angstauslösend ist. >Erlaubte Umgangsformen mit dem Wasser sind Kanalisierung, Eindämmung, Trockenlegung - wie die Freudsche Trockenlegung des >Es $\measuredangle$ zum $>$ Ich $<-$, Schiffbarmachung, Eroberung neuer Welten via See etc. Sicher haben all diese realen Handlungen in der Geschichte reale Hintergründe. Etwa die Sicherung des Überlebens gegen Fluten, Landgewinnung, vor allem aber politisch-ökonomische Motivationen. Gleichwohl gibt es eine Interdependenz zwischen realen Handlungen und deren symbolhaften Bedeutungen, fanden und finden die oben genannten Begriffe der Naturbeherrschung ihre Entsprechung in der herrschenden Sexualität. Traditionell-patriarchalisch lassen sich so Begriffe wie Kanalisierung und Eindämmung auf die Reduktion der weiblichen Sexualität zur monogamen Mutter, Begriffe wie Eroberung und Schiffbarmachung als Beschreibung der herrschenden männlichen Sexualität (mit der Ehe als >Hafen $\triangleleft$ in seiner impliziten Ambivalenz) entziffern.

Es bleibt der Kontext der Reduktion und der gleichzeitigen Reproduktion. Einerseits der Reproduktion weiblicher Sexualität zur Mutterschaft, die etwa Freud in seiner Deutung des Träumens von »Wasser« nachvollzieht. ${ }^{423}$ Andererseits in der (technischen) Reproduktion der Natur zur Kulturlandschaft mit ihren künstlichen Seen, Teichen, Kanälen oder Springbrunnen; aber auch in der verkehrstechnischen Eroberung des Wassers.

Das >relativ Neue < könnte also in der Möglichkeit und Pflicht zur Manipulation von Fließgewässern, wie sie in der Hydrographie um 1800

420 Ebd., S. 358f.

421 Vgl. ebda., S. 347f.

422 Vgl. Bessler, a.a.O., S. $11 \mathrm{ff}$.

423 Wenn Männer im Traum eine Frau aus dem Wasser retten, machen sie sie zur »Mutter«; wenn Frauen dasselbe träumen, »bekennen« sie sich zur Mutterschaft; vgl. Freud: Beiträge zur Psychologie des Liebeslebens, in: Studienausgabe Bd. V. Sexualleben. Frankfurt/M: Fischer 1972 
theoretisch fundiert wird, die praktisch aber schon länger betrieben wird, liegen. Die allfälligen literarischen Phantasien von über die Ufer tretenden sweiblichen Strömen wären dann die korrespondierenden imaginativen Entgrenzungen.

Die Kanalisierung des >weiblichen Wassers zu Fontainen dient der herrschaftlichen Lustbarkeit, seine Kanalisierung zu Wasserwegen, seine 〉Entsinnlichung`durch Geometrie zum 〉Gestaltlosen`, dient dem Fortschritt. Der See (ähnlich der Sumpf) ist bisher >gestalthaftく, ein historisch und kulturell geprägter Ort gewesen, konkrete Natur, die verschwindet, wenn sie errechnet werden soll. Er ist demnach nicht >entsinnlicht . Für das Ende des 19. Jahrhunderts zeigt Astrid E. Schwarz drei »Seeperspektiven«, entwickelt aufgrund dreier »ökologische[r] Basiskonzepte«, die »auf der konstruktionslogischen und semantischen Ebene ebenso präsent sind wie auf der sozio-politischen Ebene, in gewisser Weise deren Korrelate sind«. So gebe es den »liberalen«, den »konservativen« und den »funktionalen See«.

Der »liberale See« entspricht der »evolutionsbiologischen Konstruktion der Natur«. In seinem Innern herrscht eine Autonomie der Subjekte, die sich rational vertraglich »zum gegenseitigen Nutzen zusammengeschlossen« haben. Ein Vertragsbruch würde Kampf aller gegen alle bedeuten. Außerhalb existiert eine feindliche, zerstörerische Umwelt, was eine Konkurrenz der Subjekte um knappe Ressourcen bedeutet, »um im Überlebenskampf bestehen zu können«. Daneben existiert eine »RäuberBeute-Beziehung, die ebenfalls »bestimmten Gesetzmäßigkeiten folgen soll ${ }^{424}$ Es handelt sich um das Modell der »Nische«, dem knappen Lebensraum mit begrenzten Ressourcen, ohne »Wohlfahrt« und mit rein zweckbestimmten Vertragsabschlüssen, das vor allem Stephen Alfred Forbes vertreten hat. ${ }^{425}$ In Opposition dazu entspricht die $»$ konservative See« dem »Basiskonzept Mikrokosmos«, in dem, wie auch im gesellschaftlichen Konservativismus »dem Boden als Standortfaktor« eine enorme Bedeutung zukommt. ${ }^{426}$ Hier ist die Außenwelt nicht feindlich, sondern ein »Traditionsgefüge «, in das sich Individuum und Gemeinschaft einfügen, um dort >zu sich $২$ zu finden, eine Anpassung an die Umwelt $\mathrm{zu}$ vollziehen. In diesem besonders von Otto Zacharias vertretenen Konzept herrscht das Prinzip der »Lebensgemeinschaft« mit strikt hierarchisierten Wechselbeziehungen. »Die Natur ist organische Natur, die 
sowohl ästhetisch erfahrbar und Ort der Produktion ist. « ${ }^{427}$ Der »funktionale See« schließlich, nach dem »Basiskonzept Energie«, vertreten durch François-Alphonse Forel, konstruiert die Organismen in einem Netzwerk aus "gegenseitigen, nachbarschaftlichen Verpflichtungen«, was zu einer Paradoxie führt: der Gleichzeitigkeit des >liberalen N Nebeneinanders und der >konservativen` wechselseitigen Verpflichtung. Die soziale Steuerung erfolgt in einem »automatischen Prozeß«, also selbsttätig. »Die Mathematisierung richtet sich nicht nur auf die Beschreibung der Populationsdynamik - wie im liberalen Modell - und auch nicht auf die Produktion - wie im konservativen Modell - sondern es wird, in einer anderen Radikalität als bei den anderen beiden Positionen, die Kontrolle und Mathematisierung des >Ganzen` angestrebt.« Hier ist alles quantifizierbar und soll es auch sein, wenn noch nicht aktuell, dann jedenfalls potentiell. ${ }^{428}$

Wissenschaftlich, ökologisch ist jetzt also auch der See >innen`. Vergesellschaftetes, mathematisiertes Gebilde. Was bleibt, sind Phantasien, in denen die Gegenweltlichkeit aufrechterhalten oder wiederbegründet wird, in denen »Kultur in Natur« zurückverwandelt wird. ${ }^{429}$ In denen das $>$ Andere` der Landschaft, ihre >Weiblichkeit`, Unergründlichkeit und Numinosität behauptet werden. Dieses >Andere 〉Eigenes $<$, im >Innenraum $\prec$ definiert.

Gustave Courbet entwirft in seinen Gemälden Landschaften als weibliche Unterleiber, den weiblichen Unterleib als Landschaft. Die Natur sei für ihn »ein weibliches Wesen«, schreibt Günter Metken, »das er malend für sich beanspruchte, mit dem er verschmolz wie mit seinen Modellen«. Seine Bäume weisen Wunden auf, Felsen sind anthropomorph. Inspiriert sei er durch die »heimatliche Franche-Comté«, die »niederschlagsreiche Karstgegend des Jura«, die geprägt ist von Weihern, Waldseen und Flusstälern. »Es ist eine aquatische, flüssige und feuchte Landschaft. So auch Courbets Malerei.« Hier sei in annähernd zwei Dritteln Wasser vorhanden. »Wie vom nassen Element getragen, vertraute sich der Künstler selber, schwimmend oder träge an der Oberfläche treibend, den Gewässern an. Stille Wasser, Strömungen, Wirbel [...] speisten seine Imagination«. Ebenso Grotten, Quellen, Höhlen, >geheimnisvolle Öffnungen`, denen Wasser entquillt. Also komponiert er

427 Ebda., S. $262 f$.

428 Vgl. ebda., S. 263.

429 Vgl. Steinwachs, Gisela: Mythologie des Surrealismus oder die Rückverwandlung von Kultur in Natur. Eine strukturale Analyse von Bretons $»$ Nadja«. Neuwied, Berlin: Luchterhand 1971, S. 72f., hier in Beziehung zu Aragons »Paysan de Paris «. 
»schluchtartige Täler, dunkle Gründe und lichte[n] Himmel darüber, Helldunkelkontraste, die Blickführung von unten nach oben«. Vermittelt werde hier ein »Hinabsteigen auf die Talsohle«, ein »Eintauchen in schattige Wälder, das Vordringen zu den Quellen von Lison und Loue«. Empfangen werde man »von einer geöffneten, oben vorspringenden Felsstirn«, von »moosig bewachsen[en] Flanken«. »Zentral die dunkle Öffnung, aus der Wasser wie von weit her und aus einem unerschöpflichen Reservoire strömt: Entstehen der Welt im Feuchten.« Hier geht es überdeutlich um »Vermischungszustände der Körperränder «. ${ }^{430}$ Vom »Felsmund « schreibt Metken, der ansauge und zurückgebe, dessen Wasser sich in ein überlaufendes Becken ergieße, was weitere Strömungen der Bäche bewirke: »Überall Rinnsale, Verästelungen gleich einem Adernsystem, Blutkreislauf der Natur«, das subkutan neue »Quellen, Tümpel, Wasserfälle« speise, »Spiegel«, in denen Bäume und Felsbänder widerscheinen. ${ }^{431}$

Abb. 4: Gustave Courbet: Der Ursprung der Welt, 1866

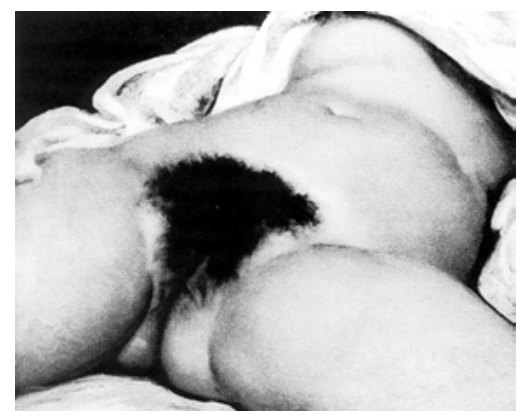

Es scheint klar, worauf das hinausläuft: auf das Bild vom »Ursprung der Welt« (1866), den nackten Unterleibstorso, der sich analog als Landschaft beschreiben lässt. Und in ähnlicher Weise auf die »Frau mit den weißen Strümpfen« (1861). Metken zitiert eine Bemerkung Jack Lindsays zu diesem ebenfalls »um die Vagina zentrierten Werk«: Würden Bildkomposition und Anordnung beibehalten und in einer Skizze »die menschlichen Partien in Felsen, Gebüsch« usw. umgewandelt, käme eine Courbet-typische Landschaft heraus. »Die Vagina bildet den Ein-

430 Theweleit, a.a.O., S. 401.

431 Vgl. Metken, Günter: Gustave Courbet. Der Ursprung der Welt. Ein Luststück. München u.a.: Prestel 1997, S. 45ff. 
gang zur Höhle und den unterirdischen Wasserläufen «. ${ }^{432}$ Was keine besondere Offenbarung angesichts der Bilder der »Felsengrotte der Loue« (beide ca. 1864) darstellt. ${ }^{433}$

Der letzte Besitzer des »Ursprungs der Welt« ist Jaques Lacan gewesen, der es sinnigerweise hinter einem Werk André Massons verborgen hat. Der Surrealist hat 1955 mit diesem einen »cache-sexe« geschaffen, eine »Landschaft, die »auf braunem Grund die Umrisse des Torso in weißer, fast ostasiatisch verschnörkelter Kalligraphie« nachgezeichnet, »zwar alles zeigend, doch nichts darstellend «. ${ }^{434}$ Masson hat bereits in den 1930er Jahren mehrfach »matriarchalische Landschaften« geschaffen. So mit der »Erde« (1939), in der er mit Öl auf Sand die Umrisse des weiblichen Körpers malt. Ein Bein, ein Arm und das Gesicht sind im Profil um den Nabel als Bild- und Weltmittelpunkt gruppiert (was alte Konzepte der Mikrokosmos-Makrokosmos-Entsprechung, hier: den Nabel der Welt, aufnimmt). Von hier »führt auf der Mittelachse eine Linie senkrecht zur Vagina und zum Anus«. Die spitzen Nägel der Hand bohren sich in eine Brust, die die Landschaft blutrot nährt oder befruchtet. Ein »geschlossene[r] Kreislauf, eine Selbstbefruchtung durch Verletzung «. ${ }^{435} \mathrm{Zu}$ diesen Landschaften gehört auch seine Tuschezeichnung »La Cascade» (1938). Hier ist der >laszive` weibliche Akt als Gebirgswildnis angelegt, der Schoß stark bewaldet, die Vulva eine zerklüftete Höhle, der der Wasserfall entspringt. ${ }^{436}$ Diese Zeichnung "verweist in ihren Lineaturen noch auf >automatische` Schreibspuren«. Diese Anklänge an das >automatische Schreiben`, das Masson im Umfeld um Breton kennengelernt hat, ${ }^{437}$ stehen in einem Zusammenhang, über den noch zu reden sein wird.

Insbesondere Breton und Masson hätten Bachofens »Mutterrecht« gelesen, schreibt Angela Lampe. Begeistert rezipiert werden »die positiven Schilderungen antiker Matriarchate als friedvolle Epochen der Gleichheit«. Mit Engels dann werde die Kausalität zwischen Matriarchatsabschaffung und der Errichtung von Klassengesellschaften betont. Nur, bei aller emphatisch-positiven Würdigung ändert sich nichts an der gängigen Zuschreibung: >Die Frau< ist auch hier ein seiner Natur verhaftetes Gattungswesen. Die ihr zugeschriebene Kraft zur Vermittlung

432 Ebda., S. $52 \mathrm{f}$.

433 Vgl. ebda., S. 47ff.

434 Ebda., S. 8 ff.

435 Vgl. Heuwinkel, Christiane, in: Lampe, Angela (Hg.): Die unheimliche

Frau. Weiblichkeit im Surrealismus. Heidelberg: Wachter Verlag 2001, S. 76, Abb. 32.

436 Vgl. ebda., S. 79.

437 Vgl. ebda., S. 76. 
»zwischen dem Menschen und dem Wunderbaren« gründet in ihrer »unverdängte[n] Nähe zur Natur, von der geheimnisvolle Mond- und reproduktive Zyklen zeugen ${ }^{4}{ }^{438}$

Matriarchale Landschaften, unheimlich. Masson habe, schreibt Heuwinkel, von Paracelsus gelernt, »dass das Studium des weiblichen Unterleibs auch das Wissen von den Ursprüngen der Welt befördere «. ${ }^{439}$ Paracelsus, der Hexen etwa als dadurch erkennbar bezeichnet, dass sie körperlich missgebildet seien. Getreu seiner Lehre, dass »alle ding, die wir im alter gebrauchen sollen, von jugent auf in uns erzogen müssen werden« zu einem »felsen, auf welchem die ding fix bleiben«, glaubt er an die enorme Auswirkung negativer Einflüsse in der Jugend, die »von hexen solchs sonderlich nach fleischlichem begird ir alter zu han, notturft erfordert«. Und solche Frauen erkenne man auch daran, dass sie ihren Männern den ehelichen Beischlaf verweigerten. ${ }^{440}$ Paracelsus, so Schneller, kalkuliere bei aller scholastischen »Selbstsicherheit« die »Inferiorität alles bloß Natürlichen wie letztlich auch bedrohlichen Teuflischen« ein. ${ }^{441}$ Bezüglich >fleischlicher Vermischung« sei er »kein Prediger der Askese«. Nicht die »Auslöschung des Leibes, sondern dessen Regulierung ist das Ziel - die Harmonisierung der Natur nach dem Vorbilde der in den Himmel projizierten Ordnung«. Das meine sein Begriff »venus« - im Gegensatz zu »luxuria«, eine »ihrer unkontrollierbaren Züge beraubte Sinnlichkeit «. ${ }^{442}$

Hexen: In der »Cascade«-Zeichnung »verflüssigt sich der Frauenkörper, wird ein organischer Teil der Landschaft, ja geht in ihr auf«. Es werde etwas »Hexenhaftes [...] spürbar«, so Angela Lampe. Nicht nur infolge der Affinität der Surrealisten zu den okkulten Betrachtungen Jules Michelets, der den »besondere[n] Genius der Frau« darin sieht, dass sie »als Fee geboren« werde, dass sie die »Natur [...] zu Hexen« mache. Die positive Konnotation des >Hexenhaften $\prec$ bei den Surrealisten zeige sich genauso darin, dass sie »das automatische Schreiben« verbänden mit der Gabe der Hexen zur conception solitaire, zur unbefruchteten Empfängnis«. ${ }^{43}$ Und damit kommt noch einmal die sun-

438 Lampe, Angela: Größter Schatten oder größtes Licht. Surrealistische Frauenentwürfe zwischen Traum und Wirklichkeit, in: a.a.O., S. 36f.

439 Heuwinkel, a.a.O., S. 76.

440 Paracelsus: De sagis et earum operibus (1537/38); zit. n. Schneller, Klaus: Paracelsus: Von den Hexen und ihren Werken, in: Becker, Gabriele et al. (Hg.): Aus der Zeit der Verzweiflung, S. 247f.

441 Schneller, a.a.O., S. 246.

442 Ebda., S. 255.

443 Lampe, a.a.O., S. 37. 
fruchtbare Weide` ins Bild. Hier übersetzt in unbewusste, sich ziellos verzweigende Zeichen, die in sumpfigen Untergründen entstehen.

Abb. 5: André Masson: La Cascade, 1938

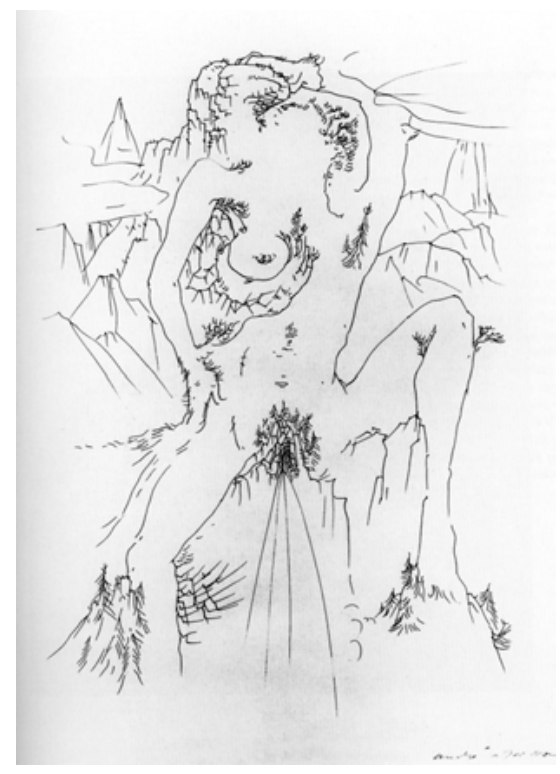

\section{Die weibliche Wildnis der sneuen Welt}

Die Inversion bzw. Bedrohung männlicher Herrschaft durch das >Weibliche wird frühneuzeitlich analog in der >neuen Welt` thematisiert. Auch hier ist die Verbindung von >Weiblichkeit $<$ und >Wildnis $<$ konstituierend. Das zeigen nicht zuletzt die Stiche von Theodor Galle. So in seinem Schreckbild »America« (ca. 1600), das die Frau als nackte, wilde Kannibalin mit einem abgeschlagenen Kopf in der Hand herumlaufen lässt: »Die Wildnis und das Weibliche, welche in der Fremde lauern, haben dem Entdecker hier buchstäblich den Kopf geraubt. « ${ }^{444}$ In Galles »Christopher Columbus entdeckt die neue Welt« (ca. 1600) erscheint ebenso »das fremde Territorium [...] in weiblicher Gestalt«, zugleich bedrohlich und verlockend, als übergroße, mit Pfeil und Bogen bewaffnete Amazonen, die im Meer auf Columbus' Schiff zuschwimmen. »Der

444 Weigel, Sigrid: Topographien der Geschlechter, S. 146; vgl. Abb. 15 ebda. 
Held aber ist - inmitten der Fluten - doppelt gepanzert gegen das Andere: durch seine Rüstung und durch den Schiffsrumpf, der ihn umgibt. $\ll^{445}$

Theweleit zeigt die Gesellschaft am Ende des Mittelalters, vor allem um 1500, als wechselseitiges Geflecht aus Entgrenzung und Begrenzung, Deterritorialisierung und Reterritorialisierung. Der dialektische Prozess beginnt im 11. Jahrhundert mit der Expansion und Erosion der mittelalterlichen Gesellschaft und der zugehörigen »Entstehung eines sich mehr und mehr begrenzenden Individuums«, eines »)zivilisierten [männlichen] Ich[s]«. Der neue Mensch entsteht also als ein neuer Mann, der die Entgrenzungen (〉Deterritorialisierungen $২$ ) vornimmt und ermöglicht« und »im selben Prozeß zu einer fest umrissenen Einheit« wird, »zu einem Zentrum von Kraft und Unternehmungsgeist, einem harten, gepanzerten Schiff, das man hinausschicken konnte, damit es die Welt aus der Perspektive Europas erfasse und >ordne««. Und doch korrespondiert »der Prozeß der eingrenzenden Ich-Bildung« und »Zentralisierung der Staatsmachten« mit einer »Tendenz zur Entgrenzung der Körper in Zeiten der gesellschaftlichen Entgrenzung und Dezentralisierung«. Wie werden »die neuen Freiheiten der menschlichen Leiber, ihre Möglichkeit und ihre Praktizierung, eingegrenzt «?

Theweleit verweist auf »zwei gegensätzliche Bewegungen« bezüglich Frauen, »wovon die eine mehr ein Frauenbild betrifft«. Einerseits werde im Prozess der sozialen Lockerungen das Madonnen-Bild »langsam dem der hohen Frau der Minneliteratur angenähert und das Bild der hohen Frau der Minne langsam durch das einer erreichbaren Geliebten ersetzt [...], wobei beide vorsichtig sexualisiert werden«. Zugleich beginne mit der Hexenverfolgung "gegen die wirkliche Erweiterung der sexuellen Lüste ein lang anhaltender Terror. Er trifft die Frauen der beherrschten Klasse, meint aber die sich drohend abzeichnende Möglichkeit eines lustvollen mann/weiblichen Produktionsverhältnisses insgesamt «. ${ }^{446}$ Er vermutet, dass »das gesellschaftlich relativ ungeformte und (speziell bei den oberen Klassen) unabsorbierte Produktionspotential der Frauen [...] zur gesellschaftlichen Produktion zugelassen [wird] in Bereichen, deren Produkte der Herrschaftsabsicherung dienen. Sie werden zugelassen als Darstellerinnen einer Fiktion der Fülle - (>das Paradies im Leib der hohen Frau wiederfinden...<) -, die dadurch entsteht, daß der Leib der Erde, die unproduzierte Natur, mit der Fiktion des unbegrenzten, alles versprechenden Frauenleibes codiert wird«. Hierbei liege die Absicherung der Herrschaft »darin, daß der Mangel zur

445 Ebda., S. 143; vgl. Abb. 9.

446 Theweleit: Männerphantasien Bd. 1, S. 381-384. 
Grunderfahrung des realen Mann/Frau-Produktionsverhältnisses wird, weil das Bild der Frauen und ihr lebendiges Dasein nie auch nur annähernd zur Deckung zu bringen sind. So wird daraus ein Produktionsverhältnis der Antiproduktion: in ihm und aus ihm entstehen Ungleichheiten, Unterdrückungen, eingrenzende, reterritorialisierende Realität. Der fiktive Leib der Frau wird zum phantastischen Schauplatz geträumter Deterritorialisierungen, während das reale Mann/Frau-Verhältnis Angelpunkt der Durchsetzung massiver Reterritorialisierungen bleibt, bzw. immer neu dazu gemacht wird. Den Stoff für die Fiktion geben dabei die Frauen der Herrschenden und exotische Frauen ab; die Frauen der unterdrückten Klassen liefern demgegenüber den Stoff für Ängste der Männer; sie werden nicht zu Bildern, sondern zu Opfern, nicht erhöht, sondern verfolgt ${ }^{447}{ }^{47}$

Landschaften werden als weiblich wahrgenommen, neu $\mathrm{zu}$ >entdeckende` als unberührt, jungfräulich, ihre Besucher unterhalten ein >Geschlechterverhältnis` zu ihnen. Neu ist daran nicht, dass äußere Natur feminisiert wird, neu ist: das neue männliche Ich gestattet sich Übergriffe, nimmt sich, eignet sich an (in den Kolonien), codiert neu, baut um, reorganisiert auf eigene Rechnung. Eine Kolonisierung der (oft zurückgekehrten) Waldwildnis in Europa gibt es schon durch mittelalterliche Kleriker; aber nicht auf eigene Rechnung, sondern die des >Herrn

Verändert haben sich mit Beginn der Neuzeit auch die Weisen der Verkörperung. Zwar existiert auch im Mittelalter die weibliche Allegorese des Raums - >Frau Welt $\ltimes$. Dieser Raum aber ist kein geographischer, sondern ein kosmologischer, dessen Realität >oxymerotisch ‘ aufgebaut ist, in dem Wissen und Erkennen nach hierarchisierten »Ähnlichkeitsbeziehungen zwischen Mikrokosmos und Makrokosmos« funktioniert. »Der Körper des Menschen ist« hierbei »ein >privilegierter Punkt««. ${ }^{448}$

Die allmähliche Auflösung dieser Beziehung, in der »der menschliche Körper seine allegorische oder kosmologische Bedeutung verliert«, in gleichem Maße aber »für das einzelne Individuum an Signifikanz« gewinnt, wobei der Leib »zum Objekten von dezentralen Machttechniken« wird, ${ }^{449}$ entsteht in Wechselwirkung mit den territorialen Entgrenzungen. Der männliche Körper geriert sich unter dem Kennzeichen der Mobilität zum aktiven, der weibliche »wird als passiver Raum gefaßt«,

447 Ebda., S. $376 f$.

448 Schülting: Wilde Frauen, fremde Welten. Kolonisierungsgeschichten aus Amerika. Reinbek: Rowohlt 1997, S. 36. Binnenzitat aus Foucault: Die Ordnung der Dinge, S. 51.

449 Schülting, a.a.O., S. 39. 
den »das mobile männliche Subjekt zu bezwingen sucht«, wenn er für die unbekannte >neue Welt $<$ steht. ${ }^{450}$ Oder den er zu verlassen, zu überwinden sucht, wenn der passive Raum für eine nicht mehr >genügende Mutter steht, deren >Brust nicht mehr alle, die ihr >fruchtbarer Schoß< gebar, ernähren kann. So in England zu Beginn des 17. Jahrhunderts bei Robert Gray, der als »einzigen >Aus-Weg^ aus« den sozialen Verheerungen durch das rasante Bevölkerungswachstum die Eroberung von Kolonien nennt. ${ }^{451}$ Sabine Schülting:

»Gesellschaftlicher Fort-Schritt wird somit buchstäblich - nicht zeitlich, sondern räumlich - gedacht und an Mobilität, an Grenzüberschreitung bzw. Verschiebung der Grenzen gebunden. Indirekt wird dies in Zusammenhang mit einer Überwindung des Weiblichen gebracht, wenn ein unvollkommener mütterlicher Körper als Metapher für den engbegrenzten Raum Englands fungiert. Die geschlechtsspezifische Arbeitsteilung, die Loslösung des Mannes vom Haus, sein Fortschreiten innerhalb des Raumes und zivilisatorischer Fortschritt sollen sich in Zukunft gegenseitig bezeichnen. Reisen wird auf der einen Seite als notwendiges Element zur kulturellen Weiterentwicklung betrachtet, auf der anderen Seite ist die Vereinfachung des Reisens ein Indikator für den Fortschritt von Wissenschaft und Technik. « ${ }^{452}$

Die »Umwertung der Mobilität und ihre[] männlichen Besetzung« gehe einher »mit eine[r] semantische[n] Überlagerung von Raum und Frauenkörper«, was die Flut von weiblichen Allegoresen von Ländern und Erdteilen in Karten seit dem 16. Jahrhundert zeigt. ${ }^{453}$ Für Europa markiert das einen Zustand »gesellschaftlicher Stagnation« oder »passiven Genuß europäischer >Zivilisation «", mithin ein »Widerstandsmoment, das überwunden werden muß ${ }^{454}$ Es bezeichnet aber auch das bereits (und seit langem) im Besitz sich Befindliche, wohingegen das >unbekannte Weibliche $<$ jenseits der Grenzen auf seine Eroberung wartet.

Und nun ist es zunehmend der Körper des Reisenden selbst, der Erfahrungen und Berichte darüber beglaubigt, nicht mehr die in der älteren Tradition übliche Berufung auf vorhergehende Autoritäten wie Marco Polo oder >die Alten`, deren `Reiseberichte` mit ihren in der mittelalterlichen Kosmologie >bekannten< Monstren und Fabelwesen kurzerhand auf die >neue Welt übertragen wurden, um »der Fremdheit dadurch zu begegnen«, dass man »sie mittels bekannter kultureller Signifikanten«

450 Ebda., S. 43.

451 Vgl. ebda., S. 35.

452 Ebda., S. $35 f$.

453 Vgl. ebda., S. 36.

454 Ebda., S. 33. 
bezeichnet. »Augenzeugenschaft« des Reisenden und »die Veränderung seines Körpers (Sonnenbrand, Falten)« sind es jetzt, die als »Ein-Drücke, die die fremden Länder« auf seinem Leib hinterlassen, »einen wahrhaftigen Text entstehen« lassen. »Der erprobte Körper des Reisenden wird zum Garanten neuzeitlicher Textproduktion. In dem Maß, wie der mobile männliche Körper in der Er-Fahrung >verschlissen` wird und verschwindet, produziert und autorisiert er einen Text, dessen Objekt der weibliche Körper ist. ${ }^{455}$ Es kann aber nicht nur um den Text gehen, sondern ebenso um die körperlichen »Ein-Drücke«, die diesen Text generieren, bzw. die später bei seiner Lektüre reproduziert werden. Dass diese Reiseberichte in der gewollten Weise beim adressierten Publikum wirken, zeigt die gesellschaftliche Funktion der »Ein-Drücke«.

\section{Zu erobernde Jungfrauen}

»In der Entdeckung Amerikas war mitgesetzt die Entdeckung der eigenen Körper. Die Entgrenzung der Ferne enthielt die Möglichkeit des Umschlags in eine Entgrenzung der Nähe. Am Horizont erschien die Erkenntnis: es gibt nur die Menschen und die Natur, nur dich unter vielen anderen und was ihr damit macht. ${ }^{456}$

Seit dem Beginn der Neuzeit, schreibt auch Sabine Schülting,

»wird das Verhältnis des Reisenden zum Raum bzw. des Eroberers zur `Neuen Welt‘ auf das Geschlechterverhältnis verschoben, womit räumliche Mobilität wie auch Kolonisierung als Funktion der Geschlechterdifferenz naturalisiert werden. Kulturelle, militärische und ökonomische Eroberung erscheint in der Metapher einer >natürlichen` Entjungferung bzw. `Befruchtung` der Frau durch den Mann und wird gar als willentliche Prostitution des feminisierten Raumes gerechtfertigt. Männlich semantisiertes Reise-Schreiben dagegen wird zum Sexualakt, der gerade in den Texten seit der Mitte des 17. Jahrhunderts nicht mehr ausschließlich auf >Entjungferungく und Befruchtung gerichtet ist, sondern nach orgastischer Befriedigung strebt. Reisen, Schreiben, sexuelle Potenz und Befriedigung bilden eine metonymische Kette, die die Basis individueller männlicher wie auch kultureller Identitätsstiftung konstituiert ${ }^{457}$

Die »europäische Tradition, in der sich die Vorstellungen vom (fremden) Raum und vom weiblichen Körper überlagern«: $\mathrm{Ob}$ in Walter Raleghs Reisebericht der Entdeckung Guyanas, Galles Stich der Lan- 
dung Vespuccis oder Samuel Purchas' Reiseberichten (1625): Stets werden unter Ausblendung dort lebender >Ureinwohner`namenlose Länder geschildert, die in »kindlicher Unschuld« der europäischen Eroberung harren, jedes Land ein »jungfräulicher weiblicher Körper [...], der bisher noch nicht erobert, besessen oder verletzt worden sei«, dessen Einwilligung zum Akt des Erobert-Werdens schlicht irrelevant ist (wie der der 〉Ureinwohner ), ein Objekt also, »das der 〉Potenz` des (englischen bzw. europäischen) Eroberers unterworfen ist«. Hierbei wird die »Überwindung geographischer Hindernisse durch den Reisenden« strukturiert durch Sexualitätsvorstellungen, die den Akt »als Unterwerfung, Entjungferung oder Vergewaltigung des weiblichen Körpers denken« (als »enjoyment« bezeichnet Ralegh den Besitz des »jungfräulichen Landes «) - was jedoch »nicht nur als Institutionalisierung eines Herrschaftsdiskurses, sondern auch als eine Subversion gelesen werden« kann. So misslingt Purchas das »Eindringen« in die Magellanstraße am »Cape Virgines« ebenso, wie Ralegh die >Penetration` der Mündung des Orinoco und damit des Inneren Guyanas. Ähnliche Widersetzlichkeiten hatte Ralegh bereits vorher »im Labyrinth der Flußarme des Orinoco« erleben müssen, »das sich als fremder, bedrohlicher Raum ohne Demarkationslinien erwiesen hatte«. Hier ähnele sich alles, permanent kreuzten sich die großen Flußarme, wie sonst nirgendwo auf der Welt, schreibt Ralegh, »und jede Insel war so von hohen Bäumen gesäumt, daß niemand über die Breite des Flusses oder die Umgebung hinaussehen konnte«. Hier, kommentiert Schülting, sind nicht nur keine Differenzen mehr auszumachen, unmöglich ist auch jede ») Durchdringung « des Landes durch den Blick« - kurz: Es kommt zu einem »Rückfall in die beunruhigende und schicksalhafte Erfahrung einer unförmigen, ungeschiedenen und finsteren Totalität«, wie Schülting Michel de Certeau zitiert. ${ }^{458}$ Das Weib entzieht sich nicht nur, es herrscht sogar.

Normalerweise aber wähnt sich der männliche Eroberer in der aktiven Rolle. Und die kommt zunehmend, was sich als Wandel bei Ralegh schon andeutet, als >Verheiratung (daher. Der Kolonialkrieg zwischen England und Spanien wird bei Ralegh »durch das Bild rivalisierender >Liebhaber` um eine Frau naturalisiert und heruntergespielt«. In einer Wahrnehmung, in der »militärische Macht [...] als männliche Potenz, ökonomische Bereicherung als sexuelle Befriedigung« erscheint, wird Guyana als goldreiches »Eldorado « zu einer »mit einer attraktiven Mitgift ausgestattete[n] Frau«. Raleghs Reisebericht, zeigt Schülting, inszeniert die englische Aneignung des »feminisierten Guyanas« als »Frau- 
entausch«. Ralegh »>entschädigt«« die indigene Bevölkerung »für ihre Gabe« zum einen mit einer »)Gegengabe`, einem Bildnis seiner Königin, der sie huldigen (sollen)«, zum anderen, behauptet Ralegh, würden »die Engländer Vergewaltigung, Frauenraub und Frauen(ver)kauf als Formen unrechtmäßiger Verfügungsgewalt über den weiblichen Körper« beenden, was sich zugleich auch propagandistisch gegen die spanischen Konquistadoren wendet. ${ }^{459}$ Rechtmäßige Verfügungsgewalt über den weiblichen Körper also. Das ist das Recht des Ehemanns.

Unter der Wahrnehmung der Virginität der Landschaft nimmt die bildliche Eroberung und >Penetration` durch die Jungfrau Queen Elizabeth I. eine besondere Stellung ein. Ralegh weist die Siegerposition seiner Königin zu, »einer Jungfrau [...], die es nicht nur vermag, Ihr eigenes Land und das Ihrer Nachbarn zu verteidigen, sondern auch in große und weitentfernte Reiche einzudringen und sie zu erobern «. ${ }^{460}$ Diese >metaphorische Entjungferung « überrasche zunächst, schreibt Schülting, entspringe aber der Notwendigkeit einer Unterscheidung zwischen eigener und spanischer Kolonisierung. Dabei bleibe der Unterschied »zwischen rechtmäßiger und unrechtmäßiger, zwischen körperlicher und metaphorischer Vergewaltigung [...] instabil«, so lange die Eroberung an körperliche[] Männlichkeit« geknüpft bleibe. Eine »weibliche Semantisierung« leiste hier per »Sublimierung und Entkörperlichung der Kolonisierung« die benötigte moralische Distanzierung der spanischen Konkurrenz. ${ }^{461}$

Grundlage der Darstellung Raleghs aber ist, dass eine Frau die eigentlich männlich definierte Regentenrolle vollgültig einnimmt. Dass das möglich ist, basiert wiederum auf der Konstruktion der »zwei Körper des Königs«, dem >politischen` und dem >natürlichen Körper`, die Ernst H. Kantorowicz ${ }^{462}$ nachgewiesen hat. Der >politische Körper< ist

459 Vgl. ebda., S. $49 f$.

460 Zit. n. ebda., S. 52.

$461 \mathrm{Vgl}$. ebda.

$462 \mathrm{Zu}$ dem allerdings etwas mehr zu sagen ist, als dass er ein »grandiose[s] Buch« geschrieben habe (Schulte, Regina: Der Körper der Königin konzeptionelle Annäherungen, in: Dies. [Hg.]: Der Körper der Königin, S. 12); hier aber nur skizziert: Kantorowicz wurde 1895 in eine wohlhabende jüdische, deutschnational gesinnte Likörfabrikantenfamilie im damals preußischen Posen geboren, wo sich die jüdische Minderheit - 5500 Juden und 50000 Deutsche und ca. 100000 Polen leben in klarer Absonderung voneinander - (Fried, Johannes: Einleitung, in: Grünewald, Eckhart et al. [Hg.]: Ernst H. Kantorowicz: Götter in Uniform. Studien zur Entwicklung des abendländischen Königtums. Stuttgart: Klett-Cotta 1998, S. 10f.) trotz eines wachsenden deutschen Antisemitismus als »Pioniere deutscher Kultur« fühlt, an Kaisergeburtstagen zusammen mit Reserve- 
unsterblich (der »König stirbt nie«, weil die Königswürde unsterblich

offizieren, Schützengilde und Kriegerverein auf den Kaiser trinkt, wie sich Ernst Toller erinnert (Toller, Ernst: Eine Jugend in Deutschland, zit. n. ebda.). Als Kriegsfreiwilliger 1914 und Freikorpskämpfer »gegen Polen, Spartakus und Räterepublik Posen, Berlin, München« zeigt Kantorowicz seine deutschnationale Gesinnung, wie er sich anlässlich der $>$ Machtergreifung ` in seinem Beurlaubungsgesuch als Ordinarius in Frankfurt/M vom 20. April 1933 - ausdrückt. Kantorowicz, der vormalige >Jünger Stefan Georges, der den >Meister« - wie das im George-Kreis üblich ist - stets um Erlaubnis für seine Werke fragt (Fried, ebda., S. 7f.), emigriert 1938 in die USA, wird Professor zunächst in Berkeley, später in Princeton. Er hatte dort geistig »einen 〉Eisernen Vorhang«« bezüglich seiner Vorgeschichte (Benson, Robert L.: Gespräch mit Eckhart Grünewald, in: a.a.O., S. 350.). Nach anfänglichem Desinteresse für die Hexenjagd gerade der Reaktionäre in Kalifornien (auch Nixon) hat er den »Loyalty Oath « unter McCarthy - neben wenigen anderen - verweigert. Sie wurden "gefeuert" und bekamen ihr Geld nur noch bis zum Ende des Haushaltsjahrs. Kantorowicz habe das Angebot in Princeton nur wegen seiner mutigen Haltung bekommen, stand doch Institutsdirektor Robert Oppenheimer »sehr weit links" (ebda., S. 365ff.). In seinem politischen Rechtfertigungs-Pamphlet »The Fundamental Issue« (1950), der einzigen politischen Äußerung, erklärt er sich für »genuin konservativ«, im persönlichen Gespräch zum »Royalisten« im Sinne Dantes. Zugleich habe er die Demokraten gewählt und mit den Bürgerrechtlern sympathisiert (ebda., S. 361f). Andererseits scheint seine Freundschaft mit Percy Ernst Schramm trotz dessen »stark deutschnationalen Tendenzen«, seiner »Parteizugehörigkeit und seine[r] Arbeit für das Kriegstagebuch des Oberkommandos der Wehrmacht « nicht gelitten zu haben, weil Kantorowicz »sonst nicht ein so großzügiges positives Gutachten über Schramm bei dessen Entnazifizierung abgegeben hätte« (ebda., S. 364). Er legte offenbar nach 1933 den »an den George-Kreis erinnernde[n] poetische[n] Sprachstil ab, vielleicht, weil ihm mit dem »Tod des >Meisters worden sei, »daß es in diesen Jahren um ganz andere Dinge ging « als zu Zeiten seiner Friedrich-Mythenschau der 20er Jahre (»Kaiser Friedrich der Zweite«, Berlin 1927); ebda., S. 355. Von diesem Buch distanziert er sich 1963: »Man soll halt ein Buch das bei Himmler auf dem Nachttisch lag und das Göring an Mussolini mit Widmung verschenkte, in völlige Vergessenheit geraten lassen « (zit. n. Kittsteiner, Heinz Dieter: Von der Macht der Bilder. Überlegungen zu Ernst H. Kantorowicz' Werk Friedrich der Zweite, in: Ernst, Wolfgang/Vismann, Cornelia [Hg.]: Geschichtskörper. Zur Aktualität von Ernst H. Kantorowicz. München: Wilhelm Fink Verlag 1998, S. 28, Fn. 50). »Kantorowicz dachte in symbolischen Formen, um eine Kategorie von Ernst Cassirer zu nehmen« (ebda., S. 351). Für Richard Faber stellt sein Spätwerk »The King's Two Bodies« von 1957 »einen unausdrücklichen, aber stetigen Widerruf der >Friedrich〈-Eloge« dar und könne »vor allem deswegen mit dem so viel älteren Buch Benjamins (partiell) verglichen werden (Faber: Walter Benjamins Ursprung des deutschen Trauerspiels und Ernst H. Kantorowicz' Die zwei Körper des Königs. Ein Vergleich, in: Ernst/Vismann, a.a.O., S. 175f.). 
ist), unabhängig von der Sterblichkeit des >natürlichen Körpers` und dessen sonstiger >Gebrechen`, wie `Schwachsinn`, Minderjährigkeit oder Weiblichkeit. ${ }^{463}$ Der >politische Körper hebt die Schwäche des >natürlichen auf, dabei sind beide »unteilbar« und »in einer Person inkorporiert und bilden einen Körper «. ${ }^{464}$

Die »mystische Funktion« von »The King's Two Bodies« wird von den »englischen Juristen der Tudorzeit und der nachfolgenden Periode vertreten « ${ }^{465}$ Der »bekannte, wenn auch apokryphe Ausspruch Ludwigs XIV. >l'état c'est moi< - wie übrigens auch der scholastische Satz >papa qui potest dici ecclesia«" sei in »England amtlich anerkannt» gewesen und 1765 beschreibt Sir William Blackstone in seinen Gesetzes-Kommentaren den »Superkörper« bzw. »politischen Körper« des Königs. Diese Kommentare sind zu lesen als eine Zusammenfassung der »Ergebnisse mehrerer Jahrhunderte politischen Denkens und juristischer Spekulation«. »Aus ihnen steigt das Gespenst eines Absolutismus hervor, der nicht wie in modernen Zeiten von einem abstrakten \Staatı oder wie im Hochmittelalter von einem abstrakten >Recht` ausgeht, sondern von einer abstrakten physiologischen Fiktion, die im weltlichen Denken kaum ihresgleichen hat.« Demnach ist der König unsterblich, weil er juristisch unsterblich ist, ebenso kann er juristisch nicht minderjährig sein, kein Unrecht tun oder nur denken oder beabsichtigen, keine Schwäche oder Torheit haben. Als »body politic« ist er unsichtbar, trotzdem juristisch »allgegenwärtig«, d.h. rechtlich »stets in allen Gerichtssälen anwesend«, ohne selbst das Richteramt ausüben zu dürfen. Die Konstruktion einer »zwiegeborenen Majestät« hat eine tief im Mittelalter wurzelnde lange und komplexe Tradition. ${ }^{466}$ Zentrale Quelle sind die »Reports « Edmund Plowdens, geschrieben und gesammelt unter Elizabeth I. Sie enthalten einschlägige Prozesse, Urteile und Argumente. Handlungen, die der König als König vollzieht, können nicht wegen Minderjährigkeit annulliert werden. »Denn der König hat in sich zwei Körper, nämlich den natürlichen (body natural) und den politischen (body politic). Sein natürlicher Körper ist für sich betrachtet ein sterblicher Körper, der allen Anfechtungen ausgesetzt ist, die sich aus der Natur oder aus Unfällen ergeben, dem Schwachsinn der frühen Kindheit oder des Alters und ähnlichen Defekten, die in den natürlichen Körpern anderer Menschen vorkommen. Dagegen ist der politische Körper ein Körper, den man nicht sehen oder anfassen kann. Er besteht aus Politik und Regie-

463 Vgl. Kantorowicz, Ernst H.: Die zwei Körper des Königs, S. $317 f f$.

464 Ebda., S. 33.

465 Ebda., S. 27.

466 Vgl. ebda., S. 28f. 
rung, er ist für die Lenkung des Volks und das öffentliche Wohl da. Dieser Körper ist völlig frei von Kindheit und Alter, ebenso von den anderen Mängeln und Schwächen, denen der natürliche Körper unterliegt. Aus diesem Grunde kann nichts, was der König in seiner politischen Leiblichkeit tut, durch einen Defekt seines natürlichen Leibs ungültig gemacht oder verhindert werden $\ll$. ${ }^{467}$

Der >politische Körperく ist offensichtlich männlich. Die byzantinische Kaiserin Irene (790-802) amtiert während der Minderjährigkeit ihres Sohnes als »Kaiser«, ähnlich »König« Maria von Ungarn im 14. Jahrhundert, »erst nach der Heirat mit Sigismund akzeptiert sie den Titel regina «. ${ }^{468}$ In England können Frauen aus eigenem Recht regieren, da hier - anders als in Frankreich etwa, kein »salisches Recht« existiert, das sie von der Thronfolge ausschließt. ${ }^{469}$ Aber auch wenn der politische Königskörper >männlich` ist, Elizabeth I. wird zwangsläufig als Frau wahrgenommen. Sie selbst »behauptete, den Körper einer Frau, aber das Herz und den Bauch eines Königs zu haben« - aber »nicht eines >Mannes $\ll$ «. ${ }^{470}$

Die Konstruktion königlicher Jungfernschaft entwickelt sich vom Einzug zur Krönung in London 1559, vom Bild »der jungfräulichen, keuschen, bräutlichen Königin, deren Haar auf dem Krönungsportrait noch mädchenhaft offen über die Schulter fällt, zur Jungfrau-Ikone« weiter, »deren Ehemann das Königreich war $->\mathrm{I}$ am already bound unto an husband, which is the kingdom of England - und die zum Schluss in einer ausgefeilten Liebessemantik den sakralen Platz der säkularisierten Jungfrau Maria besetzen soll«. Dabei verschwinde in all den »Metamorphosen«, Deutungen, und Zuschreibungen der natürliche Körper »schließlich scheinbar gänzlich« oder werde verrätselt. ${ }^{471}$

Ralegh stellt die Königin in seinem Reisebericht in einem »engen Zusammenhang mit den Amazonen« dar, differenziert sie aber auch von ihnen. »Der Aspekt der weiblichen Herrschaft verbindet England mit

467 Heißt es in Plowdens »Commentaries or reports«. Ebda., S. $31 \mathrm{f}$.

468 Ebda., S. 99.

469 Vgl. Weil, Rachel: Der königliche Leib, sein Geschlecht und die Konstruktion der Monarchie, in: Schulte, Regina (Hg.): Der Körper der Königin, S. 101. So gesehen ist es falsch, wenn Carolyn Merchant behauptet, die britischen Königinnen hätten »die natürliche Ordnung umgestürzt« (Der Tod der Natur, S. 89). Diese Meinung mochte der Franzose Jean Bodin vertreten, in England war sie rechtlich nicht haltbar. Das zeigen die »Plowden-Reports«, die gerade während der Regentschaft Elizabeths das Konstrukt der »Zwei Körper« juristisch entfalten, vgl. Kantorowicz, a.a.O., S. 25ff, Schulte, a.a.O., S. 12.

470 Schulte, ebda.

471 Ebda., S. 14f. 
dem Territorium der Amazonen $«,{ }^{472}$ das anders, als das »durch einen >jungfräulichen` Körper begrenzt[e]« Guyana an dessen Südgrenze liegend durch eine »ungezähmte weibliche Körperlichkeit» charakterisiert werde, $»$ die ihrerseits die männlichen Eroberer zu unterwerfen droht «. ${ }^{473}$ Elizabeth erscheint so den >Amazonen` von Geschlecht und Kampfkraft her ähnlich, wird aber als Jungfrau, die Territorien erobern und schützen könne, abgesetzt von einer ungezügelt aggressiven und sexuellen Körperlichkeit der >Amazonen`. Die Monarchin, die 1588 selbst bei einer Truppenparade als Amazonenkönigin auftritt, wird also bei Ralegh »weitgehend analog« zur »kämpferische[n] Jungfrau Britomart« in Edmund Spensers »Færie Queene« (1590/96) entworfen, die die Amazonenkönigin Radigund besiegt, die Herrschaft übernimmt, »die Frauen den Männern unterwirft« und so »die >rechtmäßigeく patriarchale Ordnung« (re-)etabliert. ${ }^{474}$

Das >Recht des Ehemannes« markiert einen Bildwandel, schon wegen der »historisch veränderte[n] Zielstellung europäischer Kolonialpolitik«: Wird die Virginitätsmetaphorik Ende des 16. Jahrhunderts noch auf neu entdeckte, >geschichtslose` Länder verwendet, erfährt sie im 17. Jahrhundert eine entscheidende Modifikation, denn nun gibt es bereits seit einigen Jahrzehnten europäische Besiedlung, wie in »Neuengland «.

Betont wird nun die »Fruchtbarkeit, die allerdings an europäische Befruchtung gebunden wird«. George Alsop etwa entwirft Amerika 1666 »weniger als Jungfrau, denn als [potentielle; M. T.] Mutter« mit ihrem fruchtbaren »natürliche[n] Schoß«. >Virginität» und damit noch durchzuführende >Defloration ` bleibt Voraussetzung für (englische) Kolonisierung, »wobei nun aber das Moment der >Heirat` als Metapher für eine Verbindung zwischen europäischen Siedlern und dem Land in den Vordergrund rückt«. So bei Thomas Morton (»New English Canaan, or New Canaan«, 1637). Hier »tritt die Bedeutung der Jungfräulichkeit und der Mitgift zurück. Als Reichtum der Natur dienen sie der Wertmaximierung der Braut Neuengland auf dem Frauenmarkt. Diese reiche Mitgift treibt den Bräutigam ins Bett, wo durch den gemeinsam genossenen Beischlaf die Fruchtbarkeit aktiviert wird. Morton kommt es folglich weniger auf den einmaligen Erwerb von Reichtum (bei Ralegh durch den legendären Goldschatz Eldorados) als auf die konstante Wertschöpfung auf der Grundlage natürlicher Ressourcen des Landes an«.

472 Schülting, a.a.O., S. 62.

473 Ebda., S. 53.

474 Ebda., S. 62f. Zur Rolle der Königin im herrscherlichen Jagdritual vgl. Kap. Forst I. 
Dabei versucht Morton, "ganz im Einklang mit der Geschlechtermetaphorik«, die hohe Produktivität der Kolonisation mit hohen neuenglischen Geburtenraten zu beweisen. ${ }^{475}$ Der Frau/Kolonie bleibt in diesem Prozess der >Monogamisierung ^ nur die rein reproduktive Rolle. Ein Prozess, der ebenso zielsicher als `Erhöhung ‘ daherkommt. Samuel Purchas (»Virginias Verger«, 1625):

»Doch schau dir Virginia an, betrachte ihre liebliche Erscheinung (obgleich sie sich als keusche Jungfrau nun mit wildem Dickicht und schattigem Forst verschleiert hat, da sie eher Schändung als Ehe von ihren eingeborenen Wilden erwartet), begutachte ihre Häfen, Rohstoffe, Gegebenheiten; ihre Aufgliederung durch Buchten und Flußarme in so gute und wohlproportionierte Gliedmaßen und Teile; ihre Mitgift an allerbesten Erbstücken der Natur, unversehrt, wiewohl noch nicht veredelt, [und du wirst] sehen, daß sie es verdient, vom besten Gatten umworben und geliebt zu werden. ${ }^{476}$

Das ist bestens utilitaristisch argumentiert, ansatzweise gar physikotheologisch, erklärt es doch, warum bis dahin ein virginischer Dschungel existiert - und warum er alsbald verzichtbar wird. Der Wildwuchs also ist nichts, als notwendige Verschleierung gegen die drohende Schändung durch die Wilden. Sobald der beste Gatte, der zivilisierte Europäer ihr die verdiente Liebe gibt, kann, muss dieser Schleier fallen, denn der beste Gatte allein veredelt die Erbstücke der Natur zur geordneten, fruchtbaren Üppigkeit. Er nämlich besitzt die rechtmäßige Verfügungsgewalt.

Seit der Mitte des 17. Jahrhundert wandelt sich das >weibliche Wunschterritorium vom Objekt der >Monogamisierung \langsam aber merklich zum Objekt der Flucht vor ihr, der männlichen Eskapade. »Die Landschaft - und als pars pro toto - der fremde weibliche Körper werden $\mathrm{zu}$ Lustobjekten der Reisenden.« Denn hier wird nun »Jungfräulichkeit« mit »Lüsternheit« konnotiert - zu imaginierten Gunsten des Reisenden/Schreibenden. ${ }^{477}$

Es besteht insofern auch ein Unterschied zwischen exotischen Welten und der seigenen Welt in Europa. Die exotischen Welten/Frauen dienen hier nicht als zu erobernder oder zu erwerbender Besitz, sondern nur kurzfristigem Plaisier, »arkadischer Sexualität«. Sie >gehören keinem〈, sie werden als »Nymphen« dargestellt, Jungfrauen, die im antiken 
Sinn 〉keinem Manne untertan« sind, aber willige »Nymphen« - »Prostituierte[], deren sich der Reisende in seinem Text bemächtigt und durch für ihn wertlose Gegengaben entlohnt«. Frauen »verkörpern das fremde Land, dessen sexuellem Reiz« sich der Reisende/Schreibende »nicht entziehen kann«. Die »metonymische Beziehung zwischen Frauen und Raum« imaginiert das Reisen und seine Beschreibung zum Sexualakt, »der weniger auf die Unterwerfung eines weiblichen Objekts denn auf Lust um ihrer selbst willen zielt. Die Leere einer Terra Incognita, die der Reisende durch seinen Text füllen muß, widersetzt sich der Repräsentation. Eine sexuell konnotierte Beherrschung des Raums weicht hier dem lustvollen Genuß des Raums, Lust, die aber genau aus der Nichtrepräsentierbarkeit resultiert «. ${ }^{478}$ Denn was »aus der Sprache - der männlichen Ordnung, der Weißen, des Wissens - ausgeschlossen ist, ist mit/in ihr auch nicht beschreibbar«, sagt Sigrid Weigel im Zusammenhang der Diskurse über Frauen, Wilde und Wildnis; hier konkret anhand der aus den Aufzeichnungen Georg Forsters auf der Cook-Expedition von 1773 deutlich werdenden Unfähigkeit eines Beobachters, ein Fest auf Tahiti zu beschreiben. ${ }^{479}$

Demgegenüber steht die >Terra cognitaく, die sich bereits in Besitz befindet und deshalb gegen das >Eindringen`sträubt. Das hat Dimiter Daphinoff an Texten Daniel Defoes gezeigt. Während in »Robinson Crusoe« der 〉jungfräuliche Urwald des »tropischen Eiland[s]« dem »europäischen Eindringling bereitwillig seinen Schoß« öffne, sei bei Defoe der europäische Wald »der von Mythen und Märchen her bekannte [...] Engpaß, durch den der Held hindurch gehen muß«, eine bedrohliche, sich dem Zutritt sperrende »vagina dentata ${ }^{480}{ }^{40}$ >Terra cognita ist vor allem auch das >Mutterland Hier also gibt es den rechtmäßig besessenen, festgefügten >Leib`schon längst - zentral regiert, zur >Mutter` als reproduzierend Gebärender gemacht, zum »Mutter-Land ${ }^{481}->$ La Franceく, >Britanniaく, >Germania die entsinnlichten >Mütter einer asketischen Ehemoral, die bereits seit 〉Urzeiten〈 Territorialisierten, gigantische »Figurinen« einer Geschichte,

478 Ebda., S. $75 \mathrm{ff}$.

479 Vgl. Weigel, a.a.O., S. 126.

480 Daphinoff, Dimiter: Der Wald im englischen Roman des 18. Jahrhunderts, in: Ders.: (Hg.): Der Wald. Beiträge zu einem interdisziplinären Gespräch. Freiburg/Schweiz: Universitätsverlag 1993, S. 142f.

481 Weigel, a.a.O., S. 146. 
die im Allegorischen in Natur gewendet, ${ }^{482}$ die zur »Urlandschaft« erstarrt ist. $^{483}$

Derartige Allegoresen erscheinen insbesondere in Form von Landkarten. So entwirft Matthias Quads »Allegorie des Europa« (1587) den Kontinent als Frauenkörper, »Mutter-Land«, damit als »längst territorialisiert; entsprechend abstrahiert ist die allegorische Personifikation Europas in Gestalt dieser Figur weitgehend vom konkreten, sinnlichen Leib einer Frau «. ${ }^{484}$ Ein niederländischer Stich von 1598 zeigt Elizabeth I. als Europa. Überschrift: »Het Spaens Evropa«. Ihr rechter Arm mit dem Reichsapfel in der Hand erscheint als Italien, ihr nackter Oberkörper als Frankreich, Deutschland und die Niederlande, der linke Arm mit Schwert als England und Schottland. Über ihrer linken Schulter geht die spanische Armada unter. Unter der Drohung ihres Schwerts flieht ein dreiköpfiger Papst in einem vom Klerus geruderten Boot, flankiert von Schiffen seiner Alliierten. ${ }^{485}$

Solche weiblich allegorisierten Landschaften entstehen um 1800 herum häufig als >Phantasiekarten` und/oder >erotische Parodien<. So » $L a$ Chaise des Jüngern Reisen durchs gelobte Land. Neue Auflage. Mit einer illuminierten Karte, welche einer sizenden Jungfer verglichen verden kann Arkadien, bey Amors Erben, 1799«, eine »[1]iterarisch eher unbedeutende erotische Parodie einer Reisebeschreibung. Das >Gelobte Land ' [zeigt] die Umrisse eines aus Kopf und Rumpf bestehenden Frauenkörpers und ist in sieben Gebiete eingeteilt; der Kopfbereich etwa wird als >Fürstentum Platonien 〈 bezeichnet. Landschaften oder Orte tragen teilweise Bezeichnungen, die auch in der Realität existieren, hier aber erotisch konnotiert sind: >Ich ging daher durch die goldene Aue über Keulleben, wo just Kirmse war, und über das Zotengebirge nach Pforzheim. Es ist dies eines der vornehmsten Städte des Herzogthums Schweinichen. Ein Hauptnahrungszweig hiesiger Gegend sind die unzählichen Windmühlen««. Die zur Illustration beigefügte Landkarte sei »ein simples Beispiel für die um 1800 weiter verbreiteten Phantasiekarten«. Ähnlich sind der 1802 vom Wiener Schriftsteller und Verleger Franz Johann Joseph von Reilly publizierte »Atlas von der Moralischen

482 Vgl. Benjamin, Walter: Ursprung des deutschen Trauerspiels(1925), in: Gesammelte Schriften I.1. Hg. von Rolf Tiedemann und Hermann Schweppenhäuser. Frankfurt/M: Suhrkamp 1974, S. 358.

483 Vgl. Bovenschen, Silvia: Die aktuelle Hexe, die historische Hexe und der Hexenmythos, in: Becker, Gabriele et al. (Hg.): Aus der Zeit der Verzweiflung, S. 299.

484 Weigel, a.a.O., S. 146., Abb. 16.

485 Vgl. Strong, Roy C.: Portraits of Queen Elizabeth I. Oxford: Clarendon Press 1963, S. 114 u.116, E. 32. 
Welt«, worin sich eine »Landkarte von dem Reiche der Liebe« befinde, und die Karte des gelobten Landes: Da gibt es »Wangenheim« und »Ohrfelde« am Kopf, die »Vorgebürge der guten Hoffnung« und »Busenthal« am Rumpf, »Stoßfelde«, Rothenburg, »Haargebirge«, »Naßeritz«, ein »Eiland« im »Meer« am Unterleib etc. ${ }^{486}$

\section{Die totale Inversion männlicher Herrschaft: Kannibalinnen}

Die Feminisierung neuer Territorien findet in ihrer Konstruktion als >Jungfrauen`, die es zu erobern, zu penetrieren, vergewaltigen, zu heiraten und befruchten gilt, eine Ausprägung. Die andere, die Inversion und Bedrohung männlicher Ordnung, ist mit der >Amazone〈 schon kurz angesprochen worden. Daneben wird es die `Kannibalin` sein, die als eine solche Horror-Figur der >Anderen in den frühneuzeitlichen Reiseberichten aus dem südamerikanischen Dschungel vorrangig auftaucht. Die `Kannibalin` ist ein Analogon zur europäischen Hexe.

Nach Christian Kiening sind die >großen Entdeckungen seit dem Ende des 15. Jahrhunderts nicht primär der Neugierde zuzuschreiben, ebensowenig der $»$ Verheißung neuen Wissens $«,{ }^{487}$ sondern vielmehr ökonomisch-machtpolitischen Zielen (Bodenschätze und ihr Nutzen).

»Zwar bezeugt schon vor der Entdeckung Amerikas die Fülle von Orientreiseberichten eine wachsende Faszination am Fremden, ein zunehmendes Bedürfnis, die eigene Kultur von ihren Grenzen, den inneren wie äußeren, her zu definieren. Gleichwohl galt bei der Begegnung mit den schriftlosen Völkern in Übersee das Interesse nicht dem Fremden an und für sich, sondern dessen Verwertbarkeit - in materieller, kultureller, schließlich auch spiritueller Hinsicht. $\ll^{488}$

Zugleich ist trotz aller humanistischer Ausrichtung auf Geographie und Kosmologie, auf die Vermessung der Welt, der »mundus novus«, das Neue noch lange »mehr Ergänzung als Umstürzung des Alten. Es dauerte geraume Zeit, bis in den Kosmographien die neue Welt mehr als nur

486 Vgl. Kellner, Stephan: Remota IV: Franz von Krenners schlüpfrige und schmutzige Bücher, in: Ders. (Hg.): Der »Giftschrank«. Erotik, Sexualwissenschaft, Politik und Literatur - »Remota«: Die weggesperrten Bücher der Bayerischen Staatsbibliothek. Katalog zur Ausstellung der Bayerischen Staatsbibliothek München, 2. Oktober-17. Dezember 2002, S. $186 f$.

487 Kiening, Christian: Ordnung der Fremde, in: Krüger, Klaus (Hg.): Curiositas, S. 61.

488 Ebda. 
einen Anhang bildete. Es dauerte, bis ihre Beschreibung einer der Alten Welt nahekommende Präzision erreichte. Es dauerte, bis die Wunder des Ostens aus der Wahrnehmung des Westens verschwanden, Amazonen und Riesen ihren Ort in der Topographie der Neuen Welt verloren «. ${ }^{489}$ Trotz ständiger Beteuerungen der eigenen Erfahrungen, der Augenzeugenschaft sind es die Traditionen der antiken Beschreibungen bzw. besser: Kreationen, die hier in der Frühzeit dominant bleiben. So sind es immer wieder die klassischen »Erdrandbewohner«, die beschrieben werden: die »Amyctyrae«, »die ebenso aus Plinius und den Bestiarien bekannt waren wie die Cynocephali (Hundsköpfige) und die Hyppophagi (Pferdefresser)«, vorgebliche Bewohner Ostasiens, oder, wie Raleigh für Guyana bezeugt, die antik tradierten »Blemmyae«, »Kopflose« mit Augen und Mund am Oberkörper. Hinzu kommen >Indianer`, nackt, schamlos und vor allem Kannibalen. ${ }^{490}$

So bleibt die >Erfahrung` (experiatia) lange eine ambivalente Kategorie. Einerseits hat sie rhetorischen Charakter. Andererseits »war die Sorge um einen der Welterfahrung korrespondierenden Selbst- und Heilsverlust nach wie vor gegenwärtig «. ${ }^{491}$ So erhalte die Verdammung der »curiositas« - insbesondere der »vana curiositas als eines unzulässig in göttliche Geheimnisse eindringenden Forschens [...] neue Nahrung, wenn das Schweifen in die Ferne vor moraltheologischem oder heilsgeschichtlichem Horizont erschien. Sebastian Brant kennzeichnete die erfahrung der lant als närrisch und sinnlos angesichts der Aufgabe, die Bürde der Sterblichkeit und die Gefahren des Daseins durch Weisheit zu bewältigen. Amerigo Vespucci (oder eher wohl ein Kompilator seiner Schriften) verstand den Mundus novus-Brief als Warnung an diejenigen, die das Göttliche erforschen und mehr wissen wollen, als schicklich ist «. ${ }^{492}$ Wo so etwas enden kann, zeigt das Schicksal des kynischen Philosophen Giuordano Bruno, dem es darum geht, »das Licht zu ertragen und den Blick zu befreien«, um der »Entdeckung einer Welt der Mannigfaltigkeit« wegen. ${ }^{493}$ Zum alten, tradierten Repertoire gehört auch, dass die Reisen geschildert werden als abenteuerliche Fahrten in eine fremde Welt hinein und am Ende wieder aus ihr heraus. ${ }^{494}$

Vergleichbares trifft auf die Figur des >Kannibalen`zu: Auch hier entwickelt sich kein qua Amerika-Entdeckung völlig neuer Diskurs. Der

489 Ebda., S. $61 \mathrm{f}$.

490 Vgl. ebda., $63 \mathrm{ff}$.

491 Ebda., S. 67.

492 Ebda., S. 68f.

493 Largier, Nikolaus: Rhetorische Erfahrung. Kynische Kritik und theoretische Neugierde in der Frühen Neuzeit, in: A.a.O., S. 119f. u. S. 122. 494 Vgl. Kiening, a.a.O., S. 84. 
Vorwurf der Anthropophagie als Mittel zur Stiftung von Identität und Alterität, Zivilisation und Barbarei »bildet in Europa von alters her ein rhetorisches Muster«: bei Herodot sind die Skythen gesetzlose Nomaden, die Menschenfleisch essen, Frühchristen gelten in der römischen Gesellschaft (schon wegen der Eucharistie) als Anthropophage, später bezichtigen die Christen >Ketzer` und >Hexen` der Menschenfresserei, wie Monika Wehrheim-Peuker zeigt. ${ }^{495}$ Sie untersucht die Konstruktion von Alterität in den Verschränkungen des kolonialen mit dem misogynen bzw. Hexen-Diskurs.

Der amerikanische Kannibale taucht erstmals 1493 im Kolumbusbrief auf. Er ist bereits hier Teil der grundlegenden Indianer-Dichotomie: gute Wilde (die Kontakt aufnehmen und über Kannibalen berichten) und wilde, böse, wobei der kannibalische Indianer die totale Inversion europäischer Zivilisation darstellt. Das macht ihn zum grundsätzlichen Fremdkörper jeder natürlichen Ordnung, anti-human und damit erober- und kolonisierbar, zum (wie schon Aristoteles meine) Sklaven. Was zunächst auf die Kariben gemünzt ist, wird - nicht zuletzt infolge deren rasanter Dezimierung - zuerst von Vespucci, später in französischen, deutschen und portugiesischen Berichten zum Kennzeichen kontinentaler Stämme, genauer: Brasiliens. ${ }^{496}$

In den Reiseberichten und -briefen des 16. Jahrhunderts wird dann immer wieder auf »traditionelle Muster« zurückgegriffen, wird »die Fremde« unter Verweis auf »Kannibalismus und Amazonenherrschaft [...] zu einem mythischen Terrain der Inversion und Perversion «. ${ }^{497}$

Muster, in denen die einzelnen Regionen »an Trennschärfe« verlieren, ineinander übergehen. So nennt der Deutsche Philipp von Hutten 1535 in einem Brief an den Kaiserlichen Rat Matthias Zimmermann den Orinoco »Maragnone«. Rund 20 Jahre später nennt Gonzalo Fernández de Oviedo in seinem Bericht an Kardinal Pietro Bembo über eine Expedition von 1541/42 den so Amazonas.

»Das fällt insofern aber kaum ins Gewicht, als auch die Phantasmen, mit denen die Konquistadoren leben, die Widrigkeiten, mit denen sie kämpfen, überwiegend die gleichen sind: Hier wie dort garniert die Idee kriegerisch lebender

495 Vgl. Wehrheim-Peuker, Monika: Der Kannibale - die Kannibalin. Zum Zusammenspiel von kolonialem und misogynem Diskurs, in Hanau, Katharina et al. (Hg.): GeschlechterDifferenzen, S. 24f.

496 Vgl. ebda., S. 24ff.

497 Kiening, Christian: Koloniale Texte. Das Beispiel des Philipp von Hutten, in: Puff, Helmut/Wild, Christopher (Hg.): Zwischen den Disziplinen? Perspektiven der Frühneuzeitforschung. Göttingen: Wallstein 2003, S. $197 f$. 
Frauenvölker, aus der Alten in die Neue Welt transportiert, die auf den kruden Überlebenskampf reduzierten Züge durch Dschungel und Sümpfe. « ${ }^{498}$

Auch das Amazonenland ist - bei Ralegh ebenso, wie beim Franzosen André Thevet (1558) - »ein Beispiel für verräumlichte Weiblichkeit, denn die Amazonen können vom Land [...] nicht getrennt werden«, das überwiegend als schwer erreichbar, etwa als von gewaltigen Strömungen umspülte Insel, ebenso als schwer beschreibbar geschildert werde. Der französische Apotheker Jean Mocquet erzählt von einer solchen Insel, waldbedeckt, und »Große Feminie« genannt, eingeschlossen von den Wassern des »Cyphon«, der aus dem Paradies käme. Auf der Insel würden Männer, die länger als neun Tage bleiben, von den Frauen erschlagen. Nach Thevets Theorie sind diese Amazonen entweder »nach dem Trojanischen Krieg unter Führung von Penthesilea nach Amerika gelangt« oder von Tyrannen aus verschieden griechischen und afrikanischen Gegenden vertrieben worden. „Eine Terra incognita verlangt in der Frühen Neuzeit offenbar nach Besiedelung durch die mythologische Frauengesellschaft.« Das ist ein Rückgriff auf Topoi der mittelalterlichen Kartographie, in denen die Trennung von Gut und Böse, Christlich und Nicht-Christlich allegorisch durch Amazonen markiert wird. Während jedoch im statischen Weltbild des Mittelalters »eine geographische Verortung des Anderen das Eigene stabilisieren hilft«, wirkt sich das mit der frühneuzeitlichen Expansion und Mobilität gegenteilig aus. »Denn mit der Vorstellung des Amazonenlandes wird ein Raum imaginiert, in dem europäische Eroberung und Herrschaft - politische, ökonomische und patriarchale - an ihre Grenzen stößt«. Hier nun herrscht die Inversion des »Eigenen«. Die Amazonen sind in jeder Weise physisch bedrohlich, widersetzen sich desgleichen der Eroberung, treten zudem nicht als »Handelsobjekt« - wie im »Frauentausch« Raleghs (s.o.) - auf, sondern als ökonomische Konkurrentinnen. ${ }^{499}$

Die unbekannte Welt der ungezähmten Flora und Fauna, die noch nicht eroberte Landschaft wird also imaginär besiedelt durch Gesellschaften ungezähmter Frauen. Wo diese noch keiner männlichen Ordnung, Kultur unterworfen sind, eine eigene Herrschaft ausüben, kann auch die äußere Natur noch keinerlei Kultivierung aufweisen, muss sie ebenso feindlich sein, denn die Herrschaft der Frauen entspricht der der bedrohlichen äußeren Natur.

Die Figuren der >Amazonen〈 verdeutlichen »die Instabilität von kultureller Hegemonie und Geschlechteridentität in der Frühen Neuzeit«,

498 Ebda., S. 193f.

499 Vgl. Schülting, a.a.O., S. 53ff. 
eine Bedrohung der Hierarchie »zwischen Eroberer und Eroberten«, deren mögliche Auflösung sich nur mittels Gewalt bannen lässt - hier einer »textuelle[n] Gewalt«, in der der Verweis auf die »reale Gewalt der Kolonisierung« steckt.

»Im Bild des Amazonenlandes wird das Andere des Abendlandes als feminisierter, geographisch lokalisierter Raum imaginiert, der sich nicht nur der $>\mathrm{Pe}-$ netration` durch den europäischen Mann widersetzt, sondern den Reisenden auch bedroht. Es handelt sich um die Vorstellung einer weiblich semantisierten Terra incognita, deren Funktion in der Umkehrung bzw. der Auslöschung des europäischen Textes und der europäischen Ökonomie besteht. Damit überlagern sich in den Reiseberichten der Frühen Neuzeit mittelalterliche und neuzeitliche Raumkonzeptionen. ${ }^{500}$

Dschungel, Sümpfe und eine Inversion der männlichen Ordnung. Bei der parellelen Konstruktion der Anthropophagie kommt es zunehmend $\mathrm{zu}$ einer "geschlechtsspezifische[n] Aufspaltung $\aleph^{501}$ in $"$ markierten $"$ (weiblichen) und »unmarkierten« (ebenso zunehmend entalterisierten männlichen) Kannibalismus. So entwirft Jean de Léry, calvinistischer Franzose, im 16. Jahrhundert in seiner »Histoire d'un voyage fait en la terre du Brésil« die schroffe Dichotomie männlicher und weiblicher Anthropophagie bei den Tupinambá. Während männlicher Kannibalismus als »kriegerische[s] Ritual«, mithin als kultureller Akt der Abschreckung und Rache erscheint, entspringt die Menschenfresserei der alten Frauen rein dem Lustgewinn, dem »kruden fleischlichen Genuß«, der geifernden Gier nach Menschenfleisch. ${ }^{502}$

Für Wehrheim-Peuker zeigt sich hier ein doppeltes Paradox. Im Anschluss an Homi Bhabha verweist sie auf den »Zusammenhang von othering und knowing im kolonialen Diskurs«. In der Konstruktion des Kolonisierten als Anderem wird dieser zugleich diskursiv zum komplett Beschreib- und Erkennbaren. Was zur Annäherung führt, zwangsläufig das »othering « unterminiert, unbrauchbar macht. Einerseits erhalten also männliche Kannibalen im 16. Jahrhundert per Unterstellung von Heldenhaftigkeit, Motiven der Ehre, Ritterlichkeit und der Selbstdefinition über rituelles Handeln eine kulturelle Aufwertung. Andererseits vergleichen gerade Calvinisten etwa die »Bartholomäusnacht« oder die katholische Eucharistie mit Akten barbarischer Anthropophagie. ${ }^{503}$

500 Ebda., S. 57.

501 Wehrheim-Peuker, a.a.O., S. 27.

502 Vgl. ebda., S. 23.

503 Vgl. ebda., S. 26f. 
Was also bleibt beim »othering« - »soll die Kannibalen-Figur nicht ihren gesamten Horror und Schrecken verlieren « - ist die Andere, konstruiert auf Basis der eigenen europäischen: der Hexe. »Das fremde Andere wird hier zu einer Verlängerung des eigenen Anderen, das die europäische Männerwelt zu domestizieren und zu kolonisieren angetreten war. $«{ }^{504}$ Noch in der Grimmschen »Kunsthexe«, jenem »Residual [des] mächtigen repressiven Diskurses« frühneuzeitlicher Frauen-Domestizierung, seien die Züge der Gier und Tierhaftigkeit erkennbar, die auch den Frauen der Tupinambá zugeschrieben werden. ${ }^{505}$

Abb. 6: Albert Eckhout: Tapuya-Frau, 1641

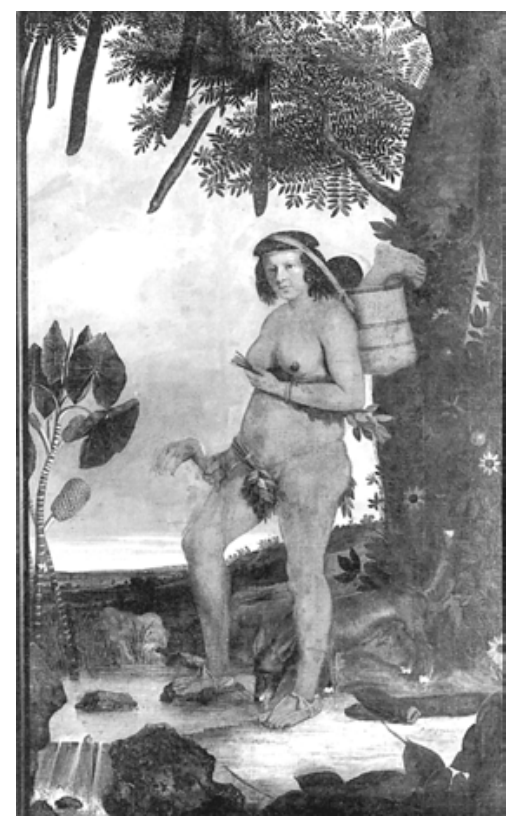

Töten, Grillen, Kochen: Im Zentrum der Konstruktionen von Hexen und Kannibalinnen steht »die Verflüssigung der Körper« ihrer Opfer. ${ }^{506} \mathrm{Im}$ »Hexenhammer" sind es vor allem Hebammen, aber auch andere alte und ökonomisch selbständige Frauen, ${ }^{507}$ die besonders ungetaufte, aber auch getaufte Kinder ohne Kreuz in der Wiege töten und stehlen. Diese

504 Ebda.

505 Vgl. ebda., S. 28.

506 Ebda.

507 Vgl. ebda. 
»kochen sie in einem Kessel, bis nach Ausscheidung der Knochen das ganze Fleisch fast trinkbar flüssig wird «. Die feste Masse werde zu Salben verarbeitet, um »Wünsche, Künste und Fahrten bequem ausführen zu können«, wer von der flüssigen »unter Hinzufügung etlicher Zeremonien trinkt, wird sofort Mitwisser und Meister der Sekte «. ${ }^{508}$ Es herrscht höchste Ansteckungsgefahr. Verflüssigung der Körper - Verflüssigung der Ordnung. Die alten Frauen der Tupinambá wiederum können laut Lérys Bericht beim Grillen der Körperteile und Innereien »kaum noch an sich halten, fangen das heruntertropfende Fett auf und lecken es gierig von den Fingern «. ${ }^{509}$ Weil im Denken der Renaissance idealerweise ein zunehmendes Lebensalter mit einer Verfestigung der Materie einhergehe, thematisiere der zeitgenössische Kannibalinnen-Diskurs die Auflösung der sozialen Ordnung: »Die Gier der alten Frauen nach Fett bildet so eine Metonymie für eine sich in gallertartiger Substanzlosigkeit auflösende Welt.« Diese »apokalyptische Konstellation« bedroht desgleichen die alte Welt, hier sind es die Hexen, die Materie verflüssigen schon weil in bereits aristotelischer Tradition das Weibliche dem Substanzlosen, Flüssigen zugeordnet wird, erst vom Männlichen formbare gestaltlose Masse. ${ }^{510}$ Und wie in der alten, so ist das zersetzende weibliche Chaos auch in der neuen Welt nicht nur von der Alten, sondern ebenso von der jungen lüsternen Verführerin repräsentiert. Die Amerigo Vespucci zugeschriebenen und vielfach übersetzten Briefe »Mundus Novus« und »Quatuor Americi Vespucci navigationes« (1503/04) inszenieren »ein heilloses sexuelles und kannibalisches Chaos« als Horror für christliche Männer. ${ }^{511}$ So werden sie an der brasilianischen Küste von jungen Indianerinnen angelockt und umgarnt, hinterrücks erschlagen und zu den hinter Hügeln sich versteckenden eingeborenen Männern gezerrt, dort gegrillt und verspeist. »Diese Schilderung inszeniert eine komplette Inversion der europäischen Männerwelt«. Sie entwirft passive Männer und aktive Frauen, dominant in Sexualität und Jagd, die christliche Männer doppelt auf ihre »Fleischlichkeit« reduzieren: als Lustund Ess-Objekte. Die Konstruktion der >Verkehrten Welt weiblicher Verderbtheit: Die Frauen jagen nicht >männlich`, >ritterlich`, nicht offen, sondern »sie locken mit ihren Körpern, sie verführen, sie täuschen, sie wecken die männliche Begierde, um die Männer zu verschlingen ${ }^{5} .{ }^{512}$

508 Hexenhammer, Teil 2, S. $31 \mathrm{f}$.

509 Wehrheim-Peuker, a.a.O.

510 Vgl. ebda., S. 29.

511 Vgl. ebda.

512 Ebda., S. 30. 
Ein Konstrukt, das fester Bestanteil des patriarchalen Kolonial-Projekts ist, in dem dann die Kolonisierung zur patriarchalen Verheißung einer »Befreiung von gefährlicher und widernatürlicher weiblicher Dominanz« wird, weibliche Zügellosigkeit durch männliche Mäßigung und >logos` ersetzt. Weibliche Dominanz als sozial-politisches Chaos: Immer wieder und in variierender Deutlichkeit sprechen die Berichte der Kolonisten vom Fehlen von Gesetz und Ordnung, Königen und Kultur (auch Agrikultur) - all das erscheint als »Legitimation und Bedrohung des kolonialen Projekts in einem«. Einerseits reetabliert hiernach die männliche Kolonialisierung »eine >natürliche` Ordnung«, andererseits dürfen »die Grenzen zu den Anderen« nicht überschritten werden, um nicht »vom indianischen Chaos verschlungen zu werden «. ${ }^{513}$

»Das Projekt der Neuzeit, die Domestizierung der Frau in Europa, scheint in der Kolonisierung Amerikas eine Verlängerung gefunden zu haben, wenn Alterität in Kategorien des Hexendiskurses konstruiert wird. Die neue Welt ist weiblich, die Kannibalin, die sowohl als alte Frau wie auch als junge Verführerin auftritt, erscheint damit als Konstrukt des zu kolonisierenden Anderen, als Figur der Inversion der europäischen Ordnung. Amerika als laszives kannibalisches Weib wird (wie in Philippe Galles Kupferstich >America um 1600) zum Sinnbild des gefährlichen Anderen, das man unterwerfen muß. Kolonisierung wird so vom aggressiven Überfall zum Überlebensprogramm umgedeutet. $\ll^{514}$

Die >ekelhafte Alte` und die >junge Verführerin`sind die zwei Versionen der nicht domestizierten Welt - nicht nur der neuen. Als böse alte Vettel, zersetzt und zersetzend, von gieriger Fleischeslust, ein Motiv schon in der griechischen und römischen Antike, das bis in die Neuzeit immer wieder auftaucht, ist sie ein Prototyp der Hexe und wird ebenso zur nicht-domestizierten, nicht menschlich verbesserten Natur-Land schaft, so beim epochemachenden Naturforscher und -ordner Buffon. ${ }^{515}$ Vergleichbares gilt für die junge Verführerin, Versucherin, den anderen Hexen-Prototyp, für die Feen, Undinen, die Jungfrauen, die nicht Untertanin von Männern sind und in ungezügelten Wildnissen wohnen. Die absolutistische Ballett-Konstruktion der Circe betont ebenso: die nicht domestizierte Natur ist `flüssig`, schwankend, sterblich, verschlingend, nicht verstetigt und unregiert: Sie muss kultiviert, zur Kultur gebracht werden. Das sind wesentliche Punkte in einer historisch-sozialen Wahrnehmung von >männlicher« und >weiblicher« Wildnis`.

513 Ebda., S. 30f.

514 Ebda., S. 31.

515 Vgl. Kap. Monströse Leiber. 


\section{Arkadischer Imperialismus}

»Leitvorstellungen [...], die beim Betrachter vorhanden sind ", schreibt Thomas Koebner, prägen auch weiterhin, im 18., 19. und 20. Jahrhundert die Bilder, die Wahrnehmungen der >anderen Welt $<$ und deren Existenz. »Zeichnet es doch gerade die exotistische Perspektive aus«, neue Länder oder Gesellschaften »auf charakteristische Weise umgeformt swahrzunehmen einzelnen oder ganzen sei, mit den Phantasien, den Hoffnungen der realen oder erfundenen Reisenden in Einklang zu bringen «. ${ }^{516} \mathrm{Oft}$ seien es »Kunsteindrücke und Lektüreerlebnisse «, die lenkten. ${ }^{517}$ Das »Bild der Wildnis« ist keine »topographisch exakte Abbildung« fremder oder kaum bekannter Gegenden, sondern "Mischung aus Dichtung und Wahrheit ${ }^{518}{ }^{5}$ Bilder, die ebenso etwas über die Wahrnehmung der (einheimischen) Natur als nun beherrschte aussagen. »Als der französische Reisende Bougainville im 18. Jahrhundert seinen Fuß auf Tahiti setzte, glaubte er sich in rokokohafte Szenerien vom Goldenen Zeitalter versetzt. Er ordnete die fremde Welt nach bestimmten Vorbildern und paßte sie seinem Erwartungshorizont ein. ${ }^{519}$

Bilder der Natur als Grundlagen des Naturbilds. Die Wahrnehmung einer neuen, nun >harmonischen`, >ganzheitlichen` Natur findet ihre VorBilder in der Malerei. Erstmals machen die Gemälde der Holländer Frans Post (1612-1680) und Albert Eckhout (ca. 1610-1665) den Gedanken anschaulich, so Maria de Fátima Costa, »dass Vegetation und Tierwelt Lateinamerikas in einem ganzheitlichen Zusammenhang dargestellt werden könnten«. In deren brasilianischen Landschaftsbildern seien »Ananas, Maracujas oder Kürbispflanzen, die ihre exotischen Früchte zur Schau stellen, Kakteen der verschiedensten Formen oder blühende Orchideen, die sich ihren Lebensraum mir Heuschrecken, Gürteltieren,

516 Koebner, Thomas: Geheimnisse der Wildnis. Zivilisationskritik und Naturexotik im Abenteuerroman, in: Ders./Pickerodt, Gerhart (Hg.): Die andere Welt. Studien zum Exotismus. Frankfurt/M: Athenäum 1987, S. 240.

517 Horace Walpole erinnern die Alpen an Salvator Rosas Bilder, die wiederum James Fenimore Cooper zu seinem »virgin land « inspirieren. Coopers Lederstrumpf-Tetralogie regt die Wildnisentwürfe Charles Sealsfields (= Karl Postel), Friedrich Gerstäckers (dessen Pazifik-Insel-Schilderungen ebenso von der Lektüre Melvilles und Defoes inspiriert sind) an, »Karl May schließlich liest alles«, und selbst Alexander von Humboldt liest »während seiner Expeditionsreise in Südamerika Georg Forsters Bericht aus der Südsee und Bernardin de Saint-Pierres Roman über das natürliche Leben auf der Insel Mauritius, Paul et Virginie«; vgl. ebda.

518 Ebda., S. 241.

519 Ebda., S. 240. 
Vögeln und Schlangen teilen«, zu sehen. Den Malern sei eine »ideale Vereinigung« von der aus naturwissenschaftlichen Studien bekannten botanischen Darstellung und künstlerischer Komposition gelungen. So seien ihre Werke zur Inspirationsquelle der Überlegungen Alexander von Humboldts zur (lateinamerikanischen) Landschaft geworden. ${ }^{520}$ Ein Jahr nach seiner Lateinamerika-Rundreise (1799-1804) schreibt er:

»Die Natur im Grossen betrachtet, der Anblick von Floren und Waldung, gewährt einen Genuß, welcher wesentlich von dem verschieden ist, welchen die Zergliederung eines organischen Körpers und das Studium seiner bewunderungswürdigsten Struktur erzeugt. ${ }^{521}$

Und so entwirft er sein programmatisches »Naturgemälde der Anden«, einen Querschnitt durch den Chimborazo, »das Profil Südamerikas vom Pazifik bis zum Atlantik «, ${ }^{522}$ in dem »[j]ede Pflanze, jedes organisierte Wesen [...] den Ort, den ihr die Natur zugewiesen hat « besetze, wie Humboldts ecuadorianischer Expeditionsbegleiter Francisco José de Caldas schreibt. ${ }^{523} »$ Welche malerischen Gegenstände für den Pinsel eines gefühlvollen Künstlers!« schwärmt Humboldt über die Überfülle der Natur des Subkontinents und empfindet als erstes dementsprechendes Werk das damals prominente »Brasilianischer Urwald « des Comte de Clarac, das 1819 zunächst als Aquarell, dann in mehreren Gemälde- und Stichversionen verbreitet wird. ${ }^{524}$

Kein Zergliedern mehr, sondern ein »Totaleindruck» von »Landschaft $~^{525}$ (der spätere Zentralbegriff der Geographie, den diese Disziplin auf Humboldt zurückführt). Humboldt spreche auch vom »»Gesamteindruckı, vom >physiognomischen Charakter - Wendungen, die bei ihm einen emotional-ästhetischen Sinn haben, und nicht nur bei ihm, sondern im gesamten Sprachgebrauch etwa zwischen 1780 und 1850«. Ludwig Trepl betont, dass in dieser Zeit noch keine »Trennung von Wissenschaft und Kunst, von jener Schärfe, die uns heute selbstverständlich

520 Vgl. Costa, Maria de Fátima: Vegetation und Bergwelt Lateinamerikas, in: Howoldt, Jenns E./Schneede, Uwe M. (Hg.): Expedition Kunst. Die Entdeckung der Natur von C. D. Friedrich bis Humboldt. Katalog zur Ausstellung in der Hamburger Kunsthalle vom 25. Oktober 2002 bis 23. Februar 2003. Hamburg, München: Dölling und Galitz 2002, S. 179.

521 Humboldt: Ideen zu einer Geographie der Pflanzen; zit. n. ebda.

522 Costa, ebda. Vgl. Kat.-Nr. 133, ebda., S. 206f.

523 Zit. n. ebda., S. 179.

524 Vgl. ebda. Vgl. Kat.-Nr. 32, ebda., S. 198.

525 Zur frühneuzeitlichen Entwicklung des Begriffs »Landschaft« vgl. Kap.

Das neue bürgerliche Subjekt entdeckt die Landschaft. 
ist « existiere, wobei Kunst und Wissenschaft nicht dasselbe seien, aber gemeinsame »Denkfiguren« besetzten. ${ }^{526}$

So sei die »naturwissenschaftliche Tätigkeit [...] Teil eines wesentlich ästhetisch aufgefaßten >richtigen Lebens«" gewesen,

»und zwar als naturwissenschaftliche. Humboldt sucht auf wissenschaftliche Weise nach Zusammenhängen, weil er Künstler ist; die Pflanzenformen trennt er freilich nicht als Biologe, sondern als Künstler, der die Physiognomie der Natur im Text darzustellen sucht, wobei ihm der Maler Vorbild ist. Zur Herstellung des Gemäldes als Text ist aber auch die Kenntnis der physischen Bedingtheit und der physischen Wirkungen der Formen im naturwissenschaftlichen Sinn nötig, und diese sind Teil der Darstellung «. ${ }^{527}$

»Physiognomik« als Ästhetik wird so »im Kontext von Krise und Ende der klassischen Naturgeschichte« gegen das Prinzip der Taxonomie gewendet, eine »im Namen der Natur- und Landschaftsästhetik«, aus der später eine »Absage im Namen der Ökologie werden« könne. Humboldts Vorbild bei der »Physiognomik der Gewächse« seien dann auch Theorie und Literatur des englischen Landschaftsgartens mit ihrer ") physiognomisch[e]< Klassifikation der Gewächse und ihrer >Gruppierungen nach dem landschaftlich wirksamen Habitus (statt nach dem botanischen System) «. ${ }^{528}$

Die gesellschaftliche Grundlage der ästhetischen Wahrnehmung ist eine Unterwerfung der Natur. So wie der Landschaftsgarten - als ästhetische Komposition einer >habituellen Ganzheit ` von Natur - deren Zurichtung als unsichtbare verlangt; im Gegensatz zur zwingend sichtbaren im Garten barocker Geometrie. Das Paradies ist ein Garten, und so entstehen nun tropische Paradiese, bevölkert von >Guten Wilden ${ }^{529}$

Donald Worsters Unterscheidung von »imperialer« und »arkadischer Ökologie«, wie sie mit der Aufklärung entstehe, ist somit nicht existent. Den arkadischen Standpunkt sieht er als »heidnisch«, von antiken Autoren wie Vergil beeinflusst, personifiziert vom britischen »geistlichen Naturalisten« Gilbert White (1720-1793) und dessen Vorstellung einer "zwingende[n] Idylle der Zufriedenheit und des Friedens«, die repräsentiert werde von »einfachen und natürlichen Menschen«, die behütet

526 Trepl, Ludwig: Geschichte der Ökologie. Vom 17. Jahrhundert bis zur Gegenwart. Frankfurt/M: Athenäum 1987, S. 104f.

527 Ebda., S. 108.

528 Ebda., S. 108f.

529 Hierzu hat vor allem Karl-Heinz Kohl gearbeitet: Entzauberter Blick. Das Bild vom Guten Wilden und die Erfahrung der Zivilisation. Berlin (W): Medusa 1981. 
von der »Vorsehung« und einem geistlichen Oberhaupt im harmonischen Naturhaushalt des ländlichen Englands leben. Den imperialen Standpunkt, beeinflusst vom »christlichen Pastoralismus«, christlicher Trennungsideologie, sieht er verkörpert von Linné und seinen Epigonen, deren Ziel eine mechanistische menschliche Herrschaft »über die Natur durch den Gebrauch von Vernunft und harte Arbeit« sei. Der Hirte opponiere weder gegen eine urbane Entfremdung, noch verschmelze er »durch seine Herde mit der Natur«, vielmehr verteidige er sie gegen die feindlichen Naturkräfte. ${ }^{530}$

Auch Trepl hält einen solchen Gegensatz zunächst für konstruiert. Schon, weil auch Linnés Arbeit physikotheologisch fundiert sei, zwar teils bereits »Ausdruck der progressiven, pro-industrialistischen Kräfte«, als Naturgeschichte« aber »vor allem das Gegenteil«. Insbesondere aber gebe es in der »Einheit der aufklärerischen Naturutopie« einen solchen Widerspruch noch nicht, sei das aufklärerische Naturideal ein »konstruktivistisch[es] «, in dem es stets um die Konstruktion »konkrete[r] Natur« gehe, nicht physikalischer oder sonst abstrakter. Das Erleben von Naturschönheit sei ein tätiges. Zwar solle der Mensch durch Vernunft eine Autonomie gegenüber der Natur erlangen, aber die Vernunft sei erneut »Natur«, die so bereits als eine in der Antike, bei »Wilden« und im einfachen Landleben existente gedacht werde. Diese »)Vernunft< richtete sich gegen >Künstlichkeit`, gegen die Un-Natur des Hofes«. Daher könne diese »konkrete, ländliche« >Natur« »gar nicht die Gegenposition zum Bürgertum, dem Träger der Aufklärung und der Industrialisierung, besetzen, weil das Unnatürliche schlechthin der Hof war«. Erst später, so Trepl, mit der »Auflösung der Gemeinsamkeit und Rationalität, von >Land bensformen« oder gesellschaftliche Naturbeziehungen, »die von denen des Bürgertums bedroht werden mußten «, könnten ») arkadisch perial« als unvereinbar erscheinen«. Darin liege »die Paradoxie des Konservativismus in der Aufklärung «. ${ }^{531}$

Rousseau etwa notiert 1774 in seinem $»$ Wörterbuch der in der Botanik gebräuchlichen Begriffe«, dass »man die Botanik» nicht »studiren könne, ohne die Nomenclatur zu erlernen «. ${ }^{532}$ Nicht nur wären »drey Jahrhunderte reich an Beobachtungen und Entdeckungen« verloren, es wäre ein unauflöslicher Widerspruch. Nur, wenn Sammler wie Reisen-

530 Worster, Donald: Nature's economy, Cambridge 1985; zit. n. Trepl, a.a.O., S. $85 f$.

531 Ebda., S. 86ff.

532 Zit. n. Drouin, Jean-Marc: Von Linné zu Darwin, in: Serres, Michel (Hg.): Elemente einer Geschichte der Wissenschaft, S. 580. 
de, Gärtner wie Liebhaber eine gemeinsame Taxonomie übernähmen, könne die Botanik »zu einem kumulativen Wissen werden «. ${ }^{533}$ Es gibt in der Tat das simperiale` (Botanisieren, Taxonomieren, Klassifizieren, Decodieren) und das >arkadische (Harmonie und Ganzheit) als die zwei Linien der `Ökologie`, die sich nicht nur nicht widersprechen, sondern untrennbar miteinander verwoben sind. ${ }^{534}$ Dass sich diese vorgebliche >Paradoxie`, trotz solcher Empfindungen, nach der von Trepl beschriebenen Auflösung zum Widerspruch entwickelt, bleibt jedoch zweifelhaft. Denn wenn >Harmonie` und >natürliches Gleichgewicht` wissenschaftlich gestützt werden sollen, bleiben >Imperialismus` und >Arkadien epistemische Zwillinge.

>Ganzheitlichkeit ist das Stichwort, mit dem Costa die Prinzipien der Humboldt-Schule etikettiert. Dazu zählt sie die »Historia Naturalis Palmarum«, botanische Zeichnungen, in denen Carl Friedrich Philipp von Matius und Johann Baptist von Spix nach ihrer Brasilien-Expedition die verschiedenen Palmenarten in ihrer jeweiligen Umgebung wiedergeben. ${ }^{535}$ Dazu zähle ebenfalls das Werk des österreichischen Illustrators Thomas Ender, der 1817/18 Brasilien bereist. »In seinen Zeichnungen und Aquarellen gelingt dem Maler eine reizvolle Kombination aus botanischer Präzision und malerischer Ansicht. Die Verbindung von naturwissenschaftlicher Strenge in der Beobachtung der Vegetation und der sorgfältigen Wiedergabe der Topographie, von Architekturdetails und Genreszenen begründete den Ausgangspunkt für einen Darstellungstypus, der unter den reisenden Künstlern auf dem amerikanischen Kontinent Schule machen sollte. $\aleph^{536}$ Möglicherweise von Ender beeinflusst reist der Augsburger Johann Moritz Rugendas 1821-1824 mit der Expedition G. H. von Langsdorffs nach Brasilien und wird anschießend von Humboldt mit Pflanzenstudien für seine Publikationen beauftragt. Rugendas arbeitet seine Naturstudien auch zu Ölgemälden aus, so der »Brasilianische Urwald«, den er an den Fürsten zu Thurn und Taxis ver-

\section{Drouin, ebda.}

534 Vgl. Kap. Das Wirken des Maschinengottes.

535 Vgl. Costa, a.a.O., S. 179; vgl. Kat.-Nr. 205, ebda., S. 224; vgl. a. Kat.-Nr. 212, S. 225: »Vögelteich am Rio S. Francisco.

536 Ebda., S. 179. Vgl. Kat.-Nr. 66, ebda. S. 196: »Ansicht der Gegend von Engenho Velho. Gezeichnet aus dem Österreichischen Gesandtschaftshause, 1817 «. Hier entfaltet sich eine beiläufige wie punktuell dramatische Szenerie. An einem Felsen über einem weiten Tal, gesäumt von einer Straße rasten Menschen unter einer Gruppe verbliebener Urwaldbäume, während ein Mann per Knüppel auf eine Schlange einprügelt. Eine Mann und eine Frau tragen Lasten auf der Straße, am Himmel fliegt ein großer Vogel. 
kauft. ${ }^{537} 1831$ reist er auf eigene Rechnung nach Mexiko. »Dort entdeckt er mit seinen teils nach der Natur gefertigten Ölstudien neue Aspekte innerhalb der naturalistischen Malerei der Humboldt-Schule. In diesen Arbeiten hält sich Rugendas nicht mehr an die reine Wiedergabe der Form, wie sie die sorgfältige Aneignung mit dem Bleistift vorgibt; er ist näher an der Natur, erfasst deren ganzen Farbenreichtum unmittelbarer, verfeinert seine Palette der Grüntöne und zeichnet mit dem Pinsel oder dem Pinselstiel Details hinzu«, damit seine Objekte klarere Konturen erhalten. ${ }^{538} \gg$ Im Repertoire der Naturphänomene erregten neben der üppigen tropischen Vegetation bereits in den ersten Aufzeichnungen der Lateinamerikanischen Landschaft auch die Bergketten, insbesondere die Vulkane große Aufmerksamkeit.« So habe schon Hernán Cortés brieflich an Karl V. von seinen Eindrücken vom Popocatépetl berichtet. Der »Pflanzenreichtum « beschwört inzwischen »Vorstellungen vom irdischen $\mathrm{Pa}$ radies« herauf, während »die imposante Topographie« eher einschüchtert oder »als spektakuläre Herausforderung empfunden« wird. So entstehen vom späten 18. bis ins 19. Jahrhundert immer wieder dramatische Bildkompositionen von glühenden Vulkanen.

»Humboldt widmete zentrale Teile seines Werkes der geognostischen Erforschung Lateinamerikas. Er plädierte für die Notwendigkeit von Reisen ins Landesinnere, um die Ausrichtung von Bergketten und deren geologische Beschaffenheit zu untersuchen. Die reisenden Künstler übernahmen diese Aufgabe mit großem wissenschaftlichen Ernst und gingen in ihrer Motivwahl über die Tradition des rein Pittoresken hinaus. Paradigmatisch für diese Haltung sind die Darstellungen des Popocatépetl auf der östlichen Seite des Tals von Mexiko. ${ }^{539}$

An der Oberfläche nun also die >üppige tropische Vegetation` als >Garten Eden`, darunter aber lauert die Bedrohung, brodeln die Vulkane. Das gefährliche Andere, die frühneuzeitlichen Dschungel, Sümpfe, Amazonen und Kannibalinnen haben sich in der Neukonstruktion im Zeitalter der Vernunft von der Oberfläche, die nun als >irdisches Paradies` reüssiert, sozusagen in den Untergrund zurückgezogen.

So erscheint die >weibliche Wildnis` als oberflächlich gezähmt, aber es brodelt noch immer untergründig. Sigrid Weigel beschreibt den $\mathrm{Zu}$ sammenhang der neuen Bilder von Frauen, Wilden und Wildnis.

537 Vgl. ebda., S. 179f. Vgl. Kat.-Nr. 170, ebda., S. 204: Das Bild zeigt einen >üppigen Dschungel mit allen möglichen Pflanzenarten und -symbiosen, einen Fluss oder See dazu.

538 Vgl. ebda., S. 180. Vgl. Kat.-Nr. 153 u. 155, ebda., S. $202 f$.

539 Ebda., S. 180. 
»Die Frau wird zum Symbol und zur Verkörperung der doppelt bewerteten Natur« - >rein « und >dämonisch . An ihrem Körper und an ihrem Bild vollzieht sich auch der Durchsetzungsprozeß eines neuen Naturbegriffs: Die Natur ist dem Menschen unterworfen, während die Bewegungen mechanisch und die Natur zum Objekt wissenschaftlicher Betrachtung und zum Gegenstand des Kunstgenusses geworden sind. ${ }^{540}$

Nach dem Ende der Hexenverfolgung »und des darin wirksamen Mythos von der Dämonologie des Weibes wird ein neuer Typ Frau entworfen: die >Unschuld«« im prekären »weiße[n] Gewand«, das kaum verbirgt, was zuvor gewesen sein soll und jederzeit kurz vorm Zerreißen steht. In allen literarischen Versuchen, diesen Typus in der Phantasie zu verlebendigen, tritt die äußerste Künstlichkeit und gefährliche Anfälligkeit der $>$ Unschuld $\ll$ zutage $\ll .{ }^{541}$

In seinem Essay »Über die Frauen« kommt auch der Co-Herausgeber der »Encyclopédie« zu der zeitgenössisch verbreiteten Feststellung, dass Frauen »zwar äußerlich zivilisierter als wir« seien, »aber innerlich sind sie wahre Wilde geblieben«, mithin: sie »unterliegen einer epidemischen Wildheit «. ${ }^{542}$ Die weibliche Wildheit zeige sich auch daran, dass Frauen »weniger Herr ihrer Sinne als wir« seien, »merkwürdige Kinder«. Die »Unfähigkeit zu Überlegung und Grundsätzen« lasse »nichts bis in eine bestimmte Tiefe des weiblichen Verstandes dringen«. Ethische und moralische Ideen »schwimmen an der Oberfläche ihrer Seele«, dafür seien Frauen selbstverliebte Egoistinnen, »selten systematisch, immer dem Augenblick unterworfen $« .{ }^{543}$ Als >Kinder $<$ werden auch immer wieder >Eingeborene` wahrgenommen. So auch 1740 vom französischen Peru- und Amazonasreisenden Charles-Marie de la Condamine. ${ }^{544}$

Der europäische Mann konstituiert sich als der Andere gegenüber $>$ Frauen ziert. Bei Rousseau (und im Folgenden Bougaineville), in der Aufklärung per se, wird der »homme sauvage« zum »Beispiel für eine glücklichere Vorstufe, für eine Art Goldenes Zeitalter $« .{ }^{545}$ Bougaineville notiert begeistert die »gute Ordnung« und soziale Hierarchie auf Tahiti. Im forcierten Konzept des Geschlechtscharakters hingegen finde sich »stereotyp«, so Weigel, »der Rekurs auf die Natur des Weibes, auf seine natürliche Moral und Anmut«, seine Inferiorität aufgrund der »schwächere[n]

540 Weigel, a.a.O., S. $127 f$.

541 Vgl. ebda., S. 130.

542 Zit. n. ebda., S. 118.

543 Zit. n. ebda., S. 122f.

544 Vgl. ebda., S. 122.

545 Ebda., S. 133. 
Konstitution «, der »andersgeartete[n] Organisation ihrer >Maschine «", wie es auch bei Kleist und Fichte nachzulesen ist. ${ }^{54}$ Und hier gründet auch der »Diskurs über die weibliche Schamhaftigkeit«, der Kompensation gefürchteter innerer Untiefen unter äußerem Schein. »Der Konzeptualisierung des weiblichen Geschlechtscharakters mit den Begriffen Unschuld, Schamhaftigkeit, Anmut und Tugend ist die Eindämmung ebenso wie die Ausgrenzung weiblicher Sexualität eingeschrieben. $\ll^{547}$ Die \Schamhaftigkeit fungiert als Leibwache einer nur oberflächlich gezügelten, gefürchteten weiblichen Wildheit. Auch im rokokohaften irdischen Paradies Tahiti Bougainevilles. Dort seien die »meisten Nymphen nackend " gewesen, da ihnen Männer und alte Frauen die normalerweise getragenen Schurze »weggenommen hatten«. Bei aller Freundlichkeit gegen die Europäer und »aller Naivität« zeigten sie »eine gewisse Art von Schamhaftigkeit; sei es, daß die Natur dem anderen Geschlecht allenthalben eine gewisse Scheu eingeprägt hat, sei es, daß sogar in einem Land, wo noch die Freiheit des Goldenen Zeitalters herrschte, die Frauen das zu verhehlen wissen, was sie am meisten wünschen. Die Männer handelten freier und offener «. ${ }^{548}$ Schillers innere $» H y a ̈ n e n «$, Diderots »Pythia«, ${ }^{549}$ bewacht von >natürlicher weiblicher Schamhaftigkeit` und `Unschuld , die nun auch den Frauen der Wilden auf Tahiti zubemessen wird, und zugleich Humboldts neues Naturbild - »Auf das Zusammenwirken der Kräfte, den Einfluß der unbelebten Schöpfung auf die belebte Thier- und Pflanzenwelt, auf diese Harmonie sollen stets meine Augen gerichtet sein ${ }^{550}$-, mit dem er 1799 seine Südamerikareise antritt: Hier kündigt sich ein neuer Umgang mit der >weiblichen Wildnis` der ‘äuBeren Natur« an, wie ihn Claudia von Werlhof für die Moderne pointiert:

»Naturschutz kann und will Natur gar nicht vor dem menschlich-männlichen Angriff schützen, sondern will in der Tat die Natur - wenn überhaupt vor sich selbst schützen, nämlich ihrer sogenannten Wildheit, Bösartigkeit oder Grausamkeit, deren anscheinend stets lauernder Einbruch nun als der wahre Angriff ausgemacht wird. Naturschutz will also eine zweite Natur (er)schaffen, die vor den angeblichen Attacken der ersten Natur geschützt werden muß! ${ }^{551}$

546 Vgl. ebda., S. 123.

547 Ebda., S. 129.

548 Zit. n. ebda., S. 135.

549 Vgl. ebda., S. 128.

550 Zit. n. ebda., S. 128.

551 Werlhof, Claudia von: Männliche Natur und künstliches Geschlecht. Texte zur Erkenntniskrise der Moderne. Wien: Wiener Frauenverlag 1991, S. 168 . 


\section{¿Weiblicher Wald` - ımännlicher Wald`}

>Weiblicher Wald ist das, was verschwinden muss, was abgelöst, überwunden, erobert, zugerichtet, erhöht, verschönert werden muss. Das Gegenprinzip, das verwirrende, uneindeutige, die Kultur bedrohende Prinzip in der äußeren Natur. Das, was in Besitz, in Abhängigkeit gebracht und dann als abhängig geschützt werden muss.

>Weiblicher`Wald ist >jungfräulich (n jeder Hinsicht: Er scheint von Menschen unbewohnt (ist wirklich >draußen ২), ist niemandes Besitz, befindet sich in einer als prekär wahrgenommenen FruchtbarkeitsSituation: Signale einer schrecken- oder ekelerregenden Eigenständigkeit zwischen >unfruchtbar` (wüst, öde, widerständig) und >überfruchtbarく, phantasmatischer Ort »der verschlingend-fruchtbaren Schlünde der Lust und der Kanäle des Lebens [...], gegen die das Ästhetische einen eigenen Typ der Lust und einen eigenen Körper etablieren muß, weil sonst >die Grenzen der Schönheit schwinden « «. ${ }^{552}$ Oder gegen die das Ökonomische den Typ des willig bloß reproduzierenden >Körpers` etablieren muss.

>Weiblicher Wald ist also alterisierter Wald, der als Repräsentant einer verkehrten Welt vollständig beseitigt werden muss, der >sterblich ist - oder, der später in einem Zustand der Hilfsbedürftigkeit wahrgenommen wird und so geschützt werden muss; vor sich selbst und seiner Verwilderung.

>Männlicher Wald - das soll im Folgenden in seinen historisch-sozialen Abläufen gezeigt werden - ist Berufungs- und Legitimationsinstanz. Prinzip klarer Hierarchien und harter Gerechtigkeit, der >Selbstbehauptung «. Ort der Erfahrung von 〉Erhabenheit`, der `höheren Werte` (und nicht der >niederen Instinkte, wie der >weibliche` Wald), vor allem sewiger Werte. Einer `Erhabenheit`, die auch dem Kriegerischen, >heroischer Kriegserfahrung zugerechnet wird. ${ }^{553}$

>Männlicher`Wald befindet sich in Besitz, ist geordnet nach >Maß und Zahlı, Ort geregelter, überschaubarer Produktionsabläufe des >notwendig-maßvollen`, Körper bereits - wenn auch wehrhafter -, der eigentlich keiner Neuordnung bedarf, schon gar keiner Verschönerung, die seine Erhabenheit antastet und womöglich herabsetzt.

Ästhetik und Ökonomie sind hier zwar immanent nicht widersprüchlich, haben aber doch den Keim des Widerspruchs in sich dadurch, dass auch der >heroische Wald nicht davor gefeit ist, unter die

552 Menninghaus, Winfried: Ekel, S. 176.

553 Vgl. Kap. Der Aufmarsch der Soldaten. 
Säge zu kommen. Zugleich könnte das `soziale Geschlecht` des Waldes unscharf werden, wenn es unter Schutz gestellt wird.

Aber es gibt offenbar eine Möglichkeit der Domestikation, eines InsHaus-hinein-Holens, bei der der Wald in einer diaphanen Konstruktion als immer schon zugehörig erscheint. So wird er etwa im deutschen $\mathrm{Hu}-$ manismus imaginiert, als aktueller Ort der blühenden Kultur, der in früheren Zeiten jedoch aus inzwischen veränderten klimatischen Gründen sehr unwirtlich gewesen sei. Hier ist der Wald zwar auch `Mutter-Land`, als allegorische Frau in rechtmäßigem Besitz, fruchtbar gemacht durch den Besitzer. Die >Weiblichkeit` hier, wie grundsätzlich in dieser Art der Allegorese, ist nur enorme Hülle, bloßer Zeichenkörper für eine als männlich gedachte Ordnung.

Der Wald wird zum Monument allegorisiert, zu einem der Ewigkeit, zur männlichen Schöpfung. Das >Weiblicher ist das Sterbliche, das $>$ Männliche〈 das >Unsterbliche〈, Kultur. Wenn in >Germanien` der >Herkynische Wald , wie er hier konstruiert wird, Eichenwald ist, dann werden (historisch später) die Eichen zu >germanischen`>Recken`, zu Soldaten. Der Wald wird zur dezidiert männlich definierten Gruppe: zur Armee, zum Heer. Oder er wird, in der anderen Variante, zur >Ständevertretung im absolutistischen Staat. Desgleichen »männliche Liebe zum Identischen «: ${ }^{554}$ auch die Ständevertretung ist nicht weiblich besetzt. Und hier entsteht analog zur >Staatsmaschine< der Wald als Maschine.

>Männlicher Wald ist entalterisierter Wald, weil er patriarchal-gesellschaftlich geforderte Tugenden repräsentieren soll. Er kann daher auch >Wildnis «sein, eben entalterisierte Wildnis, in der diese Tugenden erkennbar seien sollen, die aber von Unebenheiten, Auswüchsen usw. befreit, geglättet werden müssen. Diese Wildnis ist dann auch reformierbar. Sie ist jedenfalls Monument >ewiger Werte`, >unsterblich`, Vorbild im >Daseinskampf ${ }^{555}$ 



\section{Das ısoziale Geschlechtı der äußeren Natur Teil II: >Männliche Wildnisı}

Die »Germania« des Tacitus soll offenbar zeigen, dass - in Relation zur >dekadenten` römischen Gesellschaft - selbst die Barbaren der nördlichen Wildnis tugend- und oft beispielhaft seien. Das heißt, in gewisser Weise entwirft er einen Zusammenhang zwischen Wildnis und Tugend. Dennoch geht es nicht um ein Lob der Wildnis, sondern um die Ironie einer moralischen Unterlegenheit des Imperiums, darum, Prüfsteine für die eigene Gesellschaft aufzustellen.

Im >deutschen Humanismus` verläuft die Rezeption des Werkes keineswegs so bruchlos, wie das überwiegend behauptet worden ist. Gernot Michael Müller zeigt, dass (nicht nur) Konrad Celtis, der in zwei Ausgaben seiner »Germania generalis« um 1500 den Tacitus-Text herausgibt und mit eigenen Versen ergänzt, ${ }^{1} \gg$ die mutatio seiner patria « thematisiere. Das heißt, »daß die in der Forschung immer wieder vorgetragene Behauptung von einer Idealisierung der germanischen Vergangenheit seitens Celtis' zumindest für die Germania generalis nicht tragfähig ist ${ }^{2}{ }^{2}$ Zwar wird vom frühbürgerlichen Subjekt in der Renaissance die Landschaft - und der Wald - als ästhetische Kategorie entdeckt, und im >deutschen Humanismus explizit patriotisch reklamiert. Dabei aber wird desgleichen eine Entwicklung der »Germani« von der Barbarei zur Kul-

1 1498/1500 gibt er in Wien den Druck »Cornelij Taciti de origine et situ Germanorum Liber«, ergänzt durch den eigenen Text »Germania generalis« und das dritte Kapitel der »Norimberga« heraus, 1502 in Nürnberg den Band »Quattuor libri Amorum«, inkl. der »Germania Generalis« und der »Norimberga«; vgl. Müller, Gernot Michael: Die »Germania generalis« des Conrad Celtis. Studien mit Edition, Übersetzung und Kommentar. Tübingen: Niemeyer 2001, S. 29ff. u. S. $41 \mathrm{ff}$.

2 Ebda., S. 408. 
tur, der »Germania« zur kultivierten und urbanisierten Landschaft betont. Zwar werden die >Germanen` als wohlproportionierte Riesen, viril und kriegerisch aufgefasst, wobei dieses Kriegerische jedoch als ambivalent gilt (zumindest bei Celtis). Das Wohnen im Wald aber wird als Signum des Barbarischen eingeräumt. Allerdings durchaus nicht widerspruchsfrei. Behauptet der >deutsche Humanismus` doch programmatisch einen unwandelbaren germanischen Volkscharakter, exklusive Indigenität und göttliche Abstammung der >Germanen<, definiert mithin >Germania als ethnischen Raum. Dieser Raum aber wird als wandelbar und zum Positiven gewandelt aufgefasst. Der >Herkynische Wald ‘ fungiert hier einerseits als Ort der >Urahnen $<$ - als solcher »entfaltet [er] unermeßlich große Haine voll bejahrter Eichen, die nach Religion und alter Sitte als heilig verehrt werden $\aleph^{3}$ - andererseits als Topographie der `Germania<, der Ausdehnung ihres `Leibes`. Dieser `Herkynische Wald ist nun, im 16. Jahrhundert, aber keine schreckende Wildnis mehr, sondern Bestandteil einer harmonischen, durch Städte bestimmten Kulturlandschaft. Urbanität erscheint hier als Signum einer positiven historischen Entwicklung - in >Teutschland . In der Renaissance-Gesellschaft existiert zwar im Kontext ökonomisch-sozialer Umbrüche durchaus ein Städte-Unbehagen, im deutschen Sprachraum äußert sich das aber in Feindschaft gegen >Rom<, bzw. deren Abwertung zum einen, Idealbildern einheimischer Städte zwischen rückwärtsgewandter Utopie und Humanismus-typischem Stadtlob zum anderen. Eine direkte, bruchlos konstruierte Verbindung von >Wildnis $<$ und 〉Tugend ( aber - als positiver Gegenwelt zur Stadt - wird noch nicht postuliert. ${ }^{4}$

Erst Ende des 18. Jahrhunderts wird die »Eiche zum spezifisch >deutschen Baum«" erklärt ${ }^{5}$ und besonders seit dem 19. Jahrhundert - in der Heimatschutzbewegung und ihrem Umfeld - die >germanische Wildnis` und ihre >Recken` in Baum- und Menschen- (bzw. Männer-)Gestalt idealisiert. Und nun erscheint Wald-〉Wildnis` (neben der \Scholle〈 des >ewigen Bauern $\iota$ ) als Bild urtümlicher patriarchaler Ordnung, Raum >ewiger Werteく, als »Symbiose von Aggression und Idylle«, ${ }^{6}$ als männlich definierter Natur-Ort und somit positiv verfasste Gegenwelt zur fe-

3 Celtis, Konrad: De situ et moribus Germanie additiones; zit. n. Müller, Gernot Michael, a.a.O., S. 103.

4 Vgl. Exkurs II.

5 Vgl. Lindemann, Klaus: In den deutschen Eichenhainen webt und rauscht der deutsche Gott, in: Semmler, Josef (Hg.): Der Wald in Mittelalter und Renaissance. Düsseldorf: Droste 1991, S. 203.

6 Dupke, Thomas: Mythos Löns. Heimat, Volk und Natur im Werk von Hermann Löns. Wiesbaden: Deutscher Universitäts-Verlag 1993, S. 119. 
minisierten Großstadt, zur Urbanität als >fremder`, zur >überhitzten Zivilisation`, zur >heimat-entfremdenden Proletarisierung « der Industrie. ${ }^{7}$

Zurück zunächst zur antiken »Germania«. Tacitus beschreibt das Land als

»im großen Ganzen grauenerregend wegen seiner Wälder oder häßlich wegen seiner Moore. [...] Saatkorn trägt es in reichem Maße, Obstbäume duldet es nicht, es ist reich an Vieh, das aber meistens kleinwüchsig ist. Sogar dem Hornvieh fehlt sein charakteristisches stattliches Attribut, das Gehörn. Die Germanen freuen sich nur über die Anzahl, ist Vieh doch ihr einziger und schönster Reichtum «. ${ }^{8}$

Grauenerregende Wildnis: Das »Unschöne und Unheimliche des Landes « ${ }^{9}$ erkläre auch die 〉Reinrassigkeit « der »Germanen«, der »ursprüngliche[n] Bevölkerung«, weder durch feindliche noch freundliche Zuwanderung »vermischt«. Denn wer würde sich schon solch »unschönen Landschaften« mit einem derart »rauhen Klima und trostlosen Äußeren« aussetzen, »wäre es nicht sein Heimatland? «. ${ }^{10}$ Diese »Rassereinheit« der »Germanen«, allesamt rotblonde Recken, deren gewaltige Leiber nur zum Angriff taugten, kommentiert Lund, ergebe für Tacitus, »daß sie auch ihre moralische Integrität nicht verloren haben können «. ${ }^{11}$ Könige werden aufgrund adeliger Herkunft gewählt und haben »keine unumschränkte und willkürliche Macht«, die Wahl der »Heerführer« erfolge »aufgrund ihrer Tapferkeit«, sie »sind Anführer mehr durch ihr Beispiel als durch ihre Machtbefugnis, also eben durch die Bewunderung, die sie hervorrufen, wenn sie kühn sind «. Befehle kommen hier quasi vom zuständigen Kriegsgott, weshalb auch für Kämpfe »bestimmte Abbilder und Symbole« aus »heiligen Hainen und Wäldern « geholt würden. ${ }^{12}$ Das Prestige dieser Führer zeige sich daran, »wer die meisten und kühnsten Gefolgsleute« habe. ${ }^{13}$ »Über kleinere Angelegenheiten entscheiden nur die Führer, über größere alle« - wenn auch nach vorheriger Behandlung der »Führer« -, so bei Anklagen und Todesstrafen, wobei »Verräter« an

7 Vgl. Exkurs II.

8 Tacitus, P. Cornelius: Germania. Interpretiert, herausgegeben, übertragen, kommentiert und mit einer Bibliographie versehen von Allan A. Lund. Heidelberg: Winter 1988, S. 73.

9 Lund: Kommentar, in: a.a.O., S. 125.

10 Germania, S. 71.

11 Lund: Kommentar, S. 111.

12 Vgl. Germania, S. 77.

13 Vgl. ebda., S. 81. 
Bäumen aufgehängt, »Feiglinge«, »Kriegsscheue« und »Entehrer« des eigenen Leibes in Sümpfen ertränkt würden. ${ }^{14}{ } »$ Kapital auszuleihen« sowie »Wucherzinsen« seien unbekannt. ${ }^{15}$ Das so entworfene Anti-Rom hat aber, schon gemäß der Ambivalenz von Ehrfurcht und Abscheu in der Beschreibung, Schattenseiten. Die enorme »Geselligkeit und Gastlichkeit« führt praktisch habituell zu »Gelagen«, die in »Zänkereien«, oft »mit Totschlag und Verletzungen« enden, aber auch in Versöhnung. Die Germanen sind »Trunksüchtige«, maßlos im Durst. ${ }^{16}$ Ihre Kinder wachsen »nackt und schmutzig « auf, was allerdings auch positiv zu sein scheint, entwickeln sie doch gewaltige »Körpern [...], über die wir staunen ${ }^{17}{ }^{17}$ Zudem sollen die (erwachsenen?) Germanen gern in warmem Wasser baden. ${ }^{18}$

Anti-Rom: Niemand »belächelt dort Unmoral«, Promiskuität »wird nicht mit einem >die modernen Zeiten` abgetan«. Germaninnen leben »in wohlbehüteter Keuschheit, durch keine verlockenden Schauspiele, durch keine aufreizende Gelage verführt«. Männer und Frauen seien annähernd gleich gekleidet. Obwohl daher beim Weibe die Arme und die »den Armen am nächsten« liegenden Brustpartien nackt blieben, »nehmen die Germanen die Ehe ernst, und nichts möchte man an ihren Sitten mehr rühmen«. Ehebruch sei höchst selten und werde augenblicklich "vom Manne« bestraft: »er schneidet ihr Haar kurz, entblößt sie in der Gegenwart der Verwandten, jagt sie aus dem Haus und treibt sie mit einer Peitsche durch das ganze Dorf«. Ehebruch erscheint als exklusiv weibliches Delikt. Die »Preisgabe der Frauenehre« aber kenne »keine Gnade«: Die Delinquentin werde, unabhängig von Schönheit, Jugend, Reichtum, »keinen neuen Mann finden können «. ${ }^{19}$ Das »Geschlechtsleben der jungen Männer« beginne erst spät, weshalb »ihre Manneskraft unverbraucht« sei. Auch »mit den jungen Mädchen« hätte »man keine Eile«. Sie »haben dieselbe Jugendkraft wie die jungen Männer und den entsprechenden hohen Wuchs: ebenbürtig an Stärke vereinigen sie sich, und die Kraft der Eltern spiegelt sich in den Kindern wieder«. Die werden selbstverständlich von ihren Müttern, und nicht von Ammen oder Sklavinnen gesäugt. Familienplanung oder das Töten von Kindern nach der Geburt des Erben gelte als »entehrende Schandtat: bei ihnen ist gute Moral stärker als anderswo gute Gesetzgebung «. ${ }^{20}$ Bis auf exklusive

14 Vgl. ebda., S. 79.

15 Vgl. ebda., S. 91.

16 Vgl. ebda., S. 89.

17 Ebda., S. 87.

18 Vgl. ebda., S. 89.

19 Ebda., S. 85.

20 Ebda., S. 87. 
Ausnahmen besonders »edler Herkunft« begnügten sich die Germanen als nahezu einziges Barbarenvolk »mit nur einer Frau«. Die beste Moral hätten die Stämme, »in denen überhaupt nur Jungfrauen heiraten dürfen und es mit den Wunschträumen einer Frau ein für allemal abgetan ist. So bekommt sie einen Mann, wie sie ja nur einen Körper und ein Leben empfängt, damit sie keinen Gedanken darüber hinaus, kein Verlangen darüber hinaus hegen soll, und damit sie nicht ihren Mann, sondern die Ehe an sich als Institution lieben soll«. Mit der Hochzeitszeremonie verpflichteten sich die Frauen dazu, »im Frieden wie im Kampf dasselbe zu dulden und zu wagen«, wie ihre Männer. ${ }^{21}$ Sie begleiten ihre Männer daher auch in die Schlachten, sind in der Nähe und spornen sie an. Ihnen wohne nach germanischer Auffassung gar »etwas Heiliges und Seherisches« inne, weshalb ihre Ratschläge und Weissagungen Gewicht hätten. ${ }^{22}$ Sollte allerdings, wie hoch oben im Nordosten am Meer bei den »Sithonen«, ein Stamm von einer Frau beherrscht werden, dann ist das ein Beweis für dessen Inferiorität: »So tief stehen sie nicht nur unter dem freien Mann, sondern auch unter dem Sklaven. ${ }^{23}$

Tacitus vermittelt den Eindruck eines furchterregende Landes und einer ebensolchen Bevölkerung. ${ }^{24}$ Gemäß antiker Humoralpathologie lasse das kalte Klima keine Verdunstung der übergroßen Körper voller Flüssigkeit zu. Obwohl die >Germanen` daher als »besonders hitzig und jähzornig, ja aggressiv« beschrieben werden, als kriegerisch und faul was die Kultivierung des Landes, und damit auch, was >Kultivierung< insgesamt angeht ${ }^{25}$-, erscheinen sie >sittsamer`, als die weitaus $>$ kultivierteren $<$ Römer. Ironischerweise ist diese >Wildnis schon damals kein Urwald mehr. Schon Jahrtausende vor der »Römerzeit« verändern »noch nicht völlig seßhafte« bäuerliche Gesellschaften ihre Umwelt »nachhaltig«, wird der Wald parzellenweise gerodet und durch Äcker ersetzt, regeneriert sich nach der Aufgabe der Parzellen wieder, wenn auch möglicherweise in verändertem Aufbau und anderer Zusammensetzung. ${ }^{26}$

Für Simon Schama ist der Text »so etwas wie eine Theorie der Sozialgeographie « in der Tradition der »Historien« des griechischen Philosophen Poseidonios, wie sie auch von einer Reihe »moralisierende[r]« römischer Schriftsteller, etwa Seneca, angewendet werden, um mittels des

21 Vgl. ebda., S. 85ff.

22 Vgl. ebda., S. 77.

23 Ebda., S. 107.

24 Vgl. Lund: Kommentar, S. 111.

25 Vgl. Lund: Einleitung, S. 26ff.

26 Vgl. Küster: Geschichte des Waldes, S. 99ff. 
Kontrastes naturnaher Barbaren die Dekadenz Roms zu beklagen und die barbarischen Länder zu Prüfsteinen Roms zu machen. In seinen »Annalen« - einer »einzige[n] ironische[n] Betrachtung über die Diskrepanz zwischen erhabenen Zielen und niederträchtiger Praxis« - hat Tacitus dann auch ausgerechnet den aufständischen »Arminius« zum "wahren Helden« gemacht, zum »Hüter untergegangener Ideale, kühn, unbeirrt patriotisch und energisch, das Gegenstück zu der Welt, mit der Tacitus vertraut war und die er offensichtlich als träge, zynisch und schwach verachtete ${ }^{27}{ }^{27}$

Es entsteht also ein Bild, das des unendlichen >Herkynischen Waldes`, der >Germanien bedeckt, in dem Wildnis und Tugend sich wechselseitig nicht ausschließen oder sich gar wechselseitig bedingen. Allerdings in moralisierender Ironie, denn dieser Wald ist grauenerregend, dunkel, kalt, unfruchtbar. Zum bruchlosen Entwurf einer heroischen Gegenwelt, einer patriarchal verfassten Gemeinschaft gegen eine dekadente und korrumpierte - römische - Gesellschaft ist »Germania« erst sehr viel später in der Rezeption nördlich der Alpen im 19. Jahrhundert geworden. $\mathrm{Zu}$ einer »heroischen Landschaft«, in der die bei Tacitus geschilderten riesenhaften, starken Menschen zu >Recken`(〉wie Eichen $)$ ) werden. Sie und ihre Umwelt, die Wälder und Bäume (selbst die Moore, die ja >tugendhafter Bestrafungen dienen, wie es bei Tacitus nachzulesen ist) sind nun nicht mehr vom Typus der $>$ monströsen Leiber ${ }^{28}{ }^{2}>$ Recken und Umwelt, die sich wechselseitig bedingen, erscheinen vielmehr als klar konturierte, >gepanzerteく Körper ohne Untiefen und Auswüchse: eingegrenztes beherrschtes Leben (wie sich bereits Celtis ausdrückt ${ }^{29}$ ), strikte Ordnung, Askese des permanenten >Daseinskampfs $\measuredangle$. Das ist die >Wildnis`, von der vor allem Wilhelm Heinrich Riehl, Hermann Löns u.a. sprechen, der Wald der national-konservativen Naturschützer, aber auch Kunsthistoriker, die per >Nationalcharakter $<$ - den Symbiosen von Landschaft und >Volk $८$ - und >Kunstlandschaften $८$ in der Malerei - wie etwa mit der >Donauschule $\iota^{30}-$ überzeitliche Kontinuitäten konstruieren.

27 Schama, Simon: Der Traum von der Wildnis, S. 103f.

28 Vgl. Kap. Monströse Leiber zu idealer Schönheit.

29 Vgl. Schama, a.a.O., S. 110.

30 Vgl. Bierende, Edgar: Lucas Cranach d.Ä. und der deutsche Humanismus. Tafelmalerei im Kontext von Rhetorik, Chroniken und Fürstenspiegeln. München, Berlin: Deutscher Kunstverlag 2002, S. 33ff. u. 283ff., Anm. 92ff. Bierende verweist auf die bemerkenswerte Resistenz der Konstruktion eines >deutschen Wesens $<$ : »Noch immer finden die Begriffe der Kunstlandschaften von Franken, Bayern, Schwaben usw. in der heutigen Literatur Verwendung, wenn sie auch wohl nicht mehr mit demselben nationalen Ideengut befrachtet sein dürften wie einst. Die kritiklose Über- 
Tacitus' »furchterregendes Land und [s]eine furchteinflößende Bevölkerung « ${ }^{31}$ zeigt einen Eindruck zwischen Schauder und Bewunderung. Das lässt sich dann später spezifisch als >Erhabenheitく lesen. >Schönheit` ist hier nicht zu finden. Das (eher) >weiblich generierte Schönheitsempfinden wird nach den Erhabenheitstheorien der Aufklärung durch Kleines und Glattes ausgelöst, das >männlich generierteく Erhabenheitsempfinden durch Unermessliches, Wildes, den Selbsterhaltungstrieb Weckendes. ${ }^{32}$ Dass die Frauen in »Germania« den Männern an Körpergröße und -kraft kaum nachstehen, lässt sich so auch nicht als >Gleichberechtigung wo zugleich die männliche Suprematie gesichert ist, sind `starke` Frauen offenbar durchaus erwünscht. Zumal dann, wenn Größe und Kraft beider Geschlechter das Signum beherrschter Enthaltsamkeit der Jugend und hoher Geschlechtsmoral sein sollen.

\section{Wildnis und Kultur als diaphane Konstruktion}

In der Renaissance-Gesellschaft erhält der Tacitus-Text, nachdem er das Mittelalter hindurch unbeachtet blieb, wieder Bedeutung. Im deutschsprachigen Raum werden die >germanische Wildnis` und ihre Bäume zwar durchaus zu Monumenten einer heroischen Selbstbehauptung erklärt. Das aber nicht ohne einzuräumen, dass es sich bei den >Germanen< um Barbaren gehandelt habe, nur lebe inzwischen »in Deutschland eine Bevölkerung, die mit den einstigen barbarischen Waldbewohnern nichts mehr gemein hat. Diese sind einem kultivierten Volk gewichen, das in Städten wohnt«. Konrad Celtis gehe es nicht um eine Rekonstruktion der »historische[n] Größe eines antiken Germaniens«, schreibt Müller, sondern darum, "zwei historische Entwicklungen in Beziehung zu

nahme von alten Modellen und deren Begriffen in einer historischen Disziplin wie der Kunstgeschichte läßt Zweifel aufkommen ob des eigenen Selbstverständnisses und der Aufarbeitung der eigenen Geschichte des Faches.« So sehe Robert Suckale (»Wilhelm Pinder und die deutsche Kunstwissenschaft nach 1945«, in: Kritische Berichte. 1986, Jg. 14. H. 4, S. 5ff.) »in der deutschen Kunstgeschichte nach 1945 keine kritische Aufarbeitung, sondern ein verstärktes Weiterleben der alten Denkmuster von Volkscharakter und Biologismus«. Eine Ausnahme sei Bernhard Deckers »Das Ende des Mittelalterlichen Kultbildes und die Plastik Hans Leinbergers « (Bamberg 1985), das sich »kritisch mit dem Begriff Donaustil und einer nationalistischen Kunstgeschichte« auseinandersetze. Ebda., S. 293, Anm. 135.

31 Lund: Kommentar, S. 111.

32 Vgl. Kap. Erhabenheit 
setzen, die hinsichtlich der Gegenwart für seine patria ein vorteilhafteres Ergebnis zeitigen. Dem Verfall Roms steht der kulturelle Aufstieg Deutschlands gegenüber«. Celtis verwende demnach Basiselemente »des Geschichtsmodells der Translatio«, genauer der »Translatio imperii und Translatio studii ${ }^{33}$

Celtis, der sich selbst als »mitten im Herkynischen Walde $\ll^{34}$ geboren bezeichnet, reklamiert also die »Germania« um 1500 für »Teutschland«. Er ruft die »deutsche[n] Männer« auf, sich »die Sinnesart [ihrer] Ahnen zu eigen« zu machen, die oft Schrecken über die Römer gebracht habe. Ebenso sollen sie sich »den Bastionen Deutschlands« zuwenden und die »zerrissenen Grenzen« wieder zusammenfügen. »Schämt euch, schämt euch, unserer Nation Joch und Knechtschaft auferlegt zu haben [...]. Du freies und kräftiges Volk, du edler und tapferer Volksstamm. « ${ }^{35}$ Er verlangt die Pflege von Wissenschaft und Kunst, das aber als Widerstandsakt gegen die Dekadenz der römischen Metropole. Sei es doch »Italiens Luxus [...] und eine entsetzliche Grausamkeit bei der Gier nach dem verderblichen Geld«, das »uns [...] verdorben« habe, »offenbar wäre es besser, wir würden wieder zu jenem rüden Leben der Waldbewohner zurückkehren, solange wir nur innerhalb der Grenzen eines beherrschten Lebens blieben $«{ }^{36}$ Celtis, $\gg$ der erste bedeutende neulateinische Dichter deutscher Herkunft «, ${ }^{37}$ greife »häufig auf Catull, Horaz und Ovid sowie auf Gestalten der griechsichen Mythologie (wie Apoll und Herakles) zurück und fühlt sich geistig nicht nur den Römern, sondern auch den Griechen verwandt $«,{ }^{38}$ sehe sich als »Wegbereiter«, gar »als Klassiker der lateinischen Poesie in Deutschland und weist den Führungsanspruch des italienischen Humanismus zurück «. ${ }^{39}$

33 Müller, Gernot Michael, a.a.O., S. 433f. Der deutsche Humanismus entwerfe »folglich kein aus Italien rezipiertes Geschichtsmodell«, sondern setzte ein bewusst oppositionelles dagegen, in dem verschiedene Völker und Staaten in den verschiedenen Epochen jeweils »Träger der höchsten Macht« seien. Die »Translatio« beginne danach mit den zivilisationslehrenden Druiden, komme über die Herrschaft Karls des Großen im Imperium Romanum zu einem Höhepunkt mit den deutsch-römischen Kaisern des Hochmittelalters (vgl. ebda., S. 429 u. 434).

34 Zit. n. Schama, S. 108.

35 Zit. n. ebda., S. 109 f.

36 Ebda., S. 110.

37 Riedel, Volker: Antikenrezeption in der deutschen Literatur vom Renaissance-Humanismus bis zur Gegenwart. Eine Einführung. Stuttgart u.a.: Metzler 2000, S. 25.

38 Ebda., S. 29f.

39 Ebda., S. 31. Als »deutscher Horaz« (ebda., S. 29f.) rufe er in sapphischen Oden mehrfach »Apollon, den Erfinder der Poesie« und »Phoebus, Erfinder der schmeichelnden Leier« an, Italien bzw. den Helikon zu verlassen 
Zwar ist in der Renaissance eine gewisse »Abkehr von der Stadt ${ }^{40}$ zu beobachten, etwa im deutschsprachigen Raum oder in den Niederlanden, als Reaktion zünftisch städtebürgerlicher Schichten auf die frühkapitalistischen Umbrüche: Das bedeutet eine Entdeckung der Landschaft als neue ästhetische Kategorie (in Literartur und Malerei), aber noch keine generelle Städtefeindschaft, sondern (ins Mittelalterliche) rückwärtsgewandte Utopien idealer Städte innerhalb idealer Landschaften.

In dieser Landschaft spielt der Wald eine Rolle im Spannungsfeld zwischen vorbürgerlicher, aggregativer Wahrnehmung und neuer $\mathrm{Zu}$ schreibung. Bei Celtis etwa ist infolge klimatischer Verbesserungen aus dem ehedem barbarisch kalt-düsteren Wald der Taciteischen >Germania (und der übereinstimmenden Schilderungen anderer antiker Autoren, auf die sich zeitgenössisch humanistische Italiener in ihren abfälligen Urteilen über schlechtes Wetter und dazu komplementär über das Barbarentum nördlich der Alpen stützen ${ }^{41}$ ) eine blühende Kulturlandschaft geworden. Per »conversio siderum«, Veränderung der Gestirne und einer »neuen Sonne«, die »der Germania nun näher als früher [ist], und mit ihren Strahlen [...] segenspendend das Land« erfüllt, habe sich die Landschaft zur Fruchtbarkeit entwickelt. Zugleich entlastet diese humanismustypische »kosmische[] Konstruktion« die >Urahnen « weitgehend davon, selbst für Barbarentum und Kultivierungsunlust verantwortlich zu sein. ${ }^{42}$

»Überblicksartig stellt Celtis ein Land vor, das sich als vom Menschen planvoll geordneter und bestellter Kulturraum zu erkennen gibt und in dem sich nur noch Reste von unwegsamer und wilder Natur finden. In ihn eingebettet erheben sich gepflegte Städte. Celtis' Hinweis auf die fruchtbaren und reichlich korntragenden Äcker, auf fischreiche Flüsse, auf sonnenbeschienene Weinberge und schließlich auf den Reichtum an Bodenschätzen, den er bereits am Ende des Kapitels über die silva Hercynia erwähnt, wollen alle gleich das

und nach Deutschland zu kommen, um, so Volker Riedel, »die Herrschaft anmutiger Musen und Künste auszubreiten [...], damit die barbarische Rede entfliehe und alles Dunkel zusammenstürze«. Ein »nationale[r] Humanismus in lateinischer Sprache«, dessen »Kerngedanke« es sei, »daß die Deutschen die klassische Dichtkunst von den Italienern übernehmen sollen«, wobei Celtis allerdings einen griechischen Akzent setze; vgl. ebda., S. 26f. "Ad Apollinem repertorem poetices ut ab Italis ad Germanos veniat « heißt das nach Riedel heute bekannteste dieser programmatischen Gedichte (vgl. ebda.).

40 Eberle, Matthias: Individuum und Landschaft, S. 158f.

41 Vgl. Müller, Gernot Michael, a.a.O., S. 416.

42 Vgl. ebda., S. 415ff. 
Bild einer kultivierten Germania vermitteln, wie es Enea Silvio in seiner Germania vom zeitgenössischen Deutschland gezeichnet hat und dem auch die Worte gegolten haben, mit denen Hartmann Schedel, dem italienischen $\mathrm{Hu}-$ manisten folgend, sein Vorwort in Münzers Deutschlandkarte abgeschlossen hat. " $^{43}$

Celtis behandelt die barbarische Vergangenheit der >Germani< als historischen Fakt, ebenso »das Bild eine unwirtlichen Landschaft«, wie es die antiken Autoren entwerfen. Beides sei aber nun zugunsten einer »kultivierten und urbanisierten Germania« gewichen. ${ }^{44}$ Schedels »Weltchronik« zeigt ebenso >Germania für das »sechste Weltalter« überwiegen hier deutsche Städte.

»Sie sind in den Holzschnitten von Wiesen und nur vereinzelten kleineren Wäldern umgeben. Die Landschaft durchziehen befestigte Straßen, und Flüsse sind durch zahlreiche Brücken passierbar gemacht: alles Zeichen der menschlichen Verfügbarkeit über diesen Raum.«

Derartige Stadtbeschreibungen werden in >Teutschland « nun zunehmend häufig verfasst und transportieren das gewünschte Bild »des eigenen Landes«, einer »allenthalben vom Menschen planvoll gestaltete[n] und vor allem verstädterte[n] Landschaft «, in denen die Städte geradezu als »Träger der geschichtlichen Entwicklung« betrachtet werden - ein Bild, das paradigmatisch aus Italien übernommen wird. ${ }^{45}$ Während jedoch

43 Ebda., S. 403. Wenn Simon Schama behauptet, „Celtis’ Abhängigkeit von Tacitus war unverkennbar, sowohl in seiner Darstellung von Arminius' Sieg über die Legionen als auch in seiner Beschwörung des einfachen Waldlebens im alten Germanien« (a.a.O., S. 110), dann liegt er damit ebenso falsch, wie in seiner Version eines Widerspruchs zwischen Celtis und Enea Silvio de' Piccolomini, dem »nachmalige[n] Papst Pius II.« und dessen »typisch römische[r] Auffassung « des Tacitus-Textes, dieser beweise nur den Fortschritt der >Germanen « seit ihren barbarischen Anfängen (vgl. ebda., S. 108). Für Celtis' Darstellung ist Enea Silvios Text offenbar ebenso wesentlich, wie die Schedelsche Weltchronik, aber auch Flavio Biondos »Italia Illustrata« und der antike Autor Strabon (vgl. Müller, Gernot Michael, a.a.O., S. 411), rhetorisch rekurriert er auf Horaz, bezüglich eines >germanischen « Volkscharakters « in »eigenwilliger Weise auf den platonischen Seelenmythos «. Und in diesem Insistieren auf eine »Wesensart der Germani«, die sich historischem Wandel entziehe, der Betonung von Wandel und Kontinuität für >Germania<, unterscheidet sich Celtis »von seinen Modellautoren« wie Enea Silvio (ebda., S. 414f).

44 Ebda., S. 407. »Mitior et populus Germano nascitur orbe/Explosa ruditate fera, quam barbarus olim/Siluicola in riguis seruabat saltibus ortus« heißt es bei Celtis (zit. n. ebda.).

45 Vgl. ebda., S. 403f. 
Italien eine Kontinuität des Städtebaus seit der Antike aufweist, führt nördlich der Alpen erst die Vielzahl der Neugründungen des Hoch- und Spätmittelalters für das 15. Jahrhundert $\mathrm{zu}$ einer mit Italien vergleichbaren Städtedichte. Allerdings bleiben diese Städte innerhalb der alten, >feudalen〈 Ordnung »Fremdkörper«, relativ isoliert, vom Umland durch politische Grenzen getrennt, die sich - beschleunigt für die Reichsstädte - nur langsam auflösen. Im deutschen Humanismus nun sollen auch die deutschen Städte »zu einem bestimmenden Faktor des Landes geworden« sein. Zugleich soll klar werden, »daß sich die Trennung zwischen Stadt und wilder Natur in ein Kontinuum von gestalteter Natur aufgelöst hat. Gerade über die erreichte Urbanität definiert sich das Selbstverständnis der kultivierten Germania, die sich dem Vorbild Italien selbstbewusst an die Seite stellen kann. Celtis und Hartmann Schedel erweisen sich damit als Rezipienten einer Sichtweise« der italienischen Humanisten wie Biondo und Piccolomini, »die Raumbewußtsein und kulturelle Merkmale aufeinander bezieht «. ${ }^{46}$

In der Folge entwickele sich vor allem in Süddeutschland »ein ganzes Genre sentimentaler Ethnographie«, ${ }^{47}$ erscheine in Frankfurt am Main 1588 mit der »Silva Hercynia« von Joachim Camerarius d.J. »das allererste regionale Botanikbuch «, so Schama. ${ }^{48}$ Auch er schildert, wie nun - neben imaginierten >Urwäldern « der >Germanen ২ bzw. >Wilden Menschen ( s.u.) - von »patriotischen Topographen $«{ }^{49}$ ein >humanisierter Wald gegen die >Urbs romanum ' gestellt wird. Oden- und Schwarzwald usw. sollen »nicht als unfruchtbare Wildnis« gedacht werden, sondern »auf eine neue Weise als domestizierte Forsten«, Orte »von Gesundheit und Wohlstand «, Forste also, »die mit Ackerland und Obstgärten abwechselten und in guter Beziehung zu den Städten wie Nürnberg und Würzburg lebten «. ${ }^{50}$ Zwar ist es richtig, dass der >Herkynische Wald in bildender Kunst, Literatur und Geographie offenbar weniger snach der Natur als vielmehr nach der Phantasie entsteht. Denn inzwischen verschwindet der nach den Entvölkerungen vor allem durch die Pest >zurückgekehrte` Wald längst wieder in großflächigen Rodungen. ${ }^{51}$ Bei Schama aber erscheinen die Lobgesänge auf Wälder und Forsten in der Kulturlandschaft als Strategie, bloße Reaktion auf ihr reales Ver-

46 Ebda., S. 406.

47 Ebda., S. 115.

48 Schama, a.a.O., S. 113.

49 Ebda.

50 Ebda., S. 112.

51 Vgl. Ausleitung. 
schwinden, ${ }^{52}$ und nicht als - wie gezeigt - klares Programm im >deutschen Humanismus<.

Der >Herkynische Wald markiert - wie gesagt - die Topographie der >Germania〈, die Ausdehnung ihres >Körpers`, der aber im 16. Jahrhundert längst nicht mehr abschreckende Wildnis, sondern eine harmonische, städtisch dominierte Kulturlandschaft sein soll. Dieser >Wald aber ist eine diaphane Konstruktion. Denn er ist (und bleibt) zugleich Ort der >Urahnen<, die nun in der bildenden Kunst zeitgemäß aufbereitet werden.

\section{Die Asketisierung der »Wilden Leute» zu Urahnen}

In der deutschen Renaissance-Rezeption antiker Sozialgeographie, im Zusammenhang beginnender bürgerlicher Abgrenzung von der (südländischen) höfischen Gesellschaft, entstehen eine ganze Reihe von Bildern, deren Thema der »Wilde Mann« und die »Wilde Frau« sind. So bei Albrecht Altdorfer (»Waldmenschen«, um 1510), ${ }^{53}$ Hans Leonhart Schäufelein (»Wilder Mann und wilde Frau«) und Martin Schongauer (»Wilder Mann mit verziertem Schild«, ca. 1480). ${ }^{54}$ Barbara Eschenburg erkennt in Altdorfers »Waldmenschen «-Grafik formale Bezüge zu Giorgiones »Sturm«, deutlicher aber einen möglichen »direkten Reflex von Celtis' >Germania〈-Übersetzung«, sei doch Altdorfer der »erste, bei dem solche Waldlandschaften in größerer Anzahl sowohl unter den Zeichnungen wie auch unter den Gemälden anzutreffen sind $« .{ }^{55}$ Dabei geht es aber wohl weniger um eine Darstellung des »ungezwungene[n], aber auch wilde[n] ungezügelte[n] Leben[s] der Urbevölkerung Germaniens«, wie Eschenburg meint. ${ }^{56}$ Vielmehr vollzieht sich mit der >Germania<-Rezeption eine Verschmelzung der Figur des `Germanen` mit der des >Wilden Mannes<. Letzterer mutiert so vom tierischen zum >edlen Wilden.$~ » I n$ großen Teilen des Mittelalters hatten behaarte, kannibalistische, sexuell unersättliche wilde Männer und Frauen die Antithese zum zivilisierten Christen dargestellt. ${ }^{57}$

Im antik-römischen und mittelalterlichen Denken werden Barbaren (als Bedrohung der Gesellschaft) und Wilde Männer (als Bedrohung des Einzelnen) konzipiert als »to be enslaved to nature, to be, like animals,

52 A.a.O., S. 112.

53 Vgl. Eschenburg, Barbara: Landschaft in der deutschen Malerei, S. 49, Abb. 14.

54 Vgl. Schama, a.a.O., S. 114.

55 A.a.O., S. 48.

56 Ebda.

57 Schama, a.a.O., S. 113f. 
slaved to desire and unable to controll their passions«; haltlos und unruhig herumstreifend, unfähig zu Sesshaftigkeit, Selbstdisziplin und ausdauernder Arbeit, jähzornig, wirr und feindlich gegen alles >NormalMenschliche ২. Im Unterschied zu den Barbaren, deren Erscheinen mit der Apokalypse gleichgesetzt wird und deren Wohnort weit weg im Irgendwo liegt, ist der Wilde Mann »conventionally represented as being always present, inhabiting the immediate confines of the community. $\mathrm{He}$ is just out of sight, over the horizon, in the nearby forest, desert, mountains, or hills«, schläft in Tierhöhlen, Felsspalten oder unter großen Bäumen. Er ist ein verschlagener Dieb und Trickser, er verschleppt hilflose Frauen und Kinder in seine Behausungen, um dort Unaussprechliches mit ihnen zu tun. Anders als Barbaren lebt er als Einzelgänger, höchstens mit einer Gefährtin. Er ist unfähig, Vaterverantwortung zu übernehmen. Wenn seine Gefährtin Kinder bekommt, lässt sie sie ihrerseits an Ort und Stelle liegen »to survive or perish as they will «. ${ }^{58}$ Insbesondere in mittelalterlichen Mythen erscheint der Wilde Mann als behaart, dunkel, missgestaltet, Riese oder Zwerg, begabt mit Herkuleskräften, schnell wie der Wind, verschlagen wie ein Wolf, fuchsschlau. Fähigkeiten, die in manchen Erzählungen verwandelt sind »into a kind of natural wisdom which makes him into a magician or at least a master of disguise «. ${ }^{59}$ Matejovski verweist auf »volkskundliche Überlieferungen«, die dem Wilden Mann »dämonisch-demiurgische Qualitäten« zusprechen. Sie sollen demnach gefressenes Vieh reanimieren können, indem sie es aus den Knochen und Speiseresten wieder zusammensetzen. ${ }^{60}$ Das erinnert an verbreitete eurasische schamanische Mythen und Riten zur >Auferstehung< von Opfertieren, wie sie Carlo Ginzburg rekonstruiert und die sich u.a. wiederfinden lassen in der Edda (Thor reanimiert einen Ziegenbock, der aber hinkt, weil Bauern einen Knochen achtlos zerbrochen haben), im semitischen Verbot, die Knochen des Osterlamms zu zerbrechen (mit Nachklängen in der christlichen Passion), bei Medea und Dionysos, in den Versionen des Aschenputtel-Märchens, im Hinken des Teufels, in Verhörprotokollen spätmittelalterlicher und frühneuzeitlicher >Hexen২. Die »Asymmetrie des Gehens« ist Kennzeichen einer

58 White, Hayden: The Forms of Wildness. Archaeology of an Idea, in: Dudley, Edward/Novak, Maximillian E. (Ed.): The Wild Man Within. An Image in Western Thought from the Renaissance to Romanticism. Pittsburgh: University of Pittsburgh Press 1972, S. 20 f.

59 Ebda.

60 Matejovski, Dirk: Das Motiv des Wahnsinns in der mittelalterlichen Dichtung. Frankfurt/M: Suhrkamp 1996, S. 130f. Er beruft sich hier auf Johannsmeier, Rolf: Spielmann, Schalk und Scharlatan. Die Welt als Karneval: Volkskultur im späten Mittelalter. Reinbek: Rowohlt 1984, S. 81. 
Reise ins/Rückkehr aus dem Jenseits als »Tier, Mensch oder eine Mischung aus beidem«, letzlich als »Reinkarnation der »Herrin der Tiere« - Diana, Oriente, Holda etc. - deren AnhängerInnen ihr auf den Rücken von Ziegenböcken durch die Lüfte folgen oder in Gestalt von Wölfen, Hasen, Katzen am >Sabbat ")zwei Ausdrücke des Andersseins «. ${ }^{61}$

Als »master of disguise« erscheint insbesondere die Wilde Frau. Sie ist den mittelalterlichen Legenden nach unübertroffen hässlich, vollständig behaart, außer an ihren gewaltigen Hängebrüsten, die sie beim Rennen über die Schultern klappt. Sie ist besessen vom Verlangen nach gewöhnlichen Männern. Um arglose Ritter oder Schäfer zu verführen, erscheint sie als höchst verlockende Frau, »revealing her abiding ugliness only during sexual intercourse «. ${ }^{62}$ Das zeigt eine zumindest strukturelle Übereinstimmung mit Erzählungen von lockenden Feen, deren Natur nicht erforscht werden darf, auch mit Konstruktionen der `Frau Welt von trügerischen >jungfräulichen Landschaften`, von Hexen, Kannibalinnen usw. Die >Hässlichkeit〈 hinter der Verlockung, der vorgegaukelten Schönheit offenbart sich im durchdringenden, verschlingenden Akt, also infolge männlichen Kontroll- und Distanzverlusts, der Nichtwahrung von Grenzen, Vermischung.

Die Wilde Frau bleibt weitaus eindeutiger die Andere (vgl. die Konstruktion der Kannibalin in der neuen Welt) - wenigstens die Numinose -, als der Wilde Mann, dessen >bukolische` oder pagane Eigenschaften in der Variante als Hüter der Tiere durchaus Affinitäten zu christlichen Einsiedler-Figuren (bzw. umgekehrt) ausweisen. Die Wilde Frau aber wird erst dann zur eher positiven Figur, wenn sie als zwar rustikale, aber Untergeordnete und Abhängige erscheint.

Am Ende des Mittelalters werden »wilde Männer zu Musterbeispielen des tugendhaften und natürlichen Lebens umgearbeitet «. ${ }^{63}$ So verlieren der >Wilde Mann` und seine Frau als Bewohner heroischer Idyllen

61 Ginzburg: Hexensabbat, S. 248ff. und 266f. Vgl. Kap. Ungezügelte Pflanzen und Reptilien zum Zusammenhang von >Hinken`, Fliegenpilz und Kröte, sowie Erle und Holunder. Zwar spricht auch White bezüglich magischer Fähigkeiten von Wilden Männern und Frauen von einer beginnenden Verschmelzung mit mittelalterlichen Vorstellungen von Teufel, Dämon, Hexe(rn). Er besteht aber auf einer Unterscheidung des zeitgenössischen formalen Denkens zwischen diesen Wilden als bloße menschliche Regression ins Tierische und des Dämonischen als »edowed with evil spiritual powers«. (a.a.O., S. 22). Was allerdings über pagane - etwa keltische - Tradierungen nichts sagt.

62 Ebda., S. 21.

63 Schama, a.a.O., S. 113f. 
die »tierhaften Züge«, den Geruch der Kinderfresserei, betreiben gutmütige >wilde Männer` gar Ackerbau und Viehzucht. Der Straßburger Prediger Geiler von Kaysersberg stellt außerdem einen Zusammenhang zu frühchristlichen heiligen Einsiedlern her. ${ }^{64}$ Insofern wird hier eine (bereits alte) Variante der wechselseitigen Bedingung von >Wildnis` und >Tugend ( unter dem Signum der >Askese ' hergestellt. ${ }^{65}$

Hauptsächlich aber repräsentieren diese $>$ Wilden Leute $<$ nun ein $>U r$ bild der patriarchalen Familie: »Ein sittsames Paar hält behaarte Händchen, oder stolze Eltern tätscheln stupsnasigen kleinen Wilden den Kopf. [...] Zwar ist das Paar immer noch behaart, aber seine Nacktheit wird jetzt unter üppigem Blattwerk verborgen. Der Ehemann trägt ein Bäumchen als Stab, mit dem er seine Schutzpflichten als pater familias erfüllt. Und während die linke Hand seiner Frau die Weinranke umklammert, die für ihre Fruchtbarkeit steht, ruht ihre Rechte wohlwollend auf der Frucht ihrer Leibes. « ${ }^{66}$ Ähnlich ist das auch bei Altdorfers »Waldmenschen«. Hier hütet die nackte, aber züchtige wilde Mutter im Schutz ihrer natürlichen Behausung eines Dickichts das Kind, während der Mann, mit einem Schurz bekleidet, draußen seinen Stab zum Niederschlagen eines Gegners benutzt. ${ }^{67}$ Keine Unfähigkeit mehr zu Vater- und Mutterpflichten, im Gegenteil. Schamas Resümee dieser Entwicklung berührt nur einen unter mehreren Aspekten: »Um den deutschen Wäldern, ihren Stammesvorfahren und ihren modernen Nachkommen gerecht $\mathrm{zu}$ werden, brauchte man also ebensoviel Feingefühl wie Entschlossenheit. Ihre Bewohner mußten wild genug sein, um sich von den

64 Vgl. ebda.

65 Ähnlich ist dann auch die Figur der Maria Magdalena konstruiert. Als sie »ihr sündiges Leben bereute, zog sie sich für 30 Jahre als Einsiedlerin in die Wildnis zurück und entsagte allen weltlichen Bedürfnissen wie Kleidung und Nahrung. Sie wurde am Körper behaart und nur von ihrem üppigen langen Kopfhaar bedeckt abgebildet«. Korsch, Evelyn: Wilde Leute, in: Kuhn, Annette/Pitzen, Marianne (Hg.): Stadt der Frauen. Szenarien aus spätmittelalterlicher Geschichte und zeitgenössischer Kunst. Zürich, Dortmund: Edition Ebersbach im eFeF-Verlag 1994, S. 207. Korsch stellt zwei Stiche des >Hausbuchmeisters〈 gegenüber (»Die Wildenfamilie«, um 1480, und »Die Hl. Maria Magdalena«, um 1490). Die - hier weibliche Körperbehaarung als Signum zeigt erneut den aggregativen Charakter der Wahrnehmung. Einerseits kennzeichnet sie zügelloses, wildes Begehren und später Fruchtbarkeit - zu deren Attributen die sichtbaren Brüste und die stets vorhandenen Kinder gehören -, andererseits, bei der >reuigen Sünderin die erworbene Keuschheit, verbergen die in der Wildnis erworbenen Haare den zuvor prostituierten Leib und entziehen ihn so den Begehrlichkeiten.

66 Schama, a.a.O., S. 114.

67 Vgl. Eschenburg, a.a.O., S. 49, Abb. 14. 
erschlafften italienischen Städtern zu unterscheiden, aber nicht so wild, daß sie die alten Anklagen der Tierhaftigkeit auf sich zogen. ${ }^{68}$

Der >deutsche Wald als imaginierte Gegenwelt zum >dekadenten Rom`, also auch zum >untergegangenen` Imperium, das nun keine Führungsrolle mehr haben soll. Aber eben nicht zur Stadt generell, wie Schama nahelegt, ${ }^{69}$ werden doch von wandernden Humanisten wie Celtis ebenso wie von Meistersingern wie Hans Sachs Lobgesänge auf Städte verfasst - allerdings auf >deutsche〈 Städte und deren segensreiche Umgebung. $^{70}$ Das gehört $\gg z u m$ festen Bestandteil humanistischer Städtedarstellungen«, was diese »fundamental von mittelalterlichen Beispielen ihrer Gattung« unterscheide, »in denen der Blick über die Stadtmauern hinaus keine Rolle spielt «. ${ }^{71}$ Schon, weil erst das frühbürgerliche Subjekt die Landschaft entdecken kann. Prototyp von Darstellungen, in denen »Fruchtbarkeit und Schönheit des Umlands« das Lob der Stadt mehren, und in denen die Stadt ein explizit von »Menschen gestaltete $[\mathrm{r}]$ und kultivierte[r] Raum« ist, ist Leonardo Brunis »Laudatio Florentinae urbis«, es folgen die zwei Basel-Briefe Piccolominis. ${ }^{72}$ Aller-

68 Schama, a.a.O., S. 115.

69 So auch, wenn er schreibt, Hans Sachs orientiere seine »Klag der wilden Holtzleut uber die ungetrewen Welt« an Celtis' Paradigma, dass der Wald »den Musen lieb ist«, die Stadt aber »den Dichtern verhaßt« (a.a.O., S. 114f.).

70 Ähnlich auch die »Bamberg-Rede« von Albrecht von Eyb, der insbesondere »die Schönheit der Umgebung Bambergs hervorhob und die die Bischofstadt umgebenden Wälder für die Jagd empfahl. Die Umgebung wird hier ebenso zum Naherholungsbereich wie in Celtis' Norimberga, wo er die vor der Stadt liegende Hallerwiese als Tummelplatz für die städtische Jugend vorstellt« (Müller, Gernot Michael, a.a.O., S. 404, Fn. 4).

71 Ebda., S. 294f.

72 Vgl. Müller, Gernot Michael, a.a.O., S. 295f. Zu derartigen RenaissanceDiskussionen vor allem in Italien und Frankreich, ebenso Deutschland gehört auch die Konzeption von Idealstädten - sowohl theoretisch in Bezug auf Vitruvs »Zehn Bücher über die Architektur«, als auch praktisch (Bruni plant für Florenz um die Machtpole Dom und Palast herum konzentrische Kreise aus Häusern und Mauern, Alberti »eine Ständestadt mit klar abgesetzten Wohnvierteln«, auch Dürer entwirft viereckige Idealstädte). In diesen Zusammenhang gehören ebenso bekanntermaßen utopisch-politische Entwürfe, vor allem Thomas Mores »Utopia« (1516) oder später (1601, gedr. 1623) Tommaso Campanellas »Città del Sole« (vgl. Kluge, Walter: Die Stadt in der Utopie, in: Mahler [Hg.]: Stadt-Bilder. Allegorie, Mimesis, Imagination. Heidelberg: Winter 1999, S. 69ff. u. 72ff.). Zur weiblichen Allegorese von Städten vgl. Exkurs II. 
dings ist das >Stadtlob standsbeschreibung. ${ }^{73}$

Der Wandel der >Wilden Leute $<$ von negativen zu eher positiven Gestalten beginnt im 15. Jahrhundert. Schon zuvor ist der Charakter dieser Figuren in unterschiedlichen Bedeutungsräumen angesiedelt: Zwischen paganen Residuen (Satyrn, Faune, Silenen, Nymphen, Centauren, Minotaurus, keltische Wächter des Totenreichs, Herrinnen und Hüter der Tiere), die teils in christlichen Klausnern wieder anzutreffen sind, theologischen Zuschreibungen als »Kainskinder ${ }^{74}$ und antichristlicher triebhafter Sünde, sowie »friedfertiger Narrheit« oder rasendem Wahnsinn außerhalb höfischer Zivilisation - wobei der Gegenentwurf zum Courtoisen changiert zwischen Karikierung bzw. Verspottung der insgeheim noch gefürchteten >hässlichen` Inkarnation mythischer Naturmacht und der jederzeit möglichen »conversio« auch des höfischen Menschen zur Bestie75 -, schließlich in >volkskulturellen ^Adaptionen. Das Motiv des Aufbegehrens gegen obrigkeitliche Reglementierungen erkennt Norbert Schindler in Karnevalsumzügen des 14. bis 16. Jahrhunderts etwa in Nürnberg. Hier sei die Kostümierung zu >Wilden Leuten` als Demonstration der Stärke gedacht, zumal die benutzten Bärenfelle einen Angriff auf herrschaftliche Jagdvorrechte bedeuteten. ${ }^{76}$

Zunächst, schreibt Hayden White, hätten im Mittelalter zwei miteinander unvereinbare Bilder der Wildheit bestanden - »the one as desire, the other as punishment « - abgeleitet aus zwei disparaten kulturellen Traditionen, dem »benign imagery« der »classical archetypes« und dem

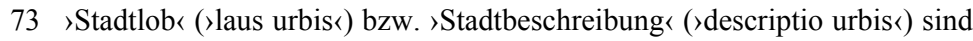
schon »zu Lebzeiten Ovids eine seit Jahrhunderten fest etablierte Gattung «, sowohl in der Poesie, als auch in Historiographie, politischen Texten, Gerichtsreden etc. Allerdings wird in solchen Texten erst seit dem Mittelalter die jeweilige Bevölkerung zu einem »das Leben einer Stadt entscheidend prägendem Element[]«. In den antiken Beschreibungen sind die Städte noch geprägt durch Topographie, Infrastruktur, Klima usw. (vgl. Holzberg, Niklas: »Ihrer Aeneas' Stadt wählt sich Venus als Sitz«. Rom aus der Sicht seiner Dichter, in: Mahler, Andreas [Hg.]: Stadt-Bilder, S. 57f. Vgl. Classen, Carl Joachim: Die Stadt im Spiegel der Descriptiones und Laudes urbium in der antiken und mittelalterlichen Literatur bis zum Ende des 12. Jahrhunderts. Hildesheim, New York: Olms 1980, S. 17 u. 29).

74 Vgl. Cartmill, Matt: Tod im Morgengrauen, S. 73ff., Ginzburg, a.a.O., S. 91ff., Matejovski, a.a.O., S. 130, White, a.a.O., S. 24, Wyss, Stephan: AskeSe, S. 164.

75 Vgl. Matejovski, a.a.O., S. 131 u. 127.

76 Vgl. Schindler, Norbert: Widerspenstige Leute. Studien zur Volkskultur in der frühen Neuzeit. Frankfurt/M: Fischer 1992, S. 131ff.; Vgl. Korsch, a.a.O. 
»malignant imagery « der »biblical ones « ${ }^{77} \mathrm{Im}$ Hochmittelalter sei es dann offenbar zu einer Verschmelzung, ja Konfudierung gekommen, wodurch eine »anomale Konzeption« entstanden sei. So zeige die Ikonographie des 13. und 14. Jahrhunderts den Wilden Mann als zugleich gut und böse, beneidet und gefürchtet, verehrt und verrufen. ${ }^{78}$ »Anomal« kann das aber nur aus der Perspektive der damaligen Theologie sein (die White anscheinend einnimmt), denn eine derartige Numinosität - und eben nicht »Gutartigkeit«, wie White behauptet - ist bereits in paganen Konstruktionen angelegt, die, so White selbst, bis zum 12. Jahrhundert zusammen mit klassisch-antiken sozusagen im sozialen wie intellektuellen »Untergrund « überlebten, um dann mit der Wiederentdeckung der »klassischen Kultur« und »humanistischer Werte« sowie darauf basierender neuer Naturkonzeptionen wieder aufzutauchen - simultan dazu vollziehe sich eine »redemption of the image of the Wild Man «. ${ }^{79}$ Die $»$ Konfusion« um diesen zerstreue sich in der »Hochkultur« erfolgreich im scholastischen Denken. Infolge dieser »Erlösung«, der Bereinigung der Natur von allen theoretischen Beschuldigungen des Bösen und im Zusammenhang mit den gesellschaftlichen Krisen sei während des 15 . Jahrhunderts die »gutartige« Konzeption des Wilden Manns von der »bösartigen« losgelöst worden,

»and writers and thinkers began to recognize the fruitfull uses in culture criticism to which a demythologized version of the benign imagery could be put. In short, sometime in the early modern period, no doubt as part of a general movement of secularization and as a function of humanism, the image of wildness was >fictionalized , that is, seperated from an imagined >essence of wildness and turned to limited use as an instrument of intracultural criticism «. ${ }^{80}$

White differenziert dabei zwischen zwei Formen, eine »verlorene Welt« zu imaginieren: im »archaism« erscheine diese Welt als gewalttätig, turbulent, animalisch, geordnet nach den Gesetzen des Dschungels, in denen der Stärkere überlebe, als die verschwundenen dunklen, formlosen Wälder Dantes, Machiavellis, Hobbes, Vicos. Im "primitivism« erscheine sie arkadisch, friedvoll, paradiesisch, latent noch immer vorhan-

77 White, a.a.O., S. 31. White stützt sich hier auf Richard Bernheimers Untersuchung »Wild Men in the Middle Ages« (1952), auch wenn er sich von dessen »Freudian language of repression and sublimation « distanziert, handele es sich doch um ein »distinctively medieval phenomenon« (ebda.).

78 Vgl. ebda.

79 Ebda., S. 22f.

80 Ebda., S. 31. 
den im »korrupten und zivilisierten Menschen«. Nur in der Naturvorstellung der Primitivisten, wie in Hans Sachs' »Klag der wilden Holtzleut«, könne der Wilde Mann den Aspekt des »Edlen Wilden« annehmen. Der tauche auf nach dem »kulturellen Zusammenbruch« des Mittelalters mit den Versuchen der Humanisten, Geschichte, Mythen und Legenden nach dem abzusuchen, was sowohl »ihre innersten Sehnsüchte nach Befreiung« ausdrücke, als auch ihre Verbundenheit mit alten Traditionen; wobei sich die Radikalität der Kritik an der bestehenden Zivilisation eben darin zeige, deren »Antityp« zu >adoptieren $<.{ }^{81}$

Zwar erscheint Whites Ansatz auch hier recht undifferenziert, sind doch in den humanistischen Entwürfen »Archaismus« und »Primitivismus« offenbar nicht ausschließlich derart klar voneinander getrennt. Wichtig aber ist der von ihm betonte Vorgang der Demythologisierung und Fiktionalisierung. In der Fiktionalisierung löst sich das >mythische Grauen auf, entsteht eine neue Sinn-Produktion. Das gilt offensichtlich nicht für die >Volkskultur ${ }^{82}$ hier bleiben die Mythen >real<, Mittel zur Lebensbewältigung. ${ }^{83}$ Innerhalb der >Hochkultur aber vollzieht sich damit ein wesentlicher Schritt zur Abstraktion: weg vom Aggregativen zum Generativen: Die Wilden Leute sind nun nicht mehr Bestandteile simultaner Bedeutungsräume (auch, wenn sie das in der Wahrnehmung insbesondere ländlicher Unterschichten noch länger bleiben), sondern (weitgehend) überführt in den einen vertikalen Raum reflexiv vermittelnder Schichten ${ }^{84}$ als >Begründer einer Genealogie. Im Bildprogramm des deutschen Humanismus dienen sie also der Konstruktion >germanischer Indigenität $<$ : der >Urahnen $<$.

Die Art und Weise dieser >Urahnen〈-Konstruktion lässt sich an Cranachs in mehren leicht variierenden Tafelbildern gemalten »Wilden Leuten« (1530) zeigen. Der bärtige Mann - spitze Ohren weisen ihn als Faun aus - sitzt vor einem düsteren, überragenden Wald auf einem Steinblock. Die Keule, mit der er zuvor den Löwen erschlagen hat, hat er in seinem Schoß aufgestellt. Neben ihm rechts steht - ebenso nackt, aber züchtig - die Frau, ein Kind auf dem Arm, ein zweites an der Hand, beide Knaben. Hinter ihr ist der Wald nur noch ein höchstens kopfhohes Gebüsch, über ihr am Horizont ragen eine Burg auf einem Felsen und der Himmel auf. ${ }^{85}$ Edgar Bierende verweist auf den Zusammenhang zwischen »dem euhemeristischen Geschichtsverständnis der christlichen

81 Vgl. ebda., S. 27f.

82 Vgl. ebda., 31.

83 Vgl. Allmann, Joachim: Der Wald in der frühen Neuzeit, S. 297ff.

84 Vgl. Czerwinski, Peter: Gegenwärtigkeit, S. 86.

85 Bierende, a.a.O., S. 239, Abb. 95. 
Humanisten« und den - hier sächsischen - »fürstlichen Machtinter essen«, die eigenen territorialen Anrechte, etwa gegenüber dem Klerus, (prä)historisch und mythisch-genealogisch zu legitimieren. ${ }^{86}$ Und so rekonstruiert er die Figuren anhand mythologisch-historischer Berichte zur sächsisch-merseburgischen Vorzeit in damaligen Chroniken: Der Mann erscheint allegorisch als Träger von »Stärke, Tapferkeit und Mannesruhm (virtus)«, als prähistorischer Sachsenfürst Hermenn - aus dem nach euhemeristischem Verständnis später der Gott Hermenn wird, hinter dem Herkules, Herakles, Hammon stehen - und zugleich als germanisch-vendischer Waldgott Zuttibero. Die Frau repräsentiert »Mutterliebe, caritas «, die sächsische Ahnherrin und die »Merseburger Jungfrau (virgo) bzw. die zweite germanisch-vendische Frauenhauptgottheit zu Merseburg «, gleichgesetzt mit Venus. ${ }^{87}$

Das aber sind noch nicht alle Zeit- und Sinnebenen, die sich hier überlagern, noch nicht alle Aspekte, die in den Figuren verschmelzen. Stephan Wyss setzt »Die Wilden Leute» in Beziehung zu anderen Hauptwerken Cranachs: »Der heilige Hieronymus als Büsser in der Wildnis« (1525) und »Die Rast auf der Flucht nach Ägypten« (1504) und entdeckt »Der heiligen Familie zweiter Teil« - wobei er eine andere Variante Cranachs wählt. ${ }^{88}$ Hier ist der Gesichtsausdruck des Mannes weniger grimmig, denn gezeichnet von »Anstrengung und Müdigkeit, auch Trauer«, das Lächeln der Frau - wie auch in der anderen Version »[b]illigend«, wohl gar »triumphierend «. Zu sehen, so Wyss, ist die »familiär bezwungene Animalität«. Der Waldgott, das Mischwesen zwischen Natur und Zivilisation, verwandt mit den »ithyphallische[n] Gestalten« im Gefolge des Dionysos usw., hat das »Tier» erschlagen. Die Tatwaffe, die Keule, treibt direkt in seinem Schoß schambedeckend »Schößlinge«. »So ist er Vater und Ehemann. « ${ }^{89}$ Die Mutter und Ehefrau rechts sei »zweifellos, was Brustbild und die Haltung des Säuglings auf dem rechten Arm betrifft, der heiligen Jungfrau nachempfunden«, auch, wenn ihre Nacktheit und das zweite Kind das zugleich dementiere. Und wie in der »Rast« wölbe sich auch hier ein wolkenlos blauer Himmel darüber: »Gott will es so. ${ }^{90}$

86 Vgl. ebda., S. 243f.

87 Vgl. ebda., S. $242 \mathrm{f}$.

88 Wyss, Stephan: AskeSe, S. 162.

89 Ebda., S. 163.

90 Ebda. Vgl. Abb. 1, S. 233. Der asketische Josef stehe hier als alter Mann unter einer mächtigen Fichte, dem Baum, unter dem »der Mann gegen das Tier« kämpft, unter dem sich Attis entmannt, um nicht »im Geschlecht des Ischtar-Weibes unterzugehen«, unter dem sich »Hieronymus die Brust« schlägt (vgl. ebda., S. 162f.). 
Entschieden ist hier der »Kampf um Hell und Dunkel, die symbolische Ambivalenz des Löwen«, nichts ist mehr offen im Kampf um die Macht, »exitus certus est « - erzwungen durch Gewalt. ${ }^{91} »$ Die Jungfrau steht im Lichte, das Tier aber liegt im Dunkel« - wenn auch im Wald dahinter, wohin sich »die Angst eben erst« verzogen hat, ${ }^{92}$ der Werwolf lauert. Der ist offenbar etymologischer Verwandter des Fauns. Der Faun glaube sich durchs Töten des Löwen selbst erlöst zu haben, sei der Verblendung erlegen, kein Faun mehr zu sein, habe aber »nur Ruhe für seine Generation« geschaffen, »schon die nächste gebiert den Werwolf« der ist unausrottbar, »weil er die Strafe für die getötete Bestie selbst ist ${ }^{93}$

Reformatorische Dialektik. Denn bei Cranach regiert selbstverständlich das »reformierte Ethos der Leidenschaftslosigkeit «. ${ }^{94}$ Das drohende »Dunkel der Leidenschaft, [...] wie es die brutale Wehr des Faunvaters« verdeutliche, ${ }^{95}$ fordert demnach permanente `Selbstprüfungen So wird gerade die »Faunenfamilie« zum Sinnbild einer »Neugeburt asketischer Ehemoral « - auch in der Wiederbelebung von Stoa und Patristik - im Kontext der »Demobilisierung weitgespannter, gesellschaftsübergreifender Sinn- und Ordnungsstrukturen wie Polis oder Reich« und der geforderten »Aufrüstung von Individuen und Kleingruppen«, in der der gesamte Glaubens- und Sittenapparat dem Einzelnen auferlegt wird, damit dieser beginnt, »ex cathedra autoritär und unfehlbar den orbis terrarum in Ordnung zu halten, beginnend mit der Disziplinierung der Familie, die nahtlos in die der Gesellschaft übergeht «. ${ }^{96}$ Gemäß des asketischen Eros hat sich im Faunen-Bild »der Sexus ins Symbol zurückgezogen, in die burgbestückte Feste über dem Haupt der Frau, in die Keule vor dem Leib des Mannes, die hier nicht ihren letzten Löwen erschlagen hat; defensive Weiblichkeit, attackierender Mann «. ${ }^{97}$

Das lutherische Eheprogramm lässt sich u.a. direkt auf die »asketische Ehemoral« des anderen (von Cranach thematisierten) Löwenbe-

91 Vgl. ebda., S. 163f. Die »christliche Löwensymbolik« ist geprägt von Ambivalenz, besser: Dualismus: Der Löwe steht für Christus und korrespondierend für Satan, Licht und Dunkelheit, Rettung und Untergang. »Die Ambivalenz aber ist die Ambivalenz jenes Dritten, für die der Löwe steht: der Macht.« (ebda., S. 20)

92 Vgl. ebda., S. 163.

93 Ebda., S. 167. Vgl. Cranachs Stich »Der Werwolf« (ca. 1512), ebda., S. 250, Abb. 18.

94 Ebda., S. 164.

95 Ebda., S. 165.

96 Ebda.

97 Ebda., S. 164. 
zwingers, des Eremiten Hieronymus zurückführen: Hieronymus, »Patron« der Renaissance, der bereit sei, von »fremden Welten« zu lernen, dessen legendäres Bestiarium nun Signum wissenschaftlicher Entzauberung, Kultivierung, Humanisierung der äußeren Natur, Zähmung der Wildnis ist, ist der »Dornauszieher $«{ }^{98}$ der den Löwen zähmt, indem er ihm »den Stachel des todbringenden Begehrens« aus dem Fleisch zieht, »den sich das sündige Elternpaar im Paradies eingetreten hatte «. ${ }^{99}$ Hieronymus propagiert zwar die »Josefs-Ehe«, in der Mann und Frau als Mönch und Nonne miteinander leben sollen. Dann zitiert er auch den Stoiker Seneca, wonach auch eine »allzu brennende Liebe für die eigene Frau« ehebrecherisch sei und der Mann sich »ihr nicht als Geliebter, sondern als Gatte nähern« solle. ${ }^{100}$

>Asket und `Jungfrau< als Vorbilder des bürgerlichen Familienvaters und der bürgerlichen Familienmutter. Die vorgebliche Keimzelle der Gesellschaft basiert auf der Negation des >Tierischen`, des Stachels des Begehrens. Dass gerade die Wilden Leute hierfür stehen sollen, verlegt das Postulat ins Vorzeitliche, schafft eine genealogische Legitimation. Die Überwindung des Animalischen ist wohl auch darin zu erkennen, dass die Körperbehaarung der Wilden in diesen Cranach-Bildern verschwunden ist.

Fiktionalisierung der $>$ Wilden Leute $<$ zu $>$ Urahnen $<$ : Es gibt einen Unterschied zwischen der jeweiligen Transformation von Wildem Mann und Wilder Frau. Der Wilde Mann (Waldgott) hat zwar >böseく Eigenschaften (er ist Einzelgänger, unfähig zur Vaterverantwortung, tut Unaussprechliches mit geraubten Frauen und Kindern), aber er hat ebenso grundsätzlich geforderte männliche Eigenschaften (er ist aktiv, tapfer, kampfstark, eroberungswillig).

Die Wilde Frau (Waldgöttin) hingegen hat keine erwünschten weiblichen Eigenschaften - auch nicht in roher Form. Sie ist vielmehr ein Wesen der >verkehrten Welt $\measuredangle$. Die Verschmelzung des Wilden Manns mit dem Germanen zum Ahnherrn ist also eine Überführung des Rohen ins Beherrschte. Die Tötung des Bösen, des `Tiers`, übernimmt er aktiv, selbst-tätig. Die Verschmelzung der Wilden Frau mit der Germanin zur Ahnherrin dagegen ist ein völliges Umkrempeln (der verkehrten Welt von >links auf >rechts $<$ ), das sie passiv erfährt: bloße Sozia des >historischen`, >epochalen` männlichen Schritts. Beide Figuren sind nun Bestandteil einer Kulturlandschaft. Während aber die >männliche Wildnis transformiert ist in den nun gewollten Wald, ist die >weibliche Wildnis

98 Ebda., S. 26.

99 Ebda., S. 29. Vgl. Exkurs I.

100 Ebda., S. 164. 
abgeschafft, ersetzt durch den Garten. Der Waldgott bleibt im Amt nun aber als Beherrscher der Waldes. Die Waldgöttin aber hat abgedankt.

Abb. 7: Cranach d. ̈..: Faun mit Familie und erschlagenem Löwen, um 1530

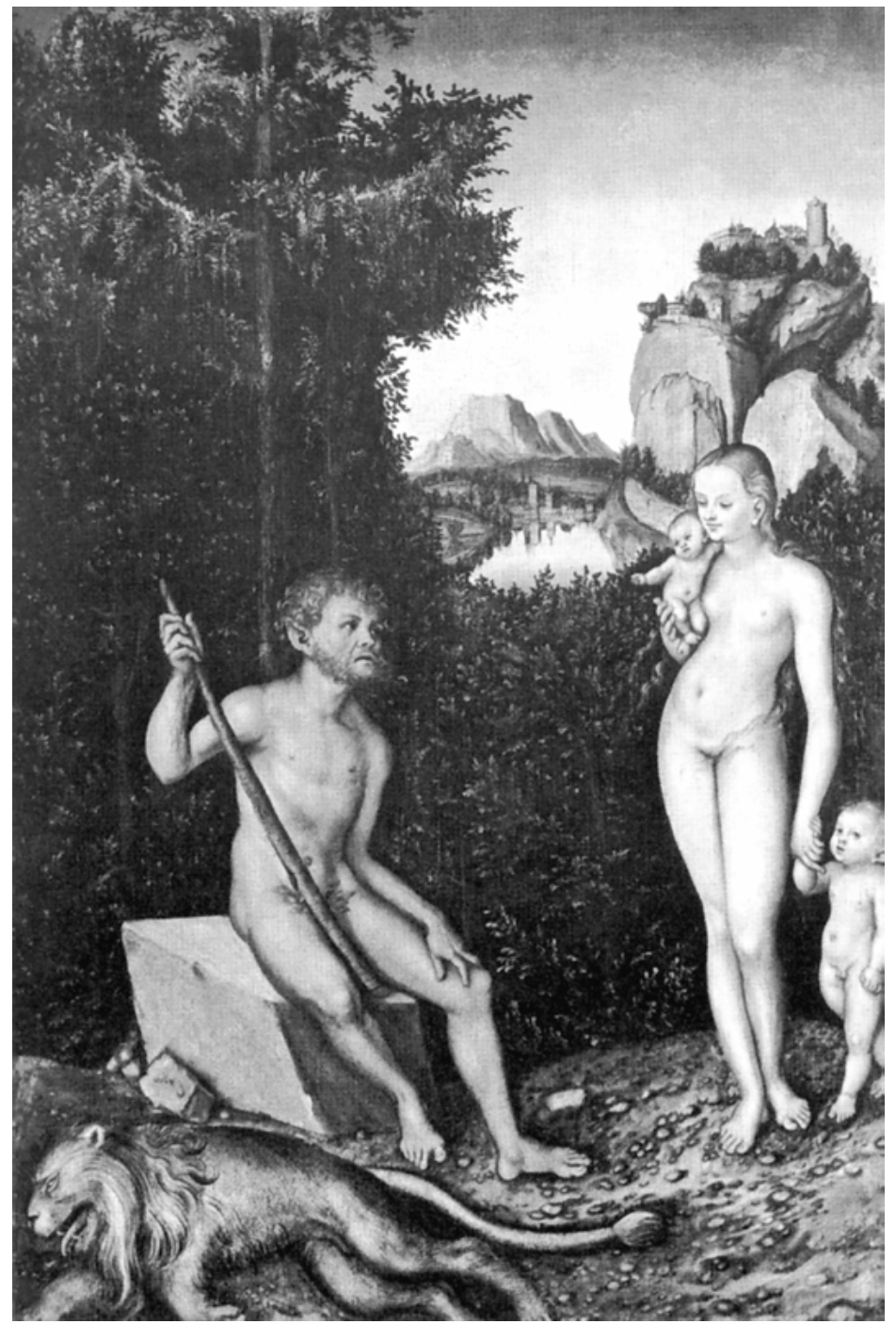




\section{Die Junggesellengeburt eines »unvermischten Volkes»}

Das >deutsche Urvolk`zeigt nach Celtis eine solche rohe Männlichkeit in der Antike und gemäß der »mutatio« eine deutlich zivilisiertere Form in der Renaissance.

»Diesem Volk verlieh die verschwenderische Natur gewaltige Gliedmaßen, die in ihrer Größe der Brust ähnlich sind und die mit hochgewachsenen Körperteilen ihre weißen Leiber über die milchfarbenen Hälse hinaus hochragen lassen. Blond ist das Haar, hell sind auch die Augen und in heller Farbe wahren ihre Glieder wohlproportioniert die rechte Statur. Stimme und Gebärden verraten innere Haltung und ihre Gemütsverfassung; die Stimme klingt nicht weibisch, sondern durch und durch männlich zeugt sie mit grobsprechendem Gaumen von kriegerischer Gesinnung. ${ }^{101}$

Noch immer »durch und durch männlich« wachse inzwischen aber »ein sanfteres Volk« heran, »da die wilde Roheit vertrieben ist« - durchs zivilisierende Wirken der Druiden, >Philosophen griechischer Lebensweise $\iota$, von den Römern aus Gallien vertrieben und nach Germanien geflohen, die zunächst ihre Riten unter Eichen zelebrieren, in abgeschiedenen Wald-Klöstern leben, dann die verstreut lebenden >Germanen ihnen Land-, Haus- und Städtebau beibringen ${ }^{102}-$, zugleich ist die

101 Celtis: De situ et moribus Germaniae additiones; zit. n. Müller, Gernot Michael, a.a.O., S. 95.

102 Vgl. Müller, a.a.O., S. 418 u. 422ff. Dass dieser in der »Norimberga« ausgebreitete Druiden-Mythos im Widerspruch zur > germanischen > Indigenitätく und >Autochthonieく steht, muss ebenso »offen bleiben«, wie das >Griechentum (der Druiden. Wichtig ist Celtis aber, sie unbedingt als "Archegeten einer von Römern unbeeinflußten Kultur« darzustellen (ebda., S. 421). Auch Schama (a.a.O., S. 112) bezieht sich auf die »Norimberga«. Sie feiere »die Vorzüge der deutschen Wälder«, inbesondere »die verbliebenen Teile des Urwalds, des Herkynischen Waldes, eines Ortes voller Druidenhaine mit >murmelnden Blättern` und >dunklen Tälern, wo laute Ströme tosen und sich über die Felsen ergießen««. Schama übersieht, dass die Druidenhaine nur insofern »gefeiert« werden, als dass sie Ausgangspunkte einer Zivilisierung der >Germanen (a.a.O., S. 166), der schreibt, Celtis fordere, »die >druidische Weisheit und die >Wald- und Feldreligion< der Germanen für die neuere Philosophie zu aktivieren«. Er sieht das in dem Kontext eines »Bemühen[s] um eine neue Identität«, was nachvollziebar »eine immere stärkere Auseinandersetzung mit der Natur« zur Folge gehabt habe: »Die von Gott geschaffene Natur bot, im Unterschied zu den von Menschen geschaffenen Dingen und Verhältnissen, direkteren und unmittelbareren Aufschluß über das Wesen der Welt. Hatte doch schon der Cusaner darauf hingewiesen, daß der Sinn der Existenz, das Wesen Gottes sich in der Schönheit und Regelmäßigkeit der Natur offenbare.« 
Wildnis der Barbaren - infolge der nun per »conversio siderum« »neuen«, weil näheren Sonne - der Kulturlandschaft gewichen. ${ }^{103}$ Das entspricht dem humanismustypischen Denken zwischen Wandel und Kontinuität. Abgesehen von diesem Schluss hat Celtis >Germania`, den >Herkynischen Wald vollständig diaphan aufgebaut. Da sind die >Germanen` nun grundsätzlich (anders, als bei Tacitus) »wohlproportioniert», wie inzwischen auch die Landschaft, sie kultivieren Wein und bearbeiten »die fetten Äcker [...] mit vierspännigem Pflug « ${ }^{104}$ (die Barbaren sind andere: Ungarn oder Lappen), ${ }^{105}$ sind leidenschaftliche und kunstfertige Jäger. Gleichzeitig halten sie »es auch nicht für Unrecht, auf Raub auszugehen, wenn sie die wilden Kämpfe des kriegsbringenden Mars im Sinne haben, und diesen an den erhabenen Höfen der Könige suchen«. Sie sind bereit, »wagemutige Risiken einzugehen, nicht träge und nicht furchtsam zu sein, zu sterben und das rosafarbene Blut im Kampf für Vaterland und die lieben Freunde auszugießen, zu jeder Bluttat bereit, wenn sie irgendein Unrecht verletzt hat «, dabei treu, standhaft und fromm, lieben Religion, alles Himmlische, Gute, Anständige und unfähig zur Lüge. ${ }^{106}$ >Germania« ernährt Mensch und Vieh, »bringt auf fruchtbarer Scholle das ährentragende Korn mit großem Zins aus« hat blumenübersäte »[f]ette Weiden«, dazu eine "gewaltige Maschinerie« von Schmelzöfen und Hämmern zur Verarbeitung der großen Erzvorkommen. ${ }^{107}$ Zugleich besteht >Germania২ aus »unermeßlich große[n] Haine[n] «oller uralter, als heilig verehrter Eichen, leben Druiden in den dichten Wäldern in "prächtigen« Klöstern. ${ }^{108}$ All das wird im Präsens erzählt.

Celtis konstituiert eine »Volksgemeinschaft« und ein damit untrennbares »Raumbewußtsein $« .{ }^{109}>$ Germania (entsinnlichte >Mutter asketischer Ehemoral, schon ewig Territorialisierte: »Mutter-Land «, gewaltige »Figurine« einer zur »Urlandschaft« erstarrten Geschichte ${ }^{110}$ ) und 〉Germaniく werden zur unauflöslichen Einheit, die »seit Anbeginn der Welt« besteht. Ein »territoriales Bewußtsein«, das nicht politisch-genealogisch, sondern ethnisch, per ewiger Siedlungskontinuität, als direkte Abstammung von einem Schöpfergott definiert wird. ${ }^{111}$

103 Vgl. Celtis: De situ; zit. n. Müller, a.a.O., S. 109.

104 Ebda.; zit. n. Müller, a.a.O., S. 95.

105 Vgl. ebda.; zit. n. Müller, a.a.O., S. 99ff.

106 Vgl. ebda.; zit. n. Müller, a.a.O., S. $95 \mathrm{ff}$.

107 Vgl. ebda.; zit. n. Müller, a.a.O., S. 107.

108 Vgl. ebda.; zit. n. Müller, a.a.O., S. 103.

109 Müller, a.a.O., S. 349.

110 Vgl. Kap. Zu erobernde Jungfrauen.

111 Vgl. Müller, a.a.O. 
Die Welt ist eine Junggesellengeburt. Der alte Gott Demogorgon spürt einen »Aufruhr« in seinem Bauch - darin trägt er die ganze Welt als rohe, chaotische Masse - »der zufällig anschwoll, und er den von der reifen Last schwangeren Unterleib auseinanderspannte, die empfangen worden war zu Anbeginn des ewigen Weltalls«. Unwillig, die brodelnde Materie länger zu ertragen, "schüttelte er den Bauch aus. Und bald waren herausgetreten Erde, Himmel und das wellenspeiende Meer, die klare und stürmische Luft« etc., sowie die Gestirne. Die geben den Dingen eine neue und ordnende Kraft. Mit diesem Geburtsakt werden auch direkt die Deutschen/Germanen als >Urvolkı erzeugt, auf eigener Erde, gar »unter seinem eigenen Himmel« mit eigenen Gestirnen. ${ }^{112}$ Dieses 〉Urvolkı, das für die deutschen Humanisten, so auch den Celtis-Schüler Heinrich Bebel (»Germani sunt indigenae«, 1501), allein als `Unbesiegte $<$ und >Unvermischteく Indigenitätskriterien erfülle, ${ }^{113}$ erhält daher eine >Ursprache $<$ - auch diese »unbefleckt«, > unvermischt`, >rein.${ }^{114}$

Das dekadente Rom der deutschen Humanisten wie Celtis, Jakob Wimpheling (bzw. Wimpfeling), Ulrich von Hutten, Bebel ist das >untergegangene Imperium , ehedem »Stammland des Humanismus«, inzwischen längst erobert und `vermischt $\iota$, »Heimat von Nachkommen der Vandalen, Goten oder Langobarden $«{ }^{115}$ Ihr dekadentes Rom ist aber ebenso aktuell das Papsttum, die katholische Kirche - und damit verbunden: der Frühkapitalismus. »Celtis betont in seinen Gedichten, etwa in

112 Celtis: De situ, zit. n. ebda., S. $91 \mathrm{ff}$.

113 Vgl. Müller, Gernot, a.a.O., S. 350f.

114 Bebel siedelt das Deutsche zeitlich vor dem Griechischen an. Ein Colmarer Anonymus (1510) und Johann Goropius Beccanus (1569, »Origines Antwerpianae«) erklären es zur »)Ursprache« der Menschheit«, hätten doch Adam und Eva im Paradies deutsch gesprochen. Hat 1534 J. Aventinus »das Deutsche zur >Ur- und Hauptsprache< erhoben«, so legt 52 Jahre danach der Niederländer Simon Stevin >empirisches Material dazu vor. 2170 »Urwörter« gebe es im »Niederländisch-Deutschen«, aber nur 265 im Griechischen und 163 im Lateinischen. Im folgenden Jahrhundert erklären Jacob Böhme Deutsch als von der babylonischen Sprachverwirrung infolge der Ursünde unbeeinträchtigt, Johann Adam Schill zur »unbefleckten Jungfrau« und »keuschen Königin«, Schottel nur »das freie uralte Deutschland « als »von fremden Sprachen unverworren«, usw. (Vgl. Best, Otto F.: Die blaue Blume im englischen Garten. Romantik - Ein Mißverständnis? Frankfurt/M: Fischer 1998, S. 43.) Best stellt die Frage, ob hier ein frühes »Zeichen deutscher Sehnsucht nach Ganzheit, Nichtabgeleitetem, Spontanem«, zu finden sei, »wie sie später nicht allein im Genie- und Heldenkult ihren Niederschlag finden wird«, und sieht zu Fichtes »Vorstellung von den Deutschen als $>$ Urvolk^ [...] nur ein[en] Schritt. Leicht zu gehen im nationalpädagogischen Aufwind« (ebda.).

115 Müller, a.a.O., S. 352. 
den >Amores`, die Unverdorbenheit der Urbewohner der deutschen Wälder gegenüber der Verdorbenheit der Mönche und Priester der römischen Kirche. $"{ }^{116}$ Was sich auch direkt auf das Lob des Tacitus beziehe, die >germanischen Ahnen benötigten keine Tempel, sondern übten ihre Religion in den Wäldern aus. »Der in diesem Lob enthaltene Tadel römischer Sitten war leicht zu verlängern und gegen die römische Kirche und deren Aufwand zu richten. $«{ }^{117}$ Das ist allerdings nicht als grundsätzliche Ablehnung von Sakralarchitektur zu interpretieren, der >nordische〈 Baustil, die Gotik wird goutiert. In Wimphelings Schrift »Teutschland« (1501) etwa wird der »kranke[] Süden« - hier herrschen die Syphilis, das Römische Imperium und in dessen Architektur der Rundbogen - mit »dem gesunden Norden« konfrontiert. Hier zeigten sich wenn auch unter lateinischem Einfluss schon deutlich verdorbene »Überreste eines freien und reinen Lebens [...]: germanisches Gewohnheitsrecht, Bürgerfreiheit, häusliche Frömmigkeit«, sowie die Architektur des gotischen Spitzbogens, »die Wimpheling als die vollkommenste und natürlichste Form des Sakralbaus pries «. ${ }^{118}$ Auch in Italien, so im Brief des »Pseudo-Raphael«, wird die Gotik zeitgleich als Abkömmling des Germanischen behauptet, allerdings als Beweis für die barbarische Abscheulichkeit dieser Architektur, eben weil sie aus den barbarischen Wäldern stamme. ${ }^{119}$

Nördlich der Alpen entstehen in bildender Kunst, Literatur und Geographie bereits damals, zum Zeitpunkt ihrer Entdeckung, die >heimischen Landschaften « eines >organisch-lebendigen` deutschen Waldes als Widerpart >toter` römischer Architektur, eines Waldes, in den sich die Städte wie Nürnberg und Würzburg (aus gotischer Architektur; auch sie >organische` Gebilde?) einpassen. Hier wird der Wald selbst zu einer Art >handelndem Subjekt . Er bringt hervor, er prägt. Dort, schreibt Celtis etwa, "wo nun Siebenbürgen liegt mit gepflegten Landschaften, hat er ein Volk erschaffen mit deutschen Sitten und deutscher Sprache $\ll .{ }^{120}$ Sitten, Sprache und Moral: Germania und Germani bilden eine untrennbare Einheit in ewiger Siedlungskontinuität. Der rohen, unbeherrschten Virilität - männliche Tugenden sind vorhanden, aber noch barbarisch grundiert - korrespondiert die Wildnis, der beherrschten - infolge der »mutatio« - der Wald in der Kulturlandschaft.

116 Eschenburg, a.a.O., S. 46.

117 Ebda., S. 34f.

118 Schama, a.a.O., S. 110f.

119 Vgl. Frankl, Paul: The Gothic. Literary Sources and Interpretations through Eight Centuries. Princeton: Princeton University Press 1960, S. 274f.

120 Celtis: De situ, zit. n. Müller, a.a.O., S. 107. 
Im frühneuzeitlichen Prozess der Reorganisation der patriarchalen Gesellschaft wird der Wald der deutschen Humanisten zum Ort, der die »Grenzen eines beherrschten Lebens« markiert. ${ }^{121}$ Dieser >männliche Wald ist eine Inszenierung der Überwindung von Wildnis. Insbesondere ihres weiblichen bzw. numinosen Teils (der nun ins Dämonische abgedrängt wird), denn gemäß der diaphanen Konstruktion als Ort der Urahnen >beweist` er die immerwährende männliche Ordnung. Die Überwindung des männlichen Teils ist damit keine Abschaffung (er bleibt als >ewige Legitimierung $\prec$ ), sondern eine Überführung ins >Maßvolle`, `Beherrschte<.

Damit ist der Wald, genauer: dieser Wald erstmals - auf >hochkultureller Ebene - >innen . Er ist erstmals nicht mehr negativ oder numinos. Der Wald erscheint so auch nicht mehr als »Handlungsort» des $»$ Wechsel[s] personaler Zustände «, ${ }^{122}$ einer »conversio zum Bestialischen «, ${ }^{123} »$ Verwilderung $«,{ }^{124}$ desgleichen nicht mehr als für »die frühe Abstraktion« des höfischen Hochmittelalters notwendiger »natürliche[r]«, »konkrete[r] Ort«, der stets »nur >draußen«, abgetrennt vom reflexionslosen Gang adeliger Begebenheiten« liegt, wie die Wildnis der »minneGrotte« Tristans und Isoldes. ${ }^{125}$ Kein Ort mehr der simultanen Wirklichkeiten, sondern bereits der systematischen. ${ }^{126} \mathrm{Er}$ ist jetzt nicht mehr Gegenwelt zur eigenen Kultur, sondern als deren Bestandteil mit ihr Gegenwelt zum >dekadenten Rom`, zum >ruinierten Imperium`. Globaler heißt das: Gegenwelt zu den Entgrenzungen am Ende des Mittelalters.

\section{Entgrenzungen - Begrenzungen: der Herkynische Wald als Reterritorialisierung}

Die Grenzen eines beherrschten Lebens gegen die Entgrenzungen der 〉Dekadenzı. Entgrenzungen der Gesellschaft und ihrer Körper - inklusive der menschlichen - im spätmittelalterlich beginnenden Prozess der sozialen Auflösungen und Neuformierungen. Ein »Vorgang« der »historische[n] Freisetzung der Individuen aus herrschaftlich stratifizierten

121 Celtis, zit. n. Schama, S. 110.

122 Am Beispiel des »Iwein« Hartmanns von Aue: Matejovski, a.a.O., S. 127.

123 Wenzel, Horst: Ze hove und ze holze - offenlîch und tougen. Zur Darstellung und Deutung des Unhöfischen in der höfischen Epik und im Niebelungenlied; zit. n. Matejovski, ebda.

124 Matejovski, ebda.

125 Czerwinski: Der Glanz der Abstraktion, S. 325.

126 Vgl. ebda., S. 348. 
und ständisch gegliederten Sozialverbänden« bei gleichzeitiger »Überführung dieser > freigesetzten ` Individuen in neue, anonym-institutionelle Zusammenhänge mit entsprechend sich verändernden Verhaltensanforderungen«, d.h. neuen Zwängen ebenso wie neuen Möglichkeiten, ${ }^{127}$ wobei in der mittelalterlichen Gesellschaft andere Verhaltensregulierungen und damit auch »andere Formen der Individualität « existieren ${ }^{128}$ als in bürgerlichen Gesellschaften, also zeitgenössische Formen und keine Proto-Formen bürgerlicher Individualität. ${ }^{129}$

Das herrschaftlich organisierte >Haus` als Basisprinzip, Muster, Modell von Sozialisation, Machtverteilung, Herrschaftsform und Partizipation »überall da, wo sich Angehörige unterschiedlichen, aber minderen Status unter patriarchalisch-hierarchische Führung begeben«, die überwiegende Mehrheit der Bevölkerung also. ${ }^{130}$ Der Körper als Besitzer von Eigenschaften. Aggregative Herrschaft und parataktische psychische Ordnung ohne Unterscheidung von sinnen die Grundlagen der mittelalterlichen Gesellschaft und ihrer Verhaltensregulierungen. ${ }^{131}$ Wenn nun also Klaus Theweleit für das endende Mittelalter von »Deterritorialisierung« spricht, dann hebt das auf eine beginnende Differenzierung zwischen >Innen rauf, dass nun ein erstrebenswertes $>$ Draußen $<$ zu existieren beginnt. Darauf, dass die Fesseln der alten Ordnung reißen - was neue Arten der Fesselung hervorrufen muss und hervorruft.

Im >deutschen Humanismus« zeigt sich ein wesentlicher »Reterritorialisierungsversuch«. Auch hier ist das ersehnte Territorium - vordergründig - codiert »mit dem Körper der unendlichen Frauen« - in diesem Fall der »Frauen der Herrschenden «. ${ }^{132}$ Zunächst also erscheint der fiktive Frauenleib als "phantastische[r] Schauplatz geträumter Deterritorialisierungen $«{ }^{133}$ Schnell aber wird klar, der Leib der >Germania ist ein endlicher, begrenzter. So wie nicht allein die geographischen Grenzen des Landes strikt feststehen sollen, sondern die Grenzen komplettiert werden durchs >Autochthone $<$ und >ethnisch Reine $<$ - mit einer Sprache als »keuscher Königin«. Hier ist die äußere Natur keine `Amazone`, $>$ Kannibalin-Hexe $\prec$, keine $>$ Jungfrau $<$ - wie die der $>$ neuen Welt $\iota-$, sie ist schon lange, >ewigく in Besitz gewesen: »Mutter-Land «. ${ }^{134}$ Hier erhalten

127 Sonntag, Michael: »Das Verborgene des Herzens«, S. 13.

128 Ebda., S. 16.

129 Vgl. ebda., S. 71.

130 Vgl. ebda., S. $52 \mathrm{ff}$.

$131 \mathrm{Vgl}$. Einleitung.

132 Theweleit: Männerphantasien 1, S. 377.

133 Ebda.

134 Weigel, Sigrid: Topographien der Geschlechter, S. 146, Text zu Abb. 16. 
die Frauen ihren Platz >zurück $`$ in einer tradierten männlichen Ordnung, die seit >Anbeginn der Welt 〈 besteht. Zwar fungieren (auch) »Wilde Frauen« in den Rollen der 〉Urahninnen`, aber eben nicht (mehr) als Bestie oder Verführerin, sondern als treusorgende Familien-Mutter. Für die >Keuschheit` der >realen` Germaninnen bürgt schon Tacitus.

Angesichts des realen frühneuzeitlichen »Mann/Frau-Verhältnis[ses]« als »Angelpunkt der Durchsetzung massiver Reterritorialisierungen schreibt Theweleit: »Die entwickelste und wirksamste Form der Codierung des Körpers der Erde mit dem Körper der unendlichen Frauen scheint die besonders einschränkende Ersetzung des Körpers >aller Frauen durch den Körper der Mutter geworden zu sein. ${ }^{135}$ Sigrid Weigel verweist auf die häufige Gestaltung von Landkarten als Frauenkörper. »Das >Mutter-Land ist dabei längst territorialisiert; entsprechend abstrahiert die allegorische Personifikation [...] weitgehend vom konkreten, sinnlichen Leib einer Frau. ${ }^{136}$ Hier fehlt dann alles Verführerische und/oder Schreckende. Auch >Germania< erscheint als >keuscheく Mütterlichkeit in den durchscheinenden Konstruktionen des deutschen $\mathrm{Hu}-$ manismus: zwischen trutziger Entbehrungsbereitschaft und beherrschter Fruchtbarkeit - jenseits jeder dekadenten >Homöostase $\prec$.

Reterritorialisierung heißt aber auch: Der in seiner Ganzheit verlorene, zerstückelte Besitz, die »zerrissenen [...] Grenzen «, ${ }^{137}$ soll(en) wieder zusammengefügt werden: Zur >Landschaft $\measuredangle$ im seit dem frühen 16. Jahrhundert neuen Sinn, worin der alte Sinn gleichwohl enthalten ist (s.u.). Zur >Germaniaく. Die Personifikation >Germaniens` erscheint als »mächtige weibliche Figurine[]《, denn »[ü]berall dort, wo Geschichte zur >erstarrten Urlandschaft $\iota$ gerinnt - im Mythos, in der Allegorie -, bevölkern mächtige weibliche Figurinen das kulturelle Panoptikum «. ${ }^{138}$ Und sie erstarren »zur stummen Stütze des Systems «. ${ }^{139}$ Bovenschen zeigt - mit Walter Benjamin - weibliche Allegorien als »rückwärtsgewandte Geschichtsruinen« und in dieser Weise als Repräsentantinnen

\section{Theweleit, a.a.O.}

136 Weigel zeigt das am Beispiel der »Allegorie der Europa« (Matthias Quad, 1587), a.a.O.

137 Celtis; zit. n. Schama, a.a.O., S. 109.

138 Bovenschen, Silvia: Die aktuelle Hexe, in: Becker, Gabriele et al.: Aus der Zeit der Verzweiflung, S. 299.

139 Weigel: »Die Städte sind weiblich und nur dem Sieger hold«. Zur Funktion des Weiblichen in Gründungsmythen und Städtedarstellungen, in Anselm, Sigrun/Becker, Barbara (Hg.): Triumph und Scheitern in der Metropole. Zur Rolle der Weiblichkeit in der Geschichte Berlins. Berlin: Reimer 1987, S. 215. 
männlicher Herrschaft. ${ }^{140}$ Nach Weigel hat die »Inanspruchnahme des Frauenbilds als Zeichenkörper für eine andere Bedeutung« eine Voraussetzung: dass »vom Leib der Frau abstrahiert« wird. Das allegorische Bild ist entsinnlicht und entlebendigt; es verweist gerade nicht auf ein weibliches Subjekt, um stattdessen etwas anderes vor- und darzustellen. Insofern ist die allegorische Personifizierung im Bild der Frau an die Verdrängung der Frau als Subjekt aus der Geschichte gebunden«. Sigrid Weigel nennt das einen »Vorgang der Entsinnlichung/Abtötung «. ${ }^{141}$

Germania ist patria: Die Figurine ist das Vaterland? Sie gehört dem Vater, ist sein Land. Der Herkynische Wald - selbst Allegorie des kriegerisch-tugendhaften >Germanen`(allen voran >Arminius` (bei Ulrich von Hutten)), der zudem nun kein Barbar mehr ist - markiert ihre Grenzen, bestimmt ihre Ausdehnung. Wald und Figurine sind hier Sehnsuchtstopoi einer >Eindeutigkeit<, der der >ewigen « Ordnung. > Vaterland besitzt >Mutterland`, bringt ihr Fruchtbarkeit und wacht über sie. So, wie Cranachs »Faunenfamilie« zum Sinnbild einer »Neugeburt asketischer Ehemoral« wird.

>Männliche` Wildnis - >weibliche` Wildnis. Ihre Konstruktion über die Figuren des Wilden Manns und der Wilden Frau lässt sich verdeutlichen mittels des zeitgleich aufkommenden Diskurses über die >Wilden ( in Übersee. Monika Wehrheim-Peuker zeigt die relativ schnelle Aufspaltung in rituell bzw. kulturell motiviert handelnde, von männlichen »virtutes« wie Ehre, Tapferkeit, Heldenhaftigkeit geleitete Kannibalen und aus nackter fleischlicher Gier getriebene Kannibalinnen. Die Kannibalen sind damit sukzessiv Entalterisierte. Zugleich repräsentiert die Kannibalin eine verderbte verkehrte Welt weiblicher Dominanz; contra naturam.

Räume und Personal bedingen sich wechselseitig. Der Dschungel der neuen Welt ist in diesem Fall ebenso contra naturam, verkehrte Welt, gierig und verschlingend, böse und/oder trügerisch verführend. Derartige Räume der Fremden, Anderen gibt es desgleichen in der alten

140 Bovenschen, a.a.O., S. 296ff. Bovenschen beschreibt die Allegorie der >Natura in dieser Weise. >Naturaく, seit der Antike Repräsentantin des Fruchtbarkeitsprinzips und der Naturbeherrschung, Ernährerin der Erde, bleibe bis ins 19. Jahrhundert eine permanent positive Gestalt, stehe aber bereits während der Aufklärung für männliche Naturbeherrschung und Vernunft (ebda.). Allerdings verweist Ernst Robert Curtius darauf, dass >Natura sich im 12. Jahrhundert, bei Alan von Lille, schon einmal dem männlichen Gott unterordnet, von der Gebärerin zur züchtigen Jungfrau wird (Europäische Literatur und lateinisches Mittelalter, S. 128).

141 Weigel: Zur Weiblichkeit imaginärer Städte, in: Fuchs, Gotthard et al. (Hg.): Mythos Metropole. Frankfurt/M: Suhrkamp 1995, S. 40. 
Welt - Hexen-Orte. Hier aber vorherrschen soll der männliche Wald. Auch hierin ist die Wildnis entalterisiert. Daraus folgt: >Männliche Wildnis ist reformierbar, indem die störenden Anteile geglättet werden. Von nichts anderem sprechen Celtis' kosmische Wende und Druidenmythos. >Weibliche Wildnis hingegen kann nur radikal umgestürzt werden - erscheint sie doch selbst als ehedem umgestürzte Ordnung.

Die Indienstnahme der heimischen Wilden Leute soll belegen, dass die propagierten asketischen Tugenden seit Vorbeginn der Geschichte gelten. Zudem steckt in diesen Figuren auch etwas von der schon von Boccaccio verwendeten Prämisse, tugendhafte Heiden als Ansporn für Christen zu nehmen, diese gefälligst zu übertreffen. ${ }^{142}$ Schon gar angesichts neuer Herausforderungen.

\section{Dämme}

Dämme sind zu errichten gegen die »große Unruhe [...], die plötzlich, gegen Ende des Mittelalters am Horizont der europäischen Kultur aufsteigt «, ${ }^{143}$ in einer Zeit, in der ebenso plötzlich, »am Ende des 15. Jahrhunderts« die Geschlechtskrankheiten »wie legitime Erben« den Platz der Lepra einnehmen, so dass etwa Ulrich von Hutten das damals gegen die Syphilis verwendete »Guajakholz« für wertvoller als alles amerikanische Gold erachtet - wobei nach Foucault trotz aller anfänglichen Exklusionen »die malafrantzos« (vorrübergehend) eher als medizinisches, denn als moralisches Problem angesehen wird. ${ }^{144}$ Die Rolle der Lepra als traumatische »Heimsuchung« und Objekt der Exklusion, Abtrennung, Reinigung übernehme der Wahnsinn. Das `Narrenschiff`, »ein eigenartiges, trunkenes Boot, das die ruhigen Flüsse des Rheinlandes und die flämischen Kanäle hinuntergleitet«, gerät zum Gegenstand »mit der größten Symbolkraft [...] in der imaginären Landschaft der Renaissance «. ${ }^{145}$ Wahnsinn und Wahnsinnige »werden bedeutendere Gestalten in ihrer Doppeldeutigkeit: Drohung und Verlachen, schwindelerregende Unvernunft der Welt und unbedeutende Lächerlichkeit der Menschen«. ${ }^{146}$ Rudolf zur Lippe sieht eine Gier der Menschen nach »leiblicher Selbsterfahrung« am Ende mittelalterlicher Herrschaftsformen, ge-

142 Erfen, Irene/Schmitt, Peter: Nachwort, in: Boccaccio: De claris mulieribus, S. $265 f$.

143 Foucault: Wahnsinn und Gesellschaft. Eine Geschichte des Wahns im Zeitalter der Vernunft. Frankfurt/M: Suhrkamp 1977 (Paris 1961), S. 31.

144 Vgl. ebda., S. $23 \mathrm{f}$.

145 Ebda., S. 25.

146 Ebda., S. 31. 
samteuropäische »körperliche Raserei« und »Tanzwut«. ${ }^{147}$ Das Lachen aber wird zunehmend gefährlich, wie Gerhild Scholz Williams anhand des »Hexenhammers« zeigt. In dem Maß, wie die »Verbindung von Magie und [vor allem weiblicher] Sexualität« seit dem Ende des 15. Jahrhunderts »bedrohliche Züge« annimmt, wird es zum »hilflose[n] Lachen der Ohnmacht angesichts der Inquisition« oder zum »teuflische[n] Gelächter gemeinsamer Sündhaftigkeit«. Weil »die völlige Umkehrung von snormalen` menschlichen Gefühlsäußerungen [...] zur Definition der Hexerei als crimen exeptum « gehöre, seien die inquisitorischen Juristen angehalten, jegliche »Gesichts- oder Körpererregung« der Pönitenden zu protokollieren. Und einer der Hauptpropagandisten der Hexenverfolgung betont Ende des 16. Jahrhunderts unter Berufung auf die früheren Institoris/Sprenger und Danaeus, Hexen dürften nicht aus den Augen gelassen werden, schildert ihre Unfähigkeit zu weinen, dass sie angesichts der Tortur oder der Hinrichtung des Öfteren »lachen und springen «. ${ }^{148}$ Es ist Jean Bodin, somit später Cheftheoretiker der Zentralmacht Inquisition, zugleich Begründer der absolutistischen Staatstheorie, der zentralen Staatsmacht, des souveränen Herrschersubjekts, mithin des »idealen Selbst«, »das die allgemeinen Gesetze und Normen setzt«. Ihm unterstehen die vielen Untertanen-Subjekte, deren Unterwerfungs-Akte unter die Autorität des Herrschers "zum überhöhten Selbst« sie in die Lage versetzen soll, den kontrollierenden Blick zu verinnerlichen, ihre vitalen Bedürfnisse distanziert wahrzunehmen »und sie nach der absolutistischen Staatsräson zu kontrollieren «. ${ }^{149}$

Dämme werden errichtet gegen die Entgrenzungen durch die Pest, »die respektlose Vermischung der Körper«, die seit Mitte des 14. Jahrhunderts Europa entvölkert, zu sozialen Desintegrationen, desgleichen zu den Prototypen der Sozialdisziplinierung führt, gewandelten Einstellungen zu Randgruppen - und Minderheiten-Verhalten. ${ }^{150}$ Aus der >ordo « wird die >gute Policey८: Frühe Versuche der Errichtung von »Ordnung und Regiment « insbesondere in Städten, aber auch in Land und Reich zielen zwar "auf den status quo mittelalterlichen ordos, in den

147 Lippe, Rudolf zur: Naturbeherrschung am Menschen, Bd. 1, S. 109.

148 Williams, Gerhild Scholz: Das Fremde erkennen: Zur Erzählfunktion des Lachens im Mittelalter und in der Frühen Neuzeit, in: Fietz, Lothar et al. (Hg.): Semiotik, Rhetorik und Soziologie des Lachens. Vergleichende Studien zum Funktionswandel des Lachens vom Mittelalter bis zur Gegenwart. Tübingen: Niemeyer 1996, S. $91 \mathrm{ff}$.

149 Braun/Kremer: Asketischer Eros, S. 83f.

150 Vgl. Foucault: Überwachen und Strafen. Die Geburt des Gefängnisses. Frankfurt/M: Suhrkamp 1989 (Paris 1975), S. 251ff., Sonntag, a.a.O., S. 107. 
auch die neue Dynamik der spätmittelalterlichen Stadt eingebunden werden sollte. Die Herausbildung städtischer Obrigkeit, das Vordringen landesherrlicher Gewalt und >guter Policey< insgesamt sind aber gerade Ausdruck dessen, daß die alte Ordnung nicht zu wahren ist «. ${ }^{151}$ Immer neue Kleider- oder Luxus-Ordnungen werden erlassen gegen die einreißenden Sitten, den Wandel von einer körperverhüllenden zu einer körperbetonenden Kleidung. Diese Ordnungen sind selten vor 1350, seitdem nehmen sie rapide zu, insbesondere gegen weibliche, aber auch gegen männliche textile `Sittenverderbnis $\prec .{ }^{152}$ Die Braguette allerdings, die modische Abwehr weiblicher Bedrohung des männlichen Genitals, wird trotz vorhandener Widerstände das gesamte 16. Jahrhundert hindurch für alle Stände zum Muss, in dem Jahrhundert, das eine allfällige "phallische Bildhaftigkeit« gegen die gewähnte Gefährdung durchs Weibliche ins Feld führt ${ }^{153}$ - während die anstößige Frauen-Mode längst wieder auf den Rückzug gezwungen ist. ${ }^{154}$ Das Motiv der >verkehrten Welt‘, weiblicher Anmaßung der männlichen, der aktiven Rolle, des Oben-Sitzens und Bestimmens, ist in der spätmittelalterlichen und frühneuzeitlichen bildenden Kunst und Literatur prägend. Frauen kämpfen um >die Hose`, schlagen ihre Männer mit Spinnrocken, zwingen sie zu >Frauenarbeiten und übernehmen statt ihrer die Hausherrschaft, tragen Musketen und lassen die Männer den Säugling hüten, reiten auf ihnen (wie immer wieder Phyllis auf Aristoteles) oder spannen sie als Zugtiere vor Wagen - all das klagt eine Rückkehr zur >wahren Ordnung < ein. ${ }^{155}$ Und das rekurriert

151 Sonntag, a.a.O., S. $133 \mathrm{f}$.

152 Vgl. ebda., S. 109; vgl. Wolter, Gundula: Die Verpackung des männlichen Geschlechts. Eine illustrierte Kulturgeschichte der Hose. Marburg: Jonas 1988, S. 30ff.; Duerr, Hans Peter: Traumzeit, S. 72.

153 Vgl. Roper, Lyndal: Ödipus und Teufel. Körper und Psyche in der Frühen Neuzeit. Frankfurt/M: Fischer 1995 (London 1994), S. 144f.; vgl. Wolter, a.a.O., S. $77 \mathrm{ff}$.

154 Vgl. Duerr, a.a.O., S. 73.

155 Denn wenn Frauen sich wie Männer gebärden, als Soldatinnen eine Festung bestürmen, dann ist, als wenn Ochsen den Schlachter schlachten, Hennen auf Hähnen sitzen, Mäuse Katzen fangen, Fische in Bäumen leben, kurz: als wenn die Weltkugel auf dem Kopf steht (vgl. Müller, Jürgen: Das Paradox als Bildform. Studien zur Ikonologie Pieter Bruegels d.Ä. München: Wilhelm Fink Verlag 1999, Abb. 50: »Verkehrte Welt«, spätes 16. Jahrhundert); vgl. Grössinger, Christa: Humour and Folly. In secular and profane prints of Northern Europe. London, Turnhout: Miller 2002, S. 95, Abb. 103: Meister des Amsterdamer Kabinetts: »Verkehrte Welt«, S. 115ff., Abb. 130: Hans Baldung Grien: »Phyllis reitet Aristoteles«, Abb. 137: Hans Schäufelein: »Frau zwingt Mann zum WindelWaschen«, Abb. 138: Eberhard Schön: »Kein edler schatz ist auff der ert, Dann ein frums weib die ehr begert«; vgl. Borin, Françoise: Frauenbilder, 
(auch) auf die - überwiegend als städtisch wahrgenommene - Erwerbstätigkeit von Frauen im ausgehenden Mittelalter, wobei allerdings »das breite Spektrum der von Frauen in den Städten verrichteten Arbeiten weniger Ausdruck ihrer Autonomie war als der von Notwendigkeit «, ${ }^{156}$ vom politischen Handeln etwa bleiben sie ausgeschlossen. Im Laufe der frühen Neuzeit ändert sich das, schon infolge der »Zurückdrängung der Eigenwirtschaft«, zugunsten eines »Statusübergewicht[s] des Mannes«, insbesondere auf bis dahin exklusiv weiblichen Feldern, denen der >weisen Frauen und Hebammen. $^{157}$

Dämme, das heißt für die Reformatoren auch: Dämme gegen >Rom২. Die Klage klerikaler Unkeuschheit gehört dabei zum festen ikonographischen Programm. Dürer lässt in einer Illustration des Brantschen »Narrenschiffs« Frau Venus Narren und Mönche an sich fesseln, umstanden von einem Affen und einem Esel als Wollust-Attribute und vom Tod. ${ }^{158}$ Heinrich Bebel, Verfasser insbesondere satirischer Schriften, setzt »bereits deutliche antiklerikale Akzente« beim propagierten »nationale[n] Selbstgefühl«. ${ }^{159} 1509$ erscheint Bebels Epos »Triumphus Veneris seu voluptatis contra virtutes« (»Triumph der Venus oder der Wollust über die Tugenden«). Darin geißelt er die zeitgenössische »Sittenverderbnis «, wobei er den Klerus explizit und zuvorderst mit einbezieht: Hier hat die Wollust die Erde, die Menschen aller Stände fest im Griff, sind die Tugenden chancenlos. ${ }^{160}$

in Duby, Georges/Perrot, Michelle (Hg.): Geschichte der Frauen. Bd. 3, Frühe Neuzeit, hg. v. Arlette Farge u. Natalie Zemon Davies. Frankfurt/M, New York, Paris: Campus 1994, S. 241ff., Abb. 25: »Der Streit um die Hose «, hölzerner Chorstuhl, Hoogstraten, Stiftskirche St. Katharina, 16. Jh., Abb. 26: »Die Frau mit der Muskete«, volkstümliches Bild, Paris 17. Jh.; vgl. Hergemöller, Bernd-Ulrich: Masculus et femina, S. 94f.

156 Wunder, Heide: Die »Krise des Spätmittelalters« im Spiegel der Geschlechterbeziehungen - Zum gesellschaftlichen Phasenmodell Ferdinand Seibts, in: Lundt, Bea/Reimöller, Helma (Hg.): Von Aufbruch und Utopie. Perspektiven einer neuen Gesellschaftsgeschichte des Mittelalters. Für und mit Ferdinand Seibt aus Anlaß seines 65. Geburtstags. Köln, Weimar: Böhlau 1992, S. 80.

157 Vgl. Bauer, Leonhard/Matis, Herbert: Geburt der Neuzeit. Vom Feudalsystem zur Marktgesellschaft. München: dtv 1988, S. 45.

158 Vgl. Müller, Jürgen, a.a.O., Abb. 41: »Von Buolschaft« (1494).

159 Riedel: Antikerezeption in der deutschen Literatur, S. 42f.

160 Cupido führt Venus, die fürchtet, ihr irdisches Reich neige sich dem Ende zu, ihre Anhänger vor. Es erscheinen die Tiere, dann die Menschen - ganz nach den gültigen Hierarchien gestaffelt -, zuvorderst der Klerus vom Papst bis herunter zu Nonnen und Mönchen, danach die weltlichen Stände vom König bis herunter zu den Landsknechten, zum Schluss die Frauen. Sie alle präsentieren sich als willige Venus-DienerInnen, wollen die ersten in ihrem Gefolge sein. Die Virtus hingegen schafft es nur, ein kleines 
Ausgerechnet das Papsttum, theoretisch eigentlich in klarster Frontstellung »gegen den Geist des Kapitalismus« und Wahrer der traditionalen Ordnung (der Prinzipien des »gerechten Preises«, der »gerechten Nahrung«, des »kanonische[n] Zinsverbot[s]《), »hat die Verbreitung der Kreditwirtschaft immens gefördert. So erhält im 14. Jahrhundert sogar die himmlische Gnade pekuniären Charakter«. Da erhält der shimmlische Schatz überschüssiger guter Werke< per Dogma »seine kapitalistische Deutung als Reserve, über die die Kirche en detail verfügen« kann. Es kommt zum 〉Ablasshandel«: die Lage der Seelen im 〉Fegefeuer` lässt sich mit Geld verbessern. Dieser »dritte Ort« wirkt sich, zusammen mit den im 13. Jahrhundert eingeführten >lässlichen Sünden` zugunsten gerade der städtischen Bürger, der Geldwirtschaft, der >Unmoralı aus. Zugleich sind der ökonomische Aufstieg der Städte und die Entstehung des Bürgertums eine Voraussetzung für die Installierung des >Purgatoriums und seiner Verheißung einer >Zukunft` (im Gegensatz zu >Himmel und $>$ Hölle $\prec$ ) insbesondere für jene Sünder, denen sie fehlt: den Bürgern. Denn die, die mit Zeit und Wissen handeln - Händler und Gelehrte als Hauptvertreter des Bürgertums also -, handeln mit etwas, das nach traditionell-christlicher Auffassung allein Gott gehört und sündigen damit per se. >Purgatorium` und >lässliche Sünden` erlauben nun zu sündigen, ohne ewiger Verdammnis anheim zu fallen. Das Jenseits wird damit kalkulierbar - auch und gerade im Wortsinn. Gleichzeitig macht das neue Bußpraktiken und neue Praktiken der (Selbst-)Kontrolle notwendig: die Ohrenbeichte. Somit profitiert auch in dieser Hinsicht die Kirche. ${ }^{161}$

Verdrängung weiblicher Produktivität, brennende Scheiterhaufen gegen eine `sichtbare $<$ Freiheit von Frauen, >neue Sittlichkeit` (die doch eigentlich ein Zurück sein soll): ${ }^{162}$ »Aus der Kulisse treten Luther und die Reformatoren, die Dammbaupläne unter dem Arm; wie so oft erscheint der Rückschritt in der Gestalt des Aufruhrs gegen die Autoritäten (die, die sowieso schon sterben) und stellt seine Fallen. Luther, gestützt weniger auf Paulus, als auf seinen Landesfürsten, bot an: den Gott innen, dafür keinen Papst mehr. ${ }^{163}$ Dieser »Gott innen« ist zeitgenössisch jedoch noch kein »Ausdruck einer \Innerlichkeit««. Noch ist nicht das Ich

Heer (Caritas, Constantia, Fides, Patientia, Spes) gegen das der Venus zu mobilisieren, was prompt in der ersten Auseinandersetzung zerschlagen wird. Virtus flieht zu Gott, der die Menschheit vernichten will, sich aber überreden lässt, Christus auf die Erde zu senden; vgl. Riedel, ebda.

161 Vgl. Bauer/Matis, a.a.O., S. 41f.; Le Goff, Jacques: Phantasie und Realität des Mittelalters. Stuttgart: Klett-Cotta 1990 (Paris 1985), S. 116ff.

$162 \mathrm{Vgl}$. Braun/Kremer, a.a.O., S. 100ff. Ich gehe weiter unten näher darauf ein.

163 Theweleit, a.a.O., S. 390. 
Wahrnehmungs-Instanz, »jede Wahrnehmung ist immer noch rextra nos $\iota$, wie es bei Luther heißt, >außer uns , bei Gott«. Es ist eine »höhere Wahrheit«, nach deren Kriterien die Person handelt; eine »Wahrheit« aber, die ebenso wie die nach wie vor elementare »soziale und kognitive Zugehörigkeit« nicht mehr fraglos-selbstverständlich, sondern »auslegungsbedürftig geworden« ist, »und damit hängt es potentiell von der >persönlichen Entscheidung، des Einzelnen ab, zu welcher Auslegung er sich bekennt«. Obwohl das frühneuzeitliche Individuum »ein auf das eigene Ich gerichtetes Selbst-Bewußtsein« noch »als Gruppenmitglied oder gegründet in überindividuelle Deutungszusammenhänge« entwickle, konstituiere sich bereits »eine der Voraussetzungen für ein SelbstBewußtsein als Selbstbewußtsein«, würden die Deutungszusammenhänge schon »über den Spiegel der Beobachtung und der Reflexion wahrgenommen . $^{164}$

\section{Das neue bürgerliche Subjekt entdeckt die Landschaft}

Umbrüche, Bedrohliches erscheinen überwiegend städtisch generiert. Zugleich wird die >Landschaft « entdeckt. Es ist Hans Sachs, der für »den individuell gesehenen und aus verschiedenen Einzelteilen zusammengesetzten Naturausschnitt« 1537 in einem allegorischen Gedicht zum ersten Mal in der deutschen Dichtung den Begriff der >Landschaft verwendet. ${ }^{165}$ Sachs, der »Vertreter des handwerklichen Stadtbürgertums mit biederen patriarchalischen Moralvorstellungen « ${ }^{166}$ der Warner vor einer weiblichen Usurpation männlicher Autorität. ${ }^{167}$ So modelt er den dritten Gesang der Ovidschen Metamorphosen« um. Aus der Frage, ob Mann oder Frau beim Liebsakt mehr Lust verspürt sowie der Antwort des Teiresias, die Frau sei überlegen, wird hier: »ob weiber oder mender zum regimentn tüglicher seyn« und ganz nach bürgerlich-christlichem Postulat ist die Frau dem Manne »underthan/Mit dem gantzen weiblichen stam ${ }^{168}{ }^{68}$ Sachs' Zielpublikum sind »Angehörige der Mittel- und Unterschicht, die er zu Gehorsam gegen die Obrigkeit und zur Übung

164 Sonntag, a.a.O., S. 87f.

165 Eberle, Matthias: Individuum und Landschaft, S. 24.

166 Riedel: Antikerezeption in der deutschen Literatur, S. 55.

167 Grössinger, a.a.O., S. 119.

168 »Comedia oder kampfgesprech zwischen Juppiter und Junos« (1534), zit. n. Riedel, a.a.O. Der »städtisch-zünftige« Meistersinger schreibt die humanistisch beliebten Wettstreit-Dramen, so das moralisierende Fastnachtsspiel »Das hoffgseindt Veneris« (1517) oder »Comedia darin die göttin Pallas die tugend und die göttin Venus die wollust verficht« (1530), ebda., S. 54. 
christlicher und patriotischer Tugenden erziehen« will, indem er immer wieder antike Stoffe - so die Odysse - nutzt und zu »moralisierenden Exempeln« umformt, »bei der die griechischen Sagen aus der Perspektive der bürgerlichen deutschen Stadtkultur des 16. Jahrhunderts als Präfigurationen des Christentums aufgefaßt werden«. ${ }^{169}$

In Sachs' allegorischem Gedicht also gibt es eine Passage, in der der Erzähler von einer Frau »auff den thurn« geführt wird, »auff dem wir beyde sahen/die landschafft ferr und nahen $« .{ }^{170}$ Und diese »landschafft « selbst, sagt Eberle, sei nicht »ein nach allegorischen, also inhaltlichen Gesichtspunkten zusammengesetztes Stück Welt«, sondern vielmehr die Oberfläche der Erde, wie sie sich dem Blick des Erzählers darstelle. Und der zählt die einzelnen Bestandteile auf - »berg, tal und finstren welder, stett, dörfer und baufelder/obstgerte und weinperg « usw. - formt sie zu einer »geschlossene[n], räumlich und stimmungsmäßig einheitliche[n], charakteristische[n] Einheit ${ }^{171}$

>Landschaft bedeute ursprünglich eine Einheit von äußerer Natur und vergesellschaftetem Menschen, sagt Eberle. Abgeleitet vom althochdeutschen »scaft« (»Beschaffenheit«, »schaffen«), also eine »Ordnung herstellen, einrichten«, bezeichnet »landscaft« die »besondere Beschaffenheit, die charakteristische Ordnung einer Gegend oder eines Landes«, die gegebene >Natur`, was »alles Hervorgebrachte« inklusive eines Volkes, das hier »von Natur aus ansässig« oder namensgebend ist. (Zugleich wird »schaffen« von »der schöpferischen Bearbeitung des Holzes« abgeleitet, »wie überhaupt der gesamte Wortbereich des Schaffens offenbar seinen Ursprung in der mit dem Wald verbundenen Tätigkeit hat«, >schaffen schaft, Gemeinschaft, Wirtschaft, Geschäft, Schöpfung ${ }^{172}$ ) »Landscaft« bezeichnet also die spezifischen Eigenschaften eines Volkes und der von ihm bewohnten Gegend, »Landessitte und Landesbeschaffenheit« als untrennbare Einheit, »eine besondere Form der physischen und Volksnatur«. Schließlich werden vom Wortstamm »natus« (geboren) sowohl Natur als auch Nation abgeleitet. ${ }^{173}$ Das heißt auch: »Land gibt es nicht an sich, sondern erst durch menschliche Arbeit.« Land ist frühmittelalterlich definiert als gerodetes, kultiviertes, bebautes, besiedeltes, im Gegensatz zum Wald, der Mark als >res nullius`. Land und Landschaft ha-

169 Ebda., S. 55f.

170 Zit. n. Eberle, a.a.O., S. 24.

171 Ebda., S. 25.

172 Vgl. Wirz, Ferdinand: Auf den Busch geklopft, S. 11.

173 Vgl. ebda., S. 15. 
ben daher auch Rechtscharakter. »Die Siedler und Bebauer des Landes, ob Bauern oder Grundherren, bilden einen Verband, eine Rechtsgenossenschaft« zur Regelung interner und externer Verhältnisse. So bilden >Boden২, die oft ältere (Landes-)〉Sitteく und Landrecht eine »untrennbare[] Einheit, die vermittelt und gebildet wird durch die Arbeit und das soziale und politische Leben der Menschen«. >Landschaft « ist so auch »Landgemeinde «, »Gerichtsgemeinde «, da 〉Land ursprünglich der »Gerichtsbezirk « ist, in dem »Landrecht gesprochen « wird. ${ }^{174}$

In der mittelhochdeutschen Bedeutung gehört dann der Landes- oder Grundherr zwingend und untrennbar dazu. »Lantschaft« ist nun die Einheit von Land, Leuten und »sämmtliche[n] lantherren« als Gerichtsgemeinde. Im 13. Jahrhundert, unter veränderten ökonomischen und politischen Bedingungen wird die »lantschaft« so zur Vertretung des Territoriums, des Landes. Die neue »lantschaft« ist ein Ständerat, in dem von Ausnahmen abgesehen - Bauern keinen Platz mehr haben, in dem stattdessen die Vertreter von Adel, Klerus und Bürgern auf den Landtagen der sich entwickelnden Territorialstaaten den Fürsten begegnen. In dieser Zeit ist die Bestimmung der >Natur` der von den Ständevertretungen gegenüber dem Herrn vertretenen Landes-Ordnung bereits prekär geworden. Daher gilt es den Gehalt an >Natur zu explizieren, ist doch das »Repräsentativorgan >lantschaft«« als Bestandteil des Fürstenstaats »eben nicht mehr naturwüchsig«. Später, im 16. Jahrhundert, im Zuge der territorialstaatlichen Regierung nach positivem, nicht mehr tradiertem Recht, bedeutet »lantschaft« kaum noch den Souverän, wird vielmehr zur Bezeichnung des Landvolks, das in der Stadt, zu deren Herrschaftsbereich es gehört, seine Waren verkauft. Die Landleute als »lantschaft « sind "gleichsam Akzidentien des Bodens, eine Art Naturbasis der Herrschaft «. ${ }^{175}$

Zugleich kommt bereits der neue, ästhetische Landschaftsbegriff in Gebrauch. Hans Sachs benutzt ihn erstmals literarisch. Urkundlich belegt ist »Landschaft« in dieser Bedeutung im deutschen Sprachraum aber schon für 1518, in der bildenden Kunst, im Vetrag eines Basler Klosters mit dem Maler Hans Herbst. Drei Jahre darauf benutzt Dürer erstmals den Begriff des »landschafft mahler[s] « für den Antwerpener Meister Joachim Patinir. ${ }^{176}$

>Landschaft» werde bereits »früh als Gegensatz zur Stadt definiert«, etwa in der Bibelübersetzung Luthers, schreibt Eberle. Hierbei handele es sich um einen politischen Gegensatz dergestalt, dass das umliegende

174 Vgl. Eberle, a.a.O., S. $15 f$.

175 Ebda., S. 16f.

176 Vgl. ebda., S. 24. 
Land von der Stadt beherrscht werde. ${ }^{177}$ Im deutschen Humanismus aber wird die >Landschaft zugleich national homogenisiert und heroisiert. Landschaft wird nun zur ästhetischen Kategorie, aber die alte Bedeutung bleibt darin enthalten: Die unabdingbare Einheit von Menschen und Land, auch, wenn die >Germanen Landschaft des >Herkynischen Waldes` (zwangsläufig) nur noch Phantasieprodukt ist.

Das frühe bürgerliche Subjekt (Hans Sachs) schaut herab vom städtischen Turm auf die Landschaft. Es eignet sich diese Landschaft an, indem es sich über die Stadt und die von ihm beklagten Eigenschaften erhebt. >Landschaft der städtisch vom Agrarischen Distanzierte, vom Ländlichen Separierte wahrnehmen. ${ }^{178}$ In der »feudale[n] Gesellschaft«, die »auf scheinbar nicht von Menschen geschaffenen, sondern natürlichen Voraussetzungen ruht «, in der die »Ordnung der Gesellschaft also noch als Ausdruck von Natur bestimmt werden kann« und daher unmittelbar auch die Menschen, können sich isolierte Individuen noch nicht denken. Hier ist »lantschaft« noch »Ausdruck von Natur für den gesellschaftlichen Menschen«, wächst die Ordnung noch »aus der Natur, das heißt aus der Grundherrschaft« heraus. »Lantschaft « kann daher noch keine individuelle Sehweise auf einen Natur-Ausschnitt bezeichnen. ${ }^{179}$ Denn, wie schon mehrfach gesagt, >Individuen s sind in agrarischen, in traditionalen Gesellschaften, deren Mitglieder sich über die Zugehörigkeit zum >Haus`, zur >familias`, zur Gruppe definieren (müssen), nicht anzutreffen. ${ }^{180}$ Erst die »im strengsten Sinne [...] entwurzelte Klasse« der Händler und Gewerbetreibenden, die »neuen Männer«, deren Existenzgrundlage freier, selbsterworbener Besitz ist, nicht mehr von Bodeneigentum

177 Vgl. ebda., S. 21.

178 Die Bezeichnung >Bürger` entstammt »dem frühmittelalterlichen Wort burg, das sich auf Burg und Stadt als befestigte Anlagen bezog. Seit dem 11. Jahrhundert sind Stadtbewohner mit vollem Bürgerrecht cives oder burgenses, mhd. Burgaere. Als im 12. Jahrhundert das Wort stat, das vordem allgemein eine >Stätte< bezeichnete, zur besonderen Kennzeichnung der Stadt gegenüber der Burg in Gebrauch kommt, drückt das bereits den Übergang zum rechtlich gefaßten Stadtbegriff aus: Die Stadtmauern umschließen einen rechtlichen Sonderbezirk«. Der ist gekennzeichnet durch vier untereinander verbundene Institutionen: den >städtischen Frieden<, >stadtbürgerliche Freiheit`, Stadtrecht und -verfassung, die von der Bürgerschaft »beschworen und bewahrt« wird, was jede >Fehde〈 verbietet; Sonntag, a.a.O., S. 64.

179 Vgl. Eberle, a.a.O., S. 18f.; vgl. Sonntag, a.a.O., S. $67 \mathrm{ff}$.

180 Vgl. Eberle, S. 40ff.; Sonntag, S. 34ff.; Bauer/Matis, S. $43 \mathrm{ff}$. 
und Grundherren abhängig, sondern von »auf eigener Arbeit beruhen$\mathrm{de}[\mathrm{m}]$, industrielle[m], >bewegliche[m] Eigentum«, schaffen eine soziale Basis von >Individualität<. Denn die bedarf der Erkenntnis eigener Identität. Was "Arbeitsteilung" in doppelter Hinsicht voraussetzt. Zunächst ist die Selbst-Erkenntnis »als besonderes Einzelwesen« nur möglich, "wenn man nicht mehr in quasi naturwüchsigen Arbeitsverhältnissen steht«. Zudem setzt dieses »Selbst-Bewußtsein« voraus, sich »konkret«, in der eigenen »Praxis als von anderen unterschieden« begreifen zu können. Dann, so Eberle, könne »sich der einzelne daranmachen, sein Verhältnis zu Natur, Gesellschaft und ihm selbst reflektorisch zu ermitteln«. Und die Stadt (und ihre Bewohner) repräsentieren sowohl hinsichtlich der Siedlungsform, als auch institutionell die gesellschaftliche Arbeitsteilung, die sowohl »Grundlage der Stadt«, als auch »aller Warenproduktion« ist. $^{181}$

Dabei sind nach Sonntag zwar schon im 12./13. Jahrhundert vornehmlich »Kaufleute und die Ministerialen (Amtsträger und Dienstmannschaft) des Stadtherrn« für die Kommunalisierung verantwortlich, werden in dieser Zeit die Fernhändler »seßhaft und leiten ihre Geschäfte von den Kontoren aus« und gehören wegen ihrer Finanzkraft bald zum Patriziat. Gleichwohl sei es noch kein dezidiert wirtschaftliches Interesse, dass »Herrenbürger, Kaufleute und Gewerbetreibende« trotz aller ständischen Grenzen (300 Jahre zuvor gehörten die einzelnen Stände noch unterschiedlichen Gerichtsgemeinden an) eine. Noch werde ") wirtschaftliches Handeln، solidarverbandlich und nicht von konkurrierenden Individuen als Träger abstrakter ökonomischer Funktionen ausgeübt«, sei »in eine politisch-rechtliche wie religiös-sinnhaft integrierte Lebenswelt eingebunden«. Aber: »Die neuen Formen städtischen Lebens drängen [...] auf Selbstverwaltung«, auf die »eigenverantwortliche Ausübung von Gerichtsbarkeit, Verwaltung und exekutiver Gewalt«. Es entstehen Bürgermeisterämter und Ratsverfassungen (»Konsulate«, die als Ableitungen aus der genossenschaftlichen Gemeindeidee zum »Inbegriff bürgerlicher Freiheit und Eigenständigkeit« werden) sowie Bürgerpflichten, wie der Wachdienst. Städtische Freiheit ist die von Grundherrschaft und Leibeigenschaft, wobei unterbürgerliche Schichten »Inwohner« oder »Insassen« sind, ohne politische Rechte. Denn die städtische Gleichheit

181 Eberle, S. 44ff. Eberle zitiert hier Henri Pirenne: Sozial- und Wirtschaftsgeschichte Europas im Mittelalter, S. 45; Leo Kofler: Zur Geschichte der bürgerlichen Gesellschaft, S. 360; Max Horkheimer: Zur Kritik der instrumentellen Vernunft, in: Kritische Theorie der Gesellschaft, S. 229f.; Karl Marx: Kapital, Bd. 1, S. 371; Jacques Le Goff: Das Hochmittelalter, S. 52. 
ist die der Bürger (»der Hausherrn mit Muntgewalt über die familia«). Ratsämter werden von Honoratioren bekleidet, ökonomisch Unabhängigen qua Besitz und Selbständigkeit, was immer wieder zu zünftischen Aufständen um Zugang und Mitspracherecht führt. Spätmittelalterliche Städte werden zum »Modell zentralisierter Ordnung« (wie sie sukzessive landesherrlich übernommen wird), zum Modell forcierter institutioneller Abhängigkeiten und damit politisch-sozialer >Modernisierung ${ }_{<}{ }^{182}$ Das zeigt sich später, seit dem 15./16. Jahrhundert, im strikten »Regiment« (trotz aller Unruhen und Auflehnungen bis ins 19. Jahrhundert): in allerlei Verordnungen, insbesondere den >moralischen Ordnungen`, der »fürsorglichen Gewalt« für den »gemeinen Mann« (wobei es von den Konstellationen der Gruppeninteressen abhängt, ob diese Ordnungen real gültig sind), sowie den zuerst in den Städten konsequent angewandten peinlichen Halsgerichtsordnungen. ${ }^{183}$ Der tradierte »Gemeinnutz« gerät ins Zwiespältige. Einerseits ist er noch im 16. Jahrhundert umfangreicher Legitimationsbegriff einer "guten Ordnung « des Gemeinwesens, wird aber schon im Spätmittelalter argumentativ zur Handels-Förderung herangezogen. Diese »ökonomische Färbung« des Verhaltensregulativs »Gemeinnutz« konkretisiert sich im 16. Jahrhundert, was »seine normative Funktion noch verstärkt«. Andererseits wird dieser städtisch geprägte »gemeine Nutz« allmählich von seinem obrigkeitlichen Konkurrenzmodell, der »guten Policey« okkupiert, was »die Revision ständischer Ordnung durch die politisch-soziale Dynamik der Frühen Neuzeit« unter wachsendem landesherrlichem Druck andeutet.

Auch ökonomisch ist die alte ständische Ordnung der Entwicklung nicht mehr gewachsen (die Bauernkriege sind ein wesentliches Anzeichen dieser Krise). Die wachsende Verbindung mit dem Handel führt auch in der Landwirtschaft zur Ausdehnung der Geldwirtschaft und in der Folge zu neuen »eigenständige[n] >sachliche[n]< Dynamiken« anstelle tradierter Ordnungen. ${ }^{184}$ Unter dem Primat der Geldwirtschaft verschwindet auch das kanonische Zinsverbot. In Norditalien wird das schon im Hochmittelalter theologisch durchaus positiv diskutiert, insbesondere durch Franziskaner wie Petrus Johannes Olivi, einen »artikulierte[n] Verteidiger des Frühkapitalismus«, der dem Kapital »samenartige Qualität« zuspricht, weil es Gewinn erzeugen könne. Was durchaus im Sinne der italienischen Stadtstaaten wie Florenz und ihrer Bankiers ist (die jene Fürstenhäuser, die dem Franziskanerorden Schutz vor der Inquisition gewähren, wiederum finanzieren). Luther (und vor ihm

182 Vgl. Sonntag, a.a.O., S. $64 \mathrm{ff}$.

183 Vgl. ebda., S. 95ff.

184 Vgl. ebda., S. $103 \mathrm{ff}$. 
Geiler von Kayserberg) wettert in der bisherigen christlich-aristotelischen Tradition, nach der Geld »unproduktiv« und bloßes Tauschmittel ist, gegen den >Wucher ${ }^{185}{ }^{18}$ Der Wunsch zurück ins Statische hält die Dynamik nicht auf - im Gegenteil. Die protestantische Gnadenlehre, die das `Seelenheil nicht mehr an Sünde, Reue und Vergebung bindet, sondern an `Erwähltheit‘, rückt das gesamte Leben und Handeln des Menschen ins Zentrum der (eigenen) Aufmerksamkeit und Überprüfung, überträgt mittels der Lehre vom »)methodische[n] Leben« die »rationale Form der Askese [...] aus dem Kloster in die Welt «, ${ }^{186}$ so dass insbesondere Calvinismus und Puritanismus »nicht nur das äußere Leben, das Verhalten vor allem in der Gemeinde, einer rigorosen Kontrolle und Disziplinierung unterzogen, sondern auch das >innere « $\ll .{ }^{187}$ Postulat und Praxis dieser permanenten Selbstkontrolle bzw. Erforschung sind feste Bestandteile einer »Liebe zu Gott « als »Rationalisierung der Welt«, die sich verwirklichen kann in Familie, Berufsarbeit, Wissenschaft, Politik. ${ }^{188}$ Der überkommene »Gemeinnutz« schließlich kann seinem »häßliche[n] Widersacher«, dem »)Eigennutz〈, zumal angesichts des Vordringens der Geldwirtschaft ${ }^{189}{ }^{19}$ nicht mehr lange standhalten. 1530 erscheint erstmals - im Fuggerschen Augsburg - ein »Lob des Eigennutzes«, verfasst vom Juristen und Stadtschreiber Conrad Peutinger, der gegen geplante Gesetze des Reichstags (gegen die Handlungs- und Bewegungsfreiheit, für Preiskontrollen und ein Monopolverbot) und für den Eigennutz der Handelshäuser und Monopolgesellschaften argumentiert. Ohne den Eigennutz, der im Übrigen zum Vorteil der Untertanen und des Staates sei, würden Handels-Risiken gar nicht in Kauf genommen. 34 Jahre später argumentiert der Ulmer Leonhard Fronsperger noch klarer. Ihm dient der Eigennutz gar zur Harmonisierung, weil die Interessen der nach göttlichem Willen Ungleichen zur Kooperation zwängen, da kein Mensch oder Gemeinwesen allein und ohne Hilfe existieren könne. Hier kommt der Gemeinnutz praktisch nicht mehr vor, weil jegliches menschliche Handeln, »von der Eheschließung über das Wirken der Geistlichkeit bis zur Verfolgung von Handelsinteressen [...] der Triebkraft individuellen Eigennutzens « entspringe. ${ }^{190}$

185 Vgl. Bauer/Matis, a.a.O., S. $152 \mathrm{ff}$.

186 Weber, Max: Die protestantische Ethik. Bd. I. Eine Aufsatzsammlung.

Hg. v. Johannes Winckelman. Gütersloh: Siebenstern-Taschenbuch-Verlag 1981, S. 346f.

187 Sonntag, a.a.O., S. 204f.

$188 \mathrm{Vgl.} \mathrm{Braun/Kremer,} \mathrm{a.a.O.,} \mathrm{S.} 104$.

189 Sonntag, a.a.O., S. 103f.

190 Ebda., S. 164f. 
Der städtische Bürger des 16. Jahrhunderts entdeckt also die Landschaft, diesen »geistigen Akt«, dessen wichtigste Merkmale das »Gegenüberstehen « und das »Umformen« sind, ${ }^{191}$ und das »am Angelpunkt zweier Welten: Einbruch der Mystik, Raserei der Hexenverfolgung, Vervielfachung der Volksaufstände und tiefgreifende politische Neuordnungen«, was »über die tiefgreifenden und definitiven Veränderungen der Beziehungen zwischen den Staatsgewalten und den Subjekten Aufschluß« gebe, so Robert Muchembled. ${ }^{192}$ Der Bürger entdeckt die Landschaft mit »individuelle[m] Blick, der die äußere Natur auf den Betrachter bezieht, es ist die Reflexion und das Werk des Künstlers, der stellvertretend für die Gesellschaft der Natur Ordnung und Sinn gibt«, wobei diese Natur »zum Spiegelbild des inneren Widerspruchs im bürgerlichen Subjekt« wird: Zum einen »freie Natur, Land außerhalb der Mauern«, das zumeist auch »außerhalb des Produktionsbereichs liegt«, da Hinweise auf Agrarwirtschaft fehlen. Das ist gegenüber den Arbeiten etwa der Brüder von Limburg etwas ebenso Neues, wie das Fehlen »der Zeichen einer übergreifenden, inhaltlich bestimmten politischen Ordnung, welche Subjekt, Natur und Gesellschaft in einem übergreifenden System vereinen«. Daher fehlen auch die über den Dingen schwebenden allegorischen Figuren, wie zuvor etwa noch beim »Hausbuchmeister«. Zum anderen werde der »gesellschaftliche[] Bereich nicht ganz aus[ge]klammert, weil Burgen, Schlösser, Städte, feste Häuser eben noch keine romantischen Versatzstücke abgeben, sondern immer noch einem je bestimmten gesellschaftlichen Macht- und Rechtsverhältnis angehören«. Zugleich geraten Burgen, Schlösser, Städte aus dem Zentrum des Be-

191 Und es braucht ja ein Subjekt, das »gegenüber der Natur« fern, separiert von ihr in der Stadt, am Hof usw. lebt, und die äußere Natur als etwas Unabhängiges von diesem Subjekt, um dieses Unabhängige als Landschaft zu sehen, als »Teil der sichtbaren Natur«, der »von einem ästhetischen Betrachter wahrgenommen « und zu ihrem Abbild gemacht wird, um ihr Wesen und sein Verhältnis zu ihr zu ergründen, da die Natur »als ganze nicht sinnlich zu erfahren ist «. Von 〉Landschaft $<$ zu sprechen, heiße Natur bewusst zu interpretieren und zugleich sich selbst zu reflektieren. ») Ge-

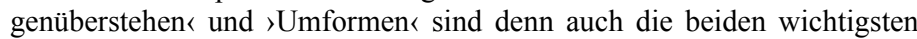
Kennzeichen der ästhetischen Naturbetrachtung und der Landschaftsmalerei. Landschaft ist nicht einfach eine Wahrnehmung der Erdoberfläche, sondern ein geistiger Akt, in dem mit Hilfe von Naturbeobachtung, Selbstreflexion und Stimmung der wahrgenommene Teil zum Abbild der ganzen Natur umgebaut und erlebt wird.« (Eberle, a.a.O., S. 8f.)

192 Muchembled: Die Erfindung des modernen Menschen, S. 132; zit. n. Sonntag, S. 142. 
trachters in den Hintergrund, sind »in erster Linie kontrastierende Kulise«. ${ }^{193}$

Der Künstler, den Eberle hier anspricht, ist Albrecht Dürer, der bereits das Subjekt »als Betrachter voraussetzt wie er es selbst ist «. ${ }^{194}$ Und dieses Subjekt erlebt in der Landschaft außerhalb der Mauern »neue Sensationen, innere wie äußere«, Voraussetzungen eines »gesteigerten Selbsterlebnisses«, in dem sich dem Individuum der »innere Widerspruch «, die Grundlage seiner Existenz, aktualisiere, in dem die Landschaftsdarstellung zum »Spiegel« dieses Widerspruchs zwischen »Natur und Gesellschaft«, »Angst und Hoffnung, Trieb und Moral« wird. ${ }^{195}$ Dieses neue Subjekt »muß sich draußen in der freien Natur einen Ort suchen«, um sich dort selbst zu finden. Hier finde es jedoch »keine eindeutigen Setzungen mehr vor«, es »wird sich seine Mitte aus der Naturbetrachtung und deren Reflexion selbst setzen müssen. Die tatsächliche, reale Örtlichkeit ist nur Anlaß und Anreger, den eigenen geistigen und inneren Standort zu ermitteln «. ${ }^{196}$ So kann die Natur der offenen Landschaft zum Ort der Bedrohung durch Sünde werden, wie in Dürers »Spaziergang« (1496/97), wo das Paar auf dem Weg zur >Unzuchtく ist, wie der Tod mit der Sanduhr hinter dem Baumstamm signalisiert. Das $>$ Laster k kann aber ebenso besiegt sein, wie es die »Madonna mit der Meerkatze« (1498/99) zeigt, wo eben diese Meerkatze als Attribut des >Lasters

193 Eberle, a.a.O., S. 156ff.

194 Ebda. Hier soll es also nicht gehen um die Frage Bierendes (Lucas Cranach d.Ä., S. 26f.) nach der »bewußte[n] oder unbewußte[n] Bewertung Dürers als das deutsche Künstlergenie des 16. Jahrhunderts«, von dem alle abhängen: Cranach wie Altdorfer etc., wie das traditionell in der Forschung betrieben werde, obwohl Dürer zu Lebzeiten kaum über Nürnberg hinaus gewürdigt worden sei (und zum >Genie` erst über deutsche >Nazarener und Romantiker >wurde ), und als Auftragnehmer von Bürgerlichen in der vom »Adel dominierten Ständegesellschaft nur eine eingeschränkte Bedeutung« gehabt habe. Dürer als Genie ist keine exklusiv deutsche Passion. So glaubt etwa auch Fedja Anzelewski, seine »Wirkung auf die zeitgenössischen Künstler, insbesondere auf die jüngeren, muß wahrhaft überwältigend gewesen sein « (Albrecht Altdorfer und das Problem der Donauschule, in: Guillaud, Jacqueline u. Maurice [Hg.]: Altdorfer und der fantastische Realismus in der deutschen Kunst. Stuttgart: Klett-Cotta 1985, S. 18). Ebensowenig soll es darum gehen, ob fürs 16. Jahrhundert noch von einem Kollektivstil die Rede sein kann (wie das mit der >Donauschule< behauptet wird), oder von Individualstilen, wie Bierende das für Cranach u.a. herausarbeiten will (ebda., S. 30ff.). Vielmehr geht es um die gesellschaftlichen Bedingungen ästhetischer Naturerfahrung.

195 Eberle, a.a.O.

196 Ebda., S. 173. 
zugleich sind, wird möglich, was der Alltag verbietet.« Dass diese Mauern nahezu in allen Landschaftsdarstellungen auftauchen, sei ein »Zeichen« für die »Selbstreflexion des Individuums«, dass sich nicht unabhängig vom sozialen Zusammenhang definiere, »auch noch nicht explizit gegen ihn ${ }^{197}{ }^{197}$

Gleichwohl seien Dürers Landschaften Zeichen einer »Abkehr von der Stadt $\ll .{ }^{198}$ Fehlen in der frühen Phase noch jegliche Hinweise auf Agrarwirtschaft, sind sie hier offenbar noch >reiner Ort frühbürgerlicher Selbstreflexion, so sind in seinem späteren graphischen Werk arbeitende Bauern, Äcker usw. sehr wohl vorhanden. Ebenso bei anderen Künstlern dieser Epoche, wie Eberle vor allem mit Hinweis auf die Bauerndarstellungen des älteren Pieter Brueghel zeigt. Auch dessen Sujet sei geprägt von dieser Stadt-Abkehr, allerdings sei es bei ihm » - zumindest in seinen Gemälden - weniger die reine Natur, die der Selbstfindung des bürgerlichen Subjekts dient, sondern eher die lebendige, scheinbar noch nicht der Geldwirtschaft unterliegende Arbeit der Landbevölkerung, deren Leben, das teils dörperisch derb, teils eben dadurch auch als freier angesehen und geschildert wird, Ausdrucksformen zeitigt, die dem des Städters als Korrektiv und Entlastung gegenübergestellt werden«. Es gebe deutliche Hinweise darauf, dass Brueghel in seiner Landschafts- und Naturauffassung geprägt sei von »kleinbürgerliche[n] Schichten«, also zünftigen Handwerkern, in Antwerpen und Brüssel, die die frühkapitalistische Expansion als Bedrohung erlebten. ${ }^{199}$

Nach den großen Pest-Wellen verdoppeln sich im Laufe des 16. Jahrhunderts in den wichtigen Handelsstädten die Einwohnerzahlen: so in London, Hamburg, Danzig, Augsburg und in Wien, Nürnberg und Regensburg. ${ }^{200}$ In Augsburg, Nürnberg und Ulm (und nicht in England), im oberdeutschen Knotenpunkt des damaligen Fernhandels mit seiner Akkumulation von Waren und Kapital (der Fuggers und Welsers etwa) die zusammen mit »der entsprechenden Bereicherungsgesinnung« die herkömmlichen »zünftisch-ständischen Vorstellungen und Praktiken von 〉Ehre und Nahrung«« längst domniniert, was häufig durch die Reichsunmittelbarkeit der Städte begünstigt wird, liegen auch die Anfänge einer offensiven Abkehr vom tradierten »Gemeinnutz«-Gedanken zugunsten des Eigennutzes. ${ }^{201}$ Zugleich zeigen sich die sozial-ökonomischen Umwälzungen, die (auch landesherrlich forcierten) Unterhöhlungen der

197 Ebda., S. $156 \mathrm{ff}$.

198 Ebda., S. $158 \mathrm{ff}$.

199 Vgl. ebda.

200 Vgl. Bauer/Matis, a.a.O., S. 130.

201 Vgl. Sonntag, a.a.O., S. 163. 
Standesordnung, die »zunehmende Auflösung« des >Hauses〈 als »Wirtschafts- und Lebenseinheit«, die »Verbreitung der Lohnarbeit durch das Verlagswesen« in wachsender Armut. In Nürnberg etwa müssen rund 30 Prozent der Bevölkerung als Arme mitversorgt werden. ${ }^{202}$ Es sind nicht von Ungefähr einige dieser oberdeutschen Städte - Nürnberg, Regensburg -, in denen wichtige Protagonisten des deutschen Humanismus wie Celtis, Dürer, Wimpheling, Sachs (der als Handwerker allerdings keine humanistische Bildung besitzt) oder Altdorfer wirken, deren Werke Indikatoren des gesellschaftlichen Umbruchs sind.

Hans Sachs, der Handwerker-Dichter ist eine Gegenfigur zu den »humanistischen Wandergelehrten« wie Celtis, Hutten oder auch Erasmus, deren »Unabhängigkeit vom Ort, von allen sozialen Ordnungen« sie zugleich aber auch finanziell in Schwierigkeiten bringt. Der HandwerkerDichter Sachs ist ortsgebunden, gebunden an die mauerumgrenzte Stadt, er produziert dezidiert pädagogisch-didaktische Texte, sein Interesse als selbsternannter Sprecher der zünftigen Gemeinschaft ist die Schaffung von Ordnung. Mit Dramen und Belehrungen soll »der Instabilität des gesellschaftlichen und moralischen Ordnungssystems dauerhaft « entgegengewirkt werden. ${ }^{203}$ Er schreibt »zu nutz und gut dem nechsten«, zur "aufferbawung guter sitten und tugent« und zur "ausreutung der laster ${ }^{204}{ }^{20}$ Er schreibt - auch unter den Bedingungen einer recht rigiden Nürnberger Zensur - Dramen und Meisterlieder, propagiert immer wieder die absolute Gewalt des Mannes im Familienverband ${ }^{205}$ (seine rigide Ehemoral hindert ihn nicht daran, die »haimlich unehelich lieb « zu besingen und eine Reihe von Zoten zu verfassen), ${ }^{206}$ er preist programmatisch angesichts des Zerfalls der tradierten Ordnung »Mediocritas, die gülden mittelmessigkeyt «, das »rechte mittel-mas«, die Einebnung der Extreme, eine »vernunftgeleitete Trieb- und Affektregelung $\aleph^{207}$ (im Sinne der protestantisch propagierten permanenten Selbst-Kontrolle), und thematisiert die Bedrohung der ständischen Gesellschaft und ihrer tradierten Werte durch die Geldwirtschaft: »Wer gelt hat, stelt man an die spicz,/Man fragt nit, sey er redlich oder frueme, $/[\ldots]$ Der irdisch got ist

202 Vgl. ebda., S. 106.

203 Klein, Dorothea: Bildung und Belehrung. Untersuchungen zum Dramenwerk des Hans Sachs. Stuttgart: Heinz 1988, S. $236 \mathrm{ff}$.

204 Zit. n. ebda., S. 245.

205 Vgl. Müller, Maria E.: Der Poet der Moralität. Untersuchungen zu Hans Sachs. Bern, Frankfurt/M, New York: Peter Lang 1985, S. 254.

206 Vgl. ebda., S. 53f.

207 Ebda., S. 213. 
icz das gelt/Auf dieser ganczen erden. $\varkappa^{208}$ Und er verfasst 1530 ein »Stadtlob«. Maria E. Müller zeigt, dass dieser »lobspruch der statt Nürnberg«, orientiert am »gemeynen nutz« und »so radikal von den städtischen Lebensbedingungen her gedacht « wie sonst nirgendwo, eine »Utopia« im Gewand einer vermeintlichen Zustandsbeschreibung ist. ${ }^{209}$ In einem allegorischen Traum gelangt der Dichter »zur holden Maienzeit« nach seinem Lustwandeln durch Wald und Flur in einen >locus ameonus $\measuredangle$. Die Stadt als 〉hortus conclusus $\measuredangle$ als »paradeiß« ihrer Bürger, ein »edel gewerb-hauß«, dessen Früchte »nutz und kurtzweil« sind, Produkte der Händler, Handwerker, Kunsthandwerker. Darüber schwebt ein wehrhafter, seine Jungen fütternder Adler: Nürnberger Wappentier und zugleich Sinnbild des »ersam weysen rat« und der »gemein«. Umringt ist er von »vier mit allerlei Attributen ausgestattete[n] Fräulein«, den Allegorien tugendhafter Herrschaftsausübung: der »weißheyt« der Politik, der »streng gerechtigkeyt« einer jeweils standesgemäßen Rechtsprechung, der »warheyt« städtischer Bündnistreue besonders dem Kaiser gegenüber und dem »frewlein schutz«, das geharnischt die Verteidigungskraft signalisiert und seinen »stehelen hamer« einsetzt, wenn friedliche Mittel versagen. ${ }^{210}$

Zehn Jahre später beklagt Sachs dann, wie wenig diese >Harmonie mit der Nürnberger Realtität zu tun hat. Im replizierenden Spruchgedicht »Von dem teuffel, dem die hell will zu eng werden« erscheine, so Müller, »Nürnberg geradezu als Sündenbabel, das durch die völlige Abwesenheit der ihm zuvor zugesprochenen Tugenden gekennzeichnet ist ${ }^{211}{ }^{11}$ Hier trifft der Wanderer nachts im Wald plötzlich auf den Teufel, der »zur Anwerbung kunstreicher Werkleute zum Ausbau seines Reiches« unterwegs ist. Der Wanderer kann ihn nicht daran hindern, denn parallel zu Sodom und Gomorra findet er keine »zehn fromme[n] und tugendhafte[n] Nürnberger Seelen«, die das gottgefällige Leben beeiden können, sind die Bürger doch inzwischen bereit, »eygnem nutz« zustre-

208 Ebda., S. 51.

209 Vgl. ebda., S. 148. »Der aktuelle Anlaß« der Entstehung des Textes, so

Müller weiter, „Sachs' Versuch, sich nach dem strengen Verweis [der zensierenden städtischen Obrigkeit, M. T.] von 1527 erneut das Wohlwollen des Rats zu sichern, ist bisher sicher überbewertet worden, und letztlich bekennen die Textinterpretationen dies ein: Sie verweisen auf eine eigenartige Mischung von Realität und Idealtopographie, als reale Stadt und ideales Gemeinwesen zugleich. Diese Ambivalenz betrifft den Gegenstand insgesamt. Der Lobpreis des Seienden ist die Darstellung dessen, was sein soll«.

210 Vgl. ebda.

211 Ebda., S. 151. 
bend selbst unsittliche Mittel anzuwenden. ${ }^{212}$ In den »Clagspruech der stat Nürenberg ob der unpillich schweren pelegrung margraff Albrechtz anno 1552« schließlich trifft der Wanderer inzwischen als »alt« erneut im Mai auf die Lichtung im Wald (wie 1530 im »lobspruch«), am Bach auf ein dort melancholisch sitzendes »herrlich, scheinparliches weib«, das »frewlein« Nürnberg, einsam und verlassen, hilf- und hoffnungslos, verraten an die Feinde gar von »Teilen der Bürgerschaft $«$, hofft nur noch auf »ain klaine sumb/Meiner kinder ghorsam und frumb/Die helffen mir noch halten schuez/Und hanthaben gemainen nuetz«. ${ }^{213}$ So sitzt >frewlein N Nürnberg allein gelassen am Bach. Die anderen, die vier aktiven allegorischen >frewlein " "weisheyt«, »gerechtigkeyt«, "warheyt« und »schutz« aber sind anscheinend Betrügerinnen.

Bei Sachs, dessen »restaurative Utopie« einer »topographisch wie moralisch [...] abgeschlossene[n], überschaubare[n] Welt« entsteht, indem er ein Idealbild abstraktiv von der Gegenwart abzieht »und in die Vergangenheit reprojiziert bzw. im Lobspruch als existent behauptet«, der eine mittelalterliche Stadtordnung restaurieren will, aber so, dass die »in ihr angelegten Widersprüche« - hervorgerufen von den Einzelnen -, »vom Ansatz her unmöglich« gemacht werden, ${ }^{214}$ bei Sachs also, dem sesshaften zünftigen Stadtbürger und zugleich literarischen >Entdecker der Landschaft (allerdings der näheren Umgebung) ist die Stadt allegorische Frau, damit eigentlich positives Gegenstück zu >Frau Welt $\iota$, der lasterhaften, mit Evas Erbsünde korrelierenden. Die Stadt (Nürnberg) als Frau - das macht ihre positive Erscheinung (zumindest in der Utopie) aus - ist als züchtiges »frewlein` der zukünftig nährende, mütterliche Leib innerhalb der Mauern des >hortus conclusus`, sie ist eine abhängige Frau, die des Schutzes bedarf, die den ihr zugewiesenen Platz im >Haus des >pater familias` einnimmt (womit sie der von Sachs selbstverständlich verlangten untergeordneten, reproduktiven Rolle realer Frauen entspricht). Dieser > weibliche Leib $<$ ist eben nicht der lockende des »abenthewer[s]« draußen vor der Mauer, der des »herrlich weib«, der Frau Welt, die eigentlich als Braut Gottes erwählt, begierig und eigennützig ins Jammertal verfällt. ${ }^{215}$

212 Vgl. ebda., S. 151f.

213 Ebda., S. 155ff.

214 Vgl. ebda., S. 153.

215 Vgl. ebda. 


\section{Die Hure Babylon}

Die Stadt als züchtiges Fräulein und so als Gegenbild zur gefallenen Frau Welt (natura lapsa), der abtrünnigen Braut. Was bei Sachs so eindeutig als Gegenüberstellung zweier abhängiger weiblicher Figuren erscheint (und jeweils gängigen Mustern der weiblichen Allegorisierung entspricht), erscheint in der Sicht des deutschen Humanismus auch anders akzentuiert. Die >Germania ist weibliche Figurine, der Wald aber personifiziert männliche Ordnung und Tugenden. Er ist nicht mehr >draußen<, sondern >innen

Zur männlichen Wildnis, die nun zum geordnet-heroischen Wald mutiert ist, passt der »Panzer gegen die Frau« bzw. seine Entstehung in »der frühbürgerlichen Revolution etwa zwischen 1450 und $1550 \ll{ }^{216}$ Und wo die Ex->Wildnis` heroisch-männlich-tugendhaft gedacht und entworfen wird, gerät das Gegenteil unweigerlich zur weiblich konnotierten Sündhaftigkeit. Wo also die >Landschaft schon vor >Urzeiten >Wildnis gilt, zeitgenössich nun die Grenzen eines beherrschten Lebens repräsentiert, da erscheint die feminisierte Stadt - in der »Imaginationsgeschichte der Stadt $~^{217}$ gehört deren $>$ Weiblichkeit« seit relativ langer Zeit zum festen Programm, zunächst mythisch, dann allegorisch als Abhängige: tugendhaft oder abtrünnig, Tochter, Braut oder Ehebrecherin, Hure, geschändet oder lasterhaft und dekadent ${ }^{218}-$ in ihrer pejorativen Funktion womöglich als potentieller Widerpart. Und so, wie erst der Bürger die >Landschaft< überhaupt entdecken kann (von der Stadt aus also - und die Humanisten sind in den Städten), wird diese >Landschaft zum Ort der (imaginären) Stadtflucht?

Luxuria und »Frau Venus« beherrschen die Welt (auch) für den deutschen Humanismus. ${ }^{219}$ Das betrifft aber programmatisch nicht die eigenen Städte, die erscheinen ja als beherrschende Bestandteile der Kulturlandschaft. Der Widerpart, die `Hure Babylon`, ist Rom. Trotz

216 Theweleit: Männerphantasien 1, S. 388.

217 Weigel, Sigrid: Topographien der Geschlechter, S. 156.

218 Vgl. Weigel, ebda., S. 157ff., vgl. Häusl, Maria: Bilder der Not. Weiblichkeits- und Geschlechtermetaphorik im Buch Jeremia. Freiburg/Br u.a.: Herder 2003, Wischnowsky, Marc: Tochter Zion. Aufnahme und Überwindung der Stadtklage in den Prophetenschriften des Alten Testaments. Neukirchen-Vluyn: Neukirchener Verlag 2001, Lorenz, Maren: Leibhaftige Geschichte, S. 110. Um im Zusammenhang des deutschen Humanismus zu bleiben, behandele ich an dieser Stelle zunächst nur dessen Feminisierung Roms. Ausführlicher beschäftige ich mich mit diesem Aspekt und seinen historischen Verläufen im Exkurs II.

219 Vgl. Riedel: Antikerezeption in der deutschen Literatur, S. 42f. 
vielfältiger Klagen über >verkehrte Welt « auch in »Teutschland«, trotz des Rechts von Frauen in hoch- und spätmittelalterlichen (auch deutschen) Städten, nach einer Frist von einem Jahr und einem Tag »frei« von grundherrlichen Ansprüchen zu sein, das Bürgerrecht (wenn sie denn die finanziellen Mittel aufbringen) zu erwerben (wobei politische Ämter aber verwehrt bleiben), privatrechtlicher Gleichberechtigung (allerdings überwiegend nicht vor Gericht), des Rechts auf eigenständige Erwerbstätigkeit - Möglichkeiten, die mit der bürgerlichen Konsolidierung am Ende des Mittelalters negiert werden: Allegorisch werden im deutschen Humanismus die >bösen Frauen` per Stadtlob-Utopie offenbar innerhalb der eigenen "patria« neutralisiert und nach Rom verschoben. $^{220}$

In den literarischen »teleologische[n] Reise[n]« von Asketen und Pilgern der frühen Neuzeit ist die Wildnis Sinnbild der »Gegnerschaft zur Welt«, Ort der »geistlichen Anfechtungen«, der Versuchungen und Prüfungen, nicht aber (oder fast nie) die Stadt. ${ }^{221}$ Hier erscheint der $» l o-$ cus terribilis«, die Wildnis als »Realität der diesseitigen« Welt, der »locus amoenus«, die Idylle als »Schatten« einer »zukünftigen Welt«. ${ }^{222}$ Was der deutsche Humanismus offenbar in eine vorgebliche Gegenwart verlegt. »Die frühneuzeitliche Stadt ist mit religiösem Vokabular ohne weiteres, möglicherweise erschöpfend beschreibbar: Sie hat Heilscharakter, sie ist Heilsinstitut [...], in ihr finden sich der bürgerliche Reformator und der reformierte Bürger, Martin Luther und Lukas Cranach.« Es leben erst ca. 10 Prozent der Menschen in rund 3000 vergleichsweise kleinen Städten im deutschen Raum. Aber, so Stephan Wyss, es beginnt der »masslose[] Prozess städtischen Wachstums«, der den Stadt-LandGegensatz sukzessiv aufhebt, den Gegensatz von Wildnis und »Heilsinstitut « - so lasse Cranach seinen »Hieronymus« aus der Wildnis ins »Gehäuse« ziehen und »alles, was den ersten noch umgeben hatte«, mit hineinnehmen. Die Stadt hat Brücken, Sinnbild des \Zivilisationsprozesses , über die/den alles »mit Heilsnotwendigkeit in die Stadt« führe. Alles ist nun innen: »Domestikation des Raumes $«{ }^{223}$

220 Überhaupt muss bei derartigen »Denkbildern« (Weigel: Topographie der Geschlechter, S. 156) grundsätzlich zwischen Frauen(-alltag) und dem (schon historisch divergierenden) diskursiven Frauenbild unterschieden werden. Zwar bestehen hier vielfältige Wechselwirkungen, aber nicht in jedem Fall Spiegelungen (Häusl, Maria: Bilder der Not, S. 4).

221 Vgl. Schilken, Dörthe: Die teleologische Reise. Von der christlichen Pilgerallegorie zu den Gegenwelten der Fantasyliteratur. Würzburg: Königshausen \& Neumann 2002, S. $62 \mathrm{f}$.

222 Ebda., S. 58.

223 Wyss, Stephan, a.a.O., S. $182 \mathrm{ff}$. 
Abb. 8: Albrecht Dürer: Die Einlochung Satans und die Weisung der Hl. Stadt (Apk. 20, 1 3; 21, 1-2 und 9-14), 1496-1498

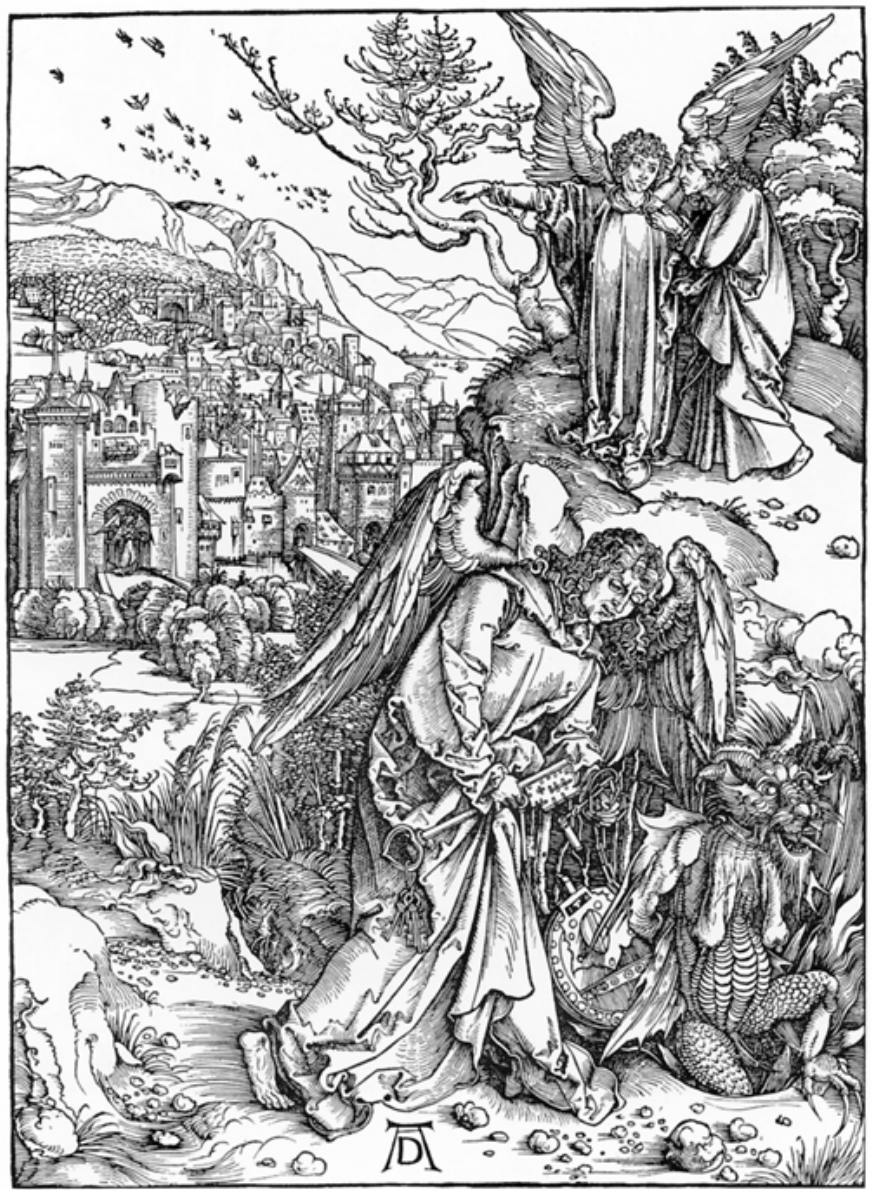

Die Wahrnehmung der (Groß-)Stadt als Dschungel, Wildnis, feminisierte Fremde in scharfem Gegensatz zur geordneten, heimatlichen Landschaft - jetzt umgekehrter Stadt-Land-Gegensatz - setzt systematisch erst im späten 19. Jahrhundert ein. Allerdings gibt es hier Vorläufer. Albrecht Dürer lässt die Wildnis in die Stadt eindringen, im Schlussbild seiner »Johannes-Apokalypse« (1496/98). Das Heilsinstitut kann auch zugrunde gerichtet sein. Diese Stadt - wahrlich kein >Jerusalem $<-$

»ist eine ganz und gar irdische, in kunterbuntem Gewirr aus mittelalterlicher Kirche, Häusern und Türmen gewürfelte Stadt. Weit entfernt, in symmetri- 
scher Vollendung dazustehen, erscheint sie im Gegenteil von Zerstörung und lange währendem Verfall gezeichnet. Ihre Ausfallstraßen enden im Dickicht, in ihrem Inneren wuchert, durch gewaltige Mauerbreschen eindringend, der Wald «. ${ }^{224}$

Die leblose, aber von Engeln bewachte Stadt - die Stadt versinnbildlicht nach gängiger Tradition auch den Staat - steht für das Heilige Römische Reich Deutscher Nation in seiner »Verwahrlosung«. Für dieses »damalige Gefühl« sei »Sebastian Brants langatmige Klage im 99. Kapitel seines Narrenschyff « von 1494 ein »beredtes Zeugnis «. ${ }^{225}$ Dürer, der 1521 »den Papst als Antichrist und den römischen Stuhl als der >höllen porten apostrophierte « und Luther als »Nachfolger« des »wahren christlichen Glaubens « bezeichnet, sich selbst $1524 \mathrm{zu}$ den »Ketzern« zählt, ${ }^{226}$ der sich 1508 zusammen mit Celtis ins Zentrum des Gemäldes »Die Marter der Zehntausend « plaziert, um die notwendige Entscheidung zwischen den Tätern - hier dem Bischof und seinem Gefolge - und den Märtyrern zu dokumentieren, ${ }^{227}$ lässt auch im Schlussbild der Apokalypse keinen Zweifel über die Urheberschaft der Reichs-Verlotterung. Dürers für die Johannesapokalypse einmalige Kombination der »Einlochung Satans« (hier kein siebenköpfiges Monster, sondern »ein echter, borstiger, hängebusiger Teufel«) mit der Weisung des Engels an Johannes, in die Stadt (Jerusalem) zu gehen, impliziert, dass nur über den Weg der Einlochung des Antichristen, der Abschaffung des Papstes die von Engeln geschützte Mission des Staats-Wiederaufbaus gelingen könne. $^{228}$

Das Papsttum stellt Dürer im Kupferstich »Das Monsterschwein« (1496) als »Monstermacht« dar, als doppelzüngiges Doppelschwein, Symbol einer »erd- und himmelsbezogene[n] schweinische[n] Herr-

224 Perrig, Alexander: Albrecht Dürer oder: Die Heimlichkeit der deutschen Ketzerei, S. 23. Abweichend von der (bis dahin) gängigen Dürer-Forschung zeigt Perrig, dass Dürers Apokalypse-Holzschnitte keine getreuen Illustrationen des biblischen Textes sind, sie weichen signifikant davon ab, sind Klage gegen die Papstkirche, »implizierte[] Häresien« (ebda., S. 28).

225 Ebda. u. S. 109, Anm. 135.

226 Ebda., S. VII.

227 Vgl. ebda., S. 53f., S. 178, Abb. 26.

228 Vgl. ebda., S. 23. Als Kaiser Maximilian I. 1510 Jakob Wimpheling beauftragt, ein Gutachten über die kurialen Missstände und Möglichkeiten ihrer Abschaffung zu verfassen, reagiert Dürer u.a. mit einer Neuauflage seiner »Apokalypse«. Dürer muss das »vorsichtige« Gutachten (gedruckt erst 1517) nicht inhaltlich kennen, schreibt Perrig. Es zähle das Signal; vgl. ebda., S. 55 
schaft « und »Ausgeburt der Hölle «. ${ }^{229}$ Das Doppelmonster steht für die geistliche und zugleich weltliche Herrschaft des Pontifex. Schon seit dem Hochmittelalter, so Perrig, kursieren (bis 1519 jedoch heimlich) Thesen, die allein dem Kaiser weltliche Herrschaft zubilligen, ihn zugleich als »rechtmäßige[n] Stellvertreter auf Erden« sehen, den weltliche Herrschaft sich anmaßenden Papst als »Monstrum « und somit »des Teufels«, zum Christusverräter aus Machtinteresse, Schuldigem am Tod Rechtgläubiger und somit zum »Antichristen« erklären. Aber auch dem Kaiser werde eine Mitschuld gegeben, da er seine Interessen und Pflichten (und die seines Volkes) dem Klerus opfere. Eine Mitschuld wird seit ca. 1490 häufig auch den »deutschen Großkaufleuten« vorgeworfen, die den Gemeinnutz missachtend Profite und sich so - wie schon Kaiser und Adel - »zu Kunden der >Babylonischen Hure«« machten. ${ }^{230}$

Monster und Hure::231 Der »Papstesel«, diese 1496 in Rom aus dem Tiber angeschwemmte antike Skulptur, wird - wie 26 Jahre später die

229 Dürer wird durch einen Holzschnitt Brants zur Geburt einer »siamesischen Sau « in Lanser inspiriert. Brant informiert damit den Kaiser per Flugblatt über die »göttliche Warnung vor einer durch >säuische Menschen • bewirkten Spaltung des Reiches«, wie es dies Prodigium zeige. Vgl. ebda., S. 36f. u. S. 174f., Abb. 22, 23.

230 Ebda., S. 28f. Vgl. Delumeau: Angst im Abendland. Die Geschichte kollektiver Ängste im Europa des 14. bis 18. Jahrhunderts. 2 Bände. Reinbek: Rowohlt 1985 (Paris 1978), S. 330ff. Als Beispiel für die Flut von Publikationen Ulrich von Huttens sei hier sein 1578 in Straßburg gedrucktes Pamphlet »Clag und vormanung gegen dem übermässigen vnchristlichen gewalt des Bapsts zum Rom vnd der ungeistlichen geistlichen durch Herren Vlrichen von Hutten Poeten vnd Orator der gantzen Christenheit vnd zuuoran dem vatterland Teutscher Nation zu nutz vnd gut von wegen gemeiner beschwernu $ß$ vnd auch seiner eigen notturft in Reymens weyß beschrieben LACTA EST ALEA Ich habs gewagt« genannt. Vgl. Gülpen, Ilonka van: Der deutsche Humanismus und die frühe Reformations-Propaganda 1520-1526. Das Lutherporträt im Dienst der Bildpublizistik. Hildesheim u.a.: Olms 2002, S. 248.

231 Gemäß dieser Auffassungen erscheint der Papst auch in Dürers »Apokalypse« gewissermaßen als Hure. Im Bild der apokalyptischen Reiter bilde eine reale Dirne »das Bindeglied zwischen Obrigkeit und Volk«. In der $»$ Racheaktion der vier Windengel« nehme als vorderster Teil des obrigkeitlichen »moralische[n] Abschaum[s]« ein Papst exakt die Kriechhaltung dieser Dirne an. »Ihm gilt der zornigste Hieb.« Perrig, a.a.O., S. 11. u. S. 158/162, Abb. 6/10. Selbstverständlich spricht auch Luther in dieser Weise vom Papsttum: »Es meynen wol etliche, man solle nu auffhören, das Bapsttum und geystlichen stand zu spotten [...]. Mit denen halt ichs nicht, sonder wie die Apocalypsis sagt: Man muß der roten huren [...] vol und wol eynschenken usw. Drumb, liebe freunde, last uns auch auffs new widder anfahren, schreiben, tichten, singen, malen und zeygen das edle 
Kalbs->Missgeburt in Sachsen - zum warnenden Zeichen gegen die Übel der römischen Kirche. Hierbei sind offenbar bei den deutschen Anti-Papisten wie Luther, Melanchton et al. die eschatologischen Ängste besonders groß gewesen. ${ }^{232}$ Im von beiden 1523 publizierten und populären Text zu Holzschnitten aus der Cranach-Werkstatt wird nach seit 1500 gängiger Praxis, derartige Prodegien als eschatologische Zeichen für »die Korruption der Papstkirche« zu lesen, ${ }^{233}$ der »scheusslich, häßlich, grewlich« Anblick, der die »ganze welt sich dafür entsetze und erzittern [lassen] muß«, zum Signum und Beweis des biblisch prophezeiten Antichristen: des Papstes, ebenso der Kleriker, Mönche, »die durch yhr fleyschlich lere den glauben vertilget und die wellt zu kalbfleisch gemacht haben ${ }^{234}$ So wird das »Mönchskalb« zur »göttliche[n] Mißfallensäußerung am Mönchsstand «. ${ }^{235}$

Der »Papstesel« wird bei seinem Auftauchen allgemein als »Zeichen göttlichen Zorns«, 1497/98 aber schon als Zeichen des »lasterhaften« Alexander VI., von Waldensern und Hussiten als göttliche Papstkritik gesehen. ${ }^{236}$ Der einzelne Körper als Analogon zum Staatskörper: So sieht auch Melanchton im Leib des Monsters den Leib der Kirche und seine Entartung. Der Widersinn eines menschlichen Oberhaupts der christlichen Gemeinde sei durch den Eselskopf auf dem menschlichen Leib sinnbildlich. Die rechte Hand als Elefantenfuß zeige die römische Unterdrückung der Seelen, die menschliche Linke den weltlichen Machtanspruch. Der rechte Ochsenfuß stehe für die geistliche Unterdrückung durch Papstdiener, der linke Greifenfuß für die Kanoniker. Fischschuppen bedecken die Figur an Hals, Armen und Beinen, symbolisieren nach Melanchton das »Meer Welt«, also die weltlichen Menschen, besonders Herrscher, die am Papst hängen (müssen), auch wenn sie ihn nicht unterstützen. Am Hintern hat der >Esel einen Altmännerkopf, was das »nahende Ende« zeige, »da >das Angesicht kommen >der rucke oder hinderst«« dies ausdrücke. Ebenso der »daraus hervor-

götzen geschlecht, wie sie verdient und wird sind. Unselig sey, der hier faul ist.« Zit. n. Gülpen: Der deutsche Humanismus, S. 324.

232 Vgl. Delumeau, a.a.O., S. 336ff.

233 Vgl. Ewinkel, Irene: De monstris, S. 39.

234 Zit. n. Gülpen, a.a.O., S. 325. Zu den Monstrositäten zählt für die AntiPapisten bekanntlich auch die katholische Eucharistie: als Menschenfresserei. In Hans Sachs' Meisterlied »Die pfaffen frassen den doten pauren« etwa wird diesem Bauern ein christliches Begräbnis verweigert. Seine Leiche wird den Klerikern vielmehr als schmackhafte Mahlzeiten serviert, damit der Bauer so »ins gweicht pfaffen flaisch pegraben« werde; vgl. Müller, Maria E., a.a.O., S. 54.

235 Ewinkel, a.a.O., S. 40.

236 Vgl. ebda. 
gehende Drache« als »letztes Aufbäumen« des Episkopats. Bezüglich dieser männlichen Teile verweist Ewinkel auf Achim Aurnhammers These, dass insbesondere die Androgynie »als Bild der sexuellen Perversion« eine eminente Rolle »in der antipäpstlichen Polemik« spiele. Die »Mannweiblichkeit« des »Papstesels« ergibt sich daraus, dass sein Rumpf durch primäre und sekundäre Geschlechtsmerkmale ausgewiesen der einer Frau ist. „Der weibliche Bauch und die Brust bildeten den Körper des Papsttums ab, d.h. jene Kardinäle, Bischöfe, Pfaffen, Mönche etc., die ihr Leben ganz den sinnlichen Genüssen verschrieben. « ${ }^{237}$ Den Päpsten, den Klerikern wird also vorgeworfen, ıwie die Weiber $z u$ sein, triebgeleitet und unersättlich; was der Eselskopf noch erweitert und verstärkt, denn der Esel gilt schon in der Antike als Sinnbild der »Geilheit «, als »Tier des Priapos und Dionysos « ${ }^{238}$

Die Hure Babylon, die »grosse gemeyne sünderin«, die »da sitzt auff viel wassern«, deren Reittier mit den sieben Köpfen also offenbar eine lebendige Brücke über den Tiber bildet, ist Rom. »Die siben haupt sind siben berg auff den das weib sitzet« - die zeitgenössische Domitianische Siebenhügelstadt in Johannestext, bei Dürer ebenso zeitgenössisch das päpstliche Rom. ${ }^{239}$ Die Hure ist gewandet in prächtige Venezianische Kleider und trägt einen Nürnberger Agleybecher, was »dem deutschen Betrachter als Inbegriff raffinierter Verführungskunst und Genußsucht erscheinen « muss. ${ }^{240}$ Zugleich ist in christlicher Auffassung die Akelei Attribut von Maria, Jesus, heiliger Geist ${ }^{241}$ - wobei hier der Becher Hohlheit und bloßen »äußerlichen Schein« nahelegt. ${ }^{242}$ Die »Schwanenhalsfauna « ihres Tiers stattet Dürer mit Gestiken und Mimiken aus, »die unweigerlich höfisches Milieu signalisieren« und »Sinnbild zeitgenössischen kurialen Getriebes« sind. Da gibt es »das keuchende Ohrenblasen gegenüber dem bedächtig zuhörenden Oberziegenbock, das katzenhafte Schleichen um die Hälse der Höhergestellten herum, das aggressiv bürokratische Fauchen, das bedenkliche Halsverdrehen und aus dem

237 Ebda., S. 41. Vgl. Abb. 63, S. 351. Mönchskalb und Papstesel seien in der Folge im konfessionellen Streit von beiden Seiten lange rezipiert und je als »Warnung vor der Reformation« oder Endzeichen des Episkopats gedeutet worden (ebda., S. 42).

238 Seligmann, Siegfried: Die magischen Heil- und Schutzmittel aus der belebten Natur. Bd. 2. Das Tierreich, S. 64.

239 Vgl. Perrig, a.a.O., S. 20. u. S. 168, Abb. 16: »Die Kaufleute vor der Babylonischen Hure, der Fall von Babylon und der Ansturm des Heeres von Ritter >Treu und Wahr «

240 Ebda.

241 Vgl. Beuchert, Marianne: Symbolik der Pflanzen, S. 15.

242 Vgl. Perrig, a.a.O., S. 105, Anm. 122. 
Mundwinkel Reden und das verständnisvolle Augenzwinkern und Schlucken $\ll .{ }^{243}$ Audienz gewährt dies »Kurienmonster« einem vor ihm knieenden dürren Dominikaner (einem Vertreter der »Wachhunde des Herrn« bzw. Papstes, seit 1231 mit der Inquisition betraut ${ }^{244}$ ) und vor allem wohlhabenden Bürgern. Offenbar Vertreter vor allem deutscher Großkaufleute, deren intensive Blickkontakte mit den Monsterköpfen als Feilschen von Handelspartnern erscheint. Also als »Sinnbild jener Komplizenschaft von Kurie und Kapital, die zu den Machtpfeilern des damaligen Papsttums gehörte «. ${ }^{245}$ Anders, als in den vorhergehenden Bildern der »Apokalypse« sind nun die Stunden des Tiers gezählt, sind Engel am Himmel und das »getreue und wahre Heer», das bei Dürer aus den irdischen Märtyrern gebildet wird. Und im Hintergrund brennt schon die Stadt. ${ }^{246}$ Ihr Fall ist Voraussetzung zum Wiederaufbau einer anderen.

Die Art von Wildnis, die Dürer den Verfall dieser `Stadt`, des Reichs markieren lässt, hat nichts mit Celtis' Herkynischem Wald gemein - sie ist monströse, gefallene Natur, Produkt der >Hureく. Wobei diese >Hurerei` doppeldeutig erscheint. Die frühkapitalistischen deutschen Großkaufleute - aber auch Kaiser und Adel - treiben Handel mit der römischen >Hureく. Sie >huren` selbst. Zwar führen Fall und Austreibung der »Hure Babylon« in den eschatologischen Schlachten zum Entstehen des »neuen Jerusalem«, der >heiligen`, >reinen`, >jungfräulichen` Stadt (Apk. 17-21). Im AT aber ist das alte >Jerusalem Ehebruchs, der >Buhlschaft $<$ schuldig. Da zürnt >JHWH«: statt »dienen« zu wollen, »legst du dich auf jedem ragenden Hügel und unter jedem grünen Baume hin, um zu buhlen. Und ich hatte dich doch als Edelrebe gepflanzt, als ganz echten Steckling. Wie hast du dich zum Wildling verwandelt, du entarteter Weinstock?« Eine »Kamelstute« sei sie, die brünstig in die Wüste läuft, hinter den »Baalim« her (Jer. 2,20ff.). Hosea 2 zeigt die Strafe (wenn auch anscheinend für Samaria bzw. deren Personifikation), vollstreckbar durch den `Ehemann $($ hier $>J H W H ८)$, der sie »nackt entkleide«, ihr die »Scham« entblöße und »ihre Torheit aufdecke vor den Augen ihrer Liebhaber«, den ১Baalim`. Er werde sie »wie zur Wüste« machen, und »sie sterben lasse[n] an Durst«, »verwüsten ihren Weinstock und ihren Feigenbaum«, die sie glaubt, von ihren Liebhabern erhalten zu haben. »Und ich mache sie zum Gebüsch und die Tiere des Feldes werden sie fressen. $«{ }^{247}$ Wegen ihrer Zügellosigkeit $\iota$, der »leicht-

243 Ebda., S. 20.

244 Vgl. ebda., S. 4.

245 Ebda., S. 21.

246 Vgl. ebda. S. $21 \mathrm{f}$.

247 Zit. n. Wischnowsky, Marc: Tochter Zion, S. 104. 
fertige[n] `Geilheit«« der an ihren Mann gebundenen Ehefrau, entzieht dieser ihr seine eigentliche Pflicht als Versorger. ${ }^{248}$ Später, in »nachexilischer Zeit« dann wandelt sich das Bild völlig. »Jerusalems Schuld« ist mit dem »Strafdienst[] in Babel [...] abgegolten« und lasse sich »neu als Ort der endzeitlichen Theophanie Jahwes in Anspruch nehmen «. ${ }^{249}$ Nun heißt es: »Komm zurück, Jungfrau Israel!«, wird - schon wegen der vorher >endgültig gescheiterten Eheく - eine völlig »neue Metaphorik notwendig«. ${ }^{250}$

Ein Perspektivenwechsel, der so vielleicht auch in Dürers Apokalypse(-Schlussbild) steckt. Zumal der zeitgenössischen deutschen TacitusRezeption die Art zu strafen bekannt vorkommen dürfte. Dessen »Germania« beschreibt für die »Germanen« etwas ganz Ähnliches. Auch hier vollstrecke der Mann selbst die Strafe an seiner >ehebrecherischen ₹rau, schneide ihr das Haar ab, entblöße sie öffentlich und treibe sie per Peitsche durchs Dorf. Die so Stigmatisierte werde keinen weiteren Ernährer mehr finden. ${ }^{251}$ Auch bei Dürer geht es um 〉Buhlschaft`, 〉Entartung〈, $>$ Verwilderung « des eigenen >Reichs $\prec$. Dürers wieder aufzubauende Stadt ist >Wüste $<$ : sowohl leblos, als auch von der Ödnis des wilden Waldes verwüstet. Sie ist großflächig von ihren Mauern entblößt. Auch hier soll völlig neu eine >reine Jungfrau< entstehen.

Durch die explizite Nennung >JHWHs` als Sprecher in Hosea 2 wird die geschlechtliche Metaphorik »aufgelöst und in Richtung kultischem Abfall vereindeutigt «, werden die »Liebhaber« zu »Baalim«. Es geht also um >Götzendienstく bzw. »falsch verstandenen Jahwedienst «, ${ }^{252}$ um »kultische Perversion «. ${ }^{253}$ Das entspricht exakt dem Vorwurf der deutschen Humanisten, der >Ketzer` und >Reformatoren` gegen die Papstkirche.

Offenbar gibt es hier zwei Ebenen in der Argumentation des deutschen Humanismus. Einerseits die zu beendende $>$ Buhlschaft $\prec$ des $>\mathrm{Hl}$. Römischen Reichs Dt. Nation`, andererseits die positive Schilderung Deutschlands, um es »als den rechtmäßigen Nachfolger des römischen Reichs nachzuweisen «. ${ }^{254}$ Hier, in der >Germania gibt es die wuchernde Wildnis der Unzucht nicht. Alles ist geordnet nach Maß und Zahl, schon wegen der damaligen allegorischen, literarischen, utopischen Stadtkonzepte. Hierbei berühren sich mittelalterlich die »Bildgeschichte der Stadt

248 Vgl. ebda., S. 107.

249 Ebda., S. 270.

250 Häusl, Maria: Bilder der Not, S. 353.

251 Vgl. Tacitus: Germania; übertr. v. Allan A. Lund, S. 85.

252 Wischnowsky, a.a.O., S. 109.

253 Ebda., S. 111.

254 Müller, Gernot Michael, a.a.O., S. 390. 
und des Weiblichen«, beide können eine allegorische Funktion übernehmen, liegen so »als figürliche Leitmotive nebeneinander«. 〉Ecclesia verkörpert die Kirche und die mauerumwehrte Stadt das >Gottes reich<. Die positive weibliche Personifizierung funktioniert per »Ent sexualisierung ihrer Bilder« zu »Reinheit und Jungfräulichkeit «. ${ }^{255}$ Das betrifft ebenfalls noch die Renaissance. »Die Stadt ist ein großes Kloster«, sagt daher Erasmus. ${ }^{256}$ Asketen aber sind ebenso wie Kaufleute und Mathematiker

»Agenten der Zahl, handeln im Auftrag, ihre Herrschaft zu errichten über den Markt, über die Wissenschaft, über den Leib. Gemeinsam ist allen die Zielsetzung, unterschieden sind nur die zu besetzenden, die $\mathrm{zu}$ beherrschenden Objekte, weshalb denn der eine ohne viel Umstände das Geschäft des andern übernehmen kann, wenn er nicht ohnehin zwei schon oder gar alle drei unter einen Hut gebracht hat «. ${ }^{257}$

Der ideale Ort, das `Gehäuse` für dieses »Bezahlen, Zählen, Mässigen $\aleph^{258}$ ist die Stadt:

»Die Zahl ist Herrschaft; wen wundert es, dass der höchste Gott mit der Zahl gekennzeichnet wird, mit der Zahl schlechthin, denn die Drei ist das Eine wie das Viele, die Einheit der unteilbaren Vielheit. Das Dogma der Drei oder der Eins, das die Una sancta gestiftet hatte, erlebt im europäischen 15. Jahrhundert eine spektakuläre Neuauflage, indem über Stadt und Land, über Natur und Ökonomie, über den gesamten Erdkreis die Zahl als einzige Herrschaft eingesetzt und verehrt wird, die Zahl, in der endlich >alle eins s sind, wie der Wunsch im alten Zentrum der Welt, im Rund der Peterskuppel sich äußerte: >Ut unum sint! $<$ In der Zahl findet die wahre Orthodoxie und Ökumene der ganzen Menschheit ihr Ziel, die Objektivität von Naturwissenschaft und Kapital markiert das Ende aller Religionskriege. Als einzige Ketzerei wird das Verhalten übrig bleiben, auf das man nicht zählen kann, das man nicht messen kann, weil es verrückt ist. ${ }^{259}$

Drei und Eins ist Vier. Die Zahl Vier erscheint als Zeichen von Herrschaft und Perfektion. Das gilt für den menschlichen und entsprechend den politischen Körper. Seit dem 15. Jahrhundert ist in Deutschland die »Quaternionentheorie« verbreitet. So in den Rechtstraktaten Peters von Andlau und Felix Hemmerlins, ebenso in Hartmann Schedels Weltchro-

255 Weigel: Topographien, S. 162.

256 Zit. n. ebda.

257 Wyss, Stephan: AskeSe, S. 188.

258 Ebda.

259 Ebda., S. 184. 
nik etc. ${ }^{260}$ Demnach ist »das Reich auf je vier Vertretern von insgesamt zehn Reichsständen, sieben adligen und drei bürgerlich-bäuerlichen, gebaut«. Politisch reale Relevanz hat die Theorie nach Müller aber nicht gehabt, vielmehr symbolische. Sie entstamme der mittelalterlichen Zahlensymbolik - die Vier als Zahl des Kosmos«, vor allem als »Abfolge der vier Weltreiche. Bei Schedel erhält letzteres eminente Bedeutung, er bringt die Quaternionen »mit der Translatio imperii in Verbindung«. Hier werden »die einzelnen Vierergruppen« (erweitert um sieben Kurfürsten zur »Erweiterung der Reichspräsenz«), »nur noch deutsche Vertreter« zu Säulen des Imperiums, was die zeitgenössisch wachsende Betonung der »deutschen Nation « des Reiches zeige. ${ }^{261}$

Körperbild und -kunst der Renaissance entstammen »dem Geist der Geometrie«, der »ideale Körper ist konstruiert als »Konfiguration« seine Teile »im Verhältnis absoluter Harmonie«. Da Vinci und Dürer studieren »mit gleichem Eifer« die »vitruvianische Figur«, wie auch Sebastian Serlio. ${ }^{262}$ Vitruvs Abhandlung über Symmetrie bei Menschen und Tempeln läuft auf eine wechselseitige Entsprechung hinaus. Da die Natur die Gliedmaßen des Menschen passend zum Gesamtkörper proportioniert habe, habe der Architekt dem nachzueifern, »mittels der Beziehung von Kreis und Quadrat«. Nach Vitruv ist der Körper »ein Quadrat einem Kreis eingeschrieben«, Arme und Beine sind verbunden durch den Nabel (die `Quelle des Lebens $`$ ), in dem sich auch die verlängerten geraden Linien der Gliedmaßen treffen, während Finger- und Zehenspitzen die Quadrateckpunkte bilden. ${ }^{263}$

〉Delikat` nennt Belting Dürers Darstellung des »idealen Menschen«, weil der - jenseits »einer bloß pädagogischen Geometrie« - dafür Adam und Eva nimmt, was ihn zwinge, »ihren Sündenfall« zu thematisieren. Das »wahre Thema« des Doppeltafelbilds (1507) seien »die paradiesisch schönen Körper, [...] nicht die biblische Geschichte«. Die »Distanzperspektive des verlorenen Paradieses« setze diese Körper »in das Licht einer Idealität, die in einem Leben mit Alter und Tod nach dem Sündenfall nur mehr als Prinzip erinnert werden kann «. ${ }^{264}$ Das aber ist nicht alles. Dürers »neuerliche Erschaffung einer Welt, die nach Maß,

260 Dies in der Folge von Quaternionenfresken im Kaisersaal des Frankfurter Römers, die um 1415 im Auftrag König Siegmunds angebracht werden. Vgl. Müller, Gernot Michael, a.a.O., S. 389.

261 Vgl. ebda., S. 389f.

262 Vgl. Belting, Hans: Bild-Anthropologie. Entwürfe für eine Bildwissenschaft. München: Wilhelm Fink Verlag 2001, S. 100ff.; Sennett, Richard: Fleisch und Stein, S. $131 \mathrm{ff}$.

263 Vgl. Sennett, a.a.O., S. 135.

264 Belting, a.a.O., S. 102. 
Zahl und Gewicht entstand und deren erste Menschen nach dem Ebenbild Gottes waren«, strebe - so Christian Schoen - »nach geistiger Durchdringung von Perspektive und Proportion $«{ }^{265}$ Genauer: Er zeige in seiner Proportionenlehre ein »Bewußtsein der eigenen Geschichte und das Bemühen, auf die nationale Zukunft prägend zu wirken«, es gehe ihm darum, sich »allein vnsern Tewczschen jünglingen « zuzuwenden; ${ }^{266}$ ebenso jedoch den hiesigen >Weibern . Seine erste maßstäbliche Figur ist weiblich, die »Gfisyrte Nymphe« (1501). 1502 entsteht der »Nemesis«-Akt, kaum »italienisch-antike[m] Ideal« verpflichtet, sondern »vielmehr eine `Stellungnahme Dürers für das Autochthone, das 'Heimische' « ${ }^{267}$ Für Adam kann Dürer zwischen sherkulischem» und >apollinischem Тyp (für den er sich entscheidet) auswählen. Für Eva hingegen ist die Suche schwieriger, Vitruv hat schließlich nur Angaben zu männlichen Proportionen gemacht. Aus eigenen Umrechnungen von Vitruvs Angaben und den Überlegungen Barbaris entsteht ein »stämmige[r] Venus-Typ ${ }^{268}$

Schoen vergleicht Dürers Doppeltafelbild mit dem Kupferstich von 1504. ${ }^{269}$ Der Stich $^{270}$ zeigt den >Garten Eden « weder als biblischen >locus voluptatis $\triangleleft$, noch als 〉locus amoenus $\triangleleft$, sondern als »dichte[n], finstere[n] Wald«, eine Natur, die man nach Schoen als »ungebändigte, bedrohliche und chaotische« empfinden könnte. Er geht dabei von einem Naturverhältnis des »Ersten Paares« aus, das von einem »dialektischen Gegensatz geprägt zu sein« scheine. Die beiden seien vor dem Wald plaziert, »nicht Teil der Natur« und »von hellem Licht beschienen $« .{ }^{271}$ Was allerdings bedeuten würde, dass Dürer die snatura lapsa piert. Schoen aber betont einen »Gegensatz zwischen vernunftbegabtem Menschen und negativ konnotiertem Wald«, sei das doch »der Ort, an dem Luxuria und Zügellosigkeit regieren«. Er verweist auf Dürers »Satyrfamilie« und den »Sündenfall« der »Kleinen Holzschnittpassion«

265 Schoen, Christian: Albrecht Dürer: Adam und Eva. Die Gemälde, ihre Geschichte und Rezeption bei Lucas Cranach d.Ä. und Hans Baldung Grien. Berlin: Reimer 2001, S. 20.

266 Ebda., S. $59 f$.

267 Ebda., S. 61 (vgl. ebda., S. 69, Abb. 14). Das Binnenzitat stammt von Anne-Marie Bonnet, die die »Nemesis« als »eigene deutsche Antwort» auf die »importierte Klassik« sieht (vgl. Bonnet: »Akt« bei Dürer. Köln: König 2001, S. 144-149).

268 Ebda., S. 61.

269 Vgl. ebda., S. 54.

$270 \gg$ Der >Adam und Eva<-Stich ist neben der >Nemesis〈 das einzige >öffentliche Beispiel, bei dem Dürer den ideal gestalteten Leib so präsentiert, daß dieser gleichsam als Paradigma stehen soll.« Ebda., S. 69.

271 Ebda., S. 112. 
(1510) und schließt aus all dem, dass Dürer ein bereits im Paradies existierendes Böses thematisiere, oder »den nordalpinen, dichten Wald als Garten Eden nobilitiert«. Darin bestehe kein Widerspruch, denn so, wie sich die beiden vorm Sündenfall ihrer - unerkannten - Nacktheit nicht schämten, sei auch dieser Wald noch nicht bedrohlich. »Erst für den postlapsaristischen Menschen lauert im Dickicht die Gefahr und in der Nacktheit die Sünde. Hinter beiden lauert schließlich der Tod als primäres Resultat der Ursünde. ${ }^{272}$ Plausibel ist das so nicht. Laut Genesis ist auch die äußere Natur (auch wenn Fauna und Flora nach platonischer und scholastischer Auffassung unter dem Menschen rangieren ${ }^{273}$ ) nach $\mathrm{Maß}$ und Zahl in Harmonie geschaffen und wird erst per »Ursünde« mit herabgerissen. Auch Dürers Stich funktioniert als diaphane Konstruktion: Wenn der idealschöne Körper ein »heimischer« sein soll, muss der Gegensatz zur »antikisch (italienisch) anmutenden« Landschaft sichtbar werden. Der >wilde $<$ Wald zeigt, es ist der >Herkynische $<$. Dafür sorgen neben dem allegorischen Gehalt - Eschen oder Elch und Steinbock; darauf verweist Schoen ja selbst. ${ }^{274}$ Erst in dieser Weise kann eine >Gefahrlosigkeitく der Wildnis vor Eintritt des `Sündenfalls` konstruiert werden. Seit dem Sündenfall aber besteht die Notwendigkeit der Zivilisierung.

Der menschliche Körper als »Meisterwerk« der Natur, »als Maß der Welt« und damit zugleich »der Mensch in den Grenzen seines Körpers «. ${ }^{275}$ Das sind auch die »Grenzen des beherrschten Lebens «. Zwar entspringt Celtis’ Vierstrukturierung der »Germania« nach Müller nicht der Quaternionentheorie, da er nirgendwo Aussagen zur politischen Ordnung mache. ${ }^{276}$ Dafür entspricht sie der verbreiteten, mittelalterlich überlieferten »Imago mundi«-Darstellung. Hier bildet das (in der Draufsicht quadratische) Jerusalem »den geographischen und heilsgeschichtlichen Mittelpunkt« den »Nabel« der Welt, jener »kreisförmigen Scheibe ${ }^{277}$ Zugleich ist die Vitruvsche Figur erkennbar. `Germania〈 hat vier Seiten, denn Celtis schildert vier Grenzen - Alpen, Rhein, Ostsee, Weichsel -, die nur höchst ungenau (schon gar in der behaupteten sethnischen Reinheit ) mit der damaligen Realität übereinstimmen, aber wegen des Ordnungsschemas können die Grenzen nicht verschoben wer-

272 Ebda.

273 Vgl. ebda., S. 113 u. 260, Anm. 233.

274 Vgl. ebda., S. 113.

275 Belting, a.a.O., S. 102.

276 Vgl. Müller, Gernot Michael, a.a.O., S. 390f.

277 Ebda., S. 373f. Die absolute Perfektion des >neuen Jerusalem` drückt sich

- schon bei Johannes - in der Würfelförmigkeit der Stadt aus; vgl.

Weigel, a.a.O., S. 161. 
den, denn dann verschöbe sich auch der Mittelpunkt. ${ }^{278}$ Den nimmt in der »Norimberga« gemäß der »gebaute[n] Ordnung« die Stadt Nürnberg ein, in der »Germania generalis« hingegen herrscht die »kosmische Ordnung« des »Imago mundi $« .{ }^{279}$ Mittelpunkt ist der »pinifer mons «, ein zwischen Franken, Thüringen und Böhmen angesiedelter Berg. Hier entspringen in dieser Konstruktion vier Flüsse in jede Himmelsrichtung. ${ }^{280}$ Damit $»$ wird ein Mittelpunkt etabliert, der nicht vom Menschen gesetzt ist, sondern der von Natur aus da ist. Die Ordnung der Germania ist eine von der Natur, näherhin von Gott, so geschaffene $\ll .{ }^{281}$ Und damit ist auch die Ordnung des Waldes eine so beschaffene, geordnet nach $\mathrm{Maß}$ und Zahl, ein harmonischer Körper in seinen Grenzen.

\section{Der Wald als sreckenhafter Ort ist ein späteres Produkt}

Der Wald der frühneuzeitlichen >Hochkultur` ist (in Distinktion zur >Volkskultur`) fiktionalisiert. Er ist in der geschilderten Weise fiktionalisierter Träger männlicher Tugenden. Wie beim Wilden Mann wird so mythisches Grauen aufgelöst und das ehedem bedrohliche Äußere nach Innen geholt - auf dem Papier, mit dem realen Wald hat das noch nichts zu tun.

Die direkte Wahrnehmung des realen Waldes selbst als >Recke<, >Heer oder >Kircheく entsteht erst später. Dazu bedarf es - gemäß seiner Rolle als sozialer Projektionsfläche - seiner >Umwandlung in eine >absolutistische Gesellschaft $<$. Strammstehen am vorgegeben Platz, das sowohl Vor-Bild als auch Widerspruch der Waldempfindung sein kann wobei Vor- und Gegen-Bild sehr wohl ineinander fallen können. ${ }^{282}$ Und es bedarf damit in Wechselwirkung der Aneignung des geordneten, nun als >innen< wahrgenommenen Waldes, der Aneignung als Forschungsraum, als Ort der >Schönheit der Schöpfung〈 oder der >Erhabenheit bzw. als Ort des Plaisiers, des Wanderns aus Lust. Frühneuzeitlich wird

278 Vgl. Müller, Gernot Michael, a.a.O., S. 386. Die Bestimmung des Mittelpunkts entspringe einem tradierten Modell, das auch die italienischen Humanisten anwenden; ebda., S. 375.

279 Müller bezieht sich hier auf Hartmut Kugler: Die Vorstellung der Stadt; ebda.

280 Vgl. ebda., S. 372f.

281 Ebda., S. $373 \mathrm{f}$.

282 So etwa bei >Heimatschützern` und konservativen Naturschützern, für die Waldbäume sich als >Recken im permanenten »Daseinskampf« befinden, denen eben dies als vorbildliche >Wildnis (gilt, wohingegen der geregelte Forst in Reih und Glied als >rein rechnerisch` aufgebaute Gebilde einer >überfremdeten` Gesellschaft beklagt wird. Vgl. Kap. Der Wald als kämpferische Volksgemeinschaft. 
der Wald noch nicht obligatorisch von Gelehrten, Reisenden, gar Spaziergängern aufgesucht. Er ist noch (Jagd-)Ort der Könige, Fürsten, aber auch Ort niederer Berufe, ebenso der Ausgeschlossenen, Vogelfreien usw. Erst unter Bedingungen der bürgerlichen Gesellschaft kann es zur Kolonisierung des eigenen Raums kommen, zur >subjektiven` und nicht mehr teleologischen Beurteilung des `Naturschönen`, kann der Wald (die Landschaft) zum Projektionsort idealer Bildkonzeptionen in Reaktion auf eine negativ empfundene soziale Realität werden, zum Objekt des zunächst romantischen, später touristischen Blicks, Ort der Entdeckungen und neuer Wahrnehmungsformen, später der beruhigenden Selbstversicherung. ${ }^{283}$

In der Idealisierung >germanischer Wildnis` seit dem 19. Jahrhundert mischen sich Erhabenheitskonzepte, Malthusianismus/Sozialdarwinismus und andererseits spezifische, in der Romantik >bewahrte « Natura«Konzepte. $^{284}$ Die Konstruktion einer die >Rasse meinschaft $<$ prägenden >Urlandschaft $<$ beruft sich u.a. auf antike Texte wie den von Tacitus, aber auch auf Plinius (s.u.). Dabei ist die Ende des 18. Jahrhunderts einsetzende >Selbstversicherung a anhand von Ur-Volk, -Sprache, -Landschaft usw. weder auf Deutschland beschränkt (sondern auch in Skandinavien oder Großbritannien beheimatet), ${ }^{285}$ noch muss sie zwingend ins Reaktionäre und Nationalistische der Heimatschutzbewegung münden. >Neuheidentum « findet sich bei Aufklärern, antiklerikalen Republikanern, später selbst bei der »Naturfreundejugend «. ${ }^{286}$

Der Wald als >reckenhafter $८$ Ort - der Wald selbst als >Recke . Die propagierte bzw. ersehnte >rauhe Sittsamkeit< lässt sich ebenso als >soldatische Tugend k lesen. Der Wald wird zum Symbol des Heeres: unverrückbar und festgewurzelt die Bäume. Und selbst da, wo sie den festen

283 Vgl. Groh, Ruth u. Dieter: Die Außenwelt der Innenwelt. Zur Kulturgeschichte der Natur 2. Frankfurt/M: Suhrkamp 1996, S. 119; Kleinspehn, Thomas: Der flüchtige Blick. Sehen und Identität in der Kultur der Neuzeit. Reinbek: Rowohlt 1989, S. 212; Eichberg, Henning: Stimmung über der Heide, in: Großklaus, Götz/Oldemeyer, Ernst (Hg.): Natur als Gegenwelt. Beiträge zur Kulturgeschichte der Natur. Karlsruhe: von Loeper 1983, S. 216ff.; Großklaus, Götz: Der Naturraum des Kulturbürgers, in: Ebda., S. 195.

284 Vgl. Bovenschen, Silvia: Die Hexe: Subjekt der Naturaneignung und Objekt der Naturbeherrschung, in: Becker Gabriele et al. (Hg.): Aus der Zeit der Verzweiflung, S. 299f.; Theweleit: Männerphantasien Bd. 1, S. 458.

285 Vgl. Eichberg, a.a.O., S. 207; Best, Otto F.: Die blaue Blume im englischen Garten, S. 241f.

286 Eichberg, a.a.O., S. $207 f$. 
Grund verloren haben, sind sie noch immer verwurzelt und stellen sich in den Weg. So werden dann in bürgerlich-nationaler Rückschau antike Texte wie die Schilderung Plinius d.Ä. vom römischen Feldzug gegen die Chauken im Jahr 47 u.Z. zu >Zeugnissen` einer vorgeblichen Kontinuität.

Zwischen Emsmündung und Elbe, heißt es bei Plinius, stünden die überall in Germanien wachsenden und dem Land die "Schatten der Kälte« hinzufügenden Eichenwälder am höchsten: »Die Küste besetzt von mit größter Üppigkeit wachsenden Eichen« - besetzt wie von den feindlichen Kriegern, wie es hier aus gegnerischer Position heißt. Und so greifen die Eichen auch an, selbst als >Seestreitmacht` (wobei sie trotzdem ihre Verwurzelung nicht aufgeben). Denn,

»unterspült von den Fluten und vom Wind geschoben, nehmen sie große Inseln mit, die sie mit ihren Wurzeln umklammern, und schwimmen so aufrecht im Gleichgewicht. Riesige Äste, die wie Takelwerk aussehen, haben unsere Flotten oft erschreckt, wenn die Woge sie wie absichtlich auf den Bug der nachts vor Anker liegenden Schiffe zuschoben und diese, nicht wissend, wie sie sich helfen könnten, eine Seeschlacht gegen die Bäume anfingen« ${ }^{287}$

In diesem nördlichen Territorium »übertreffen die Eichen die des Herzynischen Waldes (im westlichen Germanien)«, die unberührt von der Zeit noch vom Ursprung der Welt stammten, »jede ein Wunder, da sie fast unsterblich sind«. Zu den unzähligen Besonderheiten der Bäume gehöre insbesondere, dass die Wurzeln, die einander begegnen und stoßen, richtige kleine Hügel aufwerfen oder, wenn die Erde ihnen nicht behagt, sich wie Ringer empor stemmen und Bögen bilden, die so hoch sind wie die Äste und aussehen wie riesige Tore, durch die ganze Schwadronen reiten können«. ${ }^{288}>$ Recken` zwar, aber barbarische. Monströse Monumente der Urzeit. Von einer ungefähren Gleichheit der Stämme, wie sie zum Wald als Heeres-Symbol bei Canetti gehört, ist bei Plinius keine Rede. ${ }^{289}$ Zumal der ein diszipliniertes Heer auf eigener römischer Seite und kaum bei den Barbaren verorten sollte. Die Symbolik der StammGleichheit entstammt erst der Abstraktion eines >ursprünglichen< Waldes, heroisch wie seine Bewohner - die schon bei Caesar neben Wildheit auch Keuschheit und Gemeineigentum auszeichnet ${ }^{290}$-, dessen tat-

287 Naturalis historia XVI, II, zit. n. Beuchert: Symbolik der Pflanzen, S. 71. 288 Ebda.

289 Vgl. a.a.O.

290 Vgl. Schama, a.a.O., S. 99. 
sächliches Aussehen nahezu unbekannt ist; der Plinius-Text, schreibt Beuchert, sei hier der einzige »Augenzeugenbericht $« .{ }^{291}$

Eichenwälder: Die Eiche, Attribut von »Donner- und Blitzgöttern« wie Zeus und Wotan, sei »bei fast allen Völkern Sinnbild der Dauerhaftigkeit, Zähigkeit und kraftvollen Männlichkeit« (gewesen), wie Beuchert übergreifend formuliert. ${ }^{292}$ Symbol des Schwurs sei die Eiche, des Sieges und der Treue, »besonders der Fürstentreue«, schon in der griechischen Antike. Seit etwa dem 16. Jahrhundert v.u.Z. habe die Eichenverehrung aus dem Ostseeraum »kommend« Britannien erreicht, wo dann die »druidische Religion in einem Eichenkult gipfelte ${ }^{293}$ Seit dem 16. Jahrhundert wird die Eiche als »Nationalsymbol der Engländer« reklamiert. Diese »English Oak« steht in der Folge als »König der Bäume« wegen ihrer »Stärke und Erdverbundenheit« und der Haltbarkeit ihres Holzes beim Schiffsbau für den »standhaften britischen Nationalcharakter. ${ }^{294}$ Die »)teutscheく Eiche«, schreibt Klaus Lindemann, sei eigentlich »schon zwischen 725 und 731 erledigt« gewesen, und spielt damit auf die Legende vom »hl. Bonifatius« an, der in Fritzlar die DonarEiche fällt und daraus eine Kapelle macht. ${ }^{295}$ In der mittelalterlichen Literatur habe der Baum daher nur eine marginale Rolle gespielt. Lindemann verweist auf die nur »schmalen Belege« in Grimms »Deutschem Wörterbuch«, nennt die deutsche Übersetzung der lateinischen »Emblemata« im 16. Jahundert, worin Eichen als Träger unterschiedlicher Bedeutungen fungieren: »als gefällte oder gefallene repräsentiert» die Eiche »gefährliche Bürgerkriege, als aufrecht stehende die Festigkeit Karls V. im Türkenkrieg «. ${ }^{296}$ Der kämpfende Recke als >Baum` taucht auf im »Walthari-Lied«, der »erste[n] bedeutende[n] lateinische[n] Bear-

291 Beuchert, a.a.O., S. 71.

292 Ebda., S. 69f. Sie begründet das damit, dass »man Eichenholz lange Zeit für unverweslich hielt und die Kraft bewunderte, mit der die Bäume Stürmen widerstanden« und mit den Empfindungen des hohen Alters, »mit dem die langsam wachsenden Bäume das Menschenleben begleiten «.

293 Ebda., S. 70 u. 72.

294 Vgl. Lehmann, Albrecht: Von Menschen und Bäumen. Die Deutschen und ihr Wald. Reinbek: Rowohlt 1999, S. 41.

295 Vgl. Lindemann: In den frischen Eichenhainen webt und rauscht der deutsche Gott, in: Semmler, Josef (Hg.): Der Wald in Mittelalter und Renaissance, S. 200. Vgl. Schama, a.a.O., S. 239f. Auch Bonifatius selbst ist erst im 19. Jahrhundert heroisiert, nämlich »während des sogenannten Kulturkampfes zum Apostel der Deutschen hochstilisiert« worden; Köhler, Joachim: Heilige und unheilige Bäume, in: Schweizer, Harald (Hg.): »... Bäume braucht man doch!«. Das Symbol des Baumes zwischen Hoffnung und Zerstörung. Sigmaringen: Thorbecke 1986, S. 150.

296 Lindemann, a.a.O., S. $201 \mathrm{ff}$ u. Fn. 7. 
beitung eines germanischen Stoffes« aus dem 9./10. Jahrhundert, die Ekkehard von St. Gallen zugeschrieben wird. ${ }^{297}$ Hier kann der aquitanische Königssohn Walthari im Kampf gegen den burgundischen König Gunther und dessen >Mannen〈 seine »Mannheit beweisen«: »Unerschüttert « steht er gegen die Gegner, allerdings »wie der Eschbaum ${ }^{298}-$ der »Weltenbaum« der germanischen Mythologie, insbesondere der »erste Mann« und zugleich »der Speer«. ${ }^{299}$ Ganze Wälder als kämpfende Heere gibt es im altkeltischen »Câd Caddeu«, der »Schlacht der Bäume«, offenbar jedoch in anderem Sinn. Zwar sei meist behauptet worden, das Versepos schriebe »den Druiden die magische Macht« zu, »Bäume in Krieger zu verzaubern und sie in die Schlacht zu schicken«, kommentiert Ranke-Graves. Aber, wie schon Robert Davies 1809 entdeckt habe, gehe es hier nicht um "physische Auseinandersetzung«, sondern um einen »Kampf, der geistig in den Köpfen und in der Sprache der Weisen geführt wird «. ${ }^{300}$ Ein >richtig` angreifendes Wald-Heer hingegen marschiert bekanntlich am Ende von »Macbeth« auf. Shakespeares Werke zeigten, zumindest teilweise resultierend aus der rapiden Umgestaltung der Landschaft, »eine bemerkenswerte thematische Umkehrung«, sagt Robert Harrison. Wildheit lauere nicht mehr länger in den Wäldern, sondern nun »in den Herzen der Menschen - der Stadtmenschen. Die Gefahren liegen innen, nicht außen«. So werde »die Stadt unheimlich«, der Wald zugleich »unschuldig, pastoral, unterhaltend, komisch« - in den Komödien Shakespeares (die dann auch weiterhin die traditionellen Identitätswechsel und Umkehrungen beinhalten). Die »Dramen städtischer Barbarei« hingegen behandeln diese »als gottlose Auflehnung in der natürlichen Auflehnung der Dinge, das heißt der gesetzlichen Ord-

297 Heimann, Sabine: Waltharius, in: Bräuer, Rolf (Hg.): Dichtung des europäischen Mittelalters. Ein Führer durch die erzählende Literatur. München: C.H. Beck 1990, S. $117 \mathrm{ff}$. Vgl. Stichw. »Waltharius« in: Lexikon Literatur des Mittelalters, Bd. 2: Autoren und Werke. Zusammenstellung der Artikel und Redaktion: Charlotte Bretscher-Gisiger. Stuttgart, Weimar: Metzler 2002, S. 443f.

298 Zit. n. der Übersetzung der Grimms von 1813 in: Walthari=Lied - Der arme Heinrich - Lieder der alten Edda. Hamburg: Gutenberg-Verlag 1905, S. 27. Zur `nationalen Begeisterung` der Grimms vgl. Kap. >Heilige Hallen< II.

299 Beuchert, a.a.O., S. $85 \mathrm{ff}$.

300 Dafür spreche schon, »daß in allen keltischen Sprachen Bäume für Buchstaben standen; daß die druidischen Akademien in Wäldern oder Hainen begründet wurden; daß es beim Großteil der druidischen Mysterien um verschiedene Arten von Zweigen ging; und daß das älteste irische Alphabet, das Beth-Luis-Nion (〉Birke-Eberesche-Esche )《 sei. Ranke-Graves, Robert von: Die weiße Göttin, S. 41. 
nung der Dinge«. Shakespeare, schreibt Harrison, schildere die allmählichen Auflösungen der »christlichen Ära« als »grobe Verletzungen des Naturrechts $\ll$. ${ }^{301}$

»Die Gesetzlosigkeit, die [Giambattista] Vico mit den >ruchlosen Wäldern verband, hat hier in Macbeths städtischer Barbarei eine Zuflucht gefunden, aber am Ende des Stücks symbolisiert dann der wandernde Birnams-Wald die Kräfte des Naturrechts, das seine Gerechtigkeit gegen die moralische Wüste von Macbeths Natur mobilisiert. Unter diesem mächtigen Bild erscheint das Recht in seiner natürlichen Grundlage. $\ll^{302}$

Das Anti-Urbane ist hierbei aber mehrfach ironisch gebrochen. Die Prophezeiung der drei Hexen im »wüste[n] Land « - der topographischen Entsprechung der Verbrechen Macbeths und der »Unfruchtbarkeit« der Lady Macbeth -, Macbeth werde nie besiegt, bis der Wald zum Schloss heraufsteige, bezieht "sich auf den optischen Eindruck eines sich bewegenden Waldes«. Der permanent von Halluzinationen Geplagte nimmt das wörtlich. Tatsächlich aber rücken Soldaten, die sich mit den Zweigen des Waldes tarnen, an. ${ }^{303}$

Die Auffassung vom Wald als Ort des >Heiligen wird zwar in der Malerei des >deutschen Humanismus « und insbesondere bei Altdorfer bereits sichtbar. ${ }^{304}$ Erst seit der zweiten Hälfte des 18. Jahrhunderts - in Deutschland, bei Kloppstock - aber wird dies systematisch Objekt gesellschaftlicher und künstlerischer Beschwörung inklusive der pathetischen Konstruktion eines historisch-heroischen Nationalcharakters, symbolisiert durch die »deutsche Eiche«. Erst seitdem gilt: Die Bilder des >Wehrhaften $<$ - prototypisch der Eichenwald - und des > Transzendenten $<$ - prototypisch der Buchenwald - ergänzen einander. Beide reklamieren eine strikte Ordnung, wobei die $>$ Wildnis $\measuredangle$ des >Wehrhaften den dezidierten Gegenort zum Urbanen und seiner >Dekadenz` bezeichnet. Einem Urbanen, das seit dem späten 19. Jahrhundert zum Ort des >Chaos`, zum >Dschungel` erklärt werden wird, mit dem nun als Hort verwurzelter Ordnung reklamierten Wald als Widerpart. Diese >Wildnis` ist kein >Chaos`, sondern Enthusiasmus und heroischaggressive Energie. Es geht in diesen Auffassungen darum, »nur innerhalb der Grenzen eines beherrschten Lebens« zu bleiben, wie schon Celtis das formuliert hat.

301 Harrison: Wälder, S. 126f.

302 Ebda., S. 130.

303 Vgl. ebda., S. 128ff.

304 Vgl. Schama, a.a.O., S. 116. 


\section{Deutscher Waldı und `Deutscher Waldı}

Aber: der >deutsche Wald ist auch und vor allem der geordnete. Und so oszilliert dieser >deutsche Wald strikter Ordnung, zusammengehalten vom >Wehrhaften (denn auch der geregelte Forst bekämpft unerwünschten Wildwuchs radikal). Es ist der Wald als Massen-Symbol nach Canetti, als Symbol der geordneten Masse, des unverrückbaren Heers, der >heiligen Hallen` - mithin Ort >ewiger Werte` (auch der geregelte Forst erscheint als `ewig`, denn hier ist der Baum-Tod nicht mehr vorgesehen).

Massen und Hallen und steinerner Wald: In der (national-)konservativen Kunstgeschichte in Deutschland - mit fließenden Grenzen zu Nazi-Theoretikern - werden romanische Kirchen als Kampfburgen, gotische als >Wald aufgefasst. Das geschieht in Reklamation des >Germanischen`, des Waldes in seiner heroisch-antizivilisatorischen Gestalt, eines >Ur-Orts` derart ehernen Gefüges offenbar, dass hier auch WaldOrdnung im forstlich-bäuerlichen Sinn erwartet wird. So hält der >großdeutscheく Naturschützer Walther Schoenichen die Existenz von Prototypen einer geregelten Forstwirtschaft aus Eichenhainen, gepflanzt in Reih und Glied, bei den >Germanen` für wahrscheinlich. ${ }^{305}$ Der Wald als Dom bzw. der Dom als Wald sind allerdings Vorstellungen, die in positiver Auffassung systematisch im »Sturm und Drang" entstehen (und sich dabei teils auf Renaissance-Theorien stützen). Der Gemeinplatz vom >Waldesdom〈 ist dabei vordergründig nicht ideologisch festgelegt. »Heilige Hallen« gehören bis heute zum selbstverständlichen Wahrnehmungsmuster von Wald. ${ }^{306}$

Im >männlichen Wald erscheinen die Übergänge zwischen >Wildnis` und >Ordnung ^ fließend, da in dieser Konstruktion keine Widersprüche angelegt sein sollen. Entweder diese Ordnung (>rauh`, >hart`, nicht >verweichlicht` usw., kurz: hierarchisch und viril) wird als bestehende - als ewige - propagiert, dann erscheint ein Widerspruch zur Wildnis inexistent, oder die Ordnung ist geschaffen worden bzw. noch zu schaffen. Der geordnete Wald wird als Forst organisiert, wobei >geordnet` meint: gesetzlich geregelt. Das Gesetz erscheint zunächst vor allem als königlicher Jagdbann. Dieser Wald kann Wildnis sein.

305 Vgl. Kap. Der Wald als kämpferische Volksgemeinschaft. 306 Vgl. Kap. Die Schönheit der Ruinen. 


\section{Forst I: Der Wald als Körper des Königs}

Forst: Wald, der bereits lange im Besitz des Herrschers und nach dessen Vorstellungen umgestaltet ist. Das seit der Merowingerzeit verbreitete »unklare lateinische Verb forestare bedeutete >fernhalten, den Zutritt verwehren, ausschließen««. Der Wald ist >draußen « (১foris $\iota)$, denn er liegt, anders als der königliche Garten, der manchmal »silva oder Wald « genannt wird, außerhalb der Mauern: »forestis silva«. Draußen fürs gewöhnliche Volk, dem der Zutritt verwehrt wird, das hier nichts antasten, verändern, nutzen darf bei Androhung gesonderter Strafen von Geldbußen bis hin zu Kastration oder Tod. Davor sind im hochmittelalterlichen England trotz ihres "privilegium canonis« auch Kleriker nicht geschützt. ${ }^{307}$ Bis zum 6. bzw. 7. Jahrhundert »war das Jagen das allgemeine Recht der Bevölkerung«. Dann kommt es zur »Inforestation« durch die erstarkten königlichen Grundherrn. ${ }^{308}$ Forst ist also außerhalb der gewöhnlichen Öffentlichkeit und normaler Gesetzbarkeit. Innen ist er exklusiv für den König. Zwar stellt die Jagd eine »bedeutsame Nahrungsquelle dar «, ${ }^{309}$ ihre herrschaftliche Ausübung aber läuft auf etwas anderes hinaus. So werden große Areale zu Bannwäldern erklärt, zum Schutz des Wildes, denn das dient einem »fundamentalen königlichen Ritual[]«, dem Privileg der Jagd. ${ }^{310}$

»Die Wildnis jenseits der Mauern seines Hofes gehörte ganz genauso zu seiner Natur wie die zivilisierte Welt innerhalb eben dieser Mauern. [...] Die Jagd ritualisiert und bestätigt die alte Natur des Königs als Zivilisator und Eroberer des Landes. Seine Forste sind Schutzgebiete, in denen die königliche Jagd in rein symbolischer Weise die historische Eroberung der Wildnis wiederholen darf. Der König kann dieses Symbolismus nicht beraubt werden, denn dieser gehört ebenso wie seine Souveränität zu seiner Natur. Der König verkörpert und repräsentiert in seiner Person die zivilisierende Kraft der Geschichte, aber andererseits hegt er in seiner Souveränität eine Wildheit, die größer und mächtiger ist als die Wildnis selbst. Besäße er nicht diese urtümliche Natur, könnte er weder Beschützer noch Herrscher seines Reiches sein. Als Souverän des Landes überwindet der König die Wildnis, weil er von Natur aus der Aller-

307 Vgl. Harrison: Wälder, S. 90; Semmler, Josef: Der Forst des Königs, in: Ders. (Hg.): Der Wald in Mittelalter und Renaissance, S. 133f. u. 143f.

308 Vgl. Bode, Wilhelm/Hohnhorst, Martin v.: Waldwende. Vom Försterwald zum Naturwald. München: C.H. Beck 1994, S. 41, Semmler, a.a.O., S. $144 \mathrm{f}$.

309 Fumagalli, Vito: Wenn der Himmel sich verdunkelt, S. 60.

$310 \mathrm{Vgl}$. Harrison, a.a.O. 
wildeste ist. Eine Doppelnatur verknüpft daher den König mit dem Forst nicht weniger als mit dem Hof. « ${ }^{311}$

Dieser Wald ist der Ort des Herrschers - über Mensch und Natur -, weil er wild, wüst, weil er die mittelalterliche Wüste ist (die Rolle des Waldes als Rohstofflieferanten ist hier nebensächlich); und nur der Herrscher hat das Recht und die Macht, hier seine Herrschaft auszuüben.

$»$ Der König ist dort - wie der Löwe - bei sich zu Hause. « ${ }^{312}$

Hier, am Ort der >Versuchungen`, der »Buße und Offenbarung« muss die >Heiligkeit gesucht werden. Häufiger in der mittelalterlichen Literatur suchen Könige >heilige Männer`, Eremiten in oft fließendem Übergang zu >wilden Männern ` in der >Wüste` auf, um Rat zu erhalten. Beide sind sie »Männer[] des Waldes«, »Herr[en] über die Natur«. Auch der König erhält den Nimbus, schöpft er doch - »durch die Jagd oder den Umgang mit den Einsiedlern« - aus dem Wald »Heiligkeit und Legitimität ${ }^{313}$

Harrison beschreibt die Entstehung der Königs-Wälder anhand der »Abhandlung über die Gesetze des Forstes«, die 1592 von einem englischen Juristen, Richter und Wildhüter mit dem beredten Namen John Manwood verfasst worden ist. Dieser Manwood schildert dann auch eine wesentliche Voraussetzung der königlichen Jagd: die Ausrottung »räuberische[r] Tiere«, der Wölfe vor allem, wie sie Ende des 10. Jahrhunderts etwa der sächsische König Edgar betrieben habe. Übrig bleibt das Jagdwild. Erst kommt die Vernichtung, dann der Schutz. ${ }^{314}$ Das gilt besonders für Hirsche, die zum derart bevorzugten Jagdobjekt nobilitiert werden, dass mit der Zeit »Tier« europaweit zum Synonym für Hirsch wird. $^{315}$ Das rigorose Forstrecht aber führen im 11. Jahrhundert die nor-

311 Ebda., S. 96.

312 Le Goff, Jacques: Phantasie und Realität des Mittelalters, S. 94.

313 Ebda., S. 94ff.

314 Vgl. Harrison, a.a.O., S. 96.

$315 »$ Der sich verändernde Status der Hirsche schlug sich erstmals um das Jahr 1000 in neuen Bedeutungen nieder, die verschiedene Tier- und Jagdbezeichnungen in mehreren europäischen Sprachen annahmen. Im Englischen, Deutschen, Französischen und Irischen kam es während dieser Zeit dazu, daß Worte, die vorher für >Tier` oder > wildes Tier gestanden hatten (altenglisch deor, althochdeutsch wilt und tior, altirisch fiad, lateinisch bestia), sich auf die Bedeutung >Hirsch(familie)<(englisch deer, deutsch Wild, irisch fiadh) oder >Hinde, Dammhirschkuh « verengten (in der mittelhochdeutschen Jägersprache tier, französisch biche). Kurzum für Sprecher dieser Sprachen gewann >Tier` im allgemeinen die Bedeutung von 
mannischen Eroberer unter dem kommenden König Wilhelm ein. »Wilhelms Passion für die Eroberung wurde nur von seiner Passion für die Jagd übertroffen. `Er liebte die Hirsche so sehr/als ob er ihr Vater wär«", heißt es in der Chronik von Petersborough. So erklärt der Herrscher große Teile Englands zum Forst. Für den »New Forest« werden reihenweise Dörfer »abgerissen und ihre Bewohner vom Land vertrieben«. ${ }^{316}$

Der Souverän bestimmt, welche Lebewesen im Forst existieren dürfen. Dazu braucht es auch eine Forstbeamtenschaft. Die entsteht bereits in den karolingischen Gütern und Pfalzen. Diese Ebene der Forsthierarchie ist zunächst zweistufig - die dem Vorsteher unterstellten »forestarii« beschäftigen Forstknechte -, seit dem Spätmittelalter, mit der Einführung von »Magister forestarii« in großen Klostergütern dreistufig. ${ }^{317}$

In seiner »foresta regis« entscheidet der Souverän über Leben und Tod. Hier

»ist die Privatsphäre der Könige zu suchen; dort empfinden die Herrscher ihre höchste Wonne. Denn dorthin pflegen sie sich von den Staatsgeschäften zur Entspannung zurückzuziehen, um, unbehelligt vom Trubel des Hofes, die freie Luft des persönlich-privaten Bereichs zu atmen«,

heißt es im »Dialogus de scaccario«, den Richard von Ely, bischöflicher Finanzsachverständiger und Schatzmeister Heinrichs II. von England 1178 verfasst. Dieser Königsforst, fährt er fort, sei »der sichere Aufenthaltsort des Wildes «. ${ }^{318}$ Die in der Übersetzung Semmlers anklingende Trennung in Öffentlichkeit (die des Hofes) und Privatheit (im Königsforst) ist missverständlich. Denn in einer Gesellschaft, in der »jede Person Exemplar ihrer Gattung, ihres Standes oder ihrer Gruppe ist «, die jeweils unterschiedlicher Natur sind, ${ }^{319}$ in der vorbürgerlichen $»$ Kom-

>Hirsch im besonderen, so daß die Hirsche zu Tieren schlechthin wurden, Verkörperungen des Tierseins überhaupt.« Cartmill, Matt: Tod im Morgengrauen, S. 88. So wird der Hirsch im gesamten Westeuropa zum begehrtesten und semantisch zum eigentlichen Jagdobjekt, wenn etwa im modernen Spanisch das Wort für Hirsch (venado) eigentlich »der Gejagte«, der neuirische Begriff für jagen (fiadhachaim) eigentlich »hirschen«, und im modernen Englisch »vesion« zwar im Ursprung das Fleisch des gejagten Tieres, das »Wildbret« im allgemeinen, tatsächlich nun aber insbesondere das Fleisch des Hirschs bezeichnet. Vgl. ebda., S. 89. Auch im heutigen Deutschen bezeichnet »Wildbret« wohl vor allem Hirschfleisch oder zumindest das Fleisch des Schalenwilds.

316 Harrison, a.a.O., S. 97.

317 Vgl. Bode/Hohnhorst, a.a.O.

318 Zit. n. Semmler, a.a.O., S. 130.

319 Vgl. Sonntag: »Das Verborgene des Herzens«, S. 78. 
munikation eindeutiger Körper «, ${ }^{320}$ hier insbesondere >hochadeliger Körper`, kann es diese Trennung (im bürgerlichen Sinn) gar nicht geben. So zeigt Czerwinski, wie etwa Gottfrieds »Tristan und Isolde« in der

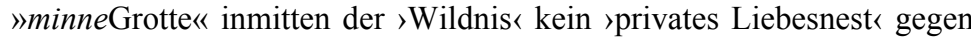
die öffentliche Ordnung errichten, sondern sie »sind nach Rang und Stand einander so unvergleichlich angemessen, daß sie - vom gemeinen Adel des Hofes dadurch abgetrennt - für sich eine eigene soziale Schicht, einen eigenen Hof bilden «. ${ }^{321}$

In ähnlicher Weise ist auch der König vom gemeinen Adel abgetrennt und nimmt in seinem Forst den seiner >Natur` gemäßen Ort ein. Zugleich ist hier der »sichere Aufenthaltsort des Wildes«. Der König schützt die Tiere in seinem Wald - und er tötet sie. Beides als exklusives Vorrecht. Mit Vorliebe Hirsche. Interessanterweise erinnert das an pagane Mythen. Artemis und Diana als griechische bzw. römische $>$ Herrin der Tiere〈 sind deren Jägerin und Beschützerin, zugleich »Göttin der Geburt $\aleph^{322}$ und der Fruchtbarkeit. Ihre Kulttiere sind Hirsche (bzw. Stiere, s.u.). Auch die »Waldungen« dieser >Tierherrinnen ßerhalb $<$, allerdings in anderen Dimensionen. $»[\mathrm{~J}]$ enseits der Polis « heißt hier in »unberührte[n] Wälder[n] « und dass sie den Menschen »niemals erscheint $\ll{ }^{323}$ >Herren $<$, >Beschützer $<$ und $>$ Jäger $<$ der Tiere sind auch der keltisch-gallische und der irische Hirschgott: Cernunnos und Herne. ${ }^{324}$

In der mittelalterlichen Realität wird der Herrscher zum >Beschützer und >Jäger` der Tiere. Mit dem Exklusivrecht über >seinen` Wald wird auch das Hauptziel seines Jagdrituals, der Hirsch »geadelt«. Der werde seit dem 9. Jahrhundert zunehmend in der Literatur zur »edlen und numinosen« Figur, zum »mit erotischer und übernatürlicher Bedeutung aufgeladenen vorbildlichen Tier[]«, zum Helden »erotischer Jagden«, gar zum Abbild von Christus oder der katholischen Kirche. ${ }^{325}$ Diesen überragenden, vornehmen Status hält Cartmill für das Ergebnis eines Bedeutungswandels:

»Im mittelalterlichen Deutsch ist edel wilt ein gebräuchlicher Ausdruck für den Hirsch. In ganz Westeuropa kam der Hirsch während des Mittelalters zu symbolischen Adelsehren. Das war neu. Im klassischen Altertum war der Hirsch das Symbol der Feigheit gewesen, so wie heute der Hase. Im Altgriechischen war >hirschhaft`(elapheios) gleichbedeutend mit >feige $<$. Achilleus

320 Czerwinski: Der Glanz der Abstraktion, S. 318

321 Ebda., S. 314.

322 Harrison, a.a.O., S. 47.

323 Ebda. u. S. 40.

324 Vgl. Cartmill, a.a.O., S. $76 f$.

325 Vgl. ebda., S. 96 u. 93. 
verhöhnt in der Ilias Agamemnons Feigheit, indem er ihm das >Herz eines Hirschs` nachsagt. Gestalten in der klassischen Literatur, die mit Hirschen und Hinden verglichen werden, sind entweder Feiglinge und Versager (Turnus in der Aeneis, Penelopes Freier in der Odyssee) oder unschuldige Opfer (Vergils Dido). Doch in der mittelalterlichen Literatur wurde dem Hirsch erstmals eine Aura des Adels, ja sogar übernatürlicher Hoheit angedichtet. « ${ }^{326}$

Der Hirsch als antiker >Feigling, ist aber nur die halbe Wahrheit. Cartmill, der dessen >Nobilitierung « zum Teil auch keltischer Verehrungstradition zuschreibt, ${ }^{327}$ referiert zwar die Aktaion-Geschichte, ${ }^{328}$ übersieht aber anscheinend wesentliche Zusammenhänge. Ranke-Graves zeigt, dass die Geschichte vom Jäger, der in den Hirsch verwandelt und von seiner eigenen Hundemeute zerrissen wird, weil er Artemis beobachtet bei »ihrer jährlichen Wiederkehr, da sie ihre Jungfräulichkeit erneuerte, indem sie nackt in einer heiligen Quelle badete; wonach sie einen neuen Liebhaber nahm«, in gleicher oder ähnlicher Weise oft im irischen, aber auch keltischen Mythos zu finden ist. Es ist eine Erzählung vom Hirschkönig als betrogenem, >gehörntem` König. Geweih und Gehörn aber symbolisieren ebenso die Krone. Der Hirsch ist auch »das königliche Tier der irischen Danaer«. Das 〉Hirschkönig〈-Motiv lässt sich zurückverfolgen bis in die Praktiken sibirischer Schamanen, den elysischen Orakelkult, die Höhlenzeichnungen von Çatal Hüyük, Altamira, Arièges usw. ${ }^{329}$ Zudem ist der Hirsch schon »in vorchristlicher Zeit [...] Lichtsymbol, Bote eines Sonnengottes [...] des gewaltig ausstrahlenden Geweihes wegen ${ }^{330}$ Mit der »Konstantinischen Wende« im frühen 4. Jahrhundert wird daraus die Epiphanie des Christus, so in der Eustachius-Legende, die später »auf den fränkischen Heiligen Hubertus übertragen wird «. ${ }^{331}$ Der Hirsch ist in paganen Mythen und Kulten Opfertier `Großer Göttinnen`, frühchristlich ist er als Gejagter eine Variante des Gekreuzigten und lässt Eustachius zum >Märtyrer` werden.

Neu ist also nicht der >Hirschkönig〈, sondern vielmehr, dass der Hirsch nun dem König >geopfert « wird. Dazu wird, ab dem 13. Jahrhundert, beginnend offenbar in Frankreich, die Etikette immer bedeutender

326 Ebda., S. 89.

327 Vgl. ebda. u. S. 76.

328 Vgl. ebda., S. $51 \mathrm{f}$.

329 Vgl. Ranke-Graves: Die weiße Göttin, S. 254f. Vgl. Burkert, Walter: Homo Necans. Interpretationen altgriechischer Opferriten. Berlin, New York: de Gruyter 1972, S. 22f u. 128f. Vgl. Ginzburg: Hexensabbat, S. $140 \mathrm{ff}$.

330 Wyss, Stephan: AskeSe, S. 174.

331 Ebda., S. 208. 
- wichtiger »als das praktische Ziel, Wild zu erlegen«. So wird die Jagd "zum Zeichen eines hohen Standes, und die Jagdbräuche« - etwa die komplizierten Details des richtigen »Aufbrechens" und »Zerwirkens" der erlegten Tiere - »erstarrten in einem höfischen Zeremoniell, das die Vornehmheit der Teilnehmer [...] demonstrieren (oder ihre Unwürdigkeit bloßstellen) sollte«, so wird auch der spezifische Sprachgebrauch etwa die korrekte Benennung des Kots der unterschiedlichen Tiere zum standesgemäßen Distinktionsinstrument; essentiell ist es hier, dem Herrscher den Kot der Hirsche zu präsentieren, um deren Qualität zu beweisen. ${ }^{332}$ Bereits im Jagdtraktat »La chace dou cerf« (13. Jahrhundert) ist erwähnt, wie der hohen Jagdgesellschaft ein ihr gemäßer, möglichst prächtiger (»jagdbarer«) Hirsch anzuzeigen sei. Ein einzelner Jäger zu Fuß begibt sich auf Fährtensuche und sammelt die »Losung«, deren »Qualität« ihm Auskunft »über das Alter und den Status des Hirsches« gibt, in seinem »Horn« oder unter seiner Bluse. Zurück im Lager, wo die Herrschaft frühstückt, legt er sie dem Lehnsherrn zur Feststellung der Jagdbarkeit des Tieres vor. ${ }^{333}$

»Die Jagd auf Hochwild erschien wegen des Waffengebrauchs auch in enger Analogie zum Waffentragen überhaupt, d.h. sie wurde von der bloßen Folge des königlichen Friedensrechtes zum davon abgelösten, eigenständigen Symbol der politisch-kriegerischen Macht eines Fürsten oder Königs. « ${ }^{334}$

Der Forst des Königs (oder Fürsten) ist der Ort des - abgesehen vom Krieg - »wichtigste[n] Blutritual[s], durch das die Hierarchie von Status und Ehre in der Umgebung des Königs geordnet« wird. Der Forst ist sozusagen ein »zweite[r] Hof«, an dem die Konkurrenz der einzelnen »Clans von Adeligen« um Gunst und Nähe des Herrschers »frei von der Herrschaft der regulären Verwaltung« stattfindet. Etwa um die Ämter der Ritt- und Jagdmeister. So dient die Jagd auch der Ausbildung junger Adeliger in »kriegerischer Reitkunst. Seit Xenophons Kynegetikos (〉Der Jäger ), der ersten Abhandlung über die Jagd, war das Jagen zu Pferde das empfohlene Verfahren gewesen, mit dem sich angehende Ritter ihre Sporen verdienten«. Der Forst ist »ein Staat im Staate«, in dem eigene Beamte jenseits herkömmlich gültigen Rechts ein eigenes Recht prak-

332 Vgl. Cartmill, a.a.O., S. 82f., Schama, a.a.O., S. 163f.

333 Vgl. Wolter-von dem Knesebeck, Harald: Aspekte der höfischen Jagd und ihrer Kritik in Bildzeugnissen des Hochmittelalters, in: Rösener, Werner (Hg.): Jagd und höfische Kultur im Mittelalter. Göttingen: Vandenhoeck \& Ruprecht 1997, S. 535f.

334 Spehr, Christoph: Jagd nach Natur, S. 61. 
tizieren, in dem komplizierte und detaillierte Initiationsriten und Zeremonien herrschen. ${ }^{335}$

»Von Anfang bis Ende war also die Jagd nicht nur ein Töten, das der Aura des königlichen Kriegsherrn Macht und Autorität verlieh, sie war auch eine rituelle Demonstration der Disziplin und Ordnung an seinem Hof. Kein Wunder, daß es als Verrat betrachtet wurde, dem König das Ziel zu verderben.« ${ }^{336}$

Die königliche Hirschjagd ist ein kultisches Ritual: Beim »Zerwirken« des Opfers muss der dafür bestimmte Jäger dieses »mit einer bestimmten Anzahl von Schnitten an bestimmten Stellen des Körpers abhäute[n] und es dann zerleg[en] und bestimmte Stücke an Personen verteil[en], denen sie nach dem Brauch« zukommen. Das Ritual scheint in verschiedenen Jahrhunderten und Gegenden Unterschiede aufzuweisen. »Im England des 16. Jahrhunderts« etwa »gingen die Zunge, die Hoden, der Mastdarm und andere hochgeschätzte Leckerbissen an den ranghöchsten Edelmann «. ${ }^{337}$ Grundsätzlich stammt das Zeremoniell, wie auch die wichtigsten Lehrbücher seit dem Mittelalter, aus Frankreich (wo Louis XV. in 50 Jahren angeblich »10000 Stück Rotwild« getötet hat) und wird zum Vorbild für Westeuropa. ${ }^{338}$ Der ranghöchste Edelmann erhält, neben Zunge und Mastdarm, die Hoden des Opfertiers. Diese Symbole männlicher Potenz gehen nun an den männlichen Herrscher. Es sind die Symbole seiner eigenen Macht und Potenz, derer er sich per Jagd versichert.

Eines der wichtigsten paganen Blutrituale ist das der Diana von Ephesos, der »vor allem Stiere, die Männlichkeit und Kraft symbolisierten und die - soweit sich das nachverfolgen läßt - an vielen Stellen männliche Menschenopfer« ersetzen, geopfert werden. »Bei den Feierlichkeiten wurden den geopferten Stieren die Hoden abgetrennt und der Göttin angeheftet«, um sie zu 〉befruchten ${ }^{339}$ (Stier- und Hirschkult sind hierbei konvergent, denn in im Irland, Kreta, Griechenland der Bronzezeit sind »sowohl Hirsch als Stier der Großen Göttin heilig «. ${ }^{340}$ Auch

335 Vgl. Schama, a.a.O., S. $163 f$.

336 Ebda., S. 164.

337 Cartmill, a.a.O., S. 83.

338 Vgl. ebda., S. 87. George Turbeviles elisabethanisches »Booke of Hunting « (1575) sei eine freie Übersetzung von Jacques du Fouilloux’ »La Vénerie« (1561).

339 Braun, Christina von: Die zwei Körper der Königin, in: Schulte, Regina (Hg.): Der Körper der Königin, S. 340. Zu den sich opfernden Männern gehören die »galloi, Eunuchenpriester, die sich zu Ehren der Muttergöttin selbst entmannten« (ebda.).

340 Ranke-Graves, a.a.O., S. 253. 
Jagd- und Opferbräuche sind in paganen Gesellschaften konvergent, die Rituale zeigen jeweils klare Übereinstimmungen. ${ }^{341}$ ) Der Kult weicht zunehmend den hellenistischen »Stiertötungsritualen« für die Götter Attis und Kybele, wobei Initianden in einer Grube (als >Mutterschoß<) vom Stierblut überströmt werden (〉Bluttaufe $<$ als >Wiedergeburt ). Ähnlich, allerdings gegensätzlich intendiert, verläuft der Mytraskult. Die 〉Großen Mütter sind hier abgeschafft, Frauen überhaupt ausgeschlossen, »kriegerische Männlichkeit« verdrängt »alles Sexuell-Weibliche«. Die diesbezüglichen Kultreliefs zeigen einen Samenerguss des sterbenden, von einem Skorpion kastrierten Stiers in einen Krater, die Verwandlung seines Schwanzes in Ähren, »Metamorphose der Zeugung nach dem Tode « und »Besessenheit von Sexualität im Negativbild «. ${ }^{342}$ Christina von Braun sieht das im Zusammenhang mit »der Durchsetzung des vollen phonetischen Alphabets im Hellenismus« mit dem »alpha« bzw. »aleph« - das »in allen semitischen Sprachen« >Stier« oder >Ochseく, damit `höchstes Opfertier`, 〉Männlichkeit`, 〉Fruchtbarkeit` bedeutet - als erstem und wichtigstem Buchstaben, mit der beginnenden Gleichsetzung von "geistige[r] Fruchtbarkeit« und Männlichkeit bzw. von Weiblichkeit, Leiblichkeit und Sterblichkeit. ${ }^{343}$

Die herrschaftliche Hirschjagd seit dem Mittelalter transportiert fleischliche männliche Potenz (die sich ebenso spezifisch umdeuten lässt ins literarische Spiel der >erotischen Jagd`, in der der Mann zum `Opfer werden kann) ebenso wie den >asketischen Eros`, den Kult >geistiger Fruchtbarkeit`, zugleich auch des `Tötens des Tiers`, der Begierde. Der Hirsch ist Spiegel des Herrschers, für den er sich opfern lassen muss. Das Opfer bezeichnet die Wiedergeburt des Herrschers, seine SelbstErhöhung. ${ }^{344}$ Und somit die rituelle aber handgreifliche Selbstvergewis-

341 Vgl. Burkert: Homo Necans, S. 23f. Burkerts Ausführungen zumindest in diesem Werk von 1972 sind aus anderen Gründen problematisch. Er beruft sich auf die >Jagdhypothese (in ihrer pessimistischen Grundierung nach 1945), den Wissenschafts-Mythos, der die `Geburt< des Menschen und damit der patriarchalen Gesellschaft - mit der Jagdausübung erklärt. Vgl. Cartmill, a.a.O., S. 13ff.; Haraway, Donna: Im Streit um die Natur der Primaten. Auftritt der Töchter im Feld des Jägers 1960-1980, in: Dies.: Die Neuerfindung der Natur; S. 123-159.

342 Burkert: Antike Mysterien. Funktionen und Gehalt. München 1990, S. 90; zit. n. Braun, Christina von, a.a.O., S. 344.

343 Vgl. Braun, Christina von, ebda., S. 342ff.

344 Eine interessante Parallele hierzu zeigt der spanische Stierkampf. In Spanien ist die Christianisierung der >Jungfrau $<$ und >Mutter $<$ Artemis/Diana zur Maria besonders konsequent. Schon frühneuzeitlich gilt hier das Dogma der »unbefleckten Empfängnis« und damit die Fast-Ebenbürtigkeit mit dem Gottes-Sohn. Eine Christianisierung führt zur nächsten: der des Stier- 
serung von >Unsterblichkeitく, denn der König ist - als »body politic« unsterblich. ${ }^{345}$ In gewisser Weise fällt dem Hirsch damit ebenso ein >body politic $<$ zu, spiegelt sich im Geweih (der \Krone $<$ ) des Hirschen, des christianisierten Sonnengottboten, auch der »Heiligenschein der Ewigkeit«, der Nimbus, wie ihn der »normannische Anonymus« als Zeichen des »rex christus«, der >göttlichen Gnade` des Königs beschreibt (in der frühmittelalterlichen Legende erhält auch der Palmsonntags-Esel einen Heiligenschein, einen »unsterbliche[n] >politische[n] Körper««). ${ }^{346}$

Der König selbst ist der Hirsch. Er ist es in der >erotischen Jagd «hier im 16. Jahrhundert Heinrich II. von Frankreich - in den »Darstellungen der Diane de Poitiers z.B., auf denen sie ohne Scham als Geliebte des Königs verherrlicht wird «, ${ }^{347}$ so in der Statue der »Diane d'Anet«, die Poitiers »im Hof ihres Landschlößchens« aufstellen lässt. Sie zeigt eine »gebieterische Diana mit entspanntem Bogen«, an den Hirsch gelehnt: Sieg »einer göttlichen Jägerin über ein edles Tier «. ${ }^{348}$ Die >erotische Jagd « wird auch schon früher dargestellt. Eine Marginalillustration des »Flämischen Stundenbuchs« aus dem frühen 14. Jahrhundert zeigt einen jungen Höfling, der mit entblößtem Hintern in eine Schüssel kotet. Ein anderer Höfling überbringt die Schüssel einer hohen Dame, die sie

kampfs, den die Kirche zuerst als heidnisch bekämpft, der heute aber stets an Festtagen >Mariens` oder lokaler weiblicher Heiliger stattfindet (Braun, Christina von, a.a.O., S. 340f.). Die moderne »Corrida« in der Arena beginnt mit einem »effeminiert[en]« Torero und einem »Stier als männliche[s] Wesen schlechthin. Während der Faena kehrt sich dieses Verhältnis um: der Stier endet, seiner Kraft beraubt, mit weiblichen Zuschreibungen, der Torero triumphiert als der Super-Macho« (Braun, Karl: Der Tod des Stiers. Fest und Ritual in Spanien. München 1997, S. 216).

345 Vgl. Kantorowicz: Die zwei Körper des Königs, S. 317ff.

346 Vgl. ebda., S. 98f. u. 103f.

347 Wind, Edgar: Heidnische Mysterien in der Renaissance, S. 94f. Wind sieht in dieser Figur allerdings »eine verkleidete Venus«, was für die Renaissance typisch sei, so auch im François Clouet zugeschriebenen »Bad der Diana«, das »in eine toilette de Vénus verwandelt« sei, »mit all dem für die Göttin der Liebe typischen Beiwerk, einschließlich einer Szene im Hintergrund, die direkt von Tizians Venus von Urbino übernommen ist«. Die »Venus-Virgo aus der Aeneis« sei die »bedeutendste« der »zusammengesetzten Figuren «. »In ihr glaubten die Renaissance-Platoniker eine hervorragende poetische Bestätigung für ihre Theorie der Einheit von Keuschheit und Liebe gefunden zu haben. Obgleich es durchaus fraglich ist, ob Vergil mit diesem Bild überhaupt ein Mysterium solcher Art vermitteln wollte, entwickelten sie daraus einen halb keuschen, halb wollüstigen Venuskult, in dem die Doppelnatur der Göttin zum höchsten Grad von Ehrfurcht oder Frivolität oder beidem zugleich gesteigert werden konnte« (ebda., S. 93f.).

348 Cartmill, a.a.O., S. 93. 
gern entgegennimmt. ${ }^{349}$ Wolter-von dem Knesebeck vermutet eine »derbe Satire« auf die in »La chace dou cerf« gezeigte Jagdzeremonie (s.o.) bzw. »auf die Minne und ihre Darstellung in Form der Jagdallegorie «. ${ }^{350}$ Denn die Produkte des Höflings gleichen in Form und Anzahl nicht menschlichen Ausscheidungen, sondern denen eines Hirsches. Es geht um die zeremonielle, respektvolle Überreichung der »Losung « an eine hohe Dame, in der sich der Absender als >jagdbar« anzeigt. Eine regelrechte »Minne-Jagd» ist etwa »Jagd « von Hadamar von Laber, entstanden Mitte des 14. Jahrhunderts im Umfeld des bayerischen Hofs. Bei den Abenteuern des »Minnejäger[s]« werden die Gefühle der Dame üblicherweise »ausgeblendet«. »[D]as Wild/die Dame« kann »sich freiwillig den Hunden« stellen oder »selbst den Hund Genâde« hetzen, oder der »Jäger mit dem Hund Troume auch im Schlaf den Wiedergängen der Geliebten« nachspüren usw. ${ }^{351}$

Andererseits ist der »Hirschkönig« auch eine streng asketische Figur. »Wie der Hirsch schreit nach frischem Wasser, so schreit meine Seele, Gott, zu dir«, heißt es im Psalm 42,2. ${ }^{352}$ Was für die christliche Zeit eindeutige »Taufsymbolik« ist, wie schon der »Physiologus« im 2. (im griechischen Original) bzw. 4. Jahrhundert (in lateinischer Übersetzung) bestätigt. Darin heißt es,

»der Hirsch stöbere Schlangen in ihren Schlupflöchern auf - schlangenfeindlich sind alle Lichtträger, denn Schlangen lieben das Dunkel -, er ziehe die Schlangen durch seine Nasenlöcher in den Magen, müsse dann aber innert drei Stunde zu trinken bekommen, ansonsten ihn das Gift töte. [...] Das giftige Reptil im Magen ist die Sünde in der Seele, die drei Stunden sind die Frist der Erlösung, drei Tage Grabesruhe Christi, drei Tage Blindheit des Saulus, das Wasser aber ist die Taufe $\ll .{ }^{353}$

Stephan Wyss hält es für möglich, dass die acht Hirsche auf der Waldlichtung (und neun Kraniche am Himmel) in Cranachs d. Ä. »Heiligem Hieronymus als Büsser in der Wildnis« (1525) mit der Zahlensymbolik der Taufe und »Luthers zwei Schwerter[n]« (dem »Reich Gottes auf

349 Vgl. Wolter-von dem Knesebeck, a.a.O., S. 570, Abb. 27.

350 Ebda., S. 535 u. 537.

351 Steckelburg, Ulrich: Hadamars von Laber »Jagd«. Untersuchungen zu Überlieferung, Textstruktur und allegorischen Sinnbildungsverfahren. Tübingen: Niemeyer 1998, S. $153 \mathrm{ff}$.

352 Zit. n. Wyss, a.a.O., S. 174.

353 Wyss, a.a.O., S. $174 \mathrm{f}$. 
Erden« und den »himmlische[n] Engelschöre[n]«) verbunden sind. ${ }^{354}$ Cranachs Stich »Sündenfall« (1509) zeigt das Paar in Eden umgeben von zahmen Tieren: einem Löwen, einem Wildschwein, je einem Pferde- und Schafpaar, vor allem einem ganzen Rudel Hirschen. In seiner Paradieszeichnung von 1530 »sitzt Eva gar auf einem ruhenden Hirschen, während sie Adam den Apfel reicht. Zu Füssen zwei Rebhühner. Das sind Mensch und Tier vor dem Fall, zahmes Wild, genügsamer Geist $\ll{ }^{355}$ Als Attribut christlicher Heiliger ist der Hirsch unter den wilden Tieren am häufigsten vertreten (29 mal), unter allen Tieren insgesamt (276) liegt er an zweiter Stelle hinter der Hauskuh (26) - insbesondere bei Walderemiten. Wilde Hirsche suchen sie,

»angezogen von ihrer Aura der Heiligkeit, [...] in ihren Klausen im Wald [auf]. Hinden geben ihnen Milch oder bringen ihnen Speise (Ägidius, Goar), Hirsche mit wundersam flammendem Geweih leuchten ihnen den Weg durch den Wald (Ida), und gehetzte Hirsche wenden sich um Rettung an die Heiligen (Neot, Chat, Ägidius und Blasius). Ägidius, der Schutzpatron der Bettler wird traditionell mit pfeildurchbohrter Hand dargestellt, die er vor eine gejagte Hirschkuh hält, um sie vor der Verfolgung durch den Gotenkönig Wamba zu beschützen. Das traditionelle irische Gebet >Fáeth Fiada` (Des Rotwilds Schrei) soll vom hl. Patrick verfaßt worden sein, als er selbst wunderbarerweise die Gestalt eines Hirsches annahm «. ${ }^{356}$

Es ist allerdings

»die Fähigkeit des Einsiedlers, die Wildnis zu zähmen - die rebellische Natur wieder unter menschliche Herrschaft zu bringen -, die seine Heiligkeit bewies. Die wilden Vögel und Tiere, die in so vielen christlichen Legenden dem Heiligen in seiner Klause Speise bringen, tun dies, weil der Heilige gut ist, nicht weil die Tiere gut wären «. ${ }^{357}$

Wenn die »Heiligen und Märtyrer - Nachfolger des gemarterten Christus - « in die Einsamkeit der Wald-Wüste fliehen, »erscheint der innere Feind, die Phantasien körperlicher Lust«, die »Versuchung« als »Versuche, den Heiligen« von seiner inneren Integrität als Repräsentanz »des göttlichen Geistes« zu trennen. Die Askesephantasien wimmeln von

354 Denn die Zahl Acht stehe für die Taufe, »Christus ist am siebten Tage der Woche auferstanden; am achten beginnt der neue Äon seiner Kirche. So wollte es die Patristik, so baute die alte Kirche die Taufkapelle als Oktagon«. Ebda. Vgl. Abb. 64.

355 Ebda. Vgl. Abb. 50 u. 51. Zur »Dornauszieherin« Diana vgl. Exkurs I.

356 Cartmill, a.a.O., S. 77.

357 Le Goff, a.a.O., S. 94. 
Verstümmelungen der >Heiligen durch Feinde oder sich selbst und von zerrissenen und wieder zusammengesetzten Körpern.

»Die Dämonen bestehen aus Menschenteilen, die mit Teilen niederer Tiere zusammengesetzt oder verschmolzen sind. Die tierische, unterhalb des Nabels angesiedelte Natur des Menschen, die die Heiligen von sich abzutrennen trachten, wird bei den Dämonen deutlich sichtbar. Es gibt gewissermaßen zwei Möglichkeiten der Verminderung des menschlichen Körpers, eine heilige und eine sündige. Der Märtyrer verstümmelt sich, um von der Begierde nicht mehr berührt werden zu können, in welcher Gestalt auch immer. Der Sünder läßt sich berühren, gibt der Begierde nach, läßt das Tier in sich zu Fleisch werden. Das beiden Möglichkeiten Gemeinsame ist die Zertrennung des Körpers, ob er sich nun in den Geist Gottes auflöst oder mit Tierischem neu zusammengestückt wird. ${ }^{358}$

Der Hirsch ist auch »das gejagte Tier«, und in der mittelalterlichen Allegorese der Jagd als Kampf Gut gegen Böse sind sich die Patristen durchaus nicht immer einig, ob Jäger oder Gejagte gut oder böse sind. ${ }^{359}$ Dass in der »ziellose[n] Wucherung« der zerrissenen Waldlandschaft und ihrer Geisterwesen in Mathis >Grünewalds` "Versuchung des Hl. Antonius« (1512/15), in der »das Menschliche ins Tierische« und »das Tierische ins Pflanzliche« übergeht, ein Dämon das Geweih eines »Dreienders« trägt, wo sowieso »Klauen [...] zu Wurzeln, Äste zu Geweihen« werden, ${ }^{360}$ passt ins Bild. Hieronymus Bosch wird in seinen »Versuchungen« noch deutlicher. Da wird im Triptychon (um 1500) der >Ketzerbischof`, »ein hohenpriesterlicher Magus«, durch Vierfingrigkeit als Dämon ausgewiesen, von einem »kapitale[n] Hirsch« im »Mantel eines Kardinals« begleitet. ${ }^{361}$ In der späteren ( $>$ Madrider $\triangleleft$ ) Version malt er »Antonius« am Bachufer unter einer notdürftig strohgedeckten »Baumhöhle« sitzend, in Kontemplation versunken und so dem »Ansturm« verdrängter Begierden ausgesetzt.

»Bosch stellte dieses Grenzerlebnis durch die tückische Verwandlung dar, worin der Baumstamm überm Haupt des Eremiten sich zu dem Schädel eines Hirsches auszuwachsen scheint, dessen weit ausgespreitetes Geweih das ganze Mittelfeld beherrscht.«

358 Gendolla, Peter: Phantasien der Askese, S. 76f.

359 Vgl. Wyss, a.a.O., S. 174.

360 Gendolla, a.a.O., S. 87.

361 Fraenger, Wilhelm: Hieronymus Bosch, S. 405, vgl. Abb. 135. 
Der sinnere Feind : Das »Unbewußte[]《 wird als »Brunst des Hirsches rege«:

»Ist doch der Hirsch seit alters her Symbol unbändiger Geschlechtskraft und Geschlechtsbegierde. Demgegenüber ist der morsche Baumstamm als vegetatives Gleichnis des Antonius zu betrachten, der durch freiwillentliche Abtötung des Trieb- und Sinnenlebens für die Welt erstarb, doch nun erlebt, daß ihm bei seinem Eintritt in die tiefste geistliche Versenkung ein Unwesen von Wollust in die Krone steigt. $\ll^{362}$

Der Hirsch als 〉Christus`, als Attribut der Askese, als Attribut des Dämonischen, Symbol der Wollust, Held >erotischer Jagden`, exklusive Beute des Herrschers und dessen Spiegelung als >König der Wälder`. Was für die bürgerliche Wahrnehmung vollkommen widersprüchlich oder »zerstückelt« erscheint, entspricht einer »transzendent bestimmten Ordnung der Welt«. ${ }^{363}$ Zumal die Zusammenhänge durchaus sichtbar sind. Die Figur des Herrschers vereint `Potenz` und 〉Heiligkeit` in sich, derer sie sich rituell per Jagd versichern kann. Ebenso bedeutet >Askese`, das 〉Tier zu töten`. Für diesen Akt braucht es allerdings die Existenz des $>$ Tieres $<$.

In gewisser Weise geriert sich der Herrscher in seinem »forestis « als Herr über Fruchtbarkeit und Geburt, als Neuschöpfer. Mit der Ausrottung der Raubtiere und der zumindest mittelbaren Vermehrung der bevorzugten Beute kommt es zu einer Neuordnung der Fauna. Der Herrscher >schafft « sich einen Raum, der seiner >Natur`, seinem >vollen Körper` gemäß ist, mit (wiederkehrenden) Zeremonien, die seiner >Natur gemäß sind. Die Neuordnung gehorcht nicht irgend gearteten >ökonomischen oder >rationalen` Grundsätzen. Auch daraus resultieren sehr viel spätere Klagen über die >Unvollkommenheit` und `Inkonsequenz` derartiger Neuordnung des Waldes. Aber, der Forst ist die Schaffung eines spezifischen Herrschaftsraumes (über die `äußere Natur $)$ ), dessen >ritueller`Zuschnitt später >rationalen und >planerischen Zugriffen, ReFormationen des Waldes, weichen kann. ${ }^{364}$ Zudem werden im deutschsprachigen Raum, wo zwischen 1350 und 1500 die Fürsten ein je »eigenes Inforestationsrecht bzw. landesherrliches Jagdregal« durchsetzen und ab 1530 die Volksjagd vollständig abgeschafft wird ${ }^{365}$ - offenbar ei-

362 Ebda., S. 304ff.

363 Sonntag, a.a.O., S. 76.

364 Und in dieser Weise werden retrospektiv immer wieder die königlichen und fürstlichen Bannwälder als erste Naturschutzgebiete bezeichnet. Vgl. Ausleitung.

365 Vgl. Spehr, a.a.O., S. 39. 
ne Reaktion auf die Bauernkriege -, in den Jagdordnungen bereits Begriffe wie »Schadentiere«, »Schad- und Raubwild«, »schadhafter Vogel« etc. benutzt, also »alle sich vom Fleisch oder den Eiern anderer Tiere ernährende und damit den Jagdertrag [bzw.] Viehbestand mindernde« Tiere bezeichnet. Dazu zählen in Kursachsen Füchse, Geier (= Raubvögel), Luchse, und Wölfe, während Bären zeitweise als Hochwild gelten. In Bayern »sind ausdrücklich Wölfe, Bären, Luchse, Otter, Iltisse und Wildkatzen genannt«, in Tirol und Salzburg Bären, Luchse, Wölfe, in Braunschweig Füchse, Luchse, Wölfe. Praktisch überall werden alle Arten Rabenvögel und - mit Ausnahme von Falken, Habichten, Sperbern, wohl als >Jagdgehilfen` - Greifvögel (oft aber auch Sperlinge und Finken) dazu gezählt. ${ }^{366}$ In den folgenden Jahrhunderten sind zumindest ansatzweise bewusste Neuordnungen der Flora zu beobachten. Genauer: Sowohl `Erscheinungsbild als auch Artenzusammensetzung und -anzahl werden verändert.

Zum einen gemäß des Hauptzwecks. Überall dort, wo sie »nicht ohnehin vorhanden « sind, lassen schon »die karolingischen Fürsten Wälder anlegen, um dort zu jagen «. ${ }^{367}$ Viele Forsten werden »so gestaltet, daß man optimal darin jagen« kann. Es entstehen eingehegte Tiergärten, » um den Wildbestand besser zu schützen«, bzw. um ihn aus anderen Waldungen zusammenzutreiben, »bevor man ihn im Verlauf der großen Jagdspektakel abschoß«. Um das Fangen zu erleichtern, werden Heckengänge vor allem aus Hainbuchen geschaffen, durch die man die Beutetiere in Gruben, Netze, Schlingen oder Weiher treibt. Zunehmend lassen die Grundherren Jagdschlösser bauen, die oft Grundlage späterer absolutistischer Großanlagen sind. ${ }^{368}$

Im Zusammenhang mit der Übertragung vieler Forste in städtischen Besitz - hier ist der Verbrauch von Holz besonders hoch - kommt es bereits im 14. Jahrhundert zu bewussten Gründungen von Kunstwäldern, dem »Tannensäen «. ${ }^{369}$ Das als frühbürgerlicher Akt, zunächst im Nürnberger Reichswald, wo 1368 der »Unternehmer« Peter Stromer erfolgreich »künstlich Kiefernsaat« ausbringt, weshalb dieses Verfahren ständig wiederholt und von hier aus auch in andere Gegenden exportiert wird. So Anfang des 15. Jahrhunderts in den Frankfurter Stadtwald oder

366 Vgl. Roosen, Rolf: Jagdsprachlicher Sachwortschatz. in gedruckten Landes-, Polizei-, Jagd- und Forstverordnungen des 15. und 16. Jahrhunderts - eine bibliographische, philologische und jagdhistorische Studie. Frankfurt/M u.a.: Peter Lang 1993, S. $147 \mathrm{ff}$.

367 Eine »Gewohnheit, die die Gonzaga und Este in Italien bis in die moderne Zeit hinein und bis heute pflegen«; Fumagalli, a.a.O., S. 60.

368 Vgl. Küster, Hansjörg: Geschichte des Waldes, S. 128.

369 Vgl. ebda., S. 129. 
im 16. Jahrhundert nach Mecklenburg und Oberschwaben, wo allerdings Fichtensamen verwendet wird. Auch diese Schonungen werden »gebannt«, die »forestarii« verbieten im Auftrag der Grundherren die Beweidung (vor allem durch Schafe und Ziegen) des jeweiligen »Geheges, Sunders oder Sondergebietes« durch Einzäunen oder »Verkehrszeichen «. ${ }^{370}$ Solche Markierungszeichen, »Hege- oder Jagdsäulen« werden ebenfalls für Jagdgebiete errichtet. ${ }^{371}$

»Wie sich das Bild der Forsten wandelte, bestimmte der Grundherr. Die Forsten entwickelten sich unterschiedlich - in Abhängigkeit von Nutzung und Unterschutzstellung. Ihr Aussehen wurde immer weniger durch natürliche Parameter wie Klima und Boden bestimmt, sondern mehr und mehr durch die Nutzungsinteressen. Ganz allgemein nahm in den Forsten die Bedeutung des Laubholzes ab. Nadelholz wurde wichtiger, wobei diese Entwicklung durch Aussaat und Aufforstung unterstützt wurde. Forsten wurden immer mehr zu Nadelwäldern, während die als Niederwälder genutzten bäuerlichen Gehölze von Laubbäumen bestanden blieben. Dieser Gegensatz prägte sich immer stärker heraus, so daß im 19. Jahrhundert sogar darüber spekuliert wurde, ein >Wald « sei aus sprachlicher Sicht ein Laubwald, ein 〉Forst८ ein Nadelwald.«

So stehe es im »Deutschen Wörterbuch« der Grimms. ${ }^{372}$

»[K]ennzeichnend für den Beginn einer Forstwirtschaft« aber ist das Durchforsten, das Entfernen störenden Unterwuchses und des sogenannten »Schwach-« und »Stangenholzes «. ${ }^{373}$ Ziel ist es, die Wuchsbedingungen der verbleibenden Jungbäume zu optimieren. Schon um 1300 verlangt Petrus de Crescentiis in seinem sich auf antike Grundlagen berufenden Werk, »daß man, wo die Wälder zu dick stehen, die >ungeschickten`Stämme aushauen solle, damit die anderen >desto baß und >schöner werden zu jrem ampt««, wie es in der späteren deutschen Übersetzung heißt. Systematisch werden Durchforstungsmaßnahmen im Bereich des heutigen Deutschland in den frühen Forstordnungen des 15. und 16. Jahrhunderts verlangt, die sich auf Crescentiis beziehen. ${ }^{374}$

Wie schon angedeutet, nach spätantikem Verständnis ist der »salus«, »der Domanialwald, der in Gallien dem merowingischen Herrscher als Rechtsnachfolger des römischen Kaisers zufiel«, für »jedermann« zur Jagd und anderen Nutzungen frei. Frühmittelalterliche »germanische[]

370 Ebda., S. 129ff.

371 Vgl. Roosen, a.a.O., S. 263.

372 Küster, a.a.O., S. 131f.

373 Mantel, Kurt: Wald und Forst in der Geschichte. Ein Lehr- und Handbuch. Alfeld b. Hannover: Schaper 1990, S. 356.

374 Vgl. ebda. 
Rechtsordnungen« führen dann zur »Patrimonialisierung«, binden diese Nutzungen an den Besitz. So beim fränkischen und langobardischen König, aber auch bei Fürsten und anderen Grundherren. Im 8. Jahrhundert wird »der karolingische Herrscher der Eigentümer des ausgedehntesten Forstbesitzes«, zum Besitzer »nicht nur des saltus, sondern auch des herrenlosen, des öden Landes, das schon die Merowinger sowie andere Fürsten innerhalb des Frankenreiches und außerhalb seiner merowingischen Grenzen einzuforsten begannen $« .{ }^{375}$ Forstrecht- und hoheit der fränkischen Herrscher im 8./9. Jahrhundert gleichen denen der normannischen Herrscher Englands weitgehend (s.o.). Dieser Forstrechtsimport aus der Normandie entstammt zunächst »expliziter oder impliziter Verleihung seitens des karolingischen Königs«, besitzen doch zunächst die Herzöge der Normandie oder die Grafen von Anjou »die Forsthoheit« nicht »als autogenes Recht«. Infolge des »Rückzugs der Königsgewalt aus seinem Einflußbereich« wächst aber dem normannischen Herrscher seit dem 10. Jahrhundert »eine vizekönigliche Stellung zu«. ${ }^{376}$ Sowohl hier als auch in Anjou wird eine »Monopolisierung « der Forsthoheit »in der Hand der Fürsten« durchgesetzt. ${ }^{377}$

In dieser Zeit kommt nicht nur das Lehnwesen, kommen auch die >Genealogien`, die >Stammbäume` auf.

»Das sind Abstammungsaufzeichnungen und oft -erfindungen, die sich dem Übergang von kognatischen auf agnatische Verwandtschaftskriterien verdanken. Bis zu den Karolingern dominiert das kognatische System mit entsprechenden Rechtsformen, wie der Realteilung im Erbgang. Zeitgleich mit dem Aufkommen des Lehnswesens beginnt im 9. und vor allem 10. Jahrhundert die agnatische Verschiebung auf den Mannesstamm. Von nun an bilden sich die `Geschlechter/ heraus, meist benannt nach dem an Bedeutung gewinnenden Zentrum ihrer Herrschaft, einer Burg, eines Guts usw. « ${ }^{378}$

Zwar bedeutet auch zuvor unter kognatischen Bedingungen »eine geschickte Heiratspolitik «, wobei stets die Frau in die Familie der Mannes »einheiratet«, für die >aufnehmende` Sippe einen materiellen und/oder ideellen Zugewinn, eine Erweiterung des >Verwandtschaftskreises $`$, damit der politisch enorm wichtigen Unterstützung. Zugleich aber bringen die herkömmlichen Sippen - konstituiert etwa über die »Verehrung vornehmer Ahnen« - im hochmittelalterlichen Prozess von »Herrschaftsbildung« und »Besitzsicherung« wachsende Probleme aufgrund »unkla-

375 Semmler, a.a.O., S. $144 f$.

376 Ebda., S. $140 \mathrm{ff}$.

377 Ebda., S. 146f.

378 Sonntag, a.a.O., S. 35. 
rer Rang- und Erbfolge« und diversifizierter Verpflichtungen eines »verheiratete[n] Mann[es]«, nämlich mindestens gegenüber der eigenen Sippe, der seiner Gattin und der seiner Mutter, was häufig zu Auseinandersetzungen führt. Abhilfe soll hier die Herausbildung des >Geschlechts` bringen. »Das bedeutendste und am schärfsten ausgeprägte 〉Geschlecht» sind die Karolinger selbst.« Deren »Organisationsmodell« auf Basis einer »agnatische[n] Zentrierung um das Hausmeieramt« ist gewissermaßen eine Vorwegnahme des Adelsgeschlechts im Hochmittelalter und dessen agnatischer Tradierung von Amt und Besitz. ${ }^{379}$

Die Zentrierung auf ein »Geschlecht«, das der männlichen Linie, und die Zentrierung der Waldungen zum Forst sind anscheinend strukturell verwandt. Beides schafft einen festgesetzten Rechtsraum, einen vom jeweiligen >Adelsgeschlecht $\prec$ genealogisch zurückverfolg- und reklamierbaren Ort. Zudem: »Immer wieder zeigt sich ein enger geographischer Zusammenhang zwischen einer Burg, einem Schloß« - aber auch »einem Kloster« - »einerseits und dem Forst andererseits. Manche Forsten sind wohl erst nach der Errichtung der Bauten ihrer Besitzer entstanden, doch meist wird das Gegenteil der Fall gewesen sein: Burg und Kloster wurden im wilden Wald errichtet«, oft als Schenkung des Königs oder Kaisers - so habe Friedrich II. »zahlreiche Forsten« Adligen vermacht -, »ihre Besitzer erhielten auf diese Weise Land, kolonisierten und verwalteten, sicherten es $\ll$. ${ }^{380}$

Christoph Spehr sieht »die Etablierung der Jagd als eigenständige[s] soziale[s] Privileg und Attribut fürstlicher und königlicher Macht« um 1200 als »abgeschlossen«. Da im »deutschen Rechtsraum« der Wildbann »den Anspruch des Königs auf Unterordnung und Waffenfolge der Fürsten« ausdrücke, betreiben ihrerseits »alle weltlichen und geistlichen Fürsten ihre eigene Inforestation $«{ }^{381}$ Schon »der karolingische Herrscher« im 8. Jahrhundert, so Josef Semmler, habe es nicht vermocht, seine Forsthoheit »zu exklusiver Jurisdiktion über die Forsten zu steigern, noch sie in seiner Hand zu behalten. Seine Stellvertreter im zerfallenden Reich zogen sie Kraft ihres Amtes an sich; er selber und seine Rechtsnachfolger statteten damit Abteien und Hochstifte aus«. Folge sei die »Zersplitterung der Forsthoheit in einzelne determinierte Nutzungsrechte «. Übrig bleibe im 10./11. Jahrhundert der »Wildbann als Jagdrecht, Fisch- und Vogelfang, Aufsicht über Eichelmast, Weide, Holzeinschlag und -verarbeitung, Imkerei, Schürfen und Metallverhüttung sowie Rodung«. Der Wildbann wird in Deutschland zum letztlich kö-

379 Vgl. ebda., S. $35 f$.

380 Küster, a.a.O., S. 125.

381 Spehr, a.a.O., S. $61 \mathrm{f}$. 
niglich verliehenen »Regal«, das bis zum 13. Jahrhundert »zum territorialen Aufbau« der (geistlichen) Fürstentümer beiträgt, insbesondere dort, »wo das Hochstift oder das weltliche Lehen eine starke Position als Grundherr besaßen«. Demgegenüber profitieren die französischen Könige »als Grund- und Territorialherr[en]« zur gleichen Zeit enorm vom normannischen Forstrecht. ${ }^{382}$ »Neben der herrschaftlichen Jagd existieren« in Westeuropa zunächst zwar auch »weiterhin Elemente der Volksjagd auf Niederwild und Raubwild«. In England aber führt die »Charta de foresta« 1217 zur Restauration der alten Jagdrechte der Grundbesitzer und bindet sie an ein bestimmtes Einkommen, ${ }^{383} 1390$ verschärft das »Staue Book" diese Bestimmungen unter Verweis auf Land- und Vermögensbesitz mit dem strengen Verbot des »Gentlemen's Game«, »Deer, Hares nor Conies« zu jagen. In Italien beginnen die »Signori« bzw. »Vollbürger eine Stadt« das Jagdrecht für sich zu monopolisieren und »die besonders hartnäckigen Volksrechte auf freie Jagd zurückzudrängen«. Auch in den deutschen Fürstentümern verdrängen bis Ende des 14. Jahrhunderts die Territorialherren tradierte königliche »Vorbehaltsrechte«, andererseits die »Volksjagden«, sichern sich die Fürsten die »Jagdhoheit« und verleihen dem niederen Adel das kostenpflichtige und vorbehaltliche »Jagdrecht«. Im Umkreis der Höfe entstehen die Gruppen der professionalen Jäger und Wildhüter. ${ }^{384}$

Eine Verwechslung mit modernen Naturschutzvorstellungen und Zeitkonzepten, möglicherweise auch eine Synchronisierung scheint vorzuliegen, wenn Harrison meint, die königliche Inforestation deklariere den Wald »als unzugänglich für die Übergriffe der Geschichte. Schon der Raum der Geschichte muß eingedämmt, beschränkt, in Schach gehalten werden, und die gefräßige Welt der gesellschaftlichen Menschheit muß daran gehindert werden, das Land völlig ihren Zielen anzupassen «. ${ }^{385}$ Herrschaftlicher Wald-Bann in der frühen Neuzeit ist als Versuch von Geschichts-Eindämmung nachvollziehbar, da sicher auch Reaktion auf gesellschaftliche Umbrüche und >Anmaßungenく. Die mittelalterliche Inforestation hingegen schafft erst >Geschichte $<$, indem sie >Null-Land und auch das Wild als >res nullius`, als »herrenlose Sache $\ll^{386}$ dem $>$ Nichts $\ll$ entreißt, oder den Besitz niederer Stände einverleibt und >nobilitiert . Diese $>$ Geschichte $\prec$ ist jedoch noch nicht linear, sie folgt dem zyklischen Ritual. Erst gemäß dieses Rituals kommt es zu

382 Vgl. Semmler, a.a.O., S. $145 f$.

383 Vgl. Spehr, a.a.O., S. 62.

384 Vgl. ebda., S. 65. Zur weiteren Entwicklung s. Kap. Forst II.

385 Harrison, a.a.O., S. 96.

386 Spehr, a.a.O., S. 61. 
einem >Stillstand $<$ - der in Wiederholungen besteht, die aber nicht >bloßes $\$ Symbol, »kein Verweis auf anderes, sondern die Sache selbst ${ }^{387}$ sind, damit stets erneut >real < -, weil nichts verändert werden darf; außer vom Herrscher oder in seinem Auftrag. Erst der geregelte Forst seit dem späten 18. Jahrhundert behauptet das Zugleich einer Transformation in lineare Zeit - linearen Geschichtsverlauf, >Fortschritt`zur Disziplinierung und exkludierenden `Normalität` des Wuchsverhaltens - und einer Transformation in >Unsterblichkeit (das Herausnehmen aus der Geschichte), weil die Bäume nicht mehr >sterben`, sondern als >schlagreif geerntet werden, weil ein einheitliches Forstbild entsteht. ${ }^{388}$

Diese Disziplinierung und Optimierung entsteht woanders, im Bemühen, »den Lauf des [...] Lebens der Zahl zu unterwerfen, der gemeinsamen Wurzel mönchischer Askese und kapitalistischer Produktion. Zunächst in den Klöstern also, wo die Glocke »achtmal in vierundzwanzig Stunden« zum Gebet ruft. Askese nach Maß und Zahl unterliegt selbst der Maßlosigkeit und verlangt eine permanente »Vervollkommnung ihrer Übungen«. Seit dem 12. Jahrhundert gibt es erste »Schlaguhren mit Räderwerk « in Klöstern, 200 Jahre später in Bürgerhaushalten. ${ }^{389}$ Martin Burckhardt beschreibt die buchstäblich >dunkle< Herkunft der mechanischen Uhr als »Wechselbalg«, als »Apokryphe der Geschichte« im »saeculum obscurum«. Sie wird von der Forschung gleichwohl versuchsweise dem Archidiakon Pacificus von Verona (gest. 846), Gerbert von Aurillac (ca. 945-1002), schließlich dem Abt Wilhelm von Hirsau (gest. 1091) zugeschrieben. Für Gerbert, der nach Kontakten mit arabischer Kultur in Spanien arabische Ziffern in die okzidentale Mathematik brachte, neue Musiknotationen erwirkte und als Silvester II. erster fränkischer Papst wird, sei das denkbar, da der sich mit Uhren und astronomischen Geräten befasst habe - zumal sich diese frühmittelalterlich-untypische »faustische« Legende vom Teufelspakt um ihn ranke. Immerhin aber sei »die Geburt der Maschine« - in Uhr und Orgel - im Mittelalter kein »nüchternes Ding«, sondern fast noch in einem »frühen, animistischen Stadium: ein beseeltes Ding. Halb Tier, halb Maschine $« .{ }^{390}$ Trotzdem ein »Zeitriß«, ${ }^{391}$ denn die »Zeit, die bislang durch die Finger rann, wird gewissermaßen handgreiflich: zur kleinen Münze«, damit aber auch »Zahlenkontinuum[]« und derart abstrahiert und transzendiert zur »Himmelsuhr«, dem »gigantischen Räderwerk« der Ideen. Was wie-

387 Sonntag, a.a.O., S. 77.

388 Vgl. Kap. Das Verschwinden von Werden und Vergehen.

389 Vgl. Wyss, Stephan, a.a.O., S. 206.

390 Burckhardt, Martin: Metamorphosen von Raum und Zeit, S. $45 \mathrm{ff}$.

391 Ebda., S. 51. 
derum einen »Wandel der Gestalt« bedeute, sei doch der transzendierte Zeitbegriff nun nicht mehr »Kreisfigur«, vielmehr »zur reinen Anschauung«, zur »Linie begradigt, genauer, zu einem Vektor, der in die Zukunft pfeilt «, geworden. ${ }^{392}$

»Mechanische Taschenuhren, die dem bürgerlichen Individuum die Verfügung über die Zeit unmittelbar in die Hand geben, kommen in der Reformationszeit zu Beginn des 16. Jahrhunderts in Mode. Unmittelbar bevor die Wissenschaft mit Galileo Galilei erstmals beginnt, von sozialen Bedürfnissen unabhängig prozesshaftes Geschehen in der Natur zu messen, [...] um ihrer vermittels einer Norm habhaft zu werden; [was] in der Behauptung einer absoluten Zeit durch Isaac Newton gipfelte. ${ }^{393}$

Dieser rein mathematische, homogene und von allem unabhängige Zeitfluss ist im mittelalterlichen Forst noch undenkbar. Hier ist alles abhängig vom Herrscher und seiner >Natur<. Gleichwohl ist der Forst von Beginn an eine >Korporation (und damit im historischen Prozess >rationalisierbar`) und in der Renaissance kommt es buchstäblich zur Wiedergeburt des mathematisch-geometrischen Körperkanons, im Absolutismus zur Zentralisierung/Totalisierung des mathematischen Zugiffs im $>$ Herrschersubjekt $\iota$.

Forst ist offenbar der Wald als Königs-Körper. ${ }^{394}$ Wenn der Staat als »corpus mysticum« der Leib ist, mit dem der König >vermählt`, dessen >Haupt $\ll$ er ist, ${ }^{395}$ gehört dann nicht der Forst zu seinem eigenen mystischen Leib, da er (anders als Hof, Staat) allein zu seiner Natur gehört, was hier exklusiv mit der Souveränität der Jagd bezeichnet, ritualisiert wird? Der Forst also als männlicher Körper (und männliche Korporation, die schon daher eigenen Gesetzen gehorcht)? Zumal hier das zweitwichtigste »Blutritual« auch zur Vorbereitung des wichtigsten, dem Krieg, dient und zugleich der Ordnung der Hierarchien im »Staat im Staate $«,{ }^{396}$ wobei das wichtigste Beutetier der Hirsch ist. Zugleich ist die Jagd rituelle Wiederkehr der Eroberung und Unterwerfung der Wildnis durch den »Allerwildeste[n]«, der einzig diese »zivilisierende Kraft« besitzt. ${ }^{397}$ Ist das nicht doch eine gewaltförmige >Vermählung , die ihn zum Oberhaupt einer Wildnis macht, die so nicht sein >eigener Körper ist, aber der, den er unumschränkt besitzt? Das lässt sich hier letztlich

392 Ebda., S. 60f.

393 Wyss, a.a.O.

394 Bzw. Fürsten-Körper.

395 Vgl. Kantorowicz, a.a.O., S. 226.

396 Schama, a.a.O., S. 163f.

397 Vgl. Harrison, a.a.O., S. 96. 
nicht entscheiden. ${ }^{398}$ Schon, weil »der >politische Körper` des Königs kein[em] kohärente[n], einheitliche[n] Konzept« im >Abendland` folgt, sondern in »viele[n] Versionen « auftaucht. ${ }^{399}$ So ist die englische Konstruktion des »Fürsten als corporation sole, als Einmann-Körperschaft, ein[] hybride[r] Begriff komplizierter Abstammung, der den auch vom Parlament repräsentierten >politischen Körperく in sich schloß«, ebenso »eine[] Reihe von Königen in der Zeit« bezeichnet, kontinental unbekannt. ${ }^{400}$

Im 16. Jahrhundert ist der König in England Queen Elizabeth I. (und vorher Mary I.). Dass der Forst auch zu ihrer Natur gehört, entspricht ihrem unsterblichen, männlich definierten spolitischen Körper८, der untrennbar mit ihrem >natürlichen Körper`verbunden ist, dessen Schwäche aber aufhebt.

Elizabeth erscheint in ihrem Forst als `Herrin der Jagd`, portraitiert als solche in George Turbeviles »Booke of Hunting«, wo ihr ein Jäger die Losung des zu jagenden Hirschen präsentiert (S. 95) und ihr später neben dem auf dem Rücken liegenden Hirsch das Weidmesser reicht (»The Queen at the kill«, S. 133). ${ }^{401}$ Ihr stehen die besten Stücke des Hirsches - Zunge, Hoden, Mastdarm - zu. Zeichen ihrer Macht und Potenz, wie beim männlichen Herrscher, zumal dann, wenn sie explizit als >Jungfrau regiert? Auch wenn der Ephesos-Kult hier sicher unbekannt ist, erscheint das doch als eine historische Ironie. Aber, Elizabeth ist, auch wenn die Königswürde männlich ist, stets König und Königin in einer Figur, ihre Weiblichkeit dient oft ideologischem, politischem Kalkül. ${ }^{402}$ So im umfangreichen und vielschichtigen Kult um sie als >jungfräuliche Königin`, der in ihren letzten Regierungsjahren bis zur Entwicklung einer »säkularisierten Jungfrau Maria« geht, deren Gatte das Königreich sei ${ }^{403}$ offenbar eine $>$ Josefs-Eheく. Was liegt da näher als auf der anderen Seite des Zuschreibungsspektrums - die >Herrin der Jagd als `Diana zu verehren? Edgar Wind vermutet dahinter, wie schon

$398 \mathrm{Zu}$ den Schwierigkeiten - schon infolge historischer Unterschiede - eindeutige Zuschreibung >weiblicher` und `männlicher` Eigenschaften vorzufinden vgl. Kap. > Weiblicher Wald $<->$ männlicher Wald .

399 Weil, Rachel: Der königliche Leib, sein Geschlecht und die Konstruktion der Monarchie, in Schulte, Regina (Hg.): Der Körper der Königin, S. 103.

400 Vgl. Kantorowicz, a.a.O., S. 44, Weil, a.a.O., S. 102.

401 Vgl. Strong, Roy C.: Portraits of Queen Elizabeth I, S. 122f.

402 Vgl. Weil, Rachel: Der königliche Leib, sein Geschlecht und die Konstruktion der Monarchie, in Schulte, Regina (Hg.): Der Körper der Königin, S. 104.

403 Vgl. Schulte, Regina: Der Körper der Königin, in: Ebda., S. 14f. 
bei Diane de Poitiers, einen maskierten Venus-Kult. ${ }^{404}$ Strong erklärt zwar ein Portait »Elizabeth as Diana at Hatfield« als falsche Zuschreibung, ${ }^{405}$ hat dafür aber einen satirischen Stich Pieter van de Heydens (1585) im Katalog, der Elizabeth als Diana über den Papst Gregor XIII. zu Gericht sitzen lässt. ${ }^{406}$

John Manwoods eingangs erwähnte »Abhandlung über die Gesetze des Forstes« erscheint 17 Jahre nach Turbeviles 1575 veröffentlichter Jagdbuch-Huldigung der Königin, also in der Endphase ihrer Regentschaft. In weiten Teilen ist Manwoods Text die Beschreibung eines Systems,

»das nur auf dem Papier existierte. Er [...] nahm an, daß in vergangenen Jahrhunderten die Vorschriften der Forstgesetze rigoros durchgesetzt worden und erst in neuester Zeit in Vergessenheit geraten seien«.

Auch, wenn davon nach Schama keine Rede sein kann, ${ }^{407}$ stellt sich doch die Frage, ob Manwoods Auffassung nicht auf den >natürlichen Körper` der Regentin abzielen. So schildert Louis Montrose das »elisabethanische Regime« auch als 40 Jahre währende »Herausforderung [...] zu gewährleisten, dass das Prestige der Königin nicht durch ihr Ge-

404 Er verweist dazu auf einen Stich Crispin van de Passes (1592 nach einem Portrait Isaac Olivers), dessen Inschrift sich »eindeutig auf Vergils Vers« beziehe: "Virgins os habitumque geris, divina virago«. Desgleichen auf den Holzschnitt Edmund Spensers im »Shepheardes Calender« (1579), der anspiele auf die Begegnung des Aeneas mit seiner Mutter Venus, die ihm als eine »der Jungfrauen Dianas« erscheint, »mit welch göttlicher Erscheinung Hobbinoll Elizas Vortrefflichkeit vergleicht«, wie es im »Calender « heißt; Wind, a.a.O., S. 94f.; vgl. Strong, a.a.O., S. 125, W. 14 u. S. 124: »Elizabeth is hymned as Venus-Virgo crowned with flowers and attended by the Graces, Muses and other nymphs«.

405 A.a.O., S. 48. Vielmehr handele es sich um eine "version of a Netherlandish allegorical piece attributed to Frans Floris or Martin de Vos«. Die meisten Falschzuschreibungen stammten aus dem 18. Jahrhundert, »when almost any elaborately attired sixteenth-century English court lady was renamed Queen Elizabeth.

406 Vgl. ebda., S. 112, E. 14. Der Stich adaptiere Tizians »Diana und Callisto«. Elizabeth-Diana wird flankiert von den Figurinen der Provinzen Holland, Gelderland, Zeeland und Friesland. Die allegorischen Gestalten von Zeit und Wahrheit entschleiern den Papst, der einige Eier ausbrütet. Ihnen entschlüpfen der Drache (sein Wappen), die Inquisition, das St. Bartholomäus-Massaker, das Attentat auf Wilhelm von Oranien. Weil es sich um einen holländischen Druck handele, verkörpere er eine Heftigkeit, die in englischen Elizabeth-Portraits kaum anzutreffen sei (vgl. ebda., S. 109).

407 Vgl. Schama, a.a.O., S. 165. 
schlecht beeinträchtigt wurde « ${ }^{408}$ Das vor allem gegenüber der ausländischen Konkurrenz, die - nach >salischem Recht $<$ - Regentinnen nur als Gattinnen oder Mütter zulassen. ${ }^{409}$ Aber in den letzten 15 Jahren ihrer sogenannten »zweite[n] Regentschaft« auch innenpolitisch. So zwingen "potentiell destabilisierende« Faktoren wie politische und religiöse Auseinandersetzung sowie eine wachsende »sozio-ökonomische Unzufriedenheit« beim Regime zu Konsolidierungsbemühungen gegenüber der Bevölkerung, so in Darstellungen Elizabeths »als Ausnahme von hinderlichen Geschlechternormen [...], deren unverletzliche Sexualität und selbstaufopfernde mütterliche Sorge eine quasi sakramentale Quelle der nationalen Wohlfahrt« sei. ${ }^{410}$ Insbesondere nach dem Tod der Monarchin kursieren Erzählungen, die »sich durch eine ebenso durchgängige wie beiläufige Misogynie« auszeichnen, über die »zügellose Unkeuschheit« der »Jungfrau « und den Verfall hinter den Masken. ${ }^{411}$

Möglich ist demnach, dass Manwood Elizabeth-Diana implizit für den vorgeblichen Verfall der Forst-Ordnung verantwortlich macht. Die Figur der >Jagdgöttin< ist anderweitig längst - so sie denn nicht für inquisitorische Zuschreibungen herhält - ikonographisch in eine dienende Funktion gepresst.

\section{Exkurs I: Diana im Blumentopf}

Die Bändigung des Schrecknisses der Natur erscheint als Umkehrung eines Gewaltverhältnisses. Die Einnahme der unberührten bzw. ’gefallenen< Natur erschließt sich über den Wechsel des Paradigmas von der ungebundenen `Herrin der Natur` zum abhängigen Ausführungsorgan ihrer Okkupanten.

>Diana ist bei Lucas Cranach d.Ä. zur »Dornauszieherin« (1530) geworden. ${ }^{412}$ Sie sitzt auf einem Hirschen, wie $>$ Eva< auf der Zeichnung aus dem selben Jahr. Was hier Kennzeichen des >Paradieses` vor dem 〉Fall ist, wird bei `Diana Kennzeichen seiner Reetablierung durch Askese. Sie zieht den >tödlichen Stachel des Begehrens`, den sich das `sündige Urpaar< eingetreten hatte, aus ihrem eigenen Fleisch. Und das Tier, der Hirsch liegt unter ihr, »besessen vom Menschen«: Wiederherstellung

408 Montrose, Louis: Elizabeth hinter dem Spiegel: Die Ein-Bildung der zwei Körper der Königin, in Schulte, Regina (Hg.): Der Körper der Königin, S. 95.

409 Vgl. Weil, in: Ebda., S. 101.

410 Vgl. Montrose, a.a.O., S. 83f.

411 Vgl. ebda., S. $96 f$.

412 Vgl. Wyss, a.a.O., S. 175, vgl. Abb. 12, S. 244. 
der »paradiesische[n] Ordnung«, die »das Tier in die Schranken« weist, "wo es so heisst, wie der Mann es nennen will «. ${ }^{413}$ So steht es in Genesis 2,19. Erst werden die Tiere geschaffen, dann das Weib - als Gehilfin.

»Wie Gerasimos/Hironymus« ziehe >Diana den Stachel, schreibt Wyss. ${ }^{414}$ Das ist nicht richtig, denn der zieht den Dorn dem Löwen aus, um das >Tier` zu zähmen. >Dianaく zähmt sich selbst, indem sie den Dorn, »der das Fleisch wild gemacht hat" entfernt, sie schafft sich als aktive Figur ab (und unterwirft das Tier in sich). Selbstdisziplinierung und Unterordnung der ehedem wilden Jungfrau, die niemandem Untertan ist, zur Jungfrau gemäß des reformatorischen Programms. Sie wird »flankiert vom Schützen Apoll« dem »Antitypus zum Sündenfall, d[er] heidnische[n] Allegorie auf die christliche Erlösung «, ${ }^{415}$ der den Pfeil auf dem gespannten Bogen liegen hat.

>Diana〈 hat ihre Waffen, "virginis arma, wie Vergil sagt «, ${ }^{416}$ - ganz offensichtlich mit dem Ausziehen des Dorns - an >Apoll abgetreten. Der Unterwerfung des Tiers geschieht mittels dieses Dorns. Er

»wird zum Pfeil des Jägers, der Sog des Triebes zum Druck des Asketen auf das Fleisch. Dem Löwen des Hieronymus ist der Hirsch Cranachs verschwistert. Was der Löwe dem antiken Asketen, ist der Hirsch dem deutschen Jäger; hatte Herakles sein Haupt mit der leuchtenden Mähne des nemeischen Löwen geschmückt, so schmückt Cranach das Haupt seines Kardinals mit der leuchtenden Hirschhorntrophäe«. ${ }^{417}$

Dieser Kardinal ist Albrecht von Brandenburg, den Cranach 1526 als »heilige[n] Hieronymus im Gehäuse« malt. Dieser asketische »Hirschkönig«, thront im Arbeitszimmer unter einem Leuchter aus Hirschgeweih, der »im Bild [...] auratisch den Mann« glorifiziert, ${ }^{418}$ der einen Rehbock, einen Biber, den gezähmten Löwen, eine Fasanenfamilie, Rebhühner, einen Papagei, einen furchtsamen Hasen unter sich hat. Der Papagei dient dem Christentum als Sinnbild der »unbefleckten Empfängnis Mariens«, er kann »Ave« sagen »wie der Engel«, und dieses »Ave« ist Umkehrung von »Eva«, also »die Erlösungstat Mariens $« .{ }^{419}$ Die Rebhühner sind »überwundene Begierde«, nach antikem Verständnis emp-

413 Ebda.

414 Vgl. ebda.

415 Ebda.

416 Wind, a.a.O., S. 95.

417 Wyss, a.a.O.

418 Ebda., S. 208, vgl. Abb. 65.

419 Ebda., S. 92. 
fangen sie »durch die Luft«, ebenso Marienvögel, weil die Jungen immer zur Mutter fänden. Der Rehbock gilt - im Gegensatz zum Hirsch als »monogam $\ll .{ }^{420}$ Der Biber erscheint als »castratio «, Sinnbild des Asketen, der sich lieber selbst entmannt, als der Versuchung nachzugeben. Das anscheinend infolge eines Irrtums im »Physiologus«, der erzählt, ein Biber habe sich selbst die Hoden abgebissen, um den Jägern nach seinem >Bibergeil $\mathrm{zu}$ entkommen und sei daraufhin sanft und friedfertig geworden. $^{421}$

Cranach ist hier Experte - über Leben und Tod. Er ist Apotheker und Jäger. ${ }^{422}$ Leidenschaftlicher Jäger ist auch Kardinal Albrecht. In seinem »Gehäuse« dient das versammelte Bestiarium als Berufungsinstanz für »die Hierarchie eines christlich gottgewollten Geschlechtslebens«: der aufopferungsvoll enthaltsame Biber, der monogame Rehbock, die Fasanenfamilie. ${ }^{423}$ Hier ist kein Ringen mehr, wie im $»$ Heiligen Hieronymus als Büsser in der Wildnis« (1525). Der Kampf mit der Wildnis ist gewonnen. Apoll und Diana weisen den Weg:

»Das Fleisch, das den Asketen bedrängt, bringt der Jäger am Tier zum Schweigen. Nicht die jungfräuliche Diana allein betreibt das Geschäft der Erlösung, sondern sie im Verband mit dem machtvollen Apoll, der den Dorn in die Sehne spannt, um ihn gegen die Kreatur zu schiessen, die ihn bedrängt, ihresgleichen zu sein. Der Pfeil ist die machtvolle und tödliche Penetranz des jungfräulichen Mannes; der Asket hat Erlösung von seinem quälenden Wunsch in der Rüstung gegen andere gefunden. $\ll^{424}$

Beide halten sich die Natur von Leibe. Für >Diana ist es eine Selbstdistanzierung.

Distanzierung und Selbstdistanzierung als Maximen einer neuen, bürgerlichen Gesellschaftsordnung. Bei Francis Bacon fungiert »die keusche Ehe [...] als Ordnungsfaktor«. Ihr Zweck sei »nicht allein die Fortpflanzung, sondern ebenso die Disziplinierung der Leidenschaften« und Sinne. Ein Absehen vom Fleisch, »Herrschaft und Kontrolle«, die desgleichen in der Wissenschaft zu gelten haben, sei doch auch hier das Streben nach Befriedigung »lasterhaft und unproduktiv $«,{ }^{425}$ ein derarti-

420 Ebda., S. $201 f$.

421 Vgl. ebda., S. 46.

422 Vgl. ebda., S. $44 f$.

423 Vgl. ebda., S. 202.

424 Ebda., S. 175.

425 Braun/Kremer: Asketischer Eros, S. 13f. 
ges Wissen »nichts als eine Kurtisane, die nur dem Vergnügen und nicht der Fruchtbarkeit und Fortpflanzung dient «. ${ }^{426}$

»Das unfruchtbare Glück aus Erkenntnis ist lasziv für Bacon wie für Luther«, notieren Horkheimer/Adorno dazu. Ihnen komme es »auf 〉operation<, das wirksame Verfahren« an - und: »Es soll kein Geheimnis geben, aber auch nicht den Wunsch nach seiner Offenbarung. ${ }^{427}$ Um die Durchsetzung eines distanzierten Naturverhältnisses geht es, per Induktion und Experiment, »d.h. sich mit Natur zu befassen, ohne sich darin zu verlieren oder durch die Berührung mit ihr schuldig zu werden«. Denn die Natur ist weiblich gedacht und das Verhältnis zu ihr ist wie das »zur Frau [...] ein Gewaltverhältnis«. Die Konsequenz ist also eine »Ehe zwischen Verstand und Natur «. ${ }^{428}$

In Bacons Staat »Nova Atlantis« ist das Volk derart keusch, dass es »Jungfrau der Welt« genannt werden könne. ${ }^{429}$ Eine »Jungfrau der Welt «, die im Herrschaftsinstitut der keuschen Ehe diszipliniert und distanziert zur wohlverstandenen Fruchtbarkeit gebracht wird, präsentiert ein anderer Großbändiger der Natur, Carl von Linné. Damit zurück zur ehemaligen 〉Herrin der Tiere` und 〉Göttin der Fruchtbarkeitく.

Das Titelbild zu Linnés 1746 erschienener »Fauna Svevica« zeigt Diana als Frau ohne Unterleib.

»Nicht zufällig hat Linné als Titelbild für seine Fauna Svevica, in der er erstmals für die Integration des Menschen in die Klasse der Vierfüßler eintritt, das uralte Fruchtbarkeitssymbol der vielbrüstigen Diana von Ephesos gewählt. « ${ }^{430}$

Als des Rätsels Lösung, was das Bindeglied zwischen Mensch und Tier ausmache, erkannte er die weiblichen Brüste. Allerdings übersieht Schiebinger, dass die >realeく »Diana von Ephesos«, obwohl sie im 17./18. Jahrhundert so dargestellt (und auch später so verstanden) wird, eben nicht vielbrüstig ist, sondern mit den Hoden der geopferten Stiere behängt. ${ }^{431}$ Darauf aber kommt es an. Zwar geht - so ist anzunehmen auch Linné von der Vielbrüstigkeit der Diana-Figuren aus, real aber

426 Bacon, Francis: Valerius Terminus. Von der Interpretation der Natur; zit. n. ebda.

427 Horkheimer/Adorno: Dialektik der Aufklärung, S. 10f.

428 Braun/Kremer, a.a.O., S. $6 f$.

429 Vgl. ebda., S. 13.

430 Schiebinger, Londa: Am Busen der Natur, S. 90.

431 Dass es sich um Stierhoden handelt, hat Gérard Seiterle nachgewiesen und das Rätsel ihrer >Vielbrüstigkeit` damit gelöst. Vgl. Seiterle: Artemis Die große Göttin von Ephesos, in: Antike Welt, 10 (1979), Heft 3, S. 314. 
wird hier eine `Große Göttin`, der in der Vorzeit fleischliche Zeichen männlicher Kraft und Potenz geopfert werden, zur bloß reproduzierenden »Nährmutter«. Aus den angeeigneten Hoden werden Brüste.

Braun/Kremer zeigen dieselbe Illustration einer stillenden >Frau Welt - »Sein Säugmutter ist die Erden«, »Emblema II« aus Michael Maiers alchemistischem Lehrbuch »Atalanta Fugiens« (1618) -, wie Schiebinger, ${ }^{432}$ sie zeigen aber auch den Zusammenhang, »Emblema I«. Hier wird der »Alchemist als Erzeuger und Gebärer vorgestellt, wogegen die Frau bzw. die Erde zur Nährmutter reduziert ist «. ${ }^{433}$ Schiebinger zeigt eine weitere zeitgenössische Illustration der Natur als Jungfrau, deren Nacktheit »die Schlichtheit ihres Wesens« dokumentiere, umgeben von Hirsch und Löwe als »Keuschheitssymbol«, sowie einer vielbrüstigen Dianastatue. Aus den Brüsten der Jungfrau rinnt Muttermilch. ${ }^{434}$ Eine Art >Maria lactans〈 also. »Das ganze Mittelalter hindurch verehrten die Gläubigen in kleinen Phiolen die Milch der Jungfrau Maria als Heilbalsam, Symbol der Gnade und ewiges Mysterium.« Das aber wegen der >Jungfräulichkeit`, wie Schiebinger selbst schreibt, weil »Maria nie die mit der Geburt assoziierten Lüste und Schmerzen (Menstruation, Sexualverkehr, Schwangerschaft oder Wehen) - ausgenommen das Stillen« - erlebt habe, weshalb sie auch die »metaphysische Verkörperung der mütterlich-nährenden Kirche« sei. ${ }^{435}$

Derartige Bildproduktionen geschehen auch in polemischer Absicht, so in England anlässlich der Vermählung Marys, der katholischen Tochter Heinrich VIII., mit dem Habsburgerprinzen Philipp: »Laut David Loades zirkulierten während Marys Regentschaft >krude Holzschnitte [...], die [Mary als] vielbrüstige Königin portraitierten, die Bischöfe, Priester und Spanier säugte.${ }^{436}{ }^{43}$ Sie nährt die Feinde an ihrem Busen. Auch die >Sapentia ${ }^{437}$ hat eine entscheidende Eigenschaft: Die weibliche Figurine säugt die Philosophen mit Weisheit, aber die Frau selbst denkt nicht. Ihre Personifikation in der Allegorie korreliert mit der Verdrängung des weiblichen Subjekts. Die Frau in der Allegorie wird als bloßer Hilfs-Körper zur starren Systemstütze. ${ }^{438}$ Hier wie da wird nicht Aktivität, sondern passive Reproduktionsleistung thematisiert.

Beim Begründer der neuzeitlichen botanischen Nomenklatur geht es noch weiter:

432 Vgl. Schiebinger, a.a.O.., S. 91, Abb. 2.2.

433 Braun/Kremer, a.a.O., S. 8f.

434 Vgl. Schiebinger, a.a.O., S. 92.

435 Ebda., S. 93.

436 Montrose, a.a.O., S. 82 u. 74.

437 Vgl. Schiebinger, a.a.O., S. 96.

438 Vgl. Weigel: Topographie der Geschlechter, S. 168ff. 
»Linnés Diana ragt nur zur Hälfte aus der fruchtbaren Erde und zeigt dem Betrachter ihren Mutterleib, das Zentrum des Lebens, und ihre nährenden Brüste. In dieser klassischen Darstellung ist ihre sonderbar eingezwängt untere Körperhälfte umgeben von Symbolen der Fruchtbarkeit (Bienen, Eicheln, Stieren, Krebsen) und der Keuschheit (Hirschen, Löwen, Rosen). Ihre hängenden, milchgefüllten Brüste versinnbildlichen die lebensspendende Kraft der Natur, der Mutter und Amme alles Lebenden. $\aleph^{439}$

Wo aber befindet sich die »fruchtbare Erde«, in die Diana so »sonderbar eingezwängt« ist? Sie steckt mitsamt der Göttin in einem Rokoko-Kübel. Diese Diana ist also mitnichten mit dem tatsächlichen Erdboden selbst verbunden, sondern ausdrücklich entfernt von ihm in einer Art kunstvoll verziertem Blumentopf. Sie ist kultiviert wie eine aus der Natur selektierte Pflanze. Aus dem ehedem Ungebundenheit bedeutenden Begriff »Jungfräulichkeit« ist Keuschheit geworden. Allerdings nicht im Sinne völliger Entsagung, sondern als abhängige, lustfreie Reproduktionsrolle innerhalb männlich gesteuerter Fortpflanzung. Diana präsentiert ihren fruchtbaren Mutterleib, nicht aber ihren Unterleib. Ihr Geschlecht ist verschwunden, dem Blick für immer entzogen, verborgen in der dunklen Erde. Von ihm bleibt nur eine dunkle Ahnung. Aber es ist (so) auch kultiviert (im Kübel), und wenn es noch benötigt wird, dann nur innerhalb dieser Schranken. Paradigmenwechsel auch der patriarchalen Auffassung des (Natur-)Geheimnisses: Vom unerklärlichen, offensiven, abgründigen Schrecknis zu dem, was man nicht sehen darf und worüber man nicht spricht. Das Geschlecht der Diana (der Natur, der Frau) ist nicht nur den Blicken der Öffentlichkeit entzogen, sondern auch ihrem eigenen Blick, ihrer Handlungskompetenz, dem »Gebrauch« nach ihrem eigenen Willen. Das Wissen um die vormalige Macht ihres Geschlechts geraten in Vergessenheit. Sein »Gebrauch« geschieht nur noch nach den Maßgaben und Wünschen ihres neuen Herren. Seine Gedanken werden zu den ihrigen.

Der präsentierte fruchtbare Mutterleib ist nur noch eine nach den Naturgesetzen (denen sich die ehemalige Herrin nun zu beugen hat) funktionierende Gebärmaschine: Gefäß zur Aufnahme und Austragung des befruchtenden männlichen Samens. Die zwei Paar Brüste dienen der nährenden Aufzucht der dann in die Welt gebrachten männlichen Frucht. Sie ist nun ausführendes Organ des Vaters - zumal des himmlischen, dessen göttlicher Geist als Stern über ihr schwebt, dessen Strahlen sie treffen, endlich erleuchten.

439 Schiebinger, a.a.O., S. 91. 
Abb. 9: Titelbild zu Linnés „Fauna Svevica“, 1746

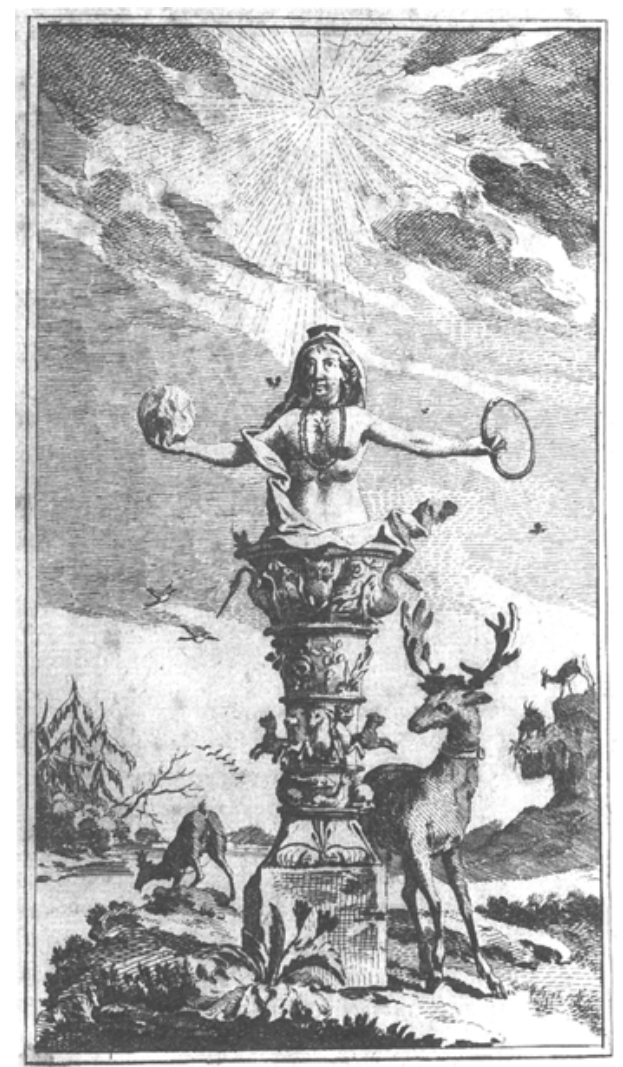

Die ehemals autonome Natur reproduziert nur noch. Nichts anderes ist mehr möglich. Die >Herrin der Tiere mehr umher nach eigenem Willen. Sie ist gefangen. Im Blumentopf. Sklavin des kultivierenden Gärtners. Des Demiurgen, der vorgefundenes Material zum Kunstwerk gestaltet. Und nur in dieser Gestalt ist das vorgefundene Material statthaft, ist Natur akzeptiert. Auch die >Herrin der Natur ist vorgefundenes Material; auf der Ebene des zu transformierenden Sinnbilds. Das gebändigte Schrecknis wird zum Spiegel der Erhabenheit des Bändigers. Der hält sie ebenso gefangen in seiner Erkenntnis ihrer Gesetze. Indem er so ihr Geheimnis enttarnt, unterwirft er sie seinem Willen. 
»Die Aufklärung verhält sich zu den Dingen wie der Diktator zu den Menschen. Er kennt sie, insofern er sie manipulieren kann. Der Mann der Wissenschaft kennt die Dinge, insofern er sie machen kann. Dadurch wird ihr An sich Für ihn. In der Verwandlung enthüllt sich das Wesen der Dinge immer mehr als je dasselbe, als Substrat von Herrschaft. Diese Identität konstituiert die Einheit der Natur. Sie so wenig wie die Einheit des Subjekts war von der magischen Beschwörung vorausgesetzt. ${ }^{440}$

Francis Bacon dringt tief in den Schoß der Natur ein, um dort die Maschine zu finden. ${ }^{441}$ Der Bändiger Linné geht diesen Weg konsequent weiter und entdeckt die Herrschaftsmaschinerie Sexualität. Die Sexualisierung der Pflanzen ist eine Erfüllung des asketischen Eros. Sie bringt die Ordnung der gesellschaftlichen Geschlechterhierarchie ins zuvor Ungeordnete, Unbändige.

Das folgt den von Foucault beschriebenen Transformationen von Herrschaft und Symbolik, von der Herrschaft über den Tod zur Herrschaft über das Leben, von der Macht des Blutes oder des Geblütes (vom >Adelsgeschlecht` zum >biologischen Geschlecht`) zur Analytik des Sexes. Der Wandel zur >politischen Technologie des Lebens` wird aber auch an anderer Stelle deutlich: in der Transformation des Strafsystems. Und hier ist eine strukturelle Übereinstimmung im Umgang mit dem Forst nicht zu übersehen.

\section{Forst II: Der Wald als absolutistische Staats-Maschine}

»[Die] politische Besetzung des Körpers ist mittels komplexer und wechselseitiger Beziehungen an seine ökonomische Nutzung gebunden; zu einem Gutteil ist der Körper als Produktionskraft von Macht- und Herrschaftsbeziehungen besetzt; auf der anderen Seite ist seine Konstituierung als Arbeitskraft nur innerhalb eines Unterwerfungssystems möglich (in welchem das Bedürfnis auch ein sorgfältig gepflegtes, kalkuliertes und ausgenutztes politisches Instrument ist); zu einer ausnutzbaren Kraft wird der Körper nur, wenn er sowohl produktiver wie unterworfener Körper ist. ${ }^{442}$

Der Forst ist ein Körper, ein Gesellschaftskörper. Die Transformationen betreffen zwangsläufig auch ihn. Der Forst ist zunächst der Ort des Blutrituals, er wird sich wandeln zum Ort der Disziplinierung seiner selbst;

440 Horkheimer/Adorno, a.a.O., S. 15.

441 Vgl. Braun/Kremer, a.a.O., S. 2.

442 Foucault, Michel: Überwachen und Strafen, S. 37. 
vom Ort der rituellen Einschreibung >voller Körper` über eine weitgehend hohle, gar schadhafte Kulisse im barocken Jagdpomp ${ }^{443}$ zum Ort der Kalkulation; vom dezidiert exklusiven Hof über die absolutistische Stände- zur autoritären Bürger-Gesellschaft.

»Wir haben jetzt eine Forstwissenschaft, weil es uns am Holze fehlt«, zitieren Wilhelm Bode und Martin von Hohnhorst Heinrich Cotta, einen der "forstliche[n] Klassiker am Beginn der Waldbauzeit« und geben ihm Recht: "Damit hatte er eben so knapp wie treffend die Aufgabe der Forstleute seiner Zeit beschrieben. Wo keine Bäume sind, also auf Heide-, Öd-, Kahlflächen und in verlichteten, verbuschten und überalterten Wäldern, war der Wald durch Saat und Pflanzung aufzubauen. Nichts lag näher.« ${ }^{444}$ Der geregelte Forst, die »Holzzucht«, wie sie treffend in der deutschen Forstfachliteratur des 19. Jahrhunderts genannt werde, ${ }^{445}$ als Ergebnis rein ökonomischer Notwendigkeit? Selbst, wenn das so wäre, gehorcht der Aufbau sozialen und ideologischen Bedingungen. Der Forst ist von Beginn an eine definierte Körperschaft, ein spezifischer Bedeutungsraum, eine Spiegelung menschlicher Vergesellschaftung in ihrer historischen Veränderung. Zudem dienen die neuen Forste explizit ästhetischen Ansprüchen. Bode/Hohnhorst übersehen die Mehrdeutigkeit von `Zuchtく, und sie übersehen noch etwas, wenn sie kritisieren, dass »der Pflanzakt des Försters bis heute zur >grünen Wohltat $<$ hochstilisiert«, werde, noch immer »Leitmotiv« sei, aber eine vorherige flächenhafte und gründliche Entwaldung schlicht verdrängt werde. ${ }^{446}$ Die Herrschaft von Maß und Zahl ist das gemeinsame Grundprinzip von Askese und Kapitalismus und Naturwissenschaft. Herrschaft und Ordnung in der Forstlandschaft bedeutet nicht nur Wiederbestockung devastierter Flächen, sondern auch, dass noch vorhandener >Wildwuchs ebenso wie nicht mehr geduldete materielle wie mentale Nutzung etwa in bäuerlichen Waldungen bekämpft und beseitigt wird. Der Wald wird behandelt als »gelehrige[r] Körper«, der >Bauer» wird ihm

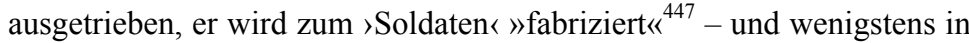
Deutschland wird der Wald seit dem Ende des 18. Jahrhunderts zum >stehenden Heer`, werden die Bäume >Recken`, >Soldaten ${ }^{448}-$, bzw. zum funktionierenden Untertan.

443 Vgl. Bode/Hohnhorst: Waldwende, S. 43f.

444 Ebda., S. 54.

445 Vgl. ebda., S. 55.

446 Vgl. ebda.

447 Foucault, a.a.O., S. 173ff.

448 Vgl. Kap. Der Aufmarsch der Soldaten. 
Der Forst ist ein Rechtssystem. Wie im Strafsystem der peinlichen Halsgerichtsordnungen die Marter- und Hinrichtungsrituale in einem sozialen Kontext ablaufen, in dem die »menschliche[n] Körper nicht die Nützlichkeit und den Marktwert haben, wie später in einer industriellen Ökonomie «, ${ }^{449}$ hat auch der vormoderne Forst mit derartiger Nützlichkeit noch nichts zu tun. Auch im Forst entfaltet sich die »physische, materielle, furchterregende Gewalt des Souveräns«. Auch hier gibt es nur »Kampf und Sieg» wie im Krieg und bei der öffentlichen Hinrichtung, ${ }^{450}$ schreibt sich der Souverän nach genau fest geschriebenen Regeln in Körper ein - die strukturelle Übereinstimmung wird deutlich. Der neue Forst der »Waldbauzeit ${ }^{451}$ hingegen gleicht dem $»$ Verwaltungsapparat« und seiner »Technik des Einzwängens der Individuen«, seiner Arbeit »mit Dressurmethoden, die am Körper nicht Zeichen, sondern Spuren hinterlassen: die Gewohnheiten des Verhaltens «. ${ }^{452}$

Im ausgehenden Mittelalter, so Spehr, weicht der »Optimismus« des "Glaubens an scholastische Rationalität und pragmatische Naturbeherrschung« der »Krise des 14. Jahrhunderts«, Entwaldung, Devastierung der Böden, Agrarkrisen, Hungersnöten, der Pest. Habe dies vereinzelt zu vor allem städtischen Nutzungsbeschränkungen etwa bei weiteren Rodungen geführt, ${ }^{453}$ seien hingegen »Wildtiernutzung« und »kulturelle Symbolik der Jagd« dem »Haupttrend der Zeitwende zur Neuzeit« gefolgt: »dem Revanchismus der herrschenden Gruppen, die ihre Superiorität durch die ökologische und gesellschaftliche Krise in vielfältiger Weise bedroht« sehen. So forciere ein Bündnis aus »alten Zentralgewalten« und »neuen, dynamischen Sozialschichten« im Bemühen einer Reetablierung ihrer Herrschaft den radikalen »Bruch mit einem regenerativen Naturverhältnis und seinen Spiegelungen in der Volkskultur«, dem »Ausstieg aus dem `ökologischen Haus`, Aufkündigung traditioneller sozialer Systeme, Militarisierung des männlichen Sozialcharakters« zwischen 1450 und $1640 .^{454}$ Spehr spricht dabei von »der künstlichen Mythologie der herrschaftlichen Jagd « im Gegensatz zum »kulturelle[n] Wildbezug«, der in der »bäuerlichen Lebenswelt [...] einen bedeutsamen Platz« einnehme. »Wildtiere waren, wie bejagt oder lästig

449 Foucault, a.a.O., S. 72.

450 Vgl. ebda., S. 67.

451 Bode/Hohnhorst, a.a.O., S. 44.

452 Foucault, a.a.O., S. 170.

453 Vgl. Spehr, a.a.O., S. 63f. Er beruft sich dabei auf Bowlus, Charles R.:

Die Umweltkrise im Europa des 14. Jahrhunderts, in: Sieferle (Hg.): Fortschritte der Naturzerstörung; S. $13 \mathrm{ff}$.

454 Vgl. ebda., S. 64f. 
auch immer, ein kulturell besetztes Phänomen, wie es in der Tradition von Fabeln, Sagen und Bauernregeln zum Ausdruck kommt. Sie spielten auch eine (medizinische, symbolische, kulturelle) Rolle im Bereich der weiblich kontrollierten Gesundheits- und Sozialwissenschaft, die von den Exponenten der neuen patriarchalen Sozialtechnologien als Hexenwissen dämonisiert und vernichtet wurde $« .{ }^{455}$ Abgesehen davon, dass magische oder heilkundliche Praktiken in vorbürgerlichen Sozialsystemen als >Wissenschaften ' zu bezeichnen einen Anachronismus darstellt, nennt Spehr keine Quellen für »kulturelle Wildbez[üge]«, obwohl es sie gibt. ${ }^{456}$ Wie »regenerativ« diese Praktiken ${ }^{457}$ und traditionelle Naturnutzungen überhaupt sind, wird nicht diskutiert. ${ }^{458}$ Von diesen Bezügen »entkleidet« komme es zur Reduktion auf Schädlingsbeseitigung, der Ausrottung von Raubtieren, die herrschaftliche Jagdstrecken oder Wollschafe, sowie von »Huftieren, die den Anbau« bedrohten. »In allen Untersuchungsländern verschwanden zwischen 1500 und 1650 Wolf und Bär nahezu restlos, in England wurden Wildschweine ganz ausgerottet. ${ }^{459}$ Kurz zuvor jedoch betont er »die zügige Ausrottung von Schädlingen und Nutzungskonkurrenten« bereits Jahrhunderte zuvor - »Bär,

455 Ebda., S. 67.

456 Siegfried Seligmann zählt für ganz Europa und (andere Kontinente) derartige Nutzungen auf. Ich beschränke mich hier auf die drei großen Raubtiere. Bären schützen vorm bösen Blick oder Behexung, wenn man sie im Stall hält oder ihn um den Stall herum oder durchs Dorf führt, auf ihm neun Schritte reiten hilft gegen neun Krankheiten (Frankreich 15. Jh.); seine Zähne sind Amulette usw. (Die magischen Heil- und Schutzmittel aus der belebten Natur. Das Tierreich, S. 35ff.). Die Asche verbrannter Luchshaut und -krallen heilt in der Antike Hautjucken. Krallen werden seit der Bronzezeit als Amulett getragen. Noch im frühen 19. Jahrhundert wird in Bayern Luchsfleisch gegen Schwindel verordnet (ebda., S. 191). Der Wolf - oder seine Teile - gelten als Talisman, die dessen Eigenschaften (»Stärke, Mut, Verwegenheit usw.«) übertragen, oder als Amulett gegen böse Tiere, Geister oder Zauber: insbesondere Fell von bestimmten Stellen, Haare, Augen dienen diesem Zweck (ebda., S. 304ff.).

457 >Mitgefühl zeigen derartige vorbürgerliche Sinnproduktionen jedenfalls nicht. Da werden lebende schwarze Katzen verbrannt, um Hexen zu bannen, lebende Kätzchen eingegraben, um Felder zu entzaubern (vgl. Seligmann, a.a.O., S. 166f.), lebendige Igel in Töpfen verbrannt und das daraus gemachte Pulver gegen Epilepsie verabreicht (vgl. ebda., S. 162), Fledermäuse an Stalltüren genagelt, um vor Behexung zu schützen (vgl. ebda., S. 87) etc.

458 Und nur an zwei Stellen belegt, wenn auch ohne Quellenangabe. So für »Murmelgenossenschaften ", in denen in den Alpen Bauern gemeinsam festlegen, wieviel Murmeltiere erbeutet werden, und für die »Urwechselwirtschaft« (vgl. Spehr, a.a.O., S. 62f.).

459 Ebda., S. 68. 
Wolf und Luchs wurden in weiten Gebieten ausgerottet, auf der britischen Insel war bis zum Ende des 12. Jahrhunderts auch der Biber vernichtet « - und schreibt das einem »relativ hemmungslose[n] Pragmatismus der Pioniere $«$ zu. ${ }^{460}$ Diese »Pioniere« dürften sich aber wohl überwiegend aus den bäuerlichen Unterschichten rekrutieren, wie das für die gewaltigen Rodungen in dieser Zeit ebenso gilt. ${ }^{461}$

Insgesamt argumentiert Spehr zu schlagwortartig. Er spricht vom »machiavellistischen« und »inquisitorische[n] Naturverhältnis«. Das Erste sei charakterisiert durch ein »zweckrationale[s] Unmittelbarkeitskalkül«, das Bodenareale und Lebewesen »gewaltförmig« einzig nach Kriterien des Herrschaftserhalts zu behandelnden »planerische[n] Größen« unterwerfe, ${ }^{462}$ das Zweite »addiert zum Kalkül den Haß«. Er beruft sich auf Hartmut Böhme: »Die Natur ist in diesem Konzept nur noch das Fremde und Sündige, dessen Macht es zu brechen gilt«, und Carolyn Merchants Darstellung Baconscher Analogisierung von inquisitorischer Praxis und wissenschaftlicher Naturerkenntnis. Daraus folge, »Gewalt und Kontrolle« gegen/über >Natur« werde »zur Selbstbestätigung eigener Identität, zum Bedürfnis, auch jenseits des direkten rationalen Kalküls«. Das »Beherrschte soll sagen, daß es nicht mehr in der Lage ist, noch Rache zu nehmen «. ${ }^{463}$ Das ist richtig, aber nur zur Hälfte. Wenn Bacons Theorien als »ideologischer Überbau über ein gesellschaftliches Programm « ${ }^{464}$ angeführt werden, kann dessen Credo einer Reetablierung menschlicher Naturbeherrschung mittels Befolgung ihrer Gesetze nicht unerwähnt bleiben. Denn es geht hier zwar um Zerstörung, aber nicht einfach nur um »ein Ritual der verbrannten Erde «, ${ }^{465}$ sondern eben auch um Herrschaft durch Neuschöpfung (selbst, wenn derartige Pläne noch lange ihrer realen Umsetzung harren sollten). ${ }^{466}$

Zurück aber zunächst zum Jagdprimat im Forst.

»An der Schwelle zur Waldbauzeit war der Förster [...] zuallererst Jäger. Ein Jäger, der vor die Reste und Kulissen eines Waldes gestellt war, der jegliche Natürlichkeit seit Menschengenerationen verloren hatte. ${ }^{467}$

460 Ebda., S. 63.

461 Vgl. Bowlus, a.a.O., S. 18 u. 22.

462 Vgl. Spehr, a.a.O., S. 66.

463 Ebda., S. 69. Das Böhme-Zitat aus: Natur und Subjekt. Frankfurt/M 1988.

464 Ebda.

465 Ebda.

466 Ich gehe weiter unten näher darauf ein.

467 Bode/Hohnhorst, a.a.O. 
Das - neben den Auswirkungen der Waldweide - offensichtlich auch als Folge der herrschaftlichen Jagd: der Überhege des Wilds und der daraus resultierenden Schäden und der Vernachlässigung der »eigentlichen Aufgabe« durch Förster, die völlig im »aufgeblähten Jagdbetrieb[]« eingespannt sind, wo Herrenjagden monatelange Vorbereitungen verlangen, gigantische $>$ Jagdstrecken < erzielt und Kosten verursacht werden, wie etwa »eine der letzten großen Prachtjagden Friedrichs I.« von Württemberg $1812 .^{468}$

»Spätestens seit dem 16. Jahrhundert ist bekannt«, schreibt Rolf Roosen, »daß eine serödigung vnd außreutung der Först vnd anderer Gehültzı, also die übermäßige Nutzung des Waldes sowohl in forstlicher als auch in jagdlicher Hinsicht ausgesprochen nachteilig ist «. ${ }^{469}$ Aber für die frühe Neuzeit gelte in den Forsten noch das Primat der Jagd, führen »überhegte[] Wildbestände« zu »recht enorm[en]« (Fraß-)Schäden in den Forsten aber auch den landwirtschaftlichen Flächen. Hier ist

»nicht die geordnete Forstwirtschaft, sondern vielmehr die Jagd vorrangig [gewesen]. Denn die geordnete Forstwirtschaft wurde kurzerhand auf wildarme Regionen verwiesen. Und das Wild ist nicht so reduziert worden, daß die Eicheln ohne Schaden wachsen konnten. Dies ist symptomatisch. Im 15. und 16. Jahrhundert rangierte die Jagd vor der Forstwirtschaft $\ll$. ${ }^{470}$

Zwar seien den damaligen »Weid- und Forstleute[n]« unter der Bezeichnung »Beschädigung« die »Verbiß-, Schäl- und Fegeschäden« durch Wild bekannt, gebe es mitunter Verordnungen zum Schutz »junge[r] Bäume mithilfe von >Stökken` oder >Dörnen « ${ }^{471}$ mit Wildschutzzäunen oder »lebendige[n] Hecken«, aber alles nur so weit, dass die Jagd nicht beeinträchtigt wird, oft müssen solche Zäune um Agrarflächen für die Pirsch eigens entfernt werden, andernorts sind sie ganz untersagt und sollen »Wildwächter« oder -hüter das Wild von den Äckern und Feldern vertreiben. Vereinzelt werden auch Entschädigungen in Aussicht gestellt. $^{472}$

Das ist die gängige Darstellung von >Forstgeschichte<: Schädigungen des Waldes aller Art sind zwar bekannt, Gegenmaßnahmen ansatzweise auch. Die Basis dafür, erwünschte Populationen auch in der Baumflora hervorzubringen und unerwünschte (falsche Baumarten, fal-

468 Ebda.

469 Roosen: Jagdsprachlicher Sachwortschatz, S. 277; Binnenzitat aus »Geiaidsordnung der Fürstenthumben Obern und Nidern Bayrn« von 1616.

470 Ebda., S. 278.

471 Ebda., S. 277f.

472 Vgl. ebda., S. $279 \mathrm{ff}$. 
scher - krummer, zu enger - Wuchs, Unterwuchs usw.) auszusondern, ist zwar bereits im Spätmittelalter geschaffen. Aber es fehlt an Stringenz und Konsequenz. Die künstliche Aufzucht von Nadelbäumen gerät in Vergessenheit - angeblich infolge des Dreißigjährigen Kriegs - wird erst im 18. Jahrhundert wiederentdeckt und von da an systematisch angewandt. $^{473}$

Die mittelalterlichen Forsten sind in Aussehen und -dehnung »keine starren Gebilde«, werden oft im Laufe der Zeit »kleiner und in Einzelteile zerrissen«, um später wieder zusammenzuwachsen oder größer zu werden. Zudem umfassen diese Forstflächen nicht nur »Waldgebiete im heutigen Sinne«, sondern »mancherlei Freiflächen, Wiesen, Äcker und Dörfer«, so dass die Größe mittelalterlicher und frühneuzeitlicher Forsten nicht "auf die Gesamtausdehnung der Waldflächen schließen« lässt. ${ }^{474}$ Aus dieser Sicht herrscht also >Flickwerk২. Der Grunderr allein setzt die Nutzung fest. Er kann roden lassen, um Kolonien zu gründen sozusagen bewegliche »Rodungsinseln«, die sich ausdehnen und wieder verengen - mit Kolonisten aus anderen Landesteilen, oder aus dem hier bereits ansässigen »wilde[n] Heer« zur Disziplinierung. ${ }^{475}$ Er kann das Land wieder verwildern lassen, zu »Wüstungen«, die aber auch infolge der Landflucht in die Städte entstehen und häufig bewusst nicht wieder besiedelt werden sollen. ${ }^{476}$ Es kommt zu enormen Strapazierungen der Waldungen um die Städte herum, bis hin zur Abholzung »kompletter Wälder«, um Nutzholz zu gewinnen: »So lange es noch Wälder zum Abholzen gab, blieb alles beim alten. $«{ }^{477}$ Dauerkonflikte entstehen, wie schon mehrfach angesprochen, aus der Jagd und den damit verbundenen Schäden bzw. dem Verbot der Unterschichten, sich mit Wild zu versorgen. Aber auch auf den niederen Adel wächst der Druck - von zwei Seiten: durch das Städtebürgertum, den kommunalen Landerwerb und durch die Territorialfürsten und deren zunehmende Forsthoheit. ${ }^{478}$

Wald- und Forsthistoriker des 20. Jahrhunderts klagen über mangelnde Kontinuitäten. Kurt Mantel lobt besonders den Fortschrittscharakter und die "vorbildlichen Formulierungen" in Richtung einer »echten Bestandspflege« der württembergischen Forstordnungen des frühen 16. Jahrhunderts - die hauptsächlich auf (von Natur aus weitgehend ortsfremdes) Nadelholz bezogen sind, und beklagt die Nichtfortsetzung

473 Vgl. Mantel: Wald und Forst in der Geschichte, S. 431f.

474 Küster, a.a.O., S. 131.

475 Vgl. ebda., S. $125 f$.

476 Vgl. ebda., S. 129.

477 Ebda., S. 137.

478 Vgl. Sonntag, a.a.O., S. 106. 
dieser »erfreulichen Anfänge« im 17. und 18. Jahrhundert als Folge des Dreißigjährigen Krieges:

$»$ Den erstmaligen Höhepunkt einer Bestandspflege im waldbaulichen Sinn brachten die Forstordnungen, die eine forstliche Begründung der Waldpflege geben. Sie forderten, durch die Eingriffe den verbleibenden Stämmen Luft und Raum zum besseren Wachstum zu geben. ${ }^{479}$

Friedrich Mager betont zwar den »Grundcharakter des raubbaulichen Forstbetriebes« vom 14. bis in die zweite Hälfte des 18. Jahrhunderts in »Altpreußen«, dem »auch die primitiven Betriebsformen« entsprochen hätten, wobei zwischen »drei Waldformen unterschieden« worden sei: dem Nutzwald, der ohne »Rücksicht auf [...] Nachhaltigkeit«, je nach Bedarf und Willkür« genutzt worden sei (»für Weide, Mast, Holzhieb, Streugewinnung und die verschiedensten gewerblichen Zwecke«), dem zu schonenden Hegewald, und der urwaldähnlichen Wildnis. ${ }^{480}$ Eine »eigentliche Waldpflege«, zu deren »Hauptmethoden« die »regelmäßige Durchforstung« gehört, sei in »größerem Maßstab [...] erst seit der Durchführung der Forstreform ausgeübt worden«. Gleichwohl seien Durchforstungsmaßnahmen hier »schon im 16. Jahrhundert bekannt gewesen«, wie ein Beleg von 1589 zeige. »Die Maßnahme der >Läuterung〈 wird [hierin] als bekannt vorausgesetzt und scheint schon lange wenigstens in den reinen Nadelholzbeständen üblich gewesen zu sein, dürfte freilich nur in den Hegerevieren der dichter besiedelten Landesteile Anwendung gefunden haben. $\ll^{481}$

So scheint Paolo Uccellos Gemälde »Nächtliche Jagd« (1460) einen bewirtschafteten Wald zu zeigen, in dem die Bäume - alle gleich groß und dick - allesamt bis zur Krone herauf per Säge >geläutert` sind. ${ }^{482}$ Gleiches gilt auch für den Hain in Botticellis »Primavera« (1482).

Die Läuterung ist ein weiteres Hauptmerkmal der Forstwirtschaft. Hierbei soll für möglichst astfreie Stämme gesorgt werden. Zwar wird die >Läuterungく immer wieder als »scharfe[r] natürliche[r] Auslesepro-

479 A.a.O., S. 356f.

480 Vgl. Mager, Friedrich: Der Wald in Altpreußen, Bd. I., S. 206.

481 Ebda., S. 231.

482 Vgl. Clark, Kenneth: Landschaft wird Kunst. Köln: Phaidon-Verlag 1962 (Oxford 1949), Abb. 20. Merkwürdigerweise spricht Clark von »uralte[r] Stille«, die der Wald ausstrahle, so, als sei er bis zum Einfall der Jäger >unberührt< gewesen, ebda., S. 14. 
zeß in der Dickungsphase ${ }^{483}$ (also ab dem Zeitpunkt, an dem die Bäume beginnen, sich zu berühren, ein >Dickicht` bilden, in dem durch Lichtmangel die unteren Äste verkümmern) bezeichnet; was so aber regelmäßig nur in gepflanzten Beständen vorkommt. >Läuterung < bezeichnet daher auch das Absägen der Äste oder eine Verschärfung der >Auslese « durch 〉Ummantelung` der Zuchtbäume mit Hilfsbäumen. So werde die Hainbuche »in Eichen- und Buchenreinsaaten [...] häufig mit der Linde zusammen in diese eingepflanzt mit der künftigen Aufgabe, durch die Ummantelung der Eichen oder Buchen deren Astreinigung zu fördern ${ }^{484}$

Der systematische Umbau bzw. Bau, die systematische Ordnung von Wäldern verfolgt nicht einfach >rein` ökonomische Zwecke, sondern desgleichen Strategien der Homogenisierung, der Exklusion des Andersartigen, Fremden, der Decodierung und Synthese, der Beherrschung/Kanalisierung von >Sinnlichkeit`, der Universalisierung und der Ästhetisierung.

Schon das Imperium Romanum, zeigt Harrison, erobert die Welt, indem es sozusagen »seine Stadtverwaltung« über die Europa bedeckende "große Waldmasse [...] triumphieren« lässt. »Die abweisende Dichte dieser Wälder« garantiere eine relative »Autonomie und Vielfalt «, den »Spielraum für kulturelle Privatheit« bzw. Differenzierung, »die notwendige >Verborgenheit` für eine sich selbst erzeugende Identität in Sprache, Sitten, Gottheiten, Traditionen, Stilen [...]. Die Wälder waren Hindernisse - für Eroberung, Hegemonie, Homogenisierung. Sie waren, mit einem Wort, Asyle kultureller Unabhängigkeit. ${ }^{485}$ Wobei es offensichtlich schon ausreichen kann, was Harrison hier nicht sieht, dass der potentielle Hegemon eine derartige Unabhängigkeit auch nur konstruiert.

»In ihrem Trieb, ihr Reich zu universalisieren, fanden die Römer Wege, diese latente Waldmasse entweder abzuholzen oder zu durchqueren. Sie waren nicht nur Invasoren, welche plünderten und brandschatzten und dann weiterzogen; sie waren Erbauer von Straßen, kaiserlichen Landstraßen, Institutionen und einem breiten integrierten >Telekommunikationsnetzı. Durch ihre Verwaltung

483 Arbeitskreis forstliche Landespflege in der Arbeitsgemeinschaft Forsteinrichtung: Biotop-Pflege im Wald. Ein Leitfaden für die forstliche Praxis. Greven: Kild-Verlag 1987, S. 28

484 Eggeling, Friedrich Karl von: Der Jäger als Land- und Forstwirt. Ein Leitfaden für Revierpraxis und Jägerprüfung. Hamburg, Berlin: Parey 1991, S. 58; Hvhbg. v. m.

485 Vgl. Harrison: Wälder, S. 71. 
gliederten sie ihre nahen und fernen Kolonien in die souveräne Ordnung ihrer Institutionen ein. Man braucht nur zu beobachten, wie der römische Architekturstil die Welt eroberte. Wenn wir durch Gallien, den Nahen Osten oder Nordafrika reisen, können wir immer noch die erstaunliche Uniformität der römischen Städte sehen, die alle nach einem einheitlichen Prototyp gebaut sind, mit denselben Strukturprinzipien und denselben Steinschnitten, derart daß das, was man in den Tälern Galliens findet, mit dem identisch ist, was man auf den Landzungen Kleinasiens antrifft. Das Reich löschte zahlreiche Variationen lokaler Kultur aus: eine Vielfalt, die durch die Latenz des Lokalen gehegt und bewahrt wurde. ${ }^{486}$

Sind in den literarischen Zeugnissen vorbürgerlicher Gesellschaften die tiefen wilden Wälder eher Neben- denn Gegenwelt, trotz oder vielleicht gar wegen aller Irrungen und Wirrungen, allen Labyrinthischen mit Sinn aufgeladen, so dienen sie seit der »Rekonstruktion der Natur zur Maschine $\ll^{487}$ als Sinnbilder einer zu beseitigenden Unordnung, Behinderung und (sinnlichen) >Abirrung<:

»Die wahre Ordnung der Erfahrung zündet zuerst ein Licht an, zeigt dann bei Licht den Weg, indem sie mit einer wohlgeordneten und gegliederten Erfahrung beginnt, keineswegs aber mit einer voreiligen und irrenden. Daraus entwickelt sie die Lehrsätze und aus diesen folgert sie wiederum neue Experimente; denn auch das göttliche Wort hat den Stoff der Dinge nicht ohne Ordnung behandelt. Man höre darum auf, sich zu wundern, wenn der Bereich der Wissenschaften nicht vollendet ist, da man ja völlig vom Wege abgeirrt war. Völlig verlassen und einsam ist die Erfahrung, sie verwirrt sich im Umherlaufen wie in einem Labyrinth in sich selbst, während doch ein wohleingerichtetes Verfahren auf festem Pfad durch die Wälder der Erfahrung zu den Lichtungen der Lehrsätze führt. « ${ }^{488}$

Bacons Aphorismus 82 lässt sich lesen als Text über >Wälder von Traditionen ‘, die es zu überwinden gelte. Aber er ist auch in anderer Hinsicht programmatisch, denn diese labyrinthischen Wälder sind nicht einfach metaphorisch, sondern sie stehen für eine Natur, über die der Mensch »durch seinen Fall« die Herrschaft verloren hat wie »den Stand der Unschuld«. Es könne aber beides »bereits in diesem Leben einigermaßen wiedergewonnen werden, die Unschuld durch Religion und Glauben, die Herrschaft durch Künste und Wissenschaften. Denn die

486 Ebda., S. $71 \mathrm{f}$.

487 Braun/Kremer, im Untertitel

488 Bacon, Francis: Novum Organum. Neues Organon der Wissenschaften.

Hg. v. Wolfgang Krohn. Lateinisch - deutsch. 2. Bde. Hamburg: Felix Meiner 1990. Bd. I, S. 177. 
Schöpfung ist durch den Fluch nicht gänzlich und bis ins Mark hinein widerspenstig gemacht worden «. ${ }^{489}$

Bacon behauptet, »reinen Tisch« mit bisherigen Traditionen, überhaupt »Tabula rasa« zu machen. »Es wäre für sich genug, wenn der menschliche Geist eben und gleich einer Tabula rasa wäre«, notiert er in der »Instauratio Magna«, allein, »die Geister der Menschen sind auf wunderliche Weise besessen, so daß die ebene und reine Oberfläche fehlt, um die Strahlen der Dinge richtig aufzufangen«. Daher bietet er sich als »einen treuen Priester der Sinne (aus denen alle Kenntnisse in den Dingen der Natur geschöpft werden muß, wenn man nicht irre werden will)« und »nicht ungeschickten Dolmetscher ihrer Orakel. Und während andere nur in Worten versprechen, die Sinne zu ehren und zu pflegen, tue ich es in der Tat. Derart ist das, was ich für die Erleuchtung der Natur, für das Anzünden und Eindringen des Lichtes vorbereite «. ${ }^{490}$ Wie ehrt ein solcher Priester die Sinne in der Tat? Die menschlichen Sinne als »Maß der Dinge« aufzufassen, sei ein kompletter »Irrtum», denn »alle Wahrnehmungen der Sinne wie des Geistes geschehen nach dem Maß der Natur des Menschen, nicht nach dem des Universums«. Menschlicher Verstand sei ein Zerrspiegel, der eingefangene Strahlen der Dinge nicht gerade reflektiert, »sondern seine Natur mit der der Dinge vermischt, sie entstellt und schändet $« .{ }^{491}$ Für das »Brautbett des Geistes und der Natur unter dem Beistand der göttlichen Güte «, ${ }^{492}$ jene $» k e u-$ sche Ehe $\ll,{ }^{493}$ die Bacon anstrebt, braucht es rationale Distanz, um die Natur zu berühren, ohne von ihr berührt zu werden. ${ }^{494}$

Wald (der unbeherrschte) ist der Ort der sinnlichen Übergriffe, Manipulator der Einbildungskraft, was für die >gefallene`, die so >weiblich gewordene` Natur insgesamt zutrifft. Weshalb die Trennung von Leib bzw. schon formiertem Körper und Geist zwingend ist. Diese Reinigung des Verstandes/Geistes von Verstrickungen und Täuschungen durchs Sinnliche, vom Körperlichen, ist eine männliche Disposition. Dass Frauen derartiges nicht gelingen kann, ızeigen sionen über weibliche Pathologie und ungezügelte Einbildungskraft und den daraus resultierenden Möglichkeiten, Monster zu gebären.

Die Verwandlung der »mittelalterliche[n] ordo« in eine »Ordnung der Dinge $:^{495}$ Die Landschaft, die erst der städtische Bürger in der frü-

489 Novum Organum II, S. $611 \mathrm{ff}$.

490 Novum Organum I, S. 49.

491 Ebda., S. 101.

492 Ebda., S. 51.

493 Braun/Kremer, a.a.O., S. 13.

494 Vgl. ebda., S. 7.

495 Burckhardt: Metamorphosen, a.a.O., S. 175. 
hen Neuzeit entdecken kann, entsteht mit der Zentralperspektive (nach Burckhardt die Vervollkommnung der Kathedrale ${ }^{496}$ ), »räumliche[s] Analogon der Mechanischen Uhr«, in der die `Erste Natur« einen abstrakte[n] Tod « erleidet und eine abstrakte Wiedergeburt »zur Zweiten Natur« erlebt, der >Platzanweiserin`, in der - im Zusammenhang mit dem Dualismus Körper-Geist - die Verkehrung des `Subjekts` vom antiken »Unterworfenen« zum Herrschenden, das 〉Objekt` vom 〉Gegenstand 〈 im älteren Sinn von >Widerstand und somit fixier- und feststellbaren wird. ${ }^{497}$ Die Landschaft entsteht also in der Zentralperspektive - die »den Körper und seine Sinne überflüssig zu machen scheint ${ }^{498}$ und damit einer >Naturverstrickung entgegenwirken soll -, deren stetige Fluchtpunktverlagerung »in die Tiefe des Raums « eine »Landnahme « ist ${ }^{499}$ - wie sie mit der >Neuen Welt desgleichen vollzogen wird, real und »im Kopf«. Dieser »neue Kontinent erschließt [...] neue Maße«, die Möglichkeit zu messen und vermessen, »eine Welt nach Maß zu errichten«. ${ }^{500}$

Der »fiktive Blick«, die »Vereinheitlichung der Wahrnehmung« schafft eine »neu gefestigte[] Ordnung $\aleph^{501}$ - wie Baltasar Graciáns $» E l$ Criticón oder Über die allgemeinen Laster der Menschheit« (1651-57) mit der Konfrontation des »zivilisierten« mit dem »)wilden〈, naiven Blick« propagiert ${ }^{502}$-, eine Ordnung, in der die Natur nun »sinnstiftende Funktion« erhält, indem sie »in ihrem als gesetzmäßig und ewig begriffenen Ablauf dem an sich Sinnleeren einen Sinn « sichert, ${ }^{503}$ die »reinen Formen [...] als transzendental begreifbar und damit als Unterpfänder höherer unvergänglicher Ordnung gültig gemacht« werden, ein $»$ Regreß«, der zugleich Progress ist. ${ }^{504}$ Der »fiktive Blick« ist ein $>$ messbarer Blick«, wie das Johannes Kepler in seiner »Physik des Sehens« grundlegt; ${ }^{505}$ Nach Kepler, der auch die »Himmelsuhr« gegen vitalistische Renaissance-Vorstellungen vom Kosmos als »große[m] Tier« stellt, sei doch die »Himmelsmaschine« kein »göttliches Lebewesen«, sondern eben Uhr, nach Maß und Zahl analysierbar. Descartes bleibt es »vorbehalten, den Rest von Natur zu denaturieren und die Uhr als Zentralme-

496 Vgl. ebda., S. 164.

497 Vgl. ebda., S. $152 \mathrm{ff}$.

498 Kleinspehn, Thomas: Der flüchtige Blick, S. 53.

499 Burckhardt, a.a.O., S. 157.

500 Ebda., S. 175.

501 Braun/Kremer, a.a.O., S. 86f.

$502 \mathrm{Vgl}$. Kleinspehn, a.a.O., S. $81 \mathrm{ff}$.

503 Braun/Kremer, a.a.O.

504 Vgl. Lippe, Rudolf zur: Naturbeherrschung am Menschen II, S. 210.

505 Kleinspehn, a.a.O., S. 83. 
tapher zu inaugurieren «. ${ }^{506}$ Franz Borkenau sieht in Descartes Denken den »ersten Höhepunkt« eine »doppelte kopernikanische Wende«, eine »Umkehrung der Scholastik«, das Bemühen,

»den Sinn und die Gesetze des menschlichen Daseins aus der äußeren >Natur abzulesen. Doch diese Umkehrung ist [...] eine bloß formelle. In Wahrheit wird das Naturbild der gesellschaftlich bedingten Auffassung des Menschen nachgebildet und diese letztere dann, im Zirkel, wiederum aus dem Naturbild erschlossen. Je stärker diese Auffassung ausgeprägt wird [...], desto mehr erscheint das Verständnis des Menschen als ein bloßes Resultat des Naturverständnisses, das menschliche Dasein als ein gesetzmäßig ablaufendes, dem Menschen selbst äußerliches Stück 〉Natur « ${ }^{507}$

Lippe widerspricht der zeitlichen Verortung. Er sehe bereits in Theorie und Praxis »des späteren 16. Jahrhunderts eine intensive Phase dieser Entwicklung und suche den Zusammenhang dieser >Verdinglichung « mit der >kapitalistischen Gesellschaft « ${ }^{508}$

Der unordentliche Wald Bacons verlangt nach »Lichtungen der Lehrsätze«, zu denen man durch »ein wohleingerichtetes Verfahren auf festem Pfad« gelangt, wenn man das »Licht« besitzt, den Pfad zu erkennen. Auch hier geht es um Homogenisierung, innerhalb eines klaren Baconschen Programms, der »männlichen Geburt der Zeit«. Mit ihr soll offenbar die >wirkliche`, >ursprünglich göttliche Natur` wieder wahrnehmbar werden. So ist der Satz, dass man Natur nur beherrscht, wenn man ihr gehorcht, ${ }^{509}$ zu verstehen. Erst die Zergliederung und Atomisierung, »die Auflösung und Trennung der Eigenschaften« durchs »göttliche Feuer des Geistes $«,{ }^{510}$ mithin erst die Disziplinierung und Reinigung von Verstand und Sinnlichkeit »durch den Gebrauch der >Instrumenteく [...] ermöglicht das Wissen über regelhafte, objektive Strukturen in der Natur«, was »die Voraussetzung der technischen Rekonstruktion der Natur durch die Mechanik ist«. Und hier wird die sonst von Francis Bacon »durchgehend mit weiblichen Metaphern belegt[e]« Natur »zum Männlichen«. ${ }^{511}$ Und damit weicht die chaotische Wildnis, der >weibli-

506 Burckhardt, a.a.O., S. 177. Zu Himmel und Erde als »überaus schöne machina« Gottes s. Kap. Monströse Leiber zu idealschönen Körpern.

507 Borkenau, Franz: Der Übergang vom feudalen zum bürgerlichen Weltbild. Darmstadt 1973 (Paris 1934); zit. n. Lippe, a.a.O., S. 210 f.

508 Ebda.

509 Vgl. Bacon: Novum Organum I, S. 271.

510 Novum Organum II, S. 351.

511 Braun/Kremer, a.a.O., S. 16. 
che Wald « - wie ein weggezogener Schleier - dem `männlichen`, geordneten; und dies ist die Natur, der man gehorcht.

»Insofern Natur als Materialisierung des göttlichen Willens begriffen wird, ist sie geordnet und männlich, nicht mehr das undurchschaubare, zu unterwerfende Chaos. Indem der Mensch die Natur unterwirft, versetzt er nicht nur sich, sondern auch sie in den Stand vor dem Sündenfall und sie verliert ihren weiblich-bedrohlichen Charakter. Ist Natur solchermaßen >vernünftig`geworden - ein Ausdruck, den Bacon selbst nicht verwendet, der sich hier aber vorbereitet - so wandelt sie sich im Verhältnis zum Subjekt vom zu unterwerfenden Objekt zum Gegenspieler im sportlichen Spiel. ${ }^{512}$

So sei es, "als wenn die göttliche Natur sich an dem unschuldigen und harmlosen Spiel der Knaben ergötze, die sich verstecken, um gefunden zu werden, und als ob sie in ihrer Nachsicht und Güte gegenüber den Menschen den menschlichen Geist zu ihrem Mitspieler in diesem Spiel auserwählt hätte«, schreibt Bacon. ${ }^{513}$ Die Verstecken spielenden Knaben sind die >männlichen Strukturen, die von einer Wissenschaft gefunden werden wollen, von der Salomon sage, »die Ehre Gottes« sei die Verhüllung des Werks, »die Ehre des Königs« seine Entdeckung. ${ }^{514}{ }^{\text {} » E i n s ~}$ mit dem göttlichen Willen und dem König ist das männliche Subjekt befähigt, ein einheitliches System des Wissens zu errichten, die Einheitswissenschaft.« Bei Bacon wandele sich die »)Liebe zum Identischen $<[\ldots]$ von der Liebe zu Gott zum Formungsprozeß von Natur «. ${ }^{515}$

Der Wald Bacons mag vorerst >metaphorisch` sein, er soll es nicht lange bleiben, denn »es ist ratsam, die Wege nicht nur anzuzeigen und $\mathrm{zu}$ befestigen, sondern sie auch zu betreten «. ${ }^{516}$ Im Insel-Staat Bensalem des »Nova Atlantis«, wo das »keusches[te] Volk« [...] unter der Sonne« lebt, regiert von Wissenschaftlern und Technikern - den >Vätern des Hauses Salomon〈, was »den patriarchalischen Charakter dieser Utopie unterstreicht $\ll^{517}$-, wo »die zweckorientierte Wissensproduktion das Prinzip, nach dem alle Bereiche des gesellschaftlichen Lebens strukturiert« sind, ist und »die Ehe ein Mittel der dort im wahrsten Sinne >herrschenden< Rationalität«, ${ }^{518}$ lässt Bacon den männlichen Neubau der Natur swahr« werden. Hier werden »alle möglichen Tiere und Vögel« ge-

512 Ebda., S. 17.

513 Bacon: Novum Organum I, S. 33.

514 Ebda.

515 Braun/Kremer, a.a.O., S. 17.

516 Bacon, a.a.O., S. 51.

517 Merchant: Der Tod der Natur, 183.

518 Braun/Kremer, a.a.O., S. 13. 
halten, um durch »Sektionen und anatomische[] Untersuchungen« und Versuchen mit Giften weitest möglich »Aufklärung über den menschlichen Körper zu erlangen« - mit »zahlreiche[n] wunderbare[n] Wirkungen«. Ebenso bei der künstlichen Neuzucht von Tieren in Größe, Körperumfang und -form, Farbe oder Fruchtbarkeit, oder der Neukreation von Reptilien, Insekten, Fischen »unter Zuhilfenahme von Verwesungsvorgängen ${ }^{5}$. 519

»Wir haben auch Verfahren, mittels derer wir Pflanzen nicht aus Samen, sondern nur durch eine bestimmte Zusammensetzung des Bodens entstehen und wachsen lassen können. Ferner erzeugen wir neue Pflanzen, die von den gewöhnlichen verschieden sind, und können Pflanzen einer Art in eine andere verwandeln. $\ll^{520}$

Derartige antizipierte >Biotechnologien` stellen zugleich den Versuch dar, »ethische[] Bedenken gegen manipulative Magie auszuräumen« (die Beispiele sind offenbar aus Giambattista della Portas »Naturmagie« von 1558 entnommen). ${ }^{521}$ Bacon will an die Tradition des Alchimismus anknüpfen, sich und seine propagierten Experimente aber zugleich vehement von dieser inquisitorisch verrufenen Praxis distanzieren, desgleichen die Konkurrenz heilkundiger Frauen für akademische Mediziner abschaffen. $^{522}$ In »Bensalem « ist weibliches Wissen inexistent - so wie in der 1662 real von Bacon gegründeten Royal Society Frauen ausgeschlossen sind - und weibliche Produktivität per Ehe wird derart für Staat und Wissenschaft ausgebeutet, dass »der Patriarch öffentlich für seine zahlreiche Nachkommenschaft geehrt wird«. Die Mutter nur dann, »wenn die gesamte Nachkommenschaft des Patriarchen von einer einzigen Frau, von einem Körper abstammt«. In ein »Gestühl« gesperrt »wird es ihr gestattet, mit den Augen der Ehrung ihres Gatten beizuwohnen, während ihr Körper, der von den Spuren der Schwangerschaften und des Stillens und der Arbeit gezeichnet ist, vor den Gästen verborgen wird «. ${ }^{523}$ Vielleicht ist dieser weibliche Körper aber auch jen-

519 Zit. n. Glaser, Horst Albert: Utopische Inseln. Beiträge zu ihrer Geschichte und Theorie. Frankfurt/M u.a.: Peter Lang 1996 S. 62.

520 Zit. n. Merchant, a.a.O., S. 187.

521 A.a.O., S. $186 f$.

$522 \mathrm{Vgl}$. Braun/Kremer, a.a.O., S. 5.

523 Ebda., S. 17. Hier zeigt sich möglicherweise eine utopische Verschärfung der spätmittelalterlichen Kirchenpraxis und ihrer strengen Trennung nach Geschlecht und Stand. Demnach gibt es bis zum Ende des 15. Jahrhunderts »oben offene, seitlich geschlossene Sitzbänke oder in sich geschlossene Einzelstühle mit Sichtluken«, damit »bestimmte Personen« den Riten von der Allgemeinheit unbeobachtet folgen können. Diese Kabinen wer- 
seits von >Gebrauchsspuren « - wie die Uhr - zur Mechanik im Gehäuse geworden, als endgültige Entstörung männlich-asketischer Wahrnehmung. Hier herrscht demnach wieder $»$ jene reine und unbefleckte Naturerkenntnis, kraft welcher Adam den Dingen, ihren Eigentümlichkeiten entsprechend, die Namen gab «. ${ }^{524}$ Eine ungezügelte und ungeregelte Vermehrung, Geilwuchs, wie im swilden Wald « wird es hier nicht mehr geben. Auch der Wald lässt sich dem Ticken der (Himmels-)Uhr unterwerfen.

Ein Waldgleichnis hat bekanntlich auch René Descartes aufgestellt:

»Mein zweiter Grundsatz war, in meinen Handlungen so fest und entschlossen zu sein wie möglich und den zweifelhaftesten Ansichten, wenn ich mich einmal für sie entschieden hätte, nicht weniger beharrlich zu folgen, als wären sie ganz gewiß. Hierin ahmte ich die Reisenden nach, die, wenn sie sich im Walde verirrt finden, nicht umherlaufen und sich bald in diese, bald in jene Richtung wenden, noch weniger an einer Stelle stehen bleiben, sondern so geradewegs wie möglich immer in der selben Richtung marschieren und davon nicht aus unbedeutenden Gründen abweichen sollten, obschon es vielleicht am Anfang bloß der Zufall gewesen ist, der ihre Wahl bestimmt hat; denn so werden sie, wenn sie nicht genau dahin kommen, wohin sie wollten, wenigstens am Ende irgendeine Gegend erreichen, wo sie sich wahrscheinlich besser befinden als mitten im Wald. ${ }^{525}$

Überall ist es »wahrscheinlich besser« als im Wald der tradierten Irrtümer. Dahinter aber liegt »das gelobte Land der Vernunft«, von dem aus, einmal erreicht, das denkende Subjekt, die »res cogitans «, seine Beziehung »zur Tradition« neu definiert, ebenso »zur Natur in ihrer Totalität«, sie zur »res extensa«, zur »verkörperten Substanz« erklärt. ${ }^{526} \mathrm{Um}$ dahin zu gelangen ist es zwingend, »so geradewegs wie möglich« den Wald zu durchqueren, sagt Descartes, selbst, wenn der Weg anfänglich zufällig gewählt wird. Linearität ist das Zauberwort: unendlicher Fluchtpunkt der Perspektive, stetiges Fort-Schreiten, das ebenso ein Herauslösen aus dem Bestehenden ist. Das heißt, zuerst gilt es, sich herauszulösen aus den »Erdichtungen« körperlicher Handlungen, Wahrnehmungen, Empfindungen, Bedürfnissen und Begierden; den bloßen »Träu-

den von den nutzenden Familien selbst errichtet und vererbt. Zwar gibt es solche Stühle für Frauen und Männer, klar scheint aber zu sein, dass die Zahl der Frauenstühle deutlich überwiegt. Vgl. Hergemöller: Masculus et femina, S. 91.

524 Novum Organum I, S. 33.

525 Descartes, René: Discours de la méthode; in: Philosophische Schriften in einem Band. Hamburg: Felix Meiner 1996, 2. Teil, S. 41.

526 Harrison, a.a.O., S. 133. 
men«, denn das, »was sich nur auf die Natur des Körpers bezieht« sei nichts anderes. ${ }^{527}$ Geist und Körper sind »substanziell verschiedene Dinge«, »in gewisser Weise gegensätzlich«, schon, weil »wir einen Körper nur teilbar, im Gegensatz dazu den Geist aber nur unteilbar denken können«. Zwar sei alles von Gott Geschaffene seiner »Natur nach unzerstörbar«, außer durch den Schöpfer selbst, weshalb der (menschliche) Körper »allgemein genommen Substanz ist und darum auch niemals untergehen kann «. ${ }^{528}$ Körper, Materie aber erscheinen bei Descartes grundsätzlich atomar geformt. Die Atome sind offenbar die letztliche Substanz, von deren Bewegung allein die unterschiedlichen Formen abhängen. ${ }^{529}$ So unterscheide sich der menschliche Körper von anderen lediglich durch die Anordnung seiner Glieder und anderen `Zufälligkeiten`, er sei »zusammengewürfelt» und eine Änderung seiner Teile, der Verlust von Gliedern bewirke bereits eine Änderung des gesamten Körpers, während »der menschliche Geist nicht so in irgendwelchen zufälligen Bestimmungen besteht, sondern reine Substanz ist«. Was belege, »daß der Körper zwar äußerst leicht untergeht, der Geist aber seiner Natur nach unsterblich ist « und »daß aus der Zerstörung des Körpers nicht die Vernichtung des Geistes folgt «. ${ }^{530}$

»Ich erkenne also, daß nichts von dem, was ich mit Hilfe der Einbildungskraft erfassen kann, zu der Kenntnis gehört, die ich von mir habe, daß ich vielmehr meinen Geist sehr sorgfältig davon abwenden muß, wenn ich seine Natur recht deutlich begreifen will. ${ }^{531}$

Nichts ist sicher, alles zu bezweifeln - es müsste demnach eigentlich heißen: »ich zweifle, also bin ich ${ }^{532}$-, alles Körperliche des Menschen und der Welt nichts als Schein, Vorurteil, ja Betrug, solange Körper und Geist, Imagination und Verstand, Wachen und Träumen verschmolzen seien. Ursache ist die menschliche Unvollkommenheit: »Denn wir sind nichts als ein Mittelding zwischen dem Vollkommenen und dem Nichts. ${ }^{533}$ Descartes will annehmen, dass nicht der allgütige und -weise

527 Descartes: Meditationen über die Grundlagen der Philosophie, in: A.a.O., 3. Teil, S. 49.

528 Ebda., S. 25.

529 Vgl. Schmidt-Biggemann, Wilhelm: Maschine und Teufel. Jean Pauls Jugendsatiren nach ihrer Modellgeschichte. Freiburg, München: Alber 1975, S. $32 \mathrm{f}$.

530 Descartes, a.a.O., S. $25 f$.

531 Ebda., S. 49ff.

532 Braun/Kremer, a.a.O., S. 22.

533 Ebda. 
Gott, »die Quelle der Wahrheit«, sondern ein mächtiger, böser und verschlagener Betrüger »allen seinen Fleiß daran gewendet habe, mich zu täuschen«. So groß sei die Ungewissheit dadurch, dass selbst solch zweifelsfreie Gewissheiten wie die Mathematik nicht mehr zweifelsfrei erschienen. Zumal die Dinge und Phänomene der Welt, sein eigenes Fleisch, Blut, seine Sinne. Er will glauben, nichts davon zu besitzen, dass alles nur Täuschung des Dämons sei. ${ }^{534}$ In dessen Werk, in dem »die Bedrohlichkeit der äußeren [zu der] der inneren Natur wird, gründet sich die Möglichkeit der Täuschung und die Notwendigkeit des Zweifels«. Descartes' anschließende Meditationen dienen der Eliminierung dieses »großen Betrüger[s] . $^{535}$

Um sich herauszulösen aus der Welt der dämonischen Trugbilder, will er den Fixpunkt des denkenden Ich finden, um von hier aus »die ganze Erde von ihrer Stelle zu bewegen«. Dieser »Punkt [des] Archimedes $«{ }^{536}$ sei der Beweis der Eigen-Existenz, da das denkende Ich die Macht hat, alles, was nicht es selbst ist, alles sinnlich Erfahrene, auch den eigenen Körper, zu negieren. Eine »Unabhängigkeitserklärung « ${ }^{537}$ des Ich, »eine Form des weißen Exorzismus, eine Geisteraustreibung $«{ }^{538}$ Der $»$ Autismus als Philosophie $«{ }^{539}$ dient zwar der Ausschaltung des >großen Betrügers`, aber die »Selbstreflexivität«, in der das Ich sich als »Identisches« wahrnimmt, weil es jegliche Denktätigkeit als allein eigene erfährt, sich in Einheit und Identität des Geistes konstituiert, macht zugleich alle Welt außerhalb des cogito zur Imagination. ${ }^{540}$ Um also auf ein »äußeres Sein« schließen zu können, sicher zu sein, »daß ich nicht allein in der Welt bin«, braucht es »eine Substanz, die unendlich, unabhängig, allwissend und allmächtig ist und von der ich selbst geschaffen bin $«,{ }^{541}$ die »Idee Gottes«, die allein [...] eine derart vollkommene Realität« enthalte, dass sie nicht vom Ich erzeugt sein könne. ${ }^{542}$ Die Gottes-Idee ist dem Menschen »eingeboren« ebenso, wie die »mathematischen Ideen« - beides ewige, unveränderliche, »universelle »Wahrheiten ${ }^{543}$

534 Vgl. Descartes, a.a.O., S. $37 \mathrm{ff}$.

535 Braun/Kremer, a.a.O.

536 Descartes, a.a.O., S. 43.

537 Burckhardt, a.a.O., S. 177f.

538 Ebda.

539 Ebda., S. 174.

$540 \mathrm{Vgl}$. Braun/Kremer, a.a.O., S. $22 \mathrm{f}$.

541 Descartes, a.a.O., S. 83.

542 Vgl. Braun/Kremer, a.a.O., S. 24.

543 Ebda., S. 32. 


\section{Verflechtungen}

Der »große Betrüger« hat seinen Ursprung in mittelalterlicher Dämonologie, etwa bei Thomas von Aquin, im Dualismus von gutem Schöpfergott und »Satan, dem allgegenwärtigen Bösen, der in alle natürlichen Zeugungsvorgänge eindringen kann und so die göttliche Ordnung in der Natur bedroht «. ${ }^{544}$ Diese Dämonologie entfaltet ihre volle Wirkung, indem sie »das Verhältnis des Menschen zur Natur einer entsetzlichen Unsicherheit« unterwirft, allerdings erst in der Zeit der Hexenverfolgung, deren Kulmination zu Zeiten Descartes' stattfindet. ${ }^{545}$ Der setzt einer »sich auflösenden Gewißheit der göttlich-natürlichen Ordnung [...] sein cogito entgegen, die Einheit des auf sich reflektierenden Denkens «. ${ }^{546}$ Diese >Einheit< ist Reaktion auf den Verlust einer anderen, der »von Gott, Mensch und Natur, die die Kirche mit dem Verlust ihrer Macht nicht mehr legitimieren konnte und durch die Dämonisierung der Sinnlichkeit, der Natur und der Frau in der Hexenverfolgung wiederherzustellen trachtete. Dem Einzelnen verblieb nur noch der Rückzug in seine Innerlichkeit«. ${ }^{547}$ Dieser Rückzug ist genauer eigentlich die Entstehung des neuzeitlichen Ich. Dieses Ich zieht sich dementsprechend auf einen herrschenden Bedeutungsraum zurück, in den ebenso die säußere Naturく verwiesen wird.

$\mathrm{Zu}$ beobachten ist eine sich steigernde Verflechtung von (entstehenden) Individuen und Gesellschaft, die man mit Norbert Elias zeigen kann - aber auch gegen ihn, insofern es sich um Brüche und qualitative Veränderungen handelt. »Diese fundamentale Verflechtung der einzelnen, menschlichen Pläne und Handlungen kann Wandlungen und Gestaltungen herbeiführen, die kein einzelner Mensch geplant oder geschaffen hat. Aus [...] der Interdependenz der Menschen ergibt sich eine Ordnung, die zwingender und stärker ist, als Wille und Vernunft der einzelnen Menschen, die sie bilden.« Diese »Verflechtungsordnung« bilde die Grundlage des Zivilisationsprozesses. ${ }^{548}$ Der verläuft nach Elias bekanntlich von relativ weitgehender sozialer Desintegration zu wachsender Integration. Qualitativ andere Sozialordnungen existieren für ihn nicht (und damit auch keine qualitativen Wechsel). Zugleich führe eine

544 Ebda., S. 22. Vgl. Delumeau: Angst im Abendland, S. $380 \mathrm{ff}$.

545 Vgl. Ebda., vgl. Authier, Michel: Die Geschichte der Brechung und Descartes' "vergessene Quellen«, in: Serres, Michel (Hg.): Elemente einer Geschichte der Wissenschaften, S. 474, Honegger: Die Hexen der Neuzeit, S. 107ff.

546 Braun/Kremer, a.a.O.

547 Ebda., S. $33 f$.

548 Vgl. Elias, Norbert: PDZ 2, S. 314. 
deutliche Abnahme äußerer Ängste seit dem Ende des Mittelalters zu habituellen Veränderungen. Infolge der »Bildung von Gewaltmonopolen« werde die Bedrohung von Menschen durch Menschen »berechenbarer. Der Alltag wird freier von Wendungen, die schockartig hereinbrechen« ${ }^{549}$ Er spricht von der Herstellung einer »Gesellschaftsapparatur«, die infolge der »Interdependenz größerer Menschengruppen voneinander« sowie der »Aussonderung physikalischer Gewalt innerhalb ihrer« die andauernden Zwänge untereinander in teils automatische, teils bewusste »Selbstzwänge« umsetze. ${ }^{550}$

Dass enorm gesteigerte Ängste und Unsicherheiten an diesen Verflechtungen beteiligt sind, oder dass neue Freiheiten neue Zwänge nach sich ziehen, findet sich bei Elias nicht. Gerade das 17. Jahrhundert ist geprägt von »schockartig« hereinbrechenden Ängsten und physischer Gewalt, den Verheerungen und Traumatisierungen des 30jährigen Krieges, den >Höhepunkten` der Inquisition. Elias schenkt der staatlichen Monopolisierung, dem Absolutismus große Aufmerksamkeit. Die Interdependenz von Inklusion und Exklusion findet sich bei ihm aber ebenfalls nicht. Dabei ist es nur folgerichtig, dass sich in der Arbeit Jean Bodins mit den »Six livres de la République« und der »Demonomanie« die Theorie des absoluten Souveräns und ein theoretisches Hauptwerk der Hexenverfolgung bündeln. »Bodin ändert an den zentralen >generativen Annahmen des paradigmatischen Hexenmusters wenig«, unterzieht diese Inhalte aber einer >Modernisierung〈, so im Begriff der »ZweckMittel-geregelte[n], schuldhafte[n] Missetat«. Seine »voraussetzungsvolle[n] Annahmen vom freien Willen und von der Verantwortlichkeit der Subjekte« und »die in den Prozessen gleich angewandten logischen Schlußfolgerungen aus wissentlich begangenen Maleficien zurechnungsfähiger Straftäter« sind, so Claudia Honegger, »auf dem Leib der Weiber ausgetragene Real-Experimente zum modernen Bild des handlungsfähigen, weltverändernden bürgerlichen Subjekts«. ${ }^{551}$ Sonntag zitiert Muchembled, wonach »die Hexenverfolgung >mit einer ersten Phase des Eindringens geschriebener Gesetze in die Dörfer zusammenfällt«. ${ }^{552}$ In der Folge geraten damit auch immaterielle >volkskulturelle` Waldnutzungen, magische Wahrnehmungen und Praktiken ins Visier, auch sie

549 Ebda., S. 325.

550 Ebda., S. 331.

551 Honegger, a.a.O., S. 102f. Zwar argumentiert Honegger bezüglich der Genese der höfischen Gesellschaft im Mittelalter mit Elias, später aber eigentlich - unausgesprochen - gegen ihn; schon, weil in seinem »Prozeß der Zivilisation« die Hexenverfolgungen überhaupt nicht vorkommen.

552 Sonntag, a.a.O., S. 139. 
werden später mit der Homogenisierung der Wälder ausgetrieben. ${ }^{553}$ Sonntag spricht vom Zusammenfallen des »Aufbau[s] zentraler Staatlichkeit und [der] epidemische Ausmaße annehmenden Verfolgungen«, verschärfter Hierarchisierung "zwischen >oben` und >unten«", abgestuften Zwangsmaßnahmen der Ein- und Ausschließung, kurz: von einer "systematisch und in großem Umfang betriebene[n] gewaltsame[n] Einübung neuer Verhaltensformen« für den größten Teil der Bevölkerung. 554

Ängste und systematische Gewaltstrukturen einerseits, neue Möglichkeiten andererseits. Die >Entdeckung « Amerikas ist auch die Entdeckung eines »Geisteskontinents«, dessen »bereits vollzogene Erschließung « [...] Newton die Absolutsetzung von Zeit und Raum überhaupt erst ermöglicht«. Seine »Philosophiae Naturalis Principia« erscheinen 1687, »zu einem Zeitpunkt«, zu dem »von einer Entdeckung eines neuen Geisteskontinents nicht mehr die Rede sein kann. Eher gewinnt Gesetzeskraft, was untergründig, wie das Selbstbewußtsein des Amerikaners, sich herausgeformt hat «. ${ }^{555}$ Burckhardt beschreibt den »Übergang zwischen Mittelalter und Neuzeit« als »Bild zweier Denk-Kontinente, die durch einen Ozean der Zeit voneinander getrennt sind «, eine gähnende Kluft. Kein leicht angestoßener Sprung über Schwellen, analog zur Ontogenese, von Kindheit über Pubertät zum Erwachsensein. Die »Übergangszeit» seit dem »Herbst des Mittelalters« sei »eher eine Übersetzungszeit, eine geistige Passage, eine transatlantische Fahrt - und wirklich [...] gibt es doch keine ärgere Erschütterung des Fundaments als eben dies: keinen festen Boden mehr unter den Füßen zu haben «. ${ }^{556}$ Allerdings, muss man ergänzen, findet auf diesen »auf schaukelnden Planken ${ }^{557}$ nicht nur eine »geistige«, sondern desgleichen körperliche Passage statt.

Auch Descartes behauptet, >reinen Tisch`zu machen. Michel Authier erweckt den Eindruck einer Art `dunklen Genies`, das mit der Methode der Tabula Rasa, hier bei der »Wissenschaft der Optik«, rücksichtslos Vorläufer wie al-Haitam, Kepler, Witelo, de Dominicis oder den Zeitgenossen Willebrord van Snel benutzt, aber verschweigt. »Mit Descartes vollzieht sich keine wissenschaftliche Revolution, allenfalls eine Revolution in der Darstellungsweise wissenschaftlicher Resultate«.

553 Vgl. Allmann, Joachim: Der Wald in der frühen Neuzeit.

554 Vgl. Sonntag, a.a.O., S. 138ff.

555 Burckhardt, a.a.O., S. 166.

556 Ebda., S. 166f.

557 Ebda. 
Zugleich erfinde er einen neuen Menschen, den $>$ Wissenschaftler $<,{ }^{558}$ der sich als »Folge des Descartesschen Diskurses $«{ }^{559}$ durchsetze. Die Umwälzung aber ist eine soziale und in der Philosophie, der Wissenschaft wird formuliert und umgesetzt, was gesellschaftlich bereits existiert. Und daraus ergeben sich in der Folge Wechselwirkungen. Descartes wird »zum Titular eines Weltbildes«, weil er das, "was in praxi längst fait accompli ist, zum Prinzip zusammenfaßt«, eine »Ratio, die sich längst in der Kultur verwurzelt hat «: ${ }^{560}$ Die konsequente Mechanisierung der Philosophie folgt der Mechanisierung der Gesellschaft, dem Ticken der Uhr, das sich längst als »urbane, ökonomische Zeit«, der Bezahlung nach geleisteten Arbeitsstunden etwa, durchgesetzt hat. Die ökonomische Zeit steht im Gegensatz zur noch in der Landwirtschaft herrschenden zyklischen Zeit (den Jahreszeiten und Witterungsbedingungen). Sie wird später auch in der Landschaft sichtbar werden, mit dem geregelten Forstwesen die zyklische Zeit des Waldes und der Waldnutzung ersetzen. Sie hat die »Kraft zu definieren und zu zerstören «. ${ }^{561}$ Sie kann Menschen tatsächlich in so etwas wie austauschbare >Maschinen deln, indem sie die vorbürgerlich geltende unabänderliche >Natur` des jeweiligen Menschen als >Bauer`, >Handwerker`, >Unehrlicher` usw. tendenziell zum >Lohnarbeiter/ nivelliert. Desgleichen entkoppelt sie tendenziell Besitz und gesellschaftliche Macht von Stand und Geblüt. VerKörperungen: Der vorbürgerliche Mensch verkörpert nicht, er ist, was er ist. Der Körper wird in der Neuzeit zum Ding, zum dienst- und verfügbaren Objekt. Als Reduktion des Leibes (der als numinoser Rest zu-

$558 »$ Mit seiner Verachtung für die Genese der Resultate erfindet Descartes einen neuen Gelehrtentyp, der seine Wissenschaft, in Unkenntnis ihrer Geschichte, als logisches Puzzle behandeln kann, dessen Stücke von der Natur hervorgebracht werden, über deren Anordnung jedoch allein die Vernunft entscheidet. Dieser neue Mensch, oft eher ignorant und arrogant als gelehrt, unterwirft sich seiner Praxis so sehr, daß er sich ihren Namen gibt: Von nun an nennt er sich >Wissenschaftlerı." Authier, a.a.O., S. $473 \mathrm{f}$.

559 Ebda., S. 474. Zwar räumt Authier hier ein, dass die Umwälzungen wissenschaftlicher Praxis auch »Folge neuer Institutionen, die für mehr Geld, Sicherheit und Informationen sorgen«, seien, schreibt über den Untergang der »peripatetische[n] Universität» durch ihre Beteiligung »an den intensiven Hexenjagden [...] - niemals loderten die Scheiterhaufen so zahlreich - « über die gleichzeitige Ausbildung »junge[r] Wissenschaftler bei den Jesuiten« und die Entstehung »eines der ersten wissenschaftlichen Kommunikationsnetze Europas« um den Pater Marin Mersenne (15881648), schließlich, dass die »Sprache des Bürgertums« die der Kleriker ersetze - am Primat Descartes soll das alles aber nicht rütteln.

560 Burckhardt, a.a.O., S. 177.

561 Sennett, Richard: Fleisch und Stein, S. $257 \mathrm{f}$. 
rückbleibt) entsteht der Körper (indogerm. für Leichnam) sprachlich im 17. Jahrhundert. ${ }^{562}$ Die Geometrisierung des Leibes zum Körper beginnt aber bekanntlich in der Renaissance. Die Philosophie der Körper-GeistSpaltung ist Nachvollzug sowohl der bürgerlichen Trennung von öffentlich und privat, als auch der »Trennung von Hand- und Kopfarbeit im Produktionsprozeß, die sich mit der Manufakturperiode im 17. Jahrhundert anbahnt «. ${ }^{563}$ Descartes ist kein radikaler Neuerer, »begründet keine Zäsur, sondern er vollzieht sie«. ${ }^{564}$

\section{Tätige Geometrie}

Descartes' methodisches Zweifeln »ist ein asketischer Reinigungsprozeß, indem die Ichwerdung mit Entsagung und Verzicht verbunden wird«, eine Selbstabspaltung des Subjekts von den Bildern des Begehrens, »die auf Entäußerung und Erfüllung drängen, die es als lebendiges Besonderes auszeichnen, die jedoch auch abhängig sind von der körperlichen Sinnlichkeit und der äußeren Natur «. ${ }^{565}$ Descartes trennt »tierische« (körperliche) von »geistigen Freuden« (der Seele). »Dem Menschen wird in dieser Konstruktion zur Natur, was erst Resultat seiner Reformation ist.« Ein vorgeschaltetes Bewusstsein bringt nach Descartes Empfindungen aus sich heraus erst nachträglich hervor. Aktiv und vital ist die Seele, der Körper hingegen passiv und mechanisch. Nur die willlentliche Ausübung kann Triebe zu Selbsterhaltungsakten machen. Die seelische Kontrolle gewährleistet eine feste Grenzziehung »gegenüber Natur und anderen Menschen«. Unreflektierte Grenzüberschreitungen durch »leidenschaftliche Hinwendung« führen zum Autonomieverlust des Subjekts, da es dann »vom 〉Objekt» des Begehrens besessen« werde. $^{566}$ Das Ausmaß der »Absage an die Leiblichkeit» schildert Walter Kutschmann anhand der »Dioptrique«. Hier postuliere Descartes die »Arbitrarität der Sinne« und die »systematische Blindheit des Menschen«, hier seien Wahrnehmungen von natürlichen Dingen und Phänomenen bloße »Metaphern für nackt mechanische Maßverhältnisse«, seien Sehende "gegenüber dem eigentlichen Sein« der Dinge - »den Qualitäten ihrer geometrischen und kinematischen Verfaßtheit« - ebenso >blind`, wie Blinde »gegenüber ihrem Äußeren«. ${ }^{567}$

562 Vgl. Kutschmann, Werner: Der Naturwissenschaftler und sein Körper, S. $34 \mathrm{ff}$.

563 Braun/Kremer, a.a.O., S. 27.

564 Burckhardt, a.a.O., S. 178.

565 Braun/Kremer, a.a.O., S. 23.

566 Ebda., S. $29 f$.

567 Kutschmann, a.a.O., S. $245 \mathrm{ff}$. 
Die Methode ist der Weg, dem nachgegangen werden muss. Sie ist das Gegenteil jeder sinnlichen Hinwendung zur Natur. Zurecht stellt Harrison eine Verbindung zwischen Descartes' Waldgleichnis und der geregelten Forstwirtschaft her.

»Descartes' Vergleich mit geradlinigem Laufen durch den Wald ist, wie Michel Serres bemerkt hat, >isomorph Geometrie selbst. Die mathematische Analyse folgt dem Weg von Zahlen und noch mehr Zahlen in linearer Folge, bis sie zu ihrem Endergebnis kommt. Der Triumph der Methode in einem Wald von Zweifeln bedeutet die Fähigkeit, an der geraden Linie mathematischer Deduktion festzuhalten. ${ }^{568}$

Der ungeordnete Wald ist Chimäre, Trugbild des `großen Betrügers «. Er ist das, was sich den Sinnen mitteilt. Er ist Leib, ${ }^{569}$ von dem abzusehen ist, wie vom eigenen, menschlichen Leib. Er beherbergt Lockungen und Schrecknisse bzw. Regungen, die beides gleichzeitig sind. Er führt vom Weg ab, schlimmer noch, es gibt keinen Weg in ihm - zumindest keinen geraden, unbeirrten. Die Methode besteht in unbeirrtem Geradeauslaufen. Genaugenommen ist das nur im geregelten Forst möglich, in dem die Bäume in geraden, geometrischen Linien angepflanzt sind, in dem es kein Unterholz und sonstigen störenden Wuchs gibt. Hier kann nichts beirren. Hier ist das Gesetz nicht abstrakt, sondern wahrnehmbar, im wahrsten Sinn des Wortes. Hier präsentieren sich die Bäume (annähernd) in den logischen Formen der 〉Früchte des göttlichen Samens «: Mathematik und Geometrie.

Descartes schließt jede »vorbewußte Erfahrung, jede prä-reflexive Erkenntnis aufgrund einer leiblichen Regung« aus, weil Erkenntnis nur per $»$ Distinktion und intellektueller Distanz zwischen der reflektierenden `Substanz` des Subjekts und der intendierten `Substanz` des Objekts möglich« sei und »die eigene Natur«« als Instrument »nur das lehren« kann, »was der Geist vorher klar und deutlich hat einsehen und in Vorstellungen der geometrisch-kinematischen Verfaßtheit des Objekts hat zusammenstellen können $« .{ }^{570}$ Bei der Erkenntnis allein aber kann es nicht bleiben. Der Geist als »Ebenbild Gottes« ist »Ausdruck der Liebe zum Identischen«, die »Reinigung des Erkenntnissuchenden in der Beziehung auf Gott« ist eine »Initiation der Naturbeherrschung «. ${ }^{571}$ Das ganz praktisch: Da Descartes den >Willen Gottes` als unendlich und in-

568 Harrison: Wälder, S. 137.

569 Vgl. Kap. Monströse Leiber.

570 Kutschmann, a.a.O., S. 210.

571 Braun/Kremer, a.a.O., S. 34. 
different postuliert, kann die Natur nicht mehr als »Offenbarung göttlicher Zwecke« begriffen werden. Diese Befreiung »von der Zweckbestimmung durch Natur« ermöglicht dem Subjekt selbst die Bestimmung und Formung der Natur »nach den mechanischen Gesetzmäßigkeiten«, die Realisierung eigener Zwecke. ${ }^{572}$

»Algebra und Geometrie, die als Grundlage für die Methode dienten, mit der Descartes zu unbezweifelbarer Wahrheit gelangen wollte, werden zur Grundlage der neuen Wissenschaft des Forstwesens. Dank solcher Methode hört der Wald auf, Ort des zufälligen Umherirrens zu sein, und wird ein ordentliches Schachbrett. Da er eine kalkulierbare Quantität wird, wird er auch geometrisch. Wie wandert man in gerader Linie durch den Wald? Zunächst pflanzt man seine Bäume in geradlinigen Reihen, wie es deutsche Förster taten. Die algebraische Geometrie duldet keine Hindernisse. ${ }^{573}$

Der »richtige[] Gebrauch der Vernunft« gleicht »der rationalen, geometrischen Planung«. Der >Wald ‘ im Gleichnis Descartes' steht für »alles, was im Laufe der Zeit nicht nach rationalem Plan, sondern nach Gewohnheit gewachsen ist «. Harrison fühlt sich hier »deutlich« an eine andere Stelle im »Discours« erinnert, das Städtegleichnis. ${ }^{574}$ Darin schildert Descartes »jene alten Städte«, die er »in Deutschland, wohin mich der Krieg, der dort noch nicht beendet ist, gerufen hatte « gesehen habe. Städte, »die - anfänglich nur Burgflecken - erst im Laufe der Zeit zu Großstädten geworden sind, verglichen mit jenen regelmäßigen Plätzen, die ein Ingenieur nach freiem Entwurf auf einer Ebene absteckt, für gewöhnlich ganz unproportioniert; zwar findet man oft ihre Häuser - betrachtet man jedes für sich - ebenso kunstvoll oder gar kunstvoller als in anderen Städten -, wenn man jedoch sieht, wie sie nebeneinanderstehen, hier ein großes, dort ein kleines, und wie sie die Straßen krumm und uneben machen, so muß man sagen, daß sie eher der Zufall so verteilt hat und nicht die Absicht vernünftiger Menschen«. Diese plan- und vernunftlose Unordnung soll offenbar die unerhörte Schwierigkeit zeigen, planvoll und vernünftig vorzugehen. Bedenke man, dass immer schon Beamte beauftragt worden seien, „die Bauten von Privatleuten zu überwachen, um sie in den Dienst der Verschönerung des Stadtbildes zu stellen, so wird man wohl einsehen, daß es schwierig ist, etwas höchst Vollkommenes zu schaffen, wenn man nur an fremden Werken herumarbeitet ${ }^{575}$ Bei bloßen Gedankenspielen aber bleibt es gar nicht. Geo-

572 Ebda., S. 32.

573 Harrison, a.a.O., S. 151.

574 Vgl. ebda., S. 138.

575 Descartes: Discours de la Methode, in: A.a.O. S. $19 \mathrm{ff}$. 
metrische Städte aus einer Hand werden im 16./17. Jahrhundert nicht nur geplant (als Idealstädte bzw. Utopiae), sondern als Residenzstädte auch gebaut, wie etwa Mannheim. Mit »der Geometrisierung des Raumes« scheine sich »die Wahrnehmung selbst instrumentell auszurichten«, schreibt Kleinspehn. »Was sich mit der Zentralperspektive in der Renaissance bereits angedeutet hat, setzt sich im Absolutismus in vielen gesellschaftlichen Bereichen durch: Der Blick wird neutral, objektiv.« Werde in den Bildern der Renaissance mittels Perspektive der Blick »gerichtet«, der Betrachter so ins Bild »einbezogen«, übe nun insbesondere die städtische Architektur »eine ähnliche Wirkung aus. Mit der $>$ Mechanisierung des Weltbildes`(Dijksterhuis) und dem Durchsetzen abstrakt-mathematischen Denkens werden die neu gegründeten absolutistischen Höfe und Städte nach streng geometrischen Vorstellungen errichtet «. ${ }^{576}$ Oder es werden bestehende Städte planmäßig verwandelt, wie ab Mitte des 17. Jahrhunderts unter Papst Alexander VII. Rom, das mit der Zeit »zu der Art von >wuchernder Stadtı geworden war, über die sich Descartes« beklagt habe, nun aber von zwei »triumphalen Lichtung[en] « beherrscht werde: der Piazza del Popolo und der Piazza Venezia, verbunden durch die »radikal lineare[] Hauptstraße[]« (daneben zwei ebensolche), die »Via del Corso: der Weg der Wege; die Tautologie der Methode; der Kurs des Diskurses «. ${ }^{577}$ Derartige planmäßige Beseitigungen und Neugründungen sind auch für den Forst relevant. Denn es geht Descartes nicht um bloße Spekulation, sondern um Herrschaft über die Natur. „Vernunft, Methode und technische Handwerkskunst kommen am Ende des Diskurses in einem säkularen Bekenntnis des Willens zur Macht zusammen. « Daher: »)Wie geht man in gerader Linie durch den Wald?« Antwort: >Methodische Abholzung.« « ${ }^{578}$ Beim Abholzen aber kann es nicht bleiben, wenn es um die Reform geht.

Im Spannungsfeld neuer gesicherter Messbarkeit von Zeit und Raum sowie sozialer Homogenisierung kommt es seit dem späten 18. Jahrhundert zur wissenschaftlichen Neudefinition des Waldes, seiner geometrischen Reproduktion zu Zwecken des größtmöglichen Ertrags, was aber nicht trennbar ist von der Schaffung bzw. Konsolidierung neuer >Ge-

576 Kleinspehn: Der flüchtige Blick, S. 84ff. Vgl. Kluge, Walter: Die Stadt in der Utopie, in: Mahler (Hg.): Stadt-Bilder, S. 69ff. u. $72 \mathrm{ff}$.

577 Harrison, a.a.O., S. 140. Wenn Harrison allerdings an dieser Stelle vom »Rätsel« einer päpstlichen »Ansteckung durch den cartesianischen Rationalismus« spricht, scheint auch hier die häufig zu beobachtende Verdrehung vorzuliegen. Nicht der >große Denker< beeinflusst den >Gang der Geschichteく, er formuliert vielmehr das, was sich längst im gesellschaftlichen $>$ Klima äußert.

578 Ebda., S. 139f. 
setze` der Alltagsbewältigung, Sinnstiftung und Ästhetik im >ländlichen Raum`. Im Zeichen der Maschine.

Descartes setzt an anderer Stelle Baum und Uhr gleich:

»Es gibt wahrhaftig keine Grundsätze in der Mechanik, die sich nicht auch auf die Physik erstrecken, deren Teil bzw. Spezies die Mechanik ist: Eine Uhr, die aus diesen und jenen Rädern zusammengesetzt ist, um die Stunden anzuzeigen, ist nicht weniger natürlich als ein Baum, der aus diesen und jenen Samen hervorgebracht ist, um bestimmte Früchte hervorzubringen. [...] Und es ist sicher, daß alle Regeln der Mechanik zur Physik gehören, dergestalt, daß alle Dinge, die künstlich sind, damit natürlich sind. « ${ }^{579}$

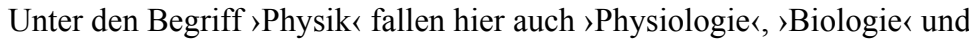
$〉$ Chemie $\prec{ }^{580}$ Baum und Uhr »folgen dem gleichen Gesetz«. Das ist der Kern, das »cartesianische Paradox «, denn das, »was - nach der Analogie der Maschine geschaut - zuvor schon zur `Sache der Natur hatte werden können, wird hier zur Natur der Sache«. Jede dieser Sachen ist dabei nichts, als eine »bloße Widerspiegelung, ein Ausdruck jenes mechanischen Regelwerks, das ihr, als eine gedankliche Blaupause, vorausgeht«. Hier liege die »cartesianische Inversion«. Als »Sprache der Natur«, als »vorgängige« gesehen wird »die immaterielle Sprache der Mechanik«, die »Himmelsuhr«, die »doch nichts anderes ist, als die Abstraktion [...] des je konkreten Räderwerks « ${ }^{581}$

Alles Künstliche ist natürlich. Alle Materie ist Maschine. Die Mechanik hat »so einen Erklärungswert für alle Phänomene der res extensa«. Damit wird sowohl eine Differenz zwischen belebter und unbelebter Materie »als Rest von Hylemorphismus«, als auch eine qualitative Differenz von tierischer und pflanzlicher Substanz negiert. ${ }^{582}$ Jegliche Naturerscheinung ist also mathematisch und aus einem Prinzip heraus erklärbar. »Weltmaschine«: In den »Principia Philosophiae« erklärt Descartes die »Homogenität der res extensa«, weshalb die »gesamte sichtbare Welt, >instar machinae«, der der Mechanik bekannte Makrokosmos den Analogieschluss auf die unsichtbaren Teile, den Mikrokosmos zulasse. ${ }^{583}$ Alle Natur unterliegt demnach dem Prinzip einer permanenten, homogenen »Bewegung von Materie«, aufgebaut »aus unendlich vielen kleinen Partikeln«, die durch Transmission »kausal miteinander

579 Principia IV, Kap. CCIII, bzw. Principes AT IX, zit. n. Schmidt-Biggemann, a.a.O., S. 33f.

$580 \mathrm{Vgl}$. Schmidt-Biggemann, a.a.O., Burckhardt, a.a.O., S. 180.

581 Burckhardt, a.a.O., S. 180f.

$582 \mathrm{Vgl}$. Schmidt-Biggemann, a.a.O., S. 33.

583 Vgl. ebda., S. 34. 
verknüpft sind«. Aber Natur ist damit auch »bloß tote Materie, vom formwirkenden Geist nach bestimmten Gesetzen in Bewegung gesetzt $\ll{ }^{584}$ Folglich ist der menschliche Körper nur »eine Gliedermaschine $[. .$.$] , die man auch an einem Leichnam wahrnimmt «. { }^{585}$ Zum »Triumph über den Körper: die gelungene Dekonstruktion«, gereicht Descartes der 〉Beweis $«$ in der Vivisektion«: Das menschliche Herz wird als »Antriebsmechanismus« vorgestellt, als »ein mechanisch dekonstruierter Mechanismus: eine >natürliche Uhr sozusagen $«{ }^{586}$ Die Entsprechung von Mikro- und Makrokosmos, im Neuplatonismus reetabliert, steht zunächst »noch ganz im Banne der Analogie des Differenten«, in der der Mensch »als Welt im kleinen« das >Ganze〈, >Wahreく enthält. ${ }^{587}$ Zunehmend wird die Analogie »einseitig« zur Bestimmung des Mikrodurch den Makrokosmos verwendet, so im Entwurf des Blutkreislaufs entsprechend dem "astronomischen Kreislauf der Erde um die Sonne« durch William Harvey zwischen 1616 und $1628 .{ }^{588}$ Von ihm übernimmt Descartes das Bild des Blutkreislaufs, allerdings wählt er im »Traité de l'Homme« konkret wahrnehmbare Vorbilder: »hydro-pneumatische Maschinen« wie Orgel mit Blasebalg und hydraulische Brunnen in Gärten. ${ }^{589}$ Wenn in der Illustration des »Compendium anatomicum« von 1696 »Blutgefäße als Zweige [...] aus dem menschlichen« - dem männlichen - »Körper herauswachsen «, ${ }^{590}$ und Wurzeln aus den Füßen, dann ist dieser Körper offenbar nicht einfach das Modell für den Baum (oder die Säule à la Vitruv), sondern Bestandteil der res extensa. Nach Harveys Entdeckung wird von Botanikern mittels der »Verknüpfung der analogischen Methode mit der experimentellen« auf »das Vorhandensein eines Saftkreislaufs bei der Pflanze« geschlossen. Schon, weil die Tierphysiologie der Pflanzenphysiologie »ein Intelligibilitätsmodell liefert «. ${ }^{591}$ Der Triumph über den menschlichen Körper besteht also da-

584 Braun/Kremer, a.a.O., S. 32.

585 Descartes: Meditationes, S. 45.

586 Burckhardt, a.a.O., S. 179.

587 Vgl. Kutschmann, a.a.O., S. 80.

588 Vgl. Kutschmann, a.a.O., S. 80f., Sennett: Fleisch und Stein, S. 323ff.,

Schmidt-Biggemann, a.a.O., S. 36.

$589 \mathrm{Vgl}$. Schmidt-Biggemann, a.a.O.

590 Sennett, a.a.O. S. 325.

591 Delaporte, François: Das zweite Naturreich, S. 10f. Zwar habe Stephen Hales diese Annahme 1727 widerlegt, auf eine »lineare Geschichte ohne Zufall noch Bruch« lasse das aber nicht schließen, weil die Widerlegung gar nicht Hales' Intention gewesen sei, vor allem aber, weil die Saftkreislauf-Theorie durchs gesamte 18. Jahrhundert Anhänger gehabt habe (vgl. ebda.). 
rin, das Herz - mittelalterlich noch »das Organ des Mitleidens «, ${ }^{592}$ im frühen 14. Jahrhundert von Henri de Mondeville im Anschluss an Galen zum mit dem Kopf »edlen Bereich « gezählt ${ }^{593}$ - wie bei Tieren zur bloßen Antriebsmaschine zu erklären.

Es gibt also nur noch »natürliche[] Automata«, die die Wissenschaft ganz »naturgemäß« animieren, »sich ihrer mit der ihnen gemäßen Methode, das heißt: der Mechanik anzunehmen. Die Mechanik usurpiert die Natur, sie denaturiert sie zur Maschine; so vermag sich der Geist zum >Herren und Eigentümer der Natur` aufzuschwingen «. ${ }^{594}$ Schließlich ist da noch die Gott-Maschine. Die »Vorstellung eines höchst vollkommenen Wesens, die in uns ist«, muss »von einer höchst vollkommenen Ursache herrühren«. Verglichen wird das »mit einer sehr vollkommenen Maschine, deren Plan im Geiste eines Erfinders ist«. Und weil ein solcher Plan eine Ursache haben muss, ist bewiesen, dass die GottesIdee »Gott selbst zum Urheber hat «. ${ }^{595}$ Die Idee gleicht also einer unübertroffenen, sich selbst und alles andere erzeugenden Maschine; reiner Geist, »reine schöpferische Kraft«, körperlos, nicht zusammengesetzt, eine ganze, »unteilbare Einheit, reine Identität von Denken und Sein«, die Endgültigkeit und »Kontinuität der kausalen Gesetzmäßigkeiten« der gesamten Materie gewährt. ${ }^{596}$ Gottesebenbildlichkeit heißt danach, dass die `reine Substanz^ Geist Ebenbild dieser `reinsten Substanz« sei.

Der Baum (oder das Tier, der menschliche Körper), die Natur als Uhrwerk ist nicht bloße Neubetrachtung, sondern ein ganz spezielles »Genesisprojekt «: der »Tod durch Vernunft« in der »Idee der Weltvernichtung«, wie sie auch Hobbes in »Vom Körper« bezüglich der Naturphilosophie äußert, und die »Wiederauferstehung durch die Vernunft $\ll .{ }^{597} »$ Kopfgeburten« als »Totgeburten«: In den »natürlichen Automata« vollzieht sich etwas, was zuvor nur gedacht oder im »memento mori« >gefühlt« werden konnte. »Natur hat sich, in die Denkmaschine eingespeist, zur natura morta verwandelt.« In spezifischer Weise: »nicht mehr die unmittelbare Natur« ist die Erste, »sondern jene zweite Natur, wie sie in den Maschinen von Raum und Zeit ihren Niederschlag gefunden hat ${ }^{598}$ Die Gewinnung von Autonomie vollzieht sich in der Selbstreduktion des männlichen Subjekts auf »reinen Geist« und der Zuordnung des Vitalen zur »Welt des Scheins«.

592 Sennett, a.a.O., S. 323.

593 Vgl. ebda., S. 208 u. 326.

594 Burckhardt, a.a.O., S. 181.

595 Descartes, a.a.O., S. 27.

596 Vgl. Braun/Kremer, a.a.O., S. 24.

597 Burckhardt, a.a.O., S. 182f.

598 Ebda., S. 181f. 
Zurück bleibt das Nicht-Identische, verfällt der »Vernichtung« bzw. Entwirklichung. Was für »[w]eibliche Produktivität in ihrer zweifachen Bestimmung als Fortpflanzung und Arbeit « ${ }^{599}$ gilt, gilt (gerade unter dem Diktum der res extensa) ebenso für die `äußere Natur`. `Frau Welt und ihre Schwestern haben ausgedient, ihre sterblichen Hervorbringungen sind ausradiert und entstehen nach der >Blaupause $<$ des >Unsterblichen neu:

»In der Übereinstimmung von Vernunft und Wille ist es uns möglich, Gott nachzuahmen und die göttliche Schöpfung nachzuvollziehen indem Natur zur Maschine rekonstruiert wird, also aus dem Geist neu hervorgebracht wird. ${ }^{600}$

Der Geist ist unsterblich. Die Natur kann einzig vom Geist erkannt und so zur Naturgesetzlichkeit (neu) geordnet werden. Diese geordnete Natur erhält so etwas von der Unsterblichkeit des Geistes. Zumal alles in ihr Uhrwerk ist.

»Bei einer Uhr kann nicht von >Werden und Vergehen` gesprochen werden. Gerade das aber ist es, was das mechanistische Regierungsideal auszeichnet und für Friedrich so attraktiv macht. Dem unliebsamen Bewußtsein des Wandels setzt er ein Ideal entgegen, das größtmögliche Gleichförmigkeit, ja Statik impliziert, denn die Bewegung einer Maschine ist in sich geschlossen; eine Uhr erhält ihren Sinn überhaupt erst aus unaufhörlichem, keiner Veränderung unterworfenem Gleichmaß. ${ }^{601}$

Barbara Stollberg-Rilinger skizziert das Regierungsideal des obersten preußischen Maschinisten. Die $»$ mechanistischen Metaphern des Rationalismus $«{ }^{602}$ betreffen desgleichen den Forst; nicht nur, weil der Monarch »sich oft selbst um die Ausbringung von Baumsaat« kümmert und zum Bäumepflanzen auffordert. ${ }^{603}$ Der Forst wird konstruiert, gebaut und funktioniert wie eine Maschine, wie eine Uhr. Das heißt, im Forst als geregeltem $>$ Altersklassenwald $\iota->$ schlagweise $\iota$, immer gleich alt und arm an Baumarten - sind >Werden und Vergehen herrscht permanentes Gleichmaß, zugleich Fortschritt. Der Forst ist nicht Natur, sondern Kultur (s.u.).

599 Braun/Kremer, a.a.O., S. 27.

600 Ebda., S. 26.

601 Stollberg-Rilinger, Barbara: Der Staat als Maschine. Zur politischen Metaphorik des absoluten Fürstenstaats. Berlin: Duncker \& Humblot 1986, S. 69.

602 Ebda.

603 Vgl. Küster: Geschichte des Waldes, S. 177. 
Zwar soll alles Uhrwerk sein, aber wenn das stetige, gleichförmige Ticken der Zeit >beweisbar ist, dann in der Zurichtung von Pflanzenformationen in Wald und Garten. Mag das Schreien von Tieren bei der Vivisektion >cartesianisch als $»$ Kreischen kaputtgehender Maschinen $«{ }^{604}$ betrachtet werden; diese Maschinen lassen sich jedoch nicht mehr reparieren. Allzu anfällige, instabile Uhrwerke demnach. Hier versagt der »formende Geist« offenbar. Die tote Materie läßt sich nicht mehr in Bewegung setzen. Auch, wenn das der autistischen res cogitans als weiterer Trug erscheinen soll: das >cartesianische Weltbild/ steckt in einem Dilemma (das gemäß der Inversion aber eigentlich keines ist; s.o.). Das mechanische und geometrische Grundmuster der Natur bedarf der möglichst weit gereinigten - Wahrnehmung, um sich zu erschließen. Der einzige hierfür in Frage kommende Sinn ist der Gesichtssinn. Beim Sehen geht es nach Descartes um die Wahrnehmung von Distanz, damit geht es aber auch um Distanz und damit die Vermeidung direkter Berührung. Descartes setzt hier, wie häufig, den Sehenden mit dem Blinden gleich. Der nimmt in der Zeichnung in »De l'Homme« die Objekte nicht direkt taktil, mit der Haut seiner Fingerspitzen wahr, sondern >übersetzt` durch die benutzten Stöcke. Die >Übersetzung`macht das Objekt instrumentell zum Unterworfenen. Die Stöcke bilden ein Dreieck, so wie sich beim Sehen zwischen den Augen und dem Objekt diese für auch Descartes offenbar so wichtige Triangulierung - als Signum der Okkupation von Sinnlichkeit - einstellt. ${ }^{605}$ Der Mensch baue, ausgehend

604 Cartmill: Tod im Morgengrauen, S. 121

605 Vgl. Abb. in Kutschmann, a.a.O., S. 237. Bei Descartes ist auch die >Dreifaltigkeit streng mathematisch, schließt er doch in seinem Gottesbeweis vom Summensatz des Dreiecks, »als logische Relation betrachtet«, auf die Existenz Gottes, die zu seiner »Wesenheit« gehöre, wie zur »Wesenheit des Dreiecks [...], daß die Summe seiner Winkel gleich zwei rechte ist « (Meditation, a.a.O., S. 119). Mit Theweleit kann man das von Lippe untersuchte königliche »Circeballett« des 16. Jahrhunderts als mächtiges Wachsen von Ödipus beschreiben, tanze doch Königin Louise an der Spitze des Najadendreiecks »die Unterwerfung der einzelnen Frau unter den Mann als Ehefrau [...]. Das Herrscherpaar selbst propagiert so im höfischen Ritual die bürgerliche Kleinfamilie, so weit ist die Unterwanderung des Absolutismus durch das Bürgertum schon fortgeschritten, ehe er sich voll entfaltet hat« (Männerphantasien 1, S. 402f.; vgl. Lippe: Naturbeherrschung am Menschen II, S. 441). Bodin jedenfalls wird in seinen »Six livres« die Familie zum »wahre[n] Ebenbild des Staates« erklären. Beide könnten - das wiesen schon die Naturgesetze - nur ein Oberhaupt haben. So habe der Ehemann die Gewalt, im »sittliche[n] Sinn heiße das: »Gewalt der Seele über den Leib, der Vernunft über die Begierde«. Letztere sei schon biblisch »das Weib«. Und glücklich sei die »Republik, in welcher der König dem Gesetz Gottes und der Natur gehorcht, die Be- 
vom Raum seines Körpers, »einen fiktiven geometrischen Raum auf, innerhalb dessen sich jeder sichtbare Gegenstand lokalisieren und in seiner Lage relativ zum Beobachter erfassen läßt«. Expliziert wird diese »natürliche Geometrie« vom »Problem der Distanzwahrnehmung«. Die hänge »nicht von irgendwelchen vom Objekt ausgehenden Bildern ab«, vielmehr von der je nach der Entfernung des Objekts veränderten Gestalt des Auges, dem »Verhältnis der beiden Augen zueinander« und von der »Klarheit oder Verschwommenheit des Objekts und seiner Konturen«. Die Augen sind dabei bloßes Instrument, denn es sei die Seele, die sieht. Und so entstünden »Irrtümer« auch dadurch, dass »das Gehirn auch autonome Bilder erzeugen kann «. ${ }^{606}$

Diesem distanzierten Auge schließlich lassen sich in Garten und Forst unveränderliche Bilder schaffen. Hier versetzt der >formende Geist « vermeintlich tote Materie in stetige, gleichförmige Bewegung. Aus Buchs, Taxus, Hainbuche usw. lassen sich gartenarchitektonisch Mauern, Skulpturen, Kabinette, Labyrinthe schaffen. Im Forst sind die Bäume durchgehend gleich alt, groß, dick und in regelmäßigen Abständen angepflanzt. Erst dieser Forst besitzt eine Perspektive - im wahrsten Sinn des Wortes. Bei einem zufällig gewachsenen Wald ist nicht oder kaum möglich, ihn >mit Blicken zu durchdringen`.

Der Eindruck des unveränderlichen Bildes ist zwar real Trompe l'œil, aber darauf kommt es an. In ihrer Logik ist der »Augenpunkt mit dem Fluchtpunkt« verbunden. Es entsteht der Eindruck einer stupenden räumlichen Homogenität, des Einheitlichen «. ${ }^{607}$ Es wird deutlich, das Trompe l'œil ist keineswegs »bloßer Augenschein [...]. Hier materialisiert sich das Gesetz der Enteignung«. Die »Verlandschaftlichung des Fluchtpunktgerüsts« ist synonym »mit einer Denaturierung der Natur ${ }^{608}$ Französischer Park und geregelter Forst haben also Gemeinsamkeiten, aber sie unterscheiden sich auch. Die »Fluchtpunktkonstruktion« des Parks fokussiert in der einen Richtung das Zentrum des herrscherlichen Schlosses, in der anderen das Unendliche. ${ }^{609}$ Im Forst besteht sie aus einer Viel-, wenn nicht Unzahl paralleler Geraden. Dieser Unterschied ist offenbar mitverantwortlich für das weitere `Schicksal Landschaftszurichtungen, wie sich im Folgenden zeigt.

amten dem Könige, die Einzelnen den Beamten, die Kinder den Eltern, die Diener dem Herrn [...]«. Zit. n. Braun/Kremer, a.a.O., S. 82 u. Lippe, a.a.O., S. 383.

606 Kutschmann, a.a.O., S. $236 \mathrm{ff}$.

607 Burckhardt, a.a.O., S. 187.

608 Ebda., S. 199.

609 Vgl. ebda., S. 187. 
»In der Identität von Natürlichkeit und Künstlichkeit wurde der Wert eines Artefaktes, wie es Descartes zur Erklärung diente, ungeheuer gesteigert. $«{ }^{610}$ Der Forst ist Artefakt. >Cartesianisch betrachtet gibt es keine Unterscheidung. Aber selbst, wenn man die Unterscheidung macht, die Bäume als Lebewesen betrachtet, bleibt der Forst Artefakt. Pflanzliches `Eigenleben ist hier ausgeschaltet. Er ist eine Maschine aus Lebewesen, die bestimmte Produktionsvorgaben erfüllen. Dass ein einheitlich gebauter Kunstwald, obwohl Pläne und ansatzweise Umsetzungen schon Jahrhunderte zuvor existieren, jetzt obligatorisch wird, dürfte nicht zuletzt auch der herrschenden Maschinenlogik, die eine derartige Reproduktion geradezu zur Pflicht macht, entstammen.

\section{Die Logik der Maschine}

Der geregelte Forst ist Produkt des Absolutismus, wie der (barocke) geometrische Garten. Aber der architektonische Garten hat auch noch eine andere zeitgenössische Ausprägung: die bürgerliche. Beide, Forst und architektonischer Garten sind Maschinen der Herrschaft über die >äußere Natur . Beide negieren das >Werden und Vergehen`.

Abb. 10: Stich aus: William Boutcher: A Treatise on Forest-Trees, 1775

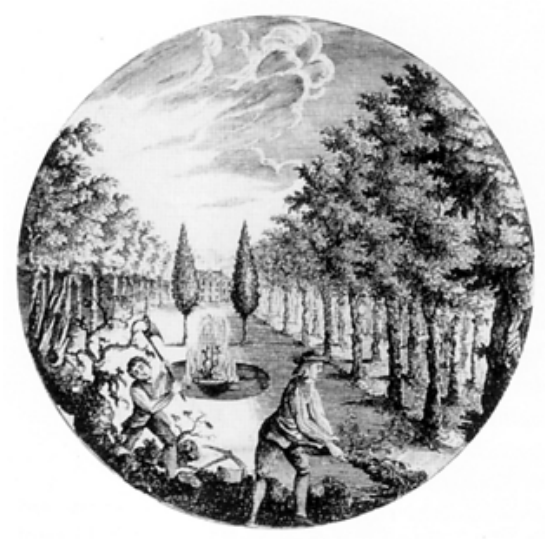

Der Forst ist >männliche` Maschine, dient der Produktion und repräsentiert sie, ist schmucklos, aber monumental, der Garten >weibliche` Maschine, dient der >bloßen

610 Schmidt-Biggemann, a.a.O., S. 35. 
sier, der Gesellschaft. Mit dem Ende des Absolutismus kommt der >französischeくGarten aus der Mode, seine Repräsentation trifft nicht mehr zu. Der geregelte Forst hingegen bleibt bestehen, beginnt einen >Siegeszug^. Er repräsentiert auch folgende, bürgerliche Gesellschaften. Die unterschiedliche geometrische Zurichtung zeigt zum Vergleich der Plan der 1606 gebauten Stadt Mannheim. Die Festung Friedrichsburg und die befestigte Stadt sind je beide äußerlich sternförmig angelegt. Die Stadt erscheint äußerlich als größere Kopie der Festung, die wiederum die Stadt okkupiert, aus der Draufsicht sitzt sie wie ein Haupt auf dem Körper. Während auch das Festungsinnere in seiner Bebauung sternförmig auf ein Zentrum ausgerichtet ist, sind die Straßen- und Häuserzüge der Stadt als rechtwinkliges Netz angelegt. ${ }^{611}$ Architektur bürgerlichen Wohnens, der Dienstbarkeit. Auch der geregelte Forst unterliegt einer solchen Architektur der Dienstbarkeit, denn wenn der menschliche Körper >dienstbar geworden ist, dann ist dieser >Wald $<$ die entsprechende ideale ‘äußere Natur - entsprechend dazu eine weitere Form des geometrischen Gartens: Neben dem >französischen

»entstand, aus bürgerlichen Voraussetzungen hervortretend, der holländische Garten, der zwar - stärker auf Nützlichkeit ausgerichtet - Obst- und Gemüsequartiere in den Lustgarten integrierte, aber doch vergleichbare geometrischarchitektonische Strukturen aufwies: quadratische Quartiere, parallele Achsen, klarere Abgrenzungen gegen das Umland (durch Kanäle oder Hecken). Die Rationalität und Naturbeherrschung des bürgerlichen Utilitarismus und des fürstlichen Absolutismus unterscheiden sich in dieser Beziehung - am Garten und seiner Geometrie - nicht so wesentlich. (Und wohl nicht nur am Garten: beide gemeinsam brachten die ebenso zentralistische und disziplinierende Manufaktur und Protofabrik hervor - Naturbeherrschung am Menschen.) $\aleph^{612}$

Der Unterschied ist sehr wohl wesentlich, liegt in den strikt »quadratische[n] Quartiere[n] « und »parallele[n] Achsen«. Und in der Abgrenzung zur Umgebung. Der absolutistische Garten ist oft eigentlich kein Garten, weil nicht umfriedet, er ufert aus, er okkupiert, >frisst $<$ die Landschaft, anstatt von ihr abgesetzt, abgegrenzt zu sein - er ist Park (diese Strukturen weist desgleichen der >englische` Landschaftsgarten auf). Und hier sind die integrierten Waldungen auch nicht >dienstbarı, sondern aufs absolute Zentrum komponiert, sternförmig etwa. Der geregelte Forst weist Strukturmerkmale des `holländischen Gartens` auf. Nicht nur bezüglich der Parallelität und Rechtwinkligkeit, sondern auch der Ab-

611 Vgl. Kleinspehn, a.a.O., S. 85.

612 Eichberg, Henning: Stimmung über der Heide, in: Großklaus, Götz/Oldemeyer, Ernst (Hg.): Natur als Gegenwelt, S. 202 
grenzung, denn mit ihm entsteht, im Unterschied zu vorherigen Nutzungen zur Viehweide und -mast usw., eine »scharfe[] Grenze zwischen Wald und Feld «. ${ }^{613}$

Das bei Bacon und Descartes exemplarisch formulierte gesellschaftliche Naturverhältnis, das >operativ-konzeptionelle` Verhältnis, das Naturerkenntnis zwingend an Experiment, Kontrolle, Manipulation bindet, zeigt sich notwendig auch bei anderen Autoren, bei Thomas Hobbes, »der die erste durchformulierte Theorie des Operativismus entwickelt hat«, auch bei Giovanni Battista Vico in dessen »Spruch, daß Menschen eigentlich nur das richtig verstehen können, was sie machen, herstellen, konstruieren $\ll .{ }^{614}$ Dazu werden - sozusagen an der Basis - vermeintliche oder reale geometrische Muster in der Landschaft gefunden und goutiert; in der Kulturlandschaft, wie in der afrikanischen >Wildnis . Martin Kempe vermerkt in seinen »Poetischen Lustgedanken«, eine »erwünschte Gegend, da die Bäume in ihrer richtigen Ordnung stunden«. Albrecht von Haller sieht in den Niederlanden nur Dörfer und "sonderlich Marsch«, die »eitel Gärten und prächtige Lusthäuser« seien. »Das Land ist aufs Schönste angebaut. Kein Baum in diesem Lande außer der Schnur wächst.« Und Gottfried Kirchen erfährt 1724 die Gegend um Mailand als »schönste« in der Lombardei, verlaufen doch »Wege und Landstraßen [...] fast alle schnurgerade, zu beiden Seiten mit fließendem Wasser eingefasset und mit Bäumen besetzt, als wenn es lauter Spaziergänger wären«. Bereits im 17. Jahrhundert notiert ein anonymer Reisender seine Freude über die Wälder in Guinea, »welche oben aus also eben sind, als wären sie mit einer Schere geebnet und verschnitten worden «. ${ }^{615}$ Um 1800 herum werden im Zuge der Industrialisierung und Verstädterung die Mauern der Städte gesprengt, »man zog aus der Stadt aufs Land, die große Vervorstädterung der mitteleuropäischen Landschaft« beginnt. »Die geometrischen Bastionskränze der Stadtfestungen wurden gleichzeitig in der >neupreußischen` Befestigungsart aufgelöst oder ersatzlos geschleift.« Mit dem Mauerfall werden auch Planung und Aufbau »geometrische[r] Idealstädte« obsolet; abgesehen von »allenfalls parzellierte[n] Stadtteilregulierungen $\ll .{ }^{616}$

Folgende ablehnend-programmatische Äußerungen wie: »Die Natur pflanzt nichts nach der Schnur«, die Rousseau seine »Julie« tun lässt, oder Saint-Simons Charakterisierung, der Barockgarten sei das »arro-

613 Radkau, Joachim/Schäfer, Ingrid: Holz, S. 146f.

614 Lenk, Hans: Der Macher der Natur? Über operativistische Fehldeutungen von Naturbegriffen der Neuzeit, in: Großklaus/Oldemeyer, a.a.O., S. 61.

615 Zit. n. Eichberg, a.a.O.

616 Ebda., S. $208 f$. 
gante Vergnügen, der Natur seinen Willen aufzuzwingen «, ${ }^{617}$ betreffen ausdrücklich die Gärten. Ihre geometrische Zurichtung wird ebenfalls für obsolet erklärt. Und auch deren >Befreiung « ist eigentlich nur eine Verlegung des >Panzers` nach >innen`, ins Unsichtbare - so, wie bei der `Zivilisierung` des `Justaucorps` der Höflinge zum Frack Ende des 18. Jahrhunderts.

Wenn Rousseau die »sogenannte[n] Leute von Geschmack« verspottet, sie forderten »überall Kunst« und seien »nie zufrieden [...], wenn sie nicht in Erscheinung tritt« und dem entgegen hält, »wahrer Geschmack« bestehe darin, »die Kunst zu verbergen, zumal wenn es sich um Werke der Natur handelt «, ${ }^{618}$ dann ist »Kunst« auch weiterhin mit $>$ Gewalt `gleichzusetzen. Säge und Axt bleiben unbedingte Basiswerkzeuge des Landschaftsgartens. Sie werden nun allerdings wie in der modernen Schönheitschirurgie angewandt. Der geregelte Forst bleibt von derartigen Anmutungen unberührt - dass es immer wieder Kritik am Erscheinungsbild gegeben hat, kann seinem enormen Aufkommen gerade seit der »große[n] und ausgebreitete[n] Revolution in Ansehung der Gärten«, wie Hirschfeldt 1785 in seiner »Theorie der Gartenkunst« formuliert, ${ }^{619}$ nichts entgegensetzen. Dass das nicht >rein ökonomisch` begründet ist, lässt sich zeigen. Ebenso (auch widersprüchliche) Zusammenhänge mit der (proto-)>touristischen` und/oder romantischen Eroberung der Landschaft oder Projekten der »Landschaftsverschönerung «. ${ }^{620}$

Nun, so Eichberg, ufere die »gebaute Gesellschaft [...] aus ins Grüne und transportierte dorthin ihre Mauern und ihre Parzellierungen«. Der

617 Zit. n. Mayer-Tasch, Peter Cornelius/Mayerhofer, Bernd: Hinter Mauern ein Paradies, S. 60ff.

618 Rousseau, Jean-Jacques: »Julie ou la Nouvelle Heloise«; zit. n. ebda., S. 62.

619 Zit. n. Eichberg, a.a.O., S. 208.

620 Eichberg beschreibt die >Entdeckung ২ der Heide; exemplarisch zu diesen Formen der $>$ Landnahme $<$ : Corbin, Alain: Meereslust. Das Abendland und die Entdeckung der Küste. Frankfurt/M: Fischer 1994 (Paris 1988), hierin auch einiges zum Gebirge. Damit beschäftigen sich desgleichen Groh, Ruth/Groh, Dieter: Weltbild und Naturaneignung. Zur Kulturgeschichte der Natur. Frankfurt/M: Suhrkamp 1991, Schama, a.a.O., der vor allem die Waldaneignung thematisiert; zu deren (früh-)romantischen Anteilen s. Duesberg, Peter: Idylle und Freiheit. Ein Entwicklungsmodell der frühromantischen Landschaft in der Wechselwirkung von äußerer und innerer Natur. Frankfurt/M: Peter Lang 1996. Zur dezidiert bürgerlichen Aneignungspraxis: König, Gudrun M.: Eine Kulturgeschichte des Spaziergangs. Spuren einer bürgerlichen Praktik 1780-1850. Wien, Köln, Weimar: Böhlau 1996. Zu den innereuropäischen Entdeckungsreisen Forsters, Heinses, Herders, Schlegels et al. und dem Vorfinden von Wäldern als »Dome« s. Kap. >Heilige Hallen< I. 
Auslagerung der Toten auf außerörtliche, ummauerte Friedhöfe folge der »Massenexodus der Lebenden im 19. Jahrhundert«. Bis zu dessen Mitte entstehen nicht nur private Landhäuser, sondern auch öffentliche Anlagen und Anstalten: Landschaftsparks, Badeanstalten, Turnhallen und -plätze, Schutzhütten und künstliche Aufstiegsmöglichkeiten in den Alpen, Aussichtstürme und künstliche Wasserfälle im Harz. ${ }^{621}$

Wenn sich die Gesellschaft »ihrer geometrischen Begrenztheit «, ${ }^{622}$ der »Geometrie als barocke[r] Verhaltensnorm « ${ }^{623}$ entledigt, bleibt also die Frage: wie? Im absolutistischen Park wird »die Grammatik des Bildes zur unmittelbaren Erfahrung«, wird »Bildraum« zum »Erfahrungsraum« (und vice versa), der Betrachter ist zugleich im Bild und ist sich seiner selbst als Betrachter bewusst. ${ }^{624}$ Diese »Grammatik« verschwindet mit dem Ende der Geometrisierung nicht, sie wandelt sich, und bleibt doch Grammatik. Was für den Landschaftsgarten gilt, gilt ebenso für die `freie Landschaft $\iota$ im Moment ihrer Aneignung. Am Beispiel des Turnens, das sich vom »freien Spielen zum Formaldrill« wandele, zeigt Eichberg selbst, »daß die Kolonisierung des Raums mit einer Kolonisierung des menschlichen Körpers einherging $«{ }^{625}$ Eine Kolonisierung allerdings, die nicht erst beginnt, sondern eine Fortsetzung ist. Eine Fortsetzung, die sich oft als Befreiung versteht, aber letztlich im hermetischen Raum stattfindet.

Der geregelte Forst bleibt als Bild- und Erfahrungsraum der Maschinengrammatik unterworfen. Schon weil seine Präsentation auch die von Drill ist. Er ist das >stehende Heer aus Canettis Massen-Symbolik. Er entspricht bürgerlicher, kapitalistischer Arbeitsethik, ist erfahrbarer »asketischer Eros« (Leo Kofler), tätige Abwesenheit von Wildwuchs par excellence. Dieser Wald braucht weiterhin eine sichtbare Grammatik. Würde diese eine verschleiernde sein, wäre er Park. Hier zeigen sich die beiden prototypischen Existenz-Formen des Waldes als gesetzlich definiertem und reguliertem Raum. Beide haben eine Grammatik, beide unterliegen gesetzlichen Bestimmungen, Raumordnungen. Was für den Nutzwald bereits explizit zutrifft, gilt für den Erholungswald (die Erholungslandschaft insgesamt) zunächst überwiegend noch informell. Naturschutzgebiete entstehen erst um die Wende zum/im 20. Jahrhundert. Nichtsdestotrotz ist die Erholungslandschaft von Beginn an >Park Übergänge zwischen Nutz- und Erholungswald sind fließend, denn es ist

621 Vgl. Eichberg, a.a.O., S. 219.

622 Ebda., S. 209.

623 Ebda., S. 202.

$624 \mathrm{Vgl}$. Burckhardt, a.a.O., S. $205 \mathrm{f}$.

625 Eichberg, a.a.O. 
in jedem Fall eine beherrschte, >befriedete`, geordnete Natur, die aufgesucht wird. ${ }^{626}$

Die wechselseitige Entsprechung von Mikro- und Makrokosmos seit dem Mittelalter hat eine Konsequenz: Es »wird, was im Kosmologischen gilt, zu einer Technik der Selbstbeherrschung, der Mäßigung. Folgerichtig wird die Tugend, Maß zu halten, die temperantia, im Verlauf des 13. und 14. Jahrhunderts zu einer Kardinaltugend«. Christine de Pizan erklärt die »Mäßigkeit« zur »Göttin«, den menschlichen Körper bereits zur »Uhr«, die nur arbeite, wenn sie reguliert sei. »Wo der Geist der Mäßigkeit zum Persönlichkeitsideal wird, wo der Takt, die mesure, zum Ethos wird, da ist es nur eine Frage der Zeit, daß sich dies auch in einem breiteren, gesellschaftlichen Diskurs niederschlägt.« Und in der politischen Literatur. Was zunächst, »äußerlich wenigstens, noch einen feudalen Anstrich« hat, wird zunehmend »der Ratio überantwortet«, um dann im »Leviathan seine Einlösung« zu finden. Verwoben ist dieser »unmerklich« ablaufende Prozess mit der Entwicklung der »Ökonomie der Zeit«, worin sich die scharfe Zäsur, der »Epochenriß« zeigt, werden doch in rund 200 Jahren die »Todsünden des Mittelalters, Geiz und Habsucht $[. .$.$] invertiert und zu Tugenden umgemodelt«, was dann »im$ Protestantismus schließlich sein geistiges Habit findet $\ll .{ }^{627}$ Der tradierte Forst königlicher Jagd ist ein Ort der Unmäßigkeit. Seine MaschinenRekonstruktion überführt ihn nicht nur in Maß und Zahl. Er totalisiert ihn auch, indem nicht mehr bestimmte Areale beansprucht werden, sondern die flächendeckende Umgestaltung und Vereinheitlichung zumindest angestrebt, aber auch weitgehend umgesetzt wird. Genau genommen bestehen beide Arten des gesetzlich geregelten Waldes seit dem Beginn der »Waldbauzeit« nebeneinander, der Begriff des Forstes allerdings geht auf die »Holzzucht« über.

Seit Mitte des 18. Jahrhunderts »änderten sich die gesellschaftlichen Normen. Der Vorrang der Jagd wurde als `Hundephilosophie〈 verspottet; `Ökonomieく wurde die Parole der Zeit«. Selbst »regierungsfromme Ökonomen geißelten die Jagdleidenschaft« wegen der Wildschäden und der Hemmnisse für die Holznutzung. »Friedrich II. von Preußen und Kaiserin Maria Theresia - die beiden mächtigsten deutschen Fürsten ihrer Zeit - waren erklärte Gegner der Jagd; von nun an wußten sich alle Jagdfeinde von höchster Stelle gedeckt. $\ll{ }^{628}$ Der Preußen-Herrscher wird zum »Virtuosen der mechanischen Staatskunst« und »ersten und größten 
Staatsmechaniker[]« ernannt. Seine »Staatsmaschine«, von Mirabeau gewürdigt, dient zeitgenössisch als Vorbild für andere deutsche Territorien, für die »österreichischen Reformen« und »allgemein als Muster«. Grundgelegt und elaboriert worden ist der Maschinenstaat bekanntlich woanders.

»Die Natur (das ist die Kunst, mit der Gott die Welt gemacht hat und lenkt) wird durch die Kunst des Menschen wie in vielen anderen Dingen so auch darin nachgeahmt, daß sie ein künstliches Tier herstellen kann. Denn da das Leben nur eine Bewegung der Glieder ist, die innerhalb eines besonders wichtigen Teils beginnt - warum sollten wir dann nicht sagen, alle Automaten (Maschinen, die sich selbst durch Federn und Räder bewegen, wie eine Uhr) hätten ein künstliches Leben? « ${ }^{629}$

Hobbes' Einleitung des »Leviathan« setzt das Herz mit einer Uhrfeder gleich, die Nerven mit Strängen, Gelenke mit »Räder[n], die den ganzen Körper so in Bewegung setzen, wie es vom Künstler beabsichtigt wurde«. Aber er bleibt nicht beim Tier:

»Die Kunst geht noch weiter, indem sie auch jenes vernünftigste, hervorragendste Werk der Natur nachahmt, den Menschen. Denn durch Kunst wird jener große Leviathan geschaffen, genannt Gemeinwesen oder Staat [...], der nichts anderes ist, als ein künstlicher Mensch, wenn auch von größerer Gestalt und Stärke als der natürliche, zu dessen Schutz und Verteidigung er ersonnen wurde. Die Souveränität stellt darin eine künstliche Seele dar, die dem ganzen Körper Leben und Bewegung gibt, die Beamten und anderen Bediensteten der Jurisdiktion und Exekutive künstliche Gelenke, Belohnung und Strafe, die mit dem Sitz der Souveränität verknüpft sind und durch die jedes Gelenk und Glied zur Verrichtung seines Dienstes veranlaßt wird, sind die Nerven, die in dem natürlichen Körper die gleiche Aufgabe erfüllen.«

Dieser Körper besitzt Eigenschaften wie »Stärke«, hier »Wohlstand und Reichtum der einzelnen Glieder«, eine »Aufgabe« (die »Sicherheit des Volkes«), er hat ein »Gedächtnis« (»die Ratgeber«), »künstliche Vernunft und künstliche[n] Wille[n]« (»Billigkeit und Gesetz«), seine »Gesundheit« ist »Eintracht«, »Aufruhr« seine »Krankheit«, »Bürgerkrieg« sein »Tod«. Die »Verträge und Übereinkommen«, durch die die Körperteile erst »geschaffen, zusammengesetzt und vereint« worden seien, gli-

629 Hobbes, Thomas: Leviathan oder Stoff, Form und Gewalt eines bürgerlichen und kirchlichen Staates. Hg. von Iring Fetscher. Frankfurt/M, Berlin, Wien: Ullstein 1976, S. 5. 
chen $\gg$ jenem >Fiat` oder >Laßt uns Menschen machen`, das Gott bei der Schöpfung aussprach «. ${ }^{630}$

Hobbes gelinge es, schreibt Stollberg-Rilinger »in verblüffender Weise, Tradition und Traditionsbruch in einem Bild erscheinen zu lassen«. ${ }^{631}$ Gemäß des »kausal-mechanischen Gesamtzusammenhangs« der >Weltmaschine sind natürlicher und politischer Körper »aus Teilen zusammengesetzte, bewegte Ganze «, nicht mehr zwei (gleichwohl untrennbar verbundene) verschiedene Sphären; vielmehr geht die politische Bewegung aus der physikalischen hervor. ${ }^{632}$ Anders ausgedrückt: Es geht um eine vertraglich geschlossene »wirkliche Einheit aller in ein und derselben Person«. Das sei »die Erzeugung jenes großen Leviathan [...], jenes sterblichen Gottes «, des Staats. »Wer diese Person verkörpert, wird Souverän genannt und besitzt [...] höchste Gewalt, und jeder andere daneben ist sein Untertan«, der »willentlich« unterwerfe, um Schutz zu erhalten. ${ }^{633}$ Diese $» k o l l e k t i v e$ Preisgabe des Rechtes aller einzelnen Bürger an die eine Instanz des Staates«, so Horst Bredekamp, zeige sich im Frontispiz des Buches, in der »Ausrichtung aller Menschen«, die sich in seinem Körper befinden, »auf den Kopf des Leviathan«. Dies sei der Moment der Staatsgründung, eine »verewigte Momentaufnahme dieses Schöpfungsaktes, in dem die multitudo ein Gesicht bekommt, wenn sie sich aus der Verfangenheit im natürlichen Recht in [eine] vertragliche Schöpfung des Leviathan befreit haben «. ${ }^{634}$ Bei Hobbes ist der menschliche »Naturzustand« ein »Kriegszustand«. Da die Natur die Menschen »hinsichtlich ihrer körperlichen und geistigen Fähigkeiten« relativ "gleich geschaffen« habe, woraus eine »Gleichheit der Hoffnungen«, Ziele zu erreichen, folge, entstünden beständig Konflikte, als deren Hauptursachen »Konkurrenz«, »Mißtrauen« und »Ruhmsucht« in der »menschlichen Natur« lägen. Hieraus ergebe sich »klar, daß die Menschen während der Zeit, in der sie ohne eine allgemeine, sie alle im Zaum haltende Macht leben, sich [...] in einem Krieg eines jeden gegen jeden « befänden. ${ }^{635}$

Bredekamp rekonstruiert die Herkunft des »Leviathan« über die Betrachtung des königlichen Doppeldeckergrabs, das den sterblichen natürlichen und den ewigen politischen Körper materialisiert, und des königlichen »Scheinleib[s]« (»effigie«), mit dem das »Bild zum authen-

630 Ebda.

631 Stollberg-Rilinger, a.a.O., S. 49.

632 Ebda., S. 50f.

633 Hobbes, a.a.O., S. 134f.

634 Bredekamp, Horst: Die zwei Körper von Thomas Hobbes' Leviathan, in: Ernst, Wolfgang/Vismann, Cornelia (Hg.): Geschichtskörper, S. 116f.

635 Hobbes, a.a.O., S. 94ff. 
tischen Stellvertreter des Herrschers gemacht wurde $«{ }^{636}$ Bei Hobbes werde der »Automat« zur »Idealform der königlichen, bewegungsfähigen effigies«, sein Begriff der »Künstlichen Ewigkeit« schlage eine »Brücke von der Inkarnation des künstlichen Lebens, den effigies, zum künstlichen Menschen «. ${ }^{637}$ So werde der »Leviathan« zu einem »Produkt der Zeitverschiebung«. Die recht kurze Zeitspanne zwischen Tod des alten und Inthronisierung des neuen Herrschers - das Interregnum, in dem gemäß des menschlichen »Naturzustands« potentiell Terror herrsche - wird zum »Dauerzustand « ausgedehnt, der »herrschaftslose Zustand « wird zur »Grundbestimmung der menschlichen Existenz«, »Leviathan« verharrt »dauerhaft im Moment [seiner] Gründung«. Die »zeremonielle Bewältigung des Interregnums« wird zur »Essenz des Staates $\ll$. ${ }^{638}$

Auch der Forst muss in gewisser Weise den Wandel, zugleich Traditionsbewahrung und -bruch, vom Körper des Königs zur Maschine, zum »künstliche[n] politische[n] Körper als Gegenstand exakter Erkenntnisse $«$, der $»$ mechanistischen Naturwissenschaft $«{ }^{639}$ vollziehen. Seine Rekonstruktion zur Maschine wandelt ihn vom rituellen Ort blutiger Einschreibungen zum Objekt mechanistischer Naturwissenschaft, vom >vollen Körper zur reproduzierbaren letztlich toten Materie, die der Geist in Bewegung setzt. Zwar wird die herrschaftliche Jagd zumindest bis zur ersten Hälfte des 19. Jahrhunderts auch weiterhin exzessiv betrieben, aber sie ist längst kein Hauptzweck mehr.

Die »epistemische Überschreibung[] ${ }^{640}$ kommt nicht unvorbereitet. Relativ früh dient Forst auch zu Profitzwecken, nicht nur zur herrschaftlichen Jagd. So nehme schon im England des 14. Jahrhundert »der Wald im juristischen und topographischen Sinne [...] zwei Bedeutungen« an, »die in krassem Widerspruch zueinander standen. Als grüner Forst des Königs wurde er streng, aber unparteiisch für die Jagd verwaltet. [...] Doch der Wald im juristischen Sinne war auch ein Ort des Profits für adelige Unternehmer«, ausbeuterischer Holznutzung unter Verbot tradierter Sammelmethoden der ansässigen Bevölkerung. Die jeweilige Entscheidung dieser Unternehmer zur Zusammenarbeit mit dem System des Königs ist, begünstigt durch dessen Geldknappheit, »im Wesentlichen eine Sache harter Kalkulation «. ${ }^{641}$

636 Bredekamp, a.a.O., S. 107.

637 Ebda., S. 111.

638 Ebda., S. 117f.

639 Stollberg-Rilinger, a.a.O., S. $54 f$.

640 Kutschmann, a.a.O., S. 322.

641 Schama, a.a.O., S. 167f. 
Der Forst lässt sich nun als eine Verknüpfung mehrerer Ebenen begreifen: Der Entsprechung von Mensch-Maschine und Wald-Maschine, der jeweiligen Reinigung von allem Irritierenden, Bedrohlichen, Untiefem, Schwankendem, ungeregelt Wachsendem. Einer projektierten bzw. ausgeführten Homogenisierung der Gesellschaft, in der noch bestehende Nischen ländlicher Ökonomie und Lebenspraxis ausgeschaltet werden. Daraus folgt eine (vermeintliche) Profitmaximierung in der Ausbeute der Ressource Holz/Wald. Angestrebt wird ein dauerhaftes, dauerhaft präsentes Regiment, in dem >Interregnien` ausgeschlossen werden, vertraglich festgezurrte Bedingungen herrschen.

Der Staat als Maschine, der Forst als Maschine: Es bestimmt der Souverän. Der »Naturzustand« gesetzloser Konkurrenz, des »Krieges eines jeden gegen jeden « soll hier nicht mehr stattfinden. Das wendet sich gegen > Waldfrevler< und >Wilderer<. Das wendet sich gegen andere Wirtschaftsformen als den Altersklassenwald, tradierte bäuerliche Formen, Nieder- oder Plenterwald, schließlich gegen alle nicht (mehr) geduldeten Bäume (was Art oder Wuchs angeht) und andere Pflanzen und Tiere.

\section{Der Aufmarsch der ıStände،}

Dass im geregelten Forstwesen zur absolutistischen Staatsmaschine analoge Prinzipien und Muster der Ordnungspolitik und deren Kategorien auch bezüglich einer gewaltförmigen Exklusion sozialer Minderheiten und Randgruppen - herrschen, zeigt Jean-Baptiste Colbert. Der zuständige Minister Ludwigs XIV. lässt mit seiner »Holzreformation« die Bäume in Reih und Glied zum Staatsdienst antreten:

»Wie immer im cartesianischen Frankreich ging es darum, Ordnung in das Chaos zu bringen. Colbert dachte sich das Königreich der Bäume ganz ähnlich wie das Königreich der Menschen: in unterschiedliche Stände geteilt, von denen jeder seine eigene Rangstellung und Verwendung hatte. An der Spitze standen die edlen Bäume Eiche und Buche, auf deren Stärke und Langlebigkeit die Verteidigung des Reiches ruhte. Unter ihnen rangierten die Weichholz-Nadelbäume, die Bourgeoisie des Pflanzenreichs, monoton in ihrem Anbau, aber für gewisse Aufgaben unentbehrlich. Selbst die Handwerker des Waldes - Esche und Linde, Weißbuche und Kastanie - hatten ihre besondere Funktion. Doch genau, wie ein ungepflegter Wald alle möglichen menschlichen Kanaillen - Banditen und Schmuggler und Vagabunden - barg, beherbergte er auch die knochigen, ungestalten, nichtsnutzigen Gewächse wie Weide und Sumpferle sowie Weißbirke. ${ }^{642}$

642 Ebda., S. 199. 
Und so sieht der große Erlass zur Abwendung der Holznot von 1669 »Bibel des französischen Forstwesens bis zur Revolution und sogar noch darüber hinaus « - vor, was an die Stelle bisherigen Wald-Chaos und einer Holznutzung je nach Bedarf zu treten hat; von Colbert in $500 \mathrm{Ar}$ tikeln auf 100 Seiten niedergelegt: Der Wald soll in zwei rigoros separierte Bereiche aufgeteilt werden, den »gemischten Bestand « - taillis composé -, gepflanzt zum kontinuierlichen Einschlag, und die »großen Bestände - grande futaie -, in denen Nutzholz in Altersklassen wachsen. »Der Raum für diese Regimenter wurde geschaffen, indem man alles bis auf den Stumpf rodete und die Schößlinge dann mit Palisaden, Erdwällen und Zäunen, die einem Vauban, dem Festungsbaumeister Ludwigs XIV., Ehre gemacht hätten, vor Tieren (und Menschen) schützte. $\ll{ }^{643}$

Der Wald als absolutistischer Staat, der keine »Kanaillen« mehr duldet. 1798 bezeichnet J.A. Cramer in seiner »Anleitung zum Forst wesen« einheimische Weichlaubhölzer als »forstliches Unkraut« und »Schanddeckel der Forstbediensteten $« .{ }^{644}$ Als Weichlaubhölzer definiert werden Birke, Eberesche, Zitterpappel, Salweide und Faulbaum. ${ }^{645}$ Der Begriff Weichlaubhölzer bezeichnet die Feinde jedes geregelten Forstwesens, egal wie weich oder hart die Hölzer tatsächlich sind, egal wie intensiv oder extensiv Wald und Forst wirtschaftlich genutzt werden. ${ }^{646}$

»Weichlaubhölzer« sind vom Standpunkt des Forstwesens her gesehen Relikte einer überwundenen ersten Natur, die sich überall ansiedeln können, selbsttätig, autonom und vor allem ungeregelt. Der Forst ist dem Willen des Herrschers unterworfen - was sich später >demokratisieren « lässt. Der Forst ist ein >Wald liegt. Regeln, die Aufenthaltsgenehmigungen aussprechen. „Weichlaubhölzer« haben kein Aufenthaltsrecht und erschleichen es sich doch im-

643 Ebda. Dass der Plan Colberts in der Realität spätestens nach seinem Tod weitgehend "papierenes Denkmal eines Waldpaternalismus« blieb, sagt Schama allerdings auch. Er sei gescheitert an der »menschlichen Wirklichkeit« eines auch weiterhin betriebenen illegalen Holzeinschlags (was hatten die notleidenden Waldbauern mit dem königlichen Schiffbau zu tun, sie brauchten Brennholz oder Eicheln und Eckern als Viehfutter). Das ändert aber nichts an der analogen Auffassung vom »Königreich« der Menschen und Bäume.

644 Zit. n. Leder, Bertram: Bisherige Beurteilung des Begriffs »Weichlaubhölzer«, in: LÖBF (Hg.): Weichlaubhölzer, S. 9.

645 Vgl. ebda., S. 10.

646 Vgl. dazu Klose, Franz/Orf, Siegfried: Forstrecht. Kommentar zum Waldrecht des Bundes und der Länder. Münster, Köln: Aschendorff u.a. 1998², S. 89f.: Wald im Sinne des deutschen Bundeswaldgesetzes ist nur der, der mit »Forstpflanzen«, also genutzten und geduldeten Pflanzen bestockt ist. 
mer wieder, gegen die Ordnung. Sie werden des Waldes verwiesen, sind vogelfrei. »Weichlaubhölzer« verstoßen permanent gegen die Regeln im beherrschten, inkulturierten Wald: Sie neigen eher als andere Bäume und Gehölze zum >Wildwuchs`, zur Mehrstämmigkeit, zu Krummwuchs und starker Verzweigung, zu Stockausschlägen, Wurzelbrut und vegetativer Vermehrung. Ihre »frühzeitige, reichliche und fast alljährliche Samenproduktion«, ihre »Mechanismen für eine weite Samenverbreitung «, die sie »zunächst gegenüber anderen « forstlich genutzten »Baumarten begünstigen «, ${ }^{647}$ machen sie zur lästigen Plage, ja Bedrohung der Forsten und ordentlichen Wälder: minderwertige `Rassen`, die sich ungezügelt und unkontrolliert vermehren und den Lebensraum hochwertiger Baumgesellschaften invasionär bedrohen.

Die auszuweisenden >Kanaillen` sind aber nicht nur Vaganten, sie srepräsentieren` frühneuzeitlich eher noch zwei andere Bevölkerungsgruppen: Hexen und Bauern. Insbesondere Weiden, Erlen, Faulbaum gelten traditionell als >Hexenbäume ২, jene Gehölze also, die nach tradierten Vorstellungen besonders gern von Hexen oder dem Teufel aufgesucht werden, unter denen Schlangen und Kröten hausen, die aber zugleich sozusagen als Inversion gegen Hexen und Schadenszauber eingesetzt werden. Diese >Inversion` liegt eigentlich in der Sache selbst.

Verrufene Orte und ihr Personal, die in ihnen lebenden Dinge bleiben verrufen - wenn auch die Begründungen andere sind. Aggregative Residuen, >Magie< (schwarze und weiße) etc. verschwinden unter der einen Erzählebene der wissenschaftlichen Deutung. Das ehedem dämonische kann nun gebannt werden durch messbare Erkenntnisse, in der Folge durch Pathologisierung und `Kriminalisierung〈 (»Schanddeckel«, $»$ Unkraut«), durch Exklusion. Das Heterogene ist ersetzt durch Eindeutigkeit.

Forstwissenschaft und Forstwirtschaft arbeiten im Gefolge von >exakter Wissenschaft und absolutistischem Staatskonzept praktisch am Tod durch >Vernunft< der alten Natur und ihrer Wiederauferstehung durch Vernunft. Die geregelte Forstwissenschaft ist der gewaltförmige Ersatz >weiblicher Produktivität $<$ der >äußeren Natur $<$ - Zyklizität, >Werden und Vergehen « - durch >männliche`. Es gibt den Tod nicht mehr im Forst. Parallel zur Biologisierung/Sexualisierung der Geschlechterhierarchie in der menschlichen Gesellschaft erfolgt die Sexualisierung der Pflanzen, unterwirft sie dem »Prinzip der Regulierungen $« .{ }^{648}$ Der Forst ist reguliert, weil er ungeregelte vegetative Fortpflanzung bekämpft, ausschließt. Vereindeutigung und Abgrenzung der Sphären: Grenzen ver-

647 Leder, in: LÖBF (Hg.): Weichlaubhölzer, S. 9.

648 Foucault, Michel: Der Wille zum Wissen, S. $173 \mathrm{ff}$. 
schwimmen nicht mehr (zwischen Wasser und Erde), das Fließen (auch der Orte) wird zum Stillstand, zur Erstarrung gebracht: Waldbau, Entwässerung, Gewässerbegradigung, Architektur, Statik.

Bäume, die eine "gute vegetative Regenerationsfähigkeit nach mechanischer Beschädigung (Eisanhang, Wildverbiß, Auf-den-Stock-setzen) ${ }^{649}$ aufweisen - Weichlaubhölzer, daneben Hainbuchen, Linden, Ahorn, Eschen und Hasel, teils auch Eichen, Ulmen u.a. ${ }^{650}$ - werden vor der >Forstreform traditionell in bäuerlicher Niederwaldwirtschaft genutzt. Diese Form der Kahlschlagwirtschaft verwandelt das Holz in >nachwachsende Rohstoffeく. Hierbei werden die Bäume »auf den Stock gesetzt«, d.h., in geringer Höhe über dem Boden abgesägt. In relativ kurzer Zeit (etwa fünf bis zehn Jahren) bilden sich per »Stockausschlag« neue Äste und Nebenstämme, die ihrerseits nach und nach abgeerntet werden können, um neuen Stockausschlägen Platz zu machen. Die Wälder können dabei in "Schlagsektoren« aufgeteilt sein, die zu unterschiedlichen Zeiten geerntet werden. Diese alte Technik, die sich bis heute nur noch aus landschaftsbildnerischen oder >ökologischen` Gründen erhalten hat, ist auf Nadelbäume nicht anwendbar. Eine gefällte Kiefer etwa bleibt ein toter Baumstumpf und kann nur durch eine Jungpflanze ersetzt werden. Gleiches gilt für Rotbuchen.

Während der Niederwald der Brennholz- und Futterlaubgewinnung dient, wird Bau- und Nutzholz im Plenterwald gewonnen, einer »besonders alte[n] Form der Waldwirtschaft«, die hauptsächlich zum Eigenbedarf betrieben wird (und heute fast verschwunden ist). Hierbei werden jeweils nur einzelne Stämme entnommen, auf den so entstandenen Lichtungen »kann sich der Wald auf natürliche Weise verjüngen«, zugleich bleibt der Boden durch ein beständiges Kronendach geschützt, was allerdings »Schattbaumarten« (Buche, Linde, Tanne, Fichte) bevorzugt und »Lichtbaumarten« benachteiligt. »Seit dem 16. Jahrhundert war die Plenterwirtschaft das Angriffsobjekt vieler landesherrlicher Forsterlasse: Sie galt als >unordentliche, der kommerziellen Nutzung [...] entgegenstehende Wirtschaftsweise.« Ähnliches gilt für den Niederwald. Hutewälder, die dritte bäuerliche Wirtschaftsform, »war in den Augen der Forstwissenschaft keine Waldformation, da er nicht der Holzproduktion diente«. Ziel der Forstwissenschaft ist - mit der späteren »logische[n] Konsequenz« der »künstliche[n] Aufforstung durch Saat oder Pflanzung « - die »Verbindung von Hochwald- Kahlschlagwirtschaft «. ${ }^{651}$

649 Leder, in: LÖBF (Hg.): Weichlaubhölzer, S. 10.

650 Vgl. Scherzinger, Wolfgang: Naturschutz im Wald, S. 343.

651 Radkau/Schäfer, a.a.O., S. 30ff. 
>Hochwald ist das alles überragende Ziel. Dieser Hochwald aber benötigt Nachhilfe, um >rein` entstehen zu können: Säuberungen per Läuterung und Durchforstung: In »Altpreußen« scheint »die Aufästung zur Unterstützung des Höhenwuchses [...] schon um 1700 und wahrscheinlich noch früher ein bekanntes Verfahren« gewesen zu sein, »jedenfalls enthält die >Renovatio Edicti wegen Pflanzung der Eichen und ObstBäume ২ vom 21. Juni 1719 in $\S$ IV die Bestimmung: >So sollen auch an Orten, wo in Unsern Heiden junge Eichen oder Buchen vorhanden, dieselben zur Beförderung des Wachstums von den überflüssigen Zweigen und anderem dabei ausschlagenden untüchtigen jungen Holze, welches die Eichen insgemein zu ersticken pflegt, fleißig gesäubert und ausgeputzt « werden. Ebenso ordnete der Oberjägermeister v. Hertefeld in seinen Anmerkungen zur Einrichtung des preußischen Forstwesens vom 18. September 1725 (§7) an, auf den Schlägen sollten beim Hieb des Brennholzes >alle geraden jungen Eichen stehen gelassen und von den Ästen gesäubert» werden «. ${ }^{652}$

Abb. 11

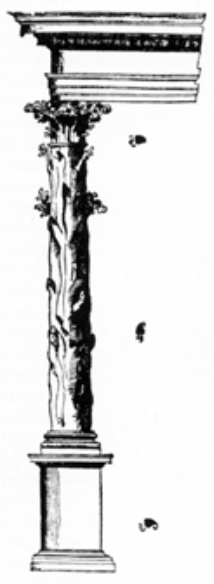

Auch im Frankreich des 17. Jahrhunderts kann Minister Colbert für seine »Holzreformation« auf einen tradierten »arborealen Klassizismus zurückgreifen«. Schon 1567 »hatte der Architekt Philibert de l'Orme dessen Axiom formuliert, indem er eine klassische Säule in ihrer elementaren Form als Baumstamm zeichnete«. Zwar handele es sich nur um eine Illustration $\mathrm{zu}$ den »Ursprüngen des Bauens« im zweiten Buch von Vitruvs »De architectura«. Aber die Abhandlung de l'Ormes sei »vom Grundsatz des französischen Klassizismus geprägt, daß man die Natur ordentlich und funktional machen sollte und daß die Wälder Frankreichs in Reih und Glied anzutreten hatten, um auf ihren richtigen Dienst am Staat zu warten«. ${ }^{653}$ Der Staatsdienst der Wälder nimmt offenbar einen wesentlichen symbolischen Platz ein.

»In der traditionellen Waldwirtschaft war die Spannweite der Umtriebszeiten enorm. Sie reichte von Niederwäldern mit fünfjährigem Umtrieb, die in den Augen der Forstleute nicht viel besser als Gestrüpp waren, bis zu Renommierwäldern mit 250jährigen Eichen. Der >Kult des Hochwaldes`war [...] >die Staatsreligion des Ancien Régime`, die in einem letztlich irrationalen Ahnen-

652 Mager, Friedrich: Der Wald in Altpreußen, Bd. I, S. $231 \mathrm{f}$.

653 Schama, a.a.O., S. 197. 
kult wurzelte; kein Wunder, daß die Revolution die Umtriebszeiten drastisch senkte. ${ }^{654}$

Spätestens mit Colberts »Holzreformation« 1660 soll das Ritual der »martelage« obligatorisch werden, wobei an diesem Tag »eine kleine Prozession« den Forst betritt, angeführt von den »Beamten des königlichen Förstercorps, der maîtrise, in surout-Röcken aus blauem Samt mit goldenen Westen und Dreispitzen auf den sorgfältig unter Perücken versteckten Köpfen«, gefolgt von Waldhütern, die zuvorderst die »grande futaie«, die königlich reservierten Nutzholzbäume (vor Holzdieben) zu schützen haben, damit sie »das richtige Alter von 100 Jahren« erreichen. Hinter den Hütern marschieren lokale Verwaltungshonoratioren und schließlich als Tagelöhner bezahlte Holzfäller. "Auf der Grundlage eines Katasterplans markierte der garde-marteau den auserwählten jungen Stamm mit dem königlichen Zeichen « - wofür ein Silberbeil mit einer Klinge in Lilienform (»marteau«) verwendet wird - »und erklärt ihn zum Schützling der Krone, bis er als großer Hundertjähriger seinen Beitrag zum Ruhm des französischen Reiches leisten würde. Diesen Riten der Adoption folgte dann ein Festessen im Walde für die Beamten und ihre Damen «. ${ }^{655}$ Offenbar besteht die »eindrucksvolle« französische »königliche Forstverwaltung« bis zu dieser Zeit weitgehend »auf dem Papier«, werden zwar die großen königlichen Jagdwälder von Compiègne und Fontainebleau »sorgfältig [...] geschützt«, gleichzeitig »Eichen- und Buchenwälder im ganzen Land« von den königlichen Beamten selbst »geplündert«. ${ }^{656}$

Ende des 17. Jahrhunderts »startete der Minister [Colbert] seine Inquisition«. Es kommt zu »erbarmungslose[n] Säuberungen« in der Forstverwaltung, Sondergerichten, die Schand- und Todesstrafen aussprechen. Der Wald als Colbertscher Ständestaat, »in Kolonnaden« gepflanzt, »säuberlich nach Rang und Bestimmung geordnet, war der Traum eines Bürokraten«. Nach seinem Tod blieb der Code Colbert in der Realität »papierenes Denkmal eines Waldpaternalismus«, gescheitert am »örtlichen Widerstand«, an der realen Holznot der Bevölkerung in »den bitteren Wintern der >kleinen Eiszeit` zu Anfang des 18. Jahrhunderts, an försterlicher Korruption und der durch die Industrialisierung explodierenden Nachfrage nach Brenn- und Bauholz. Mit der Revolution werden die Staatsforste zunächst »praktisch offen für alle«, wird

654 Radkau/Schäfer, a.a.O., S. 164. Binnenzitat v. Corvol, Andrée: L'Homme et L'Arbre dans l'Ancien Régime. Paris 1984, S. 178 u. 117.

655 Schama, a.a.O., S. $195 f$.

656 Ebda., S. 196. 
»das Wild fröhlich abgeschlachtet«, werden die Waldungen zur Hute genutzt und enorme Mengen Brennholz geschlagen. Noch vor dem Krieg mit Großbritannien (1793) beschließt die Revolutionsregierung die Wiedereinrichtung der zusammengebrochenen Staatsaufsicht. ${ }^{657}$

Ordnung ist berechenbar. In dem »bahnbrechenden Werk von Duhamel du Monceau über die Waldarbeit (deutsch 1766/1767) « ${ }^{658}$ findet sich die Illustration der Volumenberechnung von Bäumen. Der linke Baum: geradschaftig und mit Ästen erst in der Krone. ${ }^{659}$ Sein Rauminhalt »läßt sich vom Boden aus mit einfachen geometrischen Figuren berechnen«. Rechts sieht man einen »krumme[n] und stark ästige[n] Baum«. Der »ist zur Abschreckung danebengestellt. Für den Forstmathematiker waren krumme Bäume eine Horror, obwohl diese u.U. für den Schiffbau gut zu gebrauchen waren $« .{ }^{660}$ Berechenbarkeit ist dabei keine rein ökonomische Größe, sondern desgleichen sozialer Ordnungsfaktor. Der gerade und astfrei gewachsene Baum ist >gut erzogen<.

In Foucaults »Überwachen und Strafen« findet sich eine Radierung N. Andrys von 1749. Sie zeigt einen jungen Baum, dessen Krummwuchs nach und nach durch seine Fesselung an einen geraden Pfahl korrigiert werden soll: »L'orthopédie ou l'art de prévenir et de corriger dans les enfants les difformités du corps «. ${ }^{661}$ Hier wie da: Krumm- und Wildwuchs sind strengstens zu korrigieren - »Polizei des Körpers«. Der Baum ist nun »gelehrige[r] Körper«, wird vom >Bauern « zum >Soldaten erzogen. ${ }^{62}$ Und nicht nur der Baum. Zumindest in Preußen und Württemberg wird in dieser Zeit die militärische Ausbildung der Förster obligatorisch (s.u.). Gleichzeitig gelangt die Aufforstung in ihre Verantwortung und Praxis. Eine »tiefgreifende Veränderung des Berufsbildes«, verlangen doch bisherige Forstordnungen derartige Pflanzungen von Bauern; »an den Nachweis von Eichenpflanzungen« kann hier eine Heiratserlaubnis gebunden sein. ${ }^{663}$

657 Vgl. ebda., S. 198ff. Zur gängigen Korruption unter den schlecht bezahlten Forstbeamten in den deutschen Staaten, dem System der »Akzidentien«, den »Gebühren, mit denen amtliche Genehmigungen zu bezahlen waren«, die oft kassiert werden, obwohl das per Forstordnung Verbotene real gestattet wird vgl. Radkau/Schäfer, a.a.O., S. 178.

658 Radkau/Schäfer, a.a.O., S. 163.

659 Abgesehen von einem Zweiglein im unteren Drittel, vielleicht zur optischen Auflockerung, jedenfalls in der Praxis leicht zu entfernen. Vgl. ebda.

660 Ebda.

661 Foucault: Überwachen und Strafen, Abb. 30.

662 Vgl. ebda., S. $173 \mathrm{ff}$.

663 Vgl. Radkau/Schäfer, a.a.O., 172. 
Nach 1800 werden die »deutschen Forstwirte« zunehmend »»Fanatiker des Hochwaldbetriebs« mit hohen Umtriebszeiten«. Die ökonomische »Rationalität« einer derartigen »Vorliebe« ist allerdings zweifelhaft. Denn »bis weit in das 19. Jahrhundert hinein wurde der größte Teil des Holzes als Brennstoff verbraucht $\ll .{ }^{664}$ Hier sind also Nieder- und Mittelwälder eigentlich wirtschaftlicher. Zudem ist das Holz aus Mittelund Hutewäldern gerade wegen des häufigen Krummwuchses noch lange »bei Schiffbauern begehrt«. Und zumindest bis in die frühe Neuzeit erhalten Fachwerkhäuser eine »immer größere Bedeutung«. Hier sind gerade Stämme nur als Eckpfosten, als liegende Balken und im Dachstuhl notwendig, lassen sich krumm gewachsene Stämme und Äste etwa in Fassaden vielfach verwenden. ${ }^{665}$ Auch Eichenwälder zur »Lohegewinnung«, also zur Ernte der Rinde für Gerbstoffe, »brachte[n] im frühen 19. Jahrhundert Verwirrung in die `Forstökonomie««, weil »damals hohe Erträge«. Selbst die Waldweide bringt um $1830 »$ in manchen Gebieten mehr ein als alle anderen Waldnutzungen «. ${ }^{666}$

Vormoderne Ökonomie scheint desgleichen »ökologisch relativ stabil[e]«, unterholzreiche Mischwälder mit guter Bodenqualität erhalten zu haben, was »bei entsprechender Regelung« selbst auf Mast- und Weidewälder zutreffe. Zum ständigen Unmut der Forstherren, die versu chen, »die 〉Schlagräumung` durchzusetzen«, also Holzabfälle, Äste, Wurzelstöcke, die auf kahl geschlagenen Flächen liegen bleiben, argumentieren die Bauern, dass damit der Boden gedüngt werde, was zumindest aus ackerbauerlicher Sicht naheliegend erscheint (und heute bodenökologisch erwiesen ist). ${ }^{667}$ Wenn Radkau/Schäfer anführen, »die Forstreformer dagegen neigten zur Vernachlässigung des Bodens « und in diesem Kontext erwähnen, dass "sich die Bodenkunde einem wissenschaftlichen Zugang bis zum 19. Jahrhundert« entzogen habe, ${ }^{668}$ dann entsteht allerdings ein schiefes Bild. So schreibt Wolfgang Scherzinger 1996: »Obwohl zahlreiche Beobachtungen für die hohe Bedeutung des Tot- bzw. Moderholzes am Waldboden für Wachstum und Verjüngung des Naturwaldes vorliegen, wird die Behauptung, die nutzungsbedingte Holzentnahme sei für die Nährstoffbilanz im Walde irrelevant, hartnäckig aufrechterhalten.« Das ist nicht bloße Ignoranz, sondern Programm: »Totholz galt bis vor kurzem als Quelle allen Übels. Aus Angst vor Ausbruch von Baumkrankheiten, Pilzbefall oder Massenvermehrung

664 Ebda., S. 164.

665 Vgl. Küster, a.a.O., S. 141.

666 Radkau/Schäfer, a.a.O., S. 165.

667 Vgl. ebda., S. 159.

668 Ebda. 
der Schadinsekten haben Generationen von Forstleuten den Wald >entrümpelt‘.« ${ }^{669}$ Andererseits zeigt sich die ökologische Instabilität der neuen Nadelholzmonokulturen schon sehr früh: »Erschrocken und ratlos mußte man zusehen, wie ab 1776 weite Wälder Norddeutschlands auf diese Weise verheert wurden; und das war nur der Beginn einer ganzen Serie solcher Katastrophen in den Nadelwäldern." Sogar der Forstprofessor Leopold Pfeil (1783-1859), »der sonst über die Angst vor Holznot spottete, stellte fest, im Harz habe der Borkenkäfer die Fichtenwälder derart ruiniert, daß der Bergbau an manchen Orten habe eingestellt werden müssen «. ${ }^{670}$

Das für die Einführung der Altersklassenforste, hauptsächlich als Nadelholzmonokultur, immer wieder vorgebrachte Kardinal-Argument ist die >Holznot $\prec$. Diese 〉Holznot $<$ muss offenbar viel differenzierter gesehen werden. Radkau/Schäfer gehen dem »populäre[n] Motiv « ${ }^{671}$ nach. Zwar sehen auch sie regional »echte[] Holznot«, etwa aufgrund von Heidebildung durch Schafweide und Bodenerosion in Norddeutschland oder in "gebirgigen und zur Verkarstung neigenden Regionen« und/oder dort, wo großflächig Holz »in die Ferne verflößt« und verkauft wird. ${ }^{672}$ Nach Bode/Hohnhorst sind 1817 infolge des »Holländerholzhandels« ein Drittel des Schwarzwaldes und des Murgschifferwaldes kahl. ${ }^{673}$ Ebenso sei, vor allem in den harten Wintern der `kleinen Eiszeit`, für die »unteren Bevölkerungsschichten« oft eine »drückende Holznot« festzustellen. Nutznießer der Forstreformen, „auch wenn sie mit der Holznot der Armen begründet wurden«, sind aber die »ohnehin privilegierten Holzverbraucher«, Handelsgesellschaften, Exportindustrie und Residenzen. Und: »Die Holznot der Armen wurde mit der Durchsetzung des vollen Eigentumsrechts im Walde noch verschärft. « ${ }^{674}$ Denn auch für Brennholz müssen nun Marktpreise bezahlt werden. Auch das gehört zu den Maßgaben einer »verordnete[n] Holzknappheit«. Im Unterschied zur älteren, heterogenen Holzökonomie, in der etwa niedrige Brennholzpreise oft ein Zeichen obrigkeitlicher Vorsorge für Bedürftige und gewerbliche Holzverbraucher gewesen sei. In »der Zeit der Forstreform, der wachsenden Staatsverschuldung und des aufsteigenden Liberalismus gab es eine neue Logik. Mithin: »Holz wurde im Laufe des 18. Jahrhunderts nicht zuletzt deshalb knapp, weil es knapp werden sollte.« Hier kolli-

669 Scherzinger, a.a.O., S. $145 \mathrm{ff}$.

670 Radkau/Schäfer, a.a.O.

671 Ebda., S. 149.

672 Vgl. ebda., S. 156f.

673 Vgl. Bode/Hohnhorst, a.a.O., S. 33.

674 Radkau/Schäfer, a.a.O., S. 151. 
dieren alte und neue Auffassungen. Sind zuvor hohe Holzpreise synonym mit Holznot, gelten sie nun als Garant dagegen. ${ }^{675}$

Der Holz-Alarm scheint dann auch häufig mit Interessenpolitik zu tun zu haben, so wenn bestimmte Gewerbezweige hergebrachte Alleinverfügungsrechte in Gefahr sehen. Der Grad der Industrialisierung zwinge auch nicht unbedingt zu steigendem Energieverbrauch. Vielmehr sei bis zum »explosionsartige[n] industrielle[n] Wachstum des 19. Jahrhunderts« von einer zumeist auf Handarbeit basierenden »dezentrale[n] Industrialisierung «, die auch die tendenziell bereits vorhandene »Polarisierung von Zentrum und Peripherie« bremse, auszugehen. Der im 18. Jahrhundert dominante Typ ökonomischen Wachstums entspreche der »Holz- und Wasserkraftgrundlage «. Es scheine zwar aus »moderner Sicht [...] plausibel«, dass die Abhängigkeit von der `Zentralressource Holz` schließlich zur ökonomischen Misere führen müsse. »Dennoch ist es bisher kaum irgendwo gelungen, eine größere Wirtschaftskrise, die durch Holzmangel verursacht wurde, tatsächlich nachzuweisen.« Was für einige Flexibilität der vorindustriellen Gesellschaft im Umgang mit Holzmangel spreche.

Fazit: »Es ist auffallend, wie rasch die Warnrufe vor Holznot mit Beginn des 19. Jahrhunderts verschwanden, ohne daß sich die Situation der Holzversorgung verbessert hätte. « Und vor allem hochrangige Forstreformer und »Vorkämpfer des freien Marktes« wie Pfeil und Hazzi spotten über die »Hysterie« und den »fürchterlichen Lärm« von »Forstscharlatane[n]«. Eine echte Holznot sei unmöglich und möglichst hohe Preise nicht nur nützlicher »Anreiz zur Holzproduktion«, sondern desgleichen Signal für einen hohen »Stand der Industrie und Kultur«. ${ }^{676}$

Wilhelm Bode glaubt, da den Förstern die natürlichen Vorbilder per Devastierung abhanden gekommen waren, verwundere es nicht, »daß an der >Wiege der Forstwirtschaft $\iota$, nämlich in Deutschland am Ende des 18. Jahrhunderts, jegliche Vorstellung fehlt von dem, was (Natur-)Wald, seine natürliche Produktionskraft und Üppigkeit ausmacht«. Bode hält den gesteigerten Rohstoffbedarf der merkantilistischen Volkswirtschaft, also das Primärziel Holzproduktion für die Triebfeder. So sei es eben naheliegend gewesen, dort wo »keine oder nur unzureichende Bäume wuchsen«, Pflanzungen von überwiegend einer oder weniger Baumarten anzulegen.

»So wurde der Pflanzakt des Försters aus purer Notwendigkeit zum Geburtsakt des sogenannten schlagweisen, immer gleich alten und baumarten-

675 Vgl. ebda., S. 168.

676 Ebda., S. 156. 
armen Altersklassenwaldes. Er ist heute noch auf mehr als 90\% der deutschen Waldfläche das herrschende Betriebsmodell. Er ist ein Exportschlager, der als kulturelle Spitzenleistung der deutschen Kultur, so wie das Automobil, einen ungebrochenen Siegeszug um die Welt angetreten hat: Überall wo heute der Wald beseitigt oder verbraucht wird, gilt der konventionelle Altersklassenwald deutscher Prägung als die überlegene, nicht selten einzige Alternative.«

Und das, obwohl lediglich klimatische und geologische Zufälle ein derartig »durch und durch naturwidriges Waldbetriebsmodell« ermöglichten, ohne dass Wald dauerhaft verdrängt worden wäre. ${ }^{677}$

Radkau/Schäfer zufolge ist aber von »purer Notwendigkeit« gar nicht zu sprechen. Der >kritische< Blick der neuen Forstwirtschaft dürfe den »Zustand vieler Wälder« nicht per se »mit einer ökologischen Krise verwechseln«. Mit dem Ziel des »geregelten Hochwaldbetrieb[s]« beanspruchen die »selbstbewußten deutschen Forstreformer« für sich, »die >eiternden Wunden` der bisherigen >verdorbenen und unregelmäßigen Waldwirtschaft zu heilen - so die Amberger Forstverwaltung im Jahr $1800 \ll$. Die traditionelle Waldwirtschaft wird mit einem »Schwall von Verachtung« übergossen. Es »wimmelt in der Forstliteratur Ende des 18. Jahrhunderts von Klagen darüber, wie erbärmlich heruntergekommen die Wälder seien «. ${ }^{678}$ Nun spricht auch Bode davon, dass »das noch vorhandene Waldareal hinsichtlich seiner Artenvielfalt keineswegs verarmt« gewesen sei, wenigstens verglichen »mit unsere[n] öden Agrarsteppen und monokulturellen Wälder«, nur habe der damalige »Wald seine typischen Strukturelemente verloren«, seit statt dessen verbuscht oder verlichtet gewesen. ${ }^{679}$ Verbliebener Nieder-, Mittel- und Hutewald sei nur als Negativbeispiel wahrgenommen worden. Und »Urwald « habe als »Leitbild« nicht mehr zur Verfügung gestanden. ${ }^{680}$ Aber das »Leitbild « Naturwald - was auch immer darunter verstanden wird - ist ausdrücklich nicht erwünscht:

»Die `Natur` war kein Ideal für die Gründerväter der Forstwissenschaft; im Gegenteil: Die Forstreformer bekämpften geradezu die Auffassung, daß der Wald ein Geschenk der Natur sei - zu einem Produkt menschlicher Arbeit sollte er werden und dementsprechend seinen Wert bekommen. Das Pochen

677 Bode, Wilhelm: Der Deutsche Wald - Eine einzige Arche Noah?, in: Wolters, Jürgen, ARA (Hg.): Leben und Leben lassen. Biodiversität Ökonomie, Natur- und Kulturschutz im Widerstreit. Gießen: Focus 1995, S. 163.

678 Radkau/Schäfer, a.a.O., S. 157.

679 Vgl. Bode/Hohnhorst, a.a.O., S. 35.

680 Vgl. ebda., S. 39f. 
auf langjährige Erfahrung mit den natürlichen Gegebenheiten einer Lokalität war damals eher eine Position konservativer Förster, die der Verwissenschaftlichung ihres Metiers skeptisch gegenüberstanden und in den Augen der Reformer nur ihren alten \Schlendrian〈 verteidigten. Die neue Forstlehre sollte sich durch Theorie, eine leitende Idee, ein logisches System und daraus abzuleitende allgemeine Regeln auszeichnen. ${ }^{681}$

Bode will nachweisen, dass etwas aus einer Zwangslage heraus Entstandenes und nur durch klimatisch-geographischen Zufall Geglücktes keine Berechtigung mehr hat: »Das >Ethos der Holzzucht» bestärkt in dem Irrglauben an den ökonomisch schon längst gescheiterten Versuch, durch Kapitaleinsatz in den Produktionsräumen des Waldlebens rentierlich Holz zu produzieren. « ${ }^{682}$ Das übersieht - jenseits davon, wie groß die Zwangslage >Holznot< gewesen sein mag -, dass es sich dezidiert um ein Programm der möglichst totalen Umgestaltung handelt (wobei >Programm< nicht von Anfang bis Ende geplant heißt, sondern Eigendynamiken entwickeln kann). Der Wald wird als geregelter Forst zum Kapital, zum Renditeobjekt und dient nicht mehr der kontinuierlichen Nutzung bzw. Bedürfnisbefriedigung. Seine >Bestandspflege zukünftigen Erlös ausgerichtet. »Wenn man den Wald als Kapital betrachtete, dann war die Hochwaldpolitik die beste Kapitalakkumulation, solange das Wachstum der Bäume anhielt.« Auch wenn Mitte des 19. Jahrhunderts der zentrale Streit zwischen »Waldreinertragslehre« und »Bodenreinertragslehre«, also um die Frage entbrennt, ob der Wald das Kapital darstellt, oder der Boden und die Bäume nur die Zinsen; ${ }^{683}$ an der Kapitalisierung ändert das nichts.

Kapitalisierung ist aber nicht $\mathrm{zu}$ trennen von Maschinisierung, dem »Glauben an mechanistische Steuerbarkeit $«{ }^{684}$ des Waldes, überhaupt natürlicher Abläufe, von Aufschub, von einer Verwandlung natürlicher Regungen, Bedürfnisse in Herrschaftstechniken, von einer tatsächlichen Disziplinierung des Waldes (und damit auch Disziplinierung der von ihm lebenden Menschen). Der geregelte Forst erscheint als ideales Komplement einer >inneren Natur`, der all das abverlangt wird. Er ist Natur, die wie ein Uhrwerk abläuft und damit Kultur geworden ist, in der »Umtriebszeiten« herrschen und der natürliche Tod als abgeschafft erscheint. Er ist berechenbar, das heißt nicht nur: messbar, taxierbar und bezüglich des »jährlichen Zuwachses ${ }^{685}$ an Holzmasse kalkulierbar, sondern frei

681 Radkau/Schäfer, a.a.O., S. 159.

682 Bode/Hohnhorst, a.a.O., S. 183.

683 Vgl. Radkau/Schäfer, a.a.O., S. 166.

684 Bode/Hohnhorst, a.a.O.

685 Radkau/Schäfer, a.a.O., S. 162. 
von sinnlichen Übergriffen, Gefahren, Untiefen. Das trägt den Keim des Widerspruchs in sich, aber der Widerspruch selbst ist abhängig vom (nun) Bestehenden.

Harrison beschreibt das Aufkommen von Forstverwaltung und -wissenschaft seit dem ausgehenden 18. Jahrhundert als einen der Wege, »Herrschaft und Besitz« über bzw. von Natur »in der nachchristlichen Ära « zu realisieren, die Wälder zu Objekten von Analyse und Synthese zu machen, »wobei der Staat die Rolle von Descartes' denkendem Subjekt« übernehme:

»Wie leicht abzusehen, reduziert die moderne Forstwissenschaft Wälder auf ihren buchstäblichsten oder >objektivsten`Status: auf Nutzholz. Die neue >Forstmathematikı geht so weit, sie unter dem Aspekt ihres Volumens von verfügbarem Holz zu messen. Die Methode verschwört sich so mit den Gesetzen der Wirtschaft, um sich Wälder unter dem allgemeinen Begriff von >Nutzen` anzueignen, selbst in denjenigen Fällen, in denen Nutzen ästhetisch aufgefaßt wird: Wälder als Erholungsparks beispielsweise oder als >Museen der ursprünglichen Natur. ${ }^{686}$

Eine >Verschwörung` von Methode und Wirtschaftsgesetzen? Maß und Zahl sind die Grundgemeinsamkeit von Askese, Kapitalismus und Naturwissenschaft. Wenn das Nützliche schön sei, wenn »Maß und Ordnung« als die »Negation des Sinnlich-Lebendigen« die »Schönheit von Vernunft und Natur « sind, ${ }^{687}$ dann handelt es sich hierbei um eine dezidiert ästhetische Aussage. Die einzelnen Bäume und ihre Gesamtheit als Forst fungieren als »natürliche Automata«, deren Wachstum sich mathematisch exakt berechnen und Voraussagen lässt. Es handelt sich um einen möglichst weitgehend >entsinnlichten` Raum. Der Wald und seine Einzelteile werden, analog zur »Selbstauslegung der Natur im Experiment $«{ }^{688}$ zum \Selbstausleger`, zur Synthese ihrer selbst. Aber, bei aller (propagierten) »Leibfreiheit« von Naturerkenntnis, allem Vertreiben der »leibliche[n] Erfahrung« aus der Wissenschaft ${ }^{689}$ bleibt noch zu fragen, was aus einer solchen Entsinnlichung und Leibfreiheit folgt. Die Verschiebung von »Leiblichkeit in die Körperlichkeit $«{ }^{690}$ ist ja nichts für den $»$ Forscher $«$ Exklusives. Und die »Entthronung der Sinne ${ }^{691}$ ist keine Abschaffung, sondern eine Neuausrichtung.

686 Harrison, a.a.O., S. 134.

687 Braun/Kremer, a.a.O., S. 19ff.

688 Kutschmann, a.a.O., S. $256 f$.

689 Ebda., S. 254.

690 Ebda.

691 Ebda. 
Mit Norbert Elias sähe man hier um 1800 inzwischen weitgehend ihr gesamtes Affektgefüge kontrollierende soziale Individuen, die nach einer >Triebkontrolle` auch der >äußeren Natur` verlangen. Anders ausgedrückt: Weitgehend pazifizierte Menschen schaffen pazifizierte Naturräume. Das greift jedoch zu kurz. Der geregelte Forst ist nicht bloß >befriedete Natur`, sondern eine nach Beseitigung der alten völlig neu von Menschen - gegründete `Natur`; nicht nur, was die Pflanzen, sondern auch, was die nun vorherrschenden Tierarten (insbesondere Rotwild) und schließlich selbst, was neue Rituale und Mythen wie Weihnachtsbaum und Weihnachtsmann, Nationalbäume, Heilige Hallen ${ }^{692}$ betrifft. Neugründung heißt auch, der geregelte Forst ist nicht einfach eine zivilisiertere Fortführung des Königs-Forsts, sondern ein qualitativ anderer Ort. Dieser Forst ist absolutistische Maschine und bürgerliche Maschine, wobei die Räderwerke nicht nur ineinander, sondern ebenso gegeneinander laufen, ${ }^{693}$ Ort der Distinktion sowohl gegen adelige Verschwendung als auch gegen >Wildnis grundlegend diszipliniert und als etwas Neues wiederentstehen sollen. Auch hier beginnt, wie Foucault für diesen Zeitraum zeigt, Macht nicht einfach nur zu unterdrücken, sondern neu zu produzieren. >Gelehrige Körper : Der Wald als gesellschaftlicher Körper entspricht den Bedürfnissen und Wahrnehmungen des menschlichen gesellschaftlichen Körpers. Der geregelte Forst spiegelt die körperliche Formierung der Akteure seines Aufbaus wieder. Zumindest scheint er überwiegend weder als fremd, noch als künstlich erfahren worden zu sein - im Gegenteil.

»Obwohl die Wälder, die von den Forstverwaltungen begründet wurden, rein künstlich waren, wurden sie sehr bald - wenn auch meist unbewußt - als natürlich aufgefaßt. Wald in Mitteleuropa war die natürliche Landschaft, so meinte man, Wald war und ist Natur, wobei es keine Rolle spielte, welcher Baum in ihm die Vorherrschaft hatte. ${ }^{694}$

$692 \mathrm{Vgl}$. das Ende dieses Kapitels.

693 So in der Frage des >Freien Eigentums $\measuredangle$. Das »bedeutete in jedem Fall Abschaffung der >Servituten`, der traditionellen Nutzungsrechte von NichtEigentümern«, z.B. armer Bauern, und so neue Vorteile für alle Besitzenden. $\gg$ Freies Eigentum verwaltung und die adligen Grundherren: Das liberale Credo widersprach der staatlichen Kontrolle über den Privatwald [...].« Radkau/Schäfer, a.a.O., S. 170. Ähnliches gilt für die Auseinandersetzungen um das adelige Jagdregal bis zu seiner Abschaffung 1848. Vgl. Hiller, Hubertus: Jäger und Jagd. Zur Entwicklung des Jagdwesens in Deutschland zwischen 1848 und 1914. Münster: Waxmann 2003, S. 27f.

694 Küster, a.a.O., S. 190f. 
Zum Aufbau derartiger Bestände gehören nicht nur »Saatgärten« oder möglicherweise »eigene Baumschulen, Forsthäuser. Unerlässlich erscheinen auch Vorkehrungen für die Jagd als »Nebennutzung der Wälder«: Lichtungen sind anzulegen, »auf die das Wild gelockt« und auf denen es gefüttert werden soll, weshalb dort Futterkrippen plaziert und häufig Feldfrüchte angebaut werden, desgleichen Hochsitze an »den Schneisen im Wald «. ${ }^{695}$

Der Kunstwald entsteht planmäßig in derselben Zeit, in der eine breite bürgerliche, ästhetisch und moralisch vermittelte Aneignung von Landschaft und Wald beginnt. So etwa mit der >Fokussierung ‘ der Landschaft in der `Sächsischen Schweiz» seit dem Ende des 18. Jahrhunderts. Was zunächst als Interesse an zahlreichen empfindsamen Parkanlagen in der Dresdener Umgebung beginnt, "wich bald der Sehnsucht nach unberührter, nach >wilder und roher Natur. Weite Landschaft symbolisierte Ursprünglichkeit«.

Die aufkommende »Sehnsucht« zu befriedigen, werden Aussichtstürme oder -hügel errichtet. ${ }^{696}$ Diese Bauwerke sorgen für »Rundumsicht (Horizontalpanorama)« oder die Realisierung »verschiedene[r] Sichtachsen $"{ }^{697}$ und schaffen so schon einen riesenhaften Park. Beim Bemühen um ein Theater der »Verbindung der ganz wilden und rohen Natur mit der sanften und cultivirten«, wie das 1804 Wilhelm Lebrecht Götzinger beschreibt, bleibt die Frage, wie >uncultivirt` die >rohe` Natur sei. Roh sind allenfalls die Sandsteinfelsen, die dort wachsenden Fichten offenbar aber angepflanzt. In der »Frühzeit des Fremdenverkehrs« werden die »Bergeshöhen« noch »nahezu unbewaldet[]« dargestellt, 1804 behindern die Nadelbäume bereits häufig den Ausblick. ${ }^{698}$

Seit dem ausgehenden 18. Jahrhundert wird desgleichen der Wald als >stehendes Heer $\diamond$ oder als `Kathedrale $<$, >Waldesdom $<-$ bzw. umgekehrt, die gotische Kathedrale als >Wald $<$ - wahrgenommen. Derartigen Formationen gemein ist eine Ordnung, eine erkennbare Architektur, die dann als >natürliche Formation` zurück projiziert wird. Zur »dichterische[n] Verherrlichung «, ${ }^{699}$ Monumentalisierung, mythischen Projektion ist der Kunstwald hier kein Widerspruch, vielmehr besteht eine wech-

695 Ebda., S. 190.

696 Vgl. Martin, Andreas: Fokussierte Landschaft. Aussichtstürme in der Sächsischen Schweiz, in: Brednich, Rolf Wilhelm et al. (Hg.): Natur Kultur, S. $177 \mathrm{ff}$.

697 Ebda., S. 180f.

698 Vgl. ebda., S. $180 \mathrm{ff}$.

699 Küster, a.a.O., S. 191. 
selseitige Bedingung. ${ }^{700}$ So schreibt der Oberforstrat H. Burckhardt 1855 in seinem »Beitrag zur Holzerziehung«:

»Die lebendigen Monumente der Väter, die stattlichen Bäume, sie haben eine weitere Bedeutung, als bloß Quelle des Geldeinkommens zu sein. - Die Zeit der heiligen Haine ist längst zwar vorüber; aber noch heute senkt der stille erhebende Wald jenen Frieden in das Gemüth des einsamen Waldbesuchers, den ihm das Gewühl der Menschen nicht beut. ${ }^{701}$

Solche »Monumente« aus »auffällige[n] edle[n] Holzarten« sollen zur Aufwertung »[h]istorisch interessante[r] Punkte« oder »wichtige $[\mathrm{r}]$ Betriebspunkte« entweder dort gepflanzt oder, falls vorhanden und »es der Waldbestand erlaubt«, erhalten werden. »Die Ruine, die Felswand beraube nie ganz ihres Baumschmucks, und auf der abzutreibenden Berghöhe erhalte wo möglich einige standhafte Bäume als Wahrzeichen der weiten Umgegend.« Zusätzlich sollten Forstwege »gefällige Biegungen« aufweisen, der >Waldmantel solle nicht per Axt aufgeästet, oder der Bestand mit »freundlichem Laubholz« ummantelt werden. ${ }^{702}$ Solche Kulissen sind auch Ende des 18. Jahrhunderts bereits umgesetzt worden, als Alleen innerhalb der Forste. ${ }^{703}$ Küster bemerkt, dass Förster, die »landschaftsästhetisch[e]« Prinzipien wie die Burckhardts angewendet hätten, was heute in Forsten noch beobachtbar sei, »sich nicht sehr wesentlich vom Gestalter eines (englischen) Landschaftsparks des 19. Jahrhunderts« unterschieden. Auch Burckhardt selbst sei das aufgefallen. Umso brüsker weise er »Gartenanlagen« als nicht waldgemäß zurück und bei »s.g. Forstgärten« könne die »Künstelei« Geldverschwendung sein, »ohne durch Nutzen oder Schönheit zu befriedigen«. Auch hinsichtlich des Lehrbuchs für Forstästhetik von Heinrich von Salisch (1885) hält Küster es für interessant, dass Kunstwälder »schon im 19. Jahrhundert« unter Aspekten der »kulturellen Bedeutung« und der »Wohlfahrtsfunktion« betrachtet würden. ${ }^{704}$ Überraschend ist das aber nicht.

Der Wald der Aufklärung, schreibt Harrison, sei einer, der »völlig unter [den] Begriff des Nutzens« falle, genauer: der »l'utilité publique«, worunter seine Eigenschaften als Lieferant von Brennstoff und Bau-

700 Zur Entstehung »heiliger Hallen« aus hochdurchforsteten Buchenreinbeständen: Kap. >Heilige Hallen $\mathrm{I}$.

701 Burckhardt: Säen und Pflanzen nach forstlicher Praxis; zit. n. Küster, a.a.O.

702 Vgl. ebda.

703 Vgl. Küster, ebda., S. 188.

704 Vgl. ebda., S. 192. 
material, als Quelle von Steuern ebenso fallen, wie seine ästhetischen Qualitäten als Landschaft oder Park. ${ }^{705}$ Sein Gewährsmann ist »Monsieur Le Roy«, Aufseher in Versailles und Autor des Artikels »forêt« in Diderots und d'Alemberts »Encyclopédie« (1765). Dieser Artikel offenbare »die Mentalität, die dann die Zukunft der Forstverwaltung in Europa und den Vereinigten Staaten beherrscht«, womit Le Roy »als das neue Waldorakel« fungiere. ${ }^{706}$ Er definiere »forêt« als »ausgedehntes bewaldetes Gebiet im Gegensatz zu den kleineren Gebieten«, den »bois«, reduziere ihn dabei »technisch auf Grünpflanzen«, eine bloße Ansammlung von Holz »aller Altersklassen und Arten«. Schon immer seien Wälder wegen ihrer enormen Schutzwürdigkeit »als das Eigentum des Staates betrachtet und in seinem Namen verwaltet worden «, zitiert Harrison Le Roy, der hierzu auch in doppelter Ironie die Eichen-Orakel der Druiden zähle. Hier werde die »projektive[] Vergangenheits-Loslösung der Aufklärung konkret, per Geschichtsklitterung der Staat ideologisch als »universelle[r], transzendente[r] Hüter des nationalen 〉Eigentums betrachtet, Entmystifizierung des Sakralen zugunsten des einzig heiligen Werts, des »öffentlichen Interesse[s] «, betrieben. ${ }^{707}$ Nicht nur beraube der »Encyclopédie«-Artikel die Wälder einer »symbolischen Dichte [...], die sie einst besessen haben mögen«, auch Tiere würden hier kein einziges Mal erwähnt. »Der Wald als Lebensraum ist verschwunden. ${ }^{708}$ Übrig bleibe nichts als ein Konglomerat von Objekten, deren größtmögliche Nutzenausbeute der Kompetenz der Forstverwaltung, den gesammelten Erfahrungen und Beobachtungen der Förster unterliege. Hier zeige sich der »Hyper-Humanismus« des gesamten »Encyclopédie«-Unternehmens, jener »große[n] Apologie für Sensualismus, Empirizismus und eine[r] Art Proto-Positivismus«, was nur scheinbar im Widerspruch zur Sinnes-Negation und zum »mathematischen Deduktionismus « cartesianischer Prägung stehe, »doch in Wahrheit« nur ein Verzicht »auf Descartes' Metaphysik« sei. Übereinstimmung bestehe in der Auffassung vom »Subjekt der Erkenntnis und den Objekten seiner Analyse«. Identisch sei der 〉Humanismus $\measuredangle$, dessen »Erfüllung« in der »Beherrschung und Inbesitznahme der Natur« bestehe. ${ }^{709}$ In der Tat verweist auch Kutschmann auf die »strengste[n] Maßstäbe an die Selbstlosigkeit und Enthaltsamkeit des Beobachters«, der »Absichtslosigkeit«, wie sie unter dem Stichwort »Observateur« in der »Encyclopédie« po-

705 Vgl. Harrison, a.a.O., S. 147.

706 Vgl. ebda., S. 149.

707 Ebda., S. 142f.

708 Ebda., S. 148.

709 Ebda., S. 144. 
stuliert werden, was den Forderungen schon Bacons entspreche. Nur so garantiere sich der »reine[] « und »rein »lichtbringende[]< Charakter« des Experiments, das als »ein selbstläufiger, autonomer Prozeß der Natur begriffen« werde. Es gehe darum, per »Beobachtung« die Natur aufzuspüren und ihrem »Diktum« zu folgen. ${ }^{710}$ In dieser Weise lässt sich auch Le Roy verstehen. Neben dem Utilitarismus des Praktikers in den Ländereien von Versailles geht es ihm um Beobachtung der Bäume, die er sich distanzierend vom Leib hält, um der >reinen Natur $\mathrm{zu}>$ folgen $<{ }^{711}$ Das bedeutet, den genauen jeweiligen »Wachstumszyklus« der Baumarten zu kennen, ${ }^{712}$ ihre Naturgesetzlichkeit sozusagen. Natur »zu verunstalten« bzw. »zu entstellen«, wie es im »Observateur «-Artikel heißt, ${ }^{713}$ sieht Le Roy etwa in der Praxis, Bäume zu sakralisieren. Derartige `Entstellungen entspringen dem Rationalismus aus einer fehlenden oder ungenügenden Trennung von Geist und Körper(n).

Das wissenschaftliche Entsinnlichungspostulat transportiert einen sozialen Prozess. So aber wie »der mittelalterliche Mensch« kein weitgehend »leeres Gefäß « ${ }^{714}$ ist, das sich im Zivilisationsprozess äußere Zwänge internalisierend zunehmend anfüllt, kann 〉Entsinnlichung « nicht eine dementsprechende Leerung des >Gefäßes` sein. Wenn der menschliche Körper »ein geschichtlicher Vorgang « ${ }^{715}$ ist, ist er das inklusive seiner Sinnlichkeit. Alles andere würde auf eine Leugnung der Verflechtung von Körper/Wahrnehmung (ihren Formierungen) und Gesellschaft (inklusive der Widersprüche) hinauslaufen. Die propagierte Herauslösung aus sinnlicher Nähe schafft Sinnlichkeit nicht ab (wie sie behauptet), sondern spezifisch neu. Das Erkennen, die >höchste Lustく, liegt dann in der beherrschenden Distanz. So liest sich der »Observateur«, der sich mit Physik und Astronomie befasst, an entscheidender Stelle wohl nicht zufällig wie eine voyeuristische Phantasie. ${ }^{716}$

710 Kutschmann, a.a.O., S $263 \mathrm{ff}$.

711 Vgl. ebda., S. 264.

712 Vgl. Harrison, a.a.O., S. 146.

713 Zit. n. Kutschmann, a.a.O.

714 Sonntag, a.a.O., S. 147.

715 Lippe, Rudolf zur: Am eigenen Leibe, in: Kamper/Wulf (Hg.): Die Wiederkehr des Körpers, S. 28.

716 Es wird unterschieden zwischen zwei differenten Typen von Physikern, dem »Beobachter« (dem wirklich »großen« Wissenschaftler), der die Phänomene untersucht, wie die Natur selbst sie ihm zeigt, und dem experimentellen Physiker, der »sich selbst einbindet«, so die Natur nie allein als sie selbst sieht und sie deshalb immer stärker »bloß zu legen« trachtet. Der Beobachter bedient sich nur seiner Augen, was völlig ausreicht, denn »die Natur [ist] für den, der die Augen hat, entschleiert und nackt«, schlimmstenfalls ist sie »nur von einem schleierartigen leichten Gewebe 
Interessant ist an Harrisons Darstellung daher nicht seine Kritik der »Aufklärung«, interessant sind die Missverständnisse.

»Für diese Art von aufgeklärtem Humanismus, den Le Roy teilt, kann der Wald als geweihter Ort von Orakelverkündigungen, als Ort seltsamer oder monströser oder bezaubernder Erscheinungen, als imaginäre Stätte lyrischer Nostalgie und erotischer Irrfahrten, als Naturschutzgebiet, in dem wilde Tiere in Sicherheit vor den Verheerungen der Menschheit wohnen können, die das Geschäft betreibt, sich um ihre >Interessen` zu kümmern, nicht zur Debatte stehen. Es kann nur die Ansprüche der menschlichen Beherrschung und Inbesitznahme der Natur geben - die Reduzierung von Wäldern auf Nutzanwendung. ${ }^{717}$

Der elisabethanische Waldhüter Manwood hingegen verstehe den Forst noch als »Naturschutzgebiet«, vor allem auch für die dortigen Tiere, als »Zufluchtstätte«, Markierung der »Grenzen menschlicher Ausbeutung der Wildnis « ${ }^{718}$ Die so geschützte Natur sind aber nicht die Pflanzen und Tiere (um ihrer Existenz willen), geschützt wird die >Natur〈 des Königs. >Wildnis` ist hier ebenfalls nicht zwingend, der Forst kann eigens neu gegründet sein. Zudem gibt es auch noch zu Zeiten Le Roys Bannforsten, in denen Wald und Jagdwild des Herrschers vor den »Verheerungen« des >Pöbels« >geschützt« sind.

Wichtiger allerdings ist, dass die neuen (Kunst-)Wälder des »aufgeklärten Humanismus«, oder andere, ältere, von Menschen stark geprägte oder geschaffene Wälder sehr wohl als >geweihte Orteく, Stätten >seltsamer`, >erotischer`, oder nostalgischer Erfahrungen wahrgenommen werden - und sei es in Gegnerschaft zur Aufklärung. Inspiriert durch Klopstocks Ode »Der Hügel und der Hain« bildet sich 1772 der Dichterbund »Göttinger Hain« in der Nähe der Stadt im »Weender Eichenhain«, einer »alte[n] Hutelandschaft mit weit ausladenden Eichen; die Bäume hatten in die Breite wachsen können und respektable Umfänge erhalten. Sie waren sicherlich alt, wenn auch nicht so alt, daß der

bedeckt, durch welche das Auge und die Reflexion mühelos hindurchdringen«. Er »erwartet nichts von den Resultaten«, auch seiner Vorgänger, aber er ist sehr begabt, "geht Schritt um Schritt hinter der Natur her, entschleiert die geheimsten Mysterien«, wobei ihn alles »in Erstaunen« versetze, instruiere. Alle »Resultate sind für ihn gleich, weil er nichts von ihnen erwartet«. Der Experimentator hingegen will »die Maske« abziehen, die die Natur »unseren Augen verhüllt«, eine bloß»vorgebliche Maske«, die »nur in der [...] für gewöhnlich hinlänglich beschränkten Vorstellung des Experimentators« existiere. Zit. n. Kutschmann, a.a.O.

717 Harrison, a.a.O., S. 149.

718 Ebda., S. 148. 
germanische Barde schon unter ihren Ästen einst gewandelt wäre «. ${ }^{719}$ 〉Deutsche Eichen〈, >erlebte〈 Symbole für »Freiheit und Vaterland «, Ort des Schwärmens und der Erschütterung. ${ }^{720}$ Es sei »etwas sehr Merkwürdiges«, meint Küster, die Bäume »als Symbole der urwüchsigen Natur richtiggehend zu verehren«, sei doch ihr bizarrer Wuchs Ergebnis ihrer Nutzung zur Viehweide. Inzwischen wird das Vieh in Koppeln und auf Wiesen getrieben. Die Bäume als »Elemente der Kulturlandschaft« aber werden in dem Augenblick mythisch aufgeladen, in dem sie ihren Zweck verloren haben und hierfür nicht mehr eigens geschützt werden. ${ }^{721}$ Dabei ist die ökonomische Funktion dieser $>$ Haine $<$ auch in Dichterkreisen bekannt. Lessing 1778, Gottlieb Conrad Pfeffel 1796 und ein Jahr später Schiller begegnen dem »zeitgenössischen poetischen Eichen-Rauschen« spöttisch mit dem Hinweis, dass die Bäume nichts als Schweinemäster seien. ${ }^{722} 18$ Jahre vor der Entstehung des »Hainbundes« kritisiert Johann Georg Bärens die »Göttingische Gegend» dafür, dass sie »mehr für die Haußhaltung, im geringsten aber nicht für die Ergötzlichkeit bebauet ist. Denn nicht zu gedencken, daß kein einiger öffentlicher Garten anzutreffen sey«, seien auch die privaten Anlagen ästhetisch uninteressant. ${ }^{723}$ Allzusehr von ökonomischen, nützlichen Aspekten scheint ihm unter seinen »Wahrnehmungsbedingungen ${ }^{724}$ die Umgebung geprägt. 1765 werden »im Zuge der Entfestigung« Göttingens an einer Stelle Stadtmauer und Wall beseitigt, eine seit 1738 vorhandene Doppelallee wird nun außerhalb der Stadt verlängert: »eine Verlängerung der Sichtachse, eine optische Annäherung zwischen dem städtischen Raum und der umgebenden Natur «. ${ }^{725}$ Es folgt eine Umfassung der Stadt, »auf Wallhöhe« mit Hainbuchenhecken, darum »eine

719 Küster, a.a.O., S. 181.

720 Vgl. ebda.

721 Vgl. ebda., S. 182. Vergleichbares gilt für die von C. D. Friedrich häufig gemalten >knorrigen` Bäume. >Alte deutsche Eichen` werden auch im Park des Herzogs von Dessau in Wörlitz >erlebtく, also in eindeutig zu ästhetischen Zwecken gebauter Landschaft, so 1779 von Johann Heinrich Abegg. Ebda. Vgl. Best, Otto F.: Die blaue Blume im englischen Garten, S. $103 \mathrm{ff}$.

722 Vgl. Lindemann, Klaus: In den deutschen Eichenhainen webt und rauscht der deutsche Gott, in: Semmler, Josef (Hg.): Der Wald, S. 206ff.

723 Zit. n. Schwibbe, Gudrun: »....so liegt die schönste Landschaft vor den Augen ausgebreitet...«. Zur kulturellen Konstruktion von Stadt und Natur in historischen Wahrnehmungen, in: Brednich et al. (Hg.): Natur - Kultur, S. 446.

724 Schwibbe, ebda.

725 Ebda., S. 446f. 
Doppelreihe von Linden «. ${ }^{726}$ In dieser zum »Panorama« entwickelten Landschaft wird der Hainberg in den ersten Jahrzehnten des 19. Jahrhunderts zum populärsten Aussichtspunkt, aber auch »Fluchtort aus der Gesellschaft«. ${ }^{727}$

In Frankreich `erfindet` in den 1830er Jahren Claude François Denecourt das »romantische Wandern« im traditionellen Königsforst von Fontainebleau. RomantikerInnen von Victor Hugo bis George Sand »adoptier[en]« ihn als »Schutzgeist des Waldes«, habe er doch die ausgedehnten Eichenwaldungen der »königlichen Geschichte und dem kaiserlichen Staat entrissen und es dem Volk zurückgegeben«, genauer: »den städtischen Bohemiens« nebst einigen »bezaubernd malerischen« Zigeunern oder Hirten. Denecourts »außerordentliche[] Erfindung« ist der Waldweg. ${ }^{728}$ Eigentlich hat er damit eine >romantische` Variante der cartesianischen Methode kreiert. Zwar gibt es schon länger »das Netz der Kreuze und sogar Karten und Führer«, aber alle sind »grotesk rudimentär«. Denecourt beschließt, in die dichten Wälder »einzudringen, sie zu vermessen und kartographisch zu erfassen«. Nicht statistisch und inventarisierend wie staatliche Landvermesser, "sondern anschaulich beschreibend, ja poetisch«. Er wandert und hinterlässt sorgfältig Markierungen mit dem Plan, »ein Maximum an Einsamkeit mit dem garantierten Fehlen von Schrecken zu vereinbaren, wobei er wie ein Ingenieur des Pittoresken berechnete, wie er die eindrucksvollsten, verschiedenartigsten und angenehmsten Aussichten erzeugen konnte « ${ }^{729}$ Es entsteht ein Programm aus »bequeme[n] Wege[n]« und »leichte[n] Klettertouren«, nach berühmten Dichtern oder Herrschern benannten eindrucksvollen Bäumen, Grotten wie der »Druidenhöhle«. Es werden jährlich »petit[s] indicateur[s] « herausgegeben. Das Unternehmen besteht in den 1850er aus 20 markierten Routen und Dencourt wird nach langen Auseinandersetzungen mit den staatlichen Behörden schließlich zum Kurator ernannt und stellt ein "ganzes Korps« von unifomierten Aufsehern ein. ${ }^{730}$

Zwar gehen hier die Wege der Methode nicht unbedingt gerade durch den Wald, aber das ist längst nicht mehr vonnöten. Abweichungen bedeuten nur ein Maß an Naturbeherrschung, in dem nun >Poesie Linien auflockern kann. Das ändert nichts an der »strategischen Topographie«, der Inbesitznahme, Benennung, Klassifizierung und Kartogra-

726 Ebda., S. 448.

727 Ebda., S. $450 \mathrm{ff}$.

728 Vgl. Schama, a.a.O., S. $584 f$.

729 Ebda., S. 591f.

730 Vgl. ebda., 597. 
phierung, der Schaffung von »Ordnung in den Dingen $« .{ }^{731}$ Und, für Fontainebleau ist der Wald auf Nutzanwendung reduziert. Die Besucher aber erleben und fühlen Mythen und Wildnis. Dabei ist das Risiko des Sich-Verirrens noch geringer als in absolutistischen Irrgärten.

Auch im Forst ist der geordnete Aufmarsch der Colbertschen Stände ausgesetzt. Mit »der Festigung der napoleonischen Diktatur« wird in Frankreich zwar »eine strenge Forstaufsicht«, forstpolitisch aber eine den Maßnahmen in Preußen entgegengesetzte Linie etabliert. Während hier, orientiert an »der internationalen Bauholzkonjunktur« der Hochwaldbetrieb kontinuierlich ausgebaut wird,

»orientierte sich die französische Forstpolitik überwiegend an den Interessen der Eisenindustrie und der Brennholzverbraucher: Die Umtriebszeiten wurden gesenkt, ja sogar Hoch- in Niederwälder verwandelt. Die Hochwaldwirtschaft wurde als >deutsche Theorie < bezeichnet, gegen die man die Natur und den französischen Waldbau zu verteidigen habe ${ }^{732}$

Der französische Waldbau verteidigt mittlerweile die Natur. Denn tatsächlich rücken inzwischen an der Ostgrenze preußische Heere aus Fichten an. ${ }^{733}$

\section{Das Verschwinden von Werden und Vergehen}

Ab Mitte des 17. Jahrhunderts ist die »Policey« als »offensive Durchsetzung einer gesellschaftlichen Ordnung und Rollenzuweisung « in den Forsten zum einen »der systematisierte Kampf gegen die Wilderei und die ritualisierte Ausgestaltung der barocken Jagdspektakel «. ${ }^{734}$ Forstpolizei bedeutet um 1800 bereits auch die Durchsetzung eines geordneten, einheitlichen Waldbildes, dass sich auch bezüglich seiner Holzmasse und des Werts erfassen lässt. »Der Autor eines Lehrbuchs der >Waldwirtschaft und Forstpolizei` von 1798 wetterte, daß diejenigen, die die Rückkehr zur unregelmäßigen Plenterwirtschaft vorschlügen, als Verrückte oder Schädlinge des Landes verwiesen werden sollten. ${ }^{735}$

Seit Anfang des 18. Jahrhunderts wird die »Policey« verwissenschaftlicht, entstehen universitäre Lehrstühle für »Oeconomie, Policey und Cammer-Sachen« in Halle und Frankfurt/Oder, es folgen bis Jahrhundertende derartige Professuren an 23 von 36 deutschen Universi-

731 Ebda.

732 Radkau/Schäfer, a.a.O., S. 145f..

733 Vgl. Kap. Der Aufmarsch der Soldaten.

734 Spehr, Christoph: A.a.O., S. $76 f$.

735 Radkau/Schäfer, a.a.O., S. 163. 
täten. ${ }^{736}$ Hier, wo sich die neue »Gebrauchswissenschaft« (für die Verwaltung von Domänen, Regalien, Steuern, Finanzen, Politik, Polizei, Soziales) Kameralistik, »rationale[s] Naturrecht« und »geometrische[s] Methodenideal« verbinden, ist der Ursprungsort der Metapher »Staatsmaschine $\ll{ }^{737}$ In der »politischen Ökonomie« werden die ehedem »hauswirtschaftlich-patriarchalen« Strukturen auf den Staat, die »camera« übertragen, der »Suprematie« des Landesfürsten (in Deutschland) bzw. Königs (in Frankreich) unterworfen, eine Transformation ökonomischer wie politischer Herrschaft auf eine Person. Zur Beförderung »der allgemeinen Glückseligkeit«, wie das die Theoretiker des Kameralismus und Merkantilismus versichern. ${ }^{738}$ Das Forstwesen gelangt Mitte des 18. Jahrhunderts »in die Hände der Gelehrten und Ökonomen; man suchte mit demselben Naturlehre, Botanik und Mathematik zu verbinden und das Forstwesen selbst zu der Würde einer Wissenschaft zu heben«, wie es $1795 \mathrm{im} »$ Versuch einer Geschichte der deutschen Forstwirtschaft« heißt. ${ }^{739}$ Seither pendelt die Forstlehre zwischen Biologie und Ökonomie, häufig, aber ohne »dauerhaften Erfolg« sind Versuch einer Anbindung an die Nationalökonomie. ${ }^{740}$ Es entsteht eine umfangreiche Infrastruktur für Holzzucht. Und so entstehen einerseits in Deutschland, besonders in Preußen, vielfach Baumschulen (vor allem seit dem 19. Jahrhundert) - schon, weil gepflanzte Jungbäume besser gegen Wildverbiss geschützt sind, als Sämlinge ${ }^{741}$ - ebenso »von Norddeutschland ausgehend [...] forstliche[] Lehranstalten «, ${ }^{742}$ andererseits in Rück- bzw. Wechselwirkung der vegetativen Metapher Kindergärten. »Der Stand des Forstbeamten wurde zum qualifizierten Beruf, und die >Baumzucht wurde im späten 18. Jahrhundert ein angesehenes Gewerbe, das der damals ebenfalls im Aufstieg befindlichen Pädagogik, der >Kinderzucht gerne als Vorbild hingestellt wurde.« In »scharfe[m] Kontrast« zum bisherigen Bild des Försters zwischen Jagdvorrang und Korruption, setze sich nun das Bild des korrekten, gesetzes- und theoriegetreuen Beamten durch, dessen Ziel die Waldzüchtung »auf einen maximalen Holzertrag hin ist. $^{743}$ In den zur Umgestaltung vorgesehenen Gegenden wird dieses Bild nicht geteilt.

736 Vgl. Sonntag, a.a.O., S. 151.

737 Stollberg-Rilinger, a.a.O., S. 75f.; vgl. Sonntag, a.a.O.

738 Vgl. Sonntag, ebda., S. 150; Stollberg-Rilinger, ebda., S. 77.

739 Zit. n. Radkau/Schäfer, a.a.O., S. 162.

740 Vgl. ebda.

741 Vgl. Küster, a.a.O., S. 190.

742 Radkau/Schäfer, a.a.O., S. 177.

743 Ebda., S. 177f. 
In seiner mentalitäts- und sozialgeschichtlichen Untersuchung des Waldes der frühen Neuzeit im Pfälzer Raum befasst sich Joachim Allmann mit dem Fortschritt von Forstwirtschaft und -wissenschaft, dem Beginn eines »naturwissenschaftlichen Waldbaus«, der die Vermessung und Kartierung der Ländereien notwendig machte:

»Bis 1790 war mehr als ein Drittel der kurpfälzischen Wälder vermessen, entsprechend beschrieben und Nutzungspläne dafür angelegt worden. Mehrfach habe ich betont, daß diese neuartigen Methoden und Nutzungsabsichten die traditionellen Nutzungen erheblich einschränkten und das Antlitz der Wälder veränderten, ohne die Ansprüche und Gewohnheiten der traditionellen Nutzer gebührend mitzuberücksichtigen. Ein Höchstmaß an Holz zu erzielen war ihr Anliegen jedenfalls nicht, im Gegenteil waren die traditionellen Nutzungen in der Periode eines vehementen Bevölkerungswachstums unverzichtbarer denn je. Es war jedoch der Wunsch nach dem höchsten Ertrag, der die Forstbedienten nun auch in jene Regionen vordringen ließ, die vorher kaum betreten worden waren und stellenweise auch am Ende des 18. Jahrhunderts noch Urwaldcharakter besaßen. $\ll^{744}$

Dieser Charakter aber widerspricht den Erfordernissen eines wissenschaftlich-ökonomisch geregelten Umgangs mit Wald:

»Die urwaldartigen Zustände waren in den Augen von Forstleuten wie von Buchwitz oder Kling [kurpfälzische Hofkammerforsträte des späten 18. Jahrhunderts; M. T.] nicht erfreulich, weil sie allzu unterschiedliche Altersklassen auf engem Raum versammelten, nur schwer den Holzertrag abschätzen ließen, die Planung kompliziert war und eine Einrichtung nur allmählich stattfinden konnte. $\ll^{745}$

Ein Umstand, dem nur durch die wissenschaftliche Rekonstruktion der Natur beizukommen ist:

»Der Raum wurde wissenschaftlich erfaßt und geometrisch vermessen. [...] Hand in Hand mit der Neudefinition des Raumes ging die Neudefinition des Waldes, öde Flächen durfte es in ihm nicht mehr geben, und unerschlossene

744 Allmann: Der Wald in der frühen Neuzeit, S. 202. Allmann verweist auf die Schwierigkeit, das tatsächliche damalige Erscheinungsbild der Wälder aus heutiger Sicht beurteilen zu können, da die zeitgenössische Literatur den »Suchenden weitgehend im Stich« (ebda., S. 207) ließe, weshalb er sich weitgehend auf Gemälde bezieht.

745 Ebda., S. 210. 
Urwälder auch nicht. Wald wurde zur Holzproduktionsfläche, die intensive neuzeitliche Nutzung dadurch dringend. $\ll^{746}$

Vermessungen, wie sie gut ein Jahrhundert zuvor auch in Frankreich stattfinden: »Wagenladungen von Männern mit langen Perücken und langen Röcken, mit Meßlatten und Spulen von Roßhaarschnur ergossen sich in die Wälder der Normandie, Niederburgunds und der Ile de France« mit dem Ziel der Totalerfassung. So werden auch Privat- und Gemeindewälder aufgenommen, wenn sie flussnah liegen und so dem Staat potentiell nützlich sind. ${ }^{747}$

Zwei Kardinalaufgaben bestimmen die Forstwissenschaft. Zuerst die Bestandsaufnahme, »die >Taxierung` der Forsten«, Berechnung der »enthaltenen Holzmassen und des jährlichen Zuwachses«. Um das exakt ermitteln zu können, »ergab sich eine Vorliebe für den Kahlschlag und die Begründung von Reinbeständen ${ }^{748}{ }^{74}$ Und: »In Fragen des Forstwesens hängt alles vom Zeitpunkt ab.« So dienen die Kenntnisse der unterschiedlichen Böden, Lagen, klimatischen Voraussetzungen und Wuchskennzeichen der Bäume einzig der »Festlegung des richtigen Zeitrahmens für das Fällen von Bäumen« ${ }^{749}$ Beides führt zwangsläufig zu einem Ziel, der Umgestaltung ganzer Landschaften, der Neubegründung homogener >Wälder und Landschaften. Der Agrarreformer und Pfarrer Johann Friedrich Mayer, »Gipsapostel« wegen seiner Propagierung von Gipsdüngung genannt, schildert 1773, was es zu >verbessern` gibt:

»Hier sehe ich eine Wiese, da wieder einen Busch, dann einen Acker und wieder Wald, alles durcheinander, alles ist Irrgarten: See, Wald, Äcker, Büsche, Wiesen, Huten, Gärten wechseln stets ab: das Land sieht finster, wild, ist Einöde, voller Sumpf, kalt, windicht, rauh, arm und durchaus nicht fruchtbar. Das Wildbret ist Herr und der Bauer ist dürftig, so gebeugt im Elende wie der Sklave. [...] Öffnet doch die Feldungen und legt sie der Sonne zur schwängernden Erwärmung so für! Haut die so zerstreuten Waldungen nieder, gebt jedem seinen schicklichen Ort: Wiesen und Äcker leget zusammen in Ebenen und Tälern aneinander! Die Wälder säet auf Berge, umzäunt da, und verschließt zda das schädliche Wild! « ${ }^{750}$

Agrarreform und Philanthropie sehen hier in Personalunion einen wesentlichen Grund der Versklavung der Bauern: die schreckliche Unord-

746 Ebda., S. $210 f$.

747 Vgl. Schama, a.a.O., S. 198f.

748 Radkau/Schäfer, a.a.O., S. 162f.

749 Harrison, a.a.O., S. 146.

750 Zit. n. Radkau/Schäfer, a.a.O., S. 146. 
nung der Landschaft. Abhilfe sollen nicht nur strikte Entmischung bringen, sondern auch ein ökonomisches Zeitgefüge. Und dieses Zeitgefüge muss sich auch in den Dingen wiederfinden, in den Bäumen und Forsten.

Allmann skizziert für die Pfalz des ausgehenden 18. Jahrhunderts die planmäßige Vereinheitlichung der Landschaft, den »aufgeklärten $\mathrm{Zu}$ griff« auf den Wald:

»Der erste Distrikt des >Vorholz« stand nicht zuletzt darum an erster Stelle, weil er ein mittelmäßig bewachsener alter Eichenwald war, der keinen Wertzuwachs mehr erwarten ließ: Je >länger dieser Wald so stehen bleibt desto mehr wird er an seinem Werth verlieren`, lautete das Urteil, weil die Bäume wegen ihres hohen Alters nicht mehr wachsen würden. Was als Weidewald geschützt worden wäre, sollte nun gefällt werden. Der zweite Distrikt hingegen sollte - je nach späterem Bedarf - noch dreißig oder zehn Jahre stehen bleiben, während Teile des dritten Distriktes vom wachstumsbehindernden Weichholz zu befreien waren. Distrikt vierzehn sollte, sobald die Reihe an ihn kam, ganz niedergehauen, hingegen Distrikt fünfundzwanzig für die Nadelholzsaat vorbereitet werden. Alle Maßnahmen wurden, wie aus den Anmerkungen hervorgeht, mit >Notwendigkeiten` begründet, die zusammen mit den 〉Gegebenheiten` dafür ausschlaggebend waren, ob Hochwald oder Schlagwald, Laubholz oder Nadelholz der Vorzug gegeben wurde. [...] Die Bedienten des Kurfürsten und der übrigen Landesherren planten den An- und Abbau der Wälder sowie die Veränderung der Artenzusammensetzung, nicht nur als eine Art überdimensionalen Ackerbau, sondern, was wichtiger ist, die Verwendung des Holzes für generationenübergreifende Zeiträume, die, auch wenn nur eine vierzigjährige Umtriebszeit vorgesehen war, länger dauerten, als jede Generation in der linksrheinischen Pfalz seit Jahrhunderten eine Periode halbwegs gesicherter Existenz erlebt hatte ${ }^{751}$

Die Einführung der linearen Zeit? Bisher hatte die ortsansässige Bevölkerung traditionell erfahrungsorientiert - fern jeden >wissenschaftlichen Waldbaus - die Natur weitgehend extensiv genutzt und dabei hatte ihr planerisches Denken, schon aufgrund der ökonomischen Voraussetzungen, nie den Zeitraum einer Generation überschritten. ${ }^{752}$ Ihre Position im festgefügten Universum der ständischen Gesellschaft ließ ihnen gar keine andere Möglichkeit, als die der bloßen physischen Reproduktion. Zyklische Zeit, zumal aus der Sicht des fortschrittsgläubigen aufgeklärten Absolutismus.

751 Allmann, a.a.O., S. 203.

752 Vgl. ebda. 
Die Wahrnehmung des >Waldes` - von Natur überhaupt - ist immer auch ein Problem der Wahrnehmung von Zeit. In der abendländischen Zeitphilosophie haben sich im Wesentlichen seit Augustinus zwei mögliche Auffassungen vom Verlauf der Zeit durchgesetzt: die zirkuläre oder zyklische Zeittheorie geht davon aus, dass die Erde und das Leben auf ihr mehr oder weniger gleich bleibt, dass Veränderungen Wiederholungen sind, oder zu solchen führen; die lineare Zeittheorie demgegenüber spricht von einer stetigen, fortschreitenden Veränderung.

Die »Legitimität der Neuzeit«, schreibt Burckhardt im Rückgriff auf Blumenberg, basiere auf der »Mechanischen Uhr«. Mit ihr scheine »erstmals [...] die Zeit selbst entziffert« zu werden, eine »Ablösung aus der Natur« stattzufinden, besser: »aus jenem System der Entsprechungen und Analogien, wo die gemessene Zeit stets als ein Echo der sie umgebenden Natur begriffen wurde«. Mit dem Räderwerk vollzieht sich eine »handgreiflich[e]« Emanzipation der Zeitmessung von diesen Echos des Schwindens, Verrinnens, Fließens, Schmilzens, wie das mit Sonnen-, Sand-, Wasseruhren oder Kerzen wahrnehmbar war. Zeit repräsentiert nicht mehr die Elemente, sondern steht für sich selbst, sie kann jetzt beliebig produziert werden, »unabhängig von aller Periodizität, von Tag und Nacht, Ebbe und Flut, von Sternenhimmel und Sonnenstand «. ${ }^{753}$ Wirklich, körperlich erfahrbar wird diese Zäsur erst mit der Ablösung festgefügter menschlicher >Naturen২. Die lineare Zeit ist die >ökonomische Zeit`, die Zeit kapitalistischen Produzierens, weil Körper als Besitzer von Eigenschaften nicht fort-schreiten können. Die sphysische Egalisierung führt zu sozialer Ungleichheit, aber auch zu neuer, wissenschaftlich fundierter, physischer Ungleichheit. Auch die zyklische Zeit ist nicht obsolet geworden, sie erhält eine neue Bedeutung. Es entstehen zwei unterschiedliche Körper, männlicher und weiblicher. $^{754}$ Ihnen zugeordnet werden >Kultur und >Natur८, und damit lineare und zyklische Zeit. Erstere entspricht dem männlichen Prinzip der kulturellen Entwicklung, des Fortschritts, der Ordnung und des Gesetzes, der Zweifelsfreiheit, letztere dem weiblichen Prinzip der Naturverhaftung, dem Werden und Vergehen, letztlich der Regellosigkeit, dem Zweifel; zumal die lineare Zeit als übergeordnetes Gesetz und übersinnliches Phänomen - dem Menschen äußerlich - definiert wird. Werden und Vergehen bestimmen danach auch >jungfräulicheく Landschaften. Erst mit ihrer Inbesitznahme besteht die Möglichkeit, sie dem >Gesetz zu unterwerfen und damit ihrer >eigentlichen Bestimmung`zuzuführen.

753 Burckhardt, a.a.O., S. 42f.

754 Vgl. Einleitung. 
Mit Newtons absoluter, wahrer und mathematischer Zeit, die völlig unabhängig und gleichmäßig fließt, ist Zeit objektiviert, exakt messbar, befreit vom Beigeschmack des Ungefähren, von der Unsicherheit menschlicher Sinnlichkeit. Sie bleibt bestimmender Faktor des Lebens, dies aber in einer Form, die sie dem Geist erkennbar macht und ihn Macht ausüben lässt; Macht über die Natur mittels Erforschung und Anwendung ihrer >Gesetze $<$.

Die Welt und ihre Natur gehorchen Gesetzen, gehorchen der Zweckmäßigkeit. Deutlich werden Wille und Möglichkeit, sie anhand dieser zu reorganisieren, zu rekonstruieren, Fortschritt zu bewirken, ohne - wie im Mittelalter - einer allgegenwärtigen, unveränderlichen göttlichen Schöpfung zu nahe zu treten. Ein Uhrwerk tickt, immer weiter vorwärts: es herrscht die lineare Zeit. Zumindest im philosophischen und naturwissenschaftlichen Diskurs - mag auch das Alltagsleben der breiten Bevölkerung weiterhin der bloßen Reproduktion, der zyklischen Zeit geschuldet sein. Und tatsächlich kommt Bewegung in die Gesellschaft, sie wird mobiler, komplexer. Beschleunigung und cartesianischer Dualismus: Der Leib, die Natur aber steht in seiner Sinnlichkeit dem Fortschritt entgegen, erkennt nicht die Zweckmäßigkeit, die der Natur eigentlich innewohnt. Dort, wo Unzweckmäßigkeit vorherrscht, entsteht der Verdacht einer selbstverschuldeten Abweichung von der Natur ihrer eigentlichen Bestimmung -, die vom erkennenden Geist korrigiert werden muss. Der Leib, die Frau, die Natur - da, wo sie für sich selbst existieren - sind Horte des Zweifels. Es herrscht aber der unbedingte Wille zur Beseitigung des Zweifels. Die zweifelsfreie, lineare Zeit erfährt ihren Einzug in die äußere Natur mit der Nomenklatur der Pflanzen durch Linné. Charles Bonnet notiert 1781: „Wir sehen die Pflanze entstehen, wachsen, blühen und Früchte tragen, wie wir die Zeiger einer Uhr mit unmerklicher Bewegung alle Punkte eines Zifferblattes durchlaufen sehen.« Alles an der Pflanze erscheine »uns [...] mechanisch. Ihr Leben erscheint uns weniger als ein Leben denn als eine einfache Dauer«. Der Mensch pflege die Pflanze (wie das Tier) oder lasse sie eingehen, »ohne etwas zu empfinden«. Der Naturforscher zeigt aber einen nicht unwesentlichen Unterschied bei der Beobachtung und Klassifizierung von Tieren und Pflanzen. Nicht domestizierte Tiere reagieren »mit dem lebensnotwendigen Gebot der Fluchtdistanz« oder gar mit Angriff. Die Pflanze hingegen sei »das unbewegliche und passive Lebewesen. Eine wilde Pflanze ist eine Pflanze, die nicht kultiviert wurde, es ist keine Pflanze, die flieht ${ }^{755}{ }^{7}$ Sie ist damit der ideale Gegenstand der

755 Bonnet, Charles: Contemplation de la nature; zit. n. Delaporte, François: Das zweite Naturreich, S. 152. Vollständig gesichert wird die Existenz 
Analyse und Synthese, natürlicher Automat, der sich weitgehend problemlos als solcher organisieren lässt.

>Natürliche Automata`: Uhrwerke ticken immer vorwärts. Le Roy teilt, wie schon Colbert, die Bäume in Altersklassen auf: »taillis, ein Gehölz jüngerer Bäume bis zu 25 Jahren; gaulis, ein Gehölz zwischen 25 und 50 oder 60 Jahren; demi-futaye, zwischen 60 und 90 Jahren; und haute-futaye oder alte Bäume von über 90 Jahren «. ${ }^{756}$ Hier geht es nicht um >natürliche Lebenserwartung`, im Gegenteil: die ist im Forst abgeschafft. Um einen maximalen Nutzen aus einem Wald zu ziehen, müsse man exakt den »Wachstumszyklus und den Punkt kennen, an dem er aufhört, mit optimaler Geschwindigkeit zu wachsen«. Noch größer werde der Nutzen, wenn für die Bodenerhaltung gesorgt sei. »Übermäßige Verjüngung« sei wachstumsverändernd »und erschöpft den Erdboden«. $\mathrm{Zu}$ starkes Fällen aber könne den Verfaulungsbeginn der Bäume vorverlegen, da die Wurzeltiefe des Bodens nicht unbegrenzt sei. »Der Förster muß über solches Wissen in allen empirischen Einzelheiten verfügen, wenn er den Zeitpunkt des Fällens festsetzen soll. « ${ }^{757}$ Dieser FällZeitpunkt aber entmachtet den »Wachstumszyklus«, das >Werden und Vergehen`, und inthronisiert die Naturgesetzlichkeit, die `Umtriebszeit`, das heißt den exakt bestimmten Zeitpunkt, ab dem das Massenwachstum des Baumes abnimmt. >Verfalk und >Tod « sollen damit ausgeschlossen werden, sind aber zumindest verpönt. »Für alte Bäume, deren Massenzuwachs abnahm, kam im späten 19. Jahrhundert das Schlagwort >fauler Geselle auf $«{ }^{758}$ Sie verlieren an Wert. Die Exaktheit der Umtriebszeit ist dabei historisch keine unbedingt feste und auch nicht rein wissenschaftlich bestimmte Größe. Das hochwaldfixierte deutsche Forstwesen nach 1800 verlangt Umtriebszeiten von 120-180 Jahren, obwohl in dieser Zeit häufig die Meinung vertreten wird, dass »alles Laubholz in den ersten 20 Jahren am geschwindesten wachse«. Später liefert die beschleunigte Wirtschaft Gründe für geringere Umtriebszeiten. Für Buchen gelten hier heute 80 Jahre »als optimal. Das Alter, in dem das Wachstum der Bäume kulminiert, liegt viel niedriger, als früher angenommen wurde: bei Kiefern und Lärchen schon bei etwa 30 Jahren «. ${ }^{759}$

linearer Zeit 1859 mit Darwins Selektionstheorie der Entstehung der Arten. Göttliche Schöpfung wird durch Evolution abgelöst. Und doch ist diese Evolutionstheorie zunächst nichts anderes als eine Projektion der Malthusschen Bevölkerungstheorie von 1789; vgl. Kap. Die Natur erhält ein Haus im Kampf ums Dasein.

756 Harrison, a.a.O., S. 142.

757 Ebda., S. 146.

758 Radkau/Schäfer, a.a.O., S. 164.

759 Ebda. 
In der Forstwissenschaft existieren zwei korrespondierende Fachausdrücke: Sukzession und Klimax. ${ }^{760}$ >Sukzession< meint die zeitliche Abfolge der Vegetation, `Klimax` bedeutet hier das durch das örtliche Klima bedingte Endstadium der Boden- und Vegetationsentwicklung. So vollziehe sich von Natur aus die Entwicklung der Bewaldung in Mitteleuropa hauptsächlich - also abgesehen von Sonderstandorten mit besonders feuchten oder kargen Böden oder von der Gebirgsstufe - folgendermaßen: Auf Brachen oder Lichtungen siedeln sich zunächst Spreizklimmergehölze wie Brom- und Himbeeren an, sodann Pioniergehölze wie Salweiden, Birken, Ebereschen, Zitterpappeln, Haselnusssträucher etc. Nach und nach erscheinen Ahorn, Eiche, Esche, Hainbuche, Linde, Ulme und Rotbuche. Dieser Laubmischwald entwickele sich sukzessive zum Buchenwald. Damit ist idealtypisch ein >Endstadium ist dies eine Entwicklung vom Licht zum Schatten: Licht- und Halbschattbaumarten weichen schließlich den Schattbaumarten, der vorherrschenden Buche, deren dichtes Blätterdach nur noch wenige andere Schattbaumarten wie Linde, Eibe oder Stechpalme zulässt. Das bedeutet keineswegs eine natürliche Verarmung der Vegetation, da lichtliebende Gehölze auch weiterhin am Waldrand existieren und Lichtungen schon allein aufgrund sterbender Altbäume immer neu entstehen. ${ }^{761}$ Vegetation als Zeitablauf, als zyklischer zumal. Begriffe wie `Sukzession〈 und 〉Klimax aber gehorchen einem linearen Zeitverständnis. Die Natur, der Wald scheint zum Stillstand gekommen, still zu stehen, verändert sich nicht mehr, bleibt sich selbst verhaftet. Fortschritt ist nicht (mehr) möglich.

Nach Scherzinger wird inzwischen unterschieden zwischen dem deterministischen Klimaxmodell und dem Zyklusmodell. Das Klimaxmodell bezeichne nur den »ersten Vegetationsaufbau« auf Kahlflächen "als Sukzession im Sinne einer dynamischen Abfolge unterschiedlicher >Pflanzengesellschaften ‘ [...], da es den Schlußwald für statisch-konstant bzw. langfristig >stabil hält«. Das Zyklusmodell sieht im »Wald zwar Phasen unterschiedlich rascher Veränderung «, aber hier entspreche »seine gesamte Entwicklungsgeschichte einer ununterbrochenen Sukzession, und er kennt keine Statik «. ${ }^{762}$ Wie sehr die vorherrschenden »idealisierten« Sukzessionsmodelle, die Naturabläufe beschreiben sollen, tatsächlich an die Vorstellung künstlicher Waldbegründung gebunden sind, zeigen ihre Prämissen. Es wird »von einer baumfreien, im Extremfall so-

760 Vgl. Leibundgut, Hans: Waldbau als Naturschutz. Bern, Stuttgart: Haupt 1990, S. 123.

$761 \mathrm{Vgl}$. Scherzinger, a.a.O., S. 69ff.

762 Ebda., S. 71. 
gar vegetationsfreien Fläche« ausgegangen und von regelmäßigen, einander abwechselnden kompletten Pflanzengesellschaften. ${ }^{763}$ »Das Klimax-Modell sieht den Gleichgewichtszustand als Ziel, dem das Ökosystem schnellstmöglich zustrebt«, das in optimaler Klimaanpassung, aber grundsätzlich »unabhängig von den Standortbedingungen«. Nur »der ausgereifte, alte Wald« werde »als `naturnah` taxiert«, jegliche Abweichung, Störung, jeder Eingriff erscheine als »Katastrophe«. Daher sollen »Pflegekonzepte« die »klimaxfernen Sukzessionsphasen möglichst schnell« mittels Pflanzung oder Saat »überbrücken«. Ziel ist der »Schlusswald» als »Normalwald«, dessen »räumliche[] und zeitliche[] Homogenität« eine hohe Artenvielfalt garantieren soll. ${ }^{764}$ Tendiert diese Homogenität nicht zu einer Art Altersklassenwald? Zum 〉Buchendom`? Der Klimax-Wald entstammt dem »klassischen Ansatz der frühen Ökologie $\ll,{ }^{765}$ in der der $>$ Kampf ums Dasein $<$ zu einem permanenten Gleichgewicht führt. Normalwald, Standortunabhängigkeit, Stabilität und Homogenität, Hochwald. Prinzipien, die ebenso einen geregelten Forst bezeichnen könnten. Der wesentliche Unterschied besteht letztlich darin, dass der Forst möglichst Monokultur sein soll, der »naturnahe« KlimaxWald sehr artenreich. Beide sollen ein stabiles Bild bieten. Als Basis dieser Stabilität erscheint der Fortschritt, der Fortschritt der Forstwissenschaft.

Fortschritt, Emanzipation von der Natur, bedeutet Beschleunigung. Vom Standpunkt der Beschleunigung gesehen allerdings erscheint die zyklische Zeit als Stillstand. Erst die naturwissenschaftliche Rekonstruktion des Waldes zum Forst, zur übersichtlichen Ordnung gleicher Altersklassen macht in dieser Logik Zeit sichtbar. `Sinnlichkeit` ist keine zulässige, keine >objektive` Art der Wahrnehmung. Sie schafft keine Ordnung, sondern bleibt der Unordnung verhaftet und so unproduktiv. Die lineare Zeit, der Fortschritt aber, ist nach Newton den Menschen und ihrer Sinnlichkeit äußerlich, rein mathematisch bestimmbar, nicht Natur, sondern vielmehr Naturgesetz. Die reine Sinnlichkeit und ihr Ort, die Natur wären demnach gesetzlos. Eine Vermutung, die sich auch auf eine andere - schon weiter oben angeklungene - Weise aufdrängt: Die Etymologie des Wortes »Wald« verweist auf Bedeutungen wie »wild«, »wüst«, »öde« und »leer«, die des Wortes »Forst« auf das Gesetz. Was aber diesem Gesetz des Herrschers unterliegt, von ihm umgestaltet oder geschaffen (angepflanzt) wurde, darf ihm nicht wieder entgleiten, sich 
selbst überlassen werden, darf die Klimax, die Grenze zur zyklischen Zeit nicht überschreiten und damit wertlos werden.

Der Gegensatz von zyklischer und linearer Zeit als Gegensatz des weiblichen und männlichen Prinzips:

»Sie [die Frau; das weibliche Prinzip; M. T.] drehte das Rad des Schicksals, gebar, gebar wieder und begleitete die Seelen durch die Zeit dazwischen. Derart war sie gewissermaßen unsterblich, aber auf ganz andere Art, als es die spätere männliche >Unsterblichkeit` meint, die das Werden und Vergehen aus dem weibliche Unsterblichkeit besteht - gerade aufheben will. ${ }^{766}$

Der Gegensatz des Urwaldes als weiblicher und des geregelten Forstes als männlicher Wald: Der Urwald bietet das Bild der zyklischen Zeit, von Werden und Vergehen als immerwährender Einheit. In ihm existieren die Bäume vom Keimling bis zum toten Baumriesen. Die

»überirdische Offenheit der linearen Zeit im geschlossenen Kreislauf von Zeugung und Verfall, den die Natur beinhaltet, ist es, die der fortdauernden Feindschaft zwischen der institutionellen Ordnung und den Wäldern, die an ihre Grenzen reichen, auf tiefster Ebene zugrundeliegt. Gerade weil sie jenseits ihres Horizonts linearer Zeit liegen, können Wälder leicht die Psychologie der menschlichen Orientierung verwirren ${ }^{767}{ }^{767}$

Derartiges trifft aus Sicht der Forstreformer - und aus der der Forstwirtschaft nahezu unangefochten bis heute ${ }^{768}$ - auch auf traditionelle Waldwirtschaftsformen zu. ${ }^{769}$ Demgegenüber bietet der Forst das Bild des immer Gleichen - die Gleichheit des Abstandes, des Alters, der Größe und Dicke der Stämme -, der 〉Unsterblichkeit`, wenn man so will. Der >schlagweise Altersklassenwald» weist aus der Draufsicht ein Schachbrettmuster $^{770}$ auf. Errichtet wird er bevorzugt »in waldfreien Parzellen« bzw. »dort, wo man zuvor sämtlichen Baumwuchs abgeholzt hatte«. Das 〉Schachbrettく wird gebildet aus »Schlägen oder Jagen mit den dazwischen verlaufenden Forstwegen ${ }^{771}$ Hier stehen die Bäume entmischt im »Einschichtenbestand «. Kahlschlag und Altersklassenwald sind »un-

766 Werlhof, Claudia von: Männliche Natur und künstliches Geschlecht, S. 32.

767 Harrison, a.a.O., S. 23.

768 Vgl. Bode/Hohnhorst, a.a.O.; Scherzinger, a.a.O.

769 Eine derartige Verwirrung der Orientierung bestimmt bis heute weitgehend das Bild vom >Wald und seiner touristischen Aneignung; vgl. Ausleitung.

770 Vgl. Harrison, a.a.O., S. 150.

771 Küster, a.a.O., S. 188. 
trennbar miteinander verbunden«. Bei Erntereife muss jeweils die ganze Parzelle geschlagen werden, weil die geschlossen aufgezogenen Hölzer plötzlichem Licht- oder Windeinfall durch Einzelentnahme »schutzlos ausgesetzt« wären. Während im 18. Jahrhundert oft noch »Unhölzer« als Samenbäume stehen gelassen werden, ist seit Mitte des 19. Jahrhunderts die Kompletträumung, die »saubere, lupenreine Kultur« gängige Praxis. ${ }^{772}$ Dazu gehört zwingend die Entmischung: Bäume unterschiedlichen Alters und getrennt nach Arten wachsen »auf verschiedenen Waldstücken weit voneinander entfernt. Das gleichzeitige Mit- und Nacheinander durch >Kommen und Gehen` an jedem Punkt des Waldes wird durch ein räumliches Nebeneinander ersetzt. Flächenweise - man spricht von Schlägen - wachsen die gleichalten Wälder ihrer kahlschlagartigen Nutzung entgegen . $^{773}$

Sollte unerwünschter Unterwuchs, sollten nicht den Regeln entsprechend wachsende Bäume oder »Totholz« - der »Moder des Todes« auftauchen, so setzen die forstlichen Mechanismen der Läuterung und der Durchforstung ein. Faktisch unterliegt auch der Forst dem Prinzip von Werden und Vergehen. Dieses ist aber kein selbsttätiges mehr, sondern vollzieht sich (idealtypisch) rein nach forstwissenschaftlichem und -wirtschaftlichem Willen.

»Die neuen Monokultur-Forste wurden nach dem abstrakten Konzept des >normalen Waldes eingerichtet: eines idealen Waldes, dessen zufällige und natürliche Variablen auf ein Minimum reduziert wurden. ${ }^{774}$

Analog zur sozialen Formation wird die Natur in die Kategorien von >normal und >abnorm` eingeteilt. Die sich selbst überlassene Natur ist nicht normal, sie zeigt ein >abweichendes Verhalten`, durch das sie sich und ihre Umgebung gefährdet. Sie (und ihre Umgebung) muss daher (vor sich selbst) geschützt werden. Dem >Abnormen`wohnt immer auch das >Monströse $<$ inne. Das >Monströse $<$ (des Waldes, der Natur) ist zwar schon sehr alt, aber erst die >bürgerliche Vernunft< kann sich rühmen, es $\mathrm{zu}$ analysieren, $\mathrm{zu}$ quantifizieren, zu klassifizieren und $\mathrm{zu}$ behandeln. Heilung verspricht die Homogenisierung, Normierung. Geregelte Forste sind genormt, »Wälder einheitlichen Typs mit vorgeschriebenen Wuchszeiten $\ll .{ }^{775}$ Und sie sind die Norm. Das ist dann eine zutreffende Be-

772 Vgl. Bode/Hohnhorst, a.a.O., S. 70f.

773 Ebda., S. 109f.

774 Harrison, a.a.O., S. 150.

775 Ebda. 
schreibung der Situation, denn mit der fast vollständigen Bestückung der Landschaft mit Kunstwald sind Nicht-Forste nicht mehr normal.

Der geregelte Forst ist die Konstruktion eines Zugleich von fiktiver Ewigkeit und 〉Fortschritt $<$. Der Fortschritt besteht nicht nur im hegemonialen Ersatz der natürlichen Verläufe. Anders als im Primärwald, wo jeder Baum prinzipiell anders wächst, gibt es im Forst keine >Individuen mehr. Das bleibt zwar bislang weitgehend Augentäuschung, aber die Praxis der phänotypischen Selektion, die nur das genetische Material weniger »Elitebäume« berücksichtigt, strebt tendenziell zur faktischen Homogenisierung des $>$ Waldes $\measuredangle{ }^{776}$ Und doch ist bereits die Augentäuschung wirksam genug. Würde ein (Jung-)Baum durch einen anderen ersetzt, oder würde eine ganze Baumreihe abgeerntet werden, es würde dem normalen Auge nicht - oder kaum - auffallen; der (Gesamt-)Augenschein bleibt der gleiche. Die reale Fiktion der Unsterblichkeit: Die Bäume im Forst sterben nicht mehr. Sobald sie zur "Schlagreife« gelangt sind, werden sie geerntet und auf ihre Stofflichkeit reduziert, als Holz konserviert und verarbeitet. Sollte einmal dieses Holz verrotten, so ist es eben nur Holz. Eigentlich gibt es im Forst gar keine Bäume mehr, wenn man der forstlichen Begriffsverwendung folgt. Hier gibt es nur noch Holz: Hart- und Weichholz, Laub- und Nadelholz, Rundholz, Schwachholz etc. Unsterblichkeit als Fortschritt und umgekehrt. Sterben die Bäume im Forst tatsächlich nicht mehr? Vor rund 150 Jahren entdeckte Stöckhard das Phänomen des »Waldsterbens«. Der Begriff macht seine Negativkarriere jedoch erst in den letzten Jahrzehnten des 20. Jahrhunderts. Hier bedeutet > Wald der Forst. Der Begriff aber heißt ausdrücklich Waldsterben. Dahinter verbirgt sich vermutlich zweierlei: Die faktische Transformation des Waldes in den Forst führt zu einer semantischen Re-Transformation in den >Wald . Nur die menschlich geschaffene >zweite Natur wird als einzige Natur anerkannt. ${ }^{777}$ Der Forst aber unterliegt dem Diktum der Unsterblichkeit. Es gibt kein Forststerben. Hier kann eingegriffen werden; und sei es gentechnisch.

Der Wald als Maschine ist die Umsetzung der lange angekündigten »Metamorphose«, die Weltvernichtung und »Wiedergeburt durch Vernunft«, konkret: »die Ablösung von der Zeit, die Verpünktlichung des Raums und seine Auflösung in ein XYZ-Koordinatensystem - und schließlich: die Abstraktion vom Körper und von der Welt«. Von nun an werde nur das an der Natur »wahrgenommen, was an ihr Maschine ist, was dem Wissenskörper (der nach dem Bild der Maschine gedacht ist)

776 Vgl. Scherzinger, a.a.O., S. $159 f$.

$777 \mathrm{Vgl}$. Ausleitung. 
entspricht«. Eine Wahrnehmung, die spezifisch selektiv sei, nicht im Sinn eines »jeweiligen, jemeinigen Wegsehen[s]«, vielmehr beruhe die Selektion »auf jenem Habit, jener geistigen Hülle«, in die sich der »Wissenskörper [...] hineinzwängt«. Ein »Systemzwang«, auch des »Denken[s] selbst«, wobei das System, trotz der »Himmelsuhr« als »absolute[m] Vorbild«, das Gegenteil von etwas Statischem sei, sondern »eine Bewegung auf etwas hin, eine Aus- und Zurichtung. So wie die Uhren immer höherer Präzision zustreben, so folgt auch das Denken, das in die Metapher des Räderwerkautomaten eingestiegen ist, [dem] Skopus [...], alles, was existiert, zur Maschine zu machen. Womit die naturwissenschaftliche Revolution tatsächlich eine Revolution in Permanenz darstellt «. ${ }^{778}$ Der Wald als Maschine wird in den folgenden Jahrhunderten seiner Vollendung zustreben. Das heißt er wird maschinell angebaut und geerntet werden. Auf der Weltausstellung 1878 in Paris präsentiert eine amerikanische Darstellung »selbstbewußt» den Einsatz von »Lokomobilen«, fahrbaren Dampfmaschinen, die Bäume fällen und »transportable Vollgatter-Sägen« antreiben. Technisch ist das den europäischen Möglichkeiten voraus, »wenn auch wirtschaftlich überzeugende Resultate auf sich warten ließen «. ${ }^{779}$ Wohl, weil der zu erntende Wald noch kein geregelter Forst ist. So neu wie Bode/Hohnhorst schreiben sind die »weitgehend unbemerkten Veränderungen des Arbeitsplatzes Wald« also gar nicht (folgerichtig sind sie allemal), die »Prozessoren« und »Harvester«, die

»tonnenschwere[n] Maschinen, die zu ihrem rationellen Einsatz homogene Wälder, möglichst Monokulturen, benötigen um mit ihren hydraulischen Langkränen bis zu zehn Meter tief in den Wald hineinzugreifen. Sie >knipsen die Bäume ab, heben sie heraus und schneiden sie am Maschinenweg ein. Am günstigsten für ihren Einsatz ist es, wenn der Waldbestand im 20-Meter-Abstand mit Maschinenwegen erschlossen wird «. ${ }^{780}$

Die >Revolution` des Waldes ist nicht zuletzt auch eine >Revolution ২ der dort ansässigen Bevölkerung, der traditionellen Nutzer dieses Waldes. $»$ Was die Menschen mit der $>$ List der Vernunft $<$ über die äußere Natur zu vermögen begannen, das wandten sie vor allem gegen die innere Natur der Menschen, die sich nicht dagegen wehren konnten. ${ }^{781}$ Rudolf zur Lippe schreibt das über den Beginn der kapitalistischen Produktivitäts-

778 Burckhardt, a.a.O., S. 182f.

779 Radkau/Schäfer, a.a.O., S. 227.

780 Bode/Hohnhorst, a.a.O., S. 67f.

781 Lippe, Rudolf zur: Naturbeherrschung am Menschen II, S. 318. 
aneignung und Manufakturierung zuvor »brutal[]« freigesetzter traditioneller Arbeitskraft. Es passt aber ebensogut auf die (versuchten) Umwälzungen des Landlebens.

Allmann betont den Konflikt zwischen Obrigkeits- und Volkskultur. Das lässt sich auch darstellen als Konflikt zwischen wissenschaftlichem Fortschritt und Aberglauben:

»Für die traditionellen Nutzer waren die dunklen Wälder samt den urwaldartigen Regionen, deren Bedrohlichkeit [...] der Erbprinz im Finster- und Dunkelthal erlebt hatte [...], was den mentalen Bereich angeht, von Bedeutung. Sie bildeten den dringend erforderlichen Projektionsraum, insbesondere von dort kamen die übernatürlichen Wesen, besonders dorthin konnten Geister und Krankheiten gebannt werden. Diese Waldbereiche ließen es andererseits aber auch zu, verkehrstechnisch günstigere Regionen stärker zu nutzen, ohne die Funktionsfähigkeit für den mentalen Bereich in Frage zu stellen. Dem entgegen setzten die Obrigkeiten und die Wissenschaft den anderen Pol. ${ }^{782}$

Die umfassende Ausdehnung der Ordnungsmacht obrigkeitlicher Herrschaft auf Menschen der unteren Stände und die von ihnen bewohnte Landschaft beruht zumindest auf einem Missverständnis. Der Konflikt zwischen Obrigkeits- und Volkskultur ist nicht der Konflikt zwischen Ordnung und Unordnung, als der er aus Sicht der herrschenden Stände erscheint. Denn der frühneuzeitliche bäuerliche Umgang mit dem Wald und seinen Ressourcen ist weit davon entfernt, unzweckmäßig zu sein er wird genutzt. Ökonomisch zur Subsistenzsicherung: er >liefert Fleisch, Früchte, Honig, Brennholz und dient zur Viehmast usw.; mental dient er als Ort der Kompensation individueller und sozialer Ereignisse und Katastrophen, als Projektionsfläche sozial-kultureller Deutungsmuster und Ordnungsvorstellungen, allerdings noch in Residuen aggregativer Ordnung und unter den spezifischen Bedingungen einer subalternen Stellung innerhalb einer ständischen Sozialformation. »Produktion und Technologie« sind hier »keine autonomen Größen«, sondern in einen »kulturelle[n] Gesamtzusammenhang« eingebettet. ${ }^{783}$ Dazu gehören >beseelte Wälder`, deren Wert fürs »Überleben nicht weniger wichtig als die materielle Nutzbarkeit« ist. Die gefürchteten, aber für Eingeweihte verständlichen »übernatürlichen Wesen« verhängen etwa deutlich folgenreichere Strafen für »Waldfrevler«, die die »Bedürfnisse aller Generationen« gefährden, als das die Obrigkeit vermag. Dafür aber muss der Wald den »Charakter als eigenständige Welt« behalten. »Völ-

782 Allmann, a.a.O., S. 304.

783 Ebda., S. 291. 
lig in Besitz genommene Wälder waren berechenbar oder sollten es sein, sie waren verplant und konnten kaum noch Orte unheimlicher Geschehen sein, keine Projektionsräume mehr sein und zur Explikation nicht mehr herangezogen werden «. ${ }^{784}$ Allmann spricht von der »reale[n] Verankerung der zweiten Realitätsebene «. ${ }^{785}$ Das würde allerdings einem generativen Verständnis entsprechen, von Ober- und Untergründen ausgehen. Dieses vorbürgerliche Verständnis ist aber aggregativ, die Bedeutungsräume liegen auf einer Ebene, nebeneinander. Die simmateriellen Funktionen bieten sie Hilfe, andererseits können sie »Geister, die häusliche Anwesen und Menschen belästigten [...] bannen «. ${ }^{786}$ Der »beseelte Wald « ist Ort von Mensch-Tier-Metamorphosen, im »Wildfrauenloch« schützen Holzfäller die »freundlichen >Waldfrauen«« vorm »wilden Jäger« durch das Markieren von Baumstümpfen mit Kreuzen, Lichtungen sind baumlos, weil Hexen dort Feste feiern, nachts »ist der Wald tabu«, dann versinken Kinder im Sumpf, geben Waldgeister und Waldfrau keinen Störer mehr frei, »böse Förster, hartherzige Adlige, unerträgliche Wucherer«, deren Taten kaum »irdische Richter fanden«, müssen hier als »Wiedergänger« überdauern. ${ }^{787}$ Der Wald ist auch Ort ritueller Praktiken. In Vollmondnächten werden »Zauberstecken« gegen »Unholde« geschnitten, zum Bannen von Krankheiten wird Blut des Kranken in das Loch eines Baumes, dessen Fällen tabu ist, verschlossen. Zudem gibt es Frühlings- und Sommerfeste, in denen Figuren, die aus Zweigen und Blumen hergestellt sind, verehrt werden. ${ }^{788}$

Derartiger Animismus ist obrigkeitlich bloßer Aberglaube und Aufruhr. Denn in der Tat gibt es »das Beharren auf altem Herkommen«, den Nutzungsweisen als »Teil einer Struktur, die mehrere hundert Jahre lang funktionierte und von den Menschen verteidigt wurde«, Teil einer »flexible[n] Stabilität«, die »auch die Masse der Nischen« umfasst, »die notwendig war, um sich gegen obrigkeitliche Oktroyiktionen wehren $\mathrm{zu}$ können «. ${ }^{789}$ Das führt zu anhaltendem Widerstand gegen die Vermessungen und Kartierungen:

') Eingerichtete Wälder boten geringere Möglichkeiten, Unterschlupf zu finden, wie auch die >Inbesitznahmeく der Wälder und die angestrebten Veränderungen ihren Charakter als >eigenständige Welt $\iota$ und damit die zur Lebensbe-

784 Ebda., S. 289f.

785 Ebda.

786 Ebda., S. 302.

787 Ebda., S. $298 \mathrm{ff}$.

788 Vgl. ebda., S. 314f.

789 Ebda., S. $288 f$. 
wältigung hilfreichen Explikations-, Projektions- und Konditionierungsmechanismen gefährdeten. $^{790}$

Abb. 12: Hieronymus Bosch: Wälder haben Ohren, Felder haben Augen, Spätwerk

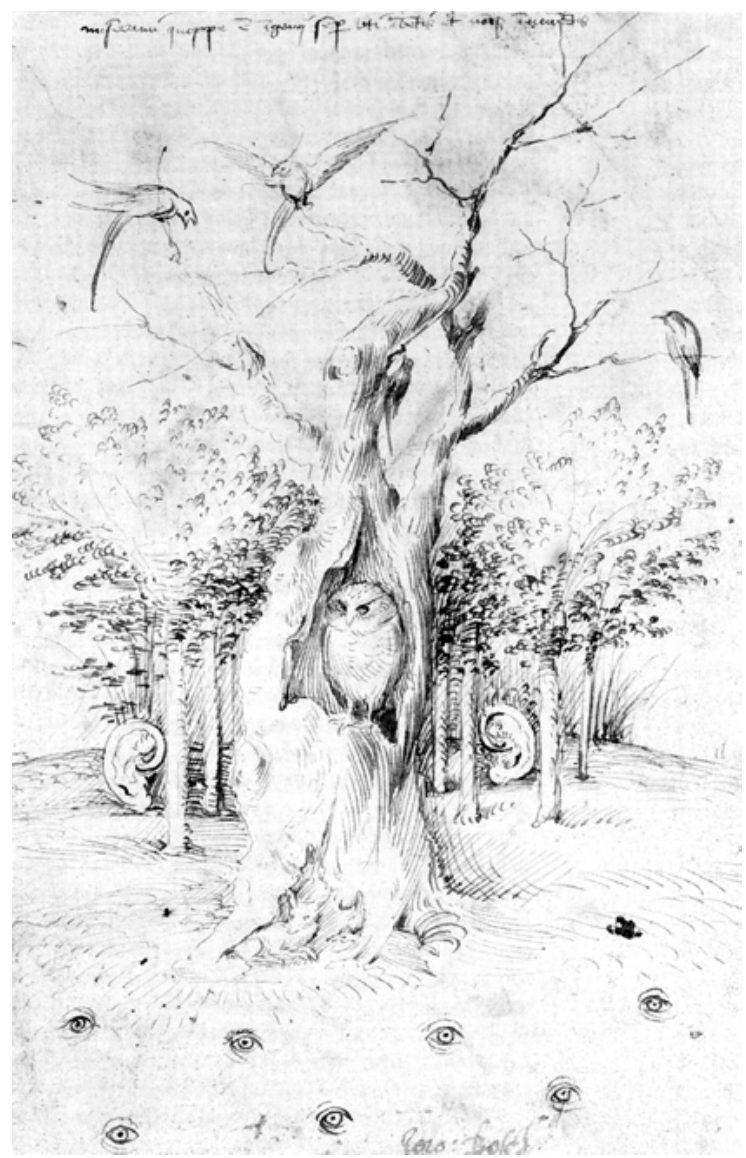

Boschs Grafik zeigt offenbar die frühneuzeitlich noch verbreitete Auffassung von >beseelten Wäldern und Landschaften

Spätestens mit Kepler geht es in der Naturauffassung darum, »den Bestandteilen des Kosmos eigene Absicht und Einsicht abzusprechen«.

790 Ebda., S. 306. 
Mit der »Herstellbarkeit von Automaten« ist dann der Beweis geliefert, »daß es sinnvoll ist, die Bewegung eines Gegenstandes entgegen den bisherigen Annahmen nicht auf diesem innewohnende Geister, sondern auf die Konstruktion und den ersten Bewegungsimpuls durch den Hersteller zurückzuführen «. ${ }^{791}$ Das zu leugnen und verstockt an die Beseeltheit der Dinge zu glauben, ist daher zutiefst unvernünftig, behindert das Schaffen von Ordnung, weil die alte Gestalt des Waldes verteidigt wird, und verhindert nicht nur dessen Neuformung nach dem Naturgesetz, sondern auch andere Berechenbarkeiten. "Wälder waren immer Räume, die nicht völlig zu kontrollieren waren, in denen sich >liederliches Gesindel genauso aufhielt wie Wilderer, >geweihte Schützen` und Ketzer. In ihnen fanden sich Rohstoffe brauchtümlicher Handlungen, die den Herrschern zunehmend suspekt wurden.« So muss deren Ziel der Zugriff auf diese traditionellen Nutzungsweisen, ihre Kontrolle und Ordnung sein. Die zu etablieren macht »Bedürfnisbefriedigung von der Herrschaft abhängig«, konditioniert zugleich »das Verhalten der Bevölkerung «. ${ }^{792}$ Deren Verhalten ist bislang umfangreich von zyklischer Zeit gesteuert.

Der »autoritäre Charakter der Uhren-Metapher« zeigt sich in der Totalisierung. Wie der Staat, so funktionieren auch die Körper der Menschen und sonstigen Lebewesen, wie die sinnere >äußere Natur` als sich stetig vorwärts bewegendes Räderwerk. »Determinismus«: Der Staat funktioniert nach den Befehlen des Fürsten, die Natur nach »von Gott festgelegten Naturgesetzen «. ${ }^{793}$ Legitimiert durchs »Allgemeinwohl« wird der Raum verändert, werden hergebrachte »Waldnutzungsweisen der bäuerlichen Bevölkerung stellenweise unmöglich gemacht oder doch stark behindert«. Neue effiziente Verwaltungen, »deren Ziel die Ausrichtung aller Waldverhältnisse auf einen vorausbestimmbaren Holzertrag war, demonstrierten, reklamierten und übten landesherrliche Macht stärker aus als je zuvor«. Mit der französischen Okkupation der Pfalz kommt es zur »Vollendung aller absolutistischen Vorstellungen «. ${ }^{794}$ Vor dem 18. Jahrhundert lassen die herrschaftlichen Bemühungen, den Wald zu »versilbern«, bäuerliche Wirtschaftsformen vergleichsweise unangetastet. Obrigkeitliche Erlasse, Veränderungen von außen sind vom System der »flexiblen Stabilität«

791 Stollberg-Rilinger, a.a.O., S. 27.

792 Allmann, a.a.O., S. 346.

793 Breger, Herbert: Die Natur als arbeitende Maschine. Zur Entstehung des Energiebegriffs in der Physik 1840-1850. Frankfurt/M, New York: Campus 1982, S. $136 \mathrm{f}$.

794 Allmann, a.a.O., S. 347f. 
integrierbar. Mit der »Abschaffung der Waldweide« und dem erzwungenen »Wandel der Wälder zu Kulturland-Formen«, dem Verbot tradierter Feste ist diese Flexibilität an ihre Grenzen gelangt, Verbindungen werden gekappt, »Erklärungsweisen verloren ihre Fundamente, Stabilität kam abhanden, sie wurde nicht von adäquaten Formen abgelöst «. ${ }^{795}$

\section{Der Aufmarsch der Soldaten}

»Ein anderer und nicht weniger wichtiger Aspekt des Waldes ist seine vielfache Unverrückbarkeit. Jeder einzelne Stamm ist festgewurzelt und gibt keiner Drohung von außen nach. Sein Widerstand ist absolut, er weicht nicht von der Stelle. Er kann gefällt, aber nicht verrückt werden. So ist er zum Symbol des Heeres geworden: ein Heer in Aufstellung, ein Heer, das unter keinen Umständen flieht; das sich bis zum letzten Mann in Stücke hauen läßt, bevor es einen Fußbreit Boden aufgibt. ${ }^{796}$

Der deutsche Förster ist Soldat. Zwar sind »die Klassiker forstlicher Gelehrsamkeit« bis zur Mitte des 19. Jahrhunderts »fast ausnahmslos bürgerlich«, das Gros der Forstleute hingegen adelige Offiziere. Die militärische Laufbahn als Voraussetzung insbesondere in Württemberg und Preußen ist seit dem 18. Jahrhundert obligatorisch. »1740 hatte Friedrich der Große für die Ausbildung der späteren Oberförster (Akademiker) vorgeschrieben, daß sie zunächst die Offizierslaufbahn zu ergreifen hatten und >zu Pferdeく ausgebildet wurden.« Diesen »berittenen Feldjäger[n]« unterstehen die einfachen Förster als »Feldjäger `zu Fuß«. Die Zwangsaffinität von militärischer und forstlicher Laufbahn endet in Preußen am 1. Oktober 1919, was aber nichts am Fortbestehen des Feldjägerkorps in Traditionsverbänden bis Ende des 2. Weltkriegs ändert, wo die ungebrochene Affinität »in den extrem hohen Kriegsverlusten sichtbar« wird. ${ }^{797}$

Auch der deutsche Baum ist Soldat. Symbol ist die Eiche. Hannß Carl von Carlowitz, sächsischer Oberberghauptmann und studierter Jurist veröffentlicht 1713 das erste Lehrbuch der Forstwirtschaft, die »Sylvicultura oeconomica oder Anweisung zur Wilden Baum-Zucht nebst gründlicher Darstellung des grossen Holtz-Mangel «. ${ }^{798}$ In diesem »bahnbrechenden« Werk vollzieht sich bereits auf der Titelseite eine Transfor-

795 Ebda., S. 321.

796 Canetti, Elias: Masse und Macht, S. 93. Der erste »Aspekt des Waldes« ist, dass er »dem Kirchengefühl« vorbaut. Vgl. Kap. `Heilige Hallen I u. II.

797 Bode/Hohnhorst, S. 45f.; vgl. Radkau/Schäfer, a.a.O., S. 176.

798 Vgl. Küster, a.a.O., S. 176. 
mation des Wirtschaftsbegriffs. Ist in deren ausführlichem Text oben »Oeconomica« noch »mit >hauswirthliche »die >Ökonomieく bereits als Nationalökonomie im modernen Sinne verstanden«. Carlowitz führt auch »den Begriff der `Nachhaltigkeit Forstlehre ein «. ${ }^{799}$ Und er bezieht sich auf die »Germania« des Tacitus. Dessen Beschreibung des »Zustand[s] der Wälder lieferte Carlowitz eine wichtige Begründung dafür, Wiederaufforstungen zu betreiben. Die alten Verhältnisse sollten wiederhergestellt werden «. ${ }^{800}$ Schon zu Beginn des 18. Jahrhunderts erscheint die enge Verknüpfung von positiver Tacitus-Rezeption, retrospektiv-utopischer Vorstellungen des >deutschen Ur-Walds mit einer beginnenden geregelten Forstwirtschaft, mit dem >deutschen Wald . Am Ende des Jahrhunderts wird diese Verknüpfung auf breiter Basis stehen.

»Es ist interessant, daß genau in der gleichen Zeit, in der Klopstock den Wald besang und der Hainbund gegründet wurde, auch die forstliche Ausbildung einsetzte, nämlich um 1770. 1763 eröffnete Hans Dietrich von Zanthier in Wernigerode im Harz die erste forstliche Meisterschule, 1770 wurde die Forstakademie in Berlin gegründet, 1772 die Forstschule auf der Solitude bei Stuttgart. 1780 wurden zum ersten Mal in Göttingen forstliche Vorlesungen gehalten, und 1785 eröffnete Heinrich Cotta seine Meisterschule im thüringischen Zillbach, aus der später die berühmte Forstakademie von Tharandt in Sachsen hervorging. $\ll^{801}$

1752 lässt Klopstock in »Die beiden Musen« die »Barden [...] in dem Eichenhain« zu »Vorbilder[n] für patriotische Gesänge« entstehen, dazu hat er »die >Lorbeerschatten` und einfachen >Haineく seiner Jugendlyrik nachträglich in 〉Eichenschatten ২ und 〉Eichen[wälder] testens mit »Hermanns Schlacht« (1769) wird die Eiche »Erkennungszeichen« seiner Poesie. In der »Deutschen Gelehrtenrepublik« begründet Klopstock, warum »die Eiche den deutschen Charakter vorzüglich gut abbildet« mit ihrer »Heiligkeit» bei »unseren ältesten Vorfahren« und beklagt die »Anmaßung« der Römer, »ihren Bürgerkranz aus Eichenlaube« zu flechten. Der poetisch-politische Kampf gegen »die >Überfremdungく der deutschen Literatur durch klassizistische französische Muster und Normen « im Zeichen pseudogermanischen Patriotismus' verläuft auf breiter Basis. ${ }^{802}$ Der Göttinger »Hainbund« bildet sich,

799 Radkau/Schäfer, a.a.O., S. 160.

800 Küster, a.a.O.

801 Ebda., S. 185.

802 Vgl. Lindemann, Klaus: In den frischen Eichenhainen ..., in: Semmler, Josef (Hg.): Der Wald, S. 203ff. 
Herder identifiziert Luther mit dem standhaften »Eichbaum «. ${ }^{803}$ Karl Wilhelm Colbe, genannt »Eichen-Kolbe« fertigt ganze Reihen populärer Radierungen und der Braunschweiger Maler Pascha Weitsch stellt »die Eichenwälder nicht mehr als ländliche Szenerie, sondern als patriotischen Tempel dar«. Sein »Eichenwald bei Querum mit Selbstporträt« (1800) ist bei aller Feierlichkeit bemerkenswert realistisch. Er malt einen Hutewald, in dem Kühe und Ziegen weiden. ${ }^{804}$

Abb. 13: Pascha Weitsch: Eichenwald bei Querum mit Selbstbildnis, 1800

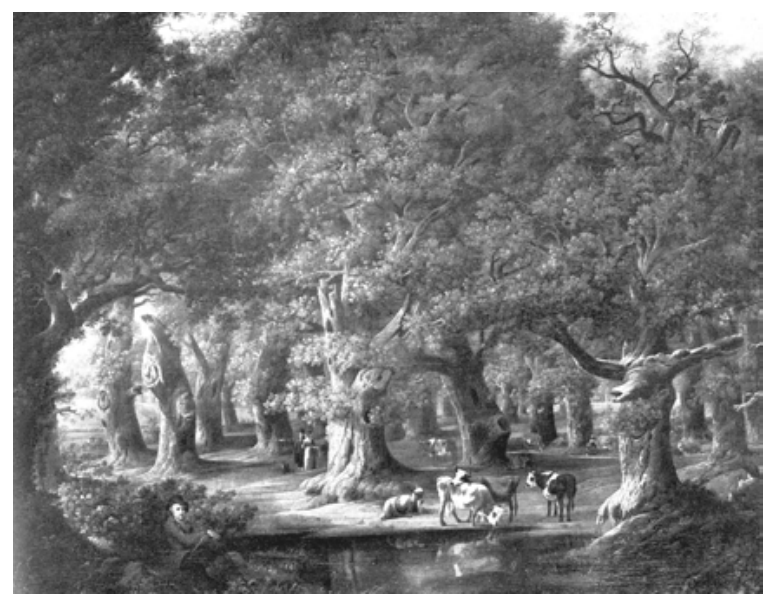

Weitschs Varianten des »Eichenwalds bei Querum« (das erste Gemälde entsteht 1784) konstruieren also >Heilige Haine, , Waldesdome`, die zugleich das Wissen um deren agrarische Nutzung dokumentieren. Sie stellen den »Höhepunkt« der Tendenz seit den 1780er Jahren dar, »die Eichbäume immer mächtiger und urtümlicher zu gestalten«. Die Wipfel des »mächtigen, urwelthaftigen Eichenwaldes« wölben sich sozusagen über dem Betrachter. Die »riesigen, zerklüfteten Stämme« sind nahezu symmetrisch angeordnet, zentriert auf »die mittlere, stärkste Eiche«. Allegorie aufs >Vaterland (und zugleich anscheinend aufs Herzogtum Braunschweig), geprägt von Klopstocks »Hermansschlacht $:^{805} » \mathrm{Du}$

803 Ebda., S. $206 \mathrm{ff}$.

804 Vgl. Schama, a.a.O., S. $120 f$.

805 Vgl. Müller-Hofstede; Annedore: Der Landschaftsmaler Pascha Johann

Friedrich Weitsch 1783-1803. Braunschweig: Waisenhaus-Buchdruckerei und Verlag 1973; S. 178 
gleichst der schattigsten Eiche/Im innersten Hain!/Der höchsten, ältesten, heiligsten Eiche/O Vaterland. ${ }^{806}$

Die Eiche als »Freiheitsbaum« ist auch durchaus revolutionär im Einsatz. Christian Friedrich Daniel Schubart lässt 1789 die »Freiheit« in antiken »Deutschen Hainen [...] unter Wodanseichen« ihren »unentweihtest $[\mathrm{n}]$ Altar« haben, sich »Hermann« in ihrem »Glanze« sonnen und als allegorische Mutter die »Deutschen an die Brust nehmen $« .{ }^{807}$ Das erinnert - abgesehen vom Interesse an Eichen - an Montesquieus TacitusRezeption. ${ }^{808}$ Für Hölderlin repräsentieren Eichen, die »Söhne des Berges « in »freiem Bunde «, das »Volk der Titanen « - nach seiner Distanzierung vom Terror seit 1793 - die drei Bürgertugenden der französischen Revolution. ${ }^{809}$

Lindemann irrt allerdings, wenn er schreibt, der »in Deutschland weitgehend erhaltene Wald [Hvhbg. v. m., M. T.]« werde »nach $1800 \mathrm{zu}$ einem der aussagekräftigsten Symbole nationalen Widerstands gegen die - inzwischen wälderlosen - Franzosen«. Der Irrtum geht zurück auf Ernst Moritz Arndt et al. Bezug nehmend auf den Raubbau vor und während der französischen Revolution und den Ressourcen-Hunger »der napoleonischen Militärmacht« auch in den besetzten Rheingebieten werde in Deutschland zunehmend politisch publizistisch von »Wäldermord« gesprochen. Zugleich notiere Mme de Staél in ihrem Buch »D'Allemagne« für Deutschland »große und häufige Waldstrecken«. Arndt stellt 1815 in seiner Schrift »Ein Wort über die Pflegung und Erhaltung der Forsten und der Bauern im Sinne einer höheren, d.h. menschlichen Gesetzgebung« eine Verbindung von Guillotine und Rodung her. Die »jetzt [...] in vielen Ländern Europas« an die Bäume gelegte Axt werde »häufig zu einer Axt, die an das ganze Volk gelegt wird«. Anders »unsere Ahnherren, die alten Germanen«, die »ihre heiligen und von keinem Beile verletzlichen Haine uralter Eichen und Buchen betraten«. Ähnliches äußert Kleist im »Katechismus der Deutschen«. Da ist Napoleon der höllische »Vatermördergeist, der herumschleicht in dem Tempel der Natur, und an allen Säulen rüttelt, auf welchen er gebaut ist $\ll .{ }^{810}$ So, wie nun der Eiche zugeschriebene Charakteristika wie »Größe, Härte, Unbeugsamkeit, Zähigkeit und Langlebigkeit« zur Identifikation der >germanische Ahnen` und zeitgenössischer `Befreiungskämpfer`verwendet werden, findet ebenso offensichtlich ei-

806 Zit. n ebda.

807 Lindemann, a.a.O., S. 208.

808 Vgl. Küster, a.a.O., S. 180.

809 Vgl. Lindemann, a.a.O., S. 209ff.

810 Ebda., S. $213 \mathrm{f}$. 
ne Identifikation des deutschen geregelten Forstwesen und seiner künstlichen Wiederaufforstungen mit >natürlicher` deutscher >Waldewigkeit statt. Dieser doppelte Kunstwald (dessen Reihen zumindest in Preußen hauptsächlich aus Fichten gebildet werden) wird gegen Frankreich in Marsch gesetzt.

Vertreten die Nadelbäume in Colberts französischem Absolutismus den Stand der Bourgeoisie, so erscheinen sie in der >Staatsmaschine Preußen - gemäß der »Suggestion, der einzelne müsse sich als >Rädchen im Getriebe< zum Zweck des Ganzen instrumentalisieren lassen $«{ }^{811}$ - als Soldaten. Als Resultat des Wiener Kongresses (1815) reicht der Flächenstaat Preußen »von der Memel bis an den Rhein«, die Ströme ebenso die Elbe - werden als wichtige »Flößstrecken von Nadelholz« genutzt. Die hier natürlich kaum wachsende Fichte wird »zum >Preußenbaum`, und die Fichtenaufforstungen, säuberlich in Reih' und Glied durchgeführt, hat man immer wieder mit in exakter Marschordnung auftretenden militärischen Verbänden verglichen «. ${ }^{812}$ Das Militär der preußischen Monarchie, dieser »grande et belle machine«, wie Mirabeau sie würdigt, sein »Geist der Ordnung und Regelmäßigkeit«, wird seinerseits als Maschine bewundert: Am »Ende [glichen] die Bewegungen eines Bataillons dem besten Uhrwerk«, versichert Friedrich Christoph Jonathan Fischer 1787 in seiner »Geschichte Friedrichs des Zweyten «. ${ }^{813}$ Mitte des Jahrhunderts definiert der Kameralist Johann Heinrich Zincke »Policey« als »gute[] obrigkeitliche[] »Einrichtung des gemeinen Wesens` deren >äußerliche Schönheit`, das heißt unter anderem eine >schöne, in die Sinne fallende Ordnung und Symmetrie , die zuallererst Ordnung der >Personen « ist«. Gesetze fließen nun »more geometrico aus einem 〉Satz` über das >Wesen der Ordnung «.${ }^{814}$ Das lässt sich für den geregelten Forst auch sagen.

Die deutsche "Forstmathematik» verbindet »Algebra, Geometrie, Stereometrie und Xylometrie« und macht das Forstwesen $\mathrm{zu}$ einer "wahrhaft strenge[n] Wissenschaft des Messens und Quantifizierens « ${ }^{815}$ Heinrich von Cotta unterscheidet in seinem frühen Lehrbuch Ende des 18. Jahrhunderts zwischen »Grundlehren und Hauptlehren der Forstwissenschaft. Die Grundlehren waren als propädeutische Fächer Mathematik und Naturwissenschaft, zu der Physik oder Naturlehre, ferner Chemie und Naturgeschichte gehörten«. Zur »Hauptlehre« zählen primär der

811 Stollberg-Rilinger, a.a.O., S. 248.

812 Küster, a.a.O., S. 189.

813 Vgl. Stollberg-Rilinger, a.a.O., S. 62.

814 Ebda., S. $118 \mathrm{f}$.

815 Harrison, a.a.O., S. 150. 
Waldbau, also die »Methoden des Anbaus von Holz« sowie die seiner Ernte, sekundär »Waldnebennutzungen« wie Jagd, Waldstreugewinnung oder Waldweide, »die ja im Wesentlichen schon abgeschafft» ist. Danach behandelt er den »Forstschutz, und zwar den Schutz des Waldes gegen Menschen, wilde Tiere, schädliche Gewächse und gegen Naturereignisse «, insbesondere »durch ungünstige Witterung $« .{ }^{816}$ Die $\gg$ Natur muss vor allem vor der Natur geschützt werden.

Auf das wissenschaftlich Exakte wird Wert gelegt. So vollzieht sich im 19. Jahrhundert »überall« die Trennung von der »Jagdwissenschaft«, die als »rein praktische Wissenschaft» nun »weitgehend geringgeschätzt« wird. ${ }^{817}$ Was die »Helden« der »Gründerzeit ${ }^{818}$ dieser Wissenschaft, wie Cotta oder Georg Ludwig Hartig, ab 1811 Chef der preußischen Forstverwaltung, in der Praxis umsetzen, ist die >Nachhaltigkeit<, bei der dem Forst nur so viel Holz entnommen wird, wie nachwächst. Dieses "Gleichgewichtsmodell der forstlichen Statik» sieht Johann Christian Hundeshagen 1831 in seinem »Lehrbuch der Forstpolizei« als »implizit[es] Vorbild »eine[r] reale[n] Volkswirtschaft «. ${ }^{819}$ Die Forstpraxis ist aber auch Politik der Forstpopulation, analog der preußischabsolutistischen >Politik der Bevölkerung〈. »)Die Stärke eines Staates`, so Friedrich II. im Anti-Machiavelli, >liegt beileibe nicht in der Ausdehnung des Territoriums [...], sondern im Wohlstand seiner Bewohner und ihrer Anzahlı. Bevölkerungsmerkmale werden statistisch erfaßt; eine wissenschaftliche Demographie bildet sich heraus, die sich explizit in den Dienst des Staates stellt. $«{ }^{820}$ Ziel ist »das Zusammenleben von Herrschaftsträgern «, ${ }^{821}$ eine symmetrische Personen-Ordnung und ihre »äußerliche Schönheit«. 1789 veröffentlicht Johann Jacob Trunk sein »Neues vollständiges Forstlehrbuch oder systematische Grundsätze des Forstrechts, der Forstpolizey und der Forstökonomie «. Darin betont der Kameralist, »Oberforstmeister für die vorderösterreichischen Lande« und Professor in Freiburg/Breisgau eine nicht nur ökonomische Funktion der Forsten. Es sollen auch »Lust und Ergötzung« hervorgerufen werden »bei einer schönen Aussicht auf grüne Wälder, die durch ihren Schatten Ruhe und Abkühlung verschaffen können«. ${ }^{822}$ Das streng Geregelte ruft

816 Küster, a.a.O., S. $185 f$.

817 Spehr, a.a.O., S. 104.

818 Harrison, a.a.O.

819 Zit. n. Köpf, Ernst Ulrich: Forstpolitik. Stuttgart: Ulmer 2002, S. 20.

820 Sonntag, a.a.O., S. 151.

821 Ebda., S. 154.

822 Zit. n. Köpf, a.a.O. Köpf sieht in derartigen Äußerungen »Differenziertheit und Modernität«, die »der Klischeevorstellung der Nachwelt spotten« (ebda.). 
»Lust und Ergötzung« hervor. Das streng Geregelte ist das Soldatische unter dem Banner der nationalen Idee: »Im frühen 19. Jahrhundert wurden die Neubegründungen von Wald und Staat im Zusammenhang gesehen. Man forstete als Maßnahme des mehr oder weniger stillen Widerstandes gegen Frankreich. ${ }^{823}$

Abb. 14: Caspar David Friedrich: Der Chasseur im Walde, 1813

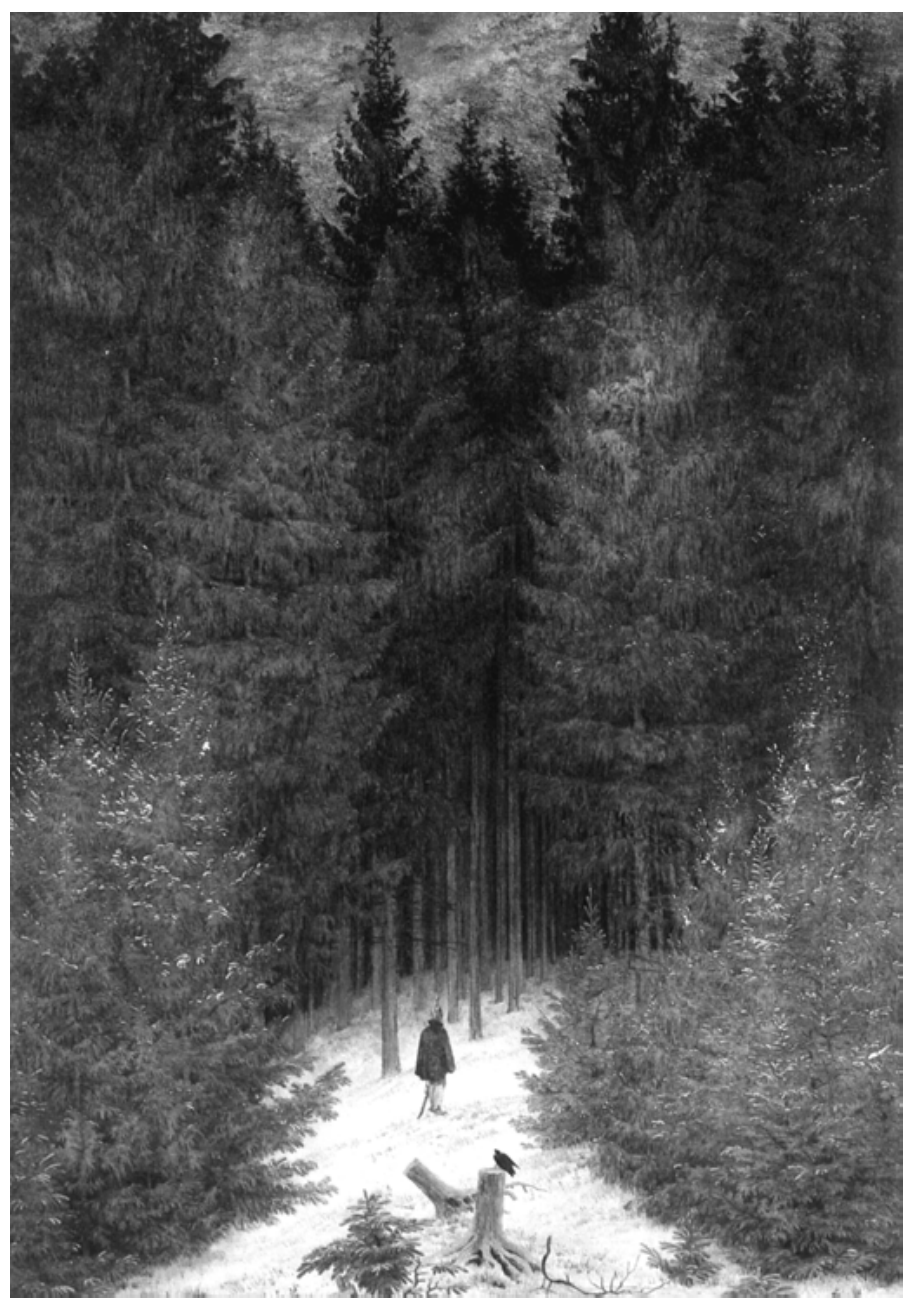

823 Küster, a.a.O., S. 183. 
Wohl eher weniger still. Friedrich Ludwig Jahn fordert, »man solle an der Grenze zu Frankreich einen undurchdringlichen Wald pflanzen, man könnte sagen, ihm schwebte ein Vorläufer des Westwalls vor «. ${ }^{824}$ Ein Fichtenwald, der zum tödlichen Hindernis werden soll. So, wie ihn Caspar David Friedrich 1813 malt: »Der Chasseur im Walde«. Da geht ein einsamer französischer Offizier auf einen düsteren Fichtenhochwald $\mathrm{zu}$, er »wird von dem gebieterischen Pfad, der zu keinem guten Ziel führt, erbarmungslos ins Innere des Waldes gezogen. [...] Wie die Zenturionen des Varus wird der chasseur von der undurchdringlichen Kette aus Tannengrün, den massierten Truppen der wiedergeborenen Germania, überragt und umzingelt«. Im Vordergrund des Pfades steht der Stumpf eines gefällten Nadelbaums. Der Baumstumpf ist Symbol eines »Soldatenmärtyrer[s]«, darauf sitzt der Rabe als Todesvogel des Franzosen. $^{825}$

Abb. 15: Georg Friedrich Kersting: Auf Vorposten, 1815

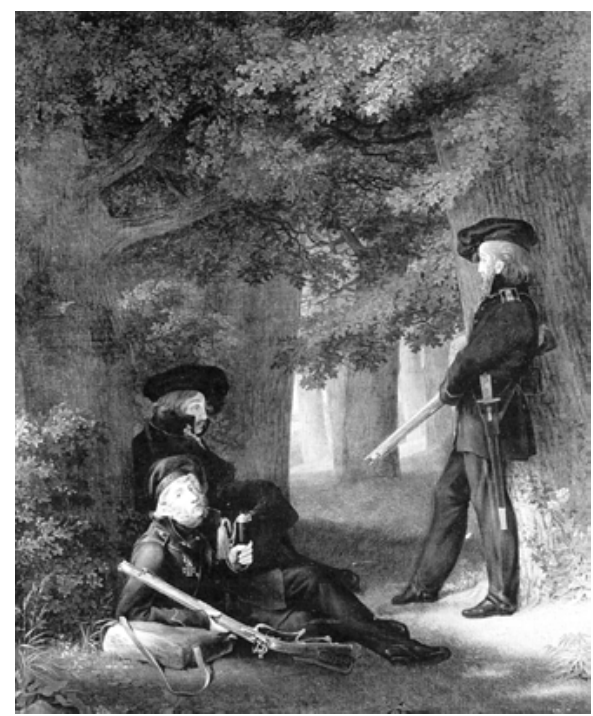

Eine andere Ikone der »Freiheitskriege ist Georg Friedrich Kerstings »Auf Vorposten«. Er zeigt den Eichenwald »tatsächlich im Kleist'schen Sinne« als »Kombattanten des deutschen Widerstandes« gegen Frankreich/Napoleon. Der Wald »deckt« die Freikorpsler der »Lützower Jä-

824 Ebda.

825 Schama, a.a.O., S. 123f.; vgl. Farbtafel 13. 
ger«: Theodor Körner, Friesen und Hartmann, ${ }^{826}$ schon mit dem 〉Eisernen Kreuz` geschmückt, das der Preußenkönig Friedrich Wilhelm III. 1813 stiftet und das in besonderen Fällen mit Eichenlaub verziert ist. Die

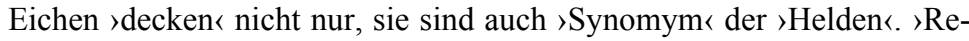
cken unter sich.

Canetti spricht vom Wald als Symbol des Heeres, in Aufstellung, unverrückbarer Formation, fäll- aber nicht verrückbar, Symbol absoluten Widerstands, des nicht-von-der-Stelle-Weichens. »Jeder einzelne Stamm ist festgewurzelt und gibt keiner Drohung von außen nach.« Er sei Symbol eines Heeres, »das unter keinen Umständen flieht; das sich bis zum letzten Mann in Stücke hauen läßt, bevor es einen Fußbreit Boden aufgibt ${ }^{827}$

Das Töten erscheint als >Lichten<: »In Kriegen geht es ums Töten. >Die Reihen der Feinde wurden gelichtet. Es geht um ein Töten in $\mathrm{Hau}$ fen. Möglichst viele Feinde werden niedergeschlagen; aus der gefährlichen Masse von lebenden Gegnern soll ein Haufen von Toten werden. Sieger ist, wer mehr Feinde getötet hat. Es ist die wachsende Masse der Nachbarn, der man im Kriege entgegentritt. Ihre Zunahme an sich ist beängstigend. Ihre Drohung, die im Wachstum allein schon enthalten ist, löst die eigene aggressive Masse aus, die zum Krieg drängt. [...] Man will die größere Masse von Lebenden sein.« Weshalb man bei »seiner Führung [...] immer überlegen zu sein« sucht. ${ }^{828}$

Unverrückbarkeit bedeutet den kategorischen Ausschluss von Flüchtigkeit, bedeutet strikte Formation, unbedingte Ordnung. Was damit in diesem Wald nach wie vor nichts zu suchen hat, ist das >Weichholz Ernst Moritz Arndt klagt 1847 in Anbetracht der »ungelösten KaiserFrage «: »O Germanien, keinen Kaiser/Kannst du finden? Keinen Stolzen?/Wo sind deine Eichenwälder?/Gibts nur noch Erlenholz zu holzen?« Erlen (und alle Weichhölzer) sind `weiblich`, sind Unordnung, Regellosigkeit, Masse. Eine Armee darf nie Masse sein. Das Wesen der Armee besteht darin, dass sie jegliche Verschiedenartigkeit von Befehlen aufhebt, dass der Befehl hier »immer genau dasselbe« bedeutet. »Eine Armee besteht nur, wenn der Befehl gleichwertig und konstant ist. Er kommt von oben, er bleibt streng isoliert.« In der Masse hingegen »breitet sich der Befehl horizontal, zwischen ihren Mitgliedern aus«. Mag er auch anfangs von oben kommen, führt er hier auf diese Weise zu

826 Vgl. Lindemann, a.a.O., S. 224.

827 Canetti: Masse und Macht, S. 93.

828 Ebda., S. 72. 
ansteckender Angst, denn in seiner sofortigen Ausbreitung zerstreut er sich sogleich. Schließlich »fliehen alle zusammen«. ${ }^{829}$

Weichlaubhölzer wachsen am oder im Sumpf. Körner, der >Märtyrer〈 des >Befreiungskrieges« dichtet 1811: »Deutsches Volk, du herrlichstes vor allen,/Deine Eichen stehn - du bist gefallen!« und an anderer Stelle: »Deutsches Volk, du konntest fallen,/Aber sinken kannst du nicht! «. ${ }^{830}$ Kategorisch »entsumpfte[r] Untergrund «, ${ }^{831}$ auf dem Eichen nicht schwanken, geschweige denn einsinken. Fester Boden, keine Vermischung der Aggregatzustände. Oder anders ausgedrückt: keine »Vermischungszustände der Körperränder «. ${ }^{832}$

Klaus Theweleit beschreibt das Empfinden des >soldatischen Mannes` im frühen 20. Jahrhunderts. Sumpf ist für diesen »die Gefahr, langsam zu versinken«, wobei es Leute gebe (im Innern), die fahrlässig oder mutwillig die Gefahr vergrößern, Regierungen, deren Autorität nur Anmaßung ist, die keine männliche Rolle (mehr) ausfüllen, „weiblich/männliche Monstren«: »Die Verhältnisse sind flüssig geworden: selbst an der Spitze des Staates nichts Hartes mehr. $«{ }^{833}$

Mit »der Waffe [ist] gegen das Versinken im Vermischten nicht viel auszurichten. Da hilft eher der innere Mann, >das Feuer der Begeisterung « gegen den >elenden Sumpf der Gegenwart««. In »den Fluten« erscheint »der politische Feind und das feindliche Prinzip Weiblichkeit beide fließen als Verkörperung des ausgebrochenen Unbewußten des soldatischen Mannes. Sumpf scheint das erste Verfestigungsstadium der Flut, noch relativ weit entfernt vom bedrohten Mann zu sein. Schlamm, Schleim, Brei - am eigenen Leib, an den eigenen Rändern, wo der Mann weich zu werden droht. Feigling. Gegen den feigen Mann, den, der sein Inneres nach außen läßt (und der auch im soldatischen Mann steckt) hilft nur >standhalten` (Arschbacken zusammenkneifen), Nationales Denken«. ${ }^{834}$ Im Sumpf, Schlamm, Schmutz versinken: Der Schmutz kommt »meist von lebendigen Körpern« her, oder steht »mit solchen in Verbindung, mit deren Rändern, wo Festes und Konturloses sich treffen und vermischen, auch und gerade beim Zerfall«. Und bei den immer wieder propagierten Entmischungen, der »säuberlichen Abgetrenntheit der Person« scheint es zumeist um eines der Geschlechter zu gehen. Das dann auch als allfälliger $»$ Code $« .{ }^{835}$ Wie weit lässt sich derartiges schon 100

829 Ebda., S. 344.

830 Zit. n. Lindemann, a.a.O., S. 219.

831 Lindemann, ebda.

832 Theweleit, Klaus: Männerphantasien 1, S. 492.

833 Ebda., S. 497f.

834 Ebda., S. $514 \mathrm{ff}$.

835 Ebda., S. 493f. 
Jahre zuvor, in den >Freiheitskriegen` gegen das napoleonische Frankreich, ausmachen?

>Standhalten`: Der Wald als Heer, das sich lieber in Stücke hauen lässt, als zu fliehen. Die >wehrhaften`, mit rauhen Borken gepanzerten Eichen sind eher individuell zugeordnete Sinnbilder, so wie die Bäume in den stehen gebliebenen Hutewäldern vorgefunden werden (qua Nutzung als eher >individuelle Gestalten $`$ ). Theodor Körner, der schon früh (1813) getötet wird, wird selbstverständlich unter einer mächtigen alten Eiche beerdigt. ${ }^{836}$ Fichten in ihrer gleichförmigen, engreihigen Anpflanzung stehen da eher für eine Armee als ganze. Namenlose, aber unerlässliche Fußtruppen, wehrhaft, `entbehrungsgewohnt` und `genügsam`. Bis heute wird die massenhafte Aufforstung mit Nadelbäumen mit ihren rasketischen ‘ Eigenschaften, dem Vermögen auf ausgelaugtesten Böden wachsen zu können, begründet. Wenn Körner den Deutschen bescheinigt, (selbst im Fallen) nicht zu versinken, dann trifft das offenbar im Umkehrschluss auf den Feind zu. »Nach dem militärischen Debakel von 1806 setzte in Preußen eine intensive Diskussion über dessen Ursachen ein.« Kritisiert, so Karen Hagemann, werden die überkommene politisch-militärische Ordnung, ebenso der ") Verfall< von steutscher Sitte und Moral« sowie [der] >Mangel an Religiösität««. Verlangt werden »eine Reorganisation von Staats- und Heeresverfassung«, insbesondere aber Neumanifestationen >deutscher Tugenden〈 in einem »>christlichteutschen Nationalcharakter[] « der infolge eines langen Einflusses französischer Kultur »entartet« sei. Definiert wird die Nation, vor allem gegen den Feind Frankreich, sozial - bürgerlich - und geschlechtsspezifisch: mit "primär männlich konnotierten Eigenschaften wie >tugend-

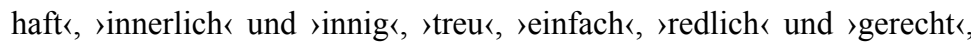
vor allem aber >ehrhaft « und >wehrhaft««. Komplementär dazu: »»Echt teutsche Frauen` hatten >fürsorglich` und `häuslich`, vor allem aber `sittlich zu sein.« Der französische »Nationalcharakter« - die Männer betreffend - hingegen wird beschrieben als »)äußerlich « und >gewandt`, >fein` und >spiegelglatt`, >falsch` und >oberflächlich`, >wollüstig` und >unzüchtigく. Er wurde so mit als >unmännlich` assoziierten, dem höfischen Adel zugeschriebenen Eigenschaften belegt «. ${ }^{837}$ Solche Zuschreibungen und Kritik gibt es - »inspiriert von der aufklärerischen Adelskritik« - bereits Jahrzehnte zuvor. Der »berühmte Medizinprofessor

836 Vgl. Schama, a.a.O., S. 123.

837 Hagemann, Karen: Heldenmütter, Kriegerbräute und Amazonen. Entwürfe »patriotischer« Weiblichkeit zur Zeit der Freiheitskriege, in: Frevert, Ute (Hg.): Militär und Gesellschaft im 19. und 20. Jahrhundert. Stuttgart: Klett-Cotta 1997, S. 181f. 
Johann Peter Frank« unterzieht 1786 »die in Adel und gebildetem Bürgertum verbreitete >weibische Edukation` der Männer einer scharfen Kritik. Sie habe Deutschlands >Heldensöhne zur >zierlichen Mannspuppe ‘ degenerieren lassen, `kaum noch kräftig genug, den seidenen Schirm der Sonne entgegen zu halten««. Hier seien keine Männer mehr zu finden, »sondern nur noch >zu Weibern herabverzärtelte Weichlinge`, die sowohl in ihrem äußeren Habitus als auch in ihrem Charakter >Weiberzüge` trügen«. Gleiches äußert sein Kollege Johann Christian Reil 1791 in Halle: »französische Stuzzer« seien aus den »Söhnen der >alten eisenharten Teutonen $[$ [...] geworden, >dürr wie Heuschrecken, ohne Rükken und Waden`, dafür aber mit >Krämpfen, Vapeurs und Mutterbeschwerden « ${ }^{838}$ Mit dem Ziel der »Bildung einer harmonischen männlichen Persönlichkeit« werden auch militärische Übungen, grundsätzlich aber kalte Bäder und Gymnastik empfohlen; ganz im Sinne Rousseaus. ${ }^{839}$

Nun weist Ute Frevert darauf hin, dass der >soldatische Mann frühen 20. Jahrhunderts und seine Erfahrungen um 1800 noch nicht existieren, weil die »Verhältnisse« in Deutschland um 1900 noch »nicht nachvollziehbar« seien, die Definition des Berliner Professors für Pädagogik und Philosophie Friedrich Paulsen, das Militär sei eine »Schule der Männlichkeit» (1902) noch »nicht kommunikabel« gewesen sei. »Aber sie waren möglicherweise wünschbar, vorstellbar im Sinne einer gesellschaftlichen Vision, die manchem Zeitgenossen im Kopf herumspukte«, dessen Erwartungshorizont eine Brücke schlagen« könne »und eine gedankliche Nähe herstellen, die einer materiellen Basis noch entbehrte $\ll{ }^{840}$ Die Visionen spuken nicht nur »im Kopf« herum, sondern

838 Frevert, Ute: Das Militär als »Schule der Männlichkeit«. Erwartungen, Angebote, Erfahrungen im 19. Jahrhundert, in: Ebda., S. 148. Mit diesen »Vapeurs" scheint ein Gipfel der Feminisierung erreicht, werden sie doch am Ende des 17. Jahrhunderts als medizinische Erklärung der Hysterie eingeführt. Vgl. Kap. Böse Ausdünstungen.

839 Vgl. Frevert, ebda. Die Kritik ist komplementär zur französischen am Ancient Regime. Die (vor-)revolutionäre Propaganda Frankreichs ist angefüllt mit pornographischen Pamphleten gegen Marie Antoinette in Wort und Bild. Auf der politischen Ebene erfüllen sie keinen anderen Zweck, als einen König, der - selbst zerrüttet von der eigenen Dekadenz, »jämmerlicher Weichling « als Konterpart des »virilen Revolutionärs« - nicht einmal das eigene »Weib« beherrschen kann, als Staatslenker schon gar am Ende zu zeigen. Vgl. Baecque, Antoine de: The »Livres remplis d horreur«: Pornographic Literature and Politics at the Beginning of the French Revolution, in: Wagner, Peter (Hg.): Erotica and the Enlightment. Frankfurt/M u.a.: Peter Lang 1991, S. 149ff.; Sennett: Fleisch und Stein, S. $360 \mathrm{f}$.

840 Frevert, a.a.O., S. 147. 
mindestens ebenso in den Körpern, wie gleich noch zu zeigen ist, $»$ Wunschmaschinen ${ }^{841}$ im herrschenden Sinn. Auch das ist eine materielle Basis.

Der preußische Staat als "grande et belle machine«, »die Bewegungen eines Bataillons« als »beste[s] Uhrwerk«: >codierte Ströme $\iota^{842}$ allemal? Aber: »Militär und Gesellschaft waren damals scharf voneinander getrennt gewesen; nur ein kleiner Prozentsatz der männlichen Einwohner kam vor 1814 überhaupt je in Berührung mit der Armee. Konzepte militärischer Männlichkeit waren daher für den allgemeinen gesellschaftlichen Verkehr relativ bedeutungslos. « Um ihnen »die spätere Resonanz $\mathrm{zu}$ verschaffen«, seien materielle und institutionelle Bedingungen zu erfüllen gewesen, sei das wechselseitige Interesse von Gesellschaft und Militär, letzteres als »Modell für zivile Verhältnisse« anzuerkennen gewesen. ${ }^{843}$

Ernst Moritz Arndt, der in propagandistischer Vorbereitung schon 1803 poetisch einen »Heldenbruder« potentiell im Freiheitskrieg gegen Napoleon >fallen` lässt, um »Eichen stolz und grün/Als Denkmal auf sein Grab« zu pflanzen, ${ }^{844}$ sieht - wie »die meisten bürgerlichen Zeitgenossen « - im stehenden Heer eine »Schule der Üppigkeit und Liederlichkeit«, einen jugendverderbenden Ort, an dem die Rekruten »Lüsten und Lastern« ausgesetzt und »dem bürgerlichen Leben für immer entfremdet « werden. ${ }^{845}$ Hier sind andere >codierte Ströme` gefragt, bürgerliche, >natürliche Männlichkeit $\iota: ~ » W o$ die hohen Eichen sausen,/Himmel an das Haupt gewandt,/Wo die starken Ströme brausen,/Alles das ist deutsches Land. ${ }^{846}$ Arndts Pädagogik will »alle Erziehung auf den Krieg gestellt« wissen, der Bürger muss »Krieger«, muss »Mann seyn, er muß innerlich und äußerlich empfinden, daß er es ist«. Schon ab der Kindheit werden »Leibesübungen und Waffenspiele« verlangt, »um ein männliches und streitbares Geschlecht erwachsen« zu lassen. In enormer Druckauflage (ca. 100.000 Stück) ruft Arndt, seit 1812 >im Dienste < des Freiherrn vom Stein, den »heiligen Volkskrieg« gegen Frankreich aus, beklagt (anders als Körner), dass die »teutschen Männer [...] in Elendigkeit und Weichlichkeit" versunken seien, dass »Bauer und Bürger» sich gegenwärtig als »wehrlosen und waffenunfähigen Mann« sähen, der mit dem Krieg nichts zu tun hätte. Sie alle sollten durch den Krieg hier-

841 Deleuze, Gilles/Guattari, Félix: Anti-Ödipus.

842 Vgl. Theweleit, a.a.O., S. 548.

843 Frevert, a.a.O., S. 146.

844 Zit. n. Lindemann, a.a.O., S. 216.

845 Frevert, a.a.O., S. 152.

846 Schenkendorf, Max von: Frühlingsgruß an das Vaterland (1814); zit. n. Lindemann, a.a.O., S. 218. 
von >befreit` werden. Die sich hier verweigern, sind »Buben oder Weichlinge « und als solche auszusondern. ${ }^{847}$ Die, die nicht stramm stehen, nicht national denken das $\gg$ krumme Holz», Weichholz an und in den Sümpfen. Das richtet sich auch gegen die »weibische Weichlichkeit» qua Adelserziehung, ${ }^{848}$ hat aber desgleichen eine besondere Vermischung/Verwirrung der Körperzustände im Sinn. >Weichlinge ( $>$ molles $`$ ) sind vor allem Homosexuelle, aber auch Onanisten, Impotente, jene, die sich der Virilität, dem heterosexuellen Koitus verweigern. Der Arzt Valentin Müller stellt 1796 in seinem »Entwurf einer gerichtlichen Arzneiwissenschaft « die Theorie auf, dass Masturbation zu Homosexualität führe; eine Theorie, der 1892 Richard von Krafft-Ebing (er spricht von »Feiglingen«) in seiner epochemachenden »Psychopathia sexualis« zur breiten Geltung verhilft. ${ }^{849}$

Propagandisten wie Arndt, der 1814 den »Deutschen Verein« gründet, >Turnvater〈 Jahn〈, 1810 Gründer des »Turnerbundes«, der »Studentenverbindungen« 1811, ${ }^{850}$ Johann Christoph Friedrich GutsMuths, der »Schnepfenthaler Erzieher« und Gymnastikpropagator, ${ }^{851}$ »und viele andere, die sich rund um die Befreiungskriege für eine streitbar-patriotische Männlichkeit stark machten

»träumten von einer umfassenden, auf sämtliche Bevölkerungsgruppen ausgedehnten kriegerischen Erziehung, die Männer zu richtigen Männern machen und der >Nation` ihre >Männlichkeit` (zurück)geben würde. Niemand aber mochte sich vorstellen, diese Erziehung im stehenden Heer, hinter Kasernenmauern stattfinden zu lassen. Vielmehr dachte man an lokale Turn- und Waf-

847 Arndt: »Geist der Zeit IV « u. »Was bedeutet Landsturm und Landwehr?« (beide 1813); zit. n. Frevert, a.a.O., S. 152.

848 Vgl. Frevert, a.a.O., S. 149.

849 Vgl. Mosse, George L.: Nationalismus und Sexualität. Bürgerliche Moral und sexuelle Normen. München, Wien: Hanser 1985 (New York 1985), S. 41. Der Begriff >molles`stammt aus der Antike. So werden »freie Männer bezeichnet, die als Pathicus homosexuellen Verkehr an sich zuließen. Dieser Ausdruck ist pejorativ und abwertend, wenn nicht Schimpfwort; kennzeichnet seine Träger als ehrlos, verweichlicht, weibisch. Ein >mollis`, (Weichling), ist derjenige, der die ihm qua Geschlecht zugeschriebene Rolle aufgibt und nicht die Härte des starken, in andere Körper eindringenden Mannes zeigt: So wird der >mollis` zum >semivir`, zu einem halben Mann, zu einer Art gesellschaftlichem Zwitter. Denn er nimmt die Rolle der Frauen ein, die aufgrund der ihnen zugeschriebenen Natur passiv sein müssen. Vgl. Braun, Karl: Die Krankheit Onania. Körperängste und die Anfänge moderner Sexualität im 18. Jahrhundert. Frankfurt/M, New York: Campus 1995, S. 148.

850 Vgl. Mosse, a.a.O., S. 95f.

851 Vgl. Frevert, a.a.O., S. 149. 
fenplätze, an öffentliche Räume inmitten vertrauter Umgebungen. Hier sollte sich die zentrale Initiation des Jünglings zum Mann, d.h. zum Bürger und Krieger vollziehen: vor den Augen der gesamten Bürgergemeinde und speziell der >Frauen und Jungfrauen $«{ }^{852}$

Schon 1793 betont GutsMuths die >Ganzheitlichkeit` des Anspruchs, die $»$ Kultur des Herzens und Geistes« und formuliert das Ideal der Verbindung von »körperliche[r] Vollkommenheit des Naturmenschen mit der Geisteskultur des verfeinerten Erdenbürgers «. ${ }^{853}$ Das greift zum Teil auf »damals populäre« Tugenden \Spartas` zurück, ${ }^{854}$ ebenso auf Tendenzen der Anthropologie, Phrenologie und Physiognomik des späten 18. Jahrhunderts, auf deren 〉Beweise〈 einer »Überlegenheit der Kaukasier« oder der Griechen, die für Männlichkeit, Schönheit, Ordnung und Maß stehen, »gegenüber der schwarzen Rasse« und deren »Egoismus, Schamlosigkeit und [...] Sinnenhaftigkeit«. Bei Jahn und Arndt tritt der »Männlichkeitskult - der Kult des männlichen Körpers, hart und geschmeidig, in Kampfpositur - [...] an die Stelle des [`griechischen〈] Freundschaftskultes«. Entscheidend ist hier »die Einheit von Körper und Geist«, bei den Turnern verwirklicht, »deren Körperkonturen sich in der Uniform, die Jahn für sie entworfen hatte, sichtbar abzeichneten. Der Nationaltypus, sein Ideal männlicher Schönheit, symbolisierte, während er die Leidenschaften im Zaum hielt, zugleich eine aggressive Männlichkeit «. ${ }^{855}$ Eine >germanischeく. In Arndts »Gesang zu singen bei Pflanzung einer deutschen Freiheitseiche im Jahre 1814, zum Gedächtnis an die Leipziger Schlacht« verschmelzen nun explizit »deutsche Eiche[n], »germanische Männer« der 〉Hermanns-Schlacht» mit den Befreiungskriegern gegen Napoleon, den »Männer[n] der Macht«, »Tapfre[n] und Freie $[\mathrm{n}] \ll$, der »unschuldige[n] Jugend «, den »Deutsche[n] von Tugend « unter dem »deutschen Gott« des »heiligen Baumes« ${ }^{856}$ Männer wie 〉Eichen<: 1806 grenzt Jahn »als strammer Antisemit und Chauvinist das deutsche Volk im Zeichen der Eiche von sogenannten >Blendlingsvölkern«« ab. Die seien »Treibhauspflanzen [ohne] echte Fortpflanzungskraft« und: »Keine tausendjährige Eiche erwuchs im Treibhaus, nur in Gottes freier Welt. $\ll^{857}$

852 Ebda., S. 152f.

853 GutsMuths: Gymnastik für die Jugend. Enthaltend eine praktische Anweisung zu Leibesübungen. Ein Beytrag zur nöthigsten Verbesserung der körperlichen Erziehung; zit. n. Frevert, ebda., S. 149.

$854 \mathrm{Vgl}$. Frevert, ebda.

855 Mosse, a.a.O., S. 98.

856 Lindemann, a.a.O., S. $216 f$.

857 Ebda., S. 216, Fn. 69. 
Jahn, dessen Aktivitäten bis in die 1840er Jahre von Armee und Staat mit deutlichem Misstrauen als »Brutstätten nationaler und liberaler Bewegungen « gesehen werden, ${ }^{858}$ >befreit den turnenden Körper aus den Hallen der »adelsständischen Exerzitien«, >sprengt» diesen Raum der Leibesübungen und deren Prinzipien »der geometrischen Körperbeherrschung «, das Menuetttanzen »nach geometrischen Choreographien« im Ballsaal, die »hohe Schule des Reitens, das Fechten auf dem Fechtboden. »Die Exerzitienkultur war gekennzeichnet durch eine dreidimensional-raumbetonte Ordnung, durch Halle und Abgeschlossenheit, Förmlichkeit und geometrisch-choreographisch regulierte Bewegungen $\ll{ }^{859}$ Diese Art der Geometrie erscheint nun >französisch`, >weibisch`, >glatt` und `äußerlich`. Gefordert wird das kämpferisch-rauhe Männliche, vor allem das innerlich Befestigte, der »emotionale Panzer«, wie Wilhelm Reich das rund 120 Jahre später analysiert, keine scheinbar bloß äußerliche Choreographie. Ein neues »Ornament« muss her. Das »aus Menschen gebildete Ornament begleitet das europäische Ich bei der Einübung in seinen jeweils neuen Körper seit der Renaissance «. ${ }^{860}$ Das bürgerliche Ich aber bildet sich vor allem gegen das höfische. Es handelt sich nicht, wie Elias das annimmt, um einen Prozess, der gesellschaftlich von >oben` nach >unten` verläuft, nicht um bloße Internalisierung äußerer Zwänge. Das bürgerliche Ich entsteht »nicht nur aus äußeren Zwängen, sondern vor allem auch gegen solche Zwänge ${ }^{861}$ - und bildet eigene aus. Aus der Perspektive der neuen bürgerlich-männlichen >Maschine einer als idealistisch-moralisch entworfenen Mittel-Zweck-Relation, ist die adlige >Maschine $<$ zynisch-dekadente Spielerei. Jahn verbindet in »Deutsches Volkstum« (1810) »Nationalismus mit bürgerlichen Idealen, dem Familienleben und ehelicher Treue [...]. Und richtig wurde von den Turnern, die sich auf den Kampf vorbereiteten, erwartet, daß sie sich sogenannter Jugendsünden wie Trägheit, Wollust und unbeherrschter sexueller Leidenschaft enthielten $«{ }^{862}$ Auf der Berliner Hasenheide werden seine Übungen und Spiele ab 1811 zum »Modell«. Hier entwickelt er »seine Turnkunst und wilde Turnspiele auf dem Turnfeld, >wo Blache und Wirre miteinander abwechseln, wo Hain, Gebüsch, Gestäude, Dickicht und offene Räume anzutreffen sind, Laubholz und Tangel-

858 Frevert, a.a.O., S. 154.

859 Eichberg: Stimmung über der Heide, in: Großklaus/Oldemeyer (Hg.): Natur als Gegenwelt, S. 209.

860 Theweleit, a.a.O., S. 553.

861 Sonntag, a.a.O., S. 148.

862 Mosse, a.a.O., S. 98. 
holz««. ${ }^{863} »$ Dickicht «, »Hain«, Stauden, »Wirre«: das klingt nahezu nach $>$ Wildnis $<$ Jahns >Wildnis $<$ ist die des >Daseinskampfes $\prec$, der Virilität, eine >Wildnis ' gegen den >Treibhausdschungel«, in dem in schwüler Hitze >unzüchtige` und `impotente Triebe wuchern. Wehrhafte, gepanzerte >Wildnis` der klaren Körperkonturen und -abgrenzungen. In der >heroischeく, »patriotische« Männer und Frauen leben - jede/r am angestammten Platz. Dem »Mann die Wehrlichkeit«, dem »Weib die Sittlichkeit«. »Patriotische Weiblichkeit« in der ersten Hälfte des 19. Jahrhunderts bedeutet, wenigstens für die »gebildeten Schichten«, »»Pflegerinnen alles Großen und Guten, was der Staat je von seinen Bürgern erwarten kann<, zu sein«. Zu erfüllen im »nicht-öffentlichen Raum«, im häuslichen, familiären. Frauen sollen »in einer der >Nationenlehre〈, >-sitte<, und >-kultur entsprechenden Weise [...] ihre >weibliche Ehre rein halten «, die Kinder in steutscher Nationalsitte erziehen und steutsche Kultur Sprache und Kleidung pflegen«. Gerade die Kleidungsfrage nimmt auch für Männer - einen breiten Raum ein. Hier geht es nicht mehr um ein tradiertes Zeichensystem ständischer Zugehörigkeit, sondern ein neues »Symbolsystem« (wie zuvor in der französischen Revolution auch) des $»$ sichtbaren Ausdruck[s] innerer [nationaler] Tugenden $\ll .{ }^{864}$ Die strikte Entmischung der Geschlechter wird forciert durch die Einführung der »Allgemeinen Wehrpflicht« 1813/14. Potentiell ist damit jeder »Mann im wehrfähigen Alter« als Staatsbürger - von sozialer Position und tatsächlichem Bürgerrecht unabhängig - »zur >Vaterlandsverteidigungく verpflichtet«. Wie in Frankreich ab 1789 ist »der Status des >Vollbürgers« der >Nation«« ans Kriegführen und Waffentragen gebunden, womit Frauen vom Bürgerstatus aus der politischen Öffentlichkeit einer militärisch-männlich definierten und beherrschten Nation ausgeschlossen sind. Zumal die »Allgemeine Wehrpflicht« Frauen endgültig auch von jeder Versorgungstätigkeit innerhalb des Militärs ausschließt. Eine Entmischung, die sich auch in der Wahrnehmung von Pflanzen, Bäumen zumal, niederschlägt. 1853 stellt Franz Theodor Bratranek, Augustinerpater und Philologe, unter dem Einfluss Humboldts und der Möglichkeit, in dessen »Pflanzengeographie« >nationaltypische Eigenschaften in Pflanzen wahrzunehmen, seine »Beiträge zu einer Aesthetik der Pflanzenwelt vor«. Er sichtet unterschiedlichste Pflanzen »nach ihrer

863 Eichberg, a.a.O. Binnenzitat: Jahn/Eiselen: Die deutsche Turnkunst, zur Einrichtung der Turnplätze dargestellt. »Unabhängig davon«, schreibt Eichberg (ebda.), »aber parallel dazu, ließen auch Schwingerfeste in der Schweiz und Wettläufe in England, erste Badeanstalten im Freien und das Rudern nach englischem Vorbild die Konfiguration der geschlossenen Räume hinter sich «.

864 Hagemann, a.a.O., S. 185f. 
Eignung, die gewünschten Wirkungen aufs Gemüt zu bezwecken«. Heimische Pflanzen sind exotischen prinzipiell vorzuziehen, »bodendeckende als die geringsten« zu betrachten. Strauchartige werden »als vulgär bzw. >Proletarier des Waldes«« klassifiziert. ${ }^{865}$ Damit wohl auch >Weichlaubhölzer` mit ihren Tendenzen zum mehrstämmigen, verzweigten Wuchs. »Obstbäume« seien »beschränkt, häuslich, weich und einförmig «. ${ }^{866}$ Sozusagen Hausfrauen, die im öffentlichen Raum des Waldes nichts zu suchen haben (dass sie dort auch wachsen, ist für die Klassifikation bedeutungslos). Lediglich »die Waldbäume können wegen ihrer Dauerhaftigkeit und Größe genügen [...]. Besonders individuell, da ungesellig, sind die Nadelbäume« ${ }^{867}$ Individualität definiert sich also als Ungeselligkeit, und die ist männlich. Bratranek:

»Wie der Mann nicht in der Friedlichkeit des Familienlebens, sondern in der breiten und mächtigen Darlegung seiner Principien [...] seine Würde und Ehre findet, so sind es auch jene gewaltigen Laubgewächse, die nicht wegen vergänglicher Blüthen und anlockender Früchte, sondern um der freien Entfaltung ihrer Kraft willen aufgesucht und festgehalten werden [...] Vor Allem bieten sich nun Eiche und Linde als Bilder kräftiger und anmuthiger Individualität dar. $\varkappa^{868}$

Das transportiert 〉Erhabenheit`, die ebenfalls als männlich, weil schroff, individuell, zur Sphäre der Selbstbehauptung und höherer, ewiger Werte gehörig definiert wird. Schönheit dagegen (»vergängliche Blüthen«, »anlockende Früchte «) als weiblich, klein, glatt, gesellig. ${ }^{869}$ Derartige >männliche Wildnis` ist ein Raum strengster Arten- bzw. GeschlechterEntmischung. Dieser vorgeblich natürliche Wald korrespondiert mit dem geregelten Forst. Auch hier herrscht strikte Entmischung nach Arten und Altersklassen. Zusätzlich ist der Forst >Kultur८, nicht >Natur২. Kultur ist >männlich`, sie ist `produziert`, schafft Werte von Dauer. Das Aufziehen der >Kultur`, das Läutern, Durchforsten, ist Sache des Försters, die erste, reproduzierende, niedere Tätigkeit des Pflanzens obliegt in der Vergan-

865 Vgl. Wimmer, Clemens Alexander: Die Fiktion des deutschen Nationalgartens im 19. Jahrhundert, in: Gröning, Gert/Schneider, Uwe (Hg.): Gartenkultur und nationale Identität. Strategien nationaler und regionaler Identitätsstiftung in der deutschen Gartenkultur. Worms: Werner 2001, S. 43.

866 Ebda.

867 Ebda.

868 Zit. n. ebda.

869 Vgl. Kap. Zur Erhabenheit verfeinert. 
genheit und auch noch häufig heute Frauen: den $»$ Kulturfrauen $«{ }^{870}$ Andere Tätigkeiten, wie das Holzmessen, müssen schon frühzeitig von männlichen Waldarbeitern betrieben werden: »Je knapper und wertvoller das Holz wurde, desto bedeutsamer wurde die Aufgabe des Holzmessens. In Frankfurt, wo diese Tätigkeit ursprünglich Frauenarbeit gewesen war, wurde 1623 bestimmt, dass >die Weibspersonen, welche sich künftig beim Holzmessen betreten lassen, ins Narrenhaus geführt` werden sollten «. ${ }^{871}$ Vergleichbares ist mit der Einführung des Forstwesens im 18. Jahrhundert für das »Holzsparen« zu beobachten. Sparen wird völlig neu vom hauswirtschaftlichen Prinzip zum politisch-öffentlichen Thema. Seine Semantik verschiebt sich entscheidend vom >unversehrten Aufbewahren〈, von der »Sicherung der Unveränderlichkeit der eigenen Welt« hin zur Expansion. Bedeutet das vorher, »bei einer bestimmten Tätigkeit mit möglichst wenig Holz auszukommen und möglichst viel Holz im Wald für die Zukunft zurückzubehalten«, geht es nun darum, »Holz so effektiv wie möglich zu nutzen, oder: möglichst viel Wald als Spielraum für ein Wachstum der Produktion zu gewinnen. Das alte aufbewahrende, haushälterische Sparen war eine Tugend der Frau gewesen; das Sparen im neuen, expansiven Sinne als Erhöhung des Wirkungsgrades war die Kunst des Erfinders und Organisators «. ${ }^{872}$

Jahns >Wildnis $<$ ist auch die >Wildnis $<$, deren $>$ Recht $<$ Riehl Jahrzehnte später einklagt. Eine männlich-tugendhafte >Wildnis $\measuredangle$, wie sie angeblich in der »Germania« des Tacitus bewiesen wird. Oder der Wald mittelalterlicher Helden, wie ihn die Grimms neu beleben. »In dieser Zeit, deren Freude zu erleben sieben Jahre Leid uns reinigten«, schreiben Jakob und Wilhelm Grimm 1813, ${ }^{873}$ "ward die Bearbeitung eines alten, in sich deutschen Gedichtes als ein geringes Opfer dargebracht. Jetzt hat sich unser gesamtes Vaterland in seinem Blute von dem französischen Aussatz wieder geheilt und zu Jugendleben wieder gestärkt. Um diesen Preis gebe nun fortan jeder Deutsche alles Andere hin und sei stets bereit, als ein freudig Opfer zu fallen. Und keiner stehe von der Gefahr $\mathrm{ab}$, sondern Denen, die aus Furcht oder Liebe ihn zurückhalten wollen, antworte er mit den schönsten Worten der reinen Jungfrau: >Nun gönnet

870 Vgl. Bode/Hohnhorst, a.a.O., S. 55 und Burschel, Peter: Der Waldbau, in Stern, Horst (Hg.): Rettet den Wald. München: Heyne 1983², S. 237.

871 Radkau/Schäfer, a.a.O., S. 169.

872 Ebda., S. 186.

873 So zumindest zitiert Ernst Schultze ihre »begeisterte[] Vorrede« zum "Armen Heinrich" 1905 im Vorwort der von ihm herausgegebenen Grimm-Übersetzungen des »Walthari-Liedes«, des »Armen Heinrich« und der $»$ Lieder der alten Edda «, S. $6 f$. 
mir’s, denn es muß sein««. Um »Geld aufzutreiben« für den »Befreiungskampf«, hätten die Grimms Hartmann von der Aues Text übersetzt und das »Büchlein « besonders in Hessen gut verkauft, als »die Sturmflut nationaler Begeisterung im Jahre 1813 alle verborgensten Kräfte des deutschen Volkes zu gewaltigem Aufbrausen brachte«, sie selbst »ihr Scherflein darbringen « wollten, zudem sie »ihre Brüder Karl und Ludwig als Freiheitskämpfer« ausgerüstet hätten, schreibt Ernst Schultz. ${ }^{874}$ Die Geschlechterrollen sind hier eindeutig verteilt: Die >reinste Jungfrau<, die sich im »Armen Heinrich« gegen allen Widerstand der Eltern opfern will, um Heinrich, der an tödlichem Aussatz erkrankt ist, zu retten. Das geht nur mit dem Blut aus ihrem »reinen Herzen«. Anti-Napoleon-Propaganda und Pflichterfüllungsgeschichte: Deutschland selber wird zum armen Heinrich, der Franzose zu seinem Aussatz und das deutsche Volk zum glühend opferwilligen Mägdelein - weibliche Allegorese, aber auch patriotische Weiblichkeit. Am Ende, nachdem Heinrich ihr Opfer verhindert, wird er von Gott gerettet und beide heiraten. ${ }^{875}$

Walthari, der aquitanische Königssohn zeigt seine »Mannheit« im Kampf gegen den burgundischen König und dessen >Mannen`, steht »unerschüttert« gegen die Gegner, wie eine Esche. ${ }^{876}$ Nachdem er die >Mannen ২ im >Wasgenwald ২ hinweggemetzelt hat, kommen schließlich König Gunthari und Hagano an die Reihe. Gunthari haut er »Bein und Schenkel bis zur Hüfte« weg, will zum »Todesstreich« ansetzen, aber Hagano hält seinen behelmten Kopf dazwischen, Waltharis Schwert birst, Hagano »haut« ihm »die vorgestreckte, Völkern und Königen durch ihre Siege furchtbare rechte Hand«ab. Walthari ist »unerschüttert«, schiebt »den blutenden Stumpf in den Schild« und kämpft mit der linken Hand weiter, mit der er »alsobald Haganos rechtes Auge ausstößt, die Schläfe durchschneidet, die Lippen spaltet und ihm zweimal drei Backenzähne aus dem Munde reißt. So nun endete der Kampf, aus welchem zwei großmütige, an Kräften gleiche Helden, keiner unversehrt, hervorgingen. Dort lag Guntharis Fuß, hier Waltharis Rechte und Haganos zitterndes Auge! So teilten sie die hunnischen Spangen! Es saßen die beiden, der dritte lag und trocknete den Blutstrom mit Blumen. Walthari rief die furchtsame Jungfrau « - seine Braut Hildgund -, um die Wunden $\mathrm{zu}$ verbinden und Wein $\mathrm{zu}$ bringen zur Feier des Unentschiedens. »Unbezwungen im Mut, ermattet am Leib scherzten unter den Bechern Hagano, der Dornige, und der Held aus Waskenland.« Sie »erneuerten [...] den blutigen Bund, hoben den König, dessen Wunde 
heftig schmerzte, aufs Roß und gingen voneinander, die Franken nach Worms, der Aquitaner in seine Heimat«. Da heiratet er Hildgund und herrscht »allen teuer und lieb« 30 Jahre. ${ }^{877}$ Was nach Czerwinski Bestandteil noch aggregativer Bedeutungsorganisation ist, ${ }^{878}$ erscheint den Freiheitskriegern um 1813 offenbar als Exempel im Sinn der Canettischen Definition des Waldes als Heeres-Symbol: sich festgewurzelt lieber in Stücke hauen zu lassen, als zu fliehen, und damit schließlich zu siegen.

Die andere Variante des Waldes als Massensymbol, die der $>$ Kathedrale (»der Wald ist über den Menschen«) bezeichnet eine Form der 〉Erhabenheit<. Die Verbindung ist auch als kriegerische zu finden. Theodor Körner entwirft 1813 im »Reiterlied» die »martialische Hochzeit [..] zwischen dem Freiheitskämpfer und dem `Liebchen Vaterland««. Vollzogen wird sie in »einer beeindruckenden Zeremonie in der Eichwaldkirche des >deutschen Gottes « ${ }^{879}$ Ludwig Uhland reimt 1812 in $»$ Freie Kunst«: »Nicht in kalten Marmorsteinen,/Nicht in Tempeln dumpf und tot:/In den frischen Eichenhainen/Webt und rauscht der deutsche Gott.« Aus Anlass des Sieges 1815 malt Karl Friedrich Schinkel $»$ Friedrichs gotische Ruine«. Sie ist hier »zwischen winterlichen Eichen aus einem neu ergrünten Eichenwald, der zudem von siegreichen Kriegern durchzogen wird, als deutscher Dom unter dem Friedensbogen mächtig wieder auferstanden $«{ }^{880}$ Erhabene Baumrecken und siegreiche Schlachten. Es ist der Theoretiker des Krieges, Carl von Clausewitz, der 1832 - ohne den Begriff zu verwenden - >Erhabenheit im »absoluten Kriege« beschreibt. »Seit Bonaparte«, schreibt er zum 〉Befreiungskrieg $<$, »hat der Krieg, indem er zuerst auf der einen Seite, dann auch auf der anderen wieder Sache des ganzen Volkes wurde, eine ganz andere Natur angenommen, oder vielmehr, er hat sich seiner wahren Natur, seiner absoluten Vollkommenheit sehr genähert«. Die aufgebotenen Mittel »hatten keine sichtbare Grenze, sondern diese verlor sich in der Energie und dem Enthusiasmus der Regierungen und ihrer Untertanen.

877 Vgl. »Walthari-Lied«, in: a.a.O., S. 34ff.

$878 »$ Jene andere, unmittelbare, konkrete Gewalt erscheint in Zeiten einer nicht-symbolischen, vor-abstrakten Kommunikation einander in der Berührung >erkennender voller Körper durchaus als positiv (z.B. ist sie das entscheidende Element der gesellschaftlichen Synthesis >Adel und wohl generell der von Kriegern und Jägern) oder zumindest, was die Perspektive der >Leidenden « angeht, als >normal $[$ [...]« Czerwinski: Der Glanz der Abstraktion, S. 260, Fußn. 187.

879 Lindemann, a.a.O., S. $220 f$.

880 Ebda., S. $223 \mathrm{f}$. 
Die Energie der Kriegführung war durch den Umfang der Mittel und das weite Feld möglichen Erfolges sowie durch die starke Anregung der Gemüter ungemein erhöht worden, das Ziel des kriegerischen Aktes war Niederwerfung des Gegners; nur dann erst, wenn er ohnmächtig zu Boden liege, glaubte man innehalten und sich über die gegenseitigen Zwecke verständigen zu können«. Allerdings mahnt Clausewitz, dass die Kriegs-Theorie nicht anhand von »idealen«, sondern von »wirklichen Verhältnissen « entwickelt werden müsse. Unwahrscheinlich sei es, »daß die Kriege alle fortan diesen großartigen Charakter haben werden«, denn »das kriegerische Element, von allen konventionellen Schranken befreit, mit seiner ganzen natürlichen Kraft losgebrochen«, habe seine Ursache in »den Verhältnissen, welche die französische Revolution in dem Innern der Länder herbeigeführt hatte« und in der »Gefahr, womit alle Völker von dem französischen bedroht waren«. Es sei ungewiss, ob nicht »nach und nach wieder eine Absonderung der Regierung von dem Volke eintreten wird «. ${ }^{881}$

Die Erfahrung von `Erhabenheit` steht im Mittelpunkt der ästhetischen Diskussion des 18. Jahrhunderts und wird an dessen Ende besonders von Kant und Hegel behandelt. Die `Erhabenheit〈, der `Enthusiasmus` entstammt >stärksten Bewegungen` wie Schrecken und Schmerz, weckt Leidenschaft, Staunen, Ehrfurcht, >existentiellen Schauder das >Große $<$ und $>$ Herrliche $<$, das, was die Einbildungskraft übersteigt. Die Vermittlungsinstanz ist das >Gemüt ২. `Erhabenheit ist dem weiblichen Verstand nicht zugänglich. Entdeckt wird die `Erhabenheitく in tiefen Wäldern, vor allem in schroffen, jähen Gebirgen, um 1800 herum und seitdem ebenso in gotischen Kathedralen. In der Natur sind nicht die Dinge und Ereignisse selbst >erhaben`, sie geben den Anstoß zur Erhabenheits-Stimmung und rufen ein Bewusstsein der >Allmacht $<$ menschlichen Geistes hervor. Denn nur dem Geist sind die Dinge und Ereignisse, die sinnliche Maßstäbe überschreiten, zugänglich. So erfährt sich der Mensch angesichts physischer Überlegenheit der `Natur-Gewalten`, als sittliches, über-sinnliches Wesen. Die furchterregende Macht hat keine Gewalt über die Seele, sie >hebt sich` vielmehr an ihr >empor ${ }^{882}$

Die »Natur des Krieges« verlange in jedem Fall, so Clausewitz, nach »Gemüts- oder Seelenstärke«, nach »Selbstbeherrschung«, der »Kraft, sich auch in den Augenblicken der heftigsten Gemütsbewegung dem Verstande noch zu unterwerfen«, die »in dem Gemüte selbst ihren Sitz hat «. Die erregte »Leidenschaft« habe ein »Gegengewicht «, das »Gefühl

881 Clausewitz, Carl von: Vom Kriege. Bonn: Dummler 1973 (Berlin 1832), S. $972 \mathrm{f}$.

882 Näheres hierzu findet sich im Kap. Zur Erhabenheit verfeinert. 
der Menschenwürde, dieser edelste Stolz, dieses innerste Seelenbedürfnis, überall als ein mit Einsicht und Verstand begabtes Wesen zu wirken«. Das halte die Leidenschaft im »Gleichgewicht, ohne sie zu vernichten« und sichere »dem Verstande erst die Herrschaft « ${ }^{883}$

Der >Enthusiasmus großer Kampfgruppen als >positive Eigenschaft ist der klassischen Erhabenheitsphilosophie noch fremd. Hier ist die Erfahrung von Erhabenheit eine von Individuen. Das klingt anscheinend auch bei Clausewitz noch nach: »Der Volksgeist des Heeres (Enthusiasmus, fanatischer Eifer, Glaube, Meinung) spricht sich im Gebirgskrieg am stärksten aus, wo jeder sich selbst überlassen ist bis zum einzelnen Soldaten hinab. Schon darum sind Gebirge für Volksbewaffnung die besten Kampfplätze.« Enthusiasmus allerdings sei kein »notwendiger Bestandteil« der »kriegerischen Tugend « des stehenden Heeres, die bestehe vielmehr aus der Unterordnung unter Gehorsam, Ordnung, Regel, Methode. Enthusiasmus aber gebe »der kriegerischen Tugend eines Heeres Leben und stärkeres Feuer«. Er gehöre, wie »Tapferkeit, Gewandtheit, Abhärtung« zu den »natürlichen Eigenschaften eines zum Kriege gerüsteten Volkes «. ${ }^{884}$

Solche »natürlichen Eigenschaften« verlangen nach angemessenen Monumenten, >Tempeln` >natürlicher Erhabenheit`, wie sie 1812 Uhland dichtend errichtet (s.o.); aus »Eichen himmelan ${ }^{885}-»$ Heldenhaine $«$, wie sie 1815 in Spandau aus Eichen und Linden für die »Gefallenen« errichtet, von Arndt 1813 »als Friedhof für große Deutsche« am »historischen Ort der Völkerschlacht von Leipzig vorgeschlagen, als »Denkmal für die Schlacht von Lützen« konzipiert werden. ${ }^{886}$

Am Ende steht dann der Fahnenmast als »Endgestalt« des Baumes. Hoch und gerade gereckt. Kein »Blattplunder« mehr, ${ }^{887}$ nur noch die

883 Clausewitz, a.a.O., S. $240 \mathrm{f}$.

884 Ebda., S. 359ff.

885 Dichtet Hoffmann von Fallersleben 1840; zit. n. Lindemann, a.a.O., S. 226.

886 Vgl. Gröning, Gert/Schneider, Uwe: Naturmystifizierung und germanische Mythologie - Die Heldenhaine, ein nationalistisches Denkmalskonzept aus dem Ersten Weltkrieg, in: Dies. (Hg.): Gartenkultur und nationale Identität, S. 100f.

887 Das ist gewissermaßen die Monumentalversion dessen, was für Schrebergärten von Kerstin Decker in der taz vom 23. April 2003 (»Häuserkampf für den Frieden«) beschrieben wird: »Jedes Mal, wenn ich an Luzern vorbeikomme, warte ich auf die kleine Gartenkolonie. Es wachsen keine Bäume dort, denn für Bäume sind diese Gärten viel zu klein. Aber fast alle haben in ihrer Mitte einen großen, baumlangen Fahnenmast. Das hat genau drei Gründe. Nur nach oben sind diese Gärten unbegrenzt, außerdem nimmt ein Mast nicht so viel Platz weg wie ein Baum, und drittens ist 
eine Fahne, Nationalzeichen, das Banner. So, wie »die stattlichen Bäume« zu »lebendigen Monumenten der Väter ${ }^{888}$ werden, wird die Fahne zum Zeichen der >Ahnen $<$. Mit Canettis Definition der »Fahnen als sichtbar gemachter Wind ${ }^{889}$ und dessen These, dass sich »im Wind die unsichtbaren Massen verkörperten, vor allem die Masse der Toten«, schließt Theweleit, "würde der domestizierte Geist der Toten in den Fahnen mächtig wehen. (Fahnen - Ahnen!) Die erhobene Fahne: das Heer der Toten kämpft mit uns«. Eine enorm gesteigerte Macht erhalten die Fahnen, "wenn man zur Masse der Toten die Masse des Toten zählt, die abgestorbenen eingesperrten Wünsche. Dann präsentiert sich in der Fahne auch das gebändigte und äußerlich sichtbar gemachte Triebleben dessen, der der Fahne folgt, in seinen Wunschfarben; dann schaukelte in den Fahnen das zur Ordnung gebrachte Fließen des Wunsches auf dem Bild einer Welle. Nicht Bewegung ist in der Fahne, vielmehr der Ausdruck von Bewegung, vielfältig benennbar (z.B. auch als tragbare Flamme, als >das Geräusch des Raubvogels über uns` etc.). Wenn sie dem Feind in die Hände fällt, geht die Masse der/des Toten in sein Gefolge über und die Ordnung der Triebe gerät außer Kontrolle - die Fahne muß zurückerobert werden $\ll .{ }^{890}$ Friedrich Ludwig Jahn, der sich daran macht, mit Turnen in >freier Natur` wehrhafte, ihre Triebe beherrschende Männer entstehen zu lassen, ist ebenso mitverantwortlich für die Gründung der Burschenschaften im Zeichen der >Freiheitskriege`. Ihre Farben sind Schwarz und Rot mit goldener Einfassung, den Uniformen von Theodor Körners »Lützowschen Freikorps« entlehnt. Auf dem Wartburgfest 1817 kommt es zur Verbrennung ») undeutscher` Bücher [...], die die ursprüngliche Kultur des Volkes vergiftet hatten «. ${ }^{891} 15$ Jahre später auf dem Hambacher Fest wird Schwarz-Rot-Gold zur >Volksfahne<.

Von der "grüne[n] Revolution« der Freiluft-Leibesübungen bleibt zunächst nicht viel übrig: »Seit den 1840er wurde das Turnen eingefangen in Hallen neuen Typs, in Turnhallen voller Geräte, an denen auf Kommando Drillübungen vollzogen wurden. Hallenschwimmbäder mit Klassen- und Geschlechtertrennung und kommerzielle Zirkusbauten ergänzten das Bild - Räume eines restaurativen, aber industriellen Zeitalters.«

der Mast gewissermaßen die Bestimmung des Baumes. Seine von allem Blattplunder befreite Endgestalt. An den vielen Mastspitzen aber wehen lauter Schweizer Fahnen.«

888 Oberforstrat Burckhardt, zit. n. Küster, a.a.O., S. 191.

889 Canetti, a.a.O., S. 95.

890 Theweleit: Männerphantasien 2, S. 329f.

891 Mosse: Ein Volk, ein Reich, ein Führer. Völkische Ursprünge des Nationalsozialismus. Königstein/Ts: Athenäum 1979 (New York 1964), S. 11. 
Was allerdings erfolgreich bleibt, ist die »körperhafte Erschließung« des Raums durch das Wandern, romantisch mit »Naturerlebnis und >unbestimmte[m] Sehen« « begründet, naturwissenschaftlich mit Pflanzenexkursionen, nationalpatriotisch und heimatbewegt mit dem »Kennenlernen des Vaterlands«. Vornehmlich »aber gab man sich pädagogisch, erzieherisch, körperbildend, beginnend mit den Ausflügen der Philantropen und fortgesetzt im lehrhaften Schulwandern des 19. Jahrhunderts « ${ }^{892}$ All das hängt offenbar auch mit der Neubegründung der Wälder zusammen. Schon wenige Jahrzehnte danach werden sie »für Natur« gehalten. »Man bemerkte nicht, daß nun Wälder aus Fichten und anderen Bäumen emporwuchsen, die es zuvor noch nie dort gegeben hatte, und übersah, daß viele Fichten in Reih' und Glied gepflanzt waren«, ebensowenig Spuren vorheriger Besiedlung oder agrarischer Nutzung (»seltsamerweise [...] auch in wissenschaftlichen Publikationen«). »Niemand zweifelte daran: Wald, die Heimat des Wildes ist gleichbedeutend mit Natur. Die Waldwesen aus Märchen und Sagen lebten nun nicht mehr nur in den eigentlichen Wildnissen, sondern auch in den neubegründeten Wäldern «. ${ }^{893}$ Zumal diese Wälder gar neue bürgerliche Ritualobjekte hervorbringen. »In den neu entstehenden Forsten setzte man die Fichten zu dicht nebeneinander. Schon nach wenigen Jahren mußte man die Waldfläche durchforsten«. Die anfallenden Jungfichten werden im 19. Jahrhundert zu Weihnachtsbäumen und verdrängen weitgehend bisherigen Schmuck wie Stechpalmen- und Mistelzweige. ${ }^{894}$ Hierbei werden Nadelbäume (wie auch >Knecht Ruprecht $\iota$ ) in vorgeblich »dauernder Kontinuität« zu Abkömmlingen des »germanischen Mythos« erklärt, zurückgeführt auf die >nordische〈 Wintersonnenwende. ${ }^{895}$

892 Eichberg, a.a.O., S. 210.

893 Küster, a.a.O., S. 202f.

894 Vgl. ebda., S. $189 f$.

895 Vgl. Weber-Kellermann, Ingeborg (Hg.): Die Familie. Eine Kulturgeschichte der Familie. Frankfurt/M: Insel 1996 (1976), S. 300f. Dagegen behauptet Anne Martin-Fugier (ohne das zu belegen), der Weihnachtsbaum sei vermutlich skandinavischen Ursprungs, im 30jährigen Krieg von Schweden nach Deutschland gebracht worden, sei aber erst seit Anfang des 19. Jahrhunderts populär. Verbürgt seien Christbäume in Straßburger Häusern schon für 1605 (Riten der Bürgerlichkeit, in: Perrot, Michelle [Hg.]: Geschichte des privaten Lebens 4. Von der Revolution zum Großen Krieg, S. 223). Nach Weber-Kellermann gibt es in »Zunftstuben der Reformationszeit«, aber noch nicht im familiären Kontext »geschenktragende Schüttelbäumchen«, am Heidelberger Hof Anfang des 18. Jahrhunderts lichtgeschmückte Buchsbäumchen (ebda.). 
Die neuen geregelten Forste, Altersklassenwälder, entstanden »vor dem Hintergrund einer nationalen Idee « oder ökonomisch begründet, ${ }^{896}$ werden zum Ausgangspunkt neuer bürgerlicher Praktiken der Naturaneignung, der Identifikation mit Orten, die immer weniger >draußen $<$ liegen. Die Maschinenförmigkeit des geregelten Forstes geht dabei in der Wahrnehmung auf, d.h., er entspricht den Identifikationen des Soldatischen, des männlich Geordneten. Da, wo das nicht ausreicht - oder tatsächlich Widersprüche zwischen realem >Waldbild ‘ und Anspruch auftauchen - halten übrig gebliebene alte Wirtschaftswälder, Hute-, Niederund Mittelwälder als (mythisch aufgeladene) Ur-Wälder her. Hier wie da: »ordnungsstiftende Signatur«. Die Ordnungsstiftung der Landschaft, des Waldes erhöht sich in dem Maße, in dem infolge gesteigerter Industrialisierung und des Wachstums der Städte das Urbane zunehmend als bedrohliche Unordnung wahrgenommen wird. Eine Unordnung, die konträr zur >männlichen` Ordnung des Waldes - weiblich konnotiert ist.

\section{Exkurs II: Die (lasterhafte) Stadt als Frau und Wildnis}

»In [den Gründungsmythen] ist die Gründung einer Stadt mit der Errichtung einer Mauer verbunden, mit deren Hilfe das Weibliche aufgespalten wird in einen wilden, dämonisierten Anteil draußen und in eine domestizierte Frau, Gattin und Mutter im Innern der Stadt. In der mythischen Urszene der Stadtgründung beispielsweise, wie sie uns in antiken griechischen Mythen in vielfältigen Variationen erzählt wird, läßt sich die Stadtmauer leicht als Schutzwall erkennen, mit dem die neu errichtete Ordnung (die Polis) gegen die wilde, ungebändigte Natur draußen abgegrenzt wird, gegen jenen Raum, in dem sich der Heros im Kampf gegen das Chaos als Drachentöter beweist. « ${ }^{897}$

Wenn im Mythos das »Bild von der weiblichen Wildnis«, personifiziert auch als Schlange, Hydra, Drachen, als Gegenbild zur Stadt fungiert, verkehrt sich das Verhältnis mit den explosionsartigen urbanen >Wucherungen` seit dem 19. Jahrhundert.

»Beim Übergang von der Stadt zur Großstadt kehrt dieser wilde Anteil wieder ins Innere der Stadt zurück. Mit dem Übergang zur Großstadt verliert nicht nur das Bild der Stadt, sondern auch das Stadtbild seine ordnungsstiftende Signatur. Gibt es auch immer wieder städtebauliche Versuche, Übersichtlichkeit, Geometrisierung und Zentrierung in der Anlage der Stadt zu erhalten oder

896 Vgl. Küster, a.a.O., S. 203.

897 Weigel, Sigrid: Topographien der Geschlechter, S. 157. 
wiederherzustellen, so zeigt sich gleichzeitig, daß das Wachstum der Großstadt sich planerischer Kontrolle entzieht. Die Beobachtung wird oft im Bild des Wucherns der Großstadt beschrieben. ${ }^{898}$

Ihre Grenzen sind uneindeutig, ihre Übergänge ins Umland desgleichen. Die Zentrierung auf einen Punkt ist zugunsten vieler, »ssozial und kulturell differenzierte[r] Zentren« aufgehoben; »die Außenseiter und Asozialen kehren in das Innere der Stadt zurück «. ${ }^{899}$ Der Begriff vom »Weichbild« der Stadt bekommt buchstäblich eine neue Bedeutung. Der stammt vermutlich vom mittelhochdeutschen "wîch« (Stadt) und »bilde« (Bild; Kreuz, das die Stadtgrenze markiert) oder »bilidi« (Recht). Was also mittelalterlich den - mauerumwehrten - Geltungsbereich des Stadtrechts bezeichnet, bedeutet in der Moderne den Siedlungs- bzw. Einzugsbereich der Stadt. Keine Mauer mehr, die den umschließt. Die Mauer sollte die innere Ordnung vor äußeren Gefahren schützen. Jetzt beginnen stattdessen Bestrebungen, die Ordnung draußen in der Landschaft zu schützen vor der metastasierenden Unordnung der Stadt, der Industrie. Burckhardt spricht vom »Geschwindigkeitsraum«, den »explodierende[n] Stadtkerne[n], die sich wie unter Dampf gesetzt in konzentrischen Kreisen ausdehnen, metastasieren, in Kreisen und Wellenbewegungen, die wie die Jahresringe der industriellen Entwicklung anmuten. Der Raum ist nicht mehr etwas, das unwandelbar, absolut und feststehend ist, sondern er gerät in die Schieflage, ins Rutschen, er reißt auf, folgt untergründigen Druckwellen, tektonischen Beben «. ${ }^{900}$ Untergründig: der Leib der Stadt bebt. Städte, die ihre Körperlichkeit, die die (und sei es nur annähernd) geometrische Grundordnung ihrer Peripherie verlieren, noch nicht durch das Schleifen der Mauern, dann aber durch explosionsartige industrielle Entwicklung. Der Stadt-Körper wird zum wuchernden Leib: Wildnis. Er metastasiert, befällt die Landschaft, verschlingt mit ihr die Landbevölkerung, proletarisiert sie. Das Mechanische erscheint als Organisches, die destruierende Technik als Naturkatastrophe. Verschlingende Stadt und verschlingende Maschine sind >weiblich $`$. Sie verschlingen nicht nur, sie spucken auch wieder aus: Proletarier.

Jean Vebers Gemälde »Die Maschine« von $1900^{901}$ plaziert eine nackte Frau mit in die Hüften gestützten Händen und hochgewirbeltem langen schwarzen Haar, sardonisch lächelnd das Geschehen zwischen

898 Ebda., S. 173.

899 Ebda.

900 Burckhardt, Martin: Metamorphosen von Raum und Zeit, S. $275 \mathrm{f}$.

901 Abgedruckt in Theweleit: Männerphantasien 1, S. 454. 
ihren Beinen betrachtend, rittlings auf eine Turbine - maschinelle Verlängerung ihres Unterleibes. Die Turbine treibt nicht nur mittels der sich in ihrer Öffnung vor- und zurückbewegenden Pleuelstange das große Schwungrad an. Sie entfacht auch einen Orkan, der aus der Öffnung entweicht und sehr klein dargestellte männliche Arbeiter durch die Luft wirbelt, um sie am Schwungrad zu zerschmettern.

»Symbol der unheimlichen geheimen Kraft der Maschine, die alles zermalmt, was ihr in die Räder kommt, was die Wege ihrer Kurbeln, Stangen und Riemen kreuzt, oder was gar sinnlos vermessen in ihre Speichen greift, - das ist das Weib. Aber auch umgekehrt: Symbol des männerwürgenden Minotaurocharakters des Weibes ist die Maschine, die kalt und grausam ohne Rast und Ruh’ Hekatomben von Männern opfert, als wären sie ein Nichts!«,

schreibt zeitgenössisch Eduard Fuchs. ${ }^{902}$ Das Maschinen-Weib, die Weib-Maschine lässt sich durchaus als Hexe verstehen - Hexen gehören, zusammen mit all den anderen sphallischen Frauen`, in dieser Zeit (wieder) zum populären Sujet der bildenden Kunst und des Kunstgewerbes. ${ }^{903}$ Sie >reitet $८$ auf der Turbine, der Pleuelstange (dem >Hexenbesen`), entfacht aus ihrem 〉Topf « einen Orkan, ihr Haar weht gegen die Windrichtung. Das alles sind Stereotype aus frühneuzeitlichen Darstellungen. ${ }^{904}$

902 Fuchs: Die Frau in der Karikatur (1906); zit. n. Bovenschen: Die aktuelle Hexe, in: Becker, Gabriele et al.: Aus der Zeit der Verzweiflung, S. 298.

903 Vgl. dazu Stelzl, Ulrike: Hexenwelt. Hexendarstellungen in der Kunst um 1900. Berlin: Frölich \& Kaufmann 1983.

$904 »$ Die Hexe ist ein >Weib wie der Wirbelwind . Diese Assoziation drängt sich durch die dynamische Bewegung und das flatternde Haar [...] geradezu auf«, schreibt Stelzl dazu. Es geht um die Dämonisierung der zerstörerischen Potenz des Windes, insbesondere des Orkans, im deutschen Volksglauben, um die besonders gefährliche Windsbraut also, die oft mit Hexen gleichgesetzt wird, belegt mit »typisch weiblichen Eigenschaften« dem »Kulturzerstörerischen«, der »Neigung zum Weinen, Zanksucht und Geschwätzigkeit« sowie zur »Tollheit«. Ebda., S. 39. Den Topf zwischen den Beinen, aus dem der Sturm entweicht, thematisiert z.B. Hans Baldung (»Die Hexen«, 1510), vgl. Abb. 2 in dieser Arbeit. Von Dürer stammt ein Kupferstich (»Die Hexe«, um 1502), auf dem die nackte Frau einen Bock reitet. »Während der Bock zum rechten Bildrand strebt, suggeriert das fliegende Haar der Frau eine Bewegung nach links « - »Sinnbild teuflischer Verkehrtheit«; vgl. Unverfehrt, Gerd (Hg.): Dürers Dinge. Einblattgraphik und Buchillustrationen Albrecht Dürers aus dem Besitz der Georg-August-Universität Göttingen. Katalog zur Ausstellung der Kunstsammlung der Universität (11.5.-21.6. 1997) Göttingen: Kunstgeschichtliches Seminar der Universität 1997, S. 208ff. 
»Indem die Allegorien des Industriezeitalters, verkörpert durch Frauengestalten, das Bezeichnete erstarren lassen und aus dem historischen Kontext heben, kann Technik wieder als bedrohliche Naturpotenz erscheinen. [...] Dort, wo der technologische Fortschritt sich hinter dem Rücken derer entwickelt, die ihn initiieren, und sich gegen sie verselbständigt, steht für diese Bedrohung auch wieder die Frau, die an dem Prozeß von Anbeginn nicht teilhatte. Zerstörerische Technik erscheint als Naturkatastrophe, analog zur vermeintlich ungebrochenen Sinnlichkeit der Frau. Allegorie und Mythos behaupten Natur gegen den Widerstand des Geschichtsverlaufs. $\ll^{905}$

Technik, die sich hinterrücks verselbständigt, als bedrohliche »Naturpotenz«: Die entfesselte Maschine wird zur >reißenden Naturく. In dem Maße, wie die Landschaft geordnet, ihre Natur »technisch-zivilisatorisch[] « gebändigt ist, zur »lieblichen Nahlandschaft« oder >erhabenen Weite` des Spaziergängers seit dem ausgehenden 18. Jahrhundert wird, ${ }^{906}$ wie der Wald zur - unbemerkten, weil der Wahrnehmung adäquaten - Maschine wird und/oder zum heroischen Ort sewiger Werte`, zum vorgeblich ruhenden Raum, geraten die städtischen Maschinen hinter dem Rücken ihrer Initiatoren zur Wildnis, zum brodelnden Raum, der seinerseits brodelnde, effeminierte Massen gebiert. Der Turiner Rechtsgelehrte Scipio Sighele (»La folla delinquente«, 1891), unübersehbar beeinflusst von Cesare Lombroso/Enrico Ferri, und der Pariser Mediziner und Populärwissenschaftler Gustav Le Bon (»Psychologie des Foules«, 1895) pointieren mit ihrer 〉Massenpsychologie`, was zeitgenössisch »gleichermaßen Narrativ der Großstadtliteratur und Großstadtreportage wie auch emblematischer Gegenstand der [...] Soziologie« ist, fußend auf der »spezifische[n] Mischung von Biologismus, Evolutionismus und Rassenlehre, die nach 1880 in der Medizin, Psychologie, Anthropologie und der entstehenden Kriminalwissenschaft hegemonial wurde $\ll:^{907}$ Die Massen sind weiblich, sexuell ungezügelt und grausam. Mit ihnen »kehrt der Naturzustand und die Barbarei in die Kultur zurück«. Die proletarisierten Massen sind »der Triumph der Triebnatur«. Reizbar und impulsiv sind sie, urteilt Le Bon, ihnen fehlt es umfassend an Geist, sie sind emotional überschäumend, so wie die anderen »Wesen

905 Bovenschen, a.a.O., S. $298 \mathrm{f}$.

906 Schneider, Helmut J.: Selbsterfahrung zu Fuß. Spaziergang und Wanderung als poetische und geschichtsphilosophische Reflexionsfigur im Zeitalter Rousseaus, in: Söring, Jürgen/Gasser, Peter (Hg.): Rousseauismus. Naturevangelium und Literatur. Frankfurt/M u.a.: Peter Lang 1999, S. 150.

907 Musner, Lutz: Stadt. Masse. Weib, in: Hödl, Günther et al. (Hg.): Frauen in der Stadt, S. 66f. 
von niederer Entwicklungshöhe«, wie »Frauen, Wilde[], Kinder[]«. »Das Weib« ist es auch, so Sighele, das die Massen zu Aufruhr und Demonstrationen anstachelt, die Männer zu Grausamkeiten und Unverschämtheiten anstachelt und sie darin noch übertreffe. ${ }^{908}$

Die Großstadt wird pathologisiert, Proletariat (und Prostitution) als eindeutiges Merkmal sozialer Degeneration diagnostiziert.

»Der Begriff der >Degeneration〈 wie auch der der 〉Dekadenz« wurde dieserart zum Gegenbegriff von Aufklärung und Fortschritt und damit zu einer negativen Folie des bürgerlichen Weltbildes, die nicht nur die Krisenphänomene der neuen Massendemokratien in Westeuropa, soziale Devianz, Anomie und Entfremdung erklären sollten, sondern den politischen Eliten auch als Abwehrbegriff gegen die ersten Machtdemonstrationen der Arbeiterbewegung dienen sollten.«

Zuschreibungen wie >Pöbel«, im ständischen Sozialgefüge frühneuzeitlicher Städte »zwar als rechtloses aber dennoch >organisches Substrat< der Kommune wahrgenommen«, werden seit der Mitte des 19. Jahrhunderts obsolet »angesichts einer durch Industrialisierung, Kapitalisierung und Landflucht verursachten Konzentration der sozialen Unterschichten in den Städten«: Die >Massen entstehen als »neuartige soziale Entität«, amorph und schon daher bedrohlich. ${ }^{909}$ Landflucht heißt >Entwurzelung , Verlust, Umkehrung tradierter Geschlechterhierarchie, die der ১Bauernstand noch garantiert hat. »In vielen Fällen«, notiert Friedrich Engels 1845 fürs Proletariat,

»wird die Familie durch die arbeitende Frau nicht ganz aufgelöst, sondern auf den Kopf gestellt. Die Frau ernährt die Familie und der Mann sitzt im Hause, verwahrt die Kinder, kehrt die Stuben und kocht. [...] Man kann sich denken, welche gerechte Entrüstung diese tatsächliche Kastration bei den Arbeitern hervorruft und welche Umkehrung aller Verhältnisse der Familie, während doch die übrigen gesellschaftlichen Verhältnisse dieselben bleiben «. ${ }^{910}$

Tatsächliche Kastration. Zumindest aber »ist dem letzten Rest der Männerherrschaft in der Proletarierwohnung aller Boden entzogen - es sei denn noch ein Stück der seit Einführung der Monogamie eingerissenen Brutalität gegen Frauen«, seit »die große Industrie die Frau aus dem Hause in die Fabrik versetzt hat und sie oft genug zur Ernährerin der

908 Vgl. ebda., S. 74f.

909 Vgl. ebda., S. 65f.

910 Engels: Die Lage der arbeitenden Klasse in England, in: MEW 21. Berlin (O): Dietz 1968, S. 369. 
Familie macht «. ${ }^{911}$ Was für Engels einen >subjektiven Faktor« auf dem Weg zur »Beseitigung der kapitalistischen Produktion und der durch sie geschaffenen Eigentumsverhältnisse« darstellt, an dessen Ende dann »die gegenseitige Zuneigung« als ausschließliches »Motiv« der »Gattenwahl« stehe. ${ }^{912}$ Aber so etwas läuft auf die Nivellierung der Geschlechterhierarchie (»tatsächliche Kastration«) hinaus. Dabei wird die strikte Abgrenzung der Geschlechterrollen voneinander als grundlegendes Erfordernis im ökonomischen, sozialen und privaten Raum wahrgenommen. »Es wurde ständig beteuert, daß Arbeitsteilung und die Unterscheidung zwischen Männlichkeit und Weiblichkeit ein dringendes Gebot des modernen Zeitalters waren. ${ }^{913}$ Nur - davon ist der wissenschaftliche Kommunismus überzeugt - arbeitet die Bourgeoisie qua kapitalistischer Produktionsverhältnisse selbst an ihrer Abschaffung. Es bewähre »sich hier wieder die Ironie der Geschichte«: Das aufstrebende Bürgertum (vor allem das protestantische) habe die Freiheit der Gattenwahl propagiert, die »Liebesehe« zum Menschenrecht erklärt, »und zwar nicht nur als droit de l'homme, sondern auch ausnahmsweise als droit de la femme«. Während Menschenrechte normalerweise »auf die herrschende Klasse [...] beschränkt blieben«, sei es hier faktisch umgekehrt, sei die herrschende Klasse »beherrscht von den bekannten ökonomischen Einflüssen«, was nur ausnahmsweise zu real »frei geschlossene[n] Ehen« führe, »während diese bei der beherrschten Klasse [...] die Regel sind . $^{914}$

Die bürgerlich geschaffene "gesellschaftliche Dynamik der Moderne« erscheint zugleich als Drohung mit Kontrollverlust und somit als Ursache ständiger Versuche, diese Dynamik »unter Kontrolle zu halten $\ll{ }^{915}$ Bedrohliche >Weiblichkeit speist sich ebenso aus anderen Gruppen, die wahrgenommen werden als Resultat sozialer Bewegung, Beschleunigung, der nun zunehmenden Durchlässigkeit bisheriger sozialer Schranken, Entgrenzungen und Vermischungen: Künstler, Bohemians, Flaneure werden im vorherrschenden normierenden medizinischpsychiatrischen Diskurs zur »Dégénérecence supérieure« ernannt, »weil hier auch das Genie eingruppiert wurde. Disharmonie, einseitige Talente, Leidenschaftlichkeit, Tendenz zum Pessimismus, Hysterie und Sensibilität zählten zu den Merkmalen künstlerischer 〉Entartung«« wie sie

911 Vgl. Ders.: Der Ursprung der Familie, des Privateigentums und des Staates. Im Anschluss an Lewis H. Morgans Forschungen. Berlin (O): Dietz 1969 (1884), S. 82.

912 Ebda., S. 93.

913 Mosse, George L.: Nationalismus und Sexualität, S. 35.

914 Engels: Der Ursprung, S. 82.

915 Mosse, a.a.O. 
auch immer wieder Max Nordau vermisst, klassifiziert und beklagt. Und diese Künstler scharen andere »Degenerierte«, Neurastheniker und Nervöse aller Art, Hysteriker um sich. ${ }^{916}$ Juden wird »zuweilen eine Verwirrung der Geschlechterrollen zur Last gelegt«, ${ }^{917}$ ein »wollüstiges Verlangen nach nicht-jüdischen Frauen«, um diese zu »verderbe[n] «. ${ }^{918}$ Homosexuelle werden charakterisiert durch ihre »feminine Erscheinung und zerrütteten Körper« (Ambroise Tardieu: »Die Vergehen gegen die Sittlichkeit«, 1860), ${ }^{919}$ »Rastlosigkeit und Exzessivität« und damit Paradebeispiele »der modernen Zeit« (Iwan Bloch: »Das Sexualleben unserer Zeit«). ${ }^{920}$ Sie alle werden feminisiert: »Emotionalität, Dominanz von körperlichen Reaktionen, Hemmungslosigkeit, Irritabilität, Lügenhaftigkeit, Unverstand, Infantilismus, Tierähnlichkeit, Instabilität, häufiger Stimmungswechsel, Instinktbetontheit, Feigheit, Ängstlichkeit - solche Eigenschaften konstituierten weibliche Normalität «. ${ }^{921}$

Damit zugleich ist hier »ein ganzes Geschlecht«, das weibliche, sozial zum kranken erklärt. ${ }^{922}$ Weibliche Emanzipation wird zum Signum >weiblicher Entartung〈, ebenso wie Prostitution. »So wie feministische Ziele sexuell konnotiert wurden, galt auch die Prostitution als sexuelle >Perversion`: Onanie, lesbische Beziehungen, Nymphomanie, Hysterie, Imbezillität, Schwachsinn stellten Entartungsäußerungen von Prostituierten dar. ${ }^{923}$

Schulemachend ist dabei Guigliamo Ferrerro/Lombroso: »Das Weib als Verbrecherin und Prostituierte«. Weibliche `Normalität ist zweigeteilt. Neben der Hurenhaftigkeit ist sie geprägt von »)Kinderliebe $>$ Mutterinstinkt «« auf der anderen Seite. »Gebärfähigkeit, Menstruation und Mutterschaft« werden zu »)körperlich[n]< Stigmata«. Beiden Kategorien - Mutter und Hure - gemein ist die »Thierähnlichkeit«, das Verbleiben im Naturzustand, was sich auch in größerer Leidensfähigkeit, Schmerzerduldung zeige, im »Urzustand«, weil Frauen und »Thiere seit undenklichen Zeiten immer dasselbe thun«, so Paul Julius Möbius (»Ueber den physiologischen Schwachsinn des Weibes«, 1900). Frauen werden zur »Inkarnation« all dessen, dem »sich das maskuline Prinzip ge-

916 Vgl. Bergmann, Anna: Die verhütete Sexualität. Die medizinische Bemächtigung des Lebens. Berlin: Aufbau Taschenbuch Verlag 1998 (Hamburg 1992), S. 267.

917 Mosse, a.a.O., S. 36.

918 Ebda., S. 178.

919 Vgl. ebda., S. 41.

920 Vgl. ebda., S. 51.

921 Bergmann, a.a.O., S. 268.

922 Vgl. ebda., S. 268.

923 Ebda., S. 273. 
rade $\mathrm{zu}$ entziehen versuchte $\ll .{ }^{924}$ Frauen und $\gg$ Entartete verletzten die Norm, denn »das normale Geschlecht ist männlich «. ${ }^{925}$ Es sieht sich offenbar gefährdet in einer Gesellschaft in >Auflösung،. Einer Gesellschaft, die droht verschlungen zu werden von »)gesellschaftsfeindliche[n] Ich-Süchtige[n]<, >schädliche[n] Raubtiere[n]<, >wilde[n] Tiere[n]<, >Krokodile[n] der Gesellschaft «, >menschliche[n] Ungeheuer[n] $\ll^{926}$

Die Kategorien von Norm und Abweichung sind (auch) Reaktionen auf eine >physische Demokratisierung und Gleichheit der Körper ein. Beide Errungenschaften sind für ihren Aufstieg an die Macht notwendig, um sich gegen die Gewalt von Seiten des Adels zu schützen und um zum Adel aufzuschließen. $"{ }^{927}$ Physische Demokratisierung aber lässt, weil es keine unterschiedlichen >Naturen der Körper mehr gibt (bis auf die eine neue, die biologische), die anderen, >niederen $<$ Körper dem bürgerlichen auf den Leib rücken. Das zwingt zum Einen zu permanenten Distinktionsleistungen nach unten und oben. ${ }^{928}$ Das bedroht zum Anderen mit Kontrollverlust. Der »Arbeiterkörper« erscheint als multiple Gefährdung: Seine >Roheit bedroht die >Kultiviertheit` des Bürgerkörpers, seine `Bereitschaft` zu Gewalt und Aufruhr bedroht die politische Herrschaft, seine Sexualität die Herrschaft des Bürgers »über die Frauen seines Standes« ${ }^{929}$ Kontrollverlust droht ebenso durch weibliche Emanzipation, droht durch Prostituierte, `Entarteteく. Kontrollverlust lässt auch beim `Bedrohten` die Gefahr des Leibes virulent werden, der >Ansteckung〈. Das »Treibhaus« urbaner Zivilisation, das Friedrich Ludwig Jahn beklagt, thematisiert auch der bedeutende deutsche Philanthrop und Pädagoge Joachim Heinrich Campe im »Väterliche[n] Rath an meine Tochter« (1796). Die meisten seiner Zeitgenossen seien degeneriert, ihre Natur entartet, so dass sie »gleich Pflanzen, die im Treibhause gezogen werden, zu einer übereilten, also unnatürlichen und verderblichen Reife in jeder Betrachtung; auch in der, daß der Fortpflanzungstrieb weit früher bei ihnen erwacht, als er, der Absicht Gottes gemäß, erwachen sollte«. Selbst »Thiere« und solche

924 Bergmann, a.a.O., S. 168f.

925 Braun, Christina von: Nicht ich: Logik, Lüge, Libido. Frankfurt/M: Verlag Neue Kritik 1985, S. 24.

926 Bergmann, a.a.O., S. 159. Sie zitiert Max Nordau: Entartung Bd. 2 (1893), Auguste Forel: Die sexuelle Frage (1904), Kraepelin, Emil: Psychiatrie (1915), Krafft-Ebing, Richard von: Psychopathia sexualis (1887).

927 Gebauer, Gunter: Ausdruck und Einbildung, in: Kamper/Wulf (Hg.): Die Wiederkehr des Körpers, S. 318.

928 Vgl. ebda., S. $323 \mathrm{ff}$.

929 Ebda., S. 320. 
Menschen, »die wir Wilde nennen«, da sie »bloß triebmäßig« verfahren, würden den vom »erhabenen Urheber der Natur selbst« erlassenen Vorschriften besonders bezüglich des Fortpflanzungstriebs verpflichtet bleiben, "seine absichtsvolle Einschränkung und die weisesten Gesetze, nach welchen er wirken soll« befolgen - obschon in roher Weise und ohne sie erkennen zu können. Der vernunftbegabte Mensch aber würde dieser Verbindung immer stärker verlustig gehen, »und zwar je verfeinerter und ausgebildeter er wird«, je größer und stärker seine »Verweichlichung, gekünstelte Bedürfnisse und Ueppigkeit« werden. Dieses Treibhaus der Wollust verwandele »in Gift und Fluch«, was dem Menschen eigentlich »zur Genesung und zum Segen gereichen sollte«, wo »durch verkehrte Erziehungsweisen« bewirkt »der schändliche und verderbliche Mißbrauch [...] von diesem Naturtriebe gemacht wird «. ${ }^{930} \mathrm{Er}$ spricht von einer Ruderalwildnis, »dem vergifteten Unkraute« und »dem Schierlinge $\ll,{ }^{931}$ die an den »labyrinthische[n] Abwege[n] « der degenerierten Menschen wachsen. ${ }^{932}$ Selbst »in feinen Gesellschaften« seien sie »eine Lieblingsmaterie der Unterhaltung und ein Gegenstand des Scherzes geworden«, all die »schlüpfrigen Vorstellungen« und »schmutzigen Zweideutigkeiten«; abgesehen von den »Ausgüssen einer unreinen Einbildungskraft « in Theatern, Bildergalerien und Büchersälen, deren einziger Sinn und Zweck darin bestehe, »den Geschlechtstrieb anzuregen und schändliche Begierden zu entzünden« und so »Seelen damit zu vergiften«. Anleitungen zur Unzucht gerade für die »junge[n] unschuldige[n] Personen« weiblichen Geschlechts. ${ }^{933}$

Treibhaus, Labyrinth, Wildnis. Weibliche Personifikation von Städten (und Territorien) ist eine strukturelle Wiederholung des »in den Gründungsmythen« bereits Vorhandenen, des sozialen Prozesses einer »Bewältigung der als doppelgestaltig gewerteten Natur«, der sich imaginär »am Bild der Frau vollzieht und dabei gespaltene Frauenbilder produziert«: Nicht begrenzte und nicht domestizierte Natur wird verglichen »mit dem wilden Anteil des Weiblichen«, erobertes, zivilisiertes und begrenztes Terrain $»$ mit seinem domestizierten Anteil ${ }^{934}$ Diese Strukturen bleiben Dispositiv: »Solange der Leib der Frauen als Wunschterri-

930 Campe, Joachim Heinrich: Väterlicher Rath für meine Tochter. Ein Gegenstück zum Thephron. Der erwachsenen weiblichen Jugend gewidmet. Braunschweig 1796 (Reprint d. 5. Aufl. Paderborn: Hüttemann 1988), S. $153 \mathrm{ff}$.

931 Ebda., S. $148 f$.

932 Ebda., S. 154.

933 Ebda., S. 160f.

934 Weigel: Topographie der Geschlechter, S. 173. 
torium anstelle des vorenthaltenen Leibs der Erde dienen kann, braucht keins der historischen Bilder abzusterben. Denn jedes ist vom entfalteten Kapitalismus reproduzierbar, neu belebbar «. ${ }^{935}$

Im Folgenden möchte ich einen historischen Überblick geben, ehe ich abschließend zur >Großstadt-Wildnis`, der Wahrnehmung von Beschleunigung und Auflösung, insbesondere im deutschsprachigen Raum seit dem 19. Jahrhundert zurückkehre.

Zunächst zu den Gründungsmythen. Sie gehen apokalyptischen Erzählungen wie der über die >Hure Babylon` voraus. Weigel referiert den Mythos der »zweite[n] Gründung Athens«, in dem der »hinkende Schmiedegott« Héphaistos beim Nachstellen der fliehenden Athene seinen Samen verliert, den Boden befruchtet, woraus Erichthónios hervorgeht. Der wird von Athene aufgezogen und »als zweiter Gründer des attischen Staates betrachtet«. Der Mythos spricht von einer Aufspaltung des weiblichen Anteils in die gebärende Funktion, hier der Erde $-\gg \mathrm{Ge}$ (oder Gaia)« -, und die aufziehende Funktion - der Jungfrau Athene -, also von einer »Integration der Matri- und Patrilinie in die Organisationsform der Polis« unter »Ausschluß der Sexualität«. Diese Polis wird gebildet von Kriegern, die unter dem Schutz der (hier Kriegsgöttin) Athene stehen, weil sie nicht aus ihrem Schoß stammen. Es gibt Variationen des Mythos: Kádmos tötet den Drachen, sät dessen Zähne aus. Daraus entstehen Krieger, die sich gegenseitig umbringen, bis auf fünf. Sie gründen Theben mit Kádmos, der seinen Triumph durch Heirat mit der Frau »Harmonia« feiert. Später wird Ödipus die Sphinx, die Theben belagert, mit List überwinden, in die Stadt einziehen und seine Mutter heiraten. $^{936}$

Weigel: »Der Drache haust an jenem Ort, an dem die Stadt nach seiner Tötung entsteht. Dem entspricht, daß die Ordnung durch das bedroht wird, aus dem und durch dessen Überwindung sie erst geschaffen wurde.« Existiert in einem Mythos eine Stadt bereits, wird sie »oft von einem Drachen bedroht [...], der vor ihren Mauern placiert ist«. Die Jungfrau, die der Drachentöter als Lohn erhält, »hat ihren Ort in der Stadt «. ${ }^{937}$ Das muss allerdings präzisiert werden. Zunächst ist diese Jungfrau das Opfer des Drachen, das er verschlingen will. Um ihn zu besänftigen, wird sie ihm geopfert und muss aus der Stadt in die Wildnis. Sie, die noch keinem Manne untertan ist, droht, von ihrem eigenen wilden Anteil - dem Drachen - verschlungen zu werden. Der Held tötet den

935 Theweleit, Klaus: Männerphantasien 1, S. 455.

936 Vgl. Weigel, a.a.O., S. $157 f$.

937 Ebda., S. 158f. 
Drachen und bringt sie in die Stadt zurück. Nun wird sie seine Frau, endgültig domestiziert.

»Für das Weibliche versinnbildlicht die Stadtmauer damit eine Aufspaltung in die ungebändigte Natur draußen und in die domestizierte, entsexualisierte Frau, ihre erstarrte, versteinerte, in den Mauern der Stadt buchstäblich gefangene Existenzweise: Die Stadtmauern, die sich drinnen in den Häuserwänden vervielfältigen, begrenzen den Ort der Frau im Sozialen als >lebendig Begrabeneく. Fortan soll sie sich drinnen, im Innern, im Verborgenen bzw. im sogenannten Privaten aufhalten - dort, wo ihr Leib nicht sichtbar ist, nur verwendbar zum >bestimmungsmäßigen Gebrauch` für den, der ihn zu seinem Besitz rechnen kann. « $^{938}$

Mit dem Verweis der Frau hinter die Mauern errichte sich der Held »einen Herrscherstuhl, so daß Frau und Stadt für ihn wechselseitig Ordnungsfunktionen erhalten «. ${ }^{939}$ Wichtig an derartigen Mythen ist der Kern der räumlichen Aufteilung zwischen den Geschlechtern: Der Mann bewegt sich in beiden Sphären, >innen` und >draußen`, die (züchtige) Frau, Gattin und Mutter, ist zwingend aufs >Innere verwiesen. Antigone verstößt dagegen, weil sie vor den Stadtmauern den toten Bruder bewacht. Sie beruft sich aufs »Gesetz des Totenreichs«, der Herrscher Kreon auf die »Götter der Väter«. Sophokles’ Text entfalte »sichtlich« den »Kampf um die Autorität des Mannes«. Kreon lässt die zuchtlose, die männliche Ordnung bedrohende Antigone zur Strafe lebendig begraben, einmauern in eine Felsenkammer - das »Brautgemach«, Hinweis »auf die ummauerten Brautgemächer der anderen Frauen, in denen ihr Geschlecht lebendig eingeschlossen ist «. ${ }^{940}$

Die weibliche Personifizierung von Städten bezeichnet Passivität und Besessenwerden oder Auflehnung gegen diese Ordnung. Städte sind Tochter, Braut, Mutter einerseits, Hure, Ehebrecherin andererseits. Sie sind weiter die >erotisch Lockende`, die Jungfrau, die Geschändete, erneut die Hure.

Für die Israel umgebenden Gesellschaften ist die weibliche StädtePersonifizierung für das 1. Jt. v.u.Z. dokumentiert. Hier »verschwimmen« die Vorstellungen von weiblich gedachten Städten und Stadtgöttinnen so stark, »daß der Stadt auch göttliche Eigenschaften zugewiesen wurden. Marc Wischnowsky erwähnt dabei Unterschiede zwischen der westsemitischen und der mesopotamischen Sphäre. In ersterer sei (wie 
im Hebräischen) die Stadt "grammatisch weiblichen Geschlechts«, in letzterer nicht. ${ }^{941}$ Eine Zuschreibung, die - wie Barbara Häusl zeigt seit Ende des 19. Jahrhunderts gängig ist, aber unhaltbar. »[N]ichtbelebte Größen« seien, anders als Lebewesen oder Personen, mittels der grammatischen Genera nicht zu erklären, da sie »nicht auf Regelhaftigkeiten der abgebildeten Wirklichkeit und Welt zurückzuführen« seien. Dass derartige Erklärungen trotzdem »regelmäßig« zu finden seien, lasse jedoch »Geschlechterrollen und -wertungen der Zeit der Verfasser erkennen. Die listenartigen adjektivischen >Beschreibungen` des femininen und maskulinen Genus führen zu einer Sexualisierung der Sprache, die auf die Wahrnehmung der Wirklichkeit zurückwirkt und diese (zumeist) patriarchal festschreibt ${ }^{942}$

Jerusalem, das »nach der Vernichtung Babylons, der >Mutter der Hurerei und aller Greuel auf Erden««, so die Apokalypse des Johannes, als neues Jerusalem, als >heilige Braut` geschmückt vom Himmel herunterkommt, ist zugleich ein >hortus conclusus`, von Mauern umgeben, dabei würfelförmig, in Länge, Breite und Höhe gleich - ein »Denkbild«, das eine »auf Gleichförmigkeit und Ordnung ausgerichtete[] Gemeinschaft repräsentiert «. ${ }^{943}$ Die alttestamentarische Personifizierung Jerusalems als »Tochter Zion« oder »Frau Zion« erfolgt in verschiedenen Kontexten. Jerusalem/Zion erscheint zunächst als klagendes Opfer, später in

941 Vgl. Wischnowsky, Marc: Tochter Zion, S. 13ff.

942 Häusl, Barbara: Bilder der Not, S. 2f.

943 Weigel, a.a.O., S. 161f. Die Idee des >himmlischen Jerusalem ২ hat in der christlich-mittelalterlichen Tradition »das diesseitige Ideal einer vollkommenen Gesellschaft verdeckt«; sie taucht bis Ende des 19. Jahrhunderts immer wieder auf (Kluge, Walter: Die Stadt der Utopie, in: Mahler, Andreas [Hg.]: Stadt-Bilder, S. 69). So etwa in Johann Valentin Andreaes »Christianopolis«, die, aufbauend auf Mores »Utopia« und Campanellas »Città del Sole«, »auch direkt von einem religiösen Heilswillen des einzelnen Menschen« ausgeht, »der nicht länger auf ein von oben kommendes >himmlisches Jerusalem « warten will«. Die Stadt soll auf der »fiktiven Insel Caphar Salama« liegen, was zugleich eine Anspielung auf »den Sieg des alttestamentarischen Judas Maccabaeus über die Feinde Israels« sei (ebda., S. 74f.). Die Vollkommenheit wird oft durch das Kreissymbol dargestellt, häufig kombiniert mit dem Quadrat (anhand biblischer Beschreibung und der Topographie des realen Jerusalem), was »das alte religiöse Symbol der Mandala« ergibt. Mandala, Quadrat und Kreis bleiben grundlegend für derartige Utopien folgender Jahrhunderte, ebenso »in der Realität etwa bei den Mormonen oder in Ebenezer Howards Gartenstädten « (ebda., S. 69). Auch Andreaes »Christianopolis« ist als Quadrat konzipiert. Die Seitenlänge von $700 \mathrm{Fuß}$ und die jeweils vier Häuserreihen sind sowohl Hinweis auf die heilige Zahl, die vier Elemente und Himmelsrichtungen, als auch dem realen Plan Heinrich Schickhardts für Freudenstadt - gedacht für Glaubensflüchtlinge - entlehnt (vgl. ebda., S. 75). 
»exilischer Zeit« wird sie »vom Opfer zur Täterin«, zur »Hure« und »Ehebrecherin«, die sich auf fremde Liebhaber einlässt, was auf die »politische Koalition mit Assur und Ägypten und ihre religiöse Apostasie abzielt, die ihren Untergang selbst verschuldet. In »nachexilischer Zeit« wendet sich die Zuschreibung. »Jerusalem wird zur weltweit verehrten Königin und Mutter reicher Nachkommenschaft«, zur Heilsgarantin und -verkünderin. Die »Schuld« gilt »aufgrund ihres Strafdienstes in Babel als abgegolten«. Die »Ehe Jahwes mit seiner Stadt« wird erneuert, »das Ende ihrer Verlassenheit und Witwenschaft zugesagt «. ${ }^{944}$ Das TochterBild fungiert als Vergleich des Stadtschicksals mit der »Vergewaltigung einer Tochter und mit der Zerstörung der Zukunft einer jungen heiratsfähigen Frau«. Da Vergewaltigung zu den realen Folgen von Frauen in Kriegen gehört, hat »das Schicksal der Stadt [...] zum Schicksal des weiblichen Teils der Bevölkerung eine metonymische Relation«. Die »Tochter als Opfer ruft Gefühle des Schmerzes, des Entsetzens und der Anteilnahme hervor«. In positiven Bezügen, etwa bei »der Aufforderung zum Jubelruf« ist die Stadt in der Rolle ihrer >Töchter`, die freudig heimkehrende Sieger empfangen. ${ }^{945}$

Personalisierte Städte (ebenso ihre Bevölkerung, aber auch fremde Könige, die ganze Menschheit, der Prophet) in Paniksituationen werden »mit einer Frau in Wehen « verglichen, wobei der Vergleich weder pejorativ ist noch auf der Geschlechterdifferenz basiert (wie der »Vergleich >Männer/Helden werden zu Frauen««), weil nur die Bedrängnis und Unausweichlichkeit thematisiert, die weibliche Geburtsaktivität insgesamt aber »ausgeblendet« wird. ${ }^{946}$ In Jeremia 49,3-5 werden hingegen klagende und zerstörte Städte wie Rabba als »selbstsichere[] und reiche[] Frau«, zugleich als »bedrohte« und am Ende vernichtete Stadt dargestellt. »Weiblichkeit repräsentiert somit nicht nur Selbstbewußtsein, sondern auch Untergang.» Selbstsicherheit wird hier zum Irrtum, an dessen Ende die Vernichtung steht. ${ }^{947}$

Gründungsmythen sind auch im ausgehenden Mittelalter und in der Renaissance anzutreffen. Weigel zeigt das anhand von Christine de Pizans »Buch von der Stadt der Frauen« (1405), das gelesen werden könne als »Versuch einer Begründung weiblicher Geschichte«. Die IchErzählerin erscheint als verwirrt über die grassierenden misogynen Urteile, etwa die »Behauptung, daß Frauen gern vergewaltigt würden«, die in Dialogen »durch die Geschichten einzelner Frauen widerlegt« wer-

944 Wischnowsky, a.a.O., S. $267 \mathrm{ff}$.

945 Vgl. Häusl, a.a.O., S. 82ff.

946 Vgl. ebda., S. 111f.

947 Vgl. ebda., S. $163 f$. 
den. Auch hier allegorische Frauengestalten, die »edle[n] Frau[en] Vernunft«, »Rechtschaffenheit« und »Gerechtigkeit«, auch hier gibt es eine Mauer, um der Stadt »Dauerhaftigkeit« und »Volkommenheit« zu verleihen. »Und indem der Entwurf überhistorisch konzipiert und der natürlichen Reproduktion enthoben ist, konstituiert sich auch diese Verbindung von Stadt und Weiblichkeit über die Verdrängung der Natur.« Zugleich aber werden Frauen »in doppelter Gestalt « präsentiert, sowohl als »Zeichenkörper«, als auch als »konkrete weibliche Subjekte« mit eigenem Namen und eigener Geschichte (die Jungfrau Maria, Heilige, edle Jungfrauen). »Weiblichkeit ist hier also nicht nur eine allegorische Form. ${ }^{948}$ Klaus Heinrich verweist im Zusammenhang mit den antiken Drachentötermythen auf die »staatserhaltende Lösung« des »MedusaProblems« durch Perseus, im Andromeda-Relief Benvenuto Cellinis $(1545 / 54)$, die $)$ seitdem eines der entscheidenden patterns in unserer $\mathrm{Zi}$ vilisation« darstelle: eine »elegante, kultivierende Teilung« Medusas in »Drachin« und Jungfrau. Andromeda ist an die Stadtmauer gekettet. Es ist also »eine Stadt, die befreit werden muß«, was »per definitionem« durch einen Herzog geschehen müsse. Links erschlägt Perseus die Drachin, rechts wird ihm von der Mutter (und dem Stadtrat) Andromeda als willige Braut übergeben: Vermählung der Stadt mit Herzog. ${ }^{949}$

Die »über die Zeiten« verbreitete Städte-Allegorisierung zu Frauen, »über deren Leiber Männer ihre Ehrkonflikte austragen, verläuft analog zur »reale[n] Vergewaltigung von >echten« Frauen« bei Stadt- und Dorferoberungen. »Bekanntestes deutsches Beispiel wurde die gewaltsame >Hochzeit` der >Magdeburger Braut` mit den Kaiserlichen Truppen im Dreißigjährigen Krieg«. ${ }^{950}$ Hier sind zudem Flugschriften verbreitet, in denen in »Gespräche[n] zwischen Feldherren« die von ihnen eroberten Städte »als umworbene Jungfrauen dargestellt sind «. ${ }^{951}$ Frühneuzeitlich wird ebenso die >lasterhafte $<$, >dekadente $<$ Stadt feminisiert - auch als Erbin des Hofes. Die »an vielen Höfen praktizierten Travestiebälle und -tänze«, so Maren Lorenz, hätten ob ihrer Sprengung der Geschlechtereindeutigkeiten als »lasterhafte[] Dekadenz und Sodomie« gegolten. $^{952}$

948 Weigel, a.a.O., S. $165 \mathrm{ff}$.

949 Vgl. Heinrich, Klaus: Das Floß der Medusa, in: Schlesier, Renate (Hg.): Faszination des Mythos. Studien zu antiken und modernen Interpretationen. Basel, Frankfurt/M: Stroemfeld 1985, S. 360f. u. Abb. 38, S. 392.

950 Lorenz, Maren: Leibhaftige Geschichte, S. 114.

951 Weigel, a.a.O., S. 173.

952 Daher, folgert sie, sei auch Hermaphroditismus »als Unordnung der Natur« während der gesamten Frühen Neuzeit mit diesen höfischen Untugenden assoziiert worden; vgl. Lorenz, a.a.O., S. 110 (mit weiteren Literaturhinweisen). 
Die »Marktpräsenz von Frauen« wird mit dem Beginn der Neuzeit männlicherseits zunehmend als Zeichen >verkehrter Welt‘, von >Weiberherrschaft gesehen. So zeigt eine zeitgenössische Karikatur, wie die Frau dem Mann das Schwert und das Geld abgenommen hat (und damit dessen ökonomische Macht). Sie schwingt die Peitsche, den (auf allen Vieren) vor den Wagen gespannten Mann anzutreiben. Dahinter stehen zwei Männer und zwei Frauen, eine Frau mit Narrenkappe, wohl für die Torheit, die Ordnung zu verkehren. ${ }^{953}$ In den Darstellungen unterscheiden sich städtische und ländliche Szenarien bezüglich der Trennung bzw. Mischung der Geschlechter deutlich voneinander. Die »Feldarbeit und der Markt« lassen Frauen vom Land aus dem ihnen "ansonsten zugewiesenen häuslichen Raum heraustreten«. In der Stadt dagegen seien »beide Geschlechter gleichermaßen« auf der Straße anzutreffen, einem »Ort des Lebens, an dem Neuigkeiten ausgetauscht werden, an dem Gerüchte entstehen«. Das »Verhalten und die Konflikte«, die Resultat »ständige[r] Nähe« seien, bildeten »ein unerschöpfliches ikonographisches und literarisches Thema«. Immer wieder werden »die Lebhaftigkeit der Wortgefechte von Männern und Frauen gezeigt, die charakteristisch für die städtische Bevölkerung ist«. Zeichen der »Beunruhigung und Sorgen«, die aus der »Neuaufteilung der Geschlechterrollen « resultieren. ${ }^{954}$

953 Vgl. Kuhn, Annette/Pitzen, Marianne (Hg.): Stadt der Frauen, S. 137, ohne Angabe von Herkunft und Ort (Quelle: Steven Ozment: When Fathers ruled. Family Life in Reformation Europe. Cambridge 1983, S. 52.)

954 Borin, Françoise: Frauenbilder, in: Duby, Georges/Perrot, Michelle (Hg.): Geschichte der Frauen. Bd. 3, Frühe Neuzeit, S. 244f. Borin illustriert das mit François Guérads Kupferstich »Die Verwirrung in Paris« (um 1720). `Zusammenleben` wird zum beherrschenden Thema der Ikonographie: Darstellungen des $>$ Liebesbaums $<$ oder des $>$ Streits um die Hose $<$, gebotener Gleicheit wie >verkehrter Welt überschreiten Grenzen, Epochen und soziale Klassen, bedienen sich aller Kunstformen »von den elitärsten bis hin zu den volkstümlichsten « und postulieren »die Wichtigkeit der moralischen und sozialen Funktion der Ehe«. Am Anfang steht die Begegnung. $»$ Die ländliche Szenerie« betone eine größere $»$ Freiheit in der Liebe [...] als in der Stadt. Die Liebesbäume variieren vom 15. bis zum 18. Jahrhundert wenig «, sind in zwei Kategorien unterteilt: Entweder sind »die Männer auf den Bäumen oder die Frauen«. Sind die Männer unten, bedienen sie sich »der Verführung Wein, Musik und Tand. Lockend und abwartend brauchen sie keine Gewalt, um die Schönen zum herabsteigen zu bewegen«. Die werbenden Frauen hingegen sind aggressiv, »bieten zwar Geschenke an«, fällen aber den Baum mit Äxten oder Sägen, benutzen Leitern oder Schlingen (vgl. ebda., S. 240f.). Weibliche Gewalt behauptet auch das Dauersujet des »Streits um die Hose«. Auch hier zwei Gruppen: »In der ersten ist der Raum diametral geteilt." Mann und Frau, oft von Geschlechter-Attributen (Kleid/Hose, Gewehr/Spindel, Spaten/Besen etc.) 
Für das 18. Jahrhundert sieht Véronique Nahoum-Grappe die Entwicklung einer »zusehends einheitlichere[n] städtische[n] Kultur in Europa [...], die ein mit femininen Attributen versehenes Bild von sich entwirft: [...] Ort der Kultur, der Hast, der Dekadenz, der Verrücktheiten und Frivolitäten, des eher >weibischen` (im unterschied zu weiblichen) Scheins, des Verlustes der wahren Werte und Tugenden? Die Stadt selbst war natürlich eine Frau «. ${ }^{955}$

Die >Weiblichkeit italienischer Städte in britischer Wahrnehmung zeigt Barbara Schaff als geprägt durch die »Grand Tour«, jene vom 16. bis ins 19. Jahrhundert exklusiv männliche Reisetradition, die jungen Adeligen institutionalisiert humanistische Bildungsideale zuführen soll anfangs individuell und tutorgeführt, seit dem 18. Jahrhundert zunehmend »normative[r] Bestandteil der englischen Kultur«. Die Tour ist auch deshalb »geschlechtsspezifisches Erlebnis«, weil »das Sammeln sexueller Erfahrungen [...] ein Programmpunkt « ist. ${ }^{956}$ Die Eroberung

umgeben, streiten sich. »In der zweiten Gruppe ist der Mann abwesend «, vorhanden nur noch sein Männlichkeits-Emblem, »eine phallische Hose«. Um sie streiten sich Frauen in einem Chaos von »Kleidern, entblößten Schenkeln, herausstehenden Brüsten«, raufen sich die Haare, beißen. Hier geht es weniger um »faktische Macht«, als um die »Angst vor der weiblichen Sexualität«, was die Gewalt erkläre. Die kurze Hose sei Sexualsymbol geworden, die lange Hose Machtsymbol. Wenn sie die Frau erringt, passiert »das Schlimmste«: Rollentausch, »verkehrte Welt«: Ein Bild aus Epinal (17. Jh.) zeigt den sitzenden Mann, eine Haube auf dem Kopf, die Spindel in der Hand, das Kind wiegend, ihm steht die Frau gegenüber, behelmt, mit Schwert und Muskete bewaffnet (vgl. ebda., S. $241 \mathrm{ff}$.).

955 Nahoum-Grappe, Véronique: Die schöne Frau, in Farge, Arlette/Davis, Natalie Zemon (Hg.): Geschichte der Frauen 3: Frühe Neuzeit, S. 107. Es ist sicher richtig, dass man sich für die beiden Jahrhunderte vorher »vor einer allzu scharfen Trennung von Stadt und Land hüten« müsse, schon weil »während der Frühen Neuzeit große Teile der ländlichen Bevölkerung Europas« in den »großen Marktflecken (etwa 2000 bis 5000 Einwohner) « leben, Orte mit einem Marktplatz als Zentrum, »um das herum sich Kirche, Wirtshaus, Friedhof, die Schmiede und die Häuser der Wohlhabenden gruppierten « und in denen sich »eine äußerst komplexe und heterogene Gesellschaft vermuten« lasse. Zugleich aber spricht NahoumGrappe auch von der »ostentative[n] Aufmachung « und demonstrativmachtvollen Prachtentfaltung der frühneuzeitlichen »europäischen Hofgesellschaften« (ebda.), womit sie das von Lorenz angeführte Moment bestätigt. Zugleich ändert die geschilderte frühneuzeitliche Wohnsituation in »Marktflecken« nichts an einer historisch kontinuierlich zu beobachtenden Allegorisierung von Städten zu Frauen. Zu fragen wäre hier allerdings nach historisch-sozial unterschiedlichen Bedeutungsgehalten.

956 Schaff, Barbara: Gendered Cities. Italienische Städte im Blick britischer Reisender, in: Mahler, Andreas (Hg.): Stadt-Bilder, S. $173 f$. 
und Aneignung der >Anderen « - das Territorium als Körper und umgekehrt -, weil dieser Körper tradiert Territorium ist.

Mit wachsender >Demokratisierung $<$ der Reise zum Massentourismus im 19. Jahrhundert nehmen »nun auch vermehrt Frauen« teil. Am Weiblichkeits-Klischee italienischer Städte ändert das noch lange nichts, schon aufgrund der in Reiseführern allfällig zitierten und klischeesierten Beschreibungen von Dichtern wie Byron, Ruskin, Henry James. ${ }^{957}$

Ein »bruchlos über Jahrhunderte fortgeschrieben[es]« Erfahrungsraster speist die Wahrnehmung/Konstruktion kultureller »Alterität und Differenz«, geprägt durch grundlegende Dichotomien: femininer, warmer, katholischer Süden versus maskuliner, kalter, protestantischer Norden. Die italienische Stadt wird so zum ersehnten und/oder schreckenden Raum, der Erfahrung der/des Anderen, des im Alltags-Zuhause Defizitären. ${ }^{958}$ Sexualisierung als Sinnstiftung: »Indem das kulturell Andere, Fremde weiblich semantisiert wird, wird es beherrschbar und erfahrbar, und kann damit in die >natürliche` Geschlechterhierarchie integriert werden. ${ }^{959}$

Venedig steht oft für alle italienischen Städte. Davon abgesetzt werden Florenz als >makellos`, Rom als >Mutter`, »Schoß der abendländischen Kultur [...] erlebt und beschrieben«. Zugleich wird Venedig zur weiblichsten aller Städte: als »Wasserstadt « tendenziell entgrenzt ${ }^{960}$ und ausgestattet mit labyrinthischen, irreleitenden, potentiell verschlingenden (Wasser-)Wegen, als altes Handelszentrum orientalisch beeinflusst; daher die »erotisch [L]ockende«, auch gespeist durch »lockere Sitten«, Karneval, Kurtisanen und den eigentümlichen Ehebrauch des sozial akzeptierten »cavaliere servente $«$ der Ehefrau, »verfallende Hure $\ll{ }^{961}$ Sie ist die »Princess Volupine« bei T.S. Eliot (1919), die es mit jedem treibt, gierig, zugleich »tuberkulös«: tödlich ansteckende Gefahr. ${ }^{962}$ Gut 100 Jahre zuvor bleibt der Benediktinermönch John Chetwode Eustace in seinem Reisebericht so lange beim neutralen »it«, wie »es um die architektonische Schönheit, den historischen Ruhm und republikanische Werte geht $\ll$. Sobald er von Korruption, Verschwendung, Luxus als potenzraubender, pathologischer Schwächungen des »Stadtkörpers" spricht, benutzt er das »she «. ${ }^{963}$ So erscheint auch die Herrschaft Österreichs ab 1802 über Venedig als »brutale Vergewaltigungsphantasie«,

957 Vgl. ebda., S. 174f.

958 Vgl. ebda., S. 175.

959 Ebda., S. 176.

960 Vgl. ebda.

961 Ebda., S. 176f.

962 Vgl. ebda., S. $183 f$.

963 Ebda. 
wobei das Opfer, gemäß des Sterotyps, daran mitschuldig zu sein scheint. »Am Ende« des sukzessiven Verfalls stehe dann

»)effeminacy<, ein weibisches Gehabe, das in einer syntaktischen Parallelkonstruktion mit Lüsternheit und Ausschweifung verbunden wird. Die Stadt erlebt eine tödliche Geschlechtsumwandlung: aus dem Arsenal, dem Ort männlicher Kampfeskraft wird ein Tanzparkett und so ist es nur logisch und gerecht, daß die freie Republik fallen muß«.

Was nicht ohne Mahnung für Eustaces eigene >britische Nation` geschrieben ist. $^{964}$

»Geschlechtsumwandlung«. In den alten Vorstellungen einer Entsprechung von Mikrokosmos und Makrokosmos sind es männliche Körper, die die Proportionen von Architektur, Stadt, Territorium bilden. ${ }^{965}$ Eigentlich ist es so der Körper des Fürsten, des Königs, der das Modell abgibt. Der Staat ist (seit der griechischen Antike) der Organismus, die Hauptstadt der Kopf, Kapitale. Dieses >Haupt` entsteht prähistorisch nach Mumford als »Implosion von Dörfern und Landstrichen«, nicht aus wirtschaftlichen Erfordernissen, »sondern aus dem Waffenmonopol ei-

964 Ebda., S. 181f. Tödliche Geschlechtsumwandlung: Das zeigt, dass Städte, auch italienische aus britischer Sicht, männlich konnotiert sein können. Schaff verweist hier auf das Florenz von Wordsworth und E. M. Forster. Anders als das >weibliche< Venedig Byrons, das - gemäß weiblicher Naturverhaftung - u.a. von »Werden und Vergehen « geprägt ist (ebda., S. 178), ist Florenz als Stadt des männlichen Kulturraums nicht das Andere, sondern das Eigene, das männlich konnotierte kulturelle Ewigkeitswerte, Genie repräsentiert: den Dom, das Denkmal Dantes etc. Hier ist »die Architektur symbolhaftes Zeichen der Männlichkeit« (ebda., S. 185), sperrt die >männliche` Kultur per männlicher Stadttopographie `weibliche` Natur aus, ist deren Exorzierung (vgl. ebda.). Hier ist nicht der >Körper`, sondern der Geist von Bedeutung, ist die Wahrnehmung »eine intellektuelle«. Forsters »Room with a View« will vorführen, dass nur Männer Florenz richtig sehen können, denn: »Frauen schauen an, Männer schauen hinein«. Bei derart verstehender Penetration ist dann auch der »phallisch konnotierte Turm des Palazzo Vecchio, der die Piazza della Signoria dominiert « nicht etwa »bedrohliches Zeichen, sondern als strahlend goldener Pfeiler vielmehr ein positiv besetztes Symbol männlicher Vitalität und Vollkommenheit, unerreichbar weit oben im Himmel, während Lucy [die weibliche Heldin] mit zu Boden gesenkten Augen den Heimweg antritt« (ebda., S. 186f.).

965 Vgl. Reudenbach, Bruno: Die Gemeinschaft als Körper und Gebäude. Francesco di Giorgios Stadtheorie und die Visualisierung von Sozialmetaphern im Mittelalter, in: Schreiner, Klaus/Schnitzler, Norbert (Hg.): Gepeinigt, begehrt, vergessen. Symbolik und Sozialbezug des Körpers im späten Mittelalter und in der frühen Neuzeit. München: Wilhelm Fink Verlag 1992; S. 171-197. 
nes Fürsten. Platon als Gesetzgeber einer idealen Stadt beschränkte ihre Größe auf die Reichweite einer Stimme, die Gesetze oder Befehle gab«. Von dieser vorgeschichtlichen Phase der Städtegründungen als Auftakt von >Hochkultur` und >Geschichte bleibt »der militärisch-administrative Kopf architektonisch erkennbar: in Burgberg oder Akropolis, Zitadelle oder Schloß. Erst mit der ersten industriellen Revolution soll eine Wucherung eingesetzt haben, deren Geschwüre in Mumfords Augen dann das Gesicht der Stadt auflösten und im Namen reiner Technologie über die ökologischen Notwendigkeiten des Zusammenlebens hinweggingen: Megalopolis«. ${ }^{966}$

Wucherungen und Geschwüre. Ein Abweg vom Haupt zum Leib.

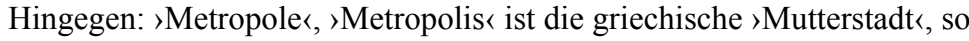
werden während der Zeit griechischer Kolonisation die Kolonien bildenden Städte wie Korinth oder Rhodos genannt, die dann mit den Kolonien aber in d.R. nur noch kulturell verbunden sind, in hellenistischer Zeit bezeichnet Metropolis die Gauhauptstädte in Ägypten.

Dass die Haupstadt >Kopf` ist, macht den Staat zum >Körper`. In dieser Kapitale aber bildet das Schloss den >Kopf`, die Stadt den 〉Körper`. Grundsätzlich aber ist das Verhältnis von >Haupt` und >Gliedern mehrdeutig. So schreibt Kantorowicz: »Die Analogie des corpus mysticum trug zur Klärung des Verhältnisses zwischen den Ständen des >politischen Körpers` und ihrem König bei; die Ehemetapher illustrierte die besondere Natur des Fiskus.« Juristisch werden hier »die wesentlichen sozialen, organischen und korporativen Elemente, die gewöhnlich dazu dienen, das Verhältnis zwischen Christus und der Kirche zu erklären« auf den Fürsten und den Staat übertragen. Danach erscheint »Christus als Bräutigam der Kirche, als Haupt des mystischen Leibes und als der mystische Leib selbst «. ${ }^{967}$

Die Geschlechtermetaphoriken für Städte und Territorien sind nichts Starres. Zur weiblichen Personifizierung/Allegorisierung kommt es, wie gezeigt, immer dann, wenn Abhängigkeit und Unterordnung (Tochter, Ehefrau) ausgedrückt werden soll. Desgleichen drückt >Weiblichkeit Bedrohung und Eroberung, Schutzlosigkeit des Opfers aus. Die >weibliche Stadt ist Nährende (Mutter), sie kann ebenso erscheinen als Lockende, Verschlingende, Verfallende oder eben Ehebrecherin (unterschiedliche Ausformungen von >Hure $`$ ), als Trägerin von Schuld. >Weiblichkeit als ordnungsstiftende Funktion ist Passivität. Aktivität wird hier zum Kennzeichen der Destruktion von Ordnung. >Weiblichkeit wird,

966 Kittler, Friedrich A.: Die Stadt ist ein Medium, in: Fuchs, Gotthard et al. (Hg.): Mythos Metropole, S. 228.

967 Kantorowicz, Ernst H.: Die zwei Körper des Königs, S. 228. 
als Kontrast zu >Männlichkeit`, mit Machtlosigkeit gleichgesetzt (und weibliche Macht mit Umsturz). ${ }^{968}>$ Männlichkeit< wiederum erscheint in aller Regel als konkrete (Subjekte, Träger von Geschichte usw.), konträr dazu allegorische $>$ Weiblichkeit :

»In der Personifikation von Ideen oder abstrakten Begriffen durch Frauengestalten ist die Erstarrung der Weiblichkeitsimagines und die Entleerung einer präsentierten Frauenfigur von ihrem konkreten Sinn am weitesten vorangeschritten. Erst dadurch, daß die dargestellte Frau nicht auf eine reale Frau referiert, kann sie zum Zeichen für anderes werden. [...] [Damit] wird die Imagination der Frau entindividualisiert und enthistorisiert. Das Bild der Frau verweist, indem es für einen Begriff steht, auf kein Subjekt und keine Geschichte. ${ }^{969}$

Der weibliche Körper in Bild und Text werde zum »Zeichenkörper[]«. Diese entleerende Allegorisierung sei »am reinsten [...] in der scholastischen Verwendung « zu beobachten, ${ }^{970}$ hier drückt sich die »vorausgegangene[] Verdrängung weiblicher Natur« als Asexualität aus. Im »Vorgang der Verbildlichung« allerdings kehrt diese verdrängte Natur zurück. ${ }^{971}$ Derartige Städtebilder seien »eher als Denkbilder denn als Abbilder zu betrachten«, sagt Sigrid Weigel, »als verräumlichtes Sinnbild einer Kultur, als paradigmatischer Ort von Zivilisationsarbeit und Kristallisationspunkt einer als Fortschritt konzipierten Geschichte, in dem die Dialektik der Naturbewältigung und der Rückkehr des Verdrängten zum Ausdruck gebracht wird und in der dies mit einer jeweils spezifischen und sich verändernden Topographie der Geschlechter verbunden ist «. ${ }^{972}$ Der Begriff »Denkbilder« aber übersieht den somati-

968 An einem Beispiel aus dem AT: »Durch den Kontrast zur konkreten Männlichkeit der militärischen Mächte macht die >Geschlechtergrenze` die Ungleichheit zwischen den Größen deutlich. Denn es werden nur Städte und Länder weiblich personifiziert, die von der Eroberung bedroht bzw. erobert sind, die nicht selbst als militärische Mächte, sondern als schutz- und machtlos beschrieben sind. Besonders deutlich wird die kontrastive Verwendung der weiblichen Personifizierung im Spruch gegen Ägypten Jer 46,3-12, da dort konkrete Männlichkeit und metaphorische Weiblichkeit auf ein und dieselbe Größe bezogen ist. Ägypten wird dann weiblich personifiziert, wenn die Schlacht verloren ist und die endgültige Niederlage festgestellt wird. Die Beschreibung der Expansionsabsicht Ägyptens geschieht hingegen durch die Nennung von Truppenteilen, die konkret aus Männern bestehen.« Häusl, a.a.O., S. 232.

969 Weigel, a.a.O., S. 167.

970 Ebda.

971 Vgl. ebda., S. $172 \mathrm{f}$.

972 Ebda., S. 156. 
schen Gehalt von Wahrnehmung. Auch, weil die Verbildlichung mit realem Geschehen korrelieren kann - und das ist häufig der Fall. Städte werden erobert und >vergewaltigt $\iota$ - real aber die Frauen in diesen Städ-

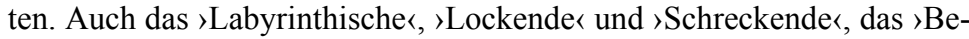
drohliche wird körperlich wahrgenommen - und als Angriff auf den Körper, als dessen drohende Auflösung. Die >weibliche Stadt rückt dem sie so Wahrnehmenden auf >den Leib<.

Was als Auflösung, Schock, Desintegration wahrgenommen wird, korreliert mit neuen Formen der Ordnung.

»Das neue Ordnungssystem von Raum und Zeit manifestiert sich nicht mehr in der Festlegung spezifischer Orte und spezifischer Zeiten, sondern in deren Auflösung. Die scheinbar beliebige und freie Bewegung im städtischen Raum trägt gerade durch die Auflösung der Bezüge und der genauso beliebigen und potentiell immer präsenten Kontrolle zur weiteren Stabilisierung von Herrschaft bei. Zwar bleiben mit der schichtspezifischen Zuschreibung bestimmter Räume - die bürgerlichen Viertel, die proletarischen Vororte - nach wie vor traditionelle Strukturen bestehen, doch dominiert jetzt weitgehend der desintegrierte, an der freien Zirkulation ausgerichtete abstrakte Raum. $«{ }^{973}$

Zur Herrschaftsstabilisierung bzw. -ausbreitung trägt hier etwa Städteplanung und Architektur bei. Es entstehen etwa neue Passagen, Galerien, Kaufhäuser vor allem, Glaspaläste, deren Konstruktion »den Raum nach außen zu öffnen« scheinen, die aber - wenigstens »zu Beginn dieses Prozesses« - exklusiv bürgerliche Orte sind, synthetische Räume, die die >proletarischen Massen draußen halten. $\mathrm{Zu}$ den Herrschaftsstrukturen des abstrakten Raums gehören auch neue Praktiken der Identifizierung von Personen, dazu »genügt der Blick des Polizisten auf bestimmte äußere Merkmale« - jenseits jeder räumlichen und zeitlichen Zuordnung. ${ }^{974}$ Aber, die Wahrnehmung von >Auflösung`, der Entstehung >amorpher Massen` zwingt die sich bedroht Wähnenden zur Konstruktion eindeutiger Merkmale, die >Gefahr lesbar machen sollen - mit den Mitteln der Kriminalanthropologie.

Deren >Ahnherr Cesare Lombroso setzt der >Demokratisierung der Physis` neue Körpernaturen entgegen. Zunächst die des (männlichen) »homo delinquens«, eine »natürliche Varietät«, gekennzeichnet durch dreifachen Atavismus: Durch das »Reversionsphänomen« der Körpermerkmale »wilder Völker und Rassen (»Neger«, »Mongoloide«) oder (Raub-)Tiere, das »Charakterphänomen« der Wildheit der Seele als Ba-

973 Kleinspehn, Thomas: Der flüchtige Blick, S. 247.

974 Vgl. ebda., S. 247f. 
sis der Physiognomie, und schließlich das »Deformationsphänomen« spezifizierbarer körperlicher Häßlichkeit und Medikalisierbarkeit. Der »Verbrechermensch« ist ein »zufällig in die Zivilisation geworfener Wilder« und damit »moralisch irre« wie alle Natur, deren ursprüngliche Boshaftigkeit Lombroso mit »Verbrechen« in Fauna und Flora nachzuweisen versucht. ${ }^{975}$ Lombrosos zweite Schöpfung ist die spezifische Verschärfung der bereits konstruierten Körpernatur >Frau<. Sie wird aufgespalten in drei Varianten. Beim »normalen Weib«, dem »halbkriminaloiden Wesen« bleiben die bösen Triebe, die ungleich stärker vorhanden seien als beim Mann, latent, neutralisiert durch »Mitleid, Muttergefühl, geringere Leidenschaftlichkeit, sexuelle Kälte, Schwäche und gering entwickelte Intelligenz«. ${ }^{976}$ Die normale Frau ist Mutter. Sie drückt die Bedrohung des Mannes aus, und stellt zugleich deren Abwehr da. Dies vor allem aufgrund ihrer Frigidität, denn »die Frigidität ist die Regel, das Gegentheil findet sich nur bei den Verbrecherinnen von Geburt«, die stets Prostituierte seien. ${ }^{977}$

Die >geborene Verbrecherin spalten. In die Masturbatorin, die den Mann aufgrund ihrer sexuellen Selbstbestimmtheit, ihrer monomanischen Selbstgenügsamkeit mit Entmachtung (seiner sexuellen Vorherrschaft) bedroht. Sie ist das »Symbol der Nicht-Gemahlin und Nicht-Mutter«, die »Inkarnation einer die Kultur bedrohenden Selbstgenügsamkeit des Lustfleisches, worin die Ströme der Libido in sich gekehrt zirkulieren «, ${ }^{978}$ sie macht sich des Verbrechens der Mit-sich-selbst-Verschwörung gegen die soziale und kulturelle Ordnung, ja gegen den Fortbestand der Bevölkerung schuldig. Der zweite Typ ist die sexuell permanent bereite Hure, die alles verschlingende, kastrierende Vagina dentata. Sie ist weitaus gefährlicher als die Masturbatorin, da sich ihr Trieb direkt gegen den Mann richtet. »Die Identität zwischen der Verbrechernatur und der Dirnennatur ist auf anatomischem und psychologischem Gebiete so vollständig wie nur möglich. ${ }^{979}$

975 Vgl. Strasser, Peter: Verbrechermenschen. Zur kriminalwissenschaftlichen Erzeugung des Bösen. Frankfurt/M, New York: Campus 1984, S. $60 \mathrm{ff}$.

976 Lombroso, Cesare/Ferrero, Guglielmi: Das Weib als Verbrecherin und Prostituirte. Anthropologische Studien gegründet auf einer Darstellung der Biologie und Psychologie des normalen Weibes. (Autorisierte Uebersetzung von Dr. Med. H. Kurella) Hamburg: Verlags-Anstalt und Druckerei 1894, S. 412.

977 Vgl. ebda., S. 388.

978 Strasser, a.a.O., S. 69.

979 Lombroso/Ferrero, S. 576. 
Weigel verweist darauf, dass in der Moderne »eine veränderte allegorische Funktionsweise« städtischer Weiblichkeit $\mathrm{zu}$ beobachten ist. »Die Stadt wird nicht mehr in der Form einer Personifikation dargestellt und das Bild der Frau nicht mehr als leere Zeichenhülle verwendet.« Die Stadt werde vielmehr »mit dem Weiblichen analogisiert» und fungiere als »semiotischer Körper, dessen Bedeutungen mit der doppelt bewerteten Natur der Frau in Verbindung stehen«. Dem gehe historisch eine diskursive "Festschreibung des bürgerlichen Frauenbilds" voraus, die begleitet werde von der »Abspaltung« eines »als dunkel und ungebändigt verstanden[en] « Weiblichen. »Wenn die moderne Stadt mit dem weiblichen Körper verglichen wird, dann geschieht dies, gerade weil die Imagination dieses Körpers voller Bedeutungen ist. « Moderne weibliche Allegorese hat »das Scheitern einer totalen Domestizierung« zur Voraussetzung, weshalb sich die Strukturen der Gründungsmythen wiederholen - und zwar »im Innern der Stadt und des Subjekts, am Bild der Frau und in der Schrift«. Die Dichotomien des Frauenbildes korrespondieren so mit denen der Räume: Haus (Ort der Familie) versus Straße (öffentlicher Ort) - wozu auch 〉öffentliche Häuser` zählen -, »Stadt der Mütter« versus »der der Huren«. ${ }^{980}$

Verbrecherinnen/Verbrecher/Raubtiere und ihre Lesbarkeit, verborgen in der urbanen Wildnis. Was seien schon die »Gefahren des Waldes und der Prärie« verglichen »mit den täglichen Chocks und Konflikten in der zivilisierten Welt«, der Mensch bleibe »das vollkommenste aller Raubtiere«, ob »er auf dem Boulevard sein Opfer unterfaßt oder in unbekannten Wäldern seine Beute durchbohrt«, zitiert Benjamin Baudelaire. Und Alexandre Dumas adaptiert gleich Coopers Lederstrumpf-Erzählungen und schreibt »Mohicans de Paris«, entfaltet hier die »Poesie des Schreckens [...] amerikanische[r] Wälder, in denen feindliche Stämme auf dem Kriegspfad« sind, den »Urwald in der d'Enfer-Straße«. Der Flaneur, so Benjamin, wird zum Abenteurer, zugleich zum Detektiven. Die Detektivgeschichte und ihre »logische Konstruktion« haben ihren »Ursprung« darin, dass die großstädtische »Masse als das Asyl« erscheine, »das den Asozialen vor seinen Verfolgern schützt«. Es braucht also neue wissenschaftliche Methoden, ihrer im Gewimmel habhaft zu werden. ${ }^{981}$

Die Stadt der Moderne ist kein wohlgeformter Körper mehr. Sie wird zum Dschungel - schon Dürer lässt Wald in die Stadt einbrechen und/oder zum katastrophalen Krankheitsfall. »Im 19. Jahrhundert wuchsen die Städte alptraumhaft an; nach London überschritten in dieser Zeit auch Paris, New York, Berlin und Chicago die Millionengrenze. 1881 
lebten bereits 70\% aller Engländer in urbanen Zentren. Am Ende dieses Jahrhunderts war London mit $4 \frac{1}{2}$ Millionen Einwohnern die größte Stadt der Welt. Seine Geschichte wurde wie die der urbanen Entwicklung allgemein vor allem als pathologischer Vorgang empfunden; man beschreibt die britische Metropole als >wen`, >rash` oder >cancer setzt sie mit negativen Beispielen aus der Bibel oder der antiken Geschichte wie Sardis, Sidon, Sodom, Tyrus und vor allem Babylon in Beziehung. ${ }^{982}$

1871 gibt es im Deutschen Reich nur acht Städte mit mehr als 100.000 Einwohnern, 1910 sind es schon 48. In diesem Zeitraum wächst der Anteil der Stadtbewohner an der Gesamtbevölkerung (1871: 41 Millionen, 1910: 65 Millionen) von 4,8 auf 21,3 Prozent an. Das Tempo der Industrialisierung »schuf die Voraussetzungen für Urbanisierung und nachhaltige Veränderungen der sozialen und materiellen Lebensbedingungen $\ll{ }^{983}$ Zur klaren Tendenz der Verstädterung gehört auch die Entstehung neuer Zentren in bisher ländlichen Gebieten, wie etwa dem Ruhrgebiet, »vornehmlich industrielle Standorte, von der großen Industrie weitgehend geschaffen und geprägt «. ${ }^{984}$ Das Deutsche Reich als »aufstrebende Großmacht« erobert sich in »den Bereichen der Eisenund Stahlerzeugung, des Maschinenbaus, der Militärtechnik, der Elektrotechnik sowie der chemischen, feinmechanischen und optischen Industrie [...] eine wichtige Position auf dem Weltmarkt «. ${ }^{985} 1885$ sind 19,3 und 1907 bereits 26,4 Prozent der deutschen Frauen erwerbstätig, zumeist in der Textil-, Bekleidungs- und Kartonageindustrie. In diesem Zeitraum steigt die Anzahl arbeitender Ehefrauen von 631.748 auf 926.667. Zeitgenössisch wird für die Arbeiterinnen eine doppelte Für-

982 Kluge, Walter, a.a.O., S. 77. Gegen derartige >Wucherungen $<$ werden zeitgenössisch in Utopien vermeintlich organischere Wohn-Einheiten entworfen. »Dabei greift man nicht nur auf die ältere Tradition der literarischen Gattung der Utopie, sondern auch auf konkrete utopische blueprints des 19. Jahrhunderts zurück, in denen politische Entwürfe und architektonische Planungen engstens verwoben sind. Owen dachte sich seine agrarisch-industriellen Kooperativen als ımoral quadrangles`, und Fourier entwarf für seine halb privaten, halb gemeinschaftlichen Lebens- und Produktionsstätten die schloßähnlichen Phalangsterien, für die er schon aus Prestigegründen den Louvre als Vorbild aufgriff« (ebda., S. 77f.). Ähnlich auch der britische Sozialist William Morris, zu dessen architektonischen Rückgriffen auch die Gotik zählt.

983 Dupke, Thomas: Mythos Löns, S. 51f.

984 Ritter, Gerhard A./Kocka, Jürgen: Bevölkerungsentwicklung und Verstädterung. Einleitung, in: Dies. (Hg.): Deutsche Sozialgeschichte 18701914. Dokumente und Skizzen. München: C.H. Beck $1982^{3}$, S. 36.

985 Dupke, a.a.O. 
sorgepflicht betont. Einerseits setze der »Gattungsdienst« der Frauen deren Widerstandsfähigkeit gegen die »Schädlichkeiten der Industriearbeiten« herab, andererseits beeinträchtigten diese »Schädlichkeiten« die »Gattungsleistung «. ${ }^{986}$ Der Anteil ehelicher Geburten in Städten ist deutlich geringer, als auf dem Land, deutlich größer aber bei den unehelichen Geburten: Im Preußen von 1914 kommen 115,4 (Stadt) auf 65,1 (Land) je 1000 Geburten. »Damit parallel geht die Zahl der Ehescheidungen. Sie betrug 1913 in Preußen auf je 1000 bestehende Ehen in Städten 24,1, auf dem Lande 5,6. Der Ehebruch als Scheidungsgrund kommt zu 87,7 Prozent auf die Städte. « ${ }^{987}$

Der Kapitalismus untergräbt die patriarchale Familie. Was Engels bereits Mitte des 19. Jahrhunderts konstatiert, treibt an dessen Ende auch die national-konservative Heimatschutzbewegung um - wenn auch aus entgegengesetzter Motivation. Der >Antikapitalismus` der Heimatbewegung ergibt sich vor allem aus einem Gefühl der Fremdheit. Kapitalisten erscheinen danach als Ausländer oder Juden, internationale, also heimatlich ungebundene Operateure, die zudem >autarke` Bauern schmarotzend unter ihre Ordnung zwingen wollen. Das Problem der Proletarisierung besteht demnach darin, dass Bauern entwurzelt, also selbst zu >Fremden gemacht werden. ${ }^{988}$ Das Problem des Kapitalismus reduziert sich so auf eines der >Moral<, eine fremde (Nicht-)Moral, die daran arbeitet, »den Bauern von seiner Moral, seinem Rechte loszuhacken«, schreibt Hermann Löns. Die Moral der Stadt ist eine >angsteinflößende`, weil »ausländische« Moral. ${ }^{989}$ Hier herrschen Krankheit und Verfall. Peter Rosegger in der programmatischen Zeitschrift »Der Kynast«:

»Sie aber nennen die moderne Großstadt mit ihrem G'schnas und ihren giftvollen Genüssen die Blüte der Kultur! Oho, das ist nicht die Blüte, das ist Fäulnis. Großstadtleben ist Entartung und Untergang, nur verlangsamt durch den beständigen Zufluß ländlicher Kräfte. [...] Ich gebe zu [...], daß die Großstädte zeit- und ortweise für die Menschheit eine Naturnotwendigkeit sind, so ähnlich, wie an einem ungesunden Körper sich Geschwüre bilden können, die

986 Tennstedt, Florian: Sozialgeschichte der Sozialpolitik in Deutschland. Vom 18. Jahrhundert bis zum ersten Weltkrieg. Göttingen: Vandenhoeck \& Ruprecht 1981, S. 153f.

987 Ritter/Kocka, a.a.O., S. 45.

988 Vgl. Zimmermann, Peter: Der Bauernroman. Antifeudalismus, Konservatismus, Faschismus. Stuttgart: Metzler 1975, S. 82.

989 Vgl. Löns, Hermann: Bauernrecht und Bauernmoral, in: Gesamtausgabe in fünf Bänden. Hg. v. Wilhelm Deimann. Hamburg: Standard-Verlag 1960/61, Bd. 5, S. 498. 
aber dann rückwirkend den ganzen Körper vergiften. [...] Diejenige Kultur ist die edelste und blühendste, die uns Gesundheit und Daseinslust giebt. « ${ }^{990}$

Diese Kultur sei die ländliche. »Der Bauernstolz [...] steht auf gutem Grunde, denn der Bauer ist das Volk, ist der Kulturträger, ist der Rasseerhalter. ${ }^{991}$ Seine Moral habe sich »in langen Jahrtausenden bewährt« und sei nicht »brüchig geworden«, weil sie »einfach«, »natürlich« und »praktisch« sei, nichts mit »fremder Art« zu tun habe. »Sie ist das Rassezuchtgesetz seiner Art, ist der Boden für das wirtschaftliche und gesellschaftliche Leben der Dorfgemeinde $\ll .{ }^{992}$ Dieser »Bauer denkt [...] unmoralisch im städtischen Sinne, und gerade darum ist sein Eheleben durchschnittlich so strenge, daß es Scheidungen so gut wie gar nicht gibt, selbst dann nicht, wenn der Mann ein Vieh und die Frau eine Metze ist«. Das Gesetz der Bauern bestehe darin, dass jeder - Bauer oder Knecht - »sich zu seiner Art halte [...], damit nicht durch fahrlässiges Freien die Grundlagen des Erbbesitzes erschüttert, nicht Führer und Volk durcheinandergewirbelt, nicht das feste Gefüge der Gemeinde gelockert werde«. Das sei die Basis, »auf dem jedes Volkes Leben und Kraft beruht« und ihr »ordnet der Bauer seine Geschlechtsmoral unter. Erben will er durch die Ehe haben, weiter nichts «. ${ }^{993}$

Für die völkische Heimatbewegung und national-konservative oder national-revolutionäre Publizistik gilt: Gerade, weil sie die Landschaft (den Wald) als Ort intakter patriarchaler Ordnung entwirft, eine Landschaft und einen Wald, die in Entsprechung hierzu als >heroisch-männlich $<$ konstruiert werden, muss dann die Stadt $>$ weiblich $<$ oder $>$ weibisch sein. Diese >Weiblichkeit $\measuredangle$ ist eine fremde. Es ist die des »Ibsenweib[s]«, der »Kameradin«, der »Heldin einer ganzen weltstädtischen Literatur vom nordischen Drama bis zum Pariser Roman«, der Emanzipierten George Bernhard Shaws, die keine Kinder habe, sondern »seelische Konflikte ${ }^{994}$ Oswald Spengler, der fatale Untergangsphilosoph und >preußische Sozialist` diagnostiziert »die Unfruchtbarkeit des zivilisierten Menschen «. ${ }^{995}$ Ihm gehe es um »die Wahl der >Lebensgefährtin « -

990 Rosegger, Peter: Rückkehr zur ländlichen Natur, in: Der Kynast. Alldeutsche Monatsschrift für Volkstum und Kunst. 1. Jg., 1. Hälfte 1899, S. $226 f$.

991 Löns, a.a.O., S. 488.

992 Ebda., S. 490f.

993 Ebda., S. 495f.

994 Spengler, Oswald: Der Untergang des Abendlandes. Umrisse eine Morphologie der Weltgeschichte. München: dtv $2000^{15}$ (München 1923; 33.47. Auflage [Neubearbeitung]), S. 680f.

995 Ebda., S. 679. 
der Bauer und jeder ursprüngliche Mensch« dagegen »wählt die Mutter seiner Kinder«. Und: »Das Urweib, das Bauernweib ist Mutter. Seine ganze von Kindheit an ersehnte Bestimmung liegt in diesem Worte beschlossen. $" ~ " 996$

Die »Dichotomie von Stadt und Land«, die im ausgehenden 19. Jahrhundert so geläufig wird, merkt Burckhardt an, »verdeckt eigentlich die Tiefe der Umwälzung, verdeckt, daß der Raum als solcher durchkreuzt und zerschnitten wird, daß dem Landschafter das Landschaftliche abhanden kommt. Das, was sich ihm auftut, ist nicht mehr Landschaft, sondern im höchsten Maße abstrakt«. Landschaft werde »ersetzt [...] durch jenes Netzwerk aus Brücken und Gleisen, das der Geschwindigkeitsmaschine den Raum bahnt«. Dieser Raum werde »)überschwemmtく von Massenprodukten, von Reproduktionen und Simulakren«, bevölkert von »Sommerfrischlern, von Großstadtflaneuren und Touristen«, werde »zum Stadtlandschaftsbild ästhetisiert «. ${ }^{997}$ Zugleich sei »das Anderswo, die Große Welt« in »den Zentren der Städte« gleich mit zentriert. Die Ferne werde ent-fernt, der gesamte Raum zum »Geschwindigkeitsraum«. Genaugenommen handele es sich um eine »sich überkreuzende, einander durchschneidende und überlagernde Vielheit von Räumen«, die etwa per Eisenbahnen »ins Hier und Jetzt« eindrängen. Es ist die Dynamik dieser heranrückenden Räume, die auch Heinrich Heine, im Nachdenken über die Eisenbahnen, >die großen Bewegungsmächte<, erfasst: >Durch die Eisenbahnen wird der Raum getötet, und es bleibt nur noch die Zeit übrig.〈 Und dann, eher bangend, denn enthusiastisch: >Mir ist als kämen die Berge und Wälder aller Länder auf Paris angerückt. Ich rieche schon den Duft der deutschen Linden; vor meiner Tür brandet die Nordsee. «" ${ }^{998}$

Die Großstadt als >weiblicher Dschungel Diskurs. Balzacs Novelle »Das Mädchen mit den Goldaugen« von 1834 kann als exemplarisch für dessen literarische Formung gelten. Paris ist hier ein unmenschliches Monster, unterteilt in mehrere »Höllenkreise«, den düstersten der Arbeiter, »die auch Frau und Kind in die Maschine einspannen«, um doch »den schwerverdienten Lohn in einer kurzen Orgie« zu verschleudern, dann die Sphäre der Kleinbürger, wo nur »verquälte « Arbeit herrscht, es folgt der »Magen von Paris«, die Sphäre des Geschäftslebens mit ihren »Ausschweifungen«, dem »seelische[n] Verschleiß«, dem »stupide[n] Spezialistentum«. Die Künstler im nächsten Höllenkreis sind »zerquält, erschöpft«, »vergnügungssüchtig«, desperat.

996 Ebda., S. 680.

997 Burckhardt: Metamorphosen, S. 275f.

998 Ebda., S. $277 f$. 
Der Adel schließlich ist von »weibischer Affektiertheit«, schlaff, launisch und »verliert sich in Süchten«. Der »Gesellschaftskörper« ist »lasterhaft krank, ja leichenhaft«. Alles ist in permanenter Bewegung, brodelt, kocht wie ein »häßlicher Vulkan«. Der städtische »Organismus« entfaltet sich in einer »Serie von Sexual-, Natur- und Körpermetaphern«, so »werden die Boulevards als Venusgürtel bezeichnet, während im Gegensatz dazu die Schenken am Stadtrand im Bild des Kot- oder Schlammgürtels gefaßt sind «. Paris als Ganzes wird als »die >diademgeschmückte Stadtく, als Königin dargestellt, >die, allzeit schwanger, von unwiderstehlichen Gelüsten gequält wird`, zugleich aber - im Hinblick auf die kulturelle Führungsposition in Europa - als von Genie platzendes Hirn «. ${ }^{999}$

In der deutschen Heimatbewegung allerdings ist eine spezifische Verkehrung der Aufspaltung des Weiblichkeitsbildes auszumachen. Domestizierte Weiblichkeit ist hier grundsätzlich ländlich sverwurzelt Nichtdomestizierte Weiblichkeit erscheint ebenso grundsätzlich als urban und daher als >entartet . Auf diese Weise zementiert sie eine Dichotomie von ländlicher Kultur und urbaner Zivilisation. Oder, in den Worten Spenglers: »Aus dem ursprünglichen Markt zur Kulturstadt und endlich zur Weltstadt herangewachsen, bringt sie das Blut und die Seele ihrer Schöpfer dieser großartigen Entwicklung und deren letzter Blüte, dem Geist der Zivilisation zum Opfer und vernichtet damit zuletzt auch sich selbst.« Zivilisation sei »der Sieg der Stadt« über das Land, die Befreiung »vom Boden«. Das mache sie »[w]urzellos«, dem »Geist verfallen ${ }^{1000}$ Was bei Spengler allerdings unaufhaltsamer Weg des $>$ zyklischen Sterbens` großer Kulturen ist.

Ernst Jünger, der Spengler-Bewunderer, ${ }^{1001}$ verwendet 1925 den Begriff »Hexenbesen «, ${ }^{1002}$ um die Ängste seiner Standesgenossen vor der Maschine zu benennen: »Es lebt aber auch in uns eine tiefe Angst vor diesem technischen Apparat, vor diesem Hexenbesen, den wir in Bewegung gesetzt haben, und dessen Wirkung wir ratlos wie die Zauberlehrlinge gegenüberstehen.« Besonders »ausgeprägt« sei diese Angst vor »einem Ausfluß des zweckmäßig denkenden Gehirns« unter »dem neuen Geschlecht, das instinktiv und unter dem Erlebnis des großen Krieges aufgewühlt eine scharfe Wendung nach der Seite des Blutes vornimmt

999 Weigel, a.a.O., S. $180 \mathrm{ff}$.

1000 Spengler, a.a.O., S. 684.

1001 Er »war so hingerissen, daß er >Den Untergang des Abendlandes` gleich zweimal las und Spengler 1932 ein Exemplar seines Buches >Der Arbeiter zueignete« (Felken, Detlef: Nachwort, in: A.a.O., S. 1251).

1002 Vgl. den Anfang dieses Exkurses. 
und daher sich einer verstandesmäßigen Weltanschauung zu entwinden strebt«. Aber die Maschine müsse »den Fangarmen des Intellekts« entwunden »und unter den Willen des Blutes« gestellt werden. »Was in der Sprache des Verstandes ein Mittel zum Fortschritt ist, heißt in der Sprache des Blutes ein Mittel zur Macht.« Und: »Der Industriearbeiter ist der erste und stärkste Faktor beim Aufmarsch des modernen Nationalismus, der eine neue und europäische Erscheinung ist. ${ }^{1003}$ Auch hier werden >Geist und das Bild einer bedrohlichen weiblichen Sexualität zusammengedacht. Das Requisit der Hexe, die >weibliche (Maschine erscheint als »Ausfluß des zweckmäßig denkenden Gehirns«, da, wo die >Instinkte des Blutes` verschwunden sind. Dieses >Blut` ist männlich, soldatisch besetzt. Es ist das »Blut der Blutsgemeinschaft«, dessen »Hochzucht» oder »die Güte seiner Mischung« ohne die »große Kraft« des »Schicksals« ohne Bedeutung sei. »Das Blut ist der Brennstoff, den die metaphysische Flamme des Schicksals verbrennt«, der »unvergeßliche[] Rausch der Zusammengehörigkeit«. ${ }^{1004}$ Bei Jünger geht es nicht um eine Dichotomie von Stadt und Land, sondern im Gegenteil um die Tilgung aller Unterschiede, den >totalen Raum`, eine >faschistische Moderne`, wie sie im »Arbeiter« entworfen wird. ${ }^{1005}$

\section{Der Wald als Ort des $>$ Daseinskampfes`}

Das Maskulinum »scheint das frühere, festere, sprödere, raschere, das thätige, bewegliche, zeugende; das femininum das spätere, kleinere, weichere, stillere, das leidende, empfangende $[\ldots] \ll{ }^{1006}$

Was Jakob Grimm 1831 analog zur Genesis für die Entstehung der grammatischen Genera postuliert, ist vor allem eine herrschende Dichotomie und Hierarchie von Geschlechtereigenschaften, die sozial erzeugt, aber naturalisiert oder, wie hier, biblisch belegt werden. Via Genealogie ist das männliche Geschlecht zuerst da gewesen, aktiv und produktiv,

1003 Jünger, Ernst: Die Maschine, in: Die Standarte, 13. Dezember 1925; zit. n. Politische Publizistik 1919-1933. Hg. von Sven Olaf Berggötz. Stuttgart: Klett-Cotta 2001, S. 159ff.

1004 Jünger: Das Blut, in: Die Standarte, 29. April 1926; zit. n. a.a.O., S. $193 \mathrm{ff}$.

1005 Vgl. Stöckemann, Ingo: Im reinen Raum. Jünger, Schmitt, Medientechnik, in: Maresch, Rudolf/Werber, Niels (Hg.): Raum - Wissen - Macht. Frankfurt/M: Suhrkamp 2002, S. 142f.

1006 Grimm, Jakob: Deutsche Grammatik 3, S. 359; zit. n. Häusl: Bilder der Not, S. 2f., Fn. 6. 
fest und spröde. Das Männliche ist also das >Ursprünglicheく. Dieses rauhe, aggressive Ideal muss auch vor dem Hintergrund entstehender bürgerlicher Männlichkeitskonzepte gegen die des Adels, befördert durch die 〉Freiheitskriege`, gelesen werden. Vor allem aber bezüglich der »Asymmetrie im Geschlechterverhältnis als einer der Grundpfeiler der bürgerlichen Gesellschaft«. ${ }^{1007}$ Hierbei geht es um die »schwierige[] Aufgabe, die Geschlechterhierarchie unter dem Postulat bürgerlicher Gleichheit festzuschreiben «, ${ }^{1008}$ was neben zunehmend medizinischen Begründungen weiblicher Inferiorität desgleichen Rückprojektionen aus der `äußeren Natur` benötigt, um Begründungen für ein neues bürgerliches Männerbild zu schaffen. Begründungen, die Hierarchie und Dichotomie als natürliche Größen reklamieren - einen 〉Organismus` gegen den >Mechanismus $<$ bloßer adliger >Mannspuppen « in Stellung bringen. Die Reklamierung >uralter Haine` als Orte, die diesen >ursprünglichen Strukturen ein Bild geben, ist seit dem ausgehenden 18. Jahrhundert in Gang. Zudem scheinen derartige Wälder, ebenso wie die seit dieser Zeit entdeckten > Waldesdome $<$ und Gebirgswildnisse, hervorragend geeignet, die Geschlechterpolarität dank ihrer männlich konnotierten >Erhabenheit`, der Momente des >Jähen` oder `Schroffen` abzubilden. ${ }^{1009}$ Während jedoch $>$ Waldesdome $<$ überwiegend zu Monumenten einer $>$ Harmonie « mit der >natürlichen Ordnung « werden - ohne allerdings bezüglich der Zuschreibungen gotischer Architektur die Dimensionen des >nordisch Rauhen< zu verlieren ${ }^{1010}$-, genügen Gebirge und ehemalige Hutewälder einem Bild der Asymmetrie, wie sie dem Geschlechterverhältnis zukommt; zugleich >wecken sie Assoziationen eines >heroischen Daseinskampfs $<$.

\section{Organismus versus Mechanismus?}

Die Suche nach dem 〉Ursprung «, den 〉Urgründen` usw. ist bereits Kennzeichen der >Geniezeit $<$. Herder wird 1771 seine Theorie der Volkslieder entwickeln, wonach >wilde` und >freiwirkende` Völker >wilde`, >freie` und >sinnliche< Lieder schaffen. Basis dieser Theorie sind die von ihm emphatisch rezipierten Werke eines keltischen »Naturgenies«, die »Ossian-Balladen . Diese seit 1760 vom Schotten James Macpherson veröf-

1007 Niemeyer, Beatrix: »Angenehme Sittenlehrer« - Briefe und Weiblichkeit im 18. Jahrhundert. Kritische Anmerkungen zu Norbert Elias, in: Klein, Gabriele/Liebsch, Katharina (Hg.): Zivilisierung des weiblichen Ich. Frankfurt/M: Suhrkamp 1997, S. 202.

1008 Ebda., S. 195.

1009 Vgl. Kap. Zur Erhabenheit verfeinert.

1010 Vgl. Kap. >Heilige Hallen` II. 
fentlichten Balladen sind dessen freie Erfindungen. ${ }^{1011}$ Vergleichbares trifft auf den »Erlkönig« zu. Dieser »König« »der germanischen Folklore« schlechthin, entstammt einem Übersetzungsfehler Herders. Er macht aus dem dänischen Lied »Die Tochter des Elfenkönigs« in seinem »Volksliederbuch«, das 1807 in dritter revidierter Auflage als »Stimmen der Völker in Liedern« erscheint, »Die Tochter des Königs der Erlen«. $»$ Eller« (dän. für »Elfen«) übersetzt er in »Erlen«, weil diese im Dialekt des Herderschen Herkunftsorts in Ostpreußen »Eller« heißen. Daraus wird in der Balladendichtung Goethes (1782) und Schuberts Vertonung - laut Michel Tournier in Frankreich das lyrische »Symbol für Deutschland«. Goethes »Phantasie«, botanische Kenntnisse mit tradierten $\mathrm{Zu}$ schreibungen verbindend, »entzündete sich an einer so genauen und urtümlichen Darstellung der Erle, denn sie ist der schwarze und unheilbringende Baum der stehenden Wasser, so wie die Weide der grüne und freundliche Baum der fließenden Wasser ist. Die Sumpferle beschwört das Bild der nebelverhangenen Ebenen und des trügerischen Bodens des Nordens herauf «, das des hier hausenden, menschen- und besonders kinderverschlingenden Luftgeistes »Erlkönig «. ${ }^{1012}$

Konstruktionen von Organischem im buchstäblichen Sinn. Hier entsteht eine >ur-tümliche Wildheit , die einen authentischen >Volkston « behauptet, >natürliches Genie`, 〉Gewachsenes` gegen das >Künstliche` des Mechanismus setzt. In Herders Denken bereitet sich »die Herausbildung des Gegensatzpaares Mechanismus/Organismus vor«, wenn auch ohne explizite Nennung der Dichotomie. ${ }^{1013}$ Seine Philosophie sei, wie die Schellings, als >profunde antipolitisch ` bezeichnet worden. Die Sphären des Staates und des Politischen werden dem »Toten«, »Unbeseelten«, »Künstlichen« zugeordnet, das eigene »Ideal menschlicher Gemeinschaft « dem »Natürlichen«. Instrumentalisiere der Staat bei Herder »alle Glieder zu Mitteln eines außerhalb seiner selbst liegenden Zweckes«, sei in der >natürlichen Gemeinschaft» »alles Mittel und Zweck zugleich«. Ein »natürliche[r] Staat« wird so zum Paradox erklärt, wobei andere Passagen eine Versöhnung von Staat und »Naturordnung« andeuten, was allerdings stets im Vagen bleibe. Als Idealfall werde aber eine Absorption des Politischen durch die »Natur« als Idealfall vorgestellt. $^{1014}$

1011 Dazu ausführlicher Kap. >Heilige Hallen` II.

1012 Brosse, Jacques: Mythologie der Bäume. Solothurn, Düsseldorf: Walter 1994 (Paris 1989), S. 195f.

1013 Vgl. Stollberg-Rilinger: Der Staat als Maschine, S. 216.

1014 Vgl. ebda., S. $214 f f$. 
Vordergründig scheinen die Konfrontationen klar. Johann Heinrich Gottlob von Justi (1705-1771), einer der »'systematische[n] Vollender der Oekonomischen, Polizei- und Kameralwissenschaften «, ${ }^{1015}$ ordnet unter dem Signum »der großen Maschine des Staates«, der desgleichen »ein einfacher moralischer Körper« ist, den Wald seiner einzigen Funktion als Holzlieferant unter. ${ }^{1016}$ Da zugleich viel Wald Raum für Siedlungen und Nahrungsmittelproduktion koste, eine möglichst zahlreiche Bevölkerung und ihr Wohlstand nach Friedrich II. aber die Stärke eines Staats bestimmen, ${ }^{1017}$ sei das »beste Verhältnis der Waldungen im Land [...], wenn sie nur die gebirgigten und andere unfruchtbare Gegenden einnehmen, die ohne langwierige Kultur zum Ackerbau und Wiesen nicht angewendet werden können; und in der That kann keine Gegend so sehr gebirgigt und unfruchtbar seyn, die nicht zum Wachstum des Holzes genutzt werden könnte« ${ }^{1018}$ Beim (Früh-)Romantiker Ludwig Tieck hingegen erscheint der Wald, in einer Landschaft, die dem Urbanen entgegengesetzt ist, ${ }^{1019}$ als Ort der Einsamkeit, durch $»$ Dichte und Dunkelheit« als Raum »hermetischer Abgeschlossenheit«. Er ist »als entferntester Punkt von der Gesellschaft [...] nicht nur ein Ort der Freiheit, er ist ebenso ein Ort der Mysterien und des Kultischen. Er wird zum Ort des Irrtums und der Verirrung und erscheint als Labyrinth des Unheimlichen«. Ebenso kann diese »Urheimat der Poesie« vom Dämonischen befreit auftauchen. ${ }^{1020}$

Die beschriebenen Unterschiede entspringen nicht einfach einer Dichotomie Staatswissenschaft - Dichtung. In der romantischen Staatskonstruktion des »Organismus« bilden Gesellschaft, Staat und Natur »einen gewachsenen Körper, der sich nicht ungestraft in seine Bestandteile zerlegen läßt«, in dem das Ganze mehr ist als die Summe seiner Teile. Diesem Ganzen »wohnt ein eigener Geist inne, der nicht aus dem Zusammenspiel der Atome (Individuen) zu entwickeln ist, sondern der Totalität selbst angehört«. Diesem »Gewachsene[n], Gewordene[n],

1015 Ebda., S. 79.

1016 Justi, Johann Heinrich Gottlob von: Die Grundfeste zu der Macht und Glückseligkeit der Staaten; zit. n. Morgenthaler, Erwin: Von der Ökonomie der Natur zur Ökologie. Die Entwicklung ökologischen Denkens und seiner sprachlichen Ausdrucksformen. Berlin: Schmidt 2000, S. $139 f$.

1017 Vgl. Sonntag: »Das Verborgene des Herzens«, S. 151.

1018 Justi, a.a.O.

1019 Vgl. Duesberg, Peter: Idylle und Freiheit, S. 356ff.

1020 Vgl. ebda., S. 358f. 
Historische[n] «, das über dem Produzierten und Konstruierten stehe, ${ }^{1021}$ gehören die »Seelenwerte des deutschen Waldes«, dessen »Gegensatz zur Gesellschaft« ein »Gefühl der Freiheit« errege, ${ }^{102}$ offensichtlich an. Es geht also um mehr, als »die Totalität des Individuums «, die es, im Widerspruch zur »Zerstörung von Natur und Individualität« durch die »kapitalistische Arbeitsteilung« per »Versöhnung von Natur und Gesellschaft « wiederzugewinnen gelte. ${ }^{1023}$ Bei Novalis, in seinem Romanfragment »Die Lehrlinge zu Sais« - der sich auf die Statue der Isis (= Natura, Diana, Sphinx) in Sais bezieht ${ }^{1024}$-, kann der Jüngling »die Isis nur finden durch die Unterstützung einer >wunderlichen Frau aus dem Walde $($ (!), die wie Weiland Paracelsus zuerst einmal das gelehrte Buch verbrennt. Nicht die instrumentelle, sezierende Vernunft weist ihm den Weg, sondern die Belebung und Beseelung der toten Natur in einem wechselseitigen Prozeß (ähnlich dem, auf dem die Hexenmagie einst beruhte) führt zum Ziel«, schreibt Bovenschen. »Die Vorstellung einer aktiv-produktiven Beherrschung der Welt im Zuge einer planmäßigen Ausbeutung der Natur war den Romantikern eine Illusion. Daher kann es nicht verwundern, daß das Weiblichkeitsbild der Romantik nicht in der bürgerlichen Diffamierungstradition stand.« Sie verweist hierbei auf eine Ablehnung der rein häuslichen Frauenrolle, wie sie zeitgenössisch bei Rousseau beschrieben werde, da der Romantik die »Frau « näher »an den Quellen der Natur« sei, Quellen einer göttlichen Erkenntnis. Eine zumindest spätere Ambivalenz derartiger Widerstände räumt sie allerdings ein. ${ }^{1025}$

Wie bereits angedeutet, ist eine so schroffe Frontstellung zwischen $>$ Mechanismus` und >Organismus` gar nicht unbedingt vorhanden. Barbara Stollberg-Rilinger zeigt, dass sich spätestens im »Irrationalismus« Adam Müllers, dessen Vorstellungen auch bei befreundeten Konservativen auf Ablehnung stoßen, ${ }^{1026}$ keine Restauration einer »alten ständischen Verfassung« darstelle, »sondern die Rückkehr zum absoluten Staat. Dem entsprechen auch Müllers lebensgeschichtliche Wendungen: Er, der den >Maschinenstaat am emphatischsten verwirft, dient ihm schließlich selbst um so effektiver, indem er sich theoretisch und prak-

1021 Vgl. Sieferle, Rolf Peter: Fortschrittsfeinde? Opposition gegen Technik und Industrie von der Romantik bis zur Gegenwart. München: C.H. Beck 1984, S. 43.

1022 Duesberg, a.a.O., S. 359.

1023 Bovenschen, Silvia: Die aktuelle Hexe, in: Becker, Gabriele et al. (Hg.): Aus der Zeit der Verzweiflung, S. 300.

1024 Vgl. ebda., S. 299.

1025 Vgl. ebda., S. 300ff.

1026 Vgl. Stollberg-Rilinger, a.a.O., S. 236f. 
tisch in den Dienst von Metternichs antiständisch-zentralistischer Politik stellt«. Seine »Polemik gegen die Maschinenmetapher« bestreitet real jede Möglichkeit »eines kritischen Maßstabes« politischer Herrschaft, wie das bei den älteren Theoretikern durchaus der Fall gewesen sei, zugunsten einer »beliebige[n] politische[n] Verfügbarkeit der Theorie «. ${ }^{1027}$ Seiner "» Idee〈 der naturgemäßen monarchistisch-republikanischen Verfassung « ist jegliche Beschränkung des Souveräns »mechanisch«, künstlich. Das »Wirken des Staatsmannes« dürfe durch keinerlei »Schranken« gestört werden. »Freiheit« entstehe, wenn »das Volk >mit erhobener Seele dem reinen Willen des Regierenden entgegen` geht, der allein Gegensätze zur »höhere[n] Harmonie verbindet «. ${ }^{1028}$ Künstlich sei auch die Pauperisierung durch das »allgemeine angeblich liberale Fabriksystem«, wohingegen die »wahrhaft natürliche Ordnung« den »natürlichen Armen« kenne. ${ }^{1029}$ Müllers Staat ist dem Absolutistischen real nah verwandt, da er »Selbstzweck« ist, alle »physischen und geistigen Kräfte« seine Bestandteile sind, eine Gewaltenteilung strikt abgelehnt wird und im Monarchen ein absolutes »Zentrum « besteht. ${ }^{1030}$

Friedrich Schlegel entwirft 1827, inzwischen »vom jugendlichen Freigeist [...] zum kaiserlichen Legationsrat und zum Metternich-Begleiter gewandelt «, ${ }^{1031}$ eine »Philosophie des Lebens «, in der er eine Naturwissenschaft, »welche die ganze Natur mit allen Wundern der Herrlichkeit, die ihr der Schöpfer verliehen hat, wirklich nur als ein totes Uhrwerk betrachtet«, als nicht nur »seichte und oberflächliche«, sondern "grundfalsche« brandmarkt. Würde doch »der Schöpfer selbst« derart »bloß als ein großer mechanischer Künstler« erscheinen, ja als »allmächtiger Uhrmacher« hingestellt, der lauter Totes zusammensetze und in Gang halte. Wenn denn »Gleichnisse auf den Schöpfer der Natur« überhaupt angebracht seien, »so wollen wir ihn doch lieber einem allwissenden Gärtner vergleichen, der aber die Bäume und Blumen, die Er pflanzt, selbst erschaffen hat ${ }^{1032}$ In diesen Passagen, schreibt Martin Burckhardt, werde »die Richtung der Verschiebung sichtbar [...]: vom Mechanismus zum Organismus, von der Ordnung zur Geschichte, von der Statik zur Dynamik«. Das sei »nicht nur eine Revolution der Denkart«, sondern vielmehr »eine Verschiebung des Denkgrundes, der Metabasis: von der Meta-Physik zur Meta-Biologie«. Der »geistige Riß«, der

1027 Ebda., S. 246.

1028 Ebda. S. $244 f$.

1029 Sieferle, a.a.O., S. 52.

1030 Stollberg-Rilinger, a.a.O., S. 245f.

1031 Burckhardt: Metamorphosen, S. 221.

1032 Zit. n. ebda., S. 221f. Vgl. Kap. Das Wirken des Maschinengottes. 
das 19. Jahrhundert vom Vorhergehenden trenne, werde vom »bukolischen Bild des >allwissenden Gärtners«« verdeckt, nehme man dieses im Sinne eines »panlogische[n] Glaubensbekenntnis[ses]« allzu wörtlich. Der den Mechanikergott absetzende Gärtnergott hege und pflege nicht einfach die vorhandene Schöpfung, sondern er verfolge offensichtlich den steten Plan, die Natur, dieses sein Kunstwerk, zu vervollkommnen«. Das sei »ein Streben, das ihn mehr als einen ambitionierten Gentechniker denn als einen allwissenden Gott ausweist «, sei es doch die permanente Nicht-Abgeschlossenheit, »die mit dem Attribut der Allwissenheit kollidiert «. ${ }^{1033}$

Und das erinnere an den »kurzen Gedankenaustausch [...], den der junge Schlegel mit Novalis >symphilosophiert : der Versuch, die Bibel (oder die Enzyklopädie) nicht als ein endliches, sondern als ein unendliches« Gebilde begreifen zu wollen, »als ein evoluierendes, sich an einer Vertikalen hinaufentwickelndes und somit: ausdifferenzierendes Ganzes«. Es zeige sich so ein »höchst dialektische[r] Gott«, mit dem »Wissen um die Prozessualität, die Zeitlichkeit aller Dinge «, der »mehr mit Schellings >Weltseele< oder Hegels >Weltgeist $<$ als mit seinesgleichen gemein hat «. Er entwickle sich und seine Intelligenz parallel zur Hinaufentwicklung seiner Geschöpfe, unterziehe »sein Werk einem beständigen Fort- und Weiterbildungsprogramm, einer divinatio«. So sei dann auch Schlegels >Naturく ein »höchst widerspruchsvolles, vielgestaltiges Wesen«, das jederzeit erscheinen könne »in der Maske der Kunst, der Wissenschaft, der Menschheit, ja selbst der Sprache«. In diesen Masken entäußere sich »die Physiognomie eines höheren, >organischen System-Begriffs «, in dem sich 〉Natur« nicht als »blindes« Geschehen ausgebe, sondern,

»wie der junge Schelling sagt: als das Älteste Systemprogramm. So hat man es bei der Gegenüberstellung von Mechanismus und Organismus zwar mit einer Asymmetrie, aber doch im wesentlichen mit der Gegenüberstellung zweier Systembegriffe zu tun. Der Systembegriff des Organischen verwirft den des Mechanischen nicht, sondern er übersteigt ihn, und zwar dergestalt, daß das Mechanische auch weiterhin, als ein Spezialfall, darin enthalten ist «. ${ }^{1034}$

Schlegels wachsender und sich verzweigender »Baum des Lebens« im >Hortus conclusus` des Gärtner-Gottes habe als Vorläufer-Metapher den »Strom, die verflüssigte Zeit«, Jahrzehnte zuvor bei Herder, der die »Na-

1033 Burckhardt, a.a.O., S. 222f.

1034 Ebda., S. 223f. 
turgeschichte des Menschen« den Prinzipien von »Tradition und organische $[n]$ Kräfte $[n]$ « unterwirft. ${ }^{1035}$

Burckhardt hat dabei etwas Bestimmtes im Blick, die »Geschichte des Computers«. Die setze mit dem Ende »des Räderwerkautomaten« ein. Der Computer sei als »Raum-und-Zeit-Maschine« die Verdinglichung des im frühen 19. Jahrhundert entstehenden »neue[n] Verständnis[ses] von Raum und Zeit« und damit die »Hypostase « des Zeitalters des >Maschinengottes $\prec$. Dieses mechanistische Zeitalter erklärt - mit den Worten René Descartes' - alles Physische zur res extensa, alles ist Uhrwerk, alle Wesen sind »natürliche Automata«. Ein Unterschied zwischen Artefakten und Lebewesen existiert damit nicht. ${ }^{1036}$ Die »universale Maschine« Computer erschöpfe sich, anders als der Räderwerkautomat, »nicht in einem bestimmten Werkzeugcharakter, sondern markiert den Raum, in dem bestimmte (auch künftige, noch nicht entwickelte) Werkzeuge aufbewahrt werden können «. ${ }^{1037}$

Ganz am Ende steht ein »Zeichenkörper«, dem »Hybride seiner selbst« entspringen. Auf diese Weise seien Fortpflanzung und somit »der Zeitprozeß in Vergangenheit und Zukunft« unter ständiger Kontrolle, simuliert in kontrollierter Genealogie. »Der Computer - in dem all dies stattfindet, der all diese Prozesse im Vorhinein zu steuern vermag -, er ist Gebärmaschine, ein Logos spermatikos par excellence. Und sein Geist: ein allwissender Gärtner. « ${ }^{1038}$

»Der Zeichenkörper, ganz in Zeichen aufgelöst, ist beliebig manipulierbar. Hier liegt das entscheidende Novum: daß es möglich ist, Mutanten, Clons und Hybride zu generieren. Es ist der Generations-Abstand dieser Mutanten, es ist die hergestellte, kalkulierte Andersheit dieser hybriden Zeichenkörper, es ist die Möglichkeit, beliebig viele Generationen zu zeugen. An die Stelle des Spiegels tritt der Baum (und so ist es ja nicht von ungefähr, daß die innere Struktur eines Computers auf Baumstrukturen beruht). Die Logik des Zeichenkörpers ist die Logik des Stammbaumes, es ist die Logik der Genealogie. Der Zeichenkörper, in jener Form, in der er digitalisiert, in den Kenotaph des Computers überführt worden ist, ist Stammvater (oder Stammmutter). Er ist, da es keiner Befruchtung durch ein Schwesterwesen mehr bedarf, Hermaphrodit. ${ }^{1039}$

1035 Ebda., S. 224.

1036 Vgl. Kap. Tätige Geometrie.

1037 Burckhardt, a.a.O., S. 309.

1038 Ebda., S. 324ff.

1039 Ebda., S. 325 f. 
Die Logik des binären Codes 0/1, entwickelt und 1854 veröffentlicht von George Boole, basiert auf einer »Besonderheit des Zahlensystems nämlich daß es nur zwei Zahlen gibt, die der Formel $X=X^{2}$ genügen: die Null und die Eins«. Die Null sei das »Nichts«, die Eins das »Universum«, definiert Boole. Das »Nichts« sei »eine Klasse«, das »Universum« ebenfalls, und zwar die, in der »alle Individuen aller Klassen versammelt sind «. ${ }^{1040}$ Aber, die Null genießt eine übergeordnete Unantastbarkeit, wie Erwin Schrödinger beschreibt. Sie habe als einzige Zahl eine »Art königliche[s] Privileg», es ist »verboten, durch Null zu dividieren - ebenso wie z.B. in vielen Parlamenten jeder Gegenstand diskutiert werden darf mit Ausnahme der Person des Herrschers. Teilt man durch Null, erhält man gewöhnlich ein unsinniges Ergebnis«. Also »muß man sich vergewissern, daß der Divisor nicht >von königlichem Blut< ist«. Andererseits kann »königliches Blut einzig wieder von königlichem Blut (durch Multiplikation) entstehen«. So ergibt die Multiplikation mit Null stets Null. ${ }^{1041}$

Booles binäre Logik des 0/1, so Burckhardt, sei nur Reflektion und Formalisierung dessen, »was mit der `Systemphilosophie〈 der Romantik bereits ein halbes Jahrhundert zuvor ins Denken gedrungen ist. Dazu ein kleines Novalis-Zitat: >Gott ist bald $1 \cdot \infty-$ bald $1 / \infty-$ bald $0 . \ll{ }^{1042}$ Novalis, selbst Naturwissenschaftler, erklärt die Denkorgane zu »Welterzeugungsorgane[n] « und daher zu »Naturgeschlechtsteile[n] . Die Mathematik sei der »vollgültigste Zeuge des Naturidealism«, der »Hauptbeweis der Sympathie und Identität der Natur und des Gemüts «. ${ }^{1043}$ Anders, als bei Goethe, Tieck, Schleiermacher, wird bei Novalis, ähnlich bei Schlegel, das Unendliche mathematisch erfassbar, ausdrückbar. »Die Logik der Mathematik als Logik des Ursprungs. « So lässt sich dann »Potenzierung und Logarithmisierung einsetzen, um den >ursprünglichen Sinn zen «. ${ }^{1044}$ Schlegel beschreibt die Geometrie als »ins innerste Wesen der Poesie verflochten «. ${ }^{1045}$ Die Poesie wird somit zur »systembildenden Form «. ${ }^{1046}$ Otto F. Best:

1040 Ebda., S. 318f.

1041 Schrödinger, Erwin: Struktur der Raum-Zeit; zit. n. ebda., S. 390, Anm. 374.

1042 Ebda., S. 390, Anm. 375.

1043 Zit. n. Best, Otto F.: Die blaue Blume im englischen Garten, S. 173.

1044 Ebda., S. 168f. u. 172.

1045 Zit. n. ebda., S. 171.

1046 Best, ebda., S. 172. 
»Daß aus der Setzung einer einzigen Beziehung, nämlich der Hinzufügung einer Einheit, der Eins, zu der Besetzungsgrundlage Null, die natürliche Zahlenreihe $0,1,2,3 \ldots$ entstanden ist, braucht kaum erwähnt zu werden. Sie ist erzeugt oder sie erzeugt sich selbst, fortschreitend ins Unendliche aus einer einzigen Relation, die man +1 bezeichnen kann. Ihr Sein, ihre Existenz beglaubigt sich allein aus dem Gesetz der progressiven Relation, das seinen Ursprung im reinen, synthetischen Denkprinzip hat.«

Es sei die »Synthesis«, die die »erzeugende Relation« logisch ermögliche. ${ }^{1047}$ Da ist nicht ganz nachvollziehbar, wenn Werner Künzel und Peter Bexte einen programmatischen Text von Lady Ada Lovelace, Tochter Lord Byrons, Mathematikerin und »erste Programmiererin der Welt « als Charles Babbages’ Mitarbeiterin bei der Herstellung der »Difference Engine« und der »Analytic Engine« vorstellen und sie betonen: »Man beachte, daß es eine romantische Frau war, welche diesen unerhörten Gedanken äußerte! « ${ }^{1048}$

In ihrem Text zur »Analytic Engine« (1842/43) spricht Lovelace davon, dass diese Maschine »die Fleisch gewordene Wissenschaft von den Operationen« sei, »besonders im Hinblick auf abstrakte Zahlen«. Sie erklärt, »daß wir mit dem Begriff Operationen jeden Prozeß meinen, der das wechselseitige Verhältnis von zwei oder mehr Dingen ändert, unabhängig von der Art dieser Relation. Das wäre die allgemeinste Definition, die sämtliche Gegenstände des Universums einschlösse...«. ${ }^{1049}$ Etwas »eigentümlich Schwärmerisches, ganz Unmathematisches« spreche aus diesem Text. »Romantische Sprachgewalt [...] in poetischen Wendungen: den Schleier der Isis von den Mysterien der Natur zu heben, Gottes Schöpfung lesbar zu machen, und zwar maschinenlesbar.« Es gehe um die Hoffnung, alles Symbolisierbare automatisch rechenbar« zu machen. Die $»$ Konsequenzen dieser Entgrenzung lösen den Taumel des schier Unabsehbaren aus«, kommentieren Künzel/Bexte. ${ }^{1050}$

Den Konventionen entsprechend verbirgt Lovelace sich bzw. ihren programmatischen Text hinter einem männlichen Pseudonym und im Anmerkungs-Apparat des vergleichsweise bedeutungslosen Textes (den sie ins Englische übersetzt) eines heute praktisch vergessenen Mannes.

1047 Ebda., S. 171.

1048 Künzel, Werner/Bexte, Peter: Maschinendenken/Denkmaschinen. An den Schaltstellen zweier Kulturen. Frankfurt/M, Leipzig: Insel 1996, S. 107.

1049 Zit. n. ebda., S. 114ff.

1050 Vgl. ebda., S. $107 \mathrm{ff}$. 
Bekannt aber ist die Lady, wenn auch überwiegend in digitalisierter Auflösung, entkörperlicht als Computersprache »ADA«. ${ }^{1051}$

Babbages »Analytic Engine« basiert auf der Jacquardmaschine, dem von Lochkarten gesteuerten französischen Webstuhl aus dem 18. Jahrhundert, mit dem sich beliebige Muster erzeugen lassen. ${ }^{1052}$ Ist die materielle Maschine Jacquards so vom Programm entkoppelt, dass sie zur »Leseapparatur« wird, die beliebig viele Muster verarbeiten kann, will Babbage den »Prozeß des Einlesens und des Ausarbeitens« schließen. Die Maschine soll von Lochkarten gesteuert Lochkarten schreiben, mit diesen gefüttert werden usw., kurz, einen »Kreislauf der Schrift« erzeugen. ${ }^{1053}$ Hier geht es um »ein Unendlichkeitskalkül«, nicht in strikter Kontinuität, sondern mit einer Maschine, die »Diskontinuitäten zu bewältigen vermag «. ${ }^{1054}$ Den Code, die Welt in Zeichen aufzulösen, hat er aber nicht und nimmt ihn auch nicht zur Kenntnis.

Pierre Lévy bemerkt zu Charles Babbage: »Ob man ihn als Erfinder, Begründer oder Vorläufer betrachtet - stets wird das Handeln des großen Mannes auf die Zukunft hin entworfen. Es kündigt an, es geht voraus, es leitet ein. Doch eine Umkehrung der Blickrichtung würde zeigen, daß der Begründer zugleich ein Erbe ist, der eine Menge von Ideen und Materialien, die zu seiner Zeit bereits verfügbar waren, benutzt, umwidmet und für eigene Zwecke verwendet. « ${ }^{1055}$ Darauf kommt es an. Was sich zeigen lässt, sind »Wiederverwendungen, Entlehnungen und Umwidmungen «, ${ }^{1056}$ ist ein diskontinuierlicher historischer Prozess der Umwandlung von Körper in Zeichen, des Ersatzes des Organischen im »Innern der Apparaturen «. ${ }^{1057}$ Es geht um

»eine Art löchriges, zerrissenes, unregelmäßiges Meta-Netz, in dem jeder Knoten, das heißt jeder Akteur, die Topologie seines eigenen Netzes seinen eigenen Zielen entsprechend bestimmt und alles, was von den benachbarten Knoten zu ihm gelangt, nach seiner Weise deutet. Jeder lebendige Knoten dieses Geflechts reinterpretiert die Vergangenheit, die ihm von den anderen überliefert wird, als müßte sie geradewegs auf die eigene Entscheidung zulaufen, und entwirft eine Zukunft, in der sich seine Optionen geradlinig fortsetzen.

1051 Vgl. ebda., S. 107.

1052 Vgl. Lévy, Pierre: Die Erfindung des Computers, in: Serres, Michel (Hg.): Elemente einer Geschichte der Wissenschaft, S. 911; Künzel/Bexte, a.a.O., S. 92.

1053 Burckhardt, a.a.O., S. 316.

1054 Ebda., S. 314.

1055 Lévy, a.a.O., S. 910 f.

1056 Ebda., S. 912.

1057 Gendolla, Peter: Geregeltes Begehren, in: Kamper, Dietmar/Wulf, Christoph (Hg.): Die Wiederkehr des Körpers, S. 171. 
Doch diese Zukunft liegt, ebenso wie das Bild der Vergangenheit, wieder in der Hand der nachfolgenden Knoten, und so ad infinitum «. ${ }^{1058}$

Was aber nichts an bestimmten romantischen Prämissen, der Gestalt des »Romantiker[s] als Logiker und Systematiker« ändert. ${ }^{1059}$ Es sei die

»Vorstellung eines der Natur innervierten höheren Systems, die dem Bild des sallwissenden Gärtners innewohnt - ja, es ist recht eigentlich die gedankliche Sprengkraft dieses Ältesten Systemprogramms (und keineswegs ein gefühliges `Zurück zur Natur`), was die Vielgestaltigkeit des romantischen Naturbegriffs und seine Verästelungen in ein ganzes Wissenstableau begreiflich macht«, ${ }^{1060}$

resümiert Burckhardt.

Die Natur als mathematisch erzeugte Abfolge unendlicher Merkmalskombinationen fungiert in dieser, aber auch anderer Weise als >unendliches Geheimnis $\measuredangle$. Das führt an `Schwellen`, ins Dunkle, Tiefe, Verschlingende, in die Nacht und ins Wasser und wieder heraus ins Leben von Maschinen, auch dieses ist »scheinhafte[s] Sein«, ${ }^{1061}$ das herabzieht in Sinnenstrudel, ins Ungewisse. Jacques Brosse erinnert an die Wiederkehr von Elfen, Feen und Undinen (im Verein mit Zwergen) als Protagonisten in den seit 1813 von E.T.A. Hoffmann und bis 1822 von den Grimms gesammelten Märchen. ${ }^{1062}$ Auch die Grimms reklamieren in ihrer Vorrede, Zugänge zu den 〉Ursprüngen〈 zu erhalten, zu dem, »was in früherer Zeit geblüht hat«, von dem so wenig übrig geblieben sei.

»Es war vielleicht gerade Zeit, diese Märchen festzuhalten, da diejenigen, die sie bewahren sollen, immer seltener werden [...]. Der epische Grund der Volksdichtung gleicht dem durch die ganze Natur in mannigfachen Abstufungen verbreiteten Grün, das sättigt und sänftigt, ohne je zu ermüden«. ${ }^{1063}$

»Ammenmärchen« werden diese Erzählungen genannt, in dem Glauben, »in ihnen Bruchstücke einer antiken Weisheit wiederzufinden«. Geburtshelferinnen, >weise Frauen, die diese Funktion auch in antiken Mythen ausüben, die als reale Hebammen frühneuzeitlich als Hexen verfolgt werden (können); in den Märchen der Grimms sitzen sie oft am Spinn-

1058 Lévy, a.a.O., S. 943.

1059 Best, a.a.O., S. 171.

1060 Burckhardt, a.a.O., S. 224.

1061 Söntgen, Beate: Täuschungsmanöver. Kunstpuppe - Weiblichkeit - Malerei, in: Müller-Tamm, Pia/Sykora, Katharina (Hg.): Puppen - Körper Automaten. Phantasmen der Moderne. Köln: Oktagon 1999, S. 125.

1062 Vgl. Brosse, a.a.O., S. 196f.

1063 Zit. n. ebda., S. 197. 
rad, sind zauberkundig, wissend, stehen »in enge[r] Verbindung mit den dunklen Kräften des Lebens «. ${ }^{1064}$ Offensichtlich geht es um die >Geheimnisse « der Geburt und des Todes, wie stets in Verbindung mit derartigen weiblichen Gestalten. Geheimnisse von Leben und Tod werden auch mit dem Wasser als zentralem »Ausdrucksträger des romantischen Naturgefühls $«{ }^{1065}$ verbunden.

»Die Unergründlichkeit und Faszination, die von diesem - zugleich abstoßenden und anziehenden - Element ausging, wurde gerne mit der Anwesenheit einer Nixe, Meerfei und dergleichen unterstrichen. Auffallend oft entbehren sie allerdings ihres Fischschwanzes bzw. scheint dieses charakteristische Merkmal weder einer gesonderten Erwähnung zu bedürfen, noch taucht es allzu häufig in bildlichen Paraphrasierungen auf. Offensichtlich genügte dem in die Betrachtung der Natur Versunkenen und über sich selbst Reflektierenden allein die Idee von der Wesenheit der Nixe bzw. die Assoziation Weiblichkeit - Wasser, um ein fast uferloses Spektrum an Gefühlen aufwallen zu lassen. ${ }^{1066}$

Jakob Grimm verzeichnet 1835 in seiner »Deutschen Mythologie« auf der Suche nach den »Urgründen« eine »schon damals ins Uferlose angewachsene Flut von Titeln und Bezeichnungen für >Meerfeiく allein im nordisch-deutschen Raum«, demgegenüber aber nur relativ wenige überlieferte Sagen. Ein »Defizit« beheben »die Romantiker und ihre Apologeten mit einigen folgenreichen Märcheninnovationen «. ${ }^{1067}$ Entlehnt auch aus Erzählungen der Volkskultur - hier kommen Wasserfrauen vor, die sich in der menschlichen Gesellschaft assimilieren, und etwa »kreißenden Menschenfrauen als Geburtshelferin und >Wehmutter hilfreich zur Seite« stehen - halten die überlieferten Elementargeister, besonders die der Gewässer einen »(legitimierten) Einzug in die Hochkultur«. ${ }^{1068}$ Und so fließt die literarische Produktion über von lockenden Frauen mit feuchten Haaren, die die männlichen Protagonisten in ihr Element zu sich herabziehen - oder damit drohen: die »Lockung« bei Goethe, die »Sirenen« bei Eichendorf, Tiecks »Melusine«, de la Motte Fouqués »Undine« usw. Sie locken und ziehen (ins Verderben) auch in der Malerei der Spätromantik, des Symbolismus und des Jugendstil; zunehmend bedrohlichere, böse Ströme, die aussaugen, Vampirinnen, Femmes fatales.

1064 Brosse, ebda.

1065 Bessler, Gabriele: Von Nixen und Wasserfrauen, S. 110.

1066 Ebda., S. $110 f$.

1067 Ebda., S. 124f.

1068 Ebda., S. $112 f$. 
All die Versprechungen, ausgetragen auf den Körpern sunendlicher Frauen`, in der (literarischen) »Zentrierung« der Frau auf ihre Sexualität im 18. Jahrhundert, die »eine Zentrierung auf die primären Geschlechtsmerkmale der Frau zur Folge« habe, ${ }^{1069}$ schreibt Theweleit, beginnen sich zu rächen. Zuvor ist es noch der allfällig lockende, magnetische »Schooß«, werden Meere »beschifft« und werden nie versiegende Brunnen als »diesseitig[e] Paradies[e]« beschworen. Hier »wird die Vagina zum utopischen Ort des Nicht-Mangels, wobei es letztlich gleichgültig ist, an welcher Frau sie sich befindet, so es nur eine hohe Schöne ist«, denn: »Die ganze Welt ist weniger als sie. $«{ }^{1070} \mathrm{Im}$ 19. Jahrhundert schlägt die zwischenzeitliche Lockerung des Frauenbilds in Adel und Bürgertum endgültig wieder um. Beginnend im »normativen Weiblichkeitsdiskurs des 18. Jahrhunderts«, der sich »zugleich als ein umfassendes Bildungsprogramm« darstelle, so Beatrix Niemeyer, erscheine der »sogenannte >natürliche` Beruf der bürgerlichen Frau, nämlich Hausfrau, Gattin und Mutter zu sein [...] auch ihr selbst schließlich als >Berufung`; die >Gewöhnung an Selbstverleugnung`, wie unter anderem Campe sie propagiert hatte, war eine Voraussetzung dafür «. ${ }^{1071}$

Ist es zuvor die »Veröffentlichung« der Frauen, so folgt nun, mit der »Machtentfaltung der europäischen Bourgeoisie (in Deutschland im Verein mit dem Adel)«, verbunden mit einer »Beschränkung der freiheitlichen Produktionsmöglichkeiten«, ihre »verordnete Verheimlichung«. Denn wieder werde dies mit dem »Territorium[] der weiblichen Körper« codiert. Die erfolgreiche Verankerung der vorhergehenden »Codierung der politischen und ästhetischen Utopien mit dem Frauenkörper im Fühlen der Männer« äußere sich spezifisch gegen diese >unendlichen Frauen`. Der Vorwurf falscher Versprechungen, des >Betrugs $\measuredangle$, die Rache richte sich nun literarisch gegen die Frauen, die zu »verschlingende[n] Dämone[n] «, zu Selbstmörderinnen im Wasser werden. In Lautreamonts »Gesang vom Ozean« richte sich die Rache gegen »das Prinzip des Fließens selber«. Er spricht von den »kristallenen Wogen« des »alte[n] Ozean[s]«:

»Die Flüsse sind geschlossen, in denen der Körper seinen Panzer auflösen und verlieren könnte. Aller eingeengte Wunsch beginnt in zu engen Räumen gefährliche Strömungen zu bekommen; unter dem Druck wachsenden Staus rich-

1069 Theweleit: Männerphantasien 1, S. 439.

1070 Ebda., S. 440f.

1071 Niemeyer, a.a.O., S. 195. 
tet sich das Interesse nach Innen und auf Vorgänge wie Ausbrüche, Durchbrüche, Einbrüche... « ${ }^{1072}$

Es sind nun »böse Ströme« und »Abgründe«, die pulsieren. Erstarrende Flüsse und »kristallene Wogen« als Rache für die >Täuschung` sind gleichzeitig aber auch Kennzeichen des >Betrugs $<$. Auch, wenn es männliche Automaten gegeben habe, so seien sie, »zumindest seit der Romantik, meist weiblich«, schreibt Beate Söntgen. Und hier, im »weiblichen Kunstmenschen aber kristallisiert [...] das Wesen des Automaten, der Puppe: die Fähigkeit zu täuschen«. Ein Vermögen, das »auf verschiedenen Ebenen« spiele, vor allem in der Verwischung der Differenz von »Natürlichem und Künstlichem«, von »Belebtem und Unbelebtem «. ${ }^{1073}$

Derartige Automaten-Frauen bezeichnen eine wesentliche gesellschaftliche `Schnittstelle`.

»Das scheinhafte Sein, das dem Weiblichen seit dem Ende des 18. Jahrhunderts zugeschrieben wird, verleiht der künstlichen Frau eine paradoxe Natürlichkeit. Trügerisch natürlich dient die weibliche Puppe vor allem den narzißtischen Strebungen ihres männlichen Schöpfers. Als komplementäres Anderes entworfen und nach dem Ideal der Vollkommenheit gebildet, nährt sie dessen Illusion eigener Ganzheit und Identität. Wie ein Fetisch täuscht die Puppe über den Mangel hinweg, den sie als weibliche Gestalt verkörpert. « ${ }^{1074}$

Söntgen beschreibt das am Beispiel von E.T.A. Hoffmanns »Der Sandmann«, in dem der Protagonist Nathanael sich in die Puppe Olimpia verliebt, deren Künstlichkeit er als einziger nicht bemerkt. Anderen kommt sie »seltsam starr und kalt« vor. Nathanael aber verleiht ihren Augen, indem er durch ein immer schärfer gestelltes Taschenfernrohr blickt, eine >feurige Liebesglut<, nimmt das von ihr einzig beherrschte Wort »Ach« als »Liebeslaut schlechthin« und beschimpft im Gegenzug seine Verlobte Klara als »lebloses, verdammtes Automat $\ll .{ }^{1075}$ Die Geschichte wird von Söntgen weitgehend in der Lesart Freuds interpretiert. Danach liege das Unheimliche nicht so sehr in der Verwechslung von Künstlichem und Lebendigem, sondern in der zwanghaften Wiederholung eines ödipalen Konflikts und seiner Materialisation im Puppenkörper, was die

1072 Theweleit, a.a.O., S. 456f.

1073 Söntgen, a.a.O., S. 125.

1074 Ebda.

1075 Ebda., S. 126f. Vgl. Hille, Karoline: »... über den Grenzen, mitten in Nüchternheit«. Prothesenkörper, Maschinenherzen, Automatenhirne, in: Müller-Tamm, Pia/Sykora, Katharina (Hg.): Puppen - Körper - Automaten, S. 142f. 
Figur des Sandmanns als dämonisches Vaterimago verdeutliche. Der Sandmann bedroht das Kind Nathanael mit Blendung (`Kastration২), renkt ihm die Glieder aus, um sie neu zu montieren. Die Puppe sei daher »eine narzißtische Projektion, die Nathanaels feminine Einstellung zum Vater sichtbar mache, und nun, in Gestalt eines weiblichen Anderen, zwanghafte Liebe hervorrufe. ${ }^{1076}$ Nun ist es am Ende der (für Nathanael) tödlichen Geschichte Olimpia, die mittels herausgerissener Augen wächsern und tot wirkt ${ }^{1077}$ - >kastriert $<$ - und die Verbindung von Augen und Genitalien gehört zu historisch bereits sehr alten Vorstellungen. Das lässt aber zumindest den sozialen Kontext um 1800 außer Acht. Denn wenn nach dem Ende der alten Einkörpertheorie (die jedoch in Freuds >Kastrationskomplex` die Rolle des Wiedergängers spielt ${ }^{1078}$ ) die Frau einen eigenen, vollkommenen Körper erhält, wenn bis 1790 die ersten Zeichnungen des weiblichen Skeletts auftauchen, ${ }^{1079}$ dann kann gerade die Puppe als vollkommenes »komplementäres Anderes« zur Entsprechung dieses weiblichen Körpers werden. In diese Richtung weist Söntgen letztlich selbst:

»Die Implantation des `Natürlichen` und des Künstlichen in den weiblichen Körper und seine Bilder wurzelt, wie Katharina Sykora nachgewiesen hat, im 18. Jahrhundert. Seitdem galt der weibliche Körper als Inbild des Natürlichen. $\mathrm{Da}$ der `natürlicheく Körper jedoch ebenfalls ein konstruierter ist, wird durch >raffinierte, sich selbst verleugnende Künstlichkeit verborgen`. Die Folge dieses Paradoxons eines >natürlichen` Körperbildes ist eine Verwirrung der Kategorien, die in Bezug auf die Puppe einen gemischten Effekt hat. Die Ununterscheidbarkeit des Natürlichen und Künstlichen im Weiblichen verlebendigt die weibliche Puppe, die gerade als künstliche Frau natürlich wirkt. In dieser kategorialen Unentscheidbarkeit liegt aber zugleich eine Irritation, die zersetzend auf das Identitätsstreben des Puppenliebhabers wirkt. « ${ }^{1080}$

Zwar geistern auch bedrohliche männliche Automaten durch die zeitgenössische Literatur, wie der geheimnisvolle >Türke < in Hoffmanns »Die Automate« von 1814, oder fünf Jahre später bei Daniel Ludwig Jassoy »ein ganzes Bestiarium« von »buckelnden und tretenden Automaten: Soldaten, Generäle, Minister, Diplomaten, Kunstforscher, Mystiker, Poeten und viele mehr«. ${ }^{1081}$ Dass aber gerade weibliche Automaten domi-

1076 Vgl. Söntgen, a.a.O., S. 127.

1077 Vgl. Hille, a.a.O.

1078 Vgl. Einleitung.

1079 Vgl. Schiebinger, Londa: Schöne Geister, S. 270f.

1080 Söntgen, a.a.O., S. 129f.

1081 Hille, a.a.O. 
nieren, scheint mit dem `neuen Geheimnis` der Frau zusammenzuhängen, die nun nicht mehr als >Mängelexemplar` einer einzigen existierenden Physis, sondern als Andere entworfen wird. Die Künstlichkeit der im 18. Jahrhundert real existierenden Räderwerkspuppen (als >vernünftige Ablösungen der vorher grassierenden magisch animierten Androiden, Golems, Homunculi, Alraunen usw.) soll gar nicht verborgen bleiben. Bei derartigen Rokoko-Puppen werden die Uhrwerke nicht versteckt, im Gegenteil solle ihr Anblick zum >Geheimnis ২ beitragen, einem Geheimnis, das sich per Vernunft lösen lässt. ${ }^{1082}$ Anders im literarischen Programm der $»$ Rätselfrau ${ }^{1083}$ des 19. Jahrhunderts. Hier wächst sich das >Mechanische $<$ in der weiblichen Variante zur Bedrohung aus, zur »toten Lebendigkeit « ${ }^{1084}$ - schon gar in seiner Ununterscheidbarkeit vom >Organischen`. Die Unheimlichkeit der >erotisch lockenden` Puppe entstammt ihrer >Ähnlichkeitく zur nun physisch anderen Frau. Dieses Zwillingspaar repräsentiert das >Andere` des >organisch` sich entwerfenden Mannes.

Die Opposition gegen den Mechanismus, den absolutistischen Maschinenstaat äußert sich oft vor allem gegen deren weibliches Personal. So in der Propaganda zur Französischen Revolution in den Bildern einer >organischen` Marianne und einer `Sexmaschine` Marie-Antoinette. Marianne, mit stets milchprallen Brüsten, »lebensspendende[n] Tugenden«, ausgestattet, mit einem mütterlichen, »großzügige[n], überfließende[n] und fruchtbare[n] weibliche[n] Körper« wird zum Kontrastbild zur flachbrüstigen, damit »lustversessene[n] und halbwüchsige[n] «, zur Mütterlichkeit unfähigen Königin, der nachgesagt wird, sie treibe es mit ihren Hofdamen und bringe ihrem Sohn die Masturbation bei, und ihn damit, gemäß der Lehre Tissots, um seine Gesundheit. ${ }^{1085}$

Unter Bezug auf Jean-Marie Villiers de Isle Adams Roman »Die neue Eva« (1886), in der ein fiktiver Thomas Alva Edison das perfekte Automatendouble einer hysterischen Opernsängerin schafft, sie so »wieder zum unbeschriebenen Körper-Zeichen« macht, »damit sie sich neu programmieren läßt«, ${ }^{1086}$ betont Manfred Schneider die Chimäre des >or-

1082 Vgl. ebda.

1083 Schneider, Manfred: Liebe und Betrug. Die Sprachen des Verlangens. München: dtv 1994 (München, Wien: Hanser 1992), S. 89.

1084 Hille, a.a.O., S. 143.

1085 Vgl. Sennett, Richard: Fleisch und Stein, S. 360. Zur Genese der AntiOnanie-Kampagnen seit Mitte des 18. Jahrhunderts vgl. Braun, Karl: Die Krankheit Onania.

1086 Schneider, a.a.O. 
ganischenく männlichen Selbstentwurfs: »Frauen sind das Programm, durch das sich Männer selbst automatisieren. « ${ }^{1087}$

\section{\Wildnis` als Wurzel der Volksgemeinschaft und Wildniß, als utopische ständische Idylle}

»Jahrhundertelang war es eine Sache des Fortschrittes, das Recht des Feldes einseitig zu vertreten; jetzt ist es dagegen auch eine Sache des Fortschrittes, das Recht der Wildnis zu vertreten neben dem Rechte des Ackerlandes. Und wenn sich der Volkswirt noch sehr sträubt und empört über diese Tatsache, so muß der volksforschende Sozialpolitiker trotzdem beharren und kämpfen auch für das Recht der Wildnis. « ${ }^{1088}$

Mitte des 19. Jahrhunderts entstehen zwei voneinander unabhängige >organische< Entwürfe einer >konservativen Wildnis` als Bedingung >beharrender`, ständischer Gesellschaftsverhältnisse. Während Wilhelm Heinrich Riehl, der sozusagen die Volkskunde erfindet, allerdings von einem ständigen Kampf um den Wald spricht, gerät dieser Wald bei Adalbert Stifter zur realitätsverleugnenden Idylle. Beide sind »in der fortschrittsbegeisterten Epoche der rapiden Industrialisierung « ${ }^{1089} \mathrm{Au}$ ßenseiter, werden aber für die Zukunft enorm einflussreich sein.

»In der Urwildnis rodet der erste Siedler: er schafft den Gegensatz von Feld und Wald und hebt damit das Verhältnis von Land und Leuten über die Linie der uranfänglichen bestialischen Natürlichkeit. Nur wo Feld und Wald ist, hört das Nomadentum auf, da bildet der Boden selbst den Grund organischer Gesellschaftszustände. $«^{1090}$

Wenn also Wilhelm Heinrich Riehl 1853 sein berühmtes »Recht auf Wildnis« propagiert, dann ist die Frage, was diese >Wildnis schon beantwortet. >Organische Gesellschaftszuständeく entstehen aufgrund von Unterwerfung der »uranfänglichen bestialischen« Natur und ihrer rastlosen Nichtsesshaftigkeit. Organisch ist erst die >Verwurzelung in der Scholle`, wie das in den folgenden publizistisch-literarischen Äußerungen der Heimatbewegung heißen wird.

Oswald Spengler spricht später vom »pflanzenhaften Drange des Blutes, das sich fortpflanzen will«, von der »Seele eines Bauern, der von

1087 Ebda., S. 87.

1088 Riehl, Wilhelm Heinrich: Land und Leute. Stuttgart, Berlin: Cotta $1908^{11}$, S. 62.

1089 Sieferle: Fortschrittsfeinde?, S. 149.

1090 Riehl, a.a.O., S. 65. 
Urzeiten her auf seiner Scholle sitzt oder von ihr Besitz ergriffen hat, um dort mit seinem Blute zu haften. Er wurzelt hier als der Enkel von Ahnen und der Ahn von künftigen Enkeln«. Dieses >Pflanzenhafteく wird aufgezehrt durch die »über alles Maß angespannte tierhafte Lebensseite« in den Großstädten der Moderne, mehr noch aber durch ein »Wachsein«, das »die Gewohnheit einer kausalen Regelung des Daseins annimmt«. Diese 〉Zivilisation Nachwuchs nun nach kausalen Begründungen verlange. »Die Natur kennt keine Gründe. Überall, wo es wirklich Leben gibt, herrscht eine innere organische Logik, ein >es`, ein Trieb, [...] vom Wachsein und dessen kausalen Verkettungen« unbemerkt. »Der Geburtenreichtum ursprünglicher Bevölkerung ist eine Naturerscheinung«, völlig unreflektiert. Dem Höhepunkt der Zivilisation aber folge zwangsläufig »das mehrhundertjährige Stadium einer entsetzlichen Entvölkerung«. Schließlich bleibe nur noch »das primitive Blut« übrig. Es entsteht der Typus des Fellachen «. ${ }^{1091}$ Ein Zurück zum Nomadentum demnach.

Bei Riehl ist die »landfeste[] Bevölkerung « Spenglers ${ }^{1092}$ bereits vorhanden, das >Pflanzenhafte ebenso, das nur einer >inneren organischen Logik folgt. Anders als die kulturpessimistische Publizistik nach 1900 jedoch erscheint bei ihm die Industrialisierung zwar als »ernstzunehmende Bedrohung«, aber noch nicht als »unausweichliches Schicksal«, noch »war ihr [...] mit staatlichen Maßnahmen zu begegnen ${ }^{1093}$ Denn aus der »deutschen Waldfreiheit, die so fremdartig aus unsern übrigen modernen Zuständen hervorlugt, strömt tieferer Einfluß auf Sitte und Charakter aller Volksschichten, als mancher Stubensitzer sich träumen läßt«. ${ }^{1094}$ Diese »Waldfreiheit« entstamme der »echt altgermanische[n]« Idee einer »Gütergemeinschaft des Waldes«. Ein »letztes überlebendes Stück Mittelalter« sei dieser Wald »mit seinen Gerechtsamen und Servituten«. Dieses »feudale Element» habe dem Landvolk »echt mittelalterlich« eine »Beisteuer« durch Laubsammeln und Holzlesen gesichert. Das sei »die Wurzel echt deutscher sozialer Zustände«, ein »nahezu kommunistisches Herkommen« im wohlverstandenen Sinn. Jeder »Demagoge« aber wisse, »daß man zuerst den Wald niederhauen muß, wenn man mit dem Mittelalter in Deutschland aufräumen will «. ${ }^{1095}$

Riehl schreibt die »Naturgeschichte des Volkes als Grundlage einer deutschen Sozialpolitik«. Das heißt, im Rahmen »seiner brisanten volks-

1091 Spengler: Der Untergang des Abendlandes, S. 679f.

1092 Ebda.

1093 Sieferle, a.a.O., S. 150.

1094 Riehl, a.a.O., S. 55.

1095 Ebda., S. $47 \mathrm{ff}$. 
psychologischen und mentalitätsgeschichtlichen Ideen« (wie Albrecht Lehmann das etwas eigenartig nennt, ${ }^{1096}$ ist doch unter Mentalitätsgeschichte etwas anderes zu verstehen), entwirft er eine wechselseitige Entsprechung bzw. Bedingung von Wald und Volk auf allen Ebenen, die er gefährdet sieht durch eigentlich >fremde` Kräfte und Mechanismen: Demokratie, Industrialisierung und Proletarisierung, wobei hier »im Grunde das Wahrnehmungsmuster der Pauperismuskritik noch nicht verlassen « wird. ${ }^{1097}$

Die Landschaft teilt er in »die zahme und die wilde Kultur unseres Bodens $«{ }^{1098}$ Beide seien unverzichtbarer Garant für das Überleben der Nation, das Feld aus ökonomischen, der Wald aus sozialpolitischen Gründen, hänge doch der Nationalcharakter davon ab: »Ein Volk muß absterben, wenn es nicht mehr zurückgreifen kann zu den Hintersassen in den Wäldern, um sich bei ihnen neue Kraft des natürlichen, rohen Volkstumes zu holen. ${ }^{1099}$

Als »erratischer Block« stehe Riehl mit seiner »vielleicht radikalste[n] modernisierungskritische[n] Position « in dieser Epoche der Industrialisierung, schreibt Sieferle. Gefahr droht hier durch den »vierten Stand «, das Proletariat, wobei sich hier hinter dem Begriff weniger ein konkrete soziale Klasse verbirgt, als vielmehr »eine Tendenz, die er wirken sieht und die sich in diesem Stand materialisiert«. Diesem »vierte[n] Stand « Einhalt gebieten sollen die >Kräfte des Beharrens $`$, die in Land, Sitte und Tradition verwurzelten Bauern als Garanten eines Konservativismus, immun gegen nivellierende »[u]npractische Theorien« wie Kommunismus oder Demokratie. ${ }^{1100}$ Aber auch sie seien bedroht von Industrialisierung und Proletarisierung, denn je mehr »die Ackererzeugnisse Gegenstand der Speculation werden, den großen Verkehrskrisen preisgegeben, umso mehr tritt auch der Bauer, den es trifft, aus seinem ursprünglichen Charakter heraus «. ${ }^{1101}$ Mehrfach verweist Riehl auf die massenhaften Waldplünderungen durch den Pöbel einer proletarisierten Landbevölkerung: »Im Jahre 1848 ward gar manches mächtige Stück Wald geopfert, um ein kleines Stückchen Popularität damit einzukaufen. Jede Revolution tut dem Wald weh; sie wird dagegen das Feld unberührt lassen, wofern sie sich nicht selber erwürgen will. ${ }^{1102}$ Die Industrie sei ein viel größerer Einebner gesellschaftlicher Gegensätze »als es alle so-

1096 Vgl. Lehmann, Albrecht: Von Menschen und Bäumen, S. 27.

1097 Sieferle, a.a.O., S. 151.

1098 Riehl, a.a.O., S. 45.

1099 Ebda., S. 52.

1100 Vgl. Sieferle, a.a.O., S. 149.

1101 Riehl: Die bürgerliche Gesellschaft (1856); zit. n. Sieferle, ebda., S. 150.

1102 Ders.: Land und Leute, S. 46. 
cialen Theorien vermögen«. Die einseitige Bevorzugung des »Industrialismus würde alle Individualität der Gruppen des socialen Lebens zerstören, was nur die völlige Erschlaffung und Entartung der Nation zur Folge haben könnte«. ${ }^{1103}$ Und sie schaffe die »ruinierten Dörfer[]«, die den »künstlichen Städte[n] « gegenüber stünden, die sich »der Natur und Geschichte trotzend» eine Bedeutung anmaßten und »erheucheln«, die ihnen nicht zukomme. Diese Städte der »reinen Treibhausblüten« in den »süd- und mitteldeutschen Kleinstaaten" seien politische Produkte der Jahre 1848/49, in denen etwa »Rheinhessen vorzugsweise demokratisch gestimmt « gewesen sei. ${ }^{1104}$

»Die Wildnis« wird für Riehl »zum Bundesgenossen des Konservativismus«. Und darin steckt der Sinn des Naturschutzes, des »Rechts auf Wildnis«. Die soziale Nivellierung soll gestoppt werden, indem »Wald und Ödland der Kultivierung« entzogen werden. Wildnis stehe für die »Erfahrung, daß es einen Bereich gibt, der dem technisch-produktiven Zugriff entzogen ist und aus sich selbst heraus existiert«; das solle »für die lebendige Differenziertheit einer nichtindustriellen Gesellschaft empfänglich machen «. ${ }^{1105}$ Nur, und das schreibt Sieferle nicht, dass die >Vielfalt hier mit strikter hierarchisierender Ungleichheit als quasi Naturzustand identifiziert wird. Und >Lebendigkeit` mit einer zähen und rohen, asketischen, aber lustigen Einfachheit der Waldbauern - unter Führung des ersten Standes. So setzt der Unterschied bei Riehl auch vor einer Industrialisierung ein; es sei der von Wald und Feld. Hier »tritt die einfachste und natürlichste Vorstufe der deutschen sozialen Vielgestaltung und Vielfarbigkeit zu Tage, jene Fälle der eigensten Volkscharaktere, darin die zähe Verjüngungskraft unsrer Nation geborgen liegt«. Die Walddorfbewohner hätten trotz zumeist großer Armut »fast durchweg ein ungleich eigeneres frischeres, geistiges Gepräge als in den reinen Felddörfern«, in denen meistens »mehr feister Wohlstand grell neben größerer Entartung der Sitten«, Geiz und »mißvergnügte Proletarier« anzutreffen seien. »Der Waldbauer ist roher, händelsüchtiger, aber auch lustiger als der Feldbauer.« Im »Waldland « liege der Speicher tradierter »Volkssitten und Trachten«, sei »Herd" volkstümlicher Kultur und Kunst, »Turnplatz der Jugend « und »Festplatz der Alten «. ${ }^{1106}$

Diese >Wildnis` also ist ein Raum der >natürlichen Hierarchie, in der es festgefügte Vorrangpositionen gibt, in der eine andauernde Ungleichheit besteht, ein rauhes und kämpferisches Leben, das jedem den vorher-

1103 Die bürgerliche Gesellschaft; zit. n. a.a.O.

1104 Land und Leute, S. 94.

1105 Sieferle, a.a.O., S. 150.

1106 Riehl, a.a.O., S. 52f. 
bestimmten Platz zuweist. In dieser Weise fungiert hier die >Wildnis $<$ als projiziertes Vor-Bild einer >organischen Gesellschaft«:

»Die Lehre von der bürgerlichen Gesellschaft ist die Lehre von der natürlichen Ungleichheit der Menschen. Ja in dieser Ungleichheit der Gaben und Berufe wurzelt die höchste Glorie der Gesellschaft, denn sie ist der Quell ihrer unerschöpflichen Lebensfülle. Wie die See das Küstenvolk in einer rohen Ursprünglichkeit frisch erhält, so wirkt gleiches der Wald bei den Binnenvölkern. « ${ }^{1107}$

Und daher:

»Freuen wir uns, daß es noch so manche Wildnis in Deutschland gibt. Es gehört zur Kraftentfaltung eines Volkes, daß es die verschiedenartigsten Entwicklungen gleichzeitig umfasse. Ein durchweg in Bildung abgeschliffenes, in Wohlstand gesättigtes Volk ist ein totes Volk, dem nichts übrig bleibt, als daß es sich mitsamt seinen Herrlichkeiten selber verbrenne wie Sardanapal. Der ausstudierte Städter, der feiste Bauer des reichen Getreidelandes, das mögen Männer der Gegenwart sein, aber der armselige Moorbauer, der rauhe zähe Waldbauer, der einsame, selbstgewisse, sagen- und liederreiche Alpenhirt, das sind die Männer der Zukunft. ${ }^{1108}$

Zäh, rauh, selbstgewiss und immer ein Lied auf den Lippen. Derartige Gestalten werden ein halbes Jahrhundert später, so in Hermann Löns' $»$ Wehrwolf«, die Identifikationsfiguren sein.

Wie stark die >Verwurzelung schen einer >beharrenden Wildnis` und den >Stände[n] des Beharrens ${ }^{1109}$ sei, wird an ökologischen Katastrophen entfaltet. Die werden zur realen Bedrohung der >Volksgesundheit «, hinterlassen, so in Italien, großflächige Kahlschläge, nicht nur devastierte Böden, sondern auch solche Völker. ${ }^{110}$ Riehl sehe "also weniger die Natur bedroht, als die Gesellschaft, wie er sie ständisch idealisierte«. ${ }^{1111}$

Riehl sieht in der »beispiellosen Vielgestalt des Bodenbaues« in Deutschland

1107 Ebda., S. 52.

1108 Ebda., S. 51.

1109 Sieferle, a.a.O., S. 150.

1110 Vgl. ebda.

1111 Ebda. Zum in der Ökologiegeschichtsschreibung häufig erhobenen Vorwurf, der national-konservative Natur- und Heimatschutz sei entweder gar nicht ökologisch, oder auf diesem Gebiet höchst naiv orientiert vgl. Kap. Der Wald als kämpferische Volksgemeinschaft. 
»nicht nur die wunderbar reiche Gliederung unserer Gesellschaftszustände vorgebildet, sondern auch der eigentümlichen Biegsamkeit, Vielseitigkeit und Empfänglichkeit deutscher Geisteskultur und Gesittung die natürlichste Wurzel gegeben ${ }^{1112}$

Wurzeln, offenbar als mächtige, auf `natürliche` Weise eigentlich unlösbare Verankerungen gedacht; der Wald, die >Wildnis` ist so das Bild einer ständischen Gemeinschaft, deren Mitglieder unverrückbar, wie >mächtige Bäume` der Geschichte trotzen. Die propagierte reich gegliederte Gesellschaft, deren Vorbild der Wald ist, unterliegt - und nur das garantiert ihr Bestehen - einer strikten Hierarchie. Und dieser Wald stellt dann auch

»ein aristokratisches Element in der Bodenkultur dar. Er gilt mehr durch das, was er vorstellt, als durch das, was er schafft und einträgt. Nur der Reiche kann Waldwirtschaft treiben, ja oft ist nicht einmal der Reiche reich genug dazu und der Staat als der Inbegriff des Landesreichtums ist darum mit Recht der erste und größte Waldbesitzer«. ${ }^{1113}$

Wenn er also von den bei aller Armut geistig so >gesundenく »deutsche[n] Walddörfern « spricht, dann erscheint deren diesbezügliches Wesen direkt abhängig von ihrer festgefügten ständischen Position. »Die alte Zeit« habe noch den »richtigen Blick« für den Adel des Waldes gehabt.

»Ein schlagenderes aristokratisches Vorrecht als das der Bannforsten ist gar nicht denkbar, und doch hat es Deutschland diesem Einzelvorrecht zu danken, daß es noch so grün bei uns aussieht, daß unsre Berge nicht entwaldet sind wie die italienischen, daß Land und Volk nicht ausgelebt und ausgetrocknet ist, daß noch herrlich große Waldstrecken als geschlossenes Ganzes später in die Hände des Staates übergehen konnten. « ${ }^{1114}$

Vom Höfischen zöge sich der Adel zeitweilig »in die Barbarei des Urwaldes« zurück, um dort »im getreuesten Nachbild des rohen Jägerlebens gleichsam die Uranfänge der Zivilisation von vorn wieder« durchzubuchstabieren. Riehl räumt die mittelalterliche und frühneuzeitliche »Waldtyrannei«, die »grausamen Züchtigungen der Waldfrevler« ein, die >den Bauern « »zu der gefährlichen Frage: >Wer bist du, Fürst?«« gebracht habe. Aber, es habe eben einen »Krieg« zweier »Parteien« um

1112 Riehl, a.a.O., S. 58.

1113 Ebda., S. 57.

1114 Ebda., S. 59. 
den Wald gegeben, in dem »das Standrecht erklärt« geherrscht habe. ${ }^{1115}$ Adel und Grausamkeit, Rauheit und Kampf: dieser Wald wird zum >organischen`Speicher ständischer und männlicher Tugenden, zum Garanten eines noch nicht »ausgetrocknet[en]«, >lebendigen` Volkes, einer vorgeblich »lebendige[n] Differenziertheit«. ${ }^{116}$

Dass die Wälder doch weichen müssen, verdanken sie einer >armseligen auf der Linie des försterlichen Hochwalds, andererseits strikt gegen die »in neuerer Zeit aus Gründen der Not oder kurzblickender Finanzweisheit immer weiter getriebene künstliche Umwandlung des stolzen Laubholzhochwaldes in kurzlebige Nadelwälder«, was dem >deutschen Wald »mindestens ebensoviel von seinem eigentümlichen Waldcharakter« genommen habe«, wie »die völlige Rodung ungeheurer Waldflächen «. ${ }^{1117}$ Diese Nadelholzkulturen verdammt er als "proletarisch «, ${ }^{1118}$ analog zur Gesellschaft unterliegt auch der Wald den Mechanismen der Nivellierung. Interessanterweise kritisiert Riehl die bäuerliche Waldwirtschaft scharf, ohne sie als solche zu identifizieren, wenn er über »nur dünne abgeschälte Stämmchen mit verdorrten Laubresten«, die sich »dem Wanderer« in Eichenschälwäldern entgegenreckten, schreibt, vom »wuchernden kümmerlichen Raumholz von Haselhecken und Hainbuchen«, der völligen Durchmischung von Feld- und Waldwirtschaft. All das sei genau genommen gar kein Wald »in unsrem Sinne«. Der »eigenste Schatz des Waldes«, die »wuchtigen Eichen- und Buchenstämme«, könnten nur in einer »reiche[n] Körperschaft, die hundert Jahre lang auf Zinsen warten kann«, heranwachsen. ${ }^{1119}$

Riehl verbinde »wilde Spekulationen« mit »souveränen ökologischen Analysen«, so Albrecht Lehmann, ${ }^{1120}$ und »eine genaue Soziographie mit einem Standpunkt, der am ehesten konservativ-romantisch zu nennen ist«, wie Sieferle schreibt. ${ }^{121}$ Der Wald Riehls ist asketisch-

\section{Ebda., S. 59f.}

1116 Sieferle, a.a.O., S. 150.

1117 Riehl, a.a.O., S. 58.

1118 Ders.: »Der Wald (Eine socialpolitische Studie)«, in: Beilage zu Nr. 17 der Allgemeinen Zeitung, 17. Januar 1852; zit. n. Dittmann, Ulrich: Waldbilder in Adalbert Stifters Studien, in: Hettche, Walter/Merkel, Hubert (Hg.): Waldbilder. Beiträge zum Interdisziplinären Kolloquium »Da ist Wald und Wald und Wald« (Adalbert Stifter). Göttingen, 19. und 20. März 1999/Fachbereich Forstwirtschaft und Umweltmanagement der Fachhochschule Hildesheim - Holzminden - Göttingen. München: Judicium 2000, S. 42.

1119 Land und Leute, S. 58f.

1120 Lehmann, a.a.O., S. 27.

1121 Sieferle, a.a.O., S. 149. 
aggressives Monument einer ursprünglichen Kultur nach der Überwindung »uranfänglicher Bestialität« und »Nomadentums« und wird noch einmal als vermeintlich >organische Gemeinschaft` gegen die Landschaften des Maschinen-Staates in Stellung gebracht. »Die Zopfzeit hatte kein Auge für den Wald«, er sei ihr »zu unordentlich in der Anlage, zu buckelig in den Formen, zu dunkel in der Farbe« gewesen, weshalb er als flache Kulisse an den Rand gedrängt, und Fürstenschlösser in »entwaldetes Flachland« gesetzt worden wären. ${ }^{1122}$ Dunkelheit gegen Aufklärung, unordentlicher Wuchs als Kennzeichen historisch gewachsener Strukturen, "mächtiger Schutzwall historischen Herkommens", aber ebenso »ewiger Unruhestifter«, ${ }^{1123}$ um den es immer wieder Kämpfe gegeben habe. Kämpfe aber, die immer schädliche »demokratische[] Zeitstimmungen« anzeigen: »Bei jeder entscheidenden Volksbewegung in Deutschland wird sogleich dem Walde der Proceß gemacht. « ${ }^{124}$

Eine derartige »sozialpolitische Dimension des Waldes« existiert im Werk des Waldschriftstellers und Landschaftsmalers Adalbert Stifter (1805-1868) nicht. ${ }^{125}$ Stifter erscheint als einer der Protagonisten der »Antithese Natur-Kultur«, dies lasse sich »besonders deutlich nachweisen « in dessen »Mappe meines Urgroßvaters «. ${ }^{1126}$ In der 3. Fassung dieses Textes wird der heimatliche Wald des Protagonisten mehrfach »Wildniß« genannt. Dieser Augustinus betont, ihm sei »die Stadt widerwärtig geworden«, daher »bin ich da heraus in die Wildniß gegangen «. ${ }^{1127}$ Diese »unwirthbaren Walde« werden als urwüchsig und unüberschaubar, anthropogen unbeeinflusst und kulturfern beschworen. Diese »Wildniß« aber ist zugleich kulturell geprägt und industriell genutzt: es gibt eine Glashütte, es werden Häuser, Felder, Wiesen, Siedlungen, Wege und die ökonomische Nutzung der »Wäldchen« beschrieben, vor allem auch in Kahlschlagswirtschaft. »Die Stilisierung des Waldlandes zum Urwaldgebiet, zu einer Landschaft jenseits der menschlichen Kultur, zu einem Ort des Ungeheuren, Geheimnisvollen, Unübersichtlichen und Urwüchsigen, ohne daß die angebliche >Wildniß dabei als gefährlich oder unzugänglich beschrieben wird, erfüllt dabei - in der to-

1122 Vgl. Riehl: Land und Leute, S. 53f.

1123 Ebda., S. 61.

1124 Der Wald (Eine socialpolitische Studie); zit. n. Dittmann, a.a.O., S. 41.

1125 Vgl. Dittmann, ebda.

1126 Gottwald, Herwig: Natur und Kultur. Wildnis, Wald und Park in Stifters Mappe-Dichtungen, in: Hettche, Walter/Merkel, Hubert (Hg.): Waldbilder, S. 90.

1127 Zit. n. ebda., S. 94. 
pischen Struktur des Texts - offenbar die Erzählstruktur einer imaginierten, sagenhaften >Gegenwelt $<$ zur >Stadt $<. ~ «{ }^{1128}$

So entsteht eine krasse Dichotomie Stadt - Waldland. Die Stadt ist auch hier gekennzeichnet durch unlösbare soziale Antagonismen, während der Wald zum harmonisch-utopischen Gesellschaftsraum wird, dessen Ständestruktur Stifter zur Idylle verklärt. Dieses >organische Miteinander ist zwar geprägt durch eine klare »Abstufung der Stände«, aber Augustinus als »sozialer Aufsteiger» verkehrt ebenso freundschaftlich mit dem führenden Ortsadel, wie mit einem Bettler. ${ }^{1129}$ Anscheinend ein >natürlicher Armer im Sinne Adam Müllers. »Der utopische Charakter der Waldgesellschaft der Mappe wird auch im völligen Fehlen von sozialen Spannungen und auch von Kriminalität klar erkennbar. « ${ }^{130}$

Stifter bezeichnet den Wald an prominenter Stelle in seinem Werk als »Garten«: Der Wald sei »auch schön, [...] weil er auch ein Garten ist, aber ein Garten eines reichen und großen Herrn, der ihn durch tausend Diener bestellen läßt; in ihm ist gar kein Unkraut, weil der Herr jedes Kräutlein liebet und schätzt - er braucht auch ein jedes für seine vielen tausend Gäste $[\ldots] \ll{ }^{1131}$ Auch in dieser Idyllisierung stecken mehrere Bezüge. Zum einen im ordnenden Zugriff auf den Wald als "sanfte Kultur«; so in der »Мappe«, im Plädoyer für eine naturnah erscheinende Kultur, die sich aber eindeutig gegen die zuvor vorhandene Natur richtet. Stifter unterscheidet dabei zwischen >guter Erstere sei gekennzeichnet durch »sanfte Wiederaufforstung«, letztere durch $»$ Rodung und anschließende Verwilderung. Das strebe eine Balance von >Kultur< und >Natur $<$ an, »die einander wechselseitig bedingen und modifizieren, deren jeweilige Zähmung und Bändigung Ziel seines (utopischen) poetischen Entwurfes ist «. ${ }^{132}$ Zum anderen feminisiert Stifter den Wald. Er verwendet Metaphern wie »Waldesbusen«, »Waldesrücken«, »Waldesschöße«, aber auch »Ohren des Waldes«. In der Erzählung »Hochwald« wird wiederholt seine »Jungfräulichkeit« gepriesen. ${ }^{1133}$ Stifters Wald aber ist kein >unberührter`, kein Primärwald, sondern kultivierter, genutzter, er ist im Besitz. Daher steht die beschworene »Jungfräulichkeit« offenbar für eine Art Hortus conclusus.

1128 Ebda., S. $94 \mathrm{f}$.

1129 Vgl. ebda., S. 103.

1130 Ebda., S. $103 f$.

$1131 »$ Der Hochwald«, Historisch Kritische Gesamtausgabe (HKG) 1,4 , S. 242.; zit. n. Schrötter, Helmuth: Adalbert Stifters ökologische Naturschau, in: Hettche/Merkel (Hg.): Waldbilder., S. 71.

1132 Gottwald, a.a.O., S. 102.

1133 Dittmann, a.a.O., S. 37ff. 
Stifter wird nachgesagt, er habe - »naturwissenschaftlich hoch gebildet und interessiert«, ohne sich als Naturwissenschaftler zu verstehen per »Einfühlungsvermögen «, »außerordentliche[r] Beobachtungsgabe und [in] einer nur als schicksalhaft zu bezeichnenden emotionalen Bindung an das Phänomen >Wald «", insbesondere aber aus »inbrünstiger Naturverehrung«, aus »Ehrfurcht vor der Schöpfung und dem Walten Gottes in ihr « ein »Ethos im Umgang mit ihr begründet«, einen universalen Nachhaltigkeitsbegriff in seinen Texten offenbart (ohne »Nachhaltigkeit« je zu benutzen, wahrscheinlich habe er den Ausdruck gar nicht gekannt). Zugleich habe er Begriffe wie Ökologie (geprägt durch Ernst Haeckel 1866) oder Ökosystem etc. antizipiert. Derart emphatische Worte findet der Oberlandforstmeister i.R. Helmuth Schrötter. ${ }^{1134}$

»Stifter trat aus ethischen, ästhetischen und weitblickenden ökonomischen Gründen für die Bewahrung der Natur, ihrer Kräfte und Geschöpfe um ihrer selbst willen und im Interesse künftiger Generationen durch einfühlsame Nutzung der Naturressourcen ein. Besonderes Gewicht erhält diese Haltung durch die damit untrennbar verbundene Naturerkenntnis. Durch die geniale Deutung seiner Naturbeobachtungen nahm Stifter zahlreiche Ergebnisse ökologischer Forschung vorweg, die erst in der zweiten Hälfte unseres Jahrhunderts gezeitigt wurden.«

Dies in seinen Metaphern und Bildern für >Wald «, die »einer späteren speziellen wissenschaftlichen Fragestellung beziehungsweise einem zeitlich bedingten Erkenntnisstand gerecht « würden. ${ }^{1135}$ So antizipiere Adalbert Stifter die >Phytozönose` (geprägt 1928 von Braun-Blanquet), wenn er in »Der Hochwald « die typischen Kombinationen und Schichtungen der Baumarten schildere, ${ }^{1136}$ die 〉Biozönose` (Karl Möbius 1877 und Gams 1918) und gar die >Biodiversität‘, wenn er vom schönen Garten Wald spreche, in dem es kein Unkraut gebe, weil »der Herr jedes Kräutlein liebet« und für all die »Gäste« benötige. ${ }^{1137}$ Ebenso sieht

1134 Vgl. Schrötter, a.a.O., S. $68 \mathrm{ff}$.

1135 Vgl. ebda.

$1136 »$ Die vielzweigige Erle geht am Wasser hin, die leichte Buche mit den schönfarbigen Schaften, die feste Eiche, die schwankenden Halme der Fichten stehen gesellig, und plaudern bei gelegentlichen Windhauchen, der alte Ahorn steht einsam und greift langarmig in die Luft - die Tannen wollen erhabene Säulengänge bilden, und die Büsche, Beeren und Ranken, gleichsam die Kinder, sind abseits und zurück in die Winkel gedrängt, daß mitten Raum bleibe für hohe Gäste.« HKG 1,4 , S. 236; zit. n. ebda.

1137 Der Hochwald, HKG 1,4 , S. 242; zit. n. ebda. 
Schrötter bei Stifter >Ökosystem $`{ }^{1138}$ bzw. >Biogeozönose` (Sukatschew 1950) metaphorisch vorformuliert, wenn dieser die »köstliche[n] Dinge des Waldes beschreibt, den Boden, der ein hunderte Meilen langer zerklüfteter Stein sei, in dessen Risse, Spalten und sonstige Öffnungen »die Wurzeln der Bäume eindringen, und über welchen der schwarze Boden liegt, auf dem die Gräser und Blumen und Beeren« wüchsen, das Wasser, das aus den Wolken regne, versickere und »irgendwo« hervorquelle, ${ }^{139}$ desgleichen die >Nahrungskette< (Slobotkin 1962) ${ }^{1140}$ >Sukzession` (Aichinger 1951) und >Klimax`(Clements 1928 und du Rietz 1930) ${ }^{1141}$ und die »Definition von Lebensformen« bei Fauna und Flora (Raunkiaer 1905 und Abel 1929), wenn er sie nach ihren »Bauführungen« klassifiziere, alternativ zu Linnés System möglicherweise nach Anpassungen an die Umwelt oder Lebensräumen gruppiere. ${ }^{1142}$

Schließlich zeige sich die Aktualität Stifters, dessen Werk durchdrungen sei von »der Naturerkenntnis mit ethischen Forderungen, ästhetischen Idealvorstellungen und Erfordernissen menschlicher Existenz« besonders in »landschaftsökologischer Sicht«, etwa, wenn er einen Obristen gegen namhafte Widerstände für die Wiederaufforstung eines Geröllhügels mit Kiefern plädieren lasse und dabei einen erstaunlichen

1138 Nach Hubert Merkel geprägt 1935 von Arthur G. Tansley; Merkel: Waldbilder: Technische Zeichnungen oder Gemälde?, in: Hettche/Ders. (Hg.): Waldbilder, S. 23.

1139 Der Waldbrunnen, Prag-Reichenberger Ausgabe (PRA) 13/2, S. 313f.; zit. n. Schrötter, a.a.O.

1140 Stifter schreibt im »Hochwald (HKG 1,4, S. 264) vom Greifvogel, der »freilich [...] ein schönes Thier« sei und an seiner Titulierung als »Raubthier« ebenso unschuldig sei, wie das von ihm gefressene Lamm, das seinerseits wieder »unschuldige« Blumen und Kräuter »ausrauf[e]. »Es muß wohl so Verordnung sein in der Welt, daß das Eine durch das Andere lebt«. Das sei - kommentiert Schrötter - in seiner Zurückweisung der utilitaristischen Einteilung in »nützliche« und »schädliche« Tiere eine »nahezu revolutionäre Haltung «, wenn man bedenke, dass im Königreich Böhmen ausweislich der »Vereinsschrift für Forst-, Jagdund Naturkunde« 1857 »an >schädlichem Federwild unter anderem 69 Adler, 202 Uhus, über 800 Habichte und mehr als 17000 Geier, Falken und Weihen abgeschossen wurden«. Ebda.

1141 In »Der beschriebene Tännling«, HKG 1,6 , S. 399f., beschreibt Stifter die Entwicklung nach Kahlschlägen: erst zeigten sich Himbeere, Einbeere, »manche seltsame fremdäugige Blume, Gräser, Gestrippe«, später per Anflug schieße »mancher Schaft« empor und Jahre später sei dann »die Pracht des Waldes« reetabliert; zit. n. ebda.

1142 Vgl. »Nachsommer«, HKG 4,1 , S. 32.; zit. n. ebda. 
»Zeithorizont von tausend Jahren bei der Gestaltung des Lebensraums« offenbare. ${ }^{1143}$

Paradoxerweise wird im selben Aufsatzband der >Stiftersche Realismus` von Walter Hettche als autopoietisch definiert. Und Schrötter beruft sich z.T. auf exakt dieselben Stellen im Werk Stifters, wie Hettche. Stifters Text bringe den »Gegenstand erst hervor«, von dem er spreche, wenn eiszapfenbeladene Nadelbäume im winterlichen Wald als »Kerzen« die »alle von Silber" schimmerten, erscheinen, als autonome Subjekte, entstanden im Konstruktionsprozess literarischer Wirklichkeit. Die »Subjektwerdung« des Waldes gehe oft »mit einer Anthropomorphisierung einher«, der Wald atmet, »Fichten stehen gesellig, und plaudern bei gelegentlichen Windhauchen«, die Bäume "schreiten heran" usw. Diese Subjektwerdung sei aber stets abhängig davon, dass der Wald seine »Würde« (Stifter), seine Integrität behalte. Die könne etwa durch Naturkatastrophen beschädigt werden, wenn Bäume »leiden«, »seufzen«, »sterben«, gleichwohl erhalten bleiben, der Wald könne Subjekt bleiben, etwa, wenn Menschen (in der Objektrolle) von stürzenden Bäumen erschlagen werden. Derartiges werde »vom Erzähler als gegeben hingenommen; die Menschen fügen sich in das zwar außergewöhnliche, aber dennoch natürliche und damit sinnvolle Geschehen«. Völlig anders werde Wald- und Baumzerstörung »bewertet, wenn der Erzähler sie nicht für sinnvoll und begründbar hält«, etwa beim Abholzen ganzer Täler. ${ }^{1144}$

Die Schwierigkeiten einer sprachlichen Wald-Konstruktion spreche Stifter selbst an, wenn er des öfteren das Attribut »unsäglich« (»der unsägliche Reiz verschiedener herbstlicher Färbungen«) verwenden lasse. Nach Hettche stößt die "Gestaltungskraft sprachlicher Zeichen« beim Versuch der Walddarstellung an ihre Grenzen, müsse der »Erzähler zu bildhaften Vergleichen greifen«, wenn die Sprache »kein geeignetes Signifikat« zur Vermittlung bereithalte. So lasse er einen Baumstamm »wie eine einzelne alterthümliche Säule« aussehen. ${ }^{1145}$ Wobei

1143 »Die Mappe meines Urgroßvaters«, HKG 1,5 , S. 165f. u. PRA 12, S. 257f.; zit. n. ebda.

1144 Hettche, Walter: Der Wald im Text, der Wald als Text, in: Ders./Merkel: Waldbilder, S. 28ff. Hettche bezieht sich auf »Die Mappe meines Urgroßvaters«, HKG 1, 5, S. 106 u. 126; »Der Waldsteig«, HKG 1, 6, S. 169; »Aus dem bairischen Walde«, in: Studien, S. 375; »Der beschriebene Tännling«, HKG 1, 6, S. 282.

1145 Ebda., S. 28. Binnenzitate aus »Der Waldgänger«, S. 8; »Der Hochwald«, Historisch Kritische Gesamtausgabe (HKG), 1, 4, S. 213. 
Hettche allerdings die soziale Konstruktion derartiger Bilder, wie das der »Säule«, unbeachtet lässt. ${ }^{1146}$

$>$ Realismus als >Autopoiesis $<$ : Wälder, die erst im bzw. als Text entstehen oder Beschreibungen von 〉Ökosystemen`, >Biogeozönosen, >Nahrungsketten`, von `Klimax` etc.? Tatsächlich ist das Paradox gar keines. Auch diese wissenschaftlichen Begriffe sind autopoietisch, bringen ihren »Gegenstand erst hervor«, lassen den bezeichneten Inhalt erst in einem >Text $<$ entstehen, der sich vorhandener Zeichen bedient und daher serkennbarく ist. Die »Unmöglichkeit der Herstellung einer Identität zwischen dem Zeichen und dem Gegenstand « ${ }^{1147}$ wäre demnach auch hier gültig.

Die sprachliche Repräsentation des Gemeinten ist »nicht nur defizitär«, sondern auch notwendige Übersetzung: Erst die künstlerische Neuschaffung, Übersetzung des Waldes oder Forstes per Kulturtechniken in ein Ordnungssystem macht ihn erfahrbar. Ein Stifterscher »Narr«, ein Hypochonder, sucht zur Heilung hiervon ein Kurbad auf, verirrt sich dort bei einem Spaziergang im fremden, unheimlichen Wald, wird von einem Holzknecht gerettet und beginnt daraufhin, den Wald zu zeichnen, bis er »schier alle Theile des dunklen Pfades in sein Zeichenbuch« bringt. Erst mittels der »Anverwandlung des zunächst unverstandenen und >unlesbaren`, als bedrohlich und chaotisch empfundenen Gefahrenraumes in ein geordnetes Zeichensystem durch die Kulturtechnik des Zeichnens« wird der »Sonderling« geheilt, resozialisiert und trifft gar im Wald seiner ehedem Verirrung seine zukünftige Frau - die Erzählung endet mit der Geburt eines Sohnes. Ein anderer Protagonist will Standorte und Lebensweisen aller Gewächse kennenlernen, sucht sie auf und sammelt, was er mit in die Wohnung nehmen kann. Da das bei Bäumen nicht möglich ist, »machte ich mir Beschreibungen, die ich zu der Sammlung einlegte«. Es entstehen Beschreibungen nach der »Bauführung« der Pflanzen, Gruppierungen, die von denen der gängigen Botanik abweichen, weil diese die Pflanzen nur nach einem oder wenigen Merkmalen (Keimblätter oder Blütenteile usw.) ordne, weshalb da »Pflanzen in einer Gruppe beisammen stehen, welche in ihrer ganzen Gestalt und in ihren meisten Eigenschaften sehr verschieden sind«. Im Prozess der »Verschriftlichung«, sagt Hettche, entstehe »eine neue Systematik, die erst zum Verstehen der Zusammenhänge führt und deren sprachliche Darstellbarkeit allererst ermöglicht«. ${ }^{1148}$ Dieses 〉Alternativmodell zur

1146 Vgl. Hettche, a.a.O.

1147 Ebda., S. 35.

1148 Ebda., S. 33f. Hettche bezieht sich auf »Waldsteig«, HKG 1, 6, S. 186f., S. 213 u. »Nachsommer«, HKG 4, 1, S. 32. 
Linnéschen Nomenklatur aber ist nichts weiter, als >wuchernde Zeichen in eine Ordnung zu bringen und sie so zu bezwingen. Die bezwingende Reorganisation der `äußeren Natur durch den »Narren« führt direkt entsprechend zu der der sinneren Natur`: Heilung, Resozialisierung, Ehe und Stammhaltergeburt.

Auch Ökologie ist eine Technik, wuchernde Zeichen durch Ordnung zu bändigen. In den klassischen Konstruktionen ihrer frühen Ausprägung entwirft auch sie stabile, harmonische Gebäude: den `Schlusswald etwa, das dringliche Ziel jeder diesbezüglichen Entwicklung.

\section{Die Natur erhält ein Haus im Kampf ums Dasein}

Im Folgenden geht es nicht um eine Diffamierung von Ökologie, sondern um eine ihrer Wurzeln, bzw. um die Schöpfung des Begriffs in einem Spannungsfeld von >mechanistischem Materialismus`, bzw. der kausal-mechanistischen Physiologie und einem >Organismus`, der ein permanentes >Kunstwollen` und `Symmetriedrängen` der Lebewesen, eine `Beseeltheit` der Materie vermengt mit sozialdarwinistischer Unerbittlichkeit. »Unter Oecologie verstehen wir« - schreibt Ernst Haeckel 1866 in seiner »Generellen Morphologie der Organismen« -

»die gesamte Wissenschaft von den Beziehungen des Organismus zur umgebenden Außenwelt, wohin wir im weiteren Sinne alle `Existenz-Bedingungen r rechnen können. Diese sind theils organischer, theils anorganischer Natur; sowohl diese als jene sind [...] von der größten Bedeutung für die Form der Organismen, weil sie dieselbe zwingen, sich ihnen anzupassen. [...] Von welcher ungeheuren Wichtigkeit alle diese Anpassungsverhältnisse für die gesamte Formbildung der Organismen sind, wie insbesondere die organischen Existenz-Bedingungen im Kampfe um das Dasein noch viel umbildender auf die Organismen einwirken, als die anorganischen, haben wir in unserer Erörterung der Selections-Theorie gezeigt. Der außerordentlichen Bedeutung dieser Verhältnisse entspricht aber ihre wissenschaftliche Behandlung nicht im Mindesten $\ll,{ }^{1149}$

beklagt der »Pionier« auf dem ersten Jenaer Lehrstuhl für Zoologie ${ }^{1150}$ die bisherige Unfähigkeit, die Umweltfaktoren »im Naturhaushalte« zu berücksichtigen. Diese klaffende Lücke werde nun von der Selektionstheorie und der daraus resultierenden Deszendenztheorie nach Darwin »vollständig ausgefüllt«. Sie zeige,

1149 Zit. n. Morgenthaler, Erwin: Von der Ökonomie der Natur zur Ökologie, S. 243f.

1150 Vgl. Morgenthaler, a.a.O., S. 242. 
»wie alle die unendlich complicierten Beziehungen, in denen sich jeder Organismus zur Außenwelt befindet, wie die beständige Wechselwirkung desselben mit allen organischen und anorganischen Existenz-Bedingungen nicht die vorbedachten Einrichtungen eines planmäßig die Natur bearbeitenden Schöpfers, sondern die notwendigen Wirkungen der existierenden Materie mit ihren unveräußerlichen Eigenschaften und deren continuirlicher Bewegung in Raum und Zeit sind «. ${ }^{1151}$

Mit einem solchen Materialismus gilt Haeckel maßgeblichen Teilen der zeitgenössischen politischen Linken - von der SPD bis Lenin - als Hoffnungsträger im Klassenkampf. Dies und die Tatsache, dass kaum ein Werk zur Ökologiegeschichte es versäumt, ihn als einen Ahnherren des Fachs zu erwähnen, gehört zu einer Widersprüchlichkeit, die eigentlich nicht in den Arbeiten Haeckels, sondern im gesellschaftlichen Naturverhältnis begründet ist.

»Ökologisches Denken steht heute in jedem Fall in der Tradition der Wissenschaft `Ökologieく, wie sie von Haeckel definiert und benannt worden ist. Dies gilt auch für die Formen ökologischen Denkens, die sich nicht mehr in die klassischen Naturwissenschaften eingebunden fühlen, und dies sind beim heutigen Stand der Entwicklung die zahlenmäßig überwiegenden und die Formen, von denen die intensive Auseinandersetzung mit der Ökologie herrührt. ${ }^{1152}$

Die Rezeption des zu Lebzeiten und darüberhinaus außerordentlich populären Haeckel scheint zwei verschiedene Personen oder voneinander getrennte Werke aufzufinden. Einerseits wird Haeckel schlicht als Schöpfer des Begriffs »Ökologie« vorgestellt, ${ }^{1153}$ oder, genauer erläuternd, als derjenige »Zoologe[] und Naturphilosoph[]«, der diesen Begriff 1866 »in die Naturwissenschaft eingeführt« habe, »um die Beziehung der Organismen untereinander und zu ihrer Umwelt zu bezeichnen«. Das geschehe in »radikale[r] Abkehr vom mechanistischen Weltbild«, wo »jedes Problem auf ein Einzelteil« zurückgeführt werde. Stattdessen gehe es Haeckel darum zu zeigen, dass »Umweltprobleme« darauf beruhen, dass »die Beziehungen zwischen den Teilen eines Systems gestört sind «, was »die hergebrachte Naturwissenschaft« mit »ihrem gewohnten linear-kausalen Denken« noch »lange nicht beachtet« habe. So schreibt es 1990 Jörg Weber in seinem 1990 mit dem »Deutschen Um-

1151 Zit. n. ebda.

1152 Ebda., S. 280.

1153 So von Helmuth Schrötter, a.a.O. S. $68 \mathrm{ff}$. 
weltpreis für Publizistik« ausgezeichneten Buch. ${ }^{154}$ In Ludwig Trepls »Geschichte der Ökologie« erfolgt die Klarstellung, Haeckel sei deutlich mehr Namengeber eines »logisch zusammenhängenden Gebiet[s]«, denn Begründer dieser Wissenschaft gewesen. ${ }^{1155}$ Selbst Jost Hermand und Ulrich Linse ergänzen das Bild des Begriffsschöpfers nur mit dem des Schöpfers des pantheistischen >Monismus`, als der er 1904 »bei der Tagung des Freidenkerbundes in Rom zum Gegenpapst « gewählt wird. ${ }^{1156}$ Stephen Jay Gould nimmt die `Erkenntnisse ২ des führenden Anthropologen und Chirurgen Paul Broca (1824-1880) - und dessen Epigonen Gustav Le Bon - zur (Gewichts-)Überlegenheit des Gehirns weißer Männer über Gehirne von Frauen (und >Wilden`) zum Anlass, »das gesamte Unternehmen, bestimmte Gruppierungen mit biologischen Bewertungen abzustempeln, als irrelevant und hochgradig gefährlichen« zu bezeichnen. ${ }^{1157}$ Im selben Buch stellt er Haeckel mit Friedrich Engels in eine »Reihe scharfsinniger Evolutionstheoretiker«. ${ }^{1158}$ Noch kürzlich erscheint Haeckel in einem Sammelband über »Naturschutz und Nationalsozialismus«, in dem es am Rande auch um die Wurzeln des Blutund-Boden-Naturschutzes im 19. Jahrhunderts geht, wieder nur als Präger der biologischen Disziplin Ökologie. ${ }^{159}$ In seiner »Geschichte der Umweltsoziologie« verweist Matthias Groß ebenfalls nur auf die an der Darwinschen Evolutionslehre orientierte, holistische Ökologie-Begründung Haeckels. ${ }^{160}$ Erwin Morgenthaler schließlich schränkt ein, der Verfechter der Todesstrafe als »vorteilhafte[m] künstliche[n] Züchtungsprozess« sei vor einem »Abgleiten [...] in allzu krassen Sozialdarwinismus $[\ldots]$ dann doch« durch »seine biologische Bildung « gehindert worden. Schon, weil Haeckel das Durchsetzen des Menschen »im natürli-

1154 Vgl. Weber, Jörg: Die Erde ist nicht Untertan. Grundrechte der Natur. Frankfurt/M: Eichborn $1993^{2}$, S. 68f.

1155 Vgl. Trepl, Ludwig: Geschichte der Ökologie, S. 113f.

1156 Vgl. Hermand, Jost: Grüne Utopien in Deutschland. Zur Geschichte des ökologischen Bewußtseins. Frankfurt/M: Fischer 1991, S. 71ff.; Linse, Ulrich: Ökopax und Anarchie. Eine Geschichte der ökologischen Bewegungen in Deutschland. München: dtv 1986, S. 17 u. 44.

1157 Gould, Steven Jay: Der Daumen des Panda. Betrachtungen zur Naturgeschichte. Frankfurt/M: Suhrkamp 1989 (New York 1980), S. 158ff.

1158 Ebda., S. 135.

1159 Vgl. Potthast, Thomas: Wissenschaftliche Ökologie und Naturschutz: Szenen einer Annäherung, in: Radkau, Joachim/Uekötter, Frank (Hg.): Naturschutz und Nationalsozialismus. Frankfurt/M, New York: Campus 2003, S. 225.

1160 Vgl. Groß, Matthias: Die Natur der Gesellschaft, S. 58. 
chen Ausleseprozess« an einer Vervollkommnung des Gehirns festmache. $^{1161}$

Für George L. Mosse hingegen ist Haeckel ein »direkter Vorfahre« der »Nazi-Euthanasie « ${ }^{1162}$ und nach Anna Bergmann gehört er »zu den ersten, die sich im Zuge ihrer Auseinandersetzung mit der Darwinschen Evolutionstheorie zu Rassenhygienikern entwickelten «. ${ }^{1163}$ Haeckel propagiert »die Rekrutierung Kranker zum Militärdienst«, verlangt »die Todesstrafe >für unverbesserliche Verbrecher und Taugenichtse«", und er ist für »die Tötung kranker und schwacher Kinder« - das sei bei Neugeborenen ethisch unbedenklich, da »sie >die höhere Wertstufe der Persönlichkeit» noch nicht erreicht hätten«. Ebenso plädiert er dafür, mittels einer »Gabe Morphium oder Cyankalium« unheilbar Kranke, besonders Geisteskranke, zu töten, worüber eine eigens einzusetzende Ärztekommission zu befinden habe, um eine Kostenentlastung von Staat und Familien zu erreichen. ${ }^{1164}$ Haeckel begründet das mit der »Kontraselektion«, der Beeinträchtigung der Selektion im 〉Daseinskampf« durch die Zivilisation. Auch Charles Darwin selbst beklagt die »Kontraselektion«. So würden bei »Wilden« die »Schwachen bald beseitigt« und die Überlebenden zeigten sich normalerweise in »kräftiger Gesundheit«. Andererseits »thun wir civilisirte alles« dafür, mittels Gesetzen und Fürsorge »den Process dieser Beseitigung aufzuhalten«, wodurch sich »die Schwachsinnigen«, »Krüppel« und »Kranken« fortpflanzten. Was, wie bei der »Zucht domesticierter Thiere« ersichtlich, zweifelsfrei »für die Rasse des Menschen im höchsten Maße schädlich sein muß«, nur könne man den Schwachen Hilfe nicht verweigern, da dies dem SympathieInstinkt widerspräche. ${ }^{1165}$ Bei Haeckel gibt es derartige Skrupel nicht.

Streng genommen, sagt Jürgen Sandmann, lasse sich der »Gedanke der Kontraselektion« aus der Selektionstheorie gar nicht ableiten, »da die Individuen, die den Kampf ums Dasein überstehen, per definitionem

1161 Vgl. Morgenthaler, a.a.O., S. 248.

1162 Mosse, George L.: Rassismus. Ein Krankheitssymptom in der europäischen Geschichte des 19. und 20. Jahrhunderts. Königstein/Ts: Athenäum 1978 (New York 1978), S. 84.

1163 Bergmann: Die verhütete Sexualität, S. 76.

1164 Vgl. Sandmann, Jürgen: Ernst Haeckels Entwicklungslehre als Teil seiner biologistischen Weltanschauung, in: Engels, Eve-Marie (Hg.): Die Rezeption von Evolutionstheorien im 19. Jahrhundert. Frankfurt/M: Suhrkamp 1995; S. 326-346, S. 335. Sandmann zitiert/bezieht sich auf: Natürliche Schöpfungsgeschichte $\left(1870^{2}\right.$ und $\left.1872^{3}\right)$, S. 155; Die Lebenswunder (1904), S. 373 u. 132ff.

1165 Vgl. Darwin, Charles: Die Abstammung des Menschen und die geschlechtliche Zuchtwahl (1871), S. 146f.; zit. n. Sandmann, a.a.O., S. $334 f$. 
die Geeignetsten sind, und das immer in Relation zu den herrschenden Lebensbedingungen«. »Kontraselektion« beziehe sich dann auch auf unabhängig von der Selektionstheorie gesetzte Wertmaßstäbe, etwa, Kranke für weniger >wertvoll $\mathrm{zu}$ halten. Haeckel aber mache keinen Unterschied »zwischen den Ergebnissen der Selektionstheorie, die nur deskriptiv-explanativen Charakter haben und dem diesen Ergebnissen normativ zugeschriebenen Wert «. ${ }^{1166}$ Er betreibt eine Begründung »der Sittenlehre auf der unerschütterlichen Basis fester Naturgesetze $\ll,{ }^{1167}$ der des >Daseinskampfes $<$. Wobei Haeckel Darwins »struggle for life« ausdrücklich abweichend in »Wettkampf um die Lebensbedürfnisse« übersetzt, weil er mit Darwins >metaphorischem` Gebrauch nicht einverstanden ist, der nicht nur den »Kampf zweier Konkurrenten um eine Existenzbedingung« meine, »sondern auch das Ringen eines Organismus mit einer Existenzbedingung«. So einer Pflanze mit einsetzender Trockenheit. Daraus gehe, so Haeckel, aber nur »Anpassung, aber keine Zuchtwirkung« hervor. ${ }^{168}$ Für die Zuchtwirkung aber braucht es Konkurrenzkämpfe, auch bei den Menschen:

»So traurig an sich auch der Kampf der verschiedenen Menschen-Arten ist, und so sehr man die Thatsache beklagen mag, daß auch hier überall >Macht vor Recht` geht, so liegt doch andererseits ein höherer Trost in dem Gedanken, daß es durchschnittlich der vollkommenere und veredeltere Mensch ist, welcher den Sieg über den anderen erringt. « ${ }^{1169}$

Im Daseinskampf also ist der Gewinner der Höherwertige, der Verlierer der Minderwertige. Dieses Handlungsresultat entspringe dabei keinem freien Willen, es sei vielmehr Resultat des »mechanisch sich vollziehenden Entwicklungsprozesses«. Aber, die Zivilisation beeinträchtige den Daseinskampf, und so die Zuchtwahl: Kontraselektion. ${ }^{1170}$ Zur Zuchtwahl gehören hier auch differente >Wertigkeiten chen 〉Rassen`. »Haeckel stellte nicht nur eine Genealogie für sämtliche Menschenrassen auf, er verband die scharfe Trennung zwischen den Rassen auch mit der Forderung, die Untüchtigen auszumerzen.« Ganz oben stehen die >Arier`, ganz unten $>$ Neger $\triangleleft$ und Juden. ${ }^{1171} »$ Unser per-

1166 Sandmann, a.a.O., S. 336.

1167 Ueber die heutige Entwickelungslehre im Verhältnisse zur Gesammtwisenschaft; zit. n. ebda., S. 333.

1168 Morgenthaler, a.a.O., S. 247.

1169 Ueber die Entstehung und den Stammbaum des Menschengeschlechts (1868); zit. n. Sandmann, a.a.O., S. 334.

1170 Vgl. Sandmann, ebda.

1171 Vgl. Mosse: Rassismus, S. 83f. 
sönliches Leben ist mehr als hundertmal so schön, so lang und so werthvoll als dasjenige des wilden Naturmenschen«. ${ }^{1172}$

Haeckel beruft sich explizit auf Joseph Arthur de Gobineau (18161882) und seinen Mitte des Jahrhunderts publizierten »Essai sur l'Inégalité des Races Humaines«. Dessen deutsche Ausgabe besorgt 1898-1901 der »Bayreuther Kreis" um Cosima Wagner. Fortan ist Gobineau posthum in Deutschland einer der wichtigsten Stichwortgeber rassistischer und vor allem antisemitischer Propaganda - obwohl Antisemitismus kein Bestandteil seiner Theorie ist. Seine »Ungleichheit der Menschenrassen « basiert auf der Existenz dreier »Grundrassen - gelb, schwarz und weiß - und der Überlegenheit der >arischen Rasse ২. Diese habe zunächst in Indien die >Elite < gebildet, später »das teutonische Erbe« geformt. Die >Arier` sind konstruiert als »das Gegenstück zum Materialismus und zur Sinnlichkeit der Gelben bzw. der Schwarzen«. Durch Vermischung mit den »Ureinwohner[n] Europas«, bei Gobineau sind das die Finnen (= >die Gelben $<$ ), >degeneriert $<$ der $>$ Rasse-Adel $<$ unweigerlich. »Diese Rassenvermischung zerstörte die weiße Rasse.« Vergleichbares gelte für die Juden. Auch sie, einstmals frei, stark, erfolgreich, seien >herabgesunken` durch Vermischung mit anderen Völkern, »die reichlich mit schwarzen Elementen verseucht waren«. Gobineau hält solche >Degeneration〈 nach dem >Gesetz〈 vom »Aufstieg und Fall der Kulturen« für unvermeidlich. In seinem späteren Werk »Renaissance« (1877) wandelt sich dieser 〉Fatalismus« zu der Hoffnung, eine derartige »Katastrophe« zu vermeiden, was nach Mosse dazu beiträgt, dass dieses Buch Gobineaus »am schnellsten bekannt wurde«, verbreitet insbesondere durch den »Alldeutschen Bund «. ${ }^{1173}$

Auch Haeckel postuliert in den »Lebenswunder[n] « die Existenz von »höheren und niederen Menschenrassen«. In seinem Denken »stehen Naturvölker und Tiere im Hinblick auf die Ausbildung ihres Verstandes nahezu auf gleichem Niveau«. Wobei er »indirekt phylogenetisch« argumentiere, so Sandmann, »indem er die zu seiner Zeit lebenden mit Vorläufern der zeitgenössischen Kulturmenschen gleichsetzt und daraus den Schluß zieht, daß sie auf einer früheren Entwicklungsstufe stehen und deshalb [...] auch weniger vollkommen und daher minder wertvoll sind «, sieht Haeckel den Prozess der Entwicklung doch als einen der Vervollkommnung an. ${ }^{1174}$ Dieses »Denksystem « legitimiert die bestehenden sozialen Verhältnisse, da es sie als Resultat natürlicher Selektionsprozesse versteht. Mit der »Analogisierung von Organismus und Gesellschaft«,

1172 Haeckel: Die Lebenswunder; zit. n. Sandmann, a.a.O., S. 337.

1173 Mosse, a.a.O., S. 54ff.

1174 Vgl. Sandmann, a.a.O. 
der »biologisch verstandene[n] Kategorie der Arbeitsteilung«, werden diese »Verhältnisse als natürliche und entwicklungsmäßig hochstehende ausgegeben«. Desgleichen erscheinen Imperialismus und Kolonialismus gemäß der phylogenetischen `Entwicklungsstufe « der kolonisierten Menschen als legitim. »Haeckel vollzog damit ebenfalls die im Gefolge der Reichsgründung einsetzende Hinwendung des ursprünglich liberalen Bürgertums zu nationalistischen Positionen. « ${ }^{1175}$

Er wird in »etlichen Veröffentlichungen nach 1933 [...] als ein dem Nationalsozialismus nahestehender Denker angesehen«. Sein Einfluss auf die faschistische Ideologie erfolgt aber auch auf indirektem Weg über Sozialanthropologen wie Ludwig Woltmann (1871-1907) oder Rassehygieniker wie Wilhelm Schallmayer (1857-1919) und Alfred Ploetz (1860-1940). ${ }^{1176}$ Schallmayer und Ploetz verstehen sich als Sozialisten (wie auch der Kriminalanthropologe Cesare Lombroso. Der ist Abgeordneter im Turiner Stadtrat von 1902 bis 1904 (also nach der Publikation seiner entscheidenden Werke), um nach Differenzen mit seiner Partei anschließend aus der Politik auszuscheiden. Sein Schüler Enrico Ferri gar verliert seinen Lehrstuhl in Pisa, nachdem er 1893 der sozialistischen Partei beitritt ${ }^{1177}$ ). Der >Sozialismus« der deutschen Rassehygieniker ist der einer »Evolution der Volksgemeinschaft durch Kampf«, einer »Leistungsgesellschaft«, in der »unter rassehygienischen Prämissen Erbrechte nicht mehr gelten«, in der alle den »ökonomischen Kampfplatz« mit ihrem jeweiligen »Erbwert« betreten, der den sozialen Status begründen soll anstelle von »Klassenzugehörigkeit und Besitz«. ${ }^{1178}$ Das heißt auch Ablehnung jeder »Pöbelherrschaft«, könne doch die »Gleichmachung der Ungleichen [...] nur ein Ideal der Schwachen sein und würde naturnotwendig eine enorme Schwächung der sozialen Gesamtleistungen zur Folge haben «. ${ }^{1179}$ So spricht Schallmayer unter dem Stichwort »Kontraselektion« davon, dass in Zukunft im Ersatz der »natürlichen Auslese« durch »sexuelle Auslese« durchaus Kranken und Schwachen »das Leben in jeder Weise erleichtert und verlän-

1175 Ebda., S. 339.

1176 Vgl. ebda.

1177 Vgl. Brömer, Rainer: Evolution und Verbrechen, in: Baumunk, Bodo M./Rieß, Jürgen (Hg.): Darwin und Darwinismus: eine Ausstellung zur Kultur- und Naturgeschichte. Katalog des Deutschen Hygiene-Museums Dresden. Berlin: Akademie Verlag 1994, S. 130.

1178 Bergmann, a.a.O., S. 125f.

1179 Schallmayer, Wilhelm: Vererbung und Auslese im Lebenslauf der Völker. Eine Staatswissenschaftliche Studie auf Grund der neueren Biologie (1903); zit. n. Bergmann, a.a.O., S. 124. 
gert« werden könne, »soweit es die Rücksicht auf sozialistische Interessen irgend zuläßt«. ${ }^{1180}$

Anders Haeckel, der wie Herbert Spencer den Darwinismus gegenteilig auslegt. »[G]erade die Deszendenztheorie« beweise, »daß die vom Sozialismus erstrebte Gleichheit der Individuen eine Unmöglichkeit« sei. Er betont, »daß in den staatlichen Organisationsverbänden der Menschen wie der Tiere weder die Rechte und Pflichten noch die Güter und Genüsse aller Staatsglieder jemals gleich sein werden, noch jemals gleich sein können«. Das »beste Gegengift gegen den bodenlosen Widersinn der sozialistischen Gleichmacherei« sei dann auch die Deszendenzheorie. Sollte diese eine politische Tendenz beinhalten, so »nur eine aristokratische [...], durchaus keine demokratische, und am wenigsten eine sozialistische $\ll .{ }^{1181}$ Das erinnert zwar an die Position des Wiener >Hygiene-Pioniers « Max Ritter von Gruber, der von der »Verblendung des Gleichheitswahns« spricht, dem sich eine neue Ethik entgegen zu stellen habe. ${ }^{1182}$ Bergmann erklärt den »Dissens in der Ausdeutung des Darwinismus« zum bloß »vordergründig[en]«. In beiden Positionen gehe es eigentlich »um dasselbe: um Nachahmung und Beherrschung der Selektion, um die Konstruktion einer >natürlichen` Ordnung «. ${ }^{1183}$

Nur, Haeckel wird von führenden Sozialisten unterschiedlicher Ausrichtung unbedingt als Sozialist (wider Willen) und Materialist (obwohl er einen mechanistischen Materialismus mit Pantheismus vermengt) gepriesen. In den Arbeiterbildungsvereinen wird sein Bestseller »Die Welträthsel« offenbar so regelmäßig studiert, wie Marx und Engels. ${ }^{1184}$ Karl Kautsky reicht 1882 bei Haeckel seine Dissertation zur »Entstehung der Ehe und Familie« ein. ${ }^{1185}$ Franz Mehring verspricht sich in seiner Rezension des Werks einen großen Schub für die sozialistische Sache und ist überzeugt, dass dessen Werk der »Sozialistenhaß doch nur anhänge, wie dem Kulturmenschen ein rudimentäres Organ aus der Zeit

1180 Beiträge zu einer Nationalbiologie (1905); zit. n. a.a.O., S. 129.

1181 Zit. n. a.a.O., S. 126f.

1182 Vgl. Gruber: Organisation der Forschung und Sammlung von Materialien über die Entartungsfrage. Vortrag vor der »Fachkommission für Gesundheitspflege der Zentralstelle für Volkswohlfahrt (1910); zit. n. ebda., S. 124.

1183 Bergman, ebda., S. 127.

1184 Vgl. ebda., S. 76. »Die Welträthsel. Gemeinverständliche Studien über monistische Philosophie« (1899) erreichen bis 1914 eine Auflagenhöhe von 300.000 und werden »in etwa 25 Sprachen übersetzt« (Kockerbeck, Christoph: Die Schönheit des Lebendigen. Ästhetische Naturwahrnehmung im 19. Jahrhundert. Wien, Köln, Weimar: Böhlau 1997, S. 82, Fn. $11)$.

1185 Vgl. Sandmann, a.a.O., S. 340. 
der Barbarei ${ }^{1186}{ }^{186}$ Lenin, der Spencer ob dessen Übertragung des >Daseinskampfs« auf die menschlichen Gesellschaften als reaktionären Philosophen und Soziologen begreift, der alle »Übertragung biologischer Begriffe auf das Gebiet der Gesellschaftswissenschaften« als bloße »Phrase« abtut, ${ }^{1187}$ sieht in Haeckels »Welträthseln« eine »Waffe des Klassenkampfes«. Dass es weltweit eine enorme Verbreitung findet, liefere »den schlagenden Beweis, daß dieses Buch >ins Volk gedrungen ist, daß es Massen von Lesern gibt, die E. Haeckel mit einem Schlage auf seine Seite gebracht hat«. Wie bedeutsam »der Kampf des Materialismus gegen Idealismus und Agnostizismus« sei, zeige ebenso »das Gebrüll der Erzreaktionäre in der Philosophie« gegen Haeckel. Dessen eigene Verleugnung des Materialismus entspringe seiner "philosophische[n] Naivität«, dem »Fehlen bestimmter Parteiziele bei ihm« und seinem »Wunsch, den herrschenden philiströsen Vorurteilen gegen den Materialismus Rechnung zu tragen «. ${ }^{1188}$ Haeckel sieht in der Tat »den vergiftenden Aberglauben des Mittelalters «, der in der »Orthodoxie der Kirchen « verbreitet werde und nach wie vor die »Sitten oder besser Unsitten« beeinflusse und damit eine notwendige neue Weltanschauung, die der Weiterentwicklung menschlicher Erkenntnis angemessen sei, gefährde. Zugleich beklagt er »jenen unerbittlichen `Kampf ums Dasein`, der vor allem im Bereich des >Militarismus` und der >Börsenspekulation« immer schärfere Formen annehme $\ll$. ${ }^{1189}$

Der Darwinist beklagt den 〉Kampf ums Dasein`? Hier zeigt sich eine bestimmte Tendenz innerhalb des Sozialdarwinismus - die von Vordenkern des Faschismus wie Chamberlain scharf kritisiert wird ${ }^{190}$-: per `Evolution` zu einer harmonischen `Schlussgesellschaft zu gelangen, in der die »narzißtische Kränkung« durch Darwin (Freud) letztlich wieder aufgehoben wird. In seinen »Welträthseln« oder »Lebenswunder[n]« verficht Haeckel »mit utopischem Elan« eine biologische Entwicklungslehre, »die zu immer höheren Formen des Lebens dränge« und sich gesellschaftlich durchsetzen werde. Basis einer neuen Gesellschaft und ihres Staats werde eine »biologisch-rationale Ordnung« sein, nicht mehr »Parteienhader und Klasseninteressen«. Mit dem von ihm initiierten weltweiten Monistenbund soll die »Popularisierung einer Identitätsphi-

1186 Zit. n. ebda.

1187 Vgl. Lenin, Wladimir Iljitsch: Materialismus und Empiriokritizismus. Kritische Bemerkungen über eine reaktionäre Philosophie. Berlin $(\mathrm{O})$ : Dietz 1981 (Genf 1908), S. 391.

1188 Ebda., S. $414 \mathrm{ff}$.

1189 Haeckel: Natürliche Schöpfungsgeschichte, S. X-XVI; zit. n. Hermand: Grüne Utopien, S. 72.

1190 Vgl. Kap. Der Wald als kämpferische Volksgemeinschaft. 
losophie von Gott und Welt (Deus sive Natura), die selbst im unscheinbarsten Naturphänomen ein Wunderwerk göttlichen Waltens erblickt«, etabliert werden. ${ }^{1191}$ Zugleich erklärt er eine neue "Sittenlehre« zur "weitaus wichtigste[n] und schwierigste[n] Anforderung, welche die practische Philosophie an die Entwickelungslehre stellt«, wobei er sich ausdrücklich auf Herbert Spencer beruft. In den »socialen Instincten der Thiere« erkennt er eine bloß quantitativ unterschiedliche »Urquelle der sittlichen Entwickelung« auch beim Menschen, hier seien daraus »sociale Pflichten« geworden. Egoismus wird demgemäß schematisch der Selbsterhaltung zugeordnet, Altruismus der Arterhaltung. »Haeckel stellt keine neuen ethischen Normen auf, sondern erklärt die herrschenden entwicklungsgeschichtlich. Analog zur »Vorstellung einer phylogenetischen Hierarchie wachsender morphologischer und physiologischer Differenziertheit der Lebewesen wird von einer im Laufe der Entwicklung immer weiter sich herausbildenden Sittlichkeit ausgegangen«. Was zugleich einen »normativen Anspruch« erhebt und eine unerbittliche Auslese im `Daseinskampf auch hier zum Prinzip erklärt. ${ }^{1192}$

Der gesellschaftliche Einfluss der Rassehygieniker ist offensichtlich groß. So nehmen Ploetz, Schallmayer und Grotjahn neben Max Weber, Werner Sombart, Frauenrechtlerinnen wie Helene Stöcker und Marianne Weber und dem SPD-Politiker Eduard Bernstein 1909 an der Gründung der »Deutschen Gesellschaft für Soziologie« teil. »In der programmatischen Gründungsschrift wurden als soziologische Problemfelder unter

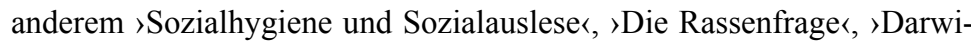
nismus und Sozialwissenschaft der Abnormitäten überhaupt « genannt.« Beim ersten Deutschen Soziologentag 1910 in Frankfurt/Main spricht Wilhelm Ploetz über »Die Begriffe der Rasse und Gesellschaft und einige damit zusammenhängende Probleme«. Er ernte zwar, so Bergmann, besonders von Max Weber heftige Kritik wegen seines Biologismus (wobei Weber »die Rassenhygiene als ernstzunehmende Forschungsrichtung« würdige), aber auch Beifall. Auch an der Gründung von Helene Stöckers »Bund für Mutterschutz« (1905) sind Rassehygieniker beteiligt. Stöcker selbst spricht sich für Maßnahmen aus, die Fortpflanzung »unheilbar Kranke[r] oder Entartete $[\mathrm{r}] \ll$ zu verhindern. ${ }^{193}$

Haeckels Schüler, langjähriger Freund und glühender Verehrer Wilhelm Bölsche - er ist, wie auch Haeckel oder Gerhard Hauptmann, Ehrenmitglied der 1905 gegründeten »Gesellschaft für Rassenhygiene« -

1191 Hermand, a.a.O., S. 72f.

1192 Vgl. Sandmann, a.a.O., S. 332f.

1193 Bergmann, a.a.O., S. 85ff. 
hat als »sozialdemokratisch-orientierte[r] Großstadt-Naturalist[]« begonnen. Mit seinem sich besonders auf Haeckel, aber auch Theodor Fechner, Goethe oder Novalis berufenden »panpsychistischen Monismus« und vor allem mit seinem zweibändigen »Liebesleben der Natur« (1898-1902) wird er zu einem der einflussreichsten Autoren eines spezifisch neuromantisch gewandelten Darwinismus. Hier wird der unbarmherzige Daseinskampf zu einer »Art erotischen Monismus oder Panerotismus, der etwas ausgesprochen >Lyrisches Evolution als ständige Höherentwicklung des Geschlechtstriebs von »niedersten Formen bei den Fliegen« bis hin »zu den erhabensten Augenblicken menschlicher Liebe« mit ihrer Verklärung der Sexualität »in den Ausdruck des Künstlerischen und Religiösen «. ${ }^{194}$ Bölsche kann damit auch Gustav Landauer beeindrucken. Landauer, 1919 von Freikorps in München ermordet, spricht sich selbst für Landsiedlungen und »einen neuromantischen Anarchismus « aus ${ }^{1195}$ und gibt Peter Kropotkins »Gegenseitige Hilfe in der Tier- und Menschenwelt« heraus. Kropotkin, der sich hier mit Darwin gegen dessen Epigonen wendet, entwickelt einen eigenen Darwinismus, in dem der >Daseinskampf $\prec$ nicht zwischen den Arten, sondern »als >metaphorischer Krieg` zwischen der Art und ihrer Umwelt« erscheint. Einerseits also entwirft er ein »sympathische[s] Bild des Tieres, begabt mit sozialem Geist «, der »helfende[n] Tiere und helfende[n] Menschen«, erfüllt von den »»Naturprinzipien` der Hilfsbereitschaft, Lebenslust, Freundschaftlichkeit, Unterstützungsbereitschaft und des Harmoniebedürfnisses und Gerechtigkeitssinnes«, andererseits spaltet er dieses auf, indem er - „auf irritierende Weise schizophren« - das Harmonische mit einem Naturbild konfrontiert, das mit »Feindlichkeit, Kampf, Bedrohtheit und Todesgefahren >aufgeladen«« wird. In diesem antagonistischen Entwurf einer »naiv-romantische[n] Idylle« und einer Umwelt der »brutalen Wildnis $«{ }^{1196}$ zeigt sich offenbar eine andere Form der sozialen (Rück-)Projektion, die Erfahrungen politischer Opposition verarbeitet.

Die Natur merzt also im Daseinskampf das Schwache und Kranke aus - und sie schafft dabei 〉Schönheit<. Die »monistische Naturästhetik« wird um 1900 zur »von vielen Schultern getragenen ästhetischen Bewegung«, zu der Schriftsteller wie Bölsche, Carl Hauptmann und Bruno Wille, die bildenden Künstler Karl Wilhelm Dieffenbach und Hermann

1194 Hermand, a.a.O. S. 74f.

1195 Linse: Ökopax und Anarchie, S. $72 \mathrm{ff}$.

1196 Holland-Cunz, Barbara: Soziales Subjekt Natur. Natur- und Geschlechterverhältnis in emanzipatorischen politischen Theorien. Frankfurt/M, New York: Campus 1994S. 153f. 
Obrist, Mäzene und »eine Reihe von Naturforschern«, wie Wilhelm Breitenbach zählen. »Für den Standpunkt dieses Personenkreises ist eine evolutionstheoretisch verbrämte Stilisierung und >Verzauberung` der Natur charakteristisch. ${ }^{1197}$ Nach Hermand ist die Wirkung dieser »neoreligiösen Form des Monismus« unter dem 〉Gegenpapst< Haeckel »auf die sogenannten Neuromantiker um 1900« nicht zu unterschätzen. Hier werde, was auch Hermann Hesse beeinflusse und die Werke Waldemar Bonsels hervorbringe, versucht, naturwissenschaftliche »trockene« Fakten »in schwärmerische >Gefühlswerte umzusetzen«. Wo die Angehörigen des Monistenbundes »das Gesellschaftliche im Auge behielten«, herrscht bei den Neuromantikern Eskapismus. Die meisten verlassen die »großen Städte und zogen aufs Land oder in die neugegründeten Gartenstädte. Wenn sie >Natur` schilderten, taten sie dies fast ausschließlich im Sinne einer monistischen oder pan-psychischen Beseelungstendenz, die deutlich ins Stimulierende, Paradiesische, wenn nicht Ekstatische tendiert ${ }^{1198}$

Der begeisterte Landschaftsmaler Haeckel ${ }^{199}$ beschreibt den »Monismus«, dessen »drei Hauptgebiete« Wissenschaft, Religion und Kunst seien, 1892 in seinen »Glaubensbekenntnissen eines Naturforschers« als >systemische< Anschauung, deren »Naturforschung als Erkenntnis des Wahren«, die »Ethik als Erziehung zum Guten« und die »Aesthetik als Pflege des Schönen «. ${ }^{1200}$ Hierbei geht es, im Kontext der um 1900 dominierenden Kunsttheorien um »die erkenntnisprägende Rolle des Sehens und seine Erlernbarkeit «. ${ }^{1201}$ Das führt zur Frage, was und wie zu Sehen erlernt werden soll.

In seinen »Kunstformen der Natur« (1899) stellt er die sechs Kategorien der »bedeutungslosen« - die er nicht vorkommen lässt -, »unbedeutenden«, »im ganzen unbedeutenden«, »mannigfaltigen, eigenartigen und reichhaltigen«, »sehr mannigfaltigen und schönen« und »äußerst mannigfaltigen, reichhaltigen und schönen Kunstformen« auf. Getreu der "phylogenetischen Ordnung« beginnt er bei den »Urpflanzen« und endet bei den Wirbeltieren. In der »kleinen Ausgabe« des Werks (1914) geschieht das einschließlich der Kunstform Mensch, hier ver-

1197 Kockerbeck, a.a.O., S. 82.

1198 Hermand, a.a.O., S. 73.

1199 1905/06 werden 40 seiner Aquarelle über die »Naturwunder der Tropenwelt « als »Wanderbilder « veröffentlicht. Darüber hinaus entstehen rund Hundert Bilder in Italien (vgl. Kockerbeck, a.a.O., S. 86, Fn. 14).

1200 Der Monismus als Band zwischen Religion und Wissenschaft; zit. n. Kockerbeck, ebda., S. 87.

1201 Kockerbeck, ebda. 
treten durch »Australische und Ozeanische Völker «. ${ }^{1202}$ Die Perspektive der Haeckelschen »Kunstformen«, so Kockerbeck, sei »ausschließlich formenästhetisch orientiert. Sie unterstellt den morphologischen Typus symmetrisch vollkommener idealer Formen«. Das verbinde platonische Ästhetik »mit Goethes morphologischem Vervollkommnungsbegriff«. Während dieser allerdings noch den Säugetieren die vollkommenste Gestalt zuschrieb, gehe es bei Haeckel, wie er 1917 in seinen »Kristallseelen « gestehe, primär um eine Auswahl nach »symmetrischen Formeigenschaften«. Dabei beteuere er, sich rein »auf die naturgetreue Wiedergabe der wirklich vorhandenen Naturerzeugnisse beschränkt« und sich jeder Stilisierung enthalten zu haben. Der »ornamentale und eigentümlich statische Eindruck« der Lithographien von Radiolarien und »höher organisierten wirbellosen Arten« stamme daher, schreibt Kockerbeck, dass Haeckels Lithograph die präsentierten »ohnehin schon symmetrisch sehr gehaltvollen Pflanzen und Tiere auf den einzelnen Tafeln nochmals symmetrisch gruppiert «. ${ }^{1203}$ Allerdings habe Richard Hoppe-Sailer 1995 darauf hingewiesen, dass bei Haeckel, ganz im Sinne alter Herbarien und Wunderkammern, eine umfangreiche »Stilisierung der Tiermotive« zu beobachten sei. Die »ausgewählten Tierarten« seien »zur Visualisierung seiner ästhetischen Überzeugungen einem mehrfachen Modifikations- und Abstraktionsprozeß unterworfen« worden, sie würden auf Kosten von »Mannigfaltigkeit«, unter Negierung ihres »Lebensumfeld $[\mathrm{s}] \ll$ und ihrer »Eigenarten« rein als poetisierte, dekorative Artefakte präsentiert, nicht als Repräsentanten lebendiger Arten, sondern als Abstraktionen »auf das Ideal ihrer Gattung«. ${ }^{1204}$

Ein Pseudo-Organismus, der Ornament und Geometrisierung feiert.

»Auch in der stereometrischen Konstruktion ihrer höchst regelmäßigen Kunstwerke verfahren sie mit der peinlichen Akkuratesse eines geschulten Geometers, und in der eleganten Ornamentik ihrer phantastischen Gitterschalen und deren vielgestaltigen Anhänge wetteifern sie mit der Phantasie der arabischen Architekten, die die Alhambra von Granada ausschmückten«,

schreibt Haeckel an anderer Stelle über die »kieselhaltigen Radiolarien «. ${ }^{1205}$ Auch Kockerbeck sieht »erhebliche wissenschaftstheoreti-

1202 Ebda., S. $92 \mathrm{f}$.

1203 Ebda., S. 94ff.

1204 Hoppe-Sailer, Richard: Der Biologe als Ästhet. Ernst Heinrich Haeckel, in: Jahrbuch des Kulturwissenschaftlichen Instituts am Wissenschaftszentrum Nordrhein-Westfalen; zit. n. ebda., S. 96, Fn. 16.

1205 Haeckel: Die Natur als Künstlerin. Mit 267 Abbildungen und zwei farbigen Kunstblättern. Berlin-Charlottenburg 1924 (Original 1914); zit. n. 
sche Probleme« in einem »Verständnis der Natur als Kunstwerk«. Denn wenn der »Schönheitswert der Naturformen« ausschließlich in ihnen selbst aufgefunden werden solle, »müssen die Organismen über ihre erhaltungsmäßige Organisation hinaus den Charakter von Kunstwerken aufweisen«, was den Darwinschen Fortschritt einer »Verbannung der Teleologie aus der Morphologie« rückgängig mache, da »ein Kunstwerk stets ein zweckhaftes Erzeugnis ist«. Bei Haeckel aber würde keine, auch keine »für ornamental geringwertig befundene Art« ausgeschlossen »aus dem >Reich des Naturschönen««, auch Ungefällige partizipierten am Gesamtkunstwerk Natur. ${ }^{1206}$ Hier sei die »Substanz als Gott-Natur« vorgestellt, die belebte wie unbelebte Materie »beseelt« und die einzelnen »Zellseelen« sind 〉kunstbegabtく, besitzen ein »Symmetriegefühl« und »ornamentale Potenz«. Anknüpfend an Novalis sieht Haeckel die Natur »aus einem inneren psychischen >Instinkt< nach ornamentaler Schönheit« streben. Als selbsternannter »mechanischer Materialist« sehe Haeckel qualitativ nur geringe »graduelle Unterschiede« zu menschlicher Kunst. ${ }^{1207}$

Im Werk Haeckels zeigt sich ein Zusammenhang von Wiederverzauberung der Welt durch Naturwissenschaft und einer ebenfalls naturwissenschaftlichen Propagierung >scharfer Ausleseく. Haeckels »beseelte Natur«, seine evolutionsbiologisch »verifizierte direkte 〉Seelenverwandtschaft « von Mensch und Tier« fungiert als Harmonisierung, die »die zumeist roh oder grausam anmutenden Selektionsprinzipien unterschlagen« lässt, sagt Kockerbeck. ${ }^{1208}$ Allerdings braucht es offenbar die gängige Abspaltung des Eugenikers, Rassehygienikers und Sozialdarwinisten vom Monisten, um in dieser Weise von >Unterschlagung $\ \mathrm{zu}$ sprechen. Wenn die `Sieger im Daseinskampf` bzw. die >höheren Entwicklungsstufen $<$ die >wertvolleren $<$ sind, die >Verlierer $<$ bzw. >niederen Entwicklungsstufen` inklusive der Menschen die >minderwertigen ‘, dann sollten erstere auch die >Schöneren`, letztere die >Hässlicheren sein. Kurz: Wenn die >Zuchtwirkung< durch >Konkurrenzkämpfeく Höherwertiges hervorbringen soll, dann auch ästhetisch Höherwertiges.

Für die Konstruktion des >natürlichen Waldes` in der »frühen Ökologie« heißt das:

Meyer, Kirsten: Der Wert der Natur. Begründungsvielfalt im Naturschutz. Bielefeld: Mentis 2003, S. 98.

1206 Vgl. Kockerbeck, a.a.O., S. 96.

1207 Vgl. ebda., S. 90f.

1208 Ebda., S. 89f. 
»Im klassischen Ansatz der frühen Ökologie wurde die ideale Klimax-Gesellschaft als Endstufe eines sukzessiven Entwicklungsprozesses in optimaler Anpassung an die Klimaverhältnisse, und im Grundsatz unabhängig von den Standortbestimmungen gedacht [...]. Das Klimax-Modell sieht den Gleichgewichtszustand als Ziel, dem das Ökosystem schnellstmöglich zustrebt. Störungen aller Art können diesen harmonischen Ruhezustand zerstören, worauf Sukzessionsprozesse eingreifen, um die Stabilität wieder herzustellen. Die Dominanz der Klimax-Phase in diesem Denkansatz erklärt auch, warum mit so hoher Übereinstimmung stets nur der ausgereifte, alte Wald als snaturnah taxiert wird. ${ }^{1209}$

In dieser bis dato dominanten Theorie erreicht der Wald einen »Gipfel, Höhepunkt «, ${ }^{1210}$ und wird so zum Monument seiner selbst. Dass diese Theorie mit der >reinen` Darwinschen Lehre einer stetigen Entwicklung nicht übereinstimmt, entspringt offenbar einem Zirkelschluss. Bäume werden nach Durchsetzungsfähigkeit von 〉Licht- $<\mathrm{zu} \gg$ Schattbaumarten hierarchisiert, wobei die Buche als >extremer Schattbaum fall den >Sieg`davonträgt. Weil die Buche im >Daseinskampf` ums Licht die stärkste ist, wird sie sich durchsetzen; weil sie sich durchsetzt, ist sie die stärkste, damit zugleich die >wertvollste und `ästhetischste art, 〉Schöpferin〈 der 〉heiligen Hallen〈. Die »Klimax-Idee« impliziere eine stetig

»zunehmende Stabilität im Waldbestand - infolge seiner räumlichen und zeitlichen Homogenität im ausgereiften Gleichgewichtszustand - gepaart mit zunehmender Artenvielfalt in der Schlußwaldgesellschaft. Diese beiden Größen bedingten einander gegenseitig, so daß eine ungestörte Waldentwicklung, z.B. durch `Nicht-Eingreifen〈, automatisch zu artenreicheren, stabileren Waldgesellschaften führen soll ${ }^{1211}$

Folglich gelten Buchenwälder als besonders artenreich (obwohl der hier herrschende Lichtmangel dem, zumindest bezüglich anderer Pflanzen, weitgehend widerspricht). In dieser traditionellen Ökologie-Auffassung gibt es so etwas wie eine >Kontraselektion<. Für die »Verfechter einer ideologisierten Gleichgewichtsthese« seien »Störungen eine schädliche Unterbrechung der von der Natur gewollten Waldkontinuität«. Daher müssten Vorsorgemaßnahmen getroffen werden, um »Sturm, Feuer und Insektenfraß« zu verhindern. »Das >Waldwesen wird« dabei »als sehr robust gegenüber natürlichen Umwelteinflüssen gesehen«; hingegen

1209 Scherzinger, Wolfgang: Naturschutz im Wald, S. 177.

1210 Ebda.

1211 Ebda., S. 178. 
könnte aus dieser Sicht »jeder anthropogene Eingriff das systemtypische Gleichgewicht erschüttern«. Das bietet in der Folge

»eine Ansatzstelle für Katastrophen, die auf die durch Menschen verschuldete Irritation reagieren und das ganze Aufbauwerk des alten Waldes vernichten können. Störungsbedingter Zusammenbruch eines Waldes wird daher, genauso wie der Kahlschlag im Forstbetrieb, als >untypische< Ausnahme und als >naturfern eingestuft ${ }^{1212}$

Scherzinger, der selbst eine - noch relativ junge - dynamische Ökologietheorie vertritt, die das Klimax-Modell für »naturwidrig« hält, verweist darauf, dass ein solches $»$ Ideal einer dauerhaft stabilen Waldgesellschaft [...] nirgends verwirklicht « sei. ${ }^{1213}$ Dieses Modell ewiggültiger Waldmonumente aber ist (auch, wenn sich hierin unterschiedliche Ausprägungen differenzieren lassen ${ }^{1214}$ ) ein in jeder Hinsicht konservatives. Es findet sich, zusammen mit dem Begriff des `Daseinskampfes`, bei nationalistischen Naturschützern wie Schoenichen, Feucht et al. Der >Daseinskampf` aber wird hier zum alles überragenden Leitthema der Waldkonstruktion, in dem >Wildnis $<$ und $>$ Kulturlandschaft $<$ verschmelzen, in dem sich endgültig männlich definierte >Wildnis` und >natürliche Tugend $<$ wechselseitig bedingen.

\section{Der Wald als kämpferische Volksgemeinschaft}

»[...] gerade hier hat die Evolutionshypothese eine Wahrheit - die Bedeutung des Kampfes - zufällig erwischt, es wäre wirklich unvernünftig, sie preiszugeben, bloss damit, >was Fortschritt der Menschheit bedeutet, endlich wahr werde « ${ }^{1215}$

Wenn die Grenze zwischen Mensch und Tier nur eine zufällige sei, kritisiert Houston Stewart Chamberlain den Darwinismus, dann könne von einem Fortschreiten gar keine Rede sein, nicht einmal von einem »Schreiten«, ob nun »nach vorn oder zurück«. Vielmehr gehe es dann um die »Pulsation« des immer Gleichen. Nehme man den `Kampf ums Dasein` ernst, dann müsse Fortschritt aus einem sich steigernden »Massaker« bestehen. Was den Vordenker der nationalsozialistischen Rasse-

1212 Ebda.

1213 Vgl. ebda.

1214 Vgl. Ausleitung.

1215 Chamberlain, Houston Stewart: Die Grundlagen des neunzehnten Jahrhunderts. 2 Bde. Ungekürzte Volksausgabe. München: F. Bruckmann $1942^{18}$. Bd. 2, S. 854. 
ideologie und Schwiegersohn Richard Wagners an der Evolutionstheorie stört, ist eine für die menschliche Gesellschaft immer wieder in Aussicht gestellte `höhere Evolution`, mit deren Erreichen der Kampf aufhöre. Für einen derartigen "paradiesische[n] Frieden«, wie ihn John Fisk voraussage, hat Chamberlain nur Spott übrig: Wenn die Seele im Kampf erzeugt worden sei, müsse sie dann ohne ihn nicht entarten? ${ }^{1216}$

Wie notwendig dieser Kampf sei, zeige das Beispiel der USA: »Wir schaudern, wenn wir die Geschichte der Vernichtung der Indianer in Nordamerika lesen: überall auf Seiten der Europäer Ungerechtigkeit, Verrat, wilde Grausamkeit; und doch, wie entscheidend war gerade dieses Zerstörungswerk für die spätere Entwicklung einer edlen, echt germanischen Nation auf diesem Boden! Der vergleichende Blick auf die südamerikanischen Mestizenkolonien zeigt es uns. « ${ }^{1217}$

Er, der mit »Wonne [...] in den monumentalen Werken Buffon's« gelesen habe, oder denen Lamarcks, zeigt sich als Verächter Haeckels und Bölsches und »der unübersehbaren >populären` Literatur zur Verbreitung afterwissenschaftlicher Scheinweisheit «. ${ }^{1218}$ Das »traurigste Beispiel umgibt uns Heutige von allen Seiten in der Verblödung der Massen durch Ernst Haeckel, dem es an Wissen nicht fehlte, wohl aber an jedem Sinn für die Nacht unseres Unwissens«. Chamberlain dagegen vertritt ein »exaktes Nichtwissen «, ${ }^{1219}$ und vor allem eine »germanische Wissenschaft «, die er als Bestandteil einer »zielbewußte[n] Verteidigung »gegen das Ungermanische« propagiert, denn: »Die heiligste Pflicht des Germanen ist, dem Germanentum zu dienen« und »Rücksicht ist Verbrechen an sich selbst «. ${ }^{1220}$ Kennzeichen dieser »germanischen Wissenschaft« seien »Gehorsam auf der einen Seite, nämlich gegen die erfahrene Natur; Eigenmacht auf der anderen, nämlich dem Menschengeist gegenüber«. Ihre Methode ist die »Erfahrung - d.h. genaue, minutiöse, unermüdliche Beobachtung - gibt das breite, felsenfeste Fundament germanischer Wissenschaft ab, gleichviel, ob sie Philologie oder Chemie oder was sonst betreffen «. ${ }^{1221}$

Auch Oswald Spengler gibt sich als Haeckelverächter, spricht von »dem seelenlosen, entseelenden Freilicht der Generation Haeckel «. ${ }^{1222}$ Der »handfeste Glaube«, den »Haeckel mit dem Namen Atom, Materie,

1216 Vgl. ebda., S. 852f.

1217 Ebda., S. 901f.

1218 Chamberlain: Lebenswege meines Denkens. München: Bruckmann $1922^{2}$, S. 120f.

1219 Ebda., S. 349.

1220 Ders.: Die Grundlagen des neunzehnten Jahrhunderts, S. 859.

1221 Ebda., S. $936 f$.

1222 Spengler: Der Untergang, S. 325. 
Energie verband«, sei »von dem Fetischismus des Neandertalermenschen nicht wesentlich verschieden «. Spengler setzt dem das »faustische Weltgefühl« entgegen, das »Tiefe anders« erlebe. »Hier erscheint als Inbegriff des wahren Seins der reine wirkende Raum. Er ist das Sein schlechthin. Deshalb wirkt das sinnlich Empfundene, das mit einer bezeichnenden Wendung, die ihm den Rang anweist, das Raumerfüllende genannt wird, als Tatsache zweiter Ordnung und im Hinblick auf den Akt des Naturerkennens als das Fragwürdige, als Schein und als Widerstand, der überwunden werden muß, wenn man als Philosoph oder Physiker den eigentlichen Gehalt des Seins erschließen will. « ${ }^{1223}$ Und gegen »die zerlegende« Methode »des zoologischen 〉Pragmatismus` der Darwinisten mit ihrer Jagd nach Kausalzusammenhängen« setze er »die anschauende und überschauende Goethes«, den Faustischen Blick«, die »vergleichende Morphologie «. ${ }^{1224}$

Was dem Rassehygieniker und Eugeniker Haeckel beschieden war, wohlwollend als dem faschistischen Denken nahestehend rezipiert zu werden, ${ }^{125}$ trifft auf den monistischen Zoologen nicht zu. Andererseits wird der >Kampf ums Dasein` zu einem zentralen Begriff nationalistischer Naturkonstruktion. In diesem Kampfbegriff treffen sich >Wildnis und >Kultur`, eine Symbiose von »Idylle und Gewalt«, wie sie Thomas Dupke für den Roman »Wehrwolf« beschreibt. ${ }^{1226}$ Auch Hermann Löns, der bis heute prominenteste deutsche Heimatdichter, gibt sich als Verächter Darwins und Haeckels. Er lehnt deren Theorien ab, weil sie ein »Erklärungsmodell« anbieten, »das die Geheimnisse der Natur entzaubert und die herausragende Stellung des Menschen in dieser Natur angreift. Für Löns ist der Mensch, auch der Urmensch, der Herrscher der Natur, dessen Position nicht angetastet werden darf«. Zugleich sind seine Texte eindeutig »unter dem Zeichen des (Sozial-)Darwinismus« geschrieben. Er entwirft aggressive Idyllen einer religiös verklärten, auratischen Natur, die er gleichzeitig voyeuristisch sexualisiert. ${ }^{1227}$

»Löns präsentiert in seinen Texten eine imaginäre Ersatzlandschaft, ein künstliches Paradies, in dem er phantasmagorisch sein Wunschdasein verwirklicht. Die >Lönssche Natur`stellt einen Identifikations-, Satisfaktions- und Stimulationsraum zugleich dar, in dem der Lönssche Jäger seine Strebungen

1223 Ebda., S. 511.

1224 Ebda., S. 140f.

1225 Vgl. Sandmann, a.a.O., S. 339.

1226 Vgl. Dupke: Mythos Löns, S. 161.

1227 Vgl. ebda., S. $121 \mathrm{f}$. 
nach Herrschaft und Urmenschentum, Sinnlichkeit und Identität befriedigen kann. ${ }^{1228}$

Dabei präsentieren sich die Texte als Abfolge von Erregung, Höhepunkt - »dem Schuß des Jägers« - und Entspannung, sowie erneut sich aufbauender Erregung »bei der nächsten Jagd «. ${ }^{122}$ Auch bei Löns hat die Natur »etwas Jungfräuliches«. ${ }^{1230}$ Die Jagd wird so zur gewaltsamen 〉Entjungferungく. Das Ganze ähnelt einerseits dem, was Theweleit als den »Lustmord«, wie er in der Freikorpsliteratur an realen proletarischen Frauen verübt wird, bezeichnet. Auch hier wird das >Lebendige « weit entfernt vom eigenen Leib - es wird ihm das Leben genommen - und zugleich wird es durch das Eindringen mit dem Schuss »ganz nah« gehabt, was »die eigentliche Befriedigung $\mathrm{zu}$ bringen« scheine. ${ }^{1231} \mathrm{Die}$ Lönsschen Jäger sind aber andererseits nicht bedroht von Frauen, sie befinden sich nicht in Großstädten, sondern sie üben Herrschaft aus in idyllischer Landschaft. Hier scheint alles seine >organische` Ordnung zu haben. Auch Hermann Löns vertritt eine »Philosophie des Organischen ${ }^{1232}$

Wie schon Riehl, entwirft Löns in seinem »Wehrwolf« zunächst die Okkupation einer >uranfänglichen Bestialitätı und die Übernahme von Herrschaft.

»Am Anfang war es wüst und leer in der Heide. Der Adler führte über Tage das große Wort, und bei Nacht hatte es der Uhu; Bär und Wolf waren Herren im Lande und hatten Macht über jegliches Getier. Kein Mensch wehrte es ihnen, denn die paar armseligen Wilden, die dort vom Jagen und Fischen lebten, waren froh, wenn sie das Leben hatten und gingen den Untieren liebendgern aus der Kehr. Dann kamen eines Abends andere Menschen zugereist, die blanke Gesichter und gelbes Haar hatten; mit Pferd und Wagen, Kind und Kegel kamen sie an. [...] Ein jeder suchte sich seinen Platz und baute sich darauf ein breites Haus « ${ }^{1233}$,

beginnt sein Roman. Löns entwirft einen Beginn von >deutscher Heimat $\iota$, geschaffen von einer tatkräftigen blonden und hellhäutigen $>$ Rasser.

1228 Ebda., S. 122.

1229 Ebda., S. $122 \mathrm{f}$.

1230 Ebda., S. 122.

1231 Theweleit: Männerphantasien, Bd. 1, S. 229 ff.

1232 Dupke, a.a.O., S. 123.

1233 Löns, Hermann: Der Wehrwolf, in: Gesamtausgabe in fünf Bänden, Bd. 3, S. 115. 
In immer neuen Anläufen - aber ohne Variationen - wird diese >Urgeschichte im Zeichen von 〉Blut und Boden`, von >Verwurzelung und Rasseく erzählt. Oswald Spengler:

»Der ursprüngliche Mensch ist ein schweifendes Tier, ein Dasein, dessen Wachsein sich ruhelos durch das Leben tastet, ganz Mikrokosmos, ortsfrei und heimatlos, mit scharfen und ängstlichen Sinnen, immer darauf bedacht, der feindlichen Natur etwas abzujagen. Eine tiefe Wandlung beginnt erst mit dem Ackerbau - denn dies ist etwas Künstliches, wie es Jägern und Hirten durchaus fern liegt: wer gräbt und pflügt, will die Natur nicht plündern, sondern abändern. Pflanzen heißt etwas nicht nehmen, sondern erzeugen. Aber damit wird man selbst zur Pflanze, nämlich Bauer. Man wurzelt in dem Boden, den man bestellt. Die Seele des Menschen entdeckt eine Seele in der Landschaft; eine neue Erdverbundenheit des Daseins, ein neues Fühlen meldet sich. Die feindliche Natur wird zur Freundin. Die Erde wird zur Mutter Erde. Zwischen säen und zeugen, Ernte und Tod, Kind und Korn entsteht eine tiefgefühlte Beziehung. [...] Und als vollkommener Ausdruck dieses Lebensgefühls entsteht überall die sinnbildliche Gestalt des Bauernhauses, das in der Anlage seiner Räume und in jedem Zuge seiner äußeren Form vom Blut seiner Bewohner redet. ${ }^{1234}$

Dieser »Bauer« als »der ewige Mensch«, der »unabhängig von aller Kultur, die in den Städten nistet« dieser »vorauf« gehe und sie überlebe, »dumpf von Geschlecht zu Geschlecht sich fortzeugend «, ist »eine mystische Seele« und »immerfließende Quelle des Blutes «. ${ }^{1235}$ Dieser »ewige Bauer« wird zum »Inbegriff einer intakten völkischen Gemeinschaft«, Symbol der »Beharrung gegenüber dem unfruchtbaren, nomadischen Zivilisationsmenschen«, führt ein hierarchisch geordnetes und stabiles Familienleben, das Generation für Generation vererbt wird. Als Individuum ist er qua Verschmelzung mit Natur und Familie kaum auszumachen. »Diese Symbiose, über Jahrhunderte gewachsen und qualitativ geprägt von den Eigentümlichkeiten einer spezifischen Landschaft und kulturellen Tradition, ist zugleich Garant dafür, daß Natur und menschliches Leben im gleichen Rhythmus schlagen. Volk und Heimat, Blut und Boden, Haus und Hof bilden eine untrennbare Einheit. « ${ }^{1236}$

Immer wieder wird das 〉Organische〈 beschworen. »Es gibt eine organische Logik, eine instinkthafte, traumsichere Logik allen Daseins im Gegensatz zu einer Logik des Anorganischen, des Verstehens, des Verstandenen.« Denn: »Die Schicksalsidee verlangt Lebenserfahrung, nicht 
wissenschaftliche Erfahrung, die Kraft des Schauens, nicht Berechnung, Tiefe, nicht Geist. « ${ }^{1237}$

Derartige Aussagen entstammen einem - wenn auch durchaus heterogenen - >völkischen ( Reservoir, in dem »Ratio und Logik als ausländisch und Gefühl und Mystik als deutsch, städtischer Kapitalismus und Liberalismus als amerikanisch und artifiziell und ländliches bäuerliches Leben als deutschvölkisch und organisch« betont werden. >Zivilisation wird hier als »etwas Äußerliches, darum erlernbar wie ein Handwerk», oberflächlich und flüchtig, anorganisch und vor allem als etwas Übernationales, nicht Abgrenzendes, definiert. Demgegenüber steht die $>$ Kultur` als »etwas Innerliches, Angeborenes, Ererbtes«, 〉historisch-organisch Gewachsenes`, weshalb dieser »Kulturbegriff dem Naturbegriff« angenähert ist, >Kultur〈 die »Art des Verkehrs mit der Natur« ausmacht, bzw. eine »Ersatzhandlung für die verlorengegangene Natur« darstellt. ${ }^{1238}$ Mit der Konfrontation von >Kulturく und `Zivilisation ২ hat sich bereits Norbert Elias beschäftigt. Hierbei untersucht er die Selbstdefinitionen qua >Zivilisation in Frankreich und England, wo Zivilisation den »Stolz auf die Bedeutung der eigenen Nation und den Fortschritt des Abendlandes und der Menschheit« ausdrücke und sich auf etwas beziehe, das ständig in Bewegung sei, sowie die Selbstdefinition qua >Kultur in Deutschland, dessen Bewegungsrichtung eine andere sei, sich auf Produkte beziehe, »in denen die Eigenart eines Volkes zum Ausdruck« komme. »Der Begriff Kultur grenzt ab. « ${ }^{1239}$

Mit diesem Kulturbegriff, insbesondere in seiner deutlich völkischen Prägung, verschmolzen sind dann auch die `natürlichen Eigenarten`. Die völkische »Suche nach nationaler Identität« spiegele sich, so Joachim Wolschke-Bulmahn, »in einer besonderen Naturästhetik wieder«. Eine »Nationalisierung der Natur« entwirft zum einen die Symbiose von den >Germanen matische Äußerungen des ausgehenden 18./frühen 19. Jahrhunderts. So hat, beeinflusst von der Philosophie Herders und anderer, der bedeutende Gartentheoretiker Friedrich Ludwig von Sckell (1750-1823) die »Verwendung >vaterländischer` Bäume und Sträucher, Pflanzungen patriotischen Charakters, Einfachheit und patriotische Bilder« gefordert. Von Alexander von Humboldt stammt die Idee der ") vaterländischen

1237 Spengler, a.a.O., S. 153.

1238 Wedemeyer, Bernd: »Zurück zur deutschen Natur«. Theorie und Praxis der völkischen Lebensreformbewegung im Spannungsfeld von »Natur«, $»$ Kultur« und »Zivilisation«, in: Brednich, Wilhelm et al. (Hg.): Natur Kultur, S. 387ff.

1239 Elias, Norbert: PDZ 1, S. 4ff. 
Pflanzengestalten und vom entscheidenden Einfluß der Vegetation eines Landes auf die Entwicklung der Kultur«. So nimmt er an, dass die Physiognomie der Pflanzen »sogar den Charakter von Völkern beeinflussen könne ${ }^{1240}$ So wird dann auch >Wildnis` als nationale Kultur eingemeindet. In diesem Sinn wird die Wichtigkeit von Pflanzensoziologie betont, um »ausländische Pflanzen« kenntlich machen und aussondern zu können. Das betont etwa 1936 Arnold Freiherr von VietinghoffRiesch in seiner Tharandter Habilitationsschrift, in der »totale[r] Staat« und die »Erhaltung der Naturkraft in ihrer Totalität als Gemeinschaftsträger ${ }^{1241}$ die »ernste Sorge« verlange, dass die »Rückkehr zum deutschen Walde auf pflanzensoziologisch durchdachte Weise erfolgt «. ${ }^{1242}$

Der Württemberger Oberforstmeister Otto Feucht spricht 1926 im von Walther Schoenichen herausgegebenen Werk »Vom grünen Dom« über die wesentlichen Werte des heimischen Waldes. So »dürfen wir darum seine mittelbare sozialpolitische Bedeutung nicht unterschätzen, insbesondere seinen seelischen Wert. [...] Und man darf wohl sagen, daß gerade der Deutsche mehr als andere Völker auf solch unwägbare Dinge Gewicht legt. Ist doch unsere ganze Kulturauffassung wesentlich auf den Wald gegründet, im Waldland herangewachsen, auch wenn sie heute vielfach von Fremdeinflüssen überwuchert und verdrängt ist«. Hier beruft sich Feucht auf Riehls »Land und Leute«, das dieser »unter dem Eindruck der nach 1848 drohenden und teilweise auch ausgeführten Waldzerschlagungen « verfasst habe. ${ }^{1243}$

Schoenichen selbst, seit 1924 Leiter der »Staatlichen Stelle für Naturdenkmalpflege in Preußen« und führender »Integrationstheoretiker« des »Bundes Heimatschutz«, also jenen, die 1928 »die kompromißbetonte >Verbindung von fortschritts-optimistischer Technikbejahung und die Rückkehr zu den handwerklich-völkischen Wurzeln des Kulturschaffens« als Ziel der neuen Naturkonzepte ausgeben« und »für einen ästhetisch befriedigenderen Ausgleich zwischen Technik und Land-

1240 Wolschke-Bulmahn, Joachim: Findlinge. Landschaftsgestaltung und die völkische Suche nach nationaler Identität im frühen 20. Jahrhundert, in: Gröning, Gert/Schneider, Uwe (Hg.): Gartenkultur und nationale Identität, S. 78.

1241 Zit. n. Küster: Geschichte des Waldes, S. 213.

1242 Zit. n. ebda., S. 215.

1243 Feucht, Otto: Vom Walde, in: Schoenichen, Walther (Hg.):: Vom grünen Dom. Ein deutsches Wald-Buch. Im Namen der Staatlichen Stelle für Naturdenkmalpflege in Preußen herausgegeben von Walther Schoenichen unter Mitwirkung von Forstmeister Otto Feucht - Teinach i.Wb., Prof. Dr. Hans Hausrath - Freiburg i.B. und Prof. Dr. Max Wolff Eberswalde. München: Callwey 1926, S. 90ff. 
schaft « plädieren, tritt - wie praktisch alle diese Vertreter - 1933 in die NSDAP ein. 1934 erwartet er in »Naturschutz im Dritten Reich«, dass sich Wilhelm Heinrich Riehls »Recht auf Wildnis« im Nationalsozialismus durchsetzt, acht Jahre später »behauptet er in seiner Studie Naturschutz als völkische und internationale Aufgabe, daß die Ausführungsbestimmungen des >Reichsnaturschutzgesetzes` die >endgültige Erfüllung der völkisch-romantischen Sehnsüchte` gebracht hätten «. ${ }^{1244}$

Schoenichen verwendet permanent kriegerische Bergriffe zur Beschreibung oder Klassifizierung von Baumarten: »Hauptwaffe der Hainbuche im Daseinskampfe ist ihre [...] Ausschlagsfähigkeit «, ${ }^{1245}$ schreibt er auch noch 1950, oder er betont die »reckenhaften Gestalten der Eichen « in alten Hutewäldern ${ }^{1246}$ usw. Eine Symbiose von Pflanze und 〉Rasse< wird hier ganz selbstverständlich entworfen: »Das Kernholz« der Eiche »hieß im Ur-Indogermanischen >dru<; ein Stamm, der sich in unserem Wort >Treue $<$ wiederfindet. Bedenkt man, daß die Treue in der sittlichen Auffassung der nordischen Rasse zu den höchsten Tugenden gezählt wurde, so darf man erwarten, daß die Eiche auch in dem Kultleben jener alten Völker eine bedeutungsvolle Stellung innegehabt haben wird«. So »als Lebensbaum schlechthin« und damit zusammenhängend, betont Schoenichen, die Verwendung von Eichenholz »für Grabzimmerungen und Särge« von »vorgeschichtlicher Zeit« bis »tief ins Mittelalter und darüber hinaus«, später dann aber »den gehobeneren Schichten vorbehalten«. Ebenso sei Eichenlaub »als Schmuck der Aschenurnen schon in vorgeschichtlicher Zeit verwendet worden«. Das »man« damals »an den Hünengräbern und sonstigen Kultstätten vielfach Eichenbäume anzupflanzen pflegte«, könne man »als sicher annehmen«, »eine Sitte, die von der Neuzeit wieder aufgenommen worden ist «, am Grab des Dichters Theodor Körner in Mecklenburg etwa; besonders aber »auf dem Friedhof unserer todesmutigen Jugend von Langemarck wurden Hunderte von jungen Eichen erstellt, die - wenn sie nach Jahrhunderten $\mathrm{zu}$ einem stattlichen Hain herangewachsen sind - ein Ehrenmal bilden werden, wie es wuchtiger und würdiger nicht erdacht werden kann «. ${ }^{1247}$ Seine Bücher sind durchzogen vom Versuch, historische Kontinuitäten $\mathrm{zu}$ konstruieren, den deutschen Wald als wehrhafte Wildnis zum >lebendigen` Monument nationaler Kultur aufzutürmen; dabei scheut er auch vor selbstverfassten Gedichten nicht zurück, um etwa die Eiche als

1244 Hermand: Grüne Utopien, S. 110 u. 113f.

1245 Schoenichen: Von deutschen Bäumen. Berlin: de Gruyter 1950, S. 143.

1246 Vgl. ebda., S. 100.

1247 Ebda., S. 112f. 
strutzige Krieger` und Garanten völkischer Freiheit vorzustellen. ${ }^{1248}$ »Die Eiche ist hart und bitter, und es ist nichts Weiches an ihr«, zitiert Schoenichen Hildegard von Bingen und folgert: »Dem entspricht wohl, wenn die Eiche dem Gemütsleben des deutschen Volkes nicht in dem selben Maße nahegestanden hat wie etwa die Linde. Der gewaltige, reckenhafte Baum galt mehr als das Wahrzeichen der völkischen Kraft und war als solches mehr Gegenstand einer bewundernden Verehrung als einer engen freundschaftlichen Vertrautheit «. ${ }^{1249}$ Die Scheu vorm großen Krieger und Führer? Eine Bewertung, die »in der Neuzeit aber erst wieder unter dem Einfluß des romantischen Geistes« überwunden werde, so bei den Grimms und ihrer »Begeister[ung]« über »den herrlichen Märchenschatz des deutschen Volkes«. Erst mit dem Ende des Klassizismus werde die Eiche dann wieder zum Lebenssinnbild in der Sepulkralkunst, oder zum Friedenszeichen (Eichenlaub), befördert durch die Turn- und Sportbewegung. ${ }^{1250}$

Im Bemühen um Kontinuität hat Schoenichen auch schon eine Art geregelte Forstwirtschaft in germanischer Urform zu bieten: »Während der Jungsteinzeit war dann der Eichenmischwald in der Urheimat der germanischen Völker [...] vielerorts vorherrschend. Daß diese Waldungen von den Erfindern des geglätteten Steinbeiles bereits stark und in mannigfaltiger Weise genutzt worden sind«, sei zweifelsfrei, »denkbar« sogar, »daß die Eichenwälder auch damals bereits in den Gesamtbetrieb der bäuerlichen Wirtschaft eingegliedert waren, wie dies später in geschichtlicher Zeit der Fall gewesen ist«. So legten »gewisse Funde« im »Berumvehner Moor[] in Ostfriesland « und im »Ihauser Moor« - Baumstümpfe in regelmäßigen Abständen - nahe, dass damals »bereits eine gewisse Pflege und Hege des Eichenwaldes« betrieben worden sei. Sicher sei so etwas »in Nordwestdeutschland in früher geschichtlicher Zeit der Fall gewesen. Aus alten Karten wird ersichtlich, daß die Einödhöfe vielfach von einem mit Eichen bestandenen Wall umgeben waren,

$1248 »$ Ich bin die Kraft, ich bin der Eigenwille!/Rauhborkig trutzt mein Stamm mit Turmes/Macht./Mein Astwerk fügt in herrisch zack'ger Tracht/sich sonderem Gesetz. Durch Laubes Fülle,/gesammelt nicht zu streng geschloss'ner Hülle,/der Sonnenstrahl zum Waldesboden lacht/und schafft, daß bunte Blütenpracht/und Rasengrün dem Erdreich rings entquille./Mein Lebenswille, nie im Kampfe weich,/strebt er nach tausendjährigem Bestehen./Stark will ich sein, doch nicht von mir/zugleich/soll finst'res Unterdrückertum ergehen:/Frei laß mit Milde ich zu meinen Füßen/die holde Kunst der Blumenträume sprießen.« Ebda., S. 121.

1249 Ebda., S. $119 f$.

1250 Vgl. ebda., S. $120 f$. 
innerhalb dessen außer Äckern und Wiesen geradlinig umrissene, zweifellos aus Pflanzungen hervorgegangene Eichenhaine lagen. Vielfach wurden derartige bäuerliche Sitze geradezu als Eichhöfe bezeichnet«. Schoenichen belegt das mit einem Protokoll von 1705. »Beachtlich« sei die oft »streng innegehaltene Verpflichtung, vor Abschluß des Ehebundes eine bestimmte Anzahl von Heistern zu pflanzen«. Derartige Belege für mittelalterliche und neuzeitliche »nordwestdeutsche[] Eichenhaine« in »fast durchweg [...] bäuerlicher Kultur«, mit Anzucht »in besonderen Baumschulen, die man als >Heisterhoff, Heisterkamp oder Telgengarten bezeichnete« ließe es als »nicht ausgeschlossen« erscheinen, derartiges sei »bis zurück zur Jungsteinzeit gang und gäbe gewesen «. ${ }^{1251}$

Der strutzigen Eiche zur Seite gestellt wird ein anderer Baum als Kennzeichen von >Volksgemeinschaft $<$ : Die Linde erscheint hier als wiederkehrende >Lindenhalleく, so wie die »Kunigundenlinde in Nürnberg, die um 1020 von »der Gemahlin Heinrichs II.« gepflanzt wurde. Weiter gebe es strenge Gerichtslinden, die teils bis ins 18. Jahrhundert genutzt worden seien, auch hier seien es Hallen, wie die Gerichtslinde »vor dem Osttor des Städtchens Neuenstadt, das schlechthin mit dem Zusatz >an der Linde〈 benannt wird«. Der »Urstamm des Baumes« sei Ruine, aber »mit einer Anzahl jüngerer Bäume umpflanzt worden, deren Geäst waagerecht ausgebreitet ist, so daß ein geschlossenes Laubdach entsteht«. Ähnlich »waren ehedem auch die Äste des alten Stammes laubenartig entfaltet, und zu ihrer Stützung war schon vor Jahrhunderten eine ansehnliche Zahl von Säulen aufgestellt«, wie aus einem Gedicht von 1504 hervorgehe. Zudem habe es massenhaft Tanzlinden gegeben, Bäume, unter und in denen getanzt worden sei, auf »quadratisch umrissene[n] Tanzsälen im Geäst der Bäume. Kein Wunder, meint Schoenichen, war doch »die Linde ehedem der Liebesgöttin Frigga geweiht, und damit war sie zugleich der Baum, der dem Herzen des Volkes am nächsten stand. Dagegen vermochte späterhin« - anders, als bei der Eiche - »auch der christliche Einfluß nicht aufzukommen, und so erteilte die Kirche schon in früher Zeit der Linde ihren Segen «. ${ }^{1252}$ Geschildert wird auch der $>$ Missbrauch dieser Monumente natürlichen »Massenbaus $«,{ }^{1253}$ so geschehen an einer »der ältesten Linden Deutschlands« (ca. 1100 Jahre alt) im »fränkischen Städtchen Staffelstein«, in deren enormen Innern der Feind sein Unwesen treiben konnte: »Bereits in der Zeit der Freiheitskriege wird berichtet, daß der französische Marschall Berthier aus

1251 Ebda., S. 94ff.

1252 Ebda., S. 156ff.

1253 Clemens-Schierbaum, Ursula: Mittelalterliche Sakralarchitektur in Ideologie und Alltag der Nationalsozialisten. Weimar: VDG 1995, S. 76ff. 
Übermut in die Höhlung des Baumes einritt und darin sein Pferd wendete. Lange war dann die Linde vernachlässigt: Zigeuner machten sie zu ihrem Unterschlupf, und Stück für Stück von ihr ging zu Grunde.« Erst seit den 1860er Jahren habe die Stadt begonnen, den Baum zu erhalten. $^{1254}$

>Wildnis` und >ursprünglicher` Wald werden oft konsequent, wie schon bei Riehl oder später bei Löns, als Resultat einer ursprünglichen Okkupation entworfen, die dann eine sesshafte >organische Einheit`von rauhen, kämpferischen Menschen in patriarchal-hierarchischen Gemeinschaften in untrennbarer Verbindung behaupten. Es entsteht eine Blutund-Boden-Genealogie, deren Ziel, auch praktisch, in Naturschutzkonzepten, »das Stillstellen einer Veränderungsdynamik « ${ }^{1255}$ ist. In diesem Rahmen erscheinen Widersprüche zwischen `Kulturlandschaft $\iota$ und `Urlandschaft « weitgehend aufgehoben. Bei einer »berühmte[n] Zusammenkunft der sogenannten Jugendbewegung auf dem Hohen Meißner bei Kassel« 1913 aus Anlass der Hundertjahrfeier der >Völkerschlacht bei Leipzig beklagt Ludwig Klages »den Untergang der Natur im Zeitalter der Industrie« und das »wenig anmutende« Aussehen geregelter, soldatisch angepflanzter Kunstwälder. In diesem Zusammenhang verweist er auf Konrad Guenthers 1910 erschienenes Buch »Der Naturschutz«, in dem dieser am Beispiel des »Hasbruchs" im Oldenburger Land ein »eigenartige[s] Naturdenkmal«« schildert, ein »Denkmal aus altgermanischer Zeit«, das »mehr von dem Leben unserer Altvorderen als Wälle und Mauern« erzähle. Guenther bezeichnet den »Hasbruch« ausdrücklich als »Hudewald«, glaubt aber, die dort wachsenden Eichen seien Tausende von Jahren alt, die Hainbuchen »uralt«, so dass er deshalb - und wegen der Vielfalt der Pflanzen und des ungehemmten Wuchses der Bäume - zugleich von einem »Urwald« ausgeht. ${ }^{1256}$ Hansjörg Küster kann nachweisen, dass diese Bäume höchstens einige Hundert Jahre alt sind und dass ihr bizarrer Wuchs gerade durch wirtschaftliche Nutzung, teils durch >Büschelpflanzung usw. entstanden ist. ${ }^{1257}$ Aber darauf kommt es nicht an. Eine anthropogene Beeinflussung wird von Guenther gar nicht geleugnet.

Bei Walther Schoenichen lässt sich eine Radikalisierung der Symbiose-Konstruktion von Wald und Gemeinschaft, von >Kultur` und >Na-

1254 Vgl. Schoenichen: Von deutschen Bäumen, S. 154.

1255 Fischer, Ludwig: Die »Urlandschaft« und ihr Schutz, in: Radkau, Joachim/Uekötter, Frank (Hg.): Naturschutz und Nationalsozialismus, S. 204.

1256 Vgl. Küster, a.a.O., s. $208 f$.

1257 Vgl. ebda., S. 209. 
tur beobachten. 1934 verfasst er sein Buch »Urwaldwildnis in deutschen Landen. Bilder vom Kampf des deutschen Menschen mit der Urlandschaft «. Hierin zeigt sich besonders deutlich, welcher Art die immer wieder beschworene >organische Lebendigkeit` ist.

»In der Wildnis reckenhafter Baumgestalten hat sich der heldische Geist germanischer Krieger immer aufs neue gestählt und gefestigt. Eine gehärtete Rasse wuchs hier heran - Geschlechter von Führern, bestimmt und befähigt, die Geschicke der Welt zu leiten. In hartem Kampfe mit dem Walde schuf sich der deutsche Mensch, mit zäher Entschlossenheit vorwärtsdringend, seinen Lebensraum. [..] Hier will uns der deutsche Wald mit seinen kühn in den Raum sich emporreckenden Säulen, mit seinen siegfriedhaften Heldengestalten erscheinen wie ein Sinnbild für das Dritte Reich deutscher Nation. « ${ }^{1258}$

Der >Kampf^ ist und bleibt in diesen Positionierungen das wesentliche Kennzeichen von Wald. Da »marschieren Wacholderbüsche auf in Reih und Glied« wie »schwärmende Schützenketten«, ist der Wald ein vom Nebel umwallter »Vorposten [...] an den Flanken des Gebirges«, und »Fichte und Bergahorn vereinigen sich zu treuer Kameradschaft am nebelfeuchten Bergeshang «. ${ }^{1259}$ Da tritt »die Fichte [...] in breiten Fronten den Vormarsch gegen die baumlose Hochgebirgslandschaft « an, begleitet vom Bergahorn, "Lärchen und Arven bilden die Vorhut. Aus schlanken, säulenförmigen Gestalten setzen sich die Regimenter dieser in kühnem Angriff vorwärtsstrebenden Truppen zusammen«, in »den vordersten Linien« nehmen die Bäume »im Trommelfeuer der nimmer ruhenden Schlacht übel zugerichtete Formen an. Hier und da aber auf Felsvorsprüngen und an steilen Hängen hat ein Recke sich seine Stellung er obert, die er mit turmhaftem Trutz behauptet «. ${ }^{1260}$

Klaus Theweleit hat eine derartige Sprache - in den Berichten der Freikorpsler - als »Anti-Produktion« charakterisiert, die eine »zerstörende und eine zeugende Seite« habe: »Aus der entlebendigten Realität baut sie ihre neuen Ordnungen. ${ }^{1261}$ Diese Sprache sei unfähig zur »Objektbeziehung« und dazu, »das Eigenleben ihres Gegenstandes ernst« zu nehmen oder zu achten. ${ }^{1262}$ Bei den völkischen Naturschützern ist eine deutlich vergleichbare "Anti-Produktion« zu beobachten. In den Beschwörungen eines lebendigen Waldes wird alles zum >Heldischen`, 〉Kämpferischen` usw. Es marschieren Monumente auf, alles erstarrt im

1258 Zit. n. ebda., S. $211 \mathrm{f}$.

1259 Zit. n. ebda., S. 213.

1260 Zit. n. Fischer, a.a.O., S. 189.

1261 Theweleit: Männerphantasien 1, S. 270.

1262 Vgl. ebda., S. 268. 
ewigen Kampf, kurz: »Was diese Sprache erfaßt, bringt sie um. Nicht nur Abwehr- sondern auch Angriffsmechanismen sind in ihr wirksam. (Die Projektion ist ein bloßer Abwehrmechanismus.) Auf das Selbst bezogen funktionieren ihre Mechanismen als Erhaltungsmechanismen. Auf die Objekte bezogen funktionieren sie als Abtötungsmechanismen. Beide sind miteinander gekoppelt; sie sind wirksam in derselben Aktion, sind zwei Wirkungen desselben Prozesses. « ${ }^{1263}$ Auch Schoenichen »entlebendigt« die von ihm ergriffenen »Realitätspartikel« in einem »parasitären sprachlichen Zugriff«. Der >Wildwuchs «, das 〉bizarre « Eigenleben der Bäume, wird so in einer »Besatzungssprache«, die »imperialistisch gegen jede Art selbstständiger lebendiger Bewegung gerichtet « ist, ${ }^{1264}$ abgetötet, seiner bedrohlichen Vitalität beraubt und zum heroischen Monument aufgebaut. Die einzig zulässige Lebensregung ist der Kampf gegen das Lebendige. Auf der »Zeugungsseite« wird die

»ihres Eigenlebens beraubte Realität [...] neu formiert, zu großen übersichtlichen Blöcken zusammengeschoben, die als Baumaterial dienen für eine übersichtlichere, zukünftige monumentale Welt«, ${ }^{1265}$

wobei in diesem Fall die Geschichte, der >Urwald « der >Germanen` die >utopische< Folie abgibt.

»Der Monumentalismus des Faschismus scheint sich als ein Sicherheitsmechanismus gegen die verwirrende Vielfalt des Lebendigen verstehen zu lassen. Je lebloser, geordneter, monumentaler die Realität erscheint, desto sicherer fühlen sich diese Männer. Die Gefahr ist die Lebendigkeit selbst. « ${ }^{1266}$

Das Gewimmel des Lebendigen ist gebannt. Die Analogisierung bzw. Symbiose von >Wildnis $<$ und 〉Gemeinschaft $<$ kann hier keine deutlichere Sprache sprechen. Die Bäume sind gepanzerte >Recken $<$, die sich im andauernden Kampf gegen das Leben >stählen`, deren Triebe sich nur in diesem Kampf ausprägen, ihre Säfte durchlaufen die gepanzerten Bahnen dieser Tiebe und die zu `Säulen` erklärten Körper, die ihrerseits fest im Boden verwurzelt allem trotzen, ohne zu fliehen.

Bereits in den 20er Jahren hat Schoenichen die später wiederaufgenommene These formuliert, bei der Deutung des sheimischen Urwalds $»$ handle [es] sich um eine Interpretationsaufgabe, wo im nacheiszeitlichen mitteleuropäischen >Urwald gewissermaßen das teleologische 
Potential einer naturhaften Entsprechung von Pflanzengesellschaft und >deutschem Volksgeist gefunden wird «. ${ }^{1267}$ Wenn Ludwig Fischer die Paradoxien Schoenichens in den Darstellungen zwischen >Urlandschaft und \Kulturlandschaft $\iota$, die ja auch nach Schoenichen entstehe durch bedingungslosen Kampf der >Germanen ‘ gegen die Wildnis, benennt, muss das differenziert werden. Zwar wandelt sich »die zentrale Metapher vom `Kämpfen und Ringen der Naturkräfte $<$ in der Urlandschaft zum `Kampf der Menschen` mit dieser«, wobei gerade ein »zumeist überlegenes >Heldentum〈 diese »Kulturleistung» verwirklicht. ${ }^{1268}$ Dafür aber, dass dieses $>$ Heldische $<$ als $>$ Rassekennzeichen $<$ sich verwirklicht, ist doch die Wildnis - selbst als Feind - notwendige Voraussetzung.

Der Wald als Heer, wie Elias Canetti ihn als ein elementares Massensymbol beschrieben hat, erscheint in zwei - vordergründig - entgegengesetzten Formationen. Das Gemeinsame vom soldatischen Wald im Sinne der Maschinenmetapher und dem Wald der Recken im Sinne des Pseudo-Organischen liegt in der strikten gepanzerten Kanalisierung lebendiger Regungen.

Derartige Zuschreibungen sind - auch, wenn die Kontinuitäten der völkischen Naturschützer zum Teil bis in die 1970er Jahre nachwirken $^{1269}$ - passé. Allerdings werden derartige >Urwälder` wie im $»$ Hasbruch«, noch immer als solche aufgefasst. ${ }^{1270}$ Im Folgenden wird es um die andere konservative Großmetapher gehen, die Rekonstruktion des Waldes zur Großkirche, die sich als in gewisser Weise folgenreicher herausgestellt hat, da sie auch jenseits ideologisch eindeutiger Verortungen bis heute immer wieder anzutreffen ist.

1267 Fischer, a.a.O., S. 187.

1268 Ebda., S. 192f.

1269 Vgl. Engels, Jens Ivo: »Hohe Zeit« und »dicker Strich«: Vergangenheitsdeutung und -bewahrung im westdeutschen Naturschutz nach dem Zweiten Weltkrieg, in: Radkau/Uekötter (Hg.), a.a.O., S. 367.

1270 Vgl. Ausleitung. 


\section{Den Wildwuchs transformieren:}

Idealbild Wald

»Der deutsche Wald wurde zum Archetyp des Verfahrens, der unordentlichen Natur die sorgsam arrangierten Konstrukte der Wissenschaft überzustülpen. Man denke nur an den Wald, den Cotta als Exempel seiner neuen Wissenschaft auswählte: im Laufe der Jahrzehnte verwandelte sein Plan ein verwildertes Flickwerk in ein ordentliches Schachbrett. Praktische Ziele hatten einen mathematischen Utilitarismus gefördert, der seinerseits geometrische Perfektion als äußeres Zeichen des gut verwalteten Waldes zu fördern schien; die rational bestimmte Anordnung von Bäumen wiederum bot neue Möglichkeiten zur Kontrolle der Natur. « ${ }^{1}$

Vom verwilderten Flickwerk zum ordentlichen Schachbrett. Henry Lowoods Darstellung offenbart den Blick aus der Draufsicht. Erst die Draufsicht macht überhaupt das Muster der Landschaftsgestaltung sichtbar. Und so, wie die Bäume des Nutzwaldes ins Schachbrett gezwungen erscheinen, erscheinen die des barocken Lustwaldes (in den Parks der kaiserlichen und fürstlichen Gartenanlagen) bevorzugt im Muster der »Sternplätze« (wohingegen die Gärten, genauer: die Parterres als Haupträume der Gärten wie Teppichmuster erscheinen). ${ }^{2}$ Landschaftsbilder werden angelegt, als könnten sie vom Betrachter von oben wahrgenommen werden. Selbst das Durchmessen oder -wandeln dürfte davon geprägt sein (obschon derart das Bild ja gar nicht erfahrbar sein kann).

1 Lowood, Henry: The Calculating Forester: Quantification, Cameral Science, And the Emergence of Scientific Forestry Management in Germany, in: The Quantifying Spirit of the Eighteenth Century. Berkeley/Calif. 1991; S. 341; zit. n. Harrison: Wälder, S. 150f.

2 Vgl. Neubauer, Erika: Wiener Barockgärten in zeitgenössischen Veduten. Dortmund: Harenberg 1980, S. 14 u. $10 f$. 
Es wären demnach die Bilder, die die Erfahrung der Landschaft prägten. Als praktischer Beweis für die Domestizierung und Vergesellschaftung der ehedem furchterregenden Natur dürfte es gelten, wenn es gelingt, die Natur per Geisteskraft (neu) zu ordnen, sie sozusagen $\mathrm{zu}$ planieren, sprich: die dreidimensionale Macht in zweidimensionale, in berechenbare Pläne zu überführen, auf die man herab schauen kann.

Von oben herab: Der Blick aus erhöhter Position auf eine geometrisch geordnete Natur erfolgt in einer Zeit, in der - bei denen, die nicht »ein unmittelbar lebensweltliches Verhältnis zur Natur « ${ }^{3}$ haben, also etwa als Bauern, Hirten usw. unter Mühen in ihr arbeiten und von ihr leben müssen - ein Bewusstsein von Naturbeherrschung sich durchgesetzt hat. In der es die »fundamentale Aufgabe des [...] >Diskurses〈 ist [...], den Dingen einen Namen zuzuteilen und ihre Existenz in diesem Namen zu benennen «. ${ }^{4}$ Eine Existenz von Natur - physikotheologisch dem Verdikt der Gefallenen entwunden, wissenschaftlich zergliedert, gerastert, Nomenklaturen und Taxonomien unterworfen - die sie zunehmend den Kategorien und Erfahrungen von Ästhetik und >Schönheit , insbesondere der $>$ Erhabenheit ${ }^{5}$ zugänglich macht. Ästhetisch fassbar wird nun selbst die (auch vorgebliche oder imaginierte) Wildnis. Zugleich aber findet ebenso die geregelte Forstwissenschaft und -wirtschaft in Frankreich und Deutschland ihre flächendeckende Verbreitung - und damit die Basis von 〉Forstästhetikı.

Es besteht ein Unterschied zwischen der Wahrnehmungsposition im Garten und der im Wald. Im Garten kommt der Blick auf die zugerichtete Natur generell von oben. Im Wald ${ }^{6}$ geht der Blick von unten nach oben, er »zwingt den Menschen aufzuschauen, dankbar für seinen überlegenen Schutz. Das »Hinaufschauen an vielen Stämmen wird zum Aufschauen überhaupt «. ${ }^{7}$ Wie in der Kathedrale. Fragt sich, in welchem Wald. Canetti spricht vom »Dom« und vom »Heer«, dem standhaften, das keinen Boden preisgibt. Der >Wald ‘ als Männermetapher von Erhabenheit und Ebenmaß, von Zucht und Ordnung. Der Wald als gesuchtes, als entworfenes und umgesetztes Idealbild.

3 Groh, Ruth/Groh, Dieter: Weltbild und Naturaneignung, S. 93.

4 Foucault, Michel: Die Ordnung der Dinge, S. 164.

5 Der philosophische Begriff des Erhabenen stammt aus der griechischen Antike. Er bedeutet Selbsterhöhung der Seele und damit Selbststeigerung des Menschen mittels enthusiastisch vorgetragener Produkte des Geistes, der Dichtkunst, hin zur Vollendung in der Katharsis, der Reinigung der Affekte.

6 Gleichzeitig adaptiert besonders der architektonische Garten Wahrnehmungsphänomene des Waldes.

7 Canetti, Elias: Masse und Macht, S. 93. 
Historisch können mehrere miteinander verwobene Spuren verfolgt werden. Der Wald (inklusive der archaischen, der paganen >heiligen Haine ) wird in seiner architektonischen Abstraktion zur (gotischen) Kathedrale (wieder-)entdeckt. Der Wald als Kirche - als positives Bild einer $\mathrm{zu}$ bewahrenden Ordnung. Und geordnet ist bzw. erscheint der Wald: aufgrund der Erforschung seines `Bauplans`, der Entreißung oder Exegese seines `Geheimnisses $`$, und/ oder aufgrund forstwissenschaftlichen und forstwirtschaftlichen Waldbaus. Die Natur ist nicht länger gesetzlos. Die Kirche wird ihrerseits zum Leitbild des Waldes oder Forstes in der Moderne seit dem Ende des 18. Jahrhunderts. Die Bilder bedingen sich wechselseitig: Erst die Entdeckung bzw. Etablierung einer (〉göttlichen $<$ ) Ordnung im Wald macht den »Ursprung des gotischen Doms aus dem Walde ${ }^{8}$ im positiven Sinn denkbar.

Cottas >deutscher Wald ist keine originäre Erfindung des ausgehenden 18. und frühen 19. Jahrhunderts - eigentlich ist er auch kein deutscher Wald. Der geregelte Forst, der regelmäßig aufgebaute und von unerwünschten Gehölzen bereinigte, >durchforstete` Bestand stammt zumindest als Postulat - im Gebiet des heutigen Deutschland schon aus dem 15./16. Jahrhundert, was wiederum auf das auf antiken Grundlagen beruhende Werk des Petrus de Crescentiis (um 1300) zurückgeht. ${ }^{9}$ Interessanterweise wird >Wald $/$ in Bilddarstellungen des 14., 15. Jahrhundert häufig so gezeigt, wie er real erst in der Moderne obligatorisch ist, als regelmäßig wachsende Anzahl gleichgroßer Bäume.

Das - buchstäbliche - Bild des der Wildnis entrissenen, des untertan gemachten Waldes gehorcht der christlichen Ikonographie des ebenfalls seit der Dichtung der Antike bekannten »lieblichen Hains«, des locus amoenus in der Wildnis, wie ihn etwa Tiberianus im 4. Jahrhundert u.Z. beschreibt. ${ }^{10}$ Die literarische Utopie im Hochmittelalter ist nicht ohne realen Hintergrund: »Wälder mit fließenden Gewässern galten seit den benediktinischen Ordensreformen um 1100 als ideale Gründe für Abteien, Klöster und Eremitagen. « ${ }^{11}$ Die Waldwildnis wird nicht einfach als >Wüste` aufgesucht, sondern tatkräftig umgestaltet. Die Lektüre im

8 Keller, Harald: Goethes Hymnus auf das Straßburger Münster, S. 13.

9 Vgl. Kap. Forst I.

10 »Über feuchtem Rasen wölbte sich der Hain, von Tau benetzt,/Viele Bächlein sprudeln murmelnd hier und dort aus reichem Quell/Strömen, gleiten, fluten, perlen in der Tropfen Lichterspiel,/Moose kleiden aus die Grotten, grüner Efeu rankt sich hin,/Aller Vögel süße Lieder tönten durch den Schatten dort.« Zit. n. Albus, Anita: Die Kunst der Künste. Erinnerungen an die Malerei. Frankfurt/M: Eichborn 1997, S. 138.

11 Albus, ebda., S. 138f. 
»Buch der Natur« ist sozusagen Fundament der Kathedrale und »Descartes' vergessene[r] Quellen «. ${ }^{12}$

Der $>$ Wald als Kirche $<$ ist erzkonservative Großmetapher - Invektive gegen eine Moderne, deren Beginn sie eigentlich erst entstammt ${ }^{13}-$ und allfälliges Stereotyp zugleich, sinnfällige Ästhetisierung und Reklamation des Waldes als männlichem Raum. Der metaphysische Glanz scheint auch immer wieder im ökologischen Diskurs durch, etwa im Postulat 〉Bewahrung der Schöpfung`, einer Kreation also, die einer höheren Ordnung gehorcht, die daher nicht angetastet werden darf. Dass diese Ordnung zumeist eine höchst profane, sprich: forstliche ist, ist kaum Ironie. Denn beim erhebenden >Waldgefühl dessen, wo Wildnis anfängt und Forst aufhört (bzw. umgekehrt), diffus.

\section{Zur Erhabenheit verfeinert}

Am Ende des 17. Jahrhunderts entwickeln sich unter dem Paradigma der Physikotheologie erste Ansätze einer Theorie der Natur-Erhabenheit. Die Physikotheologie, als Begriff schon im 17. Jahrhundert entstanden, wurde ab ca. 1700 zur »Bewegung«, die sich mit dem Ziel der Verbindung von »Naturwissenschaft und Religion zum Zwecke der Bekämpfung atheistischer und materialistischer Konsequenzen, die man aus der New Science hätte ableiten können«, rasch »in England, Deutschland, der Schweiz, Frankreich, in ganz Europa und darüber hinaus in Neuengland « ausbreitete. ${ }^{14}$ Auf Basis von Platons »Demiurgen «, dem Baumeister-Gott, erklärt sie die existierende Natur zum »Werk Gottes« und steht damit in Opposition nicht nur zu atheistisch-mechanistischen Weltbildern, sondern ebenso zur »Tradition christlicher Weltverneinung«, der Reklamation einer »natura lapsa«. Womit das christliche Weltbild »fast unbemerkt in die Moderne hinein « glitt. ${ }^{15}$ War doch nun der

12 Authier, Michel: Die Geschichte der Brechung und Descartes' vergessene Quellen, in: Serres, Michel (Hg.): Geschichte der Wissenschaften, S. 445.

13 Philosophisch-literarisch ist es offenbar Johann Gottfried Herder, dessen Abkehr von der Aufklärung und Hinwendung zum Sturm und Drang bzw. vom aufklärerischen zum idiographischen Naturideal (vgl. Trepl, Ludwig: Geschichte der Ökologie, S. 99f.) eine Basis der konservativen Kulturkritik schafft. Den »grünen Dom« (Walther Schoenichen) besingen dann mit Vorliebe auch völkische Heimatschützer. Der hier propagierte Antagonismus von Stadt und Land, von Stadtfeindschaft und -flucht also wird als Motiv auch den mittelalterlichen Pilgern, Eremiten und Klostergründern zugeschrieben.

14 Groh/Groh: Weltbild und Naturaneignung, S. 51.

15 Ebda., S. 114ff. 
Mensch »berufen, die Schöpfungsgedanken Gottes nachzuvollziehen«, wissenschaftlich Herrschaft über die Natur auszuüben. ${ }^{16}$ Denn: »Die Natur ist zum Nutzen des Menschen geschaffen - auch zu seinem ästhetischen $>$ Nutzen $<.{ }^{17}$

Der führende Cambridger Platonist Henry More entwirft um die Mitte des 17. Jahrhunderts einen »)harmonikalen`, das >Ganzeく umfassenden Naturbegriff[] christlich-platonischer Prägung«, eine »Identifizierung der Prädikate Gottes mit denen des Raumes, mit deren Hilfe eine ästhetische Kategorie entstand, die in ihrem Begriff selbst die Vermittlung von Sinnlichem und Übersinnlichem, von Physik und Metaphysik leistete: der Begriff der Unendlichkeit. Die > Ästhetik des Unendlichen [...] wurde zum Ursprung der Ästhetik des Naturerhabenen«. Das ist zwar prekär im Sinne herkömmlicher christlicher Anschauung, die die »creatio ex nihilo« lediglich als Spiegel Gottes versteht, die selbst keine göttlichen Eigenschaften aufweist. Der klassische Schönheitskanon war durch die >kopernikanische Wende jedoch schon ins Wanken geraten. More entdeckt nun »delight in disorder«, kann »pleasing Horror and Chillness« in wilder Natur ästhetisch genießen und transformiert sozusagen den Himmel auf die Erde, indem das Übersinnliche als göttliche Allgegenwart, das Metaphysische, das menschlichen Geist überwältigt und erhebt, sich verbinden lässt mit dem »Anblick großartiger Naturgegenstände ${ }^{18}{ }^{18}$

Wie More mit Ansätzen einer Subjekttheorie nimmt auch Thomas Burnet mit dem »Gemüt« als Vermittlungsinstanz Kant etwas vorweg. Burnet allerdings zeigt »das Janusgesichtige vieler Reaktionen jener Zeit auf erhabene Gegenstände der Natur«. Ihm erscheinen in seiner »Heiligen Theorie der Erde« die Berge »als das größte Beispiel von Unordnung in der gesamten Natur«, gigantische Ruinen zwar »von großer Pracht und Herrlichkeit«, aber in ihrer Monstrosität ein »abstoßendes ästhetisches Übel« - an dem jedoch nicht der Schöpfer-Gott, sondern die menschliche Sündhaftigkeit schuld sei. Trotzdem findet er Gefallen an ihrer Wildheit, da die pure Größe schon »die Idee der Unendlichkeit eingibt«. Und er macht »eine in dieser Folge fundamentale Unterscheidung«: nicht schön sei die Landschaft, sondern »sehr groß und herrlich« im Sinne von erhaben. ${ }^{19}$

In John Dennis' Erhabenheitskonzept finden sich die Alpen, wenn diese Monstrosität denn schon nicht Ergebnis der Sintflut sei, als schrof-

16 Vgl. ebda., S. 28f.

17 Ebda., S. 57.

18 Ebda., S. 123f.

19 Vgl. ebda., S. $125 \mathrm{ff}$. 
fe Mauern um den »Garden Italy«, die ihm zugleich Schrecken und Lust bereiten, »Entzücken angesichts der wilden, kühnen Formen dieses Geniestreichs der Natur«. In seiner Hierarchie erhabener Dinge steht Gott an der Spitze (seine Vorstellung ruft den "greatest and strongest Enthusiasm« hervor), es folgen Universum und Himmelskörper, Meer, Ströme und Berge. Je stärker die Dinge der äußeren Natur diese Vorstellungen erzeugen, »desto intensiver sind die entsprechenden erhabenen Gefühle« - und umgekehrt. Diese Aufwertung sinnlicher Wahrnehmung weist »dieselbe Zirkelhaftigkeit« auf, »wie die physikotheologische Lektüre des Buches der Natur ${ }^{20}{ }^{20}$ Die Alpen als Gartenmauer um Italien: Das variiert einerseits das alte Thema vom »locus amoenus in der Wildnis«, in dem die Wildnis als Schutzmauer des Gartens fungiert, was für die Tradition eines Idealbildes Wald wichtig ist, wobei die Erhabenheit im Angesicht der natürlichen Mauern um diesen Garten herum empfunden wird, andererseits ist das der Grundgedanke der Expansion des Gartens, der Verwandlung bzw. Reorganisierung der gesamten äußeren Natur (der natura lapsa) in einen Garten. Burnet und Dennis orientieren sich noch »an der pythagoreischen Ästhetik der Klassik«, was sie zur systematischen Unterscheidung von Schönem und Erhabenem zwingt. Anders Anthony Shaftesbury, der 1709 mit »The Moralists«, »einer erstaunlichen Synthese« aus "physikotheologische[m] Credo und konsequente[m] Platonismus« die »)formal mockery of princely gardens schmerzlos hinter sich lassen« kann, weil für Platonisten »alles schön« sei. »Das sinnliche Erscheinungsbild der Dinge verhüllt ihr wahres Wesen. Das Unregelmäßige, Unförmige, ja selbst das Furchtbare und Gräßliche in der Schöpfung ist nur scheinbar so, in Wahrheit sind diese Dinge >beauteous in themselves $<$; >Disorder becomes regular, corruption wholesome «, weil alles in der göttlichen Ordnung seinen zugewiesenen Platz hat. Unter idealistischer Perspektive liegen hier nützlich und schön dicht beieinander, kann auch >the wilderness gefallen. Metaphysische Prämissen begründen und rechtfertigen die neue ästhetische Erfahrung der wilden Natur«. Wie bei More, Burnet, Dennis ist auch bei Shaftesbury das Erhabene »das die Einbildungskraft des Menschen Übersteigende, das beim Anblick großer Gegenstände der äußeren Natur durch das Gefühl vermittelt wird«, wird der Kosmos zum »Fest Gottes«, bezeugen Menschenwelt und Universum in vollkommener Schönheit Vorsehung und Weisheit des Schöpfer-Gottes, der bei Shaftesbury aber zugleich »Hausvater« ist, der allem seinen Platz zuweist. Es sei gar nicht möglich, betont Shaftesbury, die Nützlichkeit aller Dinge zu beweisen,

20 Ebda., S. 128f. 
wie es dem praktischen Programm der Physikotheologen entspricht, es sei aber auch nicht nötig, da sowieso alle Dinge vollkommen seien. Kurz: Shaftesburys idealistischem Natur- entspricht sein ebensolcher Schönheitsbegriff. $^{21}$

Dass die Theorie des Naturerhabenen in Anbetracht des Hochgebirges entsteht - Burnet (1671), Dennis (1688) und Shaftesbury (1686) hatten jeweils eine »Grand Tour« durch die Alpen verarbeitet -, hat sicher damit zu tun, dass die Felsmassive dem orthodoxen christlichen Weltbild als Ergebnis der Sintflut erscheinen. Zugleich aber dürfte "wilderness« großflächig auch damals wohl nur noch hier anzutreffen gewesen sein. Shaftesbury spricht zudem vom ») horror`, der [Reisende] auch in einem riesigen, finsteren Wald ergreift $\aleph^{22}$

Ins »Zentrum der ästhetischen Diskussionen des 18. Jahrhunderts« aber gelangt »der Begriff des Erhabenen zusammen mit dem des Schönen durch die 1757 veröffentlichte Untersuchung von Edmund Burke «. ${ }^{23}$ In dieser »Philosophical Enquiry into the Origin of our Ideas of the Sublime and Beautiful« betrachtet Burke Physiologie und Psychologie von Schönheits- und Schreckensempfindungen. Während sich beim Schrecken die Körperfasern anspannten, führe die Empfindung von Schönheit zur Entspannung. Die gegensätzlichen Empfindungen hängen nach Burke mit gegensätzlichen Trieben zusammen: Das Schöne - hervorgerufen vom Kleinen, Glatten, Ebenmäßigen - mit dem Gesellschaftstrieb, da seine Empfindung doch »pleasure« erwecke, also »Genuß und Verlangen nach Teilhabe«. Das Erhabene - hervorgerufen durch das Unendliche, Leere, Unmäßige, Schroffe und Wilde - mit dem Selbsterhaltungstrieb, denn es entspreche dem Entzücken, »delight « ${ }^{24}$ Dieses Empfinden von Erhabenheit erwecke Leidenschaften, Staunen, Ehrfurcht, bringe doch der Schrecken (als Quelle des Erhabenen) wie auch der Schmerz »die stärkste Bewegung« hervor, denn zweifelsfrei seien »die Martern, die man uns antun kann, in ihren Wirkungen auf den Körper und auf das Gemüt weit größer als alle Vergnügungen, die die raffinierteste Wollust erfinden oder die lebhafteste Einbildungskraft und der gesündeste und sensibelste Körper genießen kann «. ${ }^{25}$ Die Erhabenheits-Empfindung aber entstehe, wenn der Schrecken den Selbsterhaltungstrieb aktiviere, zugleich das Wissen um die eigene Sicherheit zur

21 Vgl. ebda., S. 130f. Die Binnenzitate stammen aus Shaftesburys »The Moralists«.

22 Ebda.

23 Bätschmann, Oskar: Entfernung der Natur. Landschaftsmalerei 17501920. Köln: DuMont 1989, S. 46.

24 Vgl. ebda., S. 47.

25 Zit. n. Bätschmann, ebda., S. 255. 
Beruhigung führe. »Mit der Betrachtung der eigenen Sicherheit wird die Distanz des Schrecklichen wahrgenommen: die Erkenntnis der Sicherheit macht den Schrecken zu einem visuellen«, was dann eben »Entzücken« hervorruft - unmittelbar oder auf dem »Markt[] der Landschaftsmalerei«. Die »Ästhetisierung des Schrecklichen« verlangt explizit eine Distanzierung von, eine Distanz zur Natur. Der Schrecken wird qua Sicherheitsempfinden zum rein visuellen. Und: »Die Empfindungen der Touristen vor der unkultivierten Natur waren von dem >ungefährlichen Schrecken، solange und soweit bestimmt, als nicht der andere Begriff für das Radikale, Irreguläre und Interessante die Erfahrung und die Ziele leitete: das Pittoreske oder das Romantische.« Bis zum Ende des Jahrhunderts also. ${ }^{26}$

1790 erscheint die erste Originalausgabe von Immanuel Kants »Kritik der Urteilskraft«. Sie unterteilt die Vorstellung der Zweckmäßigkeit der Natur in eine ästhetische und eine logische. Beiden Arten der Vorstellung gemein ist nach Kant, dass sie nicht auf reiner Sinnlichkeit beruhen können. »Lust oder Unlust« ist danach »dasjenige Subjektive« an einer Vorstellung, "was gar kein Erkenntnisstück werden kann«. ${ }^{27}$ Reine Sinnlichkeit ist blind. Das Prinzip der logischen Betrachtungsweise - im Gegensatz zur ästhetischen - ist das einer reflektierenden, regulativen, und nicht bestimmenden, konstitutiven Urteilskraft:

»Es ist also nur die Materie, sofern sie organisiert ist, welche den Begriff von ihr als einem Naturzwecke notwendig bei sich führt, weil diese ihre spezifische Form zugleich Produkt der Natur ist. Aber dieser Begriff führt nun notwendig auf die Idee der gesamten Natur als eines Systems nach der Regel der Zwecke, welcher Idee nun aller Mechanism der Natur nach Prinzipien der Vernunft (wenigstens um daran die Naturerscheinung zu versuchen) untergeordnet werden muß. Das Prinzip der Vernunft ist ihr als nur subjektiv, d.i. als Maxime zuständig: Alles in der Welt ist irgendwozu gut, nichts in ihr ist umsonst; und man ist durch das Beispiel, das die Natur an ihren organischen Produkten gibt, berechtigt, ja berufen, von ihr und ihren Gesetzen nichts, als was im ganzen zweckmäßig ist, zu erwarten. $\ll^{28}$

Triumph der teleologischen Ordnung: alles in der Natur ist »irgendwozu gut«; und dies zur Erhöhung des Menschen. Denn auch, wenn Kant es ausdrücklich nicht als »ausgemacht« ansieht, dass die Zweckbestimmung der Natur eine absichtliche, und die übrige Natur für den Men-

26 Vgl. Bätschmann, ebda., S. 47ff.

27 Kant, Immanuel: Kritik der Urteilskraft. Hg. von Karl Vorländer. Hamburg: Felix Meiner 1990 (Leipzig 1799), S. 26.

28 Ebda., S. 242. 
schen gemacht sei, sprechen seine Beispiele, die die Erkenntnisunmöglichkeit mittels Lust oder Unlust belegen sollen, doch eine andere Sprache. So diene die Plage durch Ungeziefer wie Flöhe, Wanzen, Läuse doch dem Zweck, einen Antrieb zur Hygiene, und damit zur Förderung der Gesundheit zu bieten. Noch deutlicher wird es, wenn Kant auf die natürlichen Beschwernisse der »Wilden« zu sprechen kommt:

»Oder die Moskitomücken und andere stechende Insekten, welche die Wüsten von Amerika den Wilden so beschwerlich machen, seien soviel Stacheln der Tätigkeit für diese angehenden Menschen [Hvhbg. v. m.; M. T.], um die Moräste abzuleiten und die dichten, den Luftzug abhaltenden Wälder licht zu machen und dadurch, imgleichen durch den Anbau des Bodens ihren Aufenthalt zugleich gesünder zu machen. «"

Auch hier also: die Wildnis muss unterworfen werden, um Vor-Menschen zu Menschen zu veredeln. Die Natur selbst legt den Keim zu ihrer >vernünftigen` Unterwerfung und Umgestaltung. Unterwerfung und Umgestaltung aber entsprechen demnach dem Gesetz der Natur. Diejenigen aber, die sich dem Naturgesetz der >Vernunft « verweigern, ihrer selbstverschuldeten Unmündigkeit, der Natur, verhaftet bleiben, müssen womöglich von außen zu ihrem Glück gezwungen werden.

Die unterworfene (innere wie äußere) Natur - bzw. das Bewusstsein dieser Unterwerfung - ist offenbar Vorbedingung der ästhetisch-teleologischen Naturauffassung. Das Erhabene, das Sublime also, erhält als Phänomen eine besondere Bedeutung bei Kant, wie in der Aufklärungsphilosophie allgemein bis hin zu den Werken, Herders, Schellings und Schillers. Es bildet hier zunächst als »Größe« und »Vornehmheit« eine höhere Stufe der Schönheit, um dieser später explizit entgegengesetzt zu werden; so vor allem bei Kant, der Erhabenes auch noch im »formlosen Gegenstande« repräsentiert sieht, »sofern Unbegrenztheit an ihm oder durch dessen Veranlassung vorgestellt und doch Totalität derselben hinzugedacht wird «. ${ }^{30}$ Sublimierte Sinnlichkeit: Die Attraktion des Erhabenen erregt nach Kant nicht "positive Lust« (am Reiz), sondern die "negative Lust « der Bewunderung oder Achtung. ${ }^{31}$ Kant unterscheidet zwischen »Affekten« und »Leidenschaften«. Affekte beziehen sich lediglich auf das Gefühl und können »die Freiheit des Gemüts« hemmen - in Verbindung mit der »Idee des Guten« bilden sie den »Enthusiasm« -, Leidenschaften aber entstammen dem »Begehrungs-

29 Ebda., S. 243.

30 Ebda., S. 87.

31 Vgl. ebda., S. 88. 
vermögen « und heben die Gemütsfreiheit vollständig auf. ${ }^{32}$ Das LeibSeele-Problem: Sinnlichkeit als männlich gewähnte Gefahr, sich in der Natur und ihren Gewalten zu verlieren.

»Der Gegenstand eines reinen und unbedingten intellektuellen Wohlgefallens ist das moralische Gesetz in seiner Macht, die es in uns über alle und jede vor ihm vorhergehenden Triebfedern des Gemüts ausübt; und da diese Macht sich eigentlich nur durch Aufopferung ästhetisch kenntlich macht (welches eine Beraubung, obgleich zum Behuf der inneren Freiheit ist, dagegen eine unergründliche Tiefe dieses übersinnlichen Vermögens mit ihren ins Unabsehliche sich erstreckenden Folgen in uns aufdeckt): so ist das Wohlgefallen von der ästhetischen Seite (in Beziehung auf Sinnlichkeit) negativ, d.i. wider dieses Interesse, von der intellektuellen aber betrachtet positiv und mit einem Interesse verbunden. Hieraus folgt, daß das intellektuelle, an sich selbst zweckmäßige (das Moralisch-)Gute, ästhetisch beurteilt, nicht sowohl schön als vielmehr erhaben vorgestellt werden müsse, so daß es mehr das Gefühl der Achtung (welches den Reiz verschmäht) als der Liebe und der vertraulichen Zuneigung erwecke; weil die menschliche Natur nicht so von selbst, sondern nur durch Gewalt, welche die Vernunft der Sinnlichkeit antut, zu jenem Guten zusammenstimmt. Umgekehrt wird auch das, was wir in der Natur außer uns oder auch in uns (z.B. gewisse Affekte) erhaben nennen, nur als eine Macht des Gemüts, sich über gewisse Hindernisse der Sinnlichkeit durch moralische Grundsätze zu schwingen, vorgestellt und dadurch interessant werden. ${ }^{33}$

Die Gewaltigkeit der Natur als Beweis der Überlegenheit des menschlichen Geistes. »Die Macht der Natur bricht sich am prinzipiell unangreifbaren Zentrum des Menschen, seiner Vernunft, dem zeitlosen Garanten der Autonomie«, kommentiert Hartmut Böhme. »Erhaben ist nicht Natur, sondern das ratiozentrierte Selbst des Menschen. ${ }^{34}$ Noch bei Goethe oder Carl Grosse ${ }^{35}$ ist die Natur das Objekt, an dem sich die Seele durch Annäherung emporhebt, wobei sich in der ästhetischen Wahrnehmung die Illusion einer ungefähren Ebenbürtigkeit des betrachtenden Subjekt mit dem erhabenen Objekt einstellt. Dazu aber muss notwendig ein Bewusstsein der Domestizierung und Vergesellschaftung der ehedem furchterregenden Gegenwelt existieren.

»Das Fortschreiten der Naturbeherrschung hat die Möglichkeit geschaffen, das ehemals allein Fürchterliche aus der Position aktueller Sicherheit wahrzuneh-

32 Vgl. ebda., S. 119.

33 Ebda., S. 118f.

34 Böhme, Hartmut: Die Ästhetik der Ruinen, in: Kamper, Dietmar/Wulf, Christoph (Hg.): Der Schein des Schönen. Göttingen: Steidl 1989, S. 296f.

35 »Ueber das Erhabene«. Göttingen, Leipzig 1788. 
men, und damit Naturfurcht suspendiert. Damit kann das Objekt in einem neuen Licht erscheinen: Zurück bleibt der Anblick seiner puren Kraft und Größe. Da aber diese - Inbegriff der übermächtigen Naturgewalt - dem Subjekt weiterhin seine Unzulänglichkeit, Schwäche und Kleinheit bewußt machen, läßt sich der Vorgang ihrer Ummünzung in Gegenstände der Lust als ein Modus der Bewältigung, der grenzenlosen, den Zweck physischer Selbsterhaltung überschreitenden Selbstbehauptung des Subjekts gegenüber der Natur interpretieren. Angesichts ihrer wendet das Subjekt, das selbst das von realen Gefahren unabhängige bloße Gefühl der Unterlegenheit unter der Natur nicht mehr tolerieren mag, den Blick auf seine eigenen Qualitäten, seine Kraft, seine Größe. Doch ist das darin erzielte ästhetische Gleichgewicht zwischen Mensch und Natur, da es jenseits der objektiven Grenze ihrer Beherrschbarkeit besteht, die es subjektiv erweitern will, labil. Furcht und Unlust sind im Gefühl des Erhabenen nicht eigentlich eliminiert, sie sind in ihm im Hegelschen Sinne saufgehoben . $^{36}$

Kants Werk markiert nun das fortschreitende Grundmuster der Deutung eines Gefühls der Erhabenheit. Dabei konstatiert Kant zum einen die Form des »mathematisch Erhabenen«, das die Natur als »schlechthin (nicht bloß komparativ) groß « ${ }^{37}$ erscheinen lässt - das Göttliche, das Ganze, Allgemeine, Unendliche - und vor dem Hintergrund der Beschränktheit der Sinnenwelt erfordert es, »das gegebene Unendliche« widerspruchsfrei »auch nur denken zu können« ein »übersinnliches Substrat « im »menschlichen Gemüte «. ${ }^{38}$ Zum anderen behauptet er die Existenz eines »Dynamisch-Erhabenen«, in dem die Natur als »Furcht erregende « Macht erscheint, die aber »über uns keine Gewalt hat «, ${ }^{39}$ da sie uns »zwar unsere physische Ohnmacht zu erkennen« gibt, zugleich aber ein Vermögen sichtbar macht, ihr überlegen $\mathrm{zu}$ sein, »wobei die Menschlichkeit in unserer Person unerniedrigt bleibt «. ${ }^{40}$ Der Mensch erfährt sich als sittliches Wesen, dessen übersinnliches Vermögen, die reine selbständige Vernunft, seine Überlegenheit über die allgewaltige (innere und äußere) Natur dokumentiert.

»Erhaben ist, was auch nur denken zu können ein Vermögen des Gemüts beweist, das jeden Maßstab der Sinne übertrifft. ${ }^{41}$

36 Begemann, Christian: Furcht und Angst im Prozeß der Aufklärung. Frankfurt/M: Athenäum 1987, S. 147f.

37 Kant: Kritik der Urteilskraft, S. 99.

38 Ebda.

39 Ebda., S. 106.

40 Ebda., S. 107.

41 Ebda., S. 94. 
Und daher erregt die Natur »die Ideen des Erhabenen am meisten« gerade »in ihrem Chaos oder in ihrer wildesten, regellosesten Unordnung und Verwüstung «. ${ }^{42}$ (Der Gedanke an die mittelalterlichen Pilger, die sich in den europäischen Urwäldern der Versuchung des Bösen aussetzten, um ihre Seele zu reinigen, liegt hier nahe.) Erhaben aber sind nach Immanuel Kant nicht die Dinge oder Ereignisse der Natur. Sie geben vielmehr lediglich den Anstoß zu einer Stimmung des Erhabenen, indem sie in ihrer staunenmachenden Größe oder ihrer schreckenerregenden Gewalt ein Bewusstsein der Allmacht menschlichen Geistes hervorrufen. Erst ein unabhängiges »Verstandesvermögen«, eine »freie Urteilskraft«, welche der Macht der Natur nicht mehr erliegen, ermöglichen es, die Natur »als ein System nach Gesetzen « ${ }^{43}$ der Zweckmäßigkeit zu erkennen. Naturgesetze als Gesetze der Zweckmäßigkeit; die Natur selbst als Aufforderung, sie sich untertan zu machen. Und sei es zur Kunst: »Kants Theorie des Erhabenen antezipiert am Naturschönen jene Vergeistigung, die Kunst erst leistet. Was an der Natur erhaben sei, ist bei ihm nichts anders, als eben die Autonomie des Geistes angesichts der Übermacht des sinnlichen Daseins, und sie setzt erst im vergeistigten Kunstwerk sich durch. ${ }^{44}$

Kants $»$ Kritik der reinen Vernunft« (1781) bedeutet die programmatische Überwindung des cartesianischen Rationalismus, Empirismus und Mechanismus, indem sie den rein analytischen Cogito-Begriff Descartes durch einen synthetischen von Sinnlichkeit und Verstand ersetzt. Inzwischen also ist die sinnliche Wahrnehmung als notwendiger Bestandteil im Erkenntnisprozess denk- und postulierbar. Denn, so Peter Duesberg, um »neben der Begrifflichkeit auch die Gesetzmäßigkeit der äußeren Natur erfassen zu können«, bedürfe das Subjekt neben Verstand und Sinnlichkeit der »Vernunft«, die dem Verstand übergeordnet »für die höchste Form der Synthesis des Erkenntnisprozesses zuständig« sei, »mittels dort a priori angelegter Kategorien«. Damit würden der »Gesetzmäßigkeit der Natur» ihre "Abstraktheit und Unzugänglichkeit» genommen. »Die Natur wird durch die höchste Synthesis der Erkenntnis selbst ein Teil der Vernunft und diese sucht ihren Ursprung in der Gesetzmäßigkeit der Natur. Die Dauerbeziehung von Natur und Vernunft in vollkommenem Einklang bedeute zugleich: »der Mensch erhebt sich zum Beherrscher der Natur«. Hier, glaubt Duesberg, werde der Einklang von Mensch und Natur fragwürdig, da er in seiner »objekthaften

42 Ebda., S. 89.

43 Ebda.

44 Adorno, Theodor W.: Ästhetische Theorie. Frankfurt/M: Suhrkamp 1990, S. 143. 
Naturauffassung« noch immer der »Idylle der Aufklärung« entspreche, die diese Auffassung zur Bestandssicherung gebraucht habe. Der Bestand dieser Idylle sei aber gefährdet, sobald die äußere oder die innere Natur »ihr Gleichgewicht verliert «. ${ }^{45}$ Duesberg definiert Idylle als »rein äußere Natur, der jeder Bezug zum Seelischen der inneren Natur des Menschen fehlt. Aber in demselben Maß, wie die instrumentelle Beherrschung der Natur durch die Vernunft eine notwendige Voraussetzung ihrer ästhetischen Vermittlung ist, ist der ebenso durch die Vernunft geleistete Vermittlungsproze $ß$ eine notwendige Voraussetzung für das seelische Erleben von Landschaft«. Im Gegensatz zur Utopie sei Idylle sowohl topographisch, als auch »in der Anzahl ihrer Personen und Handlungsgeflechte« extrem beschränkt, notwendige Bedingung, um Glück und Konfliktlosigkeit im »einfache[n] Dasein« zu erkaufen; ein Glück (nebst einer ästhetischen Anschauung der äußeren Natur), das nur eine per Vernunft beherrschte Natur erfüllen könne. »Natur und Idylle sind Errungenschaften der Aufklärung. $\aleph^{46}$ Das impliziert, Idylle sei mit der frühromantischen Idee einer Synthese von Vernunft und Sinnlichkeit, einer »Unendlichkeit« der Landschaft obsolet geworden. Das ist nicht der Fall. Nun ist >Idylleく zweifellos >klein`, reduziert das Überwältigende aufs Überschaubare, suggerieren die Instrumentalisier- und Beherrschbarkeit des >Unerträglichen<, aber eben als Anpassung des Außen an das Innen als partielles eingehegtes Glück, einer Herstellung von Nähe, indem die äußere Natur als gezähmte korrespondiert mit einem gezähmten Innenleben. Dass in der Aufklärung die Objekthaftigkeit der Natur postuliert wird, dass Descartes »das Erkenntnisstreben« per »Ausgrenzung der unmittelbar sinnlichen Erfahrung« zum »blinden Trieb« erklärt, indem das »Ich« die »Sinne reinigen und korrigieren« soll, dass so "nichtdisziplinierte Sinnlichkeit als Wahn « erscheint, ${ }^{47}$ unterstreicht das nur. Wenn Kant dann eine - disziplinierte - Sinnlichkeit in Synthese mit Vernunft und Verstand als Erkenntnisinstrument etabliert, bedeutet das immanent logisch einen Einklang von Vernunft und Natur als Beherrschung der Natur - nämlich der inneren wie äußeren.

\section{Zurück aber zu Duesbergs Kant-Paraphrase:}

»Die kantianische Verbindungslinie zwischen Subjekt und Objekt ist noch weit entfernt von der Verschmelzung von innerer und äußerer Natur, denn die äußere Natur bleibt das vom Subjekt distanzierte und instrumentell beherrschte

45 Duesberg, Peter: Idylle und Freiheit, S. 40f.

46 Ebda., S. 68f.

47 Braun/Kremer: Asketischer Eros, S. 126f. 
Objekt. Aber diese Verbindung wird zum Ausgangspunkt für eine später einsetzende Wechselwirkung von innerer und äußerer Natur, bei dem es über die vernunftmäßige Erkenntnis zu einer seelischen Empfindung der äußeren Natur durch die innerer Natur kommt, die dann nicht mehr Verstand, Vernunft oder Geist ist, sondern Seele. Umgekehrt kann durch die Wechselwirkung von äußerer und innerer Natur die äußere Natur der Landschaft zum Stimmungsträger der inneren Natur der Seele werden.«

Kants Aufklärungskritik »durch einen in der Synthesis von Anschauen und Denken erweiterten Vernunftbegriff« sei keineswegs Gegenaufklärung, sondern das Aufbrechen einer »starre[n] Korrelation von Subjekt und Objekt als innere und äußere Natur«, mithin »Anfang des romantischen Synthese-Strebens, wie es Fichte und Novalis eigentümlich ist«. Kant sei so »Wegbereiter frühromantischer Ideen« einer Synthese von »Sinnlichkeit und Vernunft« und durch diese »Verbindungslinie« könne Romantik auch nicht als »blanker Irrationalismus« verstanden werden. Das wesentliche Merkmal aber der Frühromantik, »die Unendlichkeit der frühromantischen Landschaft « sei ohne Kants Kritik nicht denkbar. ${ }^{48}$ Zugleich ist damit ein weiteres Moment genannt, das zeigt, dass nun im >christlichen Abendland` Transzendenz auch in der äußeren Natur wieder >erfahrbar` sein kann. Die Unendlichkeit, das >Absoluteく braucht dabei allerdings symbolisch aufgeladene Materialität, ein $\mathrm{Ge}$ häuse, um >Übersinnliches` sinnlich wahrnehmbar erscheinen zu lassen, um mittels >überwältigender Größeく, mittels 〉existentiellen Schauders »schwindelnder Höhe ${ }^{49}$ den »Sprung [...] in ein metaphysisches Ganzheitserleben « zu vollziehen. ${ }^{50}$ Hegel wird einige Zeit später die gotische Kathedrale in dieser Weise als »Vollendung « der »Baukunst des Abendland[s]« begreifen, »welches das Symbol gläubiger Erhebung verkörperte«, zugleich »dienendes Gehäuse und bedeutendes Sinnbild«, unter dessen hohem Gewölbe das Fenster als »leuchtende Brücke [...] den Gläubigen mit dem Himmel« verbindet - »heilige[s] Fernweh«. ${ }^{51}$ Und all das wird Hegel an den Wald erinnern.

48 Vgl. Duesberg, a.a.O., S. $41 \mathrm{f}$.

49 Wyss, Beat: Trauer der Vollendung. Zur Geburt der Kulturkritik. Köln: DuMont $1997^{3}$, S. 84.

50 Groh/Groh, a.a.O., S. 92.

51 Wyss, a.a.O., S. 83ff. 


\section{sHeilige Hallen< I}

$»$ Der Wald ist über dem Menschen. Er mag verschlossen sein und mit allerhand Gestrüpp verwachsen; man mag Mühe haben, in ihn hineinzugelangen und noch mehr, in ihm fortzukommen. Aber seine eigentliche Dichte, das, was ihn wirklich ausmacht, sein Laub, ist oben. Es ist das Laub der einzelnen Stämme, das ineinandergreift und ein zusammenhängendes Dach bildet, es ist das Laub, das so viel vom Lichte abhält und den großen, gemeinsamen Waldschatten wirft. $\ll^{52}$

Elias Canetti entwirft mit seinem »Massensymbol« Wald offenbar einen Archetypus, eine anthropologische Konstante. Dass ein solches »Massensymbol« - eine kollektive Einheit, »die nicht aus Menschen besteh[t] und dennoch als Masse[] empfunden« werde $^{53}$ - eine Projektion sozial bedingter Menschenbilder ist, dass so ein Waldbild entsteht, von dem dann umgekehrt auf die Normen der menschlichen Existenz zurückgeschlossen wird, mag bei Canetti impliziert sein. Dass dies bestimmte historisch-soziale Bedingungen braucht, sagt er allerdings nicht.

»Die Richtung, in die er die Augen des Menschen zieht, ist die seiner eigenen Veränderung: Der Wald wächst ständig nach oben weiter. Die Gleichheit der Stämme ist eine ungefähre, auch sie ist eigentlich eine Gleichheit der Richtung. Wer einmal im Walde ist, fühlt sich geborgen; er ist nicht an seiner Spitze, wo er weiterwächst, auch nicht am Orte seiner größten Dichte. Eben diese Dichte ist sein Schutz, und der Schutz ist oben. So ist der Wald zum Vorbild der Andacht geworden. Er zwingt den Menschen aufzuschauen, dankbar für seinen überlegenen Schutz. Das Hinaufschauen an vielen Stämmen wird zu einem Aufschauen überhaupt. Der Wald baut dem Kirchengefühl vor, dem Stehen vor Gott unter Säulen und Pfeilern. Sein gleichmäßigster und darum vollkommenster Ausdruck ist die Wölbung des Doms, alle Stämme in eine höchste und untrennbare Einheit verflochten. ${ }^{54}$

Um als Schutz- und Andachtsraum wahrgenommen zu werden, muss der Wald jede vitale Bedrohlichkeit verloren haben. Hier herrscht das beschriebene Gefühl der Erhabenheit. Mensch und Wald unterliegen gemeinsam einem (Natur-)Gesetz. Der Wald wird so in jedem Fall zum Bauwerk, wobei es letztlich egal scheint, ob er dem Waldbau entstammt (und als >Natur` wahrgenommen wird), oder ob es ihn in dieser Form natürlich gewachsen gibt (s.u.).

52 Canetti: Masse und Macht, S. $92 \mathrm{f}$.

53 Ebda., S. 81.

54 Ebda., S. $92 \mathrm{f}$. 
Abb. 16: Adolph Menzel: Missionsgottesdienst in der Buchenhalle bei Bad Kösen, 1868

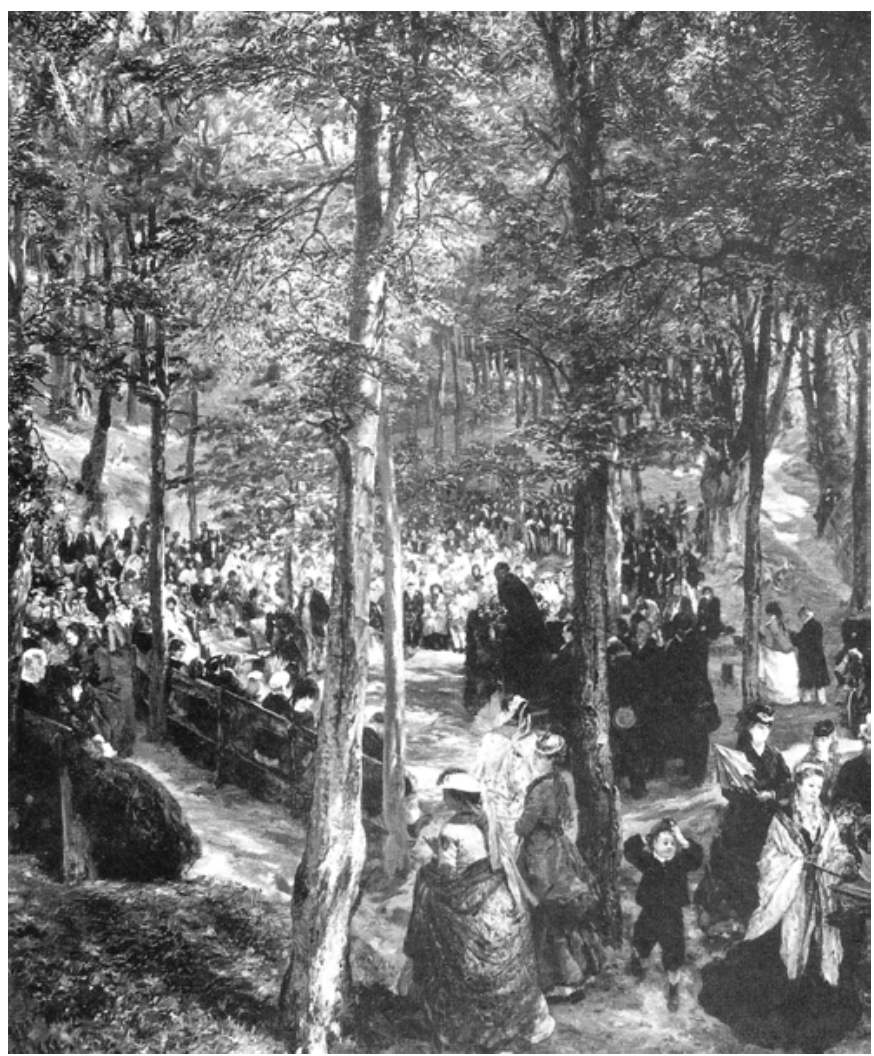

Der Wald als Kirche. »Waldesdom«, »Buchendom«, »Lindendom« (im Frühneuhochdeutschen bezeichnet >Linde « »sowohl einen heiligen Hain als auch den Lindenbaum $«),{ }^{55} »$ Heilige Hallen«. Derartige Bezeichnungen des Waldes (nicht $\mathrm{zu}$ verwechseln mit antiken oder archaischen »Heiligen Hainen«) sind offenbar erst seit dem späten 18. Jahrhundert geläufig, als einfache $>$ Hallen $`$ oder $>$ Gewölbe $<,{ }^{56}$ die aber ihre Weihung

55 Schama: Der Traum von der Wildnis, S. 116. Schama beruft sich hier auf Michael Baxandall: Die Kunst der Bildschnitzer, S. 144.

56 Grimms Deutsches Wörterbuch verzeichnet eine »lange Buchenhalle ganz durchglinzert vom Mond« aus Friedrich Heinrich Jacobis Briefroman »Woldemar« von 1779; zum Sturm und Drang zählt auch Johann Jakob Wilhelm Heinse, in dessen Künstlerroman »Ardinghello und die glücklichen Inseln« (1787) »die undurchdringlichen Eichen und Buchengewölbe und Felsen mächtiglich vor der Hitze Dampf beschirmten«. Dazu erwäh- 
zur Großkirche auch schon bei Johann Gottfried Herder erhalten - der sein Leben als Gang durch gotische Gewölbe bezeichnet und im Wald bei Nantes »einen grünen Tempel des Allmächtigen« sieht -, was seitdem zum »Gemeinplatz ${ }^{57}$ geworden ist. Das Klischee entsteht infolge zweier miteinander verwobener Voraussetzungen: Zunächst der Wiederentdeckung der Gotik - wobei allerdings Herder »die gotische Kunst [...] stets mit tiefer Abneigung betrachtet $«$ hat. ${ }^{58}$ Die umgekehrte Zuschreibung - der »Topos des gotischen Doms aus dem Walde $\ll^{59}$ - ist um einiges älter. Offenbar erscheint er erstmals im Brief des »Pseudo-Raphael« um 1510 in Rom. Hier wird der später »gotisch« genannte Stil als »maniera tedescha«, »deutscher Stil« bezeichnet und - insbesondere in seiner vorgeblichen Herkunft aus dem Wald - ausdrücklich pejorativ gewertet. $^{60}$ Nördlich der Alpen taucht die >Wald-Theorie< nach Keller »zuerst bei Michel Félibien in der >Histoire de l'Abbaye royale de St. Denis en France 1706 auf, findet sich dann bei F. Delamonce 1736, bei Boffrand 1745, bei Paul Decker 1759, bei William Warburton 1760«. ${ }^{61}$ Wobei die Beurteilung der Gotik unterschiedlich ausfällt. Die zweite Voraussetzung des Klischees ist die (Wieder-)Entdeckung des >deutschen Waldes`. Dieser >deutsche Wald mantischen Verehrung über weite Strecken devastiert, oder - dort, wo aufgeforstet wurde - bereits überwiegend derjenige im Sinne Johann Heinrich Cottas et al., zunehmend standardisierter Wirtschaftswald also (was nicht ausschließt, dass auch lange ungenutzte - >urwaldartige < Wälder als `Kathedralen` wahrgenommen und bezeichnet werden (kön-

nen die Grimms noch einen »dunklen Buchengang«, durch den »blasser Vollmondschein « sich ausbreitet aus der Feder Friedrich von Matthissons (1761-1831). Vgl. Deutsches Wörterbuch von Jacob und Wilhelm Grimm. Vierten Bandes erste Abtheilung. H.I.J. Bearb. v. Moritz Heyne. Leipzig: Verlag von S. Hirzel 1877, Stichwort »Halle«, Sp. $231 \mathrm{f}$.

57 Harrison: Wälder, S. 212.

58 Noch der alte Herder behauptete, es seien die Freimaurer gewesen, die, beschützt »durch päpstliche Bullen und besondere Freiheitsbriefe« in ganz Europa herum-»)schweiften «, um dort gotische Kirchen zu bauen (Keller, a.a.O., S. 80f.). In seinem »Vierten kritischen Wäldchen« sagt er zur Gotik: »Noch sahest du kein Naturbild, kein wahres Ideal der Schönheit: denn was man auch von Ähnlichkeit in dieser Kunst mit Bäumen, Menschen und Pflanzen [...] sagen möge: dies alles ist eine außerwesentliche oder erzwungene Ähnlichkeit.«; zit. n. Keller, a.a.O., S. 14, Fn. 20.

59 Keller, ebda., S. 13f.

60 Vgl. Frankl, Paul: The Gothic, S. 273f. Allerdings habe bereits Petrarca die Herkunft der Gotik aus dem Barbarischen angedeutet - zwar nicht »so explicitly and pointedly, but it has its root in his nationalistic construction of history« (ebda., S. 239).

61 Keller, a.a.O., S. $13 f$. 
nen). Wenn etwa Georg Forster Anfang der 1790er Jahre den Innenraum des Kölner Doms schildert -

»[d]ie Pracht des himmelan sich wölbenden Chors hat eine majestätische Einfalt, die alle Vorstellungen übertrifft. In ungeheurer Länge stehen die Gruppen schlanker Säulen da, wie die Bäume eines uralten Forstes: nur am höchsten Gipfel sind sie in eine Krone von Ästen gespalten, die sich mit ihren Nachbarn in spitzen Bogen wölbt und dem Auge, das ihnen folgen will, fast unerreichbar ist ${ }^{62}$

-, dann mag er sich einen >germanischen Urwald »Forst« allerdings, einen »Herrenwald ). Soviel ungestörte, natürlich entstandene >Astreinheit $<$ und Homogenität sind in der Landschaft nicht unbedingt zu haben.

>Heilige Hallen` sind zumeist Ergebnisse von Waldbau, von Durchforstungen - hier genauer von »Niederdurchforstungen«. Dabei, erklärt der Professor für Waldbau und Forsteinrichtung Peter Burschel, »entnimmt « man »unterständige Bäume und wenige im Wachstum zurückbleibende aus der herrschenden Schicht $«$. ${ }^{63}$ Wodurch »ganz und gar einschichtige Bestände« entstehen.

»Diese Monotonie verliert sich allerdings mit der weiteren Entwicklung, und es entstehen hallenartige Bestände, deren großer, offener Raum mit mächtigen Stämmen erfüllt ist, die wie Säulen dastehen. Alte Fichtenwälder dieser Art gibt es überall zu sehen. Unter den Kiefernalthölzern, die alle durch Niederdurchforstungen geformt worden sind, findet sich oft ein dichter Teppich von Heide oder Heidelbeeren. Und selbst viele der Buchendome in unseren Wäldern sind unschwer als Ergebnis von Niederdurchforstungseingriffen auszumachen, die auch bei dieser Baumart bis weit in das neunzehnte Jahrhundert hinein angewendet worden sind. ${ }^{64}$

Dass es sich bei hallenartigen Fichtenaltbeständen generell um >gebaute Wirtschaftswälder handelt, ergibt sich schon daraus, dass Fichten »reine oder doch von [ihnen] im wesentlichen beherrschte Bestände nur auf begrenzten Flächen«, in den Hochlagen der Mittelgebirge nämlich, bil-

62 Forster, Georg: Ansichten vom Niederrhein. Von Brabant, Flandern, Holland, England und Frankreich im April, Mai und Juni 1790. Hg. v. Ulrich Schlemmer. Stuttgart, Wien:: Erdmann 1989, S. 64.

63 Burschel: Der Waldbau, in: Stern, Horst et al.: Rettet den Wald, S. 252.

64 Ebda., S. 254. Burschels Betonung, »selbst viele der Buchendome« seien so entstanden, hängt damit zusammen, dass für »Buchenbestände« eigentlich die »Hochdurchforstung«, also die Entnahme von Bäumen aus der oberen, »herrschenden« Schicht »typisch« sei (ebda., S. 253). 
den, ${ }^{65}$ zugleich aber Nadelbäume (weit überwiegend Fichten und Kiefern) heute $» 66$ Prozent der Waldfläche $«$ in Deutschland bedecken. ${ }^{66}$ Für »Buchendome« sieht das etwas anders aus. Potentiell soll die Rotbuche (schon wegen der für sie seit mehreren tausend Jahren währenden günstigen klimatischen Bedingungen) der dominierende Baum des mitteleuropäischen Waldes sein. In der Ebene in Laubmischwäldern (vor allem mit Eichen), in höheren Lagen besonders mit Tanne (und weniger Fichte), könne sie aber auch partiell größere >Reinbestände< bilden: »Die Buche bildet ein dichtes Kronendach, durch das so wenig Licht an den Boden gelangt, daß andere Baumarten sich darunter nur schwer halten. $«{ }^{67}$ Zugleich sorgt der Schatten von Nachbarbäumen oder der eigenen Krone für ein Absterben der tiefer am Stamm sitzenden Äste, aber auch für deutlich kleinere Kronen, als bei einzelnen Bäumen. „Solche Bäume sind nun von der Statik her - geringeres Kronengewicht, weniger Sturmbelastung - in der Lage, ihr Dickenwachstum zu vernachlässigen. [...] Dadurch entstehen die säulenartigen Stämme der Waldbäume. « ${ }^{68}$ Die Tendenz »zu relativ gleichförmigen Hallenbeständen«, schreibt auch Scherzinger, werde nicht nur vom dichten »einschichtigen Kronenschluß«, sondern ebenso vom Buchenlaubstreu begünstigt, da dies »den Waldboden in zum Teil dicken Schichten abdämmt und für viele Baumsämlinge darüber hinaus toxische Wirkung hat«, was »kaum Bodenbewuchs« zulasse. ${ }^{69}$ Eine Garantie für makellose natürliche »Dome« ist das aber nicht, denn ohne waldbauliche Eingriffe wäre der Wald ja nichts Statisches. Was Burschel denn auch in gewisser Weise einräumt, wenn er die für Buchen- und Eichenbestände längst »typischen « »Hochdurchforstungen« schildert. Diese erlauben »kräftige Eingriffe in die herrschende Baumschicht«, also die Entnahme großer, älterer Bäume, was zwar zu Lücken im Kronendach und damit zu Lichteinfall führt, aber nur ein rasches Nachwachsen der unteren Baumschicht begünstigt, »da der Unterstand [die kleineren Bäume, M. T.] Boden und Schäfte gegen zu starken Lichteinfall abschirmt«. Was »für den Forstmann zwei große Vorteile« habe: Es kommt zu keiner »unerwünschten Bodenve-

65 Vgl. Burschel: Der Wald als Gesellschaft von Bäumen, in: a.a.O., S. 79.

66 Schreibt der Münchener Lehrstuhlinhaber für Forstgeschichte und -politik Richard Plochmann: Mensch und Wald, in: a.a.O., S. 215.

67 Burschel: Der Wald als Gesellschaft von Bäumen, in: a.a.O., S. 70ff.

68 Ders.: Der Baum als Einzelwesen, in: a.a.O., S. 45f.

69 Scherzinger, Wolfgang: Naturschutz im Wald, S. 78. Er beruft sich auf Leibundgut, Hans: Über die Dynamik europäischer Urwälder, in: Allgemeine Forst-Zeitung 33 (1978); Burschel, a.a.O.; Nietsch, H.: Steppenweide oder Eichenwald (1935); Knapp, H./Jeschke, L.: Naturwaldreservate und Naturwaldforschung in den ostdeutschen Bundesländern (1991). 
getation« und es bleibt gewährleistet, dass an den Stämmen der Buchen und Eichen die »schlafenden Augen« nicht austreiben (»Just aber das würden sie tun, wenn sie sich plötzlich im vollen Licht befänden.«) und sich zunächst zu dünnen Trieben, »Wasserreisern« im Jargon des »Forstmanns«, später zu »Klebästen« entwickeln. Was ästhetisch gesinnten Waldbesuchern »oft eher eine Freude sein« könnte, erklärt Burschel, sei forstlich »höchst ärgerlich«, weil es das Ziel der »Astreinheit« konterkariere. ${ }^{70}$ Nun dürfte es in Primärwäldern permanent zu Lichteinbrüchen - und damit auch zu »Klebästen« etc. - kommen, weil hier Bäume >eines natürlichen Todes sterben<. Dagegen verweist Scherzinger auf nur »kleinflächig-verschachtelte[] patches ohne flächigen Zusammenbruch«, bei denen einzelne Buchen abstürben, zuerst Äste, dann Kronen verlören, "so daß nur die Baumstümpfe wie mächtige Menhire stehenbleiben«. Auf den so entstehenden Lichtungen von höchsten $400 \mathrm{~m}^{2}$ siedelten sich nur »ausnahmsweise« Weichlaubhölzer, Himbeeren oder Weidenröschen an; »denn die im Schatten wartende Buchenverjüngung kann sich kurzfristig in die Verlichtung schieben. Es komme »höchstens nach katastrophenartigen Zusammenbrüchen zum Baumartenwechsel «. ${ }^{71}$ Derartige Erkenntnisse stammen meist aus Untersuchungen von Naturwaldreservaten oder - zellen, ${ }^{72}$ also jener Flächen, die zur Erforschung einer langfristigen Waldentwicklung von jeder Nutzung ausgenommen wurden. An anderer Stelle zeigt aber Scherzinger selbst, dass diese Flächen überwiegend $\mathrm{zu}$ klein seien, schon von daher oft »Randeinflüsse[n] « durch Wirtschaftswälder unterliegen, zudem »vor allem nach geobotanisch-waldkundlichen Gesichtspunkten«, aber »ohne Berücksichtigung faunistischer Ansprüche« ausgerichtet seien, weshalb »die volle Bandbreite des Waldentwicklungszyklus zumeist nicht repräsentiert werden kann ${ }^{73}{ }^{73}$

So scheint es mit den allenthalben verkündeten forstwissenschaftlichen Gewissheiten, wie Wald unter welchen Umständen sich entwickelt, nicht weit her zu sein. Wilhelm Bode, bis 1992 Leiter der saarländischen Landesforstverwaltung, in den 90er Jahren agrar- und forstpolitischer Sprecher des NABU und prominenter Landes-»Grüner«, spricht 1995 von der »)Diversitas Incognita des Deutschen Waldes«, vom »Wissensmangel der [...] Forstwirtschaft«. »Erste Auswertungen der Naturwaldzellenuntersuchungen nach 10 bis 20 Jahren« hätten deut-

70 Vgl. Burschel: Der Waldbau, in: a.a.O., S. 252f.

71 Scherzinger, a.a.O., S. 78.

72 Vgl. ebda. Scherzinger beruft sich erneut auf Knapp/Jeschke, zudem auf Remmert, H.: Naturschutz, ein Lesebuch (1988).

73 Ebda., S. 327ff. 
lich gemacht: »Wir wissen über die natürliche Biozönose unserer heimischen Wälder nicht viel mehr als über die Tropenwälder.« Über die natürliche Waldentwicklung gebe es »nur dürftige Erkenntnisse«. Zumal Naturwaldzellen oft qualitativ unzureichend seien. ${ }^{74}$ Auch eine Naturwaldzelle ist ein Laborversuch. In diesem Laborversuch - also im Idealbild - mag es sein, dass am Ende der Sukzessionskette >heilige Hallen ganz >ohne< menschlichen Eingriff entstanden sein werden. Nur - und hier liegt das Problem -, es gibt in der >Natur〈 kein Ende der Sukzessionskette. Das existiert eben nur im Laborversuch oder im forstlichen Idealbild. Das scheint zu genügen, um festzustellen: »Auch bei großer Altersspanne der Einzelbäume sind mehrschichtige oder gar Plenterphasen im Buchenwald eher die Ausnahme, weshalb der Altersklassenaufbau des Wirtschaftswaldes dem natürlichen Waldaufbau relativ nahe kommen kann. ${ }^{75}$

Hansjörg Küster zeigt, dass der in Forstwissenschaft und Naturschutz heute gängige Begriff der »potentiellen natürlichen Vegetation«, die mitteleuropäisch überwiegend aus Buchenwäldern bestehen soll, so nicht haltbar ist. Schon die darin enthaltene Meinung, Wälder nähmen »ein völlig natürliches Bild« an, wenn sie sich selbst überlassen würden, sei »Illusion«. So sei die mitteleuropäische Umwelt viel länger anthropogen beeinflusst, »als allgemein angenommen, nämlich schon etwa 7000 Jahre lang«. Und anhand von Pollenanalysen sei ersichtlich: Überall sei in Jahrtausenden prähistorischen Siedelwesens, in der Veränderung der Bodenbedingungen, im Wechsel von Rodungen und Wiederbewuchs, die Zusammensetzung und das Aussehen der Wälder »tiefgreifend « geändert worden, zumindest aber seien derartige Prozesse extrem beschleunigt worden. ${ }^{76}$ Und Buchenwälder, auch das zeigten Pollenanalysen, begannen »in vielen Gegenden Mitteleuropas genau in der Zeit häufiger zu werden [...], in der die Besiedlung durch den vorgeschichtlichen Ackerbauern begonnen hatte«, wenn auch »nur allmählich«. Hier schließt Küster eine Vermehrung ohne menschlichen Einfluss nicht völlig aus. ${ }^{77}$ Nur: »Der >echt natürliche` Wald vor der Siedlungsgründung hatte viele Ulmen, Eichen und Haselbüsche enthalten, im Wald, der Natur aus zweiter Hand war, gab es kaum noch Ulmen, aber viele Buchen«. Die »potentiell natürliche Vegetation« aber habe sich, trotz wiederkehrender völliger Aufgabe von Siedlungsflächen, nie mehr einge-

74 Vgl. Bode: Der Deutsche Wald - Eine einzige Arche Noah?, in: Wolters, Jürgen, ARA (Hg.): Leben und Leben lassen, S. 168f.

75 Scherzinger, a.a.O., S. 78.

76 Vgl. Küster: Geschichte des Waldes, S. 90ff. Vgl. Einleitung.

77 Vgl. ebda., S. 87f. 
stellt. Vielmehr sei mit dem Beginn der Zyklen von »Rodungen, Aufgeben von Siedlungen und Neubildungen von Wäldern« in der Jungsteinzeit die Ausbreitung der Buchen zunächst im südlichen Mitteleuropa begünstigt worden. Buchen seien zu dieser Zeit bereits in »einigen höheren Mittelgebirgen Süddeutschlands« vorgekommen. Von dort seien die Früchte offenbar von Tieren in die ehemaligen Rodungsflächen der Niederungen gebracht worden, wo sich Buchen allmählich ausbreiten konnten und »den generellen Charakter des Waldes mit der Zeit veränderten $«$, insbesondere wegen des Schattens, den sie werfen. ${ }^{78}$

Dass der Buchenwald als »potentielle natürliche Vegetation« weiter Teile Mitteleuropas gilt, entspringt - neben seiner Etablierung als letztem Glied einer Sukzessionskette - offenbar seinem ästhetisch-phänomenalen Gehalt als >natürlichem Dom<. Ironischerweise ist er somit ein real prähistorisch - wenn auch ungeplant - menschlich geschaffenes >Bauwerk`, wenigstens durch radikale Umgestaltung der >Natur entstanden. Das Klischee vom »Waldesdom« ist jedenfalls Hauptbestandteil der Vorstellungen von einer »Waldesschönheit« in der Moderne seit ungefähr 1800. Burschel und sein Kollege Jürgen Huss nennen unter dem Stichwort »Forstästhetik« zwei mögliche Vorstellungen von »Waldesschönheit«, die erfüllte Erwartung von Natur- bzw. Urwald, oder vom Wirtschaftswald, »der Teil einer Kulturlandschaft ist«:

»Da es in Mitteleuropa schon seit langem keine Urwälder mehr gibt und die Waldbesucher infolgedessen auch keine solchen kennen, kann die erste Vorstellung auf deren Schönheitsempfinden kaum Einfluß gehabt haben. Vielmehr bestimmt vor allem die zweite Vorstellung Ansprüche, die an Waldesschönheit gestellt werden. $\ll^{79}$

Waldesschönheit: Wenn Forster, Schlegel und Hegel mittelalterliche Dome an Wälder erinnern, dann geht es ihnen um »Weite und Größe«, um hohe Gewölbe auf Säulen, »ungeheure[], unendliche[] Räume«, in denen das »Vielfache«, in denen »Mannigfaltigkeit und Vereinzelung verschwinde[n] «, um den »Eindruck einer feierlichen Erhabenheit, die über das verständig Begrenzte hinausstrebt und hinwegragt«, darum, dass der »romantische Charakter christlicher Kirchen « - Hegel definiert die "gothische« Sakralarchitektur als romantische und als christliche schlechthin - »in dem Herauswachsen aus dem Boden und Empor-

78 Vgl. ebda., S. 88ff.

79 Burschel, Peter/Huss, Jürgen: Grundriß des Waldbaus. Ein Leitfaden für Studium und Praxis. Berlin: Parey 1997, S. 457. 
steigen in die Höhe« bestehe. ${ }^{80}$ Nur dürften sie derartige Wälder als Naturwälder - zumindest, was `Deutschland ropas angeht - kaum aus eigener Anschauung gekannt haben, denn als »Naturwald, also natürliche Lebensgemeinschaft (= Biozönose), die vom Menschen weitgehend unbeeinflußt war, existierte auch der Restwald spätestens seit Mitte des 18. Jahrhunderts nirgends mehr«. Und da, wo dieser Restwald existierte, war er als »natürliche Ressource des sogenannten >Hölzernen Zeitalters` [...] ausgeplündert, verlichtet, seiner herrschenden Baumschichten beraubt oder als kahlgeschlagene Fläche verbuscht. Dort, wo er noch am ehesten seinen Namen verdiente, war der Nährstoffkreislauf durch jahrhundertelangen Vieheintrieb, Plaggenund Streunutzung oder fürstliche Überhege von Schalenwildarten zerstört oder schwer geschädigt «. ${ }^{81}$

Als Bild für Dome taugen diese Wälder sicher nicht. Das müssen die Ästhetiker woanders her haben. Das Naturschöne entspringt einem Bewusstsein des Verlustes: »Sentimentalische Naturerfahrung«, die »sich am Unregelmäßigen, Unschematischen erfreut [...] Das Glück an der Natur war verflochten mit der Konzeption des Subjekts als eines Fürsichseienden und virtuell in sich Unendlichen; so projiziert es sich auf die Natur und fühlt als Abgespaltenes ihr sich nahe; seine Ohnmacht in der zur zweiten Natur versteinerten Gesellschaft wird zum Motor der Flucht in die vermeintliche erste«. In Kants Denken zeige sich, dass die Furcht »vor der Naturgewalt anachronistisch zu werden« beginnt »durchs Freiheitsbewußtsein des Subjekts«, das aber sei »dessen Angst vor der perennierenden Unfreiheit gewichen. Beides wird in der Erfahrung des Naturschönen kontaminiert. Je weniger sie sich ungetrübt vertrauen kann, desto mehr wird Kunst zu ihrer Bedingung «. ${ }^{82}$

Und so ist (letztlich) das Geordnete schön: Hegel charakterisiert die gotische Kathedrale als Gebäude, in dem sich »die selbstständige und dienende Baukunst vereinige«, im Innern als einen Raum der »totalen Umschließung «. ${ }^{83}$ Hier herrsche - weil »nämlich der christliche Geist sich in die Innerlichkeit zurückzieht« - ein »Vergessen der äußeren Natur und der zerstreuenden Betriebsamkeiten und Interessen der Endlichkeit«. Das Sonnenlicht wird »abgehalten, oder schimmert nur getrübter durch die Glasmalereien der Fenster, welche um der vollständigen Abscheidung vom äußeren Willen nothwendig sind. Was der Mensch

80 Hegel, Georg Friedrich Wilhelm: Vorlesung über die Ästhetik. II. Bd., in: Sämtliche Werke Bd. 13. Stuttgart: Fromman 1953, S. 342f. u. 334.

81 Bode, a.a.O., S. 162f.

82 Adorno: Ästhetische Theorie, S. 103.

83 A.a.O., S. 332 u. 336. 
hier bedarf, ist nicht durch die äußere Natur gegeben, sondern eine durch ihn und für ihn allein, für seine Andacht und die Beschäftigung des Innern gemachte Welt «. ${ }^{84}$ Da es hier im Dom um die »Bewegung, Unterscheidung, Vermittelung des Gemüths in seiner Erhebung vom Irdischen zum Unendlichen, zum Jenseits und Höheren« gehe, kehre die Architektur /zu einer analogen Naturform zurück, welche eine Form seyn muß der frei emporsteigenden feierlichen Sammlung und Umschließung«. Kurz: Das Interieur eines »mittelalterigen« Doms erinnere

»an die Wölbungen eines Waldes [...], dessen Baumreihen ihre Zweige zueinander neigen und zusammenschließen [...]; im Gothischen [...] steigen die Wände selbstständig und frei empor, ebenso die Pfeiler, die sich dann oben nach mehreren Richtungen auseinander breiten, und wie zufällig zusammentreffen, d.h. die Bestimmung, das Gewölbe zu tragen, ist, obschon dasselbe in der That auf den Pfeilern ruht, nicht ausdrücklich hervorgehoben und für sich hingestellt. Es ist, als trügen sie nicht, wie an dem Baume die Aeste nicht als vom Stamm getragen, sondern in ihrer Form mehr in leichter Krümmung als eine Fortsetzung des Stammes erscheinen und mit den Zweigen anderer Bäume ein Laubdach bilden. Solches Gewölbe, das für die Innerlichkeit bestimmt ist, dieß Schauerliche, das zur Betrachtung einladet, stellt der Dom dar «. ${ }^{85}$

Der Wald als »analoge Naturform«: Ein Wald allerdings, der >Wildnis nicht ist und sein kann. Ein >dienender vielmehr, ganz für die »Innerlichkeit bestimmt«, dessen 〉Bäume〈 streng geordnet sind in Anzahl und >Wuchs` nach den mystischen Zahlen drei, vier, sieben, zwölf, einer »totale[n] Gliederung « ${ }^{86}$ unterworfen, astfrei bis zur Krone. Hegel selbst kann >Wildnis $<$ nichts Positives abgewinnen: »Natur hatte bloß Umgebung zu sein für den Menschen; wo immer sich Wildnis entgegenstellte, war sie zu überwinden.« Er sah die menschlich gestaltete Umwelt als höherwertig denn die unberührte Natur an. »Der Fortschritt des Geistes war ein Weg von der Natur zur Kultur. Elysium, das verheißene Ziel, war die gebaute Landschaft. Hegel glaubte nicht an bukolische Schlaraffenländer, wo man sich tatenlos im Gesträuch rekelte. « ${ }^{87} \mathrm{Ob}$ dachlos noch dazu, wo doch für Hegel Vernunft durch Architektur repräsentiert wird. Und so bevorzugt er klar den »französischen«, den geometrischen, >vernünftigen` Barockgarten. Die gerade modischen Landschaftsgärten dagegen sind ihm ein Graus: »Es giebt in dieser Rücksicht zum größten Theil nichts Abgeschmackteres, als solche überall sichtbare

84 Ebda., S. 334f.

85 Ebda., S. $337 f$.

86 Ebda., S. 340f.

87 Wyss, Beat: Trauer der Vollendung, S. 81. 
Absichtlichkeit des Absichtslosen, solchen Zwang des Ungezwungenen.« Ja, es gehe hier sogar »der eigentliche Charakter des Gartenmäßigen verloren«, denn schließlich sei Garten ein Lokal, »das nicht mehr die Natur als solche ist, sondern zu »einer weiten Wohnung unter freiem Himmel umwandelt«, mit Bäumen »in strenger Ordnung zu großen Alleen nebeneinander [ge]pflanzt «. ${ }^{88}$ Wie äußert sich Hegel zur Analogie Dom - Wald? »Doch soll damit nicht gesagt seyn, daß die gothische Architektur sich Bäume und Wälder zum wirklichen Vorbild ihrer Formen genommen habe. ${ }^{89}$ Der Satz lässt offen, ob die Gotik unbewusste Adaption oder bewusste Abstraktion sei. Er kann aber auch bedeuten, dass Hegel bezweifelt, mittelalterliche Baumeister könnten den damals noch vorhandenen realen >wilden Wald zum Vorbild genommen haben anstatt eines imaginierten idealen. »Wußte die traditionelle Ästhetik, Hegel inbegriffen, Harmonie am Naturschönen zu rühmen, so projizierte sie die Selbstbefriedigung von Herrschaft aufs Beherrschte. ${ }^{90}$

Das »Schauerliche« des Erhabenen in Hegels »gothischen« Kathedralen entstehe durch die Weite des Raums, ebenso durchs Aufstreben der Pfeiler, deren Höhe die »Breite ihrer Basis in einer für's Auge nicht mehr berechenbaren Weise« übersteige. Die Pfeiler würden »mager, schlank und ragen so hinauf, daß der Blick die ganze Form nicht mit einem Male überschauen kann, sondern umherzuschweifen, emporzufliegen getrieben wird«, aber, 〉Gott sei Dank», dann doch nicht sich verliert, weil er »bei der sanft geneigten Wölbung der zusammentreffenden Bogen beruhigt anlangt, wie das Gemüth in seiner Andacht unruhig, bewegt vom Bogen der Endlichkeit ab sich erhebt und in Gott allein Ruhe findet $\ll .{ }^{91}$ Derartiges ist in der freien Natur noch Ende des 17. Jahrhunderts nicht zu erwarten.

88 Hegel, a.a.O., S. 351f.

89 Ebda., S. 338.

90 Adorno, a.a.O., S. 238.

91 Hegel, a.a.O., S. 338f. 


\section{Monströse Leiber zu idealschönen Körpern}

»Jeder Anblick der Weite, so Saint-Évremont 1685, »ist mit Schönheit unvereinbar, denn er flößt Grauen ein. Weitläufige Fluren, unermeßlich große Wälder, ausgedehnte Ebenen, unübersehbare Gärten sind schauderhaft; an solch unerquicklichen Orten szerstreut und verliert sich der Blickı. Das immerwährende Trachten nach Schönheit zwingt zur Einschränkung des Maßlosen.« Naturschönes und/oder Erhabenes hat hier noch keine Existenz. »Der Künstler muß verhindern, daß der Geist sich verirrt: Nach dem Beispiel Gottes, der es verstanden hat, die große Tiefe in Schranken zu halten, muß er dem Sehen Grenzen setzen.« Diese $»$ Kritik der vastitas« sei zu der Zeit in Frankreich Element des Streits zwischen den Repräsentanten der >Antike und der >Moderne, schreibt Alain Corbin. »Besonders die >Modernen〈 verabscheuen jeden Hinweis auf die ursprünglichen Naturkräfte. Sie leugnen die Schönheit der Wüste, des Waldes und des Meeres. « Was auch in der englischen Diskussion nicht anders sei. ${ }^{92}$

Aber derartige Positionen geraten unter Einfluss der Physikotheologie ins Wanken. Ein Wanken zwischen Abwehr und Verlangen. Auf ihrer Grand Tour durch die Alpen empfinden Burnet und nach ihm Dennis »einen deutlichen Abscheu vor den grauenvollen und chaotischen Szenen der pudenda der Erde. Sie wehren sich gegen all die Risse und Spalten der Natur, die zu füllen die Poesie berufen ist«. Aber beide sind schon empfänglich für das `Erhabene und dessen Ästhetik, wenn auch wider Willen. »Sie genießen das bestürzte Erstaunen, >das köstliche Grauen , die `schreckliche Freudeく. 〉Und indem ich ein unendliches Vergnügen empfand, begann ich zu zittern<, gesteht John Dennis. « ${ }^{93}$ Nicht von ungefähr fühlt sich Corbin offenbar an Verführung, Geschlechtsakt und Orgasmus ehedem standhaft tugendhafter Männer erinnert (ganz so, als habe Josef Potiphars Weib dann doch nicht widerstehen können), eine Angst-Lust, die aus dem Gefühl der Überwältigung resultiert, einer Überwältigung durchs >Weib $<$ - auch, wenn >Gott $<$ der Baumeister, der väterliche Besitzer sein soll, was aber durch die Stärke der unheimlichen Empfindungen noch nicht ganz glaubwürdig scheint. Ist es nicht doch die >Mutter ? Das erinnert an Freuds Begriff des »Unheimlichen«, der >Wiederkehr (des >Heimeligen` als >Unheimlichen (und der Erstarrung als Reaktion auf den >Kastrationsschreck beim Anblick des Medusenhaupts), mithin - historisch übergreifend - an die his-

92 Vgl. Corbin, Alain: Meereslust, S. 161.

93 Ebda., S. 162. 
torisch-semantisch unterschiedlich belegte Tradition, in der Landschaft weibliche bzw. mütterliche Schoßöffnungen zu verorten.

Burnet jedenfalls bemerkt, dass »alles, was die Einbildungskraft des Menschen übersteigt, [...] mehr oder weniger mit der Vorstellung des Unendlichen verbunden« sei, »im Gemüt die Ambivalenz von 〉Erstarrtsein` und 〉Bewunderung«« hervorrufe. Im Gemüt. Aber damit erscheint zugleich die Rettung. Denn die Ambivalenz des »pleasing kind of Stupor and Admiration«, so Burnet, wie ihn Groh/Groh paraphrasieren, nötige das Gemüt unwillkürlich, „»den erhabenen Gegenstand der Natur als Darstellung der Idee des Übersinnlichen zu begreifen « ${ }^{94}$ (und Dennis wird in seiner Erhabenheits-Hierarchie Gott an die Spitze vor dem Universum und den irdischen Naturdingen stellen, weil die Vorstellung Gottes den »greatest and strongest Enthusiasm« hervorrufe). Später wird das Prädikat »sublim« die Wahrnehmung der Naturerhabenheit kennzeichnen. Der Geist erhebt sich ästhetisierend über die Materie. Das herrschende >Haupt $<$ triumphiert über den distanzierten $>$ Unterleib $<$.

So wird die äußere Natur, so werden Landschaften $\mathrm{zu}>$ monströsen Leibern . Burnet spricht in seiner »Heiligen Theorie der Erde« von derartigem angesichts der Landschaft der Mittelmeerküste. »Disseits«, also am Meer, »gefile mir der Natur Einheit und Einfältigkeit und unübersichtliche Ebene; Jenseits«, am sehr hohen Felsen, »die viel-förmige Unordnung großer Leiber und unsinnige Zerstörung der Natur«. Es gelingt ihm bereits, diese unförmigen Riesen-Leiber als »sehr groß und herrlich $«{ }^{95} \mathrm{zu}$ bezeichnen (und damit semantisch einzugemeinden) - obwohl sie ihm ästhetisch als abstoßendes Übel erschienen -, da er sie als per Sintflut zerstörte und chaotisierte Ruinen göttlicher >Kathedralen begreift. $^{96}$ >Unförmige Riesen-Leiber`, >Monströse Leiber`, >groteske Körper : Michail Bachtin beschreibt das seit der Renaissance abgelöste Konstrukt des »grotesken Körpers«. Der ist

»von der umgebenden Welt nicht abgegrenzt, in sich geschlossen und vollendet, sondern er wächst über sich hinaus und überschreitet seine Grenzen. Er betont diejenigen Körperteile, die entweder für die äußere Welt geöffnet sind, d.h. durch die die Welt in den Körper eindringen oder aus ihm heraustreten kann, oder mit denen er selbst in die Welt vordringt, also die Öffnungen, die Wölbungen, die Verzweigungen und Auswüchse: der aufgesperrte Mund, die Scheide, die Brüste, der Phallus, der dicke Bauch, die Nase. Das Wesen des Körpers als das Prinzip des Wachstums und Über-sich-hinaus-Wachsenden

94 Groh/Groh: Weltbild und Naturaneignung, S. 126.

95 Zit. n. ebda., S. 127.

96 Vgl. ebda., S. 126. 
enthüllt sich nur in Momenten wie dem Koitus, der Schwangerschaft, der Geburt, dem Todeskampf, dem Essen, Trinken und Sich-Entleeren. [...] Von den verschiedenen Altersphasen des Körpers werden [...] [bevorzugt] jene dargestellt, die Tod und Geburt am nächsten stehen, also Kindheit und Greisenalter, mit deutlicher Betonung ihrer Nähe zu Mutterleib und Grab, zum gebärenden und verschlingenden $\mathrm{Schoß}[\ldots] \ll{ }^{97}$

So sei das groteske Gesicht eigentlich auf »den aufgerissenen Mund « reduziert, der Rest sei nur »Umrahmung der klaffenden und verschlingenden Bodenlosigkeit des Körpers« und stehe als »sperrangelweit geöffnete[s] Tor ins Körperinnere ${ }^{98}$ in engster Beziehung zum verschlingenden Schoß, und - so Menninghaus - zur »(Körper-)Hölle ${ }^{99}$, denn Bachtin zeigt, dass in Mysterienspielen Ende des 15. Jahrhunderts der »Höllenschlund« als riesige verschlingende Öffnung im Mittelpunkt der Bühne und des Publikumsinteresses steht. ${ }^{100} 300$ Jahre später ist bei Herder mit der Vorstellung derartig klaffender Schlünde, genauer »der weiblichen \Schaam«« eine »Bedrohung durch einen maximalen Ekelwert verbunden « - schon gar beim »Riesenweib«. Herder kritisiert Lessings »Laokoon« und die darin vorgebrachte Ansicht einer jedes natürliche Maß überschreitenden Größe der Götter Homers, indem er die Göttin Juno als »Riesenweib« konstruiert: Jupiter, Neptun oder Minerva »mögen so groß sein als sie wollen« - männliche Götter und Jupiters >bessere Hälfteく Minerva, römische Entsprechung zur griechischen Kopfgeburt Pallas-Athene, Göttin der Weisheit also und Erfinderin der Zahlen, keusche Ewige Jungfrau, die »Natur als Geist, die die schöpferische Kraft [Jupiter] leitet $«{ }^{101}$ - das kann Herder ertragen, aber Juno, »die Natur als Materie ist «, ${ }^{102}$ Geburtshelferin und Schutzgeist geschlechtsreifer Frauen? Bei ihr besteht Herder dann auf bloßen »Ideen von ihrer Hoheit und Größe« und setzt ein Rufzeichen dahinter.

»Nur daß diese im eigentlichen Verstande mir nicht zuerst durch die körperliche Statur vorgestellt werde: daß sich nicht auf diese, als auf den Hauptanblick, mein Auge heften dörfe: sonst verliere ich die Königin der Götter, die herrlichste der Göttinnen aus den Augen: ich sehe ein Riesenweib. Wo hat sie alsdenn, die Langstreckige? wo hat sie alsdenn im Himmel Raum? wie groß

97 Bachtin, Michael: Rabelais und seine Welt, S. 76ff.; zit. n. Menninghaus, Winfried: Ekel, S. 87.

98 Bachtin; zit. n. ebda., S. 90f.

99 Ebda.

$100 \mathrm{Vgl}$. ebda.

101 Ranke-Graves: Die weiße Göttin, S. 432.

102 Ebda. 
muß ihr himmlisches Brautgemach sein, das ihr Vulkan erbauet? wie groß der Schlüssel und das Schloß zu diesem Gemache, das kein Gott eröffnen kann als sie? wie viel Zentner Ambrosia wird sie brauchen, um ihren Körper zu säubern? wie viel Tonnen Öl, um ihn zu salben? wie groß wird ihr Kamm, ihr Gürtel, ihr Schmuck sein? wo wird sie mit Jupiter auf dem Berge Ida in ihrer süßen Umarmung Raum haben? wie, wen er sie in seine Arme faßt, an seine königliche Brust drückt, wie wird Ida und die Erde beben? - Ich mag nicht weiter, gnug! [...] Mein Auge erliegt, wenn es ins Ungeheure soll, und die Bewunderung, die ich jetzt fühle, verwandelt sich in eine Art von grauenvollem Selbstgefühle, und Schauder und Ekel.« ${ }^{103}$

Lediglich Ideen von »Hoheit und Größe« dürfen nach Herder hier existieren (demselben Herder, der im Wald bei Nantes den grünen Tempel des Herrn erblickt). Herder, kommentiert Menninghaus, steigere sich in eine derart »heftige >Vergegenwärtigung`, daß die bedrohliche Präsenz den Anschauenden einer Ohnmacht nahe bringt (>mein Auge erliegt<). Nur der apotropäische Abbruch der Beschreibung (〉gnug! ২) angesichts eines vaginalen Schlundes und eines orgasmischen Bebens, der den >Zentnern Ambrosia und den >Tonnen Öl entspräche, verhindert Schlimmeres«. Das »gnug!« sei eines »ekelhafter Sättigung, ja des Erreichens einer traumatischen Grenze«, verließen Herder doch virtuellen Angesichts einer »)hypergigantisch te«, durchlaufe er »alle Grade der Unlust bis zu ihrem anti-ästhetischen Maximalwert: `Ekel««. ${ }^{104}$

In vorbürgerlichen Gesellschaften bewohnen die monströsen Leiber noch parallele semantische Räume, können so aufgesucht und wieder verlassen werden, müssen deshalb noch nicht verdrängt werden, wie dann bereits bei Herder. Vorbürgerlich sind also Monstrositäten (sozusagen parallelweltlich) sehr wohl sinnstiftend, bürgerlich mit zunehmendem Maß semantischer Verknappung Abweichungen von Ideal und Norm. Hier bleibt ihnen dann nur entweder die erniedrigende Erhöhung zur Erhabenheit, oder die Umgestaltung gemäß der Ideale und Normen. Auch wilde Wälder haben als monströse Leiber bzw. »groteske Körper«, »keine Fassade, keine glatte, geschlossene Oberfläche, überhaupt keine äußere Expressivität«, sie erscheinen formlos, sprunghaft und lastend bewegungslos, riesig und zugleich trügerisch in ihrer Ausdehnung, auch in ihnen gibt es klaffende Bodenlosigkeit, auch sie können verschlingen und nicht wieder hergeben (oder doch ausspucken), sie »sind die fruchtbaren Körperhöhlen oder die zeugenden vorgewölbten Körperteile«,

103 Erstes Kritisches Wäldchen, S. 175f.; zit. n. Menninghaus, a.a.O., S. 121. 104 Menninghaus, a.a.O., S. 122. 
auch ihre »Tiefen des Leibes sind fruchtbar, hier geht das Alte zugrunde und wird das Neue aus dem Überfluß geboren«, fruchtbar aus sich selbst heraus. Das heißt keineswegs, dass sie in vorbürgerlichen Gesellschaften des Okzidents nicht zerstört, gerodet, geplündert usw. werden (können); um aber später in der bürgerlichen Gesellschaft als anerkannte Körper geschützt zu werden, haben sie sich der völligen Umkehrung ihrer »Produktions- und Vermeidensregeln $\ll^{105}$ zu denen der klassischen Ästhetik zu fügen (wie die Riesenweiber der Mythen); von der Produktivität zur Reproduktivität.

Fast hundert Jahre nach Burnet und Dennis jedenfalls ist in dieser Hinsicht die >Geschlechter-Hierarchie〈offenbar soweit hergestellt, dass Wilhelm Heinse in einem Brief jubeln kann:

»Triumph mein Teuerster! Ich bin auf der Höhe des Gotthard gewesen, und habe da Abend und Morgen und eine Nacht zugebracht [...]. Was ich da gesehen und gehört und erfahren habe, läßt sich mit keiner Zunge aussprechen und mit keiner Feder beschreiben. Ich habe den Anfang und das Ende der Welt gesehen, [...] ich bin mit Entzücken in die innerste, geheimste Harmonie der Wesen eingedrungen, und Herz und Geist und alle Sinne haben sich bei mir in Wonne gebadet. [...] Dies Anschauen war das Anschauen Gottes, der Natur ohne Hülle, in ihrer jungfräulichen Gestalt; alles groß und rein, alle die ungeheuren Massen daliegend in unendlicher Majestät! « ${ }^{106}$

Auch Heinse schildert einen >Geschlechtsakt`, allerdings einen regelkonformen, eine Entjungferung, Hochzeitsnacht: »Triumph«, »ohne Hülle«, »jungfräuliche[] Gestalt«, entzücktes Eindringen ins »[I]nnerste«, um zum »Anschauen Gottes« zu gelangen. Hier bedeutet »jungfräulich« nicht mehr, keinem Manne untertan zu sein, sondern >unversehrt` vom Besitz des Vaters in den des Gatten zu gelangen. Der macht sie sich ästhetisch (und damit auch ökonomisch) untertan. Derartige sexuelle Konnotationen sind offenbar symptomatisch für die >Grand Tour`. Sie ist bis ins 19. Jahrhundert hinein eine ausgesprochen "geschlechtsspezifische[] « Reisetradition, exklusiv jungen Männern der Oberschicht vorbehalten, die sich die Landschaften und desgleichen feminisierten Städte (vor allem Italiens) >erobern $<$ - wobei auch reale Sexualerfahrungen zur >Grand Tour` gehören. ${ }^{107}$

105 Ebda., S. 87.

106 Zit. n. Groh/Groh, a.a.O., S. 92.

107 Vgl. Schaff, Barbara: Gendered Cities, in: Mahler, Andreas (Hg.): StadtBilder, S. 173f. 
Bei Heinse ist also bereits »alles groß und rein«, so dass er »mit Entzücken« eingedrungen ist, um dann in »unendlicher Majestät« zu schwelgen. Burnet und Dennis sind noch nicht so weit: »Unfreiwillig entdecken die Reisenden die Macht des Unermeßlichen.« Gefühle, die scheinbar übereinstimmen mit »denen der Verfasser damals in Mode kommender kosmischer Reisebeschreibungen«, die sich ihrerseits »an der Herrlichkeit unendlicher Räume ergötzen«. Was aber nicht zu einer Täuschung führen dürfe, denn die von Burnet und Dennis geschilderten »unerhörten Verzückungen«, die »zur Verherrlichung der göttlichen Größe« beitrügen, seien eine »Mischung aus Betroffenheit, Grauen, Freude und Verlangen «. ${ }^{108}$ In der Tat dürfte ein sich Delektieren am unendlichen Raum des Kosmos ein ungleich >reineres` sein, als an materiell greifbarer Natur: Flora, Fauna, Berge, Meer. Es ist in jeder Hinsicht distanziert, weil es bloß instrumentell (per Fernrohr) bzw. bloß mathematisch erfass- und erfahrbar ist und eben nicht sinnlich, wie Wald etc., die existentiell auf den Leib rücken (können). Was zumindest so lange auch Abscheu auslöst, wie es noch dem >Außen< angehört oder anzugehören scheint, noch nicht zum >Innenraum « zählt.

Die Monstrositäten des Leibes der Natur müssen in Schönheit oder Erhabenheit verwandelt werden. Barthold Hinrich Brockes (1680-1747), Hamburger Ratsherr, Physikotheologe und Frühaufklärer schafft ab 1721 mit seinem neunbändigen Werk »Irdisches Vergnügen in Gott, bestehend in Physicalisch- und Moralischen Gedichten« eine »poetische Enzyklopädie der Bewegung «. ${ }^{109}$ Hierin macht er sich in einem frühen Gedicht »Gartengedanken«:

»An vier Säulen/Glänzt Garten, Flur und Feld in solchem Schmuck und Schein/Wie herrlich muß ihr Quell, wie schön der Schöpfer sein!/Es zeiget jede Blum, es zeiget jedes Kraut/Den wunderbaren Gott dem, der sie recht beschaut./Dies schöne Weltbuchsblatt, so hier vor Augen lieget,/Liest der zu Gottes Ruhm, der sich daran vergnüget./Im wunderschönen Weltgebäude/Sucht Gott sein Lob, o Lieb! Allein in unsrer Freude. ${ }^{110}$

Die äußere Natur wird hier als vollkommene und nützliche, die Allmacht Gottes spiegelnde Schöpfung, mithin als Garten identifiziert, »deren menschliche Gestaltung jedoch dem göttlichen Schöpfungsplan unterliegt«. Gestaltung und Beherrschung werden durch die vier Säulen ausgedrückt, die »dem Garten die geometrische Form« geben. »Aber

108 Corbin, a.a.O., S. 162.

109 Groh/Groh, a.a.O., S. 54.

110 Zit. n. Duesberg: Idylle und Freiheit, S. 148. 
diese Säulen umschließen nicht nur den Garten, sondern auch Flur und Feld, die sonst Bestandteile der freien Natur sind. Die gesamte äußere Natur wird durch diese vier Säulen eingefangen, die dadurch gleichermaßen Bestandteile des Gartens sind. « ${ }^{111}$ Brockes entwirft also eine Art »Weltinnenraum «, ${ }^{112}$ als solchen fasst später Hegel die gotische Sakralarchitektur auf. Brockes' >wunderschönes Weltgebäude` verlangt nach der menschlichen Freude an der göttlichen Schöpfung Natur als 〉Gotteslob<. Zugleich muss die Natur als Blatt des Weltbuchs gelesen, identifiziert werden können, eine »wissenschaftliche Erkenntnis des göttlichen Schöpfungsplans« und die »zivilisatorische[] Perfektionierung der göttlichen Natur« ist »moralische[r] Auftrag«. Physikalische und moralische Welt sind also eins, wie schon Brockes EnzyklopädieTitel sagt. »Die Erforschung des göttlichen Willens in der Natur« - nun auffindbar in >Vollkommenheit $\triangleleft$ und $>$ Zweckhaftigkeit $`$ ihrer >vernünftigen herrschung und ökonomische Nutzung der Natur«. Und: »Die äußere Natur wird in der Frühaufklärung durch die Beherrschung und Gestaltung zur menschlichen Vernunft, wodurch sie das Bedrohliche verliert. ${ }^{113}$ Die Ästhetik der Natur, des Waldes, aber basiert auf ihrer Beherrschung, Reorganisation und Reproduktion.

Carl von Linné beschreitet 1749 »den Weg vom >Haushalt der Natur zur >Ökonomie der Natur««, wie Groh/Groh zeigen »ganz im Geiste der Physikotheologie«, wenn auch in strengerer Systematik: Von der »Oikonomia« aristotelischer Tradition, die den »Hausvater seinen >Haushalt` im Einklang mit Gott und der Natur« bestellen lässt, zur »ökonomischen Gesellschaftstheorie eines Adam Smith und seiner Nachfolger, die lehrte, wie man den Reichtum zuerst des Einzelnen und dann der Nationen mehrt. Mehrung des Reichtums wurde von nun an identisch mit Ausbeutung der Natur und ihrer Ressourcen zugunsten materiellen Fortschritts, der heute in einen >Selbstvernichtungsfortschritt überzugehen droht«. In Linnés »Oeconomy of Nature« seien die Ökonomie Gottes und der Natur identisch, allerdings nicht im Sinne einer »Seelenheilsökonomie, sondern als durchaus irdische Veranstaltung zum Wohle des Menschen «. ${ }^{114}$ So werde immanent logisch letztlich aus der >Weltmaschine` des großen mechanistischen Werkmeisters und Schöpfers Gott, wie er in unzähligen »Maschinen-Bücher[n]« von 1550 bis

111 Duesberg, ebda., S. 147f.

112 Wyss, Beat, a.a.O., S. 81.

113 Duesberg, a.a.O., S. 148f.

$114 \mathrm{Groh} /$ Groh, a.a.O., S. 70. 
1750 gepriesen wurde ${ }^{115}$ eine $>$ Weltfabrik`, wobei es dann »konsequenterweise die religiöse Pflicht des Menschen« sei, »die natürlichen Rohstoffe in Maschinen zu seinem Nutzen zu verwandeln«. Groh/Groh sprechen bezüglich globaler Umweltzerstörung von der »Sprengkraft«, die die »Verbindung von Ökonomie der Natur und Ökonomie der Gesellschaft«, gestiftet per Imagination eines obwaltenden höheren Hausvaters, der wissenschaftlichen Naturbeherrschung verliehen habe. ${ }^{116}$

Was aber betont werden muss, ist, dass Beherrschung und Indienstnahme einhergehen mit Ästhetisierung, mit einer Verwandlung >chaotischer Zeichen` in eine Art 〉Kalligraphie`: Der >Text` der Natur soll lesbar werden und schon dazu soll dieser >Text werden (bzw. >sein $<$ ). Michel Foucault spricht über die »Struktur« der »Naturalia« im »klassischen Zeitalter« (wie er es nennt). Die neue »Naturgeschichte $\ll$ entstehe hier, in einer Zeit, in der »die Biologie nicht existierte «, denn »das Leben selbst existierte nicht. Es existierten lediglich Lebewesen, die durch einen von der Naturgeschichte gebildeten Denkraster erschienen«. Diese Naturgeschichte erscheine zwangsläufig, so der gängige Eindruck, »auf dem Gewölbe der mechanistischen Theorie von Descartes«. Sie sei »[t]atsächlich [...] dem kartesianischen Denken gleichzeitig, und nicht seinem Scheitern«, also der zunehmenden Erkenntnis der Unmöglichkeit, »die gesamte Welt in die Gesetze der geradlinigen Bewegung zu pressen«, denn es seien dieselben »episteme«, die »sowohl die Mechanik seit Descartes bis hin zu d'Alembert und die Naturgeschichte von Tournefort bis hin zu Daubenton ermöglicht« hätten. ${ }^{117}$

Vorher habe die inzwischen geläufige "große Dreiteilung [...] zwischen der Beobachtung, dem Dokument und der Fabel« nicht existiert, denn die »Zeichen waren Teile der Dinge, während sie im siebzehnten Jahrhundert zu Repräsentationsweisen wurden«. In einer »jetzt offenen Distanz zwischen den Wörtern und den Sachen « finde die Naturgeschichte »ihren Platz«. Die Dinge erscheinen »in der Tiefe der Repräsentation«. In dem »empirischen Klima, in dem sie sich entwickelt«, ist die Naturgeschichte, so Foucault, »der in der Repräsentation durch eine Analyse eröffnete Raum, die der Möglichkeit, zu benennen, vorgreift; weshalb die Naturgeschichte auch genau in jenem bestimmten Moment erschienen ist. Es handelt sich um die Möglichkeit, das zu sehen, was man wird sagen können, was man aber nicht in der Abfolge sagen könnte, noch in der Distanz sehen könnte, wenn die Wörter und Sachen

115 Vgl. ebda., S. 60.

116 Vgl. ebda., S. 71.

117 Foucault: Die Ordnung der Dinge, S. 168f. 
in ihrer Unterscheidung voneinander nicht von Anfang an in einer Repräsentation kommunizierten «. ${ }^{118}$ Mithin: »Das klassische Zeitalter gibt der Geschichte einen ganz anderen Sinn: zum ersten Mal einen Blick auf die Dinge selbst zu richten und danach zu transkribieren, was er in glatten, neutralisierten und sich treuen Wörtern aufnimmt. Man begreift, daß in dieser >Reinigung (die erste Form der Geschichte, die sich gebildet hat, die Geschichte der Natur gewesen ist. Sie hat nämlich zu ihrer Errichtung nur unvermittelt den Dingen selbst applizierte Wörter nötig. Die Dokumente dieser neuen Geschichte« - deren Ort »ein zeitloses Rechteck« ist, worin »die Wesen« entkleidet von »jeder sie umgebenden Sprache« als »Träger allein ihres Namens« sich präsentieren »mit ihren sichtbaren Oberflächen« und gemäß ihrer »gemeinsamen Züge«, daher »bereits virtuell analysiert« -, »sind keine anderen Wörter, Texte oder Archive, sondern klare Räume, in denen die Dinge nebeneinander treten: Herbarien, Naturalienkabinette, Gärten «. ${ }^{119}$ In der Folge, so muss man ergänzen, trifft das auch auf die nun praktisch neu zu gründenden bzw. $\mathrm{zu}$ >entdeckenden` Wälder zu.

$»$ Die Naturgeschichte ist nichts anderes als die Benennung des Sichtbaren.« Hierbei gehe es nicht darum, dass nun etwas prinzipiell Sichtbares jahrhundertelang durch »Unachtsamkeit der Blicke stumm geblieben war«, dass man nun »besser und aus größerer Nähe hingeschaut hätte«, sondern dass sich »ein neues Gesichtsfeld [...] in seiner ganzen Mächtigkeit gebildet« habe. Streng genommen habe sich dabei das klassische Zeitalter angestrengt, »wenn nicht so wenig wie möglich zu sehen, so doch wenigstens freiwillig das Feld seiner Erfahrung einzuengen«: auf den fast ausschließlichen Primat des Sehens - Tastsinn, Geschmack und Geruch gelten ebenso wie Hörensagen als unanalytisch, damit inakzeptabel. Aber nicht alles, was sich dem Gesichtssinn offeriert, ist für derartige wissenschaftliche Differenzierungen nutzbar. »Das Sichtfeld, in dem die Beobachtung ihre Kraft haben wird, ist nur das Residuum jener Ausschlüsse: eine von jeder anderen sinnlichen Last befreite und obendrein ins Grau in Grau übergegangene Sichtbarkeit. Dieses Feld definiert viel eher als die schließlich den Dingen selbst gegenüber aufmerksame Aufnahme die Bedingung, unter denen die Naturgeschichte und das Erscheinen ihrer gefilterten Gegenstände (Linien, Oberflächen, Formen, Reliefs) möglich werden. ${ }^{120}$

Die deskriptive Ordnung ist die »Struktur«. Sie »gestattet dem Sichtbaren, indem sie es begrenzt und filtriert, sich in Sprache zu transkri- 
bieren. Durch sie geht die Sichtbarkeit des Tiers oder der Pflanze völlig in den Diskurs über, der sie aufnimmt. Vielleicht gelingt es ihm einmal, sich selbst dem Blick durch die Wörter wiederzugeben, wie in jenen botanischen Kalligrammen, von denen Linné träumte«. Der habe sich in seiner »Philosophia botanica« gewünscht, »daß die Reihenfolge der Beschreibung, ihre Aufteilung in Paragraphen und bis hin zu den typographischen Verfahren die Gestalt der Pflanze wiedergäben; daß der Text in seinen Formvariabeln, in den Abweichungen seiner Disposition und Menge eine pflanzliche Struktur hätte «. ${ }^{121}$ Es sei »schön, wenn man der Natur folgt: von der Wurzel« über die einzelnen Pflanzenteile bis hin zu »den Blüten«, notiert Linné in der »Philosophia botanica«. Die Anzahl der Pflanzenteile müsste die Anzahl der Absätze bestimmen, die Deskription der Hauptteile in Großbuchstaben, »Teile von Teilen« klein gedruckt werden. Schließlich fehlt noch, wie beim Zeichner die »Schattierung«, sie »wird genau die ganze Geschichte der Pflanze, wie ihre Namen, ihre Struktur, ihre äußere Gesamtheit, ihre Natur und ihren Gebrauch enthalten «. ${ }^{122}$ Obwohl Georges-Louis de Buffon »ein ständiger Gegner von Linné war«, ${ }^{123}$ zeigt Foucault mit Buffons »Discours sur la manière d'étudier et de traiter l'histoire naturelle«, dass bei diesem die "gleiche Struktur« existiere, die »auch die gleiche Rolle« spiele wie bei Linné. Trotz aller Frontstellung: es dominiert der Zusammenhang der »Naturgeschichte«, es herrscht der gleiche Blick. Beide »setzen den gleichen Raster auf; ihr Blick besetzt auf den Dingen die gleiche Kontaktfläche. Die gleichen schwarzen Felder beherrschen das Unsichtbare. Die gleichen hellen und abgesetzten Felder bieten sich für die Wörter an«. ${ }^{124}$

Aber, was heißt in diesem Kontext eigentlich, >der Natur zu folgen`, wie Linné, Buffon et al.? Zunächst heißt hier »Beobachten [...], sich damit zu bescheiden, zu sehen; systematisch wenige Dinge zu sehen. $\mathrm{Zu}$ sehen, was im etwas konfusen Reichtum der Repräsentation sich

121 Ebda., S. 177.

122 Zit. n. ebda.

123 Der Comte de Buffon hat 1788 in seinen »Epoques de la nature« den »sombre abîme tu temps« zwar »noch nicht in seiner ganzen Tiefe aufgerissen «, legte aber einen wesentlichen Grundstein der Evolutionstheorie, die dem »Fundament der christlichen Schöpfungslehre« den Boden entzog (Groh/Groh, a.a.O., S. 58). Während Linné überzeugt ist, die ganze Natur per Taxonomie erfassen zu können, hält Buffon sie für zu mannigfaltig, um in einen so strengen Rahmen gepresst zu werden. Während Linné »an die Unbeweglichkeit der Natur« glaubt, »ahnen« bereits Bonnet, Diderot u.a. »die große schöpferische Kraft des Lebens, seine unerschöpfliche Macht der Transformationen« (Foucault, a.a.O., S. 166f.).

124 Foucault, a.a.O., S. 177f. 
analysieren läßt, von allen erkannt werden und so einen Namen erhalten kann, den jeder verstehen wird «. Von allem Störenden (Ähnlichkeiten, Farben usw.) bereinigt bilden die »durch die Augen gewonnenen Repräsentationen « das eigentliche Objekt der Naturgeschichte, »das genau, was sie in jene wohlgeformte Sprache übergehen läßt, die sie bauen will «. ${ }^{125}$ Der >Natur folgen`, indem die Textstruktur der pflanzlichen folge, heißt dann: »In Sprache umgesetzt, dringt die Pflanze darin ein und rekomponiert ihre reine Form unter den Augen des Lesers.« Das Objekt der Naturgeschichte ist »der Umfang, aus dem die natürlichen Wesen bestehen«. Der unterliegt vier Variablen: Form, Quantität, relative Größe der Elemente, sowie »die Weise, auf die sie im Raum eines in Beziehung zu den anderen verteilt sind «. Die lassen sich bei Pflanzen auf alle fünf Teile anwenden. Jedes sichtbar differente Organ oder Element eines Tieres oder einer Pflanze wird von je vier Werten determiniert (und beschreibbar). Diese vier Werte »nennen die Botaniker Struktur. Sie gestattet sogleich, das zu beschreiben, was man sieht, und zwar auf zwei weder widersprüchliche, noch einander ausschließende Weisen«: Anzahl und Größe, also immer berechenbare Mengen, und Formen und Dispositionen, also Identifikationen mit geometrischen Formen oder höchst evidenten Analogien:

»So kann man bestimmte, ziemlich komplexe Formen ausgehend von ihrer sichtbaren Ähnlichkeit mit dem menschlichen Körper beschreiben, der als Reserve für die Beispiele der Sichtbarkeit dient und spontan die Angel bildet zwischen dem, was man sehen, und dem, was man sagen kann. « ${ }^{126}$

Linné nennt in der »Philosophia botanica« die Körperteile, »die für Maß und Form als Archetyp dienen können: Haare, Nägel, Daumen, Handspanne, Auge, Ohr, Finger, Nabel, Penis, Vulva, Brust«. Diese die Naturgeschichte »in der Klassik in ihrem ganzen Umfang« durchlaufende Strukturtheorie »legt in ein und derselben Funktion die Rollen übereinander, die in der Sprache die Gliederung und der Satz spielen«, wodurch sie »mit der mathesis verbunden«, d.h., »das ganze Feld des Sichtbaren« auf ein Variablen-System zurückgeführt werde, in dem alle Werte kalkulierbar, zumindest aber klar und begrenzt umschreibbar sind. Eine Botanik als streng mathematische Wissenschaft erscheint aus dieser Sicht im 18. Jahrhundert als zukünftig möglich. Der Bezug der Naturgeschichte schließlich »wird durch Oberflächen und Linien gegeben, nicht durch Funktionieren oder unsichtbares Gewebe. Die Pflanze oder 
das Tier werden weniger in ihrer organischen Einheit als durch die sichtbare Heraustrennung ihrer Organe gesehen «. ${ }^{127}$ Erst nachdem die Natur in eine streng sichtbare, exklusiv per Sehkraft beschreibbare, >reine Form 'gebracht wurde, gereinigt von allem Wuchernden, in dem die Zeichen noch Teile der Dinge sind (wie vorher), von allem Fabelhaften - mithin auch Monströsen -, ist es »schön«, wie Linné sagt, der `Natur zu folgen<.

Im 12. Band seiner monumentalen »Histoire Naturelle« macht Buffon 1764 in dem Essay »De la Nature« unmissverständlich klar, welche Natur die schöne, die >eigentlicheく ist: die »gebaute Natur! Wie hat die Sorgfalt des Menschen«, der dieser Natur »zur vornehmsten Zierde« gereiche, »sie so glänzend und prächtig geschmückt!« Es sei das »edelste Erdengeschöpf«, der Mensch, der mit seiner eigenen Vermehrung zugleich die Erde mit sich zu vermehren scheine. »Alles, was sie in ihrem Schooße verbarg, bringt er durch seine Kunst an das Licht. Wie viele Schätze, die man sonst nicht kannte! Welche neuen Reichthümer! Blumen, Früchte, Getreide, alles wird zur Vollkommenheit gebracht, und bis ins Unendliche vervielfältigt. ${ }^{128}$

Buffon inszeniert eine Konfrontation von »scheußlicher« >ursprünglicher Natur und >zivilisierter`, »verjüngte[r] Natur«. Erstere existiert in beständiger Agonie, ist ruiniert, von Fäulnis erfüllt, moralisch wie physisch verfallen, bösartig, von unnützen und schmarotzenden Kreaturen in Flora und Fauna bewohnt, stellt für den Menschen eine Gefahr dar. Der ist daher zur permanenten Eroberung, Beherrschung, Verbesserung aufgefordert, "weil die Natur stets zur Zerstörung und zum Verderben treibe«, kommentiert Bätschmann, und nach Buffon sei die menschliche Herrschaft über die Natur »nur durch die beständige Eroberung« gerechtfertigt. ${ }^{129}$ So müssen Sümpfe und Moraste trocken gelegt - »jenes todte Wasser beleb[t]« -, Flüsse und Bäche kanalisiert werden, die >unnützen Tiere und Pflanzen ausgerottet, »fette « Äcker und Wiesen in den Tälern entstehen, Reben und Obstbäume auf den Hügeln, Rosen und Weinstöcke statt Dornen und Disteln. Und die Gipfel (dabei nicht nur sie) sollen »mit nützlichen Forsten bekränzt« sein, statt ehedem, noch

127 Ebda., S. 176ff.

128 Le Clerc, Georges Louis, Comte de Buffon: De la Natur (dt. z.T. v. Georg Forster), in: Bätschmann, Oskar: Entfernung der Natur, S. 269ff. Georg Forster macht sich Buffons Essay 17 Jahre später größtenteils in der Einleitung seiner Vorlesung »Anfangsgründe der Thiergeschichte« zu eigen. Das ist insofern bemerkenswert, als dass Forster selbst durchaus nicht der Verfalls-Theorie zuzuneigen scheint.

129 Bätschmann, a.a.O., S. 22. 
»wüster Erdstrich«, noch »traurige, von Menschen nie bewohnte Gegend« zu sein, »mit dichten schwarzen Wäldern überzogen«, mit

»Bäume[n] ohne Rinde, ohne Wipfel, gekrümmt, oder vor Alter hinfällig oder zerbrochen; andere in noch weit größerer Zahl an ihrem Fuße hingestreckt, um auf bereits verfaulten Holzhaufen zu modern, - ersticken und vergraben die Keime, die schon im Begriff waren, hervorzubrechen. Die Natur, die sonst überall so jugendlich glänzt, scheint hier schon abgelebt; die Erde, mit den Trümmern ihrer eigenen Produkte belastet, trägt Schutthaufen anstatt des blumigen Grüns, und abgelebte Bäume, die mit Schmarotzerpflanzen, Moosen und Schwämmen, den unreinen Früchten der Fäulnis beladen sind «. ${ }^{130}$

Die hier geschilderten »Erscheinungsformen« seien allesamt »Folgen intensiver Waldnutzung durch den Menschen!«, sagt dazu Hansjörg Küster unter Verweis auf die Devastierung weiter Landstriche am Ende des 18. Jahrhunderts, in Frankreich noch stärker, als etwa im deutschsprachigen Raum. "Sehr bezeichnend an diesem Text» sei eine Beschreibung von Natur-Eigenschaften, die Resultat übermäßiger Nutzung seien. »Die durch Kultivierung der Wildnis entstandene neue Wildnis, die Natur, die sin ihren letzten Zügen liegt, muß erneut kultiviert werden! « ${ }^{131}$ Es wird nicht ganz klar, ob Küster Buffons Essay lediglich als Beschreibung des damaligen Zustands verwendet (oder dem Comte gar Unkenntnis der Herkunft dieser Zustände vorwirft). Klar ist: für Buffon ist die sursprüngliche` Natur - offenbar nach der Verfalls-Theorie - die $\mathrm{zu}$ erobernde und zu verbessernde. Für ihn ist es diese Natur, die bei nachlassender Kultivierungsanstrengung gemäß ihres Wesens Verderben und Zerstörung bringt. Zugleich sind die vom Comte beschriebenen Wald-Phänomene nicht nur auf Übernutzung zurückzuführen. >Verkrüppelte` Bäume, Baum-Ruinen, >Totholz` usw. sind Erscheinungen der >natürlichen Sukzession<. Buffon aber propagiert das Bild vom nicht mehr hinfälligen Wald, in dem die Bäume nicht mehr >sterben`, der eine andauernde wohlproportionierte Gestalt, eine Architektur in göttlichem Auftrag erhalten soll, schön und nützlich zugleich. Hier ist das »Erdreich [...] überall zugänglich, überall so belebt als fruchtbar«. Der nützliche Forst ist schön. Er »bekränzt« die Gipfel. Er ist vom Menschen gebaut, der die vormaligen unhaltbaren Zustände beseitigt, der »diesen überflüssigen Unrath, jene schon halb vergangenen Wälder mit Feuer verbrennen, und, was das Feuer nicht aufreibt, vollends mit der Axt zerstören« soll, denn die »Wüsteney«, »Einöde«, in der der Mensch »stets 
auf seiner Hut seyn« muss vor »wilde[n] Thiere[n]«, die nicht kultivierte Natur »ist scheußlich, und liegt in ihren letzten Zügen«. Und, so sagt sich der Mensch nach Buffon schaudernd, wenn er dieses Monstrum durchwandert: »ich, nur ich allein, kann ihr Anmuth und Leben schenken«. Denn »er selbst verschönert die Natur; er bauet, erweitert und verfeinert sie« in göttlichem Auftrag, »als Vasall des Himmels, und König der Erde«, die er »veredelt, bevölkert und bereichert«. Zwar ist die Natur »die äußere Erscheinung der göttlichen Herrlichkeit« und ihr Studium führt »allmählich zum Zentrum der Allmächtigkeit«. Das aber ist ein exklusiver Vorzug des Menschen. Weil er zur »Anbetung des Schöpfers gemacht« ist, »gebietet er über alle Geschöpfe«, zwingt sie »zur Ordnung, Unterwürfigkeit und Eintracht«, zu Hierarchie und Harmonie. ${ }^{132}$ Nicht von ungefähr hat der Comte »eine umfangreiche Abhandlung über Waldbau« verfasst. Er ist auch »Inhaber der Eisenhütten von Montbard « und propagiert die »Versöhnung von Waldbau und Metallurgie«, bringt seine Arbeiter in einer »Modellsiedlung« unter. In »seinen Augen war das ganze Unternehmen eine einzige große Kette produktiver Energie, in der die Schätze von Erde, Wald und Wasser genutzt wurden, die Gott so reichlich zur Verfügung stellte ${ }^{133}$

Bätschmann nennt Buffons Ekel vor der Natur zunächst »erstaunlich[] « für den Verfasser der »populärsten und größten Naturgeschichte des 18. Jahrhunderts«, präzisiert dann aber, hier sei die nicht kultivierte Natur gemeint und verweist aufs zeitgenössische Ideal gestalteter Natur: den Landschaftsgarten. Dessen Ende des 17. Jahrhunderts in England einsetzende Entwicklung »beruhte allerdings nicht mehr auf der von Buffon noch vertretenen Auffassung von der Verfallenheit der Natur. Vielmehr ging sie von einer natürlichen Offenbarung Gottes in der Vielgestaltigkeit der Natur aus. Der Landschaftsgarten, die zu Bildern geformte Natur, stellte die ideale, schöne Form dieser Offenbarung her«. Er sollte »die Natur zur Schönheit steigern, ohne sie [...] durch Geometrie, Regularität und Symmetrie zu tyrannisieren«. ${ }^{134}$ Zugleich verweist Bätschmann auf den Widerspruch des Buffonschen Wildnis-Ekels zur Erhabenheits-Erfahrung, wie sie insbesondere durch Edmund Burkes Abhandlung propagiert wird. Letztere aber ist ausdrücklich bestimmt durch die Distanz zum Objekt, zur wilden Natur. ${ }^{135}$ Wo Distanz die Empfindungen bestimmt, soll Entzücken entstehen, nicht Ekel. Der ent-

132 Vgl. Buffon, a.a.O.

133 Schama: Der Traum von der Wildnis, S. 200.

134 Bätschmann, a.a.O., S. 23.

135 Vgl. ebda., S. 46ff. 
springt der Einbildung der Berührung, des Verschlungenwerdens, der Kontamination.

Ekel. Es ist Barthold Hinrich Brockes, der >physikalisch-moralisch dichtende Konstrukteur der Welt als Garten zwischen vier Säulen, der »in seinem Neujahrsgedicht auf das Jahr 1722 ein Paradigma verwesend-alter Weiblichkeit» liefert, das eine »erhebliche kritische Prominenz erlangen würde; und zwar als das kardinale Beispiel für zu vermeidenden Ekel«. Dabei ist die »vetula-Skoptik, die beißende Geißelung physischer und moralischer Übel der alten Frau« schon Tradition in der griechischen und lateinischen Literatur, bevor Horaz (ebenso Martial und Aristophanes) sie aufgreift. ${ }^{136}$ Bei ihm ist das alte Weib als ultimativer Ekel charakterisiert durch Gestank, faule Zähne, graues Haar, dürre, schlaffe und >welke` Brüste, Schenkel, Gesäßbacken, stetige Sekretflüsse. Gepaart und damit verschärft ist diese >Umkehrung « von >Attraktivität` mit unbändiger Fleischeslust (was auch mit einer Umkehr der Geschlechterrollen verbunden ist) und - als Kompensation des >Mangels an Reizen - Fellatio-Bereitschaft. Die Tradition der bösen alten Vettel wird in Mittelalter und früher Neuzeit in zahlreichen Variationen fortgeführt. Karl Rosenkranz entdeckt in der >Infamie , trotz hohen Alters noch »unreinen Begierden« ausgeliefert zu sein, den Prototyp der Hexe. ${ }^{137}$ Die Schilderung der Körperlandschaft ist in Brockes' Gedicht entspricht dem weitgehend, hingegen ist seine "Alte» praktisch entsexualisiert, dafür >arm` und >debilı, der Fäulnis und dem Verfall anheimgegeben. Das Gedicht ist formal als rhetorisches Streitgespräch angelegt: »B verficht die Einsicht in Größe und Vollkommenheit der Schöpfung, die selbst durch das >Nichts des Menschen` nur >verherrlicht` werde. A dagegen will zunächst überall nur traurige Vergängnis, Verfall und Ekel sehen, bevor er am Ende bekehrt wird und sich seines

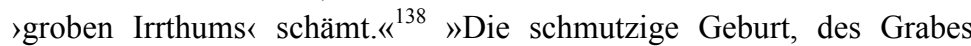
Wust und Koht/Beginnt und schliesst an uns ein Leben voller Noht« beginnt »A« seine Betrachtung des »unvollkommne[n] Fleisch[s]«. Dabei nuanciert er aber. Ist der Mensch im »Saamen [...] Schleim;/Im Mutter=Leib ein Klump, wie Käs' und Milch geronnen«, so kommen doch erst dem Tod und dem Alter die maximale Abscheu zu. Nun wird »der Leib, der edle Leib« zum »Schrecken=Bild« aus »Fäulniß, Moder, Wurm«, zum »wüsten Maden=Sack«, und kein »Moder sieht so arg,

136 Vgl. Menninghaus: Ekel, S. 135.

137 Vgl. ebda., S. 136f.

138 Ebda., S. 138. 
kein Schleim noch Schlamm so greulich,/Kein Wust so eckelhaft, kein Eiter so abscheulich,/Kein Sumpf so häßlich aus «. ${ }^{139}$

Nach Menninghaus besteht dann auch »die besondere Provokation« Brockes' in dessen »Tiefenresonanz«, die eben nicht mehr nur »Oberflächenmängel« beklage, sondern im barocken Bild des »lebend Aas« den »Blick >unter die Haut«« freigebe; hier taucht demnach schon die Drohung mit der »alten Eva« gegen das täuschende weibliche Schönheitsideal, hinter dem sich Abgründe verbergen, auf (s.u.). ${ }^{140}$ Derartige subkutane misogyne Horrorszenarien sind aber durchaus nicht erst Bestandteil frühaufklärerischer Ästhetik. Odo von Cluny propagiert im 10. Jahrhundert einen radikaleren >Blick` unter die weibliche Haut. Schon unter der >schönen Larve` der Jungen - und gerade um die geht es ihm >sieht< er nichts als Dreck, Kot, Schleim. ${ }^{141}$

In Buffons Wildnis-Ekel sind es »verjahrte« Wälder, »abgelebte« Bäume statt »jugendlicher« Natur, »Fäulnis« etc., die es zu beseitigen gilt. Noch klarer wird der Zusammenhang, wenn der Comte davon spricht, Morast und Sumpf trockenzulegen, »anstatt der Binsen und Wasserlilien, unter denen die Kröte wohnte« demnächst »süße[] und heilsame[] Kräuter hervorkommen [zu] sehen«, wie Forster übersetzt. ${ }^{142}$ In der Leipziger Übersetzung der »Histoire naturelle« von 1769 heißt es, »bald werden wir anstatt der Binse und der Wasserblume (nénuphar), woraus die Kröte ihr Gift bereitete«, die gewünschten Kräuter »hervorsprießen sehen $\ll .{ }^{143}$ Hier ist dann alles Notwendige versammelt: Sümpfe und Tümpel, traditionell als Hexen-Orte identifiziert, standorttypische Pflanzen und Tiere, die ursprünglich das weibliche Genital, die weibliche Potenz, im Mittelalter >Luxuria symbolisieren und als Hexen- und Dämonenattribute gelten. Moräste und »todte Wasser« gelten bis zum Ende des 19. Jahrhunderts als Hervorbringer des Miasma, das in der griechischen Mythologie als »Fluch der Mutter« bekannt ist, besonders wirkmächtig nach der Menopause (also bei der >vetula<). ${ }^{144}$ Auch, wenn in der >Naturgeschichte $<$ die vormalige Ununterscheid-

139 Zit. n. ebda., S. $138 f$.

140 Vgl. ebda., S. 140 u. $157 f$.

141 Vgl. Kap. Böse Ausdünstungen.

142 In: Ein Blick in das Ganze der Natur. Einleitung zu Anfangsgründen der Thiergeschichte (1781), zit. n. Kasseler Hochschulbund (Hg.): Georg Forster. Die Kasseler Jahre. Texte - Materialien - Dokumente. Zusammengestellt und bearbeitet von Silvia Merz-Horn. Kassel: Jenior \& Preßler 1990, S. 79.

143 Zit. n. Zirnstein, Gottfried: Ökologie und Umwelt in der Geschichte. Marburg: Metropolis-Verlag 1994, S. 97.

144 Vgl. Kap. Böse Ausdünstungen. 
barkeit von Beobachtung, Dokument und Fabel verschwunden ist, >die Dinge selbst $\iota$ in den Blick geraten: es sind die Dinge, die ehedem mit dem Dämonischen, vor allem dem Weiblich-Dämonischen zusammengebracht wurden, die verschwinden müssen. Nur, dass nun - neben dem Nutzen - die Ästhetik als entscheidende Kategorie auftritt. Noch einmal Menninghaus zur »Tiefendimension des alten Weibs der Ästhetiker«, zur analogen Entsorgung bedrohlicher (und potenter) Weiblichkeit:

»Das traumatische Phantasma der magna mater, mit deren Kult die häßlichobszöne Baubo verbunden war, und der an Macht und sexueller Potenz überlegenen Hexe werden gleich doppelt mit dem Bann belegt: durch Entstellung ins Harmlose - in die verschrumpelte, zahnlose, arme, asexuelle Alte ( Altmütterchen der Götter $)$ - und durch eine an Verhöhnung grenzende Verwerfung dieser Schrumpfform bedrohlicher Weiblichkeit als unästhetisch. Ästhetik ist insofern die Fortsetzung der Hexenprozesse mit anderen Mitteln - übrigens etwa um die gleiche Zeit, in denen reguläre Hexenprozesse im aufgeklärten Europa endlich begannen, der Vergangenheit anzugehören. (Auch der schöne Gegenpol der Hexe, die klassizistische Aphrodite, bietet nurmehr eine ferne, eine depotenzierende und weichgezeichnete Erinnerung an die ehemaligen Prädikate dieser großen Göttin.) « ${ }^{145}$

Und gleichfalls: So, wie die - alternde, faulende, sterbende - Natur nicht mehr mächtig ist (das sagt ihr Zustand einem Betrachter wie Buffon), keine Hexen und sonstige Dämonen mehr beherbergt (aus Sicht der distanzierten Oberschichten zumindest), lässt sie sich zum ästhetischen Problem degradieren und zugleich >erhöhen`.

Ästhetisierung: So, wie nach Edmund Burke weibliche Schönheit »überhaupt nur Schönheit für den Mann« ist, »ein Reiz, den die Natur zweckmäßigerweise ersonnen hat, damit Mann zur Fortpflanzung und damit zur Erhaltung der Gattung angeregt wird «, ${ }^{146}$ ist (bei Buffon et al.) die Schönheit der äußeren Natur nur für den Erobernden, Besitzenden.

In der Ästhetisierung und Geschlechterverortung löst sich der Widerspruch zwischen den Verfechtern einer Verfallstheorie der Natur und denen einer Naturerhabenheit auf. Bei Burke wird das Schönheitsempfinden vom Kleinen, Glatten, Ebenmäßigen hervorgerufen und erweckt den Gesellschaftstrieb, das Verlangen nach Teilhabe. Das Erhabene wird hervorgerufen durchs Unermessliche, Wilde und weckt den Selbsterhaltungstrieb, Leidenschaften, Ehrfurcht. Das Entzücken des Schreckens und des Schmerzes wird zum höchsten Entzücken - männliches Ent-

145 Menninghaus, a.a.O., S. 143.

146 Ebda., S. 157. 
zücken. Kant »reserviert dem Mann das ästhetische Register des Erhabenen, wertet dies erheblich auf und überbietet so die weibliche Schönheit noch im Feld des Ästhetischen «. ${ }^{147}$ Ebenso auf dem Feld der Erkenntnis und des Wissens: »Das schöne Geschlecht hat eben sowohl Verstand als das männliche«, konstatiert Kant, »nur ist es ein schöner Verstand, der unsrige soll ein tiefer Verstand sein, welches ein Ausdruck ist, der einerlei mit dem Erhabenen bedeutet «. ${ }^{148}$ Dieser schöne weibliche Verstand denkt auch schön, weshalb ihm das Erhabene nicht zugänglich ist. Er befindet sich permanent »unter der Herrschaft des Körpers«, kommentiert Geneviève Fraisse. Schönheit mache nach Kant das Wesen des Weibes so sehr aus, »daß Körper und Geist im Widerspruch zueinander stehen. Vom Geist Gebrauch zu machen, läuft auf den Verlust des Körpers hinaus«. Weshalb nur wenige Frauen dieses Risiko eingingen. ${ }^{149}$ Denn: »Mühsames Lernen oder peinliches Grübeln, wenn es gleich ein Frauenzimmer darin hoch bringen sollte, vertilgen die Vorzüge, die ihrem Geschlechte eigentümlich sind, und können dieselbe wohl um der Seltenheit willen zum Gegenstande einer kalten Bewunderung machen, aber sie werden zugleich die Reize schwächen, wodurch sie ihre große Gewalt über das andere Geschlecht ausüben. « ${ }^{150}$ Aber, das sei eben eine »Seltenheit«. Normalerweise trügen Frauenzimmer Wissen nur als Zierrat und Schmuck (so wie sie Uhren trügen, ohne sie als Zeitmesser zu benutzen), äfften gelehrte Frauenzimmer Männer nur nach. ${ }^{151}$

Dabei ist das Ideal der Schönheit ambivalent. Es muss hier wie da vom Besitzenden (auch der Definitionsmacht) aufrechterhalten wer-

147 Menninghaus, a.a.O., S. 157. Dem Ekel kommt bei Kant - im »Zuge der Genußbildung und der offenen Sexualisierung des Ekelhaften «-, wie der dem Ekel vorgeschalteten Scham, die Funktion zu, »die Tugendkonformität des Verhaltens negativ zu wahren«. Die Kantsche Trias »der >Gefühle des Erhabenen, des Schönen, des Ekelhaften k korreliert in ihrer affektiven Organon-Funktion mit der Trias der drei >oberen< Vermögen: das Schöne ist zuallererst dem Verstand, das Erhabene der Vernunft und das Ekelhafte der Einbildungskraft zugeordnet«. Die Einbildungskraft stehe »unserem >dunklen` körperlichen Sein wesentlich näher als die beiden anderen Vermögen«. Zugleich bedürfe es »gerade für die organische Organonfunktion einer erheblichen Assoziationsleistung« durch die Imagination (vgl. ebda., S. 183f.).

148 Kant: Beobachtungen über das Gefühl des Schönen und Erhabenen, in: Werke, Bd. 2. Darmstadt: Wissenschaftliche Buchgesellschaft 1968, S. 851.

149 Vgl. Fraisse, Geneviève: Geschlechterdifferenz. Tübingen: Edition Diskord 1996 (Paris 1996), S. 13.

150 Kant, a.a.O., S. 852.

151 Wie Fraisse (vgl. a.a.O., S. 11f.) Kants diesbezügliche Ausführungen in seiner »Anthropologie in pragmatischer Hinsicht« paraphrasiert. 
den. ${ }^{152}$ Andernfalls droht Gefahr fürs Besitzverhältnis, sprich: für den Besitzer. Der Preis des weiblichen Schönheitsideals, so Menninghaus, besteht in seiner Ausbalancierung mittels »Komplementär-Bewegungen, die den gefährdeten Platz des Mannes als Krone der Schöpfung zu sichern erlauben«. Denn, das ist der Inhalt der Konstruktion, die Schönheit ist lediglich die Larve des besonders Unvollkommenen: »Der weibliche Körper, selbstverständlich mit >jungfräulichen` Formen, mag zwar das Ideal des Schönen sein, aber diese Schönheit brauchte nicht so schön, nicht so ideal, nicht so täuschend zu sein, wenn sie nicht einen gleichermaßen weiblichen Abgrund von Häßlichkeit und Ekel zu verdecken hätte.« Dahinter lauert die vetula, Hexe, Ekelhafte. »Eine Gefährdung männlicher Suprematie ist in eine Gefährdung der schönen Frau durch sich selbst umdefiniert. $«{ }^{153}$ Analog dazu muss die ideale äußere Natur vor einer Gefährdung durch sich selbst geschützt werden. Was Buffon postuliert, ist - da gemäß der alten >natura lapsa - zwar nicht wirklich neu, markiert aber ebenso die Maxime des modernen Naturschutzes: den Schutz der geschaffenen szweiten Natur< vor den Angriffen der wilden >ersten`, mithin die Verhinderung einer vorgeblich bedrohlichen Regression.

\section{Das Wirken des Maschinengotts}

Von monströsen Leibern zu kalkulierbaren und damit wohlproportionierten Körpern: Überall im Umkreis der Physikotheologie wird die Natur in eine Ordnung gebracht. Im Bewusstsein, einer alten Tradition »die >Natur-Leiter` zu Gott« zu erkennen, da diese sich im »Buch der Natur [...] ebenso offenbare, wie in der Heiligen Schrift - formal neue Evidenz beizubringen, wurden »das Instrumentarium und die Methoden der New Science - jedenfalls dem Selbstverständnis nach und zumeist zwangsläufig auf niedrigerem Niveau - aufgegriffen«. Das Interesse verlagert sich weg "vom Weltall und den großen Fragen der Physik, Chemie und Botanik hin zum Einzelding der natürlichen Umwelt: zu Pflanzen, Tieren, dem Menschen selbst, zu geologischen Daten und

152 Das Schöne ist Resultat permanenter Eingriffe, Gewaltakte. Und so verhalten sich im idealen Raum gestalteter Natur die Landschaftsgärtner wie Schönheitschirurgen, was sich etwa an den »Ansichten« des Fürsten Pückler deutlich zeigen lässt, des `Frauenhelden` also, der auch die Natur besitzen wollte >wie eine Geliebte<, der sie ebenso seinem Willen unterwerfen wollte. So beschreibt 1941 Paul Ortwin Rave die »Parkomanie« Pücklers (Rave, Paul Ortwin: Gärten der Goethezeit. Berlin (West): Henssel 1981 (Berlin 1941), S. 137f.)

153 Menninghaus, a.a.O., S. $157 f$. 
meteorologischen Vorgängen«. Die Gelehrten verlassen buchstäblich die Bibliotheken, um draußen »im Buch der Natur zu lesen«, um mit Teleund Mikroskop, Thermo- und Barometer, »mit Botanisiertrommel und Schmetterlingsnetz, mit Seziermesser und Waage« bewaffnet auf die »Suche nach den Spuren Gottes in der Natur« zu gehen. Per systematischem Sammeln, Kalkulieren und Vergleichen, neben einfachen Experimenten, soll nicht der >Beweis $<$ der »Gültigkeit des Analogieschlusses von der Harmonie und Zweckmäßigkeit der Welt auf das Dasein ihres Baumeisters« erbracht werden; der gilt sowieso als unanfechtbar. Vielmehr geht es um >empirischeく Beweise »des zweiten Satzes des Analogieschlusses, der besagt, daß alle Naturdinge poietische Struktur haben. Mit dem Nachweis der - in sich oder in größeren Funktionszusammenhängen - zweckvollen Einrichtung des jeweiligen Beobachtungsgegenstandes galt die Aufgabe als erledigt. Der Befund wurde sodann theologisch kommentiert«, zunächst innerhalb der Forschungsberichte, später sukzessive nur noch in den Vorworten. Das Ziel ist eine »vollständige[] Inventarisierung der >Wunder der Welt ««, um »ihr Ordnung und Zweckmäßigkeit durchgängig nachzuweisen«, weshalb »eine Unzahl von Bindestrich-Theologien«, wie »Ichthyo-(Fisch-), Rana(Frosch-), [...] Chorot-(Gras-)Theologien, etc. entstehen. ${ }^{154}$ Aber, wie schon gesagt, mit der Inventur ist es nicht getan. Es besteht die Pflicht der Verwandlung zwecks Nutzung - auch das ergibt sich physikotheologisch aus der >göttlich` angelegten Zweckmäßigkeit der Naturdinge.

Aus dem Chaos der Natura lapsa wird so gewissermaßen eine Reetablierung des Paradieses, was heißt: einer beherrschten Natur. Schon Walther Hermann Rivius etwa geht 1547 entscheidend über die mittelalterliche Auffassung, »der Mensch dürfe und solle sich durch die Kunst den Ort seiner Verbannung erträglicher gestalten« hinaus: Bei Rivius (und den Autoren in seiner Folge) erlangt die »Mechanica« den Rang einer »heilsgeschichtlichen Bedeutung«, da »der Mensch sich durch ihre Ausübung wieder seiner paradiesischen Gottebenbildlichkeit nähert«, da sie so, wie `Jesum Christum, unser[] Heiland ‘ die per `Sündenfallı ausgelöste »Entzweiung mit Gott aufgehoben« habe, die Aufgabe habe, die ebenso »eingetretene Entzweiung von Mensch und Natur aufzuheben und die verlorene Herrschaft über die Natur zurückzugewinnen«. Und Francis Bacons »Nova Atlantis« erklärt in gleicher Weise das »regnum hominis« als potentiell der Vollkommenheit des himmlischen Paradieses annäherbar. Denn die verlorene Unschuld und Herrschaft über die Natur per Sündenfall könne »in diesem Leben zum größten Teil wiederge-

154 Vgl. Groh/Groh, a.a.O., S. $51 \mathrm{ff}$. 
wonnen werden, das erste durch religiösen Glauben, das zweite durch Künste und Wissenschaften ${ }^{155}$

Weltmaschine, Weltfabrik: Zwar gebe es kaum personelle Überschneidungen, insgesamt aber konstatieren Groh/Groh - bei allerdings teils »unterschiedlichen Akzenten« - eine (wenig überraschende) weitgehende Übereinstimmung des weltanschaulichen Hintergrunds frühneuzeitlicher Maschinenbauer sowie »der Träger der New Science und der physikotheologisch inspirierten Naturforscher«. Hier wie da: »dasselbe Amalgam aus antiker Naturphilosophie und christlicher Naturtheologie; dieselbe fromme Vorstellung einer vom Schöpfer in der Ordnung von Mittel und Zweck eingerichteten Weltmaschine, dieselbe Anthropozentrik, derselbe Fortschrittsoptimismus, dieselben millenaristischen Zukunftshoffnungen, dieselbe Aufwertung der Rolle des Menschen«. Namhafte Unterschiede jedoch gebe es insbesondere in den Zielsetzungen und Argumentationsstrategien. Die Vertreter der New Science und der Naturtheologie erstreben die »Einheit von Glauben und Wissen« und propagieren analog »zum zweckgerichteten menschlichen Handeln« die »Gewißheit einer rationalen Gotteserkenntnis aus der teleologischen Verfassung der natürlichen Dinge«, die Mechaniker erstreben »die Einheit von Glauben und technischem Handeln« und machen »vom altbekannten Bauplanargument umgekehrten Gebrauch: der Mechaniker, der Ingenieur konstruierten Maschinen in Analogie zum Schöpfergott«. Wobei der Ursprung jener »Dignität der Maschinenbaukunst« eben in der Figur Gottes als Baumeister, Handwerker, MechanikLehrmeister, der mit seiner Schöpfung den Menschen auch diese Kunst zur Verfügung stellte, der die Welt in streng mathematisch-mechanischer Weise konstruiert und geordnet hat, behauptet wird. So erhält die platonisch-pythagoreische Überlieferung und vor allem »die apokryphe Bibelstelle: >Du hast alles geordnet nach Maß, Zahl und Gewicht (Weisheit 11,21)« überragende Bedeutung, wird in Variationen immer wieder paraphrasiert. 1599 betont Monantholius in der Widmung seiner Neuausgabe der (pseudo-)aristotelischen »Quaestiones mechanicae«, dass Schöpfung und Erhalt der Welt »Mechanik treiben« sei und leitet aus der >Gottebenbildlichkeit` den diesbezüglichen göttlichen Auftrag (und den zum Maschinenbau) ab. Mechanik ist angewandte Geometrie, mithin die Geometrie Gottes. Was heißt, dass »der Allweise Gott und Schöpfer aller Creaturen die Machination mit seinen eigenen Händen selber Praktizieret hat«, sagt Andreas Jungnickel 1661 in seinem »Schlüssel zur Mechanica«, und »daß er die überaus schöne Machina,

155 Ebda., S. 64ff. 
Himmels und der Erden [...] bereitet hat « woraus qua Ebenbildlichkeit folge, dass auch der Mensch »alles, was er zu diesem Leben von nöthen hat, heben, legen, zerbrechen, und bauen kan«. Dreizehn Jahre später schreibt Erhard Weigel, dass die »Würckung der Natur [...] nichts als lauter Rechnen ist [...]. So würcket auch Gott selbst alles nach oberzehlten Rechen-Arten«. Leibniz schließlich bringt die »Erhöhung« des Menschen als Mechaniker, der die göttlichen Schöpfungsprinzipien nicht nur erkennt, sondern auch nachvollzieht 1710 in seiner »Theodizee« auf den Punkt: »L'homme y est donc comme un petit dieu dans son propre monde, ou microcosme, qu'il gouverne à sa mode; il y fait merveille quelquefois et son art imite la nature. ${ }^{156}$

Weltmaschine, Weltfabrik: Hier wird dann die Natur zum (potentiellen) >Weltinnenraum $<$, in angestrebter totaler Ordnung, kann sie umfangreich zur Kathedrale ernannt, bzw. als solche identifiziert werden, denn die Kathedrale ist nichts anderes, als die architektonische Repräsentation der mathematischen göttlichen Ordnung der Natur. Der Wald als Kathedrale muss demnach quantifizierbar sein, sicht- und wahrnehmbar nach Statik und Zahl. Weltmaschine, Weltfabrik: Der Maschinist ist männlich. Die Natur als >Werk Gottes`, als Gehäuse des >göttlichen Willens $<$ wird zur >Mutter Kirche $<$ (zur bereinigten >Mutter Natur $<$ bzw. zur >Hohen Frau<, über die der Herr wacht. Auch hier also: Unterwerfung durch Erhöhung. (In der konservativen Kunstgeschichte im Umkreis um Hans Sedlmayr erkennt Karl Oettinger in der südwestdeutschen Spätform der Gotik den 〉Himmelsgarten Mariens`, der erst in seiner Verfallsform, als Folge einer Art welscher Vergewaltigung, >verwaldet $<.{ }^{157}$ ) Als Kehrseite erscheint gewissermaßen die Vernichtung. Braun/Kremer zeigen das in der Zusammenschau von Francis Bacons »Vorurteilslehre« und seiner Schrift »Die männliche Geburt der Zeit«. Letztere verlangt, so Braun/Kremer, als »Gegenentwurf« weiblichen Wissens und weiblicher Produktivität die nun ausschließliche Wissensweitergabe vom Vater auf den Sohn. Die »scientia universalis« annektiert Wissen und Produktivität »der Frau«, um die Abhängigkeit von ihr zu lösen. Die Exklusion des Weiblichen mündet in der »Vorurteilslehre« in Bacons Einverständnis der inquisitorischen Hexenverfolgung durch seinen König James I., der »Hexen von ihrem ketzerischen Wahn reinigt, indem er sie vernichtet«. Denn dieser »grausame[] Enteignungsprozeß der Frauen«, so Braun/Kremer, die Ausgrenzung vor allem ihres

156 Ebda., S. $60 \mathrm{ff}$.

157 Vgl. Oettinger, Karl: Laube, Garten und Wald. Zu einer Theorie der süddeutschen Sakralkunst 1470-1520, in: Ders./Rassem, Mohammed (Hg.): Festschrift für Hans Sedlmayr. München: C.H. Beck 1962, S. $223 \mathrm{ff}$. 
heilkundigen Wissens, damit die Destruktion »ihrer Lebens- und Arbeitszusammenhänge, die ihnen noch eine relative Unabhängigkeit gewahrt hatten«, ist Konsequenz und Programm der »Vorurteilslehre«, die alles zur Idolatrie erklärt, was »Vorurteil« und »Unwissen« sei, die statt dessen alles Wissen »in die geordneten Bahnen des richtigen Glaubens zurückführen« will und die Magie der Alchimisten und Hexen verwandeln »in christliche Magie, d.h. Wissenschaft«. Wie der König den Hexen, habe man der Natur entgegenzutreten: selbstbeherrscht und innerlich gereinigt, »um sich nicht im Labyrinth der sinnlichen Erfahrung zu verlieren«. Und so sei für Bacon die »Lust der Neugier« - auch die der scholastischen Kontemplation und besonders der schroff abgelehnten Naturphilosophie der Renaissance - schlicht »eine Hure, die in der Erkenntnis nur Befriedigung und Genuß sucht«, und sie müsse transformiert werden in Fortschritts-Streben, um den Weg des menschlichen Geistes in maschinengleich geordnete Bahnen zu verlegen. Bacons hier verwendete »Metapher der glücklichen Ehe zwischen Verstand und Natur spricht am deutlichsten aus, worauf die systematische Naturbeherrschung sich gründet, auf die patriarchal beherrschte Frau«. Die »geordnete Natur« stellt in seinem Naturbegriff

»die Gesetze des Vaters, Gottes Werke, dar, aufgrund derer Natur für den menschlichen Verstand erkennbar und zugänglich ist, während alles Zufällige, alles, was jene gesetzmäßige Ordnung verhindert, stört und gezähmt werden muß, zum Weiblichen erklärt wird. Die geistige Erzeugung der Zeit als fortschreitende Erkenntnis, die letztendlich zum unendlichen Progress wird, da ihr letzter Grund die Vereinigung des männlichen Subjekts mit dem absoluten göttlichen Geist ist, der alles Sein aus sich hervorbringt, wird analog jener Erzeugung der Vernunft des absoluten Monarchen vorgestellt, als Junggesellengeburt, unter Ausschluß des sinnlichen Verhältnisses zur Frau ${ }^{158}$

Eine glückliche Ehe zwischen Verstand und Natur, beherrscht vom Patriarchen, vom maschinengleichen Geist und nicht von der Hure der Lust an der Neugier.

Die Zuordnung von >weiblich` und >männlich` ist bekanntlich nicht neu, sie unterliegt in der beginnenden Neuzeit aber im Prozess der semantischen Verknappung einer >Vereindeutigung «. Einer >Vereindeutigung gerade auch >wissenschaftlicher` Art. Carl von Linnés Nomenklatur, so Schiebinger, diese »fanatische[] `Sexualisierung` der Pflanzen« als Koinzidenz einer ») Verwissenschaftlichung 〈 der Botanik«, voll-

158 Braun/Kremer: Asketischer Eros, S. 122f. 
ziehe die europäische Geschlechterhierarchie nach. ${ }^{159}$ Zugleich ist damit ein >Beweis` der natürlichen Herkunft dieser Hierarchie erbracht. Das heißt auch:

»Die ganze Körperlichkeit der Frau verschwindet in mysteriösen Dünsten und Säften. Sie verliert die Macht über die eigene innere Natur zur selben Zeit wie diejenige über die äußere. Die durch Satan vermittelte ungeheure Macht der alten Hexe über die Naturprozesse gehört zumindest in der Theorie der einstigen Verfolger aus den städtischen Oberschichten der Vergangenheit an. Die männlichen Wissenschaftler übernehmen die Erklärung der Naturprozesse; die männlichen Ärzte die Verwaltung der weiblichen Körper. Aus der quasi naturwüchsig-gewalttätigen Beherrschung der Frau wird eine systematische. ${ }^{160}$

Streng geordnete Bahnen männlich linearen Fortschritts statt der Labyrinthe sinnlicher Wahrnehmung. Die Exklusionen bzw. Marginalisierungen sinnlicher Wahrnehmung sind Resultat »neuer Verhaltensmöglichkeiten« am Ende des Mittelalters, »die die überkommene Herrschaft bedrohen «. ${ }^{161}$ Im Transformationsprozess des menschlichen Körpers vom Besitzer festgelegter, unabänderlicher physischer Eigenschaften wie das noch im 16. Jahrhundert gilt - zum Vermittler symbolischer Eigenschaften - wie er in den Auffassungen seit dem 19. Jahrhundert vorherrscht, dem politischen Prozess also, in dem physische Ungleichheit (der Ständeangehörigen) sich auflöst, zugleich aber soziale Ungleichheit entsteht, ${ }^{162}$ und dabei wiederum eine neue physische Ungleichheit. Die Frau, vormals gemäß der Einkörpertheorien unvollkommener, >entstellter Mann, inferior aufgrund ihres sozialen Geschlechts, wird zum eigenen biologischen Geschlecht. Am Ende des 18. Jahrhunderts entwickeln Europas Anatomen die Vorstellung eines männlichen (geprägt durch physische und intellektuelle Potenz) und eines weiblichen Körpers (geprägt durch Reproduktivität), verschieden, aber jeweils >vollkommen $<{ }^{163}$ Es bleibt bei einer hierarchisierenden Differenz. Ist vorher die (differente) Anatomie Signum des sozialen Geschlechts, wird seitdem umgekehrt die soziale Position Signum des biologischen Geschlechts.

$\mathrm{Ab}$ der Wende zum 19. Jahrhundert wird »die doppelte Referentialität auf Natur« zum »zentrale[n] Element der modernen und gesellschaftspolitisch relevanten Definition der Geschlechterdifferenz«. Diese

159 Schiebinger: Am Busen der Natur, S. 27ff.

160 Honegger: Die Hexen der Neuzeit, S. 120f.

161 Theweleit: Männerphantasien Bd. 1, S. 408.

162 Vgl. Gebauer, Gunter: Ausdruck und Einbildung, in: Kamper/Wulf (Hg.):

Die Wiederkehr des Körpers, S. 313f.

163 Vgl. Schiebinger, Londa: Schöne Geister, S. 270. 
wird bezüglich ihrer Genese abgeleitet aus dem neuen dezidiert wissenschaftlichen Naturverständnis, das spezielle Praktiken der Exklusion schafft, indem es »die Kategorie Geschlecht [...] naturalisiert« dadurch, dass »der Beitrag der Frauen zur Geschichte einerseits durch die Biologie und andererseits durch die >biologische< Verortung der Frauen in der Anthropologie als nichtexistent verbucht« wird - einem Naturverständnis also, das wiederum der politisch-sozialen Legitimation der Differenz dient. Seit dem Beginn der Moderne »fungierte \Natur « in dieser Weise »als eine normative Kategorie, die zugleich die legitimatorische Grundlage für das Denken von Gesellschaft als Gesamtzusammenhang abgab« und ebenso »als Folie diente für eine geschlechtsspezifisch unterschiedliche und hierarchisierende Verortung von Männern und Frauen in der Gesellschaft«. Dies zunächst unter dem Leitgedanken der »Naturgeschichteく, dann der Evolutionstheorien: Zoologie, später Ökologie zum Einen, Medizin, Gynäkologie, Anatomie, Physiologie und die Psychologie der »zweigeschlechtlichen Identität« zum Anderen. ${ }^{164}$

Während also >weiblicher` Wald (der stört oder gezähmt werden muss, wo eine gesetzmäßige Ordnung verhindert oder nicht erkennbar scheint) als ungenutzt, unzugänglich, wild wuchernd, auf schwankendem Untergrund charakterisiert ist, ist Männerwald grundsätzlich der genutzte Wald, Wald des Königs, Forst: männlich beherrscht oder gar konnotiert. Entweder erobertes und kultiviertes, erschlossenes oder vermessenes, also >erhöhtes Weibliches`, oder dezidiert >Männliches`: Orte, die Männer schon seit langem exklusiv aufsuchen und >beherrschen<, etwa Eremitagen in der Wildnis zur Kloster(neu)gründung oder fürstliche Bannwälder, später auch eigens angelegte >Tiergärten`. Symbolische Aufladungen, wie Wald als Heer, Wald als heroische Landschaft, Wald als Ort der >Gemeinschaft` und Gegenwelt zur >dekadenten`Gesellschaft oder Wald als Kirche sind historische Resultate der Tradition des männlich-herrschenden Zugriffs.

Hierzu zählen auch Versuche, eine santhropologische Konstante von archaischen >Heiligen Hainen` zum >Waldesdom` zu sehen. Der >Waldesdom< ist ein Bild dritter Ordnung. Eines allerdings, das etwas anders als der Garten als >Paradies` (auch so ein Bild dritter Ordnung: die >Reetablierungく des >Garten Eden` bezieht sich auf ein Bild, dem wiederum reale antike Herrschaftsgärten zugrunde liegen) akzentuiert ist. Hier ist der Dom der Bezugspunkt. Dessen Vor-Bild ist das `himm-

164 Schultz, Irmgard: Umwelt- und Geschlechterforschung: eine notwendige Übersetzungsarbeit, in Nebelung, Andreas et al. (Hg.): Geschlechterverhältnisse - Naturverhältnisse, S. 30ff. 
lische Jerusalem`, das >Paradies` oder, nach unterschiedlichen - teils widerstrebenden - Wald-Theorien, der Wald. Aber erst als rein architektonisches Produkt, an dem keine lebenden Natur-Dinge mehr beteiligt sind, erst in seiner Abstraktion zum (kultischen) Gebäude also, der Übersetzung und Neuschaffung seiner Struktur, seiner >Codes` durch unbelebte Materie, wird der >Wald zum Vor-Bild dessen, was dann seinem Idealbild entspricht. Dass in der Folge auch >Wildnis` als Kathedrale wahrgenommen wird (werden kann), widerspricht dem nicht. Denn die Referenz bleibt die ideale Verkörperung der gesuchten geometrischen >göttlichen` Ordnung: die Kathedrale - hier allerdings (eher) als Ruine. ${ }^{165}$ Die beschriebene Bild-Ordnung entspringt erst der »generativsystematisch« aufgebauten Wirklichkeit der bürgerlichen Gesellschaft (Czerwinski).

Die Gegenweltlichkeit des Waldes scheint sich als eine historische Konstante zu erweisen. Die Betonung liegt jedoch auf dem Schein. Der Wald ist im vorbürgerlichen Kontext auch Gegenwelt, aber nicht in einer Welt der »generativ-systematisch geordneten, sondern aggregativ-simultan nebeneinanderliegenden Wirklichkeiten $\ll .{ }^{166}$ >Innen ßen $<$ in unserem Sinn entstehen erst, dieses >Außen $<$ muss noch entdeckt, erobert und >einverleibt « werden. Oder es muss als eigentliches >Innen (die >männliche Wildnis $\measuredangle$ ) gegen ein anderes >Außen $<$ imaginiert und in dieser Weise entdeckt werden. Erst damit kann der dialektische Prozess zwischen >es darf kein Außen mehr geben Gegenwelt geben beginnen.

Die semantische Verknappung zeigt sich als Tendenz zum >Weltinnenraum`. Die Gestalten des wilden mittelalterlichen Waldes in ihren jeweiligen Bedeutungsräumen - die Pilger und Heiligen, Köhler und Eremiten, der >Wilde Mann`, diese krasse Kontrastfigur zum höfischen Mann, Dämonen und Zauberwesen, ${ }^{167}$ Feen, Wilde Weiber und Hexen verschwinden sukzessive mit diesen Räumen zugunsten des einen Raums (oder erhalten hier nun modifizierte Rollen), in dem der Maschinen-Gott »würcket« nach »Rechen-Arten«. Dieser Gott jedoch wird im Säkularisierungsprozess im 18. und besonders 19. Jahrhundert abgelöst von der >Naturく als Idee und Legitimationsinstanz. >Naturgeschichte $<$ Die Zeichen sind nicht mehr Teile der Dinge, wie vorher, son-

165 Vgl. Kap. Die Schönheit der Ruinen.

166 Czerwinski, Peter: Der Glanz der Abstraktion, S. 348.

167 Vgl. Frühe, Ursula: Das Paradies ein Garten - der Garten ein Paradies, S. $318 \mathrm{ff}$. 
dern Funktionsweisen (Foucault). ${ }^{168}$ Zugleich beherbergt dieser eine verbliebene Bedeutungsraum die heroische Natur - auch dies Legitimationsinstanz.

Dieser Prozess betrifft zunächst die gesellschaftlichen Oberschichten, vor allem Gelehrte. Die unheimlichen bzw. numinosen Wälder und Wildnisse der Hexen und Dämonen existieren hingegen im BegehrensHaushalt der >Volkskultur` noch längere Zeit. Die in der Frühmoderne einsetzende wissenschaftliche Neudefinition des Raumes und des Waldes, seiner geometrischen Reproduktion zu Zwecken des größtmöglichen Ertrags ist dabei nicht zu trennen von der Schaffung einer neuen sozialen Ordnung, neuer >Gesetze $<$ der Alltagsbewältigung, Sinnstiftung und Ästhetik.

Die Ästhetisierung des Waldes hat seine Reproduktion zur Bedingung. Der ursprüngliche Wald, die Wildnis, erscheint als Produkt des 〉Sündenfalls`, er entspricht >weiblicher Produktivität` (die als unfruchtbar aufgefasst wird). Der Paradigmenwechsel von der Verfalls- zur Bauplantheorie ändert daran nichts. Wenn die Schönheit des Himmels und der Erde, hier des Waldes, die einer »überaus schöne[n] Machina", »geordnet nach Maß, Zahl und Gewicht« (s.o.) ist, dann verlangt das nach dem permanenten ordnenden Eingriff des Gottesebenbildes, des Maschinen-Geistes, mithin der Unterwerfung unter >männliche Produktivitätı. Einerseits begründet das eine neue Weise des Zugriffs - nicht mehr bloß Rodung usw., sondern aktive Gestaltung, Neubau und Selektion von Arten nach gewollten Zusammensetzungen - was jedoch wenigstens in der Theorie oft schon im Hochmittelalter existiert. Denn andererseits ist das Lesen im >Buch der Natur`schon Übung mittelalterlicher Pilger und Klostergründer. Bereits Augustinus begründet ja nicht nur die `Erbsünde`, sondern ebenfalls das `Buch der Naturく als `zweite Schrift Gottes« neben der Bibel.

Der Ideal-Wald ist ein Baukörper, >konstruiert` vom Großen Baumeister, >rekonstruiert` von seinen Ebenbildern. Schließlich, (seit der Romantik), wird er zur gesuchten, produzierten Gegenwelt (zur Moderne, zur Urbanität, zur »Proletarisierung«, Industrialisierung), also geordnete >Heimat` im Gegensatz zur >fremden` Großstadt, die nun Wildnis sein soll. Er ist >männliches` Monument oder unterworfener, beherrsch-

168 Dass die Brüder Grimm und andere dann wieder Märchen sammeln (oder schreiben), in denen >der Wald « von Hexen, sprechenden Tieren, Zauberwesen aller Art bevölkert ist, widerspricht dem nicht (ebensowenig später erdachte Fantasy-Epen), im Gegenteil: Diese Erzählungen sind explizit als Märchen charakterisiert, während in vorbürgerlichen Texten derartige Differenzierungen von >märchenhaften $\mathrm{zu}$ finden sind. 
ter und somit erhöhter Raum (bis hin zum Naturschutzgebiet) und muss daher geschützt werden (vor sich selbst). Der im 19. Jahrhundert als >ursprünglichく reklamierte Wald, der zumeist >heroische` Wald als Bestandteil des Gesamtkunstwerks >heroische Landschaft $\iota$, die Wildnis à la Riehl also ist männlicher Gegenentwurf zum männlichen Entwurf: Einerseits als asketisch-aggressiver Okkupant `weiblicher Wildnis`, andererseits als vermeintlich >organische Gemeinschaft` gegen die Landschaften des Maschinen-Staates.

Der Wald: ein Körper. Michail Bachtin beschreibt den »neuen Körperkanon« seit der Renaissance (im Gegensatz zum grotesken Körper): Für die »neuen Kanons« sei

»der Körper vor allem streng abgeschlossen und fertig, er ist ein einsamer, einzelner, von anderen abgegrenzter und geschlossener Körper. Daher sind alle Kennzeichen von Unförmigkeit, Wachstum und Vermehrung entfernt: Auswüchse und Verzweigungen verschwinden, Wölbungen (die an Triebe und Knospen erinnern) werden geglättet, alle Öffnungen verstopft. Die ewige Unfertigkeit des Körpers wird quasi verheimlicht, Empfängnis, Schwangerschaft, Geburt und Tod kommen in der Regel nicht vor. Das bevorzugte Alter ist das am weitesten von Mutterleib und Grab, also von den Grenzen individuellen Lebens entfernte $\ll .{ }^{169}$

Für Menninghaus erinnert das »frappierend genau « an das KörperSchönheitsideal der Klassik, wie Winckelmann, Lessing und Herder es propagieren. ${ }^{170}$ Bachtins neuer Kanon entspricht ebenso ziemlich genau dem Idealbild Wald, wie es seit dieser Zeit der Klassik systematisch in der Landschaft realisiert wird: Nur eine oder wenige Baumarten, Bäume, denen Unförmigkeit, Auswüchse und Verzweigungen aberzogen sind, die alle gleichaltrig und gleichwüchsig sind, deren ständige Unfertigkeit also verheimlicht wird, da individuelle Altersunterschiede ausgeschlossen sind, desgleichen natürliche Geburt bzw. Vermehrung wie natürlicher Tod per festgesetzter >Schlagreife<.

Der Körperkanon entsteht in der Renaissance. »Die Natur ist der Mensch im Großen. Wenn daher Kräfte in der Natur wunderbare Wirkungen zeitigen, sofern sie gebunden, gesammelt und im rechten Moment freigesetzt werden, können sie als Vorbild für die Kräfte im Menschen dienen«, fasst Edgar Wind die Renaissance-Auffassungen der Naturmagie entsprechend der Mikrokosmos-Makrokosmos-Analogie zu-

169 Bachtin: Rabelais und seine Welt, zit. n. Menninghaus: Ekel, S. 87.

170 Vgl. Menninghaus, a.a.O., S. 88. 
sammen. ${ }^{171}$ Paul Frankl spricht von den »naturalistic aesthetics « als effektive Waffen seit Petrarcas Zeiten. Deren Maxime laute: »Good art means a good nation, bad art, a bad one. $\ll^{172}$ Für Petrarca selbst habe das bedeutet, die Geschichte in zwei Epochen zu teilen - »antiquity and the Middle Ages« -, und damit, gemäß humanistischer Werte, auch die Geschichte der Kunst: »a brilliant age of good art and a gloomy one of poor art«. Ersteres sei im antiken Griechenland und Rom zu finden, also bei Petrarcas vorgeblichen Vorvätern, letzteres sei repräsentiert in der »maniera greca«, (mithin anzutreffen im mittelalterlichen Griechenland - also Byzanz), ebenso in der Gotik (also französisch und deutsch), stamme von Barbaren. ${ }^{173}$ Das Credo der >guten Kunst` als Zeichen der >guten Nation ২ lässt sich später abwandeln: Die gute Waldbaukunst zeigt die gute Nation. Was im Code Colbert oder bei Le Roy noch weitgehend bloßer Plan bleibt, wird im geregelten deutschen Hochwald Realität. Dieser Hochwald ist ein Bauwerk. Die >Forstmänner bestehen darauf, dass es sich keinesfalls um Natur, sondern um Kultur handele. ${ }^{174}$ Wie die >Forstmänner` wird auch der Hochwald der »verbürgerlichten Gesellschaft« schließlich zur »Verkörperung[] der Zukunftsvorsorge «, ${ }^{175}$ sozusagen zur Kathedrale des Agrarkapitalismus. Andererseits wird der »Hochwald « - nicht nur bei Stifter - zum vermeintlichen Gegenteil, zur konstruierten »Wildniß«.

Auch der französischen Aufklärung und der Revolution ist - das Rousseausche Naturideal Landschaftsgarten im Gepäck - die Kathedrale nicht fremd, im Gegenteil: Zur »Zeit der Jakobinerherrschaft«, schreibt Hermand, sei man nicht nur dazu übergegangen, barocke Lustgärten »in Landschaftsgärten umzugestalten, die Tiere aus den adligen Menagerien zu befreien, weiträumige Tugendparks anzulegen«, Freiheitsbäume und -haine anzulegen und Gartenstädte zu planen, sondern ebenso »in den Chören der ausgeräumten Kirchen begrünte Hügel zu Ehren des >Höchsten Wesens` zu errichten, um sich durch die Wiederversöhnung mit der Natur, die revolutio zu den ursprünglichen Zuständen, in seinen republikanischen Gefühlen zu bestärken «. ${ }^{176}$ Hermand entdeckt hier »nicht nur republikanisch-rebellische Gefühle«, sondern auch den Durchbruch »ökologische[r] Tendenzen«, in deren Zentrum das in zwei Phasen verlaufende »Pflanzen neuer Bäume« stehe. Sei zu Beginn der Revolution

171 Vgl. Wind, Edgar: Heidnische Mysterien in der Renaissance, S. 130.

172 Frankl, Paul: The Gothic, S. 275.

173 Vgl. ebda., S. 239.

174 Vgl. Radkau, Joachim/Schäfer, Ingrid: Holz, S. 159.

175 Ebda., S. 165.

176 Hermand: Grüne Utopien in Deutschland, S. 29. 
das Pflanzen von 〉Freiheitsbäumenく zumeist »ein symbolischer Akt«, werde daraus - forciert vom einflussreichen Kulturpolitiker Henri Grégoire - 1791 der Plan umfangreicher Wiederaufforstungen der zuvor nach der Freigabe adligen Privatbesitzes verwüsteten Wälder. So solle man nach Grégoire »um jeden Freiheitsbaum einen Ehrenhain von jungen Bäumen und Büschen« anlegen. »Kurz darauf sprach er bereits von >Millionen von Bäumen`, die es neu zu pflanzen gelte, um ganz Frankreich in eine fruchtbare Gartenlandschaft zu verwandeln.« Dabei argumentiere er nicht nur ökonomisch, sondern ebenso »spezifisch ökologisch[] «, indem er auf die Verhinderung von Bodenerosion und klimaverbessernde Eigenschaften der Bäume verweise. Auf dieser Erkenntnisbasis fußen dann Vorschläge, jedes Ehepaar solle bei der Trauung einen Baum pflanzen, später werden 100 Bäume verlangt. Zudem sollen die Städte mit Parks und Dachterrassen begrünt bzw. zu Gunsten von Dörfern in einer Gartenlandschaft ganz abgeschafft werden. Derartige Pläne sind aber mit der »Machtergreifung der großbürgerlichen Gironde« und deren Wirtschaftsliberalismus und Industrialismus seit 1794 Makulatur. ${ }^{177}$ In Deutschland beginnt derweil der Aufbau der geregelten Forstwirtschaft.

Wilhelm Bode erklärt die obligatorische Einführung des >Altersklassenwaldes Ende des 18. Jahrhunderts in Deutschland aus dem merkantilistischen »Primärziel Holzproduktion« und dem Fehlen jeder Vorstellung von natürlichem Wald (aufgrund dessen Verschwindens). ${ }^{178}$ Was er jedoch vernachlässigt, sind eben >Forstästhetik ^ oder >Waldesschönheit (mithin den Körperkanon und die seit der Renaissance definitorische Untrennbarkeit von »guter Kunst« und »guter Nation«, was später zur Maschine wird, zum permanenten Gleichmaß), deren Definition untrennbar mit dem Kunstwald (und sei es in seiner Negation) verbunden ist. Dabei weist er eigentlich selbst darauf hin, indem er eine Umfrage der »Schutzgemeinschaft Deutscher Wald« von 1985 anführt. Danach hätten $83 \%$ empfunden, »daß der Wald zu Deutschland gehört wie Beethoven und Goethe«, der Meinung, im Wald fände der Mensch zu sich selbst, »weil er dort der Natur am nächsten sei« hätten 94\% zugestimmt, und $» 89 \%$ empfinden kein erhebenderes Gefühl, als im Wald zu spazieren und der Natur zu lauschen «. Welcher 〉Natur» sich hier nahe gefühlt werde, »bleibt unklar« bzw. »konfus«. Dass es der real existierende, also zumeist der Altersklassenwald ist, hält er denn doch für mög-

177 Vgl. ebda., S. 29ff.

178 Vgl. Bode: Der Deutsche Wald - Eine einzige Arche Noah?, in: Wolters, Jürgen, ARA (Hg.): Leben und Leben lassen, S. 163. 
lich. ${ }^{179}$ In der Tat lässt sich zeigen: Die Kulturlandschaft der Mitte des 19. Jahrhunderts gilt als etabliertes Schönheitsideal, ästhetisch besonders wünschenswert, und zugleich als Höhepunkt der Biotop- und Artenvielfalt. $^{180}$

Der Topos vom Ursprung der gotischen Kathedrale im Wald - und umgekehrt die Ernennung des Waldes zum Dom - entstehen in der Epoche, in der dieser Wald seiner systematischen Reproduktion zum Kunstwald, zum Altersklassenforst, kurz: zum 〉Deutschen Wald zugeführt wird. Ironischerweise erscheint im zeitgenössischen (besonders im deutschsprachigen) Diskurs die Gotik häufig als »deutsche oder germanische Baukunst ${ }^{181}$ und wird (auch in England) gegen die »Herrschaft des französischen Kunstgeschmackes«, also des Barock und Rokoko, propagiert, obwohl die ersten gotischen Kathedralen in Frankreich entstanden sind. Ebenso wird der Altersklassenforst als >deutsch` reklamiert, obwohl seine Ursprünge desgleichen auch in Frankreich liegen.

Zugleich erscheint mit diesem real existierenden >Deutschen Wald der >Deutsche Wald als Sehnsuchtsort, rückwärtsgewandte Utopie, als $>$ Ur $<$-Wald eines deutschen >Urvolks $<$. >Deutscher Wald $८$ und >Deutscher Wald 'gehen dabei auseinander hervor, überlappen sich, sind häufig deckungsgleich, werden immer mal wieder als miteinander unvereinbar verstanden, bleiben aber stets voneinander abhängig.

\section{sHeilige Hallen, II}

»Mein Leben ist ein Gang durch Gothische Wölbungen oder wenigstens durch eine Allee voll grüner Schatten: die Aussicht ist immer ehrwürdig und erhaben: der Eintritt war eine Art Schauder [...] das letzte Gleichnis habe ich insonderheit in den Wäldern in Nantes gefühlet, wenn ich ging oder saß [...] und denn aufblickte, die Allee wie einen grünen Tempel des Allmächtigen vor mir sah [...] und durch die Blätter die Sonne sah. « ${ }^{182}$

179 Vgl. ebda., S. 163f.

180 Vgl. dazu Ausleitung.

181 Hegel: Ästhetik II, S. 349. Hegel selbst betont dagegen: »Wir können jedoch die geläufigere ältere Benennung beibehalten«, also »gothische Baukunst«, da »sich sehr alte Spuren« hiervon in Spanien finden ließen, wo »sich gothische Könige, bis in die Gebirge Asturiens und Galiciens zurückgedrängt, dort unabhängig erhielten« (ebda.).

182 Herder: Journal der Seereise (1770), in: Sämtliche Werke, Ed. Suphan, Bd. 4, S. 439ff.; zit. n. Keller, Harald: Goethes Hymnus auf das Straßburger Münster, S. 14, Fn. 20. 
Auf dieser Seereise nach Nantes vollzieht Herder seinen Wechsel von der Aufklärung zum Sturm und Drang. Herder, eigentlich Gotik-Verächter, ist es auch, der Goethe »auf das \Ur-« hinwies«, woraufhin dieser das »Genie« zum »Grund« erklärt. Es schaffe das Werk »aus der Tiefe seines Wesens«, wobei die Herkunft dieses Genies obskur bleibt. »Das Genie als Schöpfer, schöpferischer Geist, dem 〉Ur-८ verbunden und selber >Ur-८. >Schöpfen` und `Schaffen` gehören zusammen. Beide Verben setzen Zugrundeliegendes voraus, aus dem >geschöpft`, >erschaffen wird. Das >Geschöpf « ist das 〉Erschaffene«. « ${ }^{183}$

Die Vorsilbe »Ur-« wird zum Signum der 〉Geniezeit «. Sie »dient der Steigerung, Verstärkung, >Vertiefung〈. Sie bezeichnet die Bewegung aus einem Innern, von der Tiefe in die Höhe, bedeutet sanfänglich vorhanden`, >ursprünglich`, >unabgeleitet‘, >original<, >primitivく, >unverfälschtく, >rein`. Im Anfang Vorhandenes als Grundlage für das Spätere«. »Uralt«, »urdeutsch«, »ureigen«, »urkräftig«, der »Urbegriff«, die »Urform«, der »Urgeist «, »Urgrund «, das »Urlicht« werden Bestandteile des philosophischen Diskurses. Zur »)überreichen Entwicklung der hochdeutschen Zusammensetzung« hätten nach dem »Deutschen Wörterbuch« der Grimms nicht nur die Philosophie, sondern auch Studentensprache, Bestrebungen zur Verdeutschung, Mundarten, an prominenter Stelle ebenso das Goethesche Beispiel beigetragen. ${ }^{184}$ Bei Fichte, in seinen »Reden an die deutsche Nation« (1807/08) wird dann Deutsch zur Ursprache, die deutschen zum »Urvolk«. Er verdammt die »Nulligkeit des Zeitgeistes« und propagiert die »)Bildung〈 eines neuen Menschengeschlechts«, wofür die Deutschen besonders prädestiniert seien, da sie von den Germanen abstammten und so eine >Reinheit` der Sprache besäßen. Eine Sprache, die - mit Ausnahme bestenfalls des Griechischen - im Gegensatz zu den toten Sprachen anderer Völker eine »bis zu ihrem ersten Ausströmen aus der Naturkraft lebendige Sprache«, eine »unmittelbare Naturkraft« sei. Sie könne »das Unbildliche in den Zusammenhang des Bildlichen« zurückversetzen, Übersinnliches »mit sinnlichen Bildern« darstellen. Das gelte zwar grundsätzlich für Sprachen als gesellschaftliche Werkzeuge. Solche Sprachen aber, die sich dem Einfluss fremder Sprachen unterwürfen, seien trotz aller oberfläch-

183 Best, Otto F.: Die blaue Blume, S. 40.

184 Vgl. ebda., S. 41f. »Uralt«, so Best, sei »zunächst« nur um 1150 nachzuweisen, werde aber »nach 1480, also in der Zeit von Renaissance und Humanismus, rasch häufig. Hängt dies mit der national-antirömischen Tendenz des Ad fontes (Zu den Quellen) zusammen, die zu den Merkmalen der Bewegung des Humanismus gehört?« 
lichen Bewegung »abgeschnitten von der lebendigen Wurzel« und damit tot. $^{185}$

Dass Sprache und Genie eine unmittelbare Naturkraft seien, ist weitgehend Konsens im Geniediskurs. »Als >naturhafter` Zustand >mehrt Genie die Natur. Was im Paradies Instinkt, sei jetzt, in der Periode der 〉Selbstsonderung^ Genie, meint Novalis.« Nach Schlegel, der in seiner vorromantischen Phase wiederum das Griechische für die >Ursprache hält und die Aufgabe »deutscher Dichtkunst« in der Annäherung an diese sieht, sorgt die »sittliche Verwilderung« dafür, dass nicht alle Menschen Genie besitzen. Und: Genie sei das »für den Mann«, was »Liebe für die Frauen sei«. Der Romantiker Schlegel hat die »Idee« der »Egalisierung« von Genie. Schlegels Programm der »Vereinigung« und des »Kombinierens« entspricht dem Kanon romantischer Poesie. »Nicht Ruhe, sondern >Wechsel« « bestimmten Natur wie menschliche Geschichte. Beide seien »in ständiger Bewegung durch einander entgegenwirkende Kräfte und Energien«. Das heiße, stetig »das Chaos bilden und in Harmonie bringen $«{ }^{186}$

»)Ur-८ hat einen mystisch-magischen Klang, ist Träger von Konnotationen, die den Zeitbezug überhöhen. $«{ }^{187}$ Auch die Gotik, die gotische Kathedrale, soll >urdeutsch` sein. Wenn auch nicht bei Herder, dem es nichtsdestotrotz ums >Urgenie $<$ und seine > Wiederbelebung « geht. Herder beschreibt sein Wandeln unter »Gothische[n] Wölbungen« zehn Jahre, nachdem James Macpherson mit den »Fragments of Ancient Poetry, collected in the Highlands of Scotland« seine erste »Ossian«-Fälschung veröffentlicht, der er 1762/63 aufgrund des Erfolgs die Epen »Fingal« und »Tamora« folgen lässt. »Volkspoesie«, die Macpherson »nach keltischen Motiven im empfindsamen Zeitstil« selbst verfasst. Obwohl dessen Behauptung, es handele sich um eine Übertragung der Werke des gälischen Genie-Barden Ossian aus dem 3. Jahrhundert, sofort stark umstritten ist, wird sein Konstrukt europaweit zur Ikone, geschätzt von »Goethe, Hamann, Herder, ja Napoleon«, und es wird erst 1895 allgemein als Fälschung akzeptiert. Herder jedenfalls besorgt, enttäuscht von der ersten deutschen Übersetzung in Hexametern (Michael Denis, 1768/69) eine eigene >Rekonstruktion〈 »durch den Nebel der [...] >Übersetzung einer Übersetzung` hindurch«, wie er glaubt, um dem vorgeblichen »Naturdichter und Naturgenie« gerecht zu werden. Macphersons Original lernt er erst später kennen. Auch das wird zu einer Enttäuschung. »Was er sich als wild, abgerissen und dunkel vorgestellt hatte,

185 Zit. n. ebda., S. 44f.

186 Best, ebda., S. 47f.

187 Ebda., S. 41. 
trat ihm sanft und flüssig entgegen. Die Diskrepanz schrieb Herder freilich Macphersons Übersetzung zu.« Auf der Basis des 〉Ossian`, den er als Genie wie Homer und Shakespeare zum Gewährsmann des »Volkston[s]« erklärt und ihm »Rousseau und Shaftesbury zu Paten« bestellt, entwickelt er seine Theorie der Volkslieder 1771 in dem Aufsatz »Auszug aus einem Briefwechsel über Ossian und die Lieder alter Völker«. $»[\mathrm{~J}] \mathrm{e}>$ wilder , je >freiwirkender ein Volk sei«, schreibt er emphatisch,

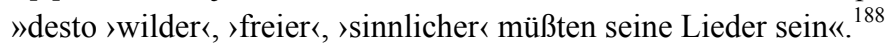

Best hält es für »ein schockierendes Paradox, daß Herder seine Ansichten über das Volkslied an gefälschten Gedichten entwickelte «. ${ }^{189}$ Dabei ist Herders Vorgehen durchaus folgerichtig. In seinen Schriften ist die Kritik am Staat als »Kunstmaschine« per se dokumentiert, der eine >naturgemäße Gemeinschaft`, >natürliche Einheiten` wie »Vaterland«, »Nation«, "Volk« entgegengesetzt werden, gleichzeitig zeigt sich die »Transformation des aufklärerischen Naturideals« ins »idiographische«, »objektiv konservativ[e]«, in dem »Land und Leute« sich innerhalb eines »geschlossenen Systems «, der »Kultur« gegenseitig entsprechen. ${ }^{190}$ Bei Herders Volksliedtheorie handelt es sich um eine Konstruktion von Ursprünglichkeit, eines >natürlichen Volkstons $<$. Das wendet sich gegen das Urbane, Rationale, Atheistische, gegen Wissenschaft, Abstraktion, Spekulation (und ist doch selbst städtisch geprägt, Spekulation und Abstraktion). Das ist strukturell ähnlich dem Vorgehen von Klopstock und anderen, die - konträr zur eigentlich allgemein bekannten realen Vorgeschichte dieser Orte - >heilige Haine` aus Hutewäldern konstruieren. Das vorgeblich Organische, die im >Dermaleinst $`$ wurzelnde nationale Kultur, all das kann gar nicht aktuell entstanden sein, muss um der Sinnstiftung willen >uralt $<$ und >ureigen $<$ sein. Nichtsdestotrotz: Die entdeckten 〉Ursprünge $<$, der >urdeutsche Wald der heroischen Landschaft, entstammen zeitgenössischer Produktion, ebenso die Auffassung einer Gotik, die bruchlos einem »deutsche[n] Naturgefühl, als die Wurzel und lebendige Quelle « ${ }^{191}$ entspringe. Sie entstehen in einer Gesellschaft, in der sich »der Abgrund zwischen Fürstenstaat und bürgerlicher Erwerbsund Tauschgesellschaft, die ihre eigenen Institutionen, Dynamiken und Gesetze hervorbringt«, vertiefe, in der »bürgerliche »Natürlichkeit`

188 Ebda., S. 242.

189 Ebda.

190 Vgl. Stollberg-Rilinger, Barbara: Der Staat als Maschine, S. 214ff.; Trepl, Ludwig: Geschichte der Ökologie, S. 99ff.

191 Schlegel, Friedrich: Briefe auf einer Reise durch die Niederlande, Rheingegenden, die Schweiz und einen Teil von Frankreich, in: Kritische Friedrich-Schlegel-Ausgabe. Hg. von Ernest Behler et al., Bd. 4, München, Paderborn, Wien: Schöningh u.a. 1959, S. 191. 
>selbst<-befreiende Entlassung aus höfischer Etikette und ständischer Separation, aus barockem Pathos und den Zwängen der vom Adel geprägten Kultur und Verkehrsformen« sei. Das Empfinden von und das Berufen auf diese >Natürlichkeit» »gilt für die Höhen der Philosophie und Rechtstheorie wie für die Ebenen der Alltagspraxis «. ${ }^{192}$ Eine $\gg$ Natürlichkeit`, die durchaus national konnotiert wird (mit Beginn des 19. Jahrhunderts insbesondere gegen Frankreich), so wenn Schlegel behauptet, jede »Nation, jedes Land hat seine eigentümliche, nur ihm eigene und angemessene Baukunst, oder ganz und gar keine«. Eine »dem Auslande nachgemachte[] Bauart« hingegen sei »das Widersinnige, und nicht nur alle Kunst, sondern auch Sitten Zerstörende«. Die Gotik sei erklärbar "mit der eigentümlichen Beschaffenheit und Bedeutung der christlichen Kirche«, vor allem aber mit »der Natur der nordischen, im Norden gebräuchlichen, und dem nordischen Klima angemessenen Bauart«, wozu auch »die Natur des Stoffes« zu rechnen sei, führe doch die »geringere Schönheit«, aber hohe Formbarkeit des Sandsteins gegenüber dem Marmor dazu, »bei steigendem Streben nach Verschönerung« die Verzierung auf die Spitze zu treiben. ${ }^{193}$ Eine `Natürlichkeit८, bei der die »Auflösung mechanistischer Sehweisen mit einer >Verzeitlichung und >Beseelung der Welt und des Staates Hand in Hand« geht, also die mechanistische »Entzeitlichung« von Staat und Welt außer Kraft gesetzt werde. »Das Ideal des statisch-geschlossenen Systems \Staatsmaschine fällt damit - wie viele andere Gegenstände einer räumlich-geometrischen Betrachtungsweise - einem strukturellen Wandel zum Opfer «, ${ }^{194}$ wobei die »räumlich-geometrische Betrachtungsweise« nicht einfach obsolet wird, sondern transformiert in eine >organisch

Die Gotik, der Schlegel »eine Bedeutung, und zwar die höchste« zuschreibt, da sie durch »bloße Nachbildung der Naturfülle« das »Unendliche gleichsam unmittelbar darstellen und vergegenwärtigen« könne, ${ }^{195}$ fußt nichtsdestotrotz auf strenger Geometrie (die zugleich christlicher Zahlenmystik entstammt), ist »angewandte Geometrie« auch in die Höhe, mit den Kreuzrippen »als Skelett einer neuen Ordnung«, einer »Revolution des Raums«, der "Anatomie eines neuartigen Wissens, das es dem Baumeister ermöglicht, die Kraftlinien zu verfolgen und sie in ein System, in ein sorgfältig austariertes Gleichgewicht, in eine balance of power aufzulösen«. In der gotischen Kathedrale wird der »Raum zum System-Raum«, zum »Denkgebäude, das einer mechanischen und ar-

192 Sonntag, Michael: »Das Verborgene des Herzens«, S. 186.

193 Vgl. Schlegel, a.a.O., S. 174 u. $180 f$.

194 Stollberg-Rilinger, a.a.O., S. 201.

195 Schlegel, a.a.O., S. 180. 
beitsteiligen Grammatik folgt«. In diesem Bau »als kosmologischer Metapher offenbart sich erstmals auch eine neue, rationale und mechanische Vorstellung der Natur«, deren Code vom »Weltarchitekt[en]« entziffert worden ist und nach Gutdünken wieder zusammengesetzt werden kann. ${ }^{196}$ Und Schlegel deutet das selbst an, wenn er schreibt, dass im Gegensatz zu den »altdeutschen Felsengebäuden«, den Burgruinen, die er auf seiner Rheinfahrt betrachtet, in »der höheren Baukunst [...] nicht mehr die wilde Natur in ihrem Klagegefängnis [...] nachgebildet oder dargestellt wird, sondern die verklärte und in der Verklärung frei und voll aufblühende Natur, als himmlische Gottesstadt und das geordnete, siderische Haus der verherrlichten Schöpfung«. Zwar ordnet er dem »deutsche[n] Naturgefühl« zwei Grundauffassungen zu; die Natur werde »als Garten oder als Wildnis« wahrgenommen. ${ }^{197}$ Die Kathedrale aber ist ihm kein Garten, sondern ein Wald. »Das Wesen der gotischen Baukunst« bestehe »in der naturähnlichen Fülle und Unendlichkeit der innern Gestaltung und äußern blumenreichen Verzierungen. Daher die unermüdlichen und unzähligen steten Wiederholungen der gleichen Zierraten, daher das Vegetabilische derselben [...], das Innigergreifende, das rührende Geheimnisvolle, das freudig Liebliche und Belebende des Eindrucks bei dem Erstaunen über die Größe «. ${ }^{198}$ Es sei ein Wald von Säulen, Knospen, »bald aus Weinreben, bald aus anderm einheimischen Laubwerk verschiedenartig gebildeten [...] stolzen Wölbung[en] eines Hohen Baumganges« innen, ein Wald ebenso außen:

»Und wenn das Ganze von außen mit allen seinen zahllosen Türmen und Türmchen aus der Ferne einem Walde nicht unähnlich sieht, so scheint das ganze Gewächse, wenn man etwas näher tritt, eher einer ungeheuern Krystallisation zu vergleichen. Es gleichen, mit einem Worte, diese Wunderwerke der Kunst, in Rücksicht auf die organische Unendlichketi [sic] und unerschöpfliche Fülle der Gestaltung, am meisten den Werken und Erzeugnissen der Natur selbst $\ll .{ }^{199}$

Einer Natur offenbar, deren »unerschöpfliche Fülle« eine erstarrte ist und sein soll. Eine Natur der erstarrten Ströme - Schlegel vergleicht die Bogenwölbung auch »mit dem Wasserstrahl eines gewaltigen Springbrunnens«, der »eben so dicht wieder herabströmte, als er emporschie $\beta \mathrm{t} \ll^{200}-$, der gelenkten Ströme, in der Gesamtgestalt des Baus nach

196 Vgl. Burckhardt, Martin: Metamorphosen, S. 32f. u. 38f.

197 Schlegel, a.a.O., S. 191.

198 Ebda., S. 179f.

199 Ebda., S. 178f.

200 Ebda. 
oben gelenkt in steinharter, asketischer Selbstbeherrschung und asketischer Leibverneinung. Eine Natur also, die von all ihren Niederungen bereinigt ist. Das >Organische $<$, das hier gegen das >Mechanische $\prec$ gestellt wird, unterscheidet sich letztlich nicht sehr davon. Barbara Stollberg-Rilinger hat am Beispiel der Staatstheorie Adam Müllers Vergleichbares gezeigt. ${ }^{201}$

Die »unmittelbare Naturkraft« des Genies zeigt sich in der Gotik. Desgleichen ein >uralter Volkston`, etwas >Heldisches`. Schlegel entdeckt das in der »Reihe von Ruinen altdeutscher Burgen, welche den Rheinstrom hinauf und herab so herrlich umkränzen«. Er konstruiert hier - erneut unter Berufung auf Tacitus - eine sergreifende` männliche Wildnis, die ihm zur Grundlage der Gotik wird. Bereits »seit den ältesten Zeiten, schon in den germanischen Wäldern«, noch vor der Entstehung von Gutshöfen oder Städten hätten die »Deutschen« Burgen gebaut, »Fürsten- und Heldensitze« zur Verteidigung und zum »stets gewaffneten Frieden«. Tempel oder Grabanlagen dagegen habe es nicht gegeben, zu diesen Zwecken seien einsame Seen oder »die Einöde des Waldes« aufgesucht worden. »Es ist also die ganze germanische Bauart, nicht wie bei anderen Völkern von den Tempeln und Gräbern, sondern allein und ganz vorzüglich von den Burgen ausgegangen«. Die Besonderheit »bei allen deutschen und gotischen Völkern« zeige sich darin, »grade die kühnsten Stellen vorzugsweise zu wählen, und Türme und Mauern auf eine oft unglaubliche Weise, wie hohe Adlernester, an die schroffsten Felsenspitzen fest zu hängen oder einzuklammern«. Zudem habe das

»deutsche Naturgefühl, die zum Bedürfnis gewordne Neigung, das Auge an dem Anblick dieser irdischen Naturherrlichkeit zu weiden, [...] auch seinen Anteil daran gehabt; mit Rührung sehen wir noch die Trümmer von des großen Theodorichs Schloß zu Terracina, oben an der Zinne des Berges, die Aussicht über das Meer weithin beherrschend«.

Und trotz aller Roh- und Plumpheit seien diese Burgen und ihre Bauart von »unverkennbar große[m] Einfluß auf die Ausbildung der gotischen Baukunst«. Denn es sei eine Vielzahl von Umständen und Zwecken, von Anpassungsleistungen an spezielle, häufig »seltsame« Gegebenheiten der (felsigen) Umgebung gewesen, die die »große Unregelmäßigkeit« hervorgerufen habe, »"welche bald ein Wohlgefallen an dem Kühnen und Seltsamen erregte, eine absichtliche Wahl desselben veranlaßte, und jene wunderbare Fantasie in der Bauart begründete, welche das Eine Element

201 Vgl. Kap. Organismus versus Mechanismus? 
der gotischen Baukunst geworden ist«. Das andere sei im »altchristlichen Kirchenstyl und seiner siderischen Bedeutung« zu finden. Zusammen lösten sie vollständig »das ganze Rätsel dieser sonderbaren Kunsterscheinung. $^{202}$

Hier geht es um die Reklamation einer vorgeblich organischen Baukunst als Ausdruck organischer Gemeinschaft von Menschen und Natur, um die >Entdeckung « der >Wurzeln` eines >männlich streitbaren Geschlechts $\triangleleft$, von etwas $>$ Heldischem $\prec$, das direkt der Natur entstammen soll, einer `Erhabenheit`, die eine natürliche bürgerliche Männlichkeit gegen verweichlichte adlige »Mannspuppen« befleißigen soll. ${ }^{203}$ Die soziale Projektion ist dabei noch >empfindsam »Rührung« über so viel Erhabenheit zu geraten. Schlegels Rheinreise findet (1804/05) in einer Übergangszeit statt, in der die Räume noch nicht vollkommen visuell vorentdeckt sind, in der die Auflösung von Irritierendem, Überraschendem, >Natur-Schönem` ins Klischee noch nicht gänzlich vollzogen ist. ${ }^{204}$

»Wandelt zur Lichtung der Höhe empor!/das ist der Waldesbasilika Chor«, reimt Joseph Victor Scheffel, der vaterländisch-heroische »Butzenscheibenlyriker« 1863 in seiner »Frau Aventiure« knapp hundert Jahre nach Herders Wähnen im »grünen Tempel des Allmächtigen« bei Nantes. ${ }^{205}$ Dazwischen liegen all die Gemälde Caspar David Friedrichs, wie etwa sein »Kreuz und Kathedrale in den Bergen« (um 1812), das eine von spitzen Türmchen geschmückte gotische Fassade zwischen ein symmetrisch angeordnetes Geviert von Fichten plaziert und somit eine >organische< Einheit schafft.

Ähnlich Karl Friedrich Schinkels Steindruck »Dom hinter Bäumen« von 1810. Hier »scheint die gotische Kirche sich aus dem Blätterwerk einer Buche herauszuentwickeln, ihre organischen Naturformen in geometrische Gebilde zu überführen«. Damit werde die Gotik aus der >heimischen Natur` abgeleitet, zugleich, so Eschenburg, werden die »Natur-

202 Vgl. Schlegel, a.a.O., S. 189ff. Für Schlegel ist der romanische Baustil noch eine »ältere« Form der Gotik, »welche man wegen einiger Ähnlichkeit mit der konstantinisch-byzantinischen christlichen Bauart die gräzisierende nennen könnte« (ebda., S. 180).

203 Vgl. Kap. Der Aufmarsch der Soldaten.

204 Vgl. Großklaus, Götz: Natur - Raum, S. 79.

205 Die Grimms nennen das »der Wald als Dom gedacht«. Deutsches Wörterbuch von Jacob und Wilhelm Grimm. Dreizehnter Band. Bearb. v. Dr. Karl von Bahder unt. Mitarb. v. Dr. Hermann Sickel. Leipzig: Verlag von S. Hirzel 1922, Sp. 1114. Von Scheffel stammen Werke wie »Als die Römer frech geworden...«, »Alt Heidelberg« oder »Der Trompeter von Säckingen $\ll$. 
formen in eine idealere, lichtere Sphäre« übertragen. Baum (in der Natur) und Dom (im »Reich des Geistes«) symbolisierten die »Überwindung des Todes« - was aber bei Schinkel vor dem Hintergrund der antinapoleonischen Kriege auch Verweis auf eine »durch die Vergangenheit legitimierte künftige Größe der deutschen Nation« sei. ${ }^{206}$

Abb. 17: Karl Friedrich Schinkel: »Dom hinter Bäumen«, 1810

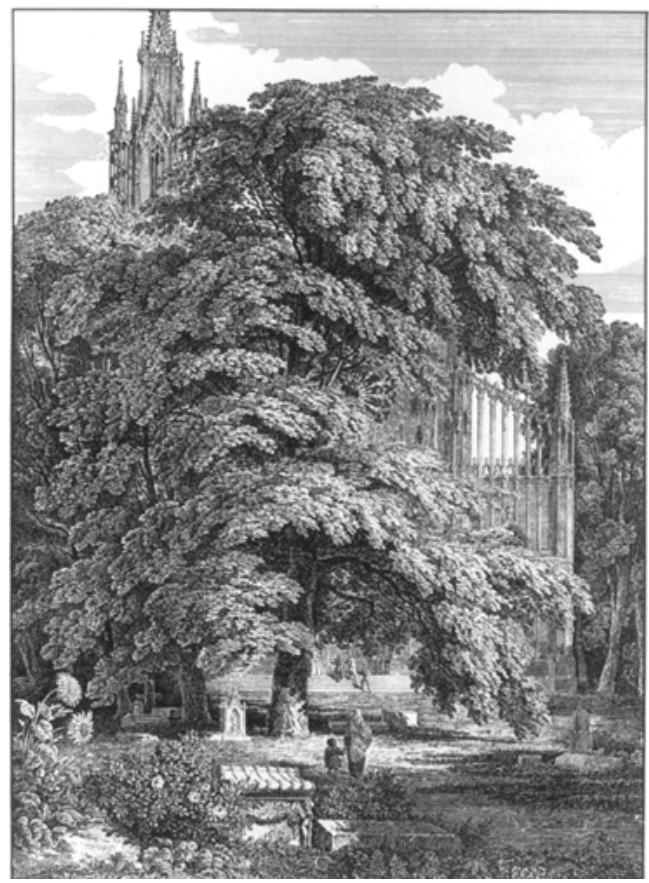

Diese >Größeく scheint 1815 (»Mittelalterliche Stadt an einem Fluß«) dann schon näher zu sein. Ist vorher die Kirche nur teilweise durchs Laub zu sehen, so lässt Schinkel sie jetzt in voller Pracht aus einem waldigen Hügel emporwachsen, ihre Turmspitzen einen Regenbogen berühren. Unten, am Fuß der Kathedrale eilen Menschen heran, die sich zu einem mächtigen Zug formieren. ${ }^{207}$

Im Laufe des 19. Jahrhunderts wird Gotik zum Ausdruck der Restauration, des Ständischen gegen die moderne Gesellschaft, andererseits, um 1900 in der historisierenden Variante der Neogotik (oder in anderen

206 Eschenburg, Barbara: Landschaft in der deutschen Malerei, S. 132. 207 Vgl. in Wyss, Beat: Trauer in Vollendung, Frontispiz. 
Neo-Stilen) auch zur Maske der kapitalistischen Produktion, zur Fabrikfassade etwa, »die nichts von dem, was drinnen geschieht, ahnen läßt «, ${ }^{208}$ bzw. zur »Repräsentationssymbolik«, in der die »Illusion« einer »Macht über den Gegenstand« einstweilen noch aufrecht erhalten wird, wobei »ornamentale Formen« an den Fabrikgebäuden dem »Sich-inSzene-Setzen[]«, der sinnbildlichen Repräsentation des Fabrikherrn und seiner Familie dienen, „um durch die derart zur Schau gestellte Aneignung des an diese Formen und Bilder geknüpften gesellschaftlichen Reichtums seinerseits kreditwürdig zu erscheinen «. ${ }^{209}$ Dabei erhält sich das Bild des Organischen, der architektonischen Analogie zum Wald. Die ganze Paradoxie derartiger Camouflage zeigt das gotisierend als Burgtor gestaltete Eingangsportal des 1823 beendeten Tunnels eines Holzschwemmkanals bei Hirschbergen im Böhmerwald. Es wird - auf der Abbildung - zum heroisch-romantischen Eingang in eine hohe Burg, gebildet von aufragenden Fichten. Tatsächlich wird oben abgeholzt, werden die Stämme durch den Tunnel im Schwemmkanal abtransportiert. $^{210}$

Das Stereotyp vom >Waldesdom $<$ findet sich erwartungsgemäß bei den Propagandisten eines nationalen, `natürlichen`, >heimat-^ und >scholleverbundenen` Lebens gegen die urbane Moderne: So in einem typischen Roman der deutschen >Heimatschutzbewegung` um 1900 Paul Kellers »Waldwinter«:

»Nun stieg ich hinauf. Die Abendsonne leuchtete mir. Der Waldweg war nicht allzubreit, und die Buchenkronen so mächtig, daß sie sich über mir schlossen $\mathrm{zu}$ einem langen Bogengange. Ich ging langsam. Es war nicht, um in Stimmung zu kommen, die war da, als das letzte Wort der harmlos-neugierigen Männer da unten an meinem Ohr kaum verklungen war. So wie man durch einen Kirchengang langsam schreitet oder durch einen alten Korridor behutsam geht, so ging ich. ${ }^{211}$

Der Protagonist ist dem »fremden«, dem »nervösen Chaos«, dem Gewimmel und der >Hysterie` der Großstadt entflohen und »heimgekehrt«.

208 Müller, Michael: Die Verdrängung des Ornaments. Zum Verhältnis von Architektur und Lebenspraxis. Frankfurt/M: Suhrkamp 1977, S. 282, Abb. 12: Weberei in Ochtrup (1893).

209 Ebda., S. 43.

210 Vgl. Abb. bei Brande, Arthur: Stifters Hochwald am Plöckenstein. Eine vegetationskundliche und waldgeschichtliche Analyse, in Hettche, Walter/Merkel, Hubert (Hg.): Waldbilder, S. 64f., Abb. 11.

211 Keller, Paul: Waldwinter. Roman aus den schlesischen Bergen. 106. bis 120. Aufl. Breslau und Leipzig: Bergstadtverlag Wilh. Gottl. Korn 1920, S. 17. 
Der Wald fungiert als Gegenwelt, längst gewendet zur gesuchten, ersehnten Gegenwelt. Dieser kathedralische Wald verweist als Ort erhabener Ruhe und Geborgenheit nicht nur »Demokratismus und Liberalismus«, eine »kümmerlich[e] und einseitig[e]« Psychologie, die Abwesenheit von »Helden« an die Großstadt. ${ }^{212}$ Der kathedralische Wald gründet auf festem Boden, kann keine Untiefen, Sümpfe, Fäulnisse, keinen Verfall aufweisen. Solch exkrementelle Funktionen sind ebenfalls längst an den Dschungel Stadt verwiesen.

Sakralisierte Heimat, >deutsche Tiefe` und >immerwährender Daseinskampf $\iota:$ »Um wieviel ernster, ärmer an Farbe und Leben« sei, im Gegensatz zu dem der »Eiche, die, einst dem Wettergott Donar geweiht, heute im ganzen mehr als früher als deutscher Baum gefeiert« werde, ${ }^{213}$

»der Wald der dichtschattenden Buche! Auch hier machtvolle Stämme, aber weniger Eigenart, mehr Ebenmaß der einzelnen Glieder. Mächtig streben die glatten grauen Säulen empor, hoch oben kreuzen sich steilbogig die Äste zu Wölbungen unter dem gleichmäßig geschlossenen Laubdach. Das ist der weihevolle Waldesdom der Dichter, der uns Urbild scheint für die Wölbungen gotischer Dome. Wenig Unterwuchs am dämmerigen Boden, nichts hindert den Blick als die geheimnisvoll sich deckenden Stämme, die immer wieder einen Durchblick ahnen lassen und doch nie ihn freigeben. Braungelbes Laub raschelt unter dem Fuß, und nur im ersten Frühjahr, wenn die kahlen Kronen noch Licht durchlassen, drängen sich hier weiße und bunte Frühlingsblumen, allerhand Blätter und Gräser zu kurzem, eiligem Leben ${ }^{214}$

Das schreibt 1926 der Forstmeister und Schoenichen-Mitstreiter Otto Feucht. Schoenichen selbst, auch in den 50er Jahren noch angesehener Naturschützer, schildert 1950 »ein Naturerlebnis«, das »alljährlich Tausenden und aber Tausenden zuteil« werde:

»In seinem Mittelpunkte steht der Buchenwald, der uns zu allen Jahreszeiten neue Offenbarungen seiner Schönheit erschließt: im ersten Frühling, wenn die Bäume noch unbelaubt stehen, die bunte Pracht so vieler anmutiger Blumen

212 So schreibt es Friedrich Lienhard, einer der Hauptpublizisten der literarischen Heimatbewegung in $»$ Vom Reichtum Deutscher Landschaft $«$, in: Die Vorherrschaft Berlins. Literarische Anregungen. Heft 4 der Flugschriften der Heimat. Leipzig, Berlin: Georg Heinrich Meyer Heimatverlag 1900, S. 9-17, zit. n. Ruprecht, Erich (Hg.): Literarische Manifeste der Jahrhundertwende 1890-1910. Stuttgart: Metzler 1970, S. 339f. u. 343.

213 Feucht: Vom Walde, von seinem Bäumen und von der Forstwirtschaft, in: Schoenichen (Hg.): Vom grünen Dom, S. 116.

214 Ebda., S. 121. 
des Waldgrundes; dann später im Mai das lichte Grün des Blättergewölbes, im Sommer die erfrischende Kühle der hohen Hallen, im Herbst den unermeßlichen Farbenzauber des welkenden Laubes. Und auch im Winter, wenn Stämme und Astwerk den heldischen Baugedanken des Buchendomes klar erkennen lassen, hat der Buchenwald seinen besonderen Zauber. ${ }^{215}$

Und er besitze »die heilsame Kraft [...] mit seinem frischen Grün und seinem Schatten, mit seinen Lebenswundern und seiner feierlichen Stille unserem Volke immer von neuem Erholung und Erhebung « zu bieten. ${ }^{216}$ Schoenichen spricht auch davon, dass im Gebirge sich ab einer bestimmten Höhe Buchen, Fichten und Tannen sich die »Herrschaft« teilen, schildert das »Naturschutzgebiet Arberseewand«, wo über der »spiegelnde[n] Fläche« des Sees an der »steil abfallenden Seewand« von »tiefdunklem Fichtenkleid sich die lichteren Kronen der Buchen wie die Kuppeln eines tausendtürmigen Märchenschlosses abheben. Oberhalb der Mischwaldzone beginnt dann das Reich der Fichte, in dem diese bis hinauf zur Baumgrenze die unbedingte Herrin ist«. Er schildert Ausnahmen, wie auf dem »Schauinsland « bei Freiburg, wo noch »in $1284 \mathrm{~m}$ Meereshöhe sich Buchenbestände finden, die alle Merkzeichen einer Kampfzone erkennen lassen ${ }^{217}{ }^{217}$ Der Wald ist hier, in der Vorstellung des reaktionären Naturschützers, Vorbild im »Daseinskampf «, hierin sei die »Wehr' « der Rotbuche »der Schatten«. Mit dem Schatten habe »die Natur« die Buche »mit einer Waffe ausgerüstet, die es ihr ermöglichte, in die festen Stellungen der feindlichen Front einzubrechen, sich hier zu behaupten und schließlich die Gegner in zähem Ringen unerbittlich niederzuzwingen ${ }^{218}{ }^{21}$ Die Buche wird so zum >heldischen` Baum. Der Wald entspringt einem »heldischen Baugedanken «.

Oswald Spengler erklärt die »gotische Weltanschauung mit ihrem Ringen zwischen Vernunft und Wille« zum »Ausdruck des Lebensgefühls jener Menschen der Kreuzzüge«. Diese Kultur sei »faustisch«, eine »Willenskultur«. Entfesselter Eroberungswille: »Wollen und Denken im Seelenbilde - das ist Richtung und Ausdehnung, Geschichte und Natur, Schicksal und Kausalität im Bilde der äußeren Welt« mit dem »Ursymbol« der »unendliche[n] Ausgedehntheit«. Das faustische »Ich« steige »in der gotischen Architektur empor; die Turmspitzen und Strebepfeiler sind >Ich〈, und deshalb ist die gesamte faustische Ethik ein >Emporく: Vervollkommnung des Ich, sittliche Arbeit am Ich, Rechtfertigung des

215 Schoenichen: Von deutschen Bäumen, S. 122.

216 Ebda., S. 138.

217 Ebda., S. 125.

218 Ebda., S. 138 u. 123. 
Ich durch Glauben und gute Werke«, schließlich »Unsterblichkeit des Ich ${ }^{219}{ }^{19} »$ Nur ein Ich, das auf sein unmittelbares Glück verzichtet«, kommentiert Beat Wyss, »wird das All begreifen lernen. Naturbeherrschung setzt die Verneinung seiner leiblichen Begehrlichkeit voraus. Durch Frustration setzt der Abendländer seine Energien frei; sein Machthunger nährt sich an der Askese. Die >blonde Bestie « wird so gezüchtet, >Menschen von Granit`, die alles wollen; eine lange Reihe hünenhafter Männer zieht durch die abendländische Geschichte «. ${ }^{220}$

Auf dem Umweg über die Gotik ist dann wieder die >männlichasketische` Grundordnung des >nordischen Waldes` zu behaupten. Auch für Spengler ist im Dom architektonisch ein »Weltgefühl[]« realisiert, dessen »ursprünglichstes Symbol« der »Hochwald der nordischen Ebenen« sei. Genauer der Laubwald

»mit dem geheimnisvollen Gewirr seiner Äste und dem Raunen der ewig bewegten Blättermassen über dem Haupte des Betrachters, hoch über der Erde, von der die Wipfel durch den Stamm sich zu lösen versuchen. Man denke wieder an die romanische Ornamentik und ihre tiefe Beziehung zum Sinn der Wälder. Der unendliche, einsame, dämmernde Wald ist die geheime Sehnsucht aller abendländischen Bauformen geblieben«.

Der >unendliche Raum` des >faustischen Willens nicht in »Zypresse und Pinie«, die »körperhaft, euklidisch« wirkten, senkrecht, säulenhaft und in dieser Weise abgeschlossen. Buche, Eiche, Linde hingegen $»$ mit den irrenden Lichtflecken und ihren schattenerfüllten Räumen wirken körperlos, grenzenlos, geistig«. Der Stamm einer Eiche wirke »wie ein unerfülltes rastloses Streben über den Wipfel hinaus. In der Esche scheint der Sieg der aufstrebenden Äste über den Zusammenhalt der Krone eben zu gelingen. Ihr Anblick hat etwas Aufgelöstes, den Anschein einer freien Verbreitung im Raum, und vielleicht wurde die Weltesche deshalb ein Symbol der nordischen Mythologie ${ }^{221}{ }^{221}$ Grenzenlosigkeit`, die nur aus gepanzerten Stämmen entstehen kann, aus Härte gegen andere und sich. >Faustische` Grenzenlosigkeit als gewaltiges Ungefähres. So wird auch das Brausen der Orgel zur Übersetzung des »Waldesrauschen[s], dessen Zauber kein antiker Dichter je empfunden hat «. Schließlich klinge das »Wort Gottes« im gotischen Gewölbe anders, als in orientalischen oder römischen Tempeln. Und so bleibe in den Vertonungen des Rauschens, von Wolfram von

219 Spengler, Oswald: Der Untergang des Abendlandes, S. 394f.

220 Wyss, Beat: Trauer in Vollendung, S. 271.

221 Spengler, a.a.O., S. 508f. 
Eschenbach bis Wagner, die »Sehnsucht [...] nach der Sprache« des »eigentlichen Tempels der abendländischen Gottesverehrung«, des Waldes »fruchtbar«. 222

Ungeheure Energien werden so beschworen, gebündelte, gebundene, aggressive Energien, die einen unendlichen Raum für sich beanspruchen. Energien, die in die >Höhe « wollen, ja müssen, schon, weil sie im Boden unverrückbar verwurzelt sind. Spengler entwirft den »Bauern« selbst als »Pflanze«, der sich die Erde zur »Freundin« mache und der seine »Wurzeln tief in den eigenen Boden« senke, und spricht vom »pflanzenhaften« Fortpflanzungsdrang des »Blutes $« .{ }^{223}$ Das ist die hinlängliche (Selbst-)Beschreibung einer gesellschaftlichen Wunsch- bzw. Realitätsproduktion des (ausgehenden) Wilhelminismus: Eine Gesellschaft, die das >Weiblicheく am Boden hält, aus dem das >Männliche hervorragt, die das Begehren nur in starren Kanälen >fließen ২ lässt (in Stämmen und Ästen), die sich zu >wehrhaften Domen in der >Natur $<$ verortet und dabei Hoffnungen aufs >Dritte Reich $<$ hegt. In mehreren Veröffentlichungen der 30er Jahre bemüht Schoenichen den »deutschen Urwald«, das darin waltende »Kämpferische«, den »unablässigen titanenhaften Widerstreit der Naturkräfte« unter dem »Lauboder Nadeldach des grünen Domes « ${ }^{224}$ Das 〉Heldische , der >deutsche Geist «, der demnach in Bäumen und »deutsche[r] Urlandschaft« wirkt, durchläuft eine Transformation in die »deutsche Kulturlandschaft«, und zwar in >gnadenlosem Ringen`. Genauer: Die >titanischen Naturkräfteく werden zu Gegnern der >Germanen〈, aber zu notwendigen, da diese mit der Landschaftskultivierung ihr eigenes »überlegenes >Heldentum〈 verwirklich[en]«, da sich die »germanische[n] Krieger« an den »reckenhafte[n] Baumgestalten « der Wildnis physisch wie geistig stets »aufs neue gestählt und gefestigt« hätten, wie Schoenichen 1934 in seiner »Urwaldwildnis in deutschen Landen « schreibt. ${ }^{225}$

National-konservative Kunsthistoriker mit Affinitäten zum Nationalsozialismus wie der Architekt und Heimatschützer Paul Schultze-Naumburg, Wilhelm Pinder oder Heinrich Lützeler erklären mittelalterliche Sakralarchitektur zum Inbegriff eines >deutschen Wesens $\measuredangle$. Um die auch französischen Ursprünge zu kontern, werden Begriffe wie »staufische Gotik«, »deutsche Sondergotik« wie Backsteingotik oder Hallenkirchen,

222 Ebda., S. 509.

223 Ebda., S. 660 u. 680.

224 Schoenichen: Zauber der Wildnis in deutscher Heimat (1935); zit. n. Fischer, Ludwig: Die »Urlandschaft« und ihr Schutz, in: Radkau, Joachim/Uekötter, Frank (Hg.): Naturschutz und Nationalsozialismus, S. $186 f$.

225 Fischer, a.a.O., S. 192 f. 
oder auch »faustische Gotik« bemüht. ${ }^{226}$ Dome werden hier zu Sinnbildern eines >wesenhaften Deutschtums`, sie sind `männliche Trutzburgen<. Lützeler und andere stimmen dem faschistischen Cheftheoretiker Alfred Rosenberg zu, der feststellt, die Architektur romanischer Bauten sei »schwer, in sich geschlossen und von höchster germanischer Männlichkeit getragen«. Von »männlich-kraftvolle[r]« Bauart, von »Urbildern heldischer Kraft«, von einem männlichen Wesen, das sich offenbare in »Demut" - im Sinne von »Gefolgschaftstreue bis in den Tod» -, in $»$ Freiheits- und Herrschaftsbewußtsein«. Friedrich Eilemann hingegen entdeckt 1933 in der Romanik das >Mütterlicheく und in der Gotik das >Männlicheく. Er schließt aus dem architektonischen Gesamtbild auf die spezifisch männlichen Fähigkeiten der Erbauer: »eine Selbstbescheidung vor dem Letzten, vor dem Führer, vor Gott «. ${ }^{227}$ Die >Männlichkeit` von gotischen Kirchen, vor allem der Backsteingotik wird auch von anderen Kunsthistorikern beschrieben, so schon 1910 von Pinder, aber auch 1941 von Lützeler. ${ }^{228}$

Diese >Männlichkeit` erfährt eine weitere Steigerung durchs Kriegerische. So werden Kirchen $\mathrm{zu} »$ Gottesburgen«, »Festungen an der Front «, »Grenzbauten«, »Bollwerk«, »Schutzwall«. Das geschieht in »massive[r] Unterstützung« von »Hitlers Verweis auf die mittelalterliche Kaiserpolitik» zur Legitimation der »Annexionsfeldzüge«, beschränkt sich darauf aber nicht. Bereits 1921 feiert Pinder die >nordische Basilika als in die »wilden Lande [...] hineingerodet«, wo sie »gleichsam in Kampfesstellung « ihre eigentliche Identität finde, »dem Feinde« die trotzige Stirn bietend. $^{229}$

Hallenkirchen als >Massenbaue zeigen eine »gleichberechtigte Kameradschaft «, das »germanische Ideal des Bundesstaates« oder hierarchische Strukturen, ${ }^{230}$ zugleich ist erwartungsgemäß der >Wald Ausgangspunkt. Für Schultze-Naumburg sehen überhaupt die »Bauwerke aus glücklichen Epochen immer so aus, als seien sie wie ein Baum, Strauch oder Felsen aus dem Boden hervorgewachsen, in dessen Grundtiefen sie wurzelten und aus dem sie genährt und behütet von allen heimischen Säften, wie ein mächtiger Stamm aufsteigen«. ${ }^{231}$ Der Dom erfahre seine »geheimnisvoll[e]« Attraktion im »ins unendliche reichen-

226 Clemens-Schierbaum, Ursula: Mittelalterliche Sakralarchitektur in Ideologie und Alltag der Nationalsozialisten, S. 134.

227 Ebda., S. $142 \mathrm{f}$

228 Vgl. ebda., S. 246, Anm. 444.

229 Vgl. ebda., S. 143f. u. 141.

230 Vgl. ebda., S. 165.

231 Schultze-Naumburg, Paul: Die Gestaltung der Landschaft durch den Menschen $\left(1922^{2}\right)$; zit. n. Sieferle: Fortschrittsfeinde?, S. 179. 
de[n] Griff des nordischen Menschen«, der als »begabter Schüler der Antike« mit der erworbenen Technik »eine neue Phantasie über die Heiligkeit und Erhabenheit des deutschen Waldes dichtet«, schwärmt er $1934{ }^{232}$ Stereotyp wird die »Naturverehrung der Germanen« und deren Manifestation im Dom beschworen, so auch von Rosenberg, der keine »Neuverwirklichung des Waldes« in den »Säulen usw.« erkennen will. Diese »deuten« vielmehr

»auf das gleiche irrationale Wesen, welches einst die wogenden dunklen Wälder und Durchblicke auf unendliche Weiten aufsuchte, dieses Wesen schuf sich aus dem gleichen Weltgefühl heraus die gotischen Strebepfeiler und die mystischen Farbspiele ${ }^{233}$

Während hier ein »metaphysische[s] Zeitgefühl« zur Grundlage der Architektur erklärt wird, ist für Pinder der Limburger Dom etwa »wahrhaft zu Ende gedachte Natur $\ll .{ }^{234}$ Natur, die als steinerne nicht mehr stirbt, vollendet >männliche` ist (weil Sterblichkeit weiblich sei).

Die Kunsthistoriker (und Heimatschützer) lassen faschistische Realitätsproduktion, oder Protoformen davon, sichtbar werden; erneut das, was Theweleit »Anti-Produktion« nennt. $^{235}$ Der bereits zu heldischen Monumenten, zu gepanzerten Recken im Daseinskampf stilisierte, zu grünen Domen, ins Ewige, Überzeitliche verwiesene, entlebendigte Wald wird in seiner Abstraktion zur Architektur, seiner abermaligen Versteinerung zur sakralen Trutzburg, zum Fels in der Brandung aus anwimmelnden Feinden, endgültig zum offenbar körperlich wahrgenommenen Monument der (Selbst-)Abtötung und Abwehr, dessen Innen ein mystisch angefüllter Hohlraum ist. Die Projektionen von Dom und Wald wirken wechselseitig. Beide sind `Kultur८, wachsen fest gefügt und unverrückbar aus der Erde. Beide sind starr, beim Wald allerdings sind gewisse Regungen dann doch unvermeidlich, werden aber (wie bei Spengler die Äste und Zweige der Buchen, Eichen, Eschen, Linden, s.o.) zu etwas eigentlich Geistigem, Sphärischen. Erst der Dom wird hier zum jäh auffahrenden, erstarrten Monumentalkörper, in dem sich - >Sicherheit ` verheißend - nichts mehr regt. Das Pflanzenhafte ist endgültig zur Ruhe gekommen, steinerne, wehrhafte Askese.

Die Konstruktion »steinerner Wälder« sei dann problematisch, kommentiert Clemens-Schierbaum, wenn aus ursprünglich »schwärmerisch

232 Zit. n. Clemens-Schierbaum, a.a.O., S. 167.

233 Zit. n. ebda.

234 Ebda., S. 169ff.

235 Vgl. Theweleit: Männerphantasien I, S. 270. 
gezogenen Vergleichen«, wie bei Forster und Schlegel, »in der NS-Zeit eine angeblich germanische Architektursymbolik wurde, die zur Stützung ideologischer Irrlehren diente «. ${ }^{236}$ So richtig es ist, die kunsthistorische Legitimierung des Verbrechens zu beklagen: Das impliziert jedoch (wenn auch wohl ungewollt), eine Gleichsetzung von Kirche mit Wald/Wald mit Kirche könne grundsätzlich harmlos sein. Aber schon die »schwärmerische« Wald-Analogisierung um 1800 feiert die Harmonie des Beherrschten, hat den beherrschten, den reproduzierten Wald als Voraussetzung. Die Kirche ist ein streng geordneter, total gegliederter, dienender >Wald , reiner Innerlichkeit vorbehalten. Auch um 1800 wird >germanische Männlichkeit` in der Gotik (und in der Natur) entdeckt. Das geschieht in der Tat unter anderen gesellschaftlichen Voraussetzungen. Wilhelminisch geprägte Gelehrte oder Nazi-Theoretiker betreiben aber keine bloße Maskerade. Die Konstruktionen vorgeblich organischer, steinerner Gemeinschaften entstammen einer Angst vorm Lebendigen, die nur als Resultat des `Zerfalls $\measuredangle$, der Zerstörung durch Modernisierung, der Zivilisation wahrgenommen werden kann. »Der nationalsozialistische und der wilhelminische Nationalismus«, schreibt Wilhelm Reich, der »das religiöse Empfinden« als mit »mystischen, psychischen Inhalten« erfülltes ursprünglich Sexuelles versteht, ${ }^{237}$ »unterscheiden sich in ihrer massenpsychologischen Basis dadurch, daß der Nationalsozialismus einen pauperisierten Mittelstand, das deutsche Imperium hingegen einen blühenden Mittelstand als Massenbasis hatte. Das Christentum des wilhelminischen Imperialismus mußte daher ein anderes sein als das Christentum des Nationalsozialismus; doch rütteln die Abänderungen der Ideologie an den Grundlagen der Weltanschauung nicht im mindesten, sie verschärfen vielmehr ihre Funktion«. Und wenn er mit Blick auf Rosenberg feststellt, es handele sich »nur um einen Austausch der Fesseln: An die Stelle des masochistischen, internationalen, religiösen Mystizismus soll der sadistisch-narzißtische des Nationalismus treten «, ${ }^{238}$ dann lässt sich das in den in die >wilden Lande hineingerodeten` germanischen Kriegerkathedralen wiederfinden.

\section{Die Schönheit der Ruinen}

Der Wald als Kirche ist bekanntlich nicht obsolet. Auch jenseits der Titulierung zum Klischee wird die Gleichsetzung von ideologisch unverdächtigen Naturschützern und Waldbauexperten des ausgehenden 20.

236 Clemens-Schierbaum, a.a.O., S. 170.

237 Vgl. Reich, Wilhelm: Die Massenpsychologie des Faschismus, S. 148.

238 Ebda., S. $118 f$. 
Jahrhunderts häufig benutzt. Sie entspricht noch immer einer gängigen gesellschaftlichen Wahrnehmung. So beschreibt der ökologisch gesinnte Schweizer Professor für Waldbau Hans Leibundgut enthusiastisch den landschaftlichen Wert der »Heiligen Hallen ${ }^{239}$ des Buchenwalds:

»Gerade durch seinen strengen, hallenförmigen Aufbau wirkt er als Erholungsraum. Nirgends sonst empfindet man so eindrücklich das Frühlingswunder. Hier entfaltet sich die erste, nicht unruhig bunte, sondern vorwiegend weisse und gelbe Blütenpracht auf großer Fläche, und nirgends sonst empfindet man so verheissungsvoll das schwellende, drängende Grün des kommenden Frühlings. Die weiten Buchenhallen mit ihrem Dämmerlicht, den schlanken, glatten, silbergrauen Stämmen und den weitgewölbten Kronen bieten wie kein anderer Ort Entspannung in der sommerlichen Schwüle. $\ll^{240}$

Der Wald als männlicher Ort. Im »Dämmerlicht« unter dem Dach des einschichtigen Kronenschlusses ${ }^{241}$ steht man zwischen »glatten, silbergrauen« Säulen, weißen und gelben Flämmchen und erlebt das »Frühlingswunder«. All dies beschwört eine österliche Kirche herauf und hat nichts gemein mit dem »weiblichen « Wald und seiner verwirrenden, gar Ängste auslösenden »unruhigen« Buntheit, seiner »sommerlichen Schwüle«, vor der die »Heiligen Hallen« ja gerade Zuflucht gewähren. Buchenkirche: In dieser Formation präsentiert sich der Wald `von Natur aus` noch immer als Sinnbild göttlicher Ordnung - beinahe. Denn noch immer bleibt dieser Ort »instabil«, ist Wildwuchs, ist Unordnung möglich:

»Mit dem Absterben der säulenhaften Giganten brechen zunächst starke Äste, später ganze Kronen ab, so daß nur die Baumstümpfe wie mächtige Menhire stehenbleiben. $\ll^{242}$

Menhire. Auch hier nimmt der Autor Zuflucht zum religiösen Vokabular, allerdings einem paganen. So werden die Baumstümpfe zu vorchristlich bretonischen Grabmonumenten verstorbener »Giganten«.

Offenbar gibt es zwischen den Benennungen des Religiösen (in allen Schattierungen), des Transzendierenden auf der einen und des $>$ Wissenschaftlichen Folge des physikotheologischen Paradigmenwechsels in die Moderne. »Auch wenn im Laufe des 18. Jahrhunderts zunehmend Natur und Ver-

239 Scherzinger: Naturschutz im Wald, S. 78.

240 Leibundgut, Hans: Waldbau als Naturschutz, S. 27; Hvhbg. v. m.; M. T.

241 Vgl. Scherzinger, a.a.O., S. 78.

242 Ebda. 
nunft an die Stelle Gottes traten«, schreiben sie, »erbten diese Begriffe doch den metaphysischen Glanz, und das teleologische Denken, ob nun bereits säkularisiert oder nicht, wurde erst durch die Entdeckungen Darwins außer Kraft gesetzt $\ll{ }^{243}$ Das Erbe des metaphysischen Glanzes ist offenbar noch immer nicht verbraucht. Das gesellschaftliche Naturverhältnis verharrt in romantischen Anschauungen. ${ }^{244}$ Scherzinger betont immer wieder »natürliche[] Dynamik als Triebfeder der Evolution bzw. der Störereignisse als Ursache von Standorts- und Artenvielfalt«, die Naivität der bis heute in der Forstwissenschaft verbreiteten Vorstellung des »Klimax-Wald[s]«, des »)stabilen` Gleichgewichtszustand[s] ${ }^{245}$ Für den Buchenwald verwendet er trotzdem das Bild der Kathedrale. Der Wald wird transzendiert zur Weihestätte seiner selbst, tendiert damit aber zum Toten - schon gar, wenn sich dann doch etwas verändert, bewegt.

Horst Stern beschreibt den »von Menschen nicht angerührten« Rothwald der Rothschilds in Niederösterreich: »Baumriesen - Tannen, Buchen, Fichten, deren Kronen den Himmel zu tragen scheinen, so fern sind sie der Erde. Es herrscht das Dämmerlicht gotischer Dome unter ihrem Dach. Mächtige Säulen liegen gebrochen am Boden, zweifach, dreifach gekreuzt, kyklopische Barrieren gegen eindringende Menschenzwerge. Wo das Kronendach im Sturz dieser Baumsäulen aufriß und Sonnenlicht einließ, streben junge Bäume, von hundert Jahren Schatten erlöst, in die Höhe, nicht selten auf den Kadavern ihrer Altvordern wachsend, deren moderndes Holz langsam zu Humus zerfällt. Mancher Baum hebt den Anfang seines Stammes einen Meter hoch über den Boden, seine dicken Wurzeln wie Stuhlbeine unter sich: da faulte die Verwandtenleiche, auf der sein Leben begann, in Jahrzehnten unter ihm heraus.« So sieht ein Wald aus, sagt Stern, der der »oft anzutreffende[n] forstliche[n] Deklassierung als >chaotisch`, als >menschenfeindlich«« entspreche. $^{246}$ Gekreuzte, gebrochene »Säulen«, eingestürzte »Dächer«: hier wird nicht nur ein >Dom` beschrieben, sondern vielmehr seine Ruine, das »Zeichen dessen, was sie einmal als intakter Bau war«, dem jedoch »im Verfall eine neue, seltsame Schönheit« zuwächst. So schildert Hartmut Böhme die »eigenartige[] Ästhetik der Ruinen «. ${ }^{247}$ Ruinen seien gekennzeichnet durch »eine prekäre Balance von erhaltener Form

243 Groh/Groh: Weltbild und Naturaneignung, S. 117.

$244 \mathrm{Vgl}$. Ausleitung.

245 Scherzinger, a.a.O., S. 81.

246 Stern, Horst: Waldeslust gestern, heute, morgen, in: Ders. et al.: Rettet den Wald, S. 19.

247 Böhme: Die Ästhetik der Ruinen, in: Kamper/Wulf (Hg.): Der Schein des Schönen, S. 287. 
und Zerstörung, von Natur und Geschichte, Gewalt und Frieden, Erinnerung und Gegenwart, Trauer und Erlösungssehnsucht, wie sie von keinem intakten Bauwerk oder Kunstobjekt erreicht wird«. Eine Ruine »ist immer das Nutzlose; die in sie eingenistete Zerstörung dementiert den ursprünglichen Zweck «. ${ }^{248}$ Der Wald als Ruine, als Nutzloser, dessen Zustand seinen ursprünglichen Zweck dementiert. Dieser Zweck kann dann wohl nur seine Nutzung, Ausbeutung sein. Erst über das Bild der Dom-Ruine lässt sich hier die Eigenexistenz des Waldes ästhetisch begründen. Mag sein, dass Stern, analog zu Herrschaft repräsentierenden Monumentalgebäuden, die verfallen, mit dem Wald als Ruine die Ferne bzw. das Verschwinden von Herrschaft über dieses Stück >Natur` ausdrücken will. Vielleicht soll die Ruine aber auch die Geschichtlichkeit (der Waldnutzung bzw. Nichtnutzung) ausdrücken. »Wo keine Ruinen vor Augen stehen, wo Geschichte sich restlos in Natur aufgelöst hat, dort hat Erinnerung keinen Halt mehr oder muß vollständig in Schrift übergegangen sein «. ${ }^{249}$ Das Ruinenbild funktioniert aber doppelt nicht: Wenn der Wald >unberührt`, Natur sein soll, kann er nicht zur Ruine werden. Dafür muss er Bauwerk bleiben. Zugleich ist das Ruinen-Konzept eine letztlich selbst-negierende Adaption.

Der Wald als Kathedralen-Ruine ist eine Wahrnehmung, die der romantischen Ruinenkonzeption entspricht. Andrea Siegmund schreibt, die Ruine sei seit ihrer Verwendung als Bedeutungsträger in der Kunst - mit jeweils unterschiedlicher Dominanz - Zeichen für Vergänglichkeit oder für eine vergangene Epoche gewesen:

»In der Romantik verbinden sich diese zwei Grundfiguren der Ruinenwahrnehmung, indem die glorifizierte Zeit der Vergangenheit in die unerreichbare Ferne gerückt und damit gleichzeitig ein Zeichen für Vergänglichkeit an sich wird. Wie in der Aufklärung wird eine zeitlich entfernte Wunschwelt thematisiert, im Gegensatz zur Aufklärung aber die Erreichung eines dieser als ideal angesehenen Zeit entsprechenden Zustandes als unmöglich erachtet. So wird die Ruine in der Romantik einerseits - wie in der Aufklärung - mit dem Aspekt der vergangenen Wunschzeit, andererseits aber auch - wie im Barock - mit dem Aspekt der Vergänglichkeit assoziiert. « ${ }^{250}$

Siegmund beschäftigt sich zwar mit der Ruine im Landschaftsgarten, aber die Übergänge zwischen Park und Wald sind fließend; was gerade

248 Ebda.

249 Ebda., S. 289.

250 Siegmund, Andrea: Die romantische Ruine im Landschaftsgarten. Ein Beitrag zum Verhältnis der Romantik zu Barock und Klassik. Würzburg: Königshausen \& Neumann 2002, S. 13. 
auch die sentimentalen und romantischen Garten-Konzepte betrifft. Die romantische Wahrnehmung bildet hier ein selbstreferentielles System. Zum einen erscheint danach die gotische Kirche als >steinerner Wald bzw. umgekehrt, zum anderen werden in romantischen Landschaftsgärten - und bereits vorher in ssentimentalen Gärten - gotische RuinenEremitagen »in der Regel in dicht bewachsenen, waldartigen Gartenteilen errichtet ${ }^{251}{ }^{25}$ So etwa die »Meierei« auf der Berliner Pfaueninsel, gebaut als Entsprechung zum »klassischen Ort des Locus Initiationis, des >verfallenen Hauses am einsamen Ort , in welchem der Volksglaube die Seher und Weisen ansiedelt«. Gebaut als Ruine einer gotischen Kirche besteht der >Verfall auch in ihrem suggerierten "parasitären landwirtschaftlichen Gebrauch«. Im Innern erstreckt sich ein neogotischer Saal, »mit stuckierten, vielteiligen Holzgewölben überspannt«, die Fenster dienen dem »vergleichende[n] Auge« zur permanenten Ineinssetzung von Architektur und der »Fülle der grünenden, lebendigen Natur«, den »Blätterdächer[n] der lebenden Bäume« draußen. Das dient dem Beweis der »Hauptthese der romantischen Architekturtheorie«, der Entwicklung der $»$ Kunstformen der Architektur aus Analogiebildungen zum Formenrepertoire von Baum, Pflanze und Mineral «. ${ }^{252}$

Die Verbindung von gotischen Ruinen und Wald in der bildenden Kunst der ersten Hälfte des 19. Jahrhunderts dient widerstreitenden Positionen; fungiert als Signum eines Versprechens monumentaler nationaler >Wiederauferstehung Friedrichs Gemälde »Die Abtei im Eichenwald« (1809) sind Kirche und Bäume Ruinen in winterlicher Dunkelheit »am Ende aller Zeiten«, wobei sich der Himmel zu lichten beginnt, was religiöse wie nationale Hoffnung ausdrücken soll. $^{253}$

Karl Blechens Aquarell »Gotische Kirchenruine« (um 1830) dagegen scheint als Dokument der Vergeblichkeit, der Aufgabe des »epochale[n] Gedanke[ns] Friedrichs, Schinkels oder Runges« intendiert. Keine »Erhebung der Natur zu einer höheren vergeistigten Existenz in der gotischen Baukunst« mehr, »sondern nur noch der Rückfall eines bestimmten gotischen Gebäudes in Natur«, dargestellt »durch das Eindringen von Büschen und Bäumen in den architektonischen Raum, der ihren Wuchs imitiert, wie auch durch die farbliche Auflösung der kör-

251 Ebda., S. 185.

252 Pieper, Jan: Das Arkanum Pfaueninsel, in: Daidalos. Architektur Kunst Kultur. Nr. 46, Dezember 1992, S. $85 f f$.

$253 \mathrm{Vgl}$. Eschenburg, a.a.O., S. 132f. 
perlichen Substanz und ihre Überführung in grünliche und ockerfarbene Naturtöne ${ }^{254}$

Abb. 18: Karl Blechen: "Gotische Kirchenruine«, um 1830

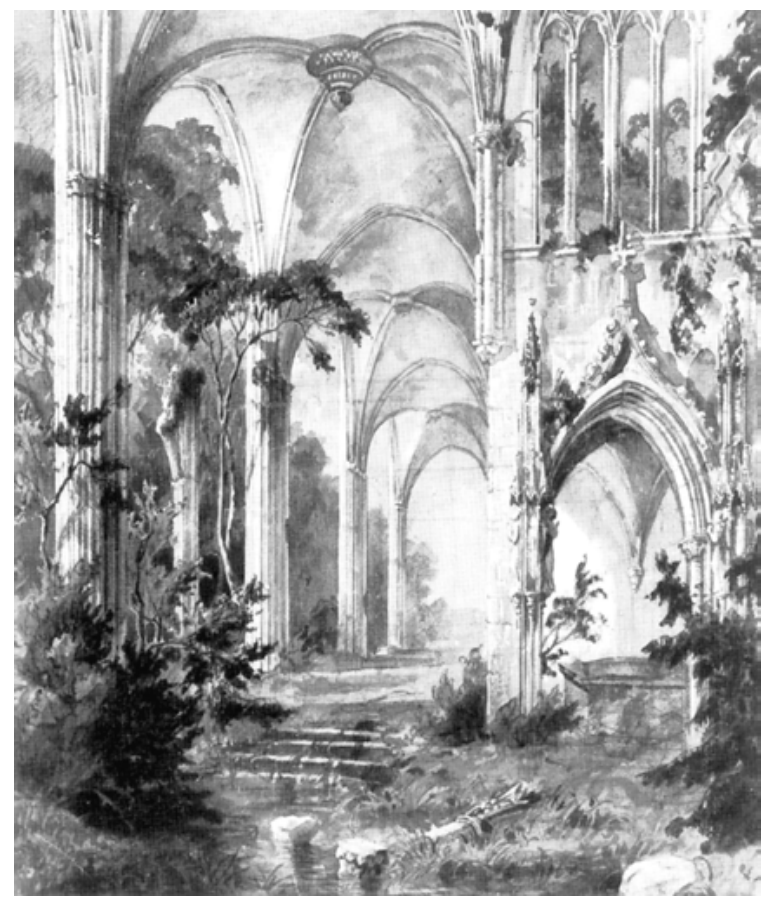

Im romantischen Landschaftsgarten kommt es programmatisch zum Bruch mit der »Harmonie« einer aufgeklärten `vernünftigen Natur`, bzw. einer Harmonie, wie sie der Landschaft noch von Herder zugeschrieben wird. »Das verweist darauf, daß die Romantik in einer Suche nach der sinnstiftenden >ganzen Natur letztlich von einem Bewußtsein der Vergeblichkeit der Sinnsuche und der >Zerrissenheit beherrscht ist«, meint Siegmund unter Hinweis auf die romantische Landschaft und ihre »untrennbare Verbindung mit dem Innern, den Gefühlen des Menschen «. ${ }^{255}$ Die Genese des »Schauerblicks« der Romantik, »der Melancholie und Schrecken« vereint, ist zurückzuführen aufs Erhabenheitskonzept der Aufklärung. Anders als hier, wo der »Schwindelblick« ausgehalten werden muss, um »die sinnlich wahrnehmbare

254 Ebda., S. 133.

255 Siegmund, a.a.O., S. 93. 
Natur unter die Größe der menschlichen Vernunft« zu unterwerfen, wird »die >dunkleく, sich der Vernunft entziehende Seite der Natur« nicht »verdrängt und aus der Ästhetik ausgegrenzt«, werden 〉Abgründe`, Zerrissenes, Bedrohliches, Unheimliches »verarbeitet und dargestellt«, in Poesie und Malerei. ${ }^{256}$

Horst Sterns »Rothwald« lässt sich lesen als Plädoyer gegen die >vernünftige Harmonie` des geregelten Forsts. Er befindet sich in einem häufigen Dilemma moderner ökologischer Argumentation zwischen dem Postulat eines Eigenwertes von Natur und der Begründung mit einem ästhetischen Wert. Die Ästhetik aber ist bestimmt durch kulturelle Überformung. Der Wald, der hier ein Organismus sein soll, bleibt so zwangsläufig Bauwerk.

In neueren Naturschutzkonzepten der Renaturierung wird die Herstellung von Ruinen-Wäldern als geeignete Maßnahme diskutiert und praktiziert. So wird für die »Erhöhung des Alt- und Totholzanteiles im Wirtschaftswald« vorgeschlagen, u.a. »einzelne Bäume so [zu] fällen, dass mannshohe Stümpfe stehen bleiben «. ${ }^{257}$ Scherzinger verweist auf den »Extremfall« solcher »Gestaltungsmaßnahmen bei [den Niederländern] Lans und Poortinga«. Sie »versuchen, einen langweiligen Forst mit Greifzug und Bulldozer zum 〉Urwald hochzufrisieren $« .{ }^{258}$ Der somit initiierte >Urwald ` wäre dann real ein Bauwerk, künstlich erzeugte Ruine als Folge >ökologischer Vernunftく. Die Kategorien verschwimmen.

Kathedralisches Gefühl, Erhabenheit der Schöpfung versus forstliche Deklassierung. Dabei wird eine Konfrontation thematisiert, die sich letztlich doch wieder aufhebt. »Als die Naturwissenschaft sich im Zuge der Säkularisation - Pantheismus, Deismus, Atheismus - aus ihrer Symbiose mit der Schöpfungstheologie löste, ihre Gegenstände nicht mehr als Werk Gottes, sondern als Werk der Natur begriffen wurden, mithin an die Stelle Gottes die Natur trat, blieb der Begriff der Natur gleichwohl mit den tradierten Bestimmungen ausgestattet. Auch wenn deren metaphysische Herkunft allmählich in Vergessenheit geriet, haben sie die moderne Naturauffassung bis in die jüngste Zeit entscheidend geprägt. « ${ }^{259}$ Womit nicht nur Ausbeutung und technische Beherrschung, wie Groh/Groh sagen, sondern auch die Reproduktion des Waldes als

256 Vgl. ebda., S. 118.

257 Willi, Georg/Broggi, Mario F.: Naturschutz im Wald. Statt lauter Holz den Wald wieder sehen, in: Hintermann, Urs et al. (Hg.): Mehr Raum für die Natur, S. 251.

258 Scherzinger, a.a.O., S. 234.

259 Groh/Groh, a.a.O., S. 50. 
Forst eine »metaphysische Rückversicherung« erhielten. Die Kathedralisierung des »unberührten Waldes« ist zumeist Abkömmling des gebauten Waldes, oder doch des als geordnet gedachten.

Am Ende sind die »Heiligen Hallen« dann ein touristischer Programmpunkt. So zeichnet sich laut »Großem ADAC Natur-Reiseführer« der gleichnamige Wald an der Mecklenburger Seenplatte durch seinen »bis zu 350 Jahre alten Buchenbestand aus. Die Bäume erreichen Stammdurchmesser von rund 1,5 m und Höhen von über $50 \mathrm{~m} \ll$. Aber, auch diese »Hallen« werden zur $>$ Ruine $<$ :

»Bis vor vier Jahrzehnten gab es kaum Unterwuchs zwischen den Baumriesen, und so hatte das Waldgebiet den Charakter einer gigantischen Halle. Heute kann man hier den Beginn der sogenannten Zerfallsphase ausmachen, einer Stufe in der natürlichen Entwicklung eines Buchenwaldes: Überalterte Bäume sterben vermehrt ab und machen jungen Buchen Platz. Neben den immer noch hallenartigen Altbeständen breiten sich deshalb auch immer stärker dschungelartige Dickichte aus «.

Das >Dschungelartige $<$ fungiert aber längst als gesuchtes schmückendes Beiwerk, gehört zum bequem und informativ ausgestatteten Ambiente. »Ein Wanderweg führt durch das 25 ha große Naturschutzgebiet, in dem Sie auch informative Schautafeln finden.« Die Anreise erfolgt per Auto und ist ausführlich beschrieben. ${ }^{260}$

\section{Bürgerliche Naturmystik}

Den Wald als >Dom` wahrzunehmen verwandelt ihn in Architektur. Das entspringt oft metaphysischen Argumenten der Ökologie, die >Schöpfung zu bewahren, was einen >höheren Baumeister` voraussetzt. Oder es benennt schlicht (auch ohne Kenntnis der Tatsachen) die Wahrheit des gebauten Wirtschaftswaldes, und entspricht den »alten bürgerlichen Zweigleisigkeiten: von rein instrumentellem und rein ästhetischem $\mathrm{Zu}-$ gang zur Natur«. Denn: »In dem Maße, wie die instrumentelle >Berührung « der Natur zum offiziellen Fortschrittsdogma wurde, verkam der ästhetische Natur-Zugang zur privat-sentimentalen Verklärung durch den Bourgeois «, sagt Großklaus. ${ }^{261}$ Der Wald als Kathedrale, das zeigt die Verbreitung des Begriffs zum Klischee, entspricht einem allgemeinen Wahrnehmungsmuster. Er ist keine bloße Metapher, sondern - phä-

260 Vgl. Der Große ADAC Natur-Reiseführer Deutschland. Faszinierende Routen zu 1300 Natursehenswürdigkeiten zwischen Rügen und Bodensee. München: ADAC-Verlag 1994, S. 120.

261 Großklaus: Natur - Raum, S. 170. 
nomenologisch ausgedrückt - eine Art des Zur-Welt-Seins. Der >Waldesdom< ist eine Form der Verwandlung vitaler Bedürfnisse in Herrschaftstechniken. Er stellt eine äußere Entsprechung zur >inneren Natur dar. Dabei geht die Naturerfahrung über eine Abriegelung durch »die erlernten psychischen Mechanismen der >Affektdämpfung` und der Triebregulierung bzw. -modulierung vom Fremden und Wilden in uns selbst« und der Abriegelung nach außen vor allem durch die »erlernten Codes der Wahrnehmung « ${ }^{262}$ hinaus. Der Wald als Sakralarchitektur ist ein Vorgang der Entlebendigung, der zugleich das Entlebte in den Rang des >wahrhaft Lebendigen< erhebt. Dass dieses Dispositiv bürgerlicher Naturerfahrung und -aneignung in der fortgeschrittenen Industriegesellschaft noch wirksam ist, stellt die Frage nach dem Wie. Dieser Wald ist einer der >Selbstbeherrschung〈, aber einer, die als Befreiung erlebt wird. Der Wald als Kathedrale hat die Erhabenheit des Sakralbauwerks zum Vorbild. Die Natur als das 〉Andere〈 wird zugleich als das `Eigene wahrgenommen. Orvar Löfgren zeigt, dass mit »der Entstehung einer rationalistischen und technologischen Naturauffassung [...], die gegen die in der bäuerlichen Kultur herrschenden >magischen` und >abergläubischen Ansichten Sturm lief«, zugleich »eine neue bürgerliche Naturmystik« entsteht. ${ }^{263}$ Diesen »in sich widersprüchlichen und mehrdimensionalen Naturbegriff« der Industriegesellschaft entfaltet er anhand der Polarisierung von Kalkül, Profit und Rationalität als Merkmal des »Produktionsleben[s]« und der Sphäre der >freien Natur als holistischem, harmonischem, »rekreative[m]« Reservat des `Auslebens der Gefühle`, der >äußeren Naturく als technisch-rational ausgebeuteter, klassifizierter, systematisch geordneter, als kontrolliertem Objekt und ihrer »romantisch-sentimentale[n] « Überhöhung. ${ }^{264}$ Bedingung sind Distanz von dieser Natur als »Produktionslandschaft « - Basis dieser Naturmystik ist die »Freizeitlandschaft«-, Urbanisierung, neue Verkehrsmittel wie Eisenbahn, später Auto, die eine rasche Erreichbarkeit, aber auch neue Sichtweisen (Kabinensituation, panoramischer Blick) hervorrufen oder verstärken, sowie eine »Zersplitterung [...] der Mensch[en] zwischen Teilwelten und neuen Polaritäten, zwischen Arbeit und Freizeit, Außenwelt und Familie, Produktion und Reproduktion«. Die Natur der Freizeitlandschaft fungiert so als »kompensatorische Sphäre« menschlicher

262 Ebda., S. 83.

263 Löfgren, Orvar: Natur, Tiere und Moral. Zur Entwicklung der bürgerlichen Naturauffassung, in: Jeggle, Utz et al. (Hg.): Volkskultur in der Moderne, S. 135.

264 Ebda., S. 143 
>Ganzheit $\iota^{265}$ Die Aufspaltung ist aber eine vordergründige. Die bevorzugt aufgesuchte $»$ nicht produktive Natur $\aleph^{266}$ - im Sinne von: nicht Bestandteil eines (agrarischen) Produktionsprozesses - entspricht der »kognitiv-symbolische[n] Karte« der »soziokulturelle[n] Orientierung und Identifikation $\ll .{ }^{267}$ Dass die aufzusuchende Landschaft real eine produzierte ist, Kulturlandschaft, zu der auch die >Wildnis` gehört, die als Freizeitlandschaft erschlossen oder angeboten wird bzw. sich innerhalb der Kulturlandschaft entwickelt hat, gehört ebenso zur Vordergründigkeit der Aufspaltung.

Die Entsprechung von >innerer` und `äußerer Natur ist eine der Beherrschung. Einer Beherrschung aber, die nicht nur repressiv, sondern auch produktiv ist (Foucault). »Sie maskiert sich, indem sie einen Diskurs produziert, der ihr anscheinend zuwiderläuft, in Wirklichkeit aber Teil ihrer weiteren Entfaltung ist. ${ }^{268}$ Was Dreyfus/Rabinow zur Auffassung Foucaults von Macht und Repressionshypothese schreiben, trifft analog auf (strikt geordnete) Kulturlandschaft und (zunehmend geforderte) Wildnis zu.

Die »Mythologie« des französischen »Guide Bleu« stamme erkennbar aus dem 19. Jahrhundert, weist Roland Barthes nach. Der Reiseführer »kennt die Landschaft kaum anders als unter der Form des Malerischen. Und malerisch ist alles, was uneben ist. Man begegnet hier der bürgerlichen Rangerhöhung des Gebirges wieder, dem alten Alpenmythos«, der mit der calvinistischen Moral verbunden sei, »und der immer wie eine bastardhafte Mischung von Naturismus und Puritanismus wirkt (Erholung durch die reine Luft, moralische Ideen beim Anblick der Gipfel, der Aufstieg als Bürgertugend usw.)«. Unter den Landschaften, die hier eine »ästhetische Existenz« erhalten, seien kaum je solche der Ebene. »Nur das Gebirge, die Schlucht, der Engpaß und der Wildbach haben Zugang zum Pantheon des Reisens, sicher deshalb, weil sie eine Moral der Mühe und der Einsamkeit zu stützen scheinen. Die Reise nach dem Blauen Führer enthüllt sich so als Kräfteersparnis, als leicht erworbenes Surrogat des Wanderns«. Damit stamme er eindeutig aus

»jener historischen Epoche, als die Bourgeoisie eine ganz neue Euphorie genoß, die darin bestand, die Mühe zu kaufen und deren Bild und deren Tugend zu bewahren, ohne ihre Last auf sich nehmen zu müssen. Es ist also im End-

265 Ebda., S. 125f. u. 130f.

266 Ebda., S. 127.

267 Großklaus, a.a.O., S. 18f.

268 Dreyfus, Hubert L./Rabinow, Paul: Michel Foucault. Jenseits von Strukturalismus und Hermeneutik. Frankfurt/M: Athenäum 1987, S. 160. 
effekt - auf sehr logische, wenngleich auch sehr törichte Weise - die Unwirtlichkeit der Landschaft, ihr Mangel an Weite oder Menschlichkeit, ihre so sehr im Gegensatz zum Glück des Reisenden stehende Unzugänglichkeit und Vertikalität, die ihre Interessantheit ausmachen. ${ }^{269}$

Die in einem solchen Reiseführer präsentierte Auswahl von - natürlichen, wie kulturellen - Denkmälern beseitige »die Wirklichkeit der Erde und zugleich die der Menschen, sie berücksichtigt nichts Gegenwärtiges, das heißt Geschichtliches, und dadurch wird das Denkmal selbst unentzifferbar und somit stumpfsinnig«. Die Geographie werde »reduziert auf die Beschreibung der unbewohnten Welt der Monumente«, was ein Festhalten an einer Mythologie zeige, »die von einem Teil der Bourgeoisie längst selbst überholt ist«. ${ }^{270}$

Barthes Text stammt von 1957. Im »Große[n] ADAC Natur-Reiseführer Deutschland« mit seinen »faszinierende[n] Routen zu $1300 \mathrm{Na}$ tursehenswürdigkeiten zwischen Rügen und Bodensee« aus den 90er Jahren und in ähnlichen Kompendien sind aber derartige Beschreibungen noch immer wiederzufinden (auch, wenn inzwischen Probleme des Umweltschutzes angesprochen werden, was aber dem >Zeitgeistく entspricht und offenbar nicht in Widerspruch zur strikten An- und Rundreise mit dem Auto steht). Auch der >Waldesdom`, die >Heiligen Hallen , inklusive ihres malerischen >Verfalls atmen noch die beschriebene »Mischung von Naturismus und Puritanismus«, die erquickende reine Luft, »moralische Ideen« beim Aufblicken ins Kronendach, der innere Nachvollzug des »Aufstieg[s] als Bürgertugend «.

Dass der >Waldesdom` als Phänomen der Wahrnehmung historisch zugleich mit dem geregelten Waldbau entsteht und mit diesem verbunden ist, habe ich mehrfach erwähnt. Diese Wahrnehmung ist also Bestandteil der technischen Zivilisation. Der Phänomenologe Phillip Thomas versucht, »unser Verhältnis zur Natur«, das »in der technischen Zivilisation in eine Krise geraten ${ }^{271}$ sei, mittels der Beschreibung »einer alternative[n] Naturerfahrung «, zu revidieren. ${ }^{272}$ Er stellt die Krise mit Heideggers »in klassischer Weise« formulierten »Technikkritik« dar. »Der Fluß ist nur noch Wasserlieferant oder treibt als >Wasserkraft Turbinen zur Stromerzeugung an, der Wald ist Forst, der Berg Stein-

269 Barthes, Roland: Mythen des Alltags. Frankfurt/M: Suhrkamp 1964 (Paris 1957), S. 59f.

270 Ebda., S. 61.

271 Thomas, Phillip: Leiblichkeit und eigene Natur. Naturphilosophische Aspekte der Leibphilosophie, in: Böhme, Gernot (Hg.): Phänomenologie der Natur. Frankfurt/M: Suhrkamp 1997, S. 291.

272 Ebda., S. 302. 
bruch.« Thomas selbst ergänzt inzwischen Hinzugekommenes: den Körper als »Organlieferanten«, die »letzte Wildnis« als »Tourismusziel«. Erstens werde die Natur »nur noch als Rohstoff« genutzt, zweitens »von Sinn« entleert, da sie »weit entfernt von konkreten Naturerfahrungen« in (populär-)wissenschaftlichen Publikationen als Ansammlung kleinster Teilchen (Atome, Gene) oder als unendliche Größe (Galaxien) erscheine. »Das Wunder des Lebens und der Natur insgesamt, das doch immer wieder fühlbar wird (in Menschen, Tieren, Pflanzen, Landschaften, im See, im Wald, beim Wandern und auch bei menschlichen Lebensvollzügen wie der Sexualität)« solle so »naturwissenschaftlich eingefangen werden. Viele Menschen sind aber enttäuscht von diesen Versuchen, denn diese können nur schwer kaschieren, daß etwas in unserem Erleben der Natur verlorengeht «. Der »Verlust « bestehe weniger »darin, daß Natur heute weder als Subjekt noch gar als etwas Beseeltes oder Heiliges gilt«, sondern »vielmehr, daß die sinnliche Erfahrung der Natur als etwas Verwandtes, Tragendes, Wunderbares oder Furchteinflößendes, als etwas, mit dem man punktuell sich eins fühlen kann« aus der dominanten naturwissenschaftlichen Perspektive »wenn nicht als etwas Mystisches, vielleicht gar Peinliches «, wenigstens aber »rein Privates gilt «. ${ }^{273}$

So beschreibt er dann den »Nachvollzug der Natur mittels des leiblichen Ich« mit diesem Beispiel:

»Betreten wir einen Hochwald, in dem die einzelnen Bäume hoch aufgeschossen, hoch aufgereckt in einigem Abstand nebeneinander stehen, die Kronen prächtig gewölbt, so wird uns merkwürdig weit, ja mitunter werden wir von dieser Atmosphäre aufgerichtet. ${ }^{274}$

Thomas nennt eine seit dem ausgehenden 18. Jahrhundert gängige Form der Wahrnehmung - also etwas, das Teil der »Krise« ist - in dem Bestreben, eine Alternative darzustellen. Mit Hermann Schmitz formuliert Thomas, dass Wahrnehmung »in diesem Falle im Grunde eine Modifikation unserer leiblichen Befindlichkeit« sei.

»Was wir dabei >am eigenen Leibe` nachvollziehen, ist der Wuchs der Bäume, ihr >Habitus`, wie es in der Botanik heißt. Ähnlich läßt sich auch ein kurz vor dem Sprung gerecktes Tier in seiner Anspannung und kraftvollen Gerichtetheit eigentlich nur leiblich nachvollziehen, weder seine Dingeigenschaften noch seine intellektuellen Leistungen sind wirklich von Bedeutung. So lassen sich

273 Ebda., S. $291 \mathrm{f}$.

274 Ebda., S. 300. 
viele Naturformen als aktuelle oder gleichsam >geronnene` Bewegungen leiblich nachvollziehen. ${ }^{275}$

Aber: Der leibliche Nachvollzug ist nichts Statisches, anthropologisch Konstantes, er unterliegt historischen Prozessen. Der von Thomas konstatierte $»$ Bruch zwischen dem einen, das lebensweltlich, und dem anderen, das wissenschaftlich als wirklich zu gelten hat « als realem »Problem des modernen Menschen ${ }^{276}$ ist oft gar keiner. Barbara Duden, die sich mit dem Verschwinden historischer Wahrnehmungsformen beschäftigt, spricht von »Denkkollektive[n] « und »wirklichkeitsmächtige[n] Embleme[n] « und zeigt, wie »eine Frau« mittels pränataler Diagnostik per Ultraschall »durch das Emblem betroffen und leibhaftig gestaltet wird «. ${ }^{277}$ Sie zeigt ebenso, dass die »erste Regung [einer] Frucht« im weiblichen Leib, die noch im 18. Jahrhundert »als bedeutungsträchtiges Erlebnis« der reale Beginn von Schwangerschaft und eines veränderten sozialen Status einer Frau darstelle, eine »vergangene Wahrnehmung« sei. Heute beginne das Gefühl der mit chemischen Reaktionen in Schwangerschaftstests. ${ }^{278}$ Auch Duden beklagt eine »Wissenschaftsgläubigkeit« als »bio bias«: die Reduktion körperlicher Erfahrung auf biologische `Fakten keit durch die Autorität des männlichen Vorurteils) « ${ }^{279}$ - denn es ist eine männliche Wissenschaft gewesen, die eine »Tradition« des intern weiblichen Austauschs über etwas, das »im Schatten oder im blinden Winkel männlicher Sinnlichkeit « ${ }^{280}$ liege, beendet hat. Aber, es geht ihr um »körperliche Wirklichkeit ${ }^{281}$ als Ort sozial-historischer Veränderungen. Was für die Wahrnehmung der sinneren Natur`zutrifft, sollte ebenso für die Wahrnehmung der >äußeren` gelten.

Auch hier wird eine >naturwissenschaftlich konstruierte Realität körperlich wahrgenommen. Albrecht Lehmann zitiert aus einer empirischen Untersuchung einen Studenten als »beispielhaft für einen ausgeprägt ökologischen Blick« und eine »heute übliche Form der Waldwahrnehmung und Waldkritik« mit den Worten: »Wenn ich irgendwo in 'ner Fichtenmonokultur rumrenne, sage ich: >Mein Gott, hier ist 'ne Wü-

275 Ebda.

276 Ebda., S. 292.

277 Duden, Barbara: Der Frauenleib als öffentlicher Ort. Vom Mißbrauch des Begriffs Leben. München: dtv 1994 (Hamburg 1991), S. 95.

278 Vgl. ebda., S. 100ff.

279 Ebda., S. 104.

280 Ebda., S. 102.

281 Ebda., S. 101. 
ste. $<$ - Aber ich frag mich halt immer im Wald, auch im Mischwald: $>$ Mein Gott, was tut sich hier ökologisch? ««. ${ }^{282}$

Noch deutlicher wird der leibliche Nachvollzug ursprünglich naturwissenschaftlicher Kategorien an anderer Stelle: »Und dann sieht man [...] Bäume vom Kopf her absterben oder von den Astenden her, kopfkrank und wie kontaktunfähig, unfähig zur Partnerschaft.« 1986 zur Hochzeit des Waldsterbens als gefürchtetes Phänomen »müssen sich auch Theologen « hiermit »auseinandersetzen" - so lautet die Begründung Harald Schweizers für das Engagement der katholisch-theologischen Fakultät der Uni Tübingen zu einer diesbezüglichen Ringvorlesung -, auch, weil »Bäume immer schon eine zentrale Rolle bei der Lebensdeutung der Menschen spielen«: Am Ende des 20. Jahrhunderts als menschliches 〉Spiegelbild«: »kopfkrank«, »kontaktunfähig«. Und weiter: »Nadelbäume lassen ihre Zweige kraftlos hängen wie schwarzes Lametta. Sarkastische Anti-Weihnacht? Im Hochsommer recken Laubbäume ihre toten Äste zum Himmel. Wandeln sich die Bäume zu Spiegelbildern von uns selbst? « ${ }^{283}$ Menschen seien Bäumen ähnlich, ebenso »eingespannt [...] zwischen Erde und Himmel; verwurzelt im Irdischen und Träger von Kronen«, betont auch Wolfgang Bartholomäus. »Abendländisches Erleben: unten die Erde, oben der Himmel; Vermittler zwischen beiden: der Baum. Das ist der Baum: in der Erde verwurzelt und an den Himmel rührend; irdisch und himmlisch zugleich; Wesen mit zwei Gesichtern. Vermittler darum auch und Verbindung zwischen Erde und Himmel. $\ll^{284}$

Gilles Deleuze und Félix Guattari haben solch omnipräsenter Hierarchisierung, der Baummetapher (die aber nicht bloße Metapher ist, sondern vielmehr >erlebbar $)$, die der Naturalisierung der sozial konstruierten Hierarchien dient, 1976 das Rhizom entgegengesetzt, die unterirdisch weitverzweigte, assimilationsfähige Sprossachse von Stauden, die an der Spitze weiterwächst, während ältere Teile allmählich absterben.

Aber auch bei Deleuze/Guattari zeigt sich hier (im Bemühen um ein antihierarchisches, >anderes Philosophieren $`$ gewissermaßen der leibli-

282 Lehmann, Albrecht: Von Menschen und Bäumen, S. 44.

283 Schweizer, Harald: Vorwort, in: Ders. (Hg.): »... Bäume braucht man doch!«, S. 7f.

284 Bartholomäus, Wolfgang: »... damit die Bäume nicht in den Himmel wachsen«. Die Metaphorik des Wachsens in der katholischen Sexualpädagogik, in: A.a.O., S. 41. 
che Nachvollzug einer zunächst naturwissenschaftlichen Begrifflichkeit. $^{285}$

Damit zurück zu den von Thomas angeführten Krisensymptomen: Flüsse als Wasserstraßen und -lieferanten, Wälder als geregelte Forsten, Orte einer quantifizierbaren Holzmenge. Was für >Forstmänner` von Bedeutung ist, ist es für FreizeitbesucherInnen nicht. Sie laufen nicht Bäume quantifizierend durch den Forst. Ihre Wahrnehmung, ob positiv oder negativ, ist eine ästhetische und eine leibliche. Die Wahrnehmung kann auch indifferent sein, weil > Wald , nach seiner sozialen Zuschreibung so aussieht, wie der durchquerte Ort. Das heißt auch: der von Thomas geschilderte leibliche Nachvollzug des Hochwalds findet im Forst statt, also in einem Raum, der Zeichen der »Krise« des Naturverhältnisses ist, zudem unterscheidet man nicht zwischen Wirtschaftswald und NichtWirtschaftswald. Für dieses `kathedralische Fühlen ist es also eigentlich unerheblich, wie `natürlich der aufgesuchte Hochwald ist.

285 Vgl. Deleuze/Guattari: Rhizom. Berlin 1977: Merve (Paris 1976). Gegen die >stehenden Heere (Canetti) setzen sie das »Nomadentum«. »Was haben denn die Nomaden gemacht? Gegen den Staatsapparat haben sie die Kriegsmaschine erfunden, die etwas ganz anderes ist als der Staatsapparat. Kriegsmaschinenrhizom gegen Staatsbaum. Der Baum ist genau die Staatsmacht. Im Laufe einer langen Geschichte war der Staat Modell für Buch und Denken: Logos, Philosophenkönig, Transzendenz der Idee, Innerlichkeit des Begriffs, Gelehrtenrepublik, Tribunal der Vernunft, das beamtete Denken, der Mensch als Gesetzgeber und Subjekt. Welche Anmaßung des Staates, das verinnerlichte Bild der Weltordnung zu sein und den Menschen zu verwurzeln.« Ebda., S. 39. 


\section{Ausleitung: Bilder dritter Ordnung}

»Was der Aufmerksamkeit entgeht, ist der Umstand, daß Bilder Leichname eines gewesenen Lebens sind. An ihnen haftet zumeist der Geruch gestorbener Liebe. Insofern sind [...] Idyllen tödlich, auch in der aktuellen Transformation des gesellschaftlichen Imaginären. $\ll^{1}$

So betrachtet Dietmar Kamper Idyllen bekanntlich als zumindest zeitweilig erträgliche Ersatzmittel, in denen »das Unerträgliche« mittels seiner Bannung ins Bild beherrscht werde, und damit die bedrohliche Mannigfaltigkeit des Lebens. Nur hier darf es erblühen, in den Grenzen, eingeschlossen und nur nach den Maßgaben dessen, der es beherrscht. ${ }^{2}$ Ästhetisierung von Herrschaft. Das Unterworfene wird als Unterworfenes - und nur als solches - zum Kunstwerk stilisiert. Dabei ist es unerheblich, ob dies den Erbauern, Nutzern, Betrachtern bewusst ist. Herrschaft als Idylle funktioniert ja, da innere und äußere Natur in ihrer sozial ebenso postulierten, wie weitgehend realisierten Erscheinungsweise analog sind.

Abschließend und ausleitend möchte ich die Strukturen und Muster zeigen, die wesentliche Bezüge der Landschaft des 19. Jahrhunderts, die als offenbar bevorzugte Kultur- und Naturschutzlandschaft der Gegenwart bezeichnet wird, in ihren Tendenzen zur Idyllisierung von >Wildnis` als Beherrschter und zugleich Konstruierter darstellen.

Im »Zielkonzept« Umweltplanung werden Landschaften zu Bildern dritter Ordnung. Sie entstehen vor dem Hintergrund »historischer Landschaftsbilder« aus der bildenden Kunst bzw. sonstiger »Leitbilder«. Diese »Leitbilder« könnten, so Ulrich Harteisen, »neben der statischen Be-

1 Kamper, Dietmar: Unmögliche Gegenwart, S. 75.

2 Vgl. ebda., S. 73f. 
standsaufnahme des Naturpotenzials« wesentliche Impulse zur »nachhaltige[n] « Landschaftsnutzung geben und erneute potentielle Leitbilder »für die Kulturlandschaft von morgen« produzieren. »Leitbilder«, was genauer auf »regionale Landschafts-Leitbilder« eingegrenzt wird, »haben in der Umweltplanung derzeit Hochkonjunktur«. Sie beruhen auf der Nennung »unverzichtbarer Qualitäten«, etwa dem Schutz »der abiotischen Ressourcen Boden, Wasser, Luft unter Verschneidung der Inhalte« mit sektorialen Leitbildern wie »Zielarten« (wildlebende Tiere und Pflanzen und ihre Lebensräume in »historisch gewachsene[r] Vielfalt «), »Wildnis« (»Entwicklung der aktuellen potentiellen natürlichen Vegetation«), insbesondere aber dem »historischen Leitbild « (Biotop- und Artenvielfalt, »regionale[s] Kulturerbe[]«, »ästhetisch reizvolle[] Landschaft $\ll){ }^{3}$ Gefordert sei eine Arbeitsmethode, mit der die Bedürfnisse von Menschen und Natur »gleichberechtigt« berücksichtigt werden. Denn der europäische Siedlungsraum sei »ein Mosaik von Kulturlandschaften, die alle bereits über eine lange Geschichte verfügen«, und erst diese »historische Komponente der Landschaft« verleihe dem Raum Identität, die Landschafts-Historizität werde »über die Kulturlandschaftsräume und -elemente erlebbar«. Die Konservierung dieser Landschaftsidentität (»Eigenart, Vielfalt und Schönheit «) verlange auch der Naturschutz ( $§ 1$ des BNatSchG). Gefordert sei ein räumlich und zeitlich orientierter Betrachtungsansatz, die Verknüpfung historisch-ökologischer und aktueller Landschaftsanalyse, sei doch die Kulturlandschaft Spiegel eines sich permanent wandelnden Mensch-Natur-Verhältnisses, zugleich auch »historisches Denkmal«, da sie sich aus in verschiedenen Epochen sozial-ökonomischer Rahmenbedingungen entstandenen Räumen und Elementen zusammensetze. Ein solch methodischer Ansatz der »Umweltplanung (zum Beispiel der Landschaftsplanung)«, wie er seit den 1970er Jahren in den Niederlanden praktiziert werde - Verknüpfung von »Arbeitsmethoden der Angewandten Historischen Geographie mit denen der Umweltplanung« - werde allerdings in Deutschland bislang »kaum verfolgt«. Dabei schärfe erst die Landnutzungsgeschichte den Blick für die Dynamik des »allgegenwärtige[n] Qualitätsverlust[es] (Verlust von Arten, Lebensräumen und ästhetischen Qualitäten)« in Kulturlandschaften. ${ }^{4}$

Leitbilder, die dazu dienen, eine gewünschte Landschaft wiederherzustellen, oder dort, wo sie den Wünschen entspricht, zu konservieren.

3 Harteisen, Ulrich: Die Bedeutung historischer Landschaftsbilder für die Umweltplanung. Kulturlandschaftsgenese der Senne - Rückblick und Perspektiven, in: Hettche/Merkel (Hg.): Waldbilder, S. 126-133.

4 Ebda., S. 151f. 
Und hier gibt es klare Vorstellungen, die sich orientieren an einer Landschaft, wie sie der Bürger zu Beginn seiner Aneignung angetroffen haben soll:

»Das Historische Leitbild, welches sich an der extensiv genutzten Kulturlandschaft Mitteleuropas des 18. und 19. Jahrhunderts orientiert, entspricht in besonderer Weise den ästhetischen Ansprüchen des Menschen an seine Umwelt. $\ll^{5}$

Abb. 19: Carl Spitzweg: Der Sonntagsspaziergang, 1841

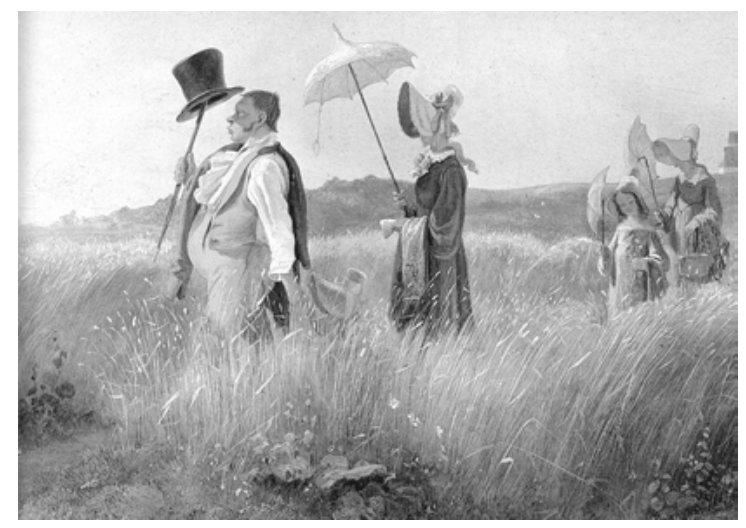

Gudrun M. König schildert die zeitgenössischen Konzepte des bürgerlichen Spaziergangs in »freye[r] Natur« als »Akte[e] moralischer Reinigung« und Aufsuchen von »Gegenbild[ern] zur einzwängenden Stadt«, zur dortigen Entfremdung, zur »Unwirtlichkeit der Zivilisation«. Auch damals gilt das ästhetische Interesse der »mannigfaltige[n] und schöne[n] Natur «, in der unterschiedliche Orte angetroffen werden sollen, denen »eine je eigene Erlebnisqualität und Erkenntnis« zustehe. So wird nach Feldern als Bildern »des menschlichen Kunstfleißes« und einer darauf gründenden Zukunftshoffnung verlangt, nach Wiesen, um »ein Gefühl ruhiger Gleichmut und stiller Zufriedenheit« zu erzeugen, Wäldern, die es gestatten, »ohne alle Störung unserer selbst und der Natur zu sein«. Diese »Annäherung des bürgerlich-städtischen Spaziergängers an die >Natur»« trage nahezu »mystische Züge«, sei als ästhetische Erfahrung Ersatz religiöser Praxis und werde »Teil seiner Orientierung in einer säkularisierten Welt«. Die »freye Natur« ist alles Nicht-Urbane, aber Kultivierte, dem zugleich mit städtischer Distanz begegnet wird,

5 Ebda., S. 127. 
»denn kein Städter wolle tauschen »mit dem Stand des Landmanns «. ${ }^{6}$ So ist dann der Spaziergang

»beileibe kein Mittel, die bürgerliche Distanz zur Natur aufzuheben, sondern er bezeichnete eben diese Distanz, er bedeutete eine Aneignung der >Natur/, die ihren Sinn der Aufrechterhaltung der Trennung dankte. Hier zeigte sich jene Nähe bei Distanz, die letztlich auch das moderne Naturgefühl bestimmt: nämlich die Illusion, Naturbeherrschung würde Unabhängigkeit von der Natur schaffen. Die bürgerliche Aneignung der Natur machte ästhetischen Genuß auf dem Spaziergang möglich und überhaupt erst nötig. Der Spaziergänger nämlich, der Nutzen und Vergnügen aus dem Erleben der Natur ziehen wollte, mußte diese decodieren . $^{7}$

Die Natur muss zum Sprechen gebracht werden, damit sie spricht, mittels Kulturtechniken, schon, um sie überhaupt aus dem Bann des nur Dahinvegetierens herauszulösen.

So betont auch Umweltplaner Harteisen: »Dynamik ist ein wichtiger >Wesenszug aller Kulturlandschaften. Im Laufe der Zeit modellieren die dynamischen Prozesse die 〉Gesichtszüge der Landschaft«« hin zu $»$ Vielfalt, Eigenart und Schönheit« ${ }^{8}$ Natur als solche demgegenüber hat keine Dynamik, keine Geschichte. Kulturlandschaft als mit zunehmender Dynamik entstandener, »keineswegs bewußt gestalteter«, ökonomischen und ästhetischen Bedürfnissen angepasster Naturraum, die »Transformation der natürlichen Ökosysteme zu naturnahen und halbnatürlichen«, schließlich auch »naturfernen Ökosystemen« sei ein zunehmend dynamischer Prozess seit ca. 7000 Jahren in Mitteleuropa, der weiter andauere. Zwar müssten streng genommen auch die »in der Neuzeit gestalteten Agrarlandschaften und Industrie- und Ballungsräume« dazu zählen. Im »Sprachgebrauch« von Umweltplanung/Naturschutz aber werde die »)Historische Kulturlandschaft〈 auf Landschaftsräume reduziert, deren gegenwärtige Biotopausstattung zum Beginn des 20. Jahrhunderts weite Teile Mitteleuropas prägten«, »traditionell extensiv« bewirtschaftet, was sie besonders für »Naturschutzstrategien« interessant mache. ${ }^{9}$

Eigenart, Vielfalt, Schönheit. Imaginationen einer als selbstverständlich vorausgesetzten Versöhnung von Kultur und Natur im Zeichen eines Gefühls des 〉Heimischseins`. Eigenart sei Ausdruck einer - noch wahrnehmbaren - historischen Entwicklung und stehe in engem Kontext

6 König, Gudrun M.: Eine Kulturgeschichte des Spaziergangs, S. 33f.

7 Ebda., S. 34.

8 Harteisen, a.a.O., S. 128.

9 Ebda., S. 127f. 
mit »Heimat und Identifikation«, wobei mit >Heimat« ein Gefühl »befriedigenderer Lebensumwelt« gemeint sei. Hinzu komme das »Bedürfnis nach sinnlicher Umwelterfahrung«, was die »Einrichtung von Naturerlebnispfaden, Waldschulen und neuerdings auch Naturerlebnisgebieten« widerspiegele und Raum für aktive Freizeitgestaltung gebe. Wie wichtig nicht nur in dieser Hinsicht Kulturlandschaft sei, sondern auch in Hinsicht auf Naturschutz, werde dadurch deutlich, dass gerade »halbnatürliche[] Biotoptypen « wie etwa trockene und feuchte Heiden, Sandmagerrasen, Feuchtwiesen, Mittel- und Niederwälder »eine herausragende Bedeutung für den Biotop- und Artenschutz« aufwiesen. ${ }^{10}$

Hier geht es um eine Erzeugung von Nähe, indem die Natur zur Kultur wird, als gezähmte korrespondierend zum gezähmten Innenleben, eben immer noch >Natur`, wenn auch nur auf eine geduldete Weise lebendig. Es ist die Aneignung des Fernen, Fremden mittels der Anpassung des Außen an das Innen als partielles abgeschirmtes Glück ${ }^{11}$ - ein Glück, das aber ausdrücklich der Abgeschirmtheit bedarf-, denn Idyllen sind

»handhabbar und der Instrumentalisierung bis zu einem gewissen Grade zugänglich. Das liegt an ihrem >Miniatur<-Charakter. Sie schaffen eine Reduktion des Überwältigenden auf ein Format, das wegen seiner Handlichkeit überschaubar und damit planbar ist.[...] Idyllen sind `klein<; sie verkleinern die Welt, die Überwelt und die Unterwelt, und kommen dem Anspruch zu herrschen entgegen. Sie bieten einen Ausschnitt und haben einen Rahmen. Ihre Realität ist flach. Aber sie täuschen den Betrachter «. ${ }^{12}$

Die Täuschung besteht in der Bedeutung der Flächen der Realität, der durchgehenden Reduktion all dessen, was sich in der Idylle zeigt, auf diese Bedeutung hin. So bleibt letztlich auch die naturnahste Landschaft ein Raum, in dem »eine abgelegte Gestalt des Lebendigen ${ }^{13}$ als Kopie, als Simulation wiederaufersteht, "um sich vor den Gefahren eines Lebens sans phrase in Sicherheit zu bringen ${ }^{14}$

Trotz aller beschworenen Lebendigkeit in der Umweltplanung: Es geht um Bilder. Und die müssen im Zweifel rekonstruiert werden. Dazu braucht es Vor-Bilder. Neben historisch-naturwissenschaftlichen Verfahren wie der Pollenanalyse (die allerdings auf in Mooren konservierten Blütenstaub angewiesen ist, archäologischen Forschungen für

10 Ebda., S. 134f.

11 Kamper, a.a.O., S. 73.

12 Ebda., S. 75

13 Ebda., S. 73.

14 Ebda. 
schriftlose prähistorische Landschaftsbilder oder »Landschaftsformen als Geschichtsquellen«, wo etwa anhand von Erosion der Einfluss auf natürliche Prozesse ermittelt werden kann, ${ }^{15}$ wird vornehmlich auf »kulturlandschaftsgenetische Quellen« zurückgegriffen. Dazu gehören archivarische Quellen, ältere Landesbeschreibungen, historische Karten, die »besondere Bedeutung « haben, da Rekonstruktionen »flächenhaft bis in das 16. Jahrhundert« möglich seien, wobei Quellenkritik (etwa bezüglich historisch bedingter Wahrnehmungs- und Gestaltungsveränderungen) unerlässlich sei, ebenso bei der Verwendung von Gemälden und Grafiken, denen Informationen über historische Landschaftsnutzung und Lebensumstände entnommen werden könnten. Landschaftsmalerei bilde zwar nach Makowski/Buderath schon seit dem späten 17. Jahrhundert »die Natur als Realität und nicht als Symbolwert« ab, aber grundsätzlich sei zu beachten, dass diese Bilder »immer eine bewußte Interpretation « beinhalten, so sei das häufige Ausklammern von Armut und sozialem Elend zu berücksichtigen. Schließlich werden Fotos herangezogen, die, was Naturmotive angehe, meist erst aus dem 20. Jahrhundert stammten, und »Sekundärquellen zur Regional-, Technik- und Sozialgeschichte eines Raumes«. ${ }^{16}$

Einer der wichtigsten Grundsätze in der Produktion von Wunschlandschaft scheint in der Entmischung zu bestehen - genauer: Einzelne Landschafts-Elemente werden nach Typen voneinander getrennt nebeneinander gestellt, und nicht kunterbunt, wild durcheinander: Niederwald (Kopfweiden) steht räumlich separiert neben Hochwald (aufragende Tannen, Buchenhallen) usw.; >halbnatürliche Biotope « neben >Wildnis`; das Ganze gleicht einem Freilichtmuseum.

In jedem Fall: Heide, Magerrasen, Mittel- und Niederwälder, »halbnatürliche Biotope« also, haben ihre Vorrangstellung nicht ohne Grund. Sie sind eindeutig durch menschliches Handeln entstanden, anthropogen geprägt, und sie sind eindeutig von der Natur bedroht, von der Sukzession. Das macht sie so wertvoll.

Wie charakterisiert Kamper Idyllen?

»Idyllen, bekannt aus Hirtendichtung und Schäferpoesie, sind Regressionen derart, daß sie einen früheren Notstand der Menschheit als ästhetische Lebensform reklamieren und ausüben. Ihre Hochwertung als gelungene Versöhnung von Natur und Kultur, zum Beispiel in der deutschen Klassik (>Am farbigen Abglanz haben wir das Leben`, Goethe) hat sich jedoch nicht lange halten können. Überhaupt ist das gewollte Paradies, der Garten mit der Mauer,

15 Vgl. Harteisen, a.a.O., S. 146ff.

16 Ebda., S. 136ff. 
hortus conclusus, locus amoenus, eine Perversion ersten Ranges, die zwangsläufig in die Hölle führt«,

denn an Idyllen

»ist historisch immer wieder demonstriert worden, daß die Herrschaft über das Unerträgliche selber unerträglich werden kann. Seltsamerweise war es bis heute nicht möglich, aus solchem Verhängnis für die Zukunft zu lernen. Im Umgang mit den Bildern bleiben die Menschen erstaunlich dumm «. ${ }^{17}$

Wie kommt es zu dieser »erstaunlichen« Dummheit? Wie Kamper selbst schreibt, ist es essentiell für den »Machtapparat«, dass Idyllen ihre Verheißungen im Begehrens-Haushalt stets erfüllen müssen; und sei es noch so »verschoben «. ${ }^{18}$ Und diese Verheißungen lösen sie ein, solange »der Machtapparat« durch alle Transformationen hindurch bestehen bleibt. Denn die Idylle, das Bild wird vom »Haushalt des Begehrens« geschaffen, ist seine Projektionsfläche und strahlt so auf ihn zurück. So, wie der »Haushalt des Begehrens« sich verändert - ohne aufzuhören, Bestandteil des »Machtapparats« bzw. selbst »Machtapparat« zu sein verändert sich seine Projektionsfläche, ohne aufzuhören, eine solche zu sein. Es ist richtig, dass »historisch immer wieder demonstriert worden« ist, »daß die Herrschaft über das Unerträgliche selbst unerträglich werden kann «, ${ }^{19}$ aber die Reaktion hierauf ist desgleichen keine Beendigung, Ablösung dieser Herrschaft - auch wenn dies behauptet wird sondern ihre Verfeinerung, Verhüllung.

Die Landschaft wird also zum Bild dritter Ordnung. Das Idealbild ist das des 19. Jahrhunderts. »Die Rodung des Waldes hatte eine Zunahme der Lebensraumvielfalt zur Folge, da zusätzlich zu den vorhandenen natürlichen Wäldern die naturnahen und halbnatürlichen Offenland-Ökosysteme entstehen konnten. Die Lebensraumvielfalt und - hiervon abhängig - die Artenvielfalt erreichten in Mitteleuropa zu Beginn des 19. Jahrhunderts ihren höchsten Stand. ${ }^{20}$ Und so orientieren sich auch die »Roten Listen der gefährdeten Arten und Biotoptypen« an der Bestandsentwicklung zu dieser Zeit, was denn auch Landschaftsgemälde von damals für die »ökologische Landschaftsanalyse« wertvoll mache. ${ }^{21}$

Offenbar aber ist die Situation in diesem 19. Jahrhundert deutlich widersprüchlicher, als das bei Harteisen erscheint. So sehr viele dunkle,

17 Kamper, a.a.O., S. 74f.

18 Ebda., S. 75.

19 Ebda.

20 Harteisen, a.a.O., S. 128.

21 Ebda., S. 143. 
geschlossene Hochwälder, deren Rodungen lichtliebenden Pflanzen neuen Lebensraum gebracht hätten, hat es offensichtlich gar nicht mehr gegeben. Stattdessen einen unaufhaltsamen Siegeszug von Nadelholz-Monokulturen, in denen von Artenvielfalt keine Rede sein kann. ${ }^{22}$ Zudem werden auch viele Tierarten rasant ausgerottet. 1835 wird etwa der letzte Wolf Westfalens bei Ascheberg erschossen, ${ }^{23}$ der letzte Luchs 1745 im Rothaargebirge. ${ }^{24}$ Otter und Biber werden ebenfalls vom Mittelalter bis ins 19. Jahrhundert - und dort besonders - »als Fischräuber bekämpft« und weitgehend ausgerottet, aber auch wegen ihres Pelzes gejagt. ${ }^{25}$

Was heißt dann Artenvielfalt? Hier sind also die erwünschten, >anmutigen Tiere gemeint. Woher weiß der intuitive Landschaftsliebhaber, wann und wo welche Artenvielfalt geherrscht haben soll? Ist das ein Kurzschluss des Leitbild-Planers von den eigenen Ergebnissen auf die Vorlieben der Bevölkerung, oder orientieren sich diese an den Ergebnissen des Experten? Am ehesten geht es wohl um eine vollständig unterworfene, >pazifizierte` Landschaft, die dem Spaziergang jederzeit zur Verfügung steht. Eine Landschaft der Romantik, die damit auch genug Nostalgie nach dem Unterworfenen, Verschwundenen beinhaltet, aber eben nur als Nostalgie. Orvar Lövgren:

$»$ Die bürgerliche Kultur erzeugt sowohl Widerwillen gegenüber der als primitiv und unkontrolliert geltenden Natur als auch Faszination angesichts der Natur als Verkörperung des Ungekünstelten, des Wilden, des Echten und Natürlichen. Aus eben dieser kulturellen Spannung erklärt sich vieles von der Komplexität der Gedanken um die innere wie die äußere Natur. ${ }^{26}$

Diese Widersprüche kommen in den Wahrnehmungen der Tierwelt »sowohl abstrakt und wissenschaftlich distanziert wie einfühlend und emotional zum Ausdruck«. Die Fauna ist einerseits biologisch-taxonomisch geordnet, was allerdings »den bürgerlichen Menschen auch ständig an seinen tierischen Hintergrund « erinnert, andererseits weitgehend auf die erwünschten, >possierlichen ^Arten dezimiert, so dass bei aller Distanz zum >Tierischen` auch moralische Qualitäten in Tieren wahrge-

22 Vgl. Bode/Hohnhorst: Waldwende, S. 83f.

23 Vgl. Tenbergen, Bernd: Westfalen im Wandel. Von der Mammutsteppe zur Agrarlandschaft. Veränderungen der Tier- und Pflanzenwelt unter dem Einfluss des Menschen. Gütersloh: Siegbert Linnemann Verlag 2002, S. 44f.

24 Vgl. ebda., S. 46f.

25 Ueckermann, Erhard: Kulturgut Jagd. Ein Führer durch die Jagdgeschichte Nordrhein-Westfalens und zu jagdhistorischen Stätten. MünsterHiltrup: Landwirtschaftsverlag 1994, S. 99.

26 Löfgren, a.a.O., S. 143f. 
nommen werden können. ${ }^{27}$ Hier scheinen viele Vögel prädestiniert, da sie über >Mittelschichttugenden` wie >Familiensinn`, >(Heimat-)Treue und >Fleiß< verfügen sollen, gar »Heldenmut im Kampf mit anderen, unerfreulichen Vögeln« zeigen, mit Raubvögeln, Aasfressern usw., die es zu dezimieren gilt. ${ }^{28}$ Solche Anthropomorphisierungen, wie sie sich auch in den oft »herzergreifenden Anekdoten« in »Brehms Tierleben« manifestieren, ${ }^{29}$ sind feste Bestandteile der »bürgerlichen Naturkunde $«$, deren weitere »wichtige Zutat» der »Gefühlsausbruch angesichts der Landschaft, der Wildnis« ist, der »häufig auf Einsamkeit basiert. Allein mit der Natur, in der Natur zu sein wird für viele ein wichtiger Teil des Landschaftserlebnisses« als Kontrast zur Menschenmenge in der Stadt. »So markant ist die Flucht des Gefühls in die Natur, daß man sie als allgemein menschlich erlebt. Das Bürgertum betrachtet sein Gefühl für die Natur als das natürliche Gefühl. « ${ }^{30}$

Ende des 19. Jahrhunderts entwickele sich so eine paradoxe Naturnutzung von Natur, die einerseits infrastrukturell domestiziert und zur »Konsumtionslandschaft« umgeformt werde, »andererseits aber« lasse man sie »verwildern« und statte sie mit Qualitäten aus, »die ihre Natürlichkeit und Primitivität, ihre Unberührtheit, betonen«. Für »den Großstadtmenschen« wird die Natur so »exotisch, und Exotik wurde zugleich domestiziert. Als nächstes wird die Natur dann natürlich. Sie symbolisiert das Echte und Unbeeinflußte im Gegensatz zu der gekünstelten, kommerziellen und vom Menschen produzierten Umwelt der Stadt «. ${ }^{31}$ Dass Lövgren so häufig von »Wildnis« spricht, hat mit der schwedischen Besonderheit im 19./20. Jahrhundert zu tun, den vorhandenen wenig besiedelten Gegenden.

Albrecht Lehmann referiert aktuelle Erwartungshaltungen an den deutschen Wald: »Mischwald« muss es sein. Nadelholz-Monokulturen gelten als »unnatürlich«, gar »unheimlich«, allemal als »ökologische Provokation«. Da herrsche »Einigkeit bis hinein in die Bevölkerungsgruppen, die den Wald nur aus dem Autofenster oder aus dem Fernsehen 〉kennen««. So wünsche sich die Mehrheit der Befragten, der Wald solle »wohlgeordnet sein, eine partielle Wildnis. - Ein richtiger Urwald paßt nicht nach Mitteleuropa ${ }^{32}$ Das Idealbild des Waldes, der Natur ist das »Panorama nach Art eines Wohnzimmerbildes«:

27 Vgl. ebda., S. 142f

28 Vgl. ebda., S. 138.

29 Vgl. ebda., S. 135.

30 Ebda., S. 131.

31 Ebda., S. 128.

32 Lehmann, Albrecht: Von Menschen und Bäumen, S. 58f. 
»Diese Form des Naturgenusses entspricht der Intention der Landschaftsmaler des 19. Jahrhunderts. Deren künstlerischer Blick auf den Wald stand auch am Anfang der Waldplanung nach Prinzipien einer Forstästhetik. Der Schöpfer dieser angewandten Kulturwissenschaft, Heinrich von Salisch, hatte sein bis heute geltendes Konzept für eine schöne Waldgestaltung als Äquivalent oder Surrogat des Kunstgenusses beschrieben. Der Wald sei, wie es Salisch ausdrückte, für den modernen Menschen, dem es an Zeit zum Theater- und Museumsbesuch mangele, eine Art Gesamtkunstwerk, zugleich Gemäldegalerie und Musentempel. $\ll^{33}$

Abb. 20: Johann Bernhard Klombeck: Waldlandschaft mit Figuren auf einem Weg an einem Bach, 1860

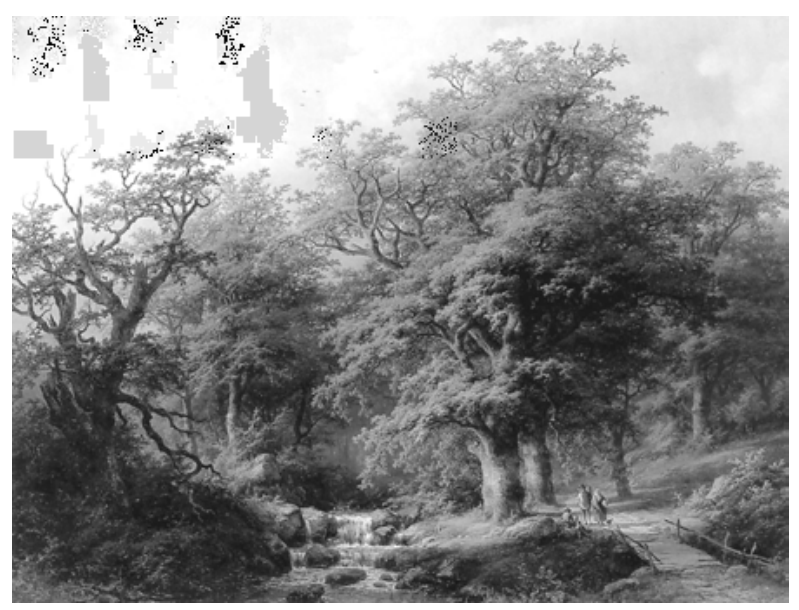

Eine der aktuell dominierenden >Wunschlandschaften〈: "partielle Wildnis« innerhalb einer als solche jederzeit erkennbaren "wohlgeordneten " Kulturlandschaft. Das Vor-Bild entstammt einer romantischen Landschaftsmalerei, die rein auf das »Gefühl « abzielt. ${ }^{34}$

33 Ebda., S. 64.

34 Als »Landschaftsmaler der Klever Romantik« steht Klombeck mit »der Wahl alltäglicher landestypischer Bildmotive« in der Tradition des niederländischen Genres des 17. Jahrhunderts. Das grenzt sich von »der weitenteils religiös inspirierten deutschen Romantik« ab, geht es doch »nicht um einen in der Landschaft durch christliche Motive ausgedrückten Erlösungshinweis, vielmehr nur ,um die Wirkung der Natur auf das Gefühl des Betrachters«. Nollert, Angelika: Johann Bernhard Klombeck - Leben und Werk, in: Städtisches Museum Haus Koekkoek Kleve (Hg.): Johann Bernhard Klombeck 1815-1893. Ein Landschaftsmaler der Klever Romantik. Kleve: Boss-Verlag 1993; S. 17 f. 
Lehmann verweist auf in den Befragungen festgestellte geschlechtsspezifische Unterschiede. Der panoramische, distanzierte Blick sei der dominante, »fast monopolisierte Blickwinkel der Männer«. Demgegenüber erscheine der weibliche Blick detailfreudig und >demokratisch $\prec$. Er sei »fast gleichberechtigt« auch auf »die Krautschicht des Waldes, auf den Moosteppich, auf Käfer und andere Kleintiere" gerichtet. »Dieser Unterschied der Sichtweise harmonisiert mit der frauenspezifischen Wahrnehmung des Waldes über >die feinen Sinne` des Gehörs und des Geruchs «. ${ }^{35}$ Sie sind also >näher dran২. Die klassischen geschlechtsspezifischen Formen der Wahrnehmungen lassen sich auch weiter nachweisen.

Das Programm der Landschaftsmalerei des 19. Jahrhunderts, der ") historischen`, >heroischen`, kurz >idealen` Landschaftsbilder[] « ${ }^{36}$ : Es weist Natur und Kunst nahezu dieselbe Funktion zu: einen »Gegensatz zum Alltag« zu bilden und dabei eine quasi medizinische Wirkung zu entfalten. ${ }^{37}$ Der Kunsttheoretiker Carl Ludwig Fernow sieht um 1800 den Menschen jeweils vorübergehend die Gesellschaft verlassen, „»um seine zerstreuten Kräfte zu sammeln und neugestärkt ins thätige Leben zurückzukehren«, empfinde sich doch das »Gemüth [...] von allen Bestimmungen frei und doch beschäftigt« angesichts von Kunst und Natur: ${ }^{38}$

»Die Aussicht in eine weite Ferne, oder in eine einsame, geschlossene Gegend, der Anblick einer erhabenen oder anmutigen, ernsten oder heiteren, ruhigen oder bewegten Naturscene, besänftigt jede leidenschaftliche Bestimmung des Gemüths, befreit es von jeder Spannung, sammelt seine zerstörten Kräfte, ladet es zur ruhigen Betrachtung ein, stärkt, erheitert und erquickt es.«

\section{Genauso wirke}

»die idealische Darstellung landschaftlicher Naturscenen auch in der Kunst; und was ihr an lebendigem Reiz und erquickender Wirklichkeit für das sinnliche Wohlgefühl abgeht, ersetzt sie der Einbildungskraft durch den in ihren Kompositionen enthaltenen poetischen Sinn; durch das Idealische, das ihre Darstellung über die Wirklichkeit erhebt, und den Geist in eine dichterische Welt versetzt $\ll .{ }^{39}$

35 Ebda., S. 65f.

36 Eberle, a.a.O., S. 216.

37 Ebda., S. 217.

38 Fernow: Über Landschaftsmalerei, in: Römische Studien, 2. Bd. Zürich 1806, S. 32 u. 25; zit. n. Eberle, ebda.

39 Fernow, a.a.O., S. 18f.; zit. n. Eberle, ebda. 
Um diese heilende, stärkende, beruhigende Wirkung zu erzielen, dürfen Natur und Kunst den Betrachter allerdings »nicht an dessen Funktion und Stellung im `thätigen Leben` erinnern. In diesem ist er `Bruchstück >Abdruck seines Geschäfts` (Schiller), >glebae adscriptus`. In der Kunst hingegen ahnt er seine Freiheit, in ihr sieht er mit Hilfe des Künstlers >die Menschheit in seiner Natur « ${ }^{40}$ Ähnlich äußert sich auch Carl Gustav Carus. ${ }^{41}$ Augenfällig geschieht das in einem historischen Zeitraum, dem 19. Jahrhundert, in dem die politische Bedeutung von $>$ Landschaft « als Ständevertretung obsolet wird. Die scheinbare Naturwüchsigkeit der Gesellschaft, ihrer Ordnung, Glieder und Mitglieder - wie noch im absolutistischen Staat - gilt nicht mehr für »das Repräsentativsystem der neuen Volksvertretungen«, den modernen Staat, die bürgerliche Gesellschaftsordnung, die Parteien. »Der einzelne Staatsbürger ist nicht mehr qua Natur in ihm enthalten, sondern der Grad seiner Integriertheit richtet sich nach der Möglichkeit seiner Einflußnahme auf sie. Wird ihm diese genommen, dann steht er dem Staat ebenso machtlos gegenüber wie der äußeren Natur. ${ }^{42}$ In dem Augenblick, in dem >Landschaft nur noch gestaltete äußere Natur, nicht mehr eine bestimmte politische Ordnung bedeutet, erscheint diese (Natur-)Landschaft als komplette Gegenwelt zur Sphäre des Politischen, zur Gesellschaft; es werden Eigengesetzlichkeiten entdeckt, auch wissenschaftlich: Haeckels Ökologie etwa. Dass in dieser Landschaft permanent Alltag stattfindet, ist in diesen Auffassungen offenbar suspendiert zugunsten einer Idylle oder Heroik. »Das Bürgertum definiert die Natur als prachtvolle Aussicht, wahre Schönheit und Echtheit«, schreibt Lövgren:

»Das Naturerlebnis wird zum Verbrauchsgut und die Landschaft zur $>v u e<, ~ z u$ einer Ansichtskarte oder einem Bild, das man von Wanderwegen, Aussichtstürmen und Rastplätzen aus betrachten und genießen kann, vielleicht aber auch bei den sonntäglichen Familienausflügen in die Kunstausstellungen der eigenen Stadt. Und dort breiten sich nun die großen Landschaften in Öl aus - mindestens ebenso prachtvoll wie die Wirklichkeit. « ${ }^{43}$

Die Landschaft gerät zunehmend in Gegensatz zur Stadt. Zum einen ist damit eine Einheit beider Topoi verneint, zum anderen gerät der Stadtbürger eben nicht zum vollständigen Bestandteil dieser Landschaft. Er sucht sie als bloß »genießender Spaziergänger « ${ }^{44}$ auf (und verlässt sie

40 Eberle, ebda.

41 Ebda., S. 22f.

42 Ebda., S. 20.

43 Löfgren, a.a.O., S. 127.

44 Eberle: Individuum und Landschaft, S. 23f. 
als solcher wieder). Die Natur wird nun im Gegensatz zur Gesellschaft zur Trägerin des >Wahren`, weil ihre Schönheit »naturgesetzlich als wahr motiviert« sei, wie Goethe meint. ${ }^{45}$ Zugleich erscheint dem Spaziergänger sein Tun als Gegenentwurf zum Teleologischen, indem er hier nicht nach einem Ziel strebt (wie sin der Gesellschaft $)$, sondern nach verlorener Harmonie. Indem die Landschaft »als Konstrukt emotional auf- und imaginär beladen wird, also gleichzeitig unberührte, kosmologische und utopische Natur symbolisiert, kann sie sin der städtischindustriellen Welt gegen diese städtisch-industrielle Welt gerichtet werden $\ll{ }^{4}{ }^{46}$

Das Idealische, das die Natur in der Darstellung über die Wirklichkeit hebt, wie Fernow sich ausdrückt, wird zum Leitbild der Bürger im ausgehenden 20. und beginnenden 21. Jahrhundert - und daher auch (trotz aller Quellenkritik) im »Zielkonzept« Umweltplanung. Das Gesamtkunstwerk Wald (Salisch) >überhöht $<$ die Natur ins >Idyllische` oder `Heroische` und trennt sie somit zuverlässig und gewünscht aus dem Alltäglichen heraus. Die inzwischen offenbar verbreiteten Aversionen gegen Nadelholz-Monokulturen dürften daher der eindeutigen Zuordnung des Holzackers zum Arbeits-Alltag entstammen.

Landschaft ist Kultur, d.h., es gibt sie nur als gemachte, bzw. ^NaturLandschaft< als gedachte, also gedanklich gemachte. Schon Georg Simmel betont den Bildcharakter von Landschaft im Gegensatz zum Wirklichkeitscharakter der Natur. Während Natur die »Einheit eines Ganzen« sei, sei Landschaft die »Abgrenzung, das Befaßtsein in einem momentanen oder dauernden Gesichtskreis«, sie »fordert [...] eine singuläre, charakterisierende Enthobenheit aus jener unzerteilbaren Einheit der Natur«. Einen »Ausschnitt aus der Natur nun seinerseits als Einheit« wahrzunehmen und nicht die »Summe einzelner Naturgegenstände« bedeute es, wenn man Natur als Landschaft betrachte. Hier »haben wir ein Kunstwerk in statu nascendi «. ${ }^{47}$ Im Landschaftsschutz, im Naturschutz (und allen anderen Schutz-Kategorien) wird das `Erscheinungsbild Ästhetik unter Schutz gestellt, nicht die >Natur২. Es geht um die Konservierung bzw. Restaurierung eines Bildes. Das ist nicht neu, aber bedeutsam. So kommentiert denn auch Manfred Smuda die Gedanken

45 Goethe an Eckermann, 5.6.1826; zit. n. Eberle, ebda., S. 10.

46 Schwarz, Astrid E.: Wasserwüste - Mikrokosmos - Ökosystem, S. 113. Binnenzitat: Hard, Gerhard: Selbstmord und Wetter, S. 263.

47 Philosophie der Landschaft, in: Brücke und Tür, hg. v. M. Susman u. M. Landman, Stuttgart 1957, S. 142ff.; zit. n. Smuda, Manfred: Natur als ästhetischer Gegenstand und als Gegenstand der Ästhetik. Zur Konstitution von Landschaft, in: Ders. (Hg.): Landschaft. Frankfurt/M: Suhrkamp 1986, S. 54. 
Simmels damit, »daß unser Landschaftssehen von der ästhetischen Erfahrung im Umgang mit der Landschaftsmalerei entscheidend mitgeprägt wird«, eine Konditionierung des Sehens, von der auch Simmel ausgehe. $^{48}$

Die Landschaftsmalerei des 19. Jahrhunderts wird zum Vor-Bild für eine zu schaffende oder zu erhaltende Landschaft. Bode/Hohnhorst bringen das in Verbindung mit der im 18. Jahrhundert grassierenden »Nutzholznot«. Nach gescheiterten Versuchen, »durch Forstpolizeigewalt (Ober- und Unterforstbediente) die Übernutzung des Waldes zu verhindern«, seien nun aus Ordnungshütern Waldbauer geworden, »zukünftig für die ausreichende Nachzucht des Holzes verantwortlich «. ${ }^{49}$ Auch »[f]orstliches Denken braucht Waldbilder «. ${ }^{50}$ »Landschaftsbilder, Waldbilder« seien »begriffliche und bildhafte Vorstellungen von Natur, wobei [...] sich Begriffe und Bilder aufeinander abbilden lassen. Es macht also gar keinen wesentlichen Unterschied, von einem Naturbegriff oder von einem Naturbild zu sprechen. Salopp könnte man sagen: Der Natur - auch der Natur im Kopf - ist es gleichgültig, wie wir sie abbilden «. ${ }^{51}$ Hubert Merkel, Professor für Waldbaugrundlagen und forstliche Biometrie, stellt heraus, »daß Wald nicht nur in einem biologischen, sondern auch in einem politischen und ökonomischen Bedeutungszusammenhang steht« und überlegt, ob nicht diejenigen, die ihn lediglich als Profitobjekt ansehen, »ein vollständigeres und damit richtigeres Waldbild« besäßen, »und vielleicht hängt die gegenwärtige Misere der mitteleuropäischen Forstwirtschaft wesentlich damit zusammen, daß wir Wald schlicht für eine Ansammlung von Bäumen halten. So gesehen wären Förster nur Gefangene ihrer Vorliebe für naive Malerei«. ${ }^{52}$

Bode/Hohnhorst beklagen vehement, dass ebenso das Bild vom mitteleuropäischen >Urwald keprägt sei von Bildern romantischer Malerei, die wiederum verwilderte Nutzwälder zum Vor-Bild nehmen. Sie illustrieren das mit einem Stich aus dem 19. Jahrhundert, auf dem unter dem Titel »Urwald im frühen Mittelalter« ein Wisent unter ১bizarren`, >knorrigenく alten Bäumen daherprescht. »Man stellte sich« also den Urwald

„so vor wie die verbliebenen und ungepflegten Mittel- und Hutewälder, die kümmerlichen Reste des einstmals prächtigen und scheinbar unerschöpflichen Urwaldes. Die Künstler der Romantik malten diesen >Urwald « mit seinem ver-

48 Vgl. Smuda, ebda., S. 54 u. 67, Anm. 27.

49 Bode/Hohnhorst: Waldwende, S. 38.

50 Merkel, Hubert: Waldbilder: Technische Zeichnungen oder Gemälde?, in: Hettche, Walter/Merkel, Hubert (Hg.): Waldbilder, S. 16.

51 Ebda., S. 18.

52 Ebda., S. 21f. 
meintlich >wilden Baumwuchs. [...] Und so ist es noch heute: Ohne, daß von forstlicher Seite Widerspruch käme, werden verwilderte Altwälder in Deutschland gern als Urwald oder urwaldartig bezeichnet und nicht selten sogar geschützt $\ll^{53}$

Derartige >Urwälder werden dann auch als bequem mit dem Auto erreichbare und mit Parkplätzen versehene Orte beschrieben: So der >Urwald am Pfrentschweiher im Fichtelgebirge: »An der stillen, fast schwermütigen Landschaft der Pfrentschwiese vorbei ostwärts wandernd, kommt man zum 〉Urwald Tschechischen Republik, wachsen vom Menschen unbeeinflußt Fichten, Kiefern, Birken und Erlen auf dem torfigen Grund des in der Mitte des 19. Jh. trockengelegten, 300 ha großen Pfrentschweihers. ${ }^{54}$ Ähnlich »Urwaldzelle und Kurpark in Braunfels/Taunus«, wobei auf die Herkunft der »Wildnis« hingewiesen wird. »Die >Urwaldzelle mit ihren Baumriesen« konnte sich »seit Jahrhunderten aus einem beweideten $\mathrm{Hu}$ tewald natürlich entwickeln«. Hier »erheben sich inmitten eines $\mathrm{Bu}$ chenwaldes 400-500jährige Eichen mit Stammdurchmessern bis zu 1,5 $\mathrm{m}$; riesige Buchen, Hainbuchen, Feldahorne und Ulmen wachsen zwischen umgestürzten, vermodernden Baumleichen und vermitteln einen Eindruck von scheinbar urtümlicher Wildnis « ${ }^{55}$

Der Begriff der »Wildnis« stamme aus Amerika, schreibt Mario F. Broggi.

»Kaum waren das wilde Nordamerika besiegt, die Indianer als Ureinwohner menschenverachtend dezimiert und die Bisons und die Wölfe systematisch abgeschlachtet, da entdeckte Amerika die Schutzwürdigkeit von Wildnis und gründete 1872 den Yellowstone-Nationalpark. Mit dem Bekenntnis zur Wildnis entstand zugleich ein Stück amerikanischer Identität. ${ }^{56}$

53 Bode/Hohnhorst, a.a.O. S. 39f. Simon Schama (a.a.O., S. 112) verweist darauf, dass derartige Wirkungen der Malerei schon der Renaissance entstammen: »Wie Christopher Wood in seiner großen Studie über Altdorfers Landschaften deutlich gemacht hat, verschwand zu der Zeit, in der der deutsche Wald als die eigentliche heimische deutsche Szenerie identifiziert wurde, ein großer Teil davon rasch unter der Axt. So mußten die Geographen, die die organische, lebendige Welt der deutschen Wälder feiern (und damit die tote Welt des römischen Mauerwerks erledigen) wollten, sie mit ihrer literarischen und visuellen Phantasie neu bepflanzen.«

54 Der Große ADAC Natur-Reiseführer, S. 630.

55 Ebda., S. 448f. Vergleichbare Beschreibungen gibt es für den nordhessischen »Urwald Sababurg« und den niedersächsischen in Nienburg. Ebda., S. 231f.

56 Broggi, Mario F.: Wildnis. Mehr Raum für die Natur, in: Hintermann, Urs et al. (Hg.): Mehr Raum für die Natur, S. 104 
In den 1960er Jahren sei das »Recht auf Wildnis gesetzlich verankert«. Rund 15 Millionen Hektar Territorium seien »inzwischen jeglicher Nutzung entzogen, und >Wilderness` ist ein gebräuchlicher Begriff geworden«. Eine Idee, die in der Schweiz »noch nicht oder nicht mehr verbreitet« sei. »Viele Leute haben Mühe, die Natur sich selbst zu überlassen«, sie werde dann als »Ödland, vergangenes Land oder Brachland« abqualifiziert, Begriffe, »die etwas Unnützes, ja Bedrohliches anzeigen«. Dabei hätten »die Naturschutzpioniere der Schweiz« exakt am 1. August 1914 ganz im amerikanischen Sinn »ein Großreservat - einen Nationalpark« gegründet. ${ }^{57}$ »Nur durch ein solches grossangelegtes Werk war zu hoffen, die noch erhalten gebliebene ursprüngliche Tierund Pflanzenwelt unseres Landes in einem bestimmten Gebiet für immer retten zu können«, schreibt damals der Zentralsekretär des »Schweizerischen Bund für Naturschutz« SBN. ${ }^{58}$ Seien in Amerika, so Broggi, »die »Naturwunder« eingerichtet worden zum »Wohl und zum Ergötzen des Volkes und der kommenden Generationen«, so sei der Schweizer Plan - als Reaktion auf Industrialisierung und Fremdenverkehr, die »Naturverödung in ihrem vollen Umfang « ${ }^{59}$ - ein »unbedingter Schutz« gewesen. »Auch die Natur gehört zum Ganzen Gottes. Es soll in ihr nichts verloren gehen. Es muss uns jedes ausgerottete Tier, jede ausgerottete Pflanze ein Schmerz sein und eine Schuld «. ${ }^{60}$

Wildnis wird dann zum Monument erklärt, wenn sie als zuverlässig überwunden gelten kann. >Wildnis` ist zulässig, gar erwünscht als $B e$ standteil eines festen Rahmens: als Teil einer gegliederten, übersichtlichen Landschaft, oder - außerhalb - im Rahmen des Tourismus: übersichtlich, zugewiesen, definiert. Beiden gemein ist, dass man sie betreten, temporär in ihnen verweilen und sie wieder verlassen kann. Man tritt scheinbar vorübergehend aus der Zivilisation heraus; tatsächlich wird sie nie verlassen. Die >Wildnis` ist fester Bestandteil ihres vorgeblichen Widerparts, der Zivilisation - und wird doch als Gegenwelt wahrgenommen. Es besteht hier ein offenbarer Zusammenhang mit dem Landschaftsgarten, auch dieser vermittelt einen scheinbar freien Wuchs. Der ist hier zwar immer als Bild gestaltet, was Eigenwuchs auch in bestimmten Grenzen oder unter Definitionen eigentlich ausschließt. Gleichwohl bildet der Landschaftsgarten das Modell und sozusagen das >Trainingsquartier` für folgende touristische oder wandernde Aneignungen >freier Natur`. Die Entstehung beider erfolgt in der gleichen

57 Ebda., S. 104ff.

58 Zit. n. ebda., S. 106.

59 Ragaz, Leonhard, in: Brunies (1914), zit. n. ebda.

60 Ragaz, Leonhard, in: Brunies (1914), zit. n. ebda. 
Epoche, unter den gleichen gesellschaftlichen Bedingungen. ${ }^{61}$ Der Landschaftsgarten entsteht als Verwirklichung eines Naturideals. Zugleich ist er der Ursprung von >Renaturierung<. In seinen »Andeutungen über Landschaftsgärtnerei« beschreibt Hermann von Pückler-Muskau, wie dieses zu bewerkstelligen sei. Hierbei geht es zuerst darum, der Kopie ein Höchstmaß an Stimmigkeit zu verleihen, d.h., Pflanzen zu verwenden, die einheimisch sind oder doch zumindest als einheimisch gelten bzw. gelten dürfen oder müssen:

»Im Park benutze ich in der Regel nur inländische oder völlig akklimatisierte Bäume und Sträucher, und vermeide gänzlich alle ausländischen Zierpflanzen; denn auch die idealisierte Natur muß dennoch immer den Charakter des Landes und Klimas tragen, wo sich die Anlage befindet, damit sie wie von selbst so erwachsen erscheinen könne, und nicht die Gewalt verrate, die ihr angetan ward. $\ll^{62}$

Die Idealisierung der Natur ist also ganz offen ein Akt der Gewaltanwendung. Der aber darf vom Resultat nicht »verraten« werden. Die >Schönheit` der geschaffenen Natur ist wie die >Schönheit` der Frau. Beiden darf man die Gewaltanwendung, die der Formgebung innewohnt, nicht anmerken. Der Landschaftsgärtner, ob Theoretiker oder Praktiker, verdingt sich als Schönheitschirurg. Er formt die Natur nach seinem Bilde - das zum Selbstbild der Geformten wird -, wozu schmerzhafte Einschnitte erforderlich sind, die jedoch im Resultat verschwinden. Denn auch die »Veränderung, die bei der Schönheitsoperation am Körper vorgenommen wurde, soll von anderen nicht als solche wahrgenommen werden. Sie soll so aussehen >wie von Natur aus` oder höchstens als eigene, erfolgreiche >Arbeit $<$ bei der Kontrolle des Körpers erscheinen «. ${ }^{63}$ Das ist die Weise, in der der Parkschöpfer aus »leidenschaftliche[r] Liebe zur Natur« diese »wie eine Geliebte besitzen, sich ihre Schönheit aneignen, sie unter seinen Willen beugen wollte - ein Bedürfnis, das ihn, den Kenner und Abgott der Frauen, zur Parkschöpfung geführt habe«. ${ }^{64}$

Ohne den beschriebenen Rahmen wäre Wildnis bedrohlich. Worauf es aber ankommt, ist die Wahrnehmung, das Erleben von Wildnis, ob-

61 Vgl. König, Gudrun M., a.a.O., S. 38ff.

62 Pückler-Muskau, Hermann Fürst von: Andeutungen über Landschaftsgärtnerei, S. 87.

63 Ensel, Angelica: Nach seinem Bilde. Schönheitschirurgie und Schöpfungsphantasien in der westlichen Medizin. Bern: eFeF-Verlag 1996, S. 23.

64 Rave, Paul Ortwin: Gärten der Goethezeit, S. 137. 
wohl es sich um Orte explizit denkmalkonservatorischer, didaktischer oder wissenschaftlicher Zielsetzung handelt. Orte, bestimmt von festen, obligatorischen Wanderwegen, die nicht verlassen werden dürfen, von Waldlehrpfaden, Hinweistafeln für Fauna und Flora, ökologische Zusammenhänge, Tafeln, die gesetzliche Grundlagen der Unterschutzstellung, Ortsgeschichte, der Park- und Benimmordnungen beinhalten, Orte, die von Biologischen Stationen u.ä. geleitet werden. Diese didaktische Wildnis erinnert nicht nur an botanische und zoologische Gärten (wobei hier oft die Sichtbarkeit von Tieren >tatsächlich`zum >Abenteuer`wird, weil anders als im normalen Zoo keine Garantie besteht), sie stammt auch aus ihnen.

Herbert Marcuse betont 1967, dass Wälder ihren Charakter als »qualitativ andere Wirklichkeit, als Gebiete des Widerspruchs« verlieren, wenn sie durch Naturschutzgebiete ersetzt werden. ${ }^{65}$ Wenn ein (selbst noch >unberührtes`) Stück Natur per Dekret, Gesetz, Vertrag zum Schutzgebiet erklärt wird, wird es damit augenblicklich in etwas anderes verwandelt. Es ist nicht mehr autonom, selbst wenn es vollständig in seiner Erscheinungsweise erhalten bleiben soll, sondern dem menschlichen Willen unterworfen, der - und nur der - nun hier bestimmt, dass diese Erscheinungsweise zu konservieren sei. Das Stück Natur wird durch diesen Willen eigentlich erst geschaffen: wenn dieser Nationalpark, jenes Naturschutzgebiet in dem und dem Jahr entstanden ist, dann legt das nahe, dass die darin enthaltene Natur bis zu diesem Zeitpunkt noch nicht dagewesen wäre.

Dass derartige >Gegenwelten` real erst gemacht werden, hat Marcuse nicht im Blick gehabt. Insofern klingt es überhaupt nicht "paradox«, dass Naturschutzgebiete »einen ebenso `künstlichen`, modellierenden Eingriff in die Landschaft« bilden, »wie reißbrettartig geplante Wohnblocks und Gewerbegebiete ${ }^{66}{ }^{6}$

65 Vgl. Marcuse, Herbert: Der eindimensionale Mensch. Studien zur Ideologie der fortgeschrittenen Industriegesellschaft. Frankfurt/M: Luchterhand 1988 (Boston/Mass 1964), S. 85f.

66 Vgl. Fischer, Norbert: Modellierte Natur. Zur Modernisierung der Landschaft im 20. Jahrhundert, in: Brednich, Wilhelm et al. (Hg.): Natur - Kultur, S. 323. 
Abb. 21: Arnold Böcklin: Herbstgedanken, 1886

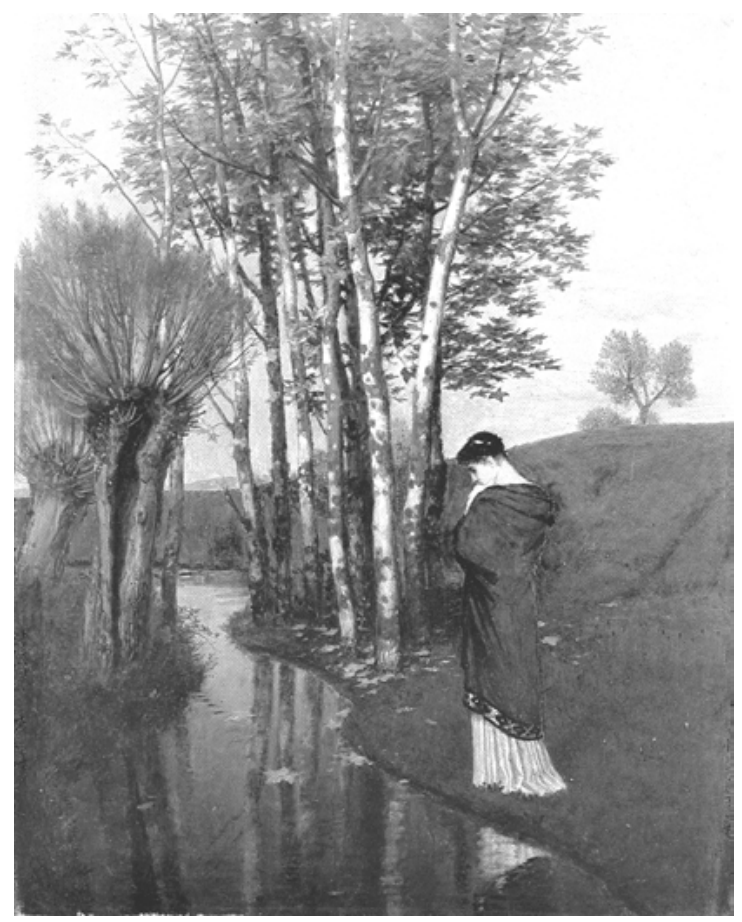

Der zweite Typ aktuell dominierender Wunschlandschaften, Kennzeichen der Entmischung und ökologische Variante bzw. Weiterentwicklung des Landschaftsgartens, Vor-Bild der >Renaturierungen läufen. Birken und Kopfweiden sorgen für ein sstimmungsvolles" Ambiente - und sind >standorttypisch ‘. Zudem gelten Kopfweiden als wertvolle >ökologische Nischen ‘. Gleichzeitig sind sie in dieser Weise ihrer ehemaligen Zugehörigkeit zum Arbeits-Alltag (Niederwald-Wirtschaft) entzogen. Im Gegensatz zum klassischen Landschaftsgarten - auch dafür steht die Kopfweide - aber ist hier die Sichtbarkeit des permanenten formgebenden Eingriffs notwendig, muss doch offenbar auch weiterhin ein seigensinniges Wuchern (die Bedrohung der szweiten Natur durch die serster) nicht nur verhindert, sondern dieses auch demonstriert weden. 



\section{Abbildungsverzeichnis}

Abb. 1, S. 83: Hieronymus Bosch: Die Versuchung des hl. Antonius (Detail des rechten Innenflügels), um 1500 (Nationalmuseum Lissabon); aus: Fraenger: Hironymus Bosch, Tafel 141

Abb. 2, S. 97: Hans Baldung Grien: Die Hexen, 1510 (Kupferstichkabinett der Staatlichen Museen zu Berlin, Inv.-Nr.: 141-1935, Foto: Jörg P. Anders) (C Bildarchiv Preußischer Kulturbesitz

Abb. 3, S. 151: Max Klinger: Eva und die Zukunft; Blatt 1: Eva, 1880 (Hamburger Kunsthalle, Kupferstichkabinett. Inv.-Nr.: 29083. Foto: Elke Walford) (C Bildarchiv Preußischer Kulturbesitz

Abb. 4, S. 173: Gustave Courbet: Der Ursprung der Welt, 1866 (Privatsammlung Paris. Foto: Musée Gustave Courbet, Ornans); aus: Schama: Der Traum von der Wildnis, S. 403

Abb. 5, S. 176: André Masson: Der Wasserfall, 1938 (Privatsammlung Paris, Foto: Comité André Masson, Paris) (C VG Bild-Kunst, Bonn 2005

Abb. 6, S. 195: Albert Eckhout: Tapuya-Frau, 1641 (The Nationalmuseum of Denmark Kopenhagen, Department of Ethnography. Inv.Nr. N 38 A 2)

Abb. 7, S. 231: Lucas Cranach d.Ä.: Faun mit Familie und erschlagenem Löwen, um 1530 (Privatbesitz Schweiz); aus Wyss, Beat: AskeSe, S. 235

Abb. 8, S.260: Albrecht Dürer: Die Einlochung Satans und die Weisung der Hl. Stadt (Apk. 20, 1 3; 21, 1-2 und 9-14), 1496-1498; aus Perrig: Albrecht Dürer, S. 169

Abb. 9, S. 306: Titelbild zu Linnés „Fauna Svevica“, 1746 (Staatsbibliothek Berlin - Preußischer Kulturbesitz. Sign.: LV 11 575) (C) Bildarchiv Preußischer Kulturbesitz 
Abb. 10, S. 339: Stich aus: William Boutcher: A Treatise on ForestTrees, 1775 (The Botany Libraries, Harvard University Cambridge/ Mass)

Abb. 11, S. 352: Illustration (Detail) aus: Philibert de 1'Orme: Le Premier Tome de l'Architecture, 1567 (Houghton Library, Harvard University Cambridge/Mass)

Abb. 12, S. 385: Hieronymus Bosch: Wälder haben Ohren, Felder haben Augen, Spätwerk (Kupferstichkabinett der Staatlichen Museen Berlin, Foto: Walter Steinkopf) (c) Bildarchiv Preußischer Kulturbesitz

Abb. 13, S. 389: Pascha Weitsch: Eichenwald bei Querum mit Selbstbildnis, 1800 (Städtisches Museum Braunschweig, Foto: Museumsfoto)

Abb. 14, S. 393: Caspar David Friedrich: Der Chasseur im Walde, 1813 (Privatsammlung Bielefeld); aus Schama, a.a.O., Tafel 13

Abb. 15, S. 394: Georg Friedrich Kersting: Auf Vorposten, 1815 (PreuBischer Kulturbesitz Nationalgalerie Berlin, Foto: Jörg P. Anders) (C) Bildarchiv Preußischer Kulturbesitz

Abb. 16, S. 514: Adolph Menzel: Missionsgottesdienst in der Buchenhalle bei Bad Kösen, 1868 (Privatbesitz, früher Berlin, Foto: Sächsische Landesbibliothek - Staats- und Universitätsbibliothek Dresden/Deutsche Fotothek)

Abb. 17, S. 562: Karl Friedrich Schinkel: Dom hinter Bäumen, 1810 (Kupferstichkabinett der Staatlichen Museen Berlin, Foto: Jörg P. Anders) (C Bildarchiv Preußischer Kulturbesitz

Abb. 18, S. 575: Karl Blechen: Gotische Kirchenruine, ca. 1830 (museum kunst palast, Düsseldorf, Foto: Landesbildstelle Rheinland)

Abb. 19, S. 587: Carl Spitzweg: Der Sonntagsspaziergang, 1841 (C) Salzburger Museum Carolino Augusteum)

Abb. 20, S. 594: Johann Bernhard Klombeck: Waldlandschaft mit Figuren auf einem Weg an einem Bach, 1860 (Stand 1993: Sammlung D. R. Dooijes, 's-Graveland. Aukt. Mak van Waay, 18./19. Feb. 1974); aus Städtisches Museum Haus Koekkoek Kleve (Hg.): Johann Bernhard Klombeck, S. 51

Abb. 21, S. 603: Arnold Böcklin: Herbstgedanken, 1886 (Privatbesitz Schweiz, Foto: Schweizerisches Institut für Kunstwissenschaft Zürich) 


\section{Bibliographie}

Adorno, Theodor W.: Ästhetische Theorie. Frankfurt/M: Suhrkamp 1990

Adorno, Theodor W.: Negative Dialektik. Frankfurt/M: Suhrkamp 1975 (1966)

Albus, Anita: Die Kunst der Künste. Erinnerungen an die Malerei. Frankfurt/M: Eichborn 1997

Allmann, Joachim: Der Wald in der frühen Neuzeit. Eine mentalitätsund sozialgeschichtliche Untersuchung am Beispiel des Pfälzer Raumes 1500-1800. Berlin: Duncker \& Humblot 1989

Andersen, Arne: Heimatschutz. Die bürgerliche Naturschutzbewegung, in: Brüggemeier, Franz-Josef/Rommelspacher, Thomas (Hg.): Besiegte Natur. München: C.H. Beck 1987; S. 143-157

Andersen, Arne: Arbeiterbewegung, Industrie und Umwelt im 19. Jahrhundert, in: Konrad, Helmut/Andersen, Arne (Hg.): Ökologie, technischer Wandel und Arbeiterbewegung; S. 69-87

Anzelewski, Fedja: Albrecht Altdorfer und das Problem der Donauschule, in: Guillaud, Jacqueline u. Maurice (Hg.): Altdorfer und der fantastische Realismus in der deutschen Kunst. Stuttgart: Klett-Cotta 1985; S. 10-47

Arbeitskreis Forstliche Landespflege in der Arbeitsgemeinschaft Forsteinrichtung: Biotop-Pflege im Wald. Ein Leitfaden für die forstliche Praxis. Greven: Kild-Verlag 1987

Authier, Michel: Die Geschichte der Brechung und Descartes' "vergessene Quellen«, in: Serres, Michel (Hg.): Elemente einer Geschichte der Wissenschaften; S. 445-485

Bacon, Francis: Neues Organon der Wissenschaften. Hg. v. Wolfgang Krohn. Lateinisch - deutsch. 2. Bde. Hamburg: Felix Meiner 1990 
Baecque, Antoine de: The »Livres remplis d'horreur«: Pornographic Literature and Politics at the Beginning of the French Revolution, in: Wagner, Peter (Ed.): Erotica and the Enlightment. Frankfurt/M u.a.: Peter Lang 1991; S. 123-165

Bätschmann, Oskar: Entfernung der Natur. Landschaftsmalerei 17501920. Köln: DuMont 1989

Barthel, Christian: Medizinische Polizey und medizinische Aufklärung. Aspekte des öffentlichen Gesundheitsdiskurses im 18. Jahrhundert. Frankfurt/M, New York: Campus 1989

Barthes, Roland: Mythen des Alltags. Frankfurt/M: Suhrkamp 1964 (Paris 1957)

Bartholomäus, Wolfgang: »... damit die Bäume nicht in den Himmel wachsen«. Die Metaphorik des Wachsens in der katholischen Sexualpädagogik, in: Schweizer, Harald (Hg.): »... Bäume braucht man doch!«; S. 41-56

Bauer, Hermann: Idee und Entstehung des Landschaftsgartens in England, in: Baumüller, Barbara et al. (Hg.): Inszenierte Natur; S. 18-37

Bauer, Leonhard/Matis, Herbert: Geburt der Neuzeit. Vom Feudalsystem zur Marktgesellschaft. München: dtv 1988

Baumann, Zygmunt: Dialektik der Ordnung. Die Moderne und der Holocaust. Hamburg: Europäische Verlags-Anstalt 1992 (Oxford 1989)

Baumüller, Barbara et al. (Hg.): Inszenierte Natur. Landschaftskunst im 19. und 20. Jahrhundert. Stuttgart: Deutsche Verlags-Anstalt 1997

Bayerl, Günter: Das Umweltproblem und seine Wahrnehmung in der Geschichte, in: Calließ, Jörg. et al. (Hg.): Mensch und Umwelt in der Geschichte; S. 47-96

Bayerl, Günter/Troitzsch, Ulrich (Hg.): Quellentexte zur Geschichte der Umwelt. Von der Antike bis heute. Göttingen, Zürich: MusterSchmidt 1998

Becker, Gabriele et al. (Hg.): Aus der Zeit der Verzweiflung. Zur Genese und Aktualität des Hexenbildes. Frankfurt/M: Suhrkamp 1977

Begemann, Christian: Furcht und Angst im Prozeß der Aufklärung. Frankfurt/M: Athenäum 1987

Belting, Hans: Bild-Anthropologie. Entwürfe für eine Bildwissenschaft. München: Wilhelm Fink Verlag 2001

Benecke, Norbert: Der Mensch und seine Haustiere. Die Geschichte einer jahrtausendealten Beziehung. Stuttgart: Theiss 1994

Benjamin, Walter: Das Kunstwerk im Zeitalter seiner technischen Reproduzierbarkeit. Frankfurt/M: Suhrkamp 1977

Benjamin, Walter: Ursprung des deutschen Trauerspiels (1925), in: Gesammelte Schriften I.1. Hg. von Rolf Tiedemann und Hermann Schweppenhäuser. Frankfurt/M: Suhrkamp 1974 
Benjamin, Walter: Charles Baudelaire. Ein Lyriker im Zeitalter des Hochkapitalismus. Hg. von Rolf Tiedemann. Frankfurt/M: Suhrkamp 1974

Benjamin, Walter: Das Passagen-Werk (1927-1940), in: Gesammelte Schriften V.1 u. V.2. Hg. v. Rolf Tiedemann. Frankfurt/M: Suhrkamp 1982

Bergmann, Anna: Die verhütete Sexualität. Die medizinische Bemächtigung des Lebens. Berlin: Aufbau Taschenbuch Verlag 1998 (Hamburg 1992)

Bessler, Gabriele: Von Nixen und Wasserfrauen. Köln: DuMont 1995

Best, Otto F.: Die blaue Blume im englischen Garten. Romantik - Ein Mißverständnis? Frankfurt/M: Fischer 1998

Beuchert, Marianne: Symbolik der Pflanzen. Frankfurt/M: Insel 1995

Bibelriether, Hans: Wald und Naturschutz, in: Stern, Horst et al.: Rettet den Wald; S. 343-360

Bibelriether, Hans: Erholung im Wald, in: Stern, Horst et al.: Rettet den Wald; S. 381-392

Bien, Günther et al. (Hg.): »Natur« im Umbruch. Zur Diskussion des Naturbegriffs in Philosophie, Naturwissenschaft und Kunsttheorie. Stuttgart-Bad Cannstatt: Frommann-Holzbog 1994

Bierende, Edgar: Lucas Cranach d.Ä. und der deutsche Humanismus. Tafelmalerei im Kontext von Rhetorik, Chroniken und Fürstenspiegeln. München, Berlin: Deutscher Kunstverlag 2002

Bitterli, Urs: Die »Wilden« und die »Zivilisierten«. Grundzüge einer Geschichte der europäisch-überseeischen Beziehungen. München: C.H. Beck 1976

Bitterli, Urs: Die exotische Insel, in: Koebner, Thomas/Pickerodt, Gerhart (Hg.): Die andere Welt; S. 11-30

Blanchard, Marc E.: Landschaftsmalerei als Bildgattung und der Diskurs der Kunstgeschichte, in: Smuda, Manfred (Hg.): Landschaft; S. 7086

Boccaccio, Giovanni: De claris mulieribus. Die großen Frauen. Lateinisch/Deutsch. Ausgewählt, übersetzt und kommentiert von Irene Erfen und Peter Schmitt. Stuttgart: Reclam 1995

Boccaccio, Giovanni: Poesie nach der Pest. Der Anfang des Decameron. Italienisch - deutsch. Neu übersetzt und erklärt von Kurt Flasch. Mainz: Dieterich 1992

Bode, Wilhelm: Der Deutsche Wald - Eine einzige Arche Noah?, in: Wolters, Jürgen, ARA (Hg.): Leben und Leben lassen. Biodiversität - Ökonomie, Natur- und Kulturschutz im Widerstreit. Gießen: Focus 1995; S. 161-182 
Bode, Wilhelm/Hohnhorst, Martin von: Waldwende. Vom Försterwald zum Naturwald. München: C.H. Beck 1994

Böhme, Gernot: Am Ende des Baconschen Zeitalters. Studien zur Wissenschaftsentwicklung. Frankfurt/M: Suhrkamp 1993

Böhme, Hartmut: Die Ästhetik der Ruinen, in: Kamper, Dietmar/Wulf, Christoph (Hg.): Der Schein des Schönen; S. 287-304

Bonnet, Anne-Marie: »Akt« bei Dürer. Köln: König 2001

Borin, Françoise: Frauenbilder, in: Duby, Georges/Perrot, Michelle (Hg.): Geschichte der Frauen. Bd. 3, Frühe Neuzeit; S. 211-271

Börner, Karl Heinz: Auf der Suche nach dem irdischen Paradies. Zur Ikonographie der geographischen Utopie. Frankfurt/M: Wörner 1984

Bourdieu, Pierre: Die feinen Unterschiede. Kritik der gesellschaftlichen Urteilskraft. Frankfurt/M: Suhrkamp $1994^{7}$ (Paris 1979)

Bovenschen, Silvia: Die aktuelle Hexe, die historische Hexe und der Hexenmythos. Die Hexe: Subjekt der Naturaneignung und Objekt der Naturbeherrschung, in: Becker, Gabriele et al. (Hg.): Aus der Zeit der Verzweiflung; S. 259-312

Bowlus, Charles R.: Die Umweltkrise im Europa des 14. Jahrhunderts, in: Sieferle, Rolf-Peter (Hg.): Fortschritte der Naturzerstörung; S. $13-30$

Brande, Arthur: Stifters Hochwald am Plöckenstein. Eine vegetationskundliche und waldgeschichtliche Analyse, in: Hettche, Walter/Merkel, Hubert (Hg.): Waldbilder; S. 47-68

Braun, Christina von: Die zwei Körper der Königin: Diana - Queen of the Media, in: Schulte, Regina (Hg.): Der Körper der Königin; S. 337-347

Braun, Christina von: Nicht ich: Logik, Lüge, Libido. Frankfurt/M: Verlag Neue Kritik 1985

Braun, Karl: Die Krankheit Onania. Körperängste und die Anfänge moderner Sexualität im 18. Jahrhundert. Frankfurt/M, New York: Campus 1995

Braun, Karl: Der Tod des Stiers. Fest und Ritual in Spanien. München: C.H. Beck 1997

Braun, Kathrin/Kremer, Elisabeth: Asketischer Eros und die Rekonstruktion der Natur zur Maschine. Oldenburg: BIS 1987

Bredekamp, Horst: Schönheit und Schrecken, in: Natur und Antike in der Renaissance. Katalog zur Ausstellung im Liebighaus - Museum alter Plastik in Frankfurt/M (5. Dezember 1985 bis 2. März 1986); S. 153-172

Bredekamp, Horst: Die zwei Körper von Thomas Hobbes' Leviathan, in: Ernst, Wolfgang/Vismann, Cornelia (Hg.): Geschichtskörper; S. 105-118 
Brednich, Wilhelm et al. (Hg.): Natur - Kultur. Volkskundliche Perspektiven auf Mensch und Umwelt. Münster u.a.: Waxmann 2001

Breger, Herbert: Die Natur als arbeitende Maschine. Zur Entstehung des Energiebegriffs in der Physik 1840-1850. Frankfurt/M, New York: Campus 1982

Bräuer, Rolf (Hg.): Dichtung des europäischen Mittelalters. Ein Führer durch die erzählende Literatur. München: C.H. Beck 1990

Breuer, Stefan: Die Gesellschaft des Verschwindens. Von der Selbstzerstörung der technischen Zivilisation. Hamburg: Junius 1992

Broggi, Mario F.: Wildnis. Mehr Raum für die Natur, in: Hintermann, Urs et al. (Hg.): Mehr Raum für die Natur; S. 103-114

Brömer, Rainer: Evolution und Verbrechen, in: Baumunk, Bodo-Michael/Rieß, Jürgen (Hg.): Darwin und Darwinismus: eine Ausstellung zur Kultur- und Naturgeschichte. Katalog des Deutschen HygieneMuseums Dresden. Berlin: Akademie Verlag 1994; S. 128-133

Bronfen, Elisabeth: Erschreckende Bilder vertrauter Art: Freuds Spiel mit einer Denkfigur, in: Lampe, Angela (Hg.): Die unheimliche Frau; S. 113-126

Brosse, Jacques: Mythologie der Bäume. Solothurn, Düsseldorf: Walter 1994 (Paris 1989)

Brüggemeier, Franz-Josef/Toyka-Seid, Michael (Hg.): Industrie-Natur. Lesebuch zur Geschichte der Umwelt im 19. Jahrhundert. Frankfurt/M, New York: Campus 1995

Bürgy, Ingrid: Wohnung der Götter und Weltenbaum. Der Baum in der germanischen Mythologie, in: Gercke, Hans (Hg.): Der Baum; S. 8285

Burckhardt, Martin: Metamorphosen von Raum und Zeit. Eine Geschichte der Wahrnehmung. Frankfurt/M, New York: Campus 1994

Burkert, Walter: Homo Necans. Interpretationen altgriechischer Opferriten. Berlin, New York: de Gruyter 1972

Burschel, Peter/Huss, Jürgen: Grundriß des Waldbaus. Ein Leitfaden für Studium und Praxis. Berlin: Parey 1997

Burschel, Peter: Der Baum als Einzelwesen, in: Stern, Horst et al.: Rettet den Wald; S. 33-62

Burschel, Peter: Der Wald als Gesellschaft von Bäumen, in: Stern, Horst et al.: Rettet den Wald; S. 63-88

Burschel, Peter: Der Wald in seiner Umwelt, in: Stern, Horst et al.: Rettet den Wald; S. 89-131

Burschel, Peter: Der Waldbau, in: Stern, Horst et al.: Rettet den Wald; S. 223-266 
Busch, Werner: Unmittelbares Naturstudium und mathematische Abstraktion bei Caspar David Friedrich, in: Howoldt, Jenns E./Schneede, Uwe M. (Hg.): Expedition Kunst; S. 17-26

Calließ, Jörg. et al. (Hg.): Mensch und Umwelt in der Geschichte. Pfaffenweiler: Centaurus 1989

Cameron, Vivian: Political Exposures: Sexuality and Caricature in the French Revolution, in: Hunt, Lynn (Hg.): Eroticism and the Body Politics. Baltimore, London: John Hopkins University Press 1990; S. 90-107

Campe, Joachim Heinrich: Väterlicher Rath für meine Tochter. Ein Gegenstück zum Thephron. Der erwachsenen weiblichen Jugend gewidmet. Braunschweig 1796 (Reprint d. 5. Aufl. Paderborn: Hüttemann 1988)

Canetti, Elias: Masse und Macht. Frankfurt/M: Fischer 1992 (1960)

Cartmill, Matt: Tod im Morgengrauen. Das Verhältnis des Menschen zu Natur und Jagd. München: Artemis \& Winkler 1993 (Cambridge/Mass, London 1993)

Chamberlain, Houston Stewart: Die Grundlagen des neunzehnten Jahrhunderts. 2 Bde. Ungekürzte Volksausgabe. München: F. Bruckmann $1942^{18}$

Chamberlain, Houston Stewart: Lebenswege meines Denkens. München: F. Bruckman $1922^{2}$

Clark, Kenneth: Landschaft wird Kunst. Köln: Phaidon-Verlag 1962 (Oxford 1949)

Classen, Carl Joachim: Die Stadt im Spiegel der Descriptiones und Laudes urbium in der antiken und mittelalterlichen Literatur bis zum Ende des zwölften Jahrhunderts. Hildesheim, New York: Olms 1980

Clausewitz, Carl von: Vom Kriege. Bonn: Dummler 1973 (Berlin 1832)

Clemens-Schierbaum, Ursula: Mittelalterliche Sakralarchitektur in Ideologie und Alltag der Nationalsozialisten. Weimar: VDG 1995

Corbin, Alain: Pesthauch und Blütenduft. Eine Geschichte des Geruchs. Berlin: Wagenbach 1984 (Paris 1982)

Corbin, Alain: Meereslust. Das Abendland und die Entdeckung der Küste. Frankfurt/M: Fischer 1994 (Paris 1988)

Costa, Maria de Fátima: Vegetation und Bergwelt Lateinamerikas, in: Howoldt, Jenns E./Schneede, Uwe M. (Hg.): Expedition Kunst; S. 179-207

Cramer, Friedrich: Das Schöne, das Schreckliche und das Erhabene. Eine chaotische Betrachtung des lebendigen Formprinzips, in: Bien, Günther et Al. (Hg.): »Natur« im Umbruch; S. 259-282

Curtius, Ernst Robert: Europäische Literatur und lateinisches Mittelalter. Bern, München: Francke 1967 (1948) 
Czerwinski, Peter: Der Glanz der Abstraktion. Frühe Formen von Reflexivität im Mittelalter. = Exempel einer Geschichte der Wahrnehmung I. Frankfurt/M, New York: Campus 1989

Czerwinski, Peter: Gegenwärtigkeit. Simultane Räume und zyklische Zeiten, Formen von Regeneration und Genealogie im Mittelalter. = Exempel einer Geschichte der Wahrnehmung II. München: Wilhelm Fink Verlag 1993

Danckert, Werner: Unehrliche Leute. Die verfemten Berufe. Bern, München: Francke 1963

Daphinoff, Dimiter: Der Wald im englischen Roman des 18. Jahrhunderts, in: Ders.: (Hg.): Der Wald. Beiträge zu einem interdisziplinären Gespräch. Freiburg/Schweiz: Universitätsverlag 1993; S. $137-$ 156

Darnton, Robert: Das große Katzenmassaker. Streifzüge durch die französische Kultur vor der Revolution. München, Wien: Hanser 1989 (New York 1984)

Daston, Lorraine: Die Lust an der Neugier in der frühneuzeitlichen Wissenschaft, in: Krüger, Klaus (Hg.): Curiositas; S. 147-175

Delaporte, François: Das zweite Naturreich. Über die Fragen des Vegetabilischen im XVIII. Jahrhundert. Frankfurt/M, Berlin, Wien: Ullstein 1983 (Paris 1979)

Deleuze, Gilles/Guattari, Félix: Anti-Ödipus. Kapitalismus und Schizophrenie I. Frankfurt/M: Suhrkamp $1992^{6}$ (Paris 1972)

Deleuze, Gilles/Guattari, Félix: Rhizom. Berlin 1977: Merve (Paris 1976)

Delumeau, Jean: Angst im Abendland. Die Geschichte kollektiver Ängste im Europa des 14. bis 18. Jahrhunderts. 2 Bände. Reinbek: Rowohlt 1985 (Paris 1978)

Der Große ADAC Natur-Reiseführer Deutschland. Faszinierende Routen zu 1300 Natursehenswürdigkeiten zwischen Rügen und Bodensee. München: ADAC-Verlag 1994

Descartes, René: Philosophische Schriften in einem Band. Hamburg: Felix Meiner 1996

Descartes, René: Über den Menschen (1625). N. d. frz. Ausgabe v. 1664 übers. und hg. v. Karl E. Rothschuh. Heidelberg: Schneider 1969

Deschner, Karlheinz: Das Kreuz mit der Kirche. Eine Sexualgeschichte des Christentums. Düsseldorf, Wien: Econ 1974

Deutsches Wörterbuch von Jacob und Wilhelm Grimm. Leipzig: Verlag von S. Hirzel 1854-1954

Diener, Pablo: Die reisenden Künstler und die Landschaftsmalerei in Iberoamerika, in: Howoldt, Jenns E./Schneede, Uwe M. (Hg.): Expedition Kunst; S. 47-55 
Dittmann, Ulrich: Waldbilder in Adalbert Stifters Studien, in: Hettche, Walter/Merkel, Hubert (Hg.): Waldbilder; S. 36-46

Dittrich, Bruno: Deutschlands Nationalparks, Naturparks und Naturreservate. Hamburg: Rasch und Röhring 1991

Douglas, Mary: Ritual, Tabu und Körpersymbolik. Sozialanthropologische Studien in Industriegesellschaft und Stammeskultur. Frankfurt/M: Suhrkamp 1981 (London 1970)

Dr. Aigremont: Volkserotik und Pflanzenwelt. Eine Darstellung alter wie moderner erotischer und sexueller Gebräuche, Vergleiche, Benennungen, Sprichwörter, Redewendungen, Rätsel, Volkslieder erotischen Zaubers und Aberglaubens, sexueller Heilkunde, die sich auf Pflanzen beziehen. Band 1 u. 2 = Rätsch, Christian: Reihe Ethnomedizin und Bewußtseinsforschung. Historische Materialien 7. Berlin: Verlag für Wissen und Bildung 1997 (Reprint v. Leipzig, Halle/S 1907-1910)

Dreyfus, Hubertus L./Rabinow, P.: Michel Foucault. Jenseits von Strukturalismus und Hermeneutik. Frankfurt/M: Athenäum 1987

Droß, Annemarie: Die erste Walpurgisnacht. Hexenverfolgung in Deutschland. Reinbek: Rowohlt 1984

Drouin, Jean-Marc: Von Linné zu Darwin: Die Forschungsreisen der Naturhistoriker, in Serres, Michel (Hg.): Elemente einer Geschichte der Wissenschaft; S. 569-595

Duby, Georges: Die Kunst des Mittelalters. - Bd. 1: Das Europa der Mönche und Ritter. 980-1140. Stuttgart - Genf 1984 - Bd. 3: Das Europa der Höfe und Städte. 1280-1440. Stuttgart, Genf: Skira, Klett-Cotta 1985 (Genf 1966)

Duby, Georges/Perrot, Michelle (Hg.): Geschichte der Frauen. Bd. 3, Frühe Neuzeit, hg. v. Arlette Farge u. Natalie Zemon Davies. Frankfurt/M, New York, Paris: Campus 1994

Duby, Georges: Das Gefährliche: die Frauen und die Toten, in: Ariès, Philippe/Ders. (Hg.): Geschichte des privaten Lebens 2. Vom Feudalzeitalter zur Renaissance. Augsburg: Bechtermünz 2000 (Paris 1985), S. 87-94

Duden, Barbara: Der Frauenleib als öffentlicher Ort. Vom Mißbrauch des Begriffs Leben. München: dtv 1994 (Hamburg 1991)

Duerr, Hans Peter: Der Mythos vom Zivilisationsprozeß. Bd. 1: Nacktheit und Scham. Bd. 2: Intimität. Bd. 3: Obszönität und Gewalt. Bd. 4: Der erotische Leib. Bd. 5: Die Tatsachen des Lebens. Frankfurt/M: Suhrkamp 1988-2002

Duerr, Hans Peter: Traumzeit. Über die Grenze zwischen Wildnis und Zivilisation. Frankfurt/M: Syndikat 1978 
Duesberg, Peter: Idylle und Freiheit. Ein Entwicklungsmodell der frühromantischen Landschaft in der Wechselwirkung von äußerer und innerer Natur. Frankfurt/M: Peter Lang 1996

Dülmen, Richard van: Gesellschaft der Frühen Neuzeit: Kulturelles Handeln und sozialer Prozess. Wien, Köln, Weimar: Böhlau 1993

Dülmen, Richard van: Norbert Elias und der Prozeß der Zivilisation. Die Zivilisationstheorie im Lichte der historischen Forschung, in: Rehberg, Karl-Siegbert (Hg.): Norbert Elias und die Menschenwissenschaften; S. 264-274

Dupke, Thomas: Mythos Löns. Heimat, Volk und Natur im Werk von Hermann Löns. Wiesbaden: Deutscher Universitäts-Verlag 1993

Eberle, Matthias: Individuum und Landschaft. Zur Entstehung und Entwicklung der Landschaftsmalerei. Gießen: Anabas-Verlag 1980

Eder, Klaus: Die Vergesellschaftung der Natur. Studien zur sozialen Evolution der praktischen Vernunft. Frankfurt/M: Suhrkamp 1988

Eggeling, Friedrich Karl von: Der Jäger als Land- und Forstwirt. Ein Leitfaden für Revierpraxis und Jägerprüfung. Hamburg, Berlin: Parey 1991

Eichberg, Henning: Stimmung über der Heide. Vom romantischen Blick zur Kolonisierung des Raums, in: Großklaus, Götz/Oldemeyer, Ernst (Hg.): Natur als Gegenwelt; S. 197-233

Elias, Norbert/Lepenies, Wolf: Zwei Reden anläßlich der Verleihung des Theodor W. Adorno-Preises 1977. Frankfurt/M: Suhrkamp 1977

Elias, Norbert: Die höfische Gesellschaft. Untersuchungen zur Soziologie des Königstums und der höfischen Aristokratie. Frankfurt/M: Suhrkamp 1989

Elias, Norbert: Wandlungen der Machtbalance zwischen den Geschlechtern am Beispiel des antiken Römerstaats; in: Völger, Gisela (Hg.): Sie und Er. Frauenmacht und Männerherrschaft im Kulturvergleich Bd. 1. Köln: Rautenstrauch-Jost-Museum 1997; S. 299-304

Elias, Norbert: Über den Prozeß der Zivilisation. Soziogenetische und psychogenetische Untersuchungen. Bd. 1: Wandlungen des Verhaltens in der weltlichen Oberschicht des Abendlandes. Bd. 2: Wandlungen der Gesellschaft. Entwurf einer Theorie der Zivilisation. Frankfurt/M: Suhrkamp $1995^{18}$ (Basel 1939)

Elias, Norbert: »Zivilisation«, in: Schäfers, Bernhard (Hg.): Grundbegriffe der Soziologie. Opladen: Westdeutscher Verlag 1995; S. $382-$ 387

Emmerling-Skala, Andreas: Bacchus in der Renaissance II. Hildesheim: Olms 1994 
Engels, Friedrich: Der Ursprung der Familie, des Privateigentums und des Staates. Im Anschluss an Lewis H. Morgans Forschungen. Berlin (O): Dietz 1969 (1884)

Engels, Friedrich: Die Lage der arbeitenden Klasse, in: MEW 21. Berlin (O): Dietz 1968

Engels, Friedrich: Brief an J. Bloch, 21./22. 9. 1890, in: MEW 37. Berlin (O): Dietz 1968

Engels, Jan Ivo: »Hohe Zeit« und »dicker Strich«: Vergangenheitsdeutung und -bewahrung im westdeutschen Naturschutz nach dem Zweiten Weltkrieg, in: Radkau, Joachim/Uekötter, Frank (Hg.): Naturschutz und Nationalsozialismus; S. 363-404

Ennen, Edith: Die Frau in der mittelalterlichen Stadt, in: Herrmann, Bernd (Hg.): Mensch und Umwelt im Mittelalter; S. 35-52.

Ensel, Angelica: Nach seinem Bilde. Schönheitschirurgie und Schöpfungsphantasien in der westlichen Medizin. Bern: eFeF-Verlag 1996

Erdheim, Mario: Unbewußtheit im Prozeß der Zivilisation, in: Rehberg, Karl-Siegbert (Hg.): Norbert Elias und die Menschenwissenschaften; S. $158-171$

Ernst, Wolfgang/Vismann, Cornelia (Hg.): Geschichtskörper. Zur Aktualität von Ernst H. Kantorowicz. München: Wilhelm Fink Verlag 1998

Eschenburg, Barbara: Landschaft in der deutschen Malerei. Vom späten Mittelalter bis heute. München: C.H. Beck 1987

Etymologisches Wörterbuch des Deutschen. Bearbeitet im Zentralinstitut für Sprachwissenschaft, Berlin. 2. Auflage, durchgesehen und ergänzt von Wolfgang Pfeiffer. Berlin: Akademie Verlag 1993

Ewinkel, Irene: De monstris. Deutung und Funktion von Wundergeburten auf Flugblättern im Deutschland des 16. Jahrhunderts. Tübingen: Niemeyer 1995

Faber, Richard: Walter Benjamins Ursprung des deutschen Trauerspiels und Ernst H. Kantorowicz' Die zwei Körper des Königs. Ein Vergleich, in: Ernst, Wolfgang/Vismann, Cornelia (Hg.): Geschichtskörper; S. 171-186

Fährmann, Sigrid: Der Göttinger Verschönerungsverein. Ein Beispiel bürgerlicher Schönheitsauffassungen und ihrer Umsetzung im 19./20. Jahrhundert, in: Brednich, Wilhelm et al. (Hg.): Natur - Kultur; S. 415-426

Fehrenbach, Frank: Leonardo da Vinci: »Mikrokosmos« und »Zweite Natur«, in: Ingensiep, Hans Werner/Hoppe-Sailer, Richard (Hg.): NaturStücke; S. 42-68 
Fischer, Hubertus: Natur, Kunst und Künstlichkeit. Adalbert Stifters Erzählung Der Waldgänger, in: Hettche, Walter/Merkel, Hubert (Hg.): Waldbilder; S. 75-89

Fischer, Ludwig: Die »Urlandschaft« und ihr Schutz, in: Radkau, Joachim/Uekötter, Frank (Hg.): Naturschutz und Nationalsozialismus; S. 181-205

Fischer, Norbert: Modellierte Natur. Zur Modernisierung der Landschaft im 20. Jahrhundert, in: Brednich, Wilhelm et al. (Hg.): Natur - Kultur, S. 317-326

Fischer-Homberger, Esther: Krankheit Frau (und andere Arbeiten zur Medizingeschichte der Frau). Bern: Huber 1979 (1969)

Forster, Georg: Ansichten vom Niederrhein. Von Brabant, Flandern, Holland, England und Frankreich im April, Mai und Juni 1790. Hg. v. Ulrich Schlemmer. Stuttgart, Wien: Erdmann 1989

Forster, Georg: Ein Blick in das Ganze der Natur. Einleitung zu Anfangsgründen der Thiergeschichte (1781), in: Kasseler Hochschulbund (Hg.): Georg Forster. Die Kasseler Jahre. Texte - Materialien Dokumente. Zusammengestellt und bearbeitet von Silvia MerzHorn. Kassel: Jenior \& Preßler 1990; S. 65-81

Forster, Georg: Über die Glückseligkeit der Lebewesen. Rede, vorgetragen anläßlich der außerordentlichen Versammlung der Gesellschaft am 16. Februar 1782, in: Kasseler Hochschulbund (Hg.): Georg Forster.; S. 47-55

Foucault, Michel: Der Wille zum Wissen. Sexualität und Wahrheit 1. Frankfurt/M: Suhrkamp 1988 (Paris 1976)

Foucault, Michel: Die Ordnung der Dinge. Eine Archäologie der Humanwissenschaften. Frankfurt/M: Suhrkamp 1974 (Paris 1966)

Foucault, Michel: Qu'est-ce qu'un auteur?, in: Bulletin de la société française de Philosophie 63 (1969), Nr. 3, S. 73-95

Foucault, Michel: Überwachen und Strafen. Die Geburt des Gefängnisses. Frankfurt/M: Suhrkamp 1989 (Paris 1975)

Foucault, Michel: Wahnsinn und Gesellschaft. Eine Geschichte des Wahns im Zeitalter der Vernunft. Frankfurt/M: Suhrkamp 1977 (Paris 1961)

Fraenger, Wilhelm: Hieronymus Bosch. Dresden, Basel: Verlag der Kunst 1994 (Dresden 1975)

Fraisse, Geneviève: Geschlechterdifferenz. Tübingen: Edition Diskord 1996 (Paris 1996)

Frankl, Paul: The Gothic. Literary Sources and Interpretations through Eight Centuries. Princeton: Princeton University Press 1960

Freud, Sigmund: Drei Abhandlungen zur Sexualtheorie, in: Studienausgabe Bd. V. Sexualleben. Frankfurt/M: Fischer 1972 
Freud, Sigmund: Neue Folge der Vorlesung zur Einführung in die Psychoanalyse, in: Gesammelte Werke Bd. XV. Frankfurt/M: Fischer 1970

Freud, Sigmund: Über die allgemeinste Erniedrigung des Liebeslebens, in: Studienausgabe Bd. V.

Frevert, Ute (Hg.): Militär und Gesellschaft im 19. und 20. Jahrhundert. Stuttgart: Klett-Cotta 1997

Frevert, Ute: Das Militär als »Schule der Männlichkeit«. Erwartungen, Angebote, Erfahrungen im 19. Jahrhundert, in: Dies. (Hg.): Militär und Gesellschaft im 19. und 20. Jahrhundert; S. 145-173

Fried, Johannes: Einleitung, in: Kantorowicz, Ernst H.: Götter in Uniform; S. 7-45

Frühe, Ursula: Das Paradies ein Garten - der Garten ein Paradies. Studien zur Literatur des Mittelalters unter Berücksichtigung der bildenden Kunst und Architektur. Frankfurt/M u.a.: Peter Lang 2002

Fumagalli, Vito: Wenn der Himmel sich verdunkelt. Lebensgefühl im Mittelalter. Berlin: Wagenbach 1988 (Bologna 1987)

Gärtner, Edgar: Arbeiterbewegung und Ökologie, in: Konrad, Helmut/Andersen, Arne (Hg.): Ökologie, technischer Wandel und Arbeiterbewegung; S. 33-44

Gebauer, Gunter: Ausdruck und Einbildung. Zur symbolischen Funktion des Körpers, in: Kamper, Dietmar/Wulf, Christoph (Hg.): Die Wiederkehr des Körpers; S. 313-329

Gendolla, Peter: Phantasien der Askese. Über die Entstehung innerer Bilder am Beispiel der »Versuchung des heiligen Antonius«. Heidelberg: Winter 1991

Gendolla, Peter: Geregeltes Begehren. Zum Verhältnis von Technologie und Sexualität, in: Kamper, Dietmar/Wulf, Christoph (Hg.): Die Wiederkehr des Körpers; S. 165-179

Gercke, Hans (Hg.): Der Baum. Heidelberg: Braus 1985

Gil, Thomas: Handlungsräume und Naturverhältnisse. Zur Kritik des ökologischen und des technokratischen Naturalismus, in: Bien, Günther et al. (Hg.): »Natur« im Umbruch; S. 79-89.

Ginzburg, Carlo: Hexensabbat. Entzifferung einer nächtlichen Geschichte. Berlin: Wagenbach 1990 (Turin 1989)

Glaser, Horst Albert: Utopische Inseln. Beiträge zu ihrer Geschichte und Theorie. Frankfurt/M u.a.: Peter Lang 1996

Gleitsmann, Rolf-Jürgen: Und immer wieder starben die Wälder. Ökosystem Wald, Waldnutzung und Energiewirtschaft in der Geschichte, in: Calließ, Jörg et al. (Hg.): Mensch und Umwelt in der Geschichte; S. $175-204$ 
Glick, Thomas F.: Naturwissenschaft, Technik und städtische Umwelt: Der »große Gestank« von 1858, in: Sieferle, Rolf Peter (Hg.): Fortschritte der Naturzerstörung; S. 95-117

Görg, Christoph: Regulation der Naturverhältnisse. Zu einer kritischen Theorie der ökologischen Krise. Münster: Westfälisches Dampfboot 2003

Goethe, Johann Wolfgang: Werke Bd. XII. Schriften zur Kunst. Schriften zur Literatur. Maximen und Reflexionen. München: dtv $1981^{9}$

Gottwald, Herwig: Natur und Kultur. Wildnis, Wald und Park in Stifters Mappe-Dichtungen, in: Hettche, Walter/Merkel, Hubert (Hg.): Waldbilder; S. 90-107

Gould, Stephen Jay: Der Daumen des Panda. Betrachtungen zur Naturgeschichte. Frankfurt/M: Suhrkamp 1989 (New York 1980)

Grimm, Jacob: Deutsche Mythologie. II. Band. Frankfurt/M, Berlin, Wien: Ullstein 1981 (Göttingen 1835)

Gröning, Gert/Schneider, Uwe: (Hg.): Gartenkultur und nationale Identität. Strategien nationaler und regionaler Identitätsstiftung in der deutschen Gartenkultur. Worms: Werner 2001

Gröning, Gert/Schneider, Uwe: Naturmystifizierung und germanische Mythologie. Die Heldenhaine, ein nationalistisches Denkmalskonzept aus dem Ersten Weltkrieg, in: Dies. (Hg.): Gartenkultur und nationale Identität; S. 94-118

Grössinger, Christa: Humour an Folly. In secular and profane prints of Northern Europe. London, Turnhout: Miller 2002

Groh, Ruth/Groh, Dieter: Weltbild und Naturaneignung. Zur Kulturgeschichte der Natur. Frankfurt/M: Suhrkamp 1991

Groh, Ruth/Groh, Dieter: Die Außenwelt der Innenwelt. Zur Kulturgeschichte der Natur 2. Frankfurt/M: Suhrkamp 1996

Groß, Matthias: Die Natur der Gesellschaft. Eine Geschichte der Umweltsoziologie. Weinheim, München: Juventa 2001

Grosser, Thomas: Neue Blicke auf die westeuropäische Kultur: Forsters Ansichten vom Niederrhein, in: Reichhardt, Rolf/Roche, Geneviève (Hg.): Weltbürger - Europäer - Deutscher - Franke. Georg Forster zum 200. Todestag. Katalog zur Ausstellung in der Universitätsbibliothek Mainz, 10. Januar-27. Februar 1994 u. Göttingen, 7. April6. Juni 1994. Mainz 1994; S. 204-222

Großklaus, Götz: Natur - Raum. Von der Utopie zur Simulation. München: Judicium 1993

Großklaus, Götz/Oldemeyer, Ernst (Hg.): Natur als Gegenwelt. Beiträge zur Kulturgeschichte der Natur. Karlsruhe: van Loeper 1983

Großklaus, Götz: Der Naturraum des Kulturbürgers, in: Ders./Oldemeyer, Ernst (Hg.): Natur als Gegenwelt; S. 169-196 
Grünewald, Eckhart: »Aber wer riskiert schon, brotlos zu werden? Nur mutige Leute.« Eckhart Grünewald im Gespräch mit Robert L. Benson, in: Ders. et al. (Hg.): Ernst H. Kantorowicz: Götter in Uniform; S. $349-368$

Grupe, Gisela: Umwelt und Bevölkerungsentwicklung im Mittelalter, in: Herrmann, Bernd (Hg.): Mensch und Umwelt im Mittelalter; S. 2434

Gülpen, Ilonka van: Der deutsche Humanismus und die frühe Reformations-Propaganda 1520-1526. Das Lutherporträt im Dienst der Bildpublizistik. Hildesheim u.a.: Olms 2002

Hagemann, Karen: Heldenmütter, Kriegerbräute und Amazonen. Entwürfe »patriotischer« Weiblichkeit zur Zeit der Freiheitskriege, in: Frevert, Ute (Hg.): Militär und Gesellschaft im 19. und 20. Jahrhundert; S. 174-200

Hamburger, Jeffrey F.: Idol Curiosity, in: Krüger, Klaus (Hg.): Curiositas; S. 19-58

Haraway, Donna: Die Neuerfindung der Natur. Primaten, Cyborgs und Frauen. Hg. u. eingeleitet Hammer, Carmen/Stieß, Immanuel. Frankfurt/M, New York: Campus 1995 (Original 1983-1989)

Harrison, Robert Pogue: Wälder. Ursprung und Spiegel der Kultur. München, Wien: Hanser 1992

Harteisen, Ulrich: Die Bedeutung historischer Landschaftsbilder für die Umweltplanung. Kulturlandschaftsgenese der Senne - Rückblick und Perspektiven, in: Hettche, Walter/Merkel, Hubert (Hg.): Waldbilder; S. 126-156

Haß, Petra: Der locus amoenus in der antiken Literatur: Zur Theorie und Geschichte eines literarischen Motivs. Bamberg: WVB 1998

Häusl, Maria: Bilder der Not. Weiblichkeits- und Geschlechtermetaphorik im Buch Jeremia. Freiburg/Br u.a.: Herder 2003

Hausrath, Hans: Geschichte des deutschen Waldbaus. Von seinen Anfängen bis 1850. Freiburg/Br: Hochschulverlag 1982

Hegel, Georg Friedrich Wilhelm: Vorlesung über die Ästhetik. II. Bd., in: Sämtliche Werke Bd. 13. Stuttgart: Fromman 1953

Heinrich, Klaus: Das Floß der Medusa, in: Schlesier, Renate (Hg.): Faszination des Mythos. Studien zu antiken und modernen Interpretationen. Basel, Frankfurt/M: Stroemfeld 1985; S. 335-398

Helas, Philine: Madensack und Mutterschoß. Zur Bildgeschichte des Bauches in der Renaissance, in: Benthien, Claudia/Wulf, Christoph (Hg.): Körperteile. Eine kulturelle Anatomie. Reinbek: Rowohlt 2001

Hennebo, Dieter: Gärten des Mittelalters. München, Zürich: ArtemisVerlag 1987 
Hergemöller, Bernd-Ulrich: Krötenkuß und schwarzer Kater. Ketzerei, Götzendienst und Unzucht in der inquisitorischen Phantasie des 13. Jahrhunderts. Warendorf: Fahlbusch 1996

Hergemöller, Bernd-Ulrich: Masculus et femina: Systematische Grundlinien einer mediävistischen Geschlechtergeschichte. Hamburg: HHL-Verlag 2001

Hermand, Jost: Grüne Utopien in Deutschland. Zur Geschichte des ökologischen Bewußtseins. Frankfurt/M: Fischer 1991

Herrmann, Bernd (Hg.): Mensch und Umwelt im Mittelalter. Stuttgart: Deutsche Verlags-Anstalt 1987

Hettche, Walter/Merkel, Hubert (Hg.): Waldbilder. Beiträge zum Interdisziplinären Kolloquium »Da ist Wald und Wald und Wald « (Adalbert Stifter). Göttingen, 19. und 20. März 1999/Fachbereich Forstwirtschaft und Umweltmanagement der Fachhochschule Hildesheim - Holzminden - Göttingen. München: Judicium 2000

Hettche, Walter: Der Wald im Text, der Wald als Text. Aspekte der Walddarstellung in Stifters Erzählwerk, in: Ders./Merkel, Hubert (Hg.): Waldbilder; S. 26-35

Heubach, Friedrich W.: Das bedingte Leben. Theorie der psycho-logischen Gegenständlichkeit der Dinge. Ein Beitrag zur Psychologie des Alltags. München: Wilhelm Fink Verlag 1996

Heuwinkel, Christiane: Surrealistische Frauenbilder, in: Lampe, Angela (Hg.): Die unheimliche Frau; S. 49-112

Hille, Karoline: »... über den Grenzen, mitten in Nüchternheit«. Prothesenkörper, Maschinenherzen, Automatenhirne, in: Müller-Tamm, Pia/Sykora, Katharina (Hg.): Puppen - Körper - Automaten; S. 140159

Hiller, Hubertus: Jäger und Jagd. Zur Entwicklung des Jagdwesens in Deutschland zwischen 1848 und 1914. Münster: Waxmann 2003

Hintermann, Urs et al. (Hg.): Mehr Raum für die Natur. Ziele, Lösungen, Visionen im Naturschutz. Thun: Ott 1995

Hobbes, Thomas: Leviathan oder Stoff, Form und Gewalt eines bürgerlichen und kirchlichen Staates. Hg. von Iring Fetscher. Frankfurt/M, Berlin, Wien: Ullstein 1976

Hoffmann, Konrad: Der Lebensbaum des Totengarten. Zur Vorgeschichte des Friedhofs, in: Schweizer, Harald (Hg.): »... Bäume braucht man doch!«; S. 187-197

Hofmann, Frank et al.: Waldnutzung in Deutschland. Bestandsaufnahmen, Handlungsbedarf und Maßnahmen zur Umsetzung des Leitbildes einer nachhaltigen Entwicklung. = Materialien zur Umweltforschung herausgegeben vom Rat von Sachverständigen für Umweltfragen Nr. 35. Stuttgart 2000 
Hofmann, Werner: Das irdische Paradies. Kunst im 19. Jahrhundert. München: Prestel 1960

Hofmann, Werner (Hg.): Eva und die Zukunft. Das Bild der Frau seit der französischen Revolution. München: Prestel 1986

Holland-Cunz, Barbara: Soziales Subjekt Natur. Natur- und Geschlechterverhältnis in emanzipatorischen politischen Theorien. Frankfurt/M, New York: Campus 1994

Holzberg, Niklas: »Ihres Aeneas' Stadt wählte sich Venus als Sitz«. Rom aus der Sicht seiner Dichter, in: Mahler, Andreas (Hg.): StadtBilder; S. 57-66

Honegger, Claudia: (Hg.): Die Hexen der Neuzeit. Studien zur Sozialgeschichte eines kulturellen Deutungsmusters. Frankfurt/M: Suhrkamp 1978

Honegger, Claudia: Die Hexen der Neuzeit. Analysen zur anderen Seite der okzidentalen Rationalisierung, in: Dies. (Hg.): Die Hexen der Neuzeit; S. 21-151

Honegger, Claudia: Die Ordnung der Geschlechter. Die Wissenschaften vom Menschen und das Weib 1750-1850. Frankfurt/M, New York: Campus 1991

Horkheimer, Max/Adorno, Theodor W.: Dialektik der Aufklärung. Philosophische Fragmente. Frankfurt/M: Fischer 1993 (1969)

Howoldt, Jenns E./Schneede, Uwe M. (Hg.): Expedition Kunst. Die Entdeckung der Natur von C. D. Friedrich bis Humboldt. Katalog zur Ausstellung in der Hamburger Kunsthalle vom 25. Oktober 2002 bis 23. Februar 2003. Hamburg, München: Dölling und Galitz 2002

Howoldt, Jenns E.: Von Caspar David Friedrich zu Carl Gustav Carus. Landschaftsmalerei zwischen ästhetischer Autonomie und wissenschaftlichem Anspruch, in: Ders./Schneede, Uwe M. (Hg.): Expedition Kunst; S. 9-16

Howoldt, Jenns E.: Zwischen Empfindung und Erkenntnis. Das Bild der Natur in Deutschland, in: Ders./Schneede, Uwe M. (Hg.): Expedition Kunst; S. 85-115

Ingensiep, Hans Werner/Hoppe-Sailer, Richard (Hg.): NaturStücke. Zur Kulturgeschichte der Natur. Ostfildern: Edition Tertium 1996

Jahn, Thomas: Krise als gesellschaftliche Erfahrungsform. Umrisse eines sozialökologischen Gesellschaftskonzeptes. Frankfurt/M: IKO Verlag für interkulturelle Kommunikation 1991

Jahn, Thomas/Wehling, Peter: Gesellschaftliche Naturverhältnisse Konturen eines theoretischen Konzepts, in: Brand, Karl-Werner (Hg.): Soziologie und Natur. Theoretische Perspektiven. Opladen: Leske + Budrich 1998; S. 75-93 
Jünger, Ernst: Politische Publizistik 1919-1933. Hg. von Sven Olaf Berggötz. Stuttgart: Klett-Cotta 2001

Jünger, Ernst: Der Waldgang. Wuppertal u.a.: Klostermann 1950

Jütte, Robert: Disziplinierungsmechanismen in der städtischen Armenfürsorge der Frühneuzeit, in: Sachße, Christoph/Tennstedt, Florian (Hg.): Soziale Sicherheit und soziale Disziplinierung; S. 101-118

Kamper, Dietmar: Unmögliche Gegenwart. Zur Theorie der Phantasie. München: Wilhelm Fink Verlag 1995

Kamper, Dietmar/Wulf, Christoph (Hg.): Der Schein des Schönen. Göttingen: Steidl 1989

Kamper, Dietmar/Wulf, Christoph (Hg.): Die Wiederkehr des Körpers. Frankfurt/M: Suhrkamp 1982

Kant, Immanuel: Beobachtungen über das Gefühl des Schönen und Erhabenen, in: Werke, Bd. 2. Darmstadt: Wissenschaftliche Buchgesellschaft 1968

Kant, Immanuel: Anthropologie in pragmatischer Hinsicht, in Werke, Bd. 10

Kant, Immanuel: Kritik der Urteilskraft. Hg. von Karl Vorländer. Hamburg: Felix Meiner 1990 (Leipzig 1799)

Kantorowicz, Ernst H.: Die zwei Körper des Königs. Eine Studie zur politischen Theologie des Mittelalters. München: dtv 1990 (Princeton 1957)

Kantorowicz, Ernst H.: Götter in Uniform. Studien zur Entwicklung des abendländischen Königtums. Hg. v. Grünewald, Eckhart et al. Stuttgart: Klett-Cotta 1998

Kastner, Angelika: Wallfahrt, Weihnachten und Stammbaum, in: Gercke, Hans (Hg.): Der Baum; S. 102-123

Kawami, Trudy S.: Antike persische Gärten, in: Carroll-Spillecke, Maureen et al. (Hg.): Der Garten von der Antike bis zum Mittelalter. Mainz : von Zabern 1995; S. 81-99

Kehn, Wolfgang: Christian Cay Lorenz Hirschfeld 1742-1792. Eine Biographie. Worms: Werner 1992

Keller, Harald: Goethes Hymnus auf das Straßburger Münster und die Wiedererweckung der Gotik im 18. Jahrhundert. 1772/1972 = Bayerische Akademie der Wissenschaften. Philosophisch-Historische Klasse. Sitzungsberichte, Jahrgang 1974, Heft 4. München 1974

Keller, Paul: Waldwinter. Roman aus den schlesischen Bergen. 106. bis 120. Aufl. Breslau und Leipzig: Bergstadtverlag Wilh. Gottl. Korn 1920

Kellner, Stephan: Remota IV: Franz von Krenners schlüpfrige und schmutzige Bücher, in: Ders. (Hg.): Der »Giftschrank«. Erotik, Sexualwissenschaft, Politik und Literatur - »Remota«: Die wegge- 
sperrten Bücher der Bayerischen Staatsbibliothek. Katalog zur Ausstellung der Bayerischen Staatsbibliothek München, 2. Oktober17. Dezember 2002, S. 171-187

Kesting, Marianne: „Arkadien in der Hirnkammer« oder: Die Enklave des Parks als Sonderfall artifizieller Landschaft, in: Smuda, Manfred (Hg.): Landschaft; S. 203-214

Kiening, Christian: Ordnung der Fremde. Brasilien und die theoretische Neugierde im 16. Jahrhundert, in: Krüger, Klaus (Hg.): Curiositas; S. 59-109

Kiening, Christian: Koloniale Texte. Das Beispiel des Philipp von Hutten, in: Puff, Helmut/Wild, Christopher (Hg.): Zwischen den Disziplinen? Perspektiven der Frühneuzeitforschung. Göttingen: Wallstein 2003

Kirsch, Rolf: Frühe Landschaftsgärten im niedersächsischen Raum. Göttingen: Cuvillier 1993

Kittsteiner, Heinz D.: Von der Macht der Bilder. Überlegungen zu Ernst H. Kantorowicz' Werk Friedrich der Zweite, in: Ernst, Wolfgang/Vismann, Cornelia (Hg.): Geschichtskörper; S. 13-30

Klein, Dorothea: Bildung und Belehrung. Untersuchungen zum Dramenwerk des Hans Sachs. Stuttgart: Heinz 1988

Klein, Gabriele/Liebsch, Katharina (Hg.): Zivilisierung des weiblichen Ich. Frankfurt/M: Suhrkamp 1997

Kleinspehn, Thomas: Der flüchtige Blick. Sehen und Identität in der Kultur der Neuzeit. Reinbek: Rowohlt 1989

Klose, Franz/Orf, Siegfried: Forstrecht. Kommentar zum Waldrecht des Bundes und der Länder. Münster, Köln: Aschendorff u.a. $1998^{2}$

Kluge, Friedrich: Etymologisches Wörterbuch der deutschen Sprache. 23., erweiterte Auflage. Bearbeitet von Elmar Seebold. Berlin, New York: de Gruyter 1999

Kluge, Thomas/Schramm, Engelbert: Wassernöte. Umwelt- und Sozialgeschichte des Trinkwassers. Aachen: Alano 1986

Kluge, Walter: Die Stadt der Utopie. Architektur als Modell der Gesellschaft, in: Mahler, Andreas (Hg.): Stadt-Bilder; S. 67-85

Koch, Elisabeth: Maior dignitas est in sexu virili. Das weibliche Geschlecht im Normensystem des 16. Jahrhunderts. Frankfurt/M: Klostermann 1991

Kockerbeck, Christoph: Die Schönheit des Lebendigen. Ästhetische Naturwahrnehmung im 19. Jahrhundert. Wien, Köln, Weimar: Böhlau 1997

Koebner, Thomas/Pickerodt, Gerhart (Hg.): Die andere Welt. Studien zum Exotismus. Frankfurt/M: Athenäum 1987 
Koebner, Thomas: Geheimnisse der Wildnis. Zivilisationskritik und Naturexotik im Abenteuerroman, in: Ders./Pickerodt, Gerhart (Hg.): Die andere Welt; S. 240-266

Köhler, Joachim: Heilige und unheilige Bäume. Der Baum in Wirklichkeit und Legende des Mittelalters, in: Schweizer, Harald (Hg.): »... Bäume braucht man doch! «; S.143-166

Kofler, Leo: Der asketische Eros. Industriekultur und Ideologie. Wien, Frankfurt/M, Zürich: Europa-Verlag 1967

Kohl, Karl-Heinz: Abwehr und Verlangen. Zur Geschichte der Ethnologie. Frankfurt/M, New York: Campus 1987

Kohl, Karl-Heinz: Entzauberter Blick. Das Bild vom guten Wilden und der Erfahrung der Zivilisation. Berlin (W): Medusa 1981

König, Gudrun M.: Eine Kulturgeschichte des Spaziergangs. Spuren einer bürgerlichen Praktik 1780-1850. Wien, Köln, Weimar: Böhlau 1996

König, Gudrun M.: Ausgegrenzt und einverleibt - Zum bürgerlichen Umgang mit Landschaft um 1800, in: Ingensiep, Hans Werner/Hoppe-Sailer, Richard (Hg.): NaturStücke; S. 167-182

Konrad, Helmut/Andersen, Arne (Hg.): Ökologie, technischer Wandel und Arbeiterbewegung. Wien, Zürich: Europaverlag 1990

Köpf, Ernst Ulrich: Forstpolitik. Stuttgart: Ulmer 2002

Krafft-Ebing, Richard von: Psychopathia sexualis. Mit der besonderen Berücksichtigung der conträren Sexualempfindungen. Eine medicinisch-gerichtliche Studie für Ärzte und Juristen. 11., stark vermehrte Auflage. Stuttgart 1901 u. 15., vermehrte Auflage (hg. v. Fuchs, Alfred). Stuttgart: Enke 1918

Kramer, Fritz: Verkehrte Welten. Zur imaginären Ethnographie des 19. Jahrhunderts. Frankfurt/M: Syndikat 1977

Kropp, Cordula: »Natur«. Soziologische Konzepte, politische Konsequenzen. Opladen: Leske + Budrich 2002

Krüger, Klaus (Hg.): Curiositas. Welterfahrung und ästhetische Neugierde in Mittelalter und früher Neuzeit. Göttingen: Wallstein 2002

Krüger, Klaus: Einleitung, in: Ders. (Hg.): Curiositas; S. 9-18

Küster, Hansjörg: Geschichte des Waldes. Von der Urzeit bis zur Gegenwart. München: C.H. Beck 1998

Kuhn, Annette/Pitzen, Marianne (Hg.): Stadt der Frauen. Szenarien aus spätmittelalterlicher Geschichte und zeitgenössischer Kunst. Zürich, Dortmund: Edition Ebersbach im eFeF-Verlag 1994

Künzel, Werner/Bexte, Peter: Maschinen/Denkmaschinen. An den Schaltstellen zweier Kulturen. Frankfurt/M, Leipzig: Insel 1996 
Kutschmann, Werner: Der Naturwissenschaftler und sein Körper. Die Rolle der »inneren Natur« in der experimentellen Naturwissenschaft der frühen Neuzeit. Frankfurt/M: Suhrkamp 1986

Labisch, Alfons: »Hygiene ist Moral - Moral ist Hygiene« - Soziale Disziplinierung durch Ärzte und Medizin, in: Sachße, Christoph/Tennstedt, Florian: Soziale Sicherheit und soziale Disziplinierung; S. 265-285

La Mettrie, Julien Offray de: Der Mensch als Maschine. Mit einem Essay von Bernd A. Laska. Nürnberg: LSR-Verlag 1985 (Leyden 1748)

Lampe, Angela (Hg.): Die unheimliche Frau. Weiblichkeit im Surrealismus. Heidelberg: Wachter Verlag 2001

Lampe, Angela: Größter Schatten oder größtes Licht. Surrealistische Frauenentwürfe zwischen Traum und Wirklichkeit, in Dies. (Hg.): Die unheimliche Frau; S. 25-48

Landweer, Hilge: Mikrophysik der Scham? Elias und Foucault im Vergleich, in: Klein, Gabriele/Liebsch, Katharina (Hg.): Zivilisierung des weiblichen Ich; S. 365-399

Laqueur, Thomas: Auf den Leib geschrieben. Die Inszenierung der Geschlechter von der Antike bis Freud. Frankfurt/M, New York: Campus 1992

Largier, Niklaus: Rhetorik der Erfahrung. Kynische Kritik und theoretische Neugierde in der Frühen Neuzeit, in: Krüger, Klaus (Hg.): $\mathrm{Cu}-$ riositas; S. 111-145

Laudert, Doris: Mythos Baum. Was Bäume uns Menschen bedeuten. Geschichte, Brauchtum, 30 Baumporträts. München u.a.: BLV 2000

Le Goff, Jacques: Phantasie und Realität des Mittelalters. Stuttgart: Klett-Cotta 1990 (Paris 1985)

Leder, Bertram: Bisherige Beurteilung und Definition des Begriffes »Weichlaubhölzer«, in: LÖBF (Hg.): Weichlaubhölzer und Sukzessionsdynamik in der naturnahen Waldwirtschaft. Möglichkeiten, Erfahrungen, Grenzen. Schriftenreihe der Landesanstalt für Ökologie, Bodenordnung und Forsten/Landesamt für Agrarordnung NordrheinWestfalen Bd. 4. 1995; S. 9-12.

Lehmann, Albrecht: Von Menschen und Bäumen. Die Deutschen und ihr Wald. Reinbek: Rowohlt 1999

Leibundgut, Hans: Waldbau als Naturschutz. Bern, Stuttgart: Haupt 1990

Lenin, Wladimir Iljitsch: Materialismus und Empiriokritizismus. Kritische Bemerkungen über eine reaktionäre Philosophie. Berlin $(\mathrm{O})$ : Dietz 1981 (Genf 1908) 
Lenk, Hans: Der Macher der Natur? Über operativistische Fehldeutungen von Naturbegriffen der Neuzeit, in: Großklaus, Götz/Oldemeyer, Ernst (Hg.): Natur als Gegenwelt; S. 59-86

Lepenies, Wolf: Das Ende der Naturgeschichte. Wandel kultureller Selbstverständlichkeiten in den Wissenschaften des 18. und 19. Jahrhunderts. München: Hanser 1976

Lévi-Strauss, Claude: Traurige Tropen. Frankfurt/M: Suhrkamp 1978 (Paris 1955)

Lévy, Pierre: Die Erfindung des Computers, in: Serres, Michel (Hg.): Elemente einer Geschichte der Wissenschaft; S. 905-944

Lexikon Literatur des Mittelalters, Bd. 2: Autoren und Werke. Zusammenstellung der Artikel und Redaktion: Charlotte Bretscher-Gisiger. Stuttgart, Weimar: Metzler 2002

Lindemann, Klaus: In den deutschen Eichenhainen webt und rauscht der deutsche Gott. Deutschlands poetische Eichenwälder, in: Semmler, Josef (Hg.): Der Wald in Mittelalter und Renaissance; S. 200-239

Linse, Ulrich: Ökopax und Anarchie. Eine Geschichte der ökologischen Bewegungen in Deutschland. München: dtv 1986

Lippe, Rudolf zur: Naturbeherrschung am Menschen. Band I: Körpererfahrung als Entfaltung von Sinnen und Beziehungen in der Ära des italienischen Kaufmannskapitals. Band II: Geometrisierung des Menschen und Repräsentation des Privaten im französischen Absolutismus. Frankfurt/M: Syndikat 1979 (1974)

Lippe, Rudolf zur: Am eigenen Leibe, in: Kamper, Dietmar/Wulf, Christoph (Hg.): Die Wiederkehr des Körpers; S. 25-39

Lobsien, Eckhard: Landschaft als Zeichen. Zur Semiotik des Schönen, Erhabenen und Pittoresken, in: Smuda, Manfred (Hg.): Landschaft; S. $159-177$

Löfgren, Orvar: Natur, Tiere und Moral. Zur Entwicklung der bürgerlichen Naturauffassung, in: Jeggle, Utz et al. (Hg.): Volkskultur in der Moderne. Probleme und Perspektiven empirischer Forschung. Reinbek: Rowohlt 1986; S. 122-144

Lombroso, Cesare/Ferrero, Guglielmo: Das Weib als Verbrecherin und Prostituirte. Anthropologische Studien gegründet auf einer Darstellung der Biologie und Psychologie des normalen Weibes. (Autorisierte Uebersetzung von Dr. Med. H. Kurella) Hamburg: VerlagsAnstalt und Druckerei 1894

Lorenz, Günther: Tiere im Leben der alten Kulturen. Schriftlose Kulturen, alter Orient, Ägypten, Griechenland und Rom. Wien, Köln, Weimar: Böhlau 2000

Löns, Hermann: Gesamtausgabe in fünf Bänden. Hg. v. Wilhelm Deimann. Hamburg: Standard-Verlag 1960/61 
Lorenz, Maren: Leibhaftige Vergangenheit. Einführung in die Körpergeschichte. Tübingen: Edition Diskord 2000

Mader, Günter: Gartenkunst des 20. Jahrhunderts. Garten- und Landschaftsarchitektur in Deutschland. Stuttgart: Deutsche Verlags-Anstalt 1999

Mager, Friedrich: Der Wald in Altpreussen. Bd. I. Köln, Graz: Böhlau 1960

Mahler, Andreas (Hg.): Stadt-Bilder. Allegorie, Mimesis, Imagination. Heidelberg: Winter 1999

Makowski, Henry/Buderath, Bernhard: Die Natur dem Menschen untertan. Ökologie im Spiegel der Landschaftsmalerei. München: Kindler 1983

Mantel, Kurt: Wald und Forst in der Geschichte. Ein Lehr- und Handbuch. Alfeld b. Hannover: Schaper 1990

Marcuse, Herbert: Der eindimensionale Mensch. Studien zur Ideologie der fortgeschrittenen Industriegesellschaft. Frankfurt/M: Luchterhand 1988 (Boston/Mass 1964)

Martin, Andreas: Fokussierte Landschaft. Aussichtstürme in der Sächsischen Schweiz, in: Brednich, Wilhelm et al. (Hg.): Natur - Kultur; S. $177-188$

Martin-Fugier, Anne: Riten der Bürgerlichkeit, in: Perrot, Michelle (Hg.): Geschichte des privaten Lebens 4. Von der Revolution zum Großen Krieg; S. 201-265

Marx, Karl: Das Kapital, in: MEW 23. Berlin (O): Dietz 1962

Marx, Karl: Ökonomisch-philosophische Manuskripte, in: MEW, Eb. 1. Berlin (O): Dietz 1968

Matejovski, Dirk: Das Motiv des Wahnsinns in der mittelalterlichen Dichtung. Frankfurt/M: Suhrkamp 1996

Mayer-Tasch, Peter Cornelius/Mayerhofer, Bernd: Hinter Mauern ein Paradies. Der mittelalterliche Garten. Frankfurt/M, Leipzig: Insel 1998

Maywald, Armin: Naturoasen in Deutschland. Ravensburg: Maier 1989

Menninghaus, Winfried: Ekel. Theorie und Geschichte einer starken Empfindung. Frankfurt/M: Suhrkamp 2002

Merchant, Carolyn: Der Tod der Natur. Ökologie, Frauen und neuzeitliche Naturwissenschaft. München: C.H. Beck 1987 (Berkeley 1980)

Merkel, Hubert: Waldbilder: Technische Zeichnungen oder Gemälde? Von der Nützlichkeit des interdisziplinären Dialogs, in: Hettche, Walter/Merkel, Hubert (Hg.): Waldbilder; S. 15-25

Metken, Günter: Gustave Courbet. Der Ursprung der Welt. Ein Luststück. München u.a.: Prestel 1997 
Meyer, Kirsten: Der Wert der Natur. Begründungsvielfalt im Naturschutz. Bielefeld: Mentis 2003

Minois, Georges: Die Hölle. Zur Geschichte einer Fiktion. München: Diederichs 1994 (Paris 1991)

Modelmog, Ilse: Die zwei Ordnungen. Industrielles Bewusstsein und Subjektanarchie. Opladen: Westdeutscher Verlag 1989

Montrose, Louis: Elizabeth hinter dem Spiegel: Die Ein-Bildung der zwei Körper der Königin, in: Schulte, Regina (Hg.): Der Körper der Königin; S. 67-98

Morgenthaler, Erwin: Von der Ökonomie der Natur zur Ökologie. Die Entwicklung ökologischen Denkens und seiner sprachlichen Ausdrucksformen. Berlin: Schmidt 2000

Moscovici, Serge: Versuch über die menschliche Geschichte der Natur. Frankfurt/M: Suhrkamp 1982 (Paris 1977)

Mosse, George L.: Nationalismus und Sexualität. Bürgerliche Moral und sexuelle Normen. München, Wien: Hanser 1985 (New York 1985)

Mosse, George L.: Ein Volk, ein Reich, ein Führer. Völkische Ursprünge des Nationalsozialismus. Königstein/Ts: Athenäum 1979 (New York 1964)

Mosse, George L.: Rassismus. Ein Krankheitssymptom in der europäischen Geschichte des 19. und 20. Jahrhunderts. Königstein/Ts: Athenäum 1978 (New York 1978)

Muchembled, Robert: Elias und die neuere historische Forschung in Frankreich, in Rehberg, Karl-Siegbert (Hg.): Norbert Elias und die Menschenwissenschaften; S. 275-287

Müller, Gernot Michael: Die »Germania generalis« des Conrad Celtis. Studien mit Edition, Übersetzung und Kommentar. Tübingen: Niemeyer 2001

Müller, Jürgen: Das Paradox als Bildform. Studien zur Ikonologie Pieter Bruegels d.Ä. München: Wilhelm Fink Verlag 1999

Müller, Klaus E.: Die bessere und die schlechtere Hälfte. Ethnologie des Geschlechterkonflikts. Frankfurt/M, New York: Campus 1989 (1984)

Müller, Maria E.: Der Poet der Moralität. Untersuchungen zu Hans Sachs. Bern, Frankfurt/M, New York: Peter Lang 1985

Müller, Maria E.: Naturwesen Mann. Zur Dialektik von Herrschaft und Knechtschaft in Ehelehren der Frühen Neuzeit, in: Wunder, Heide/Vanja, Christina (Hg.): Wandel der Geschlechterbeziehungen zu Beginn der Neuzeit; S. 43-68.

Müller, Michael: Die Verdrängung des Ornaments. Zum Verhältnis von Architektur und Lebenspraxis. Frankfurt/M: Suhrkamp 1977 
Müller-Hofstede: Annedore: Der Landschaftsmaler Pascha Johann Friedrich Weitsch 1783-1803. Braunschweig: Waisenhaus-Buchdruckerei und Verlag 1973

Müller-Tamm, Pia/Sykora, Katharina (Hg.): Puppen - Körper - Automaten. Phantasmen der Moderne. Köln: Oktagon 1999

Mumford, Lewis: Mythos der Maschine. Kultur, Technik und Macht. Frankfurt/M: Fischer 1981 (Or. 1964-66)

Musner, Lutz: Stadt. Masse. Weib. Metropolenwandel, Massenphobie und Misogynie im Fin-de-Siècle, in: Hödl, Günther et al. (Hg.): Frauen in der Stadt. Linz: Österreichischer Arbeitskreis für Stadtgeschichtsforschung 2003; S. 63-82

Nahoum-Grappe, Véronique: Die schöne Frau, in: Duby, Georges/Perrot, Michelle (Hg.): Geschichte der Frauen. Bd. 3, Frühe Neuzeit; S. 103-118

Nebelung, Andreas et al. (Hg.): Geschlechterverhältnisse - Naturverhältnisse. Feministische Auseinandersetzungen und Perspektiven der Umweltsoziologie. Opladen: Leske + Budrich 2001

Neubauer, Erika: Wiener Barockgärten in zeitgenössischen Veduten. Dortmund: Harenberg 1980

Niemeyer, Beatrix: »Angenehme Sittenlehrer« - Briefe und Weiblichkeit im 18. Jahrhundert. Kritische Anmerkungen zu Norbert Elias, in: Klein, Gabriele/Liebsch, Katharina (Hg.): Zivilisierung des weiblichen Ich; S. 185-205

Nitschke, August: Umweltschutz und Umweltwahrnehmung, in: Calließ, Jörg. et al. (Hg.): Mensch und Umwelt in der Geschichte; S. 35-46

Nitschke, August: Körper in Bewegung. Gesten, Tänze und Räume im Wandel der Geschichte. Stuttgart: Kreuz-Verlag 1989

Nollert, Angelika: Johann Bernhard Klombeck - Leben und Werk; in (Städtisches Museum Haus Koekkoek Kleve (Hg.): Johann Bernhard Klombeck 1815-1893. Ein Landschaftsmaler der Klever Romantik. Kleve: Boss-Verlag 1993); S. 13-22

Oesterdiekhoff, Georg W.: Zivilisation und Strukturgenese. Norbert Elias und Jean Piaget im Vergleich. Frankfurt/M: Suhrkamp 2000

Oettinger, Karl: Laube, Garten und Wald. Zu einer Theorie der süddeutschen Sakralkunst 1470-1520, in: Ders./Rassem, Mohammed (Hg.): Festschrift für Hans Sedlmayr. München: C.H. Beck 1962; S. 201228

Otto, Beate: Unterwasser-Literatur. Von Wasserfrauen und Wassermännern. Würzburg: Königshausen \& Neumann 2001

Pankoke, E.: Von »guter Policey« zu »socialer Politik«. »Wohlfahrt«, »Glückseligkeit« und »Freiheit« als Wertbindung aktiver Sozial- 
staatlichkeit, in: Sachße, Chr./Tennstedt, F. (Hg.): Soziale Sicherheit und soziale Disziplinierung; S. 148-180

Perrig, Alexander: Albrecht Dürer oder: Die Heimlichkeit der deutschen Ketzerei. Die Apokalypse Dürers und andere Werke von 1495 bis 1513. Weinheim: VCH 1987

Pfeiffer, K. Ludwig: Bedingungen und Bedürfnisse. Literarische Landschaften im England des 19. Jahrhunderts, in: Smuda, Manfred (Hg.): Landschaft; S.178-202

Pickerodt, Gerhart: Aufklärung und Exotismus, in: Koebner, Thomas/Pickerodt, Gerhart (Hg.): Die andere Welt; S. 121-136

Pieper, Jan: Das Arkanum Pfaueninsel, in: Daidalos. Architektur Kunst Kultur. Nr. 46, Dezember 1992; S. 78-91

Plamper, Andrea: Von der Kulturlandschaft zur Wunschlandschaft. Die visuelle Konstruktion von Natur in Museen. Münster u.a.: Waxman 1998

Platon: Phaidros. Übersetzung und Kommentar von Ernst Heitsch = Werke III 4. Göttingen: Vandenhoeck \& Ruprecht 1993

Platon: Timaios - Kritias - Philebos. $=$ Werke in acht Bänden, Bd. 7. Darmstadt: Wissenschaftliche Buchgesellschaft 1972

Plochmann, Richard: Mensch und Wald, in: Stern, Horst et al.: Rettet den Wald; S. 175-222

Poferl, Angelika: Doing Gender, Doing Nature? Einführende Bemerkungen zur Intention des Bandes, in: Nebelung, Andreas et al. (Hg.): Geschlechterverhältnisse - Naturverhältnisse; S. 9-17

Potthast, Thomas: Wissenschaftliche Ökologie und Naturschutz: Szenen einer Annäherung, in: Radkau, Joachim/Uekötter, Frank (Hg.): Naturschutz und Nationalsozialismus; S. 223-253

Pückler-Muskau, Hermann Fürst von: Andeutungen über Landschaftsgärtnerei verbunden mit ihrer praktischen Anwendung in Muskau. Hg. v. Günter J. Vaupel. Frankfurt/M, Leipzig: Insel 1996 (Stuttgart 1834)

Radkau, Joachim/Schäfer, Ingrid: Holz. Ein Naturstoff in der Technikgeschichte. Reinbek: Rowohlt 1987

Radkau, Joachim/Uekötter, Frank (Hg.): Naturschutz und Nationalsozialismus. Frankfurt/M, New York: Campus 2003

Radkau, Joachim: Naturschutz und Nationalsozialismus - wo ist das Problem?, in: Ders./Uekötter, Frank (Hg.): Naturschutz und Nationalsozialismus; S. 41-54

Ranke-Graves, Robert von: Griechische Mythologie. Quellen und Deutung. 2 Bde. Reinbek: Rowohlt 1960 (Harmondsworth, Middlesex 1955) 
Ranke-Graves, Robert von: Die weiße Göttin. Sprache des Mythos. Reinbek: Rowohlt 1985 (New York 1948)

Raphael, Max: Wiedergeburtsmagie in der Altsteinzeit. Zur Geschichte der Religion und religiöser Symbole. Herausgegeben von Shirley Chesney und Ilse Hirschfeld. Frankfurt/M: Fischer 1978

Rave, Paul Ortwin: Gärten der Goethezeit. Berlin (West): Henssel 1981 (Berlin 1941)

Ravenna, Nino/Samek-Ludovici, Sergio: Dante. Göttliche Komödie nach einer Handschrift aus dem 15. Jahrhundert. Gütersloh u.a.: Bertelsmann 1979

Rehberg, Karl-Siegbert (Hg.): Norbert Elias und die Menschenwissenschaften. Studien zur Entstehung und Wirkungsgeschichte seines Werkes. Frankfurt/M: Suhrkamp 1996

Reich, Wilhelm: Die Massenpsychologie des Faschismus. Köln: Kiepenheuer \& Witsch 1986 (Maine 1942)

Reudenbach, Bruno: Die Gemeinschaft als Körper und Gebäude. Francesco di Giorgios Stadttheorie und die Visualisierung von Sozialmetaphern im Mittelalter, in: Schreiner, Klaus/Schnitzler, Norbert (Hg.): Gepeinigt, begehrt, vergessen. Symbolik und Sozialbezug des Körpers im späten Mittelalter und in der frühen Neuzeit. München: Wilhelm Fink Verlag 1992; S. 171-198

Riedel, Volker: Antikenrezeption in der deutschen Literatur vom Renaissance-Humanismus bis zur Gegenwart. Eine Einführung. Stuttgart u.a.: Metzler 2000

Riehl, Wilhelm Heinrich: Land und Leute. Stuttgart, Berlin: Cotta $1908^{11}$

Ritter, Gerhard A./Kocka, Jürgen: Bevölkerungsentwicklung und Verstädterung. Einleitung, in: Dies. (Hg.): Deutsche Sozialgeschichte 1870-1914. Dokumente und Skizzen. München: C.H. Beck $1982^{3}$; S. $34-38$

Rivera Garretas, María-Milagros: Orte und Worte von Frauen. Eine Spurensuche im europäischen Mittelalter. München: dtv 1997 (Wien 1993/Barcelona 1990)

Roeck, Bernd: Außenseiter, Randgruppen, Minderheiten, Fremde im Deutschland der frühen Neuzeit. Göttingen: Vandenhoeck \& $\mathrm{Ru}-$ precht 1993

Rötzer, Florian: Zur Genese des Erhabenen, in: Kamper, Dietmar/Wulf, Christoph (Hg.): Der Schein des Schönen; S. 71-99

Roosen, Rolf: Jagdsprachlicher Sachwortschatz in gedruckten Landes-, Polizei-, Jagd- und Forstverordnungen des 15. und 16. Jahrhunderts - eine bibliographische, philologische und jagdhistorische Studie. Frankfurt/M u.a.: Peter Lang 1993 
Roper, Lyndal: Ödipus und der Teufel. Körper und Psyche in der Frühen Neuzeit. Frankfurt/M: Fischer 1995 (London 1994)

Rosegger, Peter: Rückkehr zur ländlichen Natur, in: Der Kynast. Alldeutsche Monatsschrift für Volkstum und Kunst. 1. Jg., 1. Hälfte 1899; S. 225-227

Rothstein, Herbert: Ökologischer Landschaftsbau. Grundlagen und Maßnahmen. Stuttgart: Ulmer 1995

Rouche, Michel: Abendländisches Frühmittelalter, in: Ariès, Philippe/Duby, Georges (Hg.): Geschichte des privaten Lebens 1. Band: Vom Römischen Imperium zum Byzantinischen Reich. Augsburg: Bechtermünz 2000 (Paris 1985); S. 389-513

Rousseau, Jean-Jacques: Émile oder über die Erziehung. Paderborn: Schöningh 1971 (Paris 1762)

Rubner, Heinrich: Deutsche Forstgeschichte 1933-1945. Forstwirtschaft, Jagd und Umwelt im NS - Staat. St. Katharinen: ScriptaMercaturae-Verlag 1985

Rüter, Hubert: Vom »Kleid Gottes« zum »Schweigen in schwarzen Wipfeln«. Formen literarischer Landschaftsgestaltung um 1900, in: Lindemann, Klaus et al. (Hg.): Umbrüche: Blicke auf Landschaft in Literatur und Kunst: 1800, 1900. Paderborn: Schöningh 1999; S. 87 162

Ruprecht, Erich (Hg.): Literarische Manifeste der Jahrhundertwende 1890-1910. Stuttgart: Metzler 1970

Russell, Jeffrey Burton: Hexerei und Geist des Mittelalters, in: Honegger, Claudia (Hg.): Die Hexen der Neuzeit; S. 159-187

Sachße, Christoph/Tennstedt, Florian (Hg.): Soziale Sicherheit und soziale Disziplinierung. Beiträge zu einer historischen Theorie der Sozialpolitik. Frankfurt/M: Suhrkamp 1986

Sandmann, Jürgen: Ernst Haeckels Entwicklungslehre als Teil seiner biologistischen Weltanschauung, in: Engels, Eve-Marie (Hg.): Die Rezeption von Evolutionstheorien im 19. Jahrhundert. Frankfurt/M: Suhrkamp 1995; S. 326-346

Schäfer, Lothar: Wandlungen des Naturverständnisses, in: Bien, Günther et al. (Hg.): »Natur« im Umbruch; S. 23-47.

Schäfer, Lothar: Zur Geschichte des Naturbegriffs, in: Baumüller, Barbara et al. (Hg.): Inszenierte Natur; S. 9-17

Schaff, Barbara: Gendered Cities. Italienische Städte im Blick britischer Reisender, in: Mahler, Andreas (Hg.): Stadt-Bilder; S. 173-196

Schama, Simon: Der Traum von der Wildnis. Natur als Imagination. München: Kindler 1996 (New York 1995)

Schapiro, Meyer: Romanische Kunst. Ausgewählte Schriften. Köln: DuMont 1987 (New York 1977) 
Scherzinger, Wolfgang: Naturschutz im Wald. Qualitätsziele einer dynamischen Waldentwicklung. Stuttgart: Ulmer 1996

Schiebinger, Londa: Am Busen der Natur. Erkenntnis und Geschlecht in den Anfängen der Wissenschaft. Stuttgart: Klett-Cotta 1995 (Boston 1993)

Schiebinger, Londa: Schöne Geister. Frauen in den Anfängen der modernen Wissenschaft. Stuttgart: Klett-Cotta 1993 (Cambridge/Mass 1989)

Schilken, Dörthe: Die teleologische Reise. Von der christlichen Pilgerallegorie zu den Gegenwelten der Fantasyliteratur. Würzburg: Königshausen \& Neumann 2002

Schindler, Norbert: Widerspenstige Leute. Studien zur Volkskultur in der frühen Neuzeit. Frankfurt/M: Fischer 1992

Schlegel, Friedrich: Briefe auf einer Reise durch die Niederlande, Rheingegenden, die Schweiz und einen Teil von Frankreich, in: Kritische Friedrich-Schlegel-Ausgabe. Hg. von Ernest Behler et al., Bd. 4, München, Paderborn, Wien: Schöningh u.a. 1959; S. 153-204

Schlesier, Renate: Konstruktionen der Weiblichkeit bei Sigmund Freud. Zum Problem von Entmythologisierung und Remythologisierung in der psychoanalytischen Theorie. Frankfurt/M: Europäische Verlagsanstalt 1981

Schmidt-Biggemann, Wilhelm: Maschinen und Teufel. Jean Pauls Jugendsatiren nach ihrer Modellgeschichte. Freiburg, München: Alber 1975

Schmitz-Emans, Monika: Wasserfrauen und Elementargeister als poetologische Chiffren, in: Pott, Hans-Georg (Hg.): Liebe und Gesellschaft. Das Geschlecht der Musen. München: Wilhelm Fink Verlag 1997; S. 181-229

Schmoll, Friedemann: Die Verteidigung organischer Ordnungen: Naturschutz und Antisemitismus zwischen Kaiserreich und Nationalsozialismus, in: Radkau, Joachim/Uekötter, Frank (Hg.): Naturschutz und Nationalsozialismus; S. 169-181

Schneider, Helmut J.: Selbsterfahrung zu Fuß. Spaziergang und Wanderung als poetische und geschichtsphilosophische Reflexionsfigur im Zeitalter Rousseaus, in: Söring, Jürgen/Gasser, Peter (Hg.): Rousseauismus. Naturevangelium und Literatur. Frankfurt/M u.a.: Peter Lang 1999; S. 133-154

Schneider, Manfred: Liebe und Betrug. Die Sprachen des Verlangens. München: dtv 1994 (München, Wien: Hanser 1992)

Schneller, Klaus: Paracelsus: von den Hexen und ihren Werken, in: Becker, Gabriele et al. (Hg.): Aus der Zeit der Verzweiflung; S. 240258 
Schoen, Christian: Albrecht Dürer: Adam und Eva. Die Gemälde, ihre Geschichte und Rezeption bei Lucas Cranach d.Ä. und Hans Baldung Grien. Berlin: Reimer 2001

Schoenichen, Walther: Vom grünen Dom. Ein deutsches Wald-Buch. Im Namen der Staatlichen Stelle für Naturdenkmalpflege in Preußen herausgegeben von Walther Schoenichen unter Mitwirkung von Forstmeister Otto Feucht - Teinach i.Wb., Prof. Dr. Hans Hausrath Freiburg i.B. und Prof. Dr. Max Wolff - Eberswalde. München: Callwey 1926

Schoenichen, Walther: Naturschutz im Dritten Reich. Einführung in Wesen und Grundlagen zeitgemäßer Naturschutz-Arbeit. Berlin-Lichterfelde: Behrmüller 1934

Schoenichen, Walther: Von deutschen Bäumen. Berlin: de Gruyter 1950

Schramm, Engelbert: Arbeiterbewegung und industrielle Umweltprobleme. Wahrnehmung und Theoriediskussionen seit der zweiten Hälfte des 19. Jahrhunderts (bis 1918), in: Konrad, Helmut/Andersen, Arne (Hg.): Ökologie, technischer Wandel und Arbeiterbewegung; S. 1-32

Schröter, Susanne: Frauenmacht oder Sklaverei der Urzeit. Wissenschaftliche Annäherung an einen Mythos. Frankfurt/M: VAS - Verlag für Akademische Schriften 1989

Schrötter, Helmuth: Adalbert Stifters ökologische Naturschau im Lichte der Nachhaltigkeit, in: Hettche, Walter/Merkel, Hubert (Hg.): Waldbilder; S. 68-74

Schubert, Ernst: Der Wald: wirtschaftliche Grundlage der spätmittelalterlichen Stadt, in: Herrmann, Bernd (Hg.): Mensch und Umwelt im Mittelalter; S. 257-274.

Schulte, Regina (Hg.): Der Körper der Königin. Geschlecht und Herrschaft in der höfischen Welt seit 1500. Frankfurt/M, New York: Campus 2002

Schulte, Regina: Der Körper der Königin - konzeptionelle Annäherungen, in: Dies. (Hg.): Der Körper der Königin; S. 9-23

Schülting, Sabine: Wilde Frauen, fremde Welten. Kolonisierungsgeschichten aus Amerika. Reinbek: Rowohlt 1997

Schultz, Irmgard: Umwelt- und Geschlechterforschung: eine notwendige Übersetzungsarbeit, in: Nebelung, Andreas et al. (Hg.): Geschlechterverhältnisse - Naturverhältnisse; S. 25-51

Schwarz, Astrid E.: Wasserwüste - Mikrokosmos - Ökosystem. Eine Geschichte der »Eroberung« des Wasserraums. Freiburg/Br: Rombach 2003 
Schweizer, Harald (Hg.): »... Bäume braucht man doch!« Das Symbol des Baumes zwischen Hoffnung und Zerstörung. Sigmaringen: Thorbecke 1986

Schweizer, Harald: Vorwort, in: Ders. (Hg.): »... Bäume braucht man doch!«; S. 7-10

Schwibbe, Gudrun: »... so liegt die schönste Landschaft vor den Augen ausgebreitet...«. Zur kulturellen Konstruktion von Stadt und Natur in historischen Wahrnehmungen, in: Brednich, Wilhelm et al. (Hg.): Natur - Kultur; S. 443-454

Sckell, Friedrich Ludwig von: Beitraege zur bildenden Gartenkunst für angehende Gartenkünstler und Gartenliebhaber. Worms: Werner 1982 (Reprint von München 1825)

Seel, Martin: Eine Ästhetik der Natur. Frankfurt/M: Suhrkamp 1996

Seiterle, Gérard: Artemis - Die große Göttin von Ephesos, in: Antike Welt, 10 (1979), Heft 3, S. 3-14

Seligmann, Siegfried: Die magischen Heil- und Schutzmittel aus der belebten Natur. Bd. 1: Das Pflanzenreich. Bd. 2: Das Tierreich. Bd. 3: Der Mensch. Aus dem Nachlaß bearbeitet und herausgegeben von Jürgen Zimmermann. Berlin: Reimer 2001

Semmler, Josef (Hg.): Der Wald in Mittelalter und Renaissance. Düsseldorf: Droste 1991

Semmler, Josef: Der Forst des Königs, in: Ders. (Hg.): Der Wald in Mittelalter und Renaissance; S. 130-147

Sennett, Richard: Fleisch und Stein. Der Körper und die Stadt in der westlichen Zivilisation. Frankfurt/M: Suhrkamp 1997 (New York 1994)

Serres, Michel (Hg.): Elemente einer Geschichte der Wissenschaften. Frankfurt/M 1995 (Paris 1989)

Sieferle, Rolf Peter: Fortschrittsfeinde? Opposition gegen Technik und Industrie von der Romantik bis zur Gegenwart. München: C.H. Beck 1984

Sieferle, Rolf-Peter (Hg.): Fortschritte der Naturzerstörung. Frankfurt/M: Suhrkamp 1988

Sieferle, Rolf Peter: Entstehung und Zerstörung der Landschaft, in: Smuda, Manfred (Hg.): Landschaft; S. 238-265

Siegmund, Andrea: Die romantische Ruine im Landschaftsgarten. Ein Beitrag zum Verhältnis der Romantik zu Barock und Klassik. Würzburg: Königshausen \& Neumann 2002

Smuda, Manfred (Hg.): Landschaft. Frankfurt/M: Suhrkamp 1986

Smuda, Manfred: Natur als ästhetischer Gegenstand und als Gegenstand der Ästhetik. Zur Konstitution von Landschaft, in: Ders. (Hg.): Landschaft; S. 44-69 
Sonntag, Michael: »Das Verborgene des Herzens«. Zur Geschichte der Individualität. Reinbek: Rowohlt 1999

Söntgen, Beate: Täuschungsmanöver. Kunstpuppe - Weiblichkeit - Malerei, in: Müller-Tamm, Pia/Sykora, Katharina (Hg.): Puppen - Körper - Automaten; S. 125-139

Spehr, Christoph: Die Jagd nach Natur. Zur historischen Entwicklung des gesellschaftlichen Naturverhältnisses in den USA, Deutschland, Großbritannien und Italien am Beispiel von Wildnutzung, Artenschutz und Jagd. Frankfurt/M: IKO - Verlag für interkulturelle Kommunikation 1994

Sprenger, Jakob/Institoris, Heinrich: Der Hexenhammer. Malleus maleficarum. A. d. Lat. übertragen u. eingeleitet v. J. W. R. Schmitt. München: dtv 1987 (Reprint v. Berlin, Barsdorf 1906)

Spengler, Oswald: Der Untergang des Abendlandes. Umrisse eine Morphologie der Weltgeschichte. München: dtv $2000^{15}$ (München 1923; 33.-47. Auflage (Neubearbeitung))

Starobinski, Jean: Kleine Geschichte des Körpergefühls. Konstanz: Universitätsverlag Konstanz 1987

Steckelburg, Ulrich: Hadamars von Laber »Jagd«. Untersuchungen zu Überlieferung, Textstruktur und allegorischen Sinnbildungsverfahren. Tübingen: Niemeyer 1998

Steigner, Paradiesbaum und Kreuz. Der Baum in der christlichen Bildtradition, in: Gercke, Hans (Hg.): Der Baum; S. 86-101

Steinwachs, Gisela: Mythologie des Surrealismus oder die Rückverwandlung von Kultur in Natur. Eine strukturale Analyse von Bretons »Nadja«. Neuwied, Berlin: Luchterhand 1971

Stelzl, Ulrike: Hexenwelt. Hexendarstellungen in der Kunst um 1900. Berlin: Frölich \& Kaufmann 1983

Stern, Horst et al.: Rettet den Wald. München: Heyne $1983^{2}$

Stern, Horst: Waldeslust - gestern, heute, morgen, in: Ders. et al.: Rettet den Wald; S. 17-32

Stöckemann, Ingo: Im reinen Raum. Jünger, Schmitt, Medientechnik, in: Maresch, Rudolf/Werber, Niels (Hg.): Raum - Wissen - Macht. Frankfurt/M: Suhrkamp 2002; S. 135-155

Stollberg-Rilinger, Barbara: Der Staat als Maschine. Zur politischen Metaphorik des absoluten Fürstenstaats. Berlin: Duncker und Humblot 1986

Strasser, Peter: Verbrechermenschen. Zur kriminalwissenschaftlichen Erzeugung des Bösen. Frankfurt/M, New York: Campus 1984

Strong, Roy C.: Portraits of Queen Elizabeth I. Oxford: Clarendon Press 1963 
Tacitus, P. Cornelius: Germania. Interpretiert, herausgegeben, übertragen, kommentiert und mit einer Bibliographie versehen von Allan A. Lund. Heidelberg: Winter 1988

Tenbergen, Bernd: Westfalen im Wandel. Von der Mammutsteppe zur Agrarlandschaft. Veränderung der Tier- und Pflanzenwelt unter dem Einfluss des Menschen. Gütersloh: Siegbert Linnemann Verlag 2002 Tennstedt, Florian: Sozialgeschichte der Sozialpolitik in Deutschland. Vom 18. Jahrhundert bis zum ersten Weltkrieg. Göttingen: Vandenhoeck \& Ruprecht 1981

Theweleit, Klaus: Männerphantasien. 1. Bd.: Frauen, Fluten, Körper, Geschichte. 2. Bd.: Männerkörper. Zur Psychoanalyse des weißen Terrors. Frankfurt/M: Verlag Roter Stern 1977

Thomas, Phillip: Leiblichkeit und eigene Natur. Naturphilosophische Aspekte der Leibphilosophie, in: Böhme, Gernot (Hg.): Phänomenologie der Natur. Frankfurt/M: Suhrkamp 1997; S. 291-302

Thoss, Dagmar: Studien zum locus amoenus im Mittelalter. Wien, Stuttgart: Braumüller 1972

Tibon-Cornillot, Michel: Die transfigurativen Körper. Zur Verflechtung von Techniken und Mythen, in: Kamper, Dietmar/Wulf, Christoph (Hg.): Die Wiederkehr des Körpers; S. 145-164

Trepl, Ludwig: Geschichte der Ökologie. Vom 17. Jahrhundert bis zur Gegenwart. Frankfurt/M: Athenäum 1987

Treut, Monika: Die grausame Frau. Zum Frauenbild bei de Sade und Sacher-Masoch. Basel, Frankfurt/M: Stroemfeld 1984

Ueckermann, Erhard: Kulturgut Jagd. Ein Führer durch die Jagdgeschichte Nordrhein-Westfalens und zu jagdhistorischen Stätten. Münster-Hiltrup: Landwirtschaftsverlag 1994

Unverfehrt, Gerd (Hg.): Dürers Dinge. Einblattgraphik und Buchillustrationen Albrecht Dürers aus dem Besitz der Georg-August-Universität Göttingen. Katalog zur Ausstellung der Kunstsammlung der Universität (11.5.-21.6. 1997) Göttingen: Kunstgeschichtliches Seminar der Universität 1997

Volgmann, Werner: Landschaftsbau. Stuttgart: Ulmer 1979

Waldenfels, Bernhard: Gänge durch die Landschaft, in: Smuda, Manfred (Hg.): Landschaft; S. 29-43

Walker, Barbara G.: Das geheime Wissen der Frauen. Ein Lexikon. Frankfurt/M: Zweitausendeins 1993 (New York 1983)

Walthari=Lied - Der arme Heinrich - Lieder der alten Edda. Übersetzt von den Brüdern Grimm. Hamburg: Gutenberg-Verlag 1905

Weber, Jörg: Die Erde ist nicht Untertan. Grundrechte der Natur. Frankfurt/M: Eichborn $1993^{2}$ 
Weber, Max: Die protestantische Ethik. Bd. I. Eine Aufsatzsammlung. Hg. v. Johannes Winckelman. Gütersloh: Siebenstern-TaschenbuchVerlag 1981

Weber-Kellermann, Ingeborg (Hg.): Die Familie. Eine Kulturgeschichte der Familie. Frankfurt/M: Insel 1996 (1976)

Wehrheim-Peuker, Monika: Der Kannibale - die Kannibalin. Zum Zusammenspiel von kolonialem und misogynem Diskurs, in: Hanau, Katharina et al. (Hg.): GeschlechterDifferenzen. Beiträge zum 14. Nachwuchskolloquium der Romanistik (Greifswald, 4.-6. Juni 1998). Bonn: Romanistischer Verlag 1999; S. 23-32

Weigel, Sigrid: Topographien der Geschlechter. Kulturgeschichtliche Studien zur Literatur. Reinbek: Rowohlt 1990

Weigel, Sigrid: Zur Weiblichkeit imaginärer Städte, in: Fuchs, Gotthard et al. (Hg.): Mythos Metropole. Frankfurt/M: Suhrkamp 1995; S. 35 45

Weigel, Sigrid: »Die Städte sind weiblich und nur dem Sieger hold«. Zur Funktion des Weiblichen in Gründungsmythen und Städtedarstellungen, in: Anselm, Sigrun/Beck, Barbara (Hg.): Triumph und Scheitern in der Metropole. Zur Rolle der Weiblichkeit in der Geschichte Berlins. Berlin: Reimer 1987; S. 207-227

Weigel, Sigrid: Die nahe Fremde - das Territorium des »Weiblichen«. Zum Verhältnis von »Wilden« und »Frauen« im Diskurs der Aufklärung, in: Koebner, Thomas/Pickerodt, Gerhart (Hg.): Die andere Welt; S. 171-199

Weil, Rachel: Der königliche Leib, sein Geschlecht und die Konstruktion der Monarchie, in: Schulte, Regina (Hg.): Der Körper der Königin; S. 99-111

Weininger, Otto: Geschlecht und Charakter. Eine prinzipielle Untersuchung. Wien, Leipzig: Braumüller $1921^{22}$ (1903)

Werlhof, Claudia von: Männliche Natur und künstliches Geschlecht. Texte zur Erkenntniskrise der Moderne. Wien: Wiener Frauenverlag 1991

Westhoff-Krummacher, Hildegard (Hg.): Als die Frauen noch sanft und engelsgleich waren. Die Sicht der Frau in der Zeit der Aufklärung und des Biedermeier. Münster: Westfälisches Landesmuseum für Kunst und Kulturgeschichte 1995

White, Hayden: The Forms of Wildness: Archaeology of an Idea, in: Dudley, Edward/Novak, Maximillian E. (Ed.): The Wild Man Within. An Image in Western Thought from the Renaissance to Romanticism. Pittsburgh: University of Pittsburgh Press 1972; S. 3-38 
Willi, Georg/Broggi, Mario F.: Naturschutz im Wald. Statt lauter Holz den Wald wieder sehen, in: Hintermann, Urs et al. (Hg.): Mehr Raum für die Natur; S. 239-258

Williams, Gerhild Scholz: Hexen und Herrschaft. Die Diskurse der Magie und Hexerei im frühneuzeitlichen Frankreich und Deutschland. München: Wilhelm Fink Verlag 1998 (Michigan 1995)

Williams, Gerhild Scholz: Das Fremde erkennen: Zur Erzählfunktion des Lachens im Mittelalter und in der Frühen Neuzeit, in: Fietz, Lothar et al. (Hg.): Semiotik, Rhetorik und Soziologie des Lachens. Vergleichende Studien zum Funktionswandel des Lachens vom Mittelalter bis zur Gegenwart. Tübingen: Niemeyer 1996; S. 82-96

Wimmer, Clemens Alexander: Geschichte der Gartentheorie. Darmstadt: Wissenschaftliche Buchgesellschaft 1989

Wimmer, Clemens Alexander: Die Fiktion des deutschen Nationalgartens im 19. Jahrhundert, in: Gröning, Gert/Schneider, Uwe (Hg.): Gartenkultur und nationale Identität.; S. 35-51

Wind, Edgar: Heidnische Mysterien in der Renaissance. Frankfurt/M: Suhrkamp 1984² (London 1958)

Wirz, Ferdinand: Auf den Busch geklopft. Der Wald und unsere Sprache. Melsungen: Neumann-Neudam 1999

Wischnowsky, Marc: Tochter Zion. Aufnahme und Überwindung der Stadtklage in den Prophetenschriften des Alten Testaments. Neukirchen-Vluyn: Neukirchener Verlag 2001

Woesler de Panafieu, Christine: Das Konzept von Weiblichkeit als Natur- und Maschinenkörper, in: Schaeffer-Hegel, Barbara/Wartmann, Brigitte (Hg.): Mythos Frau. Projektionen und Inszenierungen im Patriarchat. Berlin (West) Publica-Verlags-Gesellschaft 1984; S. 244-268

Wolf, Norbert: Landschaft und Bild. Zur europäischen Landschaftsmalerei vom 14. bis 17. Jahrhundert. Passau: Andreas-Haller-Verlag 1986

Wolschke-Bulmahn, Joachim: Findlinge. Landschaftsgestaltung und die völkische Suche nach nationaler Identität im frühen 20. Jahrhundert, in: Gröning, Gert/Schneider, Uwe (Hg.): Gartenkultur und nationale Identität.; S. 76-93

Wolter, Gundula: Die Verpackung des männlichen Geschlechts. Eine illustrierte Kulturgeschichte der Hose. Marburg: Jonas 1988

Wolter-von dem Knesebeck, Harald: Aspekte der höfischen Jagd und ihrer Kritik in Bildzeugnissen des Hochmittelalters, in: Rösener, Werner (Hg.): Jagd und höfische Kultur im Mittelalter. Göttingen: Vandenhoeck \& Ruprecht 1997 
Wunder, Heide: Die »Krise des Spätmittelalters« im Spiegel der Geschlechterbeziehungen - Zum gesellschaftlichen Phasenmodell Ferdinand Seibts, in: Lundt, Bea/Reimöller, Helma (Hg.): Von Aufbruch und Utopie. Perspektiven einer neuen Gesellschaftsgeschichte des Mittelalters. Für und mit Ferdinand Seibt aus Anlaß seines 65. Geburtstags. Köln, Weimar: Böhlau 1992; S. 73-85

Wunder, Heide/Vanja, Christina (Hg.): Wandel der Geschlechterbeziehungen zu Beginn der Neuzeit. Frankfurt/M 1991

Wunder, Heide: Überlegungen zum Wandel der Geschlechterbeziehungen im 15. und 16. Jahrhundert aus sozialgeschichtlicher Sicht, in: Dies./Vanja, Christina (Hg.): Wandel der Geschlechterbeziehungen zu Beginn der Neuzeit; S. 12-26.

Wyss, Beat: Die Welt als T-Shirt. Zur Ästhetik und Geschichte der Medien. Köln: DuMont 1997

Wyss, Beat: Trauer der Vollendung. Zur Geburt der Kulturkritik. Köln: DuMont $1997^{3}$

Wyss, Stephan: AskeSe. Ein Essay zum Selbstverständnis des herrschenden Mannes. Fribourg/Brig: Exodus 1989

Zimmermann, Peter: Der Bauernroman. Antifeudalismus, Konservatismus, Faschismus. Stuttgart: Metzler 1975

Zirnstein, Gottfried: Ökologie und Umwelt in der Geschichte. Marburg: Metropolis-Verlag 1994 


\section{Die Neuerscheinungen dieser Reihe:}

Michael Helmbrecht

Erosion des »Sozialkapitals «?

Eine kritische Diskussion der

Thesen Robert D. Putnams

Oktober 2005, ca. 100 Seiten,

kart., ca. $13,80 €$,

ISBN: 3-89942-358-5

\section{Gudrun Quenzel}

\section{Konstruktionen von Europa}

Die europäische Identität und die Kulturpolitik der

Europäischen Union

September 2005, ca. 240 Seiten, kart., ca. $25,80 €$,

ISBN: 3-89942-414-X

Nicole Grothe

\section{InnenStadtAktion - Kunst} oder Politik?

Künstlerische Praxis in der neoliberalen Stadt

September 2005, ca. 300 Seiten, kart., zahlr. Abb., ca. 25,80 €,

ISBN: 3-89942-413-1

Heike Hartung (Hg.)

Alter und Geschlecht

Repräsentationen, Geschichten und Theorien des Alter(n)s

September 2005, ca. 300 Seiten, kart., ca. $26,80 €$,

ISBN: 3-89942-349-6
Georg Glasze, Robert Pütz, Manfred Rolfes (Hg.)

Diskurs - Stadt - Kriminalität

Städtische (Un-)Sicherheiten aus der Perspektive von Stadtforschung und Kritischer Kriminalgeographie

September 2005, ca. 250 Seiten, kart., ca. $24,80 €$,

ISBN: 3-89942-408-5

Armin Stickler

Nichtregierungs-

organisationen, soziale

Bewegungen und

Global Governance

Eine kritische Bestandsaufnahme

August 2005, ca. 420 Seiten, kart., ca. $29,80 €$,

ISBN: 3-89942-407-7

Rudolf Stichweh

Inklusion und Exklusion

Studien zur

Gesellschaftstheorie

August 2005, ca. 224 Seiten,

kart., ca. $23,80 €$,

ISBN: 3-89942-390-9

Sabine Brombach,

Bettina Wahrig (Hg.)

LebensBilder

Leben und Subjektivität in neueren Ansätzen der Gender Studies

August 2005, ca. 250 Seiten, kart., zahl. z.T. farbige Abb., ca. $26,00 €$,

ISBN: 3-89942-334-8

Leseproben und weitere Informationen finden Sie unter: www.transcript-verlag.de 


\section{Die Neuerscheinungen dieser Reihe:}

Anja Frohnen

\section{Diversity in Action}

Multinationalität in globalen

Unternehmen am Beispiel Ford

Oktober 2005, ca. 240 Seiten,

kart., ca. $25,80 €$,

ISBN: 3-89942-377-1

\section{Marcus Termeer}

Verkörperungen des Waldes

Eine Körper-, Geschlechter-

und Herrschaftsgeschichte

Juli 2005, 646 Seiten,

kart., 33,80 €,

ISBN: 3-89942-388-7

\section{Christoph Wulf}

\section{Zur Genese des Sozialen}

Mimesis, Performativität, Ritual

Juli 2005, 178 Seiten,

kart., $17,80 €$,

ISBN: $3-89942-415-8$

Angela Schwarz (Hg.)

Der Park in der Metropole

Urbanes Wachstum und

städtische Parks im

19. Jahrhundert

Juli 2005, 224 Seiten,

kart., zahlr. Abb., 23,80 €,

ISBN: 3-89942-306-2

Barbara Christophe

Metamorphosen des

Leviathan in einer

post-sozialistischen

\section{Gesellschaft}

Georgiens Provinz zwischen

Fassaden der Anarchie und regulativer Allmacht

Juni 2005, 264 Seiten,

kart., 26,80 €,

ISBN: 3-89942-323-2
Gerald Willms

Scientology

Kulturbeobachtungen jenseits

der Devianz

März 2005, 422 Seiten,

kart., $29,80 €$,

ISBN: 3-89942-330-5

Matthias Groß,

Holger Hoffmann-Riem,

Wolfgang Krohn

Realexperimente

Ökologische Gestaltungs-

prozesse in der Wissens-

gesellschaft

Juni 2005, 236 Seiten,

kart., $24,80 €$,

ISBN: 3-89942-304-6

\section{Peter Fuchs}

Konturen der Modernität

Systemtheoretische Essays II.

hrsg. von Marie-Christin Fuchs

Juni 2005, 196 Seiten,

kart., $21,80 €$,

ISBN: 3-89942-335-6

Hannelore Bublitz

In der Zerstreuung

organisiert

Paradoxien und Phantasmen

der Massenkultur

Mai 2005, 172 Seiten,

kart., $17,80 €$,

ISBN: 3-89942-195-7

Helmut König,

Manfred Sicking (Hg.)

Gehört die Türkei zu Europa?

Wegweisungen für ein Europa

am Scheideweg

März 2005, 222 Seiten,

kart., $22,80 €$,

ISBN: 3-89942-328-3

Leseproben und weitere Informationen finden Sie unter: www.transcript-verlag.de 


\section{Die Neuerscheinungen dieser Reihe:}

Michael Guggenheim Organisierte Umwelt Umweltdienstleistungsfirmen zwischen Wissenschaft, Wirtschaft und Politik

März 2005, 338 Seiten, kart., $28,80 €$,

ISBN: 3-89942-296-1

\section{Thomas Kunz}

\section{Der Sicherheitsdiskurs}

Die Innere Sicherheitspolitik und ihre Kritik

Februar 2005, 422 Seiten, kart., $29,80 €$,

ISBN: 3-89942-293-7

\section{Uwe Lewitzky}

\section{Kunst für alle?}

Kunst im öffentlichen Raum zwischen Partizipation,

Intervention und Neuer

Urbanität

Januar 2005, 138 Seiten, kart., $14,80 €$,

ISBN: 3-89942-285-6

Jacqueline Holzer

Linguistische Anthropologie Eine Rekonstruktion

Januar 2005, 322 Seiten,

kart., $29,80 €$,

ISBN: 3-89942-301-1

Karl H. Hörning,

Julia Reuter (Hg.)

\section{Doing Culture}

Neue Positionen zum

Verhältnis von Kultur und

sozialer Praxis

2004, 264 Seiten,

kart., 25,80 €,

ISBN: 3-89942-243-0
Frankfurter Arbeitskreis für politische Theorie \&

Philosophie (Hg.)

Autonomie und Heteronomie der Politik

Politisches Denken zwischen

Post-Marxismus und

Poststrukturalismus

2004, 206 Seiten,

kart., $24,80 €$,

ISBN: 3-89942-262-7

Johannes Glückler

\section{Reputationsnetze}

Zur Internationalisierung von Unternehmensberatern.

Eine relationale Theorie

2004, 306 Seiten,

kart., $29,80 €$,

ISBN: 3-89942-265-1

Jan Kruse

\section{Arbeit und Ambivalenz}

Die Professionalisierung

Sozialer und Informatisierter Arbeit

2004, 370 Seiten,

kart., $29,80 €$,

ISBN: 3-89942-230-9

Gabriele Klein (Hg.)

Bewegung

Sozial- und

kulturwissenschaftliche

Konzepte

2004, 306 Seiten,

kart., $26,80 €$,

ISBN: 3-89942-199-X

\section{Leseproben und weitere Informationen finden Sie unter:}

www.transcript-verlag.de 